\title{
Development of volunteer-driven indices of biological integrity for wetlands in West Virginia
}

Walter Emil Veselka IV

West Virginia University

Follow this and additional works at: https://researchrepository.wvu.edu/etd

\section{Recommended Citation}

Veselka, Walter Emil IV, "Development of volunteer-driven indices of biological integrity for wetlands in West Virginia" (2008). Graduate Theses, Dissertations, and Problem Reports. 2619.

https://researchrepository.wvu.edu/etd/2619

This Thesis is protected by copyright and/or related rights. It has been brought to you by the The Research Repository @ WVU with permission from the rights-holder(s). You are free to use this Thesis in any way that is permitted by the copyright and related rights legislation that applies to your use. For other uses you must obtain permission from the rights-holder(s) directly, unless additional rights are indicated by a Creative Commons license in the record and/ or on the work itself. This Thesis has been accepted for inclusion in WVU Graduate Theses, Dissertations, and Problem Reports collection by an authorized administrator of The Research Repository @ WVU. For more information, please contact researchrepository@mail.wvu.edu. 


\title{
Development of Volunteer-Driven Indices of Biological Integrity for Wetlands in West Virginia
}

\section{Walter Emil Veselka IV}

Thesis submitted to the Davis College of Agriculture, Forestry, and Consumer Sciences at West Virginia University in partial fulfillment of the requirements for the degree of

\author{
Master of Science \\ in \\ Wildlife and Fisheries Resources
}

James T. Anderson, Ph.D., Major Advisor

James Rentch, Ph.D., Committee Member

Walter S. Kordek, Committee Member

Division of Forestry and Natural Resources

Morgantown, West Virginia

2008

Keywords: wetlands, anuran communities, avian communities, vegetation communities, macroinvertebrate communities, anthropogenic disturbance, West Virginia

Copyright 2008 Walter E. Veselka IV 


\section{ABSTRACT \\ Development of Volunteer-Driven Indices of Biological Integrity for Wetlands in West Virginia}

\section{Walter Emil Veselka IV}

Wetland indices of biological integrity (IBIs) are used to satisfy the water resources monitoring requirements of the Clean Water Act (CWA). However, debate still exists on what classification systems and taxa to base these IBIs upon. Our cumulative research, representing indices of biological integrity designed for regional HGM subclasses, designated HGM management classes and Cowardin et al. (1979) classes for West Virginia. The indices were derived from metrics calculated from anuran, avian, macroinvertebrate, and vegetation communities; each representing increasing levels of resources associated with gathering the necessary data. For example, avian and anuran data used to derive floodplain wetland IBI metrics can be collected by volunteers, but the disturbance scores only account for $46 \%$ and $18 \%$ of the variation in IBI scores, respectively. Alternatively, the disturbance scores account for $56 \%$ and $47 \%$ of the variation in vegetation and invertebrate IBI scores, respectively. However, if the floodplain wetland was also a scrub-shrub wetland, by adding the avian and anuran metrics of both floodplain and scrub-shrub IBIs, the resulting hybrid-class, multi-taxa IBI disturbance scores accounts for $89 \%$ of the variation in IBI scores. We evaluate each of these taxa groups alone and in combination, in single and hybrid classification schemes, to examine changes in sensitivities to the disturbance gradient. The result is a decision making tool that can assist resource managers by providing them with the opportunity to stretch finite resources; while still ensuring the monitoring captures changes in wetland communities due to human disturbance.

Keywords: Indices of biological integrity, IBIs, wetlands, disturbance, anuran communities, avian communities, macroinvertebrate communities, vegetation communities, West Virginia. 


\section{ACKNOWLEDGEMENTS}

I thank the U.S. Environmental Protection Agency (U.S. EPA) and the West Virginia Division of Natural Resources (WVDNR) for funding and resources. I thank my major advisor, and motivator, Dr. James T. Anderson for allowing me the flexibility to seize educational opportunities outside my research while providing guidance and accountability throughout this entire educational process. I thank my committee members, James Rentch for his straight-talk and hard-work identifying plants, as well as Walt Kordek, for reviewing this manuscript. I thank my mentor, friend, and role model, Bill Grafton for his uplifting conversations, support, and tireless effort in every endeavor he undertakes. I thank, Sarah McClurg, for her endless patience, love, and support of me in all my dreams, schemes, and aspirations. Adrianne Brand, Mark Hepner, Joe Osbourne, Dr. Hillar Klandorff, Jason Love, Jennifer Edalgo, Seth Lemley, Donna Hartman, Jered Studinski, Dr. Linda Butler, Dr. John Strazanac, Valerie Wells, Dane Cunningham, Clayton Schoonover, and Brian Krottfrom West Virginia University (WVU) assisted with many aspects of this project, from field work to macroinvertebrate sorting and identification, and I am grateful for their help and energy. Greg Pond, George Merovich, and the late Dr. George Seidel providedstatistical support and advice. Database management and geographic information system set-up, maintenance, and assistance would not have been nearly as painless without the help of Ben F. Gilmer IV. In closing, I express my love and thank my family and friends in Three Rivers, California, who encouraged me in so many ways to return to school and continue my education. 


\section{Table of Contents}

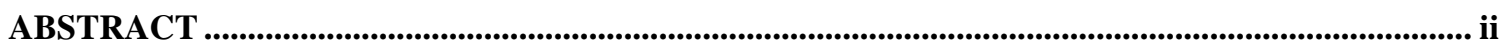

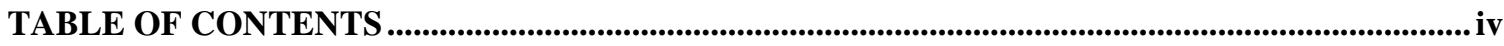

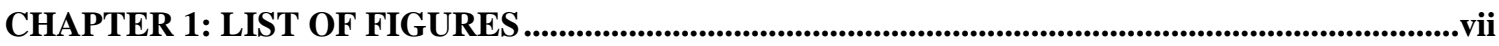

CHAPTER 2: LIST OF TABLES ........................................................................................................ viii

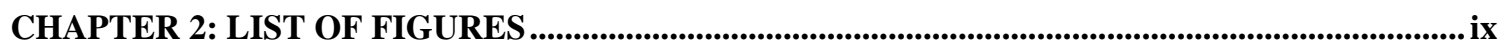

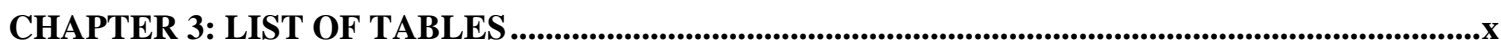

CHAPTER 3: LIST OF FIGURES ........................................................................................................

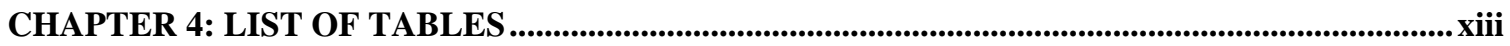

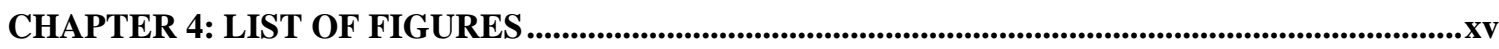

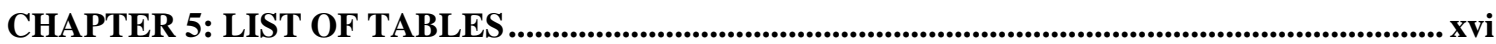

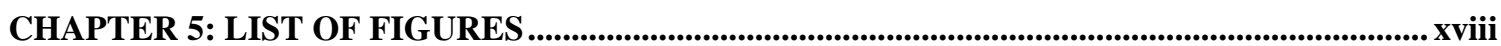

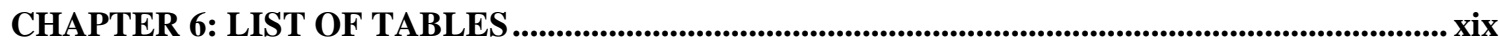

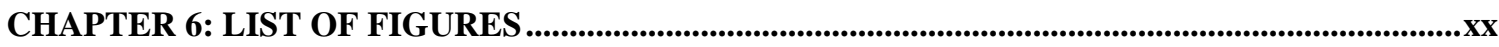

LIST OF APPENDICES........................................................................................................................ $\mathrm{xxi}$

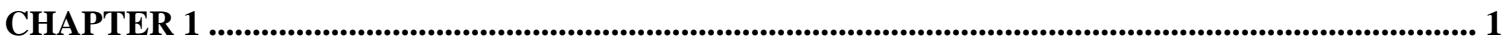

INTRODUCTION AND JUSTIFICATION FOR THE DEVELOPMENT OF WETLAND INDICES

OF BIOLOGICAL INTEGRITY FOR WETLANDS IN WEST VIRGINIA ..................................... 1

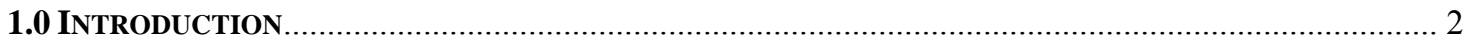

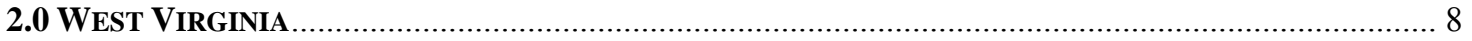

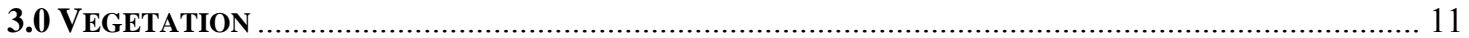

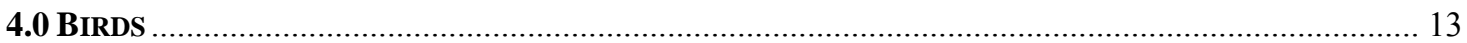

5.0 AMPHIBIANS

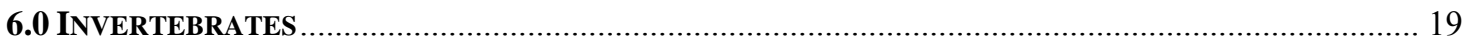

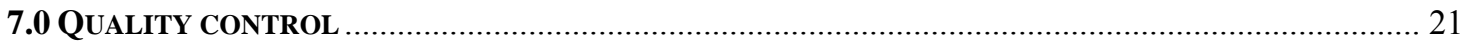

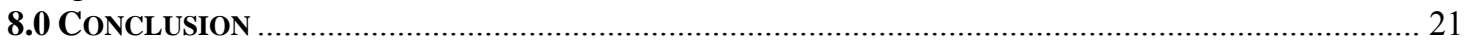

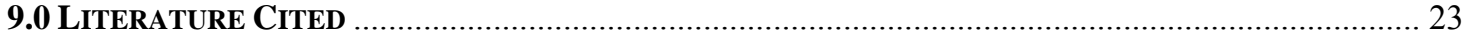

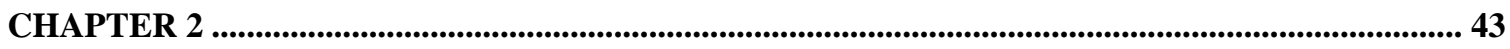

USING DUAL CLASSIFICATIONS IN THE DEVELOPMENT OF AVIAN WETLAND INDICES OF BIOLOGICAL INTEGRITY FOR WETLANDS IN WEST VIRGINIA, USA.............................. 43

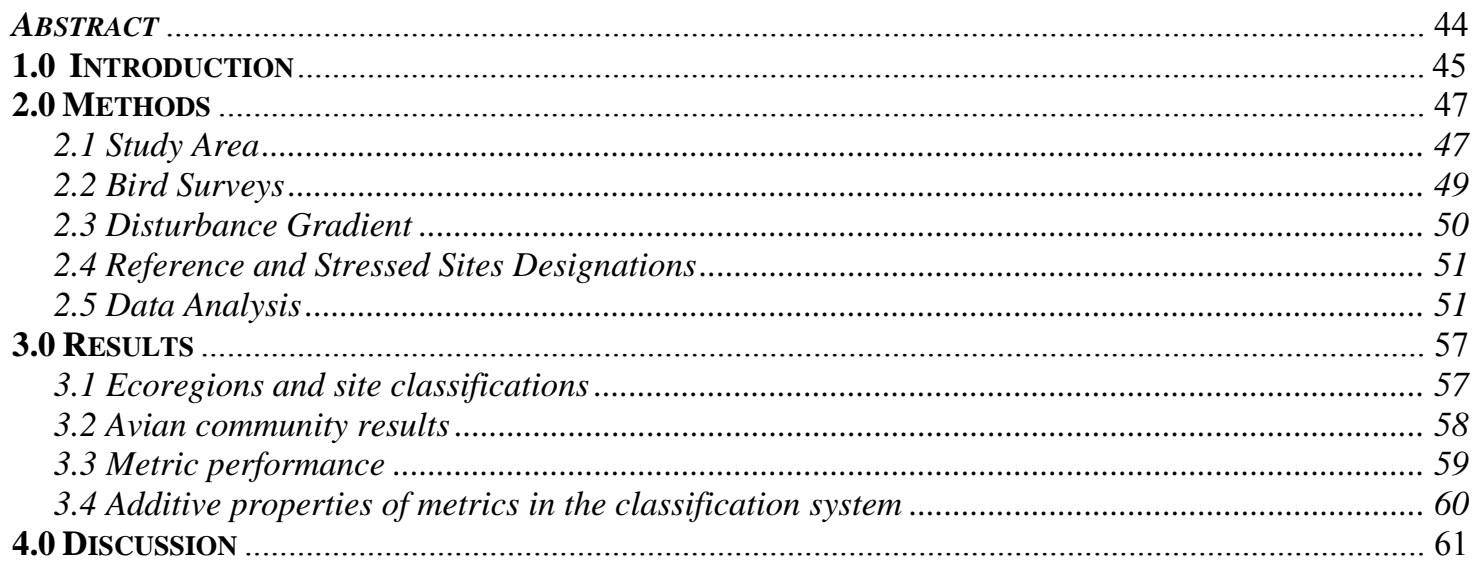


4.1 Study design

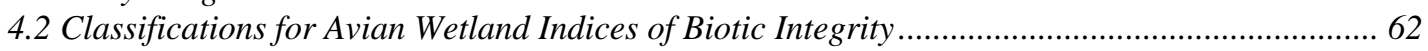

4.3 Comparison with other Avian Wetland Indices of Biological Integrity ........................................ 66

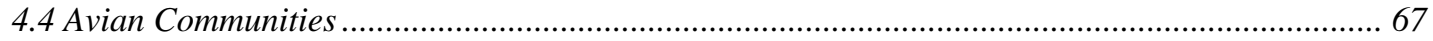

4.5 Regional HGM subclasses and Designated HGM management classes......................................... 68

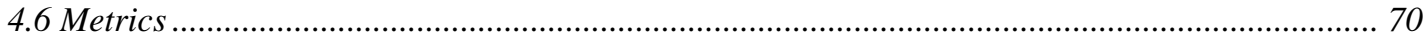

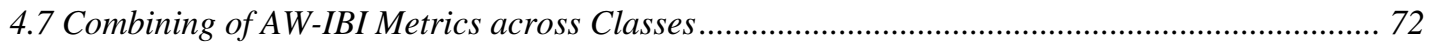

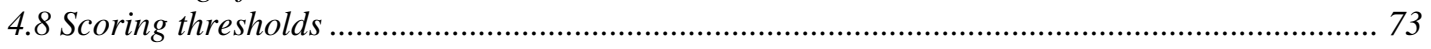

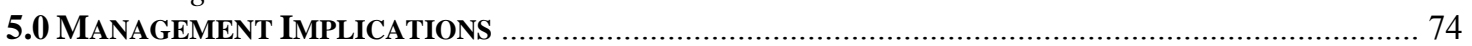

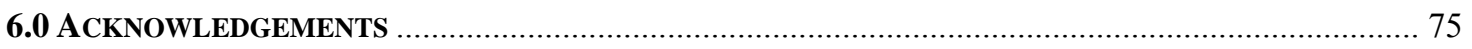

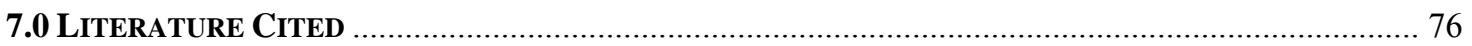

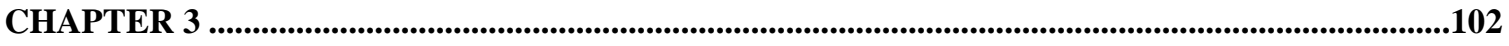

DEVELOPMENT AND EVALUATION OF ACOUSTICALLY-BASED ANURAN INDICES OF

BIOLOGICAL INTEGRITY FOR WETLANDS IN WEST VIRGINIA, USA ......................................102

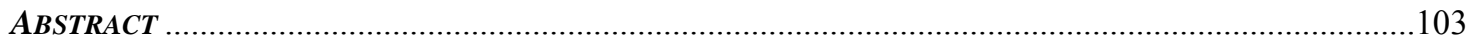

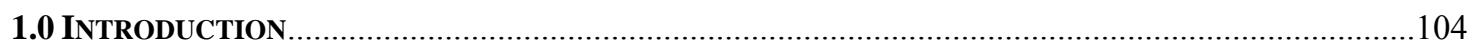

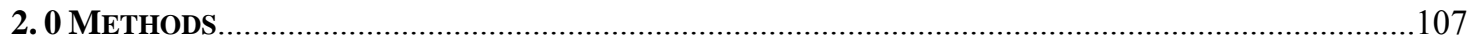

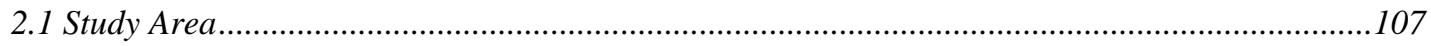

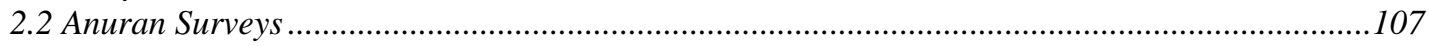

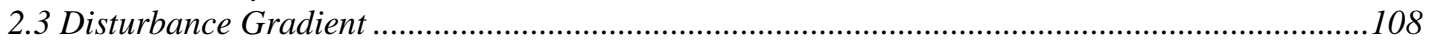

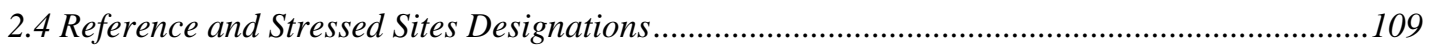

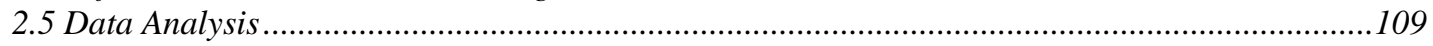

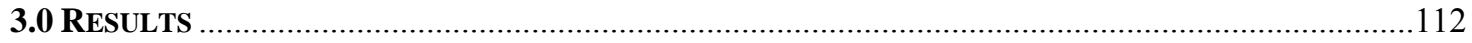

3.1 Ecoregions and site classifications ...................................................................................112

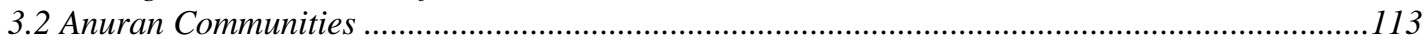

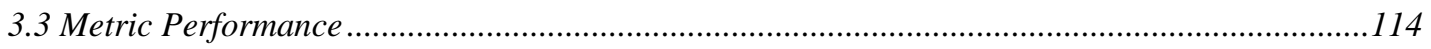

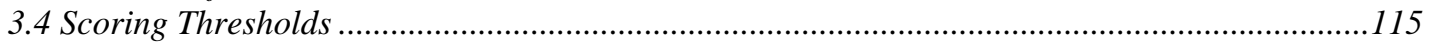

3.5Hybrid Classification Capacity of AA-IBI metrics.....................................................................115

3.6 Combining AA-IBI metric scores to form multi-taxa wetland IBIs ............................................115

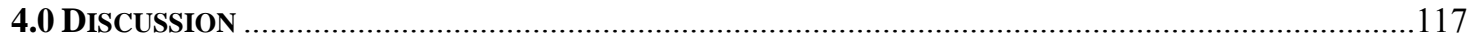

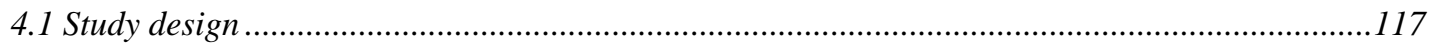

4.2 Classifications of Anuran Acoustically-based Indices of Biological Integrity ..............................118

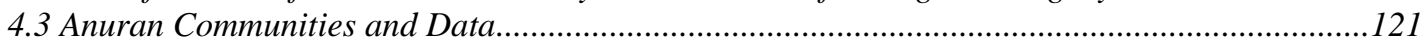

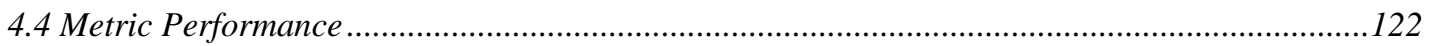

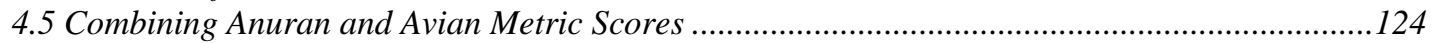

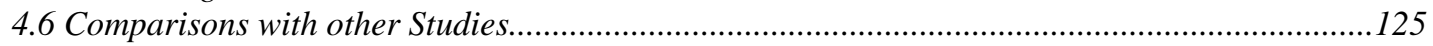

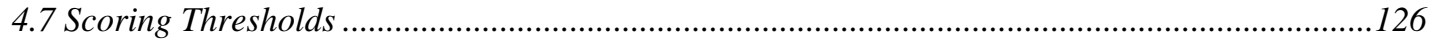

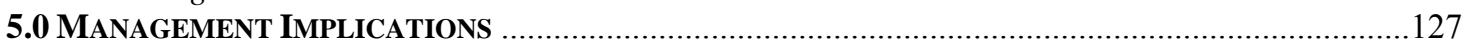

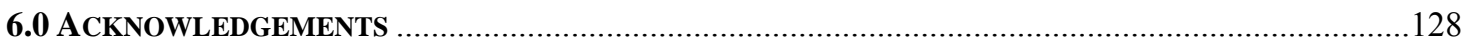

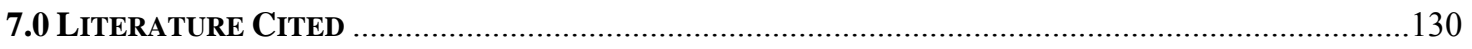

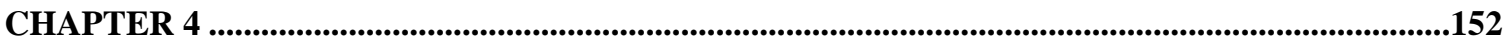

DEVELOPMENT OF VEGETATION INDICES OF BIOLOGICAL INTEGRITY FOR

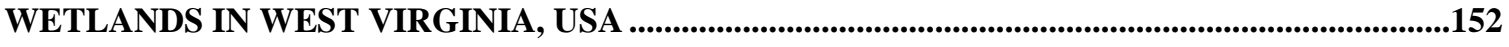

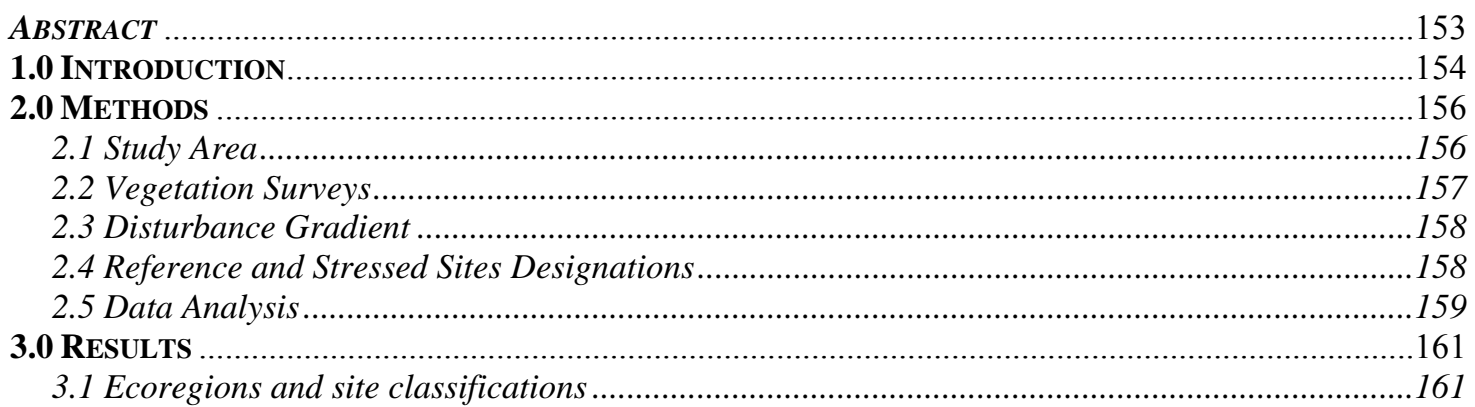




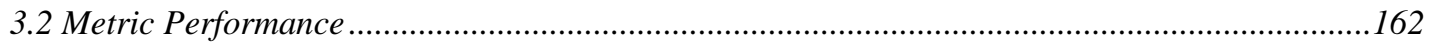

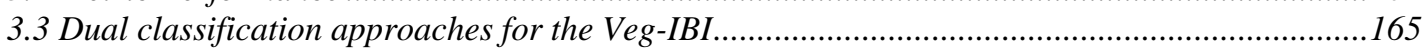

3.4 Contrasting with other West Virginia wetland indices of biological integrity ..............................166

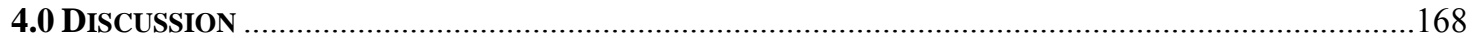

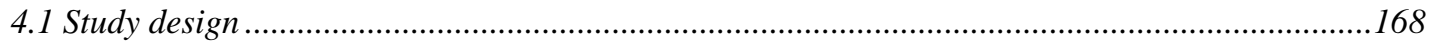

4.2 Metric Performance by Classification Scheme …………..............................................................169

4.3 Hybrid capacity of the Veg-IBI ..................................................................................................174

4.4 Comparisons with other Vegetation Indices of Biological Integrity ...........................................175

4.5 Integration with other wetland indices of biological integrity in West Virginia ...........................180

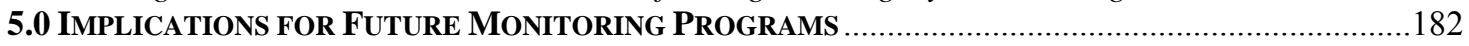

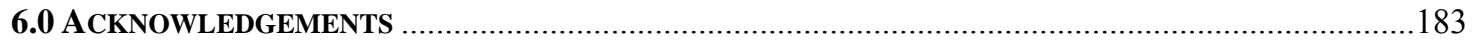

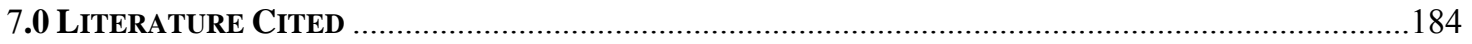

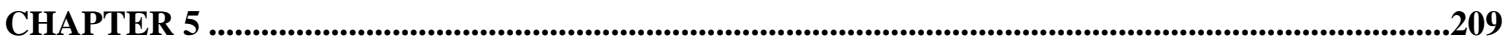

DUAL CLASSIFICATIONS USED IN DEVELOPING MACROINVERTEBRATE INDICES OF

BIOLOGICAL INTEGRITY FOR WETLANDS IN WEST VIRGINIA, USA ..................................209

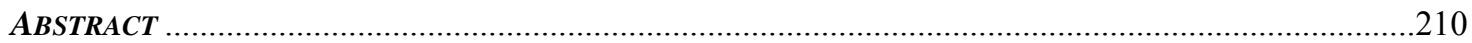

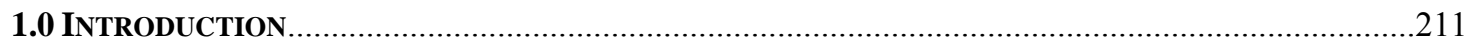

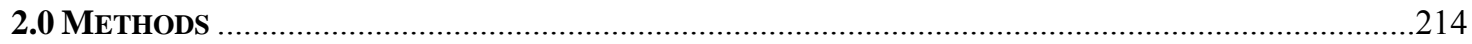

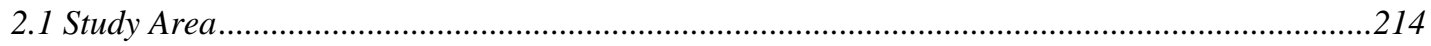

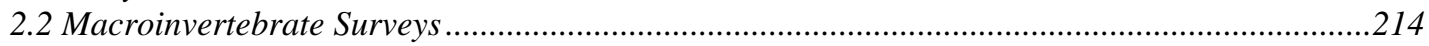

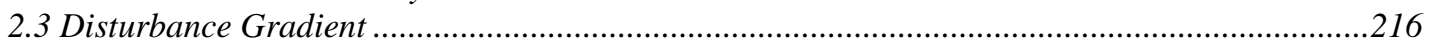

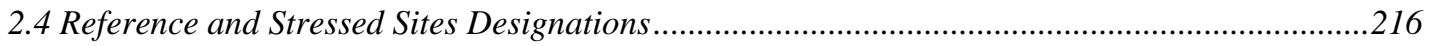

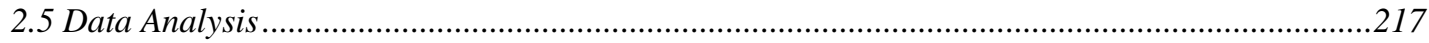

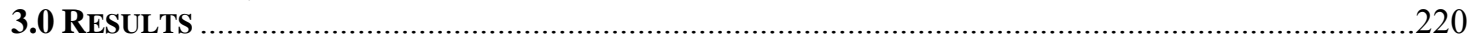

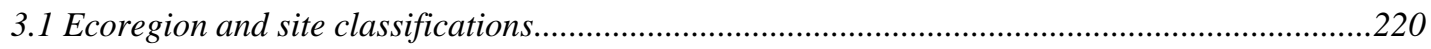

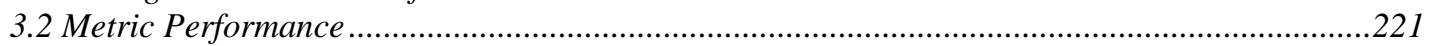

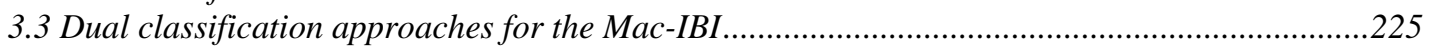

3.4 Contrasting and augmenting with other West Virginia wetland IBIs ........................................225

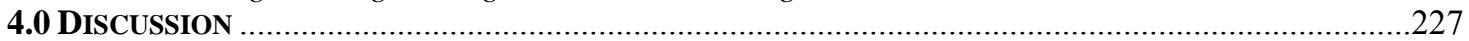

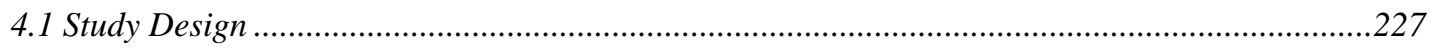

4.2 Metric Performance .........................................................................................................228

4.3Comparisons with Other Macroinvertebrate Indices of Biological Integrity ................................231

4.4 Integration with other West Virginia wetland indices of biological integrity .................................233

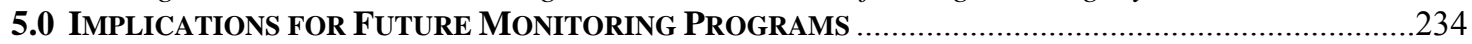

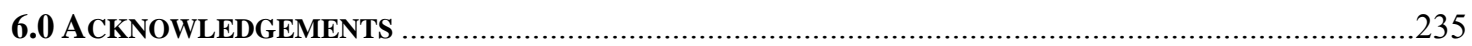

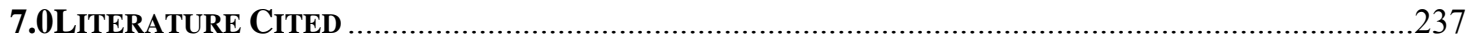

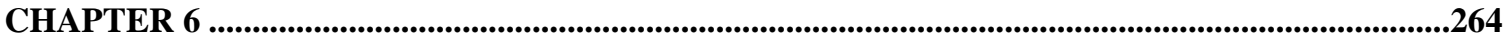

USES FOR INDICES OF BIOLOGICAL INTEGRITY FOR WETLANDS IN WEST VIRGINIA,

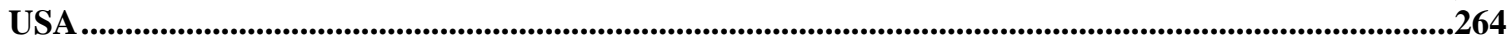

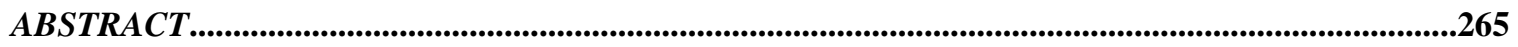

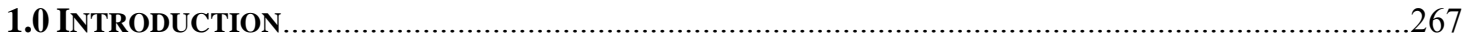

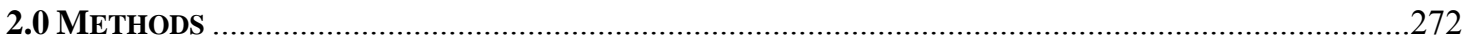

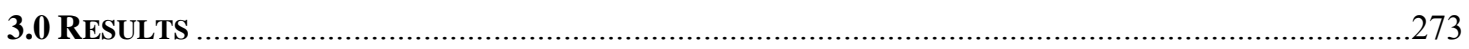

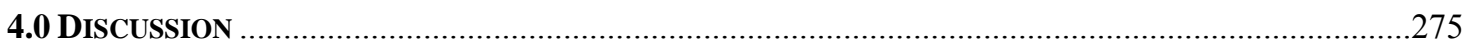

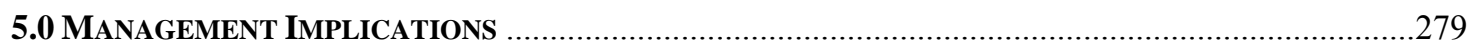

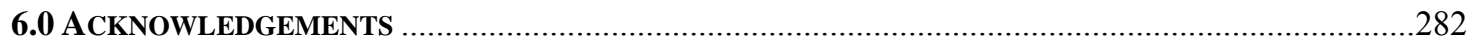

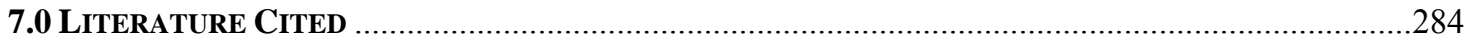

APPENDICES ........................................................................................................................................316 


\section{Chapter 1: List of Figures}

Figure 1. An example of an emergent wetland site used to develop indices of biological integrity for wetlands in West Virginia, USA from 2005-2006............................. 40

Figure 2. An example of a scrub-shrub wetland site used to develop indices of biological integrity for wetlands in West Virginia, USA from 2005-2006............................ 41

Figure 3. An example of a forested wetland site used to develop indices of biological integrity for wetlands in West Virginia, USA from 2005-2006. ............................ 42 


\section{Chapter 2: List of Tables}

Table 1. Designated hydrogeomorphic (HGM) management classes derived from regional hydrogeomorphic (HGM) subclasses ${ }^{a}$ for use in developing class specific avian wetland indices of biological integrity (AW-IBI) in West Virginia, USA from 2005-2006.

Table 2. Total number of sites by regional hydrogeomorphic (HGM) subclass, designated HGM management class, and Cowardin class by ecoregion for use in developing class specific avian wetland indices of biological integrity (AW-IBI) in West Virginia, USA from 2005-2006.

Table 3. Metrics and sub-metrics selected from the Ohio Rapid Assessment Method (Mack 2001) used to define the disturbance gradient for use in developing class specific avian wetland indices of biological integrity (AW-IBI) in West Virginia, USA from 2005-2006.

Table 4. Candidate avian community biological metrics evaluated by class according to regional Hydrogeomorphic (HGM) subclass, designated HGM management class, and the Cowardin classification schemes in building avian wetland indices of biological integrity (AW-IBI) in West Virginia, USA from 2005-2006.

Table 5. Correlated metrics based on Spearman's R ( $\mathrm{R}>0.80$ ) selected based on discrimination efficiency in differentiating between reference and stressed sites metrics used in developing class specific avian wetland indices of biological integrity (AW-IBI) in West Virginia, USA from 2005-2006.

Table 6. Analysis of variance (ANOVA) results of reference and stressed sites' metric values compared to Level 3 ecoregions (Omernik 1987; Wood et al. 1999) and the alternative classification scheme used in developing avian wetland indices of biological integrity (AW-IBI) for wetlands in West Virginia, USA from 2005-2006.

Table 7. Wilks' Lambda statistic for posthoc validation of reference and stressed sites' metric values of class-specific avian wetland indices of biological integrity (AWIBI) for wetlands in West Virginia, USA from 2005-2006.

Table 8. Reference site scoring summary used to derive scoring thresholds, and discrimination efficiency (D.E.) in developing class specific avian wetland indices of biological integrity (AW-IBI) in West Virginia, USA from 2005-2006.

Table 9. Avian species recorded and used in the formation of class specific avian wetland indices of biological integrity (AW-IBI) in West Virginia, USA from 20052006.

Table 10. Summary statistics of proportion of wetland affiliated birds by classification used in developing class specific avian wetland indices of biological integrity (AWIBI) in West Virginia, USA from 2005-2006.

Table 11. Relations between the resulting hydrogeomorphic (HGM) and Cowardin classspecific and combined avian wetland indices of biological integrity (AW-IBI) for West Virginia, USA and the disturbance gradient from 2005-2006.... 


\section{Chapter 2: List of Figures}

Figure 1. Site locations of wetlands and ecoregions (Woods et al. 1999, Omernik 1987) used in developing class-specific avian wetland indices of biological integrity (AWIBI) in West Virginia, USA from 2005-2006. Wetland sites were clustered; scale of map prevents all sites from being marked individually. Legend may indicate 1-4 wetlands per mark.

Figure 2. Box and whisker plot characteristics and resulting narrative description of reference and stressed sites' distribution of a biological metric value considered for inclusion into class-specific avian wetland indices of biological integrity (AW-IBI) in West Virginia, USA from 2005-2006. Solid ovals represent the median of metric value (courtesy of Greg Pond, U.S. EPA).

Figure 3. Frequency distribution of disturbance scores for sites used to develop classspecific avian wetland indices of biological integrity (AW-IBI) for wetlands in West Virginia, USA from 2005-2006 


\section{Chapter 3: List of Tables}

Table 1. Total number of sites by regional hydrogeomorphic (HGM) subclass, designated HGM management class, and Cowardin class by ecoregion for use in developing anuran acoustically-based indices of biological integrity (AA-IBI) in West Virginia, USA from 2005-2006.

Table 2. Designated hydrogeomorphic (HGM) management classes derived from regional HGM subclasses for use in developing class specific anuran acousticallybased wetland indices of biological integrity (AA-IBI) in West Virginia, USA from 2005-2006.

Table 3. Metrics and sub-metrics selected from the Ohio Rapid Assessment Method (Mack 2001) used to define the disturbance gradient for use in developing class specific anuran acoustically-based indices of biological integrity (AA-IBI) in West Virginia, USA from 2005-2006................................................................. 138

Table 4. List of 12 candidate metrics evaluated for inclusion into anuran acousticallybased indices of biological integrity (AA-IBI) for West Virginia, USA in 20052006

Table 5. Anuran species and corresponding coefficients of conservatism $(\mathrm{CoC})$ used in analysis for deriving anuran acoustically-based indices of biological integrity (AAIBI) in West Virginia, USA from 2005-2006.

Table 6. Spearman's R correlation matrices of metrics by classification scheme able to discriminate between reference and stressed sites metrics used in developing anuran acoustically-based indices of biological integrity (AA-IBI) in West Virginia, USA from 2005-2006. Metrics with Spearman's R values $>0.80$ were considered highly correlated.

Table 7. Candidate anuran community biological metrics evaluated by class according to regional Hydrogeomorphic (HGM) subclass, designated HGM management class, and the Cowardin classification schemes in building acoustically-based anuran wetland indices of biological integrity (AA-IBI) in West Virginia, USA from 20052006

Table 8. Analysis of variance (ANOVA) results of reference and stressed sites' metric values compared to Level 3 ecoregions (Omernik 1987, Wood et al. 1999) and the alternative classification scheme used in developing anuran acoustically-based wetland indices of biological integrity (AA-IBI) for wetlands in West Virginia, USA from 2005-2006.

Table 9. Wilks' Lambda statistic for posthoc validation of reference and stressed sites' metric values of class-specific anuran acoustically-based wetland indices of biological integrity (AA-IBI) for wetlands in West Virginia, USA from 2005-2006.

Table 10. Discrimination efficiency (D.E.) and reference site scoring summary used to derive scoring thresholds in developing class specific anuran acoustically-based wetland indices of biological integrity (AA-IBI) in West Virginia, USA from 20052006

Table 11. Frequency of species occurrences (number of wetland occur/ number of wetlands surveyed) in the 151 sites used to develop acoustically-based anuran indices of biological integrity (AA-IBI) in West Virginia, USA from 2005-2006. 146 
Table 12. Metrics comprising each anuran acoustically-based indices of biological integrity (AA-IBI) as per designated hydrogeomorphic (HGM) management class, regional HGM subclass, and Cowardin classifications; the discrimination efficiency (D.E.) of each AA-IBI, and the resulting relations of the AA-IBI with disturbance scores for wetlands in West Virginia, USA from 2005-2006.

Table 13. Relations between the disturbance scores and multi-taxa IBI that resulted from combining the anuran acoustically-based indices of biological integrity (AA-IBI) metric scores with the avian wetland indices of biological integrity (AW-IBI) metric scores from wetlands of West Virginia, USA from 2005-2006. AW-IBI-only scores are provided for comparison. 148 


\section{Chapter 3: List of Figures}

Figure 1. Site locations of wetlands and ecoregions (Woods et al. 1999; Omernik 1987) used in developing anuran acoustically-based indices of biological integrity (AAIBI) in West Virginia, USA from 2005-2006. Wetland sites were clustered; scale of map prevents all sites from being marked individually. Legend may indicate 1-4 wetlands per mark.

Figure 2. Box and whisker plot characteristics and resulting narrative description of reference and stressed sites' distribution of a biological metric value considered for inclusion into anuran acoustically-based indices of biological integrity (AA-IBI) in West Virginia, USA from 2005-2006. Solid ovals represent the median of metric value (courtesy of Greg Pond, U.S. EPA).

Figure 3. Frequency distribution of disturbance scores for sites used to develop classspecific anuran acoustically-based indices of biological integrity (AA-IBI) for wetlands in West Virginia, USA from 2005-2006. 


\section{Chapter 4: List of Tables}

Table 1. Number of sites by Cowardin and hydrogeomorphic (HGM) classification schemes and ecoregions for use in developing use in developing vegetation indices of biological integrity (Veg-IBI) for wetlands in West Virginia, USA from 20052006.

Table 2. Designated hydrogeomorphic (HGM) management classes derived from regional hydrogeomorphic (HGM) subclasses ${ }^{\mathrm{a}}$ for use in developing vegetation indices of biological integrity (Veg-IBI) for wetlands in West Virginia, USA from 2005-2006.

Table 3. Cover class scales for herbaceous vegetation plots used to derive candidate metric values for developing vegetation indices of biological integrity (Veg-IBI) for wetlands in West Virginia, USA from 2005-2006.

Table 4. Candidate metrics, the survey plot the metrics were derived from, the expected response to disturbance, and descriptions tested for inclusion into vegetation indices of biological integrity (Veg-IBI) for wetlands in West Virginia, USA from 20052006

Table 5. Metrics and sub-metrics selected from the Ohio Rapid Assessment Method (Mack 2001) used to define the disturbance gradient for use in developing vegetation indices of biological integrity (Veg-IBI) for wetlands in West Virginia, USA from 2005-2006.

Table 6. Candidate vegetation community metrics evaluated by class according to regional Hydrogeomorphic (HGM) subclass, designated HGM management class, and the Cowardin classification schemes in building vegetation indices of biological integrity (Veg-IBI) for wetlands in West Virginia, USA from 2005-2006.

Table 7. Correlated metrics $(\mathrm{R}>0.80)$ selected based on discrimination efficiency (D.E.) in differentiating between reference and stressed sites' metrics used in developing vegetation indices of biological integrity (Veg-IBI) for wetlands in West Virginia, USA from 2005-2006.

Table 8. Analysis of variance (ANOVA) results of reference and stressed sites' metric values compared to Level 3 ecoregions (Woods et al. 1999, Omernik 1987) and the alternative classification scheme used in developing vegetation indices of biological integrity (Veg-IBI) for wetlands in West Virginia, USA from 2005-2006.

Table 9. Wilks' Lambda statistic for posthoc validation of reference and stressed sites' metric values of class-specific vegetation indices of biological integrity (Veg-IBI) for wetlands in West Virginia, USA from 2005-2006.

Table 10. Relations between the resulting class-specific vegetation indices of biological integrity (Veg-IBI) for wetlands in West Virginia, USA and the disturbance gradient from 2005-2006. 202

Table 11. Reference site scoring summary used to derive scoring thresholds, and discrimination efficiency (D.E.) in developing class specific vegetation indices of biological integrity (Veg-IBI) for wetlands in West Virginia, USA from 2005-2006.

Table 12. Relations between the resulting hybrid-class vegetation indices of biological integrity (Veg-IBI) for wetlands in West Virginia, USA and the disturbance gradient from 2005-2006. 
Table 13. A comparison of the $\mathrm{R}^{2}$ values of derived single and combined vegetation indices of biological integrity (Veg-IBI), avian wetland indices of biological integrity (AW-IBI), and anuran acoustically-based indices of biological integrity (AA-IBI) for wetlands in West Virginia, USA from 2005-2006 .............................. 205 


\section{Chapter 4: List of Figures}

Figure 1. Site locations of wetlands and ecoregions (Omernik 1987, Woods et al. 1999) used in developing class-specific vegetation indices of biological integrity (Veg-IBI) in West Virginia, USA from 2005-2006. Wetland sites were clustered; scale of map prevents all sites from being marked individually. Legend may indicate 1-4 wetlands per mark. 206

Figure 2. Box and whisker plot characteristics and resulting narrative description of reference and stressed sites' distribution of a biological metric value considered for inclusion into class-specific vegetation indices of biological integrity (Veg-IBI) for wetlands in West Virginia, USA from 2005-2006Solid ovals represent the median of metric value (courtesy of Greg Pond, US EPA).

Figure 3. Frequency distribution of disturbance scores for sites used to develop classspecific vegetation indices of biological integrity (Veg-IBI) for wetlands in West Virginia, USA from 2005-2006. 


\section{Chapter 5: List of Tables}

Table 1. Number of sites by Cowardin and hydrogeomorphic (HGM) classification schemes and ecoregions for use in developing macroinvertebrate indices of biological integrity (Mac-IBI) for wetlands in West Virginia, USA from 2005-2006.

Table 2. Designated hydrogeomorphic (HGM) management classes derived from regional hydrogeomorphic (HGM) subclasses for use in developing macroinvertebrate indices of biological integrity (Mac-IBI) for wetlands in West Virginia, USA from 2005-2006.

Table 3. Metrics and sub-metrics selected from the Ohio Rapid Assessment Method (Mack 2001) used to define the disturbance gradient for use in developing macroinvertebrate indices of biological integrity (Mac-IBI) for wetlands in West Virginia, USA from 2005-2006.

Table 4. Candidate macroinvertebrate community biological metrics evaluated for inclusion into macroinvertebrate indices of biological integrity (Mac-IBI) for wetlands in West Virginia, USA from 2005-2006.

Table 5. Candidate macroinvertebrate community biological metrics that were able to discriminate between reference and stressed sites; evaluated by class according to regional Hydrogeomorphic (HGM) subclass, designated HGM management class, and the Cowardin classification schemes in building macroinvertebrate indices of biological integrity (Mac-IBI) for wetlands in West Virginia, USA from 2005-2006.

Table 6. Correlation matrix of benthic and nektonic macroinvertebrate metrics used in developing macroinvertebrate indices of biological integrity (Mac-IBI) for wetlands in West Virginia, USA from 2005-2006. Metrics with R $>0.80$ were considered correlated and selected for inclusion into the Mac-IBI based on discrimination efficiency (D.E.)

Table 7. Analysis of variance (ANOVA) results of reference and stressed sites' metric values compared to Level 3 ecoregions (Omernik 1987; Woods et al. 1999) and the alternative classification scheme used in developing macroinvertebrate indices of biological integrity (Mac-IBI) for wetlands in West Virginia, USA from 2005-2006.

Table 8. Wilks' Lambda statistic for posthoc validation of reference and stressed sites' metric values of class-specific macroinvertebrate indices of biological integrity (Mac-IBI) for wetlands in West Virginia, USA from 2005-2006.

Table 9. Relations between the resulting class-specific macroinvertebrate indices of biological integrity (Mac-IBI) derived from separate analysis of benthic and nektonic samples for wetlands in West Virginia, USA and the disturbance gradient from 2005-2006.

Table 10. Relations between the resulting class-specific macroinvertebrate indices of biological integrity (Mac-IBI) derived from combined analysis of benthic and nektonic samples for wetlands in West Virginia, USA and the disturbance gradient from 2005-2006. 
Table 11. Reference site scoring summary used to derive scoring thresholds, and discrimination efficiency (D.E.) in developing class-specific macroinvertebrate indices of biological integrity (Mac-IBI) for wetlands in West Virginia, USA from 2005-2006.

Table 12. Relations between resulting hybrid-class macroinvertebrate indices of biological integrity (Mac-IBI) for wetlands in West Virginia, USA and the disturbance gradient from 2005-2006.

Table 13. Relations between a class-specific multi-metric, multi-taxa IBI and the disturbance gradient derived from the avian wetland indices of biological integrity (AW-IBI), anuran acoustically-based index of biological integrity (AA-IBI), the vegetation index of biological integrity (Veg-IBI) and the macroinvertebrate index of biological integrity (Mac-IBI) for wetlands in West Virginia, USA from 20052006.

Table 14. A comparison of class-specific significant $\mathrm{R}^{2}$ values of the scores and the disturbance gradient resulting from the avian wetland indices of biological integrity (AW-IBI), anuran acoustically-based index of biological integrity (AA-IBI), the vegetation index of biological integrity (Veg-IBI), the macroinvertebrate index of biological integrity (Mac-IBI), and the cumulative multi-taxa, multi-metric IBI for wetlands in West Virginia, USA from 2005-2006.

Table 15. Relations between hybrid multi-metric, multi-taxa IBI and the disturbance gradient derived from the avian wetland indices of biological integrity (AW-IBI), anuran acoustically-based index of biological integrity (AA-IBI), the vegetation index of biological integrity (Veg-IBI) and the macroinvertebrate index of biological integrity (Mac-IBI) for wetlands in West Virginia, USA from 2005-2006. 


\section{Chapter 5: List of Figures}

Figure 1. Site locations of wetlands and ecoregions (Omernik 1987, Woods et al. 1999) used in developing class-specific macroinvertebrate indices of biological integrity (Mac-IBI) in West Virginia, USA from 2005-2006. One or more wetlands may be represented by dots due to map scale.

Figure 2. Box and whisker plot characteristics and resulting narrative description of reference and stressed sites' distribution of a biological metric value considered for inclusion into class-specific macroinvertebrate indices of biological integrity (MacIBI) for wetlands in West Virginia, USA from 2005-2006. Solid ovals represent the median of metric value (courtesy of Greg Pond, US EPA).

Figure 3. Frequency distribution of disturbance scores for sites used to develop classspecific macroinvertebrate indices of biological integrity (Mac-IBI) for wetlands in West Virginia, USA from 2005-2006. 


\section{Chapter 6: List of Tables}

Table 1. Metrics and sub-metrics of the Ohio Rapid Assessment Method (Mack 2001) used to define the disturbance gradient for use in developing multimetric indices of biological integrity for wetlands in West Virginia, USA from 2005-2006.

Table 2. Single and multi-taxa wetland indices of biological integrity and resulting relation with the disturbance score for wetlands in West Virginia, USA in 20052006.

Table 3. Significant $\mathrm{R}^{2}$ for class-specific single and multi-taxa indices of biological integrity (IBIs) for hydrogeomorphic (HGM) subclasses, designated HGM management classes, and Cowardin classes for wetlands of West Virginia, USA from 2005-2006.

Table 4. Multi-taxa, hybrid classification scheme wetland indices of biological integrity and resulting relation with the disturbance score for wetlands in West Virginia, USA in 2005-2006.

Table 5. Significant $\mathrm{R}^{2}$ for multi-taxa, hybrid classification schemes of indices of biological integrity (IBIs) for wetlands of West Virginia, USA from 2005-2006.. 295

Table 6. Avian community sampling summary statistics of metric scores statewide and by ecoregion used to form acoustically-based avian wetland indices of biological integrity (AW-IBI) for wetlands in West Virginia, USA 2005-2006.

Table 7. Anuran community sampling summary statistics of metric scores statewide and by ecoregion used to form acoustically-based anuran indices of biological integrity (AA-IBI) for wetlands in West Virginia, USA 2005-2006.

Table 8. Vegetation community sampling summary statistics of metric scores statewide and by ecoregion used to form vegetation indices of biological integrity (Veg-IBI) for wetlands in West Virginia, USA 2005-2006.

Table 9. Macroinvertebrate community sampling summary statistics of metric scores statewide and by ecoregion used to form macroinvertebrate indices of biological integrity (Mac-IBI) for wetlands in West Virginia, USA 2005-2006 


\section{Chapter 6: List of Figures}

Figure 1. Levels of resource commitment and corresponding taxa groups surveyed necessary for conducting indices of biological integrity (IBIs) for wetlands in West

Virginia, USA. 


\section{List of Appendices}

Appendix A. Response guild designations listed by species occurring in the MidAtlantic region for use in developing class-specific avian wetland indices of biological integrity (AW-IBI) in West Virginia, USA from 2005-2006 (Croonquist and Brooks 1991; O'Connell and Brooks 1998).................................................. 316

Appendix B. Site codes, ecoregion, location, Cowardin class, Hydrogeomorphic (HGM) subclass, origin, disturbance score, and reference/ stressed designations used to develop class-specific wetland indices of biological integrity (IBIs) in West Virginia from 2005-2006.

Appendix C. Avian species abundance and relative frequency per site used in developing class-specific avian wetland indices of biological integrity (AW-IBI) in West Virginia, USA from 2005-2006. 338

Appendix D. Part 1. Sites and corresponding metric values used in developing classspecific avian wetland indices of biological integrity (AW-IBI) in West Virginia, USA from 2005-2006. Blanks indicate a metric value of zero.

Appendix D. Part 2. Sites and corresponding metric values used in developing classspecific avian wetland indices of biological integrity (AW-IBI) in West Virginia, USA from 2005-2006. Blanks indicate a metric value of zero.

Appendix E. Avian community sampling summary statistics of metric scores statewide and by ecoregion used to form avian wetland indices of biological integrity (AW-

IBI) for wetlands in West Virginia, USA 2005-2006.

Appendix F. Avian community metrics box-and-whisker results and narrative descriptions for depressional wetlands $(\mathrm{N}=37)$. Classifications are reference $(\mathrm{R})$ and stressed (S).

Appendix G. Avian community metrics box-and-whisker results and narrative descriptions for floodplain wetlands $(\mathrm{N}=19)$. Classifications are reference $(\mathrm{R})$ and stressed (S).

Appendix H. Avian community metrics box-and-whisker results and narrative for impoundment wetlands ( $\mathrm{N}=13)$. Classifications are reference $(\mathrm{R})$ and stressed $(\mathrm{S})$.

Appendix I. Avian community metrics box-and-whisker results and narrative for emergent wetlands $(\mathrm{N}=38)$. Classifications are reference $(\mathrm{R})$ and stressed $(\mathrm{S}) \ldots . . .446$

Appendix J. Avian community metrics box-and-whisker results and narrative for scrubshrub wetlands ( $\mathrm{N}=23)$. Classifications are reference $(\mathrm{R})$ and stressed $(\mathrm{S})$.

Appendix K. Avian community metrics box-and-whisker results and narrative for forested wetlands $(\mathrm{N}=16)$. Classifications are reference $(\mathrm{R})$ and stressed $(\mathrm{S}) \ldots \ldots . .452$

Appendix L. Avian community metrics box-and-whisker results and narrative descriptions for riparian depression wetlands $(\mathrm{N}=27)$. Classifications are reference

$(\mathrm{R})$ and stressed (S

Appendix M. Avian community metrics box-and-whisker results and narrative descriptions for headwater floodplain wetlands $(\mathrm{N}=16)$. Classifications are reference $(\mathrm{R})$ and stressed $(\mathrm{S})$.

Appendix N. Anuran richness, maximum Wisconsin Index (WI) call chorus, and max estimate for anuran species by site used to form anuran acoustically-based indices of biological integrity (AA-IBI) in West Virginia, USA from 2005-2006. 461 
Appendix O. Metrics values by site used to form anuran acoustically-based indices of biological integrity (AA-IBI) in West Virginia, USA from 2005-2006. Blanks indicate a metric value of zero.

Appendix P. Anuran community sampling summary statistics of metric scores statewide and by ecoregion used to form acoustically-based anuran indices of biological integrity (AA-IBI) for wetlands in West Virginia, USA 2005-2006.

Appendix Q. Anuran community metrics box-and-whisker results and narrative descriptions for floodplain wetlands $(\mathrm{N}=14)$. Classifications are reference $(\mathrm{R})$ and stressed (S).

Appendix R. Anuran community metrics box-and-whisker results and narrative descriptions for depressional wetlands $(\mathrm{N}=33)$. Classifications are reference $(\mathrm{R})$ and stressed $(\mathrm{S})$.

Appendix S. Anuran community metrics box-and-whisker results and narrative descriptions for impoundment wetlands $(\mathrm{N}=13)$. Classifications are reference $(\mathrm{R})$ and stressed $(\mathrm{S})$.

Appendix T. Anuran community metrics box-and-whisker results and narrative descriptions for riparian depression wetlands $(\mathrm{N}=24)$. Classifications are reference (R) and stressed (S).

Appendix U. Anuran community metrics box-and-whisker results and narrative descriptions for headwater floodplain wetlands $(\mathrm{N}=12)$. Classifications are reference $(\mathrm{R})$ and stressed $(\mathrm{S})$.

Appendix V. Anuran community metrics box-and-whisker results and narrative descriptions for emergent wetlands $(\mathrm{N}=35)$. Classifications are reference $(\mathrm{R})$ and stressed (S). 496

Appendix W. Anuran community metrics box-and-whisker results and narrative descriptions for scrub-shrub wetlands $(\mathrm{N}=18)$. Classifications are reference $(\mathrm{R})$ and stressed (S).

Appendix X. Anuran community metrics box-and-whisker results and narrative descriptions for forested wetlands $(\mathrm{N}=9)$. Classifications are reference $(\mathrm{R})$ and stressed (S).

Appendix Y. Vegetation community metrics box-and-whisker results and narrative descriptions for depressional wetlands $(\mathrm{N}=37)$. Classifications are reference $(\mathrm{R})$ and stressed $(\mathrm{S})$.

Appendix Z. Vegetation community metrics box-and-whisker results s and narrative descriptions for floodplain wetlands $(\mathrm{N}=19)$. Classifications are reference $(\mathrm{R})$ and stressed (S).

Appendix AA. Vegetation community metrics box-and-whisker results and narrative descriptions for impoundment wetlands $(\mathrm{N}=13)$. Classifications are reference $(\mathrm{R})$ and stressed (S).

Appendix AB. Vegetation community metrics box-and-whisker results and narrative descriptions for emergent wetlands $(\mathrm{N}=38)$. Classifications are reference $(\mathrm{R})$ and stressed (S).

Appendix AC. Vegetation community metrics box-and-whisker results and narrative descriptions for scrub-shrub wetlands $(\mathrm{N}=23)$. Classifications are reference $(\mathrm{R})$ and stressed (S). 507 
Appendix AD. Vegetation community metrics box-and-whisker results and narrative descriptions for forested wetlands $(\mathrm{N}=16)$. Classifications are reference $(\mathrm{R})$ and stressed (S).

Appendix AE. Vegetation community metrics box-and-whisker results and narrative descriptions for riparian depression wetlands $(\mathrm{N}=27)$. Classifications are reference $(\mathrm{R})$ and stressed $(\mathrm{S})$.

Appendix AF. Vegetation community metrics box-and-whisker results and narrative descriptions for headwater floodplain wetlands $(\mathrm{N}=16)$. Classifications are reference $(\mathrm{R})$ and stressed $(\mathrm{S})$.

Appendix AG. Part 1. Relative and percent cover metric values for use in developing class-specific vegetation-based indices of biological integrity (Veg-IBI) in West Virginia, USA from 2005-2006. Blanks indicate a metric value of zero

Appendix AG. Part 2. Relative and percent cover metric values for use in developing class-specific vegetation-based indices of biological integrity (Veg-IBI) in West Virginia, USA from 2005-2006. Blanks indicate a metric value of zero.

Appendix AH. Relative and percent cover metric values of facultative wetland rating and wetter metrics for use in developing class-specific vegetation-based indices of biological integrity (Veg-IBI) in West Virginia, USA from 2005-2006. Blanks indicate a metric value of zero.

Appendix AI. Part 1. Richness metrics used in developing vegetation based indices of biological integrity (Veg-IBI) in West Virginia, USA from 2005-2006. Blanks indicate a metric value of zero.

Appendix AI. Part 2. Richness metrics used in developing vegetation based indices of biological integrity (Veg-IBI) in West Virginia, USA from 2005-2006. Blanks indicate a metric value of zero.

Appendix AJ. Importance values (IV) and mean DBH of tree strata metrics used to develop vegetation-based indices of biological integrity (Veg-IBI) for wetlands in West Virginia, USA from 2005-2006. Blanks indicate a metric value of zero. .... 546

Appendix AK. Vegetation summary statistics of metric scores statewide and by ecoregion used to form vegetation-based indices of biological integrity (Veg-IBI) for wetlands in West Virginia, USA 2005-2006. 550

Appendix AL. Nektonic macroinvertebrate community metrics box-and-whisker results and narrative descriptions for depressional wetlands $(\mathrm{N}=22)$. Classifications are reference $(\mathrm{R})$ and stressed $(\mathrm{S})$.

Appendix AM. Benthic macroinvertebrate community metrics box-and-whisker results and narrative descriptions for depressional wetlands $(\mathrm{N}=35)$. Classifications are reference $(\mathrm{R})$ and stressed $(\mathrm{S})$.

Appendix AN. Nektonic macroinvertebrate community metrics box-and-whisker results and narrative descriptions for floodplain wetlands $(\mathrm{N}=15)$. Classifications are reference $(\mathrm{R})$ and stressed $(\mathrm{S})$. 558

Appendix AO. Benthic macroinvertebrate community metrics box-and-whisker results and narrative descriptions for floodplain wetlands $(\mathrm{N}=17)$. Classifications are reference $(\mathrm{R})$ and stressed $(\mathrm{S})$.

Appendix AP. Nektonic macroinvertebrate community metrics box-and-whisker results and narrative descriptions for impoundment wetlands $(\mathrm{N}=13)$. Classifications are reference $(\mathrm{R})$ and stressed $(\mathrm{S})$. 
Appendix AQ. Benthic macroinvertebrate community metrics box-and-whisker results and narrative descriptions for impoundment wetlands $(\mathrm{N}=13)$. Classifications are reference $(\mathrm{R})$ and stressed $(\mathrm{S})$.

Appendix AR. Nektonic macroinvertebrate community metrics box-and-whisker results and narrative descriptions for riparian depression wetlands $(\mathrm{N}=17)$. Classifications are reference $(\mathrm{R})$ and stressed $(\mathrm{S})$.

Appendix AS. Benthic macroinvertebrate community metrics box-and-whisker results and narrative descriptions for riparian depression wetlands $(\mathrm{N}=26)$. Classifications are reference $(\mathrm{R})$ and stressed $(\mathrm{S})$.

Appendix AT. Nektonic macroinvertebrate community metrics box-and-whisker results and narrative descriptions for headwater floodplain wetlands $(\mathrm{N}=13)$.

Classifications are reference $(\mathrm{R})$ and stressed $(\mathrm{S})$. 570

Appendix AU. Benthic macroinvertebrate community metrics box-and-whisker results and narrative descriptions for headwater floodplain wetlands $(\mathrm{N}=14)$.

Classifications are reference $(\mathrm{R})$ and stressed $(\mathrm{S})$.

Appendix AV. Nektonic macroinvertebrate community metrics box-and-whisker results and narrative descriptions for emergent wetlands $(\mathrm{N}=28)$. Classifications are reference $(\mathrm{R})$ and stressed $(\mathrm{S})$.

Appendix AW. Benthic macroinvertebrate community metrics box-and-whisker results and narrative descriptions for emergent wetlands $(\mathrm{N}=35)$. Classifications are reference $(\mathrm{R})$ and stressed $(\mathrm{S})$

Appendix AX. Nektonic macroinvertebrate community metrics box-and-whisker results and narrative descriptions for scrub-shrub wetlands $(\mathrm{N}=19)$. Classifications are reference $(\mathrm{R})$ and stressed $(\mathrm{S})$.

Appendix AY. Benthic macroinvertebrate community metrics box-and-whisker results and narrative descriptions for scrub-shrub wetlands $(\mathrm{N}=22)$. Classifications are reference $(\mathrm{R})$ and stressed $(\mathrm{S})$.

Appendix AZ. Nektonic macroinvertebrate community metrics box-and-whisker results and narrative descriptions for forested wetlands $(\mathrm{N}=6)$. Classifications are reference (R) and stressed (S). 582

Appendix BA. Benthic macroinvertebrate community metrics box-and-whisker results and narrative descriptions for forested wetlands $(\mathrm{N}=14)$. Classifications are reference $(\mathrm{R})$ and stressed $(\mathrm{S})$.

Appendix BB. Nektonic macroinvertebrate richness, count and weight by family used to form macroinvertebrate indices of biological integrity for wetlands in West Virginia, USA 2005-2006.

Appendix BC. Benthic macroinvertebrate richness, count and weight by family used to form macroinvertebrate indices of biological integrity for wetlands in West Virginia, USA 2005-2006.

Appendix BD. Combined and stratified benthic and nektomic data summary statistics of metrics scores statewide and by ecoregion used to used to form macroinvertebrate indices of biological integrity for wetlands in West Virginia, USA 2005-2006. ... 634 


\title{
Chapter 1
}

\section{West Virginia Wetland Indices of Biological Integrity}

\section{Introduction and Justification for the Development of Wetland Indices of Biological Integrity for Wetlands in West Virginia}

\author{
Walter Veselka IV ${ }^{1}$ \\ James T. Anderson ${ }^{1,3}$ \\ Walter S. Kordek ${ }^{2}$
}

${ }^{1}$ Division of Forestry and Natural Resources, Wildlife and Fisheries Resources Program, West Virginia University, PO Box 6125, Percival Hall, Morgantown, WV 26506

${ }^{2}$ West Virginia Division of Natural Resources, Wildlife Resources Section, PO Box 67, Ward Road, Elkins, WV 26241

3 address correspondence to James T. Anderson, Ph.D., Division of Forestry and Natural Resources, Wildlife and Fisheries Resources Program, West Virginia University, PO Box 6125, Percival Hall, Morgantown, WV 26506. email: wetland@wvu.eduphone: (304) 293-2941 ext. 2445, fax: (304) 293-2441

Submitted in the style of:

Environmental Monitoring and Assessment 


\subsection{Introduction}

The Clean Water Act (CWA) of 1972 is the instrument by which water quality is protected within the United States. Through court decisions, the interpretation of this legislation has changed over time (Adler 1999; Downing et al. 2003; Murphy 2006). However, the CWA is generally considered to be effective in maintaining water quality, ensuring anti-degradation of water, and in slowing the rate of wetland loss.

The basis for the CWA focuses on "maintaining the chemical, biological, and physical integrity of waters within the United States." As this pertains to wetlands, the CWA has evolved into a process and structure by which the destruction of wetlands due to anthropogenic impacts must be mitigated, through either the creation of new wetlands, or the restoration of degraded ones. The wetlands created or restored as a result of mitigation have replicated the natural wetlands which they replaced with mixed success (Balcombe et al. 2005a,b,c; Brown and Veneman 2001; Cole and Brooks 2000a; Perry et al. 1996). However, as more research is being devoted to understanding the role wetlands play within a landscape, the prospects for successful mitigation are increasing (Brooks et al. 2005; Mitsch and Wilson 1996). Reference wetlands with minimal human impact are being used to evaluate mitigation success of wetlands with a landscape context (Bedford 1996; Brinson and Rheinhardt 1996). However, the true ecological success of these mitigated sites remains relative and subjective. For instance, mitigated wetlands are well-documented in improving water quality (Fleming-Singer and Horne 2006; Kovacic et al. 2006; Poe et al. 2003; White and Bayley 1999). However, the restoration of the biological flora and fauna, as well as the hydrologic and physical characteristics compared to natural wetlands, is questionable. Soil characteristics and hydrology of 
created wetlands are typically wetter than natural wetlands (Cole et al. 2006; Cole and Brooks 2000b), and lack variation in microtopography (Bruland and Richardson 2005; Stolt et al. 2000). Vegetation development and structure differ between natural and mitigated wetlands (Balcombe et al. 2005a; Brown and Veneman 2001); but this is not necessarily indicative of a mitigated wetland not performing the same ecosystem functions as natural wetlands (Wilson and Mitsch 1996). As may be expected, if differences in vegetation communities are not uncommon, neither are differences in invertebrate communities (Balcombe et al. 2005b; Stanczak and Keiper 2004), or avian (Brown and Smith 1998; Snell-Rood and Cristol 2003) and anuran assemblages (Balcombe et al. 2005c).

The process of determining whether wetland integrity is compromised has historically been through monitoring water chemistry. However, protecting wetlands in this manner does not ensure that the physical or biological integrity is being maintained. Chemical measurements are evidence of the condition at a point in time and the cumulative biotic effects of the chemical stressors may not be evident. Measuring physical parameters of a wetland can also overlook biological and chemical stressors affecting a system (Karr and Chu 1999; Yoder and Rankin 1995). Within the current federal wetland policy, despite the CWA mandate to protect water quality, wetland function and biotic integrity can be compromised from anthropogenic impacts in proximity to the wetlands (Harris 1988; Winter 1988; Yuan and Norton 2004). The functions that wetlands provide (e.g., the transfer and storage of water, production of plants and animals, biochemical transformation and storage, decomposition of organic materials, and provision of habitat) (Ehrenfeld 2004; Richardson 1994), occur on 
multiple spatial scales within a matrix of landscapes (Zedler 2003). Therefore evaluating the impacts and stressors that can influence wetlands also needs to be evaluated over time on a landscape basis (Bedford and Preston 1988; Hemond and Benoit 1988; Risser 1988; Whigham et al. 1988).

As the tools used to interpret and implement the CWA mandates have evolved, indices of biotic integrity (IBIs) have emerged as a cost-effective way of measuring the biological integrity of multiple systems both domestically and internationally (Karr and Chu 2000; Karr 1991; Miltner et al.2004; Moyle and Randall 1998; Simon et al. 2000; Teels et al. 2004; Veraat et al. 2004). Metrics, or biological attributes that respond minimally to natural disturbance while responding in a predictable and consistent manner to human impairment, are used to form IBIs. Biological integrity is specifically and operationally defined as the state of biota in systems with minimal human disturbance (Jackson and Davis 1995; Steedman 1995). A central premise to integrity is the assumption that all biological systems evolve towards a product of self organization resulting in community structure as a function of both positive and negative feedback (Campbell 2000). Community structure requires a prescribed amount of energy to maintain itself. With significant impacts via human impairment, the energy required to maintain this structural integrity is no longer attainable. As the system adapts, the shift will be represented by changes in biotic structure (Klopatek 1988). Changes in biotic structure should not be confused with differences in species' abundances and distributions due to differing wetland types (Brinson 1988), so a hierarchal approach to biological assessments that evaluates the community and population dynamics, within a regional landscape context, is best to detect losses in wetland function and regional 
biodiversity (Noss 1990). Deciphering the impairments of wetlands at multiple scales is important when seeking an understanding of open systems (Jacobson 2000); however, caution must be taken to consider apropos variables that are the stressors rather than symptoms or by-products of stressors. For example, the percent of impervious surface is the stressor, whereas roads and development are symptoms of the stressor (Brooks et al. 1998; Novotny et al. 2005).

A critical component in developing an IBI is the identification of an effective disturbance gradient that is sensitive enough to exhibit multiple levels of human disturbance (Mack, 2005, personal communication; U.S. EPA 2002). Local-level disturbance indices that require a site visit for assessment have been developed and used in Pennsylvania, Ohio, Minnesota, and Delaware to compare site-specific disturbance scores to biological attribute metric scores (Brooks et al. 2006; Helgen and Gernes 2002; Jacobs 2006; Mack 2001). Although each state has developed a disturbance assessment procedure, they are all based in-part on wetland stressors drawn from literature (Adamus and Brandt1990). In some of the above-mentioned states, the site level stressor gradient is augmented by data from spatial features to increase sensitivity of the disturbance index (Brooks et al. 2006). Using a geographic information system (GIS) is more cost-efficient than individual on-site visits (Brooks et al. 2004). Using only GIS derived data, a Landscape Disturbance Index (LDI) has served as the disturbance gradient in assessing human impairment (Brown and Vivas 2005). However, on-site assessments are generally more effective in demonstrating significant relations and explaining a greater part of the variability associated with metrics (Micacchion 2004). 
States have developed IBIs for wetlands using multiple assemblages of species including algae, plants, fish, macroinvertebrates, and birds (U.S. EPA 2002). By sampling multiple taxonomic groups there can be numerous candidate metrics from which to evaluate impairment to better understand the full complexity of wetland systems (Dale and Beyeler 2001; O'Connor et al. 2000).

Wetlands are commonly classified by vegetation structure (Cowardin et al. 1979) and will be referred to as the "Cowardin" classification method in this document. The Cowardin classes have been demonstrated to be an effective categorization for an amphibian-based IBI in Ohio wetlands (Miccachion 2004). This scheme groups wetlands as emergent (EM) (Figure 1), scrub-shrub (SS) (Figure 2), and forested (FO) (Figure 3); and is used in mapping by the National Wetland Inventory (NWI). An alternative to using vegetation to classify wetlands is the hydrogeomorphic (HGM) approach (Brinson 1993). The HGM classification resolves many of the shortcomings of the Cowardin approach. For example, in the Cowardin classification system a palustrine emergent wetland may be found along a river floodplain, fringing a lake, or as a prairie pothole; all of which are functionally dissimilar (Stevenson and Hauer 2002). The HGM approach is based on physical determinants of wetland structure and function, according to the geologic setting and hydrologic regime; therefore, allowing the aggregation of wetlands that are functionally similar (Smith et al. 1995).

When interpreting biological studies within wetlands it is necessary to think in terms of the influence that climate and hydrologic settings have on biological communities. This continuum is most easily thought of as a two-dimensional gradient represented by groundwater and atmospheric water. By locating the position of any 
wetland along both axes of the continuum, the potential biological expression of the wetland community can be predicted (Euliss et al. 2004). However, determining this point of hydrologic variability for wetlands is difficult and can complicate matters when attempting to apply and interpret it in relation to an IBI (Wilcox et al. 2002). Appropriate classifications, especially relative to hydrologic regimes, are essential to developing an effective IBI (Karr and Chu 1999). By classifying wetlands according to HGM subclasses, the subclasses themselves can be used as surrogate categorical variables to characterize hydrologic variability (Cole and Brooks 2000b; Cole et al. 1997; Merkey 2006). The coupling of the HGM approach of classifying wetlands with the IBI approach for measuring wetland impairment has been called for to increase the effectiveness and sensitivity in detecting disturbance (Stevenson and Hauer 2002). This technique achieved success in North Carolina (Rheinhardt et al. 1999) and Pennsylvania (Brooks et al. 2006).

In developing IBIs or bioassessments, stratification by ecoregion is important to reduce variance in the final product (Klopatek 1988; Omernik 1995). In some cases, indices can be sufficiently robust for use in multiple ecoregions (Hill et al. 2003; McCormick et al. 2001); however, multiple IBI standards have been developed to account for detectable, predictable, ecoregion variation (Mack 2001). Level 3 ecoregions (Omernik 1987) are the level of resolution used in existing regional IBI programs (Mack 2004; Micacchion 2004; Miller et al. 2006; Miller et al. 2004). 


\subsection{West Virginia}

Funding from the U.S. Environmental Protection Agency (EPA) and mandates under Section 316(b) of the CWA will enable West Virginia to develop monitoring standards and protocols that will ensure the protection of wetlands by 2011. Anticipating a shortage of future funding to support such programs, the West Virginia Division of Natural Resources (WVDNR) is focused on maximizing the effectiveness and efficiency of such a program. By borrowing lessons from other existing wetland monitoring programs, West Virginia's program development will be both time and cost-effective. Methods easily integrated into existing or planned West Virginia Wildlife Diversity Program (WDP) monitoring programs could cost less to drive this monitoring effort (Kordek, WVDNR, personal communication). West Virginia can maximize returns on expenditures, while maintaining or increasing surveying effort by selecting biological assemblages that can, at least in some capacity, be effectively surveyed by trained volunteers (Fore et al. 2001; Krzys et al. 2002; Witten 2005). Although methods implemented in this West Virginia study may differ from other monitoring programs, testing and evaluating existing IBI metrics and disturbance gradients can yield similar results (Herbst and Silldorff 2006).

The objectives in developing a wetland IBI for West Virginia are:

o Develop a protocol by which natural and mitigated wetlands can be monitored over time for changes and trends in biological integrity;

o Provide a tool by which the performance of mitigated wetlands can be compared to natural wetlands; 
o Build a series of robust IBIs for Cowardin and HGM classifications that can be applied state-wide, will be responsive to a local disturbance gradient, and that will serve as a baseline for future researchers to develop a landscape-level "Sensitivity Index" to predict the effects of land-use changes on biotic assemblages, allowing for more focused monitoring and restoration efforts. Accomplishing these objectives will occur over multiple stages. Sites will be selected across the state to represent the gradient of human impact to wetlands found in West Virginia. After intensive biological surveys at each site, a pool of potential metrics will be identified from the body of literature for each taxa group. Using the $75^{\text {th }}$ and $25^{\text {th }}$ percentile of a disturbance index, reference and stressed thresholds will be defined independently for the HGM and Cowardin classification schemes (Barbour et al. 1995). We will examine the relation between each taxa-specific suite of potential metrics and Cowardin and HGM classifications. Reference and stressed sites will then be plotted by potential metric using box-and-whisker plots. A rating system is used to examine the amount of overlap between reference and stressed sites that will generate a list of candidate metrics (Barbour et al. 1996). The candidate metrics will be tested for redundancy using Spearman's R statistic. Metrics with an r-value of $>0.80$ will be examined one-by-one to identify redundancy. The redundant candidate metrics that are least efficient in discriminating between the reference and stressed conditions will be discarded. An analysis of variance (ANOVA) will then test for an interaction between and among the remaining factors and the Level 3 aquatic ecoregion stratum within West Virginia (Barbour et al. 1999). After the elimination of metrics with an ecoregion or alternative classification scheme effect, we will examine the entire suite of metrics using 
a multivariate analysis of variance (MANOVA) to ensure the derived indices of biological integrity do not exhibit a cumulative ecoregion or alternative classification scheme effect. The resulting metrics will be included in the formation of a multimetric IBI. Each metric will be normalized to have a range of 0 to 10 , which will give us consistent scaled response levels for each metric (Bryce et al. 2002). Metrics for each biological assemblage sampled can then be added to form a taxon-specific IBI (Gerritsen 1995). These taxon-specific IBIs will then be used to compose a multi-taxa IBI (Griffith et al. 2005; O'Connor et al. 2000). Moreover, we will examine the sensitivity of hybrid IBIs, formed by combining metrics from the Cowardin and HGM classification schemes, to disturbance scores. Comparisons can then be drawn contrasting the sensitivities of multi-taxa IBI and taxon-specific IBIs using individual or hybrid wetland classifications.

Once this IBI has been developed it will provide a method for comparing like wetlands, including mitigated (i.e., constructed), with a consistent scoring technique over time. This will allow the detection of wetland trends as well as provide ways to evaluate the success of mitigation.

The wetland IBI will be used in conjunction with the existing stream condition index (Gerritsen et al. 2000), to monitor the health and quality of the states' waters, as mandated by the CWA (Kordek, 2007, personal communication). The intention is to use the wetland IBI to validate the effectiveness of a rapid wetland assessment. Wetlands assessed by the rapid assessment method will, in turn, be used to validate landscape level wetland assessments. Landscape level assessments, calibrated and verified by rapid wetland assessment methods, are the only cost-effective means of assessing the status of the wetlands in the state. Areas selected for more intensive study may be regionally (or 
otherwise) stratified such that a complete statewide wetland resource assessment could be completed on a regular basis. A similar approach is used to monitor other water bodies such that each 8-digit hydrologic unit code (HUC) is assessed once every 5 years. Selected wetlands will be evaluated using a rapid assessment procedure, and a subset will receive intensive biological surveys leading to IBIs that validate the larger sample. The results of these surveys will be used to identify individual wetlands and watersheds at risk or in poor condition. The WVDNR will use the wetland IBI to gauge the improvement in the health of these impacted wetlands. Before purchasing or restoring wetlands within impacted watersheds, an IBI can determine what wetland or series of wetlands are most biologically "intact," to maximize the effect of resources directed to restoration.

\subsection{Vegetation}

Vegetation assemblages have historically been used as a component in identifying jurisdictional wetlands (USACOE 1987), and recently used in the formation of multimetric vegetative IBIs to assess the integrity of wetlands (Chipps et al. 2006; Gernes and Helgen 2002; Mack 2004; Miller et al. 2006; Witten 2005). Plants are immobile, making plant communities well-suited as indicator assemblages, as they are susceptible to influences within their environment. For instance, vegetation communities respond in a predictable manner to anthropogenic disturbances, such as sedimentation (Mahaney et al. 2004a), nutrient enrichment (Craft and Richardson 1997; Drohan et al. 2006), and changes in hydrology (Koning 2005; Magee and Kentula 2005).

Multiple researchers from various regions within the United States and abroad have determined that hydrology is often the primary driver in the expression of wetland plant communities (Aznar et al. 2003; Kirkman et al. 2000; Koning 2005; Magee and 
Kentula 2005). There are other local effects that influence plant communities, but with varying degrees of magnitude. Age of constructed wetlands explains some variation in plant communities (Balcombe et al. 2005a). Wetland size is linked to wetland species richness, although this relation weakens from $\sim 20 \%$ of the variance explained to $\sim 10 \%$, when upland plants are included in analysis of playas in the Southern High Plains of Texas (Smith and Haukos 2002). Natural disturbances or fire influences succession of plant communities in both Canadian sphagnum wetlands and Atlantic Coastal Plain depressional wetlands (DeSteven and Toner 2004; Lachance and Lavoie 2004). The colonization by invasive or exotic species has prevented the expression of some natural vegetation assemblages regionally and in West Virginia (Drohan et al. 2006; Mahaney et al. 2004a, 2004b).

Vegetation assemblages also have been evaluated in a landscape context using GIS technologies. In Texas playas, as the percentage of agricultural land within a wetland basin increases, there is a predictable increase in plant diversity, consisting of mostly exotics and few native perennial species (Smith and Haukos 2002). In Minnesota, the proportion of disturbed land within $500 \mathrm{~m}$ of a wetland, the number of storm water inputs and the degree of cultivation explained $32 \%$ of the variation associated with percent native and herbaceous perennials (Galatowitsch et al. 2000). Ditches, canals, and other hydrologic modifiers connecting wetlands have been linked to the increased dispersal and propagation of invasive species (Aznar et al. 2003).

Vegetation metrics were designed, in part, to evaluate the recovery process of wetlands (Galatowitsch et al. 1999). This recovery process is important to understand, and should be used to identify processes that occur naturally over time, and those that can 
be accelerated with human intervention (Palmer et al. 1997). Some wetland species' seeds can remain viable in soil that had been used for agriculture for up to 50 years (Middleton 2003). Natural recolonization of wetland plant species is an effective technique for restoring abandoned agricultural fields, but in a New York study, when the native soil has been removed it is less successful (Brown 1999). Establishing vegetation structure and diversity is a critical component for restoration success of other wetland taxa (Brown et al. 1997; Calhoun et al. 2005). Creating variations in microtopography in restored wetlands leads to significant differences in soil temperature and moisture that facilitates the development of multiple plant communities and increased aboveground biomass (Bruland and Richardson 2005).

\subsection{Birds}

Avian species are among the most conspicuous and charismatic wetland species, making them ideal for biological assessment and cultivating public interest (Weller 1988). There is an extensive body of literature that suggests birds as indicators of habitat quality in both non-wetlands (Bradford et al. 1998; Canterbury et al. 2000; Croonquist and Brooks 1991; O’Connell et al.1998), and wetlands (Bryce et al. 2002; DeLuca et al. 2004; Galatowitsch et al. 1999). Metrics derived from bird data can be formulated from guilds (Brown and Smith 1998; Croonquist and Brooks 1991), which were developed focusing on using inexpensive methods that could be used consistently over a region (Brooks et al. 1991). These guilds were effective in discriminating between disturbed and undisturbed sites (Croonquist and Brooks 1991). A guild is defined as a group of species that exploit a class of environmental resources in a similar way or respond similarly to perturbations in habitat conditions (Szaro 1986). 
Many local factors, including anthropogenic stressors and natural variability, can influence the abundance and distribution of birds. The Ohio Rapid Assessment Method (ORAM) (Mack 2001) was initially developed to categorize natural wetlands for regulatory purposes and to contribute to the development of indicators of biological integrity. The robustness of ORAM was demonstrated by its effectiveness in predicting avian diversity, richness of species of concern, as well as richness of wetland dependent birds (Stapanian et al. 2004). Vehicular traffic, or proximity to roads, can alter the foraging behavior of wading birds (Stolen 2003). Other research found that even pedestrian traffic within $100 \mathrm{~m}$ of wetlands can have an influence on wetland bird communities (Francl and Schnell 2002). Moist-soil management techniques, though not a stressor and intended to maximize invertebrate and seed resources availability, affects timing and use of wetlands by waterfowl (Anderson and Smith 1999; Taft et al. 2002). Fish presence, and their affect on invertebrate populations, can limit food supply for hatchling waterfowl (Hornung and Foote 2006). Within bird communities of forested depressional wetlands, species richness and abundances of wetland associated birds were explained by the factors of forest characteristics and area (Riffell et al. 2006). The natural variability in wetland size and vegetation composition also can influence bird composition (Brown and Smith 1998; VanRees-Siewert and Dinsmore 1996), as some species are more susceptible to local influences than landscape factors, in part due to the mobility of the assemblage (Naugle et al. 2001).

Examining factors affecting wetland bird communities using GIS has been welldocumented. Spatial statistics have been developed to quantify landscape patterns depending on the study scale (McGarigal and Marks 1995). Landscape metrics such as 
diversity, which is based on Shannon's diversity index (Shannon and Weaver 1949) or Simpson's diversity index (Simpson 1949), examine the probability that any 2 patches selected at random will be different types. Contagion is another raster based landscape metric measuring the mixing of patches in a landscape and the dispersion of a single patch type throughout that landscape. Landscape patterns of diversity, contagion, mean forest-wetland patch size, and proportion of forest cover are all effective in reflecting changes in guild composition due to disturbance levels (Miller et al. 1997). A $500 \mathrm{~m}$ radius zone of influence has been used to quantify patterns of disturbance for a central Appalachian Bird Community Index (BCI) (O’Connell et al. 2000). Wetland bird species richness has also been correlated with wetland connectivity within $3 \mathrm{~km}$ (Fairbairn and Dinsmore 2001). This research was further validated as exhibited by a negative response by marsh bird communities to artificial habitat fragmentation and suburban development (Benoit and Askins 2002; DeLuca et al. 2004). Depending on the size and type of roads, non-wetland and wetland bird communities are susceptible to community effects from roads ranging from $200 \mathrm{~m}$ to $800 \mathrm{~m}$ away (Forman 2000). High biotic integrity of bird communities in New York is associated with roadlessness (Glennon and Porter 2005). The importance of landscape attributes for effective conservation is reflected in multiple scales. The relation between wetland bird assemblages and roads is most pronounced within $500 \mathrm{~m}$, whereas wetland connectivity influences assemblages up to distances of 2,500m (Whited et al. 2000). Yet we contend that for the purposes of an IBI, which can be used in a regulatory context, that wetlands should be evaluated based on local conditions. Regulation of activities on a broad, landscape level with multiple stakeholders is not logistically feasible. Landscape level characteristics may best be used 
for predicting wetland and watershed health when evaluated and modeled using local characteristics (Wardrop et al. 2007, Weller et al. 2007).

Efforts to restore avian habitat for migratory birds in forested floodplain ecosystems can be accelerated by planting early-successional tree species (Twedt et al. 2002). To continue to increase the conservation effort for wetland birds, it is important to provide regulatory recognition to small wetland complexes (Marzluff and Ewing 2001), despite the 2001 Solid Waste Authority of Northern Cook County v. U.S. Army Corps of Engineers (SWANCC) ruling (Christie and Hausmann 2003) and the 2006 Supreme Court Rapanos rulings (Murphy 2006).

\subsection{Amphibians}

The decline of amphibian populations is a well-documented trend attributed inpart to their sensitivity to human impacts (Wake 1991, Wyman 1990). Thin, permeable, unshelled eggs and life history characteristics including restrictive home ranges with requirements for both aquatic and terrestrial habitat, and limited dispersal capability make amphibians suitable subjects for bioassessments (Blaustein et al. 1994). The decline of amphibians has been linked to a number of anthropogenic sources such as habitat loss or fragmentation, acid deposition, increases in ultra-violet radiation, the spread of toxic substances, and introduction of predators and pathogens (Sparling et al. 2002). As such, it is often difficult to measure a direct cause-effect relation for amphibian declines. However, amphibian metrics have been derived and included in the making of wetland IBIs (Farr 2003; Micacchion 2004). The development of a consistent monitoring protocol, as well as an examination of amphibian IBI scores over time, may guide 
thinking relative to landscape level amphibian decline versus normal annual variation in numbers at a site (Pechmann et al. 1991).

Biotic influences on amphibian populations are a major component of amphibian community structure. For example, larval survival has been identified as the largest factor affecting population fluctuation in wood frogs (Rana sylvatica) (Berven 1990). Also, indirect competition for limited resources between species of tadpoles (i.e., those hatched early versus later) can affect the metamorphosed size and survival of the laterhatching species of amphibians (Morin 1987). Further, predation from other amphibians such as bullfrogs (Rana catesbiena) and red-spotted newts (Notophthalmus viridescens), as well as fish and odonates, can significantly affect the resulting amphibian community structure (Gascon and Travis 1992; Hecnar and M'Closkey 1997; Kurzava and Morin 1998).

Wetland size does not necessarily correlate with amphibian species richness (Semlitsch and Bodie 1998; Snodgrass et al. 2000a). However, the development of expected larval amphibian assemblages can be determined by hydroperiod, which has a weak relation to wetland size (Snodgrass et al. 2000b). The length of hydroperiod, as well as the spatial distribution of breeding pools, can impact amphibian species richness (Burne and Griffin 2005). Tree canopy cover of wetlands, which can be impacted by silvicultural treatments, may facilitate the drying of breeding pools. This can have a limiting effect on the distribution of species and can determine the outcome of amphibian community dynamics (DeMaynadier and Hunter 1998; Skelly et al. 1999). Impacts causing changes in water quality and $\mathrm{pH}$, and the subsequent changes in vegetative 
structure, are critical to habitat use and expression of amphibian communities (Anderson et al. 1999, Pehek 1995).

Many amphibian species use adjacent upland area during some aspect of their life, and in doing so typically exist as metapopulations, using several nearby wetlands interchangeably (Dodd and Cade 1998; Joyal et al. 2001; Semlitsch 1998). Disturbances within this upland area influence amphibian population viability (Gibbons 2003; Trenham and Shaffer 2005). The amount of forest area surrounding a wetland, as well as the degree of isolation within the landscape matrix in which a wetland exists, explains some of the variability exhibited by amphibian populations (Hecnar and M'Closkey 1998; Kolozsvary and Swihart 1999). However, with aquatic or other species tolerant of human influence, like the American toad (Bufo americanus), the landscape matrix may not be a good predictor of amphibian species composition (Guerry and Hunter 2002). Road densities within500-2,500 m of a wetland are associated with lower amphibian species richness (Lehtinen et al. 1999). Land use changes at distances up to $10 \mathrm{~km}$ from a wetland were linked to changes in anuran population dynamics over a 30 -year timeframe in New York (Gibbs et al. 2005).

Despite the literature suggesting that landscape indictors can negatively influence amphibian populations, these populations can recover. As the percent of forest cover increased in a previously predominately agriculture landscape, amphibian populations showed a remarkable ability to rebuild and recover (Gibbons et al. 2006). Best Management Practices (BMP) also can be implemented when amphibian habitat is impacted to mitigate many of the negative effects on these communities (Calhoun et al. 2005). 


\subsection{Invertebrates}

Wetland invertebrates, as in streams, are sensitive to disturbances from multiple types of impairments ranging from sediment and chemical stressors to community impacts from habitat alteration or landscape disturbance (Barbour et al. 1999; BendellYoung et al. 2000; Spieles and Mitsch 2000; Woodcock et al. 2005). As a result of the dynamic characteristics of wetlands, such as hydroperiod and vegetation succession, wetland invertebrate communities can represent the proliferation of multiple, diverse, ecological niches (Wissinger 1999). The multiple expressions of invertebrate communities within similar vegetation, as a function of anthropogenic impairment, has been used to form invertebrate based IBIs nationally (Burton et al. 1999; Helgen and Gernes 2002; Ohio EPA 2004) and internationally (Ortega et al. 2004). Land use disturbances quantified with GIS tools within a wetland catchment basin do not affect invertebrate metrics in the Prairie Pothole Region (Tangen et al. 2003) because invertebrate communities are often a function of more local effects that may not be adequately addressed using landscape level data alone (Johnson and Goedkoop 2002).

Invertebrate abundance and composition have been manipulated by moist-soil management techniques, a function of controlling the hydrology of a site, in wetlands as diverse as playas in Texas (Anderson and Smith 2000) and the lowland fields of England (Ausden et al. 2000). Within forested vernal pools, hydrology drives the expression of macroinvertebrate composition (Brooks 2000). As wetlands dry, terrestrial invertebrates will often colonize the site, affecting the survival of aestivating aquatic invertebrates (Batzer 2004). Woody debris and the rate of its decomposition, which is affected by saturation, is an important component of wetland invertebrate habitat (Braccia and Batzer 
2004). Vegetative structure, which affects water chemistry and is often a function of hydrology, explained macroinvertebrate community structure in emergent Maine wetlands (Woodcock et al. 2005).

The level of identification for wetland invertebrate specimens can influence the usefulness of data. Identifying specimens to the family level is faster and less prone to error than genus identification (Hilsenhoff 1988). In fact, for bioassessments, family level identification is sufficient in some cases (Gerritsen et al. 2000). Genus level identification is still important for understanding life histories and when attempting to identify environmental conditions with indicator species (King and Richardson 2002). However, using genus level identification for bioassessments can lead to added costs and increased ecological noise (Bailey et al. 2001).

Invertebrate communities have been shown to be structurally similar in comparisons between mitigated and natural wetland sites in multiple studies. However, the reasons for some of the degree of variation has been attributed to wetland age (Stanczak and Keiper 2004), a function of wetland age and vegetation structure (Balcombe et al. 2005b), and a function of wetland depth and the ability to sustain fish populations (Fairchild et al. 2000, Zimmer et al. 2000). The restoration of invertebrate communities in created wetlands can be stimulated by using vegetation plugs from natural wetlands to facilitate the colonization of some slower dispersing wetland invertebrates (Brady et al. 2002, Brown et al. 1997). The remains of wetland invertebrates, as well as drought-resistant eggs, can persist in soils even after they have been tilled (Euliss et al. 2002, 2001). This provides proof of prior wetland existence, as 
well as providing a potential source for the recolonization of the natural invertebrate communities.

\subsection{Quality control}

Quality control was conducted at every stage of data collection and analysis. Anuran and avian species' calls were learned using various audiotapes and confirmed by field technicians knowledgeable in respective taxa. Plant identification was performed by experts in field botany: William N. Grafton and Dr. James S. Rentch. Aquatic macroinvertebrate familial taxonomy was performed by myself and confirmed by Sarah McClurg, Donna Hartman, and Drs. Linda Butler and John Strazanac. Dr. James T. Anderson reviewed all methodologies and techniques incorporated into data collection for this project. Dr. George Seidel and James T. Anderson assisted in all statistical analyses.

\subsection{Conclusion}

Compromising wetland biological integrity by mismanaging the resource can have the same effect within the landscape as not managing wetlands at all. By not mitigating human impairments to wetlands, there can be broad devastating ecological effects such as the loss of biodiversity (Gibbs 2000) and changes in the health of flora and fauna populations resulting in changes in species niche-width and range boundaries (Swihart et al. 2003). Fragmentation as a result of human impacts can have far-reaching biological effects, including the rapid decline of endemic waterfowl and plant species (Liu et al. 2004; Miller et al. 1997; Saunders et al. 1991). The restoration of natural wetland ecosystems could provide ecosystem services, among them water supply and treatment, worth up to $\$ 33$ trillion per year worldwide (Costanza et al. 1997). It would be 
irrational to think that it is possible or desirable to return all North American wetlands, to pre-European settlement conditions. What are considered to be natural and pristine wetlands may actually be recovery relicts of wetlands that recovered from human impacts naturally from over a century ago (Thorson and Harris 1991). Wetland conservation, management, and mitigation strategies need to be based on realistic goals adapted to accomplishing specific objectives (Ehrenfeld 2000). Powerful tools exist to help prioritize and select areas with the greatest potential for restoration success (Russell et al. 1997). However, the process of restoring these habitats is, in and of itself, an experiment-in-progress (Mitsch et al. 1998).

The development of working wetland IBIs within West Virginia will allow resource managers the ability to consistently and effectively measure the current state of wetland ecosystems, identify potential restoration sites, and establish criteria for evaluating successful restoration (Hobbs and Harris 2001). Additionally, with the recent EPA ruling on "Compensatory Mitigation for Losses of Aquatic Resources" (40 CFR Part 230), mitigation banking becomes the preferred alternative to remedy wetland impacts. In the future, resource managers will be able to use the West Virginia wetland IBIs to ascertain, catalogue, and ensure the quality of these mitigation banks by comparing mitigation banking IBI scores to the IBI scores of wetlands found throughout the state. This represents another tool that can be used to gauge the effectiveness of "no net loss" in regards to biological integrity, and bring a measure of accountability to determine the relative success or failure of mitigation banks. 


\subsection{Literature Cited}

Adamus P.R., Brandt K. (1990). Impacts on quality of inland wetlands of the United States: A survey of indicators, techniques, and application of community-level biomonitoring data. U.S. Environmental Protection Agency, Environmental Research Laboratory. Corvallis, OR, Report, EPA/600/3-90/073.

Adler J. (1999). Swamp rules: the end of federal wetland regulation. Regulation, 22(2), 11-16.

Anderson J.T., Smith L.M. (2000). Invertebrate response to moist-soil management of playa wetlands. Ecological Applications, 10, 550-558.

Anderson J.T., Smith L.M. (1999). Carrying capacity and diel use of managed playa wetlands by nonbreeding waterbirds. Wildlife Society Bulletin, 27(2), 281-291.

Anderson A.M., Haukos D.A., Anderson J.T. (1999). Habitat use by anurans emerging and breeding in playa wetlands. Wildlife Society Bulletin, 27(3), 759-769.

Ausden M., Sutherland W.J., James R. (2001). The effects of flooding lowland wet grassland on soil macroinvertebrate prey of breeding wading birds. Journal of Applied Ecology, 38, 320-338.

Aznar J.C., Dervieux A., Grillas P. (2003). Association between aquatic vegetation and landscape indicators of human pressure. Wetlands, 23(1), 149-160.

Bailey R.C., Norris R.H., Reynoldson T.B. (2001). Taxonomic resolution of benthic macroinvertebrate communities in bioassessments. Journal of North American Benthological Society, 20(2), 280-286.

Balcombe C.K., Anderson J.T., Fortney R.H., Rentch J.S., Grafton W.N., Kordek W.S. (2005a). A comparison of plant communities in mitigation and reference wetlands in Mid-Appalachia. Wetlands, 25(1), 130-142.

Balcombe C.K., Anderson J.T., Fortney R.H., Kordek W.S. (2005b). Aquatic macroinvertebrate assemblages in mitigated and natural wetlands. Hydrobiologia, 541,175-188.

Balcombe C.K., Anderson J.T., Fortney R.H., Kordek W.S. (2005c). Wildlife use of mitigation and reference wetlands in West Virginia. Ecological Engineering, 25:85-99.

Barbour M.T., Stribling J.B., Karr J.R.(1995). Biological assessment and criteria: Tools for water resource planning and decision making. Davis W.S., Simon T.P. (Eds.), Multimetric approach for establishing biocriteria and measuring biological condition.(pp. 63-77). Ann Arbor, MI: Lewis Publishers. 
Barbour M.T., Gerritsen J., Griffith G.E., Frydenborg R., McCarron E., White J.S., Bastian M.L. (1996). A framework for biological criteria for Florida streams using benthic macroinvertebrates. Journal of North American Benthological Society, 13(2), $185-211$.

Barbour M.T., Gerritsen J., Snyder B.D., Stribling J.B. (1999). Rapid bioassessment protocols for use in streams and wadeable rivers: Periphyton, benthic macroinvertebrates and fish. U.S. Environmental Protection Agency. Washington, D.C.Report EPA 841-B99-002.

Batzer D. (2004). Movements of upland invertebrates into drying seasonal woodland ponds in northern Minnesota, U.S.A. Wetlands, 24(4), 904-907.

Bedford B., Preston E. (1988). Developing a scientific basis for assessing cumulative effects of wetland loss and degradation on landscape functions: status, perspectives, and prospects. Environmental Management, 12(5), 751-771.

Bedford B. (1996). The need to define hydrologic equivalence at the landscape scale for freshwater wetland mitigation. Ecological Applications, 6(1), 57-68.

Bendell-Young L.I., Bennet K.E., Crowe A., Kennedy C.J., Kermode A.R., Moore M.M., Plant A.L., Wood A. (2000). Ecological characteristics of wetlands receiving an industrial effluent. Ecological Applications, 10(1), 310-322.

Benoit L.K., Askins R.A. (2002). Relationship between habitat area and the distribution of tidal marsh birds. Wilson Bulletin, 114(3), 314-323.

Berven K.A. (1990). Factors affecting population fluctuations in larval and adult stages of the wood frog (Rana sylvatica). Ecology, 71(4), 1599-1608.

Blaustein A.R., Wake D.B., Sousa W.P. (1994). Amphibian declines: judging stability, persistence, and susceptibility of populations to local and global extinctions. Conservation Biology, 8(1), 60-71.

Braccia A., Batzer D. (2004). Invertebrates associated with woody debris in a southeastern U.S. forested floodplain wetland. Wetlands, 21(1), 18-31.

Bradford D.F., Franson S.E., Neale A.C., Heggem D.T., Miller G.R., Canterbury G.E. (1998). Bird species assemblages as indicators of biological integrity in Great Basin rangeland. Environmental Monitoring and Assessment, 49, 1-22.

Brady V.J., Cardinale B.J., Gathman J.P., Burton T.M. (2002). Does the facilitation of fauna recruitment benefit ecosystem restoration? An experimental study of invertebrate assemblages in wetland mesocosms. Restoration Ecology, 10(4), 617-626. 
Brinson M.M. (1988). Strategies for assessing the cumulative effects of wetland alteration on water quality. Environmental Management, 12(5), 655-662.

Brinson M.M. (1993). A hydrogeomorphic classification for wetlands. U.S. Army Engineers Waterways Experiment Station.Vicksburg, MS. Technical Report WRP-DE-4.

Brinson M.M., Rheinhardt R.(1996). The role of reference wetlands in functional assessment and mitigation. Ecological Applications, 6(1), 69-76.

Brooks R.P., Arnold D.E., Bellis E.D., Keener C.S., Croonquist M.J. (1991). A methodology from biological monitoring of cumulative impacts on wetland, stream, and riparian components of watersheds. Kusler J.A., Brooks G. (Eds.), Berne, New York: Association of Wetland Managers.

Brooks R.P., O'Connell T.J., Wardrop D.H., Jackson L.E. (1998). Towards a regional index of biological integrity: the example of forested riparian ecosystems. Environmental Monitoring and Assessment, 51:131-143.

Brooks R.T. (2000). Annual and seasonal variation and the effects of hydroperiod on benthic macroinvertebrates of seasonal forest ("vernal") ponds in central Massachusetts, U.S.A. Wetlands, 20(4), 707-715.

Brooks R.P., Wardrop D.H., Bishop J.A. (2004). Assessing wetland condition on a watershed basis in the Mid-Atlantic region using synoptic land-cover maps. Environmental Monitoring and Assessment, 94, 9-22.

Brooks R.P., Wardrop D.H., Cole C.A., Campbell D.A. (2005). Are we purveyors of wetland homogeneity? Ecological Engineering, 24(4), 331-340.

Brooks R.P., Wardrop D.H., Cole C.A. (2006). Inventorying and monitoring wetland condition and restoration potential on a watershed bases with examples from Spring Creek watershed, Pennsylvania, USA. Environmental Management,38(4), 673-687.

Brown S.C., Smith K., Batzer D. (1997). Macroinvertebrate response to wetland restoration in northern New York. Community and Ecosystem Ecology,26(5), 10161024.

Brown S.C., Smith C.R. (1998). Breeding season bird use of recently restored versus natural wetlands of New York. Journal of Wildlife Management,62(4), 1480-1491.

Brown S.C. (1999). Vegetation similiarity and avifaunal food value of restored and natural marshes in Northern New York. Restoration Ecology, 7(1), 56-68.

Brown S.C., Veneman P.L.M.(2001). Effectiveness of compensatory wetland mitigation in Massachusetts, USA. Wetlands, 21(4), 508-518. 
Brown M.T., Vivas B. (2005). Landscape development intensity index. Environmental Monitoring and Assessment, 101:289-309.

Bruland G.L., Richardson C.J. (2005). Hydrologic, edaphic, and vegetative responses to microtopographic reestablishment in a restored wetland. Restoration Ecology, 13(3), 515523.

Bryce S.A., Hughes R.M., Kaufman P.R. (2002). Development of a bird integrity index: using bird assemblages as indicators of riparian condition. Environmental Management, 30(2), 294-310.

Burne M.R., Griffin C.R. (2005). Habitat associations of pool-breeding amphibians in eastern Massachusetts, USA. Wetlands Ecology and Management, 13, 247-259.

Burton T.M., Uzarski D.G., Gathman J.P., Genet J.A., Keas B.A., Stricker C.A. (1999). Development of a preliminary invertebrate index of biotic integrity for Lake Huron coastal wetlands. Wetlands, 19(4), 869-882.

Calhoun A., Miller N.A., Klemens M.W. (2005). Conserving pool-breeding amphibians in human-dominated landscapes through local implementation of best development practices. Wetlands Ecology and Management, 13, 291-304.

Campbell D.E. (2000). Using energy systems theory to define, measure, and interpret ecological integrity and ecosystem health. Ecosystem Health, 6(3), 181-204.

Canterbury G.E., Martin T.E., Petit D.R., Petit L.J., Bradford D.F. (2000). Bird communities and habitat as ecological indicators of forest condition in regional monitoring. Conservation Biology,14(2), 544-558.

Chipps S.R., Hubbard D.E., Werlin K.B., Haugerud N.J., Powell K.A., Thompson J., Johnson T. (2006). Association between wetland disturbance and biological attributes in floodplain wetlands. Wetlands, 26, 456-467.

Christie J., Hausmann S. (2003). Various state reactions to the SWANCC decision. Wetlands, 23(3), 653-662.

Cole C.A., Brooks R.P., Wardrop D.H. (1997). Wetland hydrology as a function of hydrogeomorphic (HGM) subclass. Wetlands, 17(4), 456-467.

Cole C.A., Brooks R.P. (2000a). A comparison of the hydrologic characteristics of natural and created mainstem floodplain wetlands in Pennsylvania. Ecological Engineering, 14(3), 221-231.

Cole C.A., Brooks R.P. (2000b). Patterns of wetland hydrology in the Ridge and Valley Province, Pennsylvania, USA. Wetlands, 20(3), 438-447. 
Cole C.A., Urban C.A., Russo P., Murray J., Hoyt D., Brooks R.P. (2006). Comparison of the long-term water levels of created and natural wetlands in northern New York, USA. Ecological Engineering, 27(2), 166-172.

Costanza R., d'Arge R., de Groot R., Farber S., Grasso M., Hannon B., Limburg K., Naeem S., O'Neill R.V., Paruelo J.et al. (1997). The value of the world's ecosystem services and natural capital. Nature, 387, 253-260.

Cowardin L.M., Carter V., Golet F.C., LaRoe E.T. (1979). Classification of wetlands and deepwater habitats of the United States. U.S. Fish and Wildlife Service. Washington D.C. Report FWS/OBS-79/31.

Craft C.B., Richardson C.J. (1997). Relationships between soil nutrients and plant species composition in Everglades peatlands. Journal of Environmental Quality, 26, 224-232.

Croonquist M.J., Brooks R.P. (1991). Use of avian and mammalian guilds as indicators of cumulative impacts in riparian-wetland areas. Environmental Management, 15, 701714.

Dale V.H., Beyeler S.B. (2001). Challenges in the development and use of ecological indicators. Ecological Indicators, 1, 3-10.

DeLuca W.V., Studds C.E., Rockwood L.L., Marra P.P. (2004). Influence of land use on the integrity of marsh bird communities of Chesapeake Bay, USA. Wetlands, 24(4), 837847.

deMaynadier P.G., Hunter M.L.J. (1998). Effects of silvicultural edges on the distribution and abundance of amphibians in Maine. Conservation Biology, 12(2), 340-352.

DeSteven D., Toner M.M. (2004). Vegetation of upper coastal plain depression wetlands: environmental templates and wetland dynamics within a landscape framework.. Wetlands, 24(1), 23-42.

Dodd C.K.J., Cade B.S. (1998). Movement patterns and the conservation of amphibians in small, temporary wetlands. Canadian Journal of Zoology, 12(2), 331-339.

Downing D.M., Winer C., Wood L.D. (2003). Navigating through the Clean Water Act jurisdiction: a legal review. Wetlands, 23(3), 475-493.

Drohan P.J., Ross C.N., Anderson J.T., Fortney R.H., Rentch J.S. (2006). Soil and hydrological drivers of Typha latifolia encroachment in a marl wetland. Wetlands Ecology and Management, 14, 107-122.

Ehrenfeld J.J. (2000). Defining the limits of restoration: the need for realistic goals. Restoration Ecology, 8(1), 2-9. 
Ehrenfeld J.J. (2004). The expression of multiple functions in urban forested wetlands. Wetlands, 24(4), 719-733.

Euliss N.H.J., Mushnet D.M., Johnson D.H. (2001). Use of macroinvertebrates to identify cultivated wetlands in the Prairie Pothole Region. Wetlands, 21(2), 223-231.

Euliss N.H.J., Mushnet D.M., Johnson D.H. (2002). Using aquatic invertebrates to delineate seasonal and temporary wetlands in the Prairie Pothole Region of North American. Wetlands, 22(2), 256-262.

Euliss N.H.J., LaBaugh J.W., Fredrickson L.H., Mushnet D.M., Laubhan M.K., Swanson G.A., Winter T.C., Rosenberry D.O., Nelson R.D. (2004). The wetland continuum: a conceptual framework for interpreting biological studies. Wetlands, 24(2), 448-458.

Fairbairn S.E., Dinsmore J.J. (2001). Local and landscape level influences on wetland bird communities of the Prairie Pothole Region of Iowa, USA. Wetlands, 21(1), 41-47.

Fairchild G.W., Faulds A.M., Matta J.F. (2000). Beetle assemblages in ponds: effects of habitat and site age. Freshwater Biology, 44(3), 523-534.

Farr M.(2003). Amphibian assemblage response to anthropogenic disturbance in Pennsylvania wetlands. Master's thesis. State College, PA: Pennsylvania State University.

Fleming-Singer M.S., Horne A.J. (2006). Balancing wildlife needs and nitrate removal in constructed wetlands: the case of the Irvine Ranch Water District's San Joaquin Wildlife Sanctuary. Ecological Engineering, 26(2), 147-166.

Fore L.S., Paulsen K., O'Laughlin K. (2001). Assessing the performance of volunteers in monitoring streams. Freshwater Biology, 46, 109-123.

Forman R.T.T. (2000). Estimate of the area affected ecologically by the road system in the United States. Conservation Biology, 14(1), 31-35.

Francl K.E., Schnell G.D. (2002). Relationships of human disturbance, bird communities, and plant communities along the land-water interface of a large reservoir. Environmental Monitoring and Assessment, 73, 67-93.

Galatowitsch S.M., Whited D.C., Tester J.R. (1999). Development of community metrics to evaluate recovery of Minnesota wetlands. Journal of Aquatic Ecosystem Stress and Recovery, 6, 217-234.

Galatowitsch S.M., Whited D.C., Lehtinen R.M., Husveth J., Schik K. (2000). The vegetation of wet meadows in relation to their land-use. Environmental Monitoring and Assessment, 60, 121-144. 
Gascon C., Travis J. (1992). Does the spatial scale of experiment matter? A test with tadpoles and dragonflies. Ecology, 73(6), 2237-2243.

Gernes M.C., Helgen J.C. (2002). Indices of Biological Integrity (IBI) for Large Depressional Wetlands in Minnesota. Minnesota Pollution Control Agency. St. Paul, MN. Report to U.S. E.P.A., grant CD-995525-01.

Gerritsen J. (1995). Additive biological indices for resource management. Journal of North American Benthological Society, 14(3), 451-457.

Gerritsen J., Burton J., Barbour M.T. (2000). A stream condition index for West Virginia wadeable streams. Owing Mills, MD: Tetra Tech, Inc.

Gibbons J.W. (2003). Terrestrial habitat: a vital component for herptofauna of isolated wetlands. Wetlands, 23(3), 630-635.

Gibbons J.W., Winne C.T., Scott D.E., Willson J.D., Glaudas X., Andrews K.M., Todd B.D., Fedewa L.A., Wilkinson L., Tsaliagos R.N.et al. (2006). Remarkable amphibian biomass and abundance in an isolated wetland: implications for wetland conservation. Conservation Biology, 20(5), 1457-1465.

Gibbs J.P. (2000). Wetland loss and biodiversity conservation. Conservation Biology, 14(1), 314-317.

Gibbs J., Whiteleather K.K., Schueler F.W. (2005). Changes in frog and toad populations over 30 years in New York State. Ecological Applications, 15(4), 1148-1157.

Glennon M.J., Porter W.F. (2005). Effects of land use management on biotic integrity: an investigation of bird communities. Biological Conservation, 126, 499-511.

Griffith M.B., Hill B.H., McCormick F.H., Kaufman P.R., Herlihy A.T., Selle A.R. (2005). Comparative application of indices of biotic integrity based on periphyton, macroinvertebrates, and fish to southern Rocky Mountain streams. Ecological Indicators, 5, 117-136.

Guerry A.D., Hunter M.L.J. (2002). Amphibian distributions in a landscape of forests and agriculture: an examination of landscape composition and configuration. Conservation Biology, 16(3), 745-754.

Harris L.D. (1988). The nature of cumulative impacts on biotic diversity of wetland vertebrates. Environmental Management, 12(5), 675-693.

Hecnar S.J., M'Closkey R.T. (1997). The effects of predatory fish on amphibian species richness and distribution. Biological Conservation, 79, 123-131. 
Hecnar S.J., M'Closkey R.T. (1998). Species richness patterns of amphibians in southwestern Ontario ponds. Journal of Biogeography, 25(4), 763-772.

Helgen J.C., Gernes M.C. (2002). An invertebrate index of biological integrity (IBI) for large depressional wetlands in Minnesota. Minnesota Pollution Agency. St. Paul, MN. Report to U.S. EPA, grant CD-995525-01.

Hemond H.F., Benoit J. (1988). Cumulative impacts on water quality functions of wetlands. Environmental Management, 12(5), 639-653.

Herbst D.B., Silldorff E.L. (2006). Comparison of the performance of different bioassessment methods: similar evaluations of biotic integrity from separate programs and procedures. Journal of North American Benthological Society, 25(2), 513-530.

Hill B.H., Herlihy A.T., Kaufman P.R., DeCelles S.J., Vander Borgh M.A. (2003). Assessment of streams of the eastern United States using a periphyton index of biotic integrity. Ecological Indicators, 2, 325-328.

Hilsenhoff W.L. (1988). Rapid field assessment of organic pollution with a family-level biotic index. Journal of North American Benthological Society, 7(1), 65-68.

Hobbs R.J., Harris J.A. (2001). Restoration ecology: repairing the Earth's ecosystems in the New Millennium. Restoration Ecology, 9(2), 239-246.

Hornung J.P., Foote A.L. (2006). Aquatic invertebrate responses to fish presence and vegetation complexity in western boreal wetlands, with implications for waterbird productivity. Wetlands, 26(1), 1-12.

Jackson S., Davis W.S. (1995). Meeting the goal of biological integrity in water-resource programs of the U.S. Environmental Protection Agency. Journal of North American Benthological Society, 13, 592-597.

Jacobs A.D. (2006). Delaware Rapid Assessment Procedure v. 3.0. Delaware Department of Natural Resources and Environmental Control. Dover, DE.

Jacobson P.T. (2000). Evaluation of multi-metric bioassessment as an approach for assessing impacts of entrainment and impingement under Section 316 (b) of the Clean Water Act. Environmental Science and Policy,3, 107-115.

Johnson R.K., Goedkoop W. (2002). Littoral macroinvertebrate communities: spatial scale and ecological relationships. Freshwater Biology, 47, 1840-1854.

Joyal L.M., McCollough M., Hunter M.L.J. (2001). Landscape ecology approaches to wetland species conservation: a case study of two turtle species in Southern Maine. Conservation Biology, 15(6), 1755-1762. 
Karr J.R. (1991). Biological integrity: a long neglected aspect of water resource management. Ecological Applications, 1(1), 66-84.

Karr J.R., Chu E.W. (1999). Restoring life in running waters - better biological monitoring. Covelo, CA: Island Press.

Karr J.R., Chu E.W. (2000). Sustaining living rivers. Hydrobiologia, 422 / 423, 1-14.

King R.S., Richardson C.J. (2002). Evaluating subsampling approaches and macroinvertebrate taxonomic resolution for wetland bioassessment. Journal of North American Benthological Society, 21(1), 150-171.

Kirkman L.K., Goebel P.C., West L., Drew M.B., Palik B.J. (2000). Depressional wetland vegetation types: a question of plant community development. Wetlands, 20(2), 373-385.

Klopatek J. (1988). Some thoughts on using a landscape framework to address cumulative impacts on wetlands food chain support. Environmental Management, 12(5), 703-711.

Kolozsvary M.B., Swihart R.K. (1999). Habitat fragmentation and the distribution of amphibians: patch and landscape correlates in farmland. Canadian Journal of Zoology, 77, 1288-1299.

Koning C.O. (2005). Vegetation patterns resulting from spatial and temporal variability in hydrology, soils, and trampling in an isolated basin marsh, New Hampshire, U.S.A. Wetlands, 25(2), 239-251.

Kovacic D.A., Twait R.M., Wallace M.P., Bowling J.M.. (2006). Use of created wetlands to improve water quality in the Midwest- Lake Bloomington case study. Ecological Engineering, 28(3), 258-270.

Krzys G., Waite T.A., Stapanian M., Vucetich J.A. (2002). Assessing avian richness in remnant wetlands: towards an improved methodology. Wetlands, 22(1), 186-190.

Kurzava L.M., Morin P.J. (1998). Tests of functional equivalence: complementary roles of salamanders and fish in community organization. Ecology, 79(2), 477-489.

Lachance D., Lavoie C. (2004). Vegetation of sphagnum bogs in highly disturbed landscapes: relative influence of abiotic and anthropogenic factors. Applied Vegetation Science, 7, 183-192.

Lehtinen R.M., Galatowitsch S.M., Tester J.R.. (1999). Consequences of habitat loss and fragmentation for wetland amphibian assemblages. Wetlands, 19(1), 1-12. 
Liu H., Zhang S., Li Z., Lu X., Yang Q. (2004). Impacts on wetlands of large-scale landuse changes by agricultural development: the small Sanjiang Plain, China. Ambio, 33(6), 306-310.

Mack J.J. (2001). Ohio Rapid Assessment Method for Wetlands v. 5.0, User's manual and Scoring Forms. Ohio Environmental Protection Agency, Division of Surface Water, Wetland Ecology Unit. Columbus, OH. Ohio Technical Report WET/ 2001-1.

Mack J.J. (2004). Integrated wetland assessment program. Part 9: Field manual for the Vegetation Index of Biotic integrity for Wetlands v. 1.3. Ohio Environmental Protection Agency, Wetland Ecology Group, Division of Surface Water. Columbus, OH. Ohio EPA Technical Report WET/2004-9.

Magee T.K., Kentula M.E. (2005). Response of wetland plant species to hydrologic conditions. Wetlands Ecology and Management, 13, 163-181.

Mahaney W.M., Wardrop D.H., Brooks R.P. (2004a). Impacts of sedimentation and nitrogen enrichment on wetland plant community development. Plant Ecology, 175, 227243.

Mahaney W.M., Wardrop D.H., Brooks R.P. (2004b). Impacts of stressors on the emergence and growth of wetland plant species in Pennsylvania, U.S.A. Wetlands, 24(3), 538-549.

Marzluff J.M., Ewing K. (2001). Restoration of fragmented landscapes for the conservation of birds: a general framework and specific recommendations for urbanizing landscapes. Restoration Ecology, 9(3), 280-292.

McCormick F.H., Hughes R.M., Kaufman P.R., Peck D.V., Stoddard J.L., Herlihy A.T. (2001). Development of an index of biotic integrity for the Mid-Atlantic Highland region. Transactions of the American Fisheries Society, 130, 857-877.

McGarigal K., Marks B.J. (1995). FRAGSTATS: spatial pattern analysis program for quantifying landscape structure. Pacific Northwest Research Station, U.S. Forest Service, U.S. Department of Agriculture. Portland, OR. Gen. Tech. Rep. PNW-GTR-351.

Merkey D.H. (2006). Characterization of wetland hydrodynamics using HGM and subclassification methods in southeastern Michigan, USA. Wetlands, 26(2), 358-367.

Micacchion M. (2004). Integrated wetland assessment program. Part 7: amphibian index of biotic integrity (AmphIBI) for Ohio wetlands. Ohio Environmental Protection Agency, Wetland Ecology Group, Division of Surface Water. Columbus, OH. Ohio EPA Technical Report WET/2004-7.

Middleton B.A. (2003). Soil seed banks and the potential restoration of forested wetlands after farming. Journal of Applied Ecology, 40, 1025-1034. 
Miller J.N., Brooks R.P., Croonquist M.J. (1997). Effects of landscape patterns on biotic communities. Landscape Ecology, 12, 137-153.

Miller S.J., Wardrop D.H., Mahaney W.M., Brooks R.P. (2004). Plant-based indices of biological integrity (IBIs) for wetlands in Pennsylvania. Penn State Cooperative Wetlands Center.University Park, PA.

Miller S.J., Wardrop D.H., Mahaney W.M., Brooks R.P. (2006). A plant-based index of biological integrity (IBI) for headwater wetlands in central Pennsylvania. Ecological Indicators, 6, 290-312.

Miltner R.J., White D., Yoder C. (2004). The biotic integrity of streams in urban and suburbanizing landscapes. Landuse and Urban Planning, 69, 87-100.

Mitsch W.J., Wilson R.F. (1996). Improving the success of wetland creation and restoration with know-how, time, and self-design. Ecological Applications, 6(1), 77-83.

Mitsch W.J., Wu X., Nairn R.W., Weihe P.E., Wang N. Deal R., Boucher C.E. (1998). Creating and restoring wetlands. BioScience, 48(12), 1019-1030.

Morin P.J. (1987). Predation, breeding asynchrony, and the outcome of competition among tree frog tadpoles. Ecology, 68(3), 675-683.

Moyle P.B., Randall P.J. (1998). Evaluating the biotic integrity of watersheds in the Sierra Nevada, California. Conservation Biology, 12(6), 1318-1326.

Murphy J. (2006). Rapanos v. United States: wading through murky waters. National Wetlands Newsletter, 28(5), 15-19.

Naugle D.E., Johnson R.R., Estey M.E., Higgins K.F. (2001). A landscape approach to conserving wetland bird habitat in the Prairie Pothole Region of eastern South Dakota. Wetlands, 20(4), 588-604.

Noss R.F. (1990). Indicators for monitoring biodiversity: a hierarchical approach. Conservation Biology, 4(4), 355-364.

Novotny V., Bartosova A., O'Reilly N., Ehlinger T. (2005). Unlocking the relationship of biotic integrity of impaired waters to anthropogenic stresses. Water Research, 39, 184198.

O'Connell T.J., Jackson L.E., Brooks R.P. (1998). A bird community index of biotic integrity for the Mid-Atlantic highlands. Environmental Monitoring and Assessment, 51, 145-156.

O'Connell T.J., Jackson L.E., Brooks R.P. (2000). Bird guilds as indicators of ecological condition in the central Appalachians. Ecological Applications, 10(6), 1706-1721. 
O'Connor R., Walls T.E., Hughes R.M. (2000). Using multiple taxonomic groups to index the ecological condition of lakes. Environmental Monitoring and Assessment, 61, 207-228.

Ohio EPA. (2004). Integrated Wetland Assessment Program. Part 8: Initial development of Wetlands Invertebrate Community Index for Ohio. Ohio Environmental Protection Agency, Ecological Assessment unit, Division of Surface Water. Columbus, OH. Ohio EPA Technical Report WET/ 2004-8.

Omernik J.M. (1987). Ecoregions of the conterminous United States. Annals of the Association of American Geographers, 77:118-125.

Omernik J.M. (1995). Ecoregions: a spatial framework for environmental management. Davis W.S., Simon T.P. (Eds.),Biological assessment and criteria: tools for water resource planning and decision making. Lewis Publishers, Boca Raton, FL.

Ortega M., Velasco J., Millan A., Guerrero C. (2004). An ecological integrity index for littoral wetlands in agricultural catchments of semiarid Mediterranean regions. Environmental Management, 33(3), 412-430.

Palmer M.A., Ambrose R.F., Poff N.L. (1997). Ecological theory and community restoration ecology. Restoration Ecology, 5, 291-300.

Pechmann J.H.K., Scott D.E., Semlitsch R.D., Caldwell J.P., Vitt L.J., Gibbons J.W. (1991). Declining amphibian populations: the problem of separating human impacts from natural fluctuations. Science, 253, 892-895.

Pehek E.L. (1995). Competition, pH, and the ecology of larval Hyla andersonii. Ecology, 76(6), 1786-1793.

Perry M.C., Sibrel C.B., Gough G.A. (1996). Wetlands mitigation: partnership between an electric power company and a federal wildlife refuge. Environmental Management, 20(6), 933-939.

Poe A.C., Piehler M.F., Thompson S.P., Paerl H.W. (2003). Denitrification in a constructed wetland receiving agricultural runoff. Wetlands, 23(4), 817-826.

Rheinhardt R., Rheinhardt M.C., Brinson M.M., Faser K.E.J. (1999). Application of reference data for assessing and restoring headwater ecosystems. Restoration Ecology, $7(3), 241-251$.

Richardson C.J. (1994). Ecological functions and human values in wetlands: a framework for assessing impacts. Wetlands, 14, 1-9.

Riffell S., Burton T., Murphy M. (2006). Birds in depressional forested wetlands: area and habitat requirements and model uncertainty. Wetlands,26(1), 107-118. 
Risser P.G. (1988). General concepts for measuring cumulative impacts on wetland ecosystems. Environmental Management, 12(5), 585-589.

Russell G.D., Hawkins C.P., O'Neill M.P. (1997). The role of GIS in selecting sites for riparian restoration based on hydrology and land use. Restoration Ecology, 5(4), 56-68.

Saunders D.A., Hobbs R.J., Margules C.R. (1991). Biological consequences of ecosystem fragmentation: a review. Conservation Biology, 5(1), 18-32.

Semlitsch R.D. (1998). Biological delineation of terrestrial buffer zones for pondbreeding salamanders. Conservation Biology, 12(5), 1113-1119.

Semlitsch R.D., Bodie J.R. (1998). Are small, isolated wetland expendable? Conservation Biology, 12, 1129-1133.

Shannon C., Weaver W. (1949). The mathematical theory of communication. University of Illinois Press. Urbana, IL.

Simon T.P., Jankowski R., Morris C. (2000). Modification of an index of biotic integrity for assessing vernal ponds and small palustrine wetlands using fish, crayfish, and amphibian assemblages along southern Lake Michigan. Aquatic Ecosystem Health and Management, 3, 407-418.

Simpson E.H. (1949). Measurement of diversity. Nature, 163, 688.

Skelly D.K., Werner E.E., Cortwright S.A. (1999). Long-term distributional dynamics of a Michigan amphibian assemblage. Ecology, 80(7), 2326-2337.

Smith R.D., Ammann A., Bartoldus C., Brinson M.M. (1995). An approach for assessing wetland functions using hydrogeomorphic classification, reference wetlands, and functional indices. Waterways Experiment Station, U.S. Army Corps of Engineers. Vicksburg, MS. Technical Report WRP-DE-9.

Smith L.M., Haukos D.A. (2002). Floral diversity in relation to playa wetland area and watershed disturbance. Conservation Biology, 16(4), 964-974.

Snell-Rood E.C., Cristol D.A. (2003). Avian communities of created and natural wetlands: bottomland forests in Virginia. Condor, 105, 303-315.

Snodgrass J.W., Komoroski M.J., Bryan A.L.J., Burger J. (2000a) Relationships among isolated wetland size, hydroperiod, and amphibian species richness: implications for wetland regulations. Conservation Biology, 14, 414-419. 
Snodgrass J.W., Bryan A.L.J., Burger J. (2000b). Development of expectation of larval amphibian assemblage structure in southeastern depression wetlands. Ecological Applications, 10(4), 1219-1229.

Sparling D.W., Richter K.O., Calhoun A., Micacchion M. (2002). Methods for evaluating wetland condition \#12: Using amphibians in bioassessment of wetlands. U.S.

Environmental Protection Agency, Health and Ecological Criteria Division (Office of Science and Technology) and Wetlands Division (Office of Wetlands, Oceans, and Watersheds). Washington, DC.

Spieles D.J., Mitsch W.J. (2000). Macroinvertebrate community structure in high and low nutrient constructed wetlands. Wetlands, 20(4), 716-729.

Stanczak M., Keiper J.B. (2004). Benthic invertebrates in adjacent created and natural wetlands in northeastern Ohio, USA. Wetlands, 24(1), 212-218.

Stapanian M., Waite T.A., Krzys G., Mack J.J., Micacchion M.(2004). Rapid assessment indicator of wetland integrity as an unintended predictor of avian diversity. Hydrobiologia, 520, 119-126.

Steedman R.J. (1995). Ecosystem health as a management goal. Journal of North American Benthological Society, 13, 605-610.

Stevenson R.J., Hauer F.R. (2002). Integrating hydrogeomorphic and index of biotic integrity approaches for environmental assessment of wetlands. Journal of North American Benthological Society, 21(3), 502-513.

Stolen E.D. (2003). The effects of vehicle passage on foraging behavior of wading birds. Waterbirds, 26(4), 429-436.

Stolt M.H., Genthner M.H., Daniels W.L., Groover V.A., Nagle S., Haering K.C. (2000). Comparison of soil and other environmental conditions in constructed and adjacent palustrine reference wetlands. Wetlands, 20(4), 671-683.

Swihart R.K., Gehring T.M., Kolozsvary M.B., Nupp T.E. (2003). Responses of "resistant" vertebrates to habitat loss and fragmentation: the importance of niche breadth and range boundaries. Diversity and Distributions 9, 1-18.

Szaro R.C. (1986). Guild management: an evaluation of avian guilds as a predictive tool. Environmental Management, 10(5), 681-688.

Taft O.W., Colwell M.A., Isola C.R., Safran R.J. (2002). Waterbird responses to experimental drawdown: implications for the multispecies management of wetland mosaics. Journal of Applied Ecology, 39, 987-1001. 
Tangen B.A., Butler M.G., Ell M.J. (2003). Weak correspondence between macroinvertebrate assemblages and land use in Praire Pothole Region wetlands, USA. Wetlands, 23(1), 104-115.

Teels B.M., Mazanti L.E., Rewa C.A. (2004). Using an IBI to assess effectiveness of mitigation measures to replace loss of a wetland-stream ecosystem. Wetlands, 24(2), 375384.

Thorson R.M., Harris S.L. (1991). How "natural" are inland wetlands? An example from the Trail Wood Audubon Sanctuary in Connecticut, USA. Environmental Management, 15(5), 675-687.

Trenham P.C., Shaffer H.B. (2005). Amphibian upland habitat use and its consequences for population viability. Ecological Applications, 15(4), 1158-1168.

Twedt D.J., Wilson R.R., Henne-Kerr J.L., Grosshuesch D.A. (2002). Avian response to bottomland hardwood reforestation: the first 10 years. Restoration Ecology, 10, 645-655.

USACOE. (1987). Corps of Engineers Wetlands Delineation Manual. U.S. Army Corps of Engineers. Washington, DC. Technical Report Y-87-1.

U.S. EPA (2002). Methods for evaluating wetland condition: developing metrics and indexes of biological integrity. Office of Water, U.S. Environmental Protection Agency. Washington DC. Report EPA-822-R-02-016.

VanRees-Siewert K.L., Dinsmore J.J. (1996). Influence of wetland age on bird use of restored wetlands in Iowa. Wetlands, 16(4), 577-582.

Veraat J.A., de Groot R.S., Perello G., Riddiford N.J., Roijackers R. (2004). Selection of (bio) indicators to assess effects of freshwater use in wetlands: a case study of s'Albufera de Mallorca, Spain. Regional Environmental Change, 4, 107-117.

Wake D.B. (1991). Declining amphibian populations. Science, 253, 860.

Wardrop D.H., Kentula M.E., Stevens D.L.J., Jensen S.F., Brooks R.P. (2007). Assessment of wetland condition: an example from the Upper Juniata watershed in Pennsylvania, USA. Wetlands, 27, 416-431.

Weller D.E., Snyder M.N., Whigham D.F., Jacobs A.D., Jordan T.E. (2007). Landscape indicators of wetland condition in the Nanticoke River watershed, Maryland and Delaware, USA. Wetlands,27, 498-514.

Weller W.M. (1988) Issues and approaches in assessing cumulative impacts on waterbird habitats in wetlands. Environmental Management, 12, 695-701.

Whigham D.F., Chitterling C., Palmer B. (1988). Impacts of freshwater wetlands on water quality: a landscape perspective. Environmental Management, 12(5), 663-671. 
White J.S., Bayley S.E. (1999). Restoration of a Canadian prairie wetland with agricultural and municipal wastewater. Environmental Management, 24(1), 25-37.

Whited D.C., Galatowitsch S.M., Tester J.R., Schik K., Lehtinen R.M., Husveth J. (2000). The importance of local and regional factors in predicting effective conservation planning strategies for wetland bird communities in agricultural and urban landscapes. Landuse and Urban Planning, 49, 49-65.

Wilcox D.A., Meeker J.E., Hudson P.L., Armitage B.J., Black M.G., Uzarski D.G. (2002). Hydrologic variability and the application of index of biotic integrity metrics to wetlands: a Great Lakes evaluation. Wetlands, 22(3), 588-615.

Wilson R.F., Mitsch W.J. (1996) Functional assessment of five wetlands constructed to mitigate wetland loss in Ohio, USA. Wetlands, 16, 436-451.

Winter T.C. (1988). A conceptual framework for assessing cumulative impacts on the hydrology of nontidal wetlands. Environmental Management, 12(5), 605-620.

Wissinger S.A. (1999). Ecology of wetland invertebrates. Batzer D.P., Rader R.B., Wissinger S.A., (Eds.),Invertebrates in Freshwater Wetlands of North America, Ecology and Management. (pp. 1043-1086) New York, NY: John Wiley and Sons, Inc.

Witten M. (2005). Image-based plant estimate protocol: a field assessment method for surveying freshwater wetland vegetation in New England with volunteer groups. Lowell, MA: New England Interstate Water Pollution Control Commission.

Woodcock T., Longcore J., McAuley D., Mingo T., Bennatti C.R., Stromborg K. (2005). The role of $\mathrm{pH}$ in structuring communities of Maine wetlands macrophytes and Chironomid larvae (Diptera). Wetlands, 25(2), 306-316.

Wyman R.L. (1990). What's happening to the amphibians? Conservation Biology, 4, 350352.

Yoder C.O., Rankin E.T. (1995). Biological response signatures and the area of degradation value: new tools for interpreting multimetric data. Davis W.S., Simon T.S. (Eds.), Biological assessment and criteria: tools for water resource planning and decision making. (pp. 263-286) Boca Raton, FL: Lewis Publishers.

Yuan L.L., Norton S.B. (2004). Assessing the relative severity of stressors at a watershed scale. Environmental Monitoring and Assessment, 98, 323-349.

Zedler J.B. (2003). Wetlands at your service: reducing impacts of agriculture at the watershed scale. Frontiers in Ecology and Environment, 1(2), 65-72. 
Zimmer K.D., Hanson M.A., Butler M.J. (2000). Factors influencing invertebrate communities in prairie wetlands: a multivariate approach. Canadian Journal of Fisheries and Aquatic Sciences, 57, 76-85. 


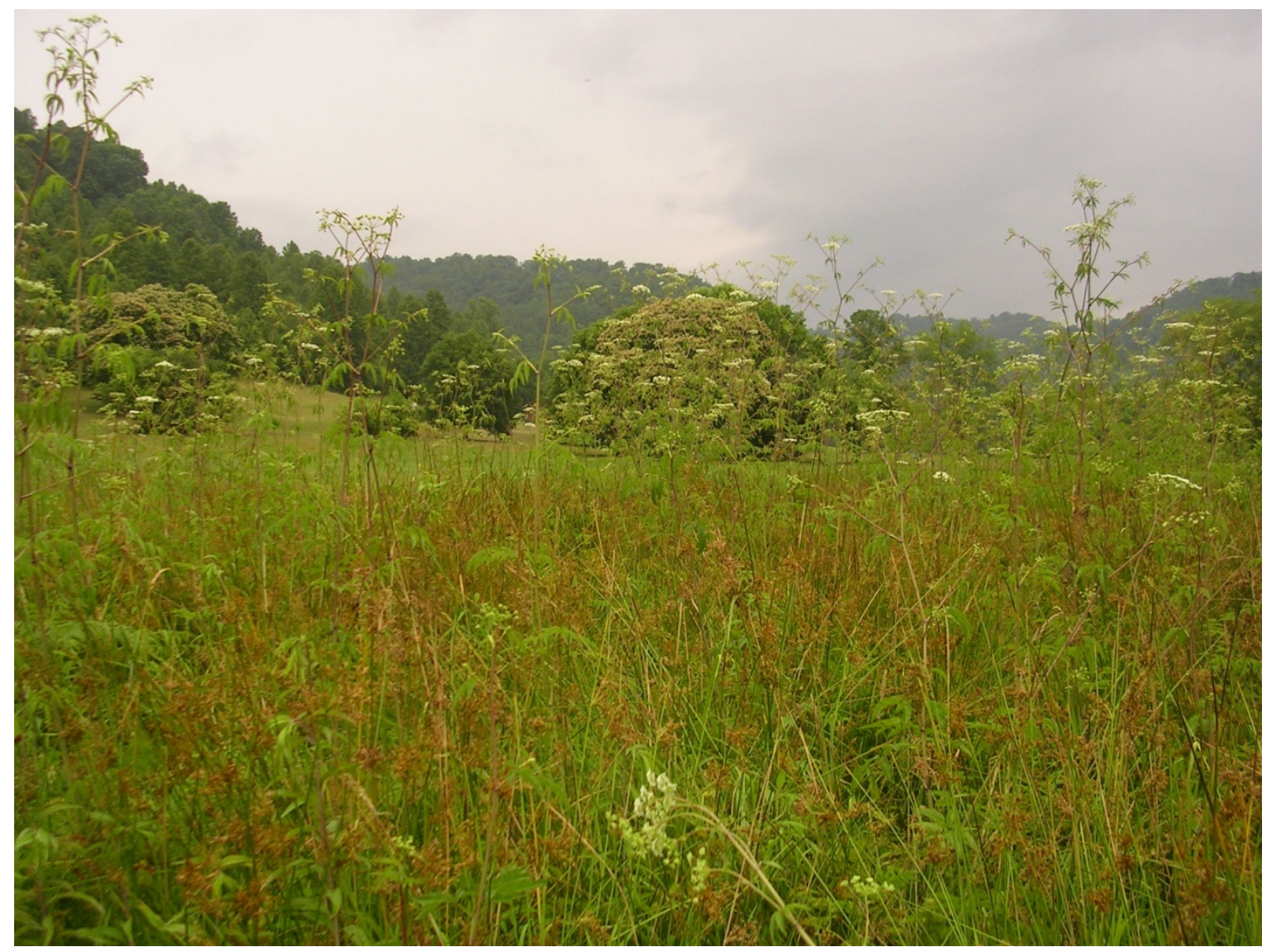

Figure 1. An example of an emergent wetland site in Wyoming county, West Virginia, used to develop indices of biological integrity for wetlands in West Virginia, USA, from 2005-2006. 


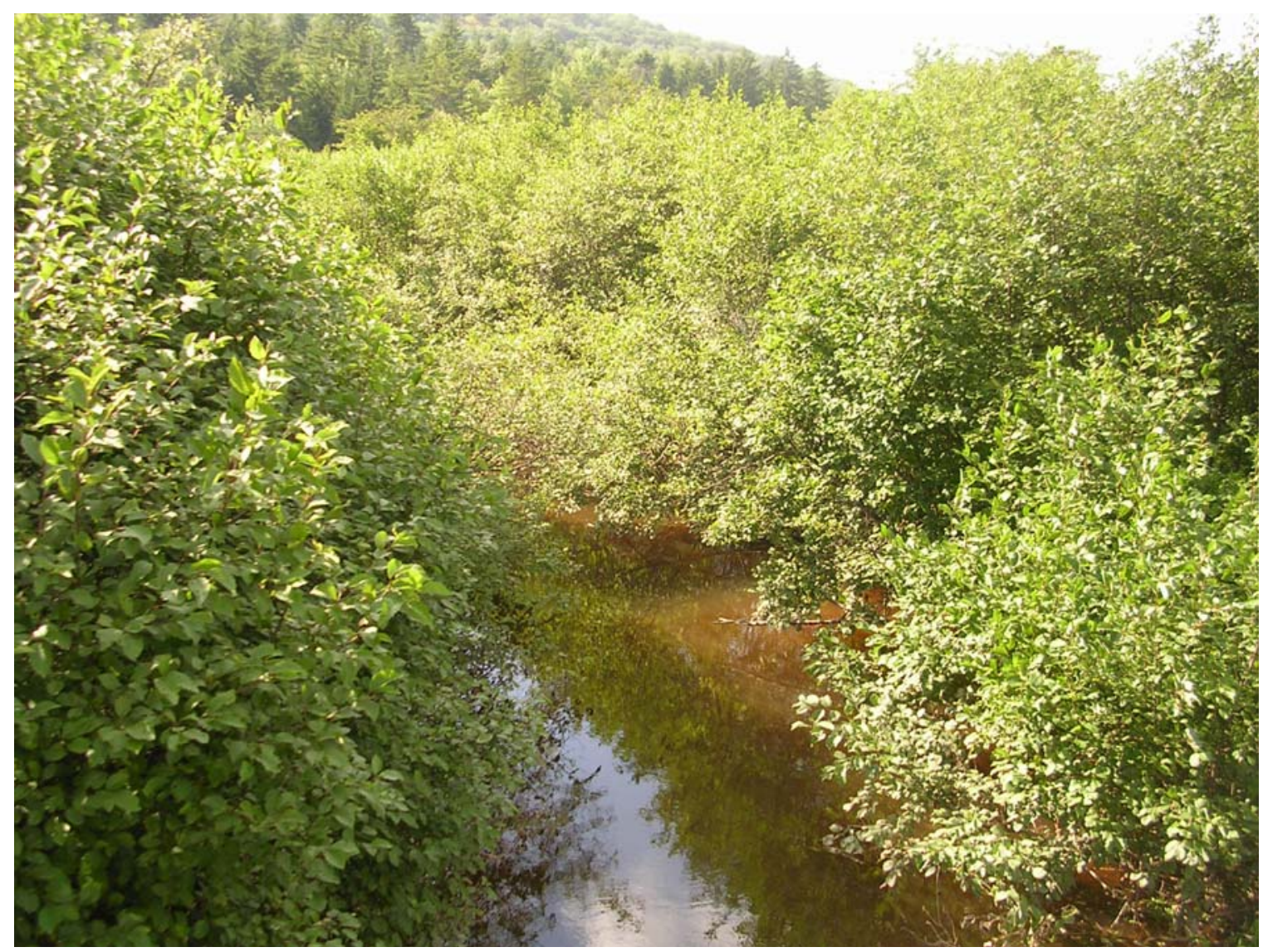

Figure 2. An example of a scrub-shrub wetland site in Pocahontas county, West Virginia, used to develop indices of biological integrity for wetlands in West Virginia, USA, from 2005-2006. 


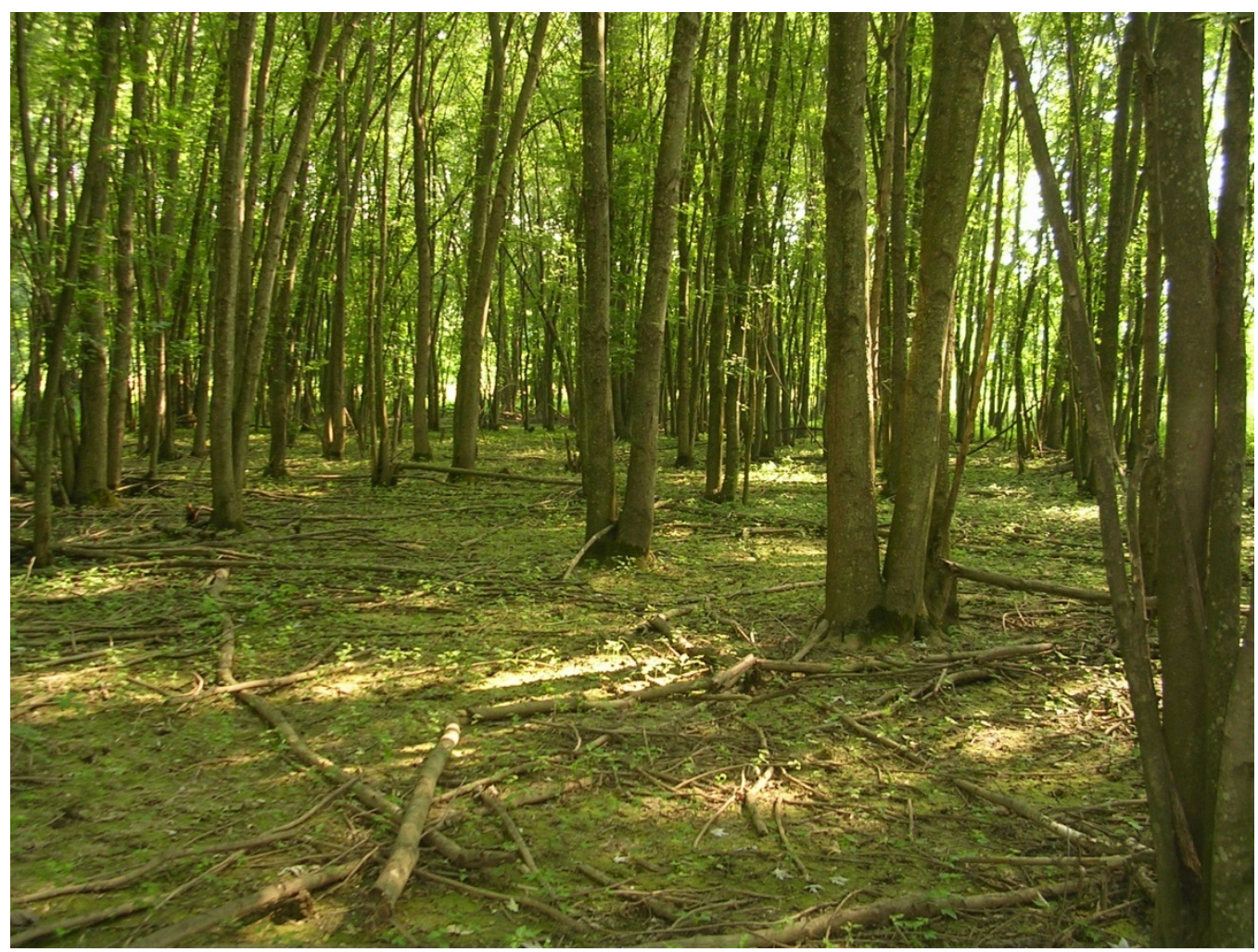

Figure 3. An example of a forested wetland site in Cabell county, West Virginia, used to develop indices of biological integrity for wetlands in West Virginia, USA, from 20052006. 


\title{
Chapter 2
}

\section{Avian Wetland Indices of Biological Integrity}

\section{Using Dual Classifications in the Development of Avian Wetland Indices of Biological Integrity for Wetlands in West Virginia, USA}

\author{
Walter Veselka IV ${ }^{1}$ \\ James T. Anderson ${ }^{1,3}$ \\ Walter S. Kordek ${ }^{2}$
}

${ }^{1}$ Division of Forestry and Natural Resources, Wildlife and Fisheries Resources Program, West Virginia University, PO Box 6125, Percival Hall, Morgantown, WV 26506

${ }^{2}$ West Virginia Division of Natural Resources, Wildlife Resources Section, PO Box 67, Ward Road, Elkins, WV 26241

3 address correspondence to James T. Anderson, Ph.D., Division of Forestry and Natural Resources, Wildlife and Fisheries Resources Program, West Virginia University, PO Box 6125, Percival Hall, Morgantown, WV 26506. email: wetland@wvu.eduphone: (304) 293-2941 ext. 2445, fax: (304) 293-2441

Submitted in the style of:

Environmental Monitoring and Assessment 


\begin{abstract}
Considerable resources are being used to develop and implement bioassessment methods for wetlands to ensure "biological integrity" is maintained under the Clean Water Act. Previous research has demonstrated avian composition is susceptible to human impairments at multiple spatial scales. Using only a local site specific disturbance gradient, we built Avian Wetland Indices of Biological Integrity (AW-IBI) specific to the Cowardin et al. (1979) and hydrogeomorphic (HGM) wetland classification schemes. The resulting class-specific AW-IBI were comprised of 1-4 metrics that varied in their sensitivity to the disturbance gradient. Sensitivity to the disturbance gradient increased, in some instances, when the metrics of each class-specific AW-IBI were combined. For example, the relation of the variability between an emergent headwater floodplain wetland and the disturbance gradient was greater when metrics sensitive to disturbance for headwater floodplain wetlands were combined (added) to those metrics sensitive to disturbance in emergent wetlands. Overall, all of the derived biological indices specific to Cowardin et al. (1979) classes of wetlands had a significant relation with the disturbance gradient; however, the biological index derived for floodplain wetlands exhibited a more consistent response to a local disturbance gradient. We suspect the consistency of this response is due to the inherent nature of the connectivity of available habitat in floodplain wetlands.
\end{abstract}

Keywords: avian composition, birds, disturbance, index of biological integrity, metrics, West Virginia, wetlands 


\subsection{Introduction}

Wetland function and biotic integrity can be compromised by anthropogenic impacts in proximity to a wetland (Harris 1988; Winter 1988; Yuan and Norton 2004). Functions that wetlands provide occur on multiple spatial scales within a matrix of landscapes (Zedler 2003). Therefore evaluating the impacts and stressors that can influence wetlands should focus on using site-specific criteria that reveal patterns within the landscape context (Bedford and Preston 1988). The mobility of avian assemblages infers that birds would be ideal candidates for assessing wetland condition from a landscape perspective (Naugle et al. 2001).Because birds are conspicuous and charismatic, the results of avian bioassessments can be easily related to the general public to help drive public policy and awareness (Weller 1988).

Using avian assemblages as indicators of impairment within riparian areas has demonstrated measurable differences in assemblage composition between minimally disturbed and agriculturally dominated watersheds in Pennsylvania (Croonquist and Brooks 1991). Bird data are formulated into response guilds that are effective indicators of human disturbance (Canterbury et al. 2000; O'Connell et al. 1998a). Guilds are better for assessment procedures than using individual species presence/ absence or abundance because no 2 species occupy the same niche, so using indicator species cannot be expected to ensure the maintenance of all other species (Hutto et al. 1987). This guild approach has been validated in numerous studies evaluating the quality of wetland habitat (Bryce et al. 2002; DeLuca et al. 2004; Galatowitsch et al. 1999). Guilds can be categorized by the nature of response to either structural, functional, or compositional changes. Structural guilds are groupings of species based on their response to site 
specific habitat characteristics, such as presence of cavity trees (Verner 1984). A functional guild is characterized by its response to changes in trophic structure (O’Connell et al. 1998a). Compositional guilds are based on population characteristics that change according to the responses and changes to the abundance and distribution of other species (O'Connell et al. 1998a). Using a combination of guilds that explore multiple elements of avian community dynamics will increase the detection probability of an ecosystem's changes in response to human impairment (Bayer and Porter 1988; Canterbury et al. 2000).

With an extensive body of potential metrics derived from previous literature (Bradford et al. 1998; Croonquist and Brooks 1991; Galatowitsch et al. 1999; O'Connell et el. 1998a), we systematically evaluated potential avian metrics for inclusion into an Avian Wetland Index of Biotic Integrity (AW-IBI) that could be used to evaluate the condition of wetlands across West Virginia. Biotic indices measuring wetland health have been based on both the Cowardin et al. (1979) system (Mack 2004) and the hydrogeomorphic (HGM) (Brinson 1993) classification system (Gernes and Helgen 2002, Galatowitsch et al. 1999). The Cowardin et al. (1979) system is used to classify the wetlands mapped by the National Wetland Inventory (NWI), and henceforth will be referred to as the Cowardin classification. Using the HGM approach to compare wetlands has been advocated because it compares wetlands that are functionally similar (Stevenson and Hauer 2002). However, its use has not been used to contrast or augment the Cowardin system, which is relatively straightforward to non-biologist resource managers and used in West Virginia for regulatory purposes (West Virginia State Code Chapter 22-11, 22-26). 
Our objective was to assess the classification systems for use in an AW-IBI that will be able to quantify the differences in bird communities between wetlands that are anthropogenically impaired and those in a natural state. In doing so we will be able to monitor the biological integrity of wetlands over time and to establish and ensure antidegradation standards are met, as well as compare the effectiveness of mitigated wetlands in replacing natural wetlands lost to development. Further, we explored using metric scores derived independently within the Cowardin and HGM-based AW-IBI to determine if a finer resolution of predicting the disturbance in wetlands can be ascertained by summing the metrics used in each classification system and comparing it to the disturbance gradient. For example, summing the resulting metric scores of the emergent AW-IBI with those of the floodplain AW-IBI gives us a greater number of metrics that are influenced by the disturbance gradient in an emergent wetland that is also a floodplain. This analysis was drawn from Gerritsen's (1995) argument that additive models are simple to understand which would make bioassessments more likely to be adopted by resource managers. Our methods reflect an attempt to construct a West Virginia avian community wetland index of biotic integrity within the parameters of existing or planned West Virginia Division of Natural Resources (WVDNR) programs and resources.

\subsection{Methods}

\section{$\underline{2.1 \text { Study Area }}$}

Study sites were selected across the U.S. Environmental Protection Agency's Level 3 aquatic ecoregions within West Virginia, USA: the Central Appalachians, the Ridge and Valley, and the Western Allegheny Plateau (Omernik 1987), as revised by 
Woods et al. (1999). Efforts were made to stratify sites across ecoregions and the Cowardin scheme by selecting random 7.5 minute quadrangles from a Geographic Information System (GIS) database. Statewide maps of wetlands according to the HGM scheme were not available and therefore could not be used to stratify according to this classification. On the ground field reconnaissance was then conducted to ascertain access to wetlands. This allowed us to maximize the number of sites (151) used in this study; 68 in 2005 and 83 in 2006, while efficiently sampling across the entire state (Figure 1). Sites were located $\geq 300 \mathrm{~m}$ from one another, and no 2 sites adjacent to one another had the same Cowardin subclass classification. Our sampling regime included individual wetlands and 20 wetland complexes in which we sampled from 2-5 sites per complex. However, each site was analyzed independently. Site location was recorded with a Geographic Positioning System (GPS) to establish a permanent survey station.

Wetlands were categorized by both the Cowardin classification system and by regional HGM subclasses (Cole et al. 1997), meaning each wetland site was categorized by both systems and that they were not mutually exclusive. For example, a palustrine emergent wetland may have been classified as a headwater floodplain or a surface water depression depending on its position in the landscape. Likewise, a headwater impoundment wetland could be either a palustrine emergent or scrub-shrub wetland, depending on vegetation development. To increase the efficiency and applicability of the AW-IBI, a guiding principle for developing a regional IBI (Brooks et al. 1998), some subclass designations were combined (Table 1). This was done to represent realistic management designations of wetland HGM subclasses and to increase sample size for statistical validity. However, enough wetlands of the regional HGM subclasses (Cole et 
al. 1997) were sampled to build headwater floodplain and riparian depression AW-IBI (Table 2). This allowed us to evaluate the difference between true HGM subclasses and our designated HGM management classes. Human-made wetlands, created as mitigation or otherwise, were designated according to the HGM designation the design mimics, in this study either depression, impoundment, or fringing wetlands.

\subsection{Bird Surveys}

Avian communities were surveyed at 1 point, twice per individual site using 5 minute single-observer 50-m radius point count surveys between 15 May and 1 July, 2005 or 2006 (Ralph et al. 1995). Surveys occurred between 30 minutes before sunrise and 1000 hours, under acceptable weather conditions (Ralph et al. 1995). All surveys were conducted at least 10 days apart. Metrics were calculated using the high count of species abundance numbers between the 2 site visits. The first visit also included a callback survey following the point count for secretive waterbirds, which were completed before 1 June to follow methods in use by the WVDNR Wildlife Diversity Program. These call-response surveys were used to detect the presence of Virginia rails (Rallus limicola), king rails (R. elegans), soras (Porzana carolina), American bitterns (Botaurus lentiginosus), least bitterns (Ixobrychus exilis), and pied-billed grebes (Podilymbus podiceps) following Gibbs and Melvin (1993). The waterbird surveys followed the methods of Balcombe et al. (2005), in which the playbacks broadcasted the target species calls for 50 seconds, followed by40 seconds of silence, before the next call would begin. These calls were broadcasted using a portable cassette player located $0.75 \mathrm{~m}$ above ground with a maximum sound pressure of $80 \mathrm{~dB} 1 \mathrm{~m}$ from the recorder. These surveys 
increased the likelihood of detecting these secretive waterbirds and can be used to monitor changes in the population over time (Gibbs and Melvin 1997).

\section{$\underline{2.3 \text { Disturbance Gradient }}$}

Defining a consistent and applicable disturbance gradient that metrics respond predictably to, is a critical step towards building an IBI (John Mack, Ohio EPA, personal communication, 2005). The Ohio Rapid Assessment Method, version 5.0 (ORAM) was developed to assess the quality of natural wetlands in Ohio (Mack 2001). It has been used in Ohio as the disturbance gradient in wetland amphibian and plant IBIs, as well as a predictor of avian diversity (Mack 2004; Micacchion 2004; Stapanian et al. 2004). The ORAM not only examines disturbances, but the habitat and landscape characteristics associated with each wetland. It is a wetland equivalent of the Rapid Bioassessment Procedure (RBP)that is used in stream research and monitoring (Barbour et al.1999).Our disturbance gradient was drawn from specific metrics and sub-metrics from the ORAM that are directly related to human disturbance on a local scale (Table 3). These metrics and submetrics formed a disturbance score that had a maximum of 39 , indicating no visible impact from human impairment. The minimum score of 4 indicated severe human impacts. The metrics selected for inclusion into the AW-IBI were based on the metrics' responses to the disturbance score. By selecting a disturbance gradient that is straightforward and easy to use, the stressors that comprise it can be manipulated by resource managers (Brooks et al. 1998). For example, if we are able to implement best management practices that minimize local stressors within the vicinity of wetlands, we would expect a demonstrable effect on the expression of biological communities within these wetlands (Calhoun et al. 2005). 


\subsection{Reference and Stressed Sites Designations}

The designation of reference and stressed sites is critical to metric testing and the formation of an IBI. We chose reference sites based on the concept of least-disturbed conditions. These sites were not intended to be pristine or free from any evidence of human manipulation, but to represent examples of what can be realistically expected from a minimally impacted wetland in West Virginia (Omernik 1995). Disturbance gradient scores in the $75^{\text {th }}$ and $25^{\text {th }}$ percentile were used to categorize reference and stressed conditions, respectively (Barbour et al. 1995). Reference and stressed designations were developed independently for Cowardin and designated HGM management class across all Level 3 ecoregions (Omernik 1987; Woods et al. 1999) because these designations were based on human impairment characteristics throughout West Virginia rather than the ecological basis of the ecoregions.

\subsection{Data Analysis}

The presence and abundance of each avian species was recorded using the high count of each species of the 2 survey periods and categorized in response guilds (Croonquist and Brooks 1991; O’Connell et al. 1998a). These response guild classifications (Appendix A) were then used to derive a list of 23 candidate metrics that have been used to detect levels of human impairment in previous studies (Table 4). These guilds were categorized according to their relation with ecosystem integrity as more or less responsive to the individual wetland characteristics of structure, function, and composition, or in some cases a combination of these characters ( $\mathrm{O}^{\prime}$ Connell et al. 1998a). 
An objective in building the AW-IBI was to ensure that like-wetlands were being compared. To develop an applicable, statewide,avian community IBI, we analyzed the data in a series of elimination steps for each candidate metric. This process enabled us to build indices of biotic integrity specific to individual HGM or Cowardin classes, which then allowed us to compare and contrast the 2 classification systems to augment one another to increase sensitivity to disturbance scores. By evaluating AW-IBIs across wetland types with an individualized approach, rather than a "one size fits all" approach, we were able to detect and characterize subtle AW-IBI differences resulting from impairments to different wetland types.

Metrics were tested for responsiveness to the human disturbance index using boxand-whisker plots. The metric values for reference sites and stressed sites for each categorization were plotted side by side. A visual comparison examining the interquartile range and median of each metric was used to designate a narrative rating of discriminatory power (Barbour et al. 1996). Metrics were classified as excellent, good, fair, or poor (Figure 2). Fair and poor metrics were removed from further analysis.

The discrimination efficiency, or effectiveness of the metric values to discriminate between reference and stressed sites, was calculated for metrics rated good and excellent (Equation 1). Those with a discrimination efficiency value below $60 \%$ were discarded from further analysis because of their inability to consistently differentiate between reference and stressed conditions.

\section{Equation 1:}

Discrimination Efficiency $=100 \times(\boldsymbol{a} / \boldsymbol{b})$

where, $\boldsymbol{a}=$ the number of stressed sites scoring below 25 th percentile of reference $\boldsymbol{b}=$ the total number of stressed sites. 
The remaining metrics were tested for redundancy using Spearman's R correlation (Hughes et al. 1998). Metrics with an R-value $>0.80$ were considered highly correlated (Table 5).Of the correlated pairs of metrics, the one with the greatest discrimination efficiency between reference and stressed sites was retained for inclusion into the AW-IBI (Table 4).If correlated metrics had the same discrimination efficiency, then both metrics were retained for further ecoregion and classification scheme screening to determine which metric was best suited for inclusion in the AW-IBIs.

Class-specific AW-IBIs were not developed for wetland classes with fewer than 5 referenceand5 stressed sites (Chipps et al. 2006). Sites were designated by sampling year. However, this effect was not tested because an individual wetland was only sampled during1 year of the study period, not both (O'Connell et al. 1998b; Reiss 2006). All statistical tests were conducted at an a priori alpha level of 0.05 (Mack 2004; Micacchion 2004).

Within the remaining suite of metrics for each of the resulting class-specific AWIBI, we tested for an ecoregion effect or alternative classification effect using a series of 2-wayanalyses of variances (ANOVA). The data were not transformed based on the observation that the violation of normality, in our case, was small and inconsequential to the overall association we measured (Miller et al. 2006). The metric values from each site (dependent variables) were individually examined for an interaction with the ecoregion, Cowardin class, and designated HGM management class (Table 6). This test was conducted to screen the remaining metrics for ecoregion or classification bias without the excess "noise" generated by redundant metrics, or those not capable of discriminating between reference and stressed conditions. Reference and stressed sites 
were used because we expected the marginally impacted wetland values to vary in their response depending on the specific stressors in each wetland. Stressed sites represent the cumulative impact of multiple stressors, whereas reference sites are those with minimal disturbances. Using both reference and stressed sites to look for differences among ecoregions and classes is one of the guidelines for implementing regional indices of biological integrity (Brooks et al. 1998).

The metrics that were significantly influenced by the ecoregion or alternative wetland classification effect were omitted as metrics capable of discriminating between reference and stressed conditions throughout West Virginia. When multiple metrics were used to derive the class-specific AW-IBI, the metrics were evaluated a final time with a multivariate analysis of variance (MANOVA), testing for a cumulative effect on the metric values at both reference and stressed sites from ecoregion or classification scheme influences (Table 7). This post-hoc analysis was meant to ensure the derived AW-IBI was appropriately classified, resulting in applicable and robust indices of biological integrity.

After the series of tests finalizing the metrics used in the resulting AW-IBI were conducted, the integer metrics, such as richness, were then normalized (0-1) to allow scoring comparisons to be made (Equation 2).

\section{Equation 2:}

Normalized value $=$ metric value $/$ maximum metric value Metrics responding positively to human impairment were inversed (Equation 3) to enable a consistent response for all metric values. 


\section{Equation 3:}

Inverted metric value $=\mid 1-($ metric responding positively to human impairment $) \mid$ Metrics included in the AW-IBI were scored on a continuous $0-10$ scale (Blocksom 2003; Bryce et al. 2002). The influence of outlier values was mitigated by using the best standard value (BSV) of each metric, which was determined to be the $95^{\text {th }}$ percentile of the highest values (Blocksom 2003). This scoring technique is consistent with the West Virginia Stream Condition Index (Gerritsen et al. 2000). This scoring technique performed better in comparisons with discrete scoring methods for metrics (Blocksom 2003). Metric scores were standardized by dividing the raw metric value by the range in that metric (Hill et al. 2003) and multiplying by 10 (Equation 4).

\section{Equation 4:}

Metric score $=10 \times\left(\right.$ raw metric value $/\left(95^{\text {th }}\right.$ percentile - low metric value $\left.)\right)$

Using the metrics appropriate for each classification, AW-IBIs were formed by summing all metrics selected for inclusion. The total number of metrics included in the AW-IBI varied by each classification. For example, the number of suitable metrics that could consistently discriminate between reference and stressed conditions in a depressional wetland was 2 , whereas 4 metrics were used to discriminate between reference and stressed sites in a floodplain wetland.

The disturbance gradient and the distribution of the AW-IBI scores for the reference sites were used to set numeric thresholds describing wetland condition (Gerritsen et al. 2000). Categorical threshold limits for AW-IBI scores were set using the $75^{\text {th }}, 25^{\text {th }}$, and $5^{\text {th }}$ percentiles for reference sites (Table 8 ). Sites scoring above the $75^{\text {th }}$ percentile were designated as excellent, those between the $25^{\text {th }}$ and $75^{\text {th }}$ percentile were 
considered good, below the $25^{\text {th }}$ percentile and above the $5^{\text {th }}$ percentile were fair, and those below the $5^{\text {th }}$ percentile represented poor wetland conditions (Hill et al. 2003; McCormick et al. 2001).

The relation between AW-IBI scores and the disturbance score were examined and plotted using simple linear regression specific to each classification. This enabled us to interpret and compare the results of our derived AW-IBI accordingly.

In addition to scoring each wetland with an individual designated HGM management and Cowardin class AW-IBI score, we used the additive properties of metrics to form a specific hybrid AW-IBI that combined the classification schemes, pending large enough sample sizes (Brinson 1993; Cole et al. 1997; Cowardin et al. 1979). This method of adding the individual metric scores of the different classes of resulting AW-IBI has not been documented in the prevailing literature, and was adopted out of an argument for implementing additive indices for resource management (Gerritsen 1995). As an example, this novel approach examines a palustrine scrub-shrub floodplain wetland using all the suitable metrics in both the scrub-shrub and floodplain AW-IBI that were not duplicated. If a metric was selected for inclusion in both classes of AW-IBI the value used in the calculation was the average metric score between the 2 classes. Hence, by increasing the number of metrics applicable to a particular wetland we will be able to determine if more metrics enabled us to ascertain wetland condition with a stronger degree of certainty. 


\subsection{Results}

\subsection{Ecoregions and site classifications}

Site classification by Cowardin, designated HGM management classes, and regional HGM subclasses (Cole et al. 1997) by ecoregion led us to remove all but 2 classes of regional HGM subclasses (riparian depression and headwater floodplain) because inadequate sample sizes did not allow comparing 5 reference to 5 stressed sites (Chipps et al. 2005). In addition, the aquatic bed (Cowardin et al. 1979) and fringing and slope (HGM) classes were also excluded due to low sample size (Table 2). A complete list of all sites and corresponding attribute data (e.g., ecoregion, location, class, etc.) can be found in Appendix B. The disturbance scores were normally distributed for all sites $($ Figure 3) $($ Skewness $=-0.04$, Kurtosis $=-0.39)$.

After the initial series of 2-way ANOVA screenings, we eliminated some metrics due to a significant ecoregion or alternative classification scheme effect (Table 7). The only metric capable of discriminating between reference and stressed sites in riparian depression wetlands, the percentage of residential and edge-tolerant species, was omitted because of a significant 2-way interaction between ecoregion and the Cowardin class. This resulted in a failure to develop a wetland AW-IBI for the riparian depression HGM subclass. The percent of single-brood species was eliminated in our floodplain AW-IBI because of a significant Cowardin classification effect. In the Cowardin-based AW-IBIs, 5 of the 6 metrics selected for inclusion in the emergent class AW-IBI were eliminated due to a significant HGM effect on metric scores. These metrics included the percent of residential and edge-tolerant species, the percentage of neotropical migrants, the percentage of habitat-specific neotropical migrants, the percentage of habitat specific 
birds, as well as the percentage of insectivorous species. Additionally, the abundance of wetland bird species and the percent of single-brooded species were eliminated from the scrub-shrub AW-IBI. Of the metrics comprising the forested AW-IBI, 2 metrics, the percentage of neotropical habitat specific species and the percentage of habitat specific species were eliminated so that there was not a significant cumulative HGM effect (Table 8).

\section{$\underline{3.2 \text { Avian community results }}$}

A total of 118 bird species was recorded in this study (Table 9). Site richness ranged from 5 to 28 species. A total of 2,297 birds was counted. A site by site record of species and abundance data can be found in Appendix C. Further, individual metric values for each site can be found in Appendix D, as well as summary statistics for each metric value by ecoregion (Appendix E). On average, birds with at least a facultative use of wetlands or greater made up the majority of surveyed individuals (Table 10).Of the top 6 most frequently occurring species, the most common (common yellowthroat, Geothlypis trichas) and the third most common species (red-winged blackbird, Agelaius phoeniceus), were wetland associated. The remaining 3 species in the top 5 most frequently occurring (song sparrow, Melospiza melodia, yellow warbler, Dendroica petechia, and gray catbird, Dumetella carolinensis) were facultative wetland species. The northern cardinal (Cardinalis cardinalis) was the sixth most frequently occurring bird species, and is not considered to have an affinity for wetlands (Croonquist and Brooks 1991). 


\subsection{Metric performance}

All metrics were subject to an initial visual screening, redundancy testing, and discrimination efficiency testing before inclusion into a class specific AW-IBI (Appendices F-M). Ten metrics were excluded from all of the resulting AW-IBI due to redundancy or the inability to discriminate between reference and stressed sites (Table 4). A complete list of sites and corresponding disturbance scores used to designate reference and stressed conditions can be found in Appendix B.

Avian wetland indices of biotic integrity were built with acceptable metrics for the Cowardin classifications, designated HGM management classes, and 1 of the 2 regional HGM subclasses (Cole et al. 1997). These indices were composed of 1 to 4 metrics dependent upon classification system (Table 4). Scoring thresholds for each class-specific avian community wetland IBI were derived from the $75^{\text {th }}, 25^{\text {th }}$, and $5^{\text {th }}$ percentile of reference site AW-IBI scores (Hill et al. 2003). Each class specific AW-IBI was able to discriminate between reference and stressed conditions $>60 \%$ of the time (Table 6).

The resultant class-specific AW-IBIs varied in their relation to and degree of response to the disturbance index (Table 10). Six of the 7 derived AW-IBIs had a significant relation to the disturbance scores. The disturbance gradient explained 11\% and $49 \%$ of the variability in AW-IBI scores in depressional wetlands and headwater floodplain wetlands, respectively. The relation between the disturbance gradient and impoundment AW-IBI scores was not significant. Cowardin based AW-IBIs scores were more consistent in their response to the disturbance gradient as it explained between $11 \%$ and $25 \%$ of the variability in these AW-IBI scores. The AW-IBI scores in headwater 
floodplains explained $49 \%$ of the variation associated with the disturbance gradient, whereas, due to a significant ecoregion and Cowardin classification scheme interaction, we could not create a robust, statewide riparian depression AW-IBI.

\subsection{Additive properties of metrics in the classification system}

When metrics from the Cowardin classification scheme were combined with metrics used in designated HGM management classes and regional HGM subclasses, results were mixed in their response to the disturbance gradient (Table 11). The depression and impoundment designated HGM management class wetlands did not exhibit a significant relation with the disturbance gradient when combined with metrics of the corresponding Cowardin classes.

The relation between the metrics in headwater floodplain and designated floodplain management class AW-IBI, combined with their Cowardin counterpart AWIBI metrics did have a significant relation with the disturbance gradient; with the exception of the headwater floodplain-emergent hybrid AW-IBI. These combined AWIBIs increased the amount of variation the disturbance gradient accounted for in all of the Cowardin based AW-IBIs. However, the results were mixed as far as the accountability of the disturbance gradient and the relation between headwater floodplain and the floodplain designated HGM management class AW-IBIs. In the case of headwater floodplain wetlands, the metrics from the scrub-shrub and forested class-specific AWIBIs increased the sensitivity to the disturbance gradient to $94 \%$ and $76 \%$, respectively. In the case of the floodplain designated HGM management class, metrics from the forested AW-IBI decreased the accountability of the disturbance gradient from $46 \%$ to 
$42 \%$, whereas metrics from the scrub-shrub and emergent AW-IBIs increased the disturbance gradient's accountability to $85 \%$ and $52 \%$, respectively.

\subsection{Discussion}

\section{$\underline{4.1 \text { Study design }}$}

The principles outlined by Brooks et al. (1998) intended to guide the development of regional indices of biotic integrity provide an excellent example of achievable goals to consider when designing an index of biotic integrity. Bird communities with high biological integrity are the desired endpoint representing least impaired wetland conditions. The elimination of an ecoregion effect on our avian wetland community indices of biotic integrity enabled us to examine and contrast the more recent and regionally specific HGM approach (Brinson 1993) with the Cowardin approach because of ample sample sizes. Our decision to combine the regional subclasses (Cole et al. 1997) into designated HGM management classes was based on the intended applicability and management implications within the objectives of developing an avian community wetland index of biotic integrity. We included analysis of regional HGM subclasses (Cole et al. 1997), if sample size permitted, which allowed evaluation of the efficacy of our designated HGM management class.

The classifications and methods were adopted so that this monitoring protocol could be easily integrated into existing WVDNR programs. For example, with limited wetland training, resource managers can differentiate between depression, floodplain, impoundment, fringing, and slope wetlands. Indeed, practicality exerted considerable leverage on design considerations for this study. For instance, sites were clustered such that sampling could be portioned into discrete "routes" which then could be assigned with 
reasonable expectation of completion by volunteers, such as conducting breeding bird point count surveys. Additionally, the local disturbance index, adopted from a modified ORAM (Mack 2001), was straightforward and was completed consistently under guidance of the scoring manual. The stressors contributing to our disturbance gradient we reassessed intuitively and represent conditions that could be quantitatively improved with a realistic expectation of improved bioassessment scores. The expectation is that this body of work will act as a baseline from which to initiate a statewide West Virginia wetland monitoring program, capable of detecting impairment and recognizing improvement and degradation in natural and mitigated wetland conditions.

\subsection{Classifications for Avian Wetland Indices of Biotic Integrity}

The significant relation between the local disturbance score and the Cowardin classification schemes indicated that independent suites of suitable metrics needed to be derived for each of these vegetation driven classifications. This indicated that bird community metrics that were used to detect human impairment would differ depending on vegetative structure. Different metrics were selected to detect impairment levels that were specific to each vegetation structure class. This result was based on strong evidence supporting the relation between vegetation development and avian communities (Brown and Smith 1998; Murkin et al. 1997; Snell-Rood and Cristol 2003; Twedt et al. 2002). The consistency of this relation is exhibited in the resulting AW-IBIs. Although only a minority of the scoring variation was explained by the disturbance gradient for many of the wetland types (Table 11), it is still measurable and reflected in the ability of all AW-IBIs to discriminate between reference and stressed sites (Table 6). 
Examining the characteristics of guilds within the Cowardin classifications explains the consistency of the relation between the disturbance scores and the AW-IBI scores. These guilds were predominately based on structural components of the ecosystem. For example, it stands to reason that the percent forest area sensitive species metric would differentiate between reference and stressed sites within the forested classification. However, an examination of factors that drive wetland vegetation structure enabled us to see why the designated HGM subclass AW-IBIs performed in the manner they did. Hydrology is the primary driver in the expressions of wetland plant communities (Aznar et al. 2003; Kirkman et al. 2000; Koning 2005; Magee and Kentula 2005). Anthropogenic effects within wetlands are not always apparent by visual reconnaissance. However, altering the hydrology of a wetland, even if the impact site is not physically located within the wetland, has measurable impacts on wetland function. In turn, an altered hydrologic regime will ultimately lead to changes in the expression of the vegetative community (Drohan et al. 2006). Furthermore, vegetative communities play a critical role in how a wetland functions within an ecosystem. For example, floodplains are more surface water driven with a deeper depth to the water table, compared to groundwater driven riparian depressions (Cole et al. 1997). As a result, plant communities are expected to differ between these 2 classes, simply based upon hydrology. Therefore, further comparisons of regional HGM subclasses would be useful for researching the effect of hydrologic variation on avian communities.

The percent of insectivorous species, and the percent year-round edge tolerant species are robust metrics that discriminated between reference and stressed conditions in all classification schemes, with the exception of the regional HGM subclass riparian 
depression. Functional trophic levels are revealed within the percent of insectivorous species metric. Year-round residential and edge tolerant species is a hybrid composition and structural metric that responds to increasing levels of human impairment. In addition to the habitat specific and neotropical migratory species metric, it further illustrates the "generalist versus specialist" approach that was successful in deriving appropriate metrics for other regional bioassessment cases (O'Connell et al. 1998a).

Impoundment wetlands are, by default, a product of altered hydrology. However, wetlands formed as a result of hydrologic change, whether natural or human-induced, still provide some ecosystem services such as water retention, water purification, refugia etc. (Hemond and Benoit 1988). Regional HGM subclasses of impounded wetlands include mainstem and headwater impoundments (Cole et al. 1997). These two impoundment HGM subclasses could also be a result of beaver (Castor canadensis) activity, inadvertent human activity, or even human attempts at creating natural wetlands. A study of wetland bird integrity in Montana found the neotropical migrants guild metrics were significantly influenced by beaver activity. This is consistent with our finding which excluded all of the neotropical migratory bird based metrics from the impoundment designated HGM management class based AW-IBI. Small sample sizes prevented us from evaluating these subclasses individually. Despite a non-significant relation with our disturbance gradient, the resultant AW-IBI was able to discriminate between reference and stressed impoundment sites. For example, metrics that measured trophic structure, percent insectivorous and percent omnivorous individuals and year-round edge tolerant birds, were effective despite variability in hydrology and vegetative structure within impoundment wetlands. 
Variability in hydrology has been identified as the cause of failure in some cases of indices of biotic integrity (Wilcox et al. 2002). Our data seems to support the conclusion that appropriate classifications, comparing apples to apples, or in our case, hydrologic regimes, are essential to developing an effective IBI (Karr 1999). The hydrologic regime of floodplain designated HGM management class wetlands, either mainstem or headwater floodplains (Cole et al. 1997), exhibits a high degree of consistency (Cole et al. 2006; Cole and Brooks 2000). Isolating this hydrologic variability through an appropriate classification, and based on previous literature, we would expect a floodplain AW-IBI to be highly responsive to a disturbance gradient (Croonquist and Brooks 1991).

Floodplain AW-IBIs differed from all of our other class specific IBIs because of a built-in measure of bias that is a product of its classification. For instance, floodplain wetlands, by definition, are linked to a water source and are always connected to a corridor that connects patches of suitable habitat (Croonquist and Brooks 1991). Alternatively, emergent, scrub-shrub, forested, and depressional wetlands can all be isolated from other wetlands, water sources and patches of suitable habitat. The connectivity of wetland floodplain ecosystems is inherent, and the connectivity and patterns of wetlands within a landscape are proven predictors of avian and other biotic communities (Galatowitsch et al. 1999; Miller et al. 1997; Whited et al. 2000). Floodplain AW-IBI scores demonstrated a strong relation with the disturbance gradient. This may be a result of stable hydrology and a degree of inherent connectivity that is a product of this classification approach. 
In this study, Shannon-Weiner's diversity index was able to differentiate between reference and stressed floodplain sites. This metric, based on evenness and richness (Magurran 1988), is an expression of higher diversity scores with decreasing levels of impairment. Richness metrics were shown to be responsive to components of the ORAM score (Stapanian et al,2004). Birds have been identified as a group where species composition reaches "equilibrium" in predictable environments (Tramer 1969). When this predictability shifts, changes in species abundances shift to favor "opportunistic" species (Tramer 1969). As impairment increases, we would expect to see greater numbers of tolerant species that would decrease evenness and be reflected in diversity scores.

\subsection{Comparison with other Avian Wetland Indices of Biological Integrity}

Our AW-IBI results varied expectedly with other avian indices of biological integrity. Some variation is to be expected from regional differences. Additionally, the differences in scale and attributes of a disturbance gradient will always change the relation to a resulting index of biological integrity.

Research from 14 wetlands in Ohio that examined ORAM scores (Mack 2001), as well as components of the ORAM scores and avian composition were comparable to our results (Stapanian et al. 2004). This research did not directly examine the relation between the ORAM-derived factors in our disturbance gradient and combined metrics representing avian integrity composition. However a significant relation was found between the variations in a disturbance gradient and species of concern, species richness, and wetland dependent birds. The variability accounted for by these variables ranged 
from $24 \%$ to $51 \%$. These relations were relatively consistent with the variability accounted for in our derived AW-IBI based on a local impairment disturbance gradient.

The regional Bird Community Index (BCI) (O'Connell et al. 1998b) was developed with a different methodology intended for the Mid-Atlantic Highlands, although many of the metrics that were incorporated into the BCI were incorporated into our class-specific AW-IBI. The disturbance gradient used in the $\mathrm{BCI}$ accounted for more of the variability in BCI scores than in our study; however, it was derived from both vegetation and land cover variables (O'Connell et al. 1998b). These are a function of, but not of direct measure of local impairment. Selecting metrics that are responsive to local disturbances was our objective and will enable us to use the AW-IBI to detect trends during long-term monitoring efforts.

In addition to disturbance, other sources such as hydrology and connectivity can account for the variability in AW-IBI scores. Furthermore, studies examining bird communities at larger spatial scales reveal that the intensity of surrounding land use and road densities play a large role in influencing both wetland and non-wetland avian communities (DeLuca et al. 2004; Forman 2000; Glennon and Porter 2005). These influences are more complex than simply altering hydrology. Not only does proximity to multiple land types influence the expression of bird communities, but so does the shape and pattern of natural and anthropogenic land uses relative to areas sampled (Miller et al. 1997; O’Connell et al. 2000; Whited et al. 2000).

\section{$\underline{4.4 \text { Avian Communities }}$}

As expected, the majority of individual birds per site had at least some degree of affinity for wetlands. However, conspicuously absent from our point count surveys were 
large numbers of waterfowl and other waterbirds. This may be due to the lack of openwater in many natural wetlands in West Virginia (Balcombe et al. 2005). Yet West Virginia wetlands support many more species than waterfowl and waterbirds. The metrics derived from avian bird communities demonstrate that birds can be used to detect local levels of human impairment quantified in our wetlands, as indicated by the discriminatory capability across all class-specific AW-IBI. This does not come as a surprise since birds have been used for bioassessments in both wetland and non-wetland circumstances, although not regionally across multiple wetland classifications (Bradford et al. 1998; DeLuca et al. 2004; O’Connell et al. 2000).

\subsection{Regional HGM subclasses and Designated HGM management classes}

Small sample size prevented independent analysis of all the regional HGM subclasses (Cole et al. 1997). However, conclusions from the resulting AW-IBI can still be made. Based upon our results, it may be that combining of isolated depression, surface water depression, and riparian depression into the depressional designated HGM management class failed to account for the complex hydrology unique to each of these systems, which is supported by other regional findings (Cole et al. 1997). Riparian and isolated depressions are groundwater-driven, which is not the case, by definition, for surface-water depressions.

When we examined riparian depressions independently, the only metric that could consistently differentiate between reference and stressed conditions was the percent of residential and edge tolerant species. However, due to a significant ecoregion and alternative classification scheme effect, we could not create a riparian depression AWIBI. This is in contrast to our depression designated HGM management class that 
exhibited a significant (albeit weak) relation between the disturbance gradient and depression AW-IBI scores as a whole. This is despite the riparian depression subclass composing 59 of the 72 sample sites used to form the depression designated HGM subclass. This result suggests further research is needed to understand the relation between human impacts on bird communities in isolated depressions, surface-water depressions, and riparian depressions.

Headwater floodplains, responded similarly to the disturbance gradient as the floodplain designated HGM management class. This is partially explained by the high proportion (29 of 35) of headwater floodplain wetlands that composed this management class. The metric that was the exception in differentiating reference and stressed conditions between these 2 classes was the Shannon-Weaver diversity index. However, the total variation of bird communities explained by the disturbance gradient in both classes differed by $<4 \%$. These 2 classes exhibited the strongest relation with the disturbance gradient of any classifications, perhaps due to the inherent nature of floodplains discussed previously.

The consistency between our testing of regional HGM subclasses and our designated HGM management classes indicate that with further validation it may be appropriate in AW-IBI to use designated HGM management classes as a unit for comparing the biological integrity of avian communities within wetlands. If this consistency withstands the rigor of further scientific testing, it would prove beneficial to assisting resource managers in making comparisons and understanding the relation between bird communities and human impairment in wetlands. However, we must 
caution that all regional HGM subclasses should to be tested for congruity with the designated HGM management classes in West Virginia before adopting this strategy.

\section{$\underline{4.6 \text { Metrics }}$}

The majority of metrics involving facultative wetland, wetland associated and wetland dependent birds failed to differentiate reference from stressed sites in every instance and therefore were not included in a resulting IBI. An examination of the prevailing literature helps to explain the lack of performance by what we collectively term, wetland "affinity" avian metrics. Both disturbance tolerant and intolerant species are captured in these metrics, which may be why they were not successful at differentiating stressed from reference conditions. For example, red-winged blackbirds (Agelaius phoeniceus) are a ubiquitous wetland associated species that are tolerant of human impairments, whereas prothonotary warblers (Protonotaria citrea) are also a wetland associated species that are sensitive to negative anthropogenic disturbances (Petit 1991). Furthermore, waterfowl and other birds that require wetlands for survival are responsive to changes in wetland hydroperiods and correspond to wetland area (Brown and Smith 1998; Kantrud and Stewart 1977; Murkin et al. 1997; VanRees-Siewert and Dinsmore 1996). However, West Virginia's terrain is not conducive to the large wetland complexes that support large numbers of these types of birds. In fact, West Virginia has less wetland area than any other state east of the Mississippi River, and is second only to Rhode Island as far as least amount of wetland area (Dahl 1990).

Some metrics are generated based on restoration expectations. However, these expectations often fall within vague goals. For example, it may no longer be appropriate to define a target for species richness as a restoration goal (Ehrenfeld 2000). Also, some 
metrics, such as proportion shrub nesters become challenging as it is difficult to explain how they may be responsive to human influence (Dale and Beyeler 2001). Further, this metric is ambiguous as both tolerant and sensitive species will nest in shrubs.

The percent carnivorous habitat-specific species metric, and the percent edge species metric were both shown to be effective in discriminating between reference and stressed sites in some classes. Yet both were rejected from inclusion from most of the class specific AW-IBIs. The percent of carnivorous habitat-specific species was often redundant with the percent habitat-specific neotropical migratory bird metric. In addition, a carnivorous habitat-specific bird species, such as the belted kingfisher (Ceryle alcyon) (10 occurrences of 2,297) or an osprey (Pandion haliaetus) (3 occurrences of $2,297)$, is a relatively uncommon find for our study. The importance of rare and minor species for bioassessments and ecosystem processes is still subject to debate (Boeken and Shachek 2006; Cao et al. 1998). Finally, the percent of edge species was redundant and inferior to the percent year-round residential and edge species metrics as both of these metrics discriminated between reference and stressed sites in every case.

Compositional metrics based on richness and abundance were not acceptable for inclusion into designated HGM management classes because of the inconsistent relation these metrics have with disturbance. The abundance of wetland affinity birds was removed from inclusion in the scrub-shrub AW-IBI after exhibiting an HGM effect. The omission of this metric is consistent with research noting densities of species can be misleading indicators of habitat quality (VanHorn 1983).

Compositional metrics that were incorporated into AW-IBIs could be explained by the "generalists versus specialist" nature of each metric (O'Connell et al. 2000). The 
compositional metrics that were effective for Cowardin classifications were based on this approach. For example, the percent of species that lay a single brood of eggs per year is a compositional metric that characterizes these single brood species as specialists because they are often restricted to patches that are relatively free of nest predators and brood parasites (Freemark and Collins 1992; O'Connell et al. 2000). This metric was capable of distinguishing between reference and stressed conditions in most classes.

\subsection{Combining of AW-IBI Metrics across Classes}

Combining metrics from the HGM based and Cowardin classification schemes showed promising signs in some cases, but not all, by increasing the amount of variability explained by the disturbance gradient. A lack of a significant relation between depression and impoundment designated HGM management class and riparian depression HGM subclass (Cole et al. 1997) wetlands when combined with the Cowardin counterpart metrics was not to be unexpected. It should be noted that the impoundment AW-IBI did not have a significant relation with the disturbance gradient alone, and the depression relation was significant but did not account for a substantial part of the AWIBI variation.

The response of the designated floodplain HGM management class metrics and the headwater floodplain metrics with the Cowardin counterparts is promising as it increased the amount of variation accounted for by the disturbance gradient in scrubshrub floodplain wetlands and in headwater floodplain forested and scrub-shrub wetlands. It should be noted that for these combined classes the amount of variation accounted for is greater than that captured in the backwards stepwise regression models for headwater floodplain wetlands and the floodplain designated management class 
wetlands that was intended to maximize the $\mathrm{R}^{2}$ values. However, because of relatively smaller sample sizes, more study sites are needed to separate the effects of natural variability in bird populations and the effect of human impairment in these wetlands.

\section{$\underline{4.8 \text { Scoring thresholds }}$}

The generation of thresholds that indicate wetland quality is necessary to account for some degree of stochasticity in sampling from year to year. Examining categorical values of site AW-IBI scores will enable monitoring to discount small changes in AWIBI scoring to determine if the integrity of a wetland is being maintained or is succumbing to the effects of impairments. The biological basis for these scoring categories is based on tested principles that have been used in previous regional studies (Hill et al. 2003; McCormick et al. 2001). However, the legitimacy and applicability of these scoring thresholds will need to be explored in future work. For example, increased sample sizes would, in theory, generate a larger variation in scoring values, for which we would need to recalibrate these proposed thresholds. Additionally, when we combine the class-specific AW-IBI to form addititive hybrid classification indices, the reference and stressed sites' designations were based on within class-specific parameters. That is to say a reference site for a Cowardin classification may not be a reference site for our designated HGM management classes. Increasing sample sizes would provide a more consistent context of what constitutes reference condition regardless of classification schemes. Therefore, these derived scoring thresholds should be regularly re-examined to refine and calibrate these thresholds, increasing their validity and interpretability. 


\subsection{Management Implications}

The objective of designing avian wetland indices of biotic integrity that can be broadly applied and integrated quickly into management action was successfully demonstrated by our methodology. New sites to validate the effectiveness of these AWIBIs can be added opportunistically. Our stressor gradient is not a theoretical principle component of chemical, physical, and/or biological stressors. Rather, this gradient is tangible and can be realistically managed and quantified by non-experts with limited training. A systematic scoring and testing protocol, based on existing methods, will allow future researchers to "append" data to our existing dataset to increase validity and test more HGM subclasses (Cole et al. 1997) or designated HGM management classes. Further, summing the metrics used in each wetland classification system has shown promise as a novel method that may increase the sensitivity of AW-IBI to a disturbance gradient. In the future, additional surveys of multiple taxonomic groups can be examined for sensitive metrics responsive to our disturbance score. These metrics could be evaluated with metrics from these resulting AW-IBI to establish multiple taxa IBIs. This approach would increase the sensitivity of our bioassessment efforts in diagnosing wetland stressors at multiple scales (Griffith et al. 2005; O'Connor et al. 2000).

Future analyses coupling site specific results with landscape patterns using Geographic Information Systems (GIS) will assist in landscape planning and will ensure wetland resources are maintained (Haig et al. 1998; Marzluff and Ewing 2001). The scoring threshold categories can be evaluated based on the capability to predict these wetland categories using landscape variables, which in turn will help guide both wetland and avian community conservation strategies (Glennon and Porter 2005; Whited et al. 
2000). In essence, our research in wetlands of West Virginia represents the beginning of an expansion in the understanding of the components that characterize the provision of wetland services and functions within the state. Furthermore, waters from West Virginia drain into both the Chesapeake Bay and the Gulf of Mexico. Protecting this state's wetlands and water resources is critically important to protecting against downstream effects of poor water quality. By maintaining healthy and functional wetlands, West Virginia will be proactive in protecting avian communities within our state while ensuring downstream water quality.

\subsection{Acknowledgements}

We thank Adrianne Brand and Mark Hepner for field help. Dr. Hillar Klandorf and Joe Osbourne assisted in preparing field crews for consistent and accurate bird identification. Greg Pond, George Merovich, and the late Dr. George Seidel provided statistical support and advice. Technical writing and logistical support was provided by Sarah McClurg. Funding was provided by the West Virginia Division of Natural Resources with assistance from U.S. EPA State Wetland Program Development Grant CD 973080-01-0. This is scientific article number xxxx of the West Virginia University Agriculture and Forestry Experiment Station. 


\subsection{Literature Cited}

Aznar J.C., Dervieux A., Grillas P. (2003). Association between aquatic vegetation and landscape indicators of human pressure. Wetlands, 23, 149-160.

Balcombe C.K., Anderson J.T., Fortney R.H., Kordek W.S. (2005). Wildlife use of mitigation and reference wetlands in West Virginia. Ecological Engineering, 25, 85-99.

Barbour M.T., Stribling J.B., Karr J.R. (1995). Biological assessment and criteria: Tools for water resource planning and decision making. Davis W.S., Simon T.P. (Eds.), Multimetric approach for establishing biocriteria and measuring biological condition. (pp. 63-77). Ann Arbor, MI: Lewis Publishers.

Barbour M.T., Gerritsen J., Griffith G.E., Frydenborg R., McCarron E., White J.S., Bastian M.L. (1996). A framework for biological criteria for Florida streams using benthic macroinvertebrates. Journal of North American Benthological Society, 13, 185211.

Barbour M.T., Gerritsen J., Snyder B.D., Stribling J.B. (1999). Rapid bioassessment protocols for use in streams and wadeable rivers: Periphyton, benthic macroinvertebrates and fish. U.S. Environmental Protection Agency. Washington, D.C. Report EPA 841-B99-002.

Bayer M., Porter W.F. (1988). Evaluation of a guild approach to habitat assessment for forest-dwelling birds. Environmental Management, 12, 797-801.

Bedford B., Preston E. (1988). Developing a scientific basis for assessing cumulative effects of wetland loss and degradation on landscape functions: status, perspectives, and prospects. Environmental Management, 12, 751-771.

Blocksom K.A. (2003). A performance comparison of metric scoring for a multimetric index for Mid-Atlantic Highlands streams. Environmental Management, 31, 670-682.

Boeken B. \& Shachek M. (2006). Linking community and ecosystem processes: the role of minor species. Ecosystems, 9, 119-127.

Bradford D.F., Franson S.E., Neale A.C., Heggem D.T., Miller G.R., Canterbury G.E. (1998). Bird species assemblages as indicators of biological integrity in Great Basin rangeland. Environmental Monitoring and Assessment, 49, 1-22.

Brinson M.M. (1993). A hydrogeomorphic classification for wetlands. U.S. Army Engineers Waterways Experiment Station. Vicksburg, MS. Technical Report WRP-DE4. 
Brooks R.P., O'Connell T.J., Wardrop D.H., Jackson L.E. (1998). Towards a regional index of biological integrity: the example of forested riparian ecosystems. Environmental Monitoring and Assessment, 51, 131-143.

Brown S.C., Smith C.R. (1998). Breeding season bird use of recently restored versus natural wetlands of New York. Journal of Wildlife Management, 62, 1480-1491.

Bryce S.A., Hughes R.M., Kaufman P.R. (2002). Development of a bird integrity index: using bird assemblages as indicators of riparian condition. Environmental Management, 30, 294-310.

Calhoun A., Miller N.A., Klemens M.W. (2005). Conserving pool-breeding amphibians in human-dominated landscapes through local implementation of best development practices. Wetlands Ecology and Management, 13, 291-304.

Canterbury G.E., Martin T.E., Petit D.R., Petit L.J., Bradford D.F. (2000). Bird communities and habitat as ecological indicators of forest condition in regional monitoring. Conservation Biology, 14, 544-558.

Cao Y., Williams D., Williams N.E. (1998). How important are rare species in aquatic ecology and bioassessment? Limnology and Oceanography, 43, 1403-1409.

Chipps S.R., Hubbard D.E., Werlin K.B., Haugerud N.J., Powell K.A., Thompson J., Johnson T. (2006). Association between wetland disturbance and biological attributes in floodplain wetlands. Wetlands, 26. 456-467.

Cole C.A., Brooks R.P., Wardrop D.H. (1997). Wetland hydrology as a function of hydrogeomorphic (HGM) subclass. Wetlands, 17, 456-467.

Cole C.A., Brooks R.P. (2000). Patterns of wetland hydrology in the Ridge and Valley province, Pennsylvania, USA. Wetlands, 20, 438-447.

Cole C.A., Urban C.A., Russo P., Murray J., Hoyt D., Brooks R.P. (2006). Comparison of the long-term water levels of created and natural wetlands in northern New York, USA. Ecological Engineering, 27, 166-172.

Cowardin L.M., Carter V., Golet F.C., LaRoe E.T. (1979). Classification of wetlands and deepwater habitats of the United States. U.S. Fish and Wildlife Service. Report FWS/ OBS-79/31.

Croonquist M.J., Brooks R.P. (1991). Use of avian and mammalian guilds as indicators of cumulative impacts in riparian-wetland areas. Environmental Management, 15, 701714.

Dahl T.E. (1990). Wetland losses in the United States:1780s to 1980s. U.S. Fish and Wildlife Service, Washington, D.C. 
Dale V.H., Beyeler S.B. (2001). Challenges in the development and use of ecological indicators. Ecological Indicators, 1, 3-10.

DeLuca W.V., Studds C.E., Rockwood L.L., Marra P.P. (2004). Influence of land use on the integrity of marsh bird communities of Chesapeake Bay, USA. Wetlands, 24, 837847.

Drohan P.J., Ross C.N., Anderson J.T., Fortney R.H., Rentch J.S. (2006). Soil and hydrological drivers of Typha latifolia encroachment in a marl wetland. Wetlands Ecology and Management, 14, 107-122.

Ehrenfeld J.J. (2000). Defining the limits of restoration: the need for realistic goals. Restoration Ecology, 8, 2-9.

Forman R.T.T. (2000). Estimate of the area affected ecologically by the road system in the United States. Conservation Biology, 14, 31-35.

Freemark K., Collins B. (1992). Landscape ecology of birds breeding in temperate forest fragments. Ecology and conservation of neotropical migrant landbirds. pp. 443-454. Hagan JM \& Johnson DW (Eds.) Smithsonian Institution Press, Washington, DC.

Galatowitsch S.M., Whited D.C., Tester J.R. (1999). Development of community metrics to evaluate recovery of Minnesota wetlands. Journal of Aquatic Ecosystem Stress and Recovery, 6, 217-234.

Gernes M.C., Helgen J.C. (2002). Indexes of Biological Integrity (IBI) for Large Depressional Wetlands in Minnesota. Minnesota Pollution Control Agency, St. Paul, $\mathrm{MN}$.

Gerritsen J. (1995). Additive biological indices for resource management. Journal of North American Benthological Society, 14, 451-457.

Gerritsen J., Burton J., Barbour M.T. (2000). A stream condition index for West Virginia wadeable streams. Tetra Tech, Inc., Owing Mills, MD.

Gibbs J.P., Melvin S.M. (1993). Call-response surveys for monitoring breeding waterbirds. Journal of Wildlife Management, 57, 27-34.

Gibbs J.P., Melvin S.M. (1997). Power to detect trends in waterbird abundance with callresponse surveys. Journal of Wildlife Management, 61, 1262-1267.

Glennon M.J., Porter W.F. (2005). Effects of land use management on biotic integrity: an investigation of bird communities. Biological Conservation, 126, 499-511. 
Griffith M.B., Hill B.H., McCormick F.H., Kaufman P.R., Herlihy A.T., Selle A.R. (2005).Comparative application of indices of biotic integrity based on periphyton, macroinvertebrates, and fish to southern Rocky Mountain streams. Ecological Indicators, $5,117-136$.

Haig S.M., Mehlman D.W., Oring L.W. (1998). Avian movements and wetland connectivity in landscape conservation. Conservation Biology, 12, 749-758.

Harris L.D. (1988). The nature of cumulative impacts on biotic diversity of wetland vertebrates. Environmental Management, 12, 675-693.

Hemond H.F., Benoit J. (1988). Cumulative impacts on water quality functions of wetlands. Environmental Management, 12, 639-653.

Hill B.H., Herlihy A.T., Kaufman P.R., DeCelles S.J., Vander Borgh M.A. (2003). Assessment of streams of the eastern United States using a periphyton index of biotic integrity. Ecological Indicators, 2, 325-328.

Hughes R.M., Kaufmann P.R., Herlihy A.T., Kincaid T.M., Reynolds L., Larsen D.P. (1998). A process for developing and evaluating indices of fish assemblage integrity. Canadian Journal of Fisheries and Aquatic Sciences, 55, 1618-1631.

Hutto R.L., Reel S., Landres P.B. (1987). A critical evaluation of the species approach to biological conservation. Endangered Species Update, 4, 1-4.

Kantrud H.A., Stewart R.E. (1977). Use of natural basin wetlands by breeding waterfowl in North Dakota. Journal of Wildlife Management, 41, 243-253.

Karr J.R. (1999). Defining and measuring river health. Freshwater Biology, 41, 221-234.

Kirkman L.K., Goebel P.C., West L., Drew M.B., Palik B.J. (2000). Depressional wetland vegetation types: a question of plant community development. Wetlands, 20, 373-385.

Koning C.O. (2005). Vegetation patterns resulting from spatial and temporal variability in hydrology, soils, and trampling in an isolated basin marsh, New Hampshire, U.S.A. Wetlands, 25, 239-251.

Mack J.J. (2001). Ohio Rapid Assessment Method for Wetlands v. 5.0, User's manual and Scoring Forms. Ohio Environmental Protection Agency, Division of Surface Water, Wetland Ecology Unit, Columbus, $\mathrm{OH}$.

Mack J.J. (2004). Integrated wetland assessment program. Part 9: Field manual for the vegetation index of biotic integrity for wetlands v. 1.3. Ohio Environmental Protection Agency, Wetland Ecology Group, Division of Surface Water, Columbus, OH. 
Magee T.K., Kentula M.E. (2005). Response of wetland plant species to hydrologic conditions. Wetlands Ecology and Management, 13, 163-181.

Magurran A.E. (1988).Ecological diversity and its measurement. Princeton University Press, Princeton, New Jersey..

Marzluff J.M., Ewing K. (2001). Restoration of fragmented landscapes for the conservation of birds: a general framework and specific recommendations for urbanizing landscapes. Restoration Ecology, 9, 280-292.

McCormick F.H., Hughes R.M., Kaufman P.R., Peck D.V., Stoddard J.L., Herlihy A.T. (2001). Development of an index of biotic integrity for the Mid-Atlantic Highland region. Transactions of the American Fisheries Society, 130, 857-877.

Micacchion M. (2004). Integrated wetland assessment program. Part 7: amphibian index of biotic integrity (AmphIBI) for Ohio wetlands. Ohio Environmental Protection Agency, Wetland Ecology Group, Division of Surface Water, Columbus, OH.

Miller S.J., Wardrop D.H., Mahaney W.M., Brooks R.P. (2006). A plant-based index of biological integrity (IBI) for headwater wetlands in central Pennsylvania. Ecological Indicators, 6, 290-312.

Miller J.N., Brooks R.P., Croonquist M.J. (1997). Effects of landscape patterns on biotic communities. Landscape Ecology, 12, 137-153.

Murkin H.R., Murkin E.J., Ball J.P. (1997). Avian habitat selection and prairie wetland dynamics: a 10 year experiment. Ecological Applications, 7, 1144-1159.

Naugle D.E., Johnson R.R., Estey M.E., Higgins K.F. (2001). A landscape approach to conserving wetland bird habitat in the Prairie Pothole Region of eastern South Dakota. Wetlands, 20, 588-604.

O'Connell T.J., Jackson L.E., Brooks R.P. (1998a). A bird community index of biotic integrity for the Mid-Atlantic highlands. Environmental Monitoring and Assessment, 51, 145-156.

O'Connell T.J., Jackson L.E., Brooks R.P. (1998b). The Bird Community Index: a tool for assessing biotic integrity in the Mid-Atlantic highlands. Penn State Cooperative Wetlands Center, University Park, PA.

O'Connell T.J., Jackson L.E., Brooks R.P. (2000). Bird guilds as indicators of ecological condition in the central Appalachians. Ecological Applications, 10, 1706-1721.

O'Connor R., Walls T.E., Hughes R.M. (2000). Using multiple taxonomic groups to index the ecological condition of lakes. Environmental Monitoring and Assessment, 61, 207-228. 
Omernik J.M. (1987). Ecoregions of the conterminous United States. Annals of the Association of American Geographers, 77, 118-125.

Omernik J.M. (1995). Ecoregions: a spatial framework for environmental management. Davis W.S., Simon T.P. (Eds.), Biological assessment and criteria: tools for water resource planning and decision making. Lewis Publishers, Boca Raton, FL.

Petit L.J. (1991). Adaptive tolerance of cowbird parasitism by prothonotary warblers: a consequence of nest-site limitation? Animal Behaviour, 41, 425-432.

Ralph C.J., Sauer J.R., Droege S.E. (1995). Monitoring bird populations by point counts: standards and applications. U.S. Forest Service. Pacific Southwest Research Station, General Technical Report PSW-GTR-149.

Reiss K.C. (2006). Florida Wetland Condition Index for depressional forested wetlands. Ecological Indicators, 6, 337-352.

Snell-Rood E.C., Cristol D.A. (2003). Avian communities of created and natural wetlands: bottomland forests in Virginia. The Condor, 105, 303-315.

Stapanian M., Waite T.A., Krzys G., Mack J.J., Micacchion M. (2004). Rapid assessment indicator of wetland integrity as an unintended predictor of avian diversity. Hydrobiologia, 520, 119-126.

Stevenson R.J., Hauer F.R. (2002). Integrating Hydrogeomorphic and Index of Biotic Integrity approaches for environmental assessment of wetlands. Journal of North American Benthological Society, 21, 502-513

Tramer E.J. (1969). Bird species diversity: components of Shannon's formula. Ecology, 50, 927-929.

Twedt D.J., Wilson R.R., Henne-Kerr J.L., Grosshuesch D.A. (2002). Avian response to bottomland hardwood reforestation: the first 10 years. Restoration Ecology, 10, 645-655.

VanHorn B. (1983). Density as a misleading indicator of habitat quality. Journal of Wildlife Management, 47, 893-901.

VanRees-Siewert K.L., Dinsmore J.J. (1996). Influence of wetland age on bird use of restored wetlands in Iowa. Wetlands, 16, 577-582.

Verner J. (1984). The guild concept applied to management of bird populations. Environmental Management, 8, 1-14.

Weller W.M. (1988). Issues and approaches in assessing cumulative impacts on waterbird habitats in wetlands. Environmental Management, 12, 695-701. 
Whited D.C., Galatowitsch S.M., Tester J.R., Schik K., Lehtinen R.M., Husveth J. (2000). The importance of local and regional factors in predicting effective conservation planning strategies for wetland bird communities in agricultural and urban landscapes. Landuse and Urban Planning, 49, 49-65

Wilcox D.A., Meeker J.E., Hudson P.L., Armitage B.J., Black M.G., Uzarski D.G. (2002). Hydrologic variability and the application of index of biotic integrity metrics to wetlands: a Great Lakes evaluation. Wetlands, 22, 588-615.

Winter T.C. (1988). A conceptual framework for assessing cumulative impacts on the hydrology of nontidal wetlands. Environmental Management, 12, 605-620.

Woods A.J., Omernik J.M., Brown D.D. (1999). Level III and IV ecoregions of Delaware, Maryland, Pennsylvania, Virginia, and West Virginia. U.S. Environmental Protection Agency, Corvallis, OR.

Yuan L.L., Norton S.B. (2004). Assessing the relative severity of stressors at a watershed scale. Environmental Monitoring and Assessment, 98, 323-349.

Zedler J.B. (2003). Wetlands at your service: reducing impacts of agriculture at the watershed scale. Frontiers in Ecology and Environment, 1, 65-72. 
Table 1. Designated hydrogeomorphic (HGM) management classes derived from regional hydrogeomorphic (HGM) subclasses ${ }^{\mathrm{a}}$ for use in developing class specific avian wetland indices of biological integrity (AW-IBI) in West Virginia, USA from 2005-2006.

\begin{tabular}{ll}
\hline Designated Management HGM subclass & Hydrogeomorphic subclass $^{\mathrm{a}}$ \\
\hline Depression & Surface water depression \\
& $\begin{array}{l}\text { Riparian depression } \\
\text { Isolated depression }\end{array}$ \\
Floodplain & Headwater floodplain \\
& Mainstem floodplain \\
Impoundment & Headwater impoundment \\
& Mainstem impoundment \\
Fringing & Fringing \\
Slope & Slope \\
\hline
\end{tabular}

${ }^{\text {a }}$ Cole et al. (1997). 
Table 2. Total number of sites by regional hydrogeomorphic (HGM) subclass, designated HGM management class, and Cowardin class by ecoregion for use in developing class specific avian wetland indices of biological integrity (AW-IBI) in West Virginia, USA from 2005-2006.

\begin{tabular}{|c|c|c|c|c|}
\hline & \multicolumn{4}{|c|}{ Level 3 U.S. Environmental Protection Agency aquatic ecoregion ${ }^{a}$} \\
\hline & Ridge and Valley & Central Appalachian & Western Alleghany Plateau & Total \\
\hline \multicolumn{5}{|c|}{ Hydrogeomorphic subclass ${ }^{b}$} \\
\hline Surface water depression ${ }^{\mathrm{c}}$ & 0 & 2 & 5 & 7 \\
\hline Riparian depression & 10 & 24 & 25 & 59 \\
\hline Isolated depression $^{c}$ & 0 & 2 & 4 & 6 \\
\hline Headwater floodplain & 10 & 15 & 4 & 29 \\
\hline Mainstem floodplain ${ }^{\mathrm{c}}$ & 2 & 2 & 1 & 5 \\
\hline Headwater impoundment ${ }^{\mathrm{c}}$ & 1 & 12 & 4 & 17 \\
\hline Mainstem impoundment ${ }^{\mathrm{c}}$ & 0 & 2 & 4 & 6 \\
\hline Fringing $^{\mathrm{c}}$ & 0 & 2 & 11 & 13 \\
\hline Slope $e^{c}$ & 4 & 4 & 0 & 8 \\
\hline Floodplain-in-stream ${ }^{c}$ & 0 & 0 & 1 & 1 \\
\hline \multicolumn{5}{|c|}{ Designated HGM Management Class } \\
\hline Depression & 10 & 28 & 34 & 72 \\
\hline Floodplain & 12 & 17 & 6 & 35 \\
\hline Impoundment & 1 & 14 & 8 & 23 \\
\hline Fringing $^{\mathrm{c}}$ & 0 & 2 & 11 & 13 \\
\hline Slope $^{\mathrm{c}}$ & 4 & 4 & 0 & 8 \\
\hline \multicolumn{5}{|l|}{ Cowardin Class } \\
\hline Emergent & 15 & 34 & 26 & 75 \\
\hline Scrub-shrub & 6 & 17 & 21 & 44 \\
\hline Forested & 6 & 14 & 11 & 31 \\
\hline Aquatic bed ${ }^{c}$ & 0 & 0 & 1 & 1 \\
\hline Total & 27 & 65 & 59 & 151 \\
\hline
\end{tabular}

a Omernik (1987), modified by Woods et al. (1999).

${ }^{\mathrm{b}}$ Cole et al. (1997).

${ }^{\mathrm{c}}$ Removed from analysis due to small sample size. 
Table 3. Metrics and sub-metrics selected from the Ohio Rapid Assessment Method (Mack 2001) used to define the disturbance gradient for use in developing class specific avian wetland indices of biological integrity (AW-IBI) in West Virginia, USA from 2005-2006.

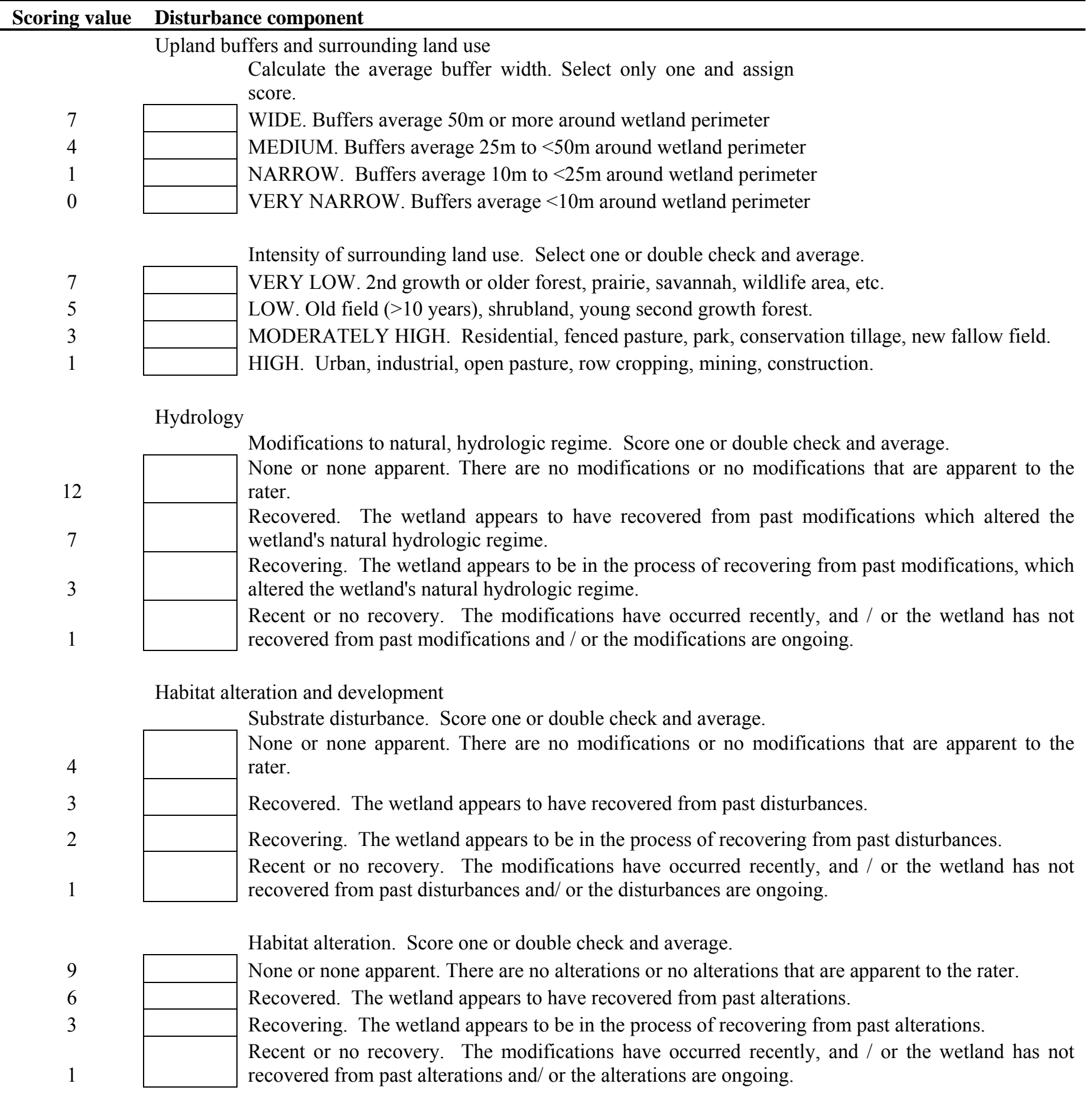


Table 4. Candidate avian community biological metrics evaluated by class according to regional Hydrogeomorphic (HGM) subclass, designated HGM management class, and the Cowardin classification schemes in building avian wetland indices of biological integrity (AW-IBI) in West Virginia, USA from 2005-2006.

\begin{tabular}{|c|c|c|c|c|c|c|c|c|c|c|}
\hline \multirow[b]{3}{*}{ Candidate avian metrics $^{\mathrm{a}}$} & \multirow[b]{3}{*}{ Guild type } & \multirow[b]{3}{*}{$\begin{array}{l}\text { Expected } \\
\text { Response to } \\
\text { Disturbance }\end{array}$} & \multicolumn{8}{|c|}{ Classification system $^{\mathrm{a}}$} \\
\hline & & & \multicolumn{2}{|c|}{ HGM subclass } & \multicolumn{3}{|c|}{ Designated HGM management class } & \multicolumn{3}{|c|}{ Cowardin classification } \\
\hline & & & $\begin{array}{l}\text { Riparian } \\
\text { Depression }\end{array}$ & $\begin{array}{l}\text { Headwater } \\
\text { Floodplain }\end{array}$ & Depression & Floodplain & Impoundment & Emergent & $\begin{array}{l}\text { Scrub- } \\
\text { Shrub }\end{array}$ & Forested \\
\hline Percent neotropical migrants ${ }^{\mathrm{b}}$ & composition & - & $*$ & $\mathrm{R}$ & $*$ & $\mathrm{R}$ & $*$ & $\mathrm{E}$ & $*$ & $\mathrm{R}$ \\
\hline $\begin{array}{l}\text { Percent habitat specific and } \\
\text { neotropical migrants }{ }^{\mathrm{b}}\end{array}$ & $\begin{array}{l}\text { composition and } \\
\text { structure }\end{array}$ & - & * & $\mathrm{R}$ & * & $\mathrm{R}$ & * & $\mathrm{E}$ & I & $\mathrm{E}$ \\
\hline Percent habitat specific ${ }^{\mathrm{b}}$ & structure & - & $*$ & $\mathrm{R}$ & $*$ & $\mathrm{R}$ & $*$ & E & $\mathrm{R}$ & E \\
\hline $\begin{array}{l}\text { Percent permanent resident and edge } \\
\text { birds }^{\mathrm{b}}\end{array}$ & $\begin{array}{l}\text { composition and } \\
\text { structure }\end{array}$ & + & $\mathrm{E}$ & I & I & I & I & E & I & I \\
\hline $\begin{array}{l}\text { Percent carnivore and habitat } \\
\text { specific }^{\mathrm{b}}\end{array}$ & $\begin{array}{l}\text { function and } \\
\text { structure }\end{array}$ & - & $*$ & I & $*$ & $\mathrm{R}$ & $*$ & $\mathrm{R}$ & * & $*$ \\
\hline Shannon-Weaver diversity index ${ }^{c}$ & composition & - & $*$ & $*$ & $*$ & I & $*$ & $*$ & $*$ & $*$ \\
\hline Percent of omnivorous birds ${ }^{\mathrm{d}}$ & function & + & * & I & * & I & I & I & I & $\mathrm{F}$ \\
\hline Percent single brood ${ }^{\mathrm{d}}$ & composition & - & * & I & $*$ & E & * & * & $\mathrm{E}$ & I \\
\hline Percent forest area sensitive $^{\mathrm{d}}$ & structure & - & $*$ & * & $*$ & * & $*$ & $*$ & $*$ & I \\
\hline Percent of insectivorous birds ${ }^{\mathrm{d}, \mathrm{e}}$ & function & - & $*$ & $\mathrm{R}$ & I & I & I & $\mathrm{E}$ & I & $\mathrm{R}$ \\
\hline Wetland bird abundance & composition & - & $*$ & * & $*$ & $*$ & $*$ & $*$ & E & $*$ \\
\hline Percent wetland dependent ${ }^{\mathrm{b}, \mathrm{f}}$ & structure & - & $*$ & * & $*$ & * & $*$ & * & $*$ & $*$ \\
\hline $\begin{array}{l}\text { Percent wetland dependent and } \\
\text { associated }{ }^{\mathrm{b}, \mathrm{f}}\end{array}$ & structure & - & $*$ & $*$ & $*$ & $*$ & $*$ & $*$ & $*$ & $*$ \\
\hline Percent facultative wetland species ${ }^{\mathrm{b}, \mathrm{f}}$ & structure & - & * & * & * & * & * & * & * & * \\
\hline Wetland species richness ${ }^{\mathrm{f}}$ & composition & - & $*$ & * & * & * & * & * & * & * \\
\hline $\begin{array}{l}\text { Wetland bird Shannon-Weaver } \\
\text { diversity }^{f}\end{array}$ & composition & + & $*$ & $*$ & $*$ & $*$ & $*$ & * & $*$ & $*$ \\
\hline Species richness ${ }^{\mathrm{c}, \mathrm{f}}$ & composition & + & * & * & * & * & * & * & * & * \\
\hline Total bird abundancec ${ }^{\mathrm{f}}$ & composition & + & * & * & * & * & * & * & $\mathrm{R}$ & * \\
\hline Percent edge species ${ }^{\mathrm{b}, \mathrm{f}}$ & structure & + & * & $\mathrm{R}$ & $*$ & $\mathrm{R}$ & $*$ & $\mathrm{R}$ & $*$ & $*$ \\
\hline Shannon's Evenness index ${ }^{\mathrm{f}}$ & composition & - & $*$ & $*$ & $*$ & $*$ & $*$ & $*$ & $\mathrm{~F}$ & $*$ \\
\hline Percent nest parasite/ predator ${ }^{\mathrm{d}, \mathrm{f}}$ & composition & - & * & $*$ & * & * & * & * & * & $\mathrm{F}$ \\
\hline Percent shrub nesters ${ }^{\mathrm{d}, \mathrm{f}}$ & structure & + & $*$ & * & $*$ & $*$ & $*$ & * & $*$ & $*$ \\
\hline
\end{tabular}

${ }^{a} \mathrm{I}=$ included into class-specific AW-IBI; R = redundancy with other metrics; F = failure due to lack of scoring range; $\mathrm{E}$ = failure due to significant ecoregion or alternative classification scheme effect;

$*$ = failure to discriminate between reference and stressed sites.

${ }^{\mathrm{b}}$ Croonquist and Brooks (1991).

${ }^{\mathrm{c}}$ Bradford et al. (1998).

${ }^{\mathrm{d}}$ O'Connell et al. (1998a).

${ }^{\mathrm{e}}$ Galatowitsch et al. (1999).

${ }^{\mathrm{f}}$ metrics excluded from all of the resullting class-specific AW-IBI due to redundancy, failure in scoring range, or inability to discriminate between reference and stressed sites. 
Table 5. Correlated metrics based on Spearman's R ( $\mathrm{R}>0.80$ ) selected based on discrimination efficiency in differentiating between reference and stressed sites metrics used in developing class specific avian wetland indices of biological integrity (AW-IBI) in West Virginia, USA from 2005-2006.

\begin{tabular}{|c|c|c|c|c|}
\hline Classification/Metric & $\begin{array}{c}\text { Discrimination } \\
\text { Efficiency }\end{array}$ & $\begin{array}{c}\text { Spearman's } \\
\mathrm{R} \\
\text { Correlation }\end{array}$ & Correlated Metric & $\begin{array}{c}\text { Discrimination } \\
\text { Efficiency }\end{array}$ \\
\hline \multicolumn{5}{|l|}{ Headwater Floodplain } \\
\hline Residential Edge $^{\mathrm{a}}$ & 100 & -0.828 & Insectivorous & 100 \\
\hline Residential Edge $^{a}$ & 100 & -0.861 & neotropical Habitat Specific & 88 \\
\hline Residential Edge $^{a}$ & 100 & 0.864 & Edge & 88 \\
\hline Residential Edge $\mathrm{e}^{\mathrm{a}}$ & 100 & -0.862 & Habitat Specific & 75 \\
\hline Residential Edge $^{a}$ & 100 & -0.830 & neotropical Migrant & 63 \\
\hline Carnivorous Habitat Specific ${ }^{a}$ & 88 & 0.853 & Insectivorous $^{\mathrm{b}}$ & 100 \\
\hline Carnivorous Habitat Specific ${ }^{\mathrm{a}}$ & 88 & 0.925 & neotropical Habitat Specific ${ }^{b}$ & 88 \\
\hline Carnivorous Habitat Specific ${ }^{a}$ & 88 & -0.823 & Edge $^{\mathrm{b}}$ & 88 \\
\hline Carnivorous Habitat Specific ${ }^{a}$ & 88 & 0.864 & Habitat Specific ${ }^{\mathrm{b}}$ & 75 \\
\hline Omnivorous $^{\mathrm{a}}$ & 75 & 0.861 & Insectivorous & 100 \\
\hline Insectivorous ${ }^{\mathrm{b}}$ & 88 & 0.866 & neotropical Habitat Specific ${ }^{b}$ & 88 \\
\hline Insectivorous ${ }^{\mathrm{b}}$ & 100 & -0.861 & neotropical Migrant ${ }^{\mathrm{b}}$ & 63 \\
\hline neotropical Habitat Specific ${ }^{\mathrm{b}}$ & 88 & 0.856 & Habitat Specific ${ }^{\mathrm{b}}$ & 75 \\
\hline neotropical Habitat Specific ${ }^{\mathrm{b}}$ & 88 & -0.825 & Edge $^{b}$ & 88 \\
\hline neotropical Habitat Specific ${ }^{\mathrm{b}}$ & 88 & 0.872 & neotropical Migrant $^{\mathrm{b}}$ & 63 \\
\hline $\operatorname{Edge}^{\mathrm{b}}$ & 88 & -0.987 & Habitat Specific & 75 \\
\hline \multicolumn{5}{|l|}{ Floodplain } \\
\hline Residential Edge $^{a}$ & 100 & -0.893 & Carnivorous Habitat Specific & 89 \\
\hline Residential Edge $^{a}$ & 100 & -0.846 & neotropical & 67 \\
\hline Residential Edge $^{a}$ & 100 & -0.887 & Habitat Specific & 78 \\
\hline Residential Edge $^{a}$ & 100 & 0.887 & Edge & 89 \\
\hline Insectivorous $^{\mathrm{a}}$ & 89 & 0.805 & neotropical Habitat Specific & 89 \\
\hline Insectivorous $^{\mathrm{a}}$ & 89 & 0.820 & neotropical & 67 \\
\hline neotropical Habitat Specific ${ }^{\mathrm{b}}$ & 89 & 0.889 & neotropical $^{\mathrm{b}}$ & 67 \\
\hline neotropical Habitat Specific ${ }^{\mathrm{b}}$ & 89 & 0.851 & Habitat Specific ${ }^{\mathrm{b}}$ & 78 \\
\hline neotropical Habitat Specific ${ }^{\mathrm{b}}$ & 89 & -0.839 & Edge $^{\mathrm{b}}$ & 89 \\
\hline neotropical Habitat Specific ${ }^{\mathrm{b}}$ & 89 & 0.893 & Carnivorous Habitat Specific ${ }^{\mathrm{b}}$ & 89 \\
\hline Edge $^{\mathrm{b}}$ & 89 & -0.989 & Habitat Specific ${ }^{\mathrm{b}}$ & 78 \\
\hline Edge $^{\mathrm{b}}$ & 89 & -0.881 & Carnivorous Habitat Specific ${ }^{\mathrm{b}}$ & 89 \\
\hline Carnivorous Habitat Specific ${ }^{b}$ & 89 & 0.890 & Habitat Specific ${ }^{\mathrm{b}}$ & 78 \\
\hline
\end{tabular}


Table 5. Continued.

\begin{tabular}{|c|c|c|c|c|}
\hline Classification/Metric & $\begin{array}{l}\text { Discrimination } \\
\text { Efficiency }\end{array}$ & $\begin{array}{c}\text { Spearman's } \\
\mathrm{R} \\
\text { Correlation } \\
\end{array}$ & Correlated Metric & $\begin{array}{l}\text { Discrimination } \\
\text { Efficiency }\end{array}$ \\
\hline \multicolumn{5}{|l|}{ Emergent } \\
\hline Habitat Specific ${ }^{a}$ & 84 & -0.966 & Edge & 79 \\
\hline Habitat Specific $^{\mathrm{a}}$ & 84 & 0.844 & Carnivorous Habitat Specific & 73 \\
\hline neotropical Habitat Specific ${ }^{a}$ & 84 & 0.903 & Carnivorous Habitat Specific & 73 \\
\hline $\begin{array}{l}\text { Edge }^{\mathrm{b}} \\
\text { Scrub-Shrub }\end{array}$ & 79 & -0.832 & Carnivorous Habitat Specific ${ }^{\mathrm{b}}$ & 73 \\
\hline Residential Edge $^{\mathrm{a}}$ & 100 & -0.828 & Habitat Specific & 67 \\
\hline $\begin{array}{l}\text { Residential Edge } \\
\text { Wetland Species }\end{array}$ & 100 & 0.825 & Edge & 58 \\
\hline Abundance $^{\mathrm{a}}$ & 75 & 0.873 & Abundance & 75 \\
\hline Shannon's Evenness ${ }^{\mathrm{a}}$ & 67 & -0.886 & Abundance $^{\mathrm{b}}$ & 67 \\
\hline $\begin{array}{l}\text { Habitat Specific }{ }^{\mathrm{b}} \\
\text { Forested }\end{array}$ & 67 & -0.999 & Edge $^{b}$ & 58 \\
\hline Residential Edge $^{\mathrm{a}}$ & 88 & -0.867 & neotropical & 88 \\
\hline Residential Edge $^{a}$ & 88 & -0.834 & Insectivorous & 75 \\
\hline Omnivorous $^{\mathrm{a}}$ & 88 & -0.803 & Insectivorous & 75 \\
\hline neotropical $^{\mathrm{b}}$ & 88 & 0.837 & Insectivorous $^{\mathrm{b}}$ & 75 \\
\hline
\end{tabular}

${ }^{\text {a}}$ Selected for inclusion into class-specific AW-IBI.

${ }^{b}$ Not included into AW-IBI due to redundancy with metric with higher discrimination efficiency. 
Table 6. Analysis of variance (ANOVA) results of reference and stressed sites' metric values compared to Level 3 ecoregions (Omernik 1987; Wood et al. 1999) and the alternative classification scheme used in developing avian wetland indices of biological integrity (AW-IBI) for wetlands in West Virginia, USA from 2005-2006.

\begin{tabular}{|c|c|c|c|c|}
\hline $\begin{array}{l}\text { Classification (number of } \\
\text { reference and impacted sites) }\end{array}$ & Validation test & $\mathrm{df}$ & $\begin{array}{c}\text { F- } \\
\text { value }\end{array}$ & p-value \\
\hline \multicolumn{5}{|c|}{ Riparian Depression AW-IBI $(n=27)$} \\
\hline \multirow[t]{3}{*}{$\begin{array}{l}\text { Percent residential and edge } \\
\text { tolerant species }{ }^{\mathrm{a}}\end{array}$} & Cowardin class & 2,26 & 1.86 & 0.2150 \\
\hline & Level 3 ecoregion & 2,26 & 0.88 & 0.4288 \\
\hline & Cowardinclass $\mathrm{x}$ Level 3 ecoregion & 2,26 & 3.76 & 0.0410 \\
\hline \multicolumn{5}{|c|}{ Headwater Floodplain AW-IBI (n=16) } \\
\hline \multirow[t]{3}{*}{$\begin{array}{l}\text { Percent residential and edge } \\
\text { tolerant species }\end{array}$} & Cowardinclass & 2,15 & 1.28 & 0.3202 \\
\hline & Level 3 ecoregion & 2,15 & 0.89 & 0.4414 \\
\hline & Cowardinclass $\mathrm{x}$ Level 3 ecoregion & 1,15 & 0.30 & 0.5939 \\
\hline \multirow[t]{3}{*}{$\begin{array}{l}\text { Percent carnivorous and } \\
\text { habitat specific species }\end{array}$} & Cowardinclass & 2,15 & 0.20 & 0.8215 \\
\hline & Level 3 ecoregion & 2,15 & 0.35 & 0.7106 \\
\hline & Cowardinclass $\mathrm{x}$ Level 3 ecoregion & 1,15 & 0.01 & 0.9076 \\
\hline \multirow[t]{3}{*}{ Percent single-brood species } & Cowardinclass & 2,15 & 0.25 & 0.7845 \\
\hline & Level 3 ecoregion & 2,15 & 0.25 & 0.7820 \\
\hline & Cowardinclass $\mathrm{x}$ Level 3 ecoregion & 1,15 & 1.88 & 0.2001 \\
\hline \multirow[t]{3}{*}{ Percent omnivorous species } & Cowardinclass & 2,15 & 0.82 & 0.4685 \\
\hline & Level 3 ecoregion & 2,15 & 0.15 & 0.8627 \\
\hline & Cowardinclass $\mathrm{x}$ Level 3 ecoregion & 1,15 & 0.15 & 0.7037 \\
\hline \multirow{4}{*}{$\begin{array}{l}\text { Depression } \mathbf{A W}-\mathbf{I B I}(\mathbf{n}=\mathbf{3 7}) \\
\text { Percent residential and edge } \\
\text { tolerant species }\end{array}$} & & & & \\
\hline & Cowardinclass & 3,36 & 2.22 & 0.1076 \\
\hline & Level 3 ecoregion & 2,36 & 0.26 & 0.7757 \\
\hline & Cowardinclass $\mathrm{x}$ Level 3 ecoregion & 3,36 & 0.64 & 0.5953 \\
\hline \multirow[t]{3}{*}{ Percent insectivorous species } & Cowardinclass & 3,36 & 2.36 & 0.0925 \\
\hline & Level 3 ecoregion & 2,36 & 0.16 & 0.8522 \\
\hline & Cowardinclass $\mathrm{x}$ Level 3 ecoregion & 3,36 & 0.43 & 0.7345 \\
\hline \multirow{4}{*}{$\begin{array}{l}\text { Floodplain AW-IBI }(\mathbf{n}=\mathbf{1 9}) \\
\text { Percent residential and edge } \\
\text { tolerant species }\end{array}$} & & & & \\
\hline & Cowardinclass & 2,18 & 1.38 & 0.2958 \\
\hline & Level 3 ecoregion & 2,18 & 0.63 & 0.5521 \\
\hline & Cowardinclass $\mathrm{x}$ Level 3 ecoregion & 4,18 & 1.43 & 0.2936 \\
\hline \multirow[t]{3}{*}{ Avian diversity } & Cowardinclass & 2,18 & 0.03 & 0.9716 \\
\hline & Level 3 ecoregion & 2,18 & 0.25 & 0.7815 \\
\hline & Cowardinclass $\mathrm{x}$ Level 3 ecoregion & 4,18 & 1.55 & 0.2612 \\
\hline \multirow[t]{3}{*}{ Percent omnivorous species } & Cowardinclass & 2,18 & 1.55 & 0.2592 \\
\hline & Level 3 ecoregion & 2,18 & 1.19 & 0.3439 \\
\hline & Cowardinclass $\mathrm{x}$ Level 3 ecoregion & 4,18 & 1.82 & 0.2012 \\
\hline \multirow[t]{2}{*}{ Percent single-brood species ${ }^{\mathrm{a}}$} & Cowardinclass & 2,18 & 7.61 & 0.0098 \\
\hline & Level 3 ecoregion & 2,18 & 1.03 & 0.3912 \\
\hline \multirow{4}{*}{ Percent insectivorous species } & Cowardinclass $\mathrm{x}$ Level 3 ecoregion & 4,18 & 0.91 & 0.4933 \\
\hline & Cowardinclass & 2,18 & 1.69 & 0.2333 \\
\hline & Level 3 ecoregion & 2,18 & 1.16 & 0.2535 \\
\hline & Cowardinclass $\mathrm{x}$ Level 3 ecoregion & 4,18 & 2.41 & 0.1182 \\
\hline
\end{tabular}


Table 6. Continued.

\begin{tabular}{|c|c|c|c|c|}
\hline $\begin{array}{l}\text { Classification (number of } \\
\text { reference and impacted sites) }\end{array}$ & Validation test & df & $\begin{array}{c}\text { F- } \\
\text { value }\end{array}$ & p-value \\
\hline \multicolumn{5}{|l|}{$\begin{array}{l}\text { Impoundment } A W-I B I \\
(n=13)\end{array}$} \\
\hline \multirow[t]{3}{*}{$\begin{array}{l}\text { Percent residential and edge } \\
\text { tolerant species }\end{array}$} & Cowardinclass & 2,12 & 0.98 & 0.4202 \\
\hline & Level 3 ecoregion & 2,12 & 2.86 & 0.1233 \\
\hline & Cowardinclass $\mathrm{x}$ Level 3 ecoregion & 1,12 & 1.50 & 0.2606 \\
\hline \multirow[t]{3}{*}{ Percent omnivorous species } & Cowardinclass & 2,12 & 0.56 & 0.5936 \\
\hline & Level 3 ecoregion & 2,12 & 0.68 & 0.5353 \\
\hline & Cowardinclass $\mathrm{x}$ Level 3 ecoregion & 1,12 & 0.57 & 0.4735 \\
\hline \multirow[t]{3}{*}{ Percent insectivorous species } & Cowardinclass & 2,12 & 0.21 & 0.8135 \\
\hline & Level 3 ecoregion & 2,12 & 1.50 & 0.2878 \\
\hline & Cowardinclass $\mathrm{x}$ Level 3 ecoregion & 1,12 & 2.57 & 0.1532 \\
\hline \multicolumn{5}{|l|}{ Emergent AW-IBI $(n=38)$} \\
\hline \multirow[t]{3}{*}{$\begin{array}{l}\text { Percent residential and edge } \\
\text { tolerant species }{ }^{\mathrm{a}}\end{array}$} & Designated $\mathrm{HGM}^{\mathrm{b}}$ management class & 4,37 & 3.29 & 0.0267 \\
\hline & Level 3 ecoregion & 2,37 & 0.86 & 0.4352 \\
\hline & Designated $\mathrm{HGM}^{\mathrm{b}}$ management class $\mathrm{x}$ Level 3 ecoregion & 6,37 & 3.33 & 0.0151 \\
\hline \multirow[t]{3}{*}{ Percent neotropical migrant ${ }^{\mathrm{a}}$} & Designated $\mathrm{HGM}^{\mathrm{b}}$ management class & 4,37 & 4.22 & 0.0095 \\
\hline & Level 3 ecoregion & 2,37 & 0.81 & 0.4583 \\
\hline & Designated $\mathrm{HGM}^{\mathrm{b}}$ management class $\mathrm{x}$ Level 3 ecoregion & 6,37 & 1.21 & 0.3330 \\
\hline \multirow[t]{3}{*}{$\begin{array}{l}\text { Percent habitat specific and } \\
\text { neotropical migrant }{ }^{\mathrm{a}}\end{array}$} & Designated $\mathrm{HGM}^{\mathrm{b}}$ management class & 4,37 & 6.28 & 0.0012 \\
\hline & Level 3 ecoregion & 2,37 & 0.04 & 0.9594 \\
\hline & Designated $\mathrm{HGM}^{\mathrm{b}}$ management class $\mathrm{x}$ Level 3 ecoregion & 6,37 & 1.35 & 0.2744 \\
\hline \multirow[t]{3}{*}{ Percent habitat specific ${ }^{a}$} & Designated $\mathrm{HGM}^{\mathrm{b}}$ management class & 4,37 & 6.73 & 0.0008 \\
\hline & Level 3 ecoregion & 2,37 & 0.37 & 0.6952 \\
\hline & Designated $\mathrm{HGM}^{\mathrm{b}}$ management class $\mathrm{x}$ Level 3 ecoregion & 6,37 & 1.87 & 0.1255 \\
\hline \multirow[t]{3}{*}{ Percent omnivorous species } & Designated $\mathrm{HGM}^{\mathrm{b}}$ management class & 4,37 & 2.61 & 0.0595 \\
\hline & Level 3 ecoregion & 2,37 & 0.03 & 0.9702 \\
\hline & Designated $\mathrm{HGM}^{\mathrm{b}}$ management class $\mathrm{x}$ Level 3 ecoregion & 6,37 & 1.50 & 0.2200 \\
\hline \multirow[t]{3}{*}{ Percent insectivorous species ${ }^{a}$} & Designated $\mathrm{HGM}^{\mathrm{b}}$ management class & 4,37 & 5.82 & 0.0019 \\
\hline & Level 3 ecoregion & 2,37 & 0.03 & 0.9738 \\
\hline & Designated $\mathrm{HGM}^{\mathrm{b}}$ management class $\mathrm{x}$ Level 3 ecoregion & 6,37 & 1.07 & 0.4054 \\
\hline \multicolumn{5}{|l|}{ Scrub-Shrub AW-IBI $(n=23)$} \\
\hline \multirow[t]{3}{*}{ Wetland bird abundance ${ }^{\mathrm{a}}$} & Designated $\mathrm{HGM}^{\mathrm{b}}$ management class & 4,22 & 3.42 & 0.0377 \\
\hline & Level 3 ecoregion & 2,22 & 0.33 & 0.7256 \\
\hline & Designated $\mathrm{HGM}^{\mathrm{b}}$ management class $\mathrm{x}$ Level 3 ecoregion & 2,22 & 1.09 & 0.3626 \\
\hline \multirow[t]{3}{*}{$\begin{array}{l}\text { Percent residential and edge } \\
\text { tolerant species }\end{array}$} & Designated $\mathrm{HGM}^{\mathrm{b}}$ management class & 4,22 & 1.00 & 0.4403 \\
\hline & Level 3 ecoregion & 2,22 & 0.44 & 0.6521 \\
\hline & Designated $\mathrm{HGM}^{\mathrm{b}}$ management class $\mathrm{x}$ Level 3 ecoregion & 2,22 & 1.77 & 0.2058 \\
\hline \multirow[t]{3}{*}{$\begin{array}{l}\text { Percent habitat specific and } \\
\text { neotropical migrant }\end{array}$} & Designated $\mathrm{HGM}^{\mathrm{b}}$ management class & 4,22 & 2.64 & 0.0785 \\
\hline & Level 3 ecoregion & 2,22 & 1.46 & 0.2657 \\
\hline & Designated $\mathrm{HGM}^{\mathrm{b}}$ management class $\mathrm{x}$ Level 3 ecoregion & 2,22 & 2.01 & 0.1705 \\
\hline \multirow[t]{3}{*}{ Percent single-brood species ${ }^{\mathrm{a}}$} & Designated $\mathrm{HGM}^{\mathrm{b}}$ management class & 4,22 & 3.63 & 0.0314 \\
\hline & Level 3 ecoregion & 2,22 & 0.02 & 0.9761 \\
\hline & Designated $\mathrm{HGM}^{\mathrm{b}}$ management class $\mathrm{x}$ Level 3 ecoregion & 2,22 & 0.23 & 0.8011 \\
\hline \multirow[t]{3}{*}{ Percent omnivorous species } & Designated $\mathrm{HGM}^{\mathrm{b}}$ management class & 4,22 & 0.54 & 0.7101 \\
\hline & Level 3 ecoregion & 2,22 & 0.91 & 0.4260 \\
\hline & Designated $\mathrm{HGM}^{\mathrm{b}}$ management class $\mathrm{x}$ Level 3 ecoregion & 2,22 & 3.52 & 0.0579 \\
\hline \multirow[t]{3}{*}{ Percent insectivorous species } & Designated $\mathrm{HGM}^{\mathrm{b}}$ management class & 4,22 & 1.20 & 0.3525 \\
\hline & Level 3 ecoregion & 2,22 & 1.00 & 0.3918 \\
\hline & Designated $\mathrm{HGM}^{\mathrm{b}}$ management class $\mathrm{x}$ Level 3 ecoregion & 2,22 & 1.83 & 0.1974 \\
\hline
\end{tabular}


Table 6. Continued.

\begin{tabular}{|c|c|c|c|c|}
\hline $\begin{array}{l}\text { Classification (number of } \\
\text { reference and impacted sites) }\end{array}$ & Validation test & $\mathrm{df}$ & $\begin{array}{c}\mathrm{F}- \\
\text { value }\end{array}$ & p-value \\
\hline \multicolumn{5}{|l|}{ Forested AW-IBI $(n=16)$} \\
\hline \multirow[t]{3}{*}{$\begin{array}{l}\text { Percent habitat specific and } \\
\text { neotropical migrant }\end{array}$} & Designated $\mathrm{HGM}^{\mathrm{b}}$ management class & 4,15 & 0.43 & 0.7838 \\
\hline & Level 3 ecoregion & 2,15 & 0.17 & 0.8443 \\
\hline & Designated $\mathrm{HGM}^{\mathrm{b}}$ management class $\mathrm{x}$ Level 3 ecoregion & 2,15 & 0.66 & 0.5468 \\
\hline \multirow[t]{3}{*}{ Percent habitat specific } & Designated $\mathrm{HGM}^{\mathrm{b}}$ management class & 4,15 & 2.48 & 0.1390 \\
\hline & Level 3 ecoregion & 2,15 & 0.16 & 0.8559 \\
\hline & Designated $\mathrm{HGM}^{\mathrm{b}}$ management class $\mathrm{x}$ Level 3 ecoregion & 2,15 & 0.86 & 0.4653 \\
\hline \multirow[t]{3}{*}{$\begin{array}{l}\text { Percent residential and edge } \\
\text { tolerant species }\end{array}$} & Designated HGM ${ }^{\mathrm{b}}$ management class & 4,15 & 1.15 & 0.4082 \\
\hline & Level 3 ecoregion & 2,15 & 0.11 & 0.8993 \\
\hline & Designated $\mathrm{HGM}^{\mathrm{b}}$ management class $\mathrm{x}$ Level 3 ecoregion & 2,15 & 1.34 & 0.3218 \\
\hline \multirow[t]{3}{*}{ Percent single-brood species } & Designated $\mathrm{HGM}^{\mathrm{b}}$ management class & 4,15 & 2.32 & 0.1563 \\
\hline & Level 3 ecoregion & 2,15 & 2.67 & 0.1376 \\
\hline & Designated $\mathrm{HGM}^{\mathrm{b}}$ management class $\mathrm{x}$ Level 3 ecoregion & 2,15 & 1.94 & 0.2134 \\
\hline \multirow[t]{3}{*}{ Percent forest-area sensitive } & Designated $\mathrm{HGM}^{\mathrm{b}}$ management class & 4,15 & 3.33 & 0.0792 \\
\hline & Level 3 ecoregion & 2,15 & 0.19 & 0.8280 \\
\hline & Designated $\mathrm{HGM}^{\mathrm{b}}$ management class $\mathrm{x}$ Level 3 ecoregion & 2,15 & 0.09 & 0.9137 \\
\hline
\end{tabular}

${ }^{\text {a }}$ Metric excluded from inclusion into class-specific AW-IBI due to a significant ecoregion, alternative classification scheme, or cumulative 2-way interaction.

${ }^{\mathrm{b}}$ Hydrogeomorphic (Brinson 1993). 
Table 7. Wilks' Lambda statistic for posthoc validation of reference and stressed sites' metric values of class-specific avian wetland indices of biological integrity (AW-IBI) for wetlands in West Virginia, USA from 2005-2006.

\begin{tabular}{|c|c|c|c|c|}
\hline Classification scheme and interaction & $\begin{array}{l}\text { Wilks' } \\
\text { Lambda }\end{array}$ & $\begin{array}{c}\mathrm{F}- \\
\text { value }\end{array}$ & $\mathrm{df}$ & p-value \\
\hline \multicolumn{5}{|l|}{ Headwater Floodplain AW-IBI $(n=16)$} \\
\hline Cowardin class & 0.4292 & 0.92 & 8,14 & 0.5278 \\
\hline Level 3 ecoregion & 0.7291 & 0.30 & 8,14 & 0.9541 \\
\hline Cowardinx Level 3 ecoregion & 0.7037 & 0.74 & 4,7 & 0.5954 \\
\hline \multicolumn{5}{|l|}{ Floodplain AW-IBI $(n=19)$} \\
\hline Cowardinclass & 0.6504 & 0.42 & 8,14 & 0.8903 \\
\hline Level 3 ecoregion & 0.7253 & 0.30 & 8,14 & 0.9518 \\
\hline Cowardinx Level 3 ecoregion & 0.2491 & 0.79 & $16,20.02$ & 0.6788 \\
\hline \multicolumn{5}{|l|}{ Depression AW-IBI $(n=37)$} \\
\hline Cowardinclass & 0.7838 & 1.17 & 6,54 & 0.3382 \\
\hline Level 3 ecoregion & 0.9798 & 0.14 & 4,54 & 0.9673 \\
\hline Cowardinx Level 3 ecoregion & 0.9009 & 0.48 & 6,54 & 0.8187 \\
\hline \multicolumn{5}{|l|}{ Impoundment $A W$-IBI $(n=13)$} \\
\hline Cowardinclass & 0.4067 & 0.95 & 6,10 & 0.5042 \\
\hline Level 3 ecoregion & 0.3989 & 0.97 & 6,10 & 0.4902 \\
\hline Cowardinx Level 3 ecoregion & 0.6255 & 1.00 & 3,5 & 0.4656 \\
\hline \multicolumn{5}{|l|}{ Scrub-Shrub AW-IBI (n=23) } \\
\hline Designated HGM ${ }^{\mathrm{a}}$ management class & 0.4102 & 0.72 & $16,34.23$ & 0.7504 \\
\hline Level 3 ecoregion & 0.5362 & 1.01 & 8,22 & 0.4598 \\
\hline $\begin{array}{l}\text { Designated } \mathrm{HGM}^{\mathrm{a}} \text { management class x Level } 3 \\
\text { ecoregion }\end{array}$ & 0.5878 & 0.84 & 8,22 & 0.5806 \\
\hline \multicolumn{5}{|l|}{ Forested AW-IBI $(n=19)$} \\
\hline Designated HGM ${ }^{\mathrm{a}}$ management class & 0.0636 & 2.06 & $12,13.52$ & 0.1013 \\
\hline Level 3 ecoregion & 0.4643 & 0.78 & 6,10 & 0.6045 \\
\hline $\begin{array}{l}\text { Designated } \mathrm{HGM}^{\mathrm{a}} \text { management class x Level } 3 \\
\text { ecoregion }\end{array}$ & 0.4952 & 0.70 & 6,10 & 0.6554 \\
\hline
\end{tabular}

\footnotetext{
${ }^{a}$ Hydrogreomorphic (Brinson 1993).
} 
Table 8. Reference site scoring summary used to derive scoring thresholds, and discrimination efficiency (D.E.) in developing class specific avian wetland indices of biological integrity (AW-IBI) in West Virginia, USA from 2005-2006.

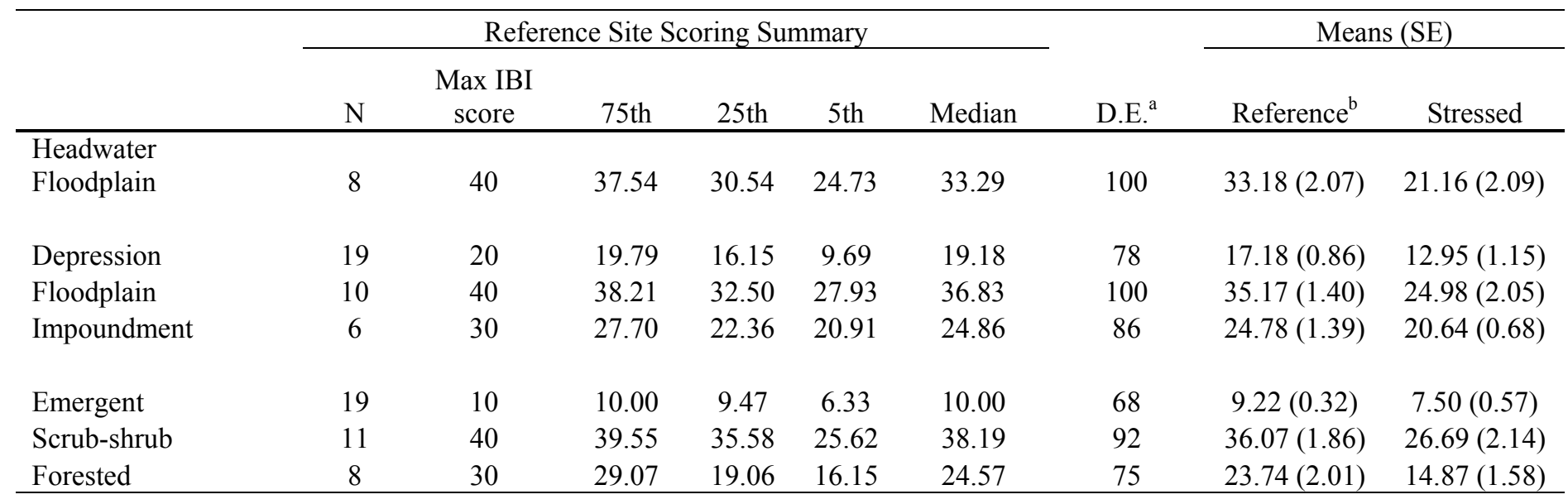

${ }^{\text {a }}$ Effectiveness of AW-IBI scores to effectively discriminate between reference and stressed sites.

${ }^{\mathrm{b}}$ All means statistically different (Tukey $\alpha=0.05$ ). 
Table 9. Avian species recorded and used in the formation of class specific avian wetland indices of biological integrity (AW-IBI) in West Virginia, USA from 2005-2006.

\begin{tabular}{|c|c|}
\hline Common Name & Scientific Name \\
\hline Acadian flycatcher & Empidonax virescens \\
\hline Alder flycatcher & Empidonax alnorum \\
\hline American crow & Corvus brachyrhynchos \\
\hline American goldfinch & Carduelis tristis \\
\hline American kestrel & Falco sparverius \\
\hline American redstart & Setophaga ruticilla \\
\hline American robin & Turdus migratorius \\
\hline American woodcock & Scolopax minor \\
\hline Baltimore oriole & Icterus galbula \\
\hline Bank swallow & Riparia riparia \\
\hline Barn swallow & Hirundo rustica \\
\hline Barred owl & Strix varia \\
\hline Belted kingfisher & Ceryle alcyon \\
\hline Black-and-white warbler & Mniotilta varia \\
\hline Black-capped chickadee & Poecile atricapilla \\
\hline Black-throated blue warbler & Dendroica caerulescens \\
\hline Black-throated green warbler & Dendroica virens \\
\hline Blue jay & Cyanocitta cristata \\
\hline Blue-gray gnatcatcher & Polioptila caerulea \\
\hline Blue-headed vireo & Vireo solitarius \\
\hline Blue-winged warbler & Vermivora pinus \\
\hline Brown thrasher & Toxostoma rufum \\
\hline Brown-headed cowbird & Molothrus ater \\
\hline Canada goose & Branta canadensis \\
\hline Carolina chickadee & Poecile carolinensis \\
\hline Carolina wren & Thryothorus ludovicianus \\
\hline Cedar waxwing & Bombycilla cedrorum \\
\hline Cerulean warbler & Dendroica cerulea \\
\hline Chestnut-sided warbler & Dendroica pensylvanica \\
\hline Chimney swift & Chaetura pelagica \\
\hline Chipping sparrow & Spizella passerina \\
\hline Common grackle & Quiscalus quiscula \\
\hline Common yellowthroat & Geothlypis trichas \\
\hline Cooper's hawk & Accipiter cooperii \\
\hline Dark-eyed junco & Junco hyemalis \\
\hline Domestic duck & not applicable \\
\hline Downy woodpecker & Picoides pubescens \\
\hline Eastern bluebird & Sialia sialis \\
\hline Eastern kingbird & Tyrannus tyrannus \\
\hline Eastern meadowlark & Sturnella magna \\
\hline Eastern phoebe & Sayornis phoebe \\
\hline Eastern towhee & Pipilo erythrophthalmus \\
\hline Eastern wood-pewee & Contopus virens \\
\hline European starling & Sturnus vulgaris \\
\hline
\end{tabular}


Table 9. Continued.

\begin{tabular}{|c|c|}
\hline Common Name & Scientific Name \\
\hline Field sparrow & Spizella pusilla \\
\hline Golden-crowned kinglet & Regulus satrapa \\
\hline Golden-winged warbler & Vermivora chrysoptera \\
\hline Grasshopper sparrow & Ammodramus savannarum \\
\hline Gray catbird & Dumetella carolinensis \\
\hline Great blue heron & Ardea herodias \\
\hline Great crested flycatcher & Myiarchus crinitus \\
\hline Green heron & Butorides virescens \\
\hline Hairy woodpecker & Picoides villosus \\
\hline Henslow's sparrow & Ammodramus henslowii \\
\hline Hermit thrush & Catharus guttatus \\
\hline Hooded merganser & Lophodytes cucullatus \\
\hline Hooded warbler & Wilsonia citrina \\
\hline House wren & Troglodytes aedon \\
\hline Indigo Bbnting & Passerina cyanea \\
\hline Kentucky warbler & Oporornis formosus \\
\hline Killdeer & Charadrius vociferus \\
\hline Louisiana waterthrush & Seiurus motacilla \\
\hline Magnolia warbler & Dendroica magnolia \\
\hline Mallard & Anas platyrhynchos \\
\hline Marsh wren & Cistothorus palustris \\
\hline Mourning dove & Zenaida macroura \\
\hline Mourning warbler & Oporornis philadelphia \\
\hline Nashville warbler & Vermivora ruficapilla \\
\hline Northern cardinal & Cardinalis cardinalis \\
\hline Northern flicker & Colaptes auratus \\
\hline Northern mockingbird & Mimus polyglottos \\
\hline Northern parula & Parula americana \\
\hline Northern rough-winged swallow & Stelgidopteryx serripennis \\
\hline Northern waterthrush & Northern Waterthrush \\
\hline Orchard oriole & Icterus spurius \\
\hline Osprey & Pandion haliaetus \\
\hline Ovenbird & Seiurus aurocapillus \\
\hline Philadelphia vireo & Vireo philadelphicus \\
\hline Pileated woodpecker & Dryocopus pileatus \\
\hline Pine warbler & Dendroica pinus \\
\hline Prothonotary warbler & Protonotaria citrea \\
\hline Purple finch & Carpodacus purpureus \\
\hline Purple martin & Progne subis \\
\hline Red-bellied woodpecker & Melanerpes carolinus \\
\hline Red-breasted nuthatch & Sitta canadensis \\
\hline Red-eyed vireo & Vireo olivaceus \\
\hline Red-tailed hawk & Buteo jamaicensis \\
\hline
\end{tabular}


Table 9. Continued.

\begin{tabular}{ll}
\hline Common Name & Scientific Name \\
\hline Red-winged blackbird & Agelaius phoeniceus \\
Rose-breasted grosbeak & Pheucticus ludovicianus \\
Ruby-crowned kinglet & Regulus calendula \\
Ruby-throated hummingbird & Archilochus colubris \\
Savannah sparrow & Passerculus sandwichensis \\
Scarlet tanager & Piranga olivacea \\
Sedge wren & Cistothorus platensis \\
Solitary sandpiper & Tringa solitaria \\
Song sparrow & Melospiza melodia \\
Spotted sandpiper & Actitis macularia \\
Swamp sparrow & Melospiza georgiana \\
Tennessee warbler & Vermivora peregrina \\
Tree swallow & Tachycineta bicolor \\
Tufted titmouse & Parus bicolor \\
Turkey vulture & Cathartes aura \\
Veery & Catharus fuscescens \\
Virginia rail & Rallus limicola \\
Warbling vireo & Vireo gilvus \\
Whip-poor-will & Caprimulgus vociferus \\
White-breasted nuthatch & Sitta carolinensis \\
White-eyed vireo & Vireo griseus \\
Willow flycatcher & Empidonax traillii \\
Winter wren & Troglodytes troglodytes \\
Wood duck & Aix sponsa \\
Wood thrush & Hylocichla mustelina \\
Yellow warbler & Dendroica petechia \\
Yellow-billed cuckoo & Coccyzus americanus \\
Yellow-breasted chat & Icteria virens \\
Yellow-rumped warbler & Dendroica coronata \\
\hline
\end{tabular}


Table 10. Summary statistics of proportion of wetland affiliated birds by classification used in developing class specific avian wetland indices of biological integrity (AW-IBI) in West Virginia, USA from 2005-2006.

\begin{tabular}{|c|c|c|c|c|c|c|}
\hline & Facultative $^{\mathrm{a}}$ & Associated $^{\mathrm{b}}$ & Dependent & $\begin{array}{l}\text { Shannon- } \\
\text { Weaver } \\
\text { Diversity }\end{array}$ & $\begin{array}{l}\text { Wetland Bird } \\
\text { Richness }^{\mathrm{c}}\end{array}$ & $\begin{array}{l}\text { Wetland Bird } \\
\text { Abundance }\end{array}$ \\
\hline Headwater Floodplain & 0.52 & 0.33 & 0.12 & 2.69 & 7.31 & 13.24 \\
\hline Riparian Depression & 0.57 & 0.30 & 0.11 & 2.69 & 7.54 & 14.98 \\
\hline Depression & 0.57 & 0.31 & 0.11 & 2.66 & 7.42 & 14.93 \\
\hline Floodplain & 0.52 & 0.31 & 0.13 & 2.68 & 7.23 & 13.11 \\
\hline Impoundment & 0.60 & 0.37 & 0.16 & 3.06 & 7.96 & 19.61 \\
\hline Emergent & 0.60 & 0.35 & 0.14 & 2.79 & 7.89 & 16.92 \\
\hline Scrub-Shrub & 0.56 & 0.34 & 0.11 & 2.77 & 7.59 & 15.45 \\
\hline Forested & 0.41 & 0.18 & 0.10 & 2.36 & 5.87 & 9.26 \\
\hline
\end{tabular}

${ }^{a}$ Includes wetland associated and dependent birds.

${ }^{\mathrm{b}}$ Includes wetland dependent birds.

${ }^{\mathrm{c}}$ Includes all birds with affiliated with facultative wetland use and greater. 
Table 11. Relations between the resulting hydrogeomorphic (HGM) and Cowardin classspecific and combined avian wetland indices of biological integrity (AW-IBI) for West Virginia, USA and the disturbance gradient from 2005-2006.

\begin{tabular}{|c|c|c|c|c|c|c|c|}
\hline & $\begin{array}{l}\text { Number of } \\
\text { metrics }\end{array}$ & $\mathrm{N}$ & df & $\begin{array}{c}\text { F- } \\
\text { value }\end{array}$ & P-value & $\mathrm{R}^{2}$ & Equation \\
\hline \multicolumn{8}{|l|}{ HGM subclass } \\
\hline Headwater Floodplain & 4 & 29 & 1,27 & 25.44 & $<0.0001$ & 0.49 & $\mathrm{y}=11.97+0.62($ Disturbance score $)$ \\
\hline \multicolumn{8}{|c|}{ Designated HGM management class } \\
\hline Depression & 2 & 72 & 1,70 & 9.71 & 0.0027 & 0.12 & $\mathrm{y}=9.52+0.23$ (Disturbance score $)$ \\
\hline Floodplain & 4 & 35 & 1,33 & 32.74 & $<0.0001$ & 0.46 & $\mathrm{y}=18.14+0.50$ (Disturbance score $)$ \\
\hline Impoundment & 3 & 23 & 1,21 & 1.14 & 0.2982 & 0.05 & $\mathrm{y}=18.15+0.15$ (Disturbance score $)$ \\
\hline \multicolumn{8}{|l|}{ Cowardin class } \\
\hline Emergent & 1 & 75 & 1,73 & 8.71 & 0.0042 & 0.11 & $\mathrm{y}=6.47+0.09$ (Disturbance score $)$ \\
\hline Scrub-Shrub & 4 & 44 & 1,42 & 13.71 & 0.0006 & 0.25 & $\mathrm{y}=17.54+0.54$ (Disturbance score) \\
\hline Forested & 3 & 31 & 1,29 & 8.48 & 0.0056 & 0.24 & $\mathrm{y}=6.07+0.47$ (Disturbance score) \\
\hline \multicolumn{8}{|l|}{ Hybrid class } \\
\hline $\begin{array}{l}\text { Headwater Floodplain / } \\
\text { Emergent }\end{array}$ & 4 & 15 & 1,13 & 4.59 & 0.0517 & 0.26 & $y=16.48+0.45$ (Disturbance score) \\
\hline $\begin{array}{l}\text { Headwater Floodplain / } \\
\text { Scrub-Shrub }\end{array}$ & 6 & 7 & 1,5 & 79.93 & 0.0003 & 0.94 & $\mathrm{y}=-2.96+1.54$ (Disturbance score) \\
\hline $\begin{array}{l}\text { Headwater Floodplain / } \\
\text { Forested }\end{array}$ & 5 & 7 & 1,5 & 15.66 & 0.0108 & 0.76 & $\mathrm{y}=-2.84+1.20$ (Disturbance score) \\
\hline Depression / Emergent & 3 & 38 & 1,36 & 3.43 & 0.0723 & 0.09 & $\mathrm{y}=15.82+0.30$ (Disturbance score $)$ \\
\hline Depression / Scrub-Shrub & 4 & 19 & 1,17 & 0.1656 & 0.6891 & 0.01 & $\mathrm{y}=23.88+0.11$ (Disturbance score) \\
\hline Depression / Forested & 4 & 14 & 1,12 & 1.4 & 0.2601 & 0.1 & $\mathrm{y}=18.77+0.31$ (Disturbance score) \\
\hline Floodplain / Emergent & 4 & 16 & 1,14 & 15.41 & 0.0015 & 0.52 & $\mathrm{y}=21.20+0.44$ (Disturbance score) \\
\hline Floodplain / Scrub-Shrub & 5 & 8 & 1,6 & 33.95 & 0.0011 & 0.85 & $\mathrm{y}=0.50+1.27$ (Disturbance score) \\
\hline Floodplain / Forested & 6 & 11 & 1,9 & 6.43 & 0.0319 & 0.42 & $y=14.43+0.95$ (Disturbance score) \\
\hline $\begin{array}{l}\text { Impoundment / Emergent } \\
\text { Impoundment / Scrub- }\end{array}$ & 3 & 14 & 1,12 & 0.63 & 0.4421 & 0.05 & $y=19.27+0.14$ (Disturbance score $)$ \\
\hline Shrub & 4 & 7 & 1,5 & 1.11 & 0.3395 & 0.18 & $\mathrm{y}=6.13+0.77$ (Disturbance score) \\
\hline Impoundment / Forested & 5 & 2 & & & & & inadequate sample size \\
\hline
\end{tabular}




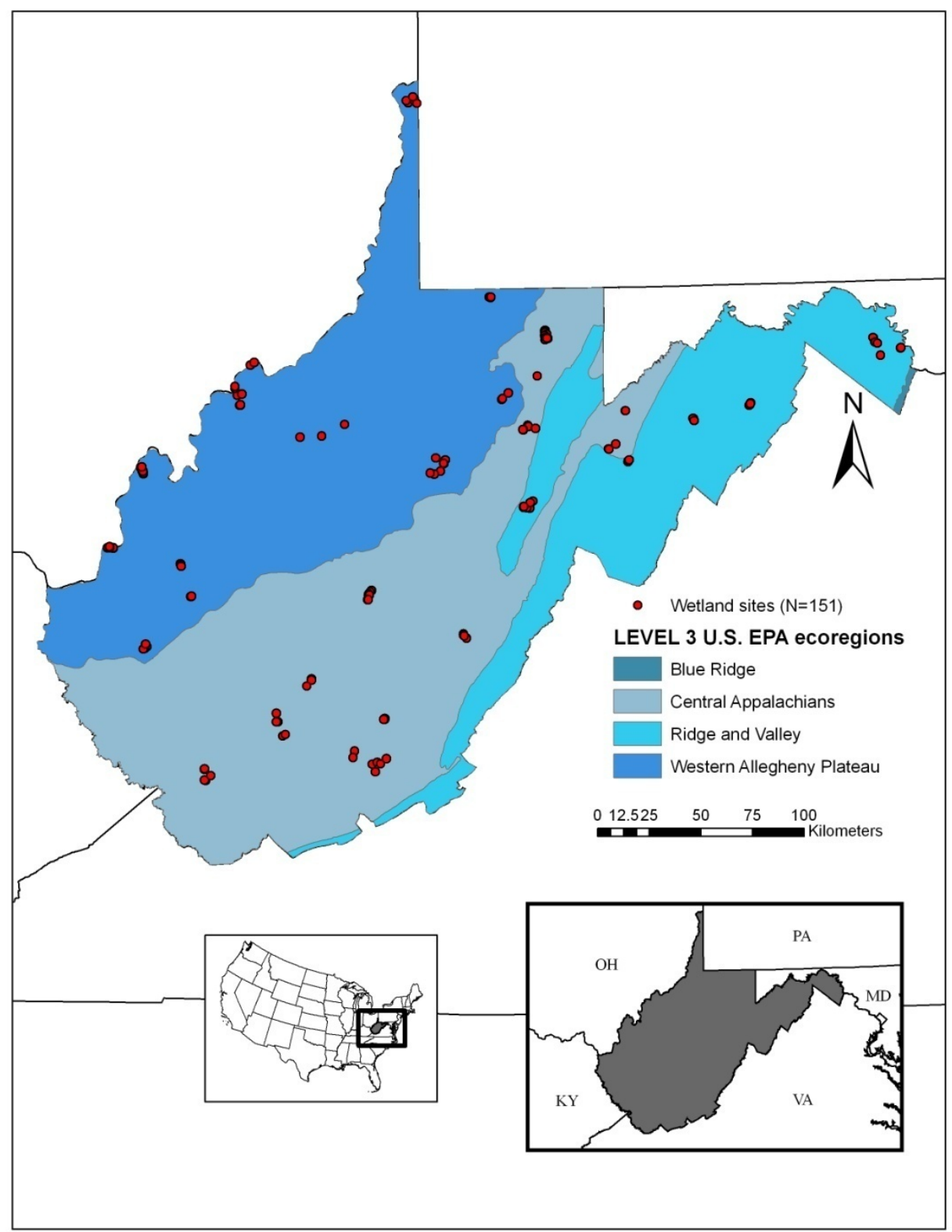

Figure 1. Site locations of wetlands and ecoregions (Woods et al. 1999, Omernik 1987) used in developing class-specific avian wetland indices of biological integrity (AW-IBI) in West Virginia, USA from 2005-2006. Wetland sites were clustered; scale of map prevents all sites from being marked individually. Legend may indicate 1-4 wetlands per mark. 


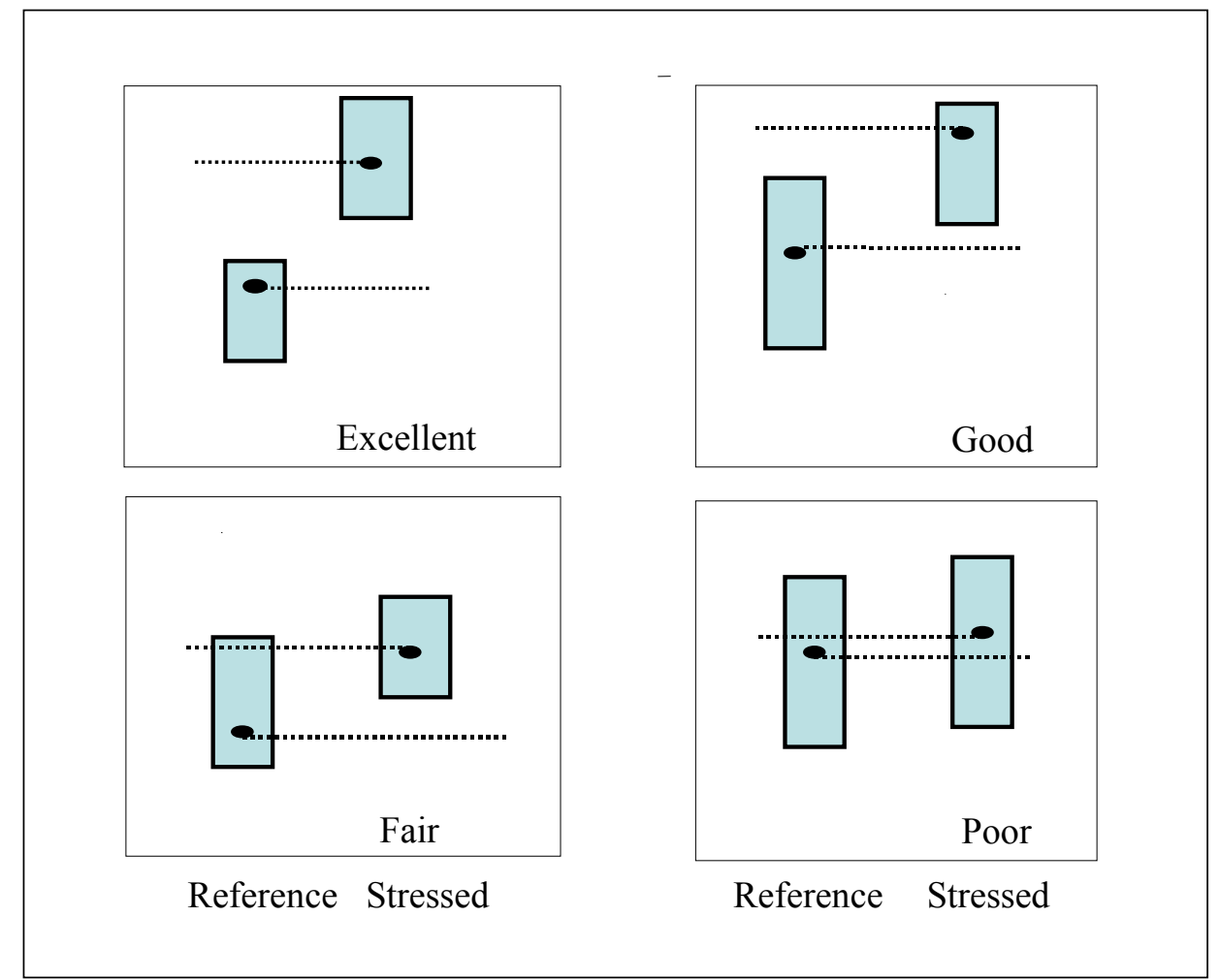

Figure 2. Box-and-whisker plot characteristics and resulting narrative description of reference and stressed sites' distribution of a biological metric value considered for inclusion into class-specific avian wetland indices of biological integrity (AW-IBI) in West Virginia, USA from 2005-2006. Solid ovals represent the median of metric value (courtesy of Greg Pond, U.S. EPA). 


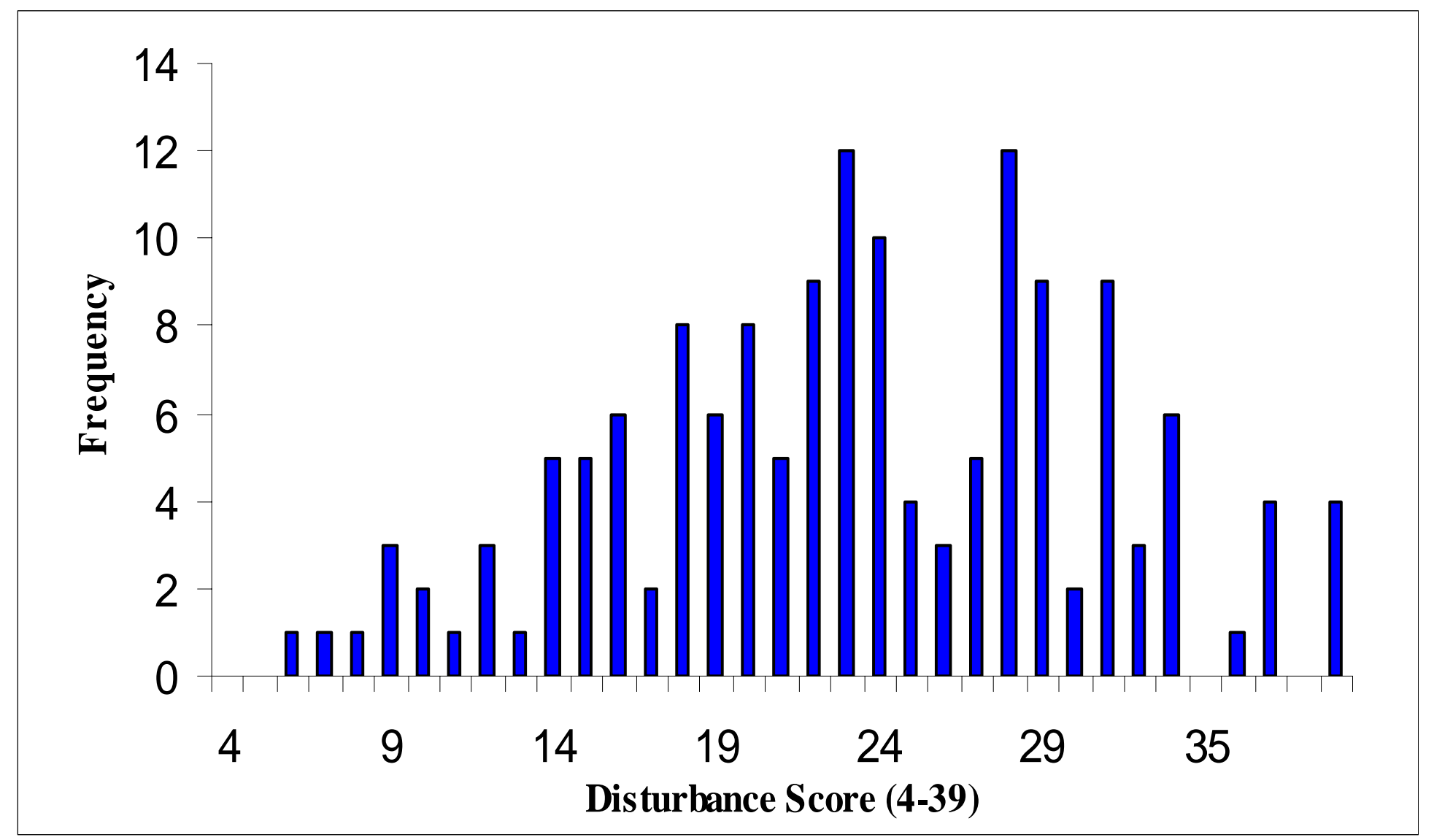

Figure 3. Frequency distribution of disturbance scores for sites used to develop class-specific avian wetland indices of biological integrity (AW-IBI) for wetlands in West Virginia, USA from 2005-2006. 


\title{
Chapter 3
}

\section{Acoustically-based Anuran Indices of Biological Integrity}

\section{Development and Evaluation of Acoustically-based Anuran Indices of Biological Integrity for Wetlands in West Virginia, USA}

\author{
Walter Veselka IV ${ }^{1}$ \\ James T. Anderson ${ }^{1,3}$ \\ Walter S. Kordek ${ }^{2}$ \\ ${ }^{1}$ Division of Forestry and Natural Resources, Wildlife and Fisheries Resources Program, \\ West Virginia University, PO Box 6125, Percival Hall, Morgantown, WV 26506 \\ ${ }^{2}$ West Virginia Division of Natural Resources, Wildlife Resources Section, PO Box 67 , \\ Ward Road, Elkins, WV 26241 \\ 3 address correspondence to James T. Anderson, Ph.D., Division of Forestry and Natural \\ Resources, Wildlife and Fisheries Resources Program, West Virginia University, PO Box \\ 6125, Percival Hall, Morgantown, WV 26506. email: wetland@wvu.edu phone: (304) \\ 293-2941 ext. 2445, fax: (304) 293-2441
}

Submitted in the style of:

Environmental Monitoring and Assessment 


\begin{abstract}
Across the United States there has been a recent push to monitor biological integrity of wetlands. This study examined using anuran call surveys, a common methodology used in many states, to derive metrics that exhibit a consistent response to levels of human impairment. These methods resulted in only 2 anuran metrics capable of consistently discriminating between reference and stressed sites. However, the resulting anuran acoustically-based indices of biological integrity (AA-IBI) exhibited a relation with the local disturbance gradient, developed regionally by the state of Ohio's Environmental Protection Agency. In addition to deriving and testing these anuran metrics against a local disturbance gradient, we combined the AA-IBI scores with metric scores from an avian wetland index of biological integrity (AW-IBI). This allowed us to compare the effectiveness of a single taxon IBI with that of a multi-metric IBI. In some cases, when metrics from avian and anuran assemblages were combined, the relation with the disturbance gradient was more consistent than with the individual taxon-specific IBI composed of these metrics. In general, the addition of anuran call-survey derived metrics provided limited additional discriminatory value beyond that provided by the AW-IBI metrics. However, anuran call-surveys should not be discontinued as they provide a relatively straight-forward introductory avenue for public participation in wetland monitoring programs, which is critical to protecting our state's wetland resources.
\end{abstract}

Keywords: anuran call surveys, indices of biological integrity, IBI, human impairment, metrics, avian wetland indices of biological integrity 


\subsection{Introduction}

Amphibians are a conspicuous taxon whose populations are responsive to changes in environmental conditions (Wake 1991; Wyman 1990). Identifying the specific causes behind the changes in amphibian populations can be difficult to ascertain (Blaustein et al. 1994; Pechmann et al. 1991). Large scale, difficult to quantify causes such as acid deposition, global warming, increases in UV radiation, the spread of toxic substances, and the introduction of predators have been suggested as factors playing a role in population fluctuations, and may affect amphibian metapopulations on a global scale (Houlahan et al. 2000; Sparling et al. 2002). Silvicultural practices, roads, and both aquatic and terrestrial habitat alterations have been suggested as factors affecting local amphibian population numbers in many areas including Maine, Minnesota, and Ontario (Houlahan and Findlay 2003; Lehtinen et al. 1999; Patrick et al. 2006; Trenham and Shaffer 2005; Trombulak and Frissel 2000).

The Clean Water Act (CWA) charges the United States Environmental Protection Agency's Office of Water with the responsibility "to restore and maintain the chemical, physical, and biological integrity of the Nation's waters." Methods for ensuring and quantifying biological integrity have advanced as more types of water bodies are being evaluated using multiple taxa groups(Gerritsen et al. 2000; Guntenspergen et al. 2002; Hill et al. 2003; Karr et al. 1986). Amphibians tend to display the characteristics suitable for developing bioassessments due to their restricted home ranges and their varying needs for both terrestrial and aquatic habitat components (Blaustein et al. 1994).

Ohio has developed an Amphibian Index of Biotic Integrity (Amph-IBI) in which greater than $50 \%$ of the variability of IBI scores can be attributed to the characteristics 
within and immediately surrounding a wetland (Micacchion 2004; Micacchion 2002). In addition to anthropogenic impacts, amphibian breeding success may be influenced by biotic factors such as predatory dragonflies and fish, and even the breeding or presence of other amphibians (Hecnar and M'Closkey 1997; Kiesecker and Blaustein 1998;Morin 1987; Skelly and Werner 1990). These biotic influences may be influenced by a wetland's hydroperiod which, in addition to wetland size and canopy cover, has been shown to explain a portion of the variation associated with amphibian species richness in South Carolina, Massachusetts, and Michigan (Burne and Griffin 2005;Skelly et al. 1999; Snodgrass et al. 2000a; Snodgrass et al. 2000b). While the habitat within and surrounding amphibian breeding areas is associated with the likelihood of species occurrence, the responses exhibited by amphibian communities are complex. For example, a previous study in West Virginia that used call surveys to compare amphibian communities between natural and mitigated wetlands revealed patterns that may be considered, by some, to be counterintuitive (Balcombe et al. 2005). Within this work, anuran species richness, abundance, and diversity were all greater in mitigated wetlands than in the natural wetlands.

Our study assessed the potential of using the commonly used protocol of the North American Amphibian Monitoring Program (NAAMP) protocol to develop anuran metrics that are able to differentiate between wetlands that are anthropogenically impaired and those in a natural state (Genet and Sargent 2003; Mossman 1994). West Virginia already uses volunteer surveyors to monitor anuran populations, so this study was intended to ascertain the possibility of creating anuran acoustically-based indices of biological integrity (AA-IBI) easily integrated into existing programs. 
The resulting AA-IBIs were designed to compare anuran community responses to disturbance within different wetland classification schemes (Cowardin et al. 1979). The Cowardin et al. system (1979) is based upon vegetative structure, and will be referred to as "Cowardin" hereafter. This classification scheme is used for mapping by the National Wetland Inventory (NWI).The hydrogeomorphic (HGM) approach of classifying wetlands is based upon a wetland's position in the landscape and hydrology (Brinson 1993). These HGM classifications have been subdivided into regional HGM subclasses (Cole et al. 1997) based upon regional wetland conditions. Stratifying IBIs by HGM class for measuring wetland impairment has been identified as a means of increasing effectiveness and sensitivity because it compares wetlands that are functionally similar (Stevenson and Hauer 2002). However, its use has not been used to contrast or augment the Cowardin system, which is relatively straightforward and used in West Virginia for regulatory purposes (West Virginia State Code Chapter 22-11, 22-26).

Our objective was to assess the classification systems for use in an AA-IBI to quantify the differences in anuran communities between wetlands that are anthropogenically impaired and those in a natural state. In doing so we will be able to monitor the biological integrity of wetlands over time, ensure antidegradation standards are met, and compare the effectiveness of mitigated wetlands in replacing natural wetlands lost to development. Further, we explored summing avian wetland-indices of biological integrity (AW-IBI) (Veselka 2008: Chapter 2) with those derived in this research to determine if multi-taxa IBIs are more responsive to the disturbance gradient than an IBI based on a single taxon. This exploratory analysis is based on the argument that additive models are simple and easy to apply (Gerritsen 1995), and that a multi-taxa 
approach can increase sensitivity to environmental stressors (Griffith et al. 2005;

O'Connor et al. 2000). In doing so we will be able to monitor the biological integrity of wetlands over time, ensure antidegradation standards are met, and compare the effectiveness of mitigated wetlands in replacing natural wetlands lost to development.

\section{0 Methods}

\section{$\underline{2.1 \text { Study Area }}$}

Most of West Virginia falls into 1 of 3 U.S. Environmental Protection Agency Level 3 aquatic ecoregions: the Central Appalachians, the Ridge and Valley, and the Western Allegheny Plateau (Omernik 1987; Woods et al. 1999).Efforts were made to stratify these study sites by ecoregion and Cowardin classification scheme; as there is no statewide HGM mapping of wetlands(Table 1) (Veselka 2008: Chapter 2). Final site selection was based on wetland accessibility, as well as efficiency considerations aimed at maximizing sampling efforts in localized areas (Figure 1) (Veselka 2008: Chapter 2). Upon selection, wetlands were identified by the Cowardin system, and further classified by regional HGM subclasses (Cole et al. 1997), meaning each site was categorized by both systems and that they were not mutually exclusive. In an effort to increase sample sizes, some subclasses were combined (Table 2) (Veselka 2008: Chapter 2). Moreover, combining regional HGM subclasses into designated HGM management classes allowed us to compare the efficacy of IBIs derived from the original HGM subclasses with the newly designated HGM management classes (Veselka 2008: Chapter 2).

\section{$\underline{2.2 \text { Anuran Surveys }}$}

Anuran communities at each site were surveyed 3 times each year according to the North American Amphibian Monitoring Program (NAAMP) guidelines (Mossman 
1994). The survey consisted of a 2 minute settling period, followed by a 5 minute listening period in which a Wisconsin Index (WI) value and species abundance estimate was assigned to each species heard according to call intensity (Balcombe et al. 2005). This index ranged from 1 to 3 and was representative of the relative abundance of species heard at each site. An index value of 1 was assigned to species with non-overlapping calls and when an exact count of individuals could be made, an index value of 2 was assigned to species whose calls overlapped and only estimations of numbers could be made, and an index value of 3 was assigned to species that were calling in full chorus. If a WI value of 3 was assigned to a species, an arbitrary abundance estimate of 50 was assigned (Balcombe et al. 2005). The highest index value recorded across the 3 survey periods for each species was used to calculate metric values at each site.

\section{$\underline{2.3 \text { Disturbance Gradient }}$}

The Ohio Rapid Assessment Method, version 5.0 (ORAM) (Mack 2001) was used to assign a disturbance value directly related to human disturbance at each site (Table 3).The disturbance score has a maximum value of 39 , indicating no visible impact of human impairment, and a minimum score of 4 indicating severe human impact. Metrics selected for inclusion into the AA-IBI were based on their responses to the disturbance score. This disturbance gradient was composed of stressors that are intuitive and can be reasonably mitigated by resource mangers (Brooks et al. 1998). By choosing a disturbance gradient that would be reflective of changes brought about by the implementation of approved best management practices, we can expect a change in anuran communities based on these changes (Calhoun et al. 2005). 


\subsection{Reference and Stressed Sites Designations}

Each site was classed as a reference or stressed wetland based on ambient condition (Omernik 1995). Disturbance gradient scores in the $75^{\text {th }}$ and $25^{\text {th }}$ percentile were used to categorize reference and stressed conditions, respectively (Barbour et al. 1995). Reference and stressed designations were developed independently for Cowardin, HGM subclass (Cole et al. 1997), and designated HGM management class across all Level 3 ecoregions (Omernik 1987, Woods et al. 1999) because these designations were based on human impairment characteristics rather than any ecological basis.

\section{$\underline{2.5 \text { Data Analysis }}$}

Presence, relative abundance, and an abundance estimate of each anuran species was recorded by site (Appendix N). The relative abundance of each species, or WI value, was used to estimate species' population numbers and used in calculating metrics. The expressions of the anuran communities were used to develop a list of 12 candidate metrics, based on existing IBI metrics and literature suggesting predictable responses to human impairment (Table 4)(Balcombe et al. 2005; Micacchion 2002; Wilson 1995). Species were assigned a Coefficient of Conservatism ( $\mathrm{C}$ of $\mathrm{C})$ value from 1-10 based on their sensitivity to disturbance that was used in formulating metrics such as the percent of sensitive species (Table 5) (Micacchion 2002). The species data were first screened to exclude sites where no anurans were detected (4 sites) or only 1 species at the site during only 1 sampling period (14 sites). This analysis is meant to provide a measure of consistency in building the resulting AA-IBI, indicating minimum criteria for detection needed to be incorporated into an AA-IBI. 
To develop a statewide IBI using anuran communities, we analyzed the data in a series of elimination steps for each candidate metric (Veselka 2008: Chapter 2). For groups with adequate sample sizes, metrics were tested for responsiveness to the human disturbance index using box-and-whisker plots (Barbour et al. 1996; Chipps et al. 2005) (Figure 2). Metrics failing to discriminate between reference and stressed sites were discarded (Veselka 2008: Chapter 2). The remaining metrics were tested for redundancy using Spearman's R correlation statistic (Hughes et al. 1998; Veselka 2008: Chapter 2). Metrics with an R-value $>0.80$ were considered highly correlated (Table 6 ). Of the correlated pairs of metrics, the one with the greatest discrimination efficiency between reference and stressed sites was retained for inclusion into the AA-IBI (Table 7). If correlated metrics had the same discrimination efficiency, then both metrics were retained for further ecoregion and classification scheme screening to determine which metric was best suited for retention (Veselka 2008: Chapter 2).

Within the remaining suite of metrics for each of the resulting class-specific AAIBIs, we tested for an ecoregion effect or alternative classification effect using a series of 2-way analyses of variance (ANOVA) (Table 8). Metric values represented the dependent variables and ecoregion and wetland classification scheme were the independent variables. When multiple metrics were used to derive the class-specific AAIBI, the metrics were evaluated a final time with a multivariate analyses of variance (MANOVA), testing for a cumulative effect of the metric values of reference and stressed site to ecoregion or classification scheme influences (Veselka 2008: Chapter 2) (Table 9). After the series of tests finalizing the metrics used in the resulting AA-IBI were 
conducted, the metrics were then normalized (0-1)and values inversed as needed to provide a consistent response to disturbance by all metrics (Veselka 2008: Chapter 2).

Metrics included in the AA-IBI were scored by multiplying by a factor of 10 to form a continuous 0-10 scale (Blocksom 2003; Bryce et al. 2002; Veselka 2008: Chapter 2). Using the metrics appropriate for each classification, AA-IBIs were formed by summing all metrics selected for inclusion (Veselka 2008: Chapter 2).

The disturbance gradient and the distribution of the AA-IBI scores for the reference sites were used to set numeric thresholds describing wetland condition (Gerritsen et al. 2000; Hill et al. 2003; McCormick et al. 2001; Veselka 2008: Chapter 2). The relation between AA-IBI scores and the disturbance score were examined using simple linear regression specific to each classification. This enabled us to interpret and compare the results of our derived AA-IBI accordingly (Veselka 2008: Chapter 2).

After scoring each wetland with its derived designated HGM management class and HGM subclass (Cole et al. 1997) AA-IBI score, we continued to test the additive properties of metrics by combining the metrics of the AA-IBI with the corresponding class-specific scores of the West Virginia avian wetland index of biological integrity (AW-IBI) (Veselka2008: Chapter 2). We wished to determine if adding the individual metric scores of multiple taxa would provide a higher level of correlation between an IBI and the disturbance gradient. Adding of the IBI metrics was facilitated because all metric scores are on the same $0-10$ scale. Using anuran and avian metrics is cost-effective as both indices of biological integrity could be derived from volunteer-collected data. For example, the 4 metric scores that make up the headwater floodplain AW-IBI were added to the single of the headwater floodplain AA-IBI metric to create a multi-taxa IBI of 5 
metrics for comparison with the disturbance gradient. The relation between the combined metrics and the disturbance gradient were then re-examined using simple linear regression and compared to the results of the single-taxa derived wetland IBI.

\subsection{Results}

\section{$\underline{3.1 \text { Ecoregions and site classifications }}$}

For groups with adequate sample size, we evaluated by ecoregion emergent and scrub-shrub Cowardin wetland classes, floodplain, depression, and impoundment designated HGM management classes, and riparian depression and headwater floodplain HGM subclasses (Cole et al. 1997) (Table 1). A complete list of all sites and corresponding attribute data (e.g., ecoregion, location, class, etc.) can be found in Appendix B. A frequency distribution indicated normal distribution of disturbance scores (Figure 3) $($ Skewness $=-0.04$, Kurtosis $=-0.39)$.

After screening sites to eliminate sites from consideration in the development of the AA-IBI where no anurans where detected (4 sites) or only 1 species was detected at 1 sampling period (14 sites); the sample size of reference and stressed sites in forested wetlands was reduced so that we were unable to evaluate metrics suitable for inclusion into a forested AA-IBI. We were not able to distinguish between reference and impacted sites in the emergent, depression, or impoundment class wetlands so we were not able to derive AA-IBIs for these wetland classes. In the remaining wetland classifications, headwater floodplain, riparian depression, floodplain and scrub-shrub wetlands, redundant metrics were eliminated (Table 6). Richness, abundance, and the ShannonWeaver diversity metrics were often correlated when able to discriminate between reference and stressed sites. For these instances, the Shannon-Weaver diversity metric 
was retained if discrimination efficiency of each of the metrics were equal, because the diversity score is a function of both species richness and abundance (Magurran 1988). The remaining metrics were scrutinized with a series of 2-way ANOVAs (Table 8). Two metrics contributing to the scrub-shrub AA-IBI, anuran relative diversity and percentage of fish-tolerant anurans, were significantly affected by the HGM classification, resulting in an absence of any Cowardin based AA-IBIs. The percentage of fish-tolerant anurans metric of the floodplain AA-IBI was significantly influenced by the Cowardin expression of the wetland, which resulted in the elimination of this metric in a floodplain AA-IBI. The cumulative MANOVA test of the remaining 2 metrics of the floodplain AA-IBI, anuran relative diversity and total relative abundance of anurans, was not significant. As a result, the class-specific AA-IBIs were sufficiently robust to consistently discriminate between reference and stressed sites throughout West Virginia, although the headwater floodplain and riparian depression AA-IBI were composed of only 1 metric.

\section{$\underline{3.2 \text { Anuran Communities }}$}

Our surveys detected the presence of 12 of the 15 anuran species documented in West Virginia that can be detected by call surveys. Northern spring peepers (Hyla crucifer) and northern green frogs (Rana clamitans) were the most frequently detected species, respectively, whereas Fowler's toad (Bufo woodhousei fowleri) was only detected at 1 site (Table 11). The Blanchards cricket frog (Acris crepitans blanchardi), eastern cricket frog (Acris crepitans crepitans), and eastern spadefoot toad (Scaphiopus holbrookii) were not detected in our study. Species richness ranged from 0 species detected at 4 sites, to 8 species detected at 2 sites. The mean number of species found per site was $3.45(\mathrm{SE}=1.86)$. 
A list of species detected and corresponding WI chorus values has been included in Appendix N. The individual metric values for each site are in Appendix O, summary statistics of metric scores statewide and by ecoregion are in Appendix P.

\subsection{Metric Performance}

All metrics were initially screened based on their ability to discriminate between reference and stressed sites independently for each classification (HGM subclass, designated HGM management class or Cowardin class) based upon the disparity among the interquartile ranges of metric values for reference and stressed conditions (Appendix Q-X). Within these classifications, only the regional HGM subclasses (Cole et al. 1997) headwater floodplain and riparian depression; the floodplain designated HGM management class, and scrub-shrub wetlands within the Cowardin class were found to have metrics capable of discriminating between reference and stressed sites statewide.

The majority of metrics were discarded before being included into ecoregionspecific AA-IBI due to an inability to discriminate between reference and stressed conditions and redundancy with other metrics (Table 7). The resulting AA-IBIs were limited in the number of remaining suitable metrics. For example, at most, only 2 metrics were suitable for inclusion into the suite of resulting class-specific AA-IBIs. The relation between the class-specific AA-IBIs and our disturbance scores were significant in all remaining cases (Table 12). However, the variation attributed to disturbance in riparian depression AA-IBI scores is essentially of no value $\left(\mathrm{R}^{2}=0.08\right)$. The variation accounted for by the disturbance score peaked at $27 \%$ in the headwater floodplain AAIBI, and was $18 \%$ in the broader floodplain AA-IBI classification. 
Relative diversity was the metric most often retained by the majority of the classes (Table 7). There was 1 case (floodplain designated HGM management class) in which relative abundance was retained along with relative diversity, but these metrics were not correlated enough to lead to 1 metric being excluded by the other (Table 6). 3.4 Scoring Thresholds

The scoring thresholds for each class of derived AA-IBI were based on the $75^{\text {th }}$, $25^{\text {th }}$, and $5^{\text {th }}$ percentile of reference AA-IBI scores (Table 10). Of the 3 classes of derived AA-IBI, 2 were able to discriminate between reference and stressed sites greater than $80 \%$ of the time. Riparian depression-based AA-IBI discriminated between reference and stressed conditions $67 \%$ of the time, although there was a significant difference between the mean reference and stressed sites' scores according to Tukey's Honestly Significance Difference test. The headwater floodplain AA-IBI was the only class in which mean scores between reference and stressed sites did not statistically differ.

\subsection{Hybrid Classification Capacity of AA-IBI metrics}

There was a lack of suitable metrics capable of discriminating between reference and stressed sites in Cowardin based AA-IBIs. This resulted in an inability to combine metrics from the HGM-based IBIs and the Cowardin based IBIs. As a result, we were not able to evaluate any potential effect of integrating these 2 classes of IBIs on the sensitivity to the disturbance score.

\subsection{Combining AA-IBI metric scores to form multi-taxa wetland IBIs}

Combining the class-specific AA-IBI metric scores with corresponding metric scores from the avian wetland indices of biological integrity (AW-IBI) increased the number of metrics that were responsive to the disturbance gradient and could be added to 
form multi-taxa IBI. We were able to examine class-specific multi-taxa IBIs for headwater floodplain and floodplain wetlands using metrics derived from the AA-IBIs and AW-IBIs. Increasing the number of metrics did not always produce an increase in disturbance score sensitivity (Table 13). In headwater floodplain wetlands, combining metric scores of the anuran and avian taxa groups resulted in increases in the variation attributed to the disturbance gradient. However, the percentage of increase, although statistically significant, was only $1 \%$. In floodplain wetlands, 5 metrics comprised the AW-IBI score, and 2 metrics made up the AA-IBI score. The resulting relation with the disturbance score was significant, and $43 \%$ of the variation in multi-taxa IBI scores was a result of the disturbance gradient. This is a decrease of $7 \%$ from the floodplain designated HGM management class AW-IBI relation with the disturbance gradient and an increase of $25 \%$ from the same classification AA-IBI.

We also examined multi-taxa hybrid-classes of IBI that were a result of combining Cowardin and HGM-based metrics from the AA-IBIs and AW-IBIs (Table 13). Combining the Cowardin based AW-IBI metrics with the riparian depression AAIBI metrics to form a multi-taxa hybrid IBI did not result in any significant relation with the disturbance gradient. In addition the multi-taxa hybrid emergent-headwater floodplain, forested-headwater floodplain, forested-floodplain, and scrub-shrubfloodplain IBIs did not show a significant relation with the disturbance gradient. Only 2 multi-taxa hybrid IBIs, the emergent-floodplain and scrub-shrub-headwater floodplain, were significantly related to the disturbance gradient. In both cases, the amount of variation attributed to the disturbance gradient decreased slightly from the corresponding AW-IBI metrics-only hybrid classifications. 


\subsection{Discussion}

\section{$\underline{4.1 \text { Study design }}$}

This study represented, in part, an effort to develop a taxa-specific IBI that could quantify changes in levels of disturbance. Additionally, it enabled us to evaluate the potential of combining taxon-specific IBIs to construct multi-taxa IBIsmore sensitive to the disturbance gradient. Each taxon-specific IBI varies relative to sensitivity, ease of data collection, and cost. Upon completion, wetland resource managers will be able to measure wetland biological integrity and its relation to human disturbance costeffectively and efficiently.

Anuran communities with high biological integrity are the desired endpoint representing least impaired wetland conditions. Contrasting the more recent and regionally specific HGM classification (Brinson 1993) with the Cowardin classification allowed us to identify the classification best suited to base an IBI upon. Our decision to combine the regional subclasses (Cole et al. 1997) into designated HGM management classes was based on the intended applicability and management implications within the objectives of developing an anuran community wetland index of biotic integrity. For comparison, we included analyses of regional HGM subclasses (Cole et al. 1997), if sample size permitted, which allowed us to look at the efficacy of our designated HGM management class.

The methodology used in our research was intended to be straight-forward and intuitive to enable users with various levels of expertise the opportunity to participate in wetland monitoring programs administered by the WVDNR or other groups. The redaction of regional HGM subclasses (Cole et al. 1997) to designated HGM 
management classes was designed not only to increase sample size, but also for ease of classification by non-professionals. For example, with minimal instruction, we expect volunteers to be able to differentiate between depression, floodplain, impoundment, fringing, and slope wetlands. Moreover, the local disturbance gradient, adopted from a modified ORAM (Mack 2001) has already been shown to be scientifically defensible and undergone numerous changes and revisions. As a result of this development process, a scoring manual, as well as workshops, are already being offered to standardize the scoring process. The scoring consistency achieved demonstrates that stressor conditions can be quantified, and improvement or rehabilitation of these stressors can be expected to produce quantifiable changes in biological communities asreflected in IBI scores.

The expectation is that this body of work can be used independently to examine the relation between anuran communities and disturbances; and further, augment the existing AW-IBI when applicable. It is the baseline from which to initiate a state-wide West Virginia wetland monitoring program, capable of detecting impairment and recognizing improvement and degradation in natural and constructed wetlands.

\subsection{Classifications of Anuran Acoustically-based Indices of Biological Integrity}

Developing an applicable IBI that can be scientifically defended represents a challenging endeavor. Using best professional judgment, it seems intuitive that there would be differences in anuran communities based on wetland classifications, regardless of whether those classifications are based on HGM setting or Cowardin classes. It is also plausible that there may be some differences in the data due to ecoregion (Omernik 1995). However, if the data are sensitive to ecoregion and wetland classification differences, the overall sample size must be increased to address these effects. The 
capacity to quickly and easily apply the results of this research to monitoring the changes in wetland biological integrity is deferred until additional data are assembled. Our objective was to find metrics that could be part of a robust state-wide wetland IBI immune to ecoregion variation. By addressing this possibility of variation, we are confident that the resulting AA-IBIs were constructed using consistent, scientific rigor.

After selecting metrics based on their ability to discriminate between reference and stressed sites and eliminating redundant metrics, we evaluated the reference and stressed sites' metric values using a series of 2-way ANOVAs. These tests were intended to identify metrics prone to ecoregion and/ or alternative classification effects. In the 3 derived HGM or HGM subclass-based AA-IBI, the majority of metrics, with the exception of percentage of fish-tolerant species in floodplain wetlands, were capable of discriminating between reference and stressed sites statewide, in spite of ecoregion or Cowardin class differences. Alternatively, the metrics of the scrub-shrub AA-IBI were subject to significant differences in values based on HGM expression, resulting in a failing AA-IBI not capable of consistently scoring scrub-shrub wetlands regardless of HGM expression. Although disappointing, this was not altogether unexpected. The wetlands that were used to develop the scrub-shrub-based AA-IBIswere developed on data from scrub-shrub wetlands. HGM and HGM subclass-based AA-IBI were based on wetland sharing similar hydrologic characteristics. Research from South Carolina, Michigan, Massachusetts, and Maine suggest that hydroperiod is the major, determining factor dictating the expression of amphibian communities (Baldwin et al. 2006; Burne and Griffin 2005;Skelly et al. 1999; Snodgrass et al. 2000a). The scrub-shrub AA-IBI 
did not inherently capture some of the variation in hydrology, resulting in inconsistent scores between HGM expressions, which led to the elimination of this class of AA-IBI.

Comparing the AA-IBI of the designated HGM management classes to the regional HGM subclasses (Cole et al. 1997), our results indicate the regional HGM subclasses seem to be better suited for detecting disturbance using anuran assemblages. However, there is a trade-off between the suitability of using HGM classes and ease with which categories can be identified. Designated HGM management classes represent broad categories easily identified with minimal training, whereas the regional HGM subclasses (Cole et al. 1997) require choices from more numerous and less intuitive categories. The regional HGM subclasses (Cole et al. 1997) are driven by water source, rather than general landscape position, that in-turn, determines hydroperiod. Therefore, because regional HGM subclasses (Cole et al. 1997) give us a better idea of the influence of hydrology and length of hydroperiod, it is not surprising that the AA-IBI developed for these subclasses perform more consistently than the designated HGM management classes.

Unfortunately, we were not able to derive AA-IBI for impounded, depressional, or emergent wetlands. Impounded wetlands are inherently products of disturbed hydrology; therefore it is not surprising that we would not be able to develop metrics capable of discriminating between reference and stressed conditions in such a system. The lack of metrics suitable for depressional wetlands is more difficult to interpret. The majority of the depressional wetlands in this study were riparian depressions (Cole et al. 1997), so it stands to reason that if a riparian depression AA-IBI was derived, a depressional AA-IBI would be similar. However, as the riparian depression AA-IBI was 
composed of only 1 metric, relative diversity, the variation associated with this metric in surface-water or isolated depressions was enough to elicit an inconsistent response between this metric and the disturbance score. Moreover, the lack of anuran metrics capable of consistently discriminating between reference and stressed conditions in emergent wetlands was not altogether unexpected. Ohio's amphibian IBI (Micacchion 2002) also failed to develop metrics suitable for an emergent wetland IBI, despite muchmore quantified data generated by their labor-intensive methodology. The variation between types of emergent wetlands in our study may have been excessive for any single, metric based on anuran call surveys to discriminate between levels of human impairment. High-elevation wetlands, bogs, high and low order floodplain wetlands, and mitigated impoundments were all represented within the Cowardin class of emergent wetlands in this study. Further research, examining these wetlands as subsets of the emergent class may identify metrics suitable for discriminating between reference and stressed conditions within emergent wetlands.

\section{$\underline{4.3}$ Anuran Communities and Data}

The species and relative abundance of each species was not surprising. Northern spring peepers, the most frequently occurring species, are the most commonly occurring anuran in the state; and the species we did not encounter are not common in West Virginia (Pauley 2001). The anuran community data were gathered using methods that are being used in at least 24 states as part of the NAAMP (Genet and Sargent 2003). Our decision to adopt these methods is a reflection of the effort to design an IBI that can be applied to existing WVDNR programs, despite counsel that the NAAMP protocol is best used to determine species presence/ absence because of the observer bias associated with 
relative abundance estimates (Genet and Sargent 2003). Of our 12 candidate metrics we selected for evaluation, only 2 did not rely on abundance data. However, previous work in West Virginia using call survey methodology indicate the relative abundance data can be used to derive consistent comparisons between sites (Balcombe et al. 2005). Moreover, other research considers manual call surveys effective at estimating relative abundance of certain species (Corn et al. 2000), so the relative abundances of the species at each wetland were used to derive metric values. Other concerns with call-surveys include capturing the presence of species that call infrequently and the temporal variation of species calls, by which species may vocalize outside NAAMP hours (Crouch and Paton 2002, Bridges and Dorcas 2000). Alternative methods, such as intensive surveys or using an acoustic Frog-logger ${ }^{\circledR}$ are expensive, of limited utility, and can be logistically difficult over a large sampling region (Corn et al. 2000). Research in Maine has shown that the presence of seasonal pools is not always an indication of breeding success (Vasconcelos and Calhoun 2006). However, egg mass surveys for some species, such as wood frogs (Rana sylvatica), within these seasonal pools, is a cost-effective and relatively accurate and precise alternative to anuran call counts (Crouch and Paton 2000).

\subsection{Metric Performance}

Of the original 12 metrics considered for inclusion into AA-IBI, 9 metrics were discarded due to inability to discriminate between reference and stressed conditions, redundancy, or a lack of adequate scoring variation between reference and stressed conditions. Of the remaining 3 metrics, the percentage of fish-tolerant species was eliminated from both the scrub-shrub and floodplain AA-IBI due to an alternative classification scheme effect (Table 8). We also eliminated the anuran relative diversity 
metric from the scrub-shrub AA-IBI due to differences in scoring attributed to the HGM expression.

The relative diversity metric most often discriminated between reference and stressed sites. In many cases, relative abundance was found to be redundant with relative diversity. However, based on the results of Spearman's R correlation matrix, it was retained for inclusion into the floodplain designated HGM management class AA-IBI (Table 6). Understanding the relation between disturbance and anuran community diversity is currently subject to debate(Schurbon and Fauth 2004; Schurbon and Fauth 2003). The argument revolves around the intermediate disturbance hypothesis that states the impact of disturbance on diversity is complex and may deviate from the linear-like relationwe assume is representative of metrics reflecting disturbance(Connell 1978; Johst and Huth 2005; Mackey and Currie 2000). Regardless of the outcome of this debate, in the context of our study in West Virginia, relative diversity remains as a metric suitable of discriminating between reference and stressed conditions using anuran call surveys. Metric performance may have been improved by selecting a more inclusive disturbance gradient. Our disturbance gradient represented site-specific conditions and did not incorporate many of the factors determined to be important to the management of amphibians. These factors include local population dynamics, the availability of amphibian breeding habitat, and metapopulation dynamics (Semlitsch 2000). Our gross population estimates, rather than quantifiable abundance counts, were a result of our attempt to create a volunteer-friendlyAA-IBI. Moreover, we did not examine the context or matrix of wetlands from which our sampled wetlands occurred in the landscape. Wetland connectivity has been cited in numerous studies as driving factor in the 
expression of amphibian assemblages (Guerry and Hunter 2002; Kolozsvary and Swihart 1999). However, this deliberation was not an oversight, but rather a product of the study design in which the same local disturbance score is used to derive metrics from avian, anuran, vegetation, and macroinvertebrate communities. We suggest that the successful development of headwater floodplain and floodplain AA-IBIs may, in part, incorporate measures of this inherent connectivity associated with these classes.

\subsection{Combining Anuran and Avian Metric Scores}

By keeping the formation of taxa-specific indices of biological integrity consistent and normalized, we were able to combine the anuran metrics with those of the AW-IBI (Veselka 2008: Chapter 2). Exploring this combined relation allowed us to identify differences in sensitivity to the disturbance gradient, as demonstrated by the successful use of multi-taxa indices of biological integrity in wetlands, lakes, and streams(Griffith et al. 2005; Guntenspergen et al. 2002, O'Connor et al. 2000).

We summed the metric scores from the resulting AA-IBIs with the previous AWIBI metric scores (Veselka 2008: Chapter 2) within the same classes and compared the composite multi-taxa IBI scores to the disturbance score using simple linear regression. The results of this analysis are promising for future research, but combining anuran and avian metrics from data collected using methods appropriate for volunteers added minimal utility value above what had been provided using only avian assemblages. The addition of 1 anuran metric score to the 4 avian metric scores within the headwater floodplain regional HGM subclass (Cole et al. 1997) resulted in an increase of only $1 \%$ in the amount of variation explained by the disturbance score; whereas the addition of 2 anuran metrics to 5 avian metrics in the composite, multi-taxa floodplain wetland IBI 
actually decreased the amount of variation explained by $7 \%$. Additionally, the anuran and avian hybrid multi-taxa IBIs results were similar to those arrived at by combining the multiple taxa within the same classes: promising but of limited value.

Changes in the amount of variation accounted for by the disturbance score as a result of combining anuran and avian metrics did not increase IBI sensitivity to the disturbance score. However, the results validate our methods and show the potential of using multiple taxa groups en masse to detect changes in biological communities due to human impairment. As more data are analyzed, more combinations of multiple taxa groups, including vegetation and macroinvertebrates, may increase the sensitivity of these composite, multi-taxa wetland IBIs. Additionally, as further research increases our sample size, we will be able to build on our initial success of evaluating hybridized IBIs built from metrics showing a consistent response to disturbance in both the Cowardin classes and designated HGM management classes.

\section{$\underline{4.6 \text { Comparisons with other Studies }}$}

The metrics derived from the AA-IBI were successful at discriminating between reference and stressed conditions. However, the number of anuran metrics limits the effectiveness of anuran call surveys to monitor the biological integrity of wetlands. Many of our metrics were drawn from Ohio's state-wide Amphibian Index of Biotic Integrity (Amph-IBI) for natural forested and shrub-scrub wetlands (Micacchion 2002). However, Ohio's methods used provided more quantitative data to discriminate between reference and stressed conditions. Ohio used the Cowardin classifications to test the metric responses to disturbance. The study was based on the combined forested/ scrubshrub class of wetlands, as they did not discern a predictable relation between amphibian 
communities and disturbance in emergent wetlands. Using the same factors used to construct our disturbance gradient, $62.3 \%$ of the variation in the 5 metric AmphIBI scoresfor forested and scrub-shrub wetlands, was attributed to the disturbance level(Micacchion 2002).

The difference in results between our research and Ohio's AmphIBI is partly due to the quantitative methodology. However, the costs associated with this quantitative data collection are high (Corn et al. 2000). Our results are valuable because they show the potential to be combined with other volunteer-driven survey methods, while still obtaining similar responses to the disturbance gradient as with other bioassessment methods (Herbst and Silldorff 2006).

\subsection{Scoring Thresholds}

The generation of scoring thresholds that indicate wetland biological integrity is necessary to account for some degree of stochasticity in sampling from year to year. Categorizing site-specific AA-IBI scores will discount minor variations in annual AA-IBI scores and focus on the larger question of whether the integrity of the wetland is being maintained or is succumbing to the effects of impairments. However, applying these scoring thresholds based on our initial results may be premature. Riparian depression and headwater floodplain AA-IBIs are based on only 1 metric score, and therefore may be better served as supplements to existing indices of biological integrity. By basing the integrity of a wetland on only 1 metric, there exists a greater chance that random anomalies in the data will influence the results. This might be mitigated by combining multiple metric scores, if not from the same taxon, then from other taxa capable of discriminating between levels of integrity in wetlands. The biological basis for these 
scoring categories is based on principles that have been used in previous regional studies (Hill et al. 2003, McCormick et al. 2001). However, the legitimacy and applicability of these scoring thresholds will need to be examined in future works. For example, increased sample sizes, would, in theory, generate a larger variation in scoring values, for which we would need to recalibrate these proposed thresholds. Additionally, when we combine class-specific AA-IBIs with others to form additive hybrid classification indices or add IBIs with different taxa, such as the AW-IBI, values must be recalculated. The reference and stressed sites' designations were based on within class-specific parameters. That is to say a reference site for a Cowardin classification may not be a reference site for our designated HGM management classes. The increased sample sizes would provide a more consistent context of what constitutes a reference condition regardless of classification scheme. Therefore these derived scoring thresholds should be re-examined on a consistent schedule as to calibrate these thresholds, increase their validity and add interpretable biological meaning.

\subsection{Management Implications}

The importance of using volunteers to collect anuran data should not be discounted because of a lack of sensitive anuran community responses to the disturbance score. Although results were mixed, combining IBI scores of multiple taxa in both the HGM and Cowardin classifications suggests further research is warranted and we continue to expect that multi-taxa wetland IBIs, as well as hybrid IBIs, will respond predictably to human disturbances.

Our disturbance gradient represents a site-specific scale. The changes in variation explained by combining IBI scores of multiple taxa may reflect a calibration effect. The 
number of metrics included in multi-taxa indices of biological integrity changes the influence of each individual metric score on an IBI. Each metric within the IBI, in theory, exhibits the greatest response to a unique, scale-specific disturbance gradient. However, metrics are included in our combined IBI because they responded to our sitespecific disturbance gradient. Knowing that these metrics respond to different scales of disturbance but remain "loyal" to the local disturbance gradient has profound effects in monitoring applicability. As additional groups and metrics are evaluated for bioassessment potential, wetland resource managers will be able to select more metrics for inclusion into a multi-taxa wetland IBI.These metrics will be responsive to stressors at multiple scales, while still exhibiting a significant relation with the local disturbance gradient. To public policy makers, wetland monitoring often occurs on this site-specific basis within a mitigation, protection, or restoration context. Monitoring changes and protecting the biological integrity of wetlands has always been mandated by the Clean Water Act, but questions remained on how to define, monitor and quantify changes in impairment. By tying the disturbance gradient to site-specific, easily-recognizable stressors, we found that combining metrics from multiple communities can reveal locallevel biological community patterns representative of impairment. Further, we used methods already used by WVDNR and others that are often volunteer-driven to gather the avian and anuran species data. These methods can be used in the future to conduct cost-effective and response oriented wetland monitoring plans to evaluate the measures taken to protect or replace our wetland resources.

\subsection{Acknowledgements}


We thank Adrianne Brand and Mark Hepner for field help. Joe Osbourne assisted in preparing field crews for consistent and accurate anuran identification. Greg Pond, George Merovich, and the late Dr. George Seidel provided statistical support and advice. Technical and logistical support was provided by Sarah McClurg. Geographic information system and database management assistance provided by Ben Gilmer. Funding was provided by the West Virginia Division of Natural Resources with assistance from U.S. EPA State Wetland Program Development Grant CD 973080-01-0. This is scientific article number xxxx of the West Virginia University Agriculture and Forestry Experiment Station. 


\subsection{Literature Cited}

Balcombe C.K., Anderson J.T., Fortney R.H., Kordek W.S. (2005). Wildlife use of mitigation and reference wetlands in West Virginia. Ecological Engineering, 25, 85-99.

Baldwin R.F., Calhoun A., deMaynadier P.G. (2006). The significance of hydroperiod and stand maturity for pool-breeding amphibians in forested landscapes. Canadian Journal of Zoology, 84, 1604-1615.

Barbour M.T., Stribling J.B., Karr J.R. (1995). Biological assessment and criteria: Tools for water resource planning and decision making. Davis W.S., Simon T.P. (Eds.), Multimetric approach for establishing biocriteria and measuring biological condition. (pp. 63-77). Ann Arbor, MI: Lewis Publishers.

Barbour M.T., Gerritsen J., Griffith G.E., Frydenborg R., McCarron E., White J.S., Bastian M.L. (1996). A framework for biological criteria for Florida streams using benthic macroinvertebrates. Journal of North American Benthological Society, 13, 185211.

Blaustein A.R., Wake D.B., Sousa W.P. (1994). Amphibian declines: judging stability, persistence, and susceptibility of populations to local and global extinctions.

Conservation Biology, 8, 60-71.

Blocksom K.A. (2003). A performance comparison of metric scoring for a multimetric index for Mid-Atlantic highlands streams. Environmental Management, 31, 670-682.

Bridges A.S., Dorcas M.E. (2000). Temporal variation in anuran calling behavior: Implications for surveys and monitoring programs. Copeia, 2, 587-592.

Brinson M.M. (1993). A hydrogeomorphic classification for wetlands. U.S. Army Engineers Waterways Experiment Station. Vicksburg, MS. Technical Report WRP-DE-4.

Brooks R.P., O'Connell T.J., Wardrop D.H., Jackson L.E. (1998). Towards a regional index of biological integrity: the example of forested riparian ecosystems. Environmental Monitoring and Assessment, 51, 131-143.

Bryce S.A., Hughes R.M., Kaufman P.R. (2002). Development of a bird integrity index: using bird assemblages as indicators of riparian condition. Environmental Management, 30, 294-310.

Burne M.R., Griffin C.R. (2005). Habitat associations of pool-breeding amphibians in eastern Massachusetts, USA. Wetlands Ecology and Management, 13, 247-259.

Calhoun A., Miller N.A., Klemens M.W. (2005). Conserving pool-breeding amphibians in human-dominated landscapes through local implementation of best development practices. Wetlands Ecology and Management, 13, 291-304. 
Chipps S.R., Hubbard D.E., Werlin K.B., Haugerud N.J., Powell K.A., Thompson J., Johnson T. (2006). Association between wetland disturbance and biological attributes in floodplain wetlands. Wetlands, 26, 456-467.

Cole C.A., Brooks R.P., Wardrop D.H. (1997). Wetland hydrology as a function of hydrogeomorphic (HGM) subclass. Wetlands, 17, 456-467.

Connell J.H. (1978). Diversity in tropical rain forests and coral reefs. Science, 199, 13021310.

Corn P.S., Muths E., Iko W.M. (2000). A comparison in Colorado of three methods to monitor breeding amphibians. Northwestern Naturalist, 81, 22-30.

Cowardin L.M., Carter V., Golet F.C., LaRoe E.T. (1979). Classification of wetlands and deepwater habitats of the United States. U.S. Fish and Wildlife Service.

Crouch W.B., Paton P., W.C. (2000). Using egg-mass counts to monitor wood frog populations. Wildlife Society Bulletin, 28, 895-901.

Crouch W.B., Paton P., W.C. (2002). Assessing the use of call-surveys to monitor breeding anurans in Rhode Island. Journal of Herpetology, 36, 185-192.

Genet K.S., Sargent L.G. (2003). Evaluation of methods and data quality from a volunteer-based amphibian call survey. Wildlife Society Bulletin, 31, 703-714.

Gerritsen J. (1995). Additive biological indices for resource management. Journal of North American Benthological Society, 14, 451-457.

Gerritsen J., Burton J. \& Barbour M.T. (2000). A stream condition index for West Virginia wadeable streams. Tetra Tech, Inc., Owing Mills, MD.

Griffith M.B., Hill B.H., McCormick F.H., Kaufman P.R., Herlihy A.T., Selle A.R. (2005). Comparative application of indices of biotic integrity based on periphyton, macroinvertebrates, and fish to southern Rocky Mountain streams. Ecological Indicators, $5,117-136$.

Guerry A.D., Hunter M.L.J. (2002). Amphibian distributions in a landscape of forests and agriculture: an examination of landscape composition and configuration. Conservation Biology, 16, 745-754.

Guntenspergen G.R., Peterson S.A., Leibowitz S.G., Cowardin L.M. (2002). Indicators of wetland condition for the Prairie Pothole Region of the United States. Environmental Monitoring and Assessment, 78, 229-252.

Hecnar S.J., M'Closkey R.T. (1997). The effects of predatory fish on amphibian species richness and distribution. Biological Conservation, 79, 123-131. 
Herbst D.B., Silldorff E.L. (2006). Comparison of the performance of different bioassessment methods: similar evaluations of biotic integrity from separate programs and procedures. Journal of North American Benthological Society, 25, 513-530.

Hill B.H., Herlihy A.T., Kaufman P.R., DeCelles S.J., Vander Borgh M.A. (2003). Assessment of streams of the eastern United States using a periphyton index of biotic integrity. Ecological Indicators, 2, 325-328.

Houlahan J.E., Findlay C.S., Schmidt B.R., Meyer A.H., Kuzmin S.L. (2000).

Quantitative evidence for global amphibian population declines. Nature, 404, 752-755.

Houlahan J.E., Findlay C.S. (2003). The effects of adjacent land use on wetland amphibian species richness and community composition. Canadian Journal of Fisheries and Aquatic Sciences, 60, 1078-1094.

Hughes R.M., Kaufmann P.R., Herlihy A.T., Kincaid T.M., Reynolds L., Larsen D.P. (1998). A process for developing and evaluating indices of fish assemblage integrity. Canadian Journal of Fisheries and Aquatic Sciences, 55, 1618-1631.

Johst K., Huth A. (2005). Testing the intermediate disturbance hypothesis: when will there be two peaks of diversity? Diversity and Distributions, 11, 111-120.

Karr J.R., Fausch K.D., Angermeier P.L., Yant P.R., Schlosser I.J. (1986). Assessing biological integrity in running waters: a method and its rationale. Illinois Natural History Survey, Urbana, IL.

Kiesecker J.M., Blaustein A.R. (1998). Effects of introduced bullfrogs and smallmouth bass on microhabitat use, growth, and survival of native red-legged frogs (Rana aurora). Conservation Biology, 12, 776-787.

Kolozsvary M.B., Swihart R.K. (1999). Habitat fragmentation and the distribution of amphibians: patch and landscape correlates in farmland. Canadian Journal of Zoology, 77, 1288-1299.

Lehtinen R.M., Galatowitsch S.M., Tester J.R. (1999). Consequences of habitat loss and fragmentation for wetland amphibian assemblages. Wetlands, 19, 1-12.

Mack J.J. (2001). Ohio Rapid Assessment Method for Wetlands v. 5.0, User's manual and Scoring Forms. Ohio Environmental Protection Agency, Division of Surface Water, Wetland Ecology Unit, Columbus, $\mathrm{OH}$.

Mackey R.L., Currie D.J. (2000). A re-examination of the expected effects of disturbance on diversity. Oikos, 88, 483-493. 
McCormick F.H., Hughes R.M., Kaufman P.R., Peck D.V., Stoddard J.L., Herlihy A.T. (2001). Development of an index of biotic integrity for the Mid-Atlantic Highland region. Transactions of the American Fisheries Society, 130, 857-877.

Magurran A.E. (1988). Ecological diversity and its measurement. Princeton University Press, Princeton, New Jersey.

Micacchion M. (2002). Amphibian Index of Biotic Integrity (AmphIBI) for Wetlands. Wetland Ecology Group, Division of Surface Water, Ohio Environmental Protection Agency, Columbus, $\mathrm{OH}$.

Micacchion M. (2004). Integrated wetland assessment program. Part 7: amphibian index of biotic integrity (AmphIBI) for Ohio wetlands. Ohio Environmental Protection Agency, Wetland Ecology Group, Division of Surface Water, Columbus, OH.

Morin P.J. (1987). Predation, breeding asynchrony, and the outcome of competition among treefrog tadpoles. Ecology, 68, 675-683.

Mossman M. (1994). Wisconsin frog and toad survey instructions. Endangered Species Branch, Department of Natural Resources, Madison, WI.

O'Connor R., Walls T.E., Hughes R.M. (2000). Using multiple taxonomic groups to index the ecological condition of lakes. Environmental Monitoring and Assessment, 61, 207-228.

Omernik J.M. (1987). Ecoregions of the conterminous United States. Annals of the Association of American Geographers, 77, 118-125.

Omernik J.M. (1995). Ecoregions: a spatial framework for environmental management. Davis WS \& Simon TP (Eds.), Biological assessment and criteria: tools for water resource planning and decision making. Lewis Publishers, Boca Raton, FL.

Patrick D.A., Hunter M.L.J., Calhoun A. (2006). Effects of experimental forestry treatments on a Maine amphibian community. Forest Ecology and Management, 234, $323-332$.

Pauley T.K. (2001). Toads and frogs of West Virginia. West Virginia Division of Natural Resources, Wildlife Resources Section, Elkins, WV.

Pechmann J.H.K., Scott D.E., Semlitsch R.D., Caldwell J.P., Vitt L., Gibbons J.W. (1991). Declining amphibian populations: the problem of separating human impacts from natural fluctuations. Science, 253, 892-895.

Schurbon J.M., Fauth J.E. (2003). Effects of prescribed burning on amphibian diversity in a Southeastern U.S. National Forest. Conservation Biology, 17, 1338-1349. 
Schurbon J.M., Fauth J.E. (2004). Fare as friend and foe of amphibians: a reply. Conservation Biology, 18, 1156-1159.

Semlitsch R.D. (2000). Principles for management of aquatic-breeding amphibians. Journal of Wildlife Management, 64, 615-631.

Skelly D.K.,Werner E.E. (1990). Behavioral and life-historical responses of larval American toads to an odonate predator. Ecology, 71, 2313-2322.

Skelly D.K., Werner E.E., Cortwright S.A. (1999). Long-term distributional dynamics of a Michigan amphibian assemblage. Ecology, 80, 2326-2337.

Snodgrass J.W., Komoroski M.J., Bryan A.L.J., Burger J. (2000a). Relationships among isolated wetland size, hydroperiod, and amphibian species richness: implications for wetland regulations. Conservation Biology, 14, 414-419.

Snodgrass J.W., Bryan A.L.J., Burger J. (2000b) Development of expectation of larval amphibian assemblage structure in southeastern depression wetlands. Ecological Applications, 10, 1219-1229.

Sparling D.W., Richter K.O., Calhoun A., Micacchion M. (2002). Methods for evaluating wetland condition. \#12. Using amphibians in bioassessment of wetlands. U.S. Environmental Protection Agency, Health and Ecological Criteria Division (Office of Science and Technology) and Wetlands Division (Office of Wetlands, Oceans, and Watersheds), Washington, DC.

Stevenson R.J., Hauer F.R. (2002). Integrating Hydrogeomorphic and Index of Biotic Integrity approaches for environmental assessment of wetlands. Journal of North American Benthological Society, 21, 502-513.

Trenham P.C., Shaffer H.B. (2005). Amphibian upland habitat use and its consequences for population viability. Ecological Applications, 15, 1158-1168.

Trombulak S.C., Frissel C.A. (2000). Review of ecological effects of roads on terrestrial and aquatic communities. Conservation Biology, 14, 18-30.

Vasconcelos D., Calhoun A. (2006). Monitoring created seasonal pools for functional success: a six-year case study of amphibian responses, Sears Island, Maine, U.S.A. Wetlands, 26, 992-1003.

Veselka W. (2008). Developing volunteer-driven indices of biological integrity. M.S. Thesis.West Virginia University, Morgantown, WV.

Wake D.B. (1991). Declining amphibian populations. Science, 253, 860.

Wilson L.A. (1995). Land Manager's Guide to Amphibians and Reptiles of the South. 
The Nature Conservancy, Southeastern Region, Chapel Hill, NC.

Woods A.J., Omernik J.M., Brown D.D. (1999). Level III and IV ecoregions of Delaware, Maryland, Pennsylvania, Virginia, and West Virginia. U.S. Environmental Protection Agency, Corvallis, OR.

WVDNR. (2006). Wildlife Conservation Action Plan- Its all about Habitat. West Virginia Division of Natural Resources. Elkins, WV.

Wyman R.L. (1990). What's happening to the amphibians? Conservation Biology, 4, 350352. 
Table 1. Total number of sites by regional hydrogeomorphic (HGM) subclass, designated HGM management class, and Cowardin classby ecoregion for use in developing anuran acousticallybased indices of biological integrity (AA-IBI) in West Virginia, USA from 2005-2006.

Level 3 U.S. Environmental Protection Agency aquatic ecoregion ${ }^{\mathrm{a}}$

Ridge and Valley $\quad$ Central Appalachian $\quad$ Western Alleghany Plateau $\quad$ Total

\section{Hydrogeomorphic subclass ${ }^{b}$}

Riparian depression

Headwater floodplain
10

10

10

12

1

\section{5}

6

6
24

15

28

17

14

34

17

14
25

4

34

6

8

72

35

23

Cowardin Class

Scrub-shrub

Forested

34

${ }^{a}$ Omernik (1987), modified by Woods et al. (1999).

${ }^{\mathrm{b}}$ Cole et al. (1997). 
Table 2. Designated hydrogeomorphic (HGM) management classes derived from regional HGM subclasses for use in developing class specific anuran acoustically-based wetland indices of biological integrity (AA-IBI) in West Virginia, USA from 2005-2006.

\begin{tabular}{ll}
\hline Designated HGM Management Class & Hydrogeomorphic subclass $^{\mathrm{a}}$ \\
\hline Depression & Surface water depression \\
& $\begin{array}{l}\text { Riparian depression } \\
\text { Isolated depression }\end{array}$ \\
Floodplain & Headwater floodplain \\
& Mainstem floodplain \\
Impoundment & Headwater impoundment \\
& Mainstem impoundment \\
Fringing & Fringing \\
Slope & Slope \\
\hline
\end{tabular}

${ }^{\text {a }}$ Cole et al. (1997). 
Table 3. Metrics and sub-metrics selected from the Ohio Rapid Assessment Method (Mack 2001) used to define the disturbance gradient for use in developing class specific anuran acoustically-based indices of biological integrity (AA-IBI) in West Virginia, USA from 2005-2006.

\section{Scoring value Disturbance component}

\section{Upland buffers and surrounding land use}

Calculate the average buffer width. Select only one and assign score.

WIDE. Buffers average $50 \mathrm{~m}$ or more around wetland perimeter MEDIUM. Buffers average $25 \mathrm{~m}$ to $<50 \mathrm{~m}$ around wetland perimeter NARROW. Buffers average $10 \mathrm{~m}$ to $<25 \mathrm{~m}$ around wetland perimeter VERY NARROW. Buffers average $<10 \mathrm{~m}$ around wetland perimeter

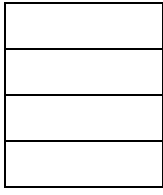

Intensity of surrounding land use. Select one or double check and average. LOW. Old field ( $>10$ years), shrubland, young second growth forest. MODERATELY HIGH. Residential, fenced pasture, park, conservation tillage, new fallow field. HIGH. Urban, industrial, open pasture, row cropping, mining, construction.

Hydrology

12

7

3

1

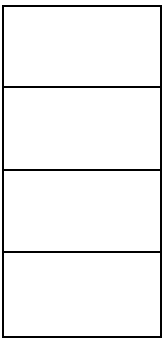

Modifications to natural, hydrologic regime. Score one or double check and average.

None or none apparent. There are no modifications or no modifications that are apparent to the rater.

Recovered. The wetland appears to have recovered from past modifications which altered the wetland's natural hydrologic regime.

Recovering. The wetland appears to be in the process of recovering from past modifications which altered the wetland's natural hydrologic regime.

Recent or no recovery. The modifications have occurred recently, and / or the wetland has not recovered from past modifications and / or the modifications are ongoing.

Habitat alteration and development

Substrate disturbance. Score one or double check and average.

None or none apparent. There are no modifications or no modifications that are apparent to the rater.

Recovered. The wetland appears to have recovered from past disturbances.

Recovering. The wetland appears to be in the process of recovering from past disturbances.

Recent or no recovery. The modifications have occurred recently, and / or the wetland has not recovered from past disturbances and/ or the disturbances are ongoing.

Habitat alteration. Score one or double check and average.

None or none apparent. There are no alterations or no alterations that are apparent to the rater.

Recovered. The wetland appears to have recovered from past alterations.

Recovering. The wetland appears to be in the process of recovering from past alterations.

Recent or no recovery. The modifications have occurred recently, and / or the wetland has not recovered from past alterations and/ or the alterations are ongoing. 
Table 4. List of 12 candidate metrics evaluated for inclusion into anuran acoustically-based indices of biological integrity (AA-IBI) for West Virginia, USA in 2005-2006.

\begin{tabular}{|c|c|c|}
\hline Metrics & $\begin{array}{c}\text { Expected } \\
\text { Response } \\
\text { to } \\
\text { Disturbance } \\
\end{array}$ & Components of Metrics \\
\hline Anuran relative diversity ${ }^{\mathrm{a}}$ & + & Shannon-Weaver diversity index score \\
\hline Percent sensitive anurans ${ }^{\mathrm{b}}$ & - & Proportion of anurans with $\mathrm{C}$ of $\mathrm{C} \geq 6$ \\
\hline $\begin{array}{l}\text { Anuran percent species of concern } \\
\text { Percent tolerant anurans } \mathbf{b}^{\mathbf{b}}\end{array}$ & $\begin{array}{c}- \\
+\end{array}$ & $\begin{array}{l}\text { Proportion of anurans listed as a West Virginia Species of Concern } \\
\text { Proportion of anurans with } \mathrm{C} \text { of } \mathrm{C} \leq 3\end{array}$ \\
\hline Percent of wood frog abundance ${ }^{b}$ & - & $\begin{array}{l}\text { Proportion of relative abundance that were wood frogs (Rana } \\
\text { sylvatica) }\end{array}$ \\
\hline Anuran richness ${ }^{\mathrm{a}}$ & + & Total anuran richness \\
\hline Total anuran relative abundance ${ }^{a}$ & + & Total anuran relative abundance \\
\hline $\begin{array}{l}\text { Modified amphibian quality } \\
\text { assessment index (AQAI) }\end{array}$ & - & A weighted index based on $\mathrm{C}$ of $\mathrm{C}$ values and relative abundance \\
\hline Average coefficient of conservatism & - & The average $\mathrm{C}$ of $\mathrm{C}$ based on species presence/ absence \\
\hline Percent upland sensitive species ${ }^{c}$ & - & Proportion of wood frogs and mountain chorus frogs \\
\hline Percent upland tolerant species ${ }^{\mathrm{c}}$ & + & Proportion of northern spring peepers and eastern American toads \\
\hline Percent species tolerant offish ${ }^{\mathrm{c}}$ & + & Proportion of northern green frogs and American bullfrogs \\
\hline
\end{tabular}

\footnotetext{
${ }^{a}$ Balcombe et al. (2005).

${ }^{\mathrm{b}}$ Micacchion (2002).

${ }^{\mathrm{c}}$ Wilson (1995).
} 
Table 5. Anuran species and corresponding coefficients of conservatism (CoC) used in analysis for deriving anuran acoustically-based indices of biological integrity (AA-IBI) in West Virginia, USA from 2005-2006.

\begin{tabular}{llcc}
\hline Species & Scientific name & CoC $^{\text {a }}$ & $\begin{array}{c}\text { West Virginia } \\
\text { Species of } \\
\text { Concern }^{b}\end{array}$ \\
\hline Eastern American toad & Bufo americanus & 1 & \\
Fowler's toad & Bufo woodhousii fowleri & 1 & \\
Northern spring peeper & Pseudacris crucifer & 2 & \\
Leopard frog & Rana pipiens & 2 & $\mathrm{x}$ \\
Northern green frog & Rana clamitans & 2 & \\
Bullfrog & Rana catesbeiana & 2 & \\
Mountain chorus frog & Pseudacris brachyphona & 3 & \\
Upland chorus frog & Pseudacris triseriata & 3 & \\
Gray treefrog & Hyla versicolor & 5 & \\
Cope's gray treefrog & Hyla chrysoscelis & 5 & \\
Wood frog & Rana sylvatica & 7 & \\
Pickerel frog & Rana palustris & 7 & \\
\hline
\end{tabular}

${ }^{\text {a }}$ Micacchion (2002) sensitivity to disturbance from 1 (tolerant) to 10 (most sensitive).

${ }^{\mathrm{b}}$ West VirginiaWildlife Diversity Program. 
Table 6. Spearman's R correlation matrices of metrics by classification scheme able to discriminate between reference and stressed sites metrics used in developing anuran acousticallybased indices of biological integrity (AA-IBI) in West Virginia, USA from 2005-2006. Metrics with Spearman's R values $>0.80$ were considered highly correlated.

\section{Headwater Floodplain}

Relative diversity ${ }^{\mathrm{a}}$

Richness

Abundance

$\begin{array}{ccc}\text { Relative diversity } & \text { Richness } & \text { Abundance } \\ 1 & & \\ 0.985 & 1 & \\ 0.867 & 0.913 & 1\end{array}$

Floodplain

Relative diversity ${ }^{\mathrm{a}}$

Richness

Abundance $^{\mathrm{a}}$

Percent fish tolerant

$\begin{array}{cccc}\text { Relative diversity } & \text { Richness } & \text { Abundance } & \text { Percent fish tolerant } \\ 1 & & & \\ 0.977 & 1 & & \\ 0.77 & 0.863 & 1 & 1 \\ 0.469 & 0.491 & 0.465 & \end{array}$

\section{Scrub-Shrub}

Relative diversity $^{\mathrm{a}}$

Relative diversity Richness Abundance Percent fish tolerant

Richness 1 0.989

0.885

Abundance

0.693

0.91

$0.7 \quad 0.638$

1

\footnotetext{
${ }^{a}$ Metric selected for inclusion into class-specific AA-IBI.
} 
Table 7. Candidate anuran community biological metrics evaluated by class according to regional Hydrogeomorphic (HGM) subclass, designated HGM management class, and the Cowardin classification schemes in building acoustically-based anuran wetland indices of biological integrity (AA-IBI) in West Virginia, USA from 2005-2006.

\begin{tabular}{|c|c|c|c|c|c|c|c|c|}
\hline \multirow[b]{2}{*}{ Candidate anuran metrics ${ }^{\mathrm{a}}$} & \multicolumn{2}{|c|}{ HGM subclass } & \multicolumn{3}{|c|}{ Designated HGM management class } & \multicolumn{3}{|c|}{ Cowardin class } \\
\hline & $\begin{array}{c}\text { Riparian } \\
\text { Depression }\end{array}$ & $\begin{array}{l}\text { Headwater } \\
\text { Floodplain }\end{array}$ & Depression & Floodplain & Impoundment & Emergent & $\begin{array}{l}\text { Scrub- } \\
\text { Shrub }\end{array}$ & Forested $^{\mathrm{b}}$ \\
\hline Anuran relative diversity ${ }^{\mathrm{c}}$ & I & I & * & I & " & $*$ & E & \\
\hline Percent sensitive anurans ${ }^{\mathrm{d}}$ & * & * & * & $*$ & * & $*$ & * & \\
\hline Anuran percent Species of Concern & $*$ & * & $*$ & $*$ & * & $*$ & $*$ & \\
\hline Percent tolerant anurans ${ }^{\mathrm{d}}$ & * & * & * & $*$ & * & * & $*$ & \\
\hline Percent of wood frog abundance ${ }^{d}$ & * & * & * & * & * & * & $*$ & \\
\hline Anuran richness ${ }^{\mathrm{c}}$ & * & $\mathrm{R}$ & * & $\mathrm{R}$ & $*$ & * & $*$ & \\
\hline Total anuran relative abundance ${ }^{c}$ & $*$ & $\mathrm{R}$ & * & I & $*$ & $*$ & $*$ & \\
\hline $\begin{array}{l}\text { Modified amphibian quality } \\
\text { assessment index (AQAI) }\end{array}$ & $*$ & $*$ & $*$ & $*$ & $*$ & $*$ & * & \\
\hline $\begin{array}{l}\text { Average coefficient of } \\
\text { conservatism }\end{array}$ & $*$ & $*$ & $*$ & $*$ & $*$ & $*$ & * & \\
\hline Percent upland sensitive species ${ }^{\mathrm{e}}$ & * & $*$ & $*$ & $*$ & * & $*$ & $*$ & \\
\hline Percent upland tolerant species ${ }^{\mathrm{e}}$ & * & * & * & $*$ & * & * & * & \\
\hline Percent species tolerant to fish ${ }^{\mathrm{e}}$ & $*$ & $*$ & $*$ & $\mathrm{E}$ & $*$ & $*$ & $\mathrm{E}$ & \\
\hline
\end{tabular}

${ }^{\mathrm{a}} \mathrm{I}$ = included in class-specific AA-IBI; R = redundancy with other metrics; $\mathrm{E}=$ excluded due to significant ecoregion or classification effect; * = failure to discriminate between reference and stressed sites.

${ }^{\mathrm{b}}$ Inadequate sample size.

${ }^{\mathrm{c}}$ Balcombe et al. (2005).

${ }^{\mathrm{d}}$ Micacchion (2002).

${ }^{\mathrm{e}}$ Wilson (1995). 
Table 8. Analysis of variance (ANOVA) results of reference and stressed sites' metric values compared to Level 3 ecoregions (Omernik 1987, Wood et al. 1999) and the alternative classification scheme used in developing anuran acoustically-based wetland indices of biological integrity (AA-IBI) for wetlands in West Virginia, USA from 2005-2006.

\begin{tabular}{|c|c|c|c|c|}
\hline $\begin{array}{l}\text { Classification (number of } \\
\text { reference and impacted sites) }\end{array}$ & Validation test & $\mathrm{df}$ & $\begin{array}{c}\mathrm{F}- \\
\text { value }\end{array}$ & p-value \\
\hline \multicolumn{5}{|c|}{ Riparian Depression AA-IBI $(n=24)$} \\
\hline \multirow[t]{3}{*}{ Anuran relative diversity } & Cowardin class & 2,23 & 1.75 & 0.2839 \\
\hline & Level 3 ecoregion & 2,23 & 0.34 & 0.7310 \\
\hline & Cowardinclass $x$ Level 3 ecoregion & 3,23 & 0.85 & 0.4931 \\
\hline \multicolumn{5}{|c|}{ Headwater Floodplain AW-IBI $(n=11)$} \\
\hline \multirow[t]{3}{*}{ Anuran relative diversity } & Cowardinclass & 2,10 & 1.75 & 0.2839 \\
\hline & Level 3 ecoregion & 2,10 & 0.34 & 0.7310 \\
\hline & Cowardinclass $\mathrm{x}$ Level 3 ecoregion & 2,10 & 0.85 & 0.4931 \\
\hline \multicolumn{5}{|l|}{ Floodplain AA-IBI $(n=14)$} \\
\hline \multirow[t]{3}{*}{ Anuran relative diversity } & Cowardinclass & 2,13 & 1.59 & 0.2786 \\
\hline & Level 3 ecoregion & 2,13 & 0.58 & 0.5867 \\
\hline & Cowardinclass $x$ Level 3 ecoregion & 3,13 & 0.21 & 0.8882 \\
\hline \multirow[t]{3}{*}{ Percent Fish tolerant species ${ }^{\mathrm{a}}$} & Cowardinclass & 2,13 & 5.24 & 0.0482 \\
\hline & Level 3 ecoregion & 2,13 & 2.09 & 0.2044 \\
\hline & Cowardinclass x Level 3 ecoregion & 3,13 & 1.55 & 0.2969 \\
\hline \multirow[t]{3}{*}{ Total relative abundance } & Cowardinclass & 2,13 & 3.06 & 0.1215 \\
\hline & Level 3 ecoregion & 2,13 & 0.11 & 0.8952 \\
\hline & Cowardinclass x Level 3 ecoregion & 3,13 & 0.03 & 0.9916 \\
\hline \multicolumn{5}{|l|}{ Scrub-shrub AA-IBI $(n=18)$} \\
\hline \multirow[t]{3}{*}{ Anuran relative diversity ${ }^{\mathrm{a}}$} & Designated $\mathrm{HGM}^{\mathrm{b}}$ management class & 4,17 & 5.90 & 0.0130 \\
\hline & Level 3 ecoregion & 2,17 & 0.84 & 0.4630 \\
\hline & Designated $\mathrm{HGM}^{\mathrm{b}}$ management class $\mathrm{x}$ Level 3 ecoregion & 2,17 & 0.50 & 0.6219 \\
\hline \multirow[t]{3}{*}{ Percent Fish tolerant species ${ }^{\mathrm{a}}$} & Designated $\mathrm{HGM}^{\mathrm{b}}$ management class & 4,17 & 4.30 & 0.0324 \\
\hline & Level 3 ecoregion & 2,17 & 0.69 & 0.5279 \\
\hline & Designated $\mathrm{HGM}^{\mathrm{b}}$ management class $\mathrm{x}$ Level 3 ecoregion & 2,17 & 0.69 & 0.5279 \\
\hline
\end{tabular}

${ }^{a}$ Metric excluded from inclusion into class-specific AA-IBI due to a significant ecoregion, alternative classification scheme, or cumulative 2-way interaction.

${ }^{\mathrm{b}}$ Hydrogeomorphic (Brinson 1993). 
Table 9. Wilks' Lambda statistic for posthoc validation of reference and stressed sites' metric values of class-specific anuran acoustically-based wetland indices of biological integrity (AAIBI) for wetlands in West Virginia, USA from 2005-2006.

\begin{tabular}{lcccc}
\hline Classification scheme and interaction & $\begin{array}{c}\text { Wilks' } \\
\text { Lambda }\end{array}$ & $\begin{array}{c}\text { F- } \\
\text { value }\end{array}$ & df & p-value \\
\hline Floodplain AA-IBI $(n=14)$ & & & & \\
Cowardin class & 0.4219 & 1.35 & 4,10 & 0.3182 \\
Level 3 ecoregion & 0.6471 & 0.61 & 4,10 & 0.6663 \\
Cowardin x Level 3 ecoregion & 0.7374 & 0.27 & 6,10 & 0.9366 \\
& & & & \\
\hline
\end{tabular}


Table 10. Discrimination efficiency (D.E.) and reference site scoring summary used to derive scoring thresholds in developing class specific anuran acoustically-based wetland indices of biological integrity (AA-IBI) in West Virginia, USA from 2005-2006.

\begin{tabular}{|c|c|c|c|c|c|c|c|c|c|}
\hline & \multicolumn{6}{|c|}{ Reference Site Scoring Summary } & \multirow[b]{2}{*}{ D.E. ${ }^{a}$} & \multicolumn{2}{|c|}{ Means (SE) } \\
\hline & $\mathrm{N}$ & $\begin{array}{c}\text { Max } \\
\text { possible IBI } \\
\text { score } \\
\end{array}$ & $\begin{array}{c}\text { 75th } \\
\text { percentile }\end{array}$ & $\begin{array}{c}25 \text { th } \\
\text { percentile }\end{array}$ & $\begin{array}{c}5 \text { th } \\
\text { percentile }\end{array}$ & Median & & Reference $^{\mathrm{b}}$ & Stressed \\
\hline Riparian Depression & 15 & 10 & 8.14 & 3.68 & 2.37 & 5.51 & 67 & $5.69(0.66)$ & $3.15(0.67)$ \\
\hline $\begin{array}{l}\text { Headwater } \\
\text { Floodplain }\end{array}$ & 5 & 10 & 10 & 6.33 & 5.24 & 6.63 & 83 & $7.59(1.02)$ & $4.13(1.25)$ \\
\hline Floodplain & 7 & 20 & 17.45 & 13.98 & 11.31 & 16.33 & 86 & $15.49(1.10)$ & $8.63(2.19)$ \\
\hline
\end{tabular}

${ }^{\text {a }}$ Effectiveness of AA-IBI scores to effectively discriminate between reference and stressed sites.

${ }^{\mathrm{b}}$ All means, except riparian depression, statistically significantly different (Tukey $\alpha=0.05$ ). 
Table 11. Frequency of species occurrences (number of wetland occur/ number of wetlands surveyed)in the 151 sites used to develop acoustically-based anuran indices of biological integrity (AA-IBI) in West Virginia, USA from 2005-2006.

\begin{tabular}{lcc}
\hline Species & Number of Sites Present & Percent Occurrence \\
\hline Northern spring peeper & 140 & $92.72 \%$ \\
Northerngreen frog & 89 & $58.94 \%$ \\
Wood frog & 56 & $37.09 \%$ \\
Gray treefrog & 54 & $35.76 \%$ \\
Pickerel frog & 48 & $31.79 \%$ \\
Eastern American toad & 43 & $28.48 \%$ \\
Bullfrog & 39 & $25.83 \%$ \\
Mountain chorus frog & 19 & $12.58 \%$ \\
Cope's gray treefrog & 14 & $9.27 \%$ \\
Upland chorus frog & 11 & $7.28 \%$ \\
Northern leopard frog & 7 & $4.64 \%$ \\
Fowler's toad & 1 & $0.66 \%$ \\
\hline
\end{tabular}


Table 12. Metrics comprising each anuran acoustically-based indices of biological integrity (AA-IBI) as per designated hydrogeomorphic (HGM) management class, regional HGM subclass, and Cowardin classifications; the discrimination efficiency (D.E.) of each AA-IBI, and the resulting relations of the AA-IBI with disturbance scores for wetlands in West Virginia, USA from 2005-2006.

\begin{tabular}{|c|c|c|c|c|c|c|c|c|}
\hline Wetland type & Metrics in AA-IBI & $\mathrm{N}$ & D.E. $^{a}$ & df & F-value & p-value & $\mathrm{R}^{2}$ & Equation \\
\hline \multicolumn{9}{|l|}{ Regional HGM subclass ${ }^{b}$} \\
\hline Riparian Depression & Relative Diversity & 52 & 67 & 1,50 & 4.32 & 0.0429 & 0.08 & $\mathrm{y}=1.53+0.12($ Disturbance score $)$ \\
\hline Headwater Floodplain & Relative Diversity & 22 & 83 & 1,21 & 7.49 & 0.0127 & 0.27 & $y=-0.52+0.20$ (Disturbance score) \\
\hline \multicolumn{9}{|c|}{ Designated HGM management class } \\
\hline Floodplain & $\begin{array}{l}\text { Relative Diversity, } \\
\text { Relative Abundance }\end{array}$ & 28 & 86 & 1,26 & 5.76 & 0.0238 & 0.18 & $\mathrm{y}=3.37+0.30$ (Disturbance score) \\
\hline
\end{tabular}

${ }^{a}$ Effectiveness of AA-IBI scores to discriminate between reference and stressed sites.

${ }^{\mathrm{b}}$ Cole et al. (1997). 
Table 13. Relations between the disturbance scores and multi-taxa IBI that resulted from combining the anuran acoustically-based indices of biological integrity (AA-IBI) metric scores with the avian wetland indices of biological integrity (AW-IBI) metric scores from wetlands of West Virginia, USA from 2005-2006. AW-IBI-only scores are provided for comparison.

\begin{tabular}{|c|c|c|c|c|c|c|c|c|}
\hline $\begin{array}{l}\text { Wetland } \\
\text { classifications }\end{array}$ & IBI groups & $\begin{array}{c}\text { Number } \\
\text { of } \\
\text { metrics }\end{array}$ & $\mathrm{N}$ & $\mathrm{df}$ & $\begin{array}{c}\text { F- } \\
\text { value }\end{array}$ & $\mathrm{p}$-value & $\mathrm{R}^{2}$ & Equation \\
\hline \multirow[t]{2}{*}{$\begin{array}{l}\text { Headwater } \\
\text { Floodplain }\end{array}$} & Multi-taxa IBI & 5 & 22 & 1,20 & 19.74 & 0.0003 & 0.50 & $\mathrm{y}=14.50+0.73$ (Disturbance score) \\
\hline & AW-IBI only & 4 & 29 & 1,27 & 25.44 & $<0.0001$ & 0.49 & $\mathrm{y}=11.98+0.62($ Disturbance score $)$ \\
\hline \multirow[t]{2}{*}{ Floodplain } & Multi-taxa IBI & 7 & 28 & 1,16 & 19.8 & 0.0001 & 0.43 & $y=26.30+0.65$ (Disturbance score $)$ \\
\hline & AW-IBI only & 5 & 35 & 1,33 & 32.74 & $<0.0001$ & 0.50 & $\mathrm{y}=21.94+0.64($ Disturbance score $)$ \\
\hline \multicolumn{9}{|l|}{$\begin{array}{l}\text { Hybrid } \\
\text { classifications }^{\text {a }}\end{array}$} \\
\hline $\begin{array}{l}\text { Emergent/ Riparian } \\
\text { Depression }\end{array}$ & Multi-taxa IBI & 2 & 28 & 1,26 & 2.12 & 0.1568 & 0.08 & $y=8.54+0.17$ (Disturbance score) \\
\hline \multirow{2}{*}{$\begin{array}{l}\text { Emergent/ } \\
\text { Headwater } \\
\text { Floodplain }\end{array}$} & Multi-taxa IBI & 5 & 13 & 1,11 & 4.79 & 0.0510 & 0.30 & $y=17.63+0.58($ Disturbance score $)$ \\
\hline & AW-IBI only & 4 & 15 & 1,13 & 4.59 & 0.0517 & 0.26 & $\mathrm{y}=16.48+0.45($ Disturbance score $)$ \\
\hline \multirow{2}{*}{$\begin{array}{l}\text { Emergent/ } \\
\text { Floodplain }\end{array}$} & Multi-taxa IBI & 6 & 14 & 1,12 & 8.69 & 0.0122 & 0.42 & $y=27.68+0.54$ (Disturbance score $)$ \\
\hline & AW-IBI only & 4 & 16 & 1,14 & 15.41 & 0.0015 & 0.52 & $\mathrm{y}=21.20+0.44$ (Disturbance score $)$ \\
\hline $\begin{array}{l}\text { Scrub-shrub/ } \\
\text { Riparian Depression }\end{array}$ & Multi-taxa IBI & 5 & 16 & 1,14 & 0.6621 & 0.4294 & 0.05 & $y=29.99+0.24$ (Disturbance score $)$ \\
\hline \multirow{2}{*}{$\begin{array}{l}\text { Scrub-Shrub/ } \\
\text { Headwater } \\
\text { Floodplain }\end{array}$} & Multi-taxa IBI & 7 & 5 & 1,3 & 23.46 & 0.0168 & 0.89 & $\mathrm{y}=0.55+1.61$ (Disturbance score $)$ \\
\hline & AW-IBI only & 6 & 7 & 1,5 & 79.93 & 0.0003 & 0.94 & $y=-2.96+1.54($ Disturbance score $)$ \\
\hline \multirow{2}{*}{$\begin{array}{l}\text { Scrub-Shrub/ } \\
\text { Floodplain }\end{array}$} & Multi-taxa IBI & 6 & 6 & 1,4 & 7.39 & 0.0531 & 0.65 & $\mathrm{y}=-1.30+1.74($ Disturbance score $)$ \\
\hline & AW-IBI only & 5 & 8 & 1,6 & 33.95 & 0.0011 & 0.85 & $\mathrm{y}=0.50+1.27$ (Disturbance score $)$ \\
\hline $\begin{array}{l}\text { Forested/ Riparian } \\
\text { Depression }\end{array}$ & Multi-taxa IBI & 4 & 8 & 1,6 & 0.0404 & 0.8473 & 0.01 & $y=24.92-0.09$ (Disturbance score $)$ \\
\hline \multirow{3}{*}{$\begin{array}{l}\text { Forested/ Headwater } \\
\text { Floodplain }\end{array}$} & Multi-taxa IBI & 6 & 4 & 1,2 & 7.66 & 0.1094 & 0.79 & $y=-56.47+3.10($ Disturbance score $)$ \\
\hline & AW-IBI only & 5 & 7 & 1,5 & 15.66 & 0.0108 & 0.76 & $\mathrm{y}=-2.84+1.20$ (Disturbance score $)$ \\
\hline & Multi-taxa IBI & 8 & 8 & 1,6 & 0.10 & 0.7542 & 0.02 & $\mathrm{y}=50.31+0.28($ Disturbance score $)$ \\
\hline Forested/ Floodplain & AW-IBI only & 6 & 11 & 1,9 & 6.43 & 0.0319 & 0.42 & $y=14.43+0.95($ Disturbance score $)$ \\
\hline
\end{tabular}

${ }^{\mathrm{a}}$ Couldnot compare to hybrid AW-IBI because riparian depression AW-IBI does not exist. 


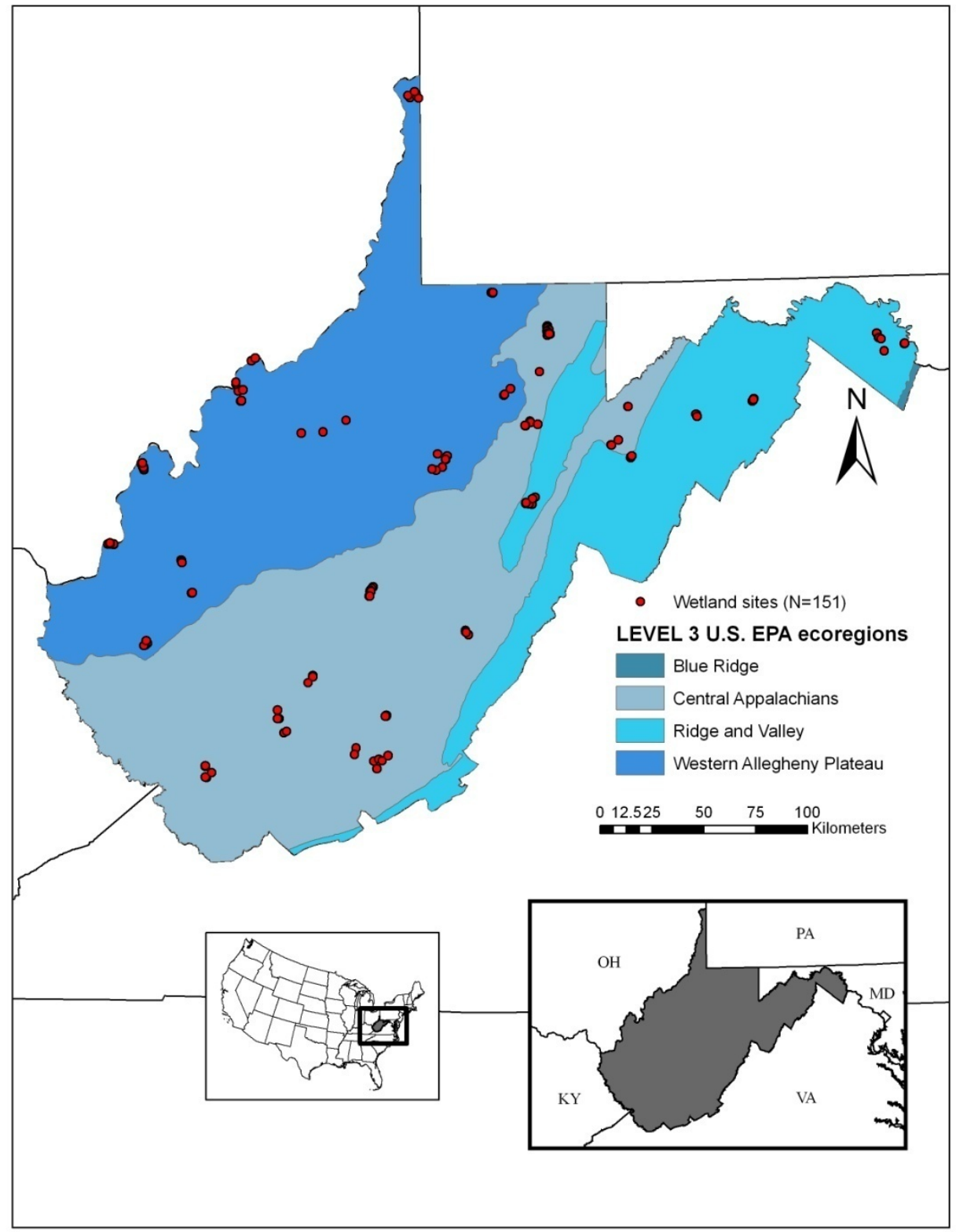

Figure 1. Site locations of wetlands and ecoregions(Woods et al. 1999; Omernik 1987) used in developing anuran acoustically-based indices of biological integrity (AA-IBI) in West Virginia, USA from 2005-2006. Wetland sites were clustered; scale of map prevents all sites from being marked individually. Legend may indicate 1-4 wetlands per mark. 


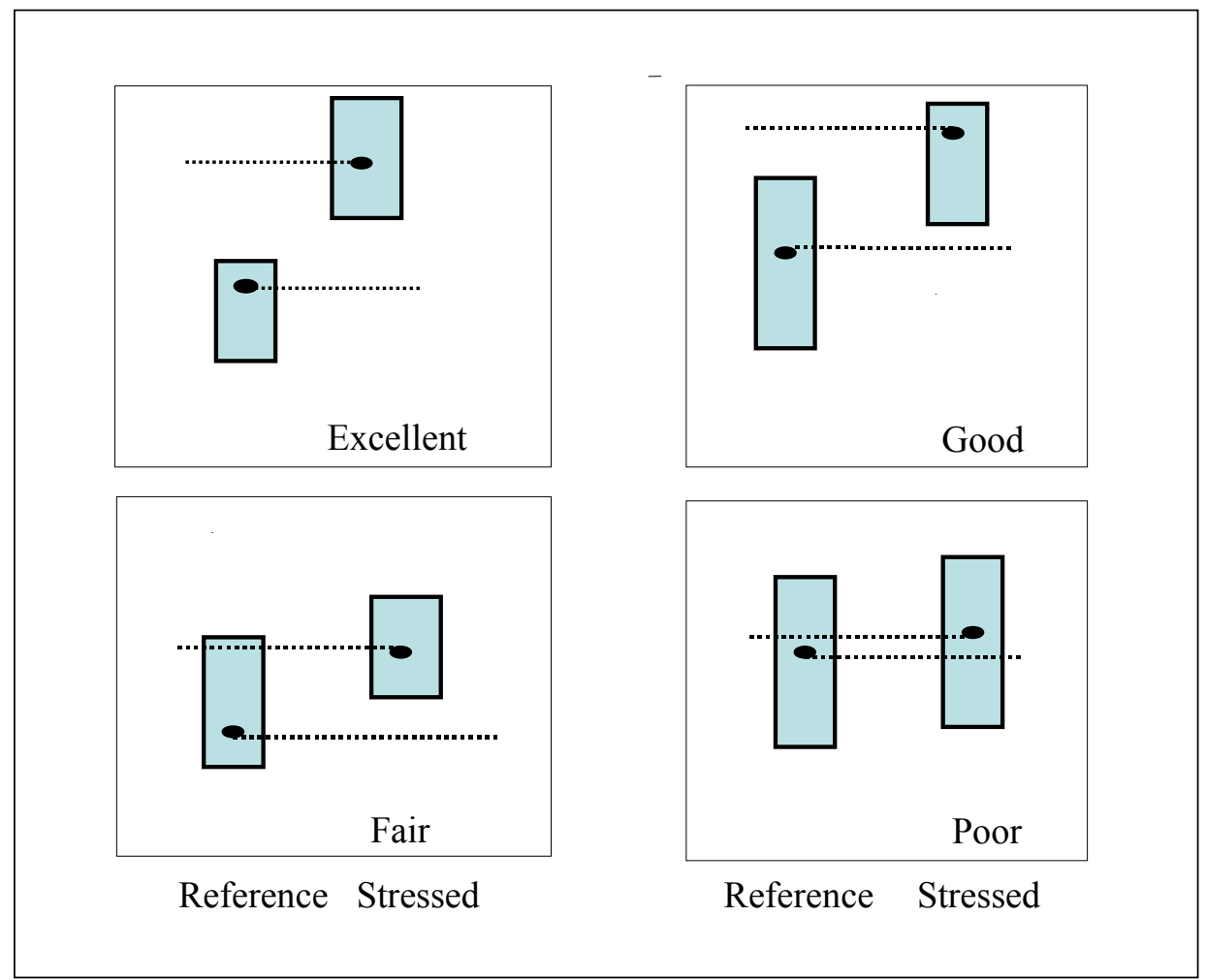

Figure 2. Box-and-whisker plot characteristics and resulting narrative description of reference and stressed sites' distribution of a biological metric value considered for inclusion into anuran acoustically-based indices of biological integrity (AA-IBI) in West Virginia, USA from 20052006. Solid ovals represent the median of metric value (courtesy of Greg Pond, U.S. EPA). 


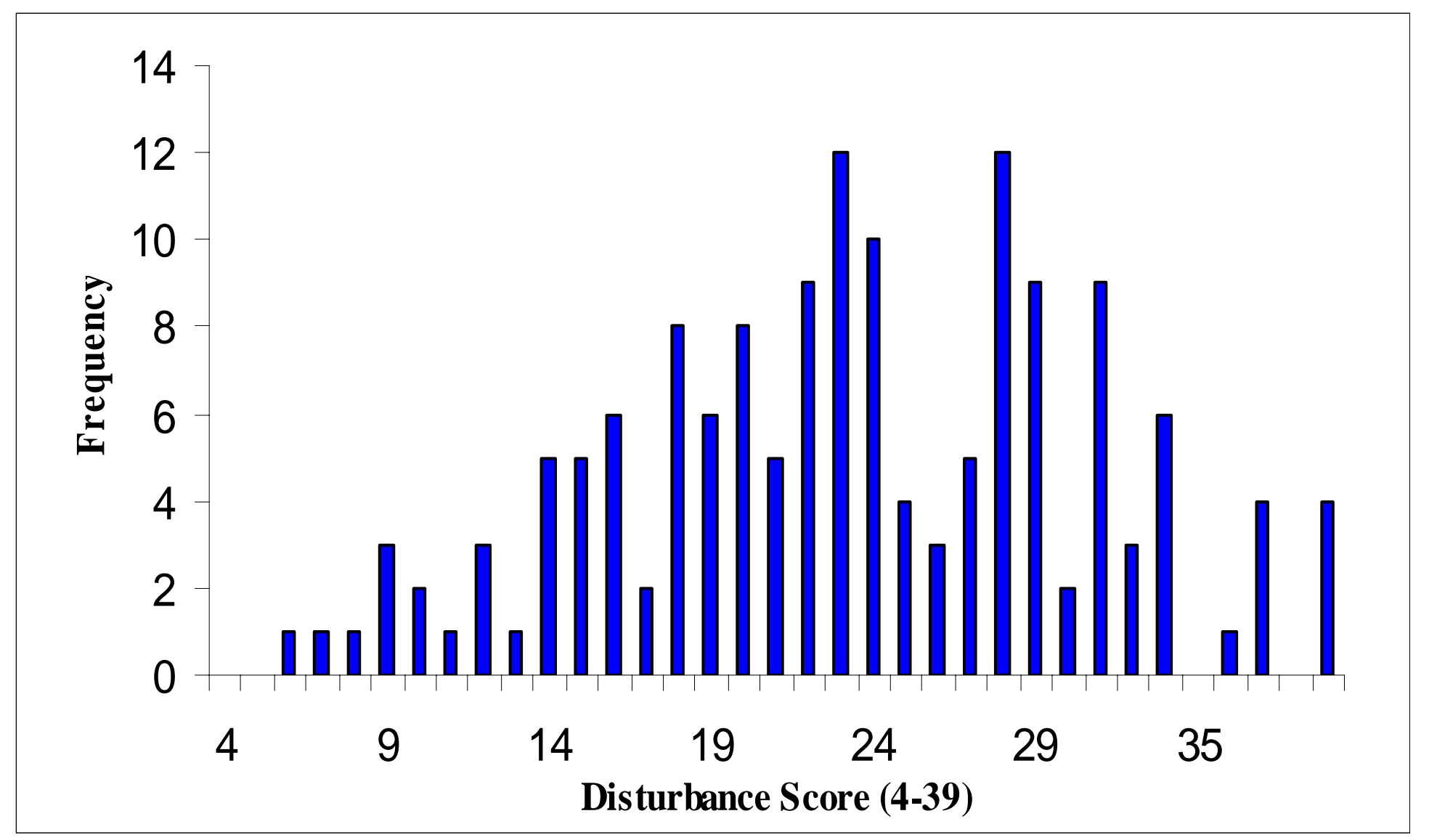

Figure 3. Frequency distribution of disturbance scores for sites used to develop class-specific anuran acoustically-based indices of biological integrity (AA-IBI) for wetlands in West Virginia, USA from 2005-2006. 


\title{
Chapter 4
}

\section{Vegetation Indices of Biological Integrity}

\section{Development of Vegetation Indices of Biological Integrity for Wetlands in West Virginia, USA}

\author{
Walter Veselka IV ${ }^{1}$ \\ James Rentch ${ }^{1}$ \\ William Grafton ${ }^{1}$ \\ Walter S. Kordek ${ }^{2}$ \\ James T. Anderson ${ }^{1,3}$
}

${ }^{1}$ Division of Forestry and Natural Resources, Wildlife and Fisheries Resources Program, West Virginia University, PO Box 6125, Percival Hall, Morgantown, WV 26506

${ }^{2}$ West Virginia Division of Natural Resources, Wildlife Resources Section, PO Box 67 , Ward Road, Elkins, WV 26241

3 address correspondence to James T. Anderson, Ph.D., Division of Forestry and Natural Resources, Wildlife and Fisheries Resources Program, West Virginia University, PO Box 6125, Percival Hall, Morgantown, WV 26506. email: wetland@wvu.eduphone: (304) 293-2941 ext. 2445, fax: (304) 293-2441

Submitted in the style of:

Environmental Monitoring and Assessment 


\begin{abstract}
Bioassessment methods for wetlands, and other bodies of water, have been developed worldwide, to measure and quantify changes in "biological integrity." These assessments are based on a classification system, meant to ensure appropriate comparisons between various wetland types. Using only a local site specific disturbance gradient, we built vegetation indices of biological integrity (Veg-IBIs) based on 2 commonly used wetland classification systems in the United States: the Cowardin et al. (1979) and hydrogeomorphic (HGM) wetland classification systems. The resulting classspecific Veg-IBIs were comprised of 1-5 metrics that varied in their sensitivity to the disturbance gradient $\left(\mathrm{R}^{2}=0.14-0.65\right)$. Additionally, like previous West Virginia derived taxa-specific IBIs, the sensitivity to the disturbance gradient increased as metrics from each of the 2 classification schemes were combined (added). The sensitivity to the disturbance gradient also increased when metrics from the avian wetland indices of biological integrity (AW-IBIs) were added to those from the Veg-IBI. For example, the disturbance score explained more variation in floodplain wetlands $\left(\mathrm{R}^{2}=0.72\right)$ using metrics from both the AW-IBI and Veg-IBI, compared to either index alone $\left(\mathrm{R}^{2}=0.46\right.$ and $\mathrm{R}^{2}=0.56$, respectively). Using this information to monitor natural wetlands, created wetlands, as well as wetland mitigation banks can help natural resource managers track the changes of the biological integrity of all wetlands in response to anthropogenic disturbance.
\end{abstract}

Keywords: macroinvertebrate communities, disturbance, index of biological integrity, metrics, West Virginia, wetlands 


\subsection{Introduction}

Vegetative communities have historically been used as a component in identifying jurisdictional wetlands (USACOE 1987). The expression of plant communities reflect the hydrologic processes that occurred while the community was developing (Kirkman et al. 2000; Magee and Kentula 2005; Rentch et al. 2008). The resulting plant communities within and around wetlands reflect hydrologic conditions, and can indicate anthropogenic disturbances such as sedimentation (Mahaney et al. 2004a,b), nutrient enrichment (Craft and Richardson 1997; Drohan et al. 2006), and changes in hydrology (Koning 2005). Identifying and quantifying changes in plant communities resulting from human impairment is one way to measure the biological integrity of wetlands (Miller et al. 2006), one of the mandates charged to the U.S. Environmental Protection Agency (US EPA) under the Federal Clean Water Act (33 U.S.C. §1251).

Identifying metrics, or attributes, of a biological community that respond consistently and predictably to human disturbance is necessary to create indices of biological integrity (Karr and Chu 1999). These indices can be used to detect change and monitor trends in wetland condition, providing a basis of comparison that can be used to prioritize wetland protection, management, or restoration efforts. Wetland indices of biological integrity (IBI) based on vegetative communities have been developed according to Cowardin et al. (1979) classes (Galatowitsch et al. 2000; Mack 2004) or the hydrogeomorphic (HGM) (Brinson 1993) approach (Gernes and Helgen 2002; Miller et al. 2006). A study from Florida integrated both approaches to form a vegetative IBI specifically for forested, depressional wetlands (Reiss 2006). Researchers have advocated using the HGM approach for bioassessments because it compares wetlands 
that are functionally similar (Stevenson and Hauer 2002). However, in constructing an IBI, augmenting one approach with the alternative may increase sensitivity to human impairment (Veselka2008: Chapter 2). Currently the Cowardin et al. (1979) system is used in West Virginia for regulatory purposes (West Virginia State Code Chapter 22-11, 22-26), and will be referred to as "Cowardin" in this document from here after. However, this study uses both the NWI classifications and a variation of the HGM classes (Brinson 1993) that is meant to be clear and straight-forward for use by policy makers and resource managers.

The objectives of our study were to identify plant community metrics suitable for inclusion into robust, statewide, vegetative indices of biological integrity (Veg-IBI) for West Virginia. These indices will have the capacity to detect and quantify changes in the vegetative community that are reflective of varying levels and types of human impairment. The metrics we evaluated for inclusion into the Veg-IBI were drawn from previous research (Chipps et al. 2006; Gernes and Helgen 2002; Mack 2004; Miller et al. 2006; Miller and Wardrop 2006). As West Virginia-specific Veg-IBIs were developed, we were able to contrast and compare the classification strategies most often used in indices of biological integrity and evaluate the effectiveness of combining metric scores from other IBIs to form a multi-metric, multi-taxa composite IBI. Combining metric scores from multiple taxa groups enabled us to determine the efficacy of combining metric scores to increase the sensitivity and consistency of the IBI response to human impairment. 


\subsection{Methods}

\section{$\underline{2.1 \text { Study Area }}$}

Efforts were made to stratify sampling across both wetland Cowardin classes and the major U.S. Environmental Protection Agency's Level 3 aquatic ecoregions within West Virginia, USA: the Central Appalachians, the Ridge and Valley, and the Western Allegheny Plateau (Woods et al. 1999, Omernik 1987) (Table 1) (Veselka 2008: Chapter 2). Because of a lack of a comprehensive wetland map by HGM classification, stratification by this scheme was not possible. However, due the number of sites used in this study (151) we are confident we adequately sampled the major HGM subclasses (Cole et al. 1997) found in West Virginia (Figure 1) (Veselka 2008: Chapter 2). All sites were analyzed independently, although our sampling regime included single wetlands (48 of 151) and 20 wetland complexes in which we sampled from 2-5 sites per complex; all located $\geq 300 \mathrm{~m}$ from one another (Veselka 2008: Chapter 2).

After categorizing wetlands by both the Cowardin and regional HGM subclass (Cole et al. 1997) type, some subclass designations were combined into designated HGM management classes (Table 2) (Veselka 2008: Chapter 2). These categorizations increased our sample size and were meant to be more intuitive and applicable for use by natural resource managers and regulators. However, enough wetlands of the regional HGM subclasses (Cole et al. 1997) were sampled to build headwater floodplain and riparian depression Veg-IBIs. This allowed us to evaluate the difference between true HGM subclasses and our designated HGM management classes (Veselka 2008: Chapter 2). 


\section{$\underline{2.2 \text { Vegetation Surveys }}$}

Our vegetation survey methodology was designed to quickly and efficiently quantify the percent cover of the dominant species within our vegetation plot. Quantitative vegetation sampling was conducted once per wetland site in July or early August of 2005 or 2006. Vegetation sampling was conducted using a nested quadrat design to match the relative size of each vegetation stratum (Balcombe et al.2005). The dominant plant community, as determined by relative size (height), was identified in each wetland and sampled. Vegetation strata were classified into tree, shrub, and herbaceous layers(USACOE 1987). Trees were sampled using a 10-m radius circular plot; the shrub layer was sampled in a 6-m radius circular plot using the same center point nested within the tree stratum; and a minimum of 40.5-m radius herbaceous plots were randomly sampled within the 10-m radius plot.

The diameter at breast height $(\mathrm{DBH})$ of trees that were $>12.0 \mathrm{~cm}$ for $1 \mathrm{stem}$, or a cumulative DBH $>20 \mathrm{~cm}$ for 2 stems, was measured to calculate basal area per species (Beltz et al. 1992). Woody vegetation between 10-cm and 6-m in height were considered shrubs. Each shrub species was recorded, and the diameter of each shrub's canopy was estimated and converted into percent cover. Herbaceous plants and woody vegetation (< $10 \mathrm{~cm}$ ), exposed substrate, woody debris, bare ground, open water, and bryophytes were recorded and percent cover estimated using a modified Daubenmire (1968) cover class scale (Table 3) (Tiner 1999). The midpoints of each cover class were used to identify candidate metric values. Herbaceous quadrats were scattered randomly and sampled until $\leq 2$ new species were detected after the initial 4 quadrats. 
Additionally, we augmented the quantitative data collection by conducting a qualitative visual walk-through the wetland community to document the presence of species not detected in the initial vegetation survey (Balcombe et al. 2005). The walkthrough allowed us to evaluate other metrics that may have been limited in their effectiveness because of non-detection using the previously discussed methodology. For example, the Floristic Quality Assessment Index scores are based on the presence of plant species and are immune to the influence of the abundance of any single plant species (Rentch and Anderson 2006). The quantitative and qualitative data of each stratum were then used to derive the candidate metrics that were tested for inclusion into the Veg-IBI (Table 4), allowing a greater number of candidate metrics.

\section{$\underline{2.3 \text { Disturbance Gradient }}$}

Our disturbance gradient was based on metrics characterizing surrounding landuse activity, width and condition of the natural wetland buffer zone, and alteration to the hydrology, habitat, or substrate; adopted from the Ohio Rapid Assessment Method version 5.0 (ORAM) (Table 5) (Mack 2001). These metrics and submetrics formed a disturbance score that ranged from 4-39, the lower the score the more apparent the evidence of human impairment. The metrics selected for inclusion into the Veg-IBI were based on their responses to the disturbance score (Veselka 2008: Chapter 2).

\subsection{Reference and Stressed Sites Designations}

Reference and stressed designations were developed independently for Cowardin, HGM subclasses (Cole et al. 1997), and designated HGM management classes across Level 3 ecoregions (Woods et al. 1999, Omernik 1987) because these designations were based on human impairment characteristics throughout West Virginia rather than the 
ecological basis of the ecoregions. Disturbance index scores in the $75^{\text {th }}$ and $25^{\text {th }}$ percentile were used to categorize reference and stressed conditions, respectively (Barbour et al. 1995). Reference sites were based on least-disturbed conditions. These sites were not intended to be pristine or free from any evidence of human manipulation, but to represent examples of what can be realistically expected from a minimally impacted wetland in West Virginia (Omernik 1995).

\section{$\underline{2.5 \text { Data Analysis }}$}

Class-specific Veg-IBIs were developed for wetland classes with $\geq 5$ referenceand5 stressed sites (Chipps et al. 2006). Sites were identified (in part) by sampling year. However, this effect was not tested because an individual wetland was only sampled during1 year of the study period, not both (Reiss 2006, O'Connell et al. 1998). All statistical tests were conducted at an a priori alpha level of 0.05 (Mack 2004, Micacchion 2004).

The vegetation plot measurements were used to derive candidate metric values that were evaluated for their capacity to discriminate between reference and stressed sites. After analyzing our data in a series of elimination steps specific to individual HGM or Cowardin classifications, we were able to contrast and use the 2 classification systems and use them to augment one another to increase sensitivity to disturbance scores (Veselka 2008: Chapter 2).

Potentially responsive metrics were identified, specific to each classification scheme, across the state of West Virginia using box-and-whisker plots (Barbour et al. 1996). After screening for redundant metrics (Hughes et al. 1998), remaining metrics were evaluated using an analyses of variance (ANOVA) test for an ecoregion interaction, 
a classification scheme interaction, and the 2-way interaction of both (Veselka 2008: Chapter 2). The resulting suite of metrics was evaluated a final time with a series of class-specific MANOVAs, testing for the cumulative effect of the metric values of reference and stressed sites to ecoregion or classification scheme influences (Veselka 2008: Chapter 2). Metrics were then normalized, inversed (when necessary) to ensure a consistent response to disturbance, and scored on a continuous 0-10 scale (Blocksom 2003; Bryce et al. 2002; Veselka 2008: Chapter 2). This scoring technique is consistent with the West Virginia Stream Condition Index (Gerritsen et al. 2000).

Using the metrics appropriate for each classification, Veg-IBIs were formed by summing all metrics selected for inclusion. The disturbance gradient and the distribution of the Veg-IBI scores for the reference sites were used to set numeric thresholds describing wetland condition (Gerritsen et al. 2000). Categorical threshold limits for Veg-IBI scores were set using the $75^{\text {th }}, 25^{\text {th }}$, and $5^{\text {th }}$ percentiles for reference sites (Hill et al. 2003; McCormick et al. 2001; Veselka 2008: Chapter 2).The relation between VegIBI scores and the disturbance score were examined and plotted using simple linear regression specific to each Veg-IBI classification (Veselka 2008: Chapter 2).

In addition to scoring each wetland with an individual designated HGM management and Cowardin class Veg-IBI score, we used the additive properties of metrics to form specific hybrid Veg-IBIs that combined the 2 classification schemes, contingent on adequately large sample sizes.

A final analysis compared the derived class-specific and hybrid Veg-IBI with other wetland indices of biological integrity in West Virginia developed for other species assemblages. Using the same sample of wetland sites, a series of avian wetland indices 
of biological integrity (AW-IBI) and anuran acoustically-based indices of biological integrity (AA-IBI) were previously developed that characterized the species assemblages' responses to disturbance. This allowed the indices to be both compared, and integrated by adding metric scores. This determined if the sensitivity to the disturbance gradient increased as metrics from other biological assemblages were added.

\subsection{Results}

\section{$\underline{3.1 \text { Ecoregions and site classifications }}$}

An apriori decision had been made to partition and build statewide specific VegIBI for both the designated HGM management class and Cowardin classification schemes (Maxted et al. 2000, Barbour et al. 1996).Adequate sample size permitted the formation of statewide Veg-IBIs for emergent, scrub-shrub, and forested wetlands, depression, floodplain, and impoundment designated HGM management class wetlands, and riparian depression and headwater floodplain HGM subclass (Cole et al. 1997) wetlands (Table 6) (Veselka 2008: Chapter 2).A complete list of sites and corresponding attribute data (e.g., ecoregion, location, class, etc.) can be found in Appendix B. The disturbance scores of sites were normally distributed (Figure 3) (Skewness $=-0.04$, Kurtosis $=-0.39$ ).

After eliminating redundant metrics (Table 7), remaining metrics were screened for ecoregion and alternate classification scheme interactions using a series of ANOVA tests (Table 8). Metric values with a significant ecoregion, classification scheme, or ecoregion $\mathrm{x}$ classification effect were subsequently removed from inclusion into the class-specific Veg-IBIs (Table 6).

Using only reference and stressed conditions, the suite of remaining metrics for each class-specific Veg-IBI were then evaluated again for a cumulative ecoregion, 
alternative classification scheme, or 2-way interaction with a MANOVA test (Table 9).

This ensured that each class-specific Veg-IBI was robust and independent of ecoregion or classification scheme influences.

\subsection{Metric Performance}

Twenty-two candidate metrics were screened based on their ability to discriminate between reference and stressed sites independent of classification (HGM subclass, designated HGM management class or Cowardin class) within each ecoregion, based upon the disparity of the interquartile ranges of metric values for reference and stressed conditions (Appendix Y-AF). Six of the 22 metrics were discarded before being included into any of the class-specific Veg-IBI due to an inability to discriminate between reference and stressed conditions, not enough scoring variation between reference and stressed conditions, and/or redundancy with other metrics (Table 6). Additionally, 3 metrics were excluded from all Veg-IBIs after the posthoc analysis revealed a significant ecoregion or classification scheme effect. All metric scores and summary statistics by ecoregion are found in Appendices AF-AL.

The Mean Coefficient of Conservatism, adjusted Floristic Quality Assessment Index (adjusted FQAI), and non-native plant richness were most often correlated to one another. If discrimination efficiency among these metrics were equal, the FQAI metric was included because it incorporates measures of both the Coefficient of Conservatism and non-native plant richness (Miller and Wardrop 2006).

The resulting class-specific Veg-IBIs included between 1 and 5 metrics capable of discriminating between reference and stressed sites, although only 7 of the 8 derived indices were significantly related to disturbance scores (Table 10). Only the 
impoundment designated HGM management class Veg-IBI scores failed to exhibit a significant relation with the disturbance gradient, despite being able to discriminate between reference and stressed sites greater than $70 \%$ of the time.

The Veg-IBI based on Cowardin classifications all exhibited a significant relation with the disturbance gradient. Within the emergent class Veg-IBI, only the adjusted FQAI metric consistently discriminated between reference and stressed sites. The disturbance scores accounted for $14 \%$ of the variation in scores.

The scrub-shrub Veg-IBI was composed of 2 metrics; the relative cover of Carex species and, the relative cover of tolerant plant species. The disturbance scores accounted for $20 \%$ of the variation in the scrub-shrub Veg-IBI scores resulting from these metrics. The adjusted FQAI metric was removed from inclusion in the scrub-shrub VegIBI after a significant ecoregion and classification effect was found. The percent cover of native hydrophytic shrubs metric was also removed because of a significant ecoregion effect.

Five metrics formed the forested Veg-IBI. These metrics were the adjusted FQAI score, the relative cover of ferns and fern allies, the relative cover of Carex species, the relative cover of native hydrophytic herbaceous vegetation, and the relative cover of invasive graminoids including Phalaris arundinacea. The disturbance gradient accounted for $35 \%$ of the variation in the forested Veg-IBI scores. The relative cover of native graminoid species and relative cover of tolerant species were eliminated from consideration as suitable metrics because of a significant 2-way interaction effect between the designated HGM management class and ecoregion. 
Among regional HGM subclasses (Cole et al. 1997),2 (riparian depression and headwater floodplain) for which specific Veg-IBIs were derived, exhibited significant relations with disturbance scores. The riparian depression Veg-IBI was built from 3 metrics; the adjusted FQAI score, the relative cover of tolerant species, and the percent cover of native shrubs. The disturbance gradient accounted for $26 \%$ of the variation in riparian depression Veg-IBI scores. Shrub richness was not included in the riparian depression Veg-IBI because it was significantly influenced by Cowardin classification.

The headwater floodplain Veg-IBI was composed of 4 metrics; the adjusted FQAI scores, the relative cover of Carex species, the mean importance value (IV) of tree species, and native shrub species richness. Based on the metrics included in the headwater floodplain Veg-IBI, $65 \%$ of the variation in scores can be attributed to the disturbance gradient. The metric discerning the mean IV of tree species with a wetland dependency rating of facultative or greater was eliminated from inclusion because it was significantly related to Cowardin classification.

As noted, with the exception of the impoundment designated HGM management class, both the floodplain and depression Veg-IBIs were significantly related to the disturbance scores. Five metrics were included in the floodplain Veg-IBI. These metrics were the mean Coefficient of Conservatism, the relative cover of Carex species, the mean IV of tree species, non-native plants from walk-through richness, and native shrub richness. Our disturbance gradient accounted for $56 \%$ of the variation in the floodplain Veg-IBI scores. As in the headwater floodplain Veg-IBI, the mean IV of tree species with a facultative or greater rating was eliminated due to a Cowardin effect. The percent 
cover of native shrub species displayed a Cowardin effect, an ecoregion effect, and an interaction effect.

With regards to the depression Veg-IBI scores, $31 \%$ of the variation in scores was attributed to the disturbance gradient. The scores of the depression Veg-IBI consisted of 2 metrics; the adjusted FQAI and the percent cover of native shrubs. As with the riparian depression Veg-IBI, the native shrub richness metric was removed after determining it exhibited a significant Cowardin classification effect.

The metrics making up the impoundment Veg-IBI, which did not exhibit a significant relation $(p=0.4308)$ included 2 metrics capable of discriminating between reference and stressed sites, the relative cover of monocot species and the relative cover of Carex species. The robust adjusted FQAI metric was excluded after the posthoc ANOVA showed a significant relation to both Cowardin class and ecoregion classification in impoundment wetlands.

Scoring thresholds based on the reference percentiles were calculated for each of the Veg-IBI classes (Table 11). All the means of Veg-IBIs that were related to the disturbance gradient varied significantly between reference and stressed sites.

\subsection{Dual classification approaches for the Veg-IBI}

The emergent Veg-IBI was only drawn from the adjusted FQAI metric; in relation to this metric, the disturbance gradient accounted for $14 \%$ of the variation in emergent Veg-IBI scores (Table 10). The sensitivity to disturbance increased in some instances when metric scores of the corresponding HGM classification were added. The emergent Veg-IBI sensitivity to disturbance increased when metrics from the HGM subclass of headwater floodplain (Cole et al. 1997) and floodplain designated HGM management 
classes were combined with the emergent Veg-IBI (Table 12). However, the amount of variation attributed to the disturbance gradient was actually less in the hybrid IBI than it would have been in a headwater floodplain or floodplain specific Veg-IBI.

Alternatively, when the metric scores from the scrub-shrub and forested Veg-IBI were combined with the corresponding designated HGM management class or HGM subclass (Cole et al. 1997) metric scores, the sensitivity to disturbance gradient increased in relation to both the Cowardin class Veg-IBI and the designated HGM management class Veg-IBI (Table 12). Impoundment Veg-IBI metrics, when evaluated with the scrub-shrub and forested Veg-IBI metrics, were not significantly influenced by the disturbance gradient.

\subsection{Contrasting with other West Virginia wetland indices of biological integrity}

The series of class-specific Veg-IBI are meant to be used as a stand-alone index for measuring biological integrity; yet we have also developed alternative indices using avian and anuran assemblages in the same sample of wetlands. This provided us with the opportunity to compare sensitivity to the disturbance gradient among the different species assemblages (Table 13). Examining the indices of biological integrity specific to HGM subclasses (i.e., riparian depression and headwater floodplain) (Cole et al. 1997), the Veg-IBI were more sensitive to the disturbance gradient than either the AA-IBI or AWIBI. In riparian depression wetlands, adding the AW-IBI metrics actually decreased sensitivity to disturbance, whereas adding both the AW-IBI and AA-IBI metrics to the Veg-IBI metrics changed the sensitivity to the disturbance gradient only slightly. Alternatively, within headwater floodplain wetlands, adding metrics from other taxonomic groups increased sensitivity to the disturbance gradient more with the addition 
of AW-IBI metrics $\left(n=29, F_{1,27}=86.47, p=<0.0001, R^{2}=0.76\right)$ than with both the AAIBI and AW-IBI metrics $\left(\mathrm{n}=22, \mathrm{~F}_{1,20}=53.87, \mathrm{p}=<0.0001, \mathrm{R}^{2}=0.73\right)$.

Impoundment wetlands did not reveal any significant relation to the disturbance gradient relative to any of the taxa-specific or combined taxa IBI metrics. However, as with the HGM subclasses' specific IBIs, the Veg-IBI was more sensitive to the disturbance gradient in depression and floodplain wetlands than the AW-IBI or AA-IBI (Table 13). The combination of Veg-IBI and AW-IBI metrics of depression wetlands did not greatly change the relation to the disturbance gradient. In floodplain wetlands, adding metric scores to the Veg-IBI metrics from the AW-IBI alone and the AW-IBI and AA-IBI together both increased sensitivity to the disturbance gradient. However, the combination of AW-IBI and Veg-IBI metric scores were more sensitive $\left(n=35, F_{1,33}=\right.$ 86.63, $\mathrm{p}=<0.0001, \mathrm{R}^{2}=0.72$ ) to the disturbance gradient than all 3 taxa-group metrics combined $\left(\mathrm{n}=28, \mathrm{~F}_{1,26}=44.44, \mathrm{p}=<0.0001, \mathrm{R}^{2}=0.63\right)$.

The Veg-IBI was more sensitive to the disturbance gradient within HGM classes than within Cowardin classes (Table 13). In emergent and scrub-shrub wetlands, the AW-IBI proved to be the most responsive to the disturbance gradient. When the Veg-IBI metrics were combined with the AW-IBI metric scores, both the emergent $\left(n=75, F_{1,73}=\right.$ 19.66, $\left.\mathrm{p}=<0.0001, \mathrm{R}^{2}=0.21\right)$ and scrub-shrub $\left(\mathrm{n}=44, \mathrm{~F}_{1,42}=22.00, \mathrm{p}=<0.0001, \mathrm{R}^{2}=\right.$ 0.34) Cowardin classes produced more sensitive multi-taxa IBIs than any single species assemblage. Alternatively, the Veg-IBI was most sensitive to the disturbance gradient in forested wetlands in comparison to the AW-IBI; however, sensitivity still increased with the addition of AW-IBI and Veg-IBI metrics $\left(n=31, F_{1,29}=26.90, p=<0.0001, R^{2}=\right.$ 0.48). 


\subsection{Discussion}

\section{$\underline{4.1 \text { Study design }}$}

Vegetation communities with high biological integrity are the desired endpoint representing least impaired wetland conditions (Brooks et al. 1998). Based on our objectives and analysis, the elimination of an ecoregion effect on the series of classspecific Veg-IBI enabled us to have a sufficient sample size to examine and contrast the more recent HGM approach (Brinson 1993) with the Cowardin approach. Our decision to combine the regional subclasses (Cole et al. 1997) into designated HGM management classes was based both a need to increase sample size, and to make IBI classifications intuitive to resource managers, rather than solely wetland specialists.

Each metric was evaluated based on its discrimination efficiency, and eliminating redundant metrics. The posthoc analysis of metric values included within the derived class-specific Veg-IBI was intended to validate our apriori classifications. The series of ANOVA tests of the metric values of reference and stressed sites for all vegetation classes was able to identify specific metrics within each classification scheme that did not respond consistently depending on ecoregion or classification scheme. After these metrics were removed, those remaining in each class were evaluated cumulatively, thus confirming that we had achieved our objective of building a series of statewide, wetland class-specific, vegetation-based indices of biological integrity. We believe our verification of no ecoregion or classification influences resulted in a series of intuitive and scientifically defensible Veg-IBIs that can be used to evaluate the effectiveness of pollution controls and to measure progress towards meeting the CWA objective of biological integrity (Jackson and Davis 1994). Moreover, the methods used to derive the 
Veg-IBI incorporate measures of multivariate analysis that are presentable in an accessible and practical format (Courtemanch 1994).

\subsection{Metric Performance by Classification Scheme}

Vegetation indices of biological integrity were composed of 1 to 5 metrics depending on classification schemes. The most common metric was the adjusted FQAI that was included in 5 of the 8 resulting class-specific Veg-IBIs. The formula for this metric was revised from other floristic quality indices (Miller and Wardrop 2006), but the robustness is not unexpected as it was essentially based on an established lineage of plant indices (Lopez and Fennessy 2002; Mack 2004; Nichols et al. 2006; Rentch and Anderson 2006). Integrating the Coefficients of Conservatism from West Virginia's FQI (Rentch and Anderson 2006) into the adjusted FQAI metric formula (Miller and Wardrop 2006) resulted in increasing discrimination efficiencies; potentially because the calculation incorporates a penalty for non-native plant richness.

Although the adjusted FQAI metric was able to discriminate between reference and impaired (impoundments and scrub-shrub wetlands) conditions, both visually and based upon discrimination efficiencies, it was not included in either classification's final Veg-IBI. This was, in part, due to a significant influence of metric values due to ecoregion classification effects. Additionally, both classifications were significantly influenced by the alternate classification scheme; meaning adjusted FQAI values in scrub-shrub wetlands are influenced by the type of HGM settings they are found in, as impoundment wetland adjusted FQAI scores are influenced by the Cowardin classes. The variation of impoundment wetlands, in our study ranging from forested beaver (Castor canadensis) impoundments to emergent mitigation impoundments, limited the 
number and effectiveness of metrics that could discriminate between reference and stressed conditions. Understanding how the value of the adjusted FQAI metric is calculated (with a penalty factor for exotic species), a recently constructed beaver impoundment may have a higher score than a decades-old, man-made impoundment; despite the beaver impoundment receiving a higher substrate and habitat alteration disturbance score.

With the exception of the scrub-shrub Veg-IBI, the floodplain Veg-IBI was the only other vegetation index significantly related to the disturbance gradient that does not include the adjusted FQAI as a metric. This was not because the adjusted FQAI did not discriminate between reference and stressed sites, but rather because the mean Coefficient of Conservatism metric facilitated efficient discrimination between the reference and stressed sites. We suspect the penalty factor associated with the adjusted FQAI influenced the interquartile distribution of the metric scores of reference sites, resulting in some of our reference sites scoring similar to that of the disturbed sites. These sites were deemed reference sites because they lacked characteristics of habitat, hydrology, or substrate alterations which can support the proliferation of non-native species in many instances (Drohan et al. 2006; Kercher and Zedler 2004; Galatowitsch et al. 1999). However, due to the nature of floodplains, they are already inherently prone to invasions by non-native species (Planty-Tabacchi et al. 1996). As a result, the mean Coefficient of Conservatism of plant species in each site is a better indicator of disturbed conditions as it doesn't overtly penalize for the proportion of non-native richness. However, a separate metric measuring the non-native richness was still included in the floodplain Veg-IBI. This metric was simply the non-native species richness counted in 
the walk-through of the plant community, without adjusting for the ratio of non-native to native species mean Coefficient of Conservatism.

The forested Veg-IBI was composed of 5 metrics, 3 of them unique to this classification; the relative cover of fern allies, the relative cover of hydrophytic herbaceous herbs, and the relative cover of Phalaris arundinacae and other invasive grasses. These metrics are similar to the "specialist" versus "generalist" nature of metrics described for avian species guilds (O’Connell et al. 2000). Forested wetlands are considerably different both structurally, and often hydrologically, than other Cowardin classes, therefore the majority of the metrics capable of discriminating between reference and stressed conditions would be unique.

Other unique specialist and generalist metrics included the relative cover of the monocot species metric for the impoundment Veg-IBI, as well as the mean IV for headwater floodplain and floodplain Veg-IBI. These 2 metrics are a further example of the "specialist" nature of metrics we described for the 4 metrics unique to the forested Veg-IBI. The relative cover of the monocot species metric increased with disturbance in impoundment wetlands. The impoundment Veg-IBI was not found to be significantly related to the disturbance scores, although it was capable of discriminating between reference and stressed conditions. Impoundment wetlands are inherently products of altered hydrology, so in a sense, they are unique as they represent a transition somewhere between the gradient of highly disturbed sites and those reaching a stable recovery point until natural hydrology can be restored. Identifying metrics that are significantly related to the disturbance gradient for impoundment wetlands has also been problematic using avian and anuran species assemblages (Veselka2008: Chapter 2,3). Therefore, as 
impoundment wetlands are themselves an anomaly in comparison to the other wetlands types, it is not altogether surprising that a metric not found in any of the other IBIs would be included in the impoundment Veg-IBI.

The mean IV metric is derived from the tree stratum and used in both the headwater floodplain and floodplain Veg-IBIs. Logic may dictate that this metric may be included in the forested Veg-IBI rather than the headwater floodplain and floodplain Veg-IBI; however, the data directed us differently. Forested wetlands can occur in multiple hydrogeomorphic contexts, including depressional vernal pools, recent beaver ponds, and floodplains. The tree species occurring in such contexts will vary depending on hydroperiod, although to be considered a forested wetland community, at least $30 \%$ of the plant community must be under the forests' canopy (Cowardin et al. 1979). The plant communities we encountered in forested wetlands included high elevation beechhemlock (Fagus grandifolia- Tsuga canadensis) forests, floodplain silver maple (Acer saccharinum) and red maple (Acer rubrum) swamps, and green ash (Fraxinus pennsylvanica) dominated mesophytic forests. The mean IV of tree species was unable to discriminate between reference and stressed sites because the number and type of tree species was inconsistent within our forested wetlands. Floodplain and headwater floodplain wetlands would often have $<20 \%$ canopy cover, although our methodology dictated we sample every vegetation stratum. Any tree included in our survey of floodplain wetlands was typically indicative of both minimal habitat alteration and low to very low surrounding land use impact; 2 factors used in calculating our disturbance score for each wetland. The IV of tree species for each sampling point must add up to 100; so a single tree species or lower numbers of trees species in each plot results in higher mean 
IV. The presence of any tree within floodplain wetlands often coincided with a lesser level of disturbance and, as these disturbance scores were used to determine reference and stressed wetlands, the higher mean IVs were indicative of lesser impacted wetlands resulting in the inclusion of the IV metrics in headwater floodplain and floodplain VegIBIs.

Other general metrics were capable of discriminating between reference and stressed sites in multiple expressions of wetland types. Besides the previously noted adjusted FQAI, 4 other metrics appeared in 2 or more classes of Veg-IBI: the relative cover of Carex species, the relative cover of tolerant species, percent cover of native shrubs, and native shrub richness. The relative cover of Carex species was included as a metric in the headwater floodplain, floodplain, impoundment, scrub-shrub, and forested Veg-IBI. The relative cover of tolerant species was included in our riparian depression and scrub-shrub Veg-IBIs. Both of these metrics were included in vegetation-based IBIs of emergent and scrub-shrub wetlands in Ohio (Mack 2004), headwater wetland complexes in Pennsylvania (Miller et al. 2006), and depressional wetlands in Minnesota (Gernes and Helgen 2002). However, the relative cover of Carex species as a metric for scrub-shrub Veg-IBI is not intuitively biologically meaningful and may be representative of the transition from emergent wetlands to scrub shrub and forested wetlands. Nevertheless, the robustness of these metrics, spanning both Cowardin and designated HGM management classes within our study was not altogether surprising. In our study, the percent cover of native shrubs was included as a metric in the riparian depression and depression Veg-IBIs; native shrub richness was included in headwater floodplain and floodplain Veg-IBI. The percent cover of native shrubs was drawn from a vegetation IBI 
for headwater wetlands in Pennsylvania, although it was not included in the final IBI (Miller et al. 2006). The Ohio vegetation IBI for emergent and scrub-shrub wetlands included a metric for native shrub richness (Mack 2004). In our study, this metric applied to HGM class-specific Veg-IBI rather than the Cowardin classification used in Ohio. Despite the success of these metrics in discriminating between reference and stressed sites, future work should reevaluate the inclusion of these metrics as they were not found effective in the aforementioned regional works.

The emergent Veg-IBI was composed of only 1 metric able to discriminate between reference and stressed conditions, the adjusted FQAI metric. This sole metric did exhibit a significant response to the disturbance gradient that accounted for a portion of the variation in the scores $\left(\mathrm{R}^{2}=0.14\right)$, although we expected more metrics suitable for inclusion into the emergent Veg-IBI. One explanation could lie in the variability of emergent wetlands. In our study, emergent wetlands were composed of high-elevation fens, high and low order floodplains, mitigated impoundment cells, and areas of poor drainage as a result of road or railroad tracks. We postulate that the variation in plant communities in the above-described wetlands throughout West Virginia was the primary reason more candidate metrics did not adequately identify the stressed and reference conditions in emergent wetlands throughout the entire state.

\subsection{Hybrid capacity of the Veg-IBI}

With the exception of emergent wetlands, all other Veg-IBIs exhibited an increased sensitivity to the disturbance gradient by combining metrics from the alternate classification scheme. By combining metrics from the Cowardin class-specific and the designated HGM management class Veg-IBI, the number of metrics increased; however, 
the emergent Veg-IBI was comprised of only 1 metric, the adjusted FQAI metric. This metric was the most common metric discriminating between reference and stressed sites, resulting in the emergent Veg-IBI often overwhelming other adjusted FQAI scores rather than bolstering the other vegetative indices. Regardless, the ability of the entire suite of both the hybrid scrub-shrub and forested Veg-IBIs to respond with greater sensitivity to disturbance validates the approach and the need for continual research into integrating both classification systems from both a biological and regulatory perspective.

\subsection{Comparisons with other Vegetation Indices of Biological Integrity}

Our study's objective was to derive baseline data for a multitude of wetland expressions for use in a statewide wetland monitoring program integrating volunteers with professionals. Our metrics were drawn from previous studies, all of which used different disturbance gradients and sampling methods (Miller at al. 2006, Mack 2004). Although these comparisons were not all biologically meaningful (wetland depressions in Minnesota to wetland depressions in West Virginia), it allows us to contrast the sensitivity of each respective IBI to its disturbance gradient.

Minnesota developed a statewide vegetation IBI for large, depressional wetlands within the emergent plant community (Gernes and Helgen 2002). The disturbance gradient accounted for $49 \%$ of the variation in the 10 metric plant IBI scores. The 2 metric depression-class Veg-IBI for West Virginia had a significant, but comparatively weaker relation with the local disturbance gradient $\left(\mathrm{R}^{2}=0.31\right)$ as did the single metric emergent Veg-IBI $\left(\mathrm{R}^{2}=0.14\right)$.Yet by augmenting the depression Veg-IBI with a Cowardin class Veg- IBI, 2 of the 3 resulting hybrid-class indices had a stronger relation to the disturbance gradient than the depression-specific metrics. The 3 metric scrub- 
shrub - depression Veg-IBI had a significant relation with the disturbance gradient $\left(\mathrm{R}^{2}=\right.$ 0.46), as well the 6 metric forested - depression Veg-IBI $\left(\mathrm{R}^{2}=0.42\right)$; although combining emergent and depression metrics resulted in an insignificant relation $\left(\mathrm{R}^{2}=0.06\right)$. Both studies encompassed multiple ecoregions, but methods varied. The Minnesota disturbance gradient was composed of similar disturbance characteristics, although it included a factor based on water chemistry and sediment concentrations. The scoring method also implemented discrete scoring (Karr et al. 1986), rather than the continuous scale we employed (Blocksom 2003; Gerritsen et al. 2000; Hill et al. 2003).

A regional study of headwater wetlands in the Ridge and Valley ecoregion in Pennsylvania developed an 8 metric, plant-based IBI which is highly responsive to their disturbance gradient (Miller et al. 2006). This study combined the HGM subclasses of slope, riparian depression, and headwater floodplain wetlands associated with streams of the second order or less fed by surface or groundwater into a group termed headwater complexes (Cole et al. 1997). The disturbance gradient, which was composed of both a GIS-analysis of a 1-km radius circle and buffer zone stressor checklist, accounted for $51.8 \%$ of the variation of plant community scores. Our study developed Veg-IBIs for 2 of the 3 HGM subclasses (Cole et al. 1997) used in the Pennsylvania study, riparian depression and headwater floodplain wetlands. However, only the headwater floodplain wetlands were consistently associated with low-order streams, as our riparian depression wetlands were comparatively more variable throughout the entire state. Our local disturbance gradient accounted for $65 \%$ and $26 \%$ of the variation in headwater floodplain and riparian depression Veg-IBI scores, respectively. 
The headwater floodplain Veg-IBI was comprised of 4 metrics, whereas the riparian depression consisted of 3. If the corresponding Cowardin class Veg-IBI metrics are also considered, the disturbance gradient may explain an even greater part of the variation in plant community metrics. Within headwater floodplain wetlands, incorporating the Cowardin class metrics resulted in a greater sensitivity to the disturbance gradient in 2 of the 3 classes. Emergent headwater floodplain scores were significant $\left(\mathrm{R}^{2}=0.61\right)$; although the combined 5-metric scrub-shrub-headwater floodplain $\left(\mathrm{R}^{2}=0.66\right)$ and 7 metric, forested-headwater floodplain $\left(\mathrm{R}^{2}=0.84\right)$ explained more variance than the class-specific headwater floodplain Veg-IBI $\left(\mathrm{R}^{2}=0.65\right)$. The statewide class-specific riparian depression Veg-IBI scores were significant in relation to the disturbance gradient $\left(\mathrm{R}^{2}=0.26\right)$, although not when combined with the emergent Veg-IBI adjusted FQAI metric score $\left(\mathrm{R}^{2}=0.00\right)$. However, when the riparian depression Veg-IBI metrics were combined with scrub-shrub and forested Veg-IBI metrics, the variation accounted for by the disturbance gradient increased to $50 \%$ and $41 \%$, respectively.

Pennsylvania research was focused on a particular wetland system of 1 ecoregion (Miller et al. 2006), hence the results would predictably involve less geographic and wetland type variability than a study encompassing multiple ecoregions. Nonetheless, our approach of combining class-specific Cowardin and HGM metric scores resulted in a series of statewide hybrid Veg-IBIs with significant portions of variation attributed directly to a local disturbance gradient.

Another regional study from Ohio, from which some metrics were drawn, developed vegetation IBIs using Cowardin classes rather than a set of HGM subclasses 
(Mack 2004). The disturbance gradient used in our research is a subset of the metrics from the Ohio Rapid Assessment Method (ORAM) version 5.0 (Mack 2001); which in its entirety, includes measures that don't directly measure human impacts such as size and connectivity to other wetlands, to deduce a wetland disturbance score. Variations of IBI scores due to the disturbance score will change as multiple iterations of each IBI are developed to match a statewide dataset (Mack 2007). However citing the initial stages of the Ohio research, the complete version of ORAM accounted for $72.5 \%$ of the variation in the 10 metric, emergent vegetation IBI, $48 \%$ in the 10 metric, scrub-shrub vegetation IBI, and $49.7 \%$ in the 10 metric, forested vegetation IBI (Mack 2004).Major differences in study methodologies include scoring the metrics, as the Ohio metric scores were calculated using an interval scoring method (Karr et al. 1986), and sampling strategies where Ohio commonly sampled a plant community using a $20 \mathrm{~m}$ by $50 \mathrm{~m}$ transect; which if used in West Virginia, would likely encompass more than 1 wetland vegetation community or take us out of the wetland area, confounding our results and interpretation. The Cowardin class Veg-IBIs developed for West Virginia included fewer metrics for each classification and, although drawn in part from the ORAM, were less responsive to the disturbance gradient. This may be due, in part, to the apriori decision to include only local components of ORAM reflecting human stressors rather than other "natural" proximity factors that can influence plant communities. The emergent Veg-IBI we developed for West Virginia was comprised of only 1 metric (the adjusted FQAI) and, although significantly related to the disturbance gradient, did not explain more than $14 \%$ of the variation in IBI scores. The disturbance score accounted for $20 \%$ and $35 \%$ of the variation in the 2 metric scrub-shrub and 5 metric forested Veg-IBI scores, respectively. 
However, the relation between the disturbance gradient and the Cowardin class Veg-IBI scores can be considerably strengthened when augmented by corresponding designated HGM management class Veg-IBI metrics. For example, in the hybrid Veg-IBI for emergent wetlands in a floodplain setting, the disturbance gradient accounts for $55 \%$ of the variation in scores. However, in emergent-depression and emergent-impoundment wetlands, the relation between Veg-IBI scores and the disturbance gradient is not significant. In fact, both the scrub-shrub and forested Veg-IBI metrics were not significant when combined with impoundment Veg-IBI metrics, although the relations with depression and floodplain Veg-IBI metrics were significant. The disturbance score accounted for $46 \%$ and $59 \%$ of the variation in scrub-shrub-depression and scrub shrubfloodplain Veg-IBI scores, respectively. The relation between forested-depression VegIBI scores $\left(\mathrm{R}^{2}=0.41\right)$ and the disturbance gradient was weaker than the scrub-shrubdepression Veg-IBI; however, the disturbance gradient accounted for more variation in the forested-floodplain Veg-IBI than any other hybrid Cowardin-designated HGM management class combination $\left(\mathrm{R}^{2}=0.68\right)$.

The resulting relations generated by the West Virginia statewide class-specific vegetation IBIs are comparable to many of the results from surrounding regional studies, despite developing these indices using a site-specific disturbance gradient representing only human stressors. We have demonstrated, in some instances, that combining the Cowardin and HGM classification schemes can increase the sensitivity to the disturbance gradient. Developing the dual classifications for monitoring the biological integrity of wetlands allowed us to simultaneously contrast and compare wetlands based on criteria more specific than the most prevalent stratum of vegetation or geomorphic setting. We 
examined all expressions of wetlands across the state and used the additive properties of metrics to evaluate the possibility of strengthening the relation with disturbance scores. However, some wetlands categorized by 1 or 2 of the classification systems, may still result in relatively minor or no variation attributed to the disturbance gradient as we have seen in our studies combining Cowardin class metrics with metrics from the impoundment designated HGM management class.

\subsection{Integration with other wetland indices of biological integrity in West Virginia}

Our study collected data from different biological communities that were used to develop different taxa-specific IBIs in the same manner (Veselka 2008: Chapters 2, 3). These studies included evaluating avian and anuran assemblages to form avian wetland indices of biological integrity (AW-IBI) and acoustically-based anuran indices of biological integrity (AA-IBI). The Veg-IBI can be a stand-alone index that is capable of evaluating wetland biological condition with 1 site visit. Alternatively, the AW-IBI and AA-IBI are composed of cumulative data recorded from 2 and 3 site visits, respectively. These methods, resulting in the AW-IBI and AA-IBI metric scores, are intended to be useful within to volunteer-driven programs. Alternatively, the Veg-IBI requires considerable plant taxonomic skill and a commitment of time that may exceed most volunteer-dependent programs.

Although capable of being used independently, metrics from each taxa-class are all based upon the same scoring regime, and can be used to bolster sensitivity to the disturbance gradient by combining IBIs between taxa. For example, combining the VegIBI metrics for emergent wetlands $\left(\mathrm{R}^{2}=0.14\right)$ with the metric scores from the corresponding emergent AW-IBI results in a multi-taxa multi-metric wetland index in 
which $21 \%$ of the variation in scores is attributable to the disturbance gradient. This was greater than the variation described by the emergent AW-IBI alone $\left(\mathrm{R}^{2}=0.11\right)$. Additionally, different combinations of taxa groups used in the IBI combinations can be used to ascertain which groups of species would be best to characterize the level of biological integrity or track changes. For example, the relation between floodplain wetlands and the disturbance gradient is significant based on Veg-IBI scores, AW-IBI scores, and acoustically-based anuran indices of biological integrity (AA-IBI) scores. However the combination of floodplain AW-IBI and Veg-IBI metrics are better explained by the disturbance gradient $\left(\mathrm{R}^{2}=0.72\right)$ than when all 3 taxa IBI metrics are combined $\left(\mathrm{R}^{2}=0.63\right)$ or the single taxa floodplain IBI is used alone $\left(\mathrm{R}^{2}\right.$ ranged from 0.18 to 0.56$)$.

An obvious intuitive question is raised when more metrics do not necessarily result in greater sensitivities to the disturbance gradient. The addition of AA-IBI metrics, in 4 of 5 cases, resulted in lower sensitivities to disturbance compared to when the VegIBI and AW-IBI are used alone. We discuss the shortcomings of the AA-IBI in previous works (Veselka 2008: Chapter 3); however, in summary, the AA-IBI is based upon methods that are more qualitative than quantitative. Additionally, a minimum criterion was to develop AA-IBI metrics based upon having 2 or more species of anurans vocalizing at 1 site. Contrasting the sensitivities to the disturbance gradient will allow natural resource managers to selectively monitor the group or groups most sensitive to human impacts in wetlands, increasing wetland monitoring efficiency and costeffectiveness. 


\subsection{Implications for Future Monitoring Programs}

Flexibility in choosing which groups of taxa can best explain the relation between biological integrity of wetlands and the local disturbance gradient is important in planning future wetland monitoring programs. Based on the Cowardin or HGM classification of a particular wetland, we can identify which biological assemblages would most likely reflect impacts resulting from human activities in the immediate vicinity. Statewide monitoring programs are intended to describe statewide wetland status, prioritize and plan wetland restoration or preservation, as well as identify areas susceptible to degradation (Wardrop et al. 2007).

Integrating rapid-based bioassessments into spatial probability modeling can identify wetlands most at-risk from anthropogenic activities (Wardrop et al. 2007). By identifying these sites, we can prioritize the protection of the most functionally significant wetlands with regards to water quality improvement, floodwater regulation, and biological integrity to ensure the conditions and functions of wetlands within watersheds throughout West Virginia are maintained (Cedfeldt et al. 2000; Weller et al. 2007).

Wetland regulations are implemented at the local scale, as the filling and dredging of larger wetlands is generally permitted on a case-by-case basis. The CWA mandates that these activities should be conducted in a manner that maintains the biological integrity of the wetland, as long as the wetland in question meets the jurisdictional requirements of the Army Corps of Engineers (USACOE 1987). The success or failure of mitigation projects resulting from the permitted activities typically hinges on a 
surrogate of biological integrity such as the survival rate of a prescribed number of plants per acre. With the advent of the recent EPA ruling on "Compensatory Mitigation for Losses of Aquatic Resources" (40 CFR Part 230) which advocates mitigation banks as the preferred mitigation alternative, the statewide Veg-IBI should be used as the benchmark to define successful mitigation. The use of the Veg-IBI for this purpose will provide an in-depth level of accountability as to the relative success of a mitigation project, better ensuring "no-net loss" of wetlands in West Virginia as it pertains to biological integrity.

\subsection{Acknowledgements}

We thank Adrianne Brand and Mark Hepner for field help and persevering in difficult field conditions. Greg Pond, George Merovich, and the late Dr. George Seidel provided statistical support and advice. Technical writing and logistical support was provided by Sarah McClurg. Funding was provided by the West Virginia Division of Natural Resources with assistance from U.S. EPA State Wetland Program Development Grant CD 973080-01-0. This is scientific article number xxxx of the West Virginia University Agriculture and Forestry Experiment Station. 


\subsection{Literature Cited}

Balcombe C.K., Anderson J.T., Fortney R.H., Rentch J.S., Grafton W.N., Kordek W.S. (2005). A comparison of plant communities in mitigation and reference wetlands in the Mid-Appalachians. Wetlands, 25, 130-142.

Barbour MT, Stribling JB, Karr JR. (1995). Biological assessment and criteria: Tools for water resource planning and decision making. Davis W.S., Simon T.P. (Eds.), Multimetric approach for establishing biocriteria and measuring biological condition. (pp. 63-77). Ann Arbor, MI: Lewis Publishers.

Barbour M.T., Gerritsen J., Griffith G.E., Frydenborg R., McCarron E., White J.S., Bastian M.L. (1996). A framework for biological criteria for Florida streams using benthic macroinvertebrates. Journal of North American Benthological Society, 13, 185211.

Beltz R.C., Bertelson D.F., Faulkner J.L., May D.M. (1992). Forest-Resources of Arkansas Resource Bulletin SO-169. USDA Forest Service, New Orleans, LA.

Blocksom K.A. (2003). A performance comparison of metric scoring for a multimetric index for Mid-Atlantic Highlands streams. Environmental Management, 31, 670-682.

Brinson MM. (1993). A hydrogeomorphic classification for wetlands. U.S. Army Engineers Waterways Experiment Station. Vicksburg, MS. Technical Report WRP-DE4.

Brooks R.P., O'Connell T.J., Wardrop D.H., Jackson L.E. (1998). Towards a regional index of biological integrity: the example of forested riparian ecosystems. Environmental Monitoring and Assessment, 51, 131-143.

Bryce S.A., Hughes R.M., Kaufman P.R. (2002). Development of a bird integrity index: using bird assemblages as indicators of riparian condition. Environmental Management, 30, 294-310.

Cedfeldt P.T., Watzin M.C., Richardson B.D. (2000). Using GIS to identify functionally significant wetlands in the Northeastern United States. Environmental Management, 26, $13-24$.

Chipps S.R., Hubbard D.E., Werlin K.B., Haugerud N.J., Powell K.A., Thompson J., Johnson T. (2006). Association between wetland disturbance and biological attributes in floodplain wetlands. Wetlands, 26, 456-467.

Cole C.A., Brooks R.P., Wardrop D.H. (1997). Wetland hydrology as a function of hydrogeomorphic (HGM) subclass. Wetlands, 17, 456-467. 
Courtemanch D.L. (1994). Bridging the old and new science of biological monitoring. Journal of North American Benthological Society, 13, 117-121.

Cowardin L.M., Carter V., Golet F.C., LaRoe E.T. (1979). Classification of wetlands and deepwater habitats of the United States. U.S. Fish and Wildlife Service. Report FWS/OBS-79/31.

Craft C.B., Richardson C.J. (1997). Relationships between soil nutrients and plant species composition in Everglades peatlands. Journal of Environmental Quality, 26, 224-232.

Daubenmire R.F. (1968). Plant Communities: A Textbook of Plant Synecology. Harper and Row, New York.

Drohan P.J., Ross C.N., Anderson J.T., Fortney R.H., Rentch J.S. (2006). Soil and hydrological drivers of Typha latifolia encroachment in a marl wetland. Wetlands Ecology and Management, 14, 107-122.

Galatowitsch S.M., Anderson N.O., Ascher P.D. (1999). Invasiveness in wetland plants in temperate North America. Wetlands, 19, 733-755.

Galatowitsch S.M., Whited D.C., Lehtinen R.M., Husveth J., Schik K. (2000). The vegetation of wet meadows in relation to their land-use. Environmental Monitoring and Assessment, 60, 121-144.

Gernes M.C., Helgen J.C. (2002). Indexes of Biological Integrity (IBI) for large depressional wetlands in Minnesota. Minnesota Pollution Control Agency, St. Paul, MN.

Gerritsen J. (1995). Additive biological indices for resource management. Journal of North American Benthological Society, 14, 451-457.

Gerritsen J., Burton J., Barbour M.T. (2000). A stream condition index for West Virginia wadeable streams. Tetra Tech, Inc., Owing Mills, MD.

Hill B.H., Herlihy A.T., Kaufman P.R., DeCelles S.J., Vander Borgh M.A. (2003). Assessment of streams of the eastern United States using a periphyton index of biotic integrity. Ecological Indicators, 2, 325-328.

Hughes R.M., Kaufmann P.R., Herlihy A.T., Kincaid T.M., Reynolds L., Larsen D.P. (1998). A process for developing and evaluating indices of fish assemblage integrity. Canadian Journal of Fisheries and Aquatic Sciences, 55, 1618-1631.

Jackson S., Davis W.S. (1994). Meeting the goal of biological integrity in water-resource programs of the U.S. Environmental Protection Agency. Journal of North American Benthological Society, 13, 592-597. 
Karr J.R., Fausch K.D., Angermeier P.L., Yant P.R., Schlosser I.J. (1986). Assessing biological integrity in running waters: a method and its rationale. Illinois Natural History Survey, Urbana, IL.

Karr J.R., Chu E.W. (1999). Restoring life in running waters - better biological monitoring. Island Press, Covelo, CA.

Kercher S.M., Zedler J.B. (2004). Multiple disturbances accelerate invasion of reed canary grass (Phalaris arundinacea) in mesocosm study. Oecologia, 138, 455-464.

Kirkman L.K., Goebel P.C., West L., Drew M.B., Palik B.J. (2000). Depressional wetland vegetation types: a question of plant community development. Wetlands, 20, 373-385.

Koning C.O. (2005). Vegetation patterns resulting from spatial and temporal variability in hydrology, soils, and trampling in an isolated basin marsh, New Hampshire, U.S.A. Wetlands, 25, 239-251.

Lopez R.D. \& Fennessy M.S. (2002). Testing the floristic quality assessment index as an indicator of wetland condition. Ecological Applications, 12, 487-497.

Mack J.J. (2001). Ohio Rapid Assessment Method for Wetlands v. 5.0, User's manual and Scoring Forms. Ohio Environmental Protection Agency, Division of Surface Water, Wetland Ecology Unit, Columbus, $\mathrm{OH}$.

Mack J.J. (2004). Integrated wetland assessment program. Part 9: Field manual for the Vegetation Index of Biotic Integrity for Wetlands v. 1.3. Ohio Environmental Protection Agency, Wetland Ecology Group, Division of Surface Water, Columbus, OH.

Mack J.J. (2007). Developing a wetland IBI with statewide application after multiple testing iterations. Ecological Indicators, 7, 864-881.

Magee T.K., Kentula M.E. (2005). Response of wetland plant species to hydrologic conditions. Wetlands Ecology and Management, 13, 163-181.

Mahaney W.M., Wardrop D.H., Brooks R.P. (2004a). Impacts of sedimentation and nitrogen enrichment on wetland plant community development. Plant Ecology, 175, 227243.

Mahaney W.M., Wardrop D.H., Brooks R.P. (2004b). Impacts of stressors on the emergence and growth of wetland plant species in Pennsylvania, U.S.A. Wetlands, 24, 538-549. 
Maxted J.R., Barbour M.T., Gerritsen J., Poretti V., Primrose N., Silvia A., Penrose D., Renfrow R. (2000). Assessment framework for mid-Atlantic coastal plain streams using benthic macroinvertebrates. Journal of North American Benthological Society, 19, 128144.

McCormick F.H., Hughes R.M., Kaufman P.R., Peck D.V., Stoddard J.L., Herlihy A.T. (2001). Development of an index of biotic integrity for the Mid-Atlantic Highlands region. Transactions of the American Fisheries Society, 130, 857-877.

Micacchion M. (2004). Integrated wetland assessment program. Part 7: amphibian index of biotic integrity (AmphIBI) for Ohio wetlands. In. Ohio Environmental Protection Agency, Wetland Ecology Group, Division of Surface Water, Columbus, OH.

Miller S.J., Wardrop D.H., Mahaney W.M., Brooks R.P. (2006). A plant-based index of biological integrity (IBI) for headwater wetlands in central Pennsylvania. Ecological Indicators, 6, 290-312.

Miller S.J., Wardrop D.H. (2006). Adapting the floristic quality assessment index to indicate anthropogenic disturbance in central Pennsylvania wetlands. Ecological Indicators, 6, 313-326.

Nichols J.D., Perry J.E., DeBerry D.A. (2006). Using a floristic quality assessment technique to evaluate plant community integrity of forested wetlands in Southeastern Virginia. Natural Areas Journal, 26, 360-639.

O'Connell T.J., Jackson L.E., Brooks R.P. (1998). A bird community index of biotic integrity for the Mid-Atlantic highlands. Environmental Monitoring and Assessment, 51, 145-156.

O'Connell T.J., Jackson L.E., Brooks R.P. (2000). Bird guilds as indicators of ecological condition in the central Appalachians. Ecological Applications, 10, 1706-1721.

Omernik J.M. (1987). Ecoregions of the conterminous United States. Annals of the Association of American Geographers, 77, 118-125.

Omernik J.M. (1995). Ecoregions: a spatial framework for environmental management. Davis W.S.\& Simon T.P. (Eds.), Biological assessment and criteria: tools for water resource planning and decision making. Lewis Publishers, Boca Raton, FL.

Planty-Tabacchi A., Tabacchi E., Naiman R.J., Deferrari C., Decamps H. (1996). Invasibility of species-rich communities in riparian areas. Conservation Biology, 10, 598607.

Reiss K.C. (2006). Florida Wetland Condition Index for depressional forested wetlands. Ecological Indicators, 6, 337-352. 
Rentch J.S., Anderson J.T. (2006). A Floristic Quality Index for West Virginia Wetland and Riparian Plant Communities. 65 p. West Virginia Agricultural \& Forestry Experiment Station, Morgantown, WV.

Rentch, J.S., Anderson J.T., Lamont S., Sencindiver J.,Eli R. (2008). Vegetation along hydrologic, edaphic, and geochemical gradients in a high-elevation poor fen in Canaan Valley, West Virginia. Wetlands Ecology and Management, 16, 237-253.

Stevenson R.J., Hauer F.R. (2002). Integrating hydrogeomorphic and index of biotic integrity approaches for environmental assessment of wetlands. Journal of North American Benthological Society, 21, 502-513.

Tiner R. (1999). Wetland Indicators: A Guide to Wetland Identification, Delineation, and Mapping. Lewis Publishers, Boca Raton, FL.

USACOE (1987). Corps of Engineers Wetlands Delineation Manual. p. 99 pages. U.S. Army Corps of Engineers, Washington, DC.

Veselka W. (2008). Developing volunteer-driven indices of biological integrity. M.S. Thesis. West Virginia University, Morgantown, WV.

Wardrop D.H., Kentula M.E., Stevens D.L.J., Jensen S.F., Brooks R.P. (2007). Assessment of wetland condition: an example from the Upper Juniata watershed in Pennsylvania, USA. Wetlands, 27, 416-431.

Weller D.E., Snyder M.N., Whigham D.F., Jacobs A.D., Jordan T.E. (2007). Landscape indicators of wetland condition in the Nanticoke River watershed, Maryland and Delaware, USA. Wetlands, 27, 498-514.

Woods A.J., Omernik J.M., Brown D.D. (1999). Level III and IV ecoregions of Delaware, Maryland, Pennsylvania, Virginia, and West Virginia. U.S. Environmental Protection Agency, Corvallis, OR. 
Table 1. Number of sites by Cowardin and hydrogeomorphic (HGM) classification schemes and ecoregions for use in developinguse in developing vegetation indices of biological integrity (Veg-IBI) for wetlands in West Virginia, USA from 2005-2006.

Level 3 U.S. Environmental Protection Agency aquatic ecoregion ${ }^{\text {a }}$

Ridge and Valley Central Appalachian Western Alleghany Plateau

Total

Hydrogeomorphic subclass ${ }^{b}$

Riparian Depression

10

24

25

59

Headwater Floodplain

10

15

4

29

Designated HGM Management Class

Depression

$10 \quad 28$

28

17

Floodplain

Impoundment

1

6

35

23

Cowardin Class

Emergent

Scrub-shrub

Forested

6

6

14

${ }^{a}$ Omernik (1987), modified by Woods et al. (1999).

${ }^{\mathrm{b}}$ Cole et al. (1997). 
Table 2. Designated hydrogeomorphic (HGM) management classes derived from regional hydrogeomorphic (HGM) subclasses ${ }^{\mathrm{a}}$ for use in developing vegetation indices of biological integrity (Veg-IBI) for wetlands in West Virginia, USA from 2005-2006.

\begin{tabular}{ll}
\hline Designated HGM Management class & Hydrogeomorphic subclass $^{\mathrm{a}}$ \\
\hline Depression & Surface water depression \\
& $\begin{array}{l}\text { Riparian depression } \\
\text { Isolated depression }\end{array}$ \\
Floodplain & Headwater floodplain \\
& Mainstem floodplain \\
Impoundment & Headwater impoundment \\
& Mainstem impoundment \\
Fringing & Fringing \\
Slope & Slope \\
\hline
\end{tabular}

${ }^{\text {a }}$ Cole et al. (1997). 
Table 3. Cover class scales for herbaceous vegetation plots used to derive candidate metric values for developing vegetation indices of biological integrity (Veg-IBI) for wetlands in West Virginia, USA from 2005-2006.

\begin{tabular}{ccc}
\hline $\begin{array}{c}\text { Cover } \\
\text { Class }\end{array}$ & $\begin{array}{c}\text { Range of } \\
\text { Cover }\end{array}$ & $\begin{array}{c}\text { Midpoint } \\
\text { value }\end{array}$ \\
\hline Trace & $<1$ & $0.0 \%$ \\
1 & $1-4 \%$ & $2.5 \%$ \\
2 & $5-15 \%$ & $10.0 \%$ \\
3 & $16-25 \%$ & $20.5 \%$ \\
4 & $26-39 \%$ & $32.5 \%$ \\
5 & $40-60 \%$ & $50.0 \%$ \\
6 & $61-74 \%$ & $67.5 \%$ \\
7 & $75-84 \%$ & $79.5 \%$ \\
8 & $85-95 \%$ & $90.0 \%$ \\
9 & $96-99 \%$ & $97.5 \%$ \\
10 & $100 \%$ & $100.0 \%$ \\
\hline
\end{tabular}


Table 4. Candidate metrics, the survey plot the metrics were derived from, the expected response to disturbance, and descriptions tested for inclusion into vegetation indices of biological integrity (Veg-IBI) for wetlands in West Virginia, USA from 2005-2006.

\begin{tabular}{|c|c|c|c|}
\hline Candidate vegetation metrics & Survey Plot ${ }^{\mathrm{a}}$ & $\begin{array}{c}\text { Expected } \\
\text { Response } \\
\text { to } \\
\text { Disturbance } \\
\end{array}$ & Description of metric \\
\hline MeanC $C^{\text {b,d }}$ & WT & - & Average coefficient of conservatism per wetland \\
\hline $\operatorname{AdjFQAI}^{\mathrm{b}, \mathrm{c}, \mathrm{d}}$ & WT & - & Adjusted Floristic Quality Assessment Index \\
\hline FernRC $C^{b}$ & Herbaceous & - & Relative cover of fern allies \\
\hline MonoRC $C^{b}$ & Herbaceous & + & Relative cover of monocot species \\
\hline NativeGramRC ${ }^{b}$ & Herbaceous & - & Relative Cover of native graminoids \\
\hline InvGrassRC ${ }^{\mathrm{b}, \mathrm{c}}$ & Herbaceous & + & Relative Cover of invasive graminoids \\
\hline NativeDicotRC $C^{\mathrm{c}}$ & Herbaceous & - & Relative cover of native dicots \\
\hline $\operatorname{DicotRC}^{\mathrm{b}}$ & Herbaceous & - & Relative cover of dicots \\
\hline CarexRC $^{b, c}$ & Herbaceous & - & $\begin{array}{l}\text { Relative cover of Carex species } \\
\text { Relative cover of tolerant species (Coefficient of }\end{array}$ \\
\hline TolerantRC $C^{b, c}$ & Herbaceous & + & Conservatism $\geq 2$ ) \\
\hline NativeHydroHrbRC ${ }^{b, c}$ & Herbaceous & - & $\begin{array}{l}\text { Relative cover of native species with facultative } \\
\text { wetness rating or greater }\end{array}$ \\
\hline PhaInvGrassRC $C^{b}$ & Herbaceous & + & $\begin{array}{l}\text { Relative cover of Phalaris species and invasive } \\
\text { graminoids }\end{array}$ \\
\hline ShrubNativePC ${ }^{c}$ & Shrub & - & Percent cover of native shrubs \\
\hline FAConlyHrbRC ${ }^{b}$ & Herbaceous & + & Relative cover of facultative-only rated species \\
\hline ShrNativeHydroPC ${ }^{c}$ & Shrub & - & Percent cover of native hydrophytic shrub species \\
\hline MeanIV $^{\mathrm{c}}$ & Tree & - & $\begin{array}{l}\text { Mean Importance Value (IV) of trees in plot } \\
\text { Mean Importance Value (IV) of facultative or greater }\end{array}$ \\
\hline TreeFACupMeanIV & Tree & - & rated trees \\
\hline TreeFACWupMeanIV & Tree & - & greater rated trees \\
\hline MeanDBH $^{\mathrm{b}}$ & Tree & - & Mean diameter-at-breast height of trees \\
\hline InvGramWTRich & WT & + & Richness of invasive graminoid species \\
\hline NonNativePlantWTRich ${ }^{\mathrm{b}}$ & WT & + & Richness of non-native plant species \\
\hline ShrubRich $^{b}$ & Shrub & - & Richness of shrub species \\
\hline NativeShrubRich $^{\mathrm{b}}$ & Shrub & - & Richness of native shrub species \\
\hline
\end{tabular}

${ }^{\mathrm{a}}$ Herbaceous layer $1 / 2 \mathrm{~m}$ radius, shrub layer $6 \mathrm{~m}$ radius, tree layer $10 \mathrm{~m}$ radius, $\mathrm{WT}=$ walk-through of wetland community and all species detected in other survey methods.

${ }^{\mathrm{b}}$ Miller et al. (2006).

${ }^{\mathrm{c}}$ Mack (2004).

${ }^{\mathrm{d}}$ Rentch and Anderson (2006). 
Table 5. Metrics and sub-metrics selected from the Ohio Rapid Assessment Method (Mack 2001) used to define the disturbance gradient for use in developing vegetation indices of biological integrity (Veg-IBI) for wetlands in West Virginia, USA from 20052006.

\section{Scoring value Disturbance component}

Upland buffers and surrounding land use

Calculate the average buffer width. Select only one and assign

score.

WIDE. Buffers average $50 \mathrm{~m}$ or more around wetland perimeter

MEDIUM. Buffers average $25 \mathrm{~m}$ to $<50 \mathrm{~m}$ around wetland perimeter

NARROW. Buffers average $10 \mathrm{~m}$ to $<25 \mathrm{~m}$ around wetland perimeter

VERY NARROW. Buffers average $<10 \mathrm{~m}$ around wetland perimeter

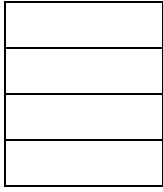

Intensity of surrounding land use. Select one or double check and average.

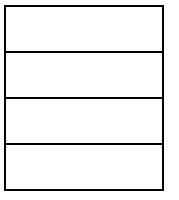

VERY LOW. 2nd growth or older forest, prairie, savannah, wildlife area, etc.

LOW. Old field ( $>10$ years), shrubland, young second growth forest.

MODERATELY HIGH. Residential, fenced pasture, park, conservation tillage, new fallow field.

HIGH. Urban, industrial, open pasture, row cropping, mining, construction.

Hydrology

12

7

3

1

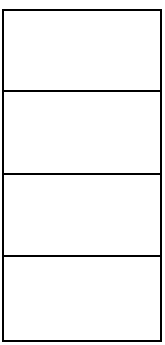

None or none apparent. There are no modifications or no modifications that are apparent to the rater.

Recovered. The wetland appears to have recovered from past modifications which altered the wetland's natural hydrologic regime.

Recovering. The wetland appears to be in the process of recovering from past modifications which altered the wetland's natural hydrologic regime.

Recent or no recovery. The modifications have occurred recently, and / or the wetland has not recovered from past modifications and / or the modifications are ongoing.

Habitat alteration and development

Substrate disturbance. Score one or double check and average.

None or none apparent. There are no modifications or no modifications that are apparent to the rater.

Recovered. The wetland appears to have recovered from past disturbances.

Recovering. The wetland appears to be in the process of recovering from past disturbances.

Recent or no recovery. The modifications have occurred recently, and / or the wetland has not recovered from past disturbances and/ or the disturbances are ongoing.

Habitat alteration. Score one or double check and average.

None or none apparent. There are no alterations or no alterations that are apparent to the rater.

Recovered. The wetland appears to have recovered from past alterations.

Recovering. The wetland appears to be in the process of recovering from past alterations.

Recent or no recovery. The modifications have occurred recently, and / or the wetland has not recovered from past alterations and/ or the alterations are ongoing. 
Table 6. Candidate vegetation community metrics evaluated by class according to regional Hydrogeomorphic (HGM) subclass, designated HGM management class, and the Cowardin classification schemes in building vegetation indices of biological integrity (Veg-IBI) for wetlands in West Virginia, USA from 2005-2006.

\begin{tabular}{|c|c|c|c|c|c|c|c|c|}
\hline \multirow[b]{3}{*}{ Candidate vegetation metrics } & \multicolumn{8}{|c|}{ Wetland Classification $^{\mathrm{a}}$} \\
\hline & \multicolumn{2}{|c|}{ HGM subclass } & \multicolumn{3}{|c|}{ Designated HGM management class } & \multicolumn{3}{|c|}{ Cowardin classification } \\
\hline & $\begin{array}{c}\text { Riparian } \\
\text { Depression }\end{array}$ & $\begin{array}{l}\text { Headwater } \\
\text { Floodplain }\end{array}$ & Depression & Floodplain & Impoundment & Emergent & $\begin{array}{l}\text { Scrub- } \\
\text { Shrub }\end{array}$ & Forested \\
\hline MeanC $C^{b, d}$ & $\mathrm{R}$ & $\mathrm{R}$ & $\mathrm{R}$ & I & $\mathrm{R}$ & $\mathrm{R}$ & $\mathrm{R}$ & $\mathrm{R}$ \\
\hline $\operatorname{AdjFQAI}^{\mathrm{b}, \mathrm{c}, \mathrm{d}}$ & $\mathrm{I}$ & I & $\mathrm{I}$ & $*$ & $\mathrm{E}$ & $\mathrm{I}$ & $\mathrm{E}$ & I \\
\hline FernRC $C^{b}$ & $*$ & $*$ & $*$ & $*$ & $*$ & $*$ & $*$ & I \\
\hline MonoRC $^{b}$ & $*$ & $*$ & $*$ & $*$ & I & $*$ & $*$ & $*$ \\
\hline CarexRC $C^{b, c}$ & $*$ & I & $*$ & I & I & * & I & I \\
\hline TolerantRC $C^{\mathrm{b}, \mathrm{c}}$ & $\mathrm{I}$ & $*$ & $*$ & $*$ & $*$ & $*$ & $\mathrm{I}$ & $\mathrm{E}$ \\
\hline NativeHydroHrbRC ${ }^{b, c}$ & $*$ & $*$ & $*$ & $*$ & $*$ & $*$ & $*$ & $\mathrm{I}$ \\
\hline PhaInvGrassRC ${ }^{\mathrm{b}}$ & $*$ & $*$ & $*$ & $*$ & $*$ & $*$ & $*$ & I \\
\hline ShrubNativePC ${ }^{c}$ & I & $*$ & $\mathrm{I}$ & $\mathrm{E}$ & $*$ & $*$ & $\mathrm{R}$ & $*$ \\
\hline ShrNativeHydroPC & $*$ & $*$ & $\mathrm{R}$ & $*$ & $*$ & $*$ & $\mathrm{E}$ & $*$ \\
\hline MeanIV $^{\mathrm{c}}$ & $*$ & I & $*$ & I & * & * & * & $*$ \\
\hline NonNativePlantWTRich ${ }^{\text {b }}$ & $\mathrm{R}$ & $\mathrm{R}$ & $\mathrm{R}$ & I & $*$ & $*$ & $\mathrm{R}$ & $\mathrm{F}$ \\
\hline NativeShrubRich $^{\mathrm{b}}$ & $\mathrm{E}$ & $\mathrm{I}$ & $\mathrm{E}$ & I & $*$ & $*$ & $*$ & $\mathrm{~F}$ \\
\hline NativeGramRC $C^{\mathrm{b}, \mathrm{e}}$ & $*$ & $*$ & $*$ & * & * & * & * & $\mathrm{E}$ \\
\hline TreeFACupMeanIV & $*$ & $\mathrm{E}$ & $*$ & $\mathrm{E}$ & $*$ & $*$ & $*$ & $*$ \\
\hline TreeFACWupMeanIV & $*$ & $\mathrm{R}$ & $*$ & $*$ & $*$ & $*$ & $*$ & $*$ \\
\hline MeanDBH ${ }^{\mathrm{b}, \mathrm{e}}$ & $*$ & $\mathrm{R}$ & $*$ & $\mathrm{R}$ & $*$ & $*$ & $*$ & $*$ \\
\hline NativeDicotRC $C^{\mathrm{c}, \mathrm{e}}$ & $*$ & $*$ & $*$ & $*$ & * & * & * & $*$ \\
\hline $\operatorname{DicotRC}^{\mathrm{b}, \mathrm{e}}$ & $*$ & $*$ & $*$ & $*$ & $*$ & $*$ & $*$ & $*$ \\
\hline FAConlyHrbRC $^{\text {b, e }}$ & $*$ & $*$ & $*$ & $*$ & $*$ & $*$ & $*$ & $*$ \\
\hline InvGramWTRich $^{\mathrm{e}}$ & $*$ & $*$ & $*$ & $*$ & $*$ & $*$ & $*$ & $*$ \\
\hline ShrubRich $^{\mathrm{b}, \mathrm{e}}$ & $*$ & $*$ & $*$ & $*$ & $*$ & $*$ & $*$ & $\mathrm{~F}$ \\
\hline
\end{tabular}

${ }^{\mathrm{a}} \mathrm{I}=$ included in class-specific Veg-IBI; $\mathrm{R}=$ redundancy with other metrics; $\mathrm{F}=$ failure due to lack of scoring range; $\mathrm{E}=$ excluded due to significant ecoregion or classification effect; $*=$ failure to discriminate between reference and stressed sites.

${ }^{\mathrm{b}}$ Derived fromMiller et al. (2006)

${ }^{\mathrm{c}}$ Derived from Mack (2004)

${ }^{\mathrm{d}}$ Rentch and Anderson (2006).

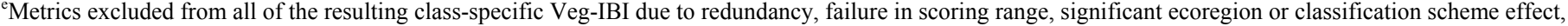
inability to discriminate between reference and stressed sites. 
Table 7. Correlated metrics ( $\mathrm{R}>0.80)$ selected based on discrimination efficiency (D.E.) in differentiating between reference and stressed sites' metrics used in developing vegetation indices of biological integrity (Veg-IBI) for wetlands in West Virginia, USA from 2005-2006.

\begin{tabular}{|c|c|c|c|c|c|c|c|c|c|}
\hline \multirow[t]{2}{*}{ Classification/metric } & D.E. & \multicolumn{8}{|c|}{ Metrics } \\
\hline & & Mean C & AdjFQAI & $\begin{array}{c}\text { Tolerant } \\
\text { RC }\end{array}$ & $\begin{array}{c}\text { Shrub } \\
\text { Native } \\
\text { PC }\end{array}$ & $\begin{array}{l}\text { NonNative } \\
\text { PlantWTRich }\end{array}$ & & & \\
\hline Mean $\mathrm{C}^{\mathrm{a}}$ & 82 & 1 & & & & & & & \\
\hline AdjFQAI $^{\mathrm{b}}$ & 82 & 0.991 & 1 & & & & & & \\
\hline Tolerant $\mathrm{RC}^{\mathrm{b}}$ & 82 & -0.477 & -0.492 & 1 & & & & & \\
\hline Shrub Native $P^{b}{ }^{b}$ & 64 & 0.166 & 0.162 & -0.063 & 1 & & & & \\
\hline NonNativePlantWTRich ${ }^{\mathrm{a}}$ & 72 & -0.827 & -0.868 & 0.349 & -0.025 & 1 & & & \\
\hline Headwater Floodplain & & Mean C & AdjFQAI & $\begin{array}{c}\text { Carex } \\
\mathrm{RC}\end{array}$ & $\begin{array}{l}\text { Mean } \\
\text { IV }\end{array}$ & $\begin{array}{l}\text { TreeFACup } \\
\text { Mean IV }\end{array}$ & $\begin{array}{l}\text { Mean } \\
\text { DBH }\end{array}$ & $\begin{array}{c}\text { NonNative } \\
\text { PlantWTRich }\end{array}$ & $\begin{array}{c}\text { Native } \\
\text { Shrub } \\
\text { Richness }\end{array}$ \\
\hline Mean $\mathrm{C}^{\mathrm{a}}$ & 88 & 1 & & & & & & & \\
\hline $\operatorname{AdjFQAI}^{\mathrm{b}}$ & 88 & 0.985 & 1 & & & & & & \\
\hline Carex $\mathrm{RC}^{\mathrm{b}}$ & 75 & 0.267 & 0.213 & 1 & & & & & \\
\hline Mean IV ${ }^{\mathrm{b}}$ & 88 & -0.145 & -0.215 & 0.123 & 1 & & & & \\
\hline TreeFACupMean IV & 88 & -0.069 & -0.112 & 0.125 & 0.765 & 1 & & & \\
\hline Mean $\mathrm{DBH}^{\mathrm{a}}$ & 88 & -0.216 & -0.264 & -0.032 & 0.937 & 0.788 & 1 & & \\
\hline NonNativePlantWTRich ${ }^{\mathrm{a}}$ & 75 & -0.762 & -0.829 & -0.014 & 0.379 & 0.199 & 0.316 & 1 & \\
\hline Native Shrub Richness ${ }^{\mathrm{b}}$ & 62 & 0.14 & 0.154 & 0.077 & 0.421 & 0.509 & 0.436 & -0.168 & 1 \\
\hline
\end{tabular}


Table 7. Continued.

\begin{tabular}{|c|c|c|c|c|c|c|c|c|c|}
\hline Classification/metric & D.E. & & & & Metrics & & & & \\
\hline Depression & & Mean C & AdjFQAI & Shrub Native PC & ShrNativeHydroPC & $\begin{array}{c}\text { NonNative } \\
\text { PlantWTRich }\end{array}$ & $\begin{array}{c}\text { Native } \\
\text { Shrub } \\
\text { Richness }\end{array}$ & & \\
\hline Mean $\mathrm{C}^{\mathrm{a}}$ & 78 & 1 & & & & & & & \\
\hline $\operatorname{AdjFQAI}^{\mathrm{b}}$ & 78 & 0.99 & 1 & & & & & & \\
\hline Shrub Native $\mathrm{PC}^{\mathrm{b}}$ & 72 & 0.119 & 0.104 & 1 & & & & & \\
\hline ShrNativeHydroPC & 67 & 0.126 & 0.108 & 0.951 & 1 & & & & \\
\hline NonNativePlantWTRich ${ }^{\mathrm{a}}$ & 67 & -0.823 & -0.873 & 0.049 & 0.063 & 1 & & & \\
\hline Native Shrub Richness ${ }^{c}$ & 67 & 0.026 & 0.003 & 0.754 & 0.698 & 0.166 & 1 & & \\
\hline Floodplain & & Mean C & Carex RC & Shrub Native PC & Mean IV & $\begin{array}{l}\text { TreeFACup } \\
\text { Mean IV }\end{array}$ & $\begin{array}{l}\text { Mean } \\
\text { DBH }\end{array}$ & $\begin{array}{l}\text { NonNative } \\
\text { PlantWTRich }\end{array}$ & $\begin{array}{c}\text { Native } \\
\text { Shrub } \\
\text { Richness }\end{array}$ \\
\hline Mean $\mathrm{C}^{\mathrm{b}}$ & 66 & 1 & & & & & & & \\
\hline Carex $\mathrm{RC}^{\mathrm{b}}$ & 89 & 0.181 & 1 & & & & & & \\
\hline Shrub Native $\mathrm{PC}^{\mathrm{c}}$ & 78 & -0.061 & 0.123 & 1 & & & & & \\
\hline Mean IV ${ }^{\mathrm{b}}$ & 89 & -0.24 & 0.089 & 0.328 & 1 & & & & \\
\hline TreeFACupMean IV ${ }^{\mathrm{c}}$ & 89 & -0.133 & 0.018 & 0.297 & 0.778 & 1 & & & \\
\hline Mean DBH ${ }^{\mathrm{a}}$ & 89 & -0.29 & -0.144 & 0.384 & 0.887 & 0.83 & 1 & & \\
\hline NonNativePlantWTRich ${ }^{\mathrm{b}}$ & 78 & -0.797 & -0.009 & -0.102 & 0.446 & 0.268 & 0.387 & 1 & \\
\hline Native Shrub Richness ${ }^{\mathrm{b}}$ & 66 & 0.063 & 0.009 & 0.623 & 0.433 & 0.504 & 0.438 & -0.06 & 1 \\
\hline Impoundment & & Mean C & AdjFQAI & Mono RC & Carex RC & & & & \\
\hline Mean $\mathrm{C}^{\mathrm{a}}$ & 86 & 1 & & & & & & & \\
\hline AdjFQAI $^{\mathrm{c}}$ & 86 & 0.984 & 1 & & & & & & \\
\hline Mono $\mathrm{RC}^{\mathrm{b}}$ & 71 & -0.204 & -0.175 & 1 & & & & & \\
\hline Carex $\mathrm{RC}^{\mathrm{b}}$ & 71 & -0.036 & 0.011 & 0.231 & 1 & & & & \\
\hline
\end{tabular}


Table 7. Continued.

\begin{tabular}{|c|c|c|c|c|c|c|c|c|c|c|c|c|c|}
\hline Classification/metric & D.E. & & & & & Metrics & & & & & & & \\
\hline Emergent & & Mean C & AdjFQAI & & & & & & & & & & \\
\hline Mean $\mathrm{C}^{\mathrm{a}}$ & 68 & 1 & & & & & & & & & & & \\
\hline AdjFQAI $^{\mathrm{b}}$ & 74 & 0.992 & 1 & & & & & & & & & & \\
\hline Scrub Shrub & & Mean C & AdjFQAI & $\begin{array}{c}\text { Carex } \\
\mathrm{RC}\end{array}$ & $\begin{array}{c}\text { Tolerant } \\
\text { RC } \\
\end{array}$ & $\begin{array}{c}\text { Shrub } \\
\text { Native PC }\end{array}$ & $\begin{array}{l}\text { ShrNative } \\
\text { HydroPC }\end{array}$ & $\begin{array}{c}\text { NonNative } \\
\text { Plant } \\
\text { WTRich } \\
\end{array}$ & & & & & \\
\hline Mean $\mathrm{C}^{\mathrm{a}}$ & 83 & 1 & & & & & & & & & & & \\
\hline AdjFQAI $^{\mathrm{c}}$ & 83 & 0.994 & 1 & & & & & & & & & & \\
\hline Carex $\mathrm{RC}^{\mathrm{b}}$ & 83 & 0.067 & 0.063 & 1 & & & & & & & & & \\
\hline Tolerant $\mathrm{RC}^{\mathrm{b}}$ & 66 & -0.562 & -0.568 & -0.119 & 1 & & & & & & & & \\
\hline Shrub Native PC & 66 & 0.327 & 0.311 & 0.236 & -0.394 & 1 & & & & & & & \\
\hline ShrNativeHydroPC ${ }^{c}$ & 66 & 0.29 & 0.266 & 0.222 & -0.343 & 0.895 & 1 & & & & & & \\
\hline NonNativePlantWTRich $^{\mathrm{a}}$ & 83 & -0.864 & -0.894 & -0.007 & 0.437 & -0.198 & -0.142 & 1 & & & & & \\
\hline Forested & & Mean C & AdjFQAI & FernRC & $\begin{array}{c}\text { Native } \\
\text { GramRC }\end{array}$ & Carex RC & $\begin{array}{c}\text { Tolerant } \\
\text { RC }\end{array}$ & $\begin{array}{c}\text { NativeHydro } \\
\text { HrbRC }\end{array}$ & $\begin{array}{c}\text { PhaInv } \\
\text { GrassRC }\end{array}$ & $\begin{array}{l}\text { InvGram } \\
\text { WTRich }\end{array}$ & $\begin{array}{c}\text { NonNative } \\
\text { PlantWTRich }\end{array}$ & $\begin{array}{l}\text { Shrub } \\
\text { Rich }\end{array}$ & $\begin{array}{c}\text { Native } \\
\text { Shrub } \\
\text { Richness }\end{array}$ \\
\hline Mean $\mathrm{C}^{\mathrm{a}}$ & 88 & 1 & & & & & & & & & & & \\
\hline AdjFQAI $^{\mathrm{b}}$ & 88 & 0.982 & 1 & & & & & & & & & & \\
\hline FernRC $^{\mathrm{b}}$ & 100 & 0.468 & 0.475 & 1 & & & & & & & & & \\
\hline NativeGramRC ${ }^{\mathrm{c}}$ & 88 & 0.065 & 0.012 & -0.098 & 1 & & & & & & & & \\
\hline Carex RC ${ }^{\mathrm{b}}$ & 63 & -0.093 & -0.128 & -0.028 & 0.631 & 1 & & & & & & & \\
\hline Tolerant $\mathrm{RC}^{\mathrm{c}}$ & 88 & -0.615 & -0.66 & -0.249 & 0.021 & 0.352 & 1 & & & & & & \\
\hline NativeHydroHrbRC ${ }^{b}$ & 63 & 0.238 & 0.288 & 0.16 & 0.226 & -0.152 & -0.646 & 1 & & & & & \\
\hline PhaInvGrassRC $^{\mathrm{b}}$ & 63 & -0.389 & -0.412 & -0.145 & 0.206 & 0.322 & 0.56 & -0.308 & 1 & & & & \\
\hline InvGramWTRich $^{\mathrm{c}}$ & 75 & -0.47 & -0.489 & -0.357 & 0.119 & 0.095 & 0.394 & -0.088 & 0.783 & 1 & & & \\
\hline NonNativePlantWTRich ${ }^{\mathrm{a}}$ & 75 & -0.749 & -0.818 & -0.511 & 0.206 & 0.173 & 0.685 & -0.395 & 0.555 & 0.618 & 1 & & \\
\hline ShrubRich $^{\mathrm{c}}$ & 88 & 0.116 & 0.067 & 0.137 & 0.259 & 0.138 & 0.069 & 0.12 & 0.213 & 0.091 & 0.085 & 1 & \\
\hline Native Shrub Richness ${ }^{\mathrm{c}}$ & 75 & 0.144 & 0.091 & 0.186 & 0.292 & 0.149 & 0.067 & 0.167 & 0.143 & 0.083 & 0.043 & 0.953 & 1 \\
\hline
\end{tabular}

${ }^{a}$ Metric not included due to redundancy with other metrics with greater discrimination efficiency.

${ }^{\mathrm{b}}$ Metric selected for inclusion into Veg-IBI.

${ }^{\mathrm{c}}$ Metric selected for inclusion into Veg-IBI, but removed in later analysis due to lack of scoring variability, significant ecoregion or alternate classification scheme effect. 
Table 8. Analysis of variance (ANOVA) results of reference and stressed sites' metric values compared to Level 3 ecoregions (Woods et al. 1999, Omernik 1987) and the alternative classification scheme used in developing vegetation indices of biological integrity (Veg-IBI) for wetlands in West Virginia, USA from 2005-2006.

\begin{tabular}{|c|c|c|c|c|}
\hline $\begin{array}{l}\text { Classification (number of } \\
\text { reference and impacted sites) }\end{array}$ & Validation test & $\mathrm{df}$ & $\begin{array}{c}\text { F- } \\
\text { value }\end{array}$ & p-value \\
\hline \multicolumn{5}{|l|}{$\begin{array}{l}\text { Riparian Depression Veg-IBI } \\
(n=27)\end{array}$} \\
\hline \multirow[t]{3}{*}{ Adjusted FQAI } & Cowardin class & 2,26 & 0.92 & 0.4168 \\
\hline & Level 3 ecoregion & 2,26 & 2.13 & 0.1464 \\
\hline & Cowardinclass $x$ Level 3 ecoregion & 3,26 & 0.36 & 0.7847 \\
\hline \multirow[t]{3}{*}{ Native Shrub Richness ${ }^{\mathrm{a}}$} & Cowardin ${ }^{\mathrm{b}}$ class & 2,26 & 4.68 & 0.0223 \\
\hline & Level 3 ecoregion & 2,26 & 0.27 & 0.7627 \\
\hline & Cowardinclass x Level 3 ecoregion & 3,26 & 0.38 & 0.7696 \\
\hline \multirow[t]{3}{*}{ Tolerant relative cover } & Cowardinclass & 2,26 & 0.06 & 0.9377 \\
\hline & Level 3 ecoregion & 2,26 & 1.92 & 0.1746 \\
\hline & Cowardinclass $\mathrm{x}$ Level 3 ecoregion & 3,26 & 0.81 & 0.5058 \\
\hline \multirow[t]{3}{*}{ Native Shrub percent cover } & Cowardinclass & 2,26 & 0.88 & 0.4328 \\
\hline & Level 3 ecoregion & 2,26 & 1.06 & 0.3668 \\
\hline & Cowardinclass $\mathrm{x}$ Level 3 ecoregion & 3,26 & 2.92 & 0.0604 \\
\hline \multicolumn{5}{|l|}{$\begin{array}{l}\text { Headwater Floodplain Veg- } \\
\text { IBI }(n=16)\end{array}$} \\
\hline \multirow[t]{3}{*}{ Adjusted FQAI } & Cowardinclass & 2,15 & 0.03 & 0.9675 \\
\hline & Level 3 ecoregion & 2,15 & 1.34 & 0.3152 \\
\hline & Cowardinclass $\mathrm{x}$ Level 3 ecoregion & 3,15 & 0.20 & 0.8922 \\
\hline \multirow[t]{3}{*}{ Native Shrub Richness } & Cowardinclass & 2,15 & 3.23 & 0.0939 \\
\hline & Level 3 ecoregion & 2,15 & 1.43 & 0.2948 \\
\hline & Cowardinclass $x$ Level 3 ecoregion & 3,15 & 0.11 & 0.9531 \\
\hline \multirow[t]{3}{*}{ Mean IV } & Cowardinclass & 2,15 & 0.65 & 0.5473 \\
\hline & Level 3 ecoregion & 2,15 & 0.87 & 0.4548 \\
\hline & Cowardinclass $\mathrm{x}$ Level 3 ecoregion & 3,15 & 0.02 & 0.9968 \\
\hline \multicolumn{5}{|l|}{ Tree Facultative or greater } \\
\hline \multirow[t]{3}{*}{ Mean IV ${ }^{\mathrm{a}}$} & Cowardinclass & 2,15 & 5.45 & 0.0321 \\
\hline & Level 3 ecoregion & 2,15 & 3.64 & 0.0751 \\
\hline & Cowardinclass $x$ Level 3 ecoregion & 3,15 & 1.97 & 0.1976 \\
\hline \multirow[t]{3}{*}{ Carex spp. relative cover } & Cowardinclass & 2,15 & 0.50 & 0.6254 \\
\hline & Level 3 ecoregion & 2,15 & 0.07 & 0.9292 \\
\hline & Cowardinclass $x$ Level 3 ecoregion & 3,15 & 0.21 & 0.8884 \\
\hline
\end{tabular}


Table 8. Continued.

\begin{tabular}{|c|c|c|c|c|}
\hline $\begin{array}{l}\text { Classification (number of } \\
\text { reference and impacted sites) }\end{array}$ & Validation test & df & $\begin{array}{c}\mathrm{F}- \\
\text { value }\end{array}$ & p-value \\
\hline \multicolumn{5}{|l|}{ Depression Veg-IBI $(n=37)$} \\
\hline \multirow[t]{3}{*}{ Adjusted FQAI } & Cowardinclass & 3,36 & 0.95 & 0.4296 \\
\hline & Level 3 ecoregion & 2,36 & 1.96 & 0.1602 \\
\hline & Cowardinclass $x$ Level 3 ecoregion & 3,36 & 0.42 & 0.7367 \\
\hline \multirow[t]{3}{*}{ Native Shrub Richness ${ }^{a}$} & Cowardinclass & 3,36 & 4.00 & 0.0172 \\
\hline & Level 3 ecoregion & 2,36 & 0.57 & 0.5715 \\
\hline & Cowardinclass $x$ Level 3 ecoregion & 3,36 & 1.16 & 0.3443 \\
\hline \multirow[t]{3}{*}{ Native Shrub percent cover } & Cowardinclass & 3,36 & 0.62 & 0.6093 \\
\hline & Level 3 ecoregion & 2,36 & 1.07 & 0.3557 \\
\hline & Cowardinclass $\mathrm{x}$ Level 3 ecoregion & 3,36 & 2.92 & 0.0516 \\
\hline \multicolumn{5}{|l|}{ Floodplain Veg-IBI $(n=19)$} \\
\hline \multirow[t]{3}{*}{ Mean C } & Cowardinclass & 2,18 & 0.24 & 0.7875 \\
\hline & Level 3 ecoregion & 2,18 & 2.16 & 0.1664 \\
\hline & Cowardinclass $x$ Level 3 ecoregion & 4,18 & 0.32 & 0.8584 \\
\hline \multicolumn{5}{|l|}{ Non-Native Plant Walk-thru } \\
\hline \multirow[t]{3}{*}{ Richness } & Cowardinclass & 2,18 & 0.24 & 0.7899 \\
\hline & Level 3 ecoregion & 2,18 & 2.63 & 0.1206 \\
\hline & Cowardinclass $x$ Level 3 ecoregion & 4,18 & 0.88 & 0.5075 \\
\hline \multirow[t]{3}{*}{ Native Shrub Richness } & Cowardinclass & 2,18 & 3.03 & 0.0938 \\
\hline & Level 3 ecoregion & 2,18 & 0.67 & 0.5338 \\
\hline & Cowardinclass $x$ Level 3 ecoregion & 4,18 & 0.21 & 0.9263 \\
\hline \multirow[t]{3}{*}{ Tree Mean IV } & Cowardinclass & 2,18 & 1.46 & 0.2774 \\
\hline & Level 3 ecoregion & 2,18 & 0.84 & 0.4595 \\
\hline & Cowardinclass $x$ Level 3 ecoregion & 4,18 & 0.41 & 0.7973 \\
\hline \multicolumn{5}{|l|}{ Tree Facultative or greater } \\
\hline \multirow[t]{3}{*}{ Mean IV } & Cowardinclass & 2,18 & 9.39 & 0.0051 \\
\hline & Level 3 ecoregion & 2,18 & 2.07 & 0.1775 \\
\hline & Cowardinclass $x$ Level 3 ecoregion & 4,18 & 2.12 & 0.1531 \\
\hline \multirow[t]{3}{*}{ Carex spp. relative cover } & Cowardinclass & 2,18 & 0.45 & 0.6487 \\
\hline & Level 3 ecoregion & 2,18 & 0.31 & 0.7372 \\
\hline & Cowardinclass $x$ Level 3 ecoregion & 4,18 & 0.22 & 0.9199 \\
\hline \multirow[t]{3}{*}{ Native Shrub percent cover ${ }^{a}$} & Cowardinclass & 2,18 & 57.01 & $<0.0001$ \\
\hline & Level 3 ecoregion & 2,18 & 19.99 & 0.0003 \\
\hline & Cowardinclass $x$ Level 3 ecoregion & 4,18 & 20.32 & $<0.0001$ \\
\hline \multicolumn{5}{|l|}{$\begin{array}{l}\text { Impoundment Veg-IBI } \\
(n=13)\end{array}$} \\
\hline \multirow[t]{3}{*}{ Adjusted FQAI ${ }^{\mathrm{a}}$} & Cowardinclass & 2,12 & 5.91 & 0.0314 \\
\hline & Level 3 ecoregion & 2,12 & 6.07 & 0.0296 \\
\hline & Cowardinclass $\mathrm{x}$ Level 3 ecoregion & 1,12 & 0.47 & 0.4688 \\
\hline \multirow[t]{3}{*}{ Monocot relative cover } & Cowardinclass & 2,12 & 1.29 & 0.3330 \\
\hline & Level 3 ecoregion & 2,12 & 0.43 & 0.6690 \\
\hline & Cowardinclass $\mathrm{x}$ Level 3 ecoregion & 1,12 & 0.00 & 0.9914 \\
\hline \multirow[t]{3}{*}{ Carex spp. relative cover } & Cowardinclass & 2,12 & 0.01 & 0.9915 \\
\hline & Level 3 ecoregion & 2,12 & 0.80 & 0.4885 \\
\hline & Cowardinclass x Level 3 ecoregion & 1,12 & 0.02 & 0.8998 \\
\hline
\end{tabular}


Table 8. Continued.

\begin{tabular}{|c|c|c|c|c|}
\hline $\begin{array}{l}\text { Classification (number of } \\
\text { reference and impacted sites) }\end{array}$ & Validation test & $\mathrm{df}$ & $\begin{array}{c}\mathrm{F}- \\
\text { value }\end{array}$ & p-value \\
\hline \multicolumn{5}{|l|}{ Emergent Veg-IBI $(n=38)$} \\
\hline \multirow[t]{3}{*}{ Adjusted FQAI } & Designated $\mathrm{HGM}^{\mathrm{b}}$ management class & 4,37 & 1.17 & 0.3491 \\
\hline & Level 3 ecoregion & 2,37 & 2.65 & 0.0900 \\
\hline & Designated $\mathrm{HGM}^{\mathrm{b}}$ management class $\mathrm{x}$ Level 3 ecoregion & 6,37 & 1.11 & 0.3853 \\
\hline \multicolumn{5}{|l|}{ Scrub-Shrub Veg-IBI $(n=23)$} \\
\hline \multirow[t]{3}{*}{ Adjusted FQAI ${ }^{\mathrm{a}}$} & Designated $\mathrm{HGM}^{\mathrm{b}}$ management class & 4,22 & 4.52 & 0.0149 \\
\hline & Level 3 ecoregion & 2,22 & 6.34 & 0.0109 \\
\hline & Designated $\mathrm{HGM}^{\mathrm{b}}$ management class $\mathrm{x}$ Level 3 ecoregion & 2,22 & 0.84 & 0.4541 \\
\hline \multirow[t]{3}{*}{ Carex spp. relative cover } & Designated $\mathrm{HGM}^{\mathrm{b}}$ management class & 4,22 & 0.56 & 0.6922 \\
\hline & Level 3 ecoregion & 2,22 & 0.60 & 0.5636 \\
\hline & Designated $\mathrm{HGM}^{\mathrm{b}}$ management class $\mathrm{x}$ Level 3 ecoregion & 2,22 & 0.25 & 0.7794 \\
\hline \multirow[t]{3}{*}{ Tolerant relative cover } & Designated $\mathrm{HGM}^{\mathrm{b}}$ management class & 4,22 & 1.17 & 0.3672 \\
\hline & Level 3 ecoregion & 2,22 & 2.59 & 0.1106 \\
\hline & Designated $\mathrm{HGM}^{\mathrm{b}}$ management class $\mathrm{x}$ Level 3 ecoregion & 2,22 & 0.01 & 0.9938 \\
\hline \multirow[t]{3}{*}{$\begin{array}{l}\text { Native Hydrophytic Shrub } \\
\text { percent cover }^{\mathrm{a}}\end{array}$} & Designated $\mathrm{HGM}^{\mathrm{b}}$ management class & 4,22 & 0.16 & 0.9552 \\
\hline & Level 3 ecoregion & 2,22 & 8.87 & 0.0033 \\
\hline & Designated $\mathrm{HGM}^{\mathrm{b}}$ management class $\mathrm{x}$ Level 3 ecoregion & 2,22 & 0.16 & 0.8517 \\
\hline \multicolumn{5}{|l|}{ Forested Veg-IBI $(n=16)$} \\
\hline \multirow[t]{3}{*}{ Adjusted FQAI } & Designated $\mathrm{HGM}^{\mathrm{b}}$ management class & 4,15 & 0.66 & 0.6414 \\
\hline & Level 3 ecoregion & 2,15 & 0.81 & 0.4841 \\
\hline & Designated $\mathrm{HGM}^{\mathrm{b}}$ management class $\mathrm{x}$ Level 3 ecoregion & 2,15 & 1.06 & 0.3970 \\
\hline \multirow[t]{3}{*}{ Fern relative cover } & Designated $\mathrm{HGM}^{\mathrm{b}}$ management class & 4,15 & 0.43 & 0.7866 \\
\hline & Level 3 ecoregion & 2,15 & 0.30 & 0.6929 \\
\hline & Designated $\mathrm{HGM}^{\mathrm{b}}$ management class $\mathrm{x}$ Level 3 ecoregion & 2,15 & 0.43 & 0.6694 \\
\hline \multirow[t]{3}{*}{$\begin{array}{l}\text { Native Graminoid relative } \\
\text { cover }^{\mathrm{a}}\end{array}$} & Designated $\mathrm{HGM}^{\mathrm{b}}$ management class & 4,15 & 4.82 & 0.1100 \\
\hline & Level 3 ecoregion & 2,15 & 4.30 & 0.0606 \\
\hline & Designated $\mathrm{HGM}^{\mathrm{b}}$ management class $\mathrm{x}$ Level 3 ecoregion & 2,15 & 7.74 & 0.0169 \\
\hline \multirow[t]{3}{*}{ Carex spp. relative cover } & Designated $\mathrm{HGM}^{\mathrm{b}}$ management class & 4,15 & 1.71 & 0.2511 \\
\hline & Level 3 ecoregion & 2,15 & 1.50 & 0.2866 \\
\hline & Designated $\mathrm{HGM}^{\mathrm{b}}$ management class $\mathrm{x}$ Level 3 ecoregion & 2,15 & 0.09 & 0.9153 \\
\hline \multirow[t]{3}{*}{ Tolerant relative cover ${ }^{\mathrm{a}}$} & Designated $\mathrm{HGM}^{\mathrm{b}}$ management class & 4,15 & 1.21 & 0.3845 \\
\hline & Level 3 ecoregion & 2,15 & 3.28 & 0.0990 \\
\hline & Designated $\mathrm{HGM}^{\mathrm{b}}$ management class $\mathrm{x}$ Level 3 ecoregion & 2,15 & 5.61 & 0.0351 \\
\hline Native Hydrophytic & Designated $\mathrm{HGM}^{\mathrm{b}}$ management class & 4,15 & 1.70 & 0.2530 \\
\hline \multirow[t]{2}{*}{ Herbaceous relative cover } & Level 3 ecoregion & 2,15 & 2.36 & 0.1645 \\
\hline & Designated $\mathrm{HGM}^{\mathrm{b}}$ management class $\mathrm{x}$ Level 3 ecoregion & 2,15 & 2.12 & 0.1909 \\
\hline \multirow{4}{*}{$\begin{array}{l}\text { Phalaris spp. and Invasive } \\
\text { Grasses relative cover }\end{array}$} & & & & \\
\hline & Designated $\mathrm{HGM}^{\mathrm{b}}$ management class & 4,15 & 0.42 & 0.7878 \\
\hline & Level 3 ecoregion & 2,15 & 0.43 & 0.6650 \\
\hline & Designated $\mathrm{HGM}^{\mathrm{b}}$ management class $\mathrm{x}$ Level 3 ecoregion & 2,15 & 1.43 & 0.3011 \\
\hline
\end{tabular}

${ }^{a}$ Metric excluded from inclusion into class-specific Veg-IBI due to a significant ecoregion, alternative classification scheme, or cumulative 2-way interaction.

${ }^{\mathrm{b}}$ Hydrogeomorphic (Brinson 1993). 
Table 9. Wilks' Lambda statistic for posthoc validation of reference and stressed sites' metric values of class-specific vegetation indices of biological integrity (Veg-IBI) for wetlands in West Virginia, USA from 2005-2006.

\begin{tabular}{|c|c|c|c|c|}
\hline Classification scheme and interaction & $\begin{array}{l}\text { Wilks' } \\
\text { Lambda }\end{array}$ & $\begin{array}{c}\text { F- } \\
\text { value }\end{array}$ & df & $\begin{array}{c}\mathrm{p}- \\
\text { value }\end{array}$ \\
\hline \multicolumn{5}{|l|}{ Headwater Floodplain Veg-IBI $(n=16)$} \\
\hline Cowardin class & 0.2074 & 1.49 & 8,10 & 0.2709 \\
\hline Level 3 ecoregion & 0.3608 & 0.83 & 8,10 & 0.5957 \\
\hline Cowardinx Level 3 ecoregion & 0.6293 & 0.22 & $12,13.52$ & 0.9942 \\
\hline \multicolumn{5}{|l|}{ Riparian Depression Veg-IBI $(n=27)$} \\
\hline Cowardinclass & 0.8512 & 0.48 & 6,34 & 0.8220 \\
\hline Level 3 ecoregion & 0.567 & 1.86 & 6,34 & 0.1168 \\
\hline Cowardinx Level 3 ecoregion & 0.4483 & 1.80 & $9,41.52$ & 0.0969 \\
\hline \multicolumn{5}{|l|}{ Floodplain Veg-IBI $(n=19)$} \\
\hline Cowardinclass & 0.167 & 1.74 & 10,12 & 0.1811 \\
\hline Level 3 ecoregion & 0.4791 & 0.53 & 10,12 & 0.8360 \\
\hline Cowardinx Level 3 ecoregion & 0.3275 & 0.42 & $20,20.85$ & 0.9722 \\
\hline \multicolumn{5}{|l|}{ Depression Veg-IBI $(n=37)$} \\
\hline Cowardinclass & 0.8702 & 0.65 & 6,54 & 0.6919 \\
\hline Level 3 ecoregion & 0.7951 & 1.64 & 4,54 & 0.1777 \\
\hline Cowardinx Level 3 ecoregion & 0.7466 & 1.42 & 6,54 & 0.2255 \\
\hline \multicolumn{5}{|l|}{ Impoundment Veg-IBI $(n=13)$} \\
\hline Cowardinclass & 0.7179 & 0.54 & 4,12 & 0.7089 \\
\hline Level 3 ecoregion & 0.7601 & 0.44 & 4,12 & 0.7769 \\
\hline Cowardinx Level 3 ecoregion & 0.9974 & 0.01 & 2,6 & 0.9921 \\
\hline \multicolumn{5}{|l|}{ Scrub-Shrub Veg-IBI $(n=23)$} \\
\hline Designated HGM ${ }^{\mathrm{a}}$ management class & 0.6394 & 0.81 & 8,26 & 0.5967 \\
\hline Level 3 ecoregion & 0.6925 & 1.31 & 4,26 & 0.2920 \\
\hline $\begin{array}{l}\text { Designated } \mathrm{HGM}^{\mathrm{a}} \text { management class x Level } 3 \\
\text { ecoregion }\end{array}$ & 0.9636 & 0.12 & 4,26 & 0.9735 \\
\hline \multicolumn{5}{|l|}{ Forested Veg-IBI $(n=19)$} \\
\hline Designated HGM ${ }^{\mathrm{a}}$ management class & 0.0559 & 0.76 & $20,10.9$ & 0.7183 \\
\hline Level 3 ecoregion & 0.1641 & 0.88 & 10,6 & 0.5911 \\
\hline $\begin{array}{l}\text { Designated } \mathrm{HGM}^{\mathrm{a}} \text { management class x Level } 3 \\
\text { ecoregion }\end{array}$ & 0.341 & 0.43 & 10,6 & 0.8874 \\
\hline
\end{tabular}

\footnotetext{
${ }^{\text {a }}$ Hydrogreomorphic (Brinson 1993).
} 
Table 10.Relations between the resulting class-specific vegetation indices of biological integrity (Veg-IBI) for wetlands in West Virginia, USA and the disturbance gradient from 2005-2006.

\begin{tabular}{|c|c|c|c|c|c|c|c|c|}
\hline Vegetation IBI & $\begin{array}{c}\text { Metrics } \\
\text { in Veg- } \\
\text { IBI }\end{array}$ & $\mathrm{N}$ & D.E. $^{\mathrm{a}}$ & df & $\begin{array}{c}\text { F- } \\
\text { value }\end{array}$ & p-value & $\mathrm{R}^{2}$ & Equation \\
\hline Riparian Depression & 3 & 59 & $100 \%$ & 1,57 & 19.87 & $<0.0001$ & 0.26 & $\mathrm{y}=4.16+0.50($ Disturbance score $)$ \\
\hline Headwater Floodplain & 4 & 29 & $100 \%$ & 1,27 & 50.00 & $<0.0001$ & 0.65 & $y=-7.21+0.76($ Disturbance score $)$ \\
\hline Depression & 2 & 72 & $78 \%$ & 1,70 & 31.79 & $<0.0001$ & 0.31 & $\mathrm{y}=0.32+0.34$ (Disturbance score) \\
\hline Floodplain & 5 & 35 & $100 \%$ & 1,33 & 42.16 & $<0.0001$ & 0.56 & $y=-0.78+0.81$ (Disturbance score) \\
\hline Impoundment & 2 & 23 & $71 \%$ & 1,21 & 0.65 & 0.4308 & 0.03 & $\mathrm{y}=3.48+0.10($ Disturbance score $)$ \\
\hline Emergent & 1 & 75 & $74 \%$ & 1,73 & 11.91 & 0.0009 & 0.14 & $\mathrm{y}=3.47+0.12($ Disturbance score $)$ \\
\hline Scrub-shrub & 2 & 44 & $92 \%$ & 1,42 & 10.33 & 0.0025 & 0.20 & $y=3.13+0.66($ Disturbance score $)$ \\
\hline Forested & 5 & 31 & $100 \%$ & 1,29 & 16.62 & 0.0005 & 0.35 & $\mathrm{y}=3.50+0.79($ Disturbance score $)$ \\
\hline
\end{tabular}

${ }^{a}$ Effectiveness of Veg-IBI scores to discriminate between reference and stressed sites. 
Table 11. Reference site scoring summary used to derive scoring thresholds, and discrimination efficiency (D.E.) in developing class specific vegetation indices of biological integrity (Veg-IBI) for wetlands in West Virginia, USA from 2005-2006.

\begin{tabular}{|c|c|c|c|c|c|c|c|c|c|}
\hline & \multicolumn{6}{|c|}{ Reference Site Scoring Summary } & \multicolumn{3}{|c|}{ Means (SE) } \\
\hline & $\mathrm{N}$ & $\begin{array}{c}\text { Max } \\
\text { possible } \\
\text { Veg-IBI } \\
\text { score }\end{array}$ & $\begin{array}{c}75 \text { th } \\
\text { percentile }\end{array}$ & $\begin{array}{c}25 \text { th } \\
\text { percentile }\end{array}$ & $\begin{array}{c}5 \text { th } \\
\text { percentile }\end{array}$ & Median & D.E. ${ }^{a}$ & Reference $^{\mathrm{b}}$ & Stressed \\
\hline $\begin{array}{l}\text { Riparian Depression } \\
\text { Headwater }\end{array}$ & 16 & 30 & 21.88 & 17.40 & 14.40 & 19.78 & $100 \%$ & $20.60(1.09)$ & $12.83(1.31)$ \\
\hline Floodplain & 8 & 30 & 21.40 & 19.88 & 19.09 & 20.57 & $100 \%$ & $20.72(0.49)$ & $5.39(1.44)$ \\
\hline Depression & 19 & 20 & 12.41 & 7.52 & 5.73 & 10.17 & $78 \%$ & $11.06(1.04)$ & $5.57(0.68)$ \\
\hline Floodplain & 10 & 50 & 33.28 & 27.78 & 12.53 & 30.40 & $100 \%$ & $27.70(2.61)$ & $11.60(2.21)$ \\
\hline Impoundment & 6 & 20 & 6.09 & 4.05 & 2.99 & 5.36 & $71 \%$ & $5.25(1.24)$ & $3.41(1.15)$ \\
\hline Emergent & 19 & 10 & 8.44 & 6.13 & 3.66 & 7.00 & $74 \%$ & $7.05(0.48)$ & $4.99(0.51)$ \\
\hline Scrub-shrub & 11 & 20 & 16.00 & 10.75 & 10.06 & & $92 \%$ & $13.71(0.89)$ & $8.87(0.85)$ \\
\hline Forested & 8 & 50 & 36.60 & 27.59 & 20.70 & 32.03 & $100 \%$ & $31.39(2.62)$ & $17.34(2.27)$ \\
\hline
\end{tabular}

${ }^{a}$ Effectiveness of Veg-IBI scores to effectively discriminate between reference and stressed sites.

${ }^{\mathrm{b}}$ All means, except impoundment, statistically significantly different (Tukey $\alpha=0.05$ ). 
Table 12.Relations between the resulting hybrid-class vegetation indices of biological integrity (Veg-IBI) for wetlands in West Virginia, USA and the disturbance gradient from 2005-2006.

\begin{tabular}{|c|c|c|c|c|c|c|c|}
\hline Vegetation IBI & $\begin{array}{c}\text { Metrics } \\
\text { in Veg- } \\
\text { IBI }\end{array}$ & $\mathrm{N}$ & df & $\begin{array}{c}\text { F- } \\
\text { value }\end{array}$ & $\begin{array}{c}\mathrm{p}- \\
\text { value }\end{array}$ & $\mathrm{R}^{2}$ & Equation \\
\hline Emergent & 1 & 75 & 1,73 & 11.91 & 0.0009 & 0.14 & $\mathrm{y}=3.47+0.12$ (Disturbance score) \\
\hline Emergent/ Riparian depression & 3 & 29 & 1,27 & 0.09 & 0.7707 & 0.00 & $\mathrm{y}=12.67+0.05($ Disturbance score $)$ \\
\hline Emergent/ Headwater floodplain & 4 & 15 & 1,13 & 20.21 & 0.0003 & 0.61 & $y=-8.75+0.82$ (Disturbance score) \\
\hline Emergent/ Depression & 2 & 38 & 1,36 & 2.28 & 0.1396 & 0.06 & $\mathrm{y}=4.23+0.10($ Disturbance score $)$ \\
\hline Emergent/ Floodplain & 6 & 16 & 1,14 & 16.96 & 0.0010 & 0.55 & $\mathrm{y}=2.30+0.94($ Disturbance score $)$ \\
\hline Emergent/ Impoundment & 3 & 14 & 1,12 & 3.16 & 0.4828 & 0.04 & $\mathrm{y}=10.45+0.12($ Disturbance score $)$ \\
\hline Scrub-shrub & 2 & 44 & 1,42 & 10.33 & 0.0025 & 0.2 & $\mathrm{y}=3.13+0.66($ Disturbance score $)$ \\
\hline $\begin{array}{l}\text { Scrub-shrub/ Riparian depression } \\
\text { Scrub-shrub/ Headwater }\end{array}$ & 3 & 18 & 1,16 & 15.85 & 0.0011 & 0.50 & $\mathrm{y}=1.05+0.83$ (Disturbance score $)$ \\
\hline floodplain & 5 & 7 & 1,5 & 9.77 & 0.0261 & 0.66 & $y=-1.70+0.89$ (Disturbance score) \\
\hline Scrub-shrub/ Depression & 4 & 19 & 1,17 & 14.64 & 0.0014 & 0.46 & $y=2.70+0.78($ Disturbance score $)$ \\
\hline Scrub-shrub/ Floodplain & 6 & 8 & 1,6 & 8.52 & 0.0267 & 0.59 & $y=-3.53+1.36$ (Disturbance score $)$ \\
\hline Scrub-shrub/Impoundment & 3 & 7 & 1,5 & 0.29 & 0.6128 & 0.05 & $\mathrm{y}=11.41+0.18($ Disturbance score $)$ \\
\hline Forested & 5 & 31 & 1,29 & 16.62 & 0.0005 & 0.35 & $y=3.50+0.79($ Disturbance score $)$ \\
\hline Forested/ Riparian depression & 7 & 12 & 1,10 & 6.88 & 0.0255 & 0.41 & $\mathrm{y}=8.50+0.97$ (Disturbance score) \\
\hline Forested/ Headwater floodplain & 7 & 7 & 1,5 & 26.16 & 0.0037 & 0.84 & $\mathrm{y}=0.30+1.23$ (Disturbance score) \\
\hline Forested/ Depression & 6 & 14 & 1,12 & 8.56 & 0.0127 & 0.42 & $\mathrm{y}=6.17+0.89($ Disturbance score $)$ \\
\hline Forested/ Floodplain & 9 & 11 & 1,9 & 18.74 & 0.0019 & 0.68 & $\mathrm{y}=1.35+1.59$ (Disturbance score $)$ \\
\hline Forested/Impoundment ${ }^{\mathrm{a}}$ & & 2 & & & & & \\
\hline
\end{tabular}

${ }^{\text {a }}$ Insufficient sample size 
Table 13. A comparison of the $\mathrm{R}^{2}$ values of derived single and combined vegetation indices of biological integrity (Veg-IBI), avian wetland indices of biological integrity (AW-IBI), and anuran acoustically-based indices of biological integrity (AA-IBI) for wetlands in West Virginia, USA from 2005-2006.

\begin{tabular}{|c|c|c|c|c|c|c|}
\hline \multirow[b]{2}{*}{ Classification } & \multicolumn{6}{|c|}{ Indices of Biological Integrity } \\
\hline & Veg-IBI & AW-IBI & AA-IBI ${ }^{\mathrm{a}}$ & $\begin{array}{l}\text { Veg-IBI x } \\
\text { AW-IBI }\end{array}$ & $\begin{array}{r}\text { Veg-IBI } \\
\text { x AA-IBI } \\
\end{array}$ & $\begin{array}{c}\text { Veg-IBI x AW-IBI } \\
\text { x AA-IBI }\end{array}$ \\
\hline Riparian Depression & 0.26 & $0.04 *$ & 0.08 & & 0.28 & \\
\hline Headwater Floodplain & 0.65 & 0.49 & 0.27 & 0.76 & 0.65 & 0.73 \\
\hline Depression & 0.31 & 0.12 & & 0.32 & & \\
\hline Floodplain & 0.56 & 0.46 & 0.18 & 0.72 & 0.50 & 0.63 \\
\hline Impoundment & $0.03 *$ & $0.05^{*}$ & & $0.09^{*}$ & & \\
\hline Emergent & 0.14 & 0.11 & & 0.21 & & \\
\hline Scrub-shrub & 0.20 & 0.25 & & 0.34 & & \\
\hline Forested & 0.35 & 0.24 & & 0.48 & & \\
\hline
\end{tabular}

${ }^{a}$ Not able to discriminate between reference and stressed sites in all classes.

* Indicates a non-significant relation. 


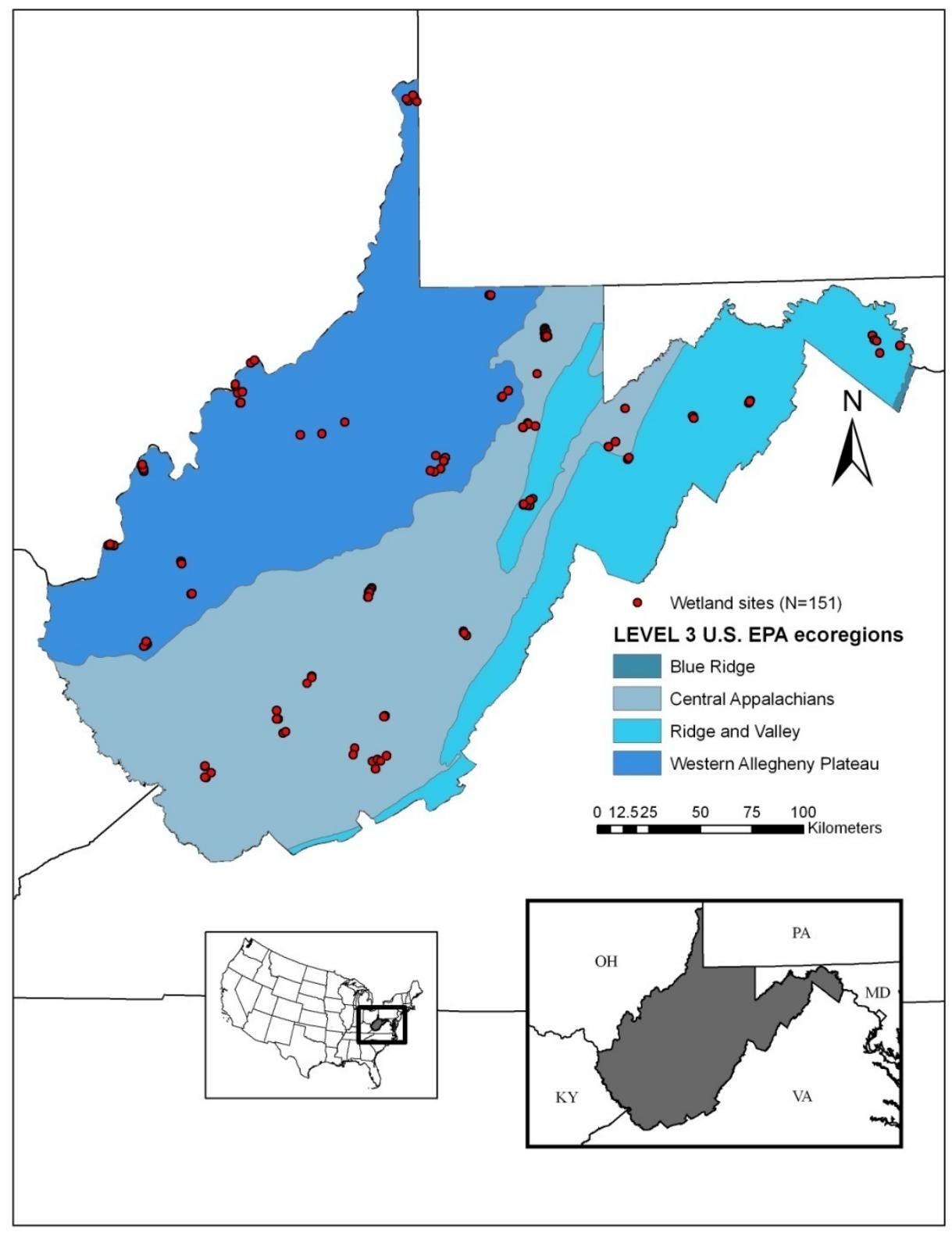

Figure 1. Site locations of wetlands and ecoregions (Omernik 1987, Woods et al. 1999) used in developing class-specific vegetation indices of biological integrity (Veg-IBI) in West Virginia, USA from 2005-2006. Wetland sites were clustered; scale of map prevents all sites from being marked individually. Legend may indicate 1-4 wetlands per mark. 


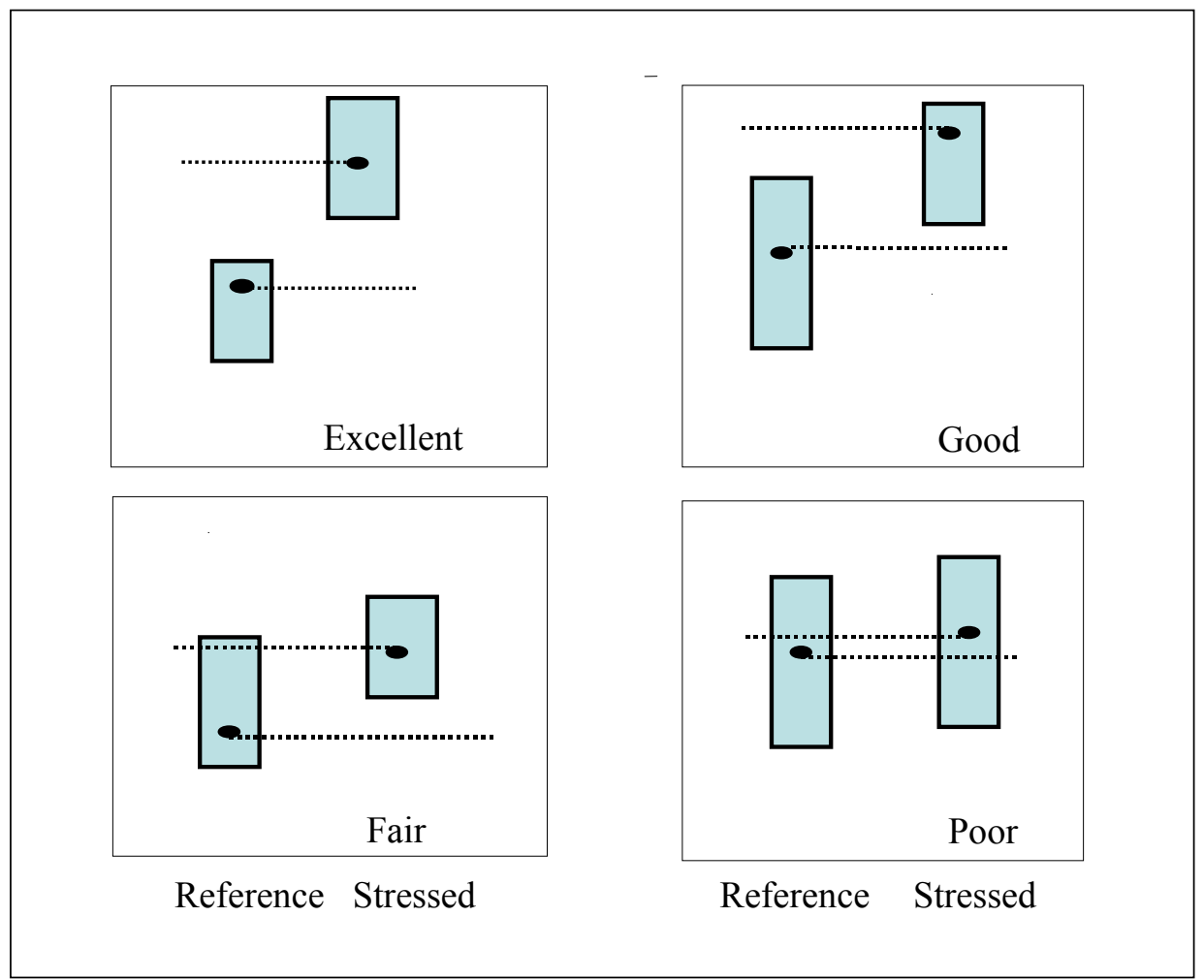

Figure 2. Box-and-whisker plot characteristics and resulting narrative description of reference and stressed sites' distribution of a biological metric value considered for inclusion into classspecific vegetation indices of biological integrity (Veg-IBI) for wetlands in West Virginia, USA from 2005-2006Solid ovals represent the median of metric value (courtesy of Greg Pond, US EPA). 


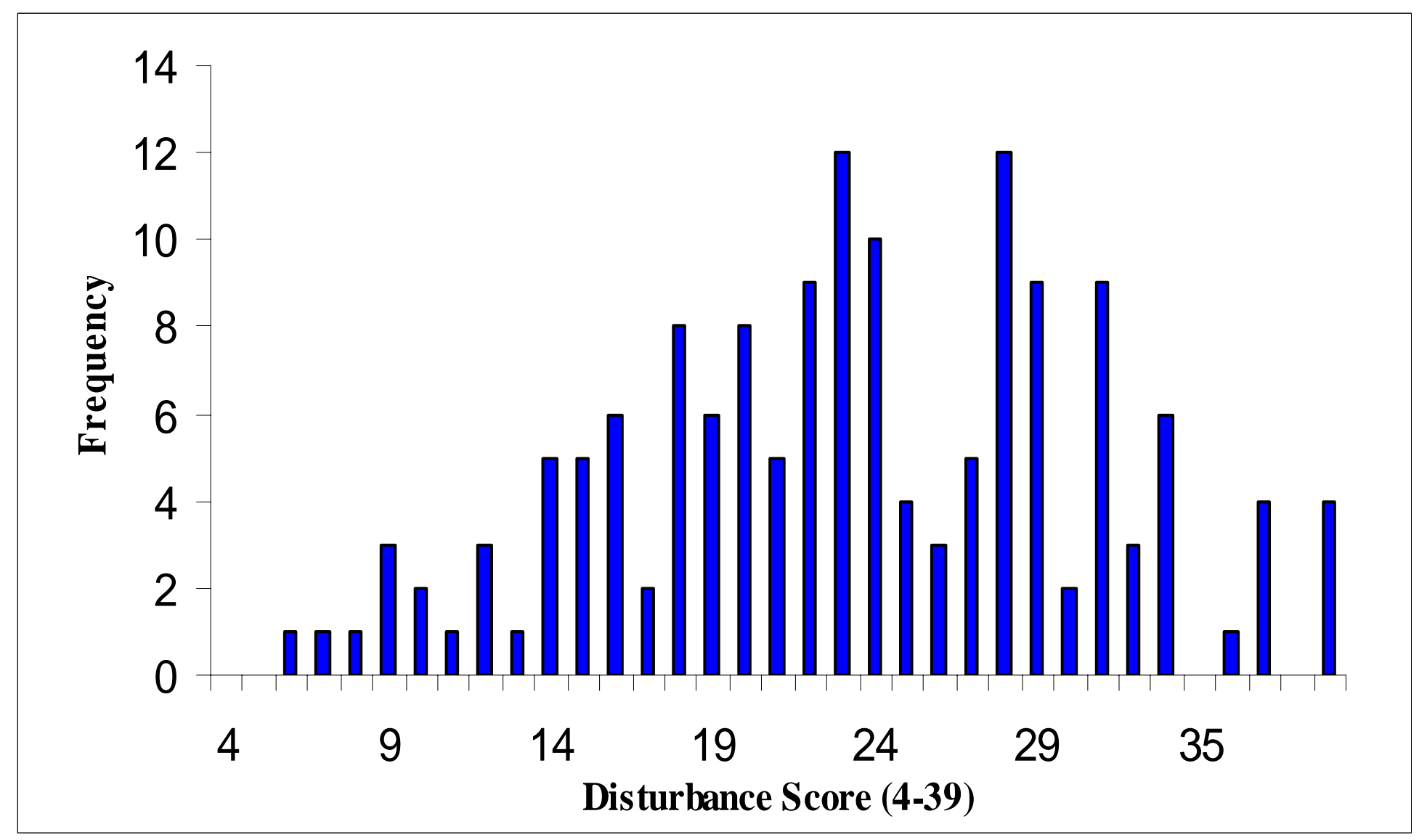

Figure 3. Frequency distribution of disturbance scores for sites used to develop class-specific vegetation indices of biological integrity (Veg-IBI) for wetlands in West Virginia, USA from 2005-2006. 


\title{
Chapter 5
}

\section{Macroinvertebrate Indices of Biological Integrity (Mac-IBI)}

\section{Dual Classifications Used in Developing Macroinvertebrate Indices of Biological Integrity for Wetlands in West Virginia, USA}

\author{
Walter Veselka IV \\ James T. Anderson, 3 \\ Walter S. Kordek ${ }^{2}$ \\ ${ }^{1}$ Division of Forestry and Natural Resources, Wildlife and Fisheries Resources Program, \\ West Virginia University, PO Box 6125, Percival Hall, Morgantown, WV 26506 \\ ${ }^{2}$ West Virginia Division of Natural Resources, Wildlife Resources Section, PO Box 67 , \\ Ward Road, Elkins, WV 26241 \\ 3 address correspondence to James T. Anderson, Ph.D., Division of Forestry and Natural \\ Resources, Wildlife and Fisheries Resources Program, West Virginia University, PO Box \\ 6125, Percival Hall, Morgantown, WV 26506. email: wetland@wvu.eduphone: (304) \\ 293-2941 ext. 2445, fax: (304) 293-2441
}

Submitted in the style of:

Environmental Monitoring and Assessment 


\begin{abstract}
Bioassessments of wetland habitats are based, in part, on consistent comparisons between wetland types. Typically, these wetland classifications are based on either the Cowardin et al. (1979) or hydrogeomorphic (HGM) wetland classification systems. By using both classification systems, we were able to derive a series of macroinvertebrate indices of biological integrity (Mac-IBI) that were compared to determine their sensitivity in detecting anthropogenic disturbance and to further determine their utility in augmenting other wetland indices of biological integrity. The resulting class-specific Mac-IBIs utilized 1-2 metrics that varied in their sensitivity to the disturbance gradient $\left(\mathrm{R}^{2}=0.11-0.47\right)$. However, unlike previous West Virginia derived taxa-specific IBIs, the sensitivity to the disturbance gradient did not increase as metrics from each of the 2 classification schemes were combined (added). Yet, sensitivity to the disturbance gradient increased when the metrics of other class-specific taxa group IBIs were added to those from the Mac-IBI. For example, the disturbance score explained more variation in floodplain wetlands $\left(\mathrm{R}^{2}=0.66\right)$ using a cumulative multi-metric, multi-taxa wetland IBI, than any of the individual taxa IBIs alone. The ramifications for policy makers in charge of designating wetland monitoring strategies include choosing which species taxa to monitor to yield the most information while maximizing efficiency and the number of wetlands monitored.
\end{abstract}

Keywords: macroinvertebrate communities, disturbance, index of biological integrity, metrics, West Virginia, wetlands 


\subsection{Introduction}

The use of aquatic invertebrates to measure the integrity, or condition of water resources in relation to pollutants, has been used extensively in lotic environments (Gerritsen et al. 2000; Hill et al. 2003; McCormick et al. 2001; Miltner et al. 2004). These actions were prompted by the U.S. Environmental Protection Agency, which has charged states with developing criteria intended to ensure and maintain "the physical, chemical, and biological integrity" of the Nation's waters under the Clean Water Act (33 U.S.C. §1251). The development and subsequent validation of indices of biological integrity (IBIs) for running waters (Karr 1999; 1991; Karr et al. 1986) is now a well accepted part of water resource monitoring. These indices have more recently been developed to measure natural wetland health and to evaluate mitigation success (Miller et al. 2006; Teels et al. 2004).

The development of wetland IBIs will allow resource managers to monitor trends in wetland conditions and provide a quantifiable basis for comparison that can be used to prioritize wetlands for conservation, management, or restoration activities. Previous work in West Virginia focused on developing wetland IBIs using anuran, avian, or vegetation assemblages (Veselka 2008: Chapter 2, 3, 4) consistent with research underway in other states (Mack 2004; Micacchion 2002; Miller et al. 2006, O’Connell et al. 2000; Stapanian et al. 2004). Macroinvertebrate assemblages also have been used to ascertain wetland condition. This approach has been tested previously, primarily in ponded freshwater wetlands (Gernes and Helgen 2002; Hicks and Nedeau 2000; Knapp 2004); however, we evaluated multiple expressions of wetland classifications, using a consistent series of steps (U.S. EPA 2002). 
Aquatic invertebrates are common and widely distributed in many types of wetlands (Batzer et al. 1999), and are good candidates for use in wetland bioassessments due to a number of inherent characteristics that lend themselves to the assessment procedure. The importance of invertebrates as both a food resource and agents in the transfer of nutrients in detritus within wetland food webs (Batzer and Wissinger 1996) suggests that macroinvertebrates can play a major role in comparing wetlands (Streever et al. 1996). The human disturbance gradient, a critical component used in developing an IBI, must be able to quantify impairments that may manifest in the biological assemblages used to drive the IBI. It should be based on local factors, such as changes in habitat, hydrology, and substrate alteration (Anderson and Smith 2000; Mack 2001); as research has indicated that landscape level Geographic Information System (GIS) tools used to quantify disturbances are not well suited for invertebrate metrics (Johnson and Goedkoop 2002; Tangen et al. 2003). Aquatic macroinvertebrates are sensitive to many stressors and pollutants, including sedimentation, changes in hydrology, and certain toxins (Barbour et al. 1999; Bendell-Young et al. 2000; Brooks 2000; Euliss and Mushnet 1999; King and Richardson 2007; Spieles and Mitsch 2000). Additionally, macroinvertebrate communities can often vary with differences in the vegetation community due to the use of macrophytes as a food source, attachment sites, refugia, or plant species-specific sites for egg-laying (Burton et al. 1999; Corbet 1999; Wissinger 1999).

However, in comparison to riverine bioassessments, wetland aquatic invertebrate bioassessments can be problematic due to a lack of habitat-specific information pertaining to each species or family, especially in regards to changes in hydrology and hydroperiod length (Batzer et al. 2001). Aquatic macroinvertebrate communities often 
are linked to hydroperiod length (Brooks 2000; Schneider and Frost 1996; Zimmer et al. 2000). This can confound baseline bioassessment data as colonization by terrestrial macroinvertebrates in wetlands occurs shortly after surface water has dried up (Batzer 2004). Moreover, there are also many different methods for sampling aquatic macroinvertebrates, some quantitative and others qualitative that, on a cost-per-unit effort basis, have relative advantages and disadvantages (Anderson and Smith 1996; Batzer et al. 1999; Brinkman and Duffy 1996; Cheal et al. 1993; Fairchild et al. 1987).

The objective of this research was to use both nektonic and benthic macroinvertebrate sampling to derive a series of macroinvertebrate indices of biological integrity (Mac-IBI) specific to Cowardin et al. (1979) wetland classes (hereafter known as "Cowardin") and hydrogeomorphic (HGM) wetland classes (Brinson 1993). These indices will have the capacity to detect and quantify changes in macroinvertebrate communities reflective of the changing levels of human impairment affecting a wetland. The metrics that compose each of the series of derived indices were drawn from previous research (Balcombe et al. 2005a; Bennet 1999; Conklin 2003; Gernes and Helgen 1999; Knapp 2004; U.S. EPA 2002). Using the Mac-IBI, developed specifically for West Virginia wetlands, we were able to contrast and compare their sensitivity to a human disturbance in commonly used wetland classification systems. Additionally, we evaluated the ability to combine scores from other taxa-specific IBIs to form a multi-taxa, multi-metric composite IBI examining any changes in sensitivity to the human disturbance gradient. 


\subsection{Methods}

\section{$\underline{2.1 \text { Study Area }}$}

Study sites were stratified across West Virginia according to ecoregion (Omernik 1987; Woods et al. 1999) and Cowardin classifications (Table 1) (Veselka 2008: Chapter 2). Geographical and logistical constraints limited sampling to a total of 151 sites in this study, (68 in 2005 and 83 in 2006) (Figure 1). Each site was analyzed independently because all sites were located $\geq 300 \mathrm{~m}$ from one another, and no 2 adjacent sites had the same Cowardin classification. Our sampling regime included single wetlands (48 of 151) and 20 wetland complexes in which we sampled from 2-5 sites per complex. Nektonic organisms were not sampled if standing water was not present, and benthic organisms were not sampled if the surface of the ground was not saturated. As a result, 111 sites were used to evaluate nektonic invertebrate metrics (40 in 2005 and 71 in 2006) and 140 sites were used to consider benthic invertebrate metrics (59 in 2005, 81 in 2006). Site location was recorded with a Geographic Positioning System (GPS) to establish a permanent survey station.

Each wetland was categorized by both the Cowardin and HGM classification systems(Cole et al. 1997), although some HGM subclass class designations were consolidated to boost sample size and applicability of the resulting Mac-IBIs (Table 2) (Brooks et al. 1998; Veselka 2008: Chapter 2). However, the efficacy of HGM subclasses derived Mac-IBIs versus designated HGM management classes was evaluated given adequate sample size (Chipps et al. 2006; Veselka 2008: Chapter 2).

\subsection{Macroinvertebrate Surveys}

We sampled macroinvertebrates between June 1 and 15 July of 2005 or 2006 (Anderson and Smith 2004; 2000; 1996). Data were collected at 10 randomly placed 5 
$\mathrm{cm}$ diameter benthic core samples $(15 \mathrm{~cm}$ deep) and by use of a $7.5 \mathrm{~cm}$ diameter watercolumn sampler (Swanson 1983). The 2 sampling methods allowed us to examine the organisms from each sampled stratum separately and together (Balcombe et al. 2005a; Euliss et al. 1992). Nektonic samples were sieved in the field using a 500 micron screen (Huener and Kadlec 1992) and preserved for identification in 70\% ethanol. Core samples were kept on ice until transported back to a laboratory and refrigerated (Balcombe et al. 2005a). Organic matter was separated from soil particles within 10 days of collection (Anderson and Smith 2000) using an elutriator (Magdych 1981). The remaining particulate was stored in $70 \%$ ethanol solution and dyed with rose bengal to help sort individual macroinvertebrates from the organic matter (Balcombe et al. 2005a; Mason and Yevich 1967). The number of individuals for each family was tallied, and biomass was obtained by oven-drying samples between $50-60{ }^{\circ} \mathrm{C}$ for at least 48 hours to a constant mass $(0.0001 \mathrm{~g})$ determined by using an analytical scale (Balcombe et al. 2005a). The macroinvertebrates were sorted and identified to family-level (McCafferty 1981; Merrit and Cummins 1984; Pennak 1989); or in some cases taxonomic Order if familial identification proved problematic. Functional feeding groups were assigned to families (Cummins and Merritt 2001). Using the relative abundance and percent biomass of each family by site, metrics were derived from the literature (Balcombe et al. 2005a; Bennet 1999; Conklin 2003; U.S. EPA 2002; Gernes and Helgen 2002; Knapp 2004), and each metric value was determined with and without the Order Oligochaeta and the Dipteran family Chironomidae to examine the effect of using different levels of resolution (Conklin 2003). 


\section{$\underline{2.3 \text { Disturbance Gradient }}$}

Our disturbance gradient was based on local factors directly attributable to anthropogenic sources, derived from portions of the Ohio Rapid Assessment Method version 5.0 (ORAM) (Table 3) (Mack 2001). These factors included surrounding landuse activity, width and condition of the natural wetland buffer zone, and alteration to the hydrology, habitat, or substrate. These metrics and submetrics formed a disturbance score that ranged from 4 to 39 , the numbers representing less human impairment as they increase. The metrics selected for inclusion into the Mac-IBI were based on their responses to the disturbance score.

\subsection{Reference and Stressed Sites Designations}

Designated reference and stressed sites were used to evaluate a metrics' response to disturbance and are critical to the formation of an IBI. However, locating reference sites that are free from any signs of human impact is not feasible (Omernik 1995). Our reference conditions were based on realistic expectations of conditions indicating minimal or least disturbed conditions, of wetlands in West Virginia (Omernik 1995). Disturbance gradient scores above and below the $75^{\text {th }}$ and $25^{\text {th }}$ percentile were used to categorize reference and stressed conditions, respectively (Barbour et al. 1995).

Reference and stressed designations were developed independently for Cowardin classes, HGM subclasses (Cole et al. 1997), and designated HGM management classes across Level 3 aquatic ecoregions (Omernik 1987;Woods et al. 1999) because these designations were based on human impairment characteristics throughout West Virginia rather than the ecological basis of the ecoregions. 


\section{$\underline{2.5 \text { Data Analysis }}$}

Nektonic and benthic macroinvertebrate data were used to derive candidate metric values that were evaluated for their capacity to discriminate between reference and stressed sites. We analyzed the benthic and nektonic community metrics data in 2 ways; by calculating the metric values separately according to sampling strategy, as well as cumulatively to contrast the results. Analyzing the benthic and nektonic metrics separately (Balcombe et al. 2005a; Euliss et al. 1992) allowed for the measurement and comparison of wetlands based on benthic community metrics even in the absence of standing water. Alternatively, when the data were combined, only sites for which both benthic and nektonic samples were collected were used to develop metrics; resulting in a decreased sample size. To develop an applicable, statewide, IBI using macroinvertebrate communities we analyzed the data in a series of elimination steps for each candidate metric. This process enabled us to build indices of biotic integrity, specific to individual HGM or Cowardin classes, which then allowed us to contrast and use the 2 classification systems to augment each other to increase sensitivity to disturbance scores (Veselka 2008: Chapter 2).

Class-specific Mac-IBIs were not developed for wetland classes with fewer than 5 reference and 5 stressed sites (Chipps et al. 2006). Metrics were initially tested for responsiveness to the human disturbance index using box-and-whisker plots (Barbour et al. 1996; Veselka 2008: Chapter 2). Metrics were classified as excellent, good, fair, or poor (Figure 2). Excellent and good metrics were retained, after further screening determined the discrimination efficiency of each metric (Veselka 2008: Chapter 2). Fair and poor metrics, as well as those not capable of discriminating between reference and stressed conditions $\geq 60 \%$, were removed from further analysis. The remaining metrics 
were tested for redundancy using Spearman's R correlation statistic (Hughes et al. 1998); of the correlated pairs of metrics, the one with the greatest discrimination efficiency between reference and stressed sites was retained for inclusion in the Mac-IBI (Veselka 2008: Chapter 2).

The remaining sets of metrics for each of the resulting class-specific Mac-IBI were tested for an ecoregion effect or alternative classification effect using a series of 2way analyses of variance (ANOVA) (Veselka 2008: Chapter 2). The metrics that were significantly influenced by the ecoregion or alternative wetland classification effect were omitted as metrics capable of discriminating between reference and stressed conditions throughout West Virginia (Veselka 2008: Chapter 2). However, in a case in which 2 redundant metrics remained with equal discrimination efficiencies and neither exhibited a significant ecoregion or classification scheme effect, the metric that utilized relative abundance was selected because the time to process and derive relative abundance was significantly less than the time needed to derive biomass. If more than 1 metric was used to derive the class-specific Mac-IBI, the metrics were evaluated a final time with a multivariate analysis of variance (MANOVA), testing for a cumulative effect of the metric values of reference and stressed site to ecoregion or classification scheme influences. This posthoc analysis was meant to ensure the derived Mac-IBI resulted in applicable and robust indices of biological integrity not subject to ecoregion or classification scheme influences.

After metrics were selected for each class-specific Mac-IBI, the metrics were scored on a continuous 0-10 scale (Blocksom 2003; Bryce et al. 2002; Gerritsen et al. 2000; Hill et al. 2003); and Mac-IBIs formed by summing all metrics selected for inclusion (Veselka 2008: Chapter 2). 
The disturbance gradient and the distribution of the Mac-IBI scores for the reference sites were used to set numeric thresholds describing wetland condition (Gerritsen et al. 2000; Hill et al. 2003; McCormick et al. 2001; Veselka 2008: Chapter 2).The relation between Mac-IBI scores and the disturbance scores were examined and plotted using simple linear regression specific to each Mac-IBI classification (Veselka 2008: Chapter 2). This enabled us to interpret and compare the results of our derived Mac-IBI accordingly.

In addition to scoring each wetland with an individual designated HGM management and Cowardinclass Mac-IBI score, we used the additive properties of metrics to form a specific hybrid Mac-IBI that combined the classification schemes (Veselka 2008: Chapter 2).Moreover, we compared the derived class-specific Mac-IBI with wetland indices of biological integrity in West Virginia developed for other species assemblages. Using the same sample of wetland sites, a series of avian wetland indices of biological integrity (AW-IBI), anuran acoustically-based indices of biological integrity (AA-IBI), and vegetation-based indices of biological integrity (Veg-IBI) have characterized the species assemblages' responses to disturbance (Veselka 2008: Chapters $2,3,4)$. The metrics in these indices are based on the same disturbance scale, as well as the same metric scoring system in which values range from 0 to 10 . This allowed the indices to be not only compared, but also integrated by adding metric scores. This determined if the sensitivity to the disturbance gradient increased as metrics from other biological assemblages increased.

Additionally, we evaluated adding the metrics from each taxa group to form the multi-taxa hybrid Cowardin- HGM wetland IBIs to ascertain if sensitivity to the disturbance score increased by attempting to classify wetlands using multiple 
classification schemes (Veselka 2008: Chapter 2). Because each of these IBIs were subjected to the same screening techniques (Veselka 2008: Chapter 2), the resulting multi-taxa, hybrid wetland IBI could be compared to the multi-taxa, class-specific approach.

\subsection{Results}

\section{$\underline{3.1 \text { Ecoregion and site classifications }}$}

Due to the number of reference and stressed sites, we evaluated 97 metrics for inclusion into class-specific Mac-IBIs for riparian depression, headwater floodplain, depression, floodplain, emergent, scrub-shrub, and forested wetlands (Table 4). A complete list of all sites and corresponding attribute data (e.g., ecoregion, location, class, etc.) can be found in Appendix B. A frequency distribution indicated normal distribution of disturbance scores (Figure 3) (Skewness $=-0.04$, Kurtosis $=-0.39$ ).

Analyzing the benthic and nektonic samples separately resulted in 16 of 97 metrics being initially selected based on the ability to discriminate between reference and stressed sites across all ecoregions among 1 or more classifications of wetlands (Table 5). Four of these metrics were redundant and eliminated by selecting the metric with the greater discrimination efficiency of the 2 that were highly correlated (Table 6). Six of the remaining metrics were eliminated because of significant ecoregion or alternate classification scheme interactions after screening by a series of analysis of variance (ANOVA) tests (Table 7). This resulted in 4 of the 5 metrics making up the impoundment Mac-IBI, as well as 2 of the 3 metrics of the scrub-shrub Mac-IBI being eliminated. Only the forested and floodplain Mac-IBI were comprised of more than 1 metric. Using only reference and stressed conditions, the 2 metrics of the forested and floodplain class-specific Mac-IBIs were evaluated for a cumulative ecoregion, alternative 
classification scheme, or interaction effect between the 2 with a MANOVA test. Both the floodplain and forested class-specific Mac-IBIs were not significantly affected (Table 8). This ensured that each class-specific Mac-IBI was robust and independent of ecoregion or classification scheme influences.

When the data were analyzed using the combined dataset from benthic and nektonic sampling, we were not able to develop a forested Mac-IBI because there was not consistent standing water from which to collect nektonic samples; resulting in only 2 reference sites and 4 stressed sites. Only 3 wetland classification schemes were found to consistently discriminate between reference and stressed sites; the headwater floodplain, floodplain, and emergent class-specific Mac-IBIs. All of these class-specific Mac-IBIs were composed of the metric, the percent of collector biomass (Table 5). The percent biomass of collectors, not including Oligochaete or Chironomid biomass was also capable of discriminating between reference and stressed sites in the floodplain Mac-IBI. Because these metrics were highly correlated $(\mathrm{R}=0.98)$ and had the same discrimination efficiency, we conducted a complete analysis using both metrics (Table 6).

\subsection{Metric Performance}

There were 13,925 and 15,532 individual macroinvertebrates in the benthic and nektonic samples collected, respectively. The benthic individuals had a dry weight mass of 54.12 grams, whereas the nektonic individuals weighted 76.35 grams. These represented a total of 42 Orders and 75 Families. Only 6 of the 28 Orders, and 19 of 57 Families in benthic samples were found exclusively in benthic situations. In the nektonic samples, 9 of the 29 Orders and 39 of the 75 families were found only in the water column. 
Ninety-seven candidate metrics were screened based on their ability to discriminate between reference and stressed sites independently for each classification (HGM subclass, designated HGM management class or Cowardinclass) within each ecoregion, based upon the disparity of the interquartile ranges of metric values for reference and stressed conditions (Appendix AL-BA). Macroinvertebrate abundance, biomass and richness for all sites can be found in Appendices BB-BC. Of these 97 metrics, only 19 remained after metrics were discarded due to an inability to discriminate between reference and stressed conditions (Table 5). These 19 metrics were then reduced to 9 class-specific Mac-IBI metrics because 10 were either redundant with other metrics, exhibited a significant interaction with ecoregion and classification scheme, or failed to have enough scoring variation to calculate metric values (Table 5).

Analyzing the benthic and nektonic communities independently, we were able to derive Mac-IBIs for all but the emergent Cowardin class. One or 2 metrics were included in each of the class-specific indices. Five of the 7 derived class-specific indices were significantly related to the disturbance score, although each of the indices discriminated between reference and stressed sites greater than $60 \%$ of the time (Table 9).

The riparian depression and depression Mac-IBIs were composed of the same metric derived from nektonic sampling: the percent biomass of the Coleopteran family Dytiscidae. Although the overall relation with the disturbance score was weak, the metric accounted for more variation in the riparian depressions HGM subclass (13\%) than the depression designated HGM management class (11\%).

The headwater floodplain Mac-IBI consisted of only 1 metric, the percent biomass of collectors, not including Oligochaete or Chironomid biomass in the calculation, drawn from benthic core samples. This metric accounted for $20 \%$ of the 
variation of disturbance scores in our headwater floodplain dataset. This metric was excluded from the larger classification of floodplain designated HGM management class due to redundancy with the benthic relative abundance of collectors, not including Oligochaete or Chironomid abundance. This metric, and the nektonic relative abundance of stressed taxa, accounted for $47 \%$ of the variation in disturbance scores of floodplain wetlands. The metric, percent biomass of stressed taxa had the same discrimination efficiency (71\%) in discriminating between reference and stressed sites as relative abundance of stressed taxa, but was excluded in favor of relative abundance because of the additional time requirements and equipment needed to ascertain biomass.

The impoundment designated HGM management class Mac-IBI was formed using 1 metric, nektonic percent biomass of Odonata excluding Oligochaete and Chironomid biomass, and was not significantly related to the disturbance gradient despite being capable of discriminating between reference and stressed sites greater than $86 \%$ of the time. Five other metrics were initially included because of their capacity to discriminate between reference and stressed sites. These included the nektonic percent biomass of stressed taxa, the nektonic relative abundance of the Odonate family Libellulidae not counting the Oligochaete or Chironomid abundance, the nektonic percent biomass of Odonata not counting Oligochaete or Chironomid biomass, the benthic percent biomass of collectors, and benthic familial richness. These metrics were later excluded as they all exhibited a significant Cowardin class-ecoregion interaction (Table 7).

The Cowardin based Mac-IBI did not perform as well as those based on the HGM approach. With independent analysis of the benthic and nektonic macroinvertebrate communities, a palustrine emergent Mac-IBI was not developed because of a failure to 
identify a metric capable of discriminating between reference and stressed sites. Only 1 metric, the percent biomass of stressed taxa from nektonic sampling, was included in the scrub-shrub Mac-IBI, after the benthic relative abundance of collectors was determined to be significantly affected by the expression of the HGM class (Table 7). The resulting index failed to exhibit a significant relation with the disturbance gradient (Table 9).

Within the Cowardin classes, only the forested Mac-IBI scores were significantly related to disturbance. Two benthic metrics, the relative abundance of predators excluding Oligochaete and Chironomid abundance, and the relative abundance of collectors excluding Oligochaete and Chironomid abundance, made up the index, which was capable of discriminating between reference and stressed scores $71 \%$ of the time. However, despite the significant relation, only $14 \%$ of the variation in scores was attributed to disturbance scores.

Results did not improve upon analyzing benthic and nektonic communities together. Using the combined dataset, Mac-IBIs were derived for 3 wetland classes, emergent, headwater floodplain, and floodplain; and consisted of 1 metric, the percent biomass of collectors. An alternative to this metric in floodplain wetlands was the percent biomass of collectors, excluding Oligochaete or Chironomid biomass; however, discrimination efficiency (71\%) remained the same and did not significantly improve the relation with the disturbance score (Table 10). In emergent and headwater floodplain wetlands, the disturbance scores accounted for $9 \%$ and $13 \%$ of the variation in Mac-IBI scores, respectively; and although statistically significant, are essentially biologically meaningless due to the minimal amount of variation accounted for by the disturbance scores. In the floodplain designated HGM management class wetland Mac-IBI, the sensitivity of the Mac-IBI scores ranged from $17-22 \%$ of variation attributed to the 
disturbance gradient. However, this is considerably less than the $47 \%$ of variation that can be attributed to disturbance scores in floodplain wetlands when nektonic and benthic metrics are derived separately. As a result, all future analyses used metrics from the stratified benthic and nektonic data because of the more consistent nature of the response to our disturbance gradient.

Scoring thresholds were derived for each of class-specific IBIs based on percentile scores of the reference sites (Table 11). The mean Mac-IBI scores of reference and stressed sites were significantly different, with the exception of the depression and impoundment designated HGM management class.

\section{$\underline{3.3 \text { Dual classification approaches for the Mac-IBI }}$}

In an effort to increase sensitivity to the disturbance gradient, we combined the metrics from both the Cowardin and HGM classification schemes to form hybrid MacIBIs. In most instances, with the exception of the scrub-shrub-impoundment Mac-IBI, this increased the number of metrics, and therefore the IBI score, in relation to the disturbance score. Despite this, none of the integrated hybrid Mac-IBIs resulted in a significant relation with the disturbance scores (Table 12).

\section{$\underline{3.4 \text { Contrasting and augmenting with other West Virginia wetland IBIs }}$}

The series of class-specific Mac-IBI were meant to be used as a standalone index for measuring biological integrity; yet we have developed alternative indices using avian, anuran, and vegetation assemblages in the same sample of wetlands. This allowed for comparisons between the sensitivities of each of the taxa-specific IBIs. The IBIs exhibiting a significant relation with the disturbance score were compared based on the amount of variation attributed to disturbance (Table 14). Using the Mac-IBIs derived from separate benthic and nektonic analysis, the relation between the Mac-IBI scores and 
the disturbance gradient were weaker than all of the corresponding Veg-IBI scores. In comparison to the suite of AW-IBIs, the Mac-IBIs were outperformed in every class with the exception of floodplain designated HGM management class, in which only slightly more variation ( $47 \%$ versus $46 \%$ ) in floodplain IBI scores was a result of the disturbance scores. Additionally, there were more class-specific IBIs, 7 Veg-IBIs and 6 AW-IBIs, that exhibited a significant relation with the disturbance gradient in comparison to macroinvertebrate communities. Of the 3 AA-IBIs significantly related to disturbance scores, the Mac-IBI was more responsive in riparian depression and floodplain wetlands. However, within headwater floodplain wetlands, more variation in AA-IBI scores $(27 \%)$ was a result of disturbance scores than in the Mac-IBI (20\%).

Upon completion of the Mac-IBIs derived from separate benthic and nektonic samples, we combined all the metric scores from the resulting class-specific wetland IBIs to form a multi-taxa wetland IBI. The resulting class-specific multi-taxa IBI included between 5 and 12 metrics depending on classification scheme (Table 13). With the exception of impoundment wetlands, in which none of the derived IBIs exhibited a significant relation with disturbance, the variation in the multi-taxa IBI scores resulting from the disturbance scores was greater than each of the best individual taxa-specific wetland IBIs (Table 15).

The final analysis using the metrics from each taxa group and each classification scheme involved creating a series of hybrid IBIs. Because we had 3Cowardinclassifications, and a total of 5 HGM classifications (3 designated HGM management classes and 2 HGM subclasses), there could have been a total of 15 possible hybrid IBI categories. Of these 15, the forested-impoundment class was eliminated due to insufficient sample size. A total of 4 hybrid multi-taxa IBIs were significantly related 
to disturbance (Table 15). These included emergent-headwater floodplain, emergentdepression, emergent-floodplain, and forested-headwater floodplain. The amount of variation in scores attributed to the disturbance gradient ranged from 33-99\%. However, we must caution that sample sizes were smaller as our dataset was partitioned.

\subsection{Discussion}

\subsection{Study Design}

Candidate metrics used to derive Mac-IBIs were extensively evaluated by analyzing benthic and nektonic community data separately (Balcombe et al. 2005a), as well as cumulatively (Anderson and Smith 1996). This approach allowed us to determine which of these 2 methods was most sensitive to disturbance. Additionally, by stratifying the analysis between benthic and nektonic communities, we were able to determine that macroinvertebrate communities could be sampled for bioassessments in the absence of standing water (i.e., forested and headwater floodplain wetlands); as well as conclude benthic samples were not necessary to differentiate between reference and stressed conditions in others (i.e., scrub-shrub and depression wetlands). The lack of sensitivity and applicable metrics responsive to the disturbance gradient in the combined benthic and nektonic community metrics' analysis was unexpected. However, the resulting conclusion suggests that when comparing macroinvertebrate communities to our current disturbance gradient in West Virginia wetlands, the analysis of macroinvertebrates should remain stratified to exhibit the greatest response to the disturbance scores.

Each candidate metric, either from the cumulative or stratified benthic and nektonic samples, was evaluated based on its discrimination efficiency. Redundant metrics with lower discrimination efficiencies were eliminated. The posthoc analysis of metric values included within the derived class-specific Mac-IBI was intended to validate 
our apriori wetland classifications. Inconsistent metrics were screened using ANOVA tests of the metric values of reference and stressed sites for all classes. This process identified specific metrics within each classification scheme that were then omitted because they did not respond consistently to ecoregion or the alternative classification scheme differences. After these metrics were removed, those remaining in each class were evaluated cumulatively by a MANOVA, confirming we had achieved our objective of building a series of statewide wetland class-specific macroinvertebrate-based indices of biological integrity. By taking steps intended to verify that the intended application of the resulting Mac-IBIs are not subject to ecoregion or classification influences; we believe our analysis resulted in a series of intuitive, but not necessarily strong, defensible Mac-IBIs that can be used to ascertain biological integrity. We suggest that our efficient methodology has scientific merit; however, with the exception of the floodplain Mac-IBI, the inconsistent response to the disturbance gradient suggests that a familial-level macroinvertebrate IBI does not respond to our current disturbance gradient.

\subsection{Metric Performance}

We tested 97 metrics in each classification scheme to identify metrics capable of consistently discriminating between reference and stressed sites. However, in relation to the total number of metrics evaluated, relatively few (8) proved to be suitable for inclusion into a macroinvertebrate-based IBI. We suspect a strong ecoregion effect demonstrated in macroinvertebrate communities, as 6 other metrics were eliminated because of differing ecoregion responses. This low number of suitable metrics responsive across the entire state of West Virginia demonstrates that macroinvertebrates do respond predictably to human impairment, as is evident by the prevalent literature from which our metrics were drawn (Balcombe et al. 2005a; Bennet 1999; Conklin 2003; 
U.S. EPA 2003; Gernes and Helgen 1999; Knapp 2004). However, more research directed at the ecoregion level may strengthen these relations.

Understanding our results and why some metrics were effective and others were not will allow us to adapt and improve the efficacy of future wetland monitoring using macroinvertebrate communities. Previous research in West Virginia has indicated that wetlands having similar characteristics exhibit large variation in macroinvertebrate communities (Balcombe et al. 2005a). The variation in our metric scores is evident in the relatively large standard errors (Appendix BD). This may be suggestive that family-level identification may not be sufficient for use in bioassessments and that genus-level identification may result in improvement (Bailey et al. 2001; King and Richardson 2002). Literature from the Ohio EPA, from which our disturbance gradient was adopted, suggests that macroinvertebrates respond in a more predictable manner to water and soil characteristics, rather than the local disturbance scale we used in our evaluation of metrics (Knapp 2006). Literature supports the viewpoint that macroinvertebrate community structure is heavily dependent on both hydroperiod and vegetation community (Brooks 2000; Burton et al. 1999; Corbet 1999;Wissinger 1999; Zimmer et al. 2000). The omission of water chemistry data and hydroperiod characteristics from consideration in our disturbance gradients and classifications may have contributed to weaker correlations than the previously derived wetland IBIs for West Virginia (Veselka 2008: Chapters 2,4), suggesting macroinvertebrate communities may be more responsive to these variables than avian or vegetation communities. As a result, we were unable to derive any significant hybrid macroinvertebrate IBIs despite previous successes at integrating metrics from each of the class-specific Cowardin and the HGM based IBIs to form hybrid IBIs that were more sensitive to disturbances than individual classes 
(Veselka 2008: Chapters 2-4). A disturbance gradient, more sensitive to the types of impairment affecting macroinvertebrate groups, derived from water and soil characteristics such as pollutant concentrations, levels of sedimentation and turbidity (Knapp 2006) may have allowed identification of a larger suite of discriminatory metrics.

Our macroinvertebrate community data were gathered using water column and core samplers (Balcombe et al. 2005a). Within the context of this study, a crucial element for using this method of sampling was time constraints. Due to the number of wetlands sampled, as well as the sampling regime in which multiple taxa were sampled throughout the field season (Veselka 2008: Chapter 2-4), it was necessary to select a macroinvertebrate sampling strategy in which collection could be completed in 1 day and samples preserved for later identification. Based on the diversity of families and orders in our samples, we believe the sampling methods were adequate.

We cannot conclusively say if our disturbance gradient was inappropriate, or if the differences in macroinvertebrate communities between ecoregions, or the taxonomic level of identification resulted in the weak relations between IBIs and the disturbance scores. We expect that all factors affected our results to some degree. Ecoregions in West Virginia follow an altitudinal gradient, suggesting that, although we sampled macroinvertebrates during the same time period, the wetlands may not have been at the same stage of phenological development due to the differences in the seasonal weather between ecoregions. Anuran sampling is conducted during different seasonal "windows" depending on physiographic region in West Virginia (Balcombe et al. 2005b); hence the development of macroinvertebrate sampling dates may provide us with more consistent data reflective of macroinvertebrate communities. 


\section{$\underline{4.3 C o m p a r i s o n s ~ w i t h ~ O t h e r ~ M a c r o i n v e r t e b r a t e ~ I n d i c e s ~ o f ~ B i o l o g i c a l ~ I n t e g r i t y ~}$}

Our objective was to derive baseline data that could be used to develop a series of class-specific Mac-IBIs that could be used in a statewide monitoring program. Our metrics, and the resulting class-specific Mac-IBIs could then be compared to other macroinvertebrate indices of biological integrity. It should be noted that we are comparing sensitivity and responsiveness of our derived Mac-IBI to our disturbance gradient to other states' IBIs and disturbance gradients. These studies did not use the same disturbance gradient, or the same methods, making the comparisons less meaningful and useful in confirming that our results are similar to those of other programs.

The invertebrate IBI for Minnesota large depressional wetlands was composed of 8 metrics, encompassed multiple ecoregions, and was derived from both dip-netting and activity traps (Gernes and Helgen 2002). The Minnesota invertebrate IBI was correlated to their human disturbance score $(\mathrm{R}=0.715)$. This variation is considerably more than is accounted for in the West Virginia 1 metric depression class Mac-IBI $\left(\mathrm{R}^{2}=0.11\right)$, despite a significant relation with the disturbance gradient and ability to discriminate between reference and stressed sites $60 \%$ of the time. Using all 5 of the multi-taxa metrics suitable for depression wetlands in West Virginia (Veselka 2008: Chapters 2-4), the amount of variation attributed to the disturbance score is only $35 \%$. The Minnesota study's disturbance gradient included a factor for water chemistry and sediment concentrations, which may have resulted in a greater sensitivity to disturbance scores. Additionally, metrics were scored in Minnesota using a discrete scoring system (Karr et al. 1986), rather than the continuous method we employed (Blocksom 2003, Hill et al. 
2003, Gerritsen et al. 2000). These factors and West Virginia's lack of equivalent large depressional wetlands may have contributed to the disparity in results.

The initial invertebrate IBI for Ohio wetlands did not separate IBIs for each Cowardin or HGM (Brinson 1993) classification (Knapp 2004). Despite this intended omission, a set of preliminary 6 and 8 metric invertebrate IBIs, using the same metrics from the ORAM v. 5.0 (Mack 2001) to represent human disturbance, was significantly related to disturbance. In this initial report researchers evaluated different discrete scoring strategies to assign metric values. Without removing outliers, the results ranged from 18 to $37 \%$ of the amount of variation in IBI scores being attributed to the disturbance gradient; with outliers removed, the results improved to $33 \%$ to $42 \%$. These results seem to be comparable with those of our derived class-specific Mac-IBIs, despite only the West Virginia wetland derived 2 metric floodplain designated HGM management class having more variation explained by our disturbance scores. In addition to differences in scoring techniques, the Ohio research used 24 hour activity traps to sample macroinvertebrate communities (Knapp 2004). Although Ohio's results were preliminary, they were not consistent with other wetland IBIs developed in the state because they included all classes of wetlands rather than formulating an IBI according to the wetland Cowardin class (Mack 2004, Micacchion 2002). This approach differed from what we accomplished in West Virginia, which was a series of class-specific wetland IBIs, designed for individual taxa groups that were intended to be used as standalone indices, capable of integration with and augmenting of others according to the state's need. 


\section{$\underline{4.4 \text { Integration with other West Virginia wetland indices of biological integrity }}$}

Our study developed different taxa-specific IBIs in the same manner (Veselka 2008: Chapters 2-4). These studies included utilizing anuran, avian, and vegetation assemblage characteristics to form avian wetland indices of biological integrity (AWIBI), acoustically-based anuran indices of biological integrity (AA-IBI), and vegetation indices of biological integrity (Veg-IBI). Although the Mac-IBI is intended to be a standalone index that is capable of evaluating wetland biological condition with a single site visit, adding the metric scores from each of the class-specific taxa produces better results than any 1 taxa-group alone. This result should be noted by wetland resource managers, as decisions involving the allocation of resources will dictate the number of taxa groups that can be efficiently monitored while producing results that are biologically meaningful and related to the disturbance gradient.

When we compare all of the cumulative multi-taxa class-specific results to the cumulative multi-taxa hybrid wetland IBIs, we must caution that small sample size must be considered. Regardless, with the exception of forested-headwater floodplain wetlands $(n=4)$, every instance of using a class-specific multi-taxa approach proved more responsive to the disturbance gradient than the hybrid classification multi-taxa approach. For example, although $70 \%$ of the variation in scores of the emergent-headwater floodplain hybrid IBI was attributed to the disturbance gradient, $81 \%$ of the multi-taxa metrics that compose the headwater-floodplain wetland IBI can be traced to disturbance scores. The integration of all 4 taxa groups leads to more consistent class-specific results; however, the logistical coordination and effort required to sample all taxa groups in any 1 wetland throughout a given year is considerable. 


\subsection{Implications for Future Monitoring Programs}

Future work will examine all the possible combinations of taxa groups in all class-specific and hybrid IBI combinations. Results will allow resource managers to make informed choices regarding the allocation of resources. Depending on results, the use of hybridized IBIs may, in some circumstances, be better suited for actual field work when resources are limited. The dilemma for wetland resource managers will be how to choose the best monitoring approach. In a scenario with infinite resources, it would undoubtedly be better to monitor the avian, anuran, vegetation, and macroinvertebrate communities of every wetland. However, the chances of this occurring are highly unlikely. Of the series of IBIs developed for West Virginia, some data used to drive the indices can be collected by volunteers; for example, bird and anuran surveys. This can be done relatively inexpensively compared to professional surveys. Invertebrates can even be collected by volunteers, but then must be identified by individuals with taxonomic training to classify the specimens to family or genus. This will increase cost, but at least time is not charged for collecting the data. Finally, detailed vegetation surveys require professionals to be at each wetland site, incurring transportation and time associated with data collection costs. This will force wetland resource managers to decide which taxonomic groups should be used to cost-effectively monitor wetlands. Eventually, after evaluating the benefit derived from sampling each taxon, a tiered approach that uses volunteer-gathered data augmented by professionals in certain circumstances may be best to efficiently and definitively monitor the status and trends of the state's wetlands. In this approach, the use of hybrid IBIs, in instances where not all taxonomic groups are evaluated, may still be the more responsive to a disturbance gradient (Veselka 2008: Chapter 2-4). This strategy can be used to conserve resources expended to measure 
wetland health by measuring only the species characteristics of wetland health most responsive to disturbance rather than expend the resources to measure all taxonomic groups in a wetland.

Our research in developing a series of statewide wetland IBIs gives water resource policy makers more tools than ever before in West Virginia regarding the best way to implement and initiate a wetland IBI program. Using these tools, and augmenting IBIs with a spatial analysis component that can be used to prioritize sites slated for management action (Wardrop et al. 2007, Weller et al. 2007), West Virginia will be in a position to implement a proactive, scientifically-based program to conserve, restore, and enhance the biological integrity of our wetlands, under the Clean Water Act. However, the decision to use the baseline data to start wetland monitoring and the initiative to implement a program capable of ensuring wetland health over the long-term ultimately rests with the natural resource policy makers in the state government.

\subsection{Acknowledgements}

We thank Valerie Wells, Dane Cunningham, Clayson Schoonover, and Brian Krott for sorting invertebrates from organic matter, Adrianne Brand and Mark Hepner for assistance in data collection, and Sarah McClurg, Seth Lemley, Donna Hartman, Jered Studinski, and Drs. Linda Butler and John Strazanac for assistance with macroinvertebrate identification. Greg Pond, George Merovich, and the late Dr. George Seidel provided statistical support and advice. Technical writing and logistical support was provided by Sarah McClurg. Geographic information system and database management assistance was provided by Ben Gilmer. Funding was provided by the West Virginia Division of Natural Resources with assistance from U.S. EPA State Wetland 
Program Development Grant CD 973080-01-0. This is scientific article number xxxx of the West Virginia University Agriculture and Forestry Experiment Station. 


\subsection{Literature Cited}

Anderson J.T., Smith L.M. (1996). A comparison of methods for sampling epiphytic and nektonic aquatic invertebrates in playa wetlands. Journal of Freshwater Ecology, 11, 219224.

Anderson J.T., Smith L.M. (2000). Invertebrate response to moist-soil management of playa wetlands. Ecological Applications, 10, 550-558.

Anderson J.T., Smith L.M. (2004). Persistence and colonization strategies of playa wetland invertebrates. Hydrobiologia, 513, 77-86.

Bailey R.C., Norris R.H., Reynoldson T.B. (2001). Taxonomic resolution of benthic macroinvertebrate communities in bioassessments. Journal of North American Benthological Society, 20, 280-286.

Balcombe C.K., Anderson J.T., Fortney R.H., Kordek W.S. (2005a). Aquatic macroinvertebrate assemblages in mitigated and natural wetlands. Hydrobiologia, 541, $175-188$.

Balcombe C.K., Anderson J.T., Fortney R.H., Kordek W.S. (2005b). Wildlife use of mitigation and reference wetlands in West Virginia. Ecological Engineering, 25, 85-99.

Barbour MT, Stribling JB, Karr JR. (1995). Biological assessment and criteria: Tools for water resource planning and decision making. Davis W.S., Simon T.P. (Eds.), Multimetric approach for establishing biocriteria and measuring biological condition. (pp. 63-77). Ann Arbor, MI: Lewis Publishers.

Barbour M.T., Gerritsen J., Griffith G.E., Frydenborg R., McCarron E., White J.S., Bastian M.L. (1996). A framework for biological criteria for Florida streams using benthic macroinvertebrates. Journal of North American Benthological Society, 13, 185211.

Barbour MT, Gerritsen J, Snyder BD, Stribling JB. (1999). Rapid bioassessment protocols for use in streams and wadeable rivers: Periphyton, benthic macroinvertebrates and fish. U.S. Environmental Protection Agency. Washington, D.C.Report EPA 841-B99-002.

Batzer D.P., Wissinger S.A. (1996). Ecology of insect communities innontidal wetlands. Annual Review of Entomology, 41, 75-100.

Batzer D.P., Rader R.B., Wissinger S.A. (1999). Invertebrates in freshwater wetlands of North America: ecology and management. John Wiley, New York, NY.

Batzer D.P., Shurtleff A.S., Rader R.B. (2001). Sampling invertebrates in wetlands. Bioassessment and management of North American freshwater wetlands. Rader R.B., Batzer D.P.\& Wissinger S.A. (Eds.), John Wiley \& Sons, New York, NY 
Batzer D. (2004). Movements of upland invertebrates into drying seasonal woodland ponds in Northern Minnesota, U.S.A. Wetlands, 24, 904-907.

Bendell-Young L.I., Bennet K.E., Crowe A., Kennedy C.J., Kermode A.R., Moore M.M., Plant A.L., Wood A. (2000). Ecological characteristics of wetlands receiving an industrial effluent. Ecological Applications, 10, 310-322.

Bennet R.J. (1999). Examination of macroinvertebrate communities and development of an invertebrate community index (ICI) for central Pennsylvania wetlands. Intercollege Graduate degree Program in Ecology. Pennsylvania State University, State College, PA.

Blocksom K.A. (2003). A performance comparison of metric scoring for a multimetric index for Mid-Atlantic highland streams. Environmental Management, 31, 670-682.

Brinkman M.A., Duffy W.G. (1996). Evaluation of four wetland aquatic invertebrate samplers and four sample sorting methods. Journal of Freshwater Ecology, 11, 193-200.

Brinson MM. (1993). A hydrogeomorphic classification for wetlands. U.S. Army Engineers Waterways Experiment Station.Vicksburg, MS. Technical Report WRP-DE-4.

Brooks R.P., O'Connell T.J., Wardrop D.H., Jackson L.E. (1998). Towards a regional index of biological integrity: the example of forested riparian ecosystems. Environmental Monitoring and Assessment, 51, 131-143.

Brooks R.T. (2000). Annual and seasonal variation and the effects of hydroperiod on benthic macroinvertebrates of seasonal forest ("vernal") ponds in central Massachusetts, U.S.A. Wetlands, 20, 707-715.

Bryce S.A., Hughes R.M., Kaufman P.R. (2002). Development of a bird integrity index: using bird assemblages as indicators of riparian condition. Environmental Management, 30, 294-310.

Burton T.M., Uzarski D.G., Gathman J.P., Genet J.A., Keas B.A., Stricker C.A. (1999). Development of a preliminary invertebrate index of biotic integrity for Lake Huron coastal wetlands. Wetlands, 19, 869-882.

Cheal F., Davis J.A., Growns J.E., Bradley J.S., Whittles F.H. (1993). The influence of sampling method on the classification of wetland macroinvertebrate communities. Hydrobiologia, 257, 47-56.

Chipps S.R., Hubbard D.E., Werlin K.B., Haugerud N.J., Powell K.A., Thimpson J., Johnson T. (2006). Association between wetland disturbance and biological attributes in floodplain wetlands. Wetlands, 26, 497-508.

Cole C.A., Brooks R.P., Wardrop D.H. (1997). Wetland hydrology as a function of hydrogeomorphic (HGM) subclass. Wetlands, 17, 456-467. 
Conklin A.M. (2003). Macroinvertebrate communities as biological indicators of condition in Pennsylvania depressional wetlands. Intercollege Graduate Degree Program in Ecology. Pennsylvania State University, State College, PA.

Corbet P.S. (1999). Dragonflies: Behavior and Ecology of Odonata. Cornell University Press, Ithaca, NY.

Cowardin L.M., Carter V., Golet F.C., LaRoe E.T. (1979). Classification of wetlands and deepwater habitats of the United States. U.S. Fish and Wildlife Service. Report FWS/ OBS-79/31

Cummins K.W., Merritt R.W. (2001). Application of invertebrate functional groups to wetland ecosystem function and biomonitoring. Bioassessment and management of North American freshwater wetlands. Rader R.B., Batzer D.P., Wissinger S.A. (Eds.), pp. 85-111. John Wiley and Sons, Inc., New York.

Euliss N.H.J., Swanson G.A., McKay J. (1992). Multiple tube sampler for benthic and pelagic invertebrates in shallow wetlands. Journal of Wildlife Management, 56, 186-191.

Euliss N.H.J., Mushnet D.M. (1999). Influence of agriculture on aquatic invertebrate communities of temporary wetlands in the Prairie Pothole Region of North Dakota. Wetlands, 19, 578-583.

Fairchild W., L., O'Niell M.C.A., Rosenberg D.M. (1987). Quantitative evaluation of the behavioral extraction of aquatic invertebrates from samples of sphagnum moss. Journal of North American Benthological Society, 6, 281-287.

Gernes M.C., Helgen J.C. (2002). Indexes of Biological Integrity (IBI) for Large Depressional Wetlands in Minnesota. Minnesota Pollution Control Agency, St. Paul, MN.

Gerritsen J., Burton J., Barbour M.T. (2000). A stream condition index for West Virginia wadeable streams. Tetra Tech, Inc., Owing Mills, MD.

Hicks A.L., Nedeau E.J. (2000). New England Freshwater Wetlands Invertebrate Biomonitoring Protocol: A manual for volunteers. 57 pages. Natural Resources and Environmental Conservation Program, Amherst, MA.

Hill B.H., Herlihy A.T., Kaufman P.R., DeCelles S.J., Vander Borgh M.A. (2003). Assessment of streams of the eastern United States using a periphyton index of biotic integrity. Ecological Indicators, 2, 325-328.

Huener J.D., Kadlec J.A. (1992). Macroinvertebrate response to marsh management strategies in Utah. Wetlands, 12, 72-78.

Hughes R.M., Kaufmann P.R., Herlihy A.T., Kincaid T.M., Reynolds L., Larsen D.P. (1998). A process for developing and evaluating indices of fish assemblage integrity. Canadian Journal of Fisheries and Aquatic Sciences, 55, 1618-1631. 
Johnson R.K., Goedkoop W. (2002). Littoral macroinvertebrate communities: spatial scale and ecological relationships. Freshwater Biology, 47, 1840-1854.

Karr J.R., Fausch K.D., Angermeier P.L., Yant P.R., Schlosser I.J. (1986). Assessing biological integrity in running waters: a method and its rationale. Illinois Natural History Survey, Urbana, IL.

Karr J.R. (1991). Biological integrity: a long neglected aspect of water resource management. Ecological Applications, 1, 66-84.

Karr J.R. (1999). Defining and measuring river health. Freshwater Biology, 41, 221-234

King R.S., Richardson C.J. (2002). Evaluating subsampling approaches and macroinvertebrate taxonomic resolution for wetland bioassessment. Journal of North American Benthological Society, 21, 150-171.

King R.S., Richardson C.J. (2007). Subsidy-stress response of macroinvertebrate community biomass to a phosphorus gradient in an oligotrophic wetland ecosystem. Journal of North American Benthological Society, 26, 491-508.

Knapp M. (2004). Initial development of wetland invertebrate community index for Ohio. Ohio Environmental Protection Agency, Division of Surface Water, Ecological Assessment, Groveport, OH.

Knapp M. (2006). Investigations of invertebrate communities in wetlands in the Huron/ Erie Lake Plains Ecoregion and Mitigation Banks. An addendum to: Integrated Wetland Assessment Program. Part 8. Initial development of wetlands invertebrate community index for Ohio. Ohio Environmental Protection Agency, Division of Surface Water, Ecological Assessment Section, Groveport, OH.

Knapp M. (2007). Density-based invertebrate community index of Ohio wetlands. Ohio Environmental Protection Agency, Division of Surface Water, Groveport, $\mathrm{OH}$.

Mack J.J. (2001). Ohio Rapid Assessment Method for Wetlands v. 5.0, User's manual and Scoring Forms. Ohio Environmental Protection Agency, Division of Surface Water, Wetland Ecology Unit, Columbus, $\mathrm{OH}$.

Mack J.J. (2004). Integrated wetland assessment program. Part 9: Field manual for the Vegetation Index of Biotic integrity for Wetlands v. 1.3. Ohio Environmental Protection Agency, Wetland Ecology Group, Division of Surface Water, Columbus, $\mathrm{OH}$.

Magdych W.P. (1981). An efficient, inexpensive elutriator design for separating benthos from sediment samples. Hydrobiologia, 85, 157-159.

Mason W.T., Yevich P.P. (1967). The use of phloxine B and rose bengal stains to facilitate sorting benthic samples. Transactions of the American Microscopical Society, $89,221-223$. 
McCafferty P.W. (1981). Aquatic entomology: the Fisherman's and Ecologists's Illustrated Guide to Insects and their Relatives. Jones and Bartlett Publishers, Sudbury, MA.

McCormick F.H., Hughes R.M., Kaufman P.R., Peck D.V., Stoddard J.L. \& Herlihy A.T. (2001). Development of an index of biotic integrity for the Mid-Atlantic Highland region. Transactions of the American Fisheries Society, 130, 857-877.

Merritt R.W., Cummins K.W.(1984). An Introduction to theAquatic Insects of North America. Kendall/ Hunt Publishing Company, Dubuque, IW.

Micacchion M. (2002). Amphibian Index of Biotic integrity (AmphIBI) for Wetlands. Wetland Ecology Group, Division of Surface Water, Ohio Environmental Protection Agency, Columbus, $\mathrm{OH}$

Miller S.J., Wardrop D.H., Mahaney W.M., Brooks R.P. (2006). A plant-based index of biological integrity (IBI) for headwater wetlands in central Pennsylvania. Ecological Indicators, 6, 290-312.

Miltner R.J., White D., Yoder C. (2004). The biotic integrity of streams in urban and suburbanizing landscapes. Landuse and Urban Planning, 69, 87-100.

O'Connell T.J., Jackson L.E., Brooks R.P. (1998). A bird community index of biotic integrity for the Mid-Atlantic highlands. Environmental Monitoring and Assessment, 51, 145-156.

O'Connell T.J., Jackson L.E., Brooks R.P. (2000). Bird guilds as indicators of ecological condition in the central Appalachians. Ecological Applications, 10, 1706-1721.

Omernik J.M. (1987). Ecoregions of the conterminous United States. Annals of the Association of American Geographers, 77, 118-125.

Omernik J.M. (1995). Ecoregions: a spatial framework for environmental management. Davis WS \& Simon TP (Eds.), Biological assessment and criteria: tools for water resource planning and decision making. Lewis Publishers, Boca Raton.

Pennak R.W. (1989). Freshwater Invertebrates of the United States: Protozoa to Mollusca. Wiley, New York.

Reiss K.C. (2006). Florida wetland condition index for depressional forested wetlands. Ecological Indicators, 6, 337-352.

Schneider D.W., Frost T.M. (1996). Habitat duration and community structure in temporary ponds. Journal of North American Benthological Society, 15, 64-86.

Spieles D.J., Mitsch W.J. (2000). Macroinvertebrate community structure in high and low nutrient constructed wetlands. Wetlands, 20, 716-729. 
Stapanian M., Waite T.A., Krzys G., Mack J.J., Micacchion M. (2004). Rapid assessment indicator of wetland integrity as an unintended predictor of avian diversity.

Hydrobiologia, 520, 119-126.

Stevenson R.J., Hauer F.R. (2002). Integrating hydrogeomorphic and index of biotic integrity approaches for environmental assessment of wetlands. Journal of North American Benthological Society, 21, 502-513.

Streever W.J., Portier K.M., Crisman T.L. (1996). A comparison of dipterans from ten created and ten natural wetlands. Wetlands, 16, 416-428.

Swanson G.A. (1983). Benthic sampling for waterfowl foods in emergent vegetation. Journal of Wildlife Management, 47.

Tangen B.A., Butler M.G., Ell M.J. (2003). Weak correspondence between macroinvertebrate assemblages and land use in Prairie Pothole Region wetlands, USA. Wetlands, 23, 104-115.

Teels B.M., Meant L.E.,Reba C.A. (2004). Using an IBI to assess effectiveness of mitigation measures to replace loss of a wetland-stream ecosystem. Wetlands, 24, 375384.

U.S. EPA (2002). Methods for evaluating wetland condition: Developing an invertebrate index of biological integrity for wetlands. Office of Water, U.S. Environmental Protection Agency, Washington, D.C.

Veselka W. (2008). Developing volunteer-driven indices of biological integrity. M.S. Thesis. West Virginia University, Morgantown, WV.

Wardrop D.H., Kentula M.E., Stevens D.L.J., Jensen S.F., Brooks R.P. (2007). Assessment of wetland condition: an example from the Upper Juniata watershed in Pennsylvania, USA. Wetlands, 27, 416-431.

Weller D.E., Snyder M.N., Whigham D.F., Jacobs A.D., Jordan T.E. (2007). Landscape indicators of wetland condition in the Nanticoke River Watershed, Maryland and Delaware, USA. Wetlands, 27, 498-514.

Wissinger S.A. (1999). Ecology of wetland invertebrates. Invertebrates in Freshwater Wetlands of North America, Ecology and Management. Batzer D.P., Rader R.B. \&Wissinger S.A. (Eds.), pp. 1043-1086. John Wiley and Sons, Inc., New York, NY

Woods A.J., Omernik J.M., Brown D.D. (1999). Level III and IV ecoregions of Delaware, Maryland, Pennsylvania, Virginia, and West Virginia. U.S. Environmental Protection Agency, Corvallis, OR.

Zimmer K.D., Hanson M.A., Butler M.J. (2000). Factors influencing invertebrate communities in prairie wetlands: a multivariate approach. Canadian Journal of Fisheries and Aquatic Sciences, 57, 76-85. 
Table 1. Number of sites by Cowardin and hydrogeomorphic (HGM) classification schemes and ecoregions for use in developing macroinvertebrate indices of biological integrity (Mac-IBI) for wetlands in West Virginia, USA from 2005-2006.

Level 3 U.S. Environmental Protection Agency aquatic ecoregion ${ }^{\mathrm{a}}$

\begin{tabular}{lcccc} 
Wetland type & Ridge and Valley & Central Appalachian & Western Alleghany Plateau & Total \\
\cline { 3 - 4 } Hydrogeomorphic subclass $^{\mathbf{b}}$ & & & & \\
Riparian Depression & 10 & 24 & 25 & 59 \\
Headwater Floodplain & 10 & 15 & 4 & 29 \\
Designated HGM Management Class & & & & 72 \\
Depression & 10 & 28 & 34 & 35 \\
Floodplain & 12 & 17 & 6 & 23 \\
Impoundment & 1 & 14 & 8 & \\
Cowardin Class & & & & 75 \\
Emergent & 15 & & 26 & 44 \\
Scrub-shrub & 6 & 34 & 21 & 31 \\
Forested & 6 & 17 & 11 & \\
\hline
\end{tabular}

${ }^{a}$ Omernik (1987), modified by Woods et al. (1999).

${ }^{\mathrm{b}}$ Cole et al. (1997). 
Table 2. Designated hydrogeomorphic (HGM) management classes derived from regional hydrogeomorphic (HGM) subclasses for use in developing macroinvertebrate indices of biological integrity (Mac-IBI) for wetlands in West Virginia, USA from 20052006.

\begin{tabular}{ll}
\hline Designated HGM Management class & Hydrogeomorphic subclass $^{\mathrm{a}}$ \\
\hline Depression & Surface water depression \\
& Riparian depression \\
& Isolated depression \\
Floodplain & Headwater floodplain \\
& Mainstem floodplain \\
Impoundment & Headwater impoundment \\
& Mainstem impoundment \\
Fringing & Fringing \\
Slope & Slope \\
\hline
\end{tabular}

${ }^{a}$ Cole et al. (1997). 
Table 3. Metrics and sub-metrics selected from the Ohio Rapid Assessment Method (Mack 2001) used to define the disturbance gradient for use in developing macroinvertebrate indices of biological integrity (Mac-IBI) for wetlands in West Virginia, USA from 2005-2006.

\footnotetext{
Scoring value Disturbance component

Upland buffers and surrounding land use

Calculate the average buffer width. Select only one and assign

score.

\begin{tabular}{l|l}
7 & \\
4 & \\
1 & \\
0 & \\
\end{tabular}

WIDE. Buffers average $50 \mathrm{~m}$ or more around wetland perimeter

MEDIUM. Buffers average $25 \mathrm{~m}$ to $<50 \mathrm{~m}$ around wetland perimeter

NARROW. Buffers average $10 \mathrm{~m}$ to $<25 \mathrm{~m}$ around wetland perimeter

VERY NARROW. Buffers average $<10 \mathrm{~m}$ around wetland perimeter

Intensity of surrounding land use. Select one or double check and average.

\begin{tabular}{l|l|}
7 & \\
5 & \\
3 & \\
1 &
\end{tabular}

VERY LOW. 2nd growth or older forest, prairie, savannah, wildlife area, etc.

LOW. Old field ( $>10$ years), shrubland, young second growth forest.

MODERATELY HIGH. Residential, fenced pasture, park, conservation tillage, new fallow field.

HIGH. Urban, industrial, open pasture, row cropping, mining, construction.

Hydrology

12

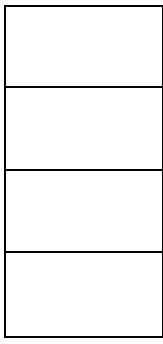

Modifications to natural, hydrologic regime. Score one or double check and average.

None or none apparent. There are no modifications or no modifications that are apparent to the rater.

Recovered. The wetland appears to have recovered from past modifications which altered the wetland's natural hydrologic regime.

Recovering. The wetland appears to be in the process of recovering from past modifications which altered the wetland's natural hydrologic regime.

Recent or no recovery. The modifications have occurred recently, and / or the wetland has not recovered from past modifications and / or the modifications are ongoing.

Habitat alteration and development

Substrate disturbance. Score one or double check and average.

4

3

2

1

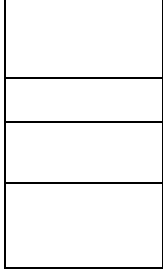

None or none apparent. There are no modifications or no modifications that are apparent to the rater.

Recovered. The wetland appears to have recovered from past disturbances.

Recovering. The wetland appears to be in the process of recovering from past disturbances.

Recent or no recovery. The modifications have occurred recently, and / or the wetland has not recovered from past disturbances and/ or the disturbances are ongoing.

Habitat alteration. Score one or double check and average.

None or none apparent. There are no alterations or no alterations that are apparent to the rater.

Recovered. The wetland appears to have recovered from past alterations.

Recovering. The wetland appears to be in the process of recovering from past alterations.

Recent or no recovery. The modifications have occurred recently, and / or the wetland has not recovered from past alterations and/ or the alterations are ongoing.
} 
Table 4. Candidate macroinvertebrate community biological metrics evaluated for inclusion into macroinvertebrate indices of biological integrity (Mac-IBI) for wetlands in West Virginia, USA from 2005-2006.

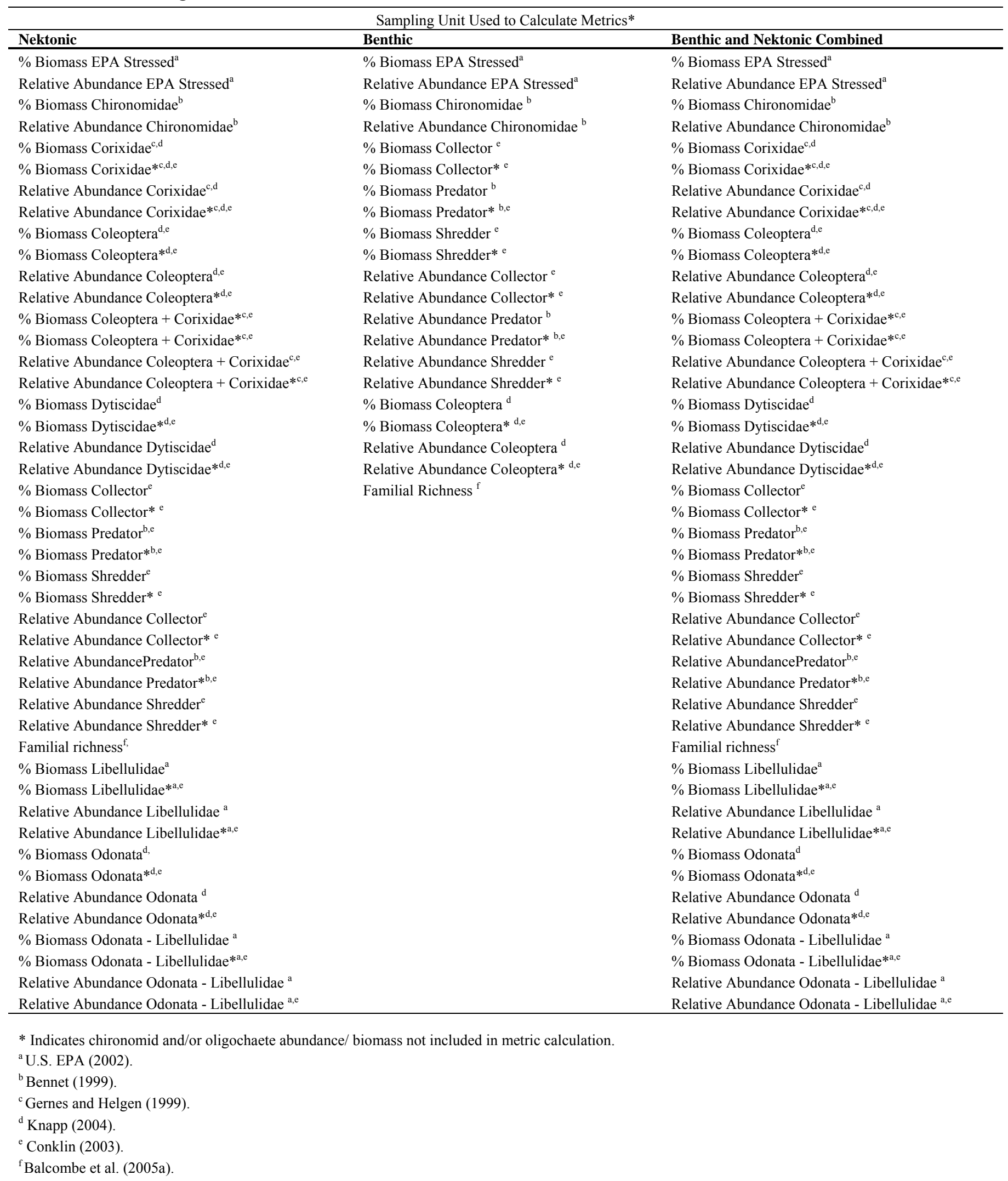


Table 5.Candidate macroinvertebrate community biological metrics that were able to discriminate between reference and stressed sites; evaluated by class according to regional Hydrogeomorphic (HGM) subclass, designated HGM management class, and the Cowardin classification schemes in building macroinvertebrate indices of biological integrity (Mac-IBI) for wetlands in West Virginia, USA from 2005-2006.

\begin{tabular}{|c|c|c|c|c|c|c|c|c|}
\hline \multirow[b]{3}{*}{ Candidate Macroinvertebrate Metrics* } & \multicolumn{8}{|c|}{ Wetland Classification $^{\mathrm{h}}$} \\
\hline & \multicolumn{2}{|c|}{ HGM Subclass } & \multicolumn{3}{|c|}{ Designated HGM Management Class } & \multicolumn{3}{|c|}{ Cowardin Classification } \\
\hline & $\begin{array}{c}\text { Riparian } \\
\text { Depression }\end{array}$ & $\begin{array}{l}\text { Headwater } \\
\text { Floodplain }\end{array}$ & Depression & Floodplain & Impoundment & Emergent & $\begin{array}{l}\text { Scrub- } \\
\text { shrub }\end{array}$ & Forested \\
\hline \multicolumn{9}{|l|}{ Nektonic community } \\
\hline$\%$ Biomass EPA Stressed $^{\mathrm{a}}$ & - & - & - & $\mathrm{N}$ & $\mathrm{E}$ & - & I & - \\
\hline Relative Abundance EPA Stressed ${ }^{a}$ & - & - & - & I & - & - & - & - \\
\hline Relative Abundance Coleoptera ${ }^{\mathrm{d}, \mathrm{g}, \mathrm{g}}$ & - & - & - & - & E & - & - & - \\
\hline$\%$ Biomass Dytiscidae $^{\mathrm{d}}$ & I & - & I & - & - & - & - & - \\
\hline Relative Abundance Libellulidae*a,e,g & - & $\mathrm{F}$ & - & - & E & - & - & - \\
\hline$\%$ Biomass Odonata* ${ }^{\mathrm{d}, \mathrm{e}}$ & - & - & - & - & I & - & - & - \\
\hline Relative Abundance Odonata ${ }^{\mathrm{d}, \mathrm{g}}$ & - & $\mathrm{F}$ & - & - & - & - & - & - \\
\hline Relative Abundance Odonata*d,g, & - & $\mathrm{F}$ & - & - & $\mathrm{R}$ & - & - & - \\
\hline \multicolumn{9}{|l|}{ Benthic community } \\
\hline$\%$ Biomass Collector ${ }^{\mathrm{e}, \mathrm{g}}$ & - & - & - & - & E & - & - & - \\
\hline$\%$ Biomass Collector* e & - & I & - & $\mathrm{R}$ & - & - & - & - \\
\hline$\%$ Biomass Predator ${ }^{\mathrm{b}, \mathrm{g}}$ & - & - & - & - & - & - & - & $\mathrm{R}$ \\
\hline$\%$ Biomass Predator* b,e,g & - & - & - & - & - & - & - & $\mathrm{R}$ \\
\hline Relative Abundance Collector ${ }^{\mathrm{e}, \mathrm{g}}$ & - & $\mathrm{R}$ & - & $\mathrm{R}$ & - & - & E & - \\
\hline Relative Abundance Collector* ${ }^{\mathrm{e}}$ & - & - & - & I & - & - & E & I \\
\hline Relative Abundance Predator ${ }^{\mathrm{b}, \mathrm{g}}$ & - & - & - & - & - & - & - & $\mathrm{R}$ \\
\hline Relative Abundance Predator* b,e & - & - & - & - & - & - & - & I \\
\hline Familial Richness $^{\mathrm{f}, \mathrm{g}}$ & - & - & - & - & E & - & - & - \\
\hline \multicolumn{9}{|l|}{ Combined nektonic and benthic communities } \\
\hline$\%$ Biomass Collector ${ }^{\mathrm{e}, \mathrm{g}}$ & - & I & - & I & - & I & - & - \\
\hline$\%$ Biomass Collector*e,g & - & & - & I & - & - & - & - \\
\hline
\end{tabular}

* Indicates chironomid and/or oligochaete abundance/ biomass not included in metric calculation.

${ }^{\mathrm{a}}$ U.S. EPA (2002).

${ }^{\mathrm{b}}$ Bennet (1999).

${ }^{\mathrm{c}}$ Gernes and Helgen (1999).

${ }^{\mathrm{d}}$ Knapp (2004).

${ }^{\mathrm{e}}$ Conklin (2003).

${ }^{\mathrm{f}}$ Balcombe et al. (2005a).

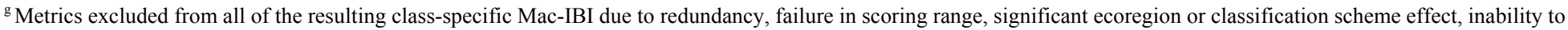
discriminate between reference and stressed sites.

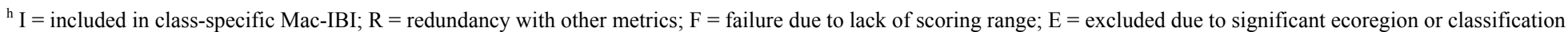
effect; $\mathrm{N}=$ not selected due to logistical requirements; - = failure to discriminate between reference and stressed sites. 
Table 6. Correlation matrix of benthic and nektonic macroinvertebrate metrics used in developing macroinvertebrate indices of biological integrity (Mac-IBI) for wetlands in West Virginia, USA from 2005-2006. Metrics with R>0.80 were considered correlated and selected for inclusion into the Mac-IBI based on discrimination efficiency (D.E.).

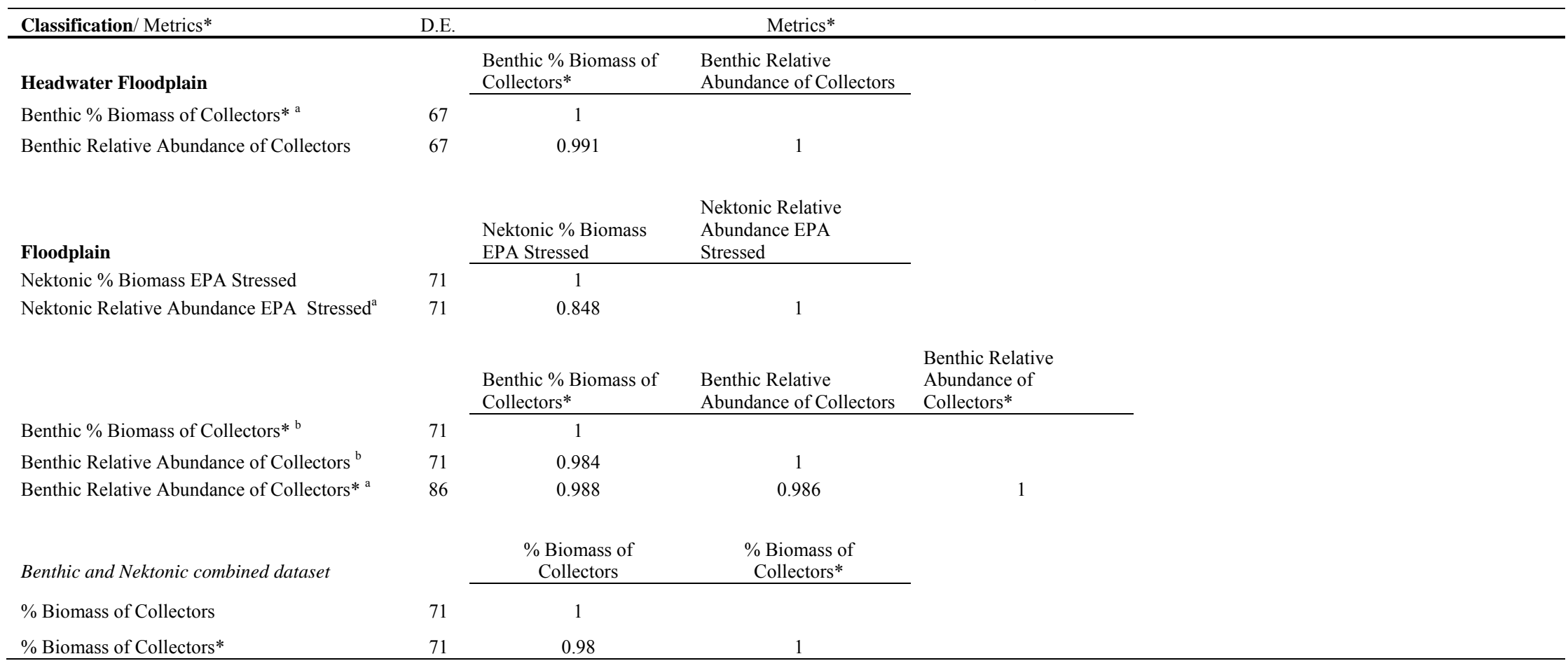




\section{Table 6. Continued.}

\begin{tabular}{|c|c|c|c|c|c|c|}
\hline Classification/metrics* & D.E. & & & Metrics* & & \\
\hline Impoundment & & $\begin{array}{l}\text { Nektonic \% Biomass } \\
\text { EPA Stressed }\end{array}$ & $\begin{array}{l}\text { Nektonic Relative } \\
\text { Abundance of } \\
\text { Coleoptera } \\
\end{array}$ & $\begin{array}{l}\text { Nektonic Relative } \\
\text { Abundance } \\
\text { Libellulidae* }\end{array}$ & $\begin{array}{l}\text { Nektonic \% Biomass } \\
\text { of Odonata* }\end{array}$ & $\begin{array}{l}\text { Nektonic Relative } \\
\text { Abundance of Odonata* }\end{array}$ \\
\hline Nektonic \% Biomass EPA Stressed ${ }^{c}$ & 86 & 1 & & & & \\
\hline Nektonic Relative Abundance of Coleoptera ${ }^{\mathrm{c}}$ & 86 & -0.398 & 1 & & & \\
\hline Nektonic Relative Abundance Libellulidae* b & 71 & 0.671 & -0.176 & 1 & & \\
\hline Nektonic $\%$ Biomass of Odonata*c & 86 & 0.612 & -0.273 & 0.743 & 1 & \\
\hline \multirow[t]{2}{*}{ Nektonic Relative Abundance of Odonata* a } & 71 & 0.295 & -0.174 & 0.645 & 0.827 & 1 \\
\hline & & $\begin{array}{l}\text { Benthic \% Biomass of } \\
\text { Collectors }\end{array}$ & Benthic family richness & & & \\
\hline Benthic $\%$ Biomass of Collectors ${ }^{c}$ & 71 & 1 & & & & \\
\hline Benthic Family Richness ${ }^{c}$ & 86 & 0.482 & 1 & & & \\
\hline Scrub-Shrub & & $\begin{array}{l}\text { Benthic Relative } \\
\text { Abundance of } \\
\text { Collectors }\end{array}$ & $\begin{array}{l}\text { Benthic Relative } \\
\text { Abundance of } \\
\text { Collectors* }\end{array}$ & & & \\
\hline Benthic Relative Abundance of Collectors ${ }^{c}$ & 63 & 1 & & & & \\
\hline Benthic Relative Abundance of Collectors* & 63 & 0.885 & 1 & & & \\
\hline Forested & & $\begin{array}{l}\text { Benthic \% Biomass of } \\
\text { Predators }\end{array}$ & $\begin{array}{l}\text { Benthic \% Biomass of } \\
\text { Predators* }\end{array}$ & $\begin{array}{l}\text { Benthic Relative } \\
\text { Abundance of } \\
\text { Collectors* }\end{array}$ & $\begin{array}{l}\text { Benthic Relative } \\
\text { Abundance of } \\
\text { Predators }\end{array}$ & $\begin{array}{l}\text { Benthic Relative } \\
\text { Abundance of } \\
\text { Predators* }\end{array}$ \\
\hline Benthic $\%$ Biomass of Predators ${ }^{b}$ & 72 & 1 & & & & \\
\hline Benthic $\%$ Biomass of Predators* ${ }^{b}$ & 72 & 0.908 & 1 & & & \\
\hline Benthic Relative Abundance of Collectors* a & 72 & -0.119 & -0.28 & 1 & & \\
\hline Benthic Relative Abundance of Predators ${ }^{b}$ & 72 & 0.951 & 0.884 & -0.129 & 1 & \\
\hline Benthic Relative Abundance of Predators* a & 85 & 0.918 & 0.963 & -0.251 & 0.952 & 1 \\
\hline
\end{tabular}

* Indicates chironomid and/or oligochaete abundance/ biomass not included in metric calculation.

${ }^{a}$ Metric selected for inclusion into Mac-IBI.

${ }^{b}$ Metric excluded due to redundancy with other metric with greater discrimination efficiency.

${ }^{\mathrm{c}}$ Metric initially selected for inclusion into Mac-IBI, but removed in later analysis due to significant ecoregion or alternative classification scheme effect. 
Table 7. Analysis of variance (ANOVA) results of reference and stressed sites' metric values compared to Level 3 ecoregions (Omernik 1987; Woods et al. 1999) and the alternative classification scheme used in developing macroinvertebrate indices of biological integrity (Mac-IBI) for wetlands in West Virginia, USA from 2005-2006.

\begin{tabular}{|c|c|c|c|c|}
\hline $\begin{array}{l}\text { Classification (number of reference and } \\
\text { stressed sites) }\end{array}$ & Validation tests & $\mathrm{df}$ & $\begin{array}{c}\mathrm{F}- \\
\text { value }\end{array}$ & p-value \\
\hline \multicolumn{5}{|l|}{ Riparian Depression Mac-IBI $(n=16)$} \\
\hline \multirow[t]{3}{*}{ Nektonic \% Biomass of Dytiscidae } & Cowardin class & 2,15 & 2.58 & 0.1451 \\
\hline & Level 3 ecoregion & 2,15 & 0.02 & 0.9818 \\
\hline & Cowardin class $x$ Level 3 ecoregion & 1,15 & 0.01 & 0.9210 \\
\hline \multicolumn{5}{|l|}{ Headwater Floodplain Mac-IBI $(n=14)$} \\
\hline \multirow[t]{3}{*}{ Benthic Collectors \% Biomass* } & Cowardin class & 2,13 & 1.04 & 0.4020 \\
\hline & Level 3 ecoregion & 2,13 & 0.02 & 0.9800 \\
\hline & Cowardin class x Level 3 ecoregion & 2,13 & 0.17 & 0.8455 \\
\hline \multicolumn{5}{|l|}{ Benthic and Nektonic Collectors \% } \\
\hline \multirow[t]{3}{*}{ Biomass $^{\mathrm{e}}$} & Cowardin class & 2,13 & 0.79 & 0.4955 \\
\hline & Level 3 ecoregion & 2,13 & 1.10 & 0.3920 \\
\hline & Cowardin class $x$ Level 3 ecoregion & 1,13 & 0.54 & 0.4910 \\
\hline \multicolumn{5}{|l|}{ Depression Mac-IBI $(n=22)$} \\
\hline \multirow[t]{3}{*}{ Nektonic \% Biomass of Dytiscidae } & Cowardin class & 3,21 & 0.36 & 0.7833 \\
\hline & Level 3 ecoregion & 2,21 & 0.39 & 0.6855 \\
\hline & Cowardin class $x$ Level 3 ecoregion & 3,21 & 0.12 & 0.9485 \\
\hline \multicolumn{5}{|l|}{ Floodplain Mac-IBI $(n=17)$} \\
\hline \multirow[t]{3}{*}{ Stressed } & Cowardin class & 2,16 & 2.02 & 0.2131 \\
\hline & Level 3 ecoregion & 2,16 & 0.64 & 0.5601 \\
\hline & Cowardin class $x$ Level 3 ecoregion & 4,16 & 1.11 & 0.4308 \\
\hline \multirow[t]{3}{*}{ Nektonic \% Biomass EPA Stressed } & Cowardin class & 2,16 & 2.59 & 0.1549 \\
\hline & Level 3 ecoregion & 2,16 & 0.35 & 0.7184 \\
\hline & Cowardin class $x$ Level 3 ecoregion & 4,16 & 0.36 & 0.8259 \\
\hline \multirow[t]{3}{*}{$\begin{array}{l}\text { Benthic Relative Abundance of } \\
\text { Collectors* }\end{array}$} & Cowardin class & 2,16 & 4.09 & 0.0596 \\
\hline & Level 3 ecoregion & 2,16 & 0.7 & 0.5261 \\
\hline & Cowardin class x Level 3 ecoregion & 4,16 & 0.69 & 0.6188 \\
\hline \multicolumn{5}{|l|}{ Benthic and Nektonic Collectors \% } \\
\hline \multirow[t]{3}{*}{ Biomass $^{\mathrm{c}}$} & Cowardin class & 2,16 & 1.38 & 0.3217 \\
\hline & Level 3 ecoregion & 2,16 & 0.96 & 0.4349 \\
\hline & Cowardin class $\mathrm{x}$ Level 3 ecoregion & 3,16 & 0.58 & 0.6481 \\
\hline \multicolumn{5}{|l|}{ Benthic and Nektomic Collectors \% } \\
\hline \multirow[t]{3}{*}{ Biomass*c } & Cowardin class & 2,16 & 1.97 & 0.2200 \\
\hline & Level 3 ecoregion & 2,16 & 1.14 & 0.3808 \\
\hline & Cowardin class $\mathrm{x}$ Level 3 ecoregion & 3,16 & 0.52 & 0.6839 \\
\hline
\end{tabular}


Table 7. Continued.

\begin{tabular}{|c|c|c|c|c|}
\hline Classification (number of reference and stressed sites) & Validation tests & $\mathrm{df}$ & F-value & $\mathrm{p}$-value \\
\hline \multicolumn{5}{|l|}{ Impoundment Mac-IBI $(n=13)$} \\
\hline \multirow[t]{3}{*}{ Benthic Family Richness ${ }^{\mathrm{b}}$} & Cowardin class & 2,12 & 2.49 & 0.1525 \\
\hline & Level 3 ecoregion & 2,12 & 1.39 & 0.3105 \\
\hline & Cowardin class $\mathrm{x}$ Level 3 ecoregion & 1,12 & 7.01 & 0.033 \\
\hline \multirow[t]{3}{*}{ Nektonic \% Biomass EPA Stressed ${ }^{b}$} & Cowardin class & 2,12 & 1.47 & 0.2926 \\
\hline & Level 3 ecoregion & 2,12 & 2.28 & 0.1731 \\
\hline & Cowardin class $\mathrm{x}$ Level 3 ecoregion & 1,12 & 12.37 & 0.0098 \\
\hline \multirow[t]{3}{*}{ Nektonic Relative Abundance of Libellulidae*b } & Cowardin class & 2,12 & 0.67 & 0.5399 \\
\hline & Level 3 ecoregion & 2,12 & 1.97 & 0.2098 \\
\hline & Cowardin class $x$ Level 3 ecoregion & 1,12 & 6.08 & 0.0431 \\
\hline \multirow[t]{3}{*}{ Nektonic Relative Abundance of Coleopterans ${ }^{b}$} & Cowardin class & 2,12 & 5.21 & 0.0411 \\
\hline & Level 3 ecoregion & 2,12 & 0.66 & 0.5481 \\
\hline & Cowardin class $x$ Level 3 ecoregion & 1,12 & 0.7 & 0.4302 \\
\hline \multirow[t]{3}{*}{ Nektonic \% Biomass of Odonata* } & Cowardin class & 2,12 & 0.24 & 0.7958 \\
\hline & Level 3 ecoregion & 2,12 & 1.85 & 0.2266 \\
\hline & Cowardin class $\mathrm{x}$ Level 3 ecoregion & 1,12 & 5.28 & 0.0551 \\
\hline \multicolumn{5}{|l|}{ Emergent Mac-IBI $(n=28)$} \\
\hline \multirow[t]{3}{*}{ Benthic and Nektonic Collectors $\%$ Biomass $^{\mathrm{c}}$} & Designated $\mathrm{HGM}^{\mathrm{a}}$ management class & 4,27 & 0.85 & 0.5158 \\
\hline & Level 3 ecoregion & 2,27 & 0.7 & 0.5114 \\
\hline & Designated $\mathrm{HGM}^{\mathrm{a}}$ management class $\mathrm{x}$ Level 3 ecoregion & 4,27 & 0.72 & 0.5925 \\
\hline \multicolumn{5}{|l|}{ Scrub-shrub Mac-IBI $(n=22)$} \\
\hline \multirow[t]{3}{*}{ Benthic Relative Abundance of Collectors ${ }^{\mathrm{b}}$} & Designated $\mathrm{HGM}^{\mathrm{a}}$ management class & 4,21 & 9.17 & 0.001 \\
\hline & Level 3 ecoregion & 2,21 & 0.96 & 0.4095 \\
\hline & Designated $\mathrm{HGM}^{\mathrm{a}}$ management class $\mathrm{x}$ Level 3 ecoregion & 2,21 & 2.55 & 0.1161 \\
\hline \multirow[t]{3}{*}{ Benthic Relative Abundance of Collectors*b } & Designated $\mathrm{HGM}^{\mathrm{a}}$ management class & 4,21 & 4.63 & 0.0152 \\
\hline & Level 3 ecoregion & 2,21 & 0.04 & 0.9567 \\
\hline & Designated $\mathrm{HGM}^{\mathrm{a}}$ management class $\mathrm{x}$ Level 3 ecoregion & 2,21 & 1.23 & 0.3249 \\
\hline \multirow[t]{3}{*}{ Nektonic \% Biomass EPA Stressed } & Designated $\mathrm{HGM}^{\mathrm{a}}$ management class & 4,21 & 1.5 & 0.2452 \\
\hline & Level 3 ecoregion & 2,21 & 0.07 & 0.9359 \\
\hline & Designated $\mathrm{HGM}^{\mathrm{a}}$ management class $\mathrm{x}$ Level 3 ecoregion & 2,21 & 0.31 & 0.7421 \\
\hline \multicolumn{5}{|l|}{ Forested Mac-IBI $(n=14)$} \\
\hline \multirow[t]{3}{*}{ Benthic Relative Abundance of Predators* } & Designated $\mathrm{HGM}^{\mathrm{a}}$ management class & 3,13 & 0.75 & 0.5618 \\
\hline & Level 3 ecoregion & 2,13 & 0.59 & 0.5856 \\
\hline & Designated $\mathrm{HGM}^{\mathrm{a}}$ management class $\mathrm{x}$ Level 3 ecoregion & 2,13 & 3.13 & 0.1171 \\
\hline
\end{tabular}


Table 7. Continued.

\begin{tabular}{|c|c|c|c|c|}
\hline Classification (number of reference and stressed sites) & Validation tests & $\mathrm{df}$ & F-value & $\mathrm{p}$-value \\
\hline \multirow[t]{3}{*}{ Benthic Relative Abundance of Collectors* } & Designated $\mathrm{HGM}^{\mathrm{a}}$ management class & 3,13 & 1.62 & 0.2808 \\
\hline & Level 3 ecoregion & 2,13 & 0.17 & 0.8497 \\
\hline & Designated $\mathrm{HGM}^{\mathrm{a}}$ management class $\mathrm{x}$ Level 3 ecoregion & 2,13 & 0.64 & 0.5595 \\
\hline
\end{tabular}

* Indicates chironomid and/or oligocheate abundance/ biomass not included in metric calculation.

${ }^{a}$ Hydrogeomorphic (Brinson 1993).

${ }^{\mathrm{b}}$ Metric excluded from inclusion into class-specific Mac-IBI due to a significant ecoregion, alternative classification scheme, or cumulative 2-way interaction.

${ }^{\mathrm{c}}$ Metric for the combined analysis of benthic and nektonic data. 
Table 8. Wilks' Lambda statistic for posthoc validation of reference and stressed sites' metric values of class-specific macroinvertebrate indices of biological integrity (Mac-IBI) for wetlands in West Virginia, USA from 2005-2006.

\begin{tabular}{lcccc}
\hline Classification scheme and interaction & $\begin{array}{c}\text { Wilks' } \\
\text { Lambda }\end{array}$ & F-value & df & p-value \\
\hline Floodplain Mac-IBI $(n=15)$ & & & & \\
Cowardin class & 0.4238 & 1.34 & 4,10 & 0.3210 \\
Level 3 ecoregion & 0.6932 & 0.50 & 4,10 & 0.7349 \\
Cowardin class x Level 3 ecoregion & 0.4509 & 0.61 & 8,10 & 0.7512 \\
& & & & \\
Forested Mac-IBI $(n=14)$ & & & & \\
Designated $\mathrm{HGM}^{\mathrm{a}}$ management class & 0.3968 & 0.98 & 6,10 & 0.4864 \\
Level 3 ecoregion & 0.7693 & 0.35 & 4,10 & 0.8380 \\
Designated $\mathrm{HGM}^{\mathrm{a}}$ management class x Level 3 ecoregion & 0.3986 & 1.46 & 4,10 & 0.2852 \\
\hline
\end{tabular}

${ }^{\text {a} H y d r o g e o m o r p h i c ~(B r i n s o n ~ 1993) . ~}$ 
Table 9. Relations between the resulting class-specific macroinvertebrate indices of biological integrity (Mac-IBI) derived from separate analysis of benthic and nektonic samples for wetlands in West Virginia, USA and the disturbance gradient from 2005-2006.

\begin{tabular}{|c|c|c|c|c|c|c|c|c|c|}
\hline Macroinvertebrate IBI & $\begin{array}{c}\text { Nektonic } \\
\text { Metrics } \\
\end{array}$ & $\begin{array}{l}\text { Benthic } \\
\text { Metrics } \\
\end{array}$ & $\mathrm{N}$ & D.E.a & $\mathrm{df}$ & F-value & $\mathrm{p}$-value & $\mathrm{R}^{2}$ & Equation \\
\hline Riparian Depression & 1 & 0 & 39 & $67 \%$ & 1.37 & 5.58 & 0.0238 & 0.13 & $y=-2.36+0.17$ (Disturbance score) \\
\hline Headwater Floodplain & 0 & 1 & 26 & $67 \%$ & 1,24 & 6.06 & 0.0214 & 0.20 & $\mathrm{y}=0.85+0.23$ (Disturbance score) \\
\hline Depression & 1 & 0 & 46 & $60 \%$ & 1,44 & 5.17 & 0.028 & 0.11 & $\mathrm{y}=-1.44+0.13$ (Disturbance score) \\
\hline Floodplain & 1 & 1 & 28 & $71 \%$ & 1,26 & 23.21 & $<0.0001$ & 0.47 & $\mathrm{y}=2.92+0.41$ (Disturbance score) \\
\hline Impoundment & 1 & 0 & 23 & $86 \%$ & 1,21 & 1.54 & 0.2286 & 0.07 & $\mathrm{y}=3.99+0.13$ (Disturbance score) \\
\hline Scrub-Shrub & 1 & 0 & 36 & $60 \%$ & 1,34 & 3.37 & 0.075 & 0.09 & $y=3.66+0.13$ (Disturbance score) \\
\hline Forested & 0 & 2 & 29 & $71 \%$ & 1,27 & 4.22 & 0.0497 & 0.14 & $\mathrm{y}=0.56+0.33$ (Disturbance score) \\
\hline
\end{tabular}

${ }^{\text {a }}$ Discrimination efficiency, or ability to discriminate between reference and stressed sites. 
Table 10. Relations between the resulting class-specific macroinvertebrate indices of biological integrity (Mac-IBI) derived from combined analysis of benthic and nektonic samples for wetlands in West Virginia, USA and the disturbance gradient from 2005-2006.

\begin{tabular}{lccccccl}
\hline Macroinvertebrate IBI & $\mathrm{N}$ & D.E. $^{\mathrm{a}}$ & $\mathrm{df}$ & $\mathrm{F}$-value & $\mathrm{p}$-value & $\mathrm{R}^{2}$ & Equation \\
\hline Headwater Floodplain & 23 & 67 & 1,21 & 3.24 & 0.0863 & 0.13 & $\mathrm{y}=0.77+0.19$ (Disturbance score) \\
& & & & & & & \\
Floodplain & 27 & 71 & 1,25 & 5.13 & 0.0325 & 0.17 & $\mathrm{y}=1.83+0.19$ (Disturbance score) \\
& 27 & 71 & 1,25 & 7.09 & 0.0133 & 0.22 & $\mathrm{y}=-0.11+0.23$ (Disturbance score) \\
& 58 & 66 & 1,56 & 5.48 & 0.0228 & 0.09 & $\mathrm{y}=3.98+0.12$ (Disturbance score) \\
\hline
\end{tabular}

${ }^{a}$ Discrimination efficiency, or ability to discriminate between reference and stressed sites. 
Table 11. Reference site scoring summary used to derive scoring thresholds, and discrimination efficiency (D.E.) in developing class-specific macroinvertebrate indices of biological integrity (Mac-IBI) for wetlands in West Virginia, USA from 2005-2006.

\begin{tabular}{|c|c|c|c|c|c|c|c|c|c|}
\hline \multirow[b]{2}{*}{ Wetland type } & \multicolumn{6}{|c|}{ Reference Site Scoring Summary } & \multirow[b]{2}{*}{ D.E. ${ }^{a}$} & \multicolumn{2}{|c|}{ Means (SE) } \\
\hline & $\mathrm{N}$ & $\begin{array}{l}\text { Max possible } \\
\text { IBI score }\end{array}$ & 75th percentile & 25th percentile & 5th percentile & Median & & Reference $^{\mathrm{b}}$ & Stressed \\
\hline Riparian Depression & 39 & 10 & 5.79 & 0.02 & 0 & 0.62 & 67 & $3.22(1.76)$ & $0.30(0.27)$ \\
\hline $\begin{array}{l}\text { Headwater } \\
\text { Floodplain }\end{array}$ & 26 & 10 & 10 & 8.33 & 7.85 & 10.00 & 67 & $9.27(0.36)^{b}$ & $6.80(1.13)$ \\
\hline Depression & 46 & 10 & 3.8 & 0 & 0 & 0.25 & 60 & $2.75(1.27)$ & $0.49(0.32)$ \\
\hline Floodplain & 28 & 20 & 18.91 & 14.75 & 12.95 & 16.25 & 71 & $16.55(0.99)^{\mathrm{b}}$ & $8.97(2.20)$ \\
\hline Impoundment & 23 & 10 & 9.85 & 8.31 & 3.79 & 9.03 & 86 & $8.09(1.19)$ & $5.72(1.07)$ \\
\hline Scrub-shrub & 36 & 10 & 10 & 7.14 & 6.59 & 10.00 & 60 & $8.72(0.53)^{b}$ & $5.68(1.23)$ \\
\hline Forested & 29 & 20 & $16 . .35$ & 9.99 & 8.39 & 12.89 & 71 & $12.99(1.47)^{\mathrm{b}}$ & $6.33(1.68)$ \\
\hline
\end{tabular}

${ }^{a}$ Effectiveness of Mac-IBI scores to effectively discriminate between reference and stressed sites.

${ }^{\mathrm{b}}$ Means statistically significantly different (Tukey $\alpha=0.05$ ). 
Table 12. Relations between resulting hybrid-class macroinvertebrate indices of biological integrity (Mac-IBI) for wetlands in West Virginia, USA and the disturbance gradient from 2005-2006.

\begin{tabular}{|c|c|c|c|c|c|c|c|c|}
\hline Hybrid Macroinvertebrate IBI & $\begin{array}{c}\text { Nektonic } \\
\text { Metrics } \\
\end{array}$ & $\begin{array}{l}\text { Benthic } \\
\text { Metrics } \\
\end{array}$ & $\mathrm{N}$ & df & F-value & $\mathrm{p}$-value & $\mathrm{R}^{2}$ & Equation \\
\hline Riparian Depression / Scrub-shrub & 1 & 1 & 13 & 1,11 & 0.48 & 0.5026 & 0.04 & $y=6.75+0.09$ (Disturbance score $)$ \\
\hline Riparian Depression / Forested & 1 & 2 & 5 & 1,3 & 0.44 & 0.5547 & 0.13 & $y=12.50-0.27$ (Disturbance score) \\
\hline Headwater Floodplain/ Scrub-shrub & 1 & 1 & 5 & 1,3 & 0.72 & 0.4577 & 0.19 & $\mathrm{y}=4.05+0.36($ Disturbance score $)$ \\
\hline Headwater Floodplain/ Forested & 0 & 3 & 6 & 1,4 & 0.12 & 0.7466 & 0.03 & $y=14.02+0.19$ (Disturbance score $)$ \\
\hline Depression/ Scrub-shrub & 2 & 0 & 14 & 1,12 & 0.61 & 0.4506 & 0.05 & $y=6.68+0.10($ Disturbance score $)$ \\
\hline Depression/ Forested & 1 & 2 & 5 & 1,3 & 0.44 & 0.5556 & 0.13 & $\mathrm{y}=12.49-0.27$ (Disturbance score) \\
\hline Floodplain/ Scrub-shrub & 2 & 1 & 6 & 1,4 & 0.41 & 0.5571 & 0.09 & $\mathrm{y}=13.78+0.30($ Disturbance score $)$ \\
\hline Floodplain/ Forested & 1 & 2 & 7 & 1,5 & 0.63 & 0.4629 & 0.11 & $\mathrm{y}=11.02+0.30$ (Disturbance score $)$ \\
\hline Impoundment/ Scrub-shrub & 2 & 0 & 7 & 1,5 & 2.00 & 0.2165 & 0.29 & $\mathrm{y}=-9.50+0.93$ (Disturbance score $)$ \\
\hline
\end{tabular}


Table 13. Relations between a class-specific multi-metric, multi-taxa IBI and the disturbance gradient derived from the avian wetland indices of biological integrity (AW-IBI), anuran acoustically-based index of biological integrity (AA-IBI), the vegetation index of biological integrity (Veg-IBI) and the macroinvertebrate index of biological integrity (Mac-IBI) for wetlands in West Virginia, USA from 2005-2006.

\begin{tabular}{|c|c|c|c|c|c|c|c|c|c|c|}
\hline \multirow[b]{2}{*}{ Wetland type } & \multicolumn{4}{|c|}{ Number of metrics by taxa group } & \multirow[b]{2}{*}{$\mathrm{N}$} & \multirow[b]{2}{*}{$\mathrm{df}$} & \multirow[b]{2}{*}{ F-value } & \multirow[b]{2}{*}{ p-value } & \multirow[b]{2}{*}{$\mathrm{R}^{2}$} & \multirow[b]{2}{*}{ Equation } \\
\hline & Anurans & Birds & Vegetation & $\begin{array}{c}\text { Macro } \\
\text { invertebrates }\end{array}$ & & & & & & \\
\hline $\begin{array}{l}\text { Riparian Depression } \\
\text { Headwater }\end{array}$ & 1 & 0 & 3 & 1 & 37 & 1,35 & 14.90 & 0.0005 & 0.3 & $y=7.07+0.62($ Disturbance score $)$ \\
\hline Floodplain & 1 & 4 & 4 & 1 & 21 & 1,19 & 79.25 & $<0.0001$ & 0.81 & $y=-2.70+2.10($ Disturbance score $)$ \\
\hline Depression & 0 & 2 & 2 & 1 & 46 & 1,44 & 23.97 & $<0.0001$ & 0.35 & $\mathrm{y}=9.96+0.63$ (Disturbance score $)$ \\
\hline Floodplain & 1 & 4 & 5 & 2 & 24 & 1,22 & 43.10 & $<0.0001$ & 0.66 & $y=26.25+1.97$ (Disturbance score) \\
\hline Impoundment & 0 & 3 & 2 & 1 & 23 & 1,21 & 3.47 & 0.0766 & 0.14 & $\mathrm{y}=25.63+0.37$ (Disturbance score) \\
\hline Emergent & 0 & 1 & 1 & 0 & 75 & 1,73 & 19.66 & $<0.0001$ & 0.21 & $y=9.93+0.21($ Disturbance score $)$ \\
\hline Scrub-shrub & 0 & 4 & 2 & 1 & 36 & 1,34 & 18.23 & $<0.0001$ & 0.35 & $y=29.79+0.79($ Disturbance score $)$ \\
\hline Forested & 0 & 3 & 5 & 2 & 29 & 1,27 & 29.05 & $<0.0001$ & 0.52 & $\mathrm{y}=13.61+1.44($ Disturbance score $)$ \\
\hline
\end{tabular}


Table 14. A comparison of class-specific significant $\mathrm{R}^{2}$ values of the scores and the disturbance gradient resulting from the avian wetland indices of biological integrity (AW-IBI), anuran acoustically-based index of biological integrity (AA-IBI), the vegetation index of biological integrity (Veg-IBI), the macroinvertebrate index of biological integrity (Mac-IBI), and the cumulative multi-taxa, multi-metric IBI for wetlands in West Virginia, USA from 2005-2006.

\begin{tabular}{|c|c|c|c|c|c|}
\hline Wetland type & AW-IBI & AA-IBI & Veg-IBI & Mac-IBI & $\begin{array}{l}\text { Cumulative } \\
\text { Wetland IBI }\end{array}$ \\
\hline \multicolumn{6}{|c|}{ Hydrogeomorphic subclass $^{\mathrm{a}}$} \\
\hline $\begin{array}{l}\text { Riparian Depression } \\
\text { Headwater }\end{array}$ & & 0.08 & 0.26 & 0.13 & 0.30 \\
\hline Floodplain & 0.49 & 0.27 & 0.65 & 0.20 & 0.81 \\
\hline \multicolumn{6}{|c|}{ Hydrogeomorphic class ${ }^{b}$} \\
\hline Depression & 0.12 & & 0.31 & 0.11 & 0.35 \\
\hline $\begin{array}{l}\text { Floodplain } \\
\text { Impoundment }\end{array}$ & 0.46 & 0.18 & 0.56 & 0.47 & 0.66 \\
\hline \multicolumn{6}{|l|}{ Cowardin class } \\
\hline Emergent & 0.11 & & 0.14 & & 0.21 \\
\hline Scrub-shrub & 0.25 & & 0.20 & & 0.35 \\
\hline Forested & 0.24 & & 0.35 & 0.14 & 0.52 \\
\hline
\end{tabular}

${ }^{\mathrm{a}}$ Cole et al. (1997).

${ }^{b}$ Brinson (1993). 
Table 15. Relations between hybrid multi-metric, multi-taxa IBI and the disturbance gradient derived from the avian wetland indices of biological integrity (AW-IBI), anuran acoustically-based index of biological integrity (AA-IBI), the vegetation index of biological integrity (Veg-IBI) and the macroinvertebrate index of biological integrity (Mac-IBI) for wetlands in West Virginia, USA from 2005-2006.

\begin{tabular}{|c|c|c|c|c|c|c|c|c|c|c|}
\hline \multirow[b]{2}{*}{ Wetland type } & \multicolumn{4}{|c|}{ Number of metrics by taxa- group } & \multirow[b]{2}{*}{$\mathrm{N}$} & \multirow[b]{2}{*}{ df } & \multirow[b]{2}{*}{ F-value } & \multirow[b]{2}{*}{ p-value } & \multirow[b]{2}{*}{$\mathrm{R}^{2}$} & \multirow[b]{2}{*}{ Equation } \\
\hline & Anurans & Birds & Vegetation & $\begin{array}{c}\text { Macro } \\
\text { invertebrates }\end{array}$ & & & & & & \\
\hline Emergent/ Headwater floodplain & 1 & 4 & 4 & 1 & 12 & 1,10 & 22.83 & 0.0007 & 0.70 & $y=-2.32+2.10($ Disturbance score $)$ \\
\hline Emergent/ Riparian depression & 1 & 1 & 3 & 1 & 21 & 1,19 & 4.27 & 0.0528 & 0.18 & $y=16.34+0.56$ (Disturbance score) \\
\hline Emergent/ Depression & 0 & 3 & 2 & 1 & 26 & 1,24 & 12.00 & 0.0020 & 0.33 & $y=16.29+0.67$ (Disturbance score $)$ \\
\hline Emergent/ Floodplain & 1 & 4 & 6 & 2 & 13 & 1,11 & 18.22 & 0.0013 & 0.62 & $y=31.50+1.95$ (Disturbance score) \\
\hline Emergent/ Impoundment & 0 & 3 & 3 & 3 & 14 & 1,12 & 3.03 & 0.1071 & 0.20 & $y=39.85+0.65$ (Disturbance score) \\
\hline $\begin{array}{l}\text { Scrub-shrub/ Headwater } \\
\text { floodplain }\end{array}$ & 1 & 6 & 5 & 2 & 4 & 1,2 & 12.77 & 0.0702 & 0.86 & $\mathrm{y}=15.16+2.52$ (Disturbance score $)$ \\
\hline Scrub-shrub/ Riparian depression & 1 & 4 & 4 & 2 & 12 & 1,10 & 3.97 & 0.0744 & 0.28 & $\mathrm{y}=42.45+0.91$ (Disturbance score) \\
\hline Scrub-shrub/ Depression & 0 & 4 & 4 & 2 & 14 & 1,12 & 2.94 & 0.1120 & 0.20 & $y=40.85+0.67$ (Disturbance score $)$ \\
\hline Scrub-shrub/ Floodplain & 1 & 5 & 6 & 3 & 5 & 1,3 & 6.18 & 0.0889 & 0.67 & $y=31.07+2.67$ (Disturbance score) \\
\hline Scrub-shrub/ Impoundment & 0 & 4 & 3 & 1 & 7 & 1,5 & 2.42 & 0.1805 & 0.33 & $\mathrm{y}=8.05+1.88($ Disturbance score $)$ \\
\hline Forested/ Headwater floodplain & 1 & 5 & 7 & 3 & 4 & 1,2 & 137.07 & 0.0072 & 0.99 & $y=--37.60+4.53$ (Disturbance score) \\
\hline Forested/ Riparian depression & 1 & 3 & 7 & 3 & 4 & 1,3 & 0.26 & 0.6619 & 0.11 & $\mathrm{y}=67.54-0.33$ (Disturbance score) \\
\hline Forested/ Depression & 0 & 4 & 6 & 3 & 5 & 1,3 & 0.28 & 0.6287 & 0.09 & $y=40.12+0.64$ (Disturbance score $)$ \\
\hline Forested/ Floodplain & 1 & 6 & 9 & 3 & 6 & 1,4 & 3.97 & 0.1170 & 0.50 & $y=50.04+2.78$ (Disturbance score $)$ \\
\hline Forested/ Impoundment ${ }^{\mathrm{a}}$ & 0 & 5 & 6 & 5 & 2 & & & & & \\
\hline
\end{tabular}

${ }^{\mathrm{a}}$ Insufficient sample size. 


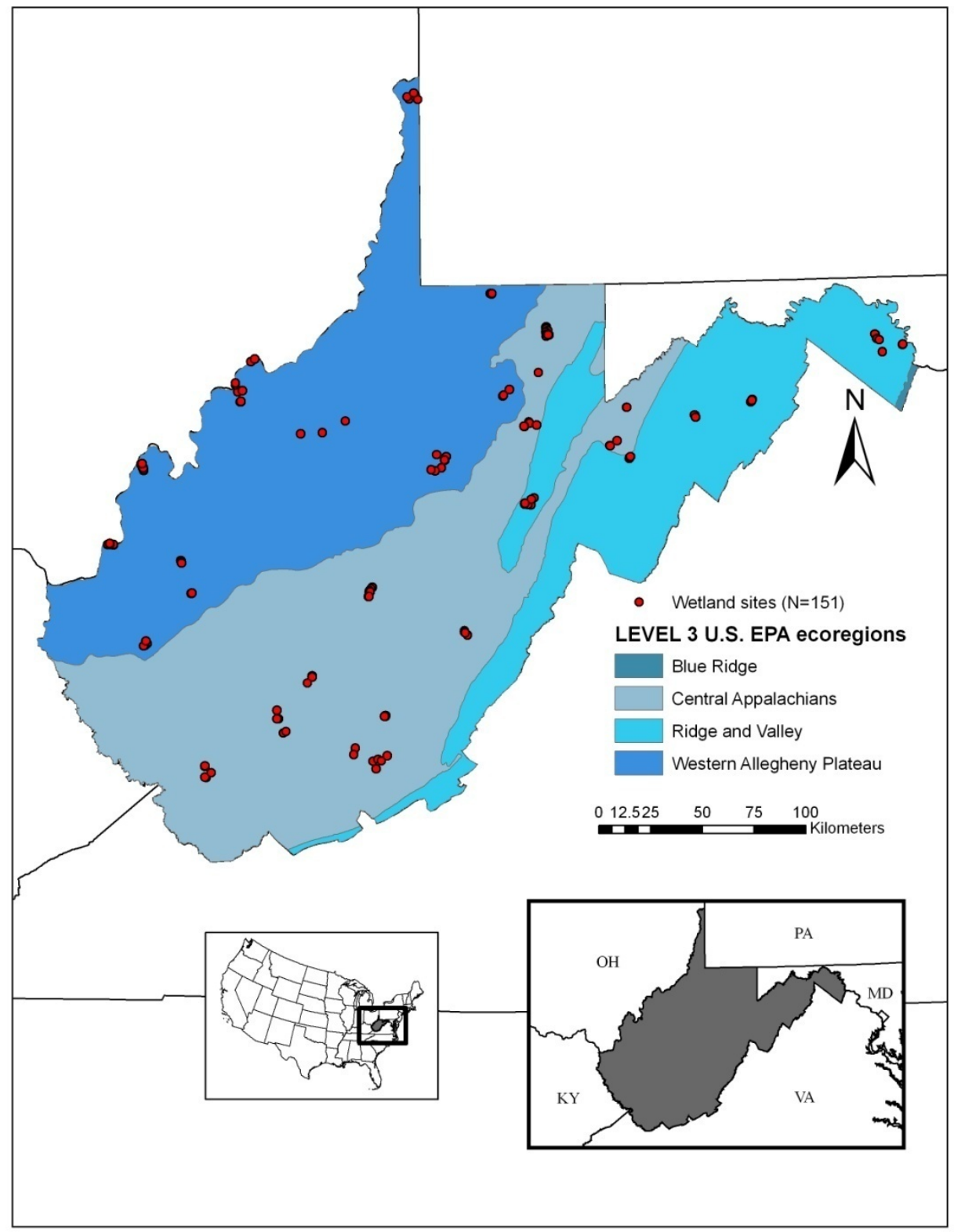

Figure 1. Site locations of wetlands and ecoregions (Omernik 1987, Woods et al. 1999) used in developing class-specific macroinvertebrate indices of biological integrity (MacIBI) in West Virginia, USA from 2005-2006. One or more wetlands may be represented by dots due to map scale. 


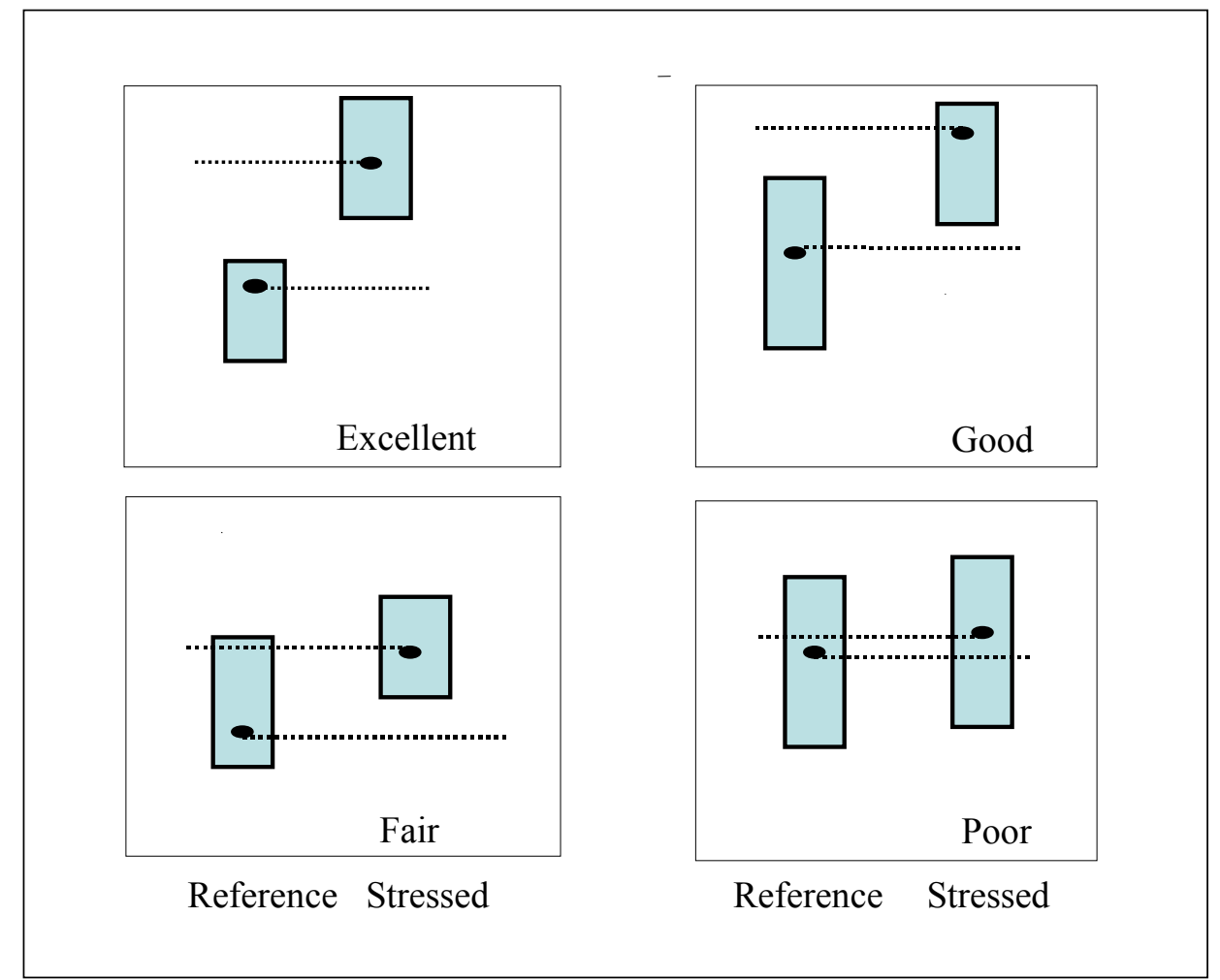

Figure 2. Box-and-whisker plot characteristics and resulting narrative description of reference and stressed sites' distribution of a biological metric value considered for inclusion into class-specific macroinvertebrate indices of biological integrity (Mac-IBI) for wetlands in West Virginia, USA from 2005-2006. Solid ovals represent the median of metric value (courtesy of Greg Pond, US EPA). 


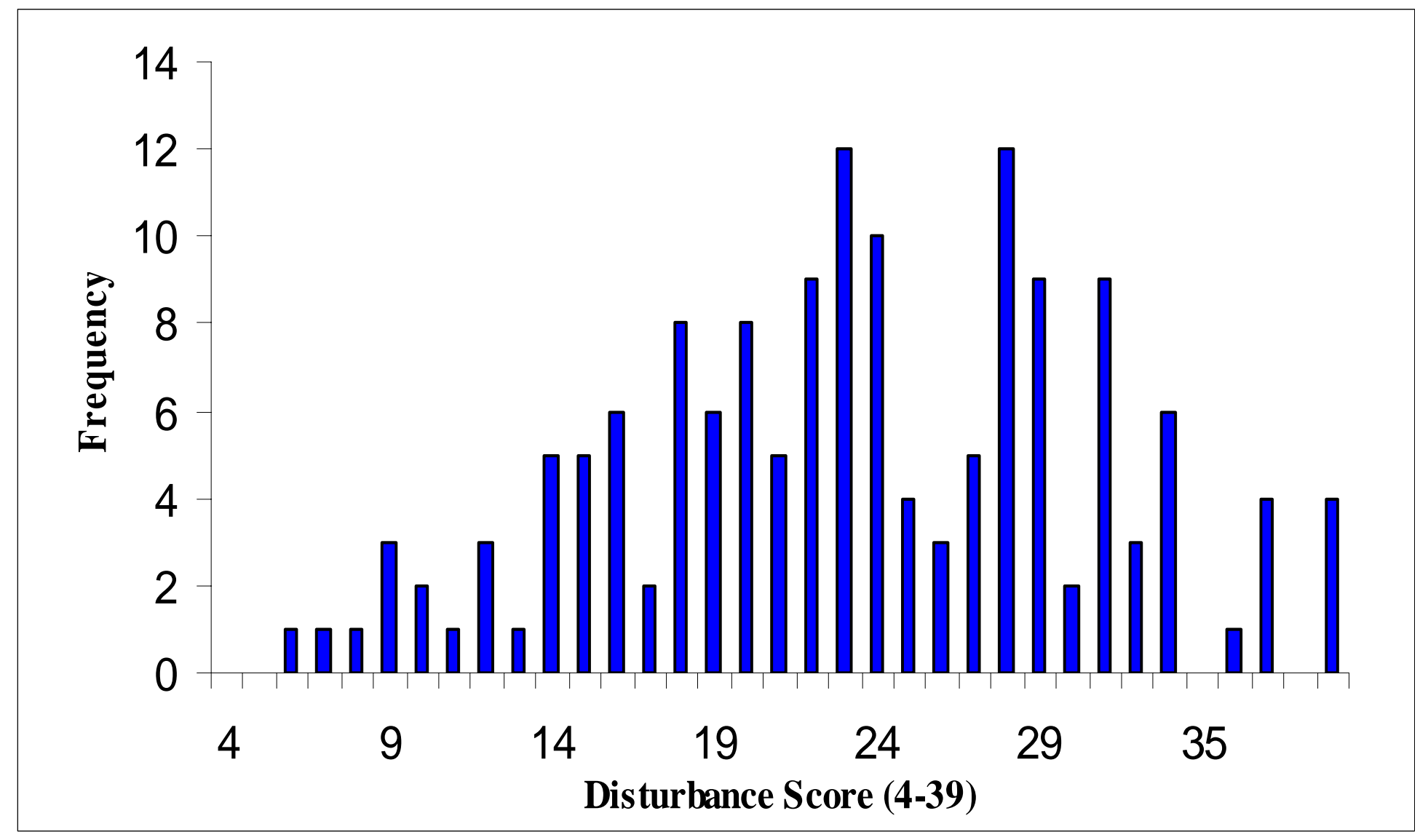

Figure 3. Frequency distribution of disturbance scores for sites used to develop class-specific macroinvertebrate indices of biological integrity (Mac-IBI) for wetlands in West Virginia, USA from 2005-2006. 


\title{
Chapter 6
}

\section{Indices of Biological Integrity Applications}

\section{Uses for Indices of Biological Integrity for Wetlands in West Virginia, USA}

\author{
Walter Veselka IV ${ }^{1}$ \\ James T. Anderson ${ }^{1,3}$ \\ Walter S. Kordek ${ }^{2}$ \\ ${ }^{1}$ Division of Forestry and Natural Resources, Wildlife and Fisheries Resources Program, \\ West Virginia University, PO Box 6125, Percival Hall, Morgantown, WV 26506 \\ ${ }^{2}$ West Virginia Division of Natural Resources, Wildlife Resources Section, PO Box 67, \\ Ward Road, Elkins, WV 26241 \\ 3 address correspondence to James T. Anderson, Ph.D., Division of Forestry and Natural \\ Resources, Wildlife and Fisheries Resources Program, West Virginia University, PO Box \\ 6125, Percival Hall, Morgantown, WV 26506. email: wetland@wvu.edu phone: (304) \\ 293-2941 ext. 2445, fax: (304) 293-2441
}

Submitted in the style of:

Environmental Monitoring and Assessment 


\begin{abstract}
The use of wetland indices of biological integrity (IBIs) to satisfy the water resources monitoring requirements of the Clean Water Act (CWA) are beginning to become as accepted as IBIs used to monitor lotic environments. However, debate still exists on what classification systems to base these IBIs upon, as well as which taxa are most sensitive to disturbance. We present the results of our cumulative body of research, representing indices of biological integrity designed for regional HGM subclasses, designated HGM management classes and Cowardin et al. (1979) classes. The indices were derived from metrics calculated from anuran, avian, macroinvertebrate, and vegetation communities; each representing increasing levels of resources associated with gathering the necessary data. For example, avian and anuran data used to derive floodplain wetland IBI metrics can be collected by volunteers, but the disturbance scores only account for $46 \%$ and $18 \%$ of the variation in IBI scores, respectively. Alternatively, the disturbance scores account for $56 \%$ and $47 \%$ of the variation in vegetation and invertebrate IBI scores, respectively. However, if the floodplain wetland was also a scrub-shrub wetland, by adding the avian and anuran metrics of both floodplain and scrub-shrub IBIs, we form a hybrid class, multi-taxa IBI where the disturbance scores account for $89 \%$ of the variation in IBI scores. In this work, we evaluate each of these taxonomic groups alone and in combination, in single and hybrid classification schemes, to examine changes in sensitivities to the disturbance gradient. The result is decision making tool that can assist water resource managers by providing them with the opportunity to stretch finite resources while ensuring the monitoring captures changes in wetland communities due to human disturbance. We also propose a new initiative to use
\end{abstract}


these tools in a manner to ensure the biological integrity of wetlands is maintained while providing an opportunity for state agencies to generate much-needed wetland restoration and creation funds.

Key words: Indices of biological integrity, IBIs, wetlands, disturbance, anuran communities, avian communities, macroinvertebrate communities, vegetation communities, West Virginia. 


\subsection{Introduction}

We have developed a series of state-wide indices that measure the biological integrity of wetlands in West Virginia. This research will allow policy makers to understand and anticipate the changes of avian, anuran, macroinvertebrate, and vegetation communities in response to increasing levels of localized human disturbance.

As such, West Virginia could effectively evaluate wetlands throughout the state over time and quantify trends by measuring the changes, or lack thereof, in biological integrity. Monitoring and assessment are a requirement of the Clean Water Act (CWA). Section 303 of the CWA directs states to adopt assessment criteria. Section 304 requires the U.S. Environmental Protection Agency (EPA) to provide guidance on how to conduct biological monitoring; and Section 305(b) requires biennial state-level reports on the condition of water bodies and aquatic ecosystems as described in previous sections. Thus, the reason for and function of indices of biological integrity is to provide regulators with the means to biologically evaluate these aquatic systems (Jackson and Davis 1994; Paulsen et al. 1998). The creation of a wetland index of biological integrity (IBI) could also be used to measure the effectiveness of mitigated wetlands in supporting biological communities; however, we must caution that, in the case of mitigated wetlands, intact biological communities are not completely indicative of functional replacement of the wetlands lost (Brown and Veneman 2001)

The Clean Water Act directive to "restore and maintain the chemical, physical, and biological integrity of the Nation's waters” (33 U.S.C. §1251- Section 101(a)) has for years, been unenforceable relative to West Virginia wetlands with regards to biological integrity because no quantitative criteria had been developed to measure this parameter. 
The use of chemical monitoring for wetlands has been largely ignored due to costs and the ambiguity and understanding what is an acceptable threshold level of particular chemical stressors. For example, if a primary function of a particular wetland is to trap non-point source pollutants and retain sediments from entering flowing water, as in the case of some floodplain wetlands, chemical levels may not be an appropriate indication of the health of a wetland (Paulsen et al. 1998). Additionally, chemical monitoring is simply a snap-shot in time and not always indicative of aquatic ecosystem health (Karr et al. 1986). It does not capture the physical changes that can affect wetland health, such as sedimentation, and vegetation and hydrologic alterations (Karr and Dudley 1981). Measuring the physical integrity of a wetland is, like chemical monitoring, also not necessarily a viable indication of wetland health. In the broadest sense, maintaining physical integrity is, in essence, ensuring wetlands are not paved over or filled in. We can delineate a wetland's edge jurisdictionally (USACOE 1987), essentially drawing a line for future landuse plans that they cannot cross. However, altering areas around a wetland will change the natural hydrology and water dynamics within a wetland, even if the physical size of a wetland remains intact (Hemond and Benoit 1988; Whigham et al. 1988; Winter 1988). It is these alterations and changes that can occur in proximity to wetlands, as well as in wetlands, that biological monitoring has been shown to be suited for capturing (Mack 2004; Micacchion 2004; Miller et al. 2006; Stapanian et al. 2004).

In selecting and evaluating a collection of biological assemblages and corresponding metrics that respond to a local site-specific disturbance gradient, it is inherent that no 1 biological assemblage or metric is capable of being the definitive rule on what is impaired and what is not, nor do biological communities respond to 
impairment at the same rates. Our disturbance gradient was based on a suite of site characteristics (Table 1) that will affect species assemblages in different ways. For example, disturbances to the natural hydrology of a wetland will likely express themselves in the macroinvertebrate and vegetation communities before becoming evident in avian communities (Brooks 2000; Koning 2005; Magee and Kentula 2005; Zimmer et al. 2000); whereas alterations to the area adjacent to wetlands may first be detected by amphibian and avian communities (Houlahan and Findlay 2003; O'Connell et al. 1998; Trombulak and Frissel 2000). However, if the disturbance continues and worsens, all communities will eventually reflect the disturbance. The changes in hydrology may lead to the expression of different plant communities, which, in turn will support changes in the avian community (Brown and Smith 1998; Twedt et al. 2000). The shift in macroinvertebrate communities may be followed by a shift in amphibian communities. As adjacent uplands are modified by landuse changes, the vegetative community may be prone to invasion by exotic and noxious species (Galatowitsch et al. 2000). The decreased cover of adjacent uplands may lead to increases in sedimentation that can cover benthic macroinvertebrate habitat and stifle macrophytic transpiration, resulting in wetland functioning in a diluted capacity with regards to filtering out and trapping pollutants (Hemond and Benoit 1988; Mahaney et al. 2004).

It is precisely because disturbances express themselves in different rates upon different biological assemblages that we chose to develop wetland IBIs for avian, anuran, vegetation, and macroinvertebrate communities. These assemblages were used to develop wetland IBIs specific to wetland type as described by the Cowardin et al. (1979) class (here after referred to as "Cowardin"), and the hydrogeomorphic (HGM) setting of a 
wetland (Brinson 1993). Additionally, we examined developing IBIs for the regionally defined HGM subclasses of wetland (Cole et al. 1997) to ascertain if this level of classification increases the sensitivity of our IBIs. The assemblages chosen for developing wetland IBIs were done to maximize the amount of information collected with the least expenditure of resources. State agencies are often limited by budgets, so each taxon group represents a different level of commitment of resources, allowing policy-makers to make cost-effective decisions in regards to monitoring wetlands (Figure 1). For example, our anuran acoustically-based indices of biological integrity (AA-IBI) was derived from methods used by existing amphibian monitoring programs (Casey and Record 1999) and is the easiest data to collect. The avian wetland indices of biological integrity (AW-IBI) are next in terms of resources needed to evaluate wetlands. Birds can be identified by sight and sound, but is a more difficult and time-consuming commitment for people to learn. Data can be collected by volunteers, but these volunteers must be trained and checked to ensure the quality of their data. Macroinvertebrate collection can be conducted by volunteers, and IBIs have been based on macroinvertebrates collected by volunteers in other states (Hicks and Nedeau 2000); but the identification of macroinvertebrates is professional-level work. The macroinvertebrate indices of biological integrity (Mac-IBI) were based on data collection methods that could be completed by volunteers in 1 day, but identification requires significantly more resources than avian and anuran assemblages with regards to actually deriving the macroinvertebrate data that make up the metrics. The vegetation based indices of biological integrity (Veg-IBI) are based on data which are the most laborious and require professional skill. Identifying plants to the species level, especially grasses and other 
monocots, is maybe necessary to develop the metrics from the raw data. Alternatively, some metrics can be derived from volunteer-gathered data and has been used to evaluate wetland condition (Witten 2005).

Our objective is to present the results of all of these indices of biological integrity in a format that can be used to make cost-effective decisions with regard to evaluating wetland health and integrity. We present the relation between each individual species assemblage and the disturbance gradient. Additionally, we combine the metrics from each IBI in combinations to reflect the different possibilities of resource commitment in order to evaluate the most cost-effective way to detect changes in wetland condition due to human impairment. For example, the Veg-IBI may be the best single taxa indicator of human disturbance; but combining the AW-IBI metrics and AA-IBI metrics (via addition) may result in a multi-taxa IBI that is more sensitive and cost-effective than the single taxa Veg-IBI. This would enable a better allocation of wetland monitoring resources, potentially resulting in more wetlands being evaluated with a greater degree of statistical certainty of identifying wetland trends. This concept was adopted from a call for the use of additive indices for resource management (Gerritsen 1995). In addition to combining metrics from different taxonomic groups to increase the sensitivity to the disturbance gradient in a class of wetlands; we take this notion one step further by integrating the wetland classification schemes. Our metrics have been tested for robustness not only throughout West Virginia, but also under different classification schemes. This means metrics developed for the emergent class of wetlands can be used in any HGM setting; alternatively, the metrics identified as effective in a floodplain setting will work regardless of that floodplain's Cowardin class. This has led us to 
develop hybrid indices of biological integrity that in some cases may be more sensitive to the disturbance gradient than the individual class-specific IBIs. With this approach, we not only can decide what is the most cost-effective way to measure disturbance in a wetland; but also the class or combination of classes to use to evaluate a wetland effectively. For example, combining the metrics from a scrub-shrub IBI and a floodplain IBI may be more sensitive to disturbance in a scrub shrub-floodplain wetland than either one alone.

\subsection{Methods}

In previous works, we developed a series of wetland indices of biological integrity using anuran, avian, macroinvertebrate, and vegetative communities (Veselka 2008: Chapters 2-5). The metrics included in each of these indices were extensively evaluated to ensure the capability to discriminate between reference and stressed sites throughout the state of West Virginia; and at the same time able to provide consistent scores for each class-specific (Cowardin or HGM-based) IBI regardless of the wetland's alternative classification. Each metric was scaled from 0-10, and the cumulative total of all the metrics for each taxa group was used to create a final IBI score, which was then evaluated in relation to the disturbance score using simple linear regression (Veselka 2008: Chapter 2-5).

First, using only the class-specific wetland IBIs that exhibited a significant relation with the disturbance scores, we added the metric scores from each taxa-specific IBI in combinations to reflect different levels of committed resources to wetland monitoring. None of the single taxa group IBIs were significantly related to the disturbance scores in the impoundment designated HGM management class, resulting in 
the omission of the impoundment classification scheme. The resulting class-specific, multi-taxa IBIs were each evaluated against the disturbance scores using simple linear regression to provide a measurement of sensitivity that was used to compare against other class-specific combinations of taxa groups.

In our second analysis, we still evaluated only the wetland metrics from the classspecific wetland IBIs that were significantly related to disturbance scores; but in this approach we combined metric scores from different classification schemes to evaluate all the possible hybrid IBI sensitivities to disturbance scores. By using simple linear regression, our results enabled us to compare the effectiveness of using metrics from both classification schemes to our class-specific multi-taxa IBIs relative to disturbance sensitivity.

\subsection{Results}

Combining the significant singular taxa group IBIs into multi-taxa class-specific IBIs resulted in significant relations for every combination (Table 2). The resulting sensitivities varied but, in every case, the sensitivity of the combined multi-taxa IBIs were greater than the lowest single taxa IBI although not always greater than the IBI with the most variation attributed to the disturbance gradient (Table 3). For each classification, combinations of taxa groups that included vegetation metrics were the most sensitive to the disturbance score. When we examined single taxa IBIs and combination IBIs that did not include vegetation metrics, the sensitivities decreased the most in riparian depression IBIs (including vegetation metrics $\mathrm{R}^{2}=0.32$, not inclusive of vegetation metrics $\mathrm{R}^{2}=0.13$ ) and the least in floodplain IBIs (including vegetation metrics $R^{2}=0.77$, not inclusive of vegetation metrics $R^{2}=0.72$ ). 
Combining the Cowardin and HGM classification schemes to form hybrid IBIs with multiple taxa, we found 49 of the 94 combinations we evaluated were significant to our disturbance scores (Table 4). We were able to evaluate the relations with the disturbance gradient based on these hybrid classifications to determine if an increase in variation can be attributed to the disturbance gradient (Table 5). We compared the classspecific IBIs with the highest sensitivities that included vegetation metrics, with those without the vegetation metrics, as an avenue to compare IBI sensitivity. We found the hybrid IBIs to be more sensitive to disturbance in 8 of the 12 classifications we evaluated. Only in the emergent-riparian depression, emergent-headwater floodplain, forestedriparian depression, and forested-depression hybrid IBIs could a greater amount of variation be attributed to the disturbance gradient by using the riparian depression, headwater floodplain, in the case of the emergent hybrid IBIs; or the forested classspecific IBIs as an alternative. In some cases, the increases in sensitivity were greater than $10 \%$. For example, the emergent-depression IBI that used avian and invertebrate metrics $\left(n=26, F_{1,24}=10.12, p=0.0040, R^{2}=0.30\right)$ was $14 \%$ more sensitive than the depression IBI using avian and invertebrate metrics $\left(n=46, F_{1,44}=8.37, p=0.0059, R^{2}=\right.$ 0.16); although less than the invertebrate and vegetation class-specific depression IBI (n $\left.=46, \mathrm{~F}_{1,44}=26.03, \mathrm{p}=<0.0001, \mathrm{R}^{2}=0.37\right)$. However, in scrub shrub-headwater floodplain wetlands, hybrid IBI scores were more sensitive than even the most sensitive headwater floodplain IBI that was formed by combining metrics from all taxa groups ( $\mathrm{n}=$ $\left.21, \mathrm{~F}_{1,19}=79.25, \mathrm{p}<0.0001, \mathrm{R}^{2}=0.81\right)$. The scrub shrub-headwater floodplain, avian and anuran IBI $\left(n=5, F_{1,3}=23.46, p=0.0168, R^{2}=0.89\right)$ and avian, macroinvertebrate, and vegetation IBI $\left(n=6, F_{1,4}=83.28, p=0.0008, R^{2}=0.95\right)$ were both more sensitive 
and would require fewer resources to evaluate a wetland fitting these 2 classifications.

The scrub shrub-riparian depression IBI was most sensitive if made up of

macroinvertebrate and vegetation metrics $\left(n=13, F_{1,11}=11.44, p=0.0061, R^{2}=0.51\right)$,

but other depression hybrid IBIs were not significantly related to the disturbance gradient if vegetation metrics were not included. If we were to evaluate this wetland without using vegetation metrics, the class-specific avian scrub shrub IBI exhibits the next highest relation with the disturbance gradient $\left(n=44, F_{1,42}=13.71, p=0.0006, R^{2}=\right.$ 0.25) applicable to this wetland.

The mean, standard error, minimum and maximum of metric values statewide and for each ecoregion, by taxa, are listed so future researchers have a reference as to the typical variability associated with each metric throughout the state (Tables 6-9).

\subsection{Discussion}

These results are intended to give wetland resource managers in West Virginia an opportunity to make a proactive choice in regards to committing resources to wetland monitoring. All wetlands can't be monitored effectively using the same criteria, and the results of our research attempts to provide a measure of clarity regarding that choice. We envision this system being used as part of a decision making process that can be implemented by making realistic choices. For example, the location of resources is a major logistical challenge in many types of field work. Wetlands in one portion of the state could never realistically be monitored extensively using vegetation surveys if the botanists are located in another. Using our results, wetland resource managers could determine that it would be a more efficient allocation of resources to send volunteers capable of collecting avian and macroinvertebrate data to 10 floodplain wetlands as 
opposed to a professional botanist to fewer wetlands. This decision could be validated knowing that $72 \%$ of the variation in avian and invertebrate combined floodplain IBI scores is attributable to disturbance scores, compared to only $56 \%$ of the variation in vegetation IBI scores. Additionally, the combining of Cowardin and HGM classes to form hybrid IBIs could allow researchers to draw stronger conclusions from the same data. For example, if the floodplain wetland used in the last example was also a scrub shrub wetland, by incorporating scrub-shrub metrics we could evaluate the wetland based only on avian and anuran assemblages, rather than collecting macroinvertebrates, resulting in $89 \%$ of the variation in IBI scores being on account of human impairment. This would save expense associated with preserving, identifying, and processing the macroinvertebrates by professional staff.

The creation of HGM subclass (Cole et al. 1997) and the designated HGM management class IBIs provide us with more tools to use than traditional Cowardin classification techniques. Basing IBIs on these HGM approaches has been called for by previous researchers (Stevenson and Hauer 2002), but the significant gains we see in sensitivity to disturbance is profound. The strong relations between floodplain and headwater floodplain based IBIs to the local disturbance score is especially important for wetland monitoring in West Virginia, which is typified by steep terrain. In fact, this terrain was carved by nearly $63,300 \mathrm{~km}$ of streams and 10,000 named streams in the state, resulting in approximately $1.03 \mathrm{~km}$ of stream for every square $\mathrm{km}$ of land, one of the highest stream densities in North America (Petty 2006). Because of this, flat land in West Virginia is a valuable commodity, and is more commonly found in the valleys of the mountainous terrain (and the tops of mountain top removal sites). Most wetlands 
associated with streams and rivers are typically small and linear, and literature suggests that they are often difficult to identify; leading to many wetlands not being included on maps such as the NWI(Anderson and Rentch 2007;Stolt and Baker 1995; Tiner 1997). As a result, we can assume in some capacity that floodplain wetlands are being lost in West Virginia to land-use changes brought on by human impacts, especially if they were never mapped or documented. Many historical floodplain wetlands, no doubt, have been lost in West Virginia prior to wetland protection as rivers were channeled and dredged to facilitate commerce. Floodplain wetlands provide many functions such as the regulation of floodwaters, sediment control, and biogeochemical transformations of nutrients and pathogens (Richardson 1994). According to the West Virginia Department of Environmental Protection (WVDEP), every major river in West Virginia has been impaired as a result of human activities (WVDEP 2004). The causes of impairment vary, but many are a result of heavy metals released from mining activities, increased fecal coliform levels, and sedimentation (WVDEP 2004). An intact floodplain wetland can only help mitigate some of the effects of these impacts. Floodplain wetlands trap sediment, filter out pollutants, and research has indicated on many levels that wetlands improve water quality (Fleming-Singer and Horne 2006; Kovacic et al. 2006; Whigham and Jordan 2003; Wilson and Mitsch 1996). Therefore, the development of highly responsive floodplain wetland IBIs that use multiple species as indicators of impairment provides an avenue from which the protection of these wetlands may be approached. As seen from our research, the sensitivity to disturbance scores can even be improved in headwater floodplain and floodplain wetlands when combined with metrics derived using the Cowardin classes. 
The remaining class-specific IBIs, based on Cowardin class, depressional designated HGM management class, and the riparian depression HGM subclass, in many cases exhibit a significant relation to the disturbance scores. However the strength of these relations are consistently below $50 \%$ of the variation in scores attributed to the local disturbance score; with the exception of the avian, macroinvertebrate, and vegetation based forested IBI, and a macroinvertebrate and vegetation based scrub-shrub-riparian depression IBI. As a result, the usefulness of these IBIs may be better served when coupled with GIS modeling of landscape variables. Because these IBIs are significantly related to the disturbance scores on a local scale, we know they respond predictably to human impairment. Other researchers have developed and tested disturbance gradients using GIS variables alone (Brown and Vivas 2005), from which IBIs have been based, as well as being integrated with local disturbance factors (Miller et al. 2006; Micacchion 2004). The use of GIS has been used to identify functionally significant wetlands, as well as prioritize restoration efforts to improve water quality (Almendinger 1999; Cedfeldt et al. 2000; Russell et al. 1997). Coupling the GIS approach with the responses of biological assemblages in response to local disturbances could be used to develop predictive models used to report on overall wetland condition in a watershed (Wardrop et al. 2007; Weller et al. 2007); enabling West Virginia to report the findings on wetland health as mandated by Section 305 (b) of the Clean Water Act.

Based on the results of our research and recognizing finite monitoring resources, we suggest that future studies should focus on floodplain wetlands. These wetlands are directly tied to one of West Virginia's greatest and most imperiled natural resources, the extensive network of streams and rivers. Our results were most consistently attributed to 
disturbance scores in floodplain wetlands, resulting in some cases where $\geq 80 \%$ of the variation of IBI scores was attributed to the local disturbance gradient. In emphasizing floodplain wetlands, we will also continue to simultaneously collect data that can be used to refine corresponding Cowardin class-specific IBIs, which were designed to be independent of HGM expression. Upon reiterations and further development of data, the Cowardin based IBIs can be used to ascertain the condition of wetlands not associated with rivers and streams. These wetlands would not be considered floodplain wetlands, resulting in the capability to modify and refine IBIs for both the Cowardin and other HGM classification schemes. In monitoring wetlands in this manner, West Virginia would begin fulfilling CWA mandates using floodplain wetlands, then expand upon an increasing knowledge base to all wetland expressions located throughout the state.

\subsection{Management Implications}

Our research provides wetland resource managers with more tools and resources than previously available to monitor wetlands in West Virginia. No doubt the most effective of these tools is the ability for managers to allocate resources to monitoring individual wetlands, drawing connections between the results of the monitoring and the link to impairment. In constructing a wetland monitoring program for the entire state while being flexible as to its potential for uses, it is important to maximize the information acquisition using the least amount of resources. Public involvement in the monitoring of wetlands should be maximized, resulting in a greater sense of public empathy for the plight of wetlands; and a larger sampling of wetland characteristics that can serve to update and strengthen the relation between monitoring and ecological research (Courtemanch 1994; Hart 1994). As previously substantiated, more research 
integrating IBI scores with landscape variables may be used to model probable wetland condition and functions; however, these models need to be constructed and tested and are not ready for immediate application.

Alternatively, with the creation of responsive IBIs, the effectiveness of mitigated wetlands in replacing natural wetlands can be compared, at least biologically. Bioassessments have, on occasion, been used as a basis for litigation (Paulsen et al. 1998) which may provide some measure of accountability ensuring mitigated wetlands are created in a manner conducive to providing biological habitat. In fact, the recently issued EPA guidelines on "Compensatory Mitigation for Losses of Aquatic Resources" (40 CFR Part 230), which calls for mitigation banks becoming the preferred mitigation alternative, specifies a need for “...measurable, enforceable ecological performance standards and regular monitoring for all types of compensation and specifying components of a complete, compensatory mitigation plan..." The series of statewide West Virginia wetland IBIs fulfills this need by establishing numeric criteria for excellent, good, marginal, or poor quality wetlands based upon biological integrity measures derived from wetland characteristics from a statewide sampling regime. In essence, the use of these IBIs in this manner will provide a new tool to gauge the success of mitigation and to hold parties accountable for failing mitigation projects.

Additionally our research could result in, with the support of the state legislature, an opportunity for West Virginia to establish a pro-active policy aimed at conserving more than just the wetland water resources of the state. We know that floodplain wetlands are sometimes not captured on Cowardin and topographic maps, but provide valuable functions to human society such as floodwater retention, the removal of 
pathogens, the immobilization of metals, and sediment control. If state government mandated that all permitted development activities within 100-m of a river or stream be surveyed for the presence of wetlands, we would undoubtedly discover and conserve more of the existing wetland resources supporting improvements to the state's water quality just by ensuring these wetlands are not eliminated. Furthermore, we can protect against the degradation of these wetlands, as mandated by the Clean Water Act, because of the highly responsive nature of floodplain IBI scores within 50-m of disturbance. By requiring preconstruction biological monitoring to establish a measure of the biological integrity of a wetland in proximity to an area slated for permitted land use change, we could ensure state permitted land-use activities follow best-management practices, which can protect biological communities against stressor impacts (Calhoun et al. 2005), by requiring companies to post bonds prior to land-use transformation. A set of reference wetlands within the same watershed would also be measured at the same time to compare with watershed wetland degradation with that of the wetland in proximity to the land use change. This bond would then be placed into a fund, similar to that established by the Surface Mining Control and Reclamation Act of 1977, which the state manages and for which it collects interest. After a set time period, the wetland in proximity to the land-use transformation, as well as the reference wetlands, can be evaluated using the same IBI criteria, and the money released (sans interest) if the wetland was not impaired biologically, or if it degraded in the same amount as the reference wetlands. If the wetland was impaired the bond would be forfeited, and the state would be responsible for creating or restoring wetlands using the bond money. A similar system would apply to mitigation banking companies to ensure the created or restored wetlands are maintained. 
Additionally, the interest from these bonds, upon maturation, could be used to restore or create wetlands where they would do the most good increasing water quality, as identified by future research. Although this would represent a bold initiative, the protection of wetlands in proximity to land-use alterations is not unprecedented; the state of Maine goes so far as to protect vernal pools, which are commonly not considered jurisdictional wetlands, from activities up to $\sim 75 \mathrm{~m}$ away (Maine Natural Resources Protection Act: Chapter 310, 335). Furthermore, this method would actually be suited to measuring the impact of riparian landuse changes because our floodplain wetland IBIs are responsive to a local disturbance gradient; whereas it is difficult to identify and locate single sources that cause stream impairment over acceptable thresholds. Thus, by protecting the wetlands and ensuring their continued capacity to immobilize heavy metals, trap sediments, and eliminate pathogens, West Virginia also would be protecting its rivers from these same impairments that are responsible for the listing of many streams on the West Virginia 303(d) list of impaired streams. This protection would ensure that West Virginia, whose rivers flow to the Chesapeake Bay and the Gulf of Mexico, would not only be known as the "birthplace of rivers" but also as a national leader and pioneer of innovative, proactive, water quality assurances.

\subsection{Acknowledgements}

We thank Adrianne Brand, Mark Hepner, and Joe Osbourne for assistance in data collection. Greg Pond, George Merovich, and the late Dr. George Seidel provided statistical support and advice. Technical writing and logistical support was provided by Sarah McClurg. Geographic information system and database management assistance was provided by Ben Gilmer. Funding was provided by the West Virginia Division of 
Natural Resources with assistance from U.S. EPA State Wetland Program Development Grant CD 973080-01-0. This is scientific article number xxxx of the West Virginia University Agriculture and Forestry Experiment Station. 


\subsection{Literature Cited}

Almendinger J.E. (1999). A method to prioritize and monitor wetland restoration for water-quality improvement. Wetlands Ecology and Management, 6, 241-251.

Anderson J.T., Rentch J.S. (2007). Errors of Wetland Omission and Commission in Mountainous Terrain. Society of Wetland Scientists 28th Annual Meeting, Sacramento, CA.

Brinson M.M. (1993). A hydrogeomorphic classification for wetlands. U.S. Army Engineers Waterways Experiment Station. Vicksburg, MS. Technical Report WRP-DE4.

Brooks R.T. (2000). Annual and seasonal variation and the effects of hydroperiod on benthic macroinvertebrates of seasonal forest ("vernal") ponds in central Massachusetts, U.S.A. Wetlands, 20, 707-715.

Brown M.T., Vivas B. (2005). Landscape development intensity index. Environmental Monitoring and Assessment, 101, 289-309.

Brown S.C., Veneman P.L.M. (2001). Effectiveness of compensatory wetland mitigation in Massachusetts, USA. Wetlands, 21, 508-518.

Brown S.C., Smith C.R. (1998). Breeding season bird use of recently restored versus natural wetlands of New York. Journal of Wildlife Management, 62, 1480-1491.

Calhoun A., Miller N.A., Klemens M.W. (2005). Conserving pool-breeding amphibians in human-dominated landscapes through local implementation of best development practices. Wetlands Ecology and Management, 13, 291-304.

Casey J., Record J. (1999). Anuran call count survey inventory and monitoring procedure. Unpublished report, U.S. Fish and Wildlife Service, Washington DC.

Cedfeldt P.T., Watzin M.C., Richardson B.D. (2000). Using GIS to identify functionally significant wetlands in the Northeastern United States. Environmental Management, 26, $13-24$.

Cole C.A., Brooks R.P., Wardrop D.H. (1997). Wetland hydrology as a function of hydrogeomorphic (HGM) subclass. Wetlands, 17, 456-467.

Courtemanch D.L. (1994). Bridging the old and new science of biological monitoring. Journal of North American Benthological Society, 13, 117-121.

Cowardin L.M., Carter V., Golet F.C., LaRoe E.T. (1979). Classification of wetlands and deepwater habitats of the United States. U.S. Fish and Wildlife Service. Report FWS/ OBS-79/31 
Fleming-Singer M.S., Horne A.J. (2006). Balancing wildlife needs and nitrate removal in constructed wetlands: the case of the Irvine Ranch Water District's San Joaquin Wildlife Sanctuary. Ecological Engineering, 26, 147-166.

Galatowitsch S.M., Whited D.C., Lehtinen R.M., Husveth J., Schik K. (2000). The vegetation of wet meadows in relation to their land-use. Environmental Monitoring and Assessment, 60, 121-144.

Gerritsen J. (1995). Additive biological indices for resource management. Journal of North American Benthological Society, 14, 451-457.

Hart D.D. (1994). Building a stronger partnership between ecological research and biological monitoring. Journal of North American Benthological Society, 13, 110-116.

Hemond H.F., Benoit J. (1988). Cumulative impacts on water quality functions of wetlands. Environmental Management, 12, 639-653.

Hicks A.L., Nedeau E.J. (2000). New England Freshwater Wetlands Invertebrate Biomonitoring Protocol: A manual for volunteers. 57 pages. Natural Resources and Environmental Conservation Program, Amherst, MA.

Houlahan J.E., Findlay C.S. (2003). The effects of adjacent land use on wetland amphibian species richness and community composition. Canadian Journal of Fisheries and Aquatic Sciences, 60, 1078-1094.

Jackson S., Davis W.S. (1994). Meeting the goal of biological integrity in water-resource programs of the U.S. Environmental Protection Agency. Journal of North American Benthological Society, 13, 592-597.

Karr J.R., Dudley D.R. (1981). Ecological perspective on water quality goals. Environmental Management, 5, 55-68.

Karr J.R., Fausch K.D., Angermeier P.L., Yant P.R., Schlosser I.J. (1986). Assessing biological integrity in running waters: a method and its rationale. Illinois Natural History Survey, Urbana, IL.

Koning C.O. (2005). Vegetation patterns resulting from spatial and temporal variability in hydrology, soils, and trampling in an isolated basin marsh, New Hampshire, U.S.A. Wetlands, 25, 239-251.

Kovacic D.A., Twait R.M., Wallace M.P., Bowling J.M. (2006). Use of created wetlands to improve water quality in the Midwest: Lake Bloomington case study. Ecological Engineering, 28, 258-270. 
Mack J.J. (2004). Integrated wetland assessment program. Part 9: Field manual for the vegetation index of biotic integrity for wetlands v. 1.3. Ohio Environmental Protection Agency, Wetland Ecology Group, Division of Surface Water, Columbus, OH.

Magee T.K., Kentula M.E. (2005). Response of wetland plant species to hydrologic conditions. Wetlands Ecology and Management, 13, 163-181.

Mahaney W.M., Wardrop D.H., Brooks R.P. (2004). Impacts of stressors on the emergence and growth of wetland plant species in Pennsylvania, U.S.A. Wetlands, 24, 538-549.

Micacchion M. (2004). Integrated wetland assessment program. Part 7: amphibian index of biotic integrity (AmphIBI) for Ohio wetlands. Ohio Environmental Protection Agency, Wetland Ecology Group, Division of Surface Water, Columbus, $\mathrm{OH}$.

Miller S.J., Wardrop D.H., Mahaney W.M., Brooks R.P. (2006). A plant-based index of biological integrity (IBI) for headwater wetlands in central Pennsylvania. Ecological Indicators, 6, 290-312.

O'Connell T.J., Jackson L.E., Brooks R.P. (1998). A bird community index of biotic integrity for the Mid-Atlantic highlands. Environmental Monitoring and Assessment, 51, 145-156.

Paulsen S.G., Hughes R.M., Larsen D.P. (1998). Critical elements in describing and understanding our nation's aquatic resources. Journal of the American Water Resources Association, 34, 995-1005.

Petty T. (2006). Streams. The West Virginia Encyclopedia. Sullivan K. (ed.), p. 944. West Virginia Humanities Council, Charleston, WV.

Richardson C.J. (1994). Ecological functions and human values in wetlands: a framework for assessing forestry impacts. Wetlands, 14, 1-9.

Russell G.D., Hawkins C.P., O'Neill M.P. (1997). The role of GIS in selecting sites for riparian restoration based on hydrology and land use. Restoration Ecology, 5, 56-68.

Stapanian M., Waite T.A., Krzys G., Mack J.J., Micacchion M. (2004). Rapid assessment indicator of wetland integrity as an unintended predictor of avian diversity.

Hydrobiologia, 520, 119-126.

Stevenson R.J., Hauer F.R. (2002). Integrating hydrogeomorphic and index of biotic integrity approaches for environmental assessment of wetlands. Journal of North American Benthological Society, 21, 502-513.

Stolt M.H., Baker J.C. (1995). Evaluation of the National Wetland Inventory maps to inventory wetlands in the southern Blue Ridge of Virginia. Wetlands, 15, 346-353. 
Tiner R. (1997). NWI maps- basic information on the nation's wetlands. BioScience, 269.

Trombulak S.C., Frissel C.A. (2000). Review of ecological effects of roads on terrestrial and aquatic communities. Conservation Biology, 14, 18-30.

Twedt D.J., Wilson R.R., Henne-Kerr J.L., Grosshuesch D.A. (2002). Avian response to bottomland hardwood reforestation: the first 10 years. Restoration Ecology, 10, 645-655.

USACOE (1987). Corps of Engineers Wetlands Delineation Manual. 99 pages. U.S. Army Corps of Engineers, Washington, DC

Veselka W. (2008). Developing volunteer-driven indices of biological integrity. M.S. Thesis. West Virginia University, Morgantown, WV.

Wardrop D.H., Kentula M.E., Stevens D.L.J., Jensen S.F., Brooks R.P. (2007).

Assessment of wetland condition: an example from the Upper Juniata watershed in Pennsylvania, USA. Wetlands, 27, 416-431.

Weller D.E., Snyder M.N., Whigham D.F., Jacobs A.D., Jordan T.E. (2007). Landscape indicators of wetland condition in the Nanticoke River Watershed, Maryland and Delaware, USA. Wetlands, 27, 498-514.

West Virginia DEP. (2004). West Virginia Section 303(d) list and supplements. West Virginia Department of Environmental Protection.

Whigham D.F., Chitterling C., Palmer B. (1988). Impacts of freshwater wetlands on water quality: a landscape perspective. Environmental Management, 12, 663-671.

Whigham D.F., Jordan T.E. (2003). Isolated wetlands and water quality. Wetlands, 23, 541-549.

Wilson R.F., Mitsch W.J. (1996). Functional assessment of five wetlands constructed to mitigate wetland loss in Ohio, USA. Wetlands, 16, 436-451.

Winter T.C. (1988). A conceptual framework for assessing cumulative impacts on the hydrology of nontidal wetlands. Environmental Management, 12, 605-620.

Witten M. (2005). Image-based plant estimate protocol: a field assessment method for surveying freshwater wetland vegetation in New England with volunteer groups. Lowell, MA: New England Interstate Water Pollution Control Commission.

Zimmer K.D., Hanson M.A., Butler M.J. (2000). Factors influencing invertebrate communities in prairie wetlands: a multivariate approach. Canadian Journal of Fisheries and Aquatic Sciences, 57, 76-85. 
Table 1. Metrics and sub-metrics of the Ohio Rapid Assessment Method (Mack 2001) used to define the disturbance gradient for use in developing multimetric indices of biological integrity for wetlands in West Virginia, USA from 2005-2006.

\footnotetext{
Scoring value Disturbance component

Upland buffers and surrounding land use

Calculate the average buffer width. Select only one and assign

score.

7

4

0

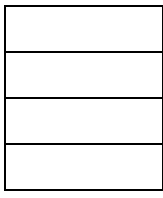

WIDE. Buffers average $50 \mathrm{~m}$ or more around wetland perimeter

MEDIUM. Buffers average $25 \mathrm{~m}$ to $<50 \mathrm{~m}$ around wetland perimeter

NARROW. Buffers average $10 \mathrm{~m}$ to $<25 \mathrm{~m}$ around wetland perimeter

VERY NARROW. Buffers average $<10 \mathrm{~m}$ around wetland perimeter

Intensity of surrounding land use. Select one or double check and average.

\begin{tabular}{l|l|}
7 & \\
5 & \\
3 & \\
& \\
\cline { 2 - 2 } &
\end{tabular}

VERY LOW. 2nd growth or older forest, prairie, savannah, wildlife area, etc.

LOW. Old field ( $>10$ years), shrubland, young second growth forest.

MODERATELY HIGH. Residential, fenced pasture, park, conservation tillage, new fallow field.

HIGH. Urban, industrial, open pasture, row cropping, mining, construction.

Hydrology

Modifications to natural, hydrologic regime. Score one or double check and average.

12

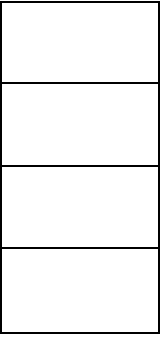

None or none apparent. There are no modifications or no modifications that are apparent to the rater.

Recovered. The wetland appears to have recovered from past modifications which altered the wetland's natural hydrologic regime.

Recovering. The wetland appears to be in the process of recovering from past modifications which altered the wetland's natural hydrologic regime.

Recent or no recovery. The modifications have occurred recently, and / or the wetland has not recovered from past modifications and / or the modifications are ongoing.

Habitat alteration and development

Substrate disturbance. Score one or double check and average.

4

None or none apparent. There are no modifications or no modifications that are apparent to the rater.

Recovered. The wetland appears to have recovered from past disturbances.

Recovering. The wetland appears to be in the process of recovering from past disturbances.

Recent or no recovery. The modifications have occurred recently, and / or the wetland has not recovered from past disturbances and/ or the disturbances are ongoing.

Habitat alteration. Score one or double check and average.

None or none apparent. There are no alterations or no alterations that are apparent to the rater.

Recovered. The wetland appears to have recovered from past alterations.

Recovering. The wetland appears to be in the process of recovering from past alterations.

Recent or no recovery. The modifications have occurred recently, and / or the wetland has not recovered from past alterations and/ or the alterations are ongoing.
} 
Table 2. Single and multi-taxa wetland indices of biological integrity and resulting relation with the disturbance score for wetlands in West Virginia, USA in 2005-2006.

\begin{tabular}{|c|c|c|c|c|c|c|c|c|}
\hline \multicolumn{3}{|c|}{ Wetland Classification } & \multirow[b]{2}{*}{$\mathrm{N}$} & \multirow[b]{2}{*}{ df } & \multirow[b]{2}{*}{$\begin{array}{c}\text { F- } \\
\text { value }\end{array}$} & \multirow[b]{2}{*}{$\mathrm{p}$-value } & \multirow[b]{2}{*}{$\mathrm{R}^{2}$} & \multirow[b]{2}{*}{ Equation } \\
\hline \multicolumn{3}{|c|}{ Taxa group(s) IBI } & & & & & & \\
\hline \multicolumn{9}{|l|}{$\begin{array}{l}\text { Riparian } \\
\text { Depression }\end{array}$} \\
\hline Anurans & & & 52 & 1,50 & 4.32 & 0.0429 & 0.08 & $\mathrm{y}=1.53+0.12($ Disturbance score $)$ \\
\hline Invertebrates & & & 39 & 1,37 & 5.58 & 0.0238 & 0.13 & $y=-2.36+0.17$ (Disturbance score) \\
\hline Vegetation & & & 59 & 1,57 & 19.87 & $<0.0001$ & 0.26 & $\mathrm{y}=4.16+0.50$ (Disturbance score) \\
\hline Anurans & Invertebrates & & 37 & 1,35 & 4.48 & 0.0416 & 0.11 & $\mathrm{y}=0.92+0.20$ (Disturbance score $)$ \\
\hline Anurans & Invertebrates & Vegetation & 37 & 1,35 & 14.90 & 0.0005 & 0.30 & $y=7.07+0.62($ Disturbance score $)$ \\
\hline Anurans & Vegetation & & 52 & 1,50 & 19.61 & $<0.0001$ & 0.28 & $\mathrm{y}=6.92+0.58$ (Disturbance score) \\
\hline Invertebrates & Vegetation & & 39 & 1,37 & 17.52 & 0.0002 & 0.32 & $y=3.27+0.61$ (Disturbance score $)$ \\
\hline Cumulative $\mathrm{V}$ & tland IBI & & 37 & 1,35 & 14.90 & 0.0005 & 0.30 & $y=7.07+0.62($ Disturbance score $)$ \\
\hline \multicolumn{9}{|l|}{$\begin{array}{l}\text { Headwater } \\
\text { Floodplain }\end{array}$} \\
\hline Anurans & & & 22 & 1,21 & 7.49 & 0.0127 & 0.27 & $y=-0.52+0.20$ (Disturbance score) \\
\hline Birds & & & 29 & 1,27 & 25.44 & $<0.0001$ & 0.49 & $\mathrm{y}=11.97+0.62$ (Disturbance score) \\
\hline Invertebrates & & & 26 & 1,24 & 6.06 & 0.0214 & 0.20 & $\mathrm{y}=0.85+0.23$ (Disturbance score) \\
\hline Vegetation & & & 29 & 1,27 & 50.00 & $<0.0001$ & 0.65 & $y=-7.21+0.76$ (Disturbance score) \\
\hline Anurans & Birds & & 22 & 1,20 & 19.74 & 0.0003 & 0.50 & $y=14.50+0.73$ (Disturbance score) \\
\hline Anurans & Birds & Invertebrates & 21 & 1,19 & 41.76 & $<0.0001$ & 0.69 & $\mathrm{y}=8.11+1.21$ (Disturbance score) \\
\hline Anurans & Birds & Vegetation & 22 & 1,20 & 53.87 & $<0.0001$ & 0.73 & $\mathrm{y}=4.48+1.58$ (Disturbance score) \\
\hline Anurans & Invertebrates & & 21 & 1,19 & 19.81 & 0.0003 & 0.51 & $y=-3.15+0.56$ (Disturbance score) \\
\hline Anurans & Invertebrates & Vegetation & 21 & 1,19 & 46.62 & $<0.0001$ & 0.71 & $\mathrm{y}=-13.95+1.45$ (Disturbance score) \\
\hline Anurans & Vegetation & & 22 & 1,20 & 37.69 & $<0.0001$ & 0.65 & $y=-10.54+1.06$ (Disturbance score) \\
\hline Birds & Invertebrates & & 26 & 1,24 & 36.34 & $<0.0001$ & 0.60 & $\mathrm{y}=10.71+0.91$ (Disturbance score) \\
\hline Birds & Vegetation & & 29 & 1,27 & 86.47 & $<0.0001$ & 0.76 & $\mathrm{y}=4.75+1.38$ (Disturbance score) \\
\hline Birds & Invertebrates & Vegetation & 26 & 1,24 & 85.77 & $<0.0001$ & 0.78 & $y=3.40+1.68$ (Disturbance score) \\
\hline Invertebrates & Vegetation & & 26 & 1,24 & 40.11 & $<0.0001$ & 0.63 & $y=-6.46+0.99$ (Disturbance score) \\
\hline Cumulative $\mathrm{V}$ & tland IBI & & 21 & 1,19 & 79.25 & $<0.0001$ & 0.81 & $y=-2.70+2.10$ (Disturbance score) \\
\hline \multicolumn{9}{|l|}{ Depression } \\
\hline \multicolumn{9}{|l|}{ Anurans } \\
\hline Birds & & & 72 & 1,70 & 9.71 & 0.0027 & 0.12 & $\mathrm{y}=9.52+0.23$ (Disturbance score) \\
\hline Invertebrates & & & 46 & 1,44 & 5.17 & 0.028 & 0.11 & $\mathrm{y}=-1.44+0.13$ (Disturbance score) \\
\hline Vegetation & & & 72 & 1,70 & 31.79 & $<0.0001$ & 0.31 & $\mathrm{y}=0.32+0.34($ Disturbance score $)$ \\
\hline Birds & Invertebrates & & 46 & 1,44 & 8.37 & 0.0059 & 0.16 & $\mathrm{y}=8.62+0.33$ (Disturbance score) \\
\hline Birds & Vegetation & & 72 & 1,70 & 33.32 & $<0.0001$ & 0.32 & $\mathrm{y}=9.84+0.58$ (Disturbance score $)$ \\
\hline Birds & Invertebrates & Vegetation & 46 & 1,44 & 23.96 & $<0.0001$ & 0.35 & $\mathrm{y}=9.96+0.3$ (Disturbance score) \\
\hline Invertebrates & Vegetation & & 46 & 1,44 & 26.03 & $<0.0001$ & 0.37 & $y=-0.11+0.43$ (Disturbance score) \\
\hline Cumulative $\mathrm{V}$ & tland IBI & & 46 & 1,44 & 23.97 & $<0.0001$ & 0.35 & $\mathrm{y}=9.96+0.63$ (Disturbance score) \\
\hline
\end{tabular}


Table 2. Continued.

\begin{tabular}{|c|c|c|c|c|c|c|c|c|}
\hline \multicolumn{3}{|c|}{ Wetland Classification } & \multirow[b]{2}{*}{$\mathrm{N}$} & \multirow[b]{2}{*}{$\mathrm{df}$} & \multirow{2}{*}{$\begin{array}{c}\text { F- } \\
\text { value }\end{array}$} & \multirow[b]{2}{*}{ p-value } & \multirow[b]{2}{*}{$\mathrm{R}^{2}$} & \multirow[b]{2}{*}{ Equation } \\
\hline \multicolumn{3}{|c|}{ Taxa group(s) IBI } & & & & & & \\
\hline \multicolumn{9}{|l|}{ Floodplain } \\
\hline Anurans & & & 28 & 1,26 & 5.76 & 0.0238 & 0.18 & $\mathrm{y}=3.37+0.30$ (Disturbance score $)$ \\
\hline Birds & & & 35 & 1,33 & 32.74 & $<0.0001$ & 0.46 & $\mathrm{y}=18.14+0.50$ (Disturbance score) \\
\hline Invertebrates & & & 28 & 1,26 & 23.21 & $<0.0001$ & 0.47 & $\mathrm{y}=2.92+0.41$ (Disturbance score) \\
\hline Vegetation & & & 35 & 1,33 & 42.16 & $<0.0001$ & 0.56 & $y=-0.78+0.81$ (Disturbance score) \\
\hline Anurans & Birds & & 28 & 1,26 & 19.81 & 0.0001 & 0.43 & $\mathrm{y}=26.30+0.65$ (Disturbance score) \\
\hline Anurans & Birds & Invertebrates & 24 & 1,22 & 31.35 & $<0.0001$ & 0.59 & $\mathrm{y}=26.15+1.18$ (Disturbance score) \\
\hline Anurans & Birds & Vegetation & 28 & 1,26 & 44.44 & $<0.0001$ & 0.63 & $\mathrm{y}=24.41+1.51$ (Disturbance score) \\
\hline Anurans & Invertebrates & & 24 & 1,22 & 14.87 & 0.0009 & 0.40 & $y=5.27+0.74($ Disturbance score $)$ \\
\hline Anurans & Invertebrates & Vegetation & 24 & 1,22 & 25.35 & $<0.0001$ & 0.54 & $\mathrm{y}=5.37+1.53$ (Disturbance score) \\
\hline Anurans & Vegetation & & 28 & 1,26 & 25.55 & $<0.0001$ & 0.50 & $\mathrm{y}=1.48+1.16($ Disturbance score $)$ \\
\hline Birds & Invertebrates & & 28 & 1,26 & 66.50 & $<0.0001$ & 0.72 & $\mathrm{y}=21.03+0.93$ (Disturbance score) \\
\hline Birds & Vegetation & & 35 & 1,33 & 86.63 & $<0.0001$ & 0.72 & $\mathrm{y}=17.35+1.31$ (Disturbance score) \\
\hline Birds & Invertebrates & Vegetation & 28 & 1,26 & 88.38 & $<0.0001$ & 0.77 & $\mathrm{y}=22.25+1.66$ (Disturbance score) \\
\hline Invertebrates & Vegetation & & 28 & 1,26 & 41.17 & $<0.0001$ & 0.61 & $\mathrm{y}=4.14+1.13$ (Disturbance score) \\
\hline Cumulative W & etland IBI & & 24 & 1,22 & 43.10 & $<0.0001$ & 0.66 & $\mathrm{y}=26.25+1.97$ (Disturbance score) \\
\hline \multicolumn{9}{|l|}{ Emergent } \\
\hline Birds & & & 75 & 1,73 & 8.71 & 0.0042 & 0.11 & $\mathrm{y}=6.47+0.09$ (Disturbance score) \\
\hline Vegetation & & & 75 & 1,73 & 11.91 & 0.0009 & 0.14 & $\mathrm{y}=3.47+0.12($ Disturbance score $)$ \\
\hline Birds & Vegetation & & 75 & 1,73 & 19.66 & $<0.0001$ & 0.21 & $\mathrm{y}=9.93+0.21$ (Disturbance score) \\
\hline Cumulative W & etland IBI & & 75 & 1,73 & 19.66 & $<0.0001$ & 0.21 & $\mathrm{y}=9.93+0.21($ Disturbance score $)$ \\
\hline \multicolumn{9}{|l|}{$\begin{array}{l}\text { Scrub- } \\
\text { shrub }\end{array}$} \\
\hline Birds & & & 44 & 1,42 & 13.71 & 0.0006 & 0.25 & $\mathrm{y}=17.54+0.54$ (Disturbance score) \\
\hline Invertebrates & & & 36 & 1,34 & 3.37 & 0.075 & 0.09 & $y=3.66+0.13$ (Disturbance score) \\
\hline Vegetation & & & 44 & 1,42 & 10.33 & 0.0025 & 0.20 & $\mathrm{y}=3.13+0.66($ Disturbance score $)$ \\
\hline Birds & Vegetation & & 44 & 1,42 & 22.00 & $<0.0001$ & 0.34 & $\mathrm{y}=22.53+0.78$ (Disturbance score) \\
\hline Cumulative W & etland IBI & & 36 & 1,34 & 18.23 & $<0.0001$ & 0.35 & $\mathrm{y}=29.79+0.79$ (Disturbance score) \\
\hline \multicolumn{9}{|l|}{ Forested } \\
\hline Birds & & & 31 & 1,29 & 8.48 & 0.0056 & 0.24 & $\mathrm{y}=6.07+0.47$ (Disturbance score) \\
\hline Invertebrates & & & 29 & 1,27 & 4.22 & 0.0497 & 0.14 & $\mathrm{y}=0.56+0.33$ (Disturbance score) \\
\hline Vegetation & & & 31 & 1,29 & 16.62 & 0.0005 & 0.35 & $\mathrm{y}=3.50+0.79$ (Disturbance score) \\
\hline Birds & Invertebrates & & 29 & 1,27 & 14.29 & 0.0008 & 0.35 & $y=7.60+0.76($ Disturbance score $)$ \\
\hline Birds & Vegetation & & 31 & 1,29 & 26.90 & $<0.0001$ & 0.48 & $\mathrm{y}=9.57+1.25$ (Disturbance score) \\
\hline Birds & Invertebrates & Vegetation & 29 & 1,27 & 29.05 & $<0.0001$ & 0.52 & $\mathrm{y}=13.61+1.44$ (Disturbance score) \\
\hline Invertebrates & Vegetation & & 29 & 1,27 & 15.19 & 0.0006 & 0.36 & $\mathrm{y}=6.57+1.01$ (Disturbance score) \\
\hline Cumulative W & etland IBI & & 29 & 1,27 & 29.05 & $<0.0001$ & 0.52 & $\mathrm{y}=13.61+1.44$ (Disturbance score) \\
\hline
\end{tabular}


Table 3. Significant $\mathrm{R}^{2}$ for class-specific single and multi-taxa indices of biological integrity (IBIs) for hydrogeomorphic (HGM) subclasses, designated HGM management classes, and Cowardin classes for wetlands of West Virginia, USA from 2005-2006.

\begin{tabular}{|c|c|c|c|c|c|c|c|c|c|}
\hline \multirow{2}{*}{\multicolumn{2}{|c|}{ Taxa groups in multi-taxa wetland IBIs }} & & \multicolumn{2}{|c|}{ HGM subclass $^{\mathrm{a}}$} & \multicolumn{2}{|c|}{$\begin{array}{l}\text { Designated HGM } \\
\text { management class }\end{array}$} & \multicolumn{3}{|c|}{ Cowardin classification } \\
\hline & & & $\begin{array}{c}\text { Riparian } \\
\text { Depression } \\
\end{array}$ & $\begin{array}{l}\text { Headwater } \\
\text { Floodplain } \\
\end{array}$ & Depression & Floodplain & Emergent & Scrub-shrub & Forested \\
\hline \multicolumn{3}{|l|}{ Anurans } & 0.08 & 0.27 & & 0.18 & & & \\
\hline \multicolumn{3}{|l|}{ Birds } & & 0.49 & 0.12 & 0.46 & 0.11 & 0.25 & 0.24 \\
\hline \multicolumn{3}{|l|}{ Invertebrates } & 0.13 & 0.20 & 0.11 & 0.47 & & & 0.14 \\
\hline \multicolumn{3}{|l|}{ Vegetation } & 0.26 & 0.65 & 0.31 & 0.56 & 0.14 & 0.20 & 0.35 \\
\hline Anurans & Birds & & & 0.5 & & 0.43 & & & \\
\hline Anurans & Birds & Invertebrates & & 0.69 & & 0.59 & & & \\
\hline Anurans & Birds & Vegetation & & 0.73 & & 0.63 & & & \\
\hline Anurans & Invertebrates & & 0.11 & 0.51 & & 0.40 & & & \\
\hline Anurans & Invertebrates & Vegetation & 0.30 & 0.71 & & 0.54 & & & \\
\hline Anurans & Vegetation & & 0.28 & 0.65 & & 0.50 & & & \\
\hline Birds & Invertebrates & & & 0.60 & 0.16 & 0.72 & & & 0.35 \\
\hline Birds & Vegetation & & & 0.76 & 0.32 & 0.72 & 0.21 & 0.34 & 0.48 \\
\hline Birds & Invertebrates & Vegetation & & 0.78 & 0.35 & 0.77 & & & 0.52 \\
\hline Invertebrates & Vegetation & & 0.32 & 0.63 & 0.37 & 0.61 & & & 0.36 \\
\hline \multicolumn{3}{|c|}{ Cumulative Wetland IBI } & 0.30 & 0.81 & 0.35 & 0.66 & 0.21 & 0.35 & 0.52 \\
\hline
\end{tabular}

${ }^{a}$ Cole et al. (1997) 
Table 4. Multi-taxa, hybrid classification scheme wetland indices of biological integrity and resulting relation with the disturbance score for wetlands in West Virginia, USA in 2005-2006.

\begin{tabular}{|c|c|c|c|c|c|c|c|c|}
\hline \multicolumn{3}{|c|}{ Wetland Classification } & \multirow[b]{2}{*}{$\mathrm{N}$} & \multirow[b]{2}{*}{ df } & \multirow[b]{2}{*}{$\begin{array}{c}\text { F- } \\
\text { value }\end{array}$} & \multirow[b]{2}{*}{ p-value } & \multirow[b]{2}{*}{$\mathrm{R}^{2}$} & \multirow[b]{2}{*}{ Equation } \\
\hline \multicolumn{3}{|c|}{ Taxa group in hybrid IBI } & & & & & & \\
\hline \multicolumn{9}{|c|}{ Emergent- Riparian Depression } \\
\hline Anurans & Birds & & 28 & 1,26 & 2.13 & 0.1568 & 0.08 & $\mathrm{y}=8.54+0.17$ (Disturbance score) \\
\hline Anurans & Birds & Invertebrates & 21 & 1,19 & 7.06 & 0.0156 & 0.27 & $\mathrm{y}=4.96+0.43$ (Disturbance score) \\
\hline Anurans & Birds & Vegetation & 28 & 1,26 & 0.92 & 0.3472 & 0.03 & $\mathrm{y}=21.48+0.20$ (Disturbance score) \\
\hline Anurans & Invertebrates & Vegetation & 21 & 1,19 & 4.69 & 0.0433 & 0.20 & $\mathrm{y}=7.97+0.56($ Disturbance score $)$ \\
\hline Anurans & Vegetation & & 28 & 1,26 & 1.23 & 0.2772 & 0.05 & $\mathrm{y}=13.00+0.21$ (Disturbance score $)$ \\
\hline Birds & Invertebrates & & 21 & 1,19 & 6.38 & 0.0206 & 0.25 & $y=3.60+0.31($ Disturbance score $)$ \\
\hline Birds & Vegetation & & 29 & 1,27 & 0.07 & 0.7947 & 0.00 & $\mathrm{y}=21.02+0.05$ (Disturbance score $)$ \\
\hline Birds & Invertebrates & Vegetation & 21 & 1,19 & 3.27 & 0.0864 & 0.15 & $\mathrm{y}=14.99+0.44$ (Disturbance score $)$ \\
\hline Invertebrates & Vegetation & & 21 & 1,19 & 3.56 & 0.0747 & 0.16 & $y=6.62+0.44$ (Disturbance score $)$ \\
\hline \multicolumn{9}{|c|}{ Emergent- Headwater Floodplain } \\
\hline Anurans & Birds & & 13 & 1,11 & 4.79 & 0.0510 & 0.30 & $\mathrm{y}=17.64+0.58($ Disturbance score $)$ \\
\hline Anurans & Birds & Invertebrates & 12 & 1,10 & 12.59 & 0.0053 & 0.56 & $\mathrm{y}=8.58+1.20($ Disturbance score $)$ \\
\hline Anurans & Birds & Vegetation & 13 & 1,11 & 14.96 & 0.0026 & 0.58 & $\mathrm{y}=8.23+1.43$ (Disturbance score) \\
\hline Anurans & Invertebrates & Vegetation & 12 & 1,10 & 14.97 & 0.0031 & 0.60 & $y=-12.66+1.41$ (Disturbance score) \\
\hline Anurans & Vegetation & & 13 & 1,11 & 11.09 & 0.0067 & 0.50 & $y=-7.35+0.93$ (Disturbance score) \\
\hline Birds & Invertebrates & & 14 & 1,12 & 13.21 & 0.0034 & 0.52 & $y=9.71+0.95($ Disturbance score $)$ \\
\hline Birds & Vegetation & & 15 & 1,13 & 20.66 & 0.0005 & 0.61 & $\mathrm{y}=7.73+1.27$ (Disturbance score) \\
\hline Birds & Invertebrates & Vegetation & 14 & 1,12 & 30.16 & $<0.0001$ & 0.72 & $y=-0.03+1.81$ (Disturbance score) \\
\hline Invertebrates & Vegetation & & 14 & 1,12 & 26.38 & 0.0002 & 0.69 & $y=-12.67+1.22$ (Disturbance score) \\
\hline \multicolumn{9}{|c|}{ Emergent- Depression } \\
\hline Birds & Invertebrates & & 26 & 1,24 & 10.12 & 0.0040 & 0.30 & $\mathrm{y}=11.72+0.58($ Disturbance score $)$ \\
\hline Birds & Vegetation & & 38 & 1,36 & 4.63 & 0.0382 & 0.11 & $\mathrm{y}=20.06+0.41$ (Disturbance score $)$ \\
\hline Birds & Invertebrates & Vegetation & 26 & 1,24 & 12.00 & 0.0020 & 0.33 & $y=16.29+0.67$ (Disturbance score $)$ \\
\hline Invertebrates & Vegetation & & 26 & 1,24 & 8.13 & 0.0088 & 0.25 & $\mathrm{y}=1.79+0.32($ Disturbance score $)$ \\
\hline \multicolumn{9}{|c|}{ Emergent- Floodplain } \\
\hline Anurans & Birds & & 14 & 1,12 & 8.69 & 0.0122 & 0.42 & $\mathrm{y}=27.68+0.54$ (Disturbance score $)$ \\
\hline Anurans & Birds & Invertebrates & 13 & 1,11 & 16.01 & 0.0020 & 0.59 & $y=26.76+1.09$ (Disturbance score) \\
\hline Anurans & Birds & Vegetation & 14 & 1,12 & 16.63 & 0.0015 & 0.58 & $\mathrm{y}=29.75+1.50$ (Disturbance score) \\
\hline Anurans & Invertebrates & Vegetation & 13 & 1,11 & 8.79 & 0.0129 & 0.44 & $\mathrm{y}=12.48+1.43$ (Disturbance score) \\
\hline Anurans & Vegetation & & 14 & 1,12 & 6.58 & 0.0248 & 0.35 & $\mathrm{y}=8.58+1.06$ (Disturbance score $)$ \\
\hline Birds & Invertebrates & & 15 & 1,13 & 38.82 & $<0.0001$ & 0.75 & $\mathrm{y}=19.28+1.00($ Disturbance score $)$ \\
\hline Birds & Vegetation & & 16 & 1,14 & 42.86 & $<0.0001$ & 0.75 & $\mathrm{y}=23.50+1.38($ Disturbance score $)$ \\
\hline Birds & Invertebrates & Vegetation & 15 & 1,13 & 46.24 & $<0.0001$ & 0.78 & $\mathrm{y}=23.91+1.87$ (Disturbance score) \\
\hline Invertebrates & Vegetation & & 15 & 1,13 & 23.99 & 0.0003 & 0.65 & $y=4.56+1.37$ (Disturbance score) \\
\hline
\end{tabular}


Table 4. Continued.

\begin{tabular}{|c|c|c|c|c|c|c|c|c|}
\hline \multicolumn{3}{|c|}{ Wetland Classification } & \multirow[b]{2}{*}{$\mathrm{N}$} & \multirow[b]{2}{*}{$\mathrm{df}$} & \multirow[b]{2}{*}{$\begin{array}{c}\text { F- } \\
\text { value }\end{array}$} & \multirow[b]{2}{*}{$\mathrm{p}$-value } & \multirow[b]{2}{*}{$\mathrm{R}^{2}$} & \multirow[b]{2}{*}{ Equation } \\
\hline \multicolumn{3}{|c|}{ Taxa group in hybrid IBI } & & & & & & \\
\hline \multicolumn{9}{|c|}{ Scrub shrub- Riparian Depression } \\
\hline Anurans & Birds & & 16 & 1,14 & 0.66 & 0.4294 & 0.05 & $\mathrm{y}=29.99+0.24$ (Disturbance score) \\
\hline Anurans & Birds & Invertebrates & 12 & 1,10 & 0.39 & 0.5468 & 0.04 & $\mathrm{y}=30.85+0.24$ (Disturbance score) \\
\hline Anurans & Birds & Vegetation & 16 & 1,14 & 6.62 & 0.0221 & 0.32 & $\mathrm{y}=32.03+1.03$ (Disturbance score) \\
\hline Anurans & Invertebrates & Vegetation & 12 & 1,10 & 7.70 & 0.0196 & 0.43 & $\mathrm{y}=7.27+0.77$ (Disturbance score) \\
\hline Anurans & Vegetation & & 16 & 1,14 & 10.00 & 0.0069 & 0.42 & $\mathrm{y}=5.63+0.85$ (Disturbance score) \\
\hline Birds & Invertebrates & & 13 & 1,11 & 0.61 & 0.4505 & 0.05 & $y=26.16+0.26$ (Disturbance score) \\
\hline Birds & Vegetation & & 18 & 1,16 & 10.21 & 0.0056 & 0.39 & $\mathrm{y}=23.85+1.13$ (Disturbance score) \\
\hline Birds & Invertebrates & Vegetation & 13 & 1,11 & 6.10 & 0.0312 & 0.36 & $\mathrm{y}=30.02+0.94$ (Disturbance score) \\
\hline Invertebrates & Vegetation & & 13 & 1,11 & 11.44 & 0.0061 & 0.51 & $\mathrm{y}=2.69+0.79$ (Disturbance score $)$ \\
\hline \multicolumn{9}{|c|}{ Scrub shrub- Headwater Floodplain } \\
\hline Anurans & Birds & & 5 & 1,3 & 23.46 & 0.0168 & 0.89 & $\mathrm{y}=0.55+1.61$ (Disturbance score) \\
\hline Anurans & Birds & Invertebrates & 5 & 1,3 & 41.92 & 0.0075 & 0.93 & $\mathrm{y}=0.50+1.85$ (Disturbance score) \\
\hline Anurans & Birds & Vegetation & 5 & 1,3 & 11.14 & 0.0445 & 0.79 & $\mathrm{y}=10.20+2.19$ (Disturbance score) \\
\hline Anurans & Invertebrates & Vegetation & 5 & 1,3 & 3.80 & 0.1462 & 0.56 & $\mathrm{y}=0.55+1.28$ (Disturbance score) \\
\hline Anurans & Vegetation & & 5 & 1,3 & 2.17 & 0.2372 & 0.42 & $\mathrm{y}=0.61+1.05$ (Disturbance score) \\
\hline Birds & Invertebrates & & 6 & 1,4 & 30.78 & 0.0052 & 0.88 & $\mathrm{y}=5.63+1.52($ Disturbance score $)$ \\
\hline Birds & Vegetation & & 7 & 1,5 & 56.29 & 0.0007 & 0.92 & $y=-4.66+2.44$ (Disturbance score) \\
\hline Birds & Invertebrates & Vegetation & 6 & 1,4 & 83.28 & 0.0008 & 0.95 & $\mathrm{y}=17.58+2.02($ Disturbance score $)$ \\
\hline Invertebrates & Vegetation & & 6 & 1,4 & 2.84 & 0.1674 & 0.42 & $\mathrm{y}=13.62+0.68$ (Disturbance score $)$ \\
\hline \multicolumn{9}{|c|}{ Scrub shrub- Depression } \\
\hline Birds & Invertebrates & & 14 & 1,12 & 0.00 & 0.9451 & 0.00 & $\mathrm{y}=27.69+0.03$ (Disturbance score) \\
\hline Birds & Vegetation & & 19 & 1,17 & 6.00 & 0.0255 & 0.26 & $\mathrm{y}=26.57+0.89$ (Disturbance score $)$ \\
\hline Birds & Invertebrates & Vegetation & 14 & 1,12 & 2.77 & 0.1221 & 0.19 & $\mathrm{y}=33.10+0.67$ (Disturbance score) \\
\hline Invertebrates & Vegetation & & 14 & 1,12 & 10.40 & 0.0073 & 0.46 & $\mathrm{y}=4.33+0.73$ (Disturbance score) \\
\hline \multicolumn{9}{|c|}{ Scrub shrub- Floodplain } \\
\hline Anurans & Birds & & 6 & 1,4 & 7.39 & 0.0531 & 0.65 & $\mathrm{y}=-1.30+1.75$ (Disturbance score) \\
\hline Anurans & Birds & Invertebrates & 5 & 1,3 & 2.18 & 0.2364 & 0.42 & $\mathrm{y}=7.11+1.95$ (Disturbance score) \\
\hline Anurans & Birds & Vegetation & 6 & 1,4 & 8.53 & 0.0432 & 0.68 & $\mathrm{y}=4.51+2.82($ Disturbance score $)$ \\
\hline Anurans & Invertebrates & Vegetation & 5 & 1,3 & 2.10 & 0.2430 & 0.41 & $\mathrm{y}=3.91+1.97$ (Disturbance score) \\
\hline Anurans & Vegetation & & 6 & 1,4 & 3.22 & 0.1471 & 0.45 & $\mathrm{y}=-10.73+1.98$ (Disturbance score) \\
\hline Birds & Invertebrates & & 6 & 1,4 & 2.82 & 0.1681 & 0.41 & $\mathrm{y}=24.41+1.01$ (Disturbance score) \\
\hline Birds & Vegetation & & 8 & 1,6 & 38.37 & 0.0008 & 0.86 & $\mathrm{y}=-3.04+2.62$ (Disturbance score) \\
\hline Birds & Invertebrates & Vegetation & 6 & 1,4 & 25.30 & 0.0073 & 0.86 & $\mathrm{y}=30.31+2.08$ (Disturbance score) \\
\hline Invertebrates & Vegetation & & 6 & 1,4 & 3.89 & 0.1200 & 0.49 & $\mathrm{y}=14.76+1.26$ (Disturbance score $)$ \\
\hline
\end{tabular}


Table 4. Continued.

\begin{tabular}{|c|c|c|c|c|c|c|c|c|}
\hline \multicolumn{3}{|c|}{ Wetland Classification } & \multirow[b]{2}{*}{$\mathrm{N}$} & \multirow[b]{2}{*}{$\mathrm{df}$} & \multirow[b]{2}{*}{$\begin{array}{c}\text { F- } \\
\text { value }\end{array}$} & \multirow[b]{2}{*}{ p-value } & \multirow[b]{2}{*}{$\mathrm{R}^{2}$} & \multirow[b]{2}{*}{ Equation } \\
\hline \multicolumn{3}{|c|}{ Taxa group in hybrid IBI } & & & & & & \\
\hline \multicolumn{9}{|c|}{ Forested- Riparian Depression } \\
\hline Anurans & Birds & & 8 & 1,6 & 0.04 & 0.8473 & 0.01 & $\mathrm{y}=24.92-0.09$ (Disturbance score) \\
\hline Anurans & Birds & Invertebrates & 4 & 1,2 & 0.82 & 0.4611 & 0.29 & $y=31.03+-0.41$ (Disturbance score) \\
\hline Anurans & Birds & Vegetation & 8 & 1,6 & 0.42 & 0.5415 & 0.07 & $y=45.88+0.46$ (Disturbance score $)$ \\
\hline Anurans & Invertebrates & Vegetation & 4 & 1,2 & 0.85 & 0.4532 & 0.30 & $y=33.87+0.13$ (Disturbance score) \\
\hline Anurans & Vegetation & & 8 & 1,6 & 1.64 & 0.2470 & 0.22 & $y=25.90+0.56($ Disturbance score $)$ \\
\hline Birds & Invertebrates & & 5 & 1,3 & 0.20 & 0.6838 & 0.06 & $\mathrm{y}=28.58-0.28$ (Disturbance score) \\
\hline Birds & Vegetation & & 12 & 1,10 & 4.39 & 0.0625 & 0.31 & $\mathrm{y}=22.56+1.10$ (Disturbance score $)$ \\
\hline Birds & Invertebrates & Vegetation & 5 & 1,3 & 0.27 & 0.6379 & 0.08 & $\mathrm{y}=39.81+0.51$ (Disturbance score $)$ \\
\hline Invertebrates & Vegetation & & 5 & 1,3 & 0.43 & 0.8175 & 0.21 & $\mathrm{y}=23.73+0.52$ (Disturbance score $)$ \\
\hline \multicolumn{9}{|c|}{ Forested- Headwater Floodplain } \\
\hline Anurans & Birds & & 4 & 1,2 & 7.67 & 0.1094 & 0.79 & $y=-56.47+3.10$ (Disturbance score $)$ \\
\hline Anurans & Birds & Invertebrates & 4 & 1,2 & 7.67 & 0.1094 & 0.79 & $y=-46.47+3.10$ (Disturbance score) \\
\hline Anurans & Birds & Vegetation & 4 & 1,2 & 19.83 & 0.0469 & 0.91 & $y=-74.90+4.95$ (Disturbance score) \\
\hline Anurans & Invertebrates & Vegetation & 4 & 1,2 & 11.41 & 0.0776 & 0.85 & $y=-22.87+2.52$ (Disturbance score) \\
\hline Anurans & Vegetation & & 4 & 1,2 & 11.41 & 0.0776 & 0.85 & $y=-32.87+2.52$ (Disturbance score $)$ \\
\hline Birds & Invertebrates & & 6 & 1,4 & 6.01 & 0.0703 & 0.60 & $\mathrm{y}=12.24+1.36($ Disturbance score $)$ \\
\hline Birds & Vegetation & & 7 & 1,5 & 32.60 & 0.0023 & 0.87 & $y=-2.54+2.42$ (Disturbance score $)$ \\
\hline Birds & Invertebrates & Vegetation & 6 & 1,4 & 12.22 & 0.0250 & 0.75 & $\mathrm{y}=15.36+2.51$ (Disturbance score $)$ \\
\hline Invertebrates & Vegetation & & 6 & 1,4 & 3.68 & 0.1277 & 0.48 & $\mathrm{y}=17.14+1.34$ (Disturbance score) \\
\hline \multicolumn{9}{|c|}{ Forested-Depression } \\
\hline Birds & Invertebrates & & 5 & 1,3 & 0.09 & 0.7817 & 0.03 & $y=36.40-0.23$ (Disturbance score) \\
\hline Birds & Vegetation & & 14 & 1,12 & 5.72 & 0.0340 & 0.32 & $\mathrm{y}=24.94+1.20($ Disturbance score $)$ \\
\hline Birds & Invertebrates & Vegetation & 5 & 1,3 & 0.29 & 0.6287 & 0.09 & $y=40.12+0.64$ (Disturbance score) \\
\hline Invertebrates & Vegetation & & 5 & 1,3 & 1.06 & 0.3787 & 0.26 & $\mathrm{y}=16.21+0.61$ (Disturbance score $)$ \\
\hline \multicolumn{9}{|c|}{ Forested-Floodplain } \\
\hline Anurans & Birds & & 8 & 1,6 & 0.11 & 0.7542 & 0.02 & $\mathrm{y}=50.31+0.28($ Disturbance score $)$ \\
\hline Anurans & Birds & Invertebrates & 6 & 1,4 & 2.42 & 0.1945 & 0.38 & $y=44.11+1.15($ Disturbance score $)$ \\
\hline Anurans & Birds & Vegetation & 8 & 1,6 & 2.18 & 0.1905 & 0.27 & $y=55.92+1.76($ Disturbance score $)$ \\
\hline Anurans & Invertebrates & Vegetation & 6 & 1,4 & 4.41 & 0.1037 & 0.52 & $\mathrm{y}=11.42+2.39$ (Disturbance score $)$ \\
\hline Anurans & Vegetation & & 8 & 1,6 & 3.63 & 0.1054 & 0.38 & $\mathrm{y}=18.12+1.56($ Disturbance score $)$ \\
\hline Birds & Invertebrates & & 7 & 1,5 & 15.65 & 0.0108 & 0.76 & $\mathrm{y}=23.15+1.44$ (Disturbance score) \\
\hline Birds & Vegetation & & 11 & 1,9 & 21.00 & 0.0013 & 0.70 & $\mathrm{y}=15.79+2.55$ (Disturbance score $)$ \\
\hline Birds & Invertebrates & Vegetation & 7 & 1,5 & 18.29 & 0.0079 & 0.79 & $\mathrm{y}=25.32+3.07$ (Disturbance score) \\
\hline Invertebrates & Vegetation & & 7 & 1,5 & 6.97 & 0.0460 & 0.58 & $\mathrm{y}=13.18+1.93$ (Disturbance score) \\
\hline
\end{tabular}


Table 5. Significant $\mathrm{R}^{2}$ for multi-taxa, hybrid classification schemes of indices of biological integrity (IBIs) for wetlands of West Virginia, USA from 2005-2006.

\begin{tabular}{|c|c|c|c|c|c|c|c|c|c|c|}
\hline & & & \multicolumn{8}{|c|}{ Hybrid classification } \\
\hline \multicolumn{3}{|c|}{$\begin{array}{l}\text { Taxa groups in multi-taxa, hybrid classification } \\
\text { wetland IBIs }\end{array}$} & $\begin{array}{l}\text { Emergent- } \\
\text { Riparian } \\
\text { Depression }\end{array}$ & $\begin{array}{l}\text { Emergent- } \\
\text { Headwater } \\
\text { Floodplain }\end{array}$ & $\begin{array}{l}\text { Emergent- } \\
\text { Depression }\end{array}$ & $\begin{array}{l}\text { Emergent- } \\
\text { Floodplain }\end{array}$ & $\begin{array}{l}\text { Scrub shrub- } \\
\text { Riparian } \\
\text { Depression }\end{array}$ & $\begin{array}{l}\text { Scrub shrub- } \\
\text { Headwater } \\
\text { Floodplain }\end{array}$ & $\begin{array}{c}\text { Scrub } \\
\text { shrub- } \\
\text { Depression }\end{array}$ & $\begin{array}{c}\text { Scrub } \\
\text { shrub- } \\
\text { Floodplain }\end{array}$ \\
\hline Birds & & & & & & 0.52 & & 0.94 & & 0.85 \\
\hline Vegetation & & & & 0.61 & & 0.55 & 0.5 & 0.66 & 0.46 & 0.59 \\
\hline Anurans & Birds & & $*$ & $*$ & & 0.42 & $*$ & 0.89 & & $*$ \\
\hline Anurans & Birds & Invertebrates & 0.27 & 0.56 & & 0.59 & * & 0.93 & & * \\
\hline Anurans & Birds & Vegetation & $*$ & 0.58 & & 0.58 & 0.32 & 0.79 & & 0.68 \\
\hline Anurans & Invertebrates & Vegetation & 0.2 & 0.6 & & 0.44 & 0.43 & * & & * \\
\hline Anurans & Vegetation & & * & 0.5 & & 0.35 & 0.42 & $*$ & & $*$ \\
\hline Birds & Invertebrates & & 0.25 & 0.52 & 0.3 & 0.75 & $*$ & 0.88 & $*$ & $*$ \\
\hline Birds & Vegetation & & $*$ & 0.61 & 0.11 & 0.75 & 0.39 & 0.92 & 0.26 & 0.86 \\
\hline Birds & Invertebrates & Vegetation & $*$ & 0.72 & 0.33 & 0.78 & 0.36 & 0.95 & $*$ & 0.86 \\
\hline Invertebrates & Vegetation & & * & 0.69 & 0.25 & 0.65 & 0.51 & $*$ & 0.46 & * \\
\hline
\end{tabular}


Table 5. Continued.

\begin{tabular}{|c|c|c|c|c|c|c|}
\hline & & & \multicolumn{4}{|c|}{ Hybrid classification } \\
\hline \multicolumn{3}{|c|}{$\begin{array}{l}\text { Taxa groups in multi-taxa, hybrid classification } \\
\text { wetland IBIs }\end{array}$} & $\begin{array}{c}\text { Forested- } \\
\text { Riparian } \\
\text { Depression } \\
\end{array}$ & $\begin{array}{l}\text { Forested- } \\
\text { Headwater } \\
\text { Floodplain } \\
\end{array}$ & $\begin{array}{l}\text { Forested- } \\
\text { Depression }\end{array}$ & $\begin{array}{l}\text { Forested- } \\
\text { Floodplain } \\
\end{array}$ \\
\hline \multicolumn{3}{|c|}{ Birds } & & 0.76 & & 0.42 \\
\hline \multicolumn{3}{|l|}{ Vegetation } & 0.41 & 0.84 & 0.42 & 0.68 \\
\hline Anurans & Birds & & $*$ & * & & $*$ \\
\hline Anurans & Birds & Invertebrates & * & * & & * \\
\hline Anurans & Birds & Vegetation & * & 0.91 & & $*$ \\
\hline Anurans & Invertebrates & Vegetation & * & $*$ & & $*$ \\
\hline Anurans & Vegetation & & * & * & & * \\
\hline Birds & Invertebrates & & $*$ & $*$ & $*$ & 0.76 \\
\hline Birds & Vegetation & & * & 0.87 & 0.32 & 0.7 \\
\hline Birds & Invertebrates & Vegetation & $*$ & 0.75 & $*$ & 0.79 \\
\hline Invertebrates & Vegetation & & $*$ & $*$ & $*$ & 0.58 \\
\hline
\end{tabular}

* Indicates not a significant relation with disturbance score. 
Table 6. Avian community sampling summary statistics of metric scores statewide and by ecoregion used to form acoustically-based avian wetland indices of biological integrity (AW-IBI) for wetlands in West Virginia, USA 2005-2006.

\begin{tabular}{|c|c|c|c|c|}
\hline Ecoregion/metric & & & & \\
\hline Statewide $(N=151)$ & Mean & $\begin{array}{l}\text { Std. } \\
\text { Error }\end{array}$ & Minimum & Maximum \\
\hline $\begin{array}{l}\text { Proportion of neotropical } \\
\text { migrants }\end{array}$ & 0.30 & 0.01 & 0.05 & 0.71 \\
\hline $\begin{array}{l}\text { Proportion of habitat specific } \\
\text { birds }\end{array}$ & 0.27 & 0.01 & 0.00 & 0.71 \\
\hline $\begin{array}{l}\text { Proportion of neotropical } \\
\text { migrants- habitat specific birds }\end{array}$ & 0.17 & 0.01 & 0.00 & 0.57 \\
\hline $\begin{array}{l}\text { Proportion of forest-area sensitive } \\
\text { birds }\end{array}$ & 0.10 & 0.01 & 0.00 & 0.74 \\
\hline $\begin{array}{l}\text { Proportion of year-round } \\
\text { residential and edge-tolerant birds }\end{array}$ & 0.49 & 0.02 & 0.05 & 0.88 \\
\hline Shannon-Weaver diversity index & 5.77 & 0.06 & 2.49 & 7.35 \\
\hline $\begin{array}{l}\text { Proportion of carnivorous-habitat } \\
\text { specific species }\end{array}$ & 0.18 & 0.01 & 0.00 & 0.62 \\
\hline $\begin{array}{l}\text { Proportion of single-brood } \\
\text { species }\end{array}$ & 0.39 & 0.01 & 0.00 & 0.76 \\
\hline $\begin{array}{l}\text { Proportion of insectivorous } \\
\text { species }\end{array}$ & 0.35 & 0.01 & 0.04 & 0.79 \\
\hline Proportion of omnivorous species & 0.52 & 0.01 & 0.19 & 0.88 \\
\hline Bird abundance & 14.85 & 0.64 & 1.00 & 40.00 \\
\hline Allegheny Highlands $(N=65)$ & & & & \\
\hline $\begin{array}{l}\text { Proportion of neotropical } \\
\text { migrants }\end{array}$ & 0.30 & 0.02 & 0.05 & 0.68 \\
\hline $\begin{array}{l}\text { Proportion of habitat specific } \\
\text { birds }\end{array}$ & 0.25 & 0.02 & 0.00 & 0.71 \\
\hline $\begin{array}{l}\text { Proportion of neotropical } \\
\text { migrants- habitat specific birds }\end{array}$ & 0.17 & 0.02 & 0.00 & 0.53 \\
\hline $\begin{array}{l}\text { Proportion of forest-area sensitive } \\
\text { birds }\end{array}$ & 0.11 & 0.02 & 0.00 & 0.74 \\
\hline $\begin{array}{l}\text { Proportion of year-round } \\
\text { residential and edge-tolerant birds }\end{array}$ & 0.48 & 0.02 & 0.11 & 0.88 \\
\hline Shannon-Weaver diversity index & 5.68 & 0.08 & 3.63 & 7.05 \\
\hline $\begin{array}{l}\text { Proportion of carnivorous-habitat } \\
\text { specific species }\end{array}$ & 0.17 & 0.01 & 0.00 & 0.62 \\
\hline $\begin{array}{l}\text { Proportion of single-brood } \\
\text { species }\end{array}$ & 0.40 & 0.02 & 0.00 & 0.70 \\
\hline $\begin{array}{l}\text { Proportion of insectivorous } \\
\text { species }\end{array}$ & 0.35 & 0.02 & 0.04 & 0.76 \\
\hline Proportion of omnivorous species & 0.53 & 0.02 & 0.19 & 0.88 \\
\hline Bird abundance & 13.05 & 0.72 & 4.00 & 26.00 \\
\hline
\end{tabular}


Table 6. Continued.

\begin{tabular}{|c|c|c|c|c|}
\hline Ecoregion/metric & & & & \\
\hline Ridge and Valley $(N=27)$ & Mean & $\begin{array}{c}\text { Std. } \\
\text { Error }\end{array}$ & Minimum & Maximum \\
\hline $\begin{array}{l}\text { Proportion of neotropical } \\
\text { migrants }\end{array}$ & 0.25 & 0.03 & 0.07 & 0.63 \\
\hline $\begin{array}{l}\text { Proportion of habitat specific } \\
\text { birds }\end{array}$ & 0.26 & 0.03 & 0.00 & 0.57 \\
\hline $\begin{array}{l}\text { Proportion of neotropical } \\
\text { migrants- habitat specific birds }\end{array}$ & 0.14 & 0.02 & 0.00 & 0.40 \\
\hline $\begin{array}{l}\text { Proportion of forest-area sensitive } \\
\text { birds }\end{array}$ & 0.09 & 0.02 & 0.00 & 0.36 \\
\hline $\begin{array}{l}\text { Proportion of year-round } \\
\text { residential and edge-tolerant birds }\end{array}$ & 0.52 & 0.04 & 0.05 & 0.87 \\
\hline Shannon-Weaver diversity index & 5.48 & 0.17 & 2.49 & 6.55 \\
\hline $\begin{array}{l}\text { Proportion of carnivorous-habitat } \\
\text { specific species }\end{array}$ & 0.16 & 0.02 & 0.00 & 0.47 \\
\hline $\begin{array}{l}\text { Proportion of single-brood } \\
\text { species }\end{array}$ & 0.37 & 0.04 & 0.04 & 0.76 \\
\hline $\begin{array}{l}\text { Proportion of insectivorous } \\
\text { species }\end{array}$ & 0.34 & 0.03 & 0.09 & 0.73 \\
\hline Proportion of omnivorous species & 0.51 & 0.03 & 0.25 & 0.85 \\
\hline Bird abundance & 14.93 & 2.00 & 1.00 & 40.00 \\
\hline $\begin{array}{l}\text { Western Allegheny Plateau } \\
(N=59)\end{array}$ & Mean & $\begin{array}{l}\text { Std. } \\
\text { Error }\end{array}$ & Minimum & Maximum \\
\hline $\begin{array}{l}\text { Proportion of neotropical } \\
\text { migrants }\end{array}$ & 0.31 & 0.02 & 0.05 & 0.71 \\
\hline $\begin{array}{l}\text { Proportion of habitat specific } \\
\text { birds }\end{array}$ & 0.29 & 0.02 & 0.07 & 0.64 \\
\hline $\begin{array}{l}\text { Proportion of neotropical } \\
\text { migrants- habitat specific birds }\end{array}$ & 0.18 & 0.02 & 0.00 & 0.57 \\
\hline $\begin{array}{l}\text { Proportion of forest-area sensitive } \\
\text { birds }\end{array}$ & 0.09 & 0.01 & 0.00 & 0.50 \\
\hline $\begin{array}{l}\text { Proportion of year-round } \\
\text { residential and edge-tolerant birds }\end{array}$ & 0.48 & 0.02 & 0.11 & 0.86 \\
\hline Shannon-Weaver diversity index & 6.00 & 0.09 & 3.86 & 7.35 \\
\hline $\begin{array}{l}\text { Proportion of carnivorous-habitat } \\
\text { specific species }\end{array}$ & 0.19 & 0.01 & 0.03 & 0.57 \\
\hline $\begin{array}{l}\text { Proportion of single-brood } \\
\text { species }\end{array}$ & 0.39 & 0.02 & 0.10 & 0.74 \\
\hline $\begin{array}{l}\text { Proportion of insectivorous } \\
\text { species }\end{array}$ & 0.35 & 0.02 & 0.07 & 0.79 \\
\hline Proportion of omnivorous species & 0.52 & 0.02 & 0.21 & 0.76 \\
\hline Bird abundance & 16.80 & 1.08 & 4.00 & 38.00 \\
\hline
\end{tabular}


Table 7. Anuran community sampling summary statistics of metric scores statewide and by ecoregion used to form acoustically-based anuran indices of biological integrity (AAIBI) for wetlands in West Virginia, USA 2005-2006.

\begin{tabular}{|c|c|c|c|c|}
\hline \multicolumn{5}{|l|}{ Ecoregion/metric } \\
\hline Statewide $(N=133)$ & Mean & $\begin{array}{l}\text { Std. } \\
\text { Error }\end{array}$ & Minimum & Maximum \\
\hline $\begin{array}{l}\text { Anuran relative Shannon-Weaver } \\
\text { diversity }\end{array}$ & 2.67 & 0.10 & 0.00 & 4.68 \\
\hline Proportion of sensitive anurans & 0.16 & 0.01 & 0.00 & 0.57 \\
\hline Proportion of anuran species-of-concern & 0.03 & 0.01 & 0.00 & 0.50 \\
\hline Proportion of tolerant anurans & 0.74 & 0.02 & 0.20 & 1.00 \\
\hline Proportion of wood frog chorus & 0.10 & 0.01 & 0.00 & 0.40 \\
\hline Anuran richness & 3.81 & 0.15 & 1.00 & 8.00 \\
\hline Total anuran abundance & 6.13 & 0.24 & 2.00 & 14.00 \\
\hline Shannon's evenness & 0.30 & 0.01 & 0.00 & 0.37 \\
\hline Anuran quality assessment index & 3.08 & 0.07 & 1.50 & 5.20 \\
\hline $\begin{array}{l}\text { Anuran mean coefficient of } \\
\text { conservatism }\end{array}$ & 3.22 & 0.08 & 1.50 & 5.25 \\
\hline Proportion of upland sensitive anurans & 0.13 & 0.01 & 0.00 & 0.43 \\
\hline Proportion of upland tolerant anurans & 0.51 & 0.02 & 0.00 & 1.00 \\
\hline Proportion of fish-tolerant anurans & 0.17 & 0.01 & 0.00 & 1.00 \\
\hline \multicolumn{5}{|l|}{ Allegheny Highlands $(N=59)$} \\
\hline $\begin{array}{l}\text { Anuran relative Shannon-Weaver } \\
\text { diversity }\end{array}$ & 2.27 & 0.16 & 0.00 & 4.68 \\
\hline Proportion of sensitive anurans & 0.11 & 0.02 & 0.00 & 0.50 \\
\hline Proportion of anuran species-of-concern & 0.03 & 0.01 & 0.00 & 0.50 \\
\hline Proportion of tolerant anurans & 0.80 & 0.03 & 0.44 & 1.00 \\
\hline Proportion of wood frog chorus & 0.08 & 0.02 & 0.00 & 0.33 \\
\hline Anuran richness & 3.27 & 0.21 & 1.00 & 8.00 \\
\hline Total anuran abundance & 5.37 & 0.33 & 2.00 & 13.00 \\
\hline Shannon's evenness & 0.28 & 0.02 & 0.00 & 0.37 \\
\hline Anuran quality assessment index & 2.82 & 0.11 & 1.50 & 4.50 \\
\hline $\begin{array}{l}\text { Anuran mean coefficient of } \\
\text { conservatism }\end{array}$ & 2.94 & 0.13 & 1.50 & 5.25 \\
\hline Proportion of upland sensitive anurans & 0.11 & 0.02 & 0.00 & 0.43 \\
\hline Proportion of upland tolerant anurans & 0.60 & 0.03 & 0.22 & 1.00 \\
\hline Proportion of fish-tolerant anurans & 0.13 & 0.02 & 0.00 & 0.50 \\
\hline
\end{tabular}


Table 7. Continued.

\begin{tabular}{|c|c|c|c|c|}
\hline Ecoregion/metric & & & & \\
\hline Ridge and Valley $(N=21)$ & Mean & $\begin{array}{l}\text { Std. } \\
\text { Error }\end{array}$ & Minimum & Maximum \\
\hline $\begin{array}{l}\text { Anuran relative Shannon-Weaver } \\
\text { diversity }\end{array}$ & 2.39 & 0.20 & 0.00 & 3.85 \\
\hline Proportion of sensitive anurans & 0.22 & 0.03 & 0.00 & 0.43 \\
\hline Proportion of anuran species-of-concern & 0.01 & 0.01 & 0.00 & 0.20 \\
\hline Proportion of tolerant anurans & 0.73 & 0.03 & 0.50 & 1.00 \\
\hline Proportion of wood frog chorus & 0.14 & 0.03 & 0.00 & 0.40 \\
\hline Anuran richness & 3.24 & 0.27 & 1.00 & 6.00 \\
\hline Total anuran abundance & 5.29 & 0.51 & 2.00 & 11.00 \\
\hline Shannon's evenness & 0.31 & 0.02 & 0.00 & 0.37 \\
\hline Anuran quality assessment index & 3.16 & 0.16 & 1.67 & 4.17 \\
\hline $\begin{array}{l}\text { Anuran mean coefficient of } \\
\text { conservatism }\end{array}$ & 3.43 & 0.20 & 1.50 & 4.67 \\
\hline Proportion of upland sensitive anurans & 0.14 & 0.03 & 0.00 & 0.40 \\
\hline Proportion of upland tolerant anurans & 0.58 & 0.04 & 0.33 & 1.00 \\
\hline Proportion of fish-tolerant anurans & 0.14 & 0.03 & 0.00 & 0.50 \\
\hline Western Allegheny Plateau $(N=53)$ & & & & \\
\hline $\begin{array}{l}\text { Anuran relative Shannon-Weaver } \\
\text { diversity }\end{array}$ & 3.23 & 0.11 & 1.47 & 4.56 \\
\hline Proportion of sensitive anurans & 0.19 & 0.02 & 0.00 & 0.57 \\
\hline Proportion of anuran species-of-concern & 0.03 & 0.01 & 0.00 & 0.50 \\
\hline Proportion of tolerant anurans & 0.67 & 0.03 & 0.20 & 1.00 \\
\hline Proportion of wood frog chorus & 0.10 & 0.02 & 0.00 & 0.40 \\
\hline Anuran richness & 4.64 & 0.21 & 2.00 & 8.00 \\
\hline Total anuran abundance & 7.30 & 0.39 & 2.00 & 14.00 \\
\hline Shannon's evenness & 0.31 & 0.00 & 0.25 & 0.37 \\
\hline Anuran quality assessment index & 3.33 & 0.11 & 1.60 & 5.20 \\
\hline $\begin{array}{l}\text { Anuran mean coefficient of } \\
\text { conservatism }\end{array}$ & 3.44 & 0.12 & 1.67 & 4.67 \\
\hline Proportion of upland sensitive anurans & 0.14 & 0.02 & 0.00 & 0.40 \\
\hline Proportion of upland tolerant anurans & 0.38 & 0.02 & 0.00 & 0.80 \\
\hline Proportion of fish-tolerant anurans & 0.23 & 0.02 & 0.00 & 1.00 \\
\hline
\end{tabular}


Table 8. Vegetation community sampling summary statistics of metric scores statewide and by ecoregion used to form vegetation indices of biological integrity (Veg-IBI) for wetlands in West Virginia, USA 2005-2006.

\begin{tabular}{|c|c|c|c|c|}
\hline Ecoregion/metric & & & & \\
\hline Statewide $(N=151)$ & Mean & Std. Error & Minimum & Maximum \\
\hline West Virginia floristic quality index & 25.47 & 0.44 & 10.17 & 40.85 \\
\hline Pennsylvania-formula floristic quality index & 22.71 & 0.43 & 10.17 & 34.26 \\
\hline Mean coefficient of conservatism & 4.39 & 0.05 & 2.83 & 6.46 \\
\hline Adjusted-formula floristic quality index & 42.17 & 0.63 & 23.59 & 64.59 \\
\hline Obligate species herbaceous relative cover & 0.50 & 0.03 & 0.00 & 1.00 \\
\hline $\begin{array}{l}\text { Facultative wet and wetter species herbaceous } \\
\text { relative cover }\end{array}$ & 0.78 & 0.02 & 0.00 & 1.00 \\
\hline Facultative wetter species herbaceous relative cover & 0.81 & 0.02 & 0.00 & 1.00 \\
\hline Facultative-only species herbaceous relative cover & 0.03 & 0.01 & 0.00 & 0.33 \\
\hline Native shrub hydrophyte proportionate cover & 0.21 & 0.03 & 0.00 & 1.70 \\
\hline Carex spp. walk-through richness & 2.93 & 0.17 & 0.00 & 8.00 \\
\hline Invasive graminoid walk-through richness & 0.50 & 0.07 & 0.00 & 4.00 \\
\hline Native plant walk-through richness & 28.36 & 0.91 & 5.00 & 64.00 \\
\hline Non-native plant walk-through richness & 3.03 & 0.26 & 0.00 & 14.00 \\
\hline Native hydrophyte walk-through richness & 23.02 & 0.72 & 5.00 & 48.00 \\
\hline Native hydrophyte herbaceous richness & 9.68 & 0.39 & 0.00 & 23.00 \\
\hline Native dicot walk-through richness & 16.96 & 0.63 & 2.00 & 48.00 \\
\hline Native dicot herbaceous richness & 5.91 & 0.31 & 0.00 & 16.00 \\
\hline Shrub richness & 2.66 & 0.21 & 0.00 & 15.00 \\
\hline Native shrub richness & 2.33 & 0.19 & 0.00 & 14.00 \\
\hline Non-native shrub richness & 0.21 & 0.04 & 0.00 & 3.00 \\
\hline Tree richness & 3.34 & 0.57 & 0.00 & 36.00 \\
\hline Mean IV & 17.46 & 2.58 & 0.00 & 100.00 \\
\hline Facultative trees and wetter Mean IV & 14.93 & 2.43 & 0.00 & 100.00 \\
\hline Facultative-wet trees and wetter Mean IV & 12.23 & 2.31 & 0.00 & 100.00 \\
\hline Mean dbh & 6.84 & 0.90 & 0.00 & 40.15 \\
\hline Fern and fern allies relative cover & 0.02 & 0.01 & 0.00 & 0.77 \\
\hline Monocots relative cover & 0.51 & 0.02 & 0.00 & 1.00 \\
\hline Native graminoid relative cover & 0.41 & 0.02 & 0.00 & 1.00 \\
\hline Invasive graminoid relative cover & 0.02 & 0.00 & 0.00 & 0.35 \\
\hline Native dicot relative cover & 0.32 & 0.02 & 0.00 & 1.00 \\
\hline Dicot relative cover & 0.37 & 0.02 & 0.00 & 1.00 \\
\hline Carex spp. relative cover & 0.07 & 0.01 & 0.00 & 0.77 \\
\hline Non-native plant relative cover & 0.06 & 0.01 & 0.00 & 0.60 \\
\hline Phalaris relative cover & 0.06 & 0.02 & 0.00 & 0.99 \\
\hline Sensitive species relative cover & 0.08 & 0.01 & 0.00 & 1.00 \\
\hline Tolerant species relative cover & 0.13 & 0.02 & 0.00 & 0.99 \\
\hline Bryophyte relative cover & 0.05 & 0.01 & 0.00 & 0.54 \\
\hline Native hydrophyte herbaceous relative cover & 0.78 & 0.02 & 0.00 & 1.00 \\
\hline Phalaris and invasive graminoid relative cover & 0.08 & 0.02 & 0.00 & 0.99 \\
\hline Native shrub proportionate cover & 0.26 & 0.03 & 0.00 & 1.70 \\
\hline Non-native shrub proportionate cover & 0.01 & 0.00 & 0.00 & 0.25 \\
\hline
\end{tabular}


Table 8. Continued.

\begin{tabular}{|c|c|c|c|c|}
\hline Ecoregion/metric & & & & \\
\hline Allegheny Highlands $(N=65)$ & Mean & Std. Error & Minimum & Maximum \\
\hline West Virginia floristic quality index & 27.37 & 0.71 & 10.17 & 40.85 \\
\hline Pennsylvania-formula floristic quality index & 24.98 & 0.65 & 10.17 & 34.26 \\
\hline Mean coefficient of conservatism & 4.48 & 0.07 & 2.83 & 5.62 \\
\hline Adjusted-formula floristic quality index & 43.50 & 0.80 & 23.59 & 56.24 \\
\hline Obligate species herbaceous relative cover & 0.45 & 0.04 & 0.00 & 1.00 \\
\hline $\begin{array}{l}\text { Facultative wet and wetter species herbaceous } \\
\text { relative cover }\end{array}$ & 0.77 & 0.03 & 0.11 & 1.00 \\
\hline Facultative wetter species herbaceous relative cover & 0.81 & 0.03 & 0.25 & 1.00 \\
\hline Facultative-only species herbaceous relative cover & 0.04 & 0.01 & 0.00 & 0.33 \\
\hline Native shrub hydrophyte proportionate cover & 0.26 & 0.05 & 0.00 & 1.65 \\
\hline Carex spp. walk-through richness & 3.35 & 0.24 & 0.00 & 8.00 \\
\hline Invasive graminoid walk-through richness & 0.59 & 0.12 & 0.00 & 4.00 \\
\hline Native plant walk-through richness & 32.31 & 1.46 & 6.00 & 64.00 \\
\hline Non-native plant walk-through richness & 2.62 & 0.38 & 0.00 & 14.00 \\
\hline Native hydrophyte walk-through richness & 26.63 & 1.11 & 6.00 & 48.00 \\
\hline Native hydrophyte herbaceous richness & 11.02 & 0.63 & 1.00 & 23.00 \\
\hline Native dicot walk-through richness & 19.59 & 1.07 & 4.00 & 48.00 \\
\hline Native dicot herbaceous richness & 6.85 & 0.54 & 0.00 & 16.00 \\
\hline Shrub richness & 2.99 & 0.38 & 0.00 & 15.00 \\
\hline Native shrub richness & 2.65 & 0.34 & 0.00 & 14.00 \\
\hline Non-native shrub richness & 0.20 & 0.06 & 0.00 & 3.00 \\
\hline Tree richness & 3.71 & 0.99 & 0.00 & 36.00 \\
\hline Mean IV & 17.30 & 3.86 & 0.00 & 100.00 \\
\hline Facultative trees and wetter Mean IV & 14.59 & 3.55 & 0.00 & 100.00 \\
\hline Facultative-wet trees and wetter Mean IV & 10.63 & 3.31 & 0.00 & 100.00 \\
\hline Mean dbh & 7.10 & 1.41 & 0.00 & 40.15 \\
\hline Fern and fern allies relative cover & 0.02 & 0.01 & 0.00 & 0.23 \\
\hline Monocots relative cover & 0.49 & 0.04 & 0.06 & 1.00 \\
\hline Native graminoid relative cover & 0.45 & 0.04 & 0.01 & 1.00 \\
\hline Invasive graminoid relative cover & 0.01 & 0.00 & 0.00 & 0.23 \\
\hline Native dicot relative cover & 0.35 & 0.03 & 0.00 & 0.91 \\
\hline Dicot relative cover & 0.37 & 0.03 & 0.00 & 0.91 \\
\hline Carex spp. relative cover & 0.08 & 0.01 & 0.00 & 0.53 \\
\hline Non-native plant relative cover & 0.03 & 0.01 & 0.00 & 0.33 \\
\hline Phalaris relative cover & 0.05 & 0.02 & 0.00 & 0.99 \\
\hline Sensitive species relative cover & 0.04 & 0.01 & 0.00 & 0.40 \\
\hline Tolerant species relative cover & 0.09 & 0.02 & 0.00 & 0.99 \\
\hline Bryophyte relative cover & 0.07 & 0.02 & 0.00 & 0.54 \\
\hline Native hydrophyte herbaceous relative cover & 0.80 & 0.03 & 0.25 & 1.00 \\
\hline Phalaris and invasive graminoid relative cover & 0.07 & 0.02 & 0.00 & 0.99 \\
\hline Native shrub proportionate cover & 0.31 & 0.05 & 0.00 & 1.65 \\
\hline Non-native shrub proportionate cover & 0.01 & 0.00 & 0.00 & 0.19 \\
\hline
\end{tabular}


Table 8. Continued.

\begin{tabular}{|c|c|c|c|c|}
\hline Ecoregion/metric & & & & \\
\hline Ridge and Valley $(N=27)$ & Mean & Std. Error & Minimum & Maximum \\
\hline West Virginia floristic quality index & 23.97 & 1.01 & 15.41 & 33.66 \\
\hline Pennsylvania-formula floristic quality index & 21.11 & 1.05 & 12.66 & 32.82 \\
\hline Mean coefficient of conservatism & 4.56 & 0.18 & 3.16 & 6.46 \\
\hline Adjusted-formula floristic quality index & 43.79 & 2.07 & 28.47 & 64.59 \\
\hline Obligate species herbaceous relative cover & 0.46 & 0.07 & 0.00 & 1.00 \\
\hline $\begin{array}{l}\text { Facultative wet and wetter species herbaceous } \\
\text { relative cover }\end{array}$ & 0.75 & 0.04 & 0.30 & 1.00 \\
\hline Facultative wetter species herbaceous relative cover & 0.79 & 0.04 & 0.41 & 1.00 \\
\hline Facultative-only species herbaceous relative cover & 0.04 & 0.02 & 0.00 & 0.31 \\
\hline Native shrub hydrophyte proportionate cover & 0.09 & 0.03 & 0.00 & 0.68 \\
\hline Carex spp. walk-through richness & 1.93 & 0.30 & 0.00 & 6.00 \\
\hline Invasive graminoid walk-through richness & 0.30 & 0.13 & 0.00 & 3.00 \\
\hline Native plant walk-through richness & 22.41 & 1.63 & 10.00 & 40.00 \\
\hline Non-native plant walk-through richness & 2.70 & 0.65 & 0.00 & 14.00 \\
\hline Native hydrophyte walk-through richness & 17.96 & 1.47 & 6.00 & 35.00 \\
\hline Native hydrophyte herbaceous richness & 7.19 & 0.60 & 1.00 & 13.00 \\
\hline Native dicot walk-through richness & 12.74 & 1.10 & 3.00 & 25.00 \\
\hline Native dicot herbaceous richness & 4.63 & 0.49 & 0.00 & 9.00 \\
\hline Shrub richness & 1.74 & 0.33 & 0.00 & 5.00 \\
\hline Native shrub richness & 1.56 & 0.29 & 0.00 & 5.00 \\
\hline Non-native shrub richness & 0.19 & 0.09 & 0.00 & 2.00 \\
\hline Tree richness & 3.00 & 1.21 & 0.00 & 21.00 \\
\hline Mean IV & 7.75 & 3.18 & 0.00 & 50.00 \\
\hline Facultative trees and wetter Mean IV & 6.19 & 2.68 & 0.00 & 50.00 \\
\hline Facultative-wet trees and wetter Mean IV & 5.30 & 2.60 & 0.00 & 50.00 \\
\hline Mean dbh & 5.50 & 2.09 & 0.00 & 34.73 \\
\hline Fern and fern allies relative cover & 0.05 & 0.03 & 0.00 & 0.77 \\
\hline Monocots relative cover & 0.45 & 0.06 & 0.00 & 1.00 \\
\hline Native graminoid relative cover & 0.36 & 0.06 & 0.00 & 1.00 \\
\hline Invasive graminoid relative cover & 0.02 & 0.02 & 0.00 & 0.35 \\
\hline Native dicot relative cover & 0.31 & 0.05 & 0.00 & 0.78 \\
\hline Dicot relative cover & 0.40 & 0.06 & 0.00 & 0.98 \\
\hline Carex spp. relative cover & 0.06 & 0.03 & 0.00 & 0.60 \\
\hline Non-native plant relative cover & 0.12 & 0.04 & 0.00 & 0.58 \\
\hline Phalaris relative cover & 0.06 & 0.03 & 0.00 & 0.72 \\
\hline Sensitive species relative cover & 0.06 & 0.02 & 0.00 & 0.34 \\
\hline Tolerant species relative cover & 0.18 & 0.05 & 0.00 & 0.73 \\
\hline Bryophyte relative cover & 0.07 & 0.03 & 0.00 & 0.49 \\
\hline Native hydrophyte herbaceous relative cover & 0.72 & 0.05 & 0.25 & 1.00 \\
\hline Phalaris and invasive graminoid relative cover & 0.09 & 0.04 & 0.00 & 0.72 \\
\hline Native shrub proportionate cover & 0.12 & 0.03 & 0.00 & 0.68 \\
\hline Non-native shrub proportionate cover & 0.01 & 0.01 & 0.00 & 0.25 \\
\hline
\end{tabular}


Table 8. Continued.

\begin{tabular}{|c|c|c|c|c|}
\hline Ecoregion/metric & & & & \\
\hline Western Allegheny Plateau $(N=59)$ & Mean & Std. Error & Minimum & Maximum \\
\hline West Virginia floristic quality index & 24.06 & 0.58 & 14.22 & 34.17 \\
\hline Pennsylvania-formula floristic quality index & 20.95 & 0.53 & 12.55 & 31.17 \\
\hline Mean coefficient of conservatism & 4.20 & 0.08 & 3.20 & 6.36 \\
\hline Adjusted-formula floristic quality index & 39.97 & 0.90 & 26.94 & 63.57 \\
\hline Obligate species herbaceous relative cover & 0.56 & 0.05 & 0.00 & 1.00 \\
\hline $\begin{array}{l}\text { Facultative wet and wetter species herbaceous } \\
\text { relative cover }\end{array}$ & 0.80 & 0.03 & 0.00 & 1.00 \\
\hline Facultative wetter species herbaceous relative cover & 0.83 & 0.03 & 0.00 & 1.00 \\
\hline Facultative-only species herbaceous relative cover & 0.03 & 0.01 & 0.00 & 0.22 \\
\hline Native shrub hydrophyte proportionate cover & 0.21 & 0.04 & 0.00 & 1.70 \\
\hline Carex spp. walk-through richness & 2.92 & 0.28 & 0.00 & 7.00 \\
\hline Invasive graminoid walk-through richness & 0.49 & 0.10 & 0.00 & 3.00 \\
\hline Native plant walk-through richness & 26.75 & 1.29 & 5.00 & 52.00 \\
\hline Non-native plant walk-through richness & 3.63 & 0.40 & 0.00 & 13.00 \\
\hline Native hydrophyte walk-through richness & 21.36 & 0.97 & 5.00 & 37.00 \\
\hline Native hydrophyte herbaceous richness & 9.34 & 0.61 & 0.00 & 20.00 \\
\hline Native dicot walk-through richness & 16.00 & 0.85 & 2.00 & 30.00 \\
\hline Native dicot herbaceous richness & 5.46 & 0.43 & 0.00 & 14.00 \\
\hline Shrub richness & 2.73 & 0.32 & 0.00 & 9.00 \\
\hline Native shrub richness & 2.32 & 0.27 & 0.00 & 7.00 \\
\hline Non-native shrub richness & 0.22 & 0.06 & 0.00 & 2.00 \\
\hline Tree richness & 3.10 & 0.82 & 0.00 & 29.00 \\
\hline Mean IV & 22.09 & 4.75 & 0.00 & 100.00 \\
\hline Facultative trees and wetter Mean IV & 19.29 & 4.63 & 0.00 & 100.00 \\
\hline Facultative-wet trees and wetter Mean IV & 17.17 & 4.45 & 0.00 & 100.00 \\
\hline Mean dbh & 7.15 & 1.41 & 0.00 & 35.44 \\
\hline Fern and fern allies relative cover & 0.01 & 0.01 & 0.00 & 0.22 \\
\hline Monocots relative cover & 0.56 & 0.04 & 0.00 & 0.98 \\
\hline Native graminoid relative cover & 0.37 & 0.04 & 0.00 & 0.95 \\
\hline Invasive graminoid relative cover & 0.02 & 0.01 & 0.00 & 0.28 \\
\hline Native dicot relative cover & 0.29 & 0.03 & 0.00 & 1.00 \\
\hline Dicot relative cover & 0.36 & 0.04 & 0.00 & 1.00 \\
\hline Carex spp. relative cover & 0.06 & 0.02 & 0.00 & 0.77 \\
\hline Non-native plant relative cover & 0.07 & 0.02 & 0.00 & 0.60 \\
\hline Phalaris relative cover & 0.07 & 0.03 & 0.00 & 0.93 \\
\hline Sensitive species relative cover & 0.12 & 0.03 & 0.00 & 1.00 \\
\hline Tolerant species relative cover & 0.15 & 0.03 & 0.00 & 0.93 \\
\hline Bryophyte relative cover & 0.01 & 0.01 & 0.00 & 0.36 \\
\hline Native hydrophyte herbaceous relative cover & 0.79 & 0.03 & 0.00 & 1.00 \\
\hline Phalaris and invasive graminoid relative cover & 0.09 & 0.03 & 0.00 & 0.93 \\
\hline Native shrub proportionate cover & 0.25 & 0.05 & 0.00 & 1.70 \\
\hline Non-native shrub proportionate cover & 0.01 & 0.01 & 0.00 & 0.19 \\
\hline
\end{tabular}


Table 9. Macroinvertebrate community sampling summary statistics of metric scores statewide and by ecoregion used to form macroinvertebrate indices of biological integrity (Mac-IBI) for wetlands in West Virginia, USA 2005-2006.

\begin{tabular}{|c|c|c|c|c|}
\hline \multicolumn{5}{|l|}{ Ecoregion/metric } \\
\hline Benthic and Nektonic Sampling Statewide $(N=106)$ & Mean & $\begin{array}{c}\text { Std. } \\
\text { Error }\end{array}$ & Minimum & Maximum \\
\hline$\%$ Biomass EPA stressed & 0.25 & 0.03 & 0.00 & 0.99 \\
\hline$\%$ Biomass collectors & 0.33 & 0.03 & 0.00 & 0.98 \\
\hline$\%$ Biomass collectors * & 0.40 & 0.03 & 0.00 & 0.98 \\
\hline$\%$ Biomass predators & 0.24 & 0.03 & 0.00 & 0.98 \\
\hline$\%$ Biomass predators * & 0.31 & 0.03 & 0.00 & 1.00 \\
\hline$\%$ Biomass shredders & 0.07 & 0.01 & 0.00 & 0.78 \\
\hline$\%$ Biomass shredders * & 0.08 & 0.02 & 0.00 & 0.90 \\
\hline$\%$ Biomass Chironomidae & 0.05 & 0.01 & 0.00 & 0.89 \\
\hline$\%$ Biomass Coleoptera & 0.10 & 0.02 & 0.00 & 0.97 \\
\hline$\%$ Biomass Coleoptera * & 0.11 & 0.02 & 0.00 & 0.99 \\
\hline \% Biomass Dytiscidae & 0.03 & 0.01 & 0.00 & 0.76 \\
\hline$\%$ Biomass Corixidae & 0.03 & 0.01 & 0.00 & 0.78 \\
\hline$\%$ Biomass Corixidae * & 0.03 & 0.01 & 0.00 & 0.78 \\
\hline$\%$ Biomass Coleoptera and Corixidae & 0.03 & 0.01 & 0.00 & 0.97 \\
\hline$\%$ Biomass Libellulidae & 0.13 & 0.02 & 0.00 & 0.97 \\
\hline$\%$ Biomass Libellulidae * & 0.15 & 0.02 & 0.00 & 0.99 \\
\hline$\%$ Biomass Odonata - Libellulidae & 0.07 & 0.02 & 0.00 & 0.73 \\
\hline \% Biomass Odonata - Libellulidae * & 0.09 & 0.02 & 0.00 & 0.76 \\
\hline$\%$ Biomass Odonata & 0.04 & 0.01 & 0.00 & 0.50 \\
\hline$\%$ Biomass Odonata * & 0.06 & 0.01 & 0.00 & 0.87 \\
\hline Relative abundance EPA stressed & 0.11 & 0.02 & 0.00 & 0.95 \\
\hline Relative abundance collector & 0.14 & 0.02 & 0.00 & 0.96 \\
\hline Relative abundance collector * & 0.29 & 0.02 & 0.00 & 0.88 \\
\hline Relative abundance predator & 0.24 & 0.02 & 0.00 & 0.81 \\
\hline Relative abundance predator * & 0.34 & 0.02 & 0.00 & 0.97 \\
\hline Relative abundance shredder & 0.19 & 0.02 & 0.00 & 0.80 \\
\hline Relative abundance shredder * & 0.29 & 0.02 & 0.00 & 1.00 \\
\hline Relative abundance Chironomidae & 0.08 & 0.01 & 0.00 & 0.61 \\
\hline Relative abundance Coleoptera & 0.11 & 0.02 & 0.00 & 0.76 \\
\hline Relative abundance Coleoptera * & 0.19 & 0.02 & 0.00 & 0.77 \\
\hline Relative abundance Dytiscidae & 0.08 & 0.01 & 0.00 & 0.70 \\
\hline Relative abundance Dytiscidae * & 0.12 & 0.02 & 0.00 & 0.85 \\
\hline Relative abundance Coleoptera and Corixidae & 0.04 & 0.01 & 0.00 & 0.63 \\
\hline Relative abundance Corixidae & 0.05 & 0.01 & 0.00 & 0.76 \\
\hline Relative abundance Corixidae * & 0.12 & 0.01 & 0.00 & 0.80 \\
\hline Relative abundance Libellulidae & 0.17 & 0.02 & 0.00 & 0.95 \\
\hline Relative abundance Libellulidae * & 0.04 & 0.01 & 0.00 & 0.80 \\
\hline Relative abundance Libellulidae & 0.06 & 0.01 & 0.00 & 0.95 \\
\hline Relative abundance Libellulidae * & 0.02 & 0.00 & 0.00 & 0.20 \\
\hline Relative abundance Odonata & 0.03 & 0.01 & 0.00 & 0.29 \\
\hline Relative abundance Odonata * & 0.04 & 0.01 & 0.00 & 0.50 \\
\hline
\end{tabular}

* Indicates metric value calculated without Oligocheata or Chironomidae. 


\section{Table 9. Continued.}

\begin{tabular}{|c|c|c|c|c|}
\hline Ecoregion/metric & & & & \\
\hline $\begin{array}{l}\text { Allegheny Highlands Benthic and Nektonic } \\
\text { Sampling }(N=46)\end{array}$ & Mean & $\begin{array}{l}\text { Std. } \\
\text { Error }\end{array}$ & Minimum & Maximum \\
\hline$\%$ Biomass EPA stressed & 0.23 & 0.04 & 0.00 & 0.89 \\
\hline$\%$ Biomass collectors & 0.30 & 0.05 & 0.00 & 0.88 \\
\hline$\%$ Biomass collectors $*$ & 0.37 & 0.05 & 0.00 & 0.90 \\
\hline$\%$ Biomass predators & 0.23 & 0.04 & 0.00 & 0.97 \\
\hline$\%$ Biomass predators * & 0.31 & 0.05 & 0.00 & 0.99 \\
\hline$\%$ Biomass shredders & 0.07 & 0.02 & 0.00 & 0.67 \\
\hline$\%$ Biomass shredders * & 0.09 & 0.02 & 0.00 & 0.69 \\
\hline$\%$ Biomass Chironomidae & 0.08 & 0.02 & 0.00 & 0.89 \\
\hline$\%$ Biomass Coleoptera & 0.10 & 0.03 & 0.00 & 0.86 \\
\hline$\%$ Biomass Coleoptera * & 0.12 & 0.03 & 0.00 & 0.89 \\
\hline$\%$ Biomass Dytiscidae & 0.03 & 0.01 & 0.00 & 0.29 \\
\hline$\%$ Biomass Corixidae & 0.03 & 0.01 & 0.00 & 0.32 \\
\hline$\%$ Biomass Corixidae * & 0.03 & 0.01 & 0.00 & 0.25 \\
\hline$\%$ Biomass Coleoptera and Corixidae & 0.04 & 0.01 & 0.00 & 0.28 \\
\hline$\%$ Biomass Libellulidae & 0.13 & 0.03 & 0.00 & 0.86 \\
\hline$\%$ Biomass Libellulidae * & 0.16 & 0.03 & 0.00 & 0.89 \\
\hline$\%$ Biomass Odonata - Libellulidae & 0.08 & 0.02 & 0.00 & 0.73 \\
\hline$\%$ Biomass Odonata - Libellulidae * & 0.11 & 0.03 & 0.00 & 0.76 \\
\hline$\%$ Biomass Odonata & 0.04 & 0.01 & 0.00 & 0.50 \\
\hline$\%$ Biomass Odonata * & 0.05 & 0.02 & 0.00 & 0.53 \\
\hline Relative abundance EPA stressed & 0.11 & 0.03 & 0.00 & 0.73 \\
\hline Relative abundance collector & 0.15 & 0.03 & 0.00 & 0.81 \\
\hline Relative abundance collector * & 0.34 & 0.03 & 0.00 & 0.80 \\
\hline Relative abundance predator & 0.19 & 0.03 & 0.00 & 0.74 \\
\hline Relative abundance predator * & 0.31 & 0.03 & 0.00 & 0.89 \\
\hline Relative abundance shredder & 0.16 & 0.02 & 0.00 & 0.80 \\
\hline Relative abundance shredder * & 0.27 & 0.03 & 0.00 & 0.80 \\
\hline Relative abundance Chironomidae & 0.10 & 0.02 & 0.00 & 0.61 \\
\hline Relative abundance Coleoptera & 0.14 & 0.03 & 0.00 & 0.76 \\
\hline Relative abundance Coleoptera * & 0.25 & 0.03 & 0.00 & 0.77 \\
\hline Relative abundance Dytiscidae & 0.07 & 0.01 & 0.00 & 0.47 \\
\hline Relative abundance Dytiscidae * & 0.12 & 0.02 & 0.00 & 0.81 \\
\hline Relative abundance Coleoptera and Corixidae & 0.03 & 0.01 & 0.00 & 0.20 \\
\hline Relative abundance Corixidae & 0.04 & 0.01 & 0.00 & 0.21 \\
\hline Relative abundance Corixidae * & 0.11 & 0.02 & 0.00 & 0.47 \\
\hline Relative abundance Libellulidae & 0.18 & 0.03 & 0.00 & 0.81 \\
\hline Relative abundance Libellulidae * & 0.04 & 0.01 & 0.00 & 0.33 \\
\hline Relative abundance Libellulidae & 0.07 & 0.02 & 0.00 & 0.50 \\
\hline Relative abundance Libellulidae * & 0.03 & 0.01 & 0.00 & 0.20 \\
\hline Relative abundance Odonata & 0.04 & 0.01 & 0.00 & 0.29 \\
\hline Relative abundance Odonata * & 0.04 & 0.01 & 0.00 & 0.50 \\
\hline
\end{tabular}

* Indicates metric value calculated without Oligocheata or Chironomidae. 


\section{Table 9. Continued.}

\begin{tabular}{|c|c|c|c|c|}
\hline Ecoregion/metric & & & & \\
\hline $\begin{array}{l}\text { Ridge and Valley Benthic and Nektonic Sampling } \\
(N=21)\end{array}$ & Mean & $\begin{array}{l}\text { Std. } \\
\text { Error }\end{array}$ & Minimum & Maximum \\
\hline$\%$ Biomass EPA stressed & 0.24 & 0.06 & 0.00 & 0.99 \\
\hline$\%$ Biomass collectors & 0.38 & 0.07 & 0.00 & 0.98 \\
\hline$\%$ Biomass collectors * & 0.40 & 0.08 & 0.00 & 0.98 \\
\hline$\%$ Biomass predators & 0.19 & 0.04 & 0.00 & 0.76 \\
\hline$\%$ Biomass predators * & 0.24 & 0.06 & 0.00 & 1.00 \\
\hline$\%$ Biomass shredders & 0.08 & 0.04 & 0.00 & 0.78 \\
\hline$\%$ Biomass shredders * & 0.11 & 0.05 & 0.00 & 0.90 \\
\hline$\%$ Biomass Chironomidae & 0.05 & 0.03 & 0.00 & 0.54 \\
\hline$\%$ Biomass Coleoptera & 0.10 & 0.03 & 0.00 & 0.63 \\
\hline$\%$ Biomass Coleoptera * & 0.11 & 0.04 & 0.00 & 0.74 \\
\hline \% Biomass Dytiscidae & 0.02 & 0.01 & 0.00 & 0.23 \\
\hline$\%$ Biomass Corixidae & 0.02 & 0.01 & 0.00 & 0.24 \\
\hline$\%$ Biomass Corixidae * & 0.01 & 0.01 & 0.00 & 0.10 \\
\hline$\%$ Biomass Coleoptera and Corixidae & 0.01 & 0.01 & 0.00 & 0.10 \\
\hline$\%$ Biomass Libellulidae & 0.11 & 0.03 & 0.00 & 0.63 \\
\hline$\%$ Biomass Libellulidae * & 0.12 & 0.04 & 0.00 & 0.74 \\
\hline$\%$ Biomass Odonata - Libellulidae & 0.04 & 0.03 & 0.00 & 0.68 \\
\hline \% Biomass Odonata - Libellulidae * & 0.04 & 0.03 & 0.00 & 0.68 \\
\hline$\%$ Biomass Odonata & 0.03 & 0.01 & 0.00 & 0.28 \\
\hline$\%$ Biomass Odonata * & 0.03 & 0.01 & 0.00 & 0.28 \\
\hline Relative abundance EPA stressed & 0.07 & 0.04 & 0.00 & 0.73 \\
\hline Relative abundance collector & 0.07 & 0.04 & 0.00 & 0.73 \\
\hline Relative abundance collector * & 0.30 & 0.05 & 0.00 & 0.83 \\
\hline Relative abundance predator & 0.29 & 0.05 & 0.00 & 0.79 \\
\hline Relative abundance predator * & 0.38 & 0.06 & 0.00 & 0.80 \\
\hline Relative abundance shredder & 0.17 & 0.03 & 0.00 & 0.54 \\
\hline Relative abundance shredder * & 0.28 & 0.06 & 0.00 & 1.00 \\
\hline Relative abundance Chironomidae & 0.12 & 0.04 & 0.00 & 0.55 \\
\hline Relative abundance Coleoptera & 0.15 & 0.04 & 0.00 & 0.62 \\
\hline Relative abundance Coleoptera * & 0.21 & 0.04 & 0.00 & 0.65 \\
\hline Relative abundance Dytiscidae & 0.09 & 0.02 & 0.00 & 0.38 \\
\hline Relative abundance Dytiscidae * & 0.11 & 0.03 & 0.00 & 0.55 \\
\hline Relative abundance Coleoptera and Corixidae & 0.04 & 0.01 & 0.00 & 0.21 \\
\hline Relative abundance Corixidae & 0.05 & 0.02 & 0.00 & 0.22 \\
\hline Relative abundance Corixidae * & 0.12 & 0.03 & 0.00 & 0.52 \\
\hline Relative abundance Libellulidae & 0.15 & 0.04 & 0.00 & 0.63 \\
\hline Relative abundance Libellulidae * & 0.03 & 0.02 & 0.00 & 0.48 \\
\hline Relative abundance Libellulidae & 0.04 & 0.03 & 0.00 & 0.58 \\
\hline Relative abundance Libellulidae * & 0.01 & 0.01 & 0.00 & 0.17 \\
\hline Relative abundance Odonata & 0.02 & 0.01 & 0.00 & 0.21 \\
\hline Relative abundance Odonata * & 0.03 & 0.01 & 0.00 & 0.28 \\
\hline
\end{tabular}

* Indicates metric value calculated without Oligocheata or Chironomidae. 


\section{Table 9. Continued.}

\begin{tabular}{|c|c|c|c|c|}
\hline Ecoregion/metric & & & & \\
\hline $\begin{array}{l}\text { Western Allegheny Plateau Benthic and Nektonic } \\
\text { Sampling }(N=39)\end{array}$ & Mean & $\begin{array}{l}\text { Std. } \\
\text { Error }\end{array}$ & Minimum & Maximum \\
\hline$\%$ Biomass EPA stressed & 0.27 & 0.05 & 0.00 & 0.85 \\
\hline$\%$ Biomass collectors & 0.35 & 0.05 & 0.00 & 0.97 \\
\hline$\%$ Biomass collectors * & 0.43 & 0.05 & 0.00 & 0.97 \\
\hline$\%$ Biomass predators & 0.28 & 0.05 & 0.00 & 0.98 \\
\hline$\%$ Biomass predators * & 0.34 & 0.06 & 0.00 & 1.00 \\
\hline$\%$ Biomass shredders & 0.05 & 0.02 & 0.00 & 0.63 \\
\hline$\%$ Biomass shredders * & 0.07 & 0.02 & 0.00 & 0.63 \\
\hline$\%$ Biomass Chironomidae & 0.02 & 0.01 & 0.00 & 0.27 \\
\hline \% Biomass Coleoptera & 0.10 & 0.03 & 0.00 & 0.97 \\
\hline$\%$ Biomass Coleoptera * & 0.11 & 0.03 & 0.00 & 0.99 \\
\hline$\%$ Biomass Dytiscidae & 0.05 & 0.02 & 0.00 & 0.76 \\
\hline$\%$ Biomass Corixidae & 0.05 & 0.02 & 0.00 & 0.78 \\
\hline$\%$ Biomass Corixidae * & 0.04 & 0.02 & 0.00 & 0.78 \\
\hline$\%$ Biomass Coleoptera and Corixidae & 0.04 & 0.03 & 0.00 & 0.97 \\
\hline$\%$ Biomass Libellulidae & 0.14 & 0.04 & 0.00 & 0.97 \\
\hline$\%$ Biomass Libellulidae * & 0.15 & 0.04 & 0.00 & 0.99 \\
\hline \% Biomass Odonata - Libellulidae & 0.07 & 0.03 & 0.00 & 0.67 \\
\hline \% Biomass Odonata - Libellulidae * & 0.09 & 0.03 & 0.00 & 0.67 \\
\hline$\%$ Biomass Odonata & 0.06 & 0.02 & 0.00 & 0.30 \\
\hline$\%$ Biomass Odonata $*$ & 0.08 & 0.03 & 0.00 & 0.87 \\
\hline Relative abundance EPA stressed & 0.13 & 0.03 & 0.00 & 0.95 \\
\hline Relative abundance collector & 0.17 & 0.04 & 0.00 & 0.96 \\
\hline Relative abundance collector * & 0.24 & 0.03 & 0.00 & 0.88 \\
\hline Relative abundance predator & 0.26 & 0.03 & 0.00 & 0.81 \\
\hline Relative abundance predator * & 0.35 & 0.04 & 0.00 & 0.97 \\
\hline Relative abundance shredder & 0.22 & 0.03 & 0.00 & 0.70 \\
\hline Relative abundance shredder * & 0.32 & 0.04 & 0.00 & 1.00 \\
\hline Relative abundance Chironomidae & 0.05 & 0.01 & 0.00 & 0.31 \\
\hline Relative abundance Coleoptera & 0.06 & 0.02 & 0.00 & 0.36 \\
\hline Relative abundance Coleoptera * & 0.12 & 0.02 & 0.00 & 0.60 \\
\hline Relative abundance Dytiscidae & 0.10 & 0.02 & 0.00 & 0.70 \\
\hline Relative abundance Dytiscidae * & 0.12 & 0.03 & 0.00 & 0.85 \\
\hline Relative abundance Coleoptera and Corixidae & 0.05 & 0.02 & 0.00 & 0.63 \\
\hline Relative abundance Corixidae & 0.06 & 0.02 & 0.00 & 0.76 \\
\hline Relative abundance Corixidae * & 0.14 & 0.03 & 0.00 & 0.80 \\
\hline Relative abundance Libellulidae & 0.17 & 0.03 & 0.00 & 0.95 \\
\hline Relative abundance Libellulidae * & 0.04 & 0.02 & 0.00 & 0.80 \\
\hline Relative abundance Libellulidae & 0.05 & 0.03 & 0.00 & 0.95 \\
\hline Relative abundance Libellulidae * & 0.01 & 0.00 & 0.00 & 0.10 \\
\hline Relative abundance Odonata & 0.02 & 0.01 & 0.00 & 0.17 \\
\hline Relative abundance Odonata * & 0.06 & 0.02 & 0.00 & 0.30 \\
\hline
\end{tabular}

* Indicates metric value calculated without Oligocheata or Chironomidae. 
Table 9. Continued.

\begin{tabular}{|c|c|c|c|c|}
\hline Ecoregion/metric & & & & \\
\hline Benthic Sampling Statewide $(N=140)$ & Mean & $\begin{array}{c}\text { Std. } \\
\text { Error }\end{array}$ & Minimum & Maximum \\
\hline$\%$ Biomass collector & 0.35 & 0.03 & 0.00 & 1.34 \\
\hline$\%$ Biomass collector * & 0.51 & 0.04 & 0.00 & 1.65 \\
\hline$\%$ Biomass predator & 0.07 & 0.02 & 0.00 & 1.00 \\
\hline$\%$ Biomass predator * & 0.13 & 0.02 & 0.00 & 1.00 \\
\hline$\%$ Biomass shredder & 0.07 & 0.02 & 0.00 & 1.00 \\
\hline$\%$ Biomass shredder * & 0.09 & 0.02 & 0.00 & 1.00 \\
\hline Relative abundance collector & 0.26 & 0.02 & 0.00 & 1.00 \\
\hline Relative abundance collector * & 0.42 & 0.03 & 0.00 & 1.00 \\
\hline Relative abundance predator & 0.11 & 0.01 & 0.00 & 1.00 \\
\hline Relative abundance predator * & 0.19 & 0.02 & 0.00 & 1.00 \\
\hline Relative abundance shredder & 0.04 & 0.01 & 0.00 & 1.00 \\
\hline Relative abundance shredder * & 0.07 & 0.01 & 0.00 & 1.00 \\
\hline$\%$ Biomass EPA stressed & 0.13 & 0.02 & 0.00 & 1.00 \\
\hline Relative abundance EPA stressed & 0.13 & 0.02 & 0.00 & 1.00 \\
\hline$\%$ Biomass Chironomidae & 0.05 & 0.02 & 0.00 & 1.00 \\
\hline Relative abundance of Chironomidae & 0.09 & 0.01 & 0.00 & 0.83 \\
\hline$\%$ Biomass Coleoptera & 0.06 & 0.01 & 0.00 & 0.84 \\
\hline$\%$ Biomass Coleoptera * & 0.10 & 0.02 & 0.00 & 1.00 \\
\hline Relative abundance Coleoptera & 0.04 & 0.01 & 0.00 & 0.50 \\
\hline Relative abundance Coleoptera * & 0.08 & 0.01 & 0.00 & 1.00 \\
\hline Family Richness & 4.31 & 0.23 & 1.00 & 14.00 \\
\hline Allegheny Highlands Benthic Sampling $(N=62)$ & Mean & $\begin{array}{l}\text { Std. } \\
\text { Error }\end{array}$ & Minimum & Maximum \\
\hline$\%$ Biomass collector & 0.25 & 0.04 & 0.00 & 1.00 \\
\hline$\%$ Biomass collector * & 0.40 & 0.05 & 0.00 & 1.00 \\
\hline$\%$ Biomass predator & 0.07 & 0.02 & 0.00 & 1.00 \\
\hline$\%$ Biomass predator * & 0.16 & 0.04 & 0.00 & 1.00 \\
\hline$\%$ Biomass shredder & 0.10 & 0.03 & 0.00 & 1.00 \\
\hline$\%$ Biomass shredder * & 0.14 & 0.04 & 0.00 & 1.00 \\
\hline Relative abundance collector & 0.17 & 0.03 & 0.00 & 1.00 \\
\hline Relative abundance collector * & 0.31 & 0.04 & 0.00 & 1.00 \\
\hline Relative abundance predator & 0.12 & 0.02 & 0.00 & 1.00 \\
\hline Relative abundance predator * & 0.24 & 0.04 & 0.00 & 1.00 \\
\hline Relative abundance shredder & 0.07 & 0.02 & 0.00 & 1.00 \\
\hline Relative abundance shredder * & 0.12 & 0.03 & 0.00 & 1.00 \\
\hline$\%$ Biomass EPA stressed & 0.08 & 0.02 & 0.00 & 1.00 \\
\hline Relative abundance EPA stressed & 0.12 & 0.02 & 0.00 & 0.69 \\
\hline$\%$ Biomass Chironomidae & 0.04 & 0.02 & 0.00 & 1.00 \\
\hline Relative abundance of Chironomidae & 0.10 & 0.02 & 0.00 & 0.69 \\
\hline$\%$ Biomass Coleoptera & 0.06 & 0.02 & 0.00 & 0.84 \\
\hline$\%$ Biomass Coleoptera * & 0.13 & 0.04 & 0.00 & 1.00 \\
\hline Relative abundance Coleoptera & 0.05 & 0.01 & 0.00 & 0.50 \\
\hline Relative abundance Coleoptera * & 0.11 & 0.03 & 0.00 & 1.00 \\
\hline Family Richness & 4.60 & 0.38 & 1.00 & 14.00 \\
\hline
\end{tabular}

* Indicates metric value calculated without Oligocheata or Chironomidae. 
Table 9. Continued.

\begin{tabular}{|c|c|c|c|c|}
\hline Ecoregion/metric & & & & \\
\hline Ridge and Valley Benthic Sampling $(N=25)$ & Mean & $\begin{array}{c}\text { Std. } \\
\text { Error }\end{array}$ & Minimum & Maximum \\
\hline$\%$ Biomass collector & 0.40 & 0.08 & 0.00 & 1.01 \\
\hline$\%$ Biomass collector * & 0.48 & 0.09 & 0.00 & 1.02 \\
\hline$\%$ Biomass predator & 0.02 & 0.01 & 0.00 & 0.13 \\
\hline$\%$ Biomass predator * & 0.08 & 0.04 & 0.00 & 1.00 \\
\hline$\%$ Biomass shredder & 0.05 & 0.04 & 0.00 & 0.98 \\
\hline$\%$ Biomass shredder * & 0.05 & 0.04 & 0.00 & 0.98 \\
\hline Relative abundance collector & 0.35 & 0.07 & 0.00 & 1.00 \\
\hline Relative abundance collector * & 0.50 & 0.09 & 0.00 & 1.25 \\
\hline Relative abundance predator & 0.12 & 0.04 & 0.00 & 0.75 \\
\hline Relative abundance predator * & 0.20 & 0.06 & 0.00 & 1.00 \\
\hline Relative abundance shredder & 0.02 & 0.02 & 0.00 & 0.36 \\
\hline Relative abundance shredder * & 0.03 & 0.02 & 0.00 & 0.36 \\
\hline$\%$ Biomass EPA stressed & 0.25 & 0.07 & 0.00 & 1.00 \\
\hline Relative abundance EPA stressed & 0.17 & 0.04 & 0.00 & 0.63 \\
\hline$\%$ Biomass Chironomidae & 0.11 & 0.06 & 0.00 & 1.00 \\
\hline Relative abundance of Chironomidae & 0.11 & 0.04 & 0.00 & 0.63 \\
\hline$\%$ Biomass Coleoptera & 0.09 & 0.04 & 0.00 & 0.78 \\
\hline$\%$ Biomass Coleoptera * & 0.10 & 0.05 & 0.00 & 0.95 \\
\hline Relative abundance Coleoptera & 0.04 & 0.02 & 0.00 & 0.50 \\
\hline Relative abundance Coleoptera * & 0.05 & 0.03 & 0.00 & 0.67 \\
\hline Family Richness & 4.04 & 0.54 & 1.00 & 9.00 \\
\hline Western Allegheny Plateau Benthic Sampling $(N=53)$ & & $\begin{array}{l}\text { Std. } \\
\text { Error }\end{array}$ & Minimum & Maximum \\
\hline$\%$ Biomass collector & 0.44 & 0.06 & 0.00 & 1.34 \\
\hline$\%$ Biomass collector $*$ & 0.64 & 0.06 & 0.00 & 1.65 \\
\hline$\%$ Biomass predator & 0.08 & 0.03 & 0.00 & 0.98 \\
\hline$\%$ Biomass predator * & 0.11 & 0.04 & 0.00 & 1.00 \\
\hline$\%$ Biomass shredder & 0.03 & 0.02 & 0.00 & 0.82 \\
\hline$\%$ Biomass shredder * & 0.04 & 0.02 & 0.00 & 0.84 \\
\hline Relative abundance collector & 0.32 & 0.04 & 0.00 & 1.00 \\
\hline Relative abundance collector * & 0.51 & 0.05 & 0.00 & 1.00 \\
\hline Relative abundance predator & 0.08 & 0.02 & 0.00 & 0.60 \\
\hline Relative abundance predator * & 0.14 & 0.03 & 0.00 & 1.00 \\
\hline Relative abundance shredder & 0.01 & 0.01 & 0.00 & 0.20 \\
\hline Relative abundance shredder * & 0.02 & 0.01 & 0.00 & 0.20 \\
\hline$\%$ Biomass EPA stressed & 0.15 & 0.04 & 0.00 & 1.00 \\
\hline Relative abundance EPA stressed & 0.13 & 0.03 & 0.00 & 1.00 \\
\hline$\%$ Biomass Chironomidae & 0.04 & 0.02 & 0.00 & 0.80 \\
\hline Relative abundance of Chironomidae & 0.07 & 0.02 & 0.00 & 0.83 \\
\hline$\%$ Biomass Coleoptera & 0.04 & 0.02 & 0.00 & 0.75 \\
\hline$\%$ Biomass Coleoptera * & 0.07 & 0.03 & 0.00 & 0.90 \\
\hline Relative abundance Coleoptera & 0.04 & 0.01 & 0.00 & 0.50 \\
\hline Relative abundance Coleoptera * & 0.05 & 0.02 & 0.00 & 0.50 \\
\hline Family Richness & 4.09 & 0.32 & 1.00 & 11.00 \\
\hline
\end{tabular}

* Indicates metric value calculated without Oligocheata or Chironomidae. 
Table 9. Continued.

\begin{tabular}{|c|c|c|c|c|}
\hline \multicolumn{5}{|l|}{ Ecoregion/metric } \\
\hline Nektonic Sampling Statewide $(N=111)$ & Mean & $\begin{array}{c}\text { Std. } \\
\text { Error }\end{array}$ & Minimum & Maximum \\
\hline$\%$ Biomass EPA stressed $^{a}$ & 0.29 & 0.03 & 0.00 & 1.00 \\
\hline Relative abundance EPA stressed & 0.32 & 0.03 & 0.00 & 1.00 \\
\hline$\%$ Biomass of Chironomidae & 0.06 & 0.01 & 0.00 & 0.97 \\
\hline Relative abundance of Chironomidae & 0.20 & 0.02 & 0.00 & 0.93 \\
\hline$\%$ Biomass of Corixidae & 0.05 & 0.01 & 0.00 & 1.00 \\
\hline$\%$ Biomass of Corixidae * & 0.05 & 0.01 & 0.00 & 1.00 \\
\hline Relative abundance of Corixidae & 0.05 & 0.01 & 0.00 & 1.00 \\
\hline Relative abundance of Corixidae * & 0.07 & 0.02 & 0.00 & 1.00 \\
\hline Percent Biomass of Coleoptera & 0.09 & 0.02 & 0.00 & 0.98 \\
\hline Percent Biomass of Coleoptera * & 0.10 & 0.02 & 0.00 & 1.00 \\
\hline Relative abundance of Coleoptera & 0.10 & 0.01 & 0.00 & 0.80 \\
\hline Relative abundance of Coleoptera * & 0.13 & 0.02 & 0.00 & 1.00 \\
\hline$\%$ Biomass of Coleoptera and Corixidae & 0.14 & 0.02 & 0.00 & 1.00 \\
\hline Relative abundance of Coleoptera and Corixidae & 0.15 & 0.02 & 0.00 & 1.00 \\
\hline Relative abundance of Coleoptera and Corixidae * & 0.15 & 0.02 & 0.00 & 1.00 \\
\hline$\%$ Biomass of Dytiscidae & 0.20 & 0.02 & 0.00 & 1.00 \\
\hline$\%$ Biomass of Dytiscidae * & 0.04 & 0.01 & 0.00 & 0.83 \\
\hline Relative abundance of Dytiscidae & 0.04 & 0.01 & 0.00 & 0.92 \\
\hline Relative abundance of Dytiscidae * & 0.05 & 0.01 & 0.00 & 0.71 \\
\hline$\%$ Biomass of collectors & 0.06 & 0.01 & 0.00 & 0.89 \\
\hline$\%$ Biomass of collectors $*$ & 0.47 & 0.03 & 0.00 & 1.00 \\
\hline$\%$ Biomass of predators & 0.50 & 0.04 & 0.00 & 1.09 \\
\hline$\%$ Biomass of predators $*$ & 0.31 & 0.03 & 0.00 & 1.00 \\
\hline$\%$ Biomass of shredders & 0.35 & 0.03 & 0.00 & 1.00 \\
\hline$\%$ Biomass of shredders * & 0.06 & 0.01 & 0.00 & 0.68 \\
\hline Relative abundance of collectors & 0.07 & 0.01 & 0.00 & 1.00 \\
\hline Relative abundance of collectors * & 0.37 & 0.03 & 0.00 & 1.00 \\
\hline Relative abundance of predators & 0.47 & 0.03 & 0.00 & 1.40 \\
\hline Relative abundance of predators * & 0.23 & 0.02 & 0.00 & 1.00 \\
\hline Relative abundance of shredders & 0.33 & 0.03 & 0.00 & 1.00 \\
\hline Relative abundance of shredders * & 0.09 & 0.02 & 0.00 & 0.73 \\
\hline Family Richness & 8.21 & 0.48 & 0.00 & 23.00 \\
\hline Relative abundance of Lestidae & 0.00 & 0.00 & 0.00 & 0.24 \\
\hline Relative abundance of Lestidae * & 0.01 & 0.01 & 0.00 & 0.63 \\
\hline$\%$ Biomass of Libellulidae & 0.00 & 0.00 & 0.00 & 0.06 \\
\hline$\%$ Biomass of Libellulidae * & 0.00 & 0.00 & 0.00 & 0.20 \\
\hline Relative abundance of Libellulidae & 0.08 & 0.02 & 0.00 & 0.76 \\
\hline Relative abundance of Libellulidae * & 0.09 & 0.02 & 0.00 & 0.77 \\
\hline$\%$ Biomass Odonata & 0.02 & 0.01 & 0.00 & 0.23 \\
\hline$\%$ Biomass Odonata * & 0.03 & 0.01 & 0.00 & 0.29 \\
\hline Relative abundance of Odonata & 0.14 & 0.02 & 0.00 & 0.98 \\
\hline Relative abundance of Odonata * & 0.15 & 0.02 & 0.00 & 1.00 \\
\hline$\%$ Biomass of Odonata - Libellulidae & 0.07 & 0.01 & 0.00 & 0.52 \\
\hline$\%$ Biomass of Odonata - Libellulidae * & 0.09 & 0.02 & 0.00 & 1.00 \\
\hline Relative abundance of Odonata - Libellulidae & 0.06 & 0.01 & 0.00 & 0.98 \\
\hline Relative abundance of Odonata - Libellulidae * & 0.07 & 0.01 & 0.00 & 1.00 \\
\hline
\end{tabular}

* Indicates metric value calculated without Oligocheata or Chironomidae. 
Table 9. Continued.

\begin{tabular}{|c|c|c|c|c|}
\hline \multicolumn{5}{|l|}{ Ecoregion/metric } \\
\hline Allegheny Highlands Nektonic Sampling $(N=46)$ & Mean & $\begin{array}{c}\text { Std. } \\
\text { Error }\end{array}$ & Minimum & Maximum \\
\hline$\%$ Biomass EPA stressed & 0.31 & 0.04 & 0.00 & 0.97 \\
\hline Relative abundance EPA stressed & 0.40 & 0.04 & 0.00 & 0.93 \\
\hline$\%$ Biomass of Chironomidae & 0.09 & 0.03 & 0.00 & 0.97 \\
\hline Relative abundance of Chironomidae & 0.28 & 0.04 & 0.00 & 0.93 \\
\hline$\%$ Biomass of Corixidae & 0.04 & 0.01 & 0.00 & 0.32 \\
\hline$\%$ Biomass of Corixidae * & 0.04 & 0.01 & 0.00 & 0.33 \\
\hline Relative abundance of Corixidae & 0.05 & 0.01 & 0.00 & 0.37 \\
\hline Relative abundance of Corixidae * & 0.08 & 0.02 & 0.00 & 0.57 \\
\hline Percent Biomass of Coleoptera & 0.09 & 0.02 & 0.00 & 0.90 \\
\hline Percent Biomass of Coleoptera * & 0.10 & 0.03 & 0.00 & 1.00 \\
\hline Relative abundance of Coleoptera & 0.09 & 0.02 & 0.00 & 0.40 \\
\hline Relative abundance of Coleoptera * & 0.14 & 0.03 & 0.00 & 1.00 \\
\hline$\%$ Biomass of Coleoptera and Corixidae & 0.12 & 0.03 & 0.00 & 0.90 \\
\hline Relative abundance of Coleoptera and Corixidae & 0.14 & 0.03 & 0.00 & 1.00 \\
\hline Relative abundance of Coleoptera and Corixidae * & 0.14 & 0.02 & 0.00 & 0.40 \\
\hline$\%$ Biomass of Dytiscidae & 0.22 & 0.03 & 0.00 & 1.00 \\
\hline$\%$ Biomass of Dytiscidae * & 0.04 & 0.02 & 0.00 & 0.83 \\
\hline Relative abundance of Dytiscidae & 0.04 & 0.02 & 0.00 & 0.92 \\
\hline Relative abundance of Dytiscidae * & 0.04 & 0.01 & 0.00 & 0.21 \\
\hline$\%$ Biomass of collectors & 0.06 & 0.02 & 0.00 & 0.50 \\
\hline$\%$ Biomass of collectors $*$ & 0.47 & 0.05 & 0.00 & 1.00 \\
\hline$\%$ Biomass of predators & 0.51 & 0.06 & 0.00 & 1.09 \\
\hline$\%$ Biomass of predators $*$ & 0.29 & 0.05 & 0.00 & 0.97 \\
\hline$\%$ Biomass of shredders & 0.36 & 0.06 & 0.00 & 1.00 \\
\hline$\%$ Biomass of shredders * & 0.05 & 0.01 & 0.00 & 0.35 \\
\hline Relative abundance of collectors & 0.06 & 0.02 & 0.00 & 0.39 \\
\hline Relative abundance of collectors * & 0.35 & 0.04 & 0.00 & 1.00 \\
\hline Relative abundance of predators & 0.50 & 0.05 & 0.00 & 1.40 \\
\hline Relative abundance of predators * & 0.18 & 0.03 & 0.00 & 0.80 \\
\hline Relative abundance of shredders & 0.30 & 0.04 & 0.00 & 1.00 \\
\hline Relative abundance of shredders * & 0.11 & 0.03 & 0.00 & 0.73 \\
\hline Family Richness & 7.35 & 0.62 & 0.00 & 21.00 \\
\hline Relative abundance of Lestidae & 0.00 & 0.00 & 0.00 & 0.05 \\
\hline Relative abundance of Lestidae * & 0.00 & 0.00 & 0.00 & 0.05 \\
\hline$\%$ Biomass of Libellulidae & 0.00 & 0.00 & 0.00 & 0.05 \\
\hline$\%$ Biomass of Libellulidae * & 0.00 & 0.00 & 0.00 & 0.06 \\
\hline Relative abundance of Libellulidae & 0.10 & 0.03 & 0.00 & 0.76 \\
\hline Relative abundance of Libellulidae * & 0.12 & 0.03 & 0.00 & 0.77 \\
\hline$\%$ Biomass Odonata & 0.03 & 0.01 & 0.00 & 0.23 \\
\hline$\%$ Biomass Odonata * & 0.05 & 0.01 & 0.00 & 0.29 \\
\hline Relative abundance of Odonata & 0.15 & 0.04 & 0.00 & 0.91 \\
\hline Relative abundance of Odonata * & 0.17 & 0.04 & 0.00 & 0.93 \\
\hline$\%$ Biomass of Odonata - Libellulidae & 0.06 & 0.02 & 0.00 & 0.50 \\
\hline$\%$ Biomass of Odonata - Libellulidae * & 0.08 & 0.02 & 0.00 & 0.60 \\
\hline Relative abundance of Odonata - Libellulidae & 0.05 & 0.02 & 0.00 & 0.50 \\
\hline Relative abundance of Odonata - Libellulidae * & 0.05 & 0.02 & 0.00 & 0.53 \\
\hline
\end{tabular}

* Indicates metric value calculated without Oligocheata or Chironomidae. 
Table 9. Continued.

\begin{tabular}{|c|c|c|c|c|}
\hline \multicolumn{5}{|l|}{ Ecoregion/metric } \\
\hline Ridge and Valley Nektonic Sampling $(N=22)$ & Mean & $\begin{array}{c}\text { Std. } \\
\text { Error }\end{array}$ & Minimum & Maximum \\
\hline$\%$ Biomass EPA stressed & 0.23 & 0.06 & 0.00 & 0.99 \\
\hline Relative abundance EPA stressed & 0.27 & 0.06 & 0.00 & 0.85 \\
\hline$\%$ Biomass of Chironomidae & 0.05 & 0.03 & 0.00 & 0.60 \\
\hline Relative abundance of Chironomidae & 0.18 & 0.05 & 0.00 & 0.75 \\
\hline$\%$ Biomass of Corixidae & 0.01 & 0.01 & 0.00 & 0.10 \\
\hline$\%$ Biomass of Corixidae * & 0.01 & 0.01 & 0.00 & 0.11 \\
\hline Relative abundance of Corixidae & 0.03 & 0.02 & 0.00 & 0.52 \\
\hline Relative abundance of Corixidae * & 0.04 & 0.03 & 0.00 & 0.61 \\
\hline Percent Biomass of Coleoptera & 0.10 & 0.03 & 0.00 & 0.63 \\
\hline Percent Biomass of Coleoptera * & 0.11 & 0.04 & 0.00 & 0.74 \\
\hline Relative abundance of Coleoptera & 0.09 & 0.02 & 0.00 & 0.43 \\
\hline Relative abundance of Coleoptera * & 0.11 & 0.03 & 0.00 & 0.55 \\
\hline$\%$ Biomass of Coleoptera and Corixidae & 0.11 & 0.04 & 0.00 & 0.63 \\
\hline Relative abundance of Coleoptera and Corixidae & 0.12 & 0.04 & 0.00 & 0.74 \\
\hline Relative abundance of Coleoptera and Corixidae * & 0.12 & 0.03 & 0.00 & 0.56 \\
\hline$\%$ Biomass of Dytiscidae & 0.15 & 0.04 & 0.00 & 0.65 \\
\hline$\%$ Biomass of Dytiscidae * & 0.02 & 0.01 & 0.00 & 0.24 \\
\hline Relative abundance of Dytiscidae & 0.03 & 0.01 & 0.00 & 0.25 \\
\hline Relative abundance of Dytiscidae * & 0.04 & 0.01 & 0.00 & 0.23 \\
\hline$\%$ Biomass of collectors & 0.06 & 0.02 & 0.00 & 0.24 \\
\hline$\%$ Biomass of collectors $*$ & 0.46 & 0.08 & 0.00 & 0.97 \\
\hline$\%$ Biomass of predators & 0.48 & 0.08 & 0.00 & 0.97 \\
\hline$\%$ Biomass of predators $*$ & 0.29 & 0.07 & 0.00 & 1.00 \\
\hline$\%$ Biomass of shredders & 0.34 & 0.08 & 0.00 & 1.00 \\
\hline$\%$ Biomass of shredders * & 0.06 & 0.02 & 0.00 & 0.29 \\
\hline Relative abundance of collectors & 0.10 & 0.05 & 0.00 & 1.00 \\
\hline Relative abundance of collectors * & 0.34 & 0.06 & 0.00 & 0.84 \\
\hline Relative abundance of predators & 0.44 & 0.07 & 0.00 & 1.26 \\
\hline Relative abundance of predators * & 0.21 & 0.05 & 0.00 & 1.00 \\
\hline Relative abundance of shredders & 0.30 & 0.07 & 0.00 & 1.00 \\
\hline Relative abundance of shredders * & 0.13 & 0.04 & 0.00 & 0.56 \\
\hline Family Richness & 8.73 & 1.29 & 0.00 & 23.00 \\
\hline Relative abundance of Lestidae & 0.02 & 0.01 & 0.00 & 0.24 \\
\hline Relative abundance of Lestidae * & 0.04 & 0.03 & 0.00 & 0.63 \\
\hline$\%$ Biomass of Libellulidae & 0.01 & 0.00 & 0.00 & 0.06 \\
\hline$\%$ Biomass of Libellulidae * & 0.01 & 0.01 & 0.00 & 0.20 \\
\hline Relative abundance of Libellulidae & 0.04 & 0.03 & 0.00 & 0.68 \\
\hline Relative abundance of Libellulidae * & 0.04 & 0.03 & 0.00 & 0.69 \\
\hline$\%$ Biomass Odonata & 0.01 & 0.01 & 0.00 & 0.19 \\
\hline$\%$ Biomass Odonata * & 0.02 & 0.01 & 0.00 & 0.22 \\
\hline Relative abundance of Odonata & 0.08 & 0.04 & 0.00 & 0.74 \\
\hline Relative abundance of Odonata * & 0.09 & 0.04 & 0.00 & 0.74 \\
\hline$\%$ Biomass of Odonata - Libellulidae & 0.05 & 0.03 & 0.00 & 0.52 \\
\hline$\%$ Biomass of Odonata - Libellulidae * & 0.07 & 0.03 & 0.00 & 0.67 \\
\hline Relative abundance of Odonata - Libellulidae & 0.04 & 0.02 & 0.00 & 0.29 \\
\hline Relative abundance of Odonata - Libellulidae * & 0.05 & 0.03 & 0.00 & 0.63 \\
\hline
\end{tabular}

* Indicates metric value calculated without Oligocheata or Chironomidae. 
Table 9. Continued.

\begin{tabular}{|c|c|c|c|c|}
\hline Ecoregion/metric & & & & \\
\hline $\begin{array}{l}\text { Western Alleghany Plateau Nektonic } \\
\text { Sampling }(N=43)\end{array}$ & Mean & $\begin{array}{l}\text { Std. } \\
\text { Error }\end{array}$ & Minimum & Maximum \\
\hline$\%$ Biomass EPA stressed & 0.29 & 0.05 & 0.00 & 1.00 \\
\hline Relative abundance EPA stressed & 0.26 & 0.04 & 0.00 & 1.00 \\
\hline$\%$ Biomass of Chironomidae & 0.02 & 0.01 & 0.00 & 0.27 \\
\hline Relative abundance of Chironomidae & 0.13 & 0.02 & 0.00 & 0.61 \\
\hline$\%$ Biomass of Corixidae & 0.07 & 0.03 & 0.00 & 1.00 \\
\hline$\%$ Biomass of Corixidae * & 0.07 & 0.03 & 0.00 & 1.00 \\
\hline Relative abundance of Corixidae & 0.07 & 0.03 & 0.00 & 1.00 \\
\hline Relative abundance of Corixidae * & 0.07 & 0.03 & 0.00 & 1.00 \\
\hline Percent Biomass of Coleoptera & 0.10 & 0.03 & 0.00 & 0.98 \\
\hline Percent Biomass of Coleoptera * & 0.10 & 0.03 & 0.00 & 1.00 \\
\hline Relative abundance of Coleoptera & 0.11 & 0.03 & 0.00 & 0.80 \\
\hline Relative abundance of Coleoptera * & 0.13 & 0.03 & 0.00 & 1.00 \\
\hline$\%$ Biomass of Coleoptera and Corixidae & 0.17 & 0.04 & 0.00 & 1.00 \\
\hline Relative abundance of Coleoptera and Corixidae & 0.17 & 0.04 & 0.00 & 1.00 \\
\hline Relative abundance of Coleoptera and Corixidae * & 0.18 & 0.04 & 0.00 & 1.00 \\
\hline$\%$ Biomass of Dytiscidae & 0.20 & 0.04 & 0.00 & 1.00 \\
\hline$\%$ Biomass of Dytiscidae * & 0.05 & 0.02 & 0.00 & 0.76 \\
\hline Relative abundance of Dytiscidae & 0.05 & 0.02 & 0.00 & 0.78 \\
\hline Relative abundance of Dytiscidae * & 0.06 & 0.02 & 0.00 & 0.71 \\
\hline$\%$ Biomass of collectors & 0.07 & 0.03 & 0.00 & 0.89 \\
\hline$\%$ Biomass of collectors $*$ & 0.48 & 0.05 & 0.00 & 1.00 \\
\hline$\%$ Biomass of predators & 0.50 & 0.05 & 0.00 & 1.00 \\
\hline$\%$ Biomass of predators * & 0.33 & 0.05 & 0.00 & 1.00 \\
\hline$\%$ Biomass of shredders & 0.34 & 0.05 & 0.00 & 1.00 \\
\hline$\%$ Biomass of shredders * & 0.06 & 0.02 & 0.00 & 0.68 \\
\hline Relative abundance of collectors & 0.06 & 0.02 & 0.00 & 0.68 \\
\hline Relative abundance of collectors * & 0.40 & 0.05 & 0.00 & 1.00 \\
\hline Relative abundance of predators & 0.47 & 0.05 & 0.00 & 1.00 \\
\hline Relative abundance of predators * & 0.30 & 0.04 & 0.00 & 1.00 \\
\hline Relative abundance of shredders & 0.37 & 0.05 & 0.00 & 1.00 \\
\hline Relative abundance of shredders * & 0.05 & 0.02 & 0.00 & 0.50 \\
\hline Family Richness & 8.86 & 0.81 & 0.00 & 22.00 \\
\hline Relative abundance of Lestidae & 0.00 & 0.00 & 0.00 & 0.01 \\
\hline Relative abundance of Lestidae * & 0.00 & 0.00 & 0.00 & 0.01 \\
\hline$\%$ Biomass of Libellulidae & 0.00 & 0.00 & 0.00 & 0.04 \\
\hline$\%$ Biomass of Libellulidae * & 0.00 & 0.00 & 0.00 & 0.05 \\
\hline Relative abundance of Libellulidae & 0.07 & 0.03 & 0.00 & 0.67 \\
\hline Relative abundance of Libellulidae * & 0.07 & 0.03 & 0.00 & 0.68 \\
\hline$\%$ Biomass Odonata & 0.01 & 0.01 & 0.00 & 0.12 \\
\hline$\%$ Biomass Odonata * & 0.02 & 0.01 & 0.00 & 0.20 \\
\hline Relative abundance of Odonata & 0.16 & 0.04 & 0.00 & 0.98 \\
\hline Relative abundance of Odonata * & 0.16 & 0.04 & 0.00 & 1.00 \\
\hline$\%$ Biomass of Odonata - Libellulidae & 0.08 & 0.02 & 0.00 & 0.50 \\
\hline$\%$ Biomass of Odonata - Libellulidae * & 0.12 & 0.03 & 0.00 & 1.00 \\
\hline Relative abundance of Odonata - Libellulidae & 0.09 & 0.03 & 0.00 & 0.98 \\
\hline Relative abundance of Odonata - Libellulidae * & 0.09 & 0.03 & 0.00 & 1.00 \\
\hline
\end{tabular}

* Indicates metric value calculated without Oligocheata or Chironomidae. 


\section{$\underline{\text { Possible taxa combination(s) }}$}

\begin{tabular}{|c|c|}
\hline $\begin{array}{l}\text { Level One } \\
\text { •Data collected and disseminated using } \\
\text { volunteer resources }\end{array}$ & $\begin{array}{l}\text { Avian assemblages } \\
\text { Anuran assemblages } \\
\text { Avian and anuran assemblages }\end{array}$ \\
\hline
\end{tabular}

\section{Level Two}

-Data collected using volunteer resources

-Data disseminated using professional resources

Invertebrate assemblages

Invertebrate and anuran assemblages

Invertebrate and avian assemblages

Invertebrate, anuran, and avian assemblages

\section{Level Three}

-Data collected and disseminated using professional resources

Figure 1. Levels of resource commitment and corresponding taxa groups surveyed necessary for conducting indices of biological integrity (IBIs) for wetlands in West Virginia, USA. 


\section{APPENDICES}

Appendix A. Response guild designations listed by species occurring in the Mid-Atlantic region for use in developing classspecific avian wetland indices of biological integrity (AW-IBI) in West Virginia, USA, from 2005-2006 (Croonquist and Brooks 1991; O'Connell and Brooks 1998).

\begin{tabular}{|c|c|c|c|c|c|c|c|c|c|}
\hline Species & Latin name & $\begin{array}{c}\text { Wetland } \\
\text { Dependency }\end{array}$ & $\begin{array}{c}\text { Habitat } \\
\text { Specificity }\end{array}$ & $\begin{array}{c}\text { Trophic } \\
\text { Level }\end{array}$ & $\begin{array}{c}\text { Migratory } \\
\text { Status }\end{array}$ & $\begin{array}{l}\text { Single- } \\
\text { Brood }\end{array}$ & $\begin{array}{l}\text { Forest area } \\
\text { Sensitive }\end{array}$ & $\begin{array}{l}\text { Shrub- } \\
\text { nesting }\end{array}$ & $\begin{array}{l}\text { Nest predator/ } \\
\text { Brood parasite }\end{array}$ \\
\hline Cooper's Hawk & Accipiter cooperii & 0 & 5 & 5 & 4 & 0 & 0 & 0 & 0 \\
\hline Sharp-Shinned Hawk & Accipiter striatus & 0 & 3 & 4 & 3 & 0 & 0 & 0 & 0 \\
\hline Spotted Sandpiper & Actitis macularia & 5 & 3 & 4 & 5 & 0 & 0 & 0 & 0 \\
\hline Red-Winged Blackbird & Agelaius phoeniceus & 3 & 1 & 1 & 3 & 0 & 0 & 1 & 0 \\
\hline Wood Duck & Aix sponsa & 5 & 5 & 3 & 4 & 0 & 0 & 0 & 0 \\
\hline Henslow's Sparrow & Ammodramus henslowii & 3 & 3 & 2 & 4 & 0 & 0 & 0 & 0 \\
\hline Grasshopper Sparrow & Ammodramus savannarum & 1 & 3 & 2 & 4 & 0 & 0 & 0 & 0 \\
\hline American Widgeon & Anas americana & 5 & 3 & 2 & 4 & 0 & 0 & 0 & 0 \\
\hline Mallard & Anas platyrhynchos & 5 & 1 & 1 & 3 & 0 & 0 & 0 & 0 \\
\hline Ruby-Throated Hummingbird & Archilochus colubris & 1 & 1 & 3 & 5 & 0 & 0 & 0 & 0 \\
\hline Great Egret & Ardea alba & 5 & 3 & 4 & 4 & 0 & 0 & 0 & 0 \\
\hline Great Blue Heron & Ardea herodias & 5 & 3 & 4 & 4 & 0 & 0 & 0 & 0 \\
\hline Cedar Waxwing & Bombycilla cedrorum & 0 & 1 & 3 & 3 & 1 & 0 & 0 & 0 \\
\hline Ruffed Grouse & Bonasa umbellus & 0 & 3 & 1 & 3 & 0 & 0 & 0 & 0 \\
\hline
\end{tabular}

Wetland Dependency: $5=$ dependent, 3 =associated, $1=$ facultative use, wetlands not essential, $0=$ upland or occasional use.

Habitat Specificity: $5=$ stenotypic, specialist; $3=$ landscape dependent; $1=$ generalists.

Trophic Level status: $5=$ restricted diet, $4=$ carnivore, generalists; $3=$ herbivore specialist; $2=$ herbivore generalists; $1=$ omnivore.

Migratory Status: 5=neotropical migrant; $4=$ short distance migrant; $3=$ year round resident; $2=$ nonbreeding season resident ; $1=$ migratory transient; $0=$ occasional.

Single Brood, Forest Area sensitive, shrub-nesting, nest predator/ brood parasite indicated by 1 . 
Appendix A. Continued.

\begin{tabular}{|c|c|c|c|c|c|c|c|c|c|}
\hline Species & Latin name & $\begin{array}{c}\text { Wetland } \\
\text { Dependency }\end{array}$ & $\begin{array}{c}\text { Habitat } \\
\text { Specificity }\end{array}$ & $\begin{array}{l}\text { Trophic } \\
\text { Level }\end{array}$ & $\begin{array}{l}\text { Migratory } \\
\text { Status }\end{array}$ & $\begin{array}{l}\text { Single- } \\
\text { Brood }\end{array}$ & $\begin{array}{l}\text { Forest area } \\
\text { Sensitive }\end{array}$ & $\begin{array}{l}\text { Shrub- } \\
\text { nesting }\end{array}$ & $\begin{array}{l}\text { Nest predator/ } \\
\text { Brood parasite }\end{array}$ \\
\hline American Bittern & Botaurus lentiginosus & 5 & 5 & 3 & 4 & 0 & 0 & 0 & 0 \\
\hline Canada Goose & Branta canadensis & 5 & 3 & 2 & 4 & 0 & 0 & 0 & 0 \\
\hline Great Horned Owl & Bubo virginianus & 0 & 1 & 4 & 3 & 0 & 0 & 0 & 0 \\
\hline Red-Tailed Hawk & Buteo jamaicensis & 0 & 1 & 4 & 3 & 0 & 0 & 0 & 0 \\
\hline Red-Shouldered Hawk & Buteo lineatus & 3 & 3 & 4 & 3 & 0 & 0 & 0 & 0 \\
\hline Broad-Winged Hawk & Buteo platypterus & 0 & 5 & 5 & 5 & 0 & 0 & 0 & 0 \\
\hline Green Heron & Butorides virescens & 5 & 3 & 4 & 4 & 0 & 0 & 0 & 0 \\
\hline Chuck-will's Widow & Caprimulgus carolinensis & & & & & 0 & 0 & 0 & 0 \\
\hline Whip-poor-will & Caprimulgus vociferus & 0 & 3 & 4 & 5 & 0 & 0 & 0 & 0 \\
\hline Northern Cardinal & Cardinalis cardinalis & 0 & 1 & 2 & 3 & 0 & 0 & 1 & 0 \\
\hline Pine Siskin & Carduelis pinus & 0 & 3 & 1 & 3 & 0 & 0 & 0 & 0 \\
\hline American Goldfinch & Carduelis tristis & 0 & 1 & 2 & 3 & 1 & 0 & 1 & 0 \\
\hline House Finch & Carpodacus mexicanus & 0 & 1 & 2 & 3 & 0 & 0 & 0 & 0 \\
\hline Purple Finch & Carpodacus purpureus & 0 & 1 & 2 & 3 & 1 & 0 & 0 & 0 \\
\hline
\end{tabular}

Wetland Dependency: 5=dependent, 3 =associated, 1 =facultative use, wetlands not essential, $0=$ upland or occasional use.

Habitat Specificity: 5=stenotypic, specialist; 3=landscape dependent; 1=generalists.

Trophic Level status: $5=$ =restricted diet, 4=carnivore, generalists; $3=$ herbivore specialist; $2=$ herbivore generalists; $1=$ omnivore.

Migratory Status: $5=$ neotropical migrant; $4=$ short distance migrant; $3=$ year round resident; $2=$ nonbreeding season resident ; $1=$ migratory transient; $0=$ occasional.

Single Brood, Forest Area sensitive, shrub-nesting, nest predator/ brood parasite indicated by 1 . 
Appendix A. Continued.

\begin{tabular}{|c|c|c|c|c|c|c|c|c|c|}
\hline Species & Latin name & $\begin{array}{c}\text { Wetland } \\
\text { Dependency }\end{array}$ & $\begin{array}{c}\text { Habitat } \\
\text { Specificity }\end{array}$ & $\begin{array}{c}\text { Trophic } \\
\text { Level }\end{array}$ & $\begin{array}{c}\text { Migratory } \\
\text { Status }\end{array}$ & $\begin{array}{l}\text { Single- } \\
\text { Brood }\end{array}$ & $\begin{array}{l}\text { Forest area } \\
\text { Sensitive }\end{array}$ & $\begin{array}{l}\text { Shrub- } \\
\text { nesting }\end{array}$ & $\begin{array}{l}\text { Nest predator/ } \\
\text { Brood parasite }\end{array}$ \\
\hline Turkey Vulture & Cathartes aura & 0 & 1 & 4 & 3 & 0 & 0 & 0 & 0 \\
\hline Veery & Catharus fuscescens & 3 & 3 & 1 & 5 & 1 & 1 & 0 & 0 \\
\hline Hermit Thrush & Catharus guttatus & 0 & 3 & 1 & 5 & 0 & 1 & 0 & 0 \\
\hline Swainson's Thrush & Catharus ustulatus & 1 & 3 & 1 & 5 & 0 & 0 & 0 & 0 \\
\hline Brown Creeper & Certhia americana & 1 & 5 & 4 & 3 & 1 & 1 & 0 & 0 \\
\hline Belted Kingfisher & Ceryle alcyon & 5 & 5 & 5 & 3 & 0 & 0 & 0 & 0 \\
\hline Chimney Swift & Chaetura pelagica & 0 & 1 & 4 & 5 & 1 & 0 & 0 & 0 \\
\hline Killdeer & Charadrius vociferus & 0 & 1 & 4 & 3 & 0 & 0 & 0 & 0 \\
\hline Common Nighthawk & Chordeiles minor & & & & & 0 & 0 & 0 & 0 \\
\hline Marsh Wren & Cistothorus palustris & 5 & & & & 0 & 0 & 0 & 0 \\
\hline Sedge Wren & Cistothorus platensis & 3 & 3 & 4 & 4 & 0 & 0 & 0 & 0 \\
\hline Evening Grosbeak & Coccothraustes vespertinus & 0 & 3 & 2 & 2 & 0 & 0 & 0 & 0 \\
\hline Yellow-Billed Cuckoo & Coccyzus americanus & 0 & 1 & 1 & 5 & 1 & 0 & 1 & 0 \\
\hline Black-billed Cuckoo & Cоссудиs erythropthalmus & 0 & 1 & 1 & 5 & 1 & 0 & 1 & 0 \\
\hline
\end{tabular}

Wetland Dependency: 5=dependent, 3 =associated, 1 =facultative use, wetlands not essential, $0=$ upland or occasional use.

Habitat Specificity: 5=stenotypic, specialist; 3=landscape dependent; 1=generalists.

Trophic Level status: 5=restricted diet, 4=carnivore, generalists; $3=$ herbivore specialist; $2=$ herbivore generalists; $1=$ omnivore.

Migratory Status: 5=neotropical migrant; 4=short distance migrant; $3=$ =ear round resident; $2=$ nonbreeding season resident ; $1=$ migratory transient; $0=$ occasional.

Single Brood, Forest Area sensitive, shrub-nesting, nest predator/ brood parasite indicated by 1 . 
Appendix A. Continued.

\begin{tabular}{|c|c|c|c|c|c|c|c|c|c|}
\hline Species & Latin name & $\begin{array}{c}\text { Wetland } \\
\text { Dependency }\end{array}$ & $\begin{array}{l}\text { Habitat } \\
\text { Specificity }\end{array}$ & $\begin{array}{c}\text { Trophic } \\
\text { Level }\end{array}$ & $\begin{array}{l}\text { Migratory } \\
\text { Status }\end{array}$ & $\begin{array}{l}\text { Single- } \\
\text { Brood }\end{array}$ & $\begin{array}{l}\text { Forest area } \\
\text { Sensitive }\end{array}$ & $\begin{array}{l}\text { Shrub- } \\
\text { nesting }\end{array}$ & $\begin{array}{l}\text { Nest predator/ } \\
\text { Brood parasite }\end{array}$ \\
\hline Northern Flicker & Colaptes auratus & 0 & 3 & 1 & 3 & 1 & 0 & 0 & 0 \\
\hline Northern Bobwhite & Colinus virginianus & 0 & 3 & 1 & 3 & 0 & 0 & 0 & 0 \\
\hline Eastern Wood-Pewee & Contopus virens & 0 & 1 & 4 & 5 & 1 & 0 & 0 & 0 \\
\hline American Crow & Corvus brachyrhynchos & 0 & 1 & 1 & 3 & 1 & 0 & 0 & 1 \\
\hline Common Raven & Corvus corax & 1 & 3 & 1 & 3 & 1 & 1 & 0 & 1 \\
\hline Blue Jay & Cyanocitta cristata & 0 & 1 & 2 & 3 & 0 & 0 & 0 & 1 \\
\hline Black-throated Blue Warbler & Dendroica caerulescens & 1 & 3 & 4 & 5 & 1 & 1 & 1 & 0 \\
\hline Cerulean Warbler & Dendroica cerulea & 3 & 3 & 4 & 5 & 1 & 1 & 0 & 0 \\
\hline Yellow-Rumped Warbler & Dendroica coronata & 1 & 3 & 1 & 5 & 0 & 1 & 0 & 0 \\
\hline Prairie Warbler & Dendroica discolor & 0 & 1 & 4 & 5 & 1 & 0 & 0 & 0 \\
\hline Yellow-Throated Warbler & Dendroica dominica & 3 & 3 & 4 & 5 & 1 & 1 & 0 & 0 \\
\hline Blackburnian Warbler & Dendroica fusca & 1 & 5 & 4 & 5 & 0 & 1 & 0 & 0 \\
\hline Magnolia Warbler & Dendroica magnolia & 0 & 1 & 4 & 5 & 1 & 1 & 1 & 0 \\
\hline Chestnut-Sided Warbler & Dendroica pensylvanica & 0 & 1 & 4 & 5 & 1 & 0 & 1 & 0 \\
\hline
\end{tabular}

Wetland Dependency: 5=dependent, $3=$ =associated, 1 =facultative use, wetlands not essential, $0=$ upland or occasional use.

Habitat Specificity: 5=stenotypic, specialist; 3=landscape dependent; 1=generalists.

Trophic Level status: 5=restricted diet, 4=carnivore, generalists; $3=$ herbivore specialist; $2=$ herbivore generalists; $1=$ omnivore.

Migratory Status: $5=$ neotropical migrant; $4=$ short distance migrant; $3=$ year round resident; $2=$ nonbreeding season resident ; $1=$ migratory transient; $0=$ occasional.

Single Brood, Forest Area sensitive, shrub-nesting, nest predator/ brood parasite indicated by 1. 
Appendix A. Continued.

\begin{tabular}{|c|c|c|c|c|c|c|c|c|c|}
\hline Species & Latin name & $\begin{array}{c}\text { Wetland } \\
\text { Dependency }\end{array}$ & $\begin{array}{c}\text { Habitat } \\
\text { Specificity }\end{array}$ & $\begin{array}{l}\text { Trophic } \\
\text { Level }\end{array}$ & $\begin{array}{c}\text { Migratory } \\
\text { Status }\end{array}$ & $\begin{array}{l}\text { Single- } \\
\text { Brood }\end{array}$ & $\begin{array}{l}\text { Forest area } \\
\text { Sensitive }\end{array}$ & $\begin{array}{l}\text { Shrub- } \\
\text { nesting }\end{array}$ & $\begin{array}{l}\text { Nest predator/ } \\
\text { Brood parasite }\end{array}$ \\
\hline Yellow Warbler & Dendroica petechia & 1 & 1 & 4 & 5 & 1 & 0 & 1 & 0 \\
\hline Pine Warbler & Dendroica pinus & 0 & 3 & 4 & 5 & 1 & 1 & 0 & 0 \\
\hline Blackpoll Warbler & Dendroica striata & 1 & 5 & 4 & 5 & 0 & 0 & 0 & 0 \\
\hline Black-throated Green Warbler & Dendroica virens & 0 & 3 & 4 & 5 & 1 & 1 & 0 & 0 \\
\hline Bobolink & Dolichonyx oryzivorus & 0 & 3 & 2 & 4 & 1 & 0 & 0 & 0 \\
\hline Pileated Woodpecker & Dryocopus pileatus & 0 & 5 & 4 & 3 & 1 & 1 & 0 & 0 \\
\hline Gray Catbird & Dumetella carolinensis & 1 & 1 & 1 & 3 & 0 & 0 & 1 & 0 \\
\hline Alder Flycatcher & Empidonax alnorum & 5 & 3 & 4 & 5 & 1 & 0 & 1 & 0 \\
\hline Least Flycatcher & Empidonax minimus & 0 & 1 & 4 & 5 & 1 & 0 & 0 & 0 \\
\hline Willow Flycatcher & Empidonax traillii & 5 & 3 & 4 & 5 & 1 & 0 & 1 & 0 \\
\hline Acadian Flycatcher & Empidonax virescens & 3 & 3 & 4 & 5 & 0 & 1 & 0 & 0 \\
\hline Horned Lark & Eremophila alpestris & 0 & 1 & 2 & 4 & 0 & 0 & 0 & 0 \\
\hline Semipalmated Sandpiper & Erolia pusilla & 5 & 3 & 4 & 1 & 0 & 0 & 0 & 0 \\
\hline Rusty Blackbird & Euphagus carolinus & 3 & 3 & 1 & 1 & 0 & 0 & 0 & 0 \\
\hline
\end{tabular}

Wetland Dependency: 5=dependent, 3 =associated, 1 =facultative use, wetlands not essential, $0=$ upland or occasional use.

Habitat Specificity: 5=stenotypic, specialist; 3=landscape dependent; 1=generalists.

Trophic Level status: 5=restricted diet, 4=carnivore, generalists; $3=$ herbivore specialist; $2=$ herbivore generalists; $1=$ omnivore.

Migratory Status: 5=neotropical migrant; 4=short distance migrant; $3=$ =ear round resident; $2=$ nonbreeding season resident ; $1=$ migratory transient; $0=$ occasional.

Single Brood, Forest Area sensitive, shrub-nesting, nest predator/ brood parasite indicated by 1. 
Appendix A. Continued.

\begin{tabular}{|c|c|c|c|c|c|c|c|c|c|}
\hline Species & Latin name & $\begin{array}{c}\text { Wetland } \\
\text { Dependency }\end{array}$ & $\begin{array}{c}\text { Habitat } \\
\text { Specificity }\end{array}$ & $\begin{array}{l}\text { Trophic } \\
\text { Level }\end{array}$ & $\begin{array}{c}\text { Migratory } \\
\text { Status }\end{array}$ & $\begin{array}{l}\text { Single- } \\
\text { Brood }\end{array}$ & $\begin{array}{l}\text { Forest area } \\
\text { Sensitive }\end{array}$ & $\begin{array}{l}\text { Shrub- } \\
\text { nesting }\end{array}$ & $\begin{array}{l}\text { Nest predator/ } \\
\text { Brood parasite }\end{array}$ \\
\hline American Kestrel & Falco sparverius & 0 & 1 & 4 & 0 & 0 & 0 & 0 & 0 \\
\hline Common Yellowthroat & Geothlypis trichas & 3 & 1 & 4 & 4 & 0 & 0 & 1 & 0 \\
\hline Blue Grosbeak & Guiraca caerulea & 1 & 3 & 2 & 5 & 0 & 0 & 0 & 0 \\
\hline Worm-Eating Warbler & Helmitheros vermivorus & 0 & 3 & 4 & 5 & 1 & 1 & 0 & 0 \\
\hline Cliff Swallow & Hirundo pyrrhonota & 3 & 3 & 4 & 5 & 1 & 0 & 0 & 0 \\
\hline Barn Swallow & Hirundo rustica & 0 & 1 & 4 & 5 & 0 & 0 & 0 & 0 \\
\hline Wood Thrush & Hylocichla mustelina & 0 & 3 & 1 & 5 & 0 & 0 & 0 & 0 \\
\hline Yellow-Breasted Chat & Icteria virens & 1 & 3 & 4 & 5 & 0 & 0 & 1 & 0 \\
\hline Baltimore Oriole & Icterus galbula & 0 & 1 & 1 & 5 & 1 & 0 & 0 & 0 \\
\hline Orchard Oriole & Icterus spurius & 3 & 1 & 1 & 5 & 1 & 0 & 0 & 0 \\
\hline Dark-Eyed Junco & Junco hyemalis & 0 & 1 & 1 & 3 & 0 & 0 & 0 & 0 \\
\hline Loggerhead Shrike & Lanius ludovicianus & & & & & 0 & 0 & 0 & 0 \\
\hline Swainson's Warbler & Limnothlypis swainsonii & 5 & 5 & 4 & 5 & 0 & 0 & 0 & 0 \\
\hline Hooded Merganser & Lophodytes cucullatus & 5 & 5 & 3 & 4 & 0 & 0 & 0 & 0 \\
\hline
\end{tabular}

Wetland Dependency: 5=dependent, $3=$ =associated, 1 =facultative use, wetlands not essential, $0=$ upland or occasional use.

Habitat Specificity: 5=stenotypic, specialist; 3=landscape dependent; 1=generalists.

Trophic Level status: 5=restricted diet, 4=carnivore, generalists; $3=$ herbivore specialist; $2=$ herbivore generalists; $1=$ omnivore.

Migratory Status: $5=$ neotropical migrant; $4=$ short distance migrant; $3=$ year round resident; $2=$ nonbreeding season resident ; $1=$ migratory transient; $0=$ occasional.

Single Brood, Forest Area sensitive, shrub-nesting, nest predator/ brood parasite indicated by 1. 
Appendix A. Continued.

\begin{tabular}{|c|c|c|c|c|c|c|c|c|c|}
\hline Species & Latin name & $\begin{array}{c}\text { Wetland } \\
\text { Dependency }\end{array}$ & $\begin{array}{c}\text { Habitat } \\
\text { Specificity }\end{array}$ & $\begin{array}{c}\text { Trophic } \\
\text { Level }\end{array}$ & $\begin{array}{c}\text { Migratory } \\
\text { Status }\end{array}$ & $\begin{array}{l}\text { Single- } \\
\text { Brood }\end{array}$ & $\begin{array}{l}\text { Forest area } \\
\text { Sensitive }\end{array}$ & $\begin{array}{l}\text { Shrub- } \\
\text { nesting }\end{array}$ & $\begin{array}{l}\text { Nest predator/ } \\
\text { Brood parasite }\end{array}$ \\
\hline Red Crossbill & Loxia curvirostra & 0 & 3 & 3 & 2 & 0 & 0 & 0 & 0 \\
\hline Eastern Screech Owl & Megascops asio & 0 & 5 & 4 & 3 & 0 & 0 & 0 & 0 \\
\hline Red-Billed Woodpecker & Melanerpes carolinus & 1 & 3 & 1 & 3 & 1 & 0 & 0 & 0 \\
\hline Red-Headed Woodpecker & Melanerpes erythrocephalus & 1 & 3 & 1 & 3 & 0 & 0 & 0 & 0 \\
\hline Wild Turkey & Meleagris gallopavo & 0 & 3 & 1 & 3 & 0 & 0 & 0 & 0 \\
\hline Swamp Sparrow & Melospiza georgiana & 5 & 3 & 1 & 3 & 0 & 0 & 0 & 0 \\
\hline Song Sparrow & Melospiza melodia & 1 & 1 & 1 & 3 & 0 & 0 & 0 & 0 \\
\hline Northern Mockingbird & Mimus polyglottos & 0 & 1 & 1 & 3 & 0 & 0 & 1 & 0 \\
\hline Black-and-White Warbler & Mniotilta varia & 0 & 3 & 4 & 5 & 1 & 1 & 0 & 0 \\
\hline Brown-Headed Cowbird & Molothrus ater & 0 & 1 & 1 & 3 & 0 & 0 & 0 & 1 \\
\hline Great Crested Flycatcher & Myiarchus crinitus & 0 & 3 & 4 & 5 & 1 & 0 & 0 & 0 \\
\hline Northern Waterthrush & Northern Waterthrush & 5 & 3 & 4 & 5 & 1 & 1 & 0 & 0 \\
\hline Domestic duck & not applicable & 3 & 1 & 1 & 3 & 0 & 0 & 0 & 0 \\
\hline Kentucky Warbler & Oporornis formosus & 3 & 3 & 4 & 5 & 1 & 1 & 0 & 0 \\
\hline
\end{tabular}

Wetland Dependency: 5=dependent, 3 =associated, 1 =facultative use, wetlands not essential, $0=$ upland or occasional use.

Habitat Specificity: 5=stenotypic, specialist; 3=landscape dependent; 1=generalists.

Trophic Level status: 5=restricted diet, 4=carnivore, generalists; $3=$ herbivore specialist; $2=$ herbivore generalists; $1=$ omnivore.

Migratory Status: 5=neotropical migrant; 4=short distance migrant; $3=$ =ear round resident; $2=$ nonbreeding season resident ; $1=$ migratory transient; $0=$ occasional.

Single Brood, Forest Area sensitive, shrub-nesting, nest predator/ brood parasite indicated by 1. 
Appendix A. Continued.

\begin{tabular}{|c|c|c|c|c|c|c|c|c|c|}
\hline Species & Latin name & $\begin{array}{l}\text { Wetland } \\
\text { Dependency }\end{array}$ & $\begin{array}{l}\text { Habitat } \\
\text { Specificity }\end{array}$ & $\begin{array}{l}\text { Trophic } \\
\text { Level }\end{array}$ & $\begin{array}{l}\text { Migratory } \\
\text { Status }\end{array}$ & $\begin{array}{l}\text { Single- } \\
\text { Brood }\end{array}$ & $\begin{array}{l}\text { Forest area } \\
\text { Sensitive }\end{array}$ & $\begin{array}{l}\text { Shrub- } \\
\text { nesting }\end{array}$ & $\begin{array}{l}\text { Nest predator/ } \\
\text { Brood parasite }\end{array}$ \\
\hline Mourning Warbler & Oporornis philadelphia & 0 & 3 & 4 & 5 & 1 & 0 & 0 & 0 \\
\hline Osprey & Pandion haliaetus & 5 & 5 & 5 & 3 & 0 & 0 & 0 & 0 \\
\hline Northern Parula & Parula americana & 3 & 3 & 4 & 5 & 1 & 0 & 0 & 0 \\
\hline Tufted Titmouse & Parus bicolor & 1 & 3 & 1 & 3 & 1 & 0 & 0 & 0 \\
\hline House Sparrow & Passer domesticus & 0 & 1 & 1 & 3 & 0 & 0 & 0 & 0 \\
\hline Savannah Sparrow & Passerculus sandwichensis & 1 & 1 & 2 & 4 & 0 & 0 & 0 & 0 \\
\hline Indigo Bunting & Passerina cyanea & 1 & 1 & 1 & 5 & 0 & 0 & 1 & 0 \\
\hline Rose-Breasted Grosbeak & Pheucticus ludovicianus & 0 & 1 & 1 & 5 & 1 & 0 & 0 & 0 \\
\hline Downy Woodpecker & Picoides pubescens & 0 & 1 & 4 & 3 & 1 & 0 & 0 & 0 \\
\hline Hairy Woodpecker & Picoides villosus & 0 & 3 & 4 & 3 & 1 & 1 & 0 & 0 \\
\hline Pine Grosbeak & Pinicola enucleator & 0 & 3 & 2 & 2 & 0 & 0 & 0 & 0 \\
\hline Eastern Towhee & Pipilo erythrophthalmus & 0 & 1 & 1 & 4 & 0 & 0 & 0 & 0 \\
\hline Scarlet Tanager & Piranga olivacea & 0 & 1 & 1 & 5 & 1 & 1 & 0 & 0 \\
\hline Summer Tanager & Piranga rubra & 0 & 1 & 1 & 5 & 1 & 0 & 0 & 0 \\
\hline
\end{tabular}

Wetland Dependency: 5=dependent, 3 =associated, 1 =facultative use, wetlands not essential, $0=$ upland or occasional use.

Habitat Specificity: 5=stenotypic, specialist; 3=landscape dependent; 1=generalists.

Trophic Level status: $5=$ =restricted diet, 4=carnivore, generalists; $3=$ herbivore specialist; $2=$ herbivore generalists; $1=$ omnivore.

Migratory Status: $5=$ neotropical migrant; $4=$ short distance migrant; $3=$ year round resident; $2=$ nonbreeding season resident ; $1=$ migratory transient; $0=$ occasional.

Single Brood, Forest Area sensitive, shrub-nesting, nest predator/ brood parasite indicated by 1 . 
Appendix A. Continued.

\begin{tabular}{|c|c|c|c|c|c|c|c|c|c|}
\hline Species & Latin name & $\begin{array}{c}\text { Wetland } \\
\text { Dependency }\end{array}$ & $\begin{array}{l}\text { Habitat } \\
\text { Specificity }\end{array}$ & $\begin{array}{l}\text { Trophic } \\
\text { Level }\end{array}$ & $\begin{array}{l}\text { Migratory } \\
\text { Status }\end{array}$ & $\begin{array}{l}\text { Single- } \\
\text { Brood }\end{array}$ & $\begin{array}{l}\text { Forest area } \\
\text { Sensitive }\end{array}$ & $\begin{array}{l}\text { Shrub- } \\
\text { nesting }\end{array}$ & $\begin{array}{l}\text { Nest predator/ } \\
\text { Brood parasite }\end{array}$ \\
\hline Black-capped Chickadee & Poecile atricapilla & 0 & 1 & 1 & 3 & 1 & 0 & 0 & 0 \\
\hline Carolina Chickadee & Poecile carolinensis & 0 & 1 & 1 & 3 & 1 & 0 & 0 & 0 \\
\hline Blue-Gray Gnatcatcher & Polioptila caerulea & 1 & 3 & 4 & 5 & 1 & 0 & 0 & 0 \\
\hline Vesper Sparrow & Pooecetes gramineus & 0 & 3 & 2 & 4 & 0 & 0 & 0 & 0 \\
\hline Purple Martin & Progne subis & 3 & 3 & 4 & 5 & 0 & 0 & 0 & 0 \\
\hline Prothonotary Warbler & Protonotaria citrea & 5 & 5 & 4 & 5 & 1 & 0 & 1 & 0 \\
\hline Common Grackle & Quiscalus quiscula & 0 & 1 & 1 & 3 & 1 & 0 & 0 & 1 \\
\hline Virginia Rail & Rallus limicola & 5 & 5 & 4 & 4 & 0 & 0 & 0 & 0 \\
\hline Ruby-Crowned Kinglet & Regulus calendula & 1 & 3 & 1 & 2 & 0 & 0 & 0 & 0 \\
\hline Golden-Crowned Kinglet & Regulus satrapa & 1 & 3 & 4 & 3 & 0 & 1 & 0 & 0 \\
\hline Bank Swallow & Riparia riparia & 3 & 5 & 4 & 5 & 0 & 0 & 0 & 0 \\
\hline Eastern Phoebe & Sayornis phoebe & 0 & 1 & 4 & 4 & 0 & 0 & 0 & 0 \\
\hline American Woodcock & Scolopax minor & 5 & 3 & 5 & 4 & 0 & 0 & 0 & 0 \\
\hline Ovenbird & Seiurus aurocapillus & 0 & 3 & 4 & 5 & 1 & 1 & 0 & 0 \\
\hline
\end{tabular}

Wetland Dependency: 5=dependent, 3 =associated, 1 =facultative use, wetlands not essential, $0=$ upland or occasional use.

Habitat Specificity: 5=stenotypic, specialist; 3=landscape dependent; 1=generalists.

Trophic Level status: $5=$ =restricted diet, 4=carnivore, generalists; $3=$ herbivore specialist; $2=$ herbivore generalists; $1=$ omnivore.

Migratory Status: $5=$ neotropical migrant; $4=$ short distance migrant; $3=$ year round resident; $2=$ nonbreeding season resident ; $1=$ migratory transient; $0=$ occasional.

Single Brood, Forest Area sensitive, shrub-nesting, nest predator/ brood parasite indicated by 1. 
Appendix A. Continued.

\begin{tabular}{|c|c|c|c|c|c|c|c|c|c|}
\hline Species & Latin name & $\begin{array}{c}\text { Wetland } \\
\text { Dependency }\end{array}$ & $\begin{array}{c}\text { Habitat } \\
\text { Specificity }\end{array}$ & $\begin{array}{l}\text { Trophic } \\
\text { Level }\end{array}$ & $\begin{array}{l}\text { Migratory } \\
\text { Status }\end{array}$ & $\begin{array}{l}\text { Single- } \\
\text { Brood }\end{array}$ & $\begin{array}{l}\text { Forest area } \\
\text { Sensitive }\end{array}$ & $\begin{array}{l}\text { Shrub- } \\
\text { nesting }\end{array}$ & $\begin{array}{l}\text { Nest predator/ } \\
\text { Brood parasite }\end{array}$ \\
\hline Louisiana Waterthrush & Seiurus motacilla & 5 & 3 & 4 & 5 & 1 & 1 & 0 & 0 \\
\hline American Redstart & Setophaga ruticilla & 0 & 1 & 4 & 5 & 1 & 1 & 0 & 0 \\
\hline Eastern Bluebird & Sialia sialis & 0 & 5 & 1 & 3 & 0 & 0 & 0 & 0 \\
\hline Red-Breasted Nuthatch & Sitta canadensis & 0 & 5 & 1 & 3 & 1 & 1 & 0 & 0 \\
\hline White-Breasted Nuthatch & Sitta carolinensis & 0 & 5 & 1 & 3 & 1 & 1 & 0 & 0 \\
\hline Yellow-Bellied Sapsucker & Sphyrapicus varius & 0 & 5 & 1 & 5 & 1 & 0 & 0 & 0 \\
\hline Dickcissel & Spiza americana & 0 & 3 & 2 & 5 & 0 & 0 & 0 & 0 \\
\hline American Tree Sparrow & Spizella arborea & 0 & 1 & 2 & 2 & 0 & 0 & 0 & 0 \\
\hline Chipping Sparrow & Spizella passerina & 0 & 1 & 1 & 4 & 0 & 0 & 1 & 0 \\
\hline Field Sparrow & Spizella pusilla & 0 & 1 & 1 & 3 & 0 & 0 & 0 & 0 \\
\hline Northern Rough-Winged Swallow & Stelgidopteryx serripennis & 3 & 3 & 4 & 5 & 1 & 0 & 0 & 0 \\
\hline Barred Owl & Strix varia & 0 & 5 & 4 & 3 & 0 & 0 & 0 & 0 \\
\hline Eastern Meadowlark & Sturnella magna & 0 & 1 & 1 & 3 & 0 & 0 & 0 & 0 \\
\hline European Starling & Sturnus vulgaris & 0 & 3 & 1 & 3 & 0 & 0 & 0 & 1 \\
\hline
\end{tabular}

Wetland Dependency: 5=dependent, 3 =associated, 1 =facultative use, wetlands not essential, $0=$ upland or occasional use.

Habitat Specificity: 5=stenotypic, specialist; 3=landscape dependent; 1=generalists.

Trophic Level status: 5=restricted diet, 4=carnivore, generalists; $3=$ herbivore specialist; $2=$ herbivore generalists; $1=$ omnivore.

Migratory Status: 5=neotropical migrant; 4=short distance migrant; $3=$ =ear round resident; $2=$ nonbreeding season resident ; $1=$ migratory transient; $0=$ occasional.

Single Brood, Forest Area sensitive, shrub-nesting, nest predator/ brood parasite indicated by 1. 
Appendix A. Continued.

\begin{tabular}{|c|c|c|c|c|c|c|c|c|c|}
\hline Species & Latin name & $\begin{array}{c}\text { Wetland } \\
\text { Dependency }\end{array}$ & $\begin{array}{c}\text { Habitat } \\
\text { Specificity }\end{array}$ & $\begin{array}{c}\text { Trophic } \\
\text { Level } \\
\end{array}$ & $\begin{array}{c}\text { Migratory } \\
\text { Status } \\
\end{array}$ & $\begin{array}{l}\text { Single- } \\
\text { Brood }\end{array}$ & $\begin{array}{l}\text { Forest area } \\
\text { Sensitive } \\
\end{array}$ & $\begin{array}{l}\text { Shrub- } \\
\text { nesting }\end{array}$ & $\begin{array}{l}\text { Nest predator/ } \\
\text { Brood parasite }\end{array}$ \\
\hline Tree Swallow & Tachycineta bicolor & 1 & 5 & 4 & 5 & 1 & 0 & 0 & 0 \\
\hline Bewick's Wren & Thryomanes bewickii & 0 & 1 & 2 & 3 & 0 & 0 & 0 & 0 \\
\hline Carolina Wren & Thryothorus ludovicianus & 0 & 1 & 4 & 3 & 0 & 0 & 0 & 0 \\
\hline Brown Thrasher & Toxostoma rufum & 0 & 1 & 1 & 3 & 0 & 0 & 1 & 0 \\
\hline Solitary Sandpiper & Tringa solitaria & 5 & 3 & 4 & 1 & 0 & 0 & 0 & 0 \\
\hline House Wren & Troglodytes aedon & 0 & 1 & 4 & 4 & 0 & 0 & 0 & 0 \\
\hline Winter Wren & Troglodytes troglodytes & 3 & 3 & 4 & 3 & 1 & 1 & 0 & 0 \\
\hline American Robin & Turdus migratorius & 0 & 1 & 1 & 3 & 0 & 0 & 0 & 0 \\
\hline Eastern Kingbird & Tyrannus tyrannus & 0 & 3 & 4 & 5 & 1 & 0 & 0 & 0 \\
\hline Golden-Winged Warbler & Vermivora chrysoptera & 1 & 3 & 4 & 5 & 1 & 0 & 0 & 0 \\
\hline Tennessee Warbler & Vermivora peregrina & 0 & 1 & 4 & 1 & 0 & 0 & 0 & 0 \\
\hline Blue-Winged Warbler & Vermivora pinus & 1 & 3 & 4 & 5 & 1 & 0 & 0 & 0 \\
\hline Nashville Warbler & Vermivora ruficapilla & 1 & 1 & 4 & 5 & 1 & 0 & 0 & 0 \\
\hline Bell's Vireo & Vireo bellii & 0 & 3 & 4 & 5 & 0 & 0 & 0 & 0 \\
\hline
\end{tabular}

Wetland Dependency: 5=dependent, $3=$ =associated, 1 =facultative use, wetlands not essential, $0=$ upland or occasional use.

Habitat Specificity: 5=stenotypic, specialist; 3=landscape dependent; 1=generalists.

Trophic Level status: 5=restricted diet, 4=carnivore, generalists; $3=$ herbivore specialist; $2=$ herbivore generalists; $1=$ omnivore.

Migratory Status: $5=$ neotropical migrant; $4=$ short distance migrant; $3=$ year round resident; $2=$ nonbreeding season resident ; $1=$ migratory transient; $0=$ occasional.

Single Brood, Forest Area sensitive, shrub-nesting, nest predator/ brood parasite indicated by 1. 
Appendix A. Continued.

\begin{tabular}{|c|c|c|c|c|c|c|c|c|c|}
\hline Species & Latin name & $\begin{array}{c}\text { Wetland } \\
\text { Dependency }\end{array}$ & $\begin{array}{c}\text { Habitat } \\
\text { Specificity }\end{array}$ & $\begin{array}{c}\text { Trophic } \\
\text { Level }\end{array}$ & $\begin{array}{l}\text { Migratory } \\
\text { Status }\end{array}$ & $\begin{array}{l}\text { Single- } \\
\text { Brood }\end{array}$ & $\begin{array}{l}\text { Forest area } \\
\text { Sensitive }\end{array}$ & $\begin{array}{l}\text { Shrub- } \\
\text { nesting }\end{array}$ & $\begin{array}{l}\text { Nest predator/ } \\
\text { Brood parasite }\end{array}$ \\
\hline Yellow-Throated Vireo & Vireo flavifrons & 1 & 1 & 4 & 5 & 1 & 0 & 0 & 0 \\
\hline Warbling Vireo & Vireo gilvus & 0 & 1 & 4 & 5 & 1 & 0 & 0 & 0 \\
\hline White-Eyed Vireo & Vireo griseus & 3 & 3 & 4 & 5 & 1 & 1 & 1 & 0 \\
\hline Red-Eyed Vireo & Vireo olivaceus & 0 & 1 & 4 & 5 & 1 & 0 & 1 & 0 \\
\hline Philadelphia Vireo & Vireo philadelphicus & 0 & 1 & 4 & 1 & 0 & 0 & 0 & 0 \\
\hline Blue-Headed Vireo & Vireo solitarius & 0 & 3 & 4 & 5 & 1 & 1 & 0 & 0 \\
\hline Canada Warbler & Wilsonia canadensis & 1 & 1 & 4 & 5 & 1 & 1 & 0 & 0 \\
\hline Hooded Warbler & Wilsonia citrina & 3 & 3 & 4 & 5 & 1 & 1 & 1 & 0 \\
\hline Wilson's Warbler & Wilson's Warbler & 3 & 3 & 4 & 1 & 0 & 0 & 0 & 0 \\
\hline Mourning Dove & Zenaida macroura & 0 & 1 & 2 & 3 & 0 & 0 & 0 & 0 \\
\hline White-Throated Sparrow & Zonotrichia albicollis & 0 & 1 & 1 & 3 & 0 & 0 & 0 & 0 \\
\hline
\end{tabular}

Wetland Dependency: 5=dependent, $3=$ =associated, $1=$ facultative use, wetlands not essential, $0=$ upland or occasional use.

Habitat Specificity: 5=stenotypic, specialist; $3=$ landscape dependent; $1=$ =generalists.

Trophic Level status: $5=$ =restricted diet, $4=$ =arnivore, generalists; $3=$ herbivore specialist; $2=$ herbivore generalists; $1=$ omnivore.

Migratory Status: 5=neotropical migrant; $4=$ short distance migrant; $3=$ year round resident; $2=$ nonbreeding season resident ; $1=$ migratory transient; $0=$ occasional.

Single Brood, Forest Area sensitive, shrub-nesting, nest predator/ brood parasite indicated by 1. 
Appendix B. Site codes, ecoregion, location, Cowardin class, Hydrogeomorphic (HGM) subclass, origin, disturbance score, and reference/ stressed designations used to develop class-specific wetland indices of biological integrity (IBIs) in West Virginia from 2005-2006.

\begin{tabular}{|c|c|c|c|c|c|c|c|c|c|}
\hline Site Code & Ecoregion $^{\mathrm{a}}$ & UTMx & UTMy & Cowardin ${ }^{b}$ & $\begin{array}{l}\text { Cowardin } \mathrm{R} / \mathrm{S}^{\mathrm{C}} \\
\text { designation }\end{array}$ & $\begin{array}{l}\text { HGM subclass } \\
\text { (Cole et al. 1997) }\end{array}$ & $\begin{array}{l}\mathrm{HGM} \mathrm{R} / \mathrm{S}^{\mathrm{c}} \\
\text { designation }\end{array}$ & Origin & Disturbance Score \\
\hline CFCROS & 69 & 471974.01 & 4191083.28 & EM & & headwater floodplain & & natural & 23 \\
\hline CFECUR & 69 & 475086.61 & 4180030.30 & SS & & riparian depression & $\mathrm{R}$ & natural & 26.5 \\
\hline CFEINC & 69 & 476377.20 & 4180819.65 & EM & S & headwater impoundment & $\mathrm{S}$ & natural & 10.5 \\
\hline CFSLCH & 69 & 471978.27 & 4186916.22 & SS & & headwater floodplain & & natural & 27.5 \\
\hline CFSLIN & 69 & 472580.44 & 4186906.75 & EM & $\mathrm{R}$ & headwater floodplain & & natural & 27.5 \\
\hline CGBRID & 69 & 562820.75 & 4229682.04 & SS & $\mathrm{R}$ & headwater floodplain & $\mathrm{R}$ & natural & 39 \\
\hline CGCPAS & 69 & 564291.44 & 4227601.43 & SS & $\mathrm{R}$ & headwater floodplain & $\mathrm{R}$ & natural & 39 \\
\hline CGROAD & 69 & 563203.21 & 4228790.99 & FO & $\mathrm{R}$ & slope & & natural & 35.5 \\
\hline CGTRHE & 69 & 562849.95 & 4229196.62 & $\mathrm{FO}$ & $\mathrm{R}$ & slope & & natural & 31 \\
\hline CHNEER & 70 & 425323.03 & 4263651.17 & SS & $\mathrm{S}$ & headwater impoundment & & natural & 21 \\
\hline $\mathrm{CHSACH}$ & 70 & 430616.99 & 4247808.83 & SS & $\mathrm{S}$ & riparian depression & S & natural & 16 \\
\hline CHSAFO & 70 & 430465.63 & 4247816.18 & $\mathrm{FO}$ & $\mathrm{S}$ & headwater floodplain & $\mathrm{S}$ & natural & 13 \\
\hline CHSARR & 70 & 430767.87 & 4248062.35 & EM & $\mathrm{S}$ & mainstem floodplain & $\mathrm{S}$ & natural & 6 \\
\hline CHTREE & 70 & 425706.21 & 4262531.73 & $\mathrm{FO}$ & & riparian depression & & natural & 23 \\
\hline CHWWBW & 70 & 425517.25 & 4263436.99 & SS & $\mathrm{S}$ & headwater impoundment & $\mathrm{S}$ & mitigation & 18.5 \\
\hline CHWWEM & 70 & 425514.31 & 4263179.89 & EM & & riparian depression & & natural & 23.5 \\
\hline
\end{tabular}

\footnotetext{
${ }^{\mathrm{b}}$ Cowardin classes: $\mathrm{EM}=$ Emergent, $\mathrm{SS}=$ Scrub-shrub, $\mathrm{FO}=$ Forested.
}

${ }^{\mathrm{a}}$ Ecoregion: 67 = Ridge and Valley, $69=$ Central Appalachians, $70=$ Western Allegheny Plateau

${ }^{\mathrm{c}} \mathrm{R}=$ reference, $\mathrm{S}=$ stressed. 
Appendix B. Continued.

\begin{tabular}{|c|c|c|c|c|c|c|c|c|c|}
\hline Site Code & Ecoregion $^{\mathrm{a}}$ & UTMx & UTMy & Cowardin $^{\mathrm{b}}$ & $\begin{array}{l}\text { Cowardin } \mathrm{R} / \mathrm{S}^{\mathrm{c}} \\
\text { designation }\end{array}$ & $\begin{array}{l}\text { HGM subclass } \\
\text { (Cole et al. 1997) }\end{array}$ & $\begin{array}{l}\mathrm{HGM} \mathrm{R} / \mathrm{S}^{\mathrm{c}} \\
\text { designation }\end{array}$ & Origin & Disturbance Score \\
\hline CHWWFO & 70 & 425400.14 & 4263773.99 & FO & $\mathrm{S}$ & headwater impoundment & $\mathrm{S}$ & natural & 18.5 \\
\hline CVABBW & 69 & 633103.19 & 4319691.35 & EM & $\mathrm{R}$ & headwater floodplain & & natural & 29 \\
\hline CVABCT & 69 & 633226.45 & 4319366.87 & EM & $\mathrm{R}$ & headwater floodplain & $\mathrm{R}$ & natural & 34 \\
\hline CVTIMB & 69 & 636507.69 & 4322059.22 & SS & & riparian depression & $\mathrm{R}$ & natural & 28 \\
\hline DSPICN & 67 & 642625.79 & 4313855.23 & SS & $\mathrm{R}$ & slope & $\mathrm{R}$ & natural & 36.5 \\
\hline DSROAR & 67 & 642463.70 & 4313302.17 & EM & $\mathrm{R}$ & headwater floodplain & $\mathrm{R}$ & natural & 39 \\
\hline DSWILD & 67 & 642973.28 & 4314272.17 & SS & $\mathrm{R}$ & slope & $\mathrm{R}$ & natural & 39 \\
\hline EPCMEM & 67 & 762221.31 & 4371598.78 & EM & & riparian depression & & natural & 19.5 \\
\hline EPCMFO & 67 & 762488.36 & 4371541.38 & $\mathrm{FO}$ & $\mathrm{S}$ & riparian depression & & natural & 18 \\
\hline EPDMFO & 67 & 761333.18 & 4373782.33 & $\mathrm{FO}$ & $\mathrm{S}$ & headwater floodplain & & natural & 21.5 \\
\hline EPDMPU & 67 & 761577.57 & 4373610.32 & SS & $\mathrm{S}$ & headwater floodplain & $\mathrm{S}$ & natural & 17.5 \\
\hline EPKYVE & 67 & 765034.40 & 4365206.47 & EM & & headwater floodplain & & natural & 22.5 \\
\hline EPRRXC & 67 & 763621.83 & 4371053.41 & FO & $\mathrm{S}$ & riparian depression & & natural & 20 \\
\hline EPSHEM & 67 & 774868.67 & 4368871.15 & EM & & riparian depression & & natural & 23 \\
\hline EPSHSS & 67 & 774668.67 & 4368706.80 & SS & $\mathrm{S}$ & riparian depression & & natural & 17.5 \\
\hline GBBARN & 70 & 391069.62 & 4271692.43 & SS & & riparian depression & & natural & 26 \\
\hline
\end{tabular}

${ }^{\mathrm{a}}$ Ecoregion: $67=$ Ridge and Valley, $69=$ Central Appalachians, $70=$ Western Allegheny Plateau.

${ }^{\mathrm{b}}$ Cowardinclasses: $\mathrm{EM}=$ Emergent, $\mathrm{SS}=$ Scrub-shrub, $\mathrm{FO}=$ Forested.

${ }^{\mathrm{c}} \mathrm{R}=$ reference, $\mathrm{S}=$ stressed. 
Appendix B. Continued.

\begin{tabular}{|c|c|c|c|c|c|c|c|c|c|}
\hline Site Code & Ecoregion $^{\mathrm{a}}$ & UTMx & UTMy & Cowardin $^{\mathrm{b}}$ & $\begin{array}{l}\text { CowardinR/ } \mathrm{S}^{\mathrm{c}} \\
\text { designation }\end{array}$ & $\begin{array}{l}\text { HGM subclass } \\
\text { (Cole et al. 1997) }\end{array}$ & $\begin{array}{l}\text { HGM R/ S } \\
\text { designation }\end{array}$ & Origin & Disturbance Score \\
\hline GBHOEF & 70 & 390000.91 & 4271677.51 & SS & & riparian depression & $\mathrm{R}$ & natural & 28 \\
\hline GBJENK & 70 & 391336.78 & 4271734.34 & SS & & mainstem impoundment & $\mathrm{R}$ & natural & 28 \\
\hline GBMAPL & 70 & 391085.79 & 4272250.28 & FO & & surface water depression & $\mathrm{R}$ & natural & 29 \\
\hline GBNOFO & 70 & 392949.13 & 4271460.72 & FO & & riparian depression & $\mathrm{R}$ & natural & 30.5 \\
\hline GBNOSS & 70 & 392864.38 & 4271526.66 & SS & & riparian depression & & natural & 23.5 \\
\hline GBPLOT & 70 & 390995.72 & 4271850.21 & EM & $\mathrm{R}$ & riparian depression & & natural & 25.5 \\
\hline HCBEAV & 70 & 539107.79 & 4489651.55 & EM & $\mathrm{R}$ & headwater impoundment & & natural & 25 \\
\hline HCMITI & 70 & 540224.16 & 4487637.53 & EM & & riparian depression & & mitigation & 19 \\
\hline HCPIPE & 70 & 538091.41 & 4490714.51 & EM & & riparian depression & & natural & 19 \\
\hline HCRANG & 70 & 539012.33 & 4488728.32 & EM & & riparian depression & & natural & 17 \\
\hline HIBRID & 69 & 509173.09 & 4169620.04 & FO & $\mathrm{S}$ & riparian depression & $\mathrm{S}$ & natural & 16 \\
\hline HIGATE & 69 & 522508.65 & 4166557.42 & FO & & mainstem floodplain & & natural & 23 \\
\hline HIJHPK & 69 & 520896.31 & 4167158.68 & FO & & headwater floodplain & & natural & 28.5 \\
\hline HIJHTU & 69 & 518493.41 & 4166288.97 & EM & $\mathrm{S}$ & riparian depression & $\mathrm{S}$ & natural & 14.5 \\
\hline HIPENC & 69 & 525233.15 & 4169097.73 & EM & $\mathrm{R}$ & headwater impoundment & $\mathrm{R}$ & natural & 32 \\
\hline HISEWG & 69 & 509915.29 & 4172726.96 & FO & & mainstem floodplain & & natural & 24 \\
\hline
\end{tabular}

\footnotetext{
${ }^{\mathrm{a}}$ Ecoregion: $67=$ Ridge and Valley, $69=$ Central Appalachians, $70=$ Western Allegheny Plateau.
}

${ }^{\mathrm{b}}$ Cowardinclasses: $\mathrm{EM}=$ Emergent, $\mathrm{SS}=$ Scrub-shrub, $\mathrm{FO}=$ Forested.

${ }^{\mathrm{c}} \mathrm{R}=$ reference, $\mathrm{S}=$ stressed. 
Appendix B. Continued.

\begin{tabular}{|c|c|c|c|c|c|c|c|c|c|}
\hline Site Code & Ecoregion $^{\mathrm{a}}$ & UTMx & UTMy & Cowardin $^{\text {b }}$ & $\begin{array}{l}\text { CowardinR/ } \mathrm{S}^{\mathrm{c}} \\
\text { designation }\end{array}$ & $\begin{array}{l}\text { HGM subclass } \\
\text { (Cole et al. 1997) }\end{array}$ & $\begin{array}{l}\mathrm{HGM} \mathrm{R} / \mathrm{S}^{\mathrm{c}} \\
\text { designation }\end{array}$ & Origin & Disturbance Score \\
\hline HITRLR & 69 & 519863.68 & 4162636.08 & EM & $\mathrm{S}$ & riparian depression & $\mathrm{S}$ & natural & 15.5 \\
\hline MCFOUR & 70 & 406635.56 & 4310843.03 & EM & $\mathrm{R}$ & riparian depression & $\mathrm{R}$ & natural & 32.5 \\
\hline MCMEME & 70 & 407114.19 & 4309269.14 & EM & $\mathrm{R}$ & mainstem impoundment & $\mathrm{R}$ & manmade & 30 \\
\hline MCMFOR & 70 & 407137.73 & 4308870.48 & $\mathrm{FO}$ & & riparian depression & $\mathrm{R}$ & manmade & 29 \\
\hline MCNPFO & 70 & 406108.70 & 4310559.18 & $\mathrm{FO}$ & $\mathrm{R}$ & surface water depression & $\mathrm{R}$ & natural & 31.5 \\
\hline MCPOND & 70 & 407376.85 & 4307940.29 & $\mathrm{AB}$ & & isolated depression & $\mathrm{S}$ & manmade & 9.5 \\
\hline MCPOST & 70 & 407360.09 & 4307509.33 & SS & & mainstem impoundment & & manmade & 25 \\
\hline MCTELE & 70 & 406792.34 & 4308838.63 & SS & & riparian depression & & manmade & 21.5 \\
\hline ME5092 & 69 & 598571.26 & 4355049.82 & SS & $\mathrm{S}$ & riparian depression & $\mathrm{S}$ & natural & 11.5 \\
\hline MESCOX & 69 & 591596.31 & 4328816.43 & EM & & riparian depression & & mitigation & 18 \\
\hline MESCRO & 69 & 591482.81 & 4329057.51 & EM & & headwater impoundment & $\mathrm{S}$ & mitigation & 17.5 \\
\hline MESCUP & 69 & 591712.71 & 4329122.08 & EM & & headwater impoundment & $\mathrm{S}$ & mitigation & 17 \\
\hline MESIGN & 69 & 594210.99 & 4330594.33 & EM & & riparian depression & & natural & 24 \\
\hline MESILV & 69 & 594132.25 & 4330927.11 & SS & & riparian depression & & natural & 24 \\
\hline METETR & 69 & 597570.89 & 4329663.27 & EM & $\mathrm{S}$ & surface water depression & $\mathrm{S}$ & manmade & 7 \\
\hline MEWOLF & 69 & 593867.97 & 4331171.92 & SS & $\mathrm{R}$ & riparian depression & $\mathrm{R}$ & natural & 33 \\
\hline
\end{tabular}

\footnotetext{
${ }^{\mathrm{a}}$ Ecoregion: $67=$ Ridge and Valley, $69=$ Central Appalachians, $70=$ Western Allegheny Plateau.

${ }^{b}$ Cowardinclasses: $\mathrm{EM}=$ Emergent, $\mathrm{SS}=$ Scrub-shrub, $\mathrm{FO}=$ Forested.

${ }^{\mathrm{c}} \mathrm{R}=$ reference, $\mathrm{S}=$ stressed.
} 
Appendix B. Continued.

\begin{tabular}{|c|c|c|c|c|c|c|c|c|c|}
\hline Site Code & Ecoregion $^{\mathrm{a}}$ & UTMx & UTMy & Cowardin ${ }^{b}$ & $\begin{array}{l}\text { CowardinR/ } \mathrm{S}^{\mathrm{c}} \\
\text { designation }\end{array}$ & $\begin{array}{l}\text { HGM subclass } \\
\text { (Cole et al. 1997) }\end{array}$ & $\begin{array}{l}\text { HGM R/ Sc } \\
\text { designation }\end{array}$ & Origin & Disturbance Score \\
\hline MRBESS & 69 & 524326.40 & 4188085.26 & SS & & mainstem impoundment & $\mathrm{R}$ & natural & 26 \\
\hline MRFARM & 69 & 524385.44 & 4188482.81 & EM & $\mathrm{R}$ & slope & & natural & 27 \\
\hline MRFORE & 69 & 524454.19 & 4188272.82 & FO & $\mathrm{R}$ & riparian depression & $\mathrm{R}$ & natural & 32.5 \\
\hline MRSSSS & 69 & 524641.53 & 4188638.39 & SS & $\mathrm{R}$ & riparian depression & $\mathrm{R}$ & natural & 30.5 \\
\hline MRWEST & 69 & 523960.30 & 4188265.48 & EM & $\mathrm{R}$ & riparian depression & & natural & 25 \\
\hline MU55SS & 69 & 516658.49 & 4246368.09 & SS & & riparian depression & $\mathrm{R}$ & natural & 27.5 \\
\hline MUDBOA & 70 & 407368.48 & 4222212.05 & EM & $\mathrm{R}$ & fringing & $\mathrm{R}$ & natural & 28 \\
\hline MUDEND & 70 & 409136.75 & 4223182.67 & SS & & fringing & & natural & 24 \\
\hline MUDRIC & 70 & 408516.34 & 4224785.50 & SS & & fringing & $\mathrm{R}$ & natural & 28 \\
\hline MUDRIP & 70 & 409223.45 & 4223347.78 & SS & & fringing & & natural & 24 \\
\hline MUDTRA & 70 & 408020.04 & 4222449.52 & SS & $\mathrm{S}$ & fringing & & manmade & 20 \\
\hline MUEPAH & 69 & 516150.16 & 4246455.17 & EM & & isolated depression & & mitigation & 22 \\
\hline MUMINE & 69 & 518089.52 & 4250923.29 & FO & & slope & & natural & 28.5 \\
\hline MUPOWR & 69 & 517473.09 & 4250134.17 & FO & $\mathrm{R}$ & headwater floodplain & $\mathrm{R}$ & natural & 31 \\
\hline MUPULL & 69 & 516820.09 & 4249186.13 & EM & $\mathrm{R}$ & headwater floodplain & & natural & 27.5 \\
\hline MUVBRD & 69 & 517205.10 & 4248541.57 & EM & $\mathrm{R}$ & riparian depression & $\mathrm{R}$ & natural & 31.5 \\
\hline
\end{tabular}

âcoregion: $67=$ Ridge and Valley, $69=$ Central Appalachians, $70=$ Western Allegheny Plateau.

${ }^{\mathrm{b}}$ Cowardinclasses: $\mathrm{EM}=$ Emergent, $\mathrm{SS}=$ Scrub-shrub, $\mathrm{FO}=$ Forested.

${ }^{\mathrm{c}} \mathrm{R}=$ reference, $\mathrm{S}=$ stressed. 
Appendix B. Continued.

\begin{tabular}{|c|c|c|c|c|c|c|c|c|c|}
\hline Site Code & Ecoregion $^{\mathrm{a}}$ & UTMx & UTMy & Cowardin ${ }^{\mathrm{b}}$ & $\begin{array}{l}\text { CowardinR/ } \mathrm{S}^{\mathrm{c}} \\
\text { designation }\end{array}$ & $\begin{array}{l}\text { HGM subclass } \\
\text { (Cole et al. 1997) }\end{array}$ & $\begin{array}{l}\text { HGM R/ S } \\
\text { designation }\end{array}$ & Origin & Disturbance Score \\
\hline MUVCRN & 69 & 516663.13 & 4248597.40 & EM & & mainstem impoundment & & natural & 23.5 \\
\hline OHHSFO & 69 & 486726.19 & 4204379.08 & $\mathrm{FO}$ & & headwater floodplain & & natural & 30.5 \\
\hline OHINNS & 69 & 489012.70 & 4207767.52 & EM & & headwater floodplain & S & natural & 20 \\
\hline OHKMRT & 69 & 489003.17 & 4207234.86 & EM & $\mathrm{S}$ & headwater impoundment & S & mitigation & 9 \\
\hline PA29TH & 70 & 451974.57 & 4349022.47 & EM & $\mathrm{S}$ & surface water depression & $\mathrm{S}$ & natural & 14.5 \\
\hline PA83CR & 70 & 459390.55 & 4360390.46 & EM & & surface water depression & S & natural & 16 \\
\hline PAFAMD & 70 & 455150.87 & 4346356.35 & EM & $\mathrm{S}$ & mainstem impoundment & $\mathrm{S}$ & natural & 13.5 \\
\hline PAJCPY & 70 & 451986.58 & 4350105.90 & EM & & surface water depression & & natural & 20.5 \\
\hline PALOUD & 70 & 452937.17 & 4345749.99 & SS & $\mathrm{S}$ & riparian depression & $\mathrm{S}$ & natural & 8 \\
\hline PAPEFO & 70 & 454455.37 & 4340747.67 & FO & & headwater floodplain & & natural & 29 \\
\hline PAPEIM & 70 & 454110.68 & 4340787.73 & EM & $\mathrm{S}$ & isolated depression & $\mathrm{S}$ & manmade & 9.5 \\
\hline PAPESW & 70 & 454429.44 & 4341097.03 & SS & & headwater floodplain & & natural & 26.5 \\
\hline PAWILL & 70 & 461172.76 & 4361677.52 & SS & $\mathrm{S}$ & fringing & $\mathrm{S}$ & manmade & 18.5 \\
\hline PCBLUE & 70 & 581293.37 & 4343766.39 & EM & & riparian depression & & mitigation & 22 \\
\hline PCLPFO & 70 & 584396.09 & 4346844.44 & $\mathrm{FO}$ & $\mathrm{R}$ & fringing & $\mathrm{R}$ & natural & 34 \\
\hline PCROAD & 70 & 581759.53 & 4344161.29 & EM & $\mathrm{S}$ & headwater floodplain & $\mathrm{S}$ & mitigation & 12 \\
\hline
\end{tabular}

\footnotetext{
${ }^{\mathrm{a}}$ Ecoregion: $67=$ Ridge and Valley, $69=$ Central Appalachians, $70=$ Western Allegheny Plateau.
}

${ }^{\mathrm{b}}$ Cowardinclasses: $\mathrm{EM}=$ Emergent, $\mathrm{SS}=$ Scrub-shrub, $\mathrm{FO}=$ Forested.

${ }^{\mathrm{c}} \mathrm{R}=$ reference, $\mathrm{S}=$ stressed. 
Appendix B. Continued.

\begin{tabular}{|c|c|c|c|c|c|c|c|c|c|}
\hline Site Code & Ecoregion $^{\mathrm{a}}$ & UTMx & UTMy & Cowardin $^{\text {b }}$ & $\begin{array}{l}\text { CowardinR/ } \mathrm{S}^{\mathrm{c}} \\
\text { designation }\end{array}$ & $\begin{array}{l}\text { HGM subclass } \\
\text { (Cole et al. 1997) }\end{array}$ & $\begin{array}{l}\text { HGM R/ S } \\
\text { designation }\end{array}$ & Origin & Disturbance Score \\
\hline PEMIDW & 70 & 575319.40 & 4393384.71 & EM & & riparian depression & & manmade & 21.5 \\
\hline PERDDP & 70 & 576195.70 & 4393447.11 & EM & & isolated depression & & manmade & 17.5 \\
\hline PETHUM & 70 & 575869.39 & 4393128.30 & EM & $\mathrm{R}$ & riparian depression & $\mathrm{R}$ & natural & 26.5 \\
\hline PETOSS & 70 & 575100.98 & 4393427.83 & SS & $\mathrm{S}$ & riparian depression & & manmade & 21 \\
\hline RIASIA & 70 & 493933.77 & 4325989.71 & EM & & riparian depression & & natural & 20 \\
\hline RIBRID & 70 & 483478.17 & 4325431.95 & EM & $\mathrm{S}$ & riparian depression & $\mathrm{S}$ & natural & 8.5 \\
\hline RIEAST & 70 & 505155.40 & 4331458.27 & SS & $\mathrm{R}$ & floodplain in-stream & $\mathrm{R}$ & natural & 31 \\
\hline SJBOAT & 70 & 553817.61 & 4314292.95 & EM & & fringing & & manmade & 19.5 \\
\hline SJBRID & 70 & 551595.30 & 4308792.29 & SS & $\mathrm{S}$ & fringing & $\mathrm{S}$ & manmade & 13.5 \\
\hline SJCHUR & 70 & 553162.97 & 4312635.85 & SS & & fringing & & natural & 22 \\
\hline SJGLAD & 70 & 549304.99 & 4315181.92 & EM & & riparian depression & & natural & 23 \\
\hline SJMUDL & 70 & 546681.89 & 4307905.42 & FO & & riparian depression & $\mathrm{R}$ & natural & 27 \\
\hline SJPLOT & 70 & 553304.39 & 4312414.21 & EM & $\mathrm{S}$ & riparian depression & $\mathrm{S}$ & natural & 13.5 \\
\hline SJTELE & 70 & 548484.71 & 4307308.08 & EM & $\mathrm{S}$ & isolated depression & S & natural & 14.5 \\
\hline SMDTSS & 67 & 701441.57 & 4341087.61 & SS & $\mathrm{R}$ & headwater floodplain & $\mathrm{R}$ & natural & 36.5 \\
\hline SMFOFL & 67 & 701906.33 & 4342063.24 & FO & $\mathrm{R}$ & headwater floodplain & $\mathrm{R}$ & natural & 36.5 \\
\hline
\end{tabular}

\footnotetext{
${ }^{\mathrm{a}}$ Ecoregion: $67=$ Ridge and Valley, $69=$ Central Appalachians, $70=$ Western Allegheny Plateau.

${ }^{b}$ Cowardinclasses: $\mathrm{EM}=$ Emergent, $\mathrm{SS}=$ Scrub-shrub, $\mathrm{FO}=$ Forested.

${ }^{\mathrm{c}} \mathrm{R}=$ reference, $\mathrm{S}=$ stressed
} 
Appendix B. Continued.

\begin{tabular}{|c|c|c|c|c|c|c|c|c|c|}
\hline Site Code & Ecoregion $^{\mathrm{a}}$ & UTMx & UTMy & Cowardin $^{\text {b }}$ & $\begin{array}{l}\text { CowardinR/ } \mathrm{S}^{\mathrm{c}} \\
\text { designation }\end{array}$ & $\begin{array}{l}\text { HGM subclass } \\
\text { (Cole et al. 1997) }\end{array}$ & $\begin{array}{l}\text { HGM R/ } \mathrm{S}^{\mathrm{c}} \\
\text { designation }\end{array}$ & Origin & Disturbance Score \\
\hline SMLPEM & 67 & 701813.06 & 4341692.18 & EM & $\mathrm{R}$ & headwater floodplain & $\mathrm{R}$ & natural & 36.5 \\
\hline SMSEFL & 67 & 701657.15 & 4341357.63 & EM & $\mathrm{R}$ & headwater impoundment & $\mathrm{R}$ & natural & 30.5 \\
\hline SMSTEM & 67 & 701178.93 & 4340693.63 & EM & $\mathrm{R}$ & headwater floodplain & & natural & 30.5 \\
\hline TRSPFO & 70 & 535844.63 & 4487835.71 & FO & & riparian depression & $\mathrm{R}$ & natural & 28.5 \\
\hline TRSPRI & 70 & 535011.37 & 4488866.58 & SS & $\mathrm{S}$ & fringing & $\mathrm{S}$ & natural & 18 \\
\hline TVFARM & 67 & 594752.26 & 4290868.05 & EM & $\mathrm{S}$ & riparian depression & $\mathrm{S}$ & natural & 15 \\
\hline TVISLE & 67 & 593490.58 & 4290989.45 & FO & & mainstem floodplain & & natural & 30 \\
\hline TVNEWT & 67 & 596407.82 & 4294176.49 & EM & & riparian depression & & natural & 20.5 \\
\hline TVPOUT & 67 & 594994.36 & 4293572.02 & EM & & riparian depression & & natural & 23.5 \\
\hline TVVBEM & 67 & 591865.70 & 4291645.36 & EM & $\mathrm{S}$ & slope & $\mathrm{S}$ & natural & 9 \\
\hline TVVBIM & 67 & 591950.19 & 4291462.02 & EM & & riparian depression & & manmade & 18 \\
\hline TVVBRV & 67 & 591920.29 & 4291352.02 & FO & $\mathrm{R}$ & mainstem floodplain & $\mathrm{R}$ & natural & 34 \\
\hline TVVBSS & 67 & 592032.24 & 4291607.52 & SS & $\mathrm{R}$ & riparian depression & $\mathrm{R}$ & manmade & 31 \\
\hline UDC001 & 69 & 602201.49 & 4377359.56 & SS & $\mathrm{R}$ & riparian depression & $\mathrm{R}$ & natural & 29 \\
\hline UDC002 & 69 & 602038.52 & 4376963.94 & EM & & headwater impoundment & & manmade & 20 \\
\hline UDC003 & 69 & 602413.85 & 4376440.18 & EM & & riparian depression & & natural & 22.5 \\
\hline
\end{tabular}

${ }^{\text {a }}$ Ecoregion: $67=$ Ridge and Valley, $69=$ Central Appalachians, $70=$ Western Allegheny Plateau.

${ }^{\mathrm{b}}$ Cowardinclasses: $\mathrm{EM}=$ Emergent, $\mathrm{SS}=$ Scrub-shrub, $\mathrm{FO}=$ Forested.

${ }^{\mathrm{c}} \mathrm{R}=$ reference, $\mathrm{S}=$ stressed. 
Appendix B. Continued.

\begin{tabular}{|c|c|c|c|c|c|c|c|c|c|}
\hline Site Code & Ecoregion $^{\mathrm{a}}$ & UTMx & UTMy & Cowardin $^{\text {b }}$ & $\begin{array}{l}\text { CowardinR/ } \mathrm{S}^{\mathrm{c}} \\
\text { designation }\end{array}$ & $\begin{array}{l}\text { HGM subclass } \\
\text { (Cole et al. 1997) }\end{array}$ & $\begin{array}{l}\text { HGM R/ S } \\
\text { designation }\end{array}$ & Origin & Disturbance Score \\
\hline UDC004 & 69 & 602188.63 & 4375849.63 & FO & & riparian depression & & natural & 23 \\
\hline UDC005 & 69 & 602159.27 & 4374776.00 & EM & $\mathrm{S}$ & isolated depression & S & natural & 12 \\
\hline UDC007 & 69 & 602360.03 & 4374524.27 & SS & & riparian depression & & natural & 23.5 \\
\hline UDC008 & 69 & 602414.08 & 4373761.24 & SS & & surface water depression & $\mathrm{R}$ & manmade & 28 \\
\hline UDC012 & 69 & 602317.31 & 4372622.88 & EM & & headwater impoundment & & natural & 22 \\
\hline UDC013 & 69 & 603563.04 & 4373327.15 & SS & & headwater impoundment & $\mathrm{R}$ & manmade & 27.5 \\
\hline UDC014 & 69 & 603502.05 & 4373177.51 & SS & $\mathrm{R}$ & headwater floodplain & & natural & 28.5 \\
\hline UDC015 & 69 & 603742.33 & 4373121.78 & SS & & headwater impoundment & & manmade & 23 \\
\hline UDC016 & 69 & 602641.92 & 4375901.37 & EM & & riparian depression & & natural & 22.5 \\
\hline UDC017 & 69 & 602867.23 & 4375663.08 & EM & & headwater impoundment & & natural & 22.5 \\
\hline UDC018 & 69 & 603128.37 & 4373455.05 & EM & & headwater floodplain & S & natural & 19.5 \\
\hline UDC019 & 69 & 603169.43 & 4373195.39 & FO & & headwater impoundment & & natural & 24.5 \\
\hline UDC020 & 69 & 603088.50 & 4375415.43 & EM & & headwater impoundment & & manmade & 22.5 \\
\hline VEPCON & 69 & 641127.08 & 4338137.96 & EM & & headwater floodplain & S & mitigation & 19 \\
\hline VEPCOS & 69 & 641451.23 & 4338080.36 & EM & & riparian depression & & mitigation & 22 \\
\hline WBBARN & 67 & 673918.98 & 4334374.17 & EM & $\mathrm{S}$ & headwater floodplain & $\mathrm{S}$ & mitigation & 15.5 \\
\hline
\end{tabular}

\footnotetext{
${ }^{\mathrm{a}}$ Ecoregion: $67=$ Ridge and Valley, $69=$ Central Appalachians, $70=$ Western Allegheny Plateau.

${ }^{b}$ Cowardinclasses: $\mathrm{EM}=$ Emergent, $\mathrm{SS}=$ Scrub-shrub, $\mathrm{FO}=$ Forested.

${ }^{\mathrm{c}} \mathrm{R}=$ reference, $\mathrm{S}=$ stressed.
} 
Appendix B. Site codes, ecoregion, location, NWI class, Hydrogeomorphic subclass, origin, Disturbance score, and reference/

stressed designations used to develop class-specific wetland indices of biological integrity (IBIs) in West Virginia from 2005-2006.

\begin{tabular}{|c|c|c|c|c|c|c|c|c|c|}
\hline Site Code & Ecoregion $^{\mathrm{a}}$ & UTMx & UTMy & Cowardin $^{\mathrm{b}}$ & $\begin{array}{l}\text { CowardinR/ } \mathrm{S}^{\mathrm{c}} \\
\text { designation }\end{array}$ & $\begin{array}{l}\text { HGM subclass } \\
\text { (Cole et al. 1997) }\end{array}$ & 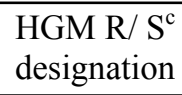 & Origin & Disturbance Score \\
\hline WBCORN & 67 & 674210.94 & 4334514.97 & EM & & headwater floodplain & $\mathrm{S}$ & mitigation & 16 \\
\hline WBROAD & 67 & 674507.77 & 4333367.67 & EM & $\mathrm{S}$ & slope & $\mathrm{S}$ & natural & 13.5 \\
\hline WYBEAV & 69 & 437027.12 & 4163806.72 & FO & $\mathrm{S}$ & riparian depression & $\mathrm{S}$ & natural & 15 \\
\hline WYCHWE & 69 & 437146.50 & 4158673.14 & EM & $\mathrm{R}$ & fringing & $\mathrm{R}$ & natural & 28 \\
\hline WYHCEA & 69 & 437557.26 & 4158505.22 & EM & & fringing & & natural & 22 \\
\hline WYINTR & 69 & 440277.95 & 4160832.91 & FO & $\mathrm{S}$ & riparian depression & & natural & 21 \\
\hline WYTHOR & 69 & 437130.74 & 4164044.53 & EM & $\mathrm{S}$ & riparian depression & $\mathrm{S}$ & natural & 13.5 \\
\hline
\end{tabular}

${ }^{\mathrm{a}}$ Ecoregion: $67=$ Ridge and Valley, $69=$ Central Appalachians, $70=$ Western Allegheny Plateau.

${ }^{\mathrm{b}}$ Cowardinclasses: $\mathrm{EM}=$ Emergent, $\mathrm{SS}=$ Scrub-shrub, FO=Forested.

${ }^{\mathrm{c}} \mathrm{R}=$ reference, $\mathrm{S}=$ stressed. 
Appendix C. Avian species abundance and relative frequency per site used in developing classspecific avian wetland indices of biological integrity (AW-IBI) in West Virginia, USA from 2005-2006.

\begin{tabular}{|c|c|c|c|c|c|}
\hline SiteCode & Species & & Latin name & Number observed & $\begin{array}{c}\text { Frequency } \\
\text { per Site }\end{array}$ \\
\hline \multirow[t]{17}{*}{ CFCROS } & Site abundance: & 31 & & & \\
\hline & American Goldfinch & & Carduelis tristis & 4 & 0.1290 \\
\hline & American Robin & & Turdus migratorius & 1 & 0.0323 \\
\hline & Blue-Gray Gnatcatcher & & Polioptila caerulea & 1 & 0.0323 \\
\hline & Blue-Headed Vireo & & Vireo solitarius & 1 & 0.0323 \\
\hline & Blue-Winged Warbler & & Vermivora pinus & 1 & 0.0323 \\
\hline & Carolina Chickadee & & Poecile carolinensis & 1 & 0.0323 \\
\hline & Carolina Wren & & Thryothorus ludovicianus & 1 & 0.0323 \\
\hline & Common Yellowthroat & & Geothlypis trichas & 1 & 0.0323 \\
\hline & Indigo Bunting & & Passerina cyanea & 2 & 0.0645 \\
\hline & Northern Cardinal & & Cardinalis cardinalis & 1 & 0.0323 \\
\hline & Northern Waterthrush & & Northern Waterthrush & 1 & 0.0323 \\
\hline & Red-Eyed Vireo & & Vireo olivaceus & 1 & 0.0323 \\
\hline & Red-Winged Blackbird & & Agelaius phoeniceus & 8 & 0.2581 \\
\hline & Song Sparrow & & Melospiza melodia & 1 & 0.0323 \\
\hline & Wood Thrush & & Hylocichla mustelina & 1 & 0.0323 \\
\hline & Yellow Warbler & & Dendroica petechia & 5 & 0.1613 \\
\hline \multirow[t]{14}{*}{ CFECUR } & Site abundance: & 16 & & & \\
\hline & American Goldfinch & & Carduelis tristis & 1 & 0.0625 \\
\hline & American Redstart & & Setophaga ruticilla & 1 & 0.0625 \\
\hline & Blue-Gray Gnatcatcher & & Polioptila caerulea & 1 & 0.0625 \\
\hline & Blue-Winged Warbler & & Vermivora pinus & 1 & 0.0625 \\
\hline & Carolina Chickadee & & Poecile carolinensis & 1 & 0.0625 \\
\hline & Eastern Towhee & & Pipilo erythrophthalmus & 1 & 0.0625 \\
\hline & Field Sparrow & & Spizella pusilla & 1 & 0.0625 \\
\hline & Northern Cardinal & & Cardinalis cardinalis & 2 & 0.1250 \\
\hline & Ovenbird & & Seiurus aurocapillus & 1 & 0.0625 \\
\hline & Song Sparrow & & Melospiza melodia & 3 & 0.1875 \\
\hline & White-Eyed Vireo & & Vireo griseus & 1 & 0.0625 \\
\hline & Wood Thrush & & Hylocichla mustelina & 1 & 0.0625 \\
\hline & Yellow Warbler & & Dendroica petechia & 1 & 0.0625 \\
\hline
\end{tabular}


Appendix C. Continued.

\begin{tabular}{|c|c|c|c|c|c|}
\hline SiteCode & Species & & Latin name & Number observed & $\begin{array}{c}\text { Frequency } \\
\text { per Site }\end{array}$ \\
\hline \multirow[t]{13}{*}{ CFEINC } & Site abundance: & 19 & & & \\
\hline & Carolina Chickadee & & Poecile carolinensis & 1 & 0.0526 \\
\hline & European Starling & & Sturnus vulgaris & 2 & 0.1053 \\
\hline & Gray Catbird & & Dumetella carolinensis & 2 & 0.1053 \\
\hline & Great Crested Flycatcher & & Myiarchus crinitus & 1 & 0.0526 \\
\hline & Mallard & & Anas platyrhynchos & 1 & 0.0526 \\
\hline & Mourning Dove & & Zenaida macroura & 1 & 0.0526 \\
\hline & Northern Cardinal & & Cardinalis cardinalis & 1 & 0.0526 \\
\hline & Northern Parula & & Parula americana & 1 & 0.0526 \\
\hline & Red-Eyed Vireo & & Vireo olivaceus & 1 & 0.0526 \\
\hline & Red-Winged Blackbird & & Agelaius phoeniceus & 4 & 0.2105 \\
\hline & Song Sparrow & & Melospiza melodia & 2 & 0.1053 \\
\hline & Tree Swallow & & Tachycineta bicolor & 2 & 0.1053 \\
\hline \multirow[t]{22}{*}{ CFSLCH } & Site abundance: & 29 & & & \\
\hline & American Crow & & Corvus brachyrhynchos & 2 & 0.0690 \\
\hline & American Goldfinch & & Carduelis tristis & 1 & 0.0345 \\
\hline & Blue-Headed Vireo & & Vireo solitarius & 1 & 0.0345 \\
\hline & Blue-Winged Warbler & & Vermivora pinus & 1 & 0.0345 \\
\hline & Carolina Chickadee & & Poecile carolinensis & 2 & 0.0690 \\
\hline & Carolina Wren & & Thryothorus ludovicianus & 1 & 0.0345 \\
\hline & Chestnut-Sided Warbler & & Dendroica pensylvanica & 1 & 0.0345 \\
\hline & Gray Catbird & & Dumetella carolinensis & 1 & 0.0345 \\
\hline & Indigo Bunting & & Passerina cyanea & 1 & 0.0345 \\
\hline & Indigo Bunting & & Passerina cyanea & 1 & 0.0345 \\
\hline & Northern Cardinal & & Cardinalis cardinalis & 1 & 0.0345 \\
\hline & Northern Parula & & Parula americana & 1 & 0.0345 \\
\hline & Northern Waterthrush & & Northern Waterthrush & 1 & 0.0345 \\
\hline & Red-Winged Blackbird & & Agelaius phoeniceus & 2 & 0.0690 \\
\hline & Song Sparrow & & Melospiza melodia & 1 & 0.0345 \\
\hline & Swamp Sparrow & & Melospiza georgiana & 1 & 0.0345 \\
\hline & Tree Swallow & & Tachycineta bicolor & 1 & 0.0345 \\
\hline & Tufted Titmouse & & Parus bicolor & 6 & 0.2069 \\
\hline & Wood Duck & & Aix sponsa & 1 & 0.0345 \\
\hline & Wood Thrush & & Hylocichla mustelina & 1 & 0.0345 \\
\hline & Yellow Warbler & & Dendroica petechia & 1 & 0.0345 \\
\hline
\end{tabular}


Appendix C. Continued.

\begin{tabular}{|c|c|c|c|c|}
\hline SiteCode & Species & Latin name & Number observed & $\begin{array}{c}\text { Frequency } \\
\text { per Site }\end{array}$ \\
\hline \multirow[t]{23}{*}{ CFSLIN } & Site abundance: & & & \\
\hline & Blue-Gray Gnatcatcher & Polioptila caerulea & 1 & 0.0417 \\
\hline & Blue-Headed Vireo & Vireo solitarius & 1 & 0.0417 \\
\hline & Brown-Headed Cowbird & Molothrus ater & 1 & 0.0417 \\
\hline & Carolina Chickadee & Poecile carolinensis & 1 & 0.0417 \\
\hline & Carolina Wren & Thryothorus ludovicianus & 1 & 0.0417 \\
\hline & Common Yellowthroat & Geothlypis trichas & 1 & 0.0417 \\
\hline & Eastern Towhee & Pipilo erythrophthalmus & 1 & 0.0417 \\
\hline & Gray Catbird & Dumetella carolinensis & 1 & 0.0417 \\
\hline & Great Crested Flycatcher & Myiarchus crinitus & 1 & 0.0417 \\
\hline & House Wren & Troglodytes aedon & 1 & 0.0417 \\
\hline & Indigo Bunting & Passerina cyanea & 1 & 0.0417 \\
\hline & Mourning Dove & Zenaida macroura & 1 & 0.0417 \\
\hline & Northern Cardinal & Cardinalis cardinalis & 1 & 0.0417 \\
\hline & Northern Parula & Parula americana & 1 & 0.0417 \\
\hline & Northern Waterthrush & Northern Waterthrush & 1 & 0.0417 \\
\hline & Ovenbird & Seiurus aurocapillus & 2 & 0.0833 \\
\hline & Red-Winged Blackbird & Agelaius phoeniceus & 2 & 0.0833 \\
\hline & Song Sparrow & Melospiza melodia & 1 & 0.0417 \\
\hline & Tree Swallow & Tachycineta bicolor & 1 & 0.0417 \\
\hline & Tufted Titmouse & Parus bicolor & 1 & 0.0417 \\
\hline & White-Eyed Vireo & Vireo griseus & 1 & 0.0417 \\
\hline & Yellow Warbler & Dendroica petechia & 1 & 0.0417 \\
\hline \multirow[t]{14}{*}{ CGBRID } & Site abundance: & & & \\
\hline & Acadian Flycatcher & Empidonax virescens & 1 & 0.0476 \\
\hline & Alder Flycatcher & Empidonax alnorum & 2 & 0.0952 \\
\hline & Black-capped Chickadee & Poecile atricapilla & 1 & 0.0476 \\
\hline & Black-throated Green Warbler & Dendroica virens & 2 & 0.0952 \\
\hline & Blue Jay & Cyanocitta cristata & 1 & 0.0476 \\
\hline & Blue-Headed Vireo & Vireo solitarius & 1 & 0.0476 \\
\hline & Common Yellowthroat & Geothlypis trichas & 2 & 0.0952 \\
\hline & Golden-Crowned Kinglet & Regulus satrapa & 2 & 0.0952 \\
\hline & Northern Waterthrush & Northern Waterthrush & 2 & 0.0952 \\
\hline & Red-Breasted Nuthatch & Sitta canadensis & 2 & 0.0952 \\
\hline & Red-Winged Blackbird & Agelaius phoeniceus & 1 & 0.0476 \\
\hline & Tree Swallow & Tachycineta bicolor & 3 & 0.1429 \\
\hline & Yellow Warbler & Dendroica petechia & 1 & 0.0476 \\
\hline
\end{tabular}


Appendix C. Continued.

\begin{tabular}{|c|c|c|c|c|}
\hline SiteCode & Species & Latin name & Number observed & $\begin{array}{c}\text { Frequency } \\
\text { per Site }\end{array}$ \\
\hline \multirow[t]{15}{*}{ CGCPAS } & Site abundance: & & & \\
\hline & American Redstart & Setophaga ruticilla & 1 & 0.0556 \\
\hline & Black-capped Chickadee & Poecile atricapilla & 1 & 0.0556 \\
\hline & Black-throated Green Warbler & Dendroica virens & 1 & 0.0556 \\
\hline & Blue Jay & Cyanocitta cristata & 2 & 0.1111 \\
\hline & Blue-Headed Vireo & Vireo solitarius & 1 & 0.0556 \\
\hline & Common Yellowthroat & Geothlypis trichas & 1 & 0.0556 \\
\hline & Magnolia Warbler & Dendroica magnolia & 1 & 0.0556 \\
\hline & Northern Parula & Parula americana & 1 & 0.0556 \\
\hline & Northern Waterthrush & Northern Waterthrush & 2 & 0.1111 \\
\hline & Red-Billed Woodpecker & Melanerpes carolinus & 1 & 0.0556 \\
\hline & Rose-Breasted Grosbeak & Pheucticus ludovicianus & 1 & 0.0556 \\
\hline & Ruby-Crowned Kinglet & Regulus calendula & 1 & 0.0556 \\
\hline & Yellow Warbler & Dendroica petechia & 2 & 0.1111 \\
\hline & Yellow-Rumped Warbler & Dendroica coronata & 2 & 0.1111 \\
\hline \multirow[t]{12}{*}{ CGROAD } & Site abundance: $\quad 13$ & & & \\
\hline & Black-capped Chickadee & Poecile atricapilla & 1 & 0.0769 \\
\hline & Blue-Headed Vireo & Vireo solitarius & 1 & 0.0769 \\
\hline & Eastern Towhee & Pipilo erythrophthalmus & 1 & 0.0769 \\
\hline & Golden-Crowned Kinglet & Regulus satrapa & 2 & 0.1538 \\
\hline & Magnolia Warbler & Dendroica magnolia & 2 & 0.1538 \\
\hline & Purple Finch & Carpodacus purpureus & 1 & 0.0769 \\
\hline & Purple Martin & Progne subis & 1 & 0.0769 \\
\hline & Red-Eyed Vireo & Vireo olivaceus & 1 & 0.0769 \\
\hline & Rose-Breasted Grosbeak & Pheucticus ludovicianus & 1 & 0.0769 \\
\hline & Tufted Titmouse & Parus bicolor & 1 & 0.0769 \\
\hline & Yellow Warbler & Dendroica petechia & 1 & 0.0769 \\
\hline
\end{tabular}


Appendix C. Continued.

\begin{tabular}{|c|c|c|c|c|}
\hline SiteCode & Species & Latin name & Number observed & $\begin{array}{c}\text { Frequency } \\
\text { per Site }\end{array}$ \\
\hline \multirow[t]{17}{*}{ CGTRHE } & Site abundance: & & & \\
\hline & American Redstart & Setophaga ruticilla & 1 & 0.0526 \\
\hline & American Robin & Turdus migratorius & 1 & 0.0526 \\
\hline & Black-and-White Warbler & Mniotilta varia & 1 & 0.0526 \\
\hline & Black-capped Chickadee & Poecile atricapilla & 1 & 0.0526 \\
\hline & Black-throated Blue Warbler & Dendroica caerulescens & 1 & 0.0526 \\
\hline & Black-throated Green Warbler & Dendroica virens & 2 & 0.1053 \\
\hline & Blue-Headed Vireo & Vireo solitarius & 1 & 0.0526 \\
\hline & Eastern Phoebe & Sayornis phoebe & 1 & 0.0526 \\
\hline & Golden-Crowned Kinglet & Regulus satrapa & 2 & 0.1053 \\
\hline & Hermit Thrush & Catharus guttatus & 2 & 0.1053 \\
\hline & Magnolia Warbler & Dendroica magnolia & 1 & 0.0526 \\
\hline & Red-Breasted Nuthatch & Sitta canadensis & 1 & 0.0526 \\
\hline & Rose-Breasted Grosbeak & Pheucticus ludovicianus & 1 & 0.0526 \\
\hline & Veery & Catharus fuscescens & 1 & 0.0526 \\
\hline & Wood Thrush & Hylocichla mustelina & 1 & 0.0526 \\
\hline & Yellow-Rumped Warbler & Dendroica coronata & 1 & 0.0526 \\
\hline \multirow[t]{14}{*}{ CHNEER } & Site abundance: $\quad 24$ & & & \\
\hline & Blue Jay & Cyanocitta cristata & 1 & 0.0417 \\
\hline & Canada Goose & Branta canadensis & 1 & 0.0417 \\
\hline & Carolina Wren & Thryothorus ludovicianus & 1 & 0.0417 \\
\hline & Cedar Waxwing & Bombycilla cedrorum & 1 & 0.0417 \\
\hline & Common Grackle & Quiscalus quiscula & 1 & 0.0417 \\
\hline & Common Yellowthroat & Geothlypis trichas & 1 & 0.0417 \\
\hline & Gray Catbird & Dumetella carolinensis & 1 & 0.0417 \\
\hline & Green Heron & Butorides virescens & 2 & 0.0833 \\
\hline & Northern Cardinal & Cardinalis cardinalis & 1 & 0.0417 \\
\hline & Red-Winged Blackbird & Agelaius phoeniceus & 8 & 0.3333 \\
\hline & Song Sparrow & Melospiza melodia & 2 & 0.0833 \\
\hline & Tree Swallow & Tachycineta bicolor & 3 & 0.1250 \\
\hline & Yellow Warbler & Dendroica petechia & 1 & 0.0417 \\
\hline
\end{tabular}


Appendix C. Continued.

\begin{tabular}{|c|c|c|c|c|c|}
\hline SiteCode & Species & & Latin name & Number observed & $\begin{array}{c}\text { Frequency } \\
\text { per Site }\end{array}$ \\
\hline \multirow[t]{17}{*}{$\mathrm{CHSACH}$} & Site abundance: & 33 & & & \\
\hline & American Goldfinch & & Carduelis tristis & 2 & 0.0606 \\
\hline & American Robin & & Turdus migratorius & 1 & 0.0303 \\
\hline & Blue Jay & & Cyanocitta cristata & 1 & 0.0303 \\
\hline & Cedar Waxwing & & Bombycilla cedrorum & 2 & 0.0606 \\
\hline & Common Grackle & & Quiscalus quiscula & 3 & 0.0909 \\
\hline & Common Yellowthroat & & Geothlypis trichas & 1 & 0.0303 \\
\hline & European Starling & & Sturnus vulgaris & 2 & 0.0606 \\
\hline & Field Sparrow & & Spizella pusilla & 1 & 0.0303 \\
\hline & Green Heron & & Butorides virescens & 1 & 0.0303 \\
\hline & House Wren & & Troglodytes aedon & 1 & 0.0303 \\
\hline & Northern Flicker & & Colaptes auratus & 1 & 0.0303 \\
\hline & Northern Mockingbird & & Mimus polyglottos & 1 & 0.0303 \\
\hline & Orchard Oriole & & Icterus spurius & 1 & 0.0303 \\
\hline & Red-Winged Blackbird & & Agelaius phoeniceus & 10 & 0.3030 \\
\hline & Song Sparrow & & Melospiza melodia & 3 & 0.0909 \\
\hline & Willow Flycatcher & & Empidonax traillii & 2 & 0.0606 \\
\hline \multirow[t]{11}{*}{ CHSAFO } & Site abundance: & 21 & & & \\
\hline & American Robin & & Turdus migratorius & 2 & 0.0952 \\
\hline & Blue Jay & & Cyanocitta cristata & 1 & 0.0476 \\
\hline & Brown-Headed Cowbird & & Molothrus ater & 1 & 0.0476 \\
\hline & Carolina Chickadee & & Poecile carolinensis & 5 & 0.2381 \\
\hline & Gray Catbird & & Dumetella carolinensis & 1 & 0.0476 \\
\hline & Northern Cardinal & & Cardinalis cardinalis & 2 & 0.0952 \\
\hline & Pileated Woodpecker & & Dryocopus pileatus & 1 & 0.0476 \\
\hline & Song Sparrow & & Melospiza melodia & 6 & 0.2857 \\
\hline & Tufted Titmouse & & Parus bicolor & 1 & 0.0476 \\
\hline & Whip-poor-will & & Caprimulgus vociferus & 1 & 0.0476 \\
\hline
\end{tabular}


Appendix C. Continued.

\begin{tabular}{|c|c|c|c|c|c|}
\hline SiteCode & Species & & Latin name & Number observed & $\begin{array}{c}\text { Frequency } \\
\text { per Site }\end{array}$ \\
\hline \multirow[t]{16}{*}{ CHSARR } & Site abundance: & 31 & & & \\
\hline & American Goldfinch & & Carduelis tristis & 1 & 0.0323 \\
\hline & American Robin & & Turdus migratorius & 1 & 0.0323 \\
\hline & Carolina Wren & & Thryothorus ludovicianus & 1 & 0.0323 \\
\hline & Common Grackle & & Quiscalus quiscula & 1 & 0.0323 \\
\hline & European Starling & & Sturnus vulgaris & 2 & 0.0645 \\
\hline & Gray Catbird & & Dumetella carolinensis & 2 & 0.0645 \\
\hline & Green Heron & & Butorides virescens & 2 & 0.0645 \\
\hline & House Wren & & Troglodytes aedon & 1 & 0.0323 \\
\hline & Mallard & & Anas platyrhynchos & 12 & 0.3871 \\
\hline & Northern Cardinal & & Cardinalis cardinalis & 2 & 0.0645 \\
\hline & Northern Flicker & & Colaptes auratus & 1 & 0.0323 \\
\hline & Red-Billed Woodpecker & & Melanerpes carolinus & 1 & 0.0323 \\
\hline & Red-Eyed Vireo & & Vireo olivaceus & 1 & 0.0323 \\
\hline & Song Sparrow & & Melospiza melodia & 2 & 0.0645 \\
\hline & Spotted Sandpiper & & Actitis macularia & 1 & 0.0323 \\
\hline \multirow[t]{15}{*}{ CHTREE } & Site abundance: & 17 & & & \\
\hline & American Redstart & & Setophaga ruticilla & 2 & 0.1176 \\
\hline & American Robin & & Turdus migratorius & 2 & 0.1176 \\
\hline & Carolina Chickadee & & Poecile carolinensis & 1 & 0.0588 \\
\hline & Common Yellowthroat & & Geothlypis trichas & 1 & 0.0588 \\
\hline & Eastern Towhee & & Pipilo erythrophthalmus & 1 & 0.0588 \\
\hline & Indigo Bunting & & Passerina cyanea & 1 & 0.0588 \\
\hline & Northern Cardinal & & Cardinalis cardinalis & 1 & 0.0588 \\
\hline & Pileated Woodpecker & & Dryocopus pileatus & 1 & 0.0588 \\
\hline & Red-Billed Woodpecker & & Melanerpes carolinus & 1 & 0.0588 \\
\hline & Red-Eyed Vireo & & Vireo olivaceus & 2 & 0.1176 \\
\hline & Song Sparrow & & Melospiza melodia & 1 & 0.0588 \\
\hline & Tennessee Warbler & & Vermivora peregrina & 1 & 0.0588 \\
\hline & Tufted Titmouse & & Parus bicolor & 1 & 0.0588 \\
\hline & Wood Thrush & & Hylocichla mustelina & 1 & 0.0588 \\
\hline
\end{tabular}


Appendix C. Continued.

\begin{tabular}{|c|c|c|c|c|c|}
\hline SiteCode & Species & & Latin name & Number observed & $\begin{array}{c}\text { Frequency } \\
\text { per Site }\end{array}$ \\
\hline \multirow[t]{21}{*}{ CHWWBW } & Site abundance: & 49 & & & \\
\hline & American Goldfinch & & Carduelis tristis & 1 & 0.0204 \\
\hline & Barn Swallow & & Hirundo rustica & 1 & 0.0204 \\
\hline & Brown Thrasher & & Toxostoma rufum & 1 & 0.0204 \\
\hline & Carolina Wren & & Thryothorus ludovicianus & 1 & 0.0204 \\
\hline & Common Grackle & & Quiscalus quiscula & 5 & 0.1020 \\
\hline & Common Yellowthroat & & Geothlypis trichas & 2 & 0.0408 \\
\hline & European Starling & & Sturnus vulgaris & 6 & 0.1224 \\
\hline & Gray Catbird & & Dumetella carolinensis & 1 & 0.0204 \\
\hline & Great Blue Heron & & Ardea herodias & 1 & 0.0204 \\
\hline & Green Heron & & Butorides virescens & 3 & 0.0612 \\
\hline & House Wren & & Troglodytes aedon & 1 & 0.0204 \\
\hline & Northern Flicker & & Colaptes auratus & 1 & 0.0204 \\
\hline & Red-Billed Woodpecker & & Melanerpes carolinus & 1 & 0.0204 \\
\hline & Red-Winged Blackbird & & Agelaius phoeniceus & 15 & 0.3061 \\
\hline & Song Sparrow & & Melospiza melodia & 3 & 0.0612 \\
\hline & Tree Swallow & & Tachycineta bicolor & 1 & 0.0204 \\
\hline & Warbling Vireo & & Vireo gilvus & 1 & 0.0204 \\
\hline & Winter Wren & & Troglodytes troglodytes & 1 & 0.0204 \\
\hline & Wood Duck & & Aix sponsa & 1 & 0.0204 \\
\hline & Yellow Warbler & & Dendroica petechia & 2 & 0.0408 \\
\hline
\end{tabular}


Appendix C. Continued.

\begin{tabular}{|c|c|c|c|c|c|}
\hline SiteCode & Species & & Latin name & Jumber observed & $\begin{array}{c}\text { Frequency } \\
\text { per Site }\end{array}$ \\
\hline \multirow[t]{21}{*}{ CHWWEM } & Site abundance: & 42 & & & \\
\hline & American Goldfinch & & Carduelis tristis & 2 & 0.0476 \\
\hline & American Robin & & Turdus migratorius & 4 & 0.0952 \\
\hline & Carolina Chickadee & & Poecile carolinensis & 2 & 0.0476 \\
\hline & Carolina Wren & & Thryothorus ludovicianus & 1 & 0.0238 \\
\hline & Common Grackle & & Quiscalus quiscula & 1 & 0.0238 \\
\hline & Common Yellowthroat & & Geothlypis trichas & 2 & 0.0476 \\
\hline & Eastern Bluebird & & Sialia sialis & 1 & 0.0238 \\
\hline & Eastern Phoebe & & Sayornis phoebe & 1 & 0.0238 \\
\hline & Hairy Woodpecker & & Picoides villosus & 1 & 0.0238 \\
\hline & Indigo Bunting & & Passerina cyanea & 1 & 0.0238 \\
\hline & Northern Cardinal & & Cardinalis cardinalis & 1 & 0.0238 \\
\hline & Northern Flicker & & Colaptes auratus & 1 & 0.0238 \\
\hline & Northern Waterthrush & & Northern Waterthrush & 1 & 0.0238 \\
\hline & Red-Winged Blackbird & & Agelaius phoeniceus & 10 & 0.2381 \\
\hline & Savannah Sparrow & & Passerculus sandwichensis & 2 & 0.0476 \\
\hline & Song Sparrow & & Melospiza melodia & 5 & 0.1190 \\
\hline & Tree Swallow & & Tachycineta bicolor & 1 & 0.0238 \\
\hline & Tufted Titmouse & & Parus bicolor & 1 & 0.0238 \\
\hline & Winter Wren & & Troglodytes troglodytes & 1 & 0.0238 \\
\hline & Yellow Warbler & & Dendroica petechia & 3 & 0.0714 \\
\hline
\end{tabular}


Appendix C. Continued.

\begin{tabular}{|c|c|c|c|c|}
\hline SiteCode & Species & Latin name & Number observed & $\begin{array}{c}\text { Frequency } \\
\text { per Site }\end{array}$ \\
\hline \multirow[t]{21}{*}{ CHWWFO } & Site abundance: & & & \\
\hline & Black-and-White Warbler & Mniotilta varia & 1 & 0.0227 \\
\hline & Blue Jay & Cyanocitta cristata & 1 & 0.0227 \\
\hline & Carolina Chickadee & Poecile carolinensis & 5 & 0.1136 \\
\hline & Common Grackle & Quiscalus quiscula & 4 & 0.0909 \\
\hline & Cooper's Hawk & Accipiter cooperii & 1 & 0.0227 \\
\hline & Domestic duck & & 1 & 0.0227 \\
\hline & European Starling & Sturnus vulgaris & 1 & 0.0227 \\
\hline & Gray Catbird & Dumetella carolinensis & 1 & 0.0227 \\
\hline & Great Blue Heron & Ardea herodias & 4 & 0.0909 \\
\hline & Great Crested Flycatcher & Myiarchus crinitus & 1 & 0.0227 \\
\hline & Green Heron & Butorides virescens & 2 & 0.0455 \\
\hline & Mallard & Anas platyrhynchos & 7 & 0.1591 \\
\hline & Northern Cardinal & Cardinalis cardinalis & 1 & 0.0227 \\
\hline & Northern Flicker & Colaptes auratus & 2 & 0.0455 \\
\hline & Pileated Woodpecker & Dryocopus pileatus & 1 & 0.0227 \\
\hline & Red-Billed Woodpecker & Melanerpes carolinus & 1 & 0.0227 \\
\hline & Ruby-Throated Hummingbird & Archilochus colubris & 1 & 0.0227 \\
\hline & Tufted Titmouse & Parus bicolor & 3 & 0.0682 \\
\hline & White-Breasted Nuthatch & Sitta carolinensis & 3 & 0.0682 \\
\hline & Wood Duck & Aix sponsa & 3 & 0.0682 \\
\hline \multirow[t]{14}{*}{ CVABBW } & Site abundance: & & & \\
\hline & Acadian Flycatcher & Empidonax virescens & 1 & 0.0588 \\
\hline & Black-and-White Warbler & Mniotilta varia & 1 & 0.0588 \\
\hline & Black-capped Chickadee & Poecile atricapilla & 2 & 0.1176 \\
\hline & Black-throated Green Warbler & Dendroica virens & 1 & 0.0588 \\
\hline & Blue-Headed Vireo & Vireo solitarius & 1 & 0.0588 \\
\hline & Common Yellowthroat & Geothlypis trichas & 2 & 0.1176 \\
\hline & Eastern Towhee & Pipilo erythrophthalmus & 1 & 0.0588 \\
\hline & Marsh Wren & Cistothorus palustris & 2 & 0.1176 \\
\hline & Pileated Woodpecker & Dryocopus pileatus & 1 & 0.0588 \\
\hline & Red-Breasted Nuthatch & Sitta canadensis & 1 & 0.0588 \\
\hline & Ruby-Crowned Kinglet & Regulus calendula & 1 & 0.0588 \\
\hline & Swamp Sparrow & Melospiza georgiana & 2 & 0.1176 \\
\hline & Wood Thrush & Hylocichla mustelina & 1 & 0.0588 \\
\hline
\end{tabular}


Appendix C. Continued.

\begin{tabular}{|c|c|c|c|c|}
\hline SiteCode & Species & Latin name & Number observed & $\begin{array}{l}\text { Frequency } \\
\text { per Site }\end{array}$ \\
\hline \multirow[t]{18}{*}{ CVABCT } & Site abundance: & & & \\
\hline & Acadian Flycatcher & Empidonax virescens & 1 & 0.0476 \\
\hline & American Crow & Corvus brachyrhynchos & 1 & 0.0476 \\
\hline & Black-capped Chickadee & Poecile atricapilla & 1 & 0.0476 \\
\hline & Black-throated Green Warbler & Dendroica virens & 2 & 0.0952 \\
\hline & Blue Jay & Cyanocitta cristata & 1 & 0.0476 \\
\hline & Blue-Headed Vireo & Vireo solitarius & 1 & 0.0476 \\
\hline & Brown-Headed Cowbird & Molothrus ater & 1 & 0.0476 \\
\hline & Common Yellowthroat & Geothlypis trichas & 1 & 0.0476 \\
\hline & Eastern Towhee & Pipilo erythrophthalmus & 1 & 0.0476 \\
\hline & Magnolia Warbler & Dendroica magnolia & 1 & 0.0476 \\
\hline & Marsh Wren & Cistothorus palustris & 2 & 0.0952 \\
\hline & Red-Eyed Vireo & Vireo olivaceus & 2 & 0.0952 \\
\hline & Savannah Sparrow & Passerculus sandwichensis & 1 & 0.0476 \\
\hline & Song Sparrow & Melospiza melodia & 2 & 0.0952 \\
\hline & Swamp Sparrow & Melospiza georgiana & 1 & 0.0476 \\
\hline & Wood Thrush & Hylocichla mustelina & 1 & 0.0476 \\
\hline & Yellow Warbler & Dendroica petechia & 1 & 0.0476 \\
\hline \multirow[t]{11}{*}{ CVTIMB } & Site abundance: & & & \\
\hline & Acadian Flycatcher & Empidonax virescens & 2 & 0.1176 \\
\hline & Alder Flycatcher & Empidonax alnorum & 1 & 0.0588 \\
\hline & Black-capped Chickadee & Poecile atricapilla & 2 & 0.1176 \\
\hline & Blue Jay & Cyanocitta cristata & 1 & 0.0588 \\
\hline & Chestnut-Sided Warbler & Dendroica pensylvanica & 1 & 0.0588 \\
\hline & Common Yellowthroat & Geothlypis trichas & 3 & 0.1765 \\
\hline & Field Sparrow & Spizella pusilla & 1 & 0.0588 \\
\hline & Red-Winged Blackbird & Agelaius phoeniceus & 3 & 0.1765 \\
\hline & Swamp Sparrow & Melospiza georgiana & 2 & 0.1176 \\
\hline & Yellow Warbler & Dendroica petechia & 1 & 0.0588 \\
\hline
\end{tabular}


Appendix C. Continued.

\begin{tabular}{|c|c|c|c|c|}
\hline SiteCode & Species & Latin name & Number observed & $\begin{array}{c}\text { Frequency } \\
\text { per Site }\end{array}$ \\
\hline \multirow[t]{12}{*}{ DSPICN } & Site abundance: & & & \\
\hline & Black-and-White Warbler & Mniotilta varia & 1 & 0.0625 \\
\hline & Black-capped Chickadee & Poecile atricapilla & 2 & 0.1250 \\
\hline & Black-throated Green Warbler & Dendroica virens & 2 & 0.1250 \\
\hline & Blue Jay & Cyanocitta cristata & 2 & 0.1250 \\
\hline & Chestnut-Sided Warbler & Dendroica pensylvanica & 2 & 0.1250 \\
\hline & Eastern Towhee & Pipilo erythrophthalmus & 2 & 0.1250 \\
\hline & Mourning Warbler & Oporornis philadelphia & 1 & 0.0625 \\
\hline & Nashville Warbler & Vermivora ruficapilla & 1 & 0.0625 \\
\hline & Ovenbird & Seiurus aurocapillus & 1 & 0.0625 \\
\hline & Red-Eyed Vireo & Vireo olivaceus & 1 & 0.0625 \\
\hline & Yellow Warbler & Dendroica petechia & 1 & 0.0625 \\
\hline \multirow[t]{13}{*}{ DSROAR } & Site abundance: & & & \\
\hline & Blue Jay & Cyanocitta cristata & 1 & 0.0714 \\
\hline & Chestnut-Sided Warbler & Dendroica pensylvanica & 1 & 0.0714 \\
\hline & Common Yellowthroat & Geothlypis trichas & 2 & 0.1429 \\
\hline & Eastern Towhee & Pipilo erythrophthalmus & 2 & 0.1429 \\
\hline & Golden-Crowned Kinglet & Regulus satrapa & 1 & 0.0714 \\
\hline & Hermit Thrush & Catharus guttatus & 1 & 0.0714 \\
\hline & Northern Parula & Parula americana & 1 & 0.0714 \\
\hline & Purple Finch & Carpodacus purpureus & 1 & 0.0714 \\
\hline & Purple Martin & Progne subis & 1 & 0.0714 \\
\hline & Red-Eyed Vireo & Vireo olivaceus & 1 & 0.0714 \\
\hline & Veery & Catharus fuscescens & 1 & 0.0714 \\
\hline & Yellow Warbler & Dendroica petechia & 1 & 0.0714 \\
\hline \multirow[t]{13}{*}{ DSWILD } & Site abundance: & & & \\
\hline & American Robin & Turdus migratorius & 1 & 0.0714 \\
\hline & Black-capped Chickadee & Poecile atricapilla & 2 & 0.1429 \\
\hline & Black-throated Green Warbler & Dendroica virens & 1 & 0.0714 \\
\hline & Blue-Headed Vireo & Vireo solitarius & 1 & 0.0714 \\
\hline & Chestnut-Sided Warbler & Dendroica pensylvanica & 1 & 0.0714 \\
\hline & Dark-Eyed Junco & Junco hyemalis & 1 & 0.0714 \\
\hline & Eastern Towhee & Pipilo erythrophthalmus & 2 & 0.1429 \\
\hline & Golden-Crowned Kinglet & Regulus satrapa & 1 & 0.0714 \\
\hline & Hermit Thrush & Catharus guttatus & 1 & 0.0714 \\
\hline & Mourning Warbler & Oporornis philadelphia & 1 & 0.0714 \\
\hline & Pine Warbler & Dendroica pinus & 1 & 0.0714 \\
\hline & Yellow Warbler & Dendroica petechia & 1 & 0.0714 \\
\hline
\end{tabular}


Appendix C. Continued.

\begin{tabular}{|c|c|c|c|c|c|}
\hline SiteCode & Species & & Latin name & Number observed & $\begin{array}{c}\text { Frequency } \\
\text { per Site }\end{array}$ \\
\hline \multirow[t]{17}{*}{ EPCMEM } & Site abundance: & 38 & & & \\
\hline & American Robin & & Turdus migratorius & 2 & 0.0526 \\
\hline & Baltimore Oriole & & Icterus galbula & 1 & 0.0263 \\
\hline & Blue Jay & & Cyanocitta cristata & 1 & 0.0263 \\
\hline & Blue-Gray Gnatcatcher & & Polioptila caerulea & 1 & 0.0263 \\
\hline & Eastern Phoebe & & Sayornis phoebe & 1 & 0.0263 \\
\hline & Gray Catbird & & Dumetella carolinensis & 1 & 0.0263 \\
\hline & Northern Cardinal & & Cardinalis cardinalis & 2 & 0.0526 \\
\hline & Northern Flicker & & Colaptes auratus & 1 & 0.0263 \\
\hline & Northern Mockingbird & & Mimus polyglottos & 1 & 0.0263 \\
\hline & Red-Eyed Vireo & & Vireo olivaceus & 1 & 0.0263 \\
\hline & Red-Tailed Hawk & & Buteo jamaicensis & 1 & 0.0263 \\
\hline & Red-Winged Blackbird & & Agelaius phoeniceus & 18 & 0.4737 \\
\hline & Song Sparrow & & Melospiza melodia & 3 & 0.0789 \\
\hline & Tree Swallow & & Tachycineta bicolor & 2 & 0.0526 \\
\hline & Yellow Warbler & & Dendroica petechia & 1 & 0.0263 \\
\hline & Yellow-Breasted Chat & & Icteria virens & 1 & 0.0263 \\
\hline \multirow[t]{15}{*}{ EPCMFO } & Site abundance: & 25 & & & \\
\hline & American Redstart & & Setophaga ruticilla & 1 & 0.0400 \\
\hline & Brown-Headed Cowbird & & Molothrus ater & 4 & 0.1600 \\
\hline & Carolina Chickadee & & Poecile carolinensis & 3 & 0.1200 \\
\hline & Carolina Wren & & Thryothorus ludovicianus & 1 & 0.0400 \\
\hline & Common Grackle & & Quiscalus quiscula & 1 & 0.0400 \\
\hline & Eastern Phoebe & & Sayornis phoebe & 1 & 0.0400 \\
\hline & Gray Catbird & & Dumetella carolinensis & 1 & 0.0400 \\
\hline & Mallard & & Anas platyrhynchos & 6 & 0.2400 \\
\hline & Northern Cardinal & & Cardinalis cardinalis & 2 & 0.0800 \\
\hline & Northern Mockingbird & & Mimus polyglottos & 1 & 0.0400 \\
\hline & Pileated Woodpecker & & Dryocopus pileatus & 1 & 0.0400 \\
\hline & Red-Winged Blackbird & & Agelaius phoeniceus & 1 & 0.0400 \\
\hline & Tufted Titmouse & & Parus bicolor & 1 & 0.0400 \\
\hline & Yellow Warbler & & Dendroica petechia & 1 & 0.0400 \\
\hline
\end{tabular}


Appendix C. Continued.

\begin{tabular}{|c|c|c|c|c|c|}
\hline SiteCode & Species & & Latin name & Number observed & $\begin{array}{c}\text { Frequency } \\
\text { per Site }\end{array}$ \\
\hline \multirow[t]{12}{*}{ EPDMFO } & Site abundance: & 15 & & & \\
\hline & American Crow & & Corvus brachyrhynchos & 1 & 0.0667 \\
\hline & American Robin & & Turdus migratorius & 2 & 0.1333 \\
\hline & Brown Thrasher & & Toxostoma rufum & 1 & 0.0667 \\
\hline & Carolina Chickadee & & Poecile carolinensis & 2 & 0.1333 \\
\hline & Cedar Waxwing & & Bombycilla cedrorum & 1 & 0.0667 \\
\hline & Downy Woodpecker & & Picoides pubescens & 1 & 0.0667 \\
\hline & Eastern Wood-Pewee & & Contopus virens & 1 & 0.0667 \\
\hline & Northern Cardinal & & Cardinalis cardinalis & 3 & 0.2000 \\
\hline & Northern Flicker & & Colaptes auratus & 1 & 0.0667 \\
\hline & Red-Billed Woodpecker & & Melanerpes carolinus & 1 & 0.0667 \\
\hline & Tufted Titmouse & & Parus bicolor & 1 & 0.0667 \\
\hline \multirow[t]{8}{*}{ EPDMPU } & Site abundance: & 11 & & & \\
\hline & American Crow & & Corvus brachyrhynchos & 1 & 0.0909 \\
\hline & American Goldfinch & & Carduelis tristis & 2 & 0.1818 \\
\hline & Carolina Chickadee & & Poecile carolinensis & 4 & 0.3636 \\
\hline & Carolina Wren & & Thryothorus ludovicianus & 1 & 0.0909 \\
\hline & Eastern Towhee & & Pipilo erythrophthalmus & 1 & 0.0909 \\
\hline & Indigo Bunting & & Passerina cyanea & 1 & 0.0909 \\
\hline & Northern Cardinal & & Cardinalis cardinalis & 1 & 0.0909 \\
\hline
\end{tabular}


Appendix C. Continued.

\begin{tabular}{|c|c|c|c|c|c|}
\hline SiteCode & Species & & Latin name & Number observed & $\begin{array}{c}\text { Frequency } \\
\text { per Site }\end{array}$ \\
\hline \multirow[t]{21}{*}{ EPKYVE } & Site abundance: & 42 & & & \\
\hline & American Goldfinch & & Carduelis tristis & 3 & 0.0714 \\
\hline & American Robin & & Turdus migratorius & 2 & 0.0476 \\
\hline & American Robin & & Turdus migratorius & 2 & 0.0476 \\
\hline & Baltimore Oriole & & Icterus galbula & 1 & 0.0238 \\
\hline & Belted Kingfisher & & Ceryle alcyon & 1 & 0.0238 \\
\hline & Blue Jay & & Cyanocitta cristata & 1 & 0.0238 \\
\hline & Canada Goose & & Branta canadensis & 8 & 0.1905 \\
\hline & Common Yellowthroat & & Geothlypis trichas & 1 & 0.0238 \\
\hline & Field Sparrow & & Spizella pusilla & 2 & 0.0476 \\
\hline & Gray Catbird & & Dumetella carolinensis & 2 & 0.0476 \\
\hline & Great Crested Flycatcher & & Myiarchus crinitus & 1 & 0.0238 \\
\hline & Green Heron & & Butorides virescens & 2 & 0.0476 \\
\hline & Mourning Dove & & Zenaida macroura & 1 & 0.0238 \\
\hline & Northern Cardinal & & Cardinalis cardinalis & 2 & 0.0476 \\
\hline & Northern Mockingbird & & Mimus polyglottos & 1 & 0.0238 \\
\hline & Red-Billed Woodpecker & & Melanerpes carolinus & 1 & 0.0238 \\
\hline & Red-Winged Blackbird & & Agelaius phoeniceus & 6 & 0.1429 \\
\hline & Tree Swallow & & Tachycineta bicolor & 3 & 0.0714 \\
\hline & Yellow Warbler & & Dendroica petechia & 1 & 0.0238 \\
\hline & Yellow-Breasted Chat & & Icteria virens & 1 & 0.0238 \\
\hline \multirow[t]{12}{*}{ EPRRXC } & Site abundance: & 14 & & & \\
\hline & Baltimore Oriole & & Icterus galbula & 1 & 0.0714 \\
\hline & Brown-Headed Cowbird & & Molothrus ater & 3 & 0.2143 \\
\hline & Carolina Chickadee & & Poecile carolinensis & 1 & 0.0714 \\
\hline & Eastern Phoebe & & Sayornis phoebe & 1 & 0.0714 \\
\hline & Eastern Wood-Pewee & & Contopus virens & 1 & 0.0714 \\
\hline & Hairy Woodpecker & & Picoides villosus & 1 & 0.0714 \\
\hline & Hermit Thrush & & Catharus guttatus & 1 & 0.0714 \\
\hline & Indigo Bunting & & Passerina cyanea & 1 & 0.0714 \\
\hline & Northern Cardinal & & Cardinalis cardinalis & 2 & 0.1429 \\
\hline & Red-Billed Woodpecker & & Melanerpes carolinus & 1 & 0.0714 \\
\hline & Scarlet Tanager & & Piranga olivacea & 1 & 0.0714 \\
\hline
\end{tabular}


Appendix C.Continued.

\begin{tabular}{|c|c|c|c|c|c|}
\hline SiteCode & Species & & Latin name & Number observed & $\begin{array}{c}\text { Frequency } \\
\text { per Site }\end{array}$ \\
\hline \multirow[t]{16}{*}{ EPSHEM } & Site abundance: & 26 & & & \\
\hline & American Goldfinch & & Carduelis tristis & 2 & 0.0769 \\
\hline & Blue-Gray Gnatcatcher & & Polioptila caerulea & 1 & 0.0385 \\
\hline & Carolina Chickadee & & Poecile carolinensis & 3 & 0.1154 \\
\hline & Carolina Wren & & Thryothorus ludovicianus & 1 & 0.0385 \\
\hline & Cedar Waxwing & & Bombycilla cedrorum & 1 & 0.0385 \\
\hline & Common Grackle & & Quiscalus quiscula & 2 & 0.0769 \\
\hline & Common Yellowthroat & & Geothlypis trichas & 2 & 0.0769 \\
\hline & Gray Catbird & & Dumetella carolinensis & 1 & 0.0385 \\
\hline & Mallard & & Anas platyrhynchos & 2 & 0.0769 \\
\hline & Northern Cardinal & & Cardinalis cardinalis & 3 & 0.1154 \\
\hline & Northern Mockingbird & & Mimus polyglottos & 1 & 0.0385 \\
\hline & Northern Waterthrush & & Northern Waterthrush & 2 & 0.0769 \\
\hline & Red-Winged Blackbird & & Agelaius phoeniceus & 1 & 0.0385 \\
\hline & Song Sparrow & & Melospiza melodia & 3 & 0.1154 \\
\hline & Wood Thrush & & Hylocichla mustelina & 1 & 0.0385 \\
\hline \multirow[t]{19}{*}{ EPSHSS } & Site abundance: & 30 & & & \\
\hline & American Goldfinch & & Carduelis tristis & 2 & 0.0667 \\
\hline & American Robin & & Turdus migratorius & 1 & 0.0333 \\
\hline & Canada Goose & & Branta canadensis & 2 & 0.0667 \\
\hline & Carolina Chickadee & & Poecile carolinensis & 1 & 0.0333 \\
\hline & Common Yellowthroat & & Geothlypis trichas & 3 & 0.1000 \\
\hline & Eastern Wood-Pewee & & Contopus virens & 2 & 0.0667 \\
\hline & Gray Catbird & & Dumetella carolinensis & 1 & 0.0333 \\
\hline & Great Crested Flycatcher & & Myiarchus crinitus & 1 & 0.0333 \\
\hline & Hermit Thrush & & Catharus guttatus & 1 & 0.0333 \\
\hline & Indigo Bunting & & Passerina cyanea & 2 & 0.0667 \\
\hline & Mourning Dove & & Zenaida macroura & 1 & 0.0333 \\
\hline & Northern Cardinal & & Cardinalis cardinalis & 2 & 0.0667 \\
\hline & Northern Flicker & & Colaptes auratus & 1 & 0.0333 \\
\hline & Northern Mockingbird & & Mimus polyglottos & 2 & 0.0667 \\
\hline & Pileated Woodpecker & & Dryocopus pileatus & 2 & 0.0667 \\
\hline & Song Sparrow & & Melospiza melodia & 4 & 0.1333 \\
\hline & White-Eyed Vireo & & Vireo griseus & 1 & 0.0333 \\
\hline & Willow Flycatcher & & Empidonax traillii & 1 & 0.0333 \\
\hline
\end{tabular}


Appendix C. Continued.

\begin{tabular}{|c|c|c|c|c|c|}
\hline SiteCode & Species & & Latin name & Number observed & $\begin{array}{c}\text { Frequency } \\
\text { per Site }\end{array}$ \\
\hline \multirow[t]{15}{*}{ GBBARN } & Site abundance: & 24 & & & \\
\hline & American Goldfinch & & Carduelis tristis & 1 & 0.0417 \\
\hline & Blue-Gray Gnatcatcher & & Polioptila caerulea & 1 & 0.0417 \\
\hline & Blue-Headed Vireo & & Vireo solitarius & 1 & 0.0417 \\
\hline & Brown-Headed Cowbird & & Molothrus ater & 1 & 0.0417 \\
\hline & Carolina Wren & & Thryothorus ludovicianus & 1 & 0.0417 \\
\hline & Common Yellowthroat & & Geothlypis trichas & 2 & 0.0833 \\
\hline & Eastern Bluebird & & Sialia sialis & 1 & 0.0417 \\
\hline & Field Sparrow & & Spizella pusilla & 3 & 0.1250 \\
\hline & Indigo Bunting & & Passerina cyanea & 1 & 0.0417 \\
\hline & Red-Winged Blackbird & & Agelaius phoeniceus & 5 & 0.2083 \\
\hline & Song Sparrow & & Melospiza melodia & 3 & 0.1250 \\
\hline & Tree Swallow & & Tachycineta bicolor & 2 & 0.0833 \\
\hline & White-Eyed Vireo & & Vireo griseus & 1 & 0.0417 \\
\hline & Yellow Warbler & & Dendroica petechia & 1 & 0.0417 \\
\hline \multirow[t]{16}{*}{ GBHOEF } & Site abundance: & 44 & & & \\
\hline & American Goldfinch & & Carduelis tristis & 2 & 0.0455 \\
\hline & Bank Swallow & & Riparia riparia & 18 & 0.4091 \\
\hline & Canada Goose & & Branta canadensis & 3 & 0.0682 \\
\hline & Carolina Wren & & Thryothorus ludovicianus & 1 & 0.0227 \\
\hline & Common Grackle & & Quiscalus quiscula & 1 & 0.0227 \\
\hline & Common Yellowthroat & & Geothlypis trichas & 2 & 0.0455 \\
\hline & Eastern Kingbird & & Tyrannus tyrannus & 2 & 0.0455 \\
\hline & Eastern Phoebe & & Sayornis phoebe & 1 & 0.0227 \\
\hline & Field Sparrow & & Spizella pusilla & 1 & 0.0227 \\
\hline & Indigo Bunting & & Passerina cyanea & 1 & 0.0227 \\
\hline & Killdeer & & Charadrius vociferus & 1 & 0.0227 \\
\hline & Red-Winged Blackbird & & Agelaius phoeniceus & 5 & 0.1136 \\
\hline & Song Sparrow & & Melospiza melodia & 1 & 0.0227 \\
\hline & Tree Swallow & & Tachycineta bicolor & 2 & 0.0455 \\
\hline & Willow Flycatcher & & Empidonax traillii & 3 & 0.0682 \\
\hline
\end{tabular}


Appendix C. Continued.

\begin{tabular}{|c|c|c|c|c|c|}
\hline SiteCode & Species & & Latin name & Number observed & $\begin{array}{l}\text { Frequency } \\
\text { per Site }\end{array}$ \\
\hline \multirow[t]{13}{*}{ GBJENK } & Site abundance: & 39 & & & \\
\hline & American Crow & & Corvus brachyrhynchos & 1 & 0.0256 \\
\hline & Brown-Headed Cowbird & & Molothrus ater & 1 & 0.0256 \\
\hline & Canada Goose & & Branta canadensis & 16 & 0.4103 \\
\hline & Common Grackle & & Quiscalus quiscula & 2 & 0.0513 \\
\hline & Common Yellowthroat & & Geothlypis trichas & 2 & 0.0513 \\
\hline & Field Sparrow & & Spizella pusilla & 2 & 0.0513 \\
\hline & Great Blue Heron & & Ardea herodias & 1 & 0.0256 \\
\hline & Mallard & & Anas platyrhynchos & 2 & 0.0513 \\
\hline & Orchard Oriole & & Icterus spurius & 1 & 0.0256 \\
\hline & Red-Winged Blackbird & & Agelaius phoeniceus & 8 & 0.2051 \\
\hline & Tree Swallow & & Tachycineta bicolor & 2 & 0.0513 \\
\hline & Yellow Warbler & & Dendroica petechia & 1 & 0.0256 \\
\hline \multirow[t]{15}{*}{ GBMAPL } & Site abundance: & 19 & & & \\
\hline & Blue-Gray Gnatcatcher & & Polioptila caerulea & 1 & 0.0526 \\
\hline & Carolina Wren & & Thryothorus ludovicianus & 1 & 0.0526 \\
\hline & Chestnut-Sided Warbler & & Dendroica pensylvanica & 1 & 0.0526 \\
\hline & Common Yellowthroat & & Geothlypis trichas & 3 & 0.1579 \\
\hline & Downy Woodpecker & & Picoides pubescens & 1 & 0.0526 \\
\hline & Eastern Kingbird & & Tyrannus tyrannus & 1 & 0.0526 \\
\hline & Field Sparrow & & Spizella pusilla & 1 & 0.0526 \\
\hline & Gray Catbird & & Dumetella carolinensis & 1 & 0.0526 \\
\hline & Indigo Bunting & & Passerina cyanea & 1 & 0.0526 \\
\hline & Northern Cardinal & & Cardinalis cardinalis & 1 & 0.0526 \\
\hline & Red-Breasted Nuthatch & & Sitta canadensis & 2 & 0.1053 \\
\hline & Red-Eyed Vireo & & Vireo olivaceus & 1 & 0.0526 \\
\hline & Tufted Titmouse & & Parus bicolor & 3 & 0.1579 \\
\hline & White-Eyed Vireo & & Vireo griseus & 1 & 0.0526 \\
\hline
\end{tabular}


Appendix C. Continued.

\begin{tabular}{|c|c|c|c|c|c|}
\hline SiteCode & Species & & Latin name & Number observed & $\begin{array}{c}\text { Frequency } \\
\text { per Site }\end{array}$ \\
\hline \multirow[t]{18}{*}{ GBNOFO } & Site abundance: & 26 & & & \\
\hline & American Goldfinch & & Carduelis tristis & 1 & 0.0385 \\
\hline & Blue-Gray Gnatcatcher & & Polioptila caerulea & 1 & 0.0385 \\
\hline & Brown-Headed Cowbird & & Molothrus ater & 1 & 0.0385 \\
\hline & Carolina Wren & & Thryothorus ludovicianus & 2 & 0.0769 \\
\hline & Common Grackle & & Quiscalus quiscula & 1 & 0.0385 \\
\hline & Common Yellowthroat & & Geothlypis trichas & 1 & 0.0385 \\
\hline & Eastern Phoebe & & Sayornis phoebe & 1 & 0.0385 \\
\hline & Field Sparrow & & Spizella pusilla & 1 & 0.0385 \\
\hline & Gray Catbird & & Dumetella carolinensis & 1 & 0.0385 \\
\hline & Northern Mockingbird & & Mimus polyglottos & 1 & 0.0385 \\
\hline & Prothonotary Warbler & & Protonotaria citrea & 1 & 0.0385 \\
\hline & Red-Eyed Vireo & & Vireo olivaceus & 1 & 0.0385 \\
\hline & Red-Winged Blackbird & & Agelaius phoeniceus & 5 & 0.1923 \\
\hline & Song Sparrow & & Melospiza melodia & 5 & 0.1923 \\
\hline & White-Eyed Vireo & & Vireo griseus & 1 & 0.0385 \\
\hline & Willow Flycatcher & & Empidonax traillii & 1 & 0.0385 \\
\hline & Yellow Warbler & & Dendroica petechia & 1 & 0.0385 \\
\hline \multirow[t]{15}{*}{ GBNOSS } & Site abundance: & 26 & & & \\
\hline & Bank Swallow & & Riparia riparia & 3 & 0.1154 \\
\hline & Barn Swallow & & Hirundo rustica & 2 & 0.0769 \\
\hline & Carolina Wren & & Thryothorus ludovicianus & 1 & 0.0385 \\
\hline & Common Yellowthroat & & Geothlypis trichas & 2 & 0.0769 \\
\hline & Eastern Bluebird & & Sialia sialis & 1 & 0.0385 \\
\hline & Field Sparrow & & Spizella pusilla & 1 & 0.0385 \\
\hline & Gray Catbird & & Dumetella carolinensis & 1 & 0.0385 \\
\hline & Northern Cardinal & & Cardinalis cardinalis & 1 & 0.0385 \\
\hline & Red-Eyed Vireo & & Vireo olivaceus & 1 & 0.0385 \\
\hline & Red-Winged Blackbird & & Agelaius phoeniceus & 7 & 0.2692 \\
\hline & Song Sparrow & & Melospiza melodia & 3 & 0.1154 \\
\hline & White-Eyed Vireo & & Vireo griseus & 1 & 0.0385 \\
\hline & Willow Flycatcher & & Empidonax traillii & 1 & 0.0385 \\
\hline & Yellow Warbler & & Dendroica petechia & 1 & 0.0385 \\
\hline
\end{tabular}


Appendix C. Continued.

\begin{tabular}{|c|c|c|c|c|c|}
\hline SiteCode & Species & & Latin name & Number observed & $\begin{array}{c}\text { Frequency } \\
\text { per Site }\end{array}$ \\
\hline \multirow[t]{15}{*}{ GBPLOT } & Site abundance: & 38 & & & \\
\hline & Blue-Headed Vireo & & Vireo solitarius & 1 & 0.0263 \\
\hline & Brown-Headed Cowbird & & Molothrus ater & 1 & 0.0263 \\
\hline & Canada Goose & & Branta canadensis & 13 & 0.3421 \\
\hline & Carolina Wren & & Thryothorus ludovicianus & 1 & 0.0263 \\
\hline & Common Yellowthroat & & Geothlypis trichas & 1 & 0.0263 \\
\hline & Field Sparrow & & Spizella pusilla & 1 & 0.0263 \\
\hline & Indigo Bunting & & Passerina cyanea & 1 & 0.0263 \\
\hline & Killdeer & & Charadrius vociferus & 1 & 0.0263 \\
\hline & Mallard & & Anas platyrhynchos & 1 & 0.0263 \\
\hline & Red-Winged Blackbird & & Agelaius phoeniceus & 7 & 0.1842 \\
\hline & Song Sparrow & & Melospiza melodia & 5 & 0.1316 \\
\hline & Tree Swallow & & Tachycineta bicolor & 2 & 0.0526 \\
\hline & Willow Flycatcher & & Empidonax traillii & 2 & 0.0526 \\
\hline & Yellow Warbler & & Dendroica petechia & 1 & 0.0263 \\
\hline \multirow[t]{19}{*}{ HCBEAV } & Site abundance: & 26 & & & \\
\hline & American Robin & & Turdus migratorius & 2 & 0.0769 \\
\hline & Blue-Gray Gnatcatcher & & Polioptila caerulea & 1 & 0.0385 \\
\hline & Blue-Winged Warbler & & Vermivora pinus & 1 & 0.0385 \\
\hline & Brown-Headed Cowbird & & Molothrus ater & 1 & 0.0385 \\
\hline & Carolina Chickadee & & Poecile carolinensis & 1 & 0.0385 \\
\hline & Common Grackle & & Quiscalus quiscula & 1 & 0.0385 \\
\hline & Common Yellowthroat & & Geothlypis trichas & 2 & 0.0769 \\
\hline & Eastern Towhee & & Pipilo erythrophthalmus & 1 & 0.0385 \\
\hline & Field Sparrow & & Spizella pusilla & 3 & 0.1154 \\
\hline & Gray Catbird & & Dumetella carolinensis & 1 & 0.0385 \\
\hline & Northern Cardinal & & Cardinalis cardinalis & 1 & 0.0385 \\
\hline & Red-Breasted Nuthatch & & Sitta canadensis & 1 & 0.0385 \\
\hline & Red-Winged Blackbird & & Agelaius phoeniceus & 2 & 0.0769 \\
\hline & Scarlet Tanager & & Piranga olivacea & 1 & 0.0385 \\
\hline & Song Sparrow & & Melospiza melodia & 2 & 0.0769 \\
\hline & Tree Swallow & & Tachycineta bicolor & 2 & 0.0769 \\
\hline & Wood Thrush & & Hylocichla mustelina & 1 & 0.0385 \\
\hline & Yellow Warbler & & Dendroica petechia & 2 & 0.0769 \\
\hline
\end{tabular}


Appendix C. Continued.

\begin{tabular}{|c|c|c|c|c|c|}
\hline SiteCode & Species & & Latin name & Number observed & $\begin{array}{c}\text { Frequency } \\
\text { per Site }\end{array}$ \\
\hline \multirow[t]{20}{*}{ HCMITI } & Site abundance: & 30 & & & \\
\hline & American Redstart & & Setophaga ruticilla & 1 & 0.0333 \\
\hline & Blue-Gray Gnatcatcher & & Polioptila caerulea & 1 & 0.0333 \\
\hline & Carolina Chickadee & & Poecile carolinensis & 1 & 0.0333 \\
\hline & Cedar Waxwing & & Bombycilla cedrorum & 1 & 0.0333 \\
\hline & Common Grackle & & Quiscalus quiscula & 1 & 0.0333 \\
\hline & Common Yellowthroat & & Geothlypis trichas & 2 & 0.0667 \\
\hline & Eastern Towhee & & Pipilo erythrophthalmus & 1 & 0.0333 \\
\hline & Field Sparrow & & Spizella pusilla & 2 & 0.0667 \\
\hline & Gray Catbird & & Dumetella carolinensis & 1 & 0.0333 \\
\hline & Green Heron & & Butorides virescens & 1 & 0.0333 \\
\hline & Killdeer & & Charadrius vociferus & 1 & 0.0333 \\
\hline & Marsh Wren & & Cistothorus palustris & 1 & 0.0333 \\
\hline & Northern Cardinal & & Cardinalis cardinalis & 1 & 0.0333 \\
\hline & Red-Winged Blackbird & & Agelaius phoeniceus & 6 & 0.2000 \\
\hline & Song Sparrow & & Melospiza melodia & 3 & 0.1000 \\
\hline & Tree Swallow & & Tachycineta bicolor & 3 & 0.1000 \\
\hline & Willow Flycatcher & & Empidonax traillii & 1 & 0.0333 \\
\hline & Wood Duck & & Aix sponsa & 1 & 0.0333 \\
\hline & Yellow Warbler & & Dendroica petechia & 1 & 0.0333 \\
\hline \multirow[t]{16}{*}{ HCPIPE } & Site abundance: & 35 & & & \\
\hline & American Robin & & Turdus migratorius & 2 & 0.0571 \\
\hline & Blue Jay & & Cyanocitta cristata & 1 & 0.0286 \\
\hline & Cedar Waxwing & & Bombycilla cedrorum & 2 & 0.0571 \\
\hline & Common Grackle & & Quiscalus quiscula & 1 & 0.0286 \\
\hline & Common Yellowthroat & & Geothlypis trichas & 2 & 0.0571 \\
\hline & Eastern Towhee & & Pipilo erythrophthalmus & 2 & 0.0571 \\
\hline & Field Sparrow & & Spizella pusilla & 2 & 0.0571 \\
\hline & Mourning Dove & & Zenaida macroura & 1 & 0.0286 \\
\hline & Northern Cardinal & & Cardinalis cardinalis & 1 & 0.0286 \\
\hline & Red-Winged Blackbird & & Agelaius phoeniceus & 12 & 0.3429 \\
\hline & Song Sparrow & & Melospiza melodia & 2 & 0.0571 \\
\hline & Tree Swallow & & Tachycineta bicolor & 1 & 0.0286 \\
\hline & Willow Flycatcher & & Empidonax traillii & 2 & 0.0571 \\
\hline & Yellow Warbler & & Dendroica petechia & 3 & 0.0857 \\
\hline & Yellow-Breasted Chat & & Icteria virens & 1 & 0.0286 \\
\hline
\end{tabular}


Appendix C. Continued.

\begin{tabular}{|c|c|c|c|c|c|}
\hline SiteCode & Species & & Latin name & Number observed & $\begin{array}{c}\text { Frequency } \\
\text { per Site }\end{array}$ \\
\hline \multirow[t]{14}{*}{ HCRANG } & Site abundance: & 28 & & & \\
\hline & American Goldfinch & & Carduelis tristis & 2 & 0.0714 \\
\hline & American Robin & & Turdus migratorius & 1 & 0.0357 \\
\hline & Cedar Waxwing & & Bombycilla cedrorum & 2 & 0.0714 \\
\hline & Common Grackle & & Quiscalus quiscula & 2 & 0.0714 \\
\hline & Common Yellowthroat & & Geothlypis trichas & 2 & 0.0714 \\
\hline & Eastern Towhee & & Pipilo erythrophthalmus & 2 & 0.0714 \\
\hline & Field Sparrow & & Spizella pusilla & 2 & 0.0714 \\
\hline & Mourning Dove & & Zenaida macroura & 1 & 0.0357 \\
\hline & Red-Winged Blackbird & & Agelaius phoeniceus & 7 & 0.2500 \\
\hline & Willow Flycatcher & & Empidonax traillii & 1 & 0.0357 \\
\hline & Willow Flycatcher & & Empidonax traillii & 2 & 0.0714 \\
\hline & Yellow Warbler & & Dendroica petechia & 3 & 0.1071 \\
\hline & Yellow-Breasted Chat & & Icteria virens & 1 & 0.0357 \\
\hline \multirow[t]{17}{*}{ HIBRID } & Site abundance: & 32 & & & \\
\hline & American Goldfinch & & Carduelis tristis & 2 & 0.0625 \\
\hline & American Robin & & Turdus migratorius & 1 & 0.0313 \\
\hline & Baltimore Oriole & & Icterus galbula & 1 & 0.0313 \\
\hline & Barn Swallow & & Hirundo rustica & 1 & 0.0313 \\
\hline & Brown-Headed Cowbird & & Molothrus ater & 1 & 0.0313 \\
\hline & Common Grackle & & Quiscalus quiscula & 3 & 0.0938 \\
\hline & Gray Catbird & & Dumetella carolinensis & 1 & 0.0313 \\
\hline & House Wren & & Troglodytes aedon & 1 & 0.0313 \\
\hline & Northern Cardinal & & Cardinalis cardinalis & 1 & 0.0313 \\
\hline & Northern Flicker & & Colaptes auratus & 1 & 0.0313 \\
\hline & Red-Winged Blackbird & & Agelaius phoeniceus & 6 & 0.1875 \\
\hline & Song Sparrow & & Melospiza melodia & 3 & 0.0938 \\
\hline & Tree Swallow & & Tachycineta bicolor & 5 & 0.1563 \\
\hline & Warbling Vireo & & Vireo gilvus & 2 & 0.0625 \\
\hline & Willow Flycatcher & & Empidonax traillii & 1 & 0.0313 \\
\hline & Yellow Warbler & & Dendroica petechia & 2 & 0.0625 \\
\hline
\end{tabular}


Appendix C. Continued.

\begin{tabular}{|c|c|c|c|c|c|}
\hline SiteCode & Species & & Latin name & Number observed & $\begin{array}{c}\text { Frequency } \\
\text { per Site }\end{array}$ \\
\hline \multirow[t]{21}{*}{ HIGATE } & Site abundance: & 24 & & & \\
\hline & American Goldfinch & & Carduelis tristis & 1 & 0.0417 \\
\hline & American Robin & & Turdus migratorius & 1 & 0.0417 \\
\hline & American Robin & & Turdus migratorius & 1 & 0.0417 \\
\hline & Belted Kingfisher & & Ceryle alcyon & 1 & 0.0417 \\
\hline & Blue Jay & & Cyanocitta cristata & 1 & 0.0417 \\
\hline & Blue-Gray Gnatcatcher & & Polioptila caerulea & 2 & 0.0833 \\
\hline & Carolina Chickadee & & Poecile carolinensis & 2 & 0.0833 \\
\hline & Carolina Wren & & Thryothorus ludovicianus & 1 & 0.0417 \\
\hline & Common Yellowthroat & & Geothlypis trichas & 2 & 0.0833 \\
\hline & Eastern Phoebe & & Sayornis phoebe & 1 & 0.0417 \\
\hline & Gray Catbird & & Dumetella carolinensis & 1 & 0.0417 \\
\hline & Great Crested Flycatcher & & Myiarchus crinitus & 1 & 0.0417 \\
\hline & Indigo Bunting & & Passerina cyanea & 1 & 0.0417 \\
\hline & Northern Cardinal & & Cardinalis cardinalis & 1 & 0.0417 \\
\hline & Northern Waterthrush & & Northern Waterthrush & 1 & 0.0417 \\
\hline & Red-Billed Woodpecker & & Melanerpes carolinus & 1 & 0.0417 \\
\hline & Red-Eyed Vireo & & Vireo olivaceus & 1 & 0.0417 \\
\hline & Song Sparrow & & Melospiza melodia & 1 & 0.0417 \\
\hline & Tufted Titmouse & & Parus bicolor & 2 & 0.0833 \\
\hline & Yellow Warbler & & Dendroica petechia & 1 & 0.0417 \\
\hline
\end{tabular}


Appendix C. Continued.

\begin{tabular}{|c|c|c|c|c|c|}
\hline SiteCode & Species & & Latin name & Number observed & $\begin{array}{c}\text { Frequency } \\
\text { per Site }\end{array}$ \\
\hline \multirow[t]{21}{*}{ HIJHPK } & Site abundance: & 24 & & & \\
\hline & American Crow & & Corvus brachyrhynchos & 1 & 0.0417 \\
\hline & American Robin & & Turdus migratorius & 1 & 0.0417 \\
\hline & Blue Jay & & Cyanocitta cristata & 1 & 0.0417 \\
\hline & Blue-Headed Vireo & & Vireo solitarius & 1 & 0.0417 \\
\hline & Carolina Chickadee & & Poecile carolinensis & 3 & 0.1250 \\
\hline & Carolina Wren & & Thryothorus ludovicianus & 3 & 0.1250 \\
\hline & Cedar Waxwing & & Bombycilla cedrorum & 1 & 0.0417 \\
\hline & Chestnut-Sided Warbler & & Dendroica pensylvanica & 1 & 0.0417 \\
\hline & Common Yellowthroat & & Geothlypis trichas & 0 & 0.0000 \\
\hline & Eastern Towhee & & Pipilo erythrophthalmus & 2 & 0.0833 \\
\hline & Eastern Wood-Pewee & & Contopus virens & 1 & 0.0417 \\
\hline & Gray Catbird & & Dumetella carolinensis & 1 & 0.0417 \\
\hline & Great Crested Flycatcher & & Myiarchus crinitus & 1 & 0.0417 \\
\hline & Northern Cardinal & & Cardinalis cardinalis & 1 & 0.0417 \\
\hline & Northern Parula & & Parula americana & 1 & 0.0417 \\
\hline & Red-Billed Woodpecker & & Melanerpes carolinus & 1 & 0.0417 \\
\hline & Scarlet Tanager & & Piranga olivacea & 1 & 0.0417 \\
\hline & Tufted Titmouse & & Parus bicolor & 1 & 0.0417 \\
\hline & Winter Wren & & Troglodytes troglodytes & 1 & 0.0417 \\
\hline & Wood Thrush & & Hylocichla mustelina & 1 & 0.0417 \\
\hline \multirow[t]{17}{*}{ HIJHTU } & Site abundance: & 21 & & & \\
\hline & Acadian Flycatcher & & Empidonax virescens & 1 & 0.0476 \\
\hline & American Goldfinch & & Carduelis tristis & 2 & 0.0952 \\
\hline & Blue Jay & & Cyanocitta cristata & 1 & 0.0476 \\
\hline & Blue-Gray Gnatcatcher & & Polioptila caerulea & 1 & 0.0476 \\
\hline & Blue-Headed Vireo & & Vireo solitarius & 1 & 0.0476 \\
\hline & Carolina Chickadee & & Poecile carolinensis & 3 & 0.1429 \\
\hline & Eastern Phoebe & & Sayornis phoebe & 1 & 0.0476 \\
\hline & Eastern Towhee & & Pipilo erythrophthalmus & 1 & 0.0476 \\
\hline & Gray Catbird & & Dumetella carolinensis & 1 & 0.0476 \\
\hline & Hooded Warbler & & Wilsonia citrina & 1 & 0.0476 \\
\hline & Indigo Bunting & & Passerina cyanea & 1 & 0.0476 \\
\hline & Northern Cardinal & & Cardinalis cardinalis & 2 & 0.0952 \\
\hline & Orchard Oriole & & Icterus spurius & 1 & 0.0476 \\
\hline & Red-Winged Blackbird & & Agelaius phoeniceus & 1 & 0.0476 \\
\hline & Song Sparrow & & Melospiza melodia & 2 & 0.0952 \\
\hline & Tufted Titmouse & & Parus bicolor & 1 & 0.0476 \\
\hline
\end{tabular}


Appendix C. Continued.

\begin{tabular}{|c|c|c|c|c|c|}
\hline SiteCode & Species & & Latin name & Number observed & $\begin{array}{c}\text { Frequency } \\
\text { per Site }\end{array}$ \\
\hline \multirow[t]{18}{*}{ HIPENC } & Site abundance: & 32 & & & \\
\hline & American Robin & & Turdus migratorius & 1 & 0.0313 \\
\hline & Blue-Gray Gnatcatcher & & Polioptila caerulea & 2 & 0.0625 \\
\hline & Blue-Headed Vireo & & Vireo solitarius & 1 & 0.0313 \\
\hline & Blue-Winged Warbler & & Vermivora pinus & 2 & 0.0625 \\
\hline & Carolina Chickadee & & Poecile carolinensis & 1 & 0.0313 \\
\hline & Common Yellowthroat & & Geothlypis trichas & 1 & 0.0313 \\
\hline & Eastern Towhee & & Pipilo erythrophthalmus & 2 & 0.0625 \\
\hline & Field Sparrow & & Spizella pusilla & 1 & 0.0313 \\
\hline & Green Heron & & Butorides virescens & 1 & 0.0313 \\
\hline & Hermit Thrush & & Catharus guttatus & 1 & 0.0313 \\
\hline & House Wren & & Troglodytes aedon & 1 & 0.0313 \\
\hline & Mourning Dove & & Zenaida macroura & 1 & 0.0313 \\
\hline & Northern Waterthrush & & Northern Waterthrush & 1 & 0.0313 \\
\hline & Red-Winged Blackbird & & Agelaius phoeniceus & 12 & 0.3750 \\
\hline & Scarlet Tanager & & Piranga olivacea & 1 & 0.0313 \\
\hline & Sedge Wren & & Cistothorus platensis & 1 & 0.0313 \\
\hline & Song Sparrow & & Melospiza melodia & 2 & 0.0625 \\
\hline \multirow[t]{16}{*}{ HISEWG } & Site abundance: & 21 & & & \\
\hline & American Redstart & & Setophaga ruticilla & 2 & 0.0952 \\
\hline & American Robin & & Turdus migratorius & 1 & 0.0476 \\
\hline & Blue-Headed Vireo & & Vireo solitarius & 1 & 0.0476 \\
\hline & Blue-Headed Vireo & & Vireo solitarius & 1 & 0.0476 \\
\hline & Blue-Winged Warbler & & Vermivora pinus & 1 & 0.0476 \\
\hline & Carolina Chickadee & & Poecile carolinensis & 1 & 0.0476 \\
\hline & Carolina Wren & & Thryothorus ludovicianus & 1 & 0.0476 \\
\hline & Eastern Towhee & & Pipilo erythrophthalmus & 1 & 0.0476 \\
\hline & Eastern Wood-Pewee & & Contopus virens & 1 & 0.0476 \\
\hline & Hermit Thrush & & Catharus guttatus & 1 & 0.0476 \\
\hline & Mourning Warbler & & Oporornis philadelphia & 1 & 0.0476 \\
\hline & Northern Flicker & & Colaptes auratus & 2 & 0.0952 \\
\hline & Northern Waterthrush & & Northern Waterthrush & 1 & 0.0476 \\
\hline & Red-Eyed Vireo & & Vireo olivaceus & 1 & 0.0476 \\
\hline & Song Sparrow & & Melospiza melodia & 5 & 0.2381 \\
\hline
\end{tabular}


Appendix C. Continued.

\begin{tabular}{|c|c|c|c|c|c|}
\hline SiteCode & Species & & Latin name & Number observed & $\begin{array}{c}\text { Frequency } \\
\text { per Site }\end{array}$ \\
\hline \multirow[t]{18}{*}{ HITRLR } & Site abundance: & 27 & & & \\
\hline & American Crow & & Corvus brachyrhynchos & 1 & 0.0370 \\
\hline & American Robin & & Turdus migratorius & 3 & 0.1111 \\
\hline & Blue-Gray Gnatcatcher & & Polioptila caerulea & 1 & 0.0370 \\
\hline & Carolina Wren & & Thryothorus ludovicianus & 1 & 0.0370 \\
\hline & Common Yellowthroat & & Geothlypis trichas & 1 & 0.0370 \\
\hline & Eastern Wood-Pewee & & Contopus virens & 1 & 0.0370 \\
\hline & Field Sparrow & & Spizella pusilla & 1 & 0.0370 \\
\hline & Gray Catbird & & Dumetella carolinensis & 1 & 0.0370 \\
\hline & House Wren & & Troglodytes aedon & 1 & 0.0370 \\
\hline & Indigo Bunting & & Passerina cyanea & 1 & 0.0370 \\
\hline & Northern Cardinal & & Cardinalis cardinalis & 1 & 0.0370 \\
\hline & Northern Mockingbird & & Mimus polyglottos & 1 & 0.0370 \\
\hline & Orchard Oriole & & Icterus spurius & 1 & 0.0370 \\
\hline & Red-Billed Woodpecker & & Melanerpes carolinus & 1 & 0.0370 \\
\hline & Red-Winged Blackbird & & Agelaius phoeniceus & 8 & 0.2963 \\
\hline & Tree Swallow & & Tachycineta bicolor & 2 & 0.0741 \\
\hline & Yellow Warbler & & Dendroica petechia & 1 & 0.0370 \\
\hline \multirow[t]{15}{*}{ MCFOUR } & Site abundance: & 21 & & & \\
\hline & American Crow & & Corvus brachyrhynchos & 1 & 0.0476 \\
\hline & American Goldfinch & & Carduelis tristis & 1 & 0.0476 \\
\hline & Blue-Winged Warbler & & Vermivora pinus & 3 & 0.1429 \\
\hline & Brown Thrasher & & Toxostoma rufum & 1 & 0.0476 \\
\hline & Carolina Chickadee & & Poecile carolinensis & 1 & 0.0476 \\
\hline & Common Grackle & & Quiscalus quiscula & 1 & 0.0476 \\
\hline & Common Yellowthroat & & Geothlypis trichas & 2 & 0.0952 \\
\hline & Eastern Towhee & & Pipilo erythrophthalmus & 3 & 0.1429 \\
\hline & Field Sparrow & & Spizella pusilla & 2 & 0.0952 \\
\hline & Gray Catbird & & Dumetella carolinensis & 1 & 0.0476 \\
\hline & Indigo Bunting & & Passerina cyanea & 2 & 0.0952 \\
\hline & Kentucky Warbler & & Oporornis formosus & 1 & 0.0476 \\
\hline & Scarlet Tanager & & Piranga olivacea & 1 & 0.0476 \\
\hline & Wood Thrush & & Hylocichla mustelina & 1 & 0.0476 \\
\hline
\end{tabular}


Appendix C. Continued.

\begin{tabular}{|c|c|c|c|c|c|}
\hline SiteCode & Species & & Latin name & Number observed & $\begin{array}{c}\text { Frequency } \\
\text { per Site }\end{array}$ \\
\hline \multirow[t]{15}{*}{ MCMEME } & Site abundance: & 47 & & & \\
\hline & American Crow & & Corvus brachyrhynchos & 1 & 0.0213 \\
\hline & American Robin & & Turdus migratorius & 1 & 0.0213 \\
\hline & Canada Goose & & Branta canadensis & 8 & 0.1702 \\
\hline & Common Grackle & & Quiscalus quiscula & 3 & 0.0638 \\
\hline & Common Yellowthroat & & Geothlypis trichas & 2 & 0.0426 \\
\hline & Eastern Kingbird & & Tyrannus tyrannus & 3 & 0.0638 \\
\hline & Great Blue Heron & & Ardea herodias & 3 & 0.0638 \\
\hline & Indigo Bunting & & Passerina cyanea & 2 & 0.0426 \\
\hline & Killdeer & & Charadrius vociferus & 1 & 0.0213 \\
\hline & Mallard & & Anas platyrhynchos & 1 & 0.0213 \\
\hline & Osprey & & Pandion haliaetus & 1 & 0.0213 \\
\hline & Red-Winged Blackbird & & Agelaius phoeniceus & 10 & 0.2128 \\
\hline & Song Sparrow & & Melospiza melodia & 3 & 0.0638 \\
\hline & Tree Swallow & & Tachycineta bicolor & 8 & 0.1702 \\
\hline \multirow[t]{21}{*}{ MCMFOR } & Site abundance: & 32 & & & \\
\hline & American Robin & & Turdus migratorius & 4 & 0.1250 \\
\hline & Blue Jay & & Cyanocitta cristata & 1 & 0.0313 \\
\hline & Brown-Headed Cowbird & & Molothrus ater & 1 & 0.0313 \\
\hline & Carolina Wren & & Thryothorus ludovicianus & 1 & 0.0313 \\
\hline & Cedar Waxwing & & Bombycilla cedrorum & 1 & 0.0313 \\
\hline & Common Grackle & & Quiscalus quiscula & 1 & 0.0313 \\
\hline & Eastern Bluebird & & Sialia sialis & 2 & 0.0625 \\
\hline & Eastern Kingbird & & Tyrannus tyrannus & 1 & 0.0313 \\
\hline & Eastern Towhee & & Pipilo erythrophthalmus & 1 & 0.0313 \\
\hline & Eastern Wood-Pewee & & Contopus virens & 2 & 0.0625 \\
\hline & Hairy Woodpecker & & Picoides villosus & 1 & 0.0313 \\
\hline & Mallard & & Anas platyrhynchos & 2 & 0.0625 \\
\hline & Prothonotary Warbler & & Protonotaria citrea & 1 & 0.0313 \\
\hline & Red-Winged Blackbird & & Agelaius phoeniceus & 3 & 0.0938 \\
\hline & Sedge Wren & & Cistothorus platensis & 2 & 0.0625 \\
\hline & Song Sparrow & & Melospiza melodia & 1 & 0.0313 \\
\hline & White-Eyed Vireo & & Vireo griseus & 1 & 0.0313 \\
\hline & Wood Duck & & Aix sponsa & 3 & 0.0938 \\
\hline & Wood Thrush & & Hylocichla mustelina & 1 & 0.0313 \\
\hline & Yellow Warbler & & Dendroica petechia & 2 & 0.0625 \\
\hline
\end{tabular}


Appendix C. Continued.

\begin{tabular}{|c|c|c|c|c|c|}
\hline SiteCode & Species & & Latin name & Number observed & $\begin{array}{c}\text { Frequency } \\
\text { per Site }\end{array}$ \\
\hline \multirow[t]{15}{*}{ MCNPFO } & Site abundance: & 14 & & & \\
\hline & American Robin & & Turdus migratorius & 1 & 0.0714 \\
\hline & Brown Thrasher & & Toxostoma rufum & 1 & 0.0714 \\
\hline & Carolina Chickadee & & Poecile carolinensis & 1 & 0.0714 \\
\hline & Common Yellowthroat & & Geothlypis trichas & 1 & 0.0714 \\
\hline & Eastern Towhee & & Pipilo erythrophthalmus & 1 & 0.0714 \\
\hline & Eastern Wood-Pewee & & Contopus virens & 1 & 0.0714 \\
\hline & Field Sparrow & & Spizella pusilla & 1 & 0.0714 \\
\hline & Indigo Bunting & & Passerina cyanea & 1 & 0.0714 \\
\hline & Kentucky Warbler & & Oporornis formosus & 1 & 0.0714 \\
\hline & Northern Cardinal & & Cardinalis cardinalis & 1 & 0.0714 \\
\hline & Ovenbird & & Seiurus aurocapillus & 1 & 0.0714 \\
\hline & Red-Eyed Vireo & & Vireo olivaceus & 1 & 0.0714 \\
\hline & Wood Thrush & & Hylocichla mustelina & 1 & 0.0714 \\
\hline & Yellow Warbler & & Dendroica petechia & 1 & 0.0714 \\
\hline \multirow[t]{16}{*}{ MCPOND } & Site abundance: & 15 & & & \\
\hline & American Crow & & Corvus brachyrhynchos & 1 & 0.0667 \\
\hline & American Goldfinch & & Carduelis tristis & 1 & 0.0667 \\
\hline & Carolina Chickadee & & Poecile carolinensis & 1 & 0.0667 \\
\hline & Common Yellowthroat & & Geothlypis trichas & 1 & 0.0667 \\
\hline & Eastern Towhee & & Pipilo erythrophthalmus & 1 & 0.0667 \\
\hline & Field Sparrow & & Spizella pusilla & 1 & 0.0667 \\
\hline & Gray Catbird & & Dumetella carolinensis & 1 & 0.0667 \\
\hline & Great Blue Heron & & Ardea herodias & 1 & 0.0667 \\
\hline & Mourning Dove & & Zenaida macroura & 1 & 0.0667 \\
\hline & Northern Cardinal & & Cardinalis cardinalis & 1 & 0.0667 \\
\hline & Northern Mockingbird & & Mimus polyglottos & 1 & 0.0667 \\
\hline & Northern Parula & & Parula americana & 1 & 0.0667 \\
\hline & Song Sparrow & & Melospiza melodia & 1 & 0.0667 \\
\hline & White-Eyed Vireo & & Vireo griseus & 1 & 0.0667 \\
\hline & Wood Thrush & & Hylocichla mustelina & 1 & 0.0667 \\
\hline
\end{tabular}


Appendix C. Continued.

\begin{tabular}{|c|c|c|c|c|c|}
\hline SiteCode & Species & & Latin name & Number observed & $\begin{array}{c}\text { Frequency } \\
\text { per Site }\end{array}$ \\
\hline \multirow[t]{16}{*}{ MCPOST } & Site abundance: & 23 & & & \\
\hline & American Redstart & & Setophaga ruticilla & 1 & 0.0435 \\
\hline & Blue-Gray Gnatcatcher & & Polioptila caerulea & 1 & 0.0435 \\
\hline & Carolina Chickadee & & Poecile carolinensis & 1 & 0.0435 \\
\hline & Common Grackle & & Quiscalus quiscula & 3 & 0.1304 \\
\hline & Common Yellowthroat & & Geothlypis trichas & 2 & 0.0870 \\
\hline & Eastern Kingbird & & Tyrannus tyrannus & 2 & 0.0870 \\
\hline & Eastern Towhee & & Pipilo erythrophthalmus & 1 & 0.0435 \\
\hline & Eastern Wood-Pewee & & Contopus virens & 1 & 0.0435 \\
\hline & European Starling & & Sturnus vulgaris & 3 & 0.1304 \\
\hline & Gray Catbird & & Dumetella carolinensis & 2 & 0.0870 \\
\hline & Indigo Bunting & & Passerina cyanea & 1 & 0.0435 \\
\hline & Mallard & & Anas platyrhynchos & 1 & 0.0435 \\
\hline & Red-Billed Woodpecker & & Melanerpes carolinus & 1 & 0.0435 \\
\hline & Red-Winged Blackbird & & Agelaius phoeniceus & 2 & 0.0870 \\
\hline & Song Sparrow & & Melospiza melodia & 1 & 0.0435 \\
\hline \multirow[t]{16}{*}{ MCTELE } & Site abundance: & 20 & & & \\
\hline & American Crow & & Corvus brachyrhynchos & 1 & 0.0500 \\
\hline & Blue Jay & & Cyanocitta cristata & 1 & 0.0500 \\
\hline & Brown Thrasher & & Toxostoma rufum & 1 & 0.0500 \\
\hline & Brown-Headed Cowbird & & Molothrus ater & 2 & 0.1000 \\
\hline & Carolina Chickadee & & Poecile carolinensis & 2 & 0.1000 \\
\hline & Carolina Wren & & Thryothorus ludovicianus & 1 & 0.0500 \\
\hline & Eastern Towhee & & Pipilo erythrophthalmus & 1 & 0.0500 \\
\hline & Eastern Wood-Pewee & & Contopus virens & 1 & 0.0500 \\
\hline & Gray Catbird & & Dumetella carolinensis & 1 & 0.0500 \\
\hline & Indigo Bunting & & Passerina cyanea & 1 & 0.0500 \\
\hline & Northern Cardinal & & Cardinalis cardinalis & 1 & 0.0500 \\
\hline & Red-Winged Blackbird & & Agelaius phoeniceus & 3 & 0.1500 \\
\hline & Song Sparrow & & Melospiza melodia & 2 & 0.1000 \\
\hline & White-Eyed Vireo & & Vireo griseus & 1 & 0.0500 \\
\hline & Yellow-Breasted Chat & & Icteria virens & 1 & 0.0500 \\
\hline
\end{tabular}


Appendix C. Continued.

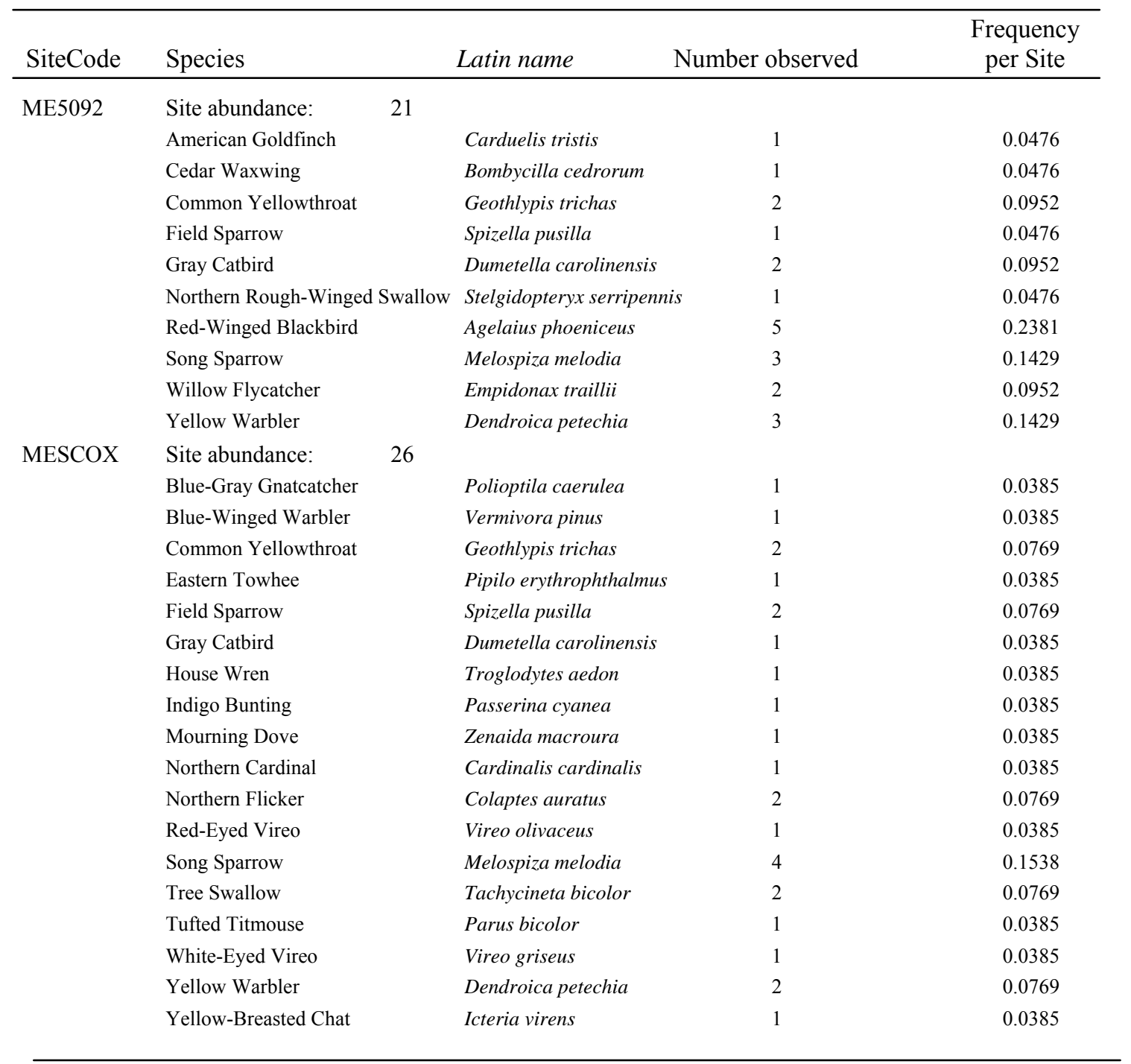


Appendix C. Continued.

\begin{tabular}{|c|c|c|c|c|c|}
\hline SiteCode & Species & & Latin name & Number observed & $\begin{array}{c}\text { Frequency } \\
\text { per Site }\end{array}$ \\
\hline \multirow[t]{15}{*}{ MESCRO } & Site abundance: & 31 & & & \\
\hline & American Goldfinch & & Carduelis tristis & 2 & 0.0645 \\
\hline & Common Yellowthroat & & Geothlypis trichas & 1 & 0.0323 \\
\hline & Field Sparrow & & Spizella pusilla & 1 & 0.0323 \\
\hline & Gray Catbird & & Dumetella carolinensis & 2 & 0.0645 \\
\hline & House Wren & & Troglodytes aedon & 2 & 0.0645 \\
\hline & Indigo Bunting & & Passerina cyanea & 2 & 0.0645 \\
\hline & Northern Parula & & Parula americana & 1 & 0.0323 \\
\hline & Orchard Oriole & & Icterus spurius & 1 & 0.0323 \\
\hline & Red-Winged Blackbird & & Agelaius phoeniceus & 10 & 0.3226 \\
\hline & Song Sparrow & & Melospiza melodia & 3 & 0.0968 \\
\hline & Tree Swallow & & Tachycineta bicolor & 2 & 0.0645 \\
\hline & Willow Flycatcher & & Empidonax traillii & 1 & 0.0323 \\
\hline & Wood Duck & & Aix sponsa & 1 & 0.0323 \\
\hline & Yellow Warbler & & Dendroica petechia & 2 & 0.0645 \\
\hline \multirow[t]{16}{*}{ MESCUP } & Site abundance: & 22 & & & \\
\hline & American Goldfinch & & Carduelis tristis & 1 & 0.0455 \\
\hline & Cedar Waxwing & & Bombycilla cedrorum & 2 & 0.0909 \\
\hline & Common Yellowthroat & & Geothlypis trichas & 1 & 0.0455 \\
\hline & Eastern Kingbird & & Tyrannus tyrannus & 1 & 0.0455 \\
\hline & Eastern Phoebe & & Sayornis phoebe & 1 & 0.0455 \\
\hline & Eastern Towhee & & Pipilo erythrophthalmus & 1 & 0.0455 \\
\hline & European Starling & & Sturnus vulgaris & 3 & 0.1364 \\
\hline & Field Sparrow & & Spizella pusilla & 2 & 0.0909 \\
\hline & Gray Catbird & & Dumetella carolinensis & 1 & 0.0455 \\
\hline & Indigo Bunting & & Passerina cyanea & 1 & 0.0455 \\
\hline & Red-Winged Blackbird & & Agelaius phoeniceus & 1 & 0.0455 \\
\hline & Song Sparrow & & Melospiza melodia & 3 & 0.1364 \\
\hline & Tree Swallow & & Tachycineta bicolor & 2 & 0.0909 \\
\hline & Wood Thrush & & Hylocichla mustelina & 1 & 0.0455 \\
\hline & Yellow Warbler & & Dendroica petechia & 1 & 0.0455 \\
\hline
\end{tabular}


Appendix C. Continued.

\begin{tabular}{|c|c|c|c|c|c|}
\hline SiteCode & Species & & Latin name & Number observed & $\begin{array}{c}\text { Frequency } \\
\text { per Site }\end{array}$ \\
\hline \multirow[t]{14}{*}{ MESIGN } & Site abundance: & 21 & & & \\
\hline & American Goldfinch & & Carduelis tristis & 1 & 0.0476 \\
\hline & American Robin & & Turdus migratorius & 1 & 0.0476 \\
\hline & Cedar Waxwing & & Bombycilla cedrorum & 2 & 0.0952 \\
\hline & Common Yellowthroat & & Geothlypis trichas & 1 & 0.0476 \\
\hline & Eastern Towhee & & Pipilo erythrophthalmus & 1 & 0.0476 \\
\hline & Gray Catbird & & Dumetella carolinensis & 3 & 0.1429 \\
\hline & House Wren & & Troglodytes aedon & 2 & 0.0952 \\
\hline & Indigo Bunting & & Passerina cyanea & 1 & 0.0476 \\
\hline & Northern Cardinal & & Cardinalis cardinalis & 1 & 0.0476 \\
\hline & Red-Winged Blackbird & & Agelaius phoeniceus & 2 & 0.0952 \\
\hline & Song Sparrow & & Melospiza melodia & 3 & 0.1429 \\
\hline & Tufted Titmouse & & Parus bicolor & 2 & 0.0952 \\
\hline & Yellow Warbler & & Dendroica petechia & 1 & 0.0476 \\
\hline \multirow[t]{16}{*}{ MESILV } & Site abundance: & 29 & & & \\
\hline & Acadian Flycatcher & & Empidonax virescens & 1 & 0.0345 \\
\hline & American Goldfinch & & Carduelis tristis & 1 & 0.0345 \\
\hline & Blue-Headed Vireo & & Vireo solitarius & 1 & 0.0345 \\
\hline & Blue-Winged Warbler & & Vermivora pinus & 1 & 0.0345 \\
\hline & Cedar Waxwing & & Bombycilla cedrorum & 1 & 0.0345 \\
\hline & Common Yellowthroat & & Geothlypis trichas & 3 & 0.1034 \\
\hline & Eastern Phoebe & & Sayornis phoebe & 1 & 0.0345 \\
\hline & Field Sparrow & & Spizella pusilla & 1 & 0.0345 \\
\hline & Indigo Bunting & & Passerina cyanea & 1 & 0.0345 \\
\hline & Northern Mockingbird & & Mimus polyglottos & 1 & 0.0345 \\
\hline & Red-Winged Blackbird & & Agelaius phoeniceus & 8 & 0.2759 \\
\hline & Song Sparrow & & Melospiza melodia & 3 & 0.1034 \\
\hline & Tufted Titmouse & & Parus bicolor & 1 & 0.0345 \\
\hline & Yellow Warbler & & Dendroica petechia & 3 & 0.1034 \\
\hline & Yellow-Breasted Chat & & Icteria virens & 2 & 0.0690 \\
\hline
\end{tabular}


Appendix C. Continued.

\begin{tabular}{|c|c|c|c|c|}
\hline SiteCode & Species & Latin name & Number observed & $\begin{array}{c}\text { Frequency } \\
\text { per Site }\end{array}$ \\
\hline \multirow[t]{9}{*}{ METETR } & Site abundance: & & & \\
\hline & Barn Swallow & Hirundo rustica & 2 & 0.0909 \\
\hline & Eastern Bluebird & Sialia sialis & 2 & 0.0909 \\
\hline & Green Heron & Butorides virescens & 2 & 0.0909 \\
\hline & Red-Winged Blackbird & Agelaius phoeniceus & 9 & 0.4091 \\
\hline & Ruby-Throated Hummingbirc & Archilochus colubris & 1 & 0.0455 \\
\hline & Song Sparrow & Melospiza melodia & 4 & 0.1818 \\
\hline & Tree Swallow & Tachycineta bicolor & 1 & 0.0455 \\
\hline & Yellow Warbler & Dendroica petechia & 1 & 0.0455 \\
\hline \multirow[t]{15}{*}{ MEWOLF } & Site abundance: & & & \\
\hline & Cedar Waxwing & Bombycilla cedrorum & 1 & 0.0400 \\
\hline & Common Yellowthroat & Geothlypis trichas & 6 & 0.2400 \\
\hline & Eastern Bluebird & Sialia sialis & 1 & 0.0400 \\
\hline & Eastern Towhee & Pipilo erythrophthalmus & 1 & 0.0400 \\
\hline & Gray Catbird & Dumetella carolinensis & 3 & 0.1200 \\
\hline & Indigo Bunting & Passerina cyanea & 1 & 0.0400 \\
\hline & Northern Cardinal & Cardinalis cardinalis & 1 & 0.0400 \\
\hline & Northern Waterthrush & Northern Waterthrush & 1 & 0.0400 \\
\hline & Orchard Oriole & Icterus spurius & 1 & 0.0400 \\
\hline & Red-Eyed Vireo & Vireo olivaceus & 1 & 0.0400 \\
\hline & Red-Winged Blackbird & Agelaius phoeniceus & 1 & 0.0400 \\
\hline & Song Sparrow & Melospiza melodia & 3 & 0.1200 \\
\hline & Wood Duck & Aix sponsa & 1 & 0.0400 \\
\hline & Yellow Warbler & Dendroica petechia & 3 & 0.1200 \\
\hline
\end{tabular}


Appendix C. Continued.

\begin{tabular}{|c|c|c|c|c|c|}
\hline SiteCode & Species & & Latin name & Number observed & $\begin{array}{c}\text { Frequency } \\
\text { per Site }\end{array}$ \\
\hline \multirow[t]{15}{*}{ MRBESS } & Site abundance: & 16 & & & \\
\hline & Blue-Gray Gnatcatcher & & Polioptila caerulea & 1 & 0.0625 \\
\hline & Blue-Headed Vireo & & Vireo solitarius & 1 & 0.0625 \\
\hline & Carolina Chickadee & & Poecile carolinensis & 1 & 0.0625 \\
\hline & Cedar Waxwing & & Bombycilla cedrorum & 1 & 0.0625 \\
\hline & Common Grackle & & Quiscalus quiscula & 1 & 0.0625 \\
\hline & Common Yellowthroat & & Geothlypis trichas & 1 & 0.0625 \\
\hline & Eastern Towhee & & Pipilo erythrophthalmus & 1 & 0.0625 \\
\hline & Eastern Wood-Pewee & & Contopus virens & 1 & 0.0625 \\
\hline & Hooded Warbler & & Wilsonia citrina & 1 & 0.0625 \\
\hline & Ovenbird & & Seiurus aurocapillus & 1 & 0.0625 \\
\hline & Red-Winged Blackbird & & Agelaius phoeniceus & 3 & 0.1875 \\
\hline & White-Breasted Nuthatch & & Sitta carolinensis & 1 & 0.0625 \\
\hline & Wood Thrush & & Hylocichla mustelina & 1 & 0.0625 \\
\hline & Yellow-Breasted Chat & & Icteria virens & 1 & 0.0625 \\
\hline \multirow[t]{15}{*}{ MRFARM } & Site abundance: & 19 & & & \\
\hline & American Goldfinch & & Carduelis tristis & 2 & 0.1053 \\
\hline & Carolina Chickadee & & Poecile carolinensis & 1 & 0.0526 \\
\hline & Cedar Waxwing & & Bombycilla cedrorum & 1 & 0.0526 \\
\hline & Chestnut-Sided Warbler & & Dendroica pensylvanica & 2 & 0.1053 \\
\hline & Common Yellowthroat & & Geothlypis trichas & 1 & 0.0526 \\
\hline & Eastern Towhee & & Pipilo erythrophthalmus & 2 & 0.1053 \\
\hline & Field Sparrow & & Spizella pusilla & 1 & 0.0526 \\
\hline & Grasshopper Sparrow & & Ammodramus savannarum & 1 & 0.0526 \\
\hline & Gray Catbird & & Dumetella carolinensis & 1 & 0.0526 \\
\hline & House Wren & & Troglodytes aedon & 1 & 0.0526 \\
\hline & Indigo Bunting & & Passerina cyanea & 3 & 0.1579 \\
\hline & Red-Eyed Vireo & & Vireo olivaceus & 1 & 0.0526 \\
\hline & Red-Winged Blackbird & & Agelaius phoeniceus & 1 & 0.0526 \\
\hline & Yellow Warbler & & Dendroica petechia & 1 & 0.0526 \\
\hline
\end{tabular}


Appendix C. Continued.

\begin{tabular}{|c|c|c|c|c|c|}
\hline SiteCode & Species & & Latin name & Number observed & $\begin{array}{c}\text { Frequency } \\
\text { per Site }\end{array}$ \\
\hline \multirow[t]{13}{*}{ MRFORE } & Site abundance: & 15 & & & \\
\hline & American Goldfinch & & Carduelis tristis & 1 & 0.0667 \\
\hline & Common Grackle & & Quiscalus quiscula & 1 & 0.0667 \\
\hline & Common Yellowthroat & & Geothlypis trichas & 2 & 0.1333 \\
\hline & Eastern Towhee & & Pipilo erythrophthalmus & 2 & 0.1333 \\
\hline & Eastern Wood-Pewee & & Contopus virens & 1 & 0.0667 \\
\hline & Field Sparrow & & Spizella pusilla & 1 & 0.0667 \\
\hline & Indigo Bunting & & Passerina cyanea & 1 & 0.0667 \\
\hline & Ovenbird & & Seiurus aurocapillus & 2 & 0.1333 \\
\hline & Red-Eyed Vireo & & Vireo olivaceus & 1 & 0.0667 \\
\hline & White-Eyed Vireo & & Vireo griseus & 1 & 0.0667 \\
\hline & Wood Thrush & & Hylocichla mustelina & 1 & 0.0667 \\
\hline & Yellow Warbler & & Dendroica petechia & 1 & 0.0667 \\
\hline \multirow[t]{14}{*}{ MRSSSS } & Site abundance: & 18 & & & \\
\hline & Blue Jay & & Cyanocitta cristata & 1 & 0.0556 \\
\hline & Blue-Gray Gnatcatcher & & Polioptila caerulea & 1 & 0.0556 \\
\hline & Blue-Headed Vireo & & Vireo solitarius & 1 & 0.0556 \\
\hline & Carolina Chickadee & & Poecile carolinensis & 2 & 0.1111 \\
\hline & Common Yellowthroat & & Geothlypis trichas & 1 & 0.0556 \\
\hline & Eastern Towhee & & Pipilo erythrophthalmus & 2 & 0.1111 \\
\hline & Gray Catbird & & Dumetella carolinensis & 2 & 0.1111 \\
\hline & Red-Eyed Vireo & & Vireo olivaceus & 1 & 0.0556 \\
\hline & Red-Winged Blackbird & & Agelaius phoeniceus & 1 & 0.0556 \\
\hline & Scarlet Tanager & & Piranga olivacea & 1 & 0.0556 \\
\hline & White-Breasted Nuthatch & & Sitta carolinensis & 1 & 0.0556 \\
\hline & Wood Thrush & & Hylocichla mustelina & 3 & 0.1667 \\
\hline & Yellow Warbler & & Dendroica petechia & 1 & 0.0556 \\
\hline
\end{tabular}


Appendix C. Continued.

\begin{tabular}{|c|c|c|c|c|c|}
\hline SiteCode & Species & & Latin name & Jumber observed & $\begin{array}{c}\text { Frequency } \\
\text { per Site }\end{array}$ \\
\hline \multirow[t]{15}{*}{ MRWEST } & Site abundance: & 17 & & & \\
\hline & American Goldfinch & & Carduelis tristis & 1 & 0.0588 \\
\hline & Blue-Headed Vireo & & Vireo solitarius & 1 & 0.0588 \\
\hline & Carolina Chickadee & & Poecile carolinensis & 2 & 0.1176 \\
\hline & Cedar Waxwing & & Bombycilla cedrorum & 1 & 0.0588 \\
\hline & Eastern Towhee & & Pipilo erythrophthalmus & 1 & 0.0588 \\
\hline & Field Sparrow & & Spizella pusilla & 2 & 0.1176 \\
\hline & Golden-Winged Warbler & & Vermivora chrysoptera & 2 & 0.1176 \\
\hline & Indigo Bunting & & Passerina cyanea & 1 & 0.0588 \\
\hline & Northern Cardinal & & Cardinalis cardinalis & 1 & 0.0588 \\
\hline & Northern Flicker & & Colaptes auratus & 1 & 0.0588 \\
\hline & Ovenbird & & Seiurus aurocapillus & 1 & 0.0588 \\
\hline & Red-Eyed Vireo & & Vireo olivaceus & 1 & 0.0588 \\
\hline & Savannah Sparrow & & Passerculus sandwichensis & 1 & 0.0588 \\
\hline & Wood Thrush & & Hylocichla mustelina & 1 & 0.0588 \\
\hline \multirow[t]{14}{*}{ MU55SS } & Site abundance: & 18 & & & \\
\hline & Carolina Wren & & Thryothorus ludovicianus & 1 & 0.0556 \\
\hline & Cedar Waxwing & & Bombycilla cedrorum & 1 & 0.0556 \\
\hline & Common Yellowthroat & & Geothlypis trichas & 2 & 0.1111 \\
\hline & Eastern Towhee & & Pipilo erythrophthalmus & 1 & 0.0556 \\
\hline & Field Sparrow & & Spizella pusilla & 1 & 0.0556 \\
\hline & Gray Catbird & & Dumetella carolinensis & 2 & 0.1111 \\
\hline & House Wren & & Troglodytes aedon & 2 & 0.1111 \\
\hline & Indigo Bunting & & Passerina cyanea & 2 & 0.1111 \\
\hline & Northern Mockingbird & & Mimus polyglottos & 1 & 0.0556 \\
\hline & Northern Waterthrush & & Northern Waterthrush & 1 & 0.0556 \\
\hline & Red-Winged Blackbird & & Agelaius phoeniceus & 2 & 0.1111 \\
\hline & Song Sparrow & & Melospiza melodia & 1 & 0.0556 \\
\hline & Yellow Warbler & & Dendroica petechia & 1 & 0.0556 \\
\hline
\end{tabular}


Appendix C. Continued.

\begin{tabular}{|c|c|c|c|c|c|}
\hline SiteCode & Species & & Latin name & Number observed & $\begin{array}{c}\text { Frequency } \\
\text { per Site }\end{array}$ \\
\hline \multirow[t]{13}{*}{ MUDBOA } & Site abundance: & 14 & & & \\
\hline & Acadian Flycatcher & & Empidonax virescens & 1 & 0.0714 \\
\hline & American Redstart & & Setophaga ruticilla & 2 & 0.1429 \\
\hline & Barred Owl & & Strix varia & 1 & 0.0714 \\
\hline & Blue-Gray Gnatcatcher & & Polioptila caerulea & 1 & 0.0714 \\
\hline & Blue-Headed Vireo & & Vireo solitarius & 1 & 0.0714 \\
\hline & Cerulean Warbler & & Dendroica cerulea & 1 & 0.0714 \\
\hline & Dark-Eyed Junco & & Junco hyemalis & 2 & 0.1429 \\
\hline & Northern Parula & & Parula americana & 1 & 0.0714 \\
\hline & Northern Waterthrush & & Northern Waterthrush & 1 & 0.0714 \\
\hline & Ovenbird & & Seiurus aurocapillus & 1 & 0.0714 \\
\hline & Red-Eyed Vireo & & Vireo olivaceus & 1 & 0.0714 \\
\hline & Red-Winged Blackbird & & Agelaius phoeniceus & 1 & 0.0714 \\
\hline
\end{tabular}


Appendix C. Continued.

\begin{tabular}{|c|c|c|c|c|c|}
\hline SiteCode & Species & & Latin name & Number observed & $\begin{array}{c}\text { Frequency } \\
\text { per Site }\end{array}$ \\
\hline \multirow[t]{29}{*}{ MUDEND } & Site abundance: & 44 & & & \\
\hline & Acadian Flycatcher & & Empidonax virescens & 1 & 0.0227 \\
\hline & Black-and-White Warbler & & Mniotilta varia & 1 & 0.0227 \\
\hline & Black-capped Chickadee & & Poecile atricapilla & 2 & 0.0455 \\
\hline & Blue-Gray Gnatcatcher & & Polioptila caerulea & 2 & 0.0455 \\
\hline & Blue-Headed Vireo & & Vireo solitarius & 1 & 0.0227 \\
\hline & Brown-Headed Cowbird & & Molothrus ater & 1 & 0.0227 \\
\hline & Carolina Wren & & Thryothorus ludovicianus & 1 & 0.0227 \\
\hline & Cerulean Warbler & & Dendroica cerulea & 1 & 0.0227 \\
\hline & Dark-Eyed Junco & & Junco hyemalis & 2 & 0.0455 \\
\hline & Eastern Bluebird & & Sialia sialis & 1 & 0.0227 \\
\hline & Eastern Phoebe & & Sayornis phoebe & 2 & 0.0455 \\
\hline & European Starling & & Sturnus vulgaris & 1 & 0.0227 \\
\hline & Indigo Bunting & & Passerina cyanea & 1 & 0.0227 \\
\hline & Mourning Dove & & Zenaida macroura & 1 & 0.0227 \\
\hline & Northern Cardinal & & Cardinalis cardinalis & 1 & 0.0227 \\
\hline & Northern Flicker & & Colaptes auratus & 2 & 0.0455 \\
\hline & Northern Mockingbird & & Mimus polyglottos & 1 & 0.0227 \\
\hline & Northern Parula & & Parula americana & 2 & 0.0455 \\
\hline & Orchard Oriole & & Icterus spurius & 1 & 0.0227 \\
\hline & Pileated Woodpecker & & Dryocopus pileatus & 1 & 0.0227 \\
\hline & Red-Billed Woodpecker & & Melanerpes carolinus & 1 & 0.0227 \\
\hline & Red-Winged Blackbird & & Agelaius phoeniceus & 2 & 0.0455 \\
\hline & Song Sparrow & & Melospiza melodia & 2 & 0.0455 \\
\hline & Tree Swallow & & Tachycineta bicolor & 4 & 0.0909 \\
\hline & White-Breasted Nuthatch & & Sitta carolinensis & 1 & 0.0227 \\
\hline & Wood Duck & & Aix sponsa & 5 & 0.1136 \\
\hline & Yellow Warbler & & Dendroica petechia & 2 & 0.0455 \\
\hline & Yellow-Breasted Chat & & Icteria virens & 1 & 0.0227 \\
\hline
\end{tabular}


Appendix C. Continued.

\begin{tabular}{|c|c|c|c|c|c|}
\hline SiteCode & Species & & Latin name & Number observed & $\begin{array}{c}\text { Frequency } \\
\text { per Site }\end{array}$ \\
\hline \multirow[t]{18}{*}{ MUDRIC } & Site abundance: & 18 & & & \\
\hline & Acadian Flycatcher & & Empidonax virescens & 1 & 0.0556 \\
\hline & American Redstart & & Setophaga ruticilla & 2 & 0.1111 \\
\hline & American Robin & & Turdus migratorius & 1 & 0.0556 \\
\hline & Black-and-White Warbler & & Mniotilta varia & 1 & 0.0556 \\
\hline & Blue-Gray Gnatcatcher & & Polioptila caerulea & 1 & 0.0556 \\
\hline & Eastern Phoebe & & Sayornis phoebe & 1 & 0.0556 \\
\hline & Eastern Towhee & & Pipilo erythrophthalmus & 1 & 0.0556 \\
\hline & Green Heron & & Butorides virescens & 1 & 0.0556 \\
\hline & Hermit Thrush & & Catharus guttatus & 1 & 0.0556 \\
\hline & House Wren & & Troglodytes aedon & 1 & 0.0556 \\
\hline & Ovenbird & & Seiurus aurocapillus & 1 & 0.0556 \\
\hline & Red-Eyed Vireo & & Vireo olivaceus & 1 & 0.0556 \\
\hline & Red-Winged Blackbird & & Agelaius phoeniceus & 1 & 0.0556 \\
\hline & Scarlet Tanager & & Piranga olivacea & 1 & 0.0556 \\
\hline & White-Breasted Nuthatch & & Sitta carolinensis & 1 & 0.0556 \\
\hline & White-Eyed Vireo & & Vireo griseus & 1 & 0.0556 \\
\hline & Wood Thrush & & Hylocichla mustelina & 1 & 0.0556 \\
\hline
\end{tabular}


Appendix C. Continued.

\begin{tabular}{|c|c|c|c|c|c|}
\hline SiteCode & Species & & Latin name & Number observed & $\begin{array}{c}\text { Frequency } \\
\text { per Site }\end{array}$ \\
\hline \multirow[t]{28}{*}{ MUDRIP } & Site abundance: & 39 & & & \\
\hline & Acadian Flycatcher & & Empidonax virescens & 1 & 0.0256 \\
\hline & American Goldfinch & & Carduelis tristis & 3 & 0.0769 \\
\hline & Belted Kingfisher & & Ceryle alcyon & 1 & 0.0256 \\
\hline & Black-and-White Warbler & & Mniotilta varia & 1 & 0.0256 \\
\hline & Blue-Gray Gnatcatcher & & Polioptila caerulea & 1 & 0.0256 \\
\hline & Carolina Chickadee & & Poecile carolinensis & 1 & 0.0256 \\
\hline & Cedar Waxwing & & Bombycilla cedrorum & 1 & 0.0256 \\
\hline & Cerulean Warbler & & Dendroica cerulea & 1 & 0.0256 \\
\hline & Chestnut-Sided Warbler & & Dendroica pensylvanica & 1 & 0.0256 \\
\hline & Chipping Sparrow & & Spizella passerina & 1 & 0.0256 \\
\hline & Common Yellowthroat & & Geothlypis trichas & 2 & 0.0513 \\
\hline & Eastern Phoebe & & Sayornis phoebe & 3 & 0.0769 \\
\hline & Eastern Towhee & & Pipilo erythrophthalmus & 1 & 0.0256 \\
\hline & Eastern Wood-Pewee & & Contopus virens & 1 & 0.0256 \\
\hline & European Starling & & Sturnus vulgaris & 1 & 0.0256 \\
\hline & Gray Catbird & & Dumetella carolinensis & 1 & 0.0256 \\
\hline & Green Heron & & Butorides virescens & 1 & 0.0256 \\
\hline & Indigo Bunting & & Passerina cyanea & 1 & 0.0256 \\
\hline & Mourning Dove & & Zenaida macroura & 1 & 0.0256 \\
\hline & Northern Flicker & & Colaptes auratus & 1 & 0.0256 \\
\hline & Northern Parula & & Parula americana & 2 & 0.0513 \\
\hline & Pileated Woodpecker & & Dryocopus pileatus & 1 & 0.0256 \\
\hline & Red-Winged Blackbird & & Agelaius phoeniceus & 5 & 0.1282 \\
\hline & Song Sparrow & & Melospiza melodia & 2 & 0.0513 \\
\hline & Wood Duck & & Aix sponsa & 1 & 0.0256 \\
\hline & Yellow Warbler & & Dendroica petechia & 2 & 0.0513 \\
\hline & Yellow-Breasted Chat & & Icteria virens & 1 & 0.0256 \\
\hline
\end{tabular}


Appendix C. Continued.

\begin{tabular}{|c|c|c|c|c|c|}
\hline SiteCode & Species & & Latin name & Number observed & $\begin{array}{c}\text { Frequency } \\
\text { per Site }\end{array}$ \\
\hline \multirow[t]{22}{*}{ MUDTRA } & Site abundance: & 31 & & & \\
\hline & American Goldfinch & & Carduelis tristis & 1 & 0.0323 \\
\hline & Black-and-White Warbler & & Mniotilta varia & 1 & 0.0323 \\
\hline & Blue-Gray Gnatcatcher & & Polioptila caerulea & 1 & 0.0323 \\
\hline & Carolina Chickadee & & Poecile carolinensis & 2 & 0.0645 \\
\hline & Common Yellowthroat & & Geothlypis trichas & 3 & 0.0968 \\
\hline & Downy Woodpecker & & Picoides pubescens & 2 & 0.0645 \\
\hline & Eastern Phoebe & & Sayornis phoebe & 1 & 0.0323 \\
\hline & Eastern Towhee & & Pipilo erythrophthalmus & 1 & 0.0323 \\
\hline & Gray Catbird & & Dumetella carolinensis & 2 & 0.0645 \\
\hline & Green Heron & & Butorides virescens & 2 & 0.0645 \\
\hline & Indigo Bunting & & Passerina cyanea & 3 & 0.0968 \\
\hline & Northern Cardinal & & Cardinalis cardinalis & 1 & 0.0323 \\
\hline & Northern Cardinal & & Cardinalis cardinalis & 1 & 0.0323 \\
\hline & Northern Flicker & & Colaptes auratus & 1 & 0.0323 \\
\hline & Orchard Oriole & & Icterus spurius & 1 & 0.0323 \\
\hline & Red-Winged Blackbird & & Agelaius phoeniceus & 2 & 0.0645 \\
\hline & Song Sparrow & & Melospiza melodia & 2 & 0.0645 \\
\hline & Tufted Titmouse & & Parus bicolor & 1 & 0.0323 \\
\hline & White-Eyed Vireo & & Vireo griseus & 1 & 0.0323 \\
\hline & Yellow Warbler & & Dendroica petechia & 1 & 0.0323 \\
\hline & Yellow-Breasted Chat & & Icteria virens & 1 & 0.0323 \\
\hline
\end{tabular}


Appendix C. Continued.

\begin{tabular}{|c|c|c|c|c|}
\hline SiteCode & Species & Latin name & Jumber observed & $\begin{array}{c}\text { Frequency } \\
\text { per Site }\end{array}$ \\
\hline \multirow[t]{17}{*}{ MUEPAH } & Site abundance: & & & \\
\hline & American Goldfinch & Carduelis tristis & 1 & 0.0455 \\
\hline & American Goldfinch & Carduelis tristis & 1 & 0.0455 \\
\hline & American Robin & Turdus migratorius & 1 & 0.0455 \\
\hline & Common Yellowthroat & Geothlypis trichas & 2 & 0.0909 \\
\hline & Eastern Phoebe & Sayornis phoebe & 1 & 0.0455 \\
\hline & Eastern Towhee & Pipilo erythrophthalmus & 1 & 0.0455 \\
\hline & Field Sparrow & Spizella pusilla & 1 & 0.0455 \\
\hline & Green Heron & Butorides virescens & 1 & 0.0455 \\
\hline & Indigo Bunting & Passerina cyanea & 2 & 0.0909 \\
\hline & Mourning Dove & Zenaida macroura & 1 & 0.0455 \\
\hline & Northern Flicker & Colaptes auratus & 1 & 0.0455 \\
\hline & Northern Rough-Winged Swallow & Stelgidopteryx serripennis & 2 & 0.0909 \\
\hline & Red-Winged Blackbird & Agelaius phoeniceus & 3 & 0.1364 \\
\hline & Savannah Sparrow & Passerculus sandwichensis & 1 & 0.0455 \\
\hline & Song Sparrow & Melospiza melodia & 2 & 0.0909 \\
\hline & Yellow Warbler & Dendroica petechia & 1 & 0.0455 \\
\hline \multirow[t]{17}{*}{ MUMINE } & Site abundance: & & & \\
\hline & American Goldfinch & Carduelis tristis & 1 & 0.0500 \\
\hline & Blue Jay & Cyanocitta cristata & 1 & 0.0500 \\
\hline & Blue-Gray Gnatcatcher & Polioptila caerulea & 1 & 0.0500 \\
\hline & Blue-Headed Vireo & Vireo solitarius & 1 & 0.0500 \\
\hline & Blue-Winged Warbler & Vermivora pinus & 2 & 0.1000 \\
\hline & Carolina Chickadee & Poecile carolinensis & 2 & 0.1000 \\
\hline & Common Yellowthroat & Geothlypis trichas & 1 & 0.0500 \\
\hline & Eastern Towhee & Pipilo erythrophthalmus & 1 & 0.0500 \\
\hline & Gray Catbird & Dumetella carolinensis & 2 & 0.1000 \\
\hline & Northern Flicker & Colaptes auratus & 1 & 0.0500 \\
\hline & Northern Flicker & Colaptes auratus & 1 & 0.0500 \\
\hline & Ovenbird & Seiurus aurocapillus & 1 & 0.0500 \\
\hline & Pileated Woodpecker & Dryocopus pileatus & 1 & 0.0500 \\
\hline & Song Sparrow & Melospiza melodia & 2 & 0.1000 \\
\hline & Tufted Titmouse & Parus bicolor & 1 & 0.0500 \\
\hline & White-Eyed Vireo & Vireo griseus & 1 & 0.0500 \\
\hline
\end{tabular}


Appendix C. Continued.

\begin{tabular}{|c|c|c|c|c|c|}
\hline SiteCode & Species & & Latin name & Number observed & $\begin{array}{c}\text { Frequency } \\
\text { per Site }\end{array}$ \\
\hline \multirow[t]{16}{*}{ MUPOWR } & Site abundance: & 23 & & & \\
\hline & Alder Flycatcher & & Empidonax alnorum & 1 & 0.0435 \\
\hline & American Redstart & & Setophaga ruticilla & 1 & 0.0435 \\
\hline & Carolina Chickadee & & Poecile carolinensis & 2 & 0.0870 \\
\hline & Cedar Waxwing & & Bombycilla cedrorum & 3 & 0.1304 \\
\hline & Common Grackle & & Quiscalus quiscula & 3 & 0.1304 \\
\hline & Common Yellowthroat & & Geothlypis trichas & 1 & 0.0435 \\
\hline & Eastern Towhee & & Pipilo erythrophthalmus & 1 & 0.0435 \\
\hline & Gray Catbird & & Dumetella carolinensis & 1 & 0.0435 \\
\hline & Northern Flicker & & Colaptes auratus & 1 & 0.0435 \\
\hline & Northern Parula & & Parula americana & 1 & 0.0435 \\
\hline & Ovenbird & & Seiurus aurocapillus & 1 & 0.0435 \\
\hline & Red-Eyed Vireo & & Vireo olivaceus & 1 & 0.0435 \\
\hline & Red-Winged Blackbird & & Agelaius phoeniceus & 2 & 0.0870 \\
\hline & Song Sparrow & & Melospiza melodia & 3 & 0.1304 \\
\hline & Tufted Titmouse & & Parus bicolor & 1 & 0.0435 \\
\hline \multirow[t]{20}{*}{ MUPULL } & Site abundance: & 31 & & & \\
\hline & Alder Flycatcher & & Empidonax alnorum & 1 & 0.0323 \\
\hline & American Goldfinch & & Carduelis tristis & 2 & 0.0645 \\
\hline & American Redstart & & Setophaga ruticilla & 1 & 0.0323 \\
\hline & Cedar Waxwing & & Bombycilla cedrorum & 1 & 0.0323 \\
\hline & Common Yellowthroat & & Geothlypis trichas & 2 & 0.0645 \\
\hline & European Starling & & Sturnus vulgaris & 1 & 0.0323 \\
\hline & Gray Catbird & & Dumetella carolinensis & 2 & 0.0645 \\
\hline & Hairy Woodpecker & & Picoides villosus & 1 & 0.0323 \\
\hline & Northern Cardinal & & Cardinalis cardinalis & 1 & 0.0323 \\
\hline & Northern Waterthrush & & Northern Waterthrush & 1 & 0.0323 \\
\hline & Red-Eyed Vireo & & Vireo olivaceus & 2 & 0.0645 \\
\hline & Red-Winged Blackbird & & Agelaius phoeniceus & 3 & 0.0968 \\
\hline & Sedge Wren & & Cistothorus platensis & 1 & 0.0323 \\
\hline & Song Sparrow & & Melospiza melodia & 5 & 0.1613 \\
\hline & Tree Swallow & & Tachycineta bicolor & 1 & 0.0323 \\
\hline & Tufted Titmouse & & Parus bicolor & 1 & 0.0323 \\
\hline & White-Eyed Vireo & & Vireo griseus & 1 & 0.0323 \\
\hline & Willow Flycatcher & & Empidonax traillii & 1 & 0.0323 \\
\hline & Yellow Warbler & & Dendroica petechia & 3 & 0.0968 \\
\hline
\end{tabular}


Appendix C. Continued.

\begin{tabular}{|c|c|c|c|c|c|}
\hline SiteCode & Species & & Latin name & Number observed & $\begin{array}{c}\text { Frequency } \\
\text { per Site }\end{array}$ \\
\hline \multirow[t]{20}{*}{ MUVBRD } & Site abundance: & 32 & & & \\
\hline & American Redstart & & Setophaga ruticilla & 1 & 0.0313 \\
\hline & Blue-Gray Gnatcatcher & & Polioptila caerulea & 1 & 0.0313 \\
\hline & Cedar Waxwing & & Bombycilla cedrorum & 1 & 0.0313 \\
\hline & Common Grackle & & Quiscalus quiscula & 1 & 0.0313 \\
\hline & Common Yellowthroat & & Geothlypis trichas & 2 & 0.0625 \\
\hline & Eastern Bluebird & & Sialia sialis & 1 & 0.0313 \\
\hline & House Wren & & Troglodytes aedon & 1 & 0.0313 \\
\hline & Indigo Bunting & & Passerina cyanea & 1 & 0.0313 \\
\hline & Northern Cardinal & & Cardinalis cardinalis & 1 & 0.0313 \\
\hline & Northern Mockingbird & & Mimus polyglottos & 1 & 0.0313 \\
\hline & Red-Billed Woodpecker & & Melanerpes carolinus & 1 & 0.0313 \\
\hline & Red-Winged Blackbird & & Agelaius phoeniceus & 7 & 0.2188 \\
\hline & Sedge Wren & & Cistothorus platensis & 1 & 0.0313 \\
\hline & Sedge Wren & & Cistothorus platensis & 1 & 0.0313 \\
\hline & Song Sparrow & & Melospiza melodia & 3 & 0.0938 \\
\hline & Tree Swallow & & Tachycineta bicolor & 5 & 0.1563 \\
\hline & Tufted Titmouse & & Parus bicolor & 1 & 0.0313 \\
\hline & Willow Flycatcher & & Empidonax traillii & 1 & 0.0313 \\
\hline & Yellow Warbler & & Dendroica petechia & 1 & 0.0313 \\
\hline \multirow[t]{14}{*}{ MUVCRN } & Site abundance: & 31 & & & \\
\hline & American Goldfinch & & Carduelis tristis & 1 & 0.0323 \\
\hline & American Robin & & Turdus migratorius & 1 & 0.0323 \\
\hline & Cedar Waxwing & & Bombycilla cedrorum & 1 & 0.0323 \\
\hline & Common Yellowthroat & & Geothlypis trichas & 1 & 0.0323 \\
\hline & Field Sparrow & & Spizella pusilla & 2 & 0.0645 \\
\hline & Gray Catbird & & Dumetella carolinensis & 1 & 0.0323 \\
\hline & Mallard & & Anas platyrhynchos & 5 & 0.1613 \\
\hline & Red-Winged Blackbird & & Agelaius phoeniceus & 8 & 0.2581 \\
\hline & Song Sparrow & & Melospiza melodia & 3 & 0.0968 \\
\hline & Tree Swallow & & Tachycineta bicolor & 2 & 0.0645 \\
\hline & Tufted Titmouse & & Parus bicolor & 1 & 0.0323 \\
\hline & Willow Flycatcher & & Empidonax traillii & 2 & 0.0645 \\
\hline & Yellow Warbler & & Dendroica petechia & 3 & 0.0968 \\
\hline
\end{tabular}


Appendix C. Continued.

\begin{tabular}{|c|c|c|c|c|}
\hline SiteCode & Species & Latin name & Number observed & $\begin{array}{c}\text { Frequency } \\
\text { per Site }\end{array}$ \\
\hline \multirow[t]{13}{*}{ OHHSFO } & Site abundance: & & & \\
\hline & American Robin & Turdus migratorius & 1 & 0.0625 \\
\hline & Carolina Chickadee & Poecile carolinensis & 2 & 0.1250 \\
\hline & Carolina Wren & Thryothorus ludovicianus & 2 & 0.1250 \\
\hline & Common Yellowthroat & Geothlypis trichas & 1 & 0.0625 \\
\hline & Eastern Towhee & Pipilo erythrophthalmus & 2 & 0.1250 \\
\hline & Gray Catbird & Dumetella carolinensis & 2 & 0.1250 \\
\hline & Hooded Warbler & Wilsonia citrina & 1 & 0.0625 \\
\hline & Northern Cardinal & Cardinalis cardinalis & 1 & 0.0625 \\
\hline & Northern Parula & Parula americana & 1 & 0.0625 \\
\hline & Red-Billed Woodpecker & Melanerpes carolinus & 1 & 0.0625 \\
\hline & White-Breasted Nuthatch & Sitta carolinensis & 1 & 0.0625 \\
\hline & Wood Thrush & Hylocichla mustelina & 1 & 0.0625 \\
\hline \multirow[t]{19}{*}{ OHINNS } & Site abundance: & & & \\
\hline & American Robin & Turdus migratorius & 1 & 0.0345 \\
\hline & Black-and-White Warbler & Mniotilta varia & 1 & 0.0345 \\
\hline & Blue-Gray Gnatcatcher & Polioptila caerulea & 1 & 0.0345 \\
\hline & Blue-Headed Vireo & Vireo solitarius & 1 & 0.0345 \\
\hline & Carolina Chickadee & Poecile carolinensis & 3 & 0.1034 \\
\hline & Common Yellowthroat & Geothlypis trichas & 2 & 0.0690 \\
\hline & Eastern Bluebird & Sialia sialis & 2 & 0.0690 \\
\hline & Eastern Kingbird & Tyrannus tyrannus & 1 & 0.0345 \\
\hline & Eastern Towhee & Pipilo erythrophthalmus & 1 & 0.0345 \\
\hline & Great Crested Flycatcher & Myiarchus crinitus & 1 & 0.0345 \\
\hline & Indigo Bunting & Passerina cyanea & 1 & 0.0345 \\
\hline & Northern Cardinal & Cardinalis cardinalis & 1 & 0.0345 \\
\hline & Northern Rough-Winged Swallow & Stelgidopteryx serripennis & 2 & 0.0690 \\
\hline & Northern Waterthrush & Northern Waterthrush & 1 & 0.0345 \\
\hline & Red-Winged Blackbird & Agelaius phoeniceus & 5 & 0.1724 \\
\hline & Ruby-Throated Hummingbird & Archilochus colubris & 1 & 0.0345 \\
\hline & Song Sparrow & Melospiza melodia & 3 & 0.1034 \\
\hline & Tufted Titmouse & Parus bicolor & 1 & 0.0345 \\
\hline
\end{tabular}


Appendix C. Continued.

\begin{tabular}{|c|c|c|c|c|c|}
\hline SiteCode & Species & & Latin name & Number observed & $\begin{array}{c}\text { Frequency } \\
\text { per Site }\end{array}$ \\
\hline \multirow[t]{12}{*}{ OHKMRT } & Site abundance: & 25 & & & \\
\hline & Acadian Flycatcher & & Empidonax virescens & 1 & 0.0400 \\
\hline & American Goldfinch & & Carduelis tristis & 4 & 0.1600 \\
\hline & American Robin & & Turdus migratorius & 1 & 0.0400 \\
\hline & Blue-Headed Vireo & & Vireo solitarius & 1 & 0.0400 \\
\hline & Gray Catbird & & Dumetella carolinensis & 1 & 0.0400 \\
\hline & Northern Mockingbird & & Mimus polyglottos & 1 & 0.0400 \\
\hline & Red-Winged Blackbird & & Agelaius phoeniceus & 6 & 0.2400 \\
\hline & Red-Winged Blackbird & & Agelaius phoeniceus & 6 & 0.2400 \\
\hline & Tree Swallow & & Tachycineta bicolor & 1 & 0.0400 \\
\hline & Willow Flycatcher & & Empidonax traillii & 1 & 0.0400 \\
\hline & Yellow Warbler & & Dendroica petechia & 2 & 0.0800 \\
\hline \multirow[t]{23}{*}{ PA29TH } & Site abundance: & 64 & & & \\
\hline & American Goldfinch & & Carduelis tristis & 2 & 0.0313 \\
\hline & American Robin & & Turdus migratorius & 2 & 0.0313 \\
\hline & Blue-Gray Gnatcatcher & & Polioptila caerulea & 3 & 0.0469 \\
\hline & Carolina Wren & & Thryothorus ludovicianus & 2 & 0.0313 \\
\hline & Cedar Waxwing & & Bombycilla cedrorum & 19 & 0.2969 \\
\hline & Common Grackle & & Quiscalus quiscula & 1 & 0.0156 \\
\hline & Common Yellowthroat & & Geothlypis trichas & 2 & 0.0313 \\
\hline & European Starling & & Sturnus vulgaris & 1 & 0.0156 \\
\hline & Gray Catbird & & Dumetella carolinensis & 1 & 0.0156 \\
\hline & Great Blue Heron & & Ardea herodias & 1 & 0.0156 \\
\hline & Green Heron & & Butorides virescens & 1 & 0.0156 \\
\hline & House Wren & & Troglodytes aedon & 2 & 0.0313 \\
\hline & Mourning Dove & & Zenaida macroura & 1 & 0.0156 \\
\hline & Northern Cardinal & & Cardinalis cardinalis & 3 & 0.0469 \\
\hline & Northern Flicker & & Colaptes auratus & 2 & 0.0313 \\
\hline & Red-Billed Woodpecker & & Melanerpes carolinus & 1 & 0.0156 \\
\hline & Red-Winged Blackbird & & Agelaius phoeniceus & 6 & 0.0938 \\
\hline & Song Sparrow & & Melospiza melodia & 5 & 0.0781 \\
\hline & Tree Swallow & & Tachycineta bicolor & 2 & 0.0313 \\
\hline & Tufted Titmouse & & Parus bicolor & 3 & 0.0469 \\
\hline & Willow Flycatcher & & Empidonax traillii & 3 & 0.0469 \\
\hline & Yellow Warbler & & Dendroica petechia & 1 & 0.0156 \\
\hline
\end{tabular}


Appendix C. Continued.

\begin{tabular}{|c|c|c|c|c|}
\hline SiteCode & Species & Latin name & Number observed & $\begin{array}{c}\text { Frequency } \\
\text { per Site }\end{array}$ \\
\hline \multirow[t]{18}{*}{ PA83CR } & Site abundance: & & & \\
\hline & Acadian Flycatcher & Empidonax virescens & 1 & 0.0385 \\
\hline & American Goldfinch & Carduelis tristis & 3 & 0.1154 \\
\hline & American Robin & Turdus migratorius & 1 & 0.0385 \\
\hline & Blue Jay & Cyanocitta cristata & 3 & 0.1154 \\
\hline & Brown-Headed Cowbird & Molothrus ater & 1 & 0.0385 \\
\hline & Carolina Chickadee & Poecile carolinensis & 3 & 0.1154 \\
\hline & Cedar Waxwing & Bombycilla cedrorum & 1 & 0.0385 \\
\hline & Common Grackle & Quiscalus quiscula & 3 & 0.1154 \\
\hline & Eastern Towhee & Pipilo erythrophthalmus & 1 & 0.0385 \\
\hline & Gray Catbird & Dumetella carolinensis & 1 & 0.0385 \\
\hline & Indigo Bunting & Passerina cyanea & 1 & 0.0385 \\
\hline & Northern Cardinal & Cardinalis cardinalis & 1 & 0.0385 \\
\hline & Northern Rough-Winged Swallow & Stelgidopteryx serripennis & 1 & 0.0385 \\
\hline & Red-Billed Woodpecker & Melanerpes carolinus & 1 & 0.0385 \\
\hline & Red-Eyed Vireo & Vireo olivaceus & 1 & 0.0385 \\
\hline & Scarlet Tanager & Piranga olivacea & 1 & 0.0385 \\
\hline & Song Sparrow & Melospiza melodia & 2 & 0.0769 \\
\hline
\end{tabular}


Appendix C. Continued.

\begin{tabular}{|c|c|c|c|c|c|}
\hline SiteCode & Species & & Latin name & Number observed & $\begin{array}{c}\text { Frequency } \\
\text { per Site }\end{array}$ \\
\hline \multirow[t]{28}{*}{ PAFAMD } & Site abundance: & 51 & & & \\
\hline & American Goldfinch & & Carduelis tristis & 1 & 0.0196 \\
\hline & American Robin & & Turdus migratorius & 1 & 0.0196 \\
\hline & Belted Kingfisher & & Ceryle alcyon & 1 & 0.0196 \\
\hline & Blue-Gray Gnatcatcher & & Polioptila caerulea & 1 & 0.0196 \\
\hline & Carolina Chickadee & & Poecile carolinensis & 3 & 0.0588 \\
\hline & Cedar Waxwing & & Bombycilla cedrorum & 3 & 0.0588 \\
\hline & Common Grackle & & Quiscalus quiscula & 1 & 0.0196 \\
\hline & Eastern Bluebird & & Sialia sialis & 1 & 0.0196 \\
\hline & Eastern Phoebe & & Sayornis phoebe & 1 & 0.0196 \\
\hline & Eastern Wood-Pewee & & Contopus virens & 1 & 0.0196 \\
\hline & Great Blue Heron & & Ardea herodias & 1 & 0.0196 \\
\hline & Great Crested Flycatcher & & Myiarchus crinitus & 1 & 0.0196 \\
\hline & Hairy Woodpecker & & Picoides villosus & 2 & 0.0392 \\
\hline & Indigo Bunting & & Passerina cyanea & 1 & 0.0196 \\
\hline & Mallard & & Anas platyrhynchos & 4 & 0.0784 \\
\hline & Mourning Dove & & Zenaida macroura & 4 & 0.0784 \\
\hline & Northern Cardinal & & Cardinalis cardinalis & 2 & 0.0392 \\
\hline & Northern Flicker & & Colaptes auratus & 2 & 0.0392 \\
\hline & Red-Billed Woodpecker & & Melanerpes carolinus & 1 & 0.0196 \\
\hline & Red-Tailed Hawk & & Buteo jamaicensis & 1 & 0.0196 \\
\hline & Red-Tailed Hawk & & Buteo jamaicensis & 1 & 0.0196 \\
\hline & Red-Winged Blackbird & & Agelaius phoeniceus & 5 & 0.0980 \\
\hline & Song Sparrow & & Melospiza melodia & 3 & 0.0588 \\
\hline & Tufted Titmouse & & Parus bicolor & 3 & 0.0588 \\
\hline & Willow Flycatcher & & Empidonax traillii & 1 & 0.0196 \\
\hline & Wood Duck & & Aix sponsa & 4 & 0.0784 \\
\hline & Yellow Warbler & & Dendroica petechia & 1 & 0.0196 \\
\hline
\end{tabular}


Appendix C. Continued.

\begin{tabular}{|c|c|c|c|c|}
\hline SiteCode & Species & Latin name & Number observed & $\begin{array}{c}\text { Frequency } \\
\text { per Site }\end{array}$ \\
\hline \multirow[t]{27}{*}{ PAJCPY } & Site abundance: & & & \\
\hline & Acadian Flycatcher & Empidonax virescens & 1 & 0.0196 \\
\hline & American Goldfinch & Carduelis tristis & 3 & 0.0588 \\
\hline & Blue-Gray Gnatcatcher & Polioptila caerulea & 1 & 0.0196 \\
\hline & Blue-Headed Vireo & Vireo solitarius & 1 & 0.0196 \\
\hline & Canada Goose & Branta canadensis & 5 & 0.0980 \\
\hline & Carolina Chickadee & Poecile carolinensis & 3 & 0.0588 \\
\hline & Cedar Waxwing & Bombycilla cedrorum & 2 & 0.0392 \\
\hline & Common Yellowthroat & Geothlypis trichas & 1 & 0.0196 \\
\hline & Cooper's Hawk & Accipiter cooperii & 1 & 0.0196 \\
\hline & Downy Woodpecker & Picoides pubescens & 2 & 0.0392 \\
\hline & Gray Catbird & Dumetella carolinensis & 1 & 0.0196 \\
\hline & Great Blue Heron & Ardea herodias & 1 & 0.0196 \\
\hline & Hairy Woodpecker & Picoides villosus & 1 & 0.0196 \\
\hline & House Wren & Troglodytes aedon & 3 & 0.0588 \\
\hline & Indigo Bunting & Passerina cyanea & 1 & 0.0196 \\
\hline & Mallard & Anas platyrhynchos & 7 & 0.1373 \\
\hline & Northern Flicker & Colaptes auratus & 2 & 0.0392 \\
\hline & Northern Waterthrush & Northern Waterthrush & 1 & 0.0196 \\
\hline & Pileated Woodpecker & Dryocopus pileatus & 1 & 0.0196 \\
\hline & Red-Billed Woodpecker & Melanerpes carolinus & 1 & 0.0196 \\
\hline & Red-Eyed Vireo & Vireo olivaceus & 1 & 0.0196 \\
\hline & Ruby-Throated Hummingbird & Archilochus colubris & 1 & 0.0196 \\
\hline & Tufted Titmouse & Parus bicolor & 2 & 0.0392 \\
\hline & Turkey Vulture & Cathartes aura & 5 & 0.0980 \\
\hline & Wood Duck & Aix sponsa & 1 & 0.0196 \\
\hline & Yellow Warbler & Dendroica petechia & 2 & 0.0392 \\
\hline
\end{tabular}


Appendix C. Continued.

\begin{tabular}{|c|c|c|c|c|}
\hline SiteCode & Species & Latin name & Number observed & $\begin{array}{c}\text { Frequency } \\
\text { per Site }\end{array}$ \\
\hline \multirow[t]{23}{*}{ PALOUD } & Site abundance: & & & \\
\hline & Acadian Flycatcher & Empidonax virescens & 1 & 0.0313 \\
\hline & Blue-Gray Gnatcatcher & Polioptila caerulea & 1 & 0.0313 \\
\hline & Brown-Headed Cowbird & Molothrus ater & 2 & 0.0625 \\
\hline & Carolina Chickadee & Poecile carolinensis & 3 & 0.0938 \\
\hline & Cedar Waxwing & Bombycilla cedrorum & 2 & 0.0625 \\
\hline & Common Yellowthroat & Geothlypis trichas & 1 & 0.0313 \\
\hline & Eastern Phoebe & Sayornis phoebe & 1 & 0.0313 \\
\hline & European Starling & Sturnus vulgaris & 2 & 0.0625 \\
\hline & Gray Catbird & Dumetella carolinensis & 1 & 0.0313 \\
\hline & Great Crested Flycatcher & Myiarchus crinitus & 1 & 0.0313 \\
\hline & Indigo Bunting & Passerina cyanea & 2 & 0.0625 \\
\hline & Mallard & Anas platyrhynchos & 1 & 0.0313 \\
\hline & Northern Cardinal & Cardinalis cardinalis & 1 & 0.0313 \\
\hline & Northern Mockingbird & Mimus polyglottos & 1 & 0.0313 \\
\hline & Northern Rough-Winged Swallow & Stelgidopteryx serripennis & 2 & 0.0625 \\
\hline & Red-Billed Woodpecker & Melanerpes carolinus & 1 & 0.0313 \\
\hline & Red-Eyed Vireo & Vireo olivaceus & 1 & 0.0313 \\
\hline & Scarlet Tanager & Piranga olivacea & 1 & 0.0313 \\
\hline & Song Sparrow & Melospiza melodia & 3 & 0.0938 \\
\hline & Tree Swallow & Tachycineta bicolor & 2 & 0.0625 \\
\hline & White-Eyed Vireo & Vireo griseus & 1 & 0.0313 \\
\hline & Yellow Warbler & Dendroica petechia & 1 & 0.0313 \\
\hline
\end{tabular}


Appendix C. Continued.

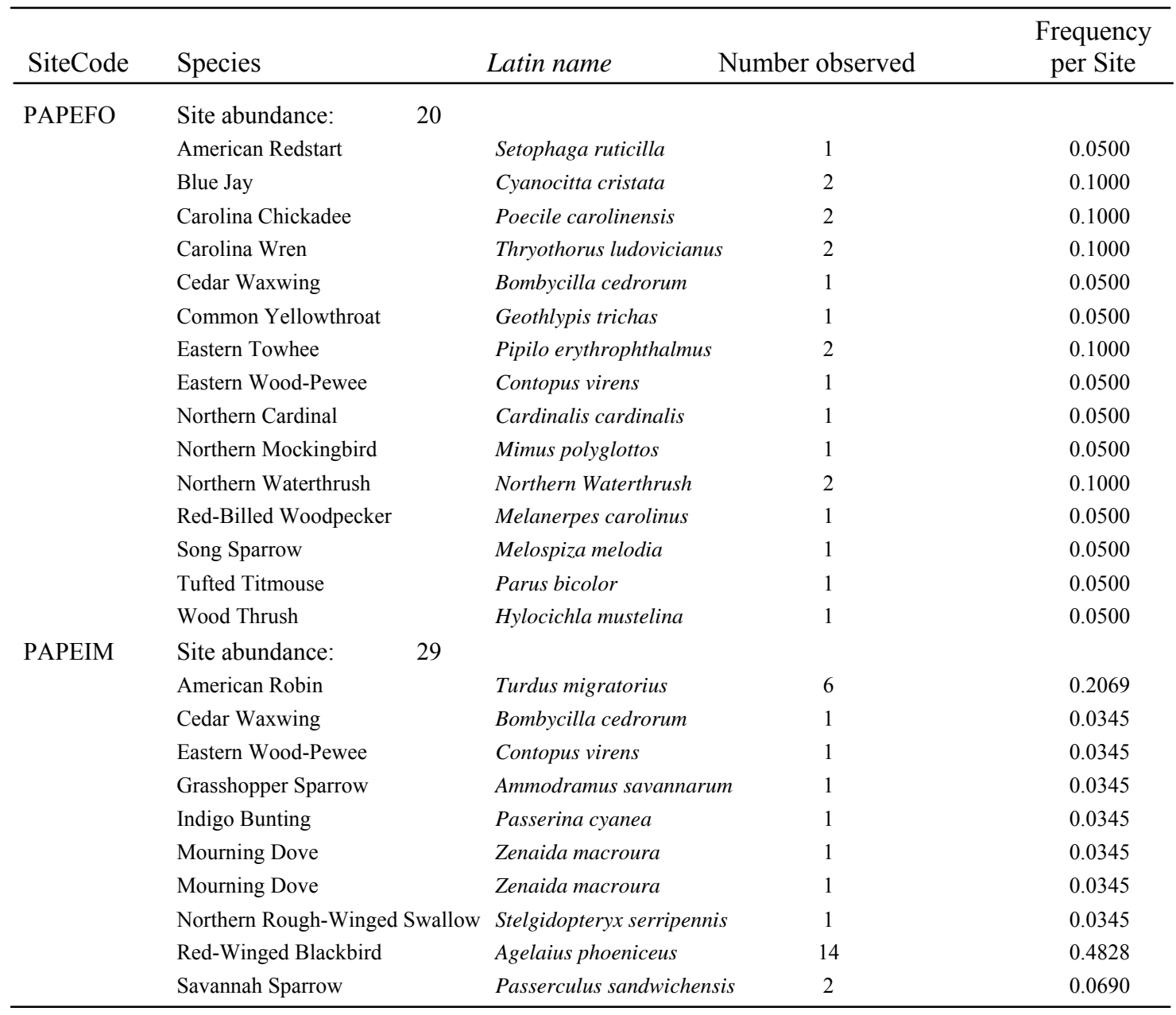


Appendix C. Continued.

\begin{tabular}{|c|c|c|c|c|c|}
\hline SiteCode & Species & & Latin name & Number observed & $\begin{array}{c}\text { Frequency } \\
\text { per Site }\end{array}$ \\
\hline \multirow[t]{25}{*}{ PAPESW } & Site abundance: & 40 & & & \\
\hline & American Robin & & Turdus migratorius & 2 & 0.0500 \\
\hline & Belted Kingfisher & & Ceryle alcyon & 2 & 0.0500 \\
\hline & Black-and-White Warbler & & Mniotilta varia & 2 & 0.0500 \\
\hline & Carolina Chickadee & & Poecile carolinensis & 3 & 0.0750 \\
\hline & Carolina Wren & & Thryothorus ludovicianus & 1 & 0.0250 \\
\hline & Cedar Waxwing & & Bombycilla cedrorum & 2 & 0.0500 \\
\hline & Common Yellowthroat & & Geothlypis trichas & 1 & 0.0250 \\
\hline & Eastern Kingbird & & Tyrannus tyrannus & 2 & 0.0500 \\
\hline & Eastern Wood-Pewee & & Contopus virens & 1 & 0.0250 \\
\hline & European Starling & & Sturnus vulgaris & 1 & 0.0250 \\
\hline & Indigo Bunting & & Passerina cyanea & 1 & 0.0250 \\
\hline & Northern Cardinal & & Cardinalis cardinalis & 1 & 0.0250 \\
\hline & Northern Flicker & & Colaptes auratus & 3 & 0.0750 \\
\hline & Orchard Oriole & & Icterus spurius & 1 & 0.0250 \\
\hline & Pileated Woodpecker & & Dryocopus pileatus & 1 & 0.0250 \\
\hline & Red-Billed Woodpecker & & Melanerpes carolinus & 1 & 0.0250 \\
\hline & Red-Tailed Hawk & & Buteo jamaicensis & 1 & 0.0250 \\
\hline & Red-Winged Blackbird & & Agelaius phoeniceus & 6 & 0.1500 \\
\hline & Song Sparrow & & Melospiza melodia & 3 & 0.0750 \\
\hline & Tree Swallow & & Tachycineta bicolor & 1 & 0.0250 \\
\hline & Tufted Titmouse & & Parus bicolor & 1 & 0.0250 \\
\hline & White-Eyed Vireo & & Vireo griseus & 1 & 0.0250 \\
\hline & Willow Flycatcher & & Empidonax traillii & 1 & 0.0250 \\
\hline & Wood Duck & & Aix sponsa & 1 & 0.0250 \\
\hline
\end{tabular}


Appendix C. Continued.

\begin{tabular}{|c|c|c|c|c|c|}
\hline SiteCode & Species & & Latin name & Number observed & $\begin{array}{c}\text { Frequency } \\
\text { per Site }\end{array}$ \\
\hline \multirow[t]{18}{*}{ PAWILL } & Site abundance: & 41 & & & \\
\hline & American Robin & & Turdus migratorius & 2 & 0.0488 \\
\hline & Barn Swallow & & Hirundo rustica & 2 & 0.0488 \\
\hline & Belted Kingfisher & & Ceryle alcyon & 2 & 0.0488 \\
\hline & Blue Jay & & Cyanocitta cristata & 1 & 0.0244 \\
\hline & Cedar Waxwing & & Bombycilla cedrorum & 3 & 0.0732 \\
\hline & Common Grackle & & Quiscalus quiscula & 2 & 0.0488 \\
\hline & Domestic duck & & & 1 & 0.0244 \\
\hline & European Starling & & Sturnus vulgaris & 1 & 0.0244 \\
\hline & Gray Catbird & & Dumetella carolinensis & 1 & 0.0244 \\
\hline & Green Heron & & Butorides virescens & 1 & 0.0244 \\
\hline & Mallard & & Anas platyrhynchos & 2 & 0.0488 \\
\hline & Mourning Dove & & Zenaida macroura & 2 & 0.0488 \\
\hline & Northern Cardinal & & Cardinalis cardinalis & 3 & 0.0732 \\
\hline & Northern Flicker & & Colaptes auratus & 1 & 0.0244 \\
\hline & Red-Winged Blackbird & & Agelaius phoeniceus & 12 & 0.2927 \\
\hline & Song Sparrow & & Melospiza melodia & 2 & 0.0488 \\
\hline & Wood Duck & & Aix sponsa & 3 & 0.0732 \\
\hline \multirow[t]{18}{*}{ PCBLUE } & Site abundance: & 25 & & & \\
\hline & American Crow & & Corvus brachyrhynchos & 1 & 0.0400 \\
\hline & American Goldfinch & & Carduelis tristis & 1 & 0.0400 \\
\hline & Brown-Headed Cowbird & & Molothrus ater & 1 & 0.0400 \\
\hline & Carolina Wren & & Thryothorus ludovicianus & 1 & 0.0400 \\
\hline & Common Grackle & & Quiscalus quiscula & 1 & 0.0400 \\
\hline & Common Yellowthroat & & Geothlypis trichas & 2 & 0.0800 \\
\hline & Eastern Kingbird & & Tyrannus tyrannus & 1 & 0.0400 \\
\hline & Eastern Towhee & & Pipilo erythrophthalmus & 1 & 0.0400 \\
\hline & Field Sparrow & & Spizella pusilla & 2 & 0.0800 \\
\hline & Gray Catbird & & Dumetella carolinensis & 2 & 0.0800 \\
\hline & Northern Cardinal & & Cardinalis cardinalis & 1 & 0.0400 \\
\hline & Red-Eyed Vireo & & Vireo olivaceus & 1 & 0.0400 \\
\hline & Red-Winged Blackbird & & Agelaius phoeniceus & 4 & 0.1600 \\
\hline & Song Sparrow & & Melospiza melodia & 2 & 0.0800 \\
\hline & Tree Swallow & & Tachycineta bicolor & 2 & 0.0800 \\
\hline & Yellow Warbler & & Dendroica petechia & 1 & 0.0400 \\
\hline & Yellow-Breasted Chat & & Icteria virens & 1 & 0.0400 \\
\hline
\end{tabular}


Appendix C. Continued.

\begin{tabular}{|c|c|c|c|c|c|}
\hline SiteCode & Species & & Latin name & Number observed & $\begin{array}{c}\text { Frequency } \\
\text { per Site }\end{array}$ \\
\hline \multirow[t]{13}{*}{ PCLPFO } & Site abundance: & 19 & & & \\
\hline & American Goldfinch & & Carduelis tristis & 1 & 0.0526 \\
\hline & American Redstart & & Setophaga ruticilla & 4 & 0.2105 \\
\hline & American Woodcock & & Scolopax minor & 1 & 0.0526 \\
\hline & Baltimore Oriole & & Icterus galbula & 1 & 0.0526 \\
\hline & Cedar Waxwing & & Bombycilla cedrorum & 4 & 0.2105 \\
\hline & Eastern Towhee & & Pipilo erythrophthalmus & 1 & 0.0526 \\
\hline & Eastern Wood-Pewee & & Contopus virens & 2 & 0.1053 \\
\hline & Gray Catbird & & Dumetella carolinensis & 1 & 0.0526 \\
\hline & Indigo Bunting & & Passerina cyanea & 1 & 0.0526 \\
\hline & Northern Flicker & & Colaptes auratus & 1 & 0.0526 \\
\hline & Northern Parula & & Parula americana & 1 & 0.0526 \\
\hline & Wood Thrush & & Hylocichla mustelina & 1 & 0.0526 \\
\hline \multirow[t]{17}{*}{ PCROAD } & Site abundance: & 28 & & & \\
\hline & American Goldfinch & & Carduelis tristis & 4 & 0.1429 \\
\hline & Baltimore Oriole & & Icterus galbula & 1 & 0.0357 \\
\hline & Brown-Headed Cowbird & & Molothrus ater & 1 & 0.0357 \\
\hline & Common Grackle & & Quiscalus quiscula & 2 & 0.0714 \\
\hline & Common Yellowthroat & & Geothlypis trichas & 2 & 0.0714 \\
\hline & Field Sparrow & & Spizella pusilla & 1 & 0.0357 \\
\hline & Green Heron & & Butorides virescens & 1 & 0.0357 \\
\hline & Indigo Bunting & & Passerina cyanea & 1 & 0.0357 \\
\hline & Killdeer & & Charadrius vociferus & 2 & 0.0714 \\
\hline & Northern Cardinal & & Cardinalis cardinalis & 1 & 0.0357 \\
\hline & Northern Flicker & & Colaptes auratus & 1 & 0.0357 \\
\hline & Red-Winged Blackbird & & Agelaius phoeniceus & 2 & 0.0714 \\
\hline & Song Sparrow & & Melospiza melodia & 3 & 0.1071 \\
\hline & Tree Swallow & & Tachycineta bicolor & 3 & 0.1071 \\
\hline & Willow Flycatcher & & Empidonax traillii & 1 & 0.0357 \\
\hline & Yellow Warbler & & Dendroica petechia & 2 & 0.0714 \\
\hline
\end{tabular}


Appendix C. Continued.

\begin{tabular}{|c|c|c|c|c|c|}
\hline SiteCode & Species & & Latin name & Number observed & $\begin{array}{c}\text { Frequency } \\
\text { per Site }\end{array}$ \\
\hline \multirow[t]{18}{*}{ PEMIDW } & Site abundance: & 22 & & & \\
\hline & Acadian Flycatcher & & Empidonax virescens & 1 & 0.0455 \\
\hline & American Goldfinch & & Carduelis tristis & 1 & 0.0455 \\
\hline & American Robin & & Turdus migratorius & 1 & 0.0455 \\
\hline & Baltimore Oriole & & Icterus galbula & 1 & 0.0455 \\
\hline & Baltimore Oriole & & Icterus galbula & 1 & 0.0455 \\
\hline & Blue-Winged Warbler & & Vermivora pinus & 1 & 0.0455 \\
\hline & Common Yellowthroat & & Geothlypis trichas & 1 & 0.0455 \\
\hline & Eastern Phoebe & & Sayornis phoebe & 1 & 0.0455 \\
\hline & Eastern Towhee & & Pipilo erythrophthalmus & 2 & 0.0909 \\
\hline & Indigo Bunting & & Passerina cyanea & 1 & 0.0455 \\
\hline & Red-Eyed Vireo & & Vireo olivaceus & 1 & 0.0455 \\
\hline & Red-Winged Blackbird & & Agelaius phoeniceus & 3 & 0.1364 \\
\hline & Scarlet Tanager & & Piranga olivacea & 2 & 0.0909 \\
\hline & Song Sparrow & & Melospiza melodia & 1 & 0.0455 \\
\hline & Tufted Titmouse & & Parus bicolor & 1 & 0.0455 \\
\hline & Wood Thrush & & Hylocichla mustelina & 1 & 0.0455 \\
\hline & Yellow Warbler & & Dendroica petechia & 2 & 0.0909 \\
\hline \multirow[t]{12}{*}{ PERDDP } & Site abundance: & 28 & & & \\
\hline & American Goldfinch & & Carduelis tristis & 2 & 0.0714 \\
\hline & Cedar Waxwing & & Bombycilla cedrorum & 1 & 0.0357 \\
\hline & Common Yellowthroat & & Geothlypis trichas & 1 & 0.0357 \\
\hline & Eastern Towhee & & Pipilo erythrophthalmus & 1 & 0.0357 \\
\hline & Field Sparrow & & Spizella pusilla & 1 & 0.0357 \\
\hline & Mourning Dove & & Zenaida macroura & 3 & 0.1071 \\
\hline & Red-Winged Blackbird & & Agelaius phoeniceus & 10 & 0.3571 \\
\hline & Song Sparrow & & Melospiza melodia & 4 & 0.1429 \\
\hline & Tree Swallow & & Tachycineta bicolor & 2 & 0.0714 \\
\hline & Winter Wren & & Troglodytes troglodytes & 1 & 0.0357 \\
\hline & Yellow Warbler & & Dendroica petechia & 2 & 0.0714 \\
\hline
\end{tabular}


Appendix C. Continued.

\begin{tabular}{|c|c|c|c|c|}
\hline SiteCode & Species & Latin name & Number observed & $\begin{array}{c}\text { Frequency } \\
\text { per Site }\end{array}$ \\
\hline \multirow[t]{17}{*}{ PETHUM } & Site abundance: & & & \\
\hline & Acadian Flycatcher & Empidonax virescens & 1 & 0.0556 \\
\hline & Blue-Winged Warbler & Vermivora pinus & 1 & 0.0556 \\
\hline & Carolina Wren & Thryothorus ludovicianus & 2 & 0.1111 \\
\hline & Common Yellowthroat & Geothlypis trichas & 1 & 0.0556 \\
\hline & Eastern Phoebe & Sayornis phoebe & 1 & 0.0556 \\
\hline & Eastern Towhee & Pipilo erythrophthalmus & 1 & 0.0556 \\
\hline & Gray Catbird & Dumetella carolinensis & 1 & 0.0556 \\
\hline & Great Crested Flycatcher & Myiarchus crinitus & 1 & 0.0556 \\
\hline & Hairy Woodpecker & Picoides villosus & 1 & 0.0556 \\
\hline & Northern Mockingbird & Mimus polyglottos & 1 & 0.0556 \\
\hline & Red-Eyed Vireo & Vireo olivaceus & 1 & 0.0556 \\
\hline & Red-Winged Blackbird & Agelaius phoeniceus & 1 & 0.0556 \\
\hline & Song Sparrow & Melospiza melodia & 2 & 0.1111 \\
\hline & Tufted Titmouse & Parus bicolor & 1 & 0.0556 \\
\hline & Wood Thrush & Hylocichla mustelina & 1 & 0.0556 \\
\hline & Yellow Warbler & Dendroica petechia & 1 & 0.0556 \\
\hline \multirow[t]{18}{*}{ PETOSS } & Site abundance: & & & \\
\hline & Acadian Flycatcher & Empidonax virescens & 1 & 0.0400 \\
\hline & American Robin & Turdus migratorius & 1 & 0.0400 \\
\hline & Baltimore Oriole & Icterus galbula & 1 & 0.0400 \\
\hline & Blue-Winged Warbler & Vermivora pinus & 1 & 0.0400 \\
\hline & Carolina Chickadee & Poecile carolinensis & 1 & 0.0400 \\
\hline & Common Yellowthroat & Geothlypis trichas & 1 & 0.0400 \\
\hline & Eastern Phoebe & Sayornis phoebe & 1 & 0.0400 \\
\hline & Indigo Bunting & Passerina cyanea & 1 & 0.0400 \\
\hline & Mourning Dove & Zenaida macroura & 1 & 0.0400 \\
\hline & Northern Cardinal & Cardinalis cardinalis & 1 & 0.0400 \\
\hline & Northern Rough-Winged Swallow & Stelgidopteryx serripennis & 1 & 0.0400 \\
\hline & Orchard Oriole & Icterus spurius & 1 & 0.0400 \\
\hline & Red-Winged Blackbird & Agelaius phoeniceus & 5 & 0.2000 \\
\hline & Song Sparrow & Melospiza melodia & 3 & 0.1200 \\
\hline & Tufted Titmouse & Parus bicolor & 2 & 0.0800 \\
\hline & Wood Thrush & Hylocichla mustelina & 1 & 0.0400 \\
\hline & Yellow Warbler & Dendroica petechia & 2 & 0.0800 \\
\hline
\end{tabular}


Appendix C. Continued.

\begin{tabular}{|c|c|c|c|c|c|}
\hline SiteCode & Species & & Latin name & Number observed & $\begin{array}{c}\text { Frequency } \\
\text { per Site }\end{array}$ \\
\hline \multirow[t]{20}{*}{ RIASIA } & Site abundance: & 35 & & & \\
\hline & American Crow & & Corvus brachyrhynchos & 2 & 0.0571 \\
\hline & American Robin & & Turdus migratorius & 3 & 0.0857 \\
\hline & Carolina Chickadee & & Poecile carolinensis & 2 & 0.0571 \\
\hline & Carolina Wren & & Thryothorus ludovicianus & 1 & 0.0286 \\
\hline & Cedar Waxwing & & Bombycilla cedrorum & 1 & 0.0286 \\
\hline & Common Grackle & & Quiscalus quiscula & 1 & 0.0286 \\
\hline & Common Yellowthroat & & Geothlypis trichas & 2 & 0.0571 \\
\hline & Eastern Towhee & & Pipilo erythrophthalmus & 1 & 0.0286 \\
\hline & Field Sparrow & & Spizella pusilla & 3 & 0.0857 \\
\hline & Gray Catbird & & Dumetella carolinensis & 2 & 0.0571 \\
\hline & Indigo Bunting & & Passerina cyanea & 2 & 0.0571 \\
\hline & Killdeer & & Charadrius vociferus & 1 & 0.0286 \\
\hline & Northern Mockingbird & & Mimus polyglottos & 2 & 0.0571 \\
\hline & Orchard Oriole & & Icterus spurius & 2 & 0.0571 \\
\hline & Song Sparrow & & Melospiza melodia & 2 & 0.0571 \\
\hline & Tree Swallow & & Tachycineta bicolor & 2 & 0.0571 \\
\hline & Tufted Titmouse & & Parus bicolor & 2 & 0.0571 \\
\hline & Yellow Warbler & & Dendroica petechia & 2 & 0.0571 \\
\hline & Yellow-Breasted Chat & & Icteria virens & 2 & 0.0571 \\
\hline
\end{tabular}


Appendix C. Continued.

\begin{tabular}{|c|c|c|c|c|c|}
\hline SiteCode & Species & & Latin name & Number observed & $\begin{array}{c}\text { Frequency } \\
\text { per Site }\end{array}$ \\
\hline \multirow[t]{24}{*}{ RIBRID } & Site abundance: & 31 & & & \\
\hline & Acadian Flycatcher & & Empidonax virescens & 1 & 0.0323 \\
\hline & American Redstart & & Setophaga ruticilla & 1 & 0.0323 \\
\hline & American Robin & & Turdus migratorius & 2 & 0.0645 \\
\hline & Belted Kingfisher & & Ceryle alcyon & 1 & 0.0323 \\
\hline & Blue-Gray Gnatcatcher & & Polioptila caerulea & 1 & 0.0323 \\
\hline & Blue-Winged Warbler & & Vermivora pinus & 1 & 0.0323 \\
\hline & Carolina Chickadee & & Poecile carolinensis & 3 & 0.0968 \\
\hline & Carolina Wren & & Thryothorus ludovicianus & 1 & 0.0323 \\
\hline & Cedar Waxwing & & Bombycilla cedrorum & 2 & 0.0645 \\
\hline & Cerulean Warbler & & Dendroica cerulea & 1 & 0.0323 \\
\hline & Chipping Sparrow & & Spizella passerina & 2 & 0.0645 \\
\hline & Eastern Towhee & & Pipilo erythrophthalmus & 1 & 0.0323 \\
\hline & Gray Catbird & & Dumetella carolinensis & 1 & 0.0323 \\
\hline & Indigo Bunting & & Passerina cyanea & 1 & 0.0323 \\
\hline & Northern Cardinal & & Cardinalis cardinalis & 1 & 0.0323 \\
\hline & Ovenbird & & Seiurus aurocapillus & 1 & 0.0323 \\
\hline & Red-Billed Woodpecker & & Melanerpes carolinus & 1 & 0.0323 \\
\hline & Red-Eyed Vireo & & Vireo olivaceus & 1 & 0.0323 \\
\hline & Red-Winged Blackbird & & Agelaius phoeniceus & 2 & 0.0645 \\
\hline & Song Sparrow & & Melospiza melodia & 2 & 0.0645 \\
\hline & Tufted Titmouse & & Parus bicolor & 1 & 0.0323 \\
\hline & Wood Thrush & & Hylocichla mustelina & 1 & 0.0323 \\
\hline & Yellow Warbler & & Dendroica petechia & 2 & 0.0645 \\
\hline
\end{tabular}


Appendix C. Continued.

\begin{tabular}{|c|c|c|c|c|c|}
\hline SiteCode & Species & & Latin name & Number observed & $\begin{array}{c}\text { Frequency } \\
\text { per Site }\end{array}$ \\
\hline \multirow[t]{18}{*}{ RIEAST } & Site abundance: & 23 & & & \\
\hline & Acadian Flycatcher & & Empidonax virescens & 2 & 0.0870 \\
\hline & Blue-Gray Gnatcatcher & & Polioptila caerulea & 2 & 0.0870 \\
\hline & Carolina Chickadee & & Poecile carolinensis & 2 & 0.0870 \\
\hline & Carolina Wren & & Thryothorus ludovicianus & 1 & 0.0435 \\
\hline & Chipping Sparrow & & Spizella passerina & 1 & 0.0435 \\
\hline & Eastern Towhee & & Pipilo erythrophthalmus & 1 & 0.0435 \\
\hline & Great Crested Flycatcher & & Myiarchus crinitus & 1 & 0.0435 \\
\hline & Indigo Bunting & & Passerina cyanea & 1 & 0.0435 \\
\hline & Northern Cardinal & & Cardinalis cardinalis & 1 & 0.0435 \\
\hline & Northern Parula & & Parula americana & 2 & 0.0870 \\
\hline & Ovenbird & & Seiurus aurocapillus & 1 & 0.0435 \\
\hline & Red-Billed Woodpecker & & Melanerpes carolinus & 1 & 0.0435 \\
\hline & Scarlet Tanager & & Piranga olivacea & 1 & 0.0435 \\
\hline & Song Sparrow & & Melospiza melodia & 3 & 0.1304 \\
\hline & Tufted Titmouse & & Parus bicolor & 1 & 0.0435 \\
\hline & Wood Thrush & & Hylocichla mustelina & 1 & 0.0435 \\
\hline & Yellow Warbler & & Dendroica petechia & 1 & 0.0435 \\
\hline \multirow[t]{15}{*}{ SJBOAT } & Site abundance: & 22 & & & \\
\hline & American Goldfinch & & Carduelis tristis & 1 & 0.0455 \\
\hline & Blue-Gray Gnatcatcher & & Polioptila caerulea & 1 & 0.0455 \\
\hline & Blue-Winged Warbler & & Vermivora pinus & 1 & 0.0455 \\
\hline & Eastern Towhee & & Pipilo erythrophthalmus & 2 & 0.0909 \\
\hline & Gray Catbird & & Dumetella carolinensis & 1 & 0.0455 \\
\hline & Indigo Bunting & & Passerina cyanea & 2 & 0.0909 \\
\hline & Kentucky Warbler & & Oporornis formosus & 2 & 0.0909 \\
\hline & Mallard & & Anas platyrhynchos & 2 & 0.0909 \\
\hline & Northern Cardinal & & Cardinalis cardinalis & 1 & 0.0455 \\
\hline & Ovenbird & & Seiurus aurocapillus & 1 & 0.0455 \\
\hline & Scarlet Tanager & & Piranga olivacea & 2 & 0.0909 \\
\hline & Tree Swallow & & Tachycineta bicolor & 4 & 0.1818 \\
\hline & White-Breasted Nuthatch & & Sitta carolinensis & 1 & 0.0455 \\
\hline & Yellow Warbler & & Dendroica petechia & 1 & 0.0455 \\
\hline
\end{tabular}


Appendix C. Continued.

\begin{tabular}{|c|c|c|c|c|c|}
\hline SiteCode & Species & & Latin name & Number observed & $\begin{array}{c}\text { Frequency } \\
\text { per Site }\end{array}$ \\
\hline \multirow[t]{13}{*}{ SJBRID } & Site abundance: & 23 & & & \\
\hline & American Goldfinch & & Carduelis tristis & 2 & 0.0870 \\
\hline & Barn Swallow & & Hirundo rustica & 2 & 0.0870 \\
\hline & Brown-Headed Cowbird & & Molothrus ater & 1 & 0.0435 \\
\hline & Common Grackle & & Quiscalus quiscula & 1 & 0.0435 \\
\hline & Common Yellowthroat & & Geothlypis trichas & 1 & 0.0435 \\
\hline & Eastern Towhee & & Pipilo erythrophthalmus & 1 & 0.0435 \\
\hline & Field Sparrow & & Spizella pusilla & 2 & 0.0870 \\
\hline & Indigo Bunting & & Passerina cyanea & 2 & 0.0870 \\
\hline & Northern Cardinal & & Cardinalis cardinalis & 1 & 0.0435 \\
\hline & Red-Winged Blackbird & & Agelaius phoeniceus & 5 & 0.2174 \\
\hline & Song Sparrow & & Melospiza melodia & 3 & 0.1304 \\
\hline & Tree Swallow & & Tachycineta bicolor & 2 & 0.0870 \\
\hline \multirow[t]{20}{*}{ SJCHUR } & Site abundance: & 29 & & & \\
\hline & Acadian Flycatcher & & Empidonax virescens & 1 & 0.0345 \\
\hline & Alder Flycatcher & & Empidonax alnorum & 1 & 0.0345 \\
\hline & American Goldfinch & & Carduelis tristis & 1 & 0.0345 \\
\hline & Blue-Gray Gnatcatcher & & Polioptila caerulea & 1 & 0.0345 \\
\hline & Blue-Winged Warbler & & Vermivora pinus & 2 & 0.0690 \\
\hline & Brown-Headed Cowbird & & Molothrus ater & 1 & 0.0345 \\
\hline & Common Yellowthroat & & Geothlypis trichas & 1 & 0.0345 \\
\hline & Eastern Phoebe & & Sayornis phoebe & 1 & 0.0345 \\
\hline & Eastern Towhee & & Pipilo erythrophthalmus & 1 & 0.0345 \\
\hline & Green Heron & & Butorides virescens & 1 & 0.0345 \\
\hline & Indigo Bunting & & Passerina cyanea & 3 & 0.1034 \\
\hline & Mallard & & Anas platyrhynchos & 1 & 0.0345 \\
\hline & Orchard Oriole & & Icterus spurius & 1 & 0.0345 \\
\hline & Red-Winged Blackbird & & Agelaius phoeniceus & 2 & 0.0690 \\
\hline & Song Sparrow & & Melospiza melodia & 5 & 0.1724 \\
\hline & Tree Swallow & & Tachycineta bicolor & 1 & 0.0345 \\
\hline & White-Breasted Nuthatch & & Sitta carolinensis & 1 & 0.0345 \\
\hline & Willow Flycatcher & & Empidonax traillii & 2 & 0.0690 \\
\hline & Yellow Warbler & & Dendroica petechia & 2 & 0.0690 \\
\hline
\end{tabular}


Appendix C. Continued.

\begin{tabular}{|c|c|c|c|c|c|}
\hline SiteCode & Species & & Latin name & Number observed & $\begin{array}{c}\text { Frequency } \\
\text { per Site }\end{array}$ \\
\hline \multirow[t]{19}{*}{ SJGLAD } & Site abundance: & 22 & & & \\
\hline & Acadian Flycatcher & & Empidonax virescens & 1 & 0.0455 \\
\hline & American Goldfinch & & Carduelis tristis & 1 & 0.0455 \\
\hline & American Redstart & & Setophaga ruticilla & 1 & 0.0455 \\
\hline & Black-capped Chickadee & & Poecile atricapilla & 1 & 0.0455 \\
\hline & Blue-Gray Gnatcatcher & & Polioptila caerulea & 1 & 0.0455 \\
\hline & Blue-Headed Vireo & & Vireo solitarius & 1 & 0.0455 \\
\hline & Blue-Winged Warbler & & Vermivora pinus & 2 & 0.0909 \\
\hline & Common Yellowthroat & & Geothlypis trichas & 1 & 0.0455 \\
\hline & Eastern Towhee & & Pipilo erythrophthalmus & 1 & 0.0455 \\
\hline & Field Sparrow & & Spizella pusilla & 2 & 0.0909 \\
\hline & Gray Catbird & & Dumetella carolinensis & 1 & 0.0455 \\
\hline & Indigo Bunting & & Passerina cyanea & 2 & 0.0909 \\
\hline & Northern Cardinal & & Cardinalis cardinalis & 1 & 0.0455 \\
\hline & Ovenbird & & Seiurus aurocapillus & 1 & 0.0455 \\
\hline & Scarlet Tanager & & Piranga olivacea & 1 & 0.0455 \\
\hline & Song Sparrow & & Melospiza melodia & 2 & 0.0909 \\
\hline & White-Eyed Vireo & & Vireo griseus & 1 & 0.0455 \\
\hline & Yellow Warbler & & Dendroica petechia & 1 & 0.0455 \\
\hline
\end{tabular}


Appendix C. Continued.

\begin{tabular}{|c|c|c|c|c|c|}
\hline SiteCode & Species & & Latin name & Number observed & $\begin{array}{c}\text { Frequency } \\
\text { per Site }\end{array}$ \\
\hline \multirow[t]{22}{*}{ SJMUDL } & Site abundance: & 24 & & & \\
\hline & Acadian Flycatcher & & Empidonax virescens & 1 & 0.0417 \\
\hline & Baltimore Oriole & & Icterus galbula & 1 & 0.0417 \\
\hline & Black-and-White Warbler & & Mniotilta varia & 1 & 0.0417 \\
\hline & Blue-Gray Gnatcatcher & & Polioptila caerulea & 2 & 0.0833 \\
\hline & Blue-Winged Warbler & & Vermivora pinus & 1 & 0.0417 \\
\hline & Carolina Chickadee & & Poecile carolinensis & 1 & 0.0417 \\
\hline & Carolina Wren & & Thryothorus ludovicianus & 1 & 0.0417 \\
\hline & Common Grackle & & Quiscalus quiscula & 1 & 0.0417 \\
\hline & Common Yellowthroat & & Geothlypis trichas & 1 & 0.0417 \\
\hline & Downy Woodpecker & & Picoides pubescens & 1 & 0.0417 \\
\hline & Eastern Towhee & & Pipilo erythrophthalmus & 2 & 0.0833 \\
\hline & Field Sparrow & & Spizella pusilla & 1 & 0.0417 \\
\hline & Gray Catbird & & Dumetella carolinensis & 1 & 0.0417 \\
\hline & Indigo Bunting & & Passerina cyanea & 2 & 0.0833 \\
\hline & Northern Cardinal & & Cardinalis cardinalis & 1 & 0.0417 \\
\hline & Red-Eyed Vireo & & Vireo olivaceus & 1 & 0.0417 \\
\hline & Scarlet Tanager & & Piranga olivacea & 1 & 0.0417 \\
\hline & Song Sparrow & & Melospiza melodia & 1 & 0.0417 \\
\hline & Wood Thrush & & Hylocichla mustelina & 1 & 0.0417 \\
\hline & Yellow Warbler & & Dendroica petechia & 1 & 0.0417 \\
\hline & Yellow-Breasted Chat & & Icteria virens & 1 & 0.0417 \\
\hline
\end{tabular}


Appendix C. Continued.

\begin{tabular}{|c|c|c|c|c|c|}
\hline SiteCode & Species & & Latin name & Number observed & $\begin{array}{c}\text { Frequency } \\
\text { per Site }\end{array}$ \\
\hline \multirow[t]{18}{*}{ SJPLOT } & Site abundance: & 25 & & & \\
\hline & Acadian Flycatcher & & Empidonax virescens & 1 & 0.0400 \\
\hline & American Goldfinch & & Carduelis tristis & 2 & 0.0800 \\
\hline & Barn Swallow & & Hirundo rustica & 2 & 0.0800 \\
\hline & Black-and-White Warbler & & Mniotilta varia & 1 & 0.0400 \\
\hline & Blue-Gray Gnatcatcher & & Polioptila caerulea & 1 & 0.0400 \\
\hline & Common Grackle & & Quiscalus quiscula & 1 & 0.0400 \\
\hline & Common Yellowthroat & & Geothlypis trichas & 2 & 0.0800 \\
\hline & Eastern Towhee & & Pipilo erythrophthalmus & 2 & 0.0800 \\
\hline & Field Sparrow & & Spizella pusilla & 1 & 0.0400 \\
\hline & Indigo Bunting & & Passerina cyanea & 1 & 0.0400 \\
\hline & Killdeer & & Charadrius vociferus & 1 & 0.0400 \\
\hline & Red-Eyed Vireo & & Vireo olivaceus & 1 & 0.0400 \\
\hline & Red-Winged Blackbird & & Agelaius phoeniceus & 1 & 0.0400 \\
\hline & Song Sparrow & & Melospiza melodia & 3 & 0.1200 \\
\hline & Tree Swallow & & Tachycineta bicolor & 3 & 0.1200 \\
\hline & Willow Flycatcher & & Empidonax traillii & 1 & 0.0400 \\
\hline & Yellow Warbler & & Dendroica petechia & 1 & 0.0400 \\
\hline \multirow[t]{15}{*}{ SJTELE } & Site abundance: & 19 & & & \\
\hline & Acadian Flycatcher & & Empidonax virescens & 2 & 0.1053 \\
\hline & American Redstart & & Setophaga ruticilla & 1 & 0.0526 \\
\hline & Blue-Gray Gnatcatcher & & Polioptila caerulea & 1 & 0.0526 \\
\hline & Brown-Headed Cowbird & & Molothrus ater & 1 & 0.0526 \\
\hline & Eastern Phoebe & & Sayornis phoebe & 1 & 0.0526 \\
\hline & Eastern Towhee & & Pipilo erythrophthalmus & 1 & 0.0526 \\
\hline & Field Sparrow & & Spizella pusilla & 1 & 0.0526 \\
\hline & Indigo Bunting & & Passerina cyanea & 3 & 0.1579 \\
\hline & Mourning Dove & & Zenaida macroura & 1 & 0.0526 \\
\hline & Northern Parula & & Parula americana & 1 & 0.0526 \\
\hline & Ovenbird & & Seiurus aurocapillus & 1 & 0.0526 \\
\hline & Scarlet Tanager & & Piranga olivacea & 1 & 0.0526 \\
\hline & Song Sparrow & & Melospiza melodia & 2 & 0.1053 \\
\hline & Yellow Warbler & & Dendroica petechia & 2 & 0.1053 \\
\hline
\end{tabular}


Appendix C. Continued.

\begin{tabular}{|c|c|c|c|c|c|}
\hline SiteCode & Species & & Latin name & Number observed & $\begin{array}{c}\text { Frequency } \\
\text { per Site }\end{array}$ \\
\hline \multirow[t]{16}{*}{ SMDTSS } & Site abundance: & 24 & & & \\
\hline & American Goldfinch & & Carduelis tristis & 1 & 0.0417 \\
\hline & Black-capped Chickadee & & Poecile atricapilla & 1 & 0.0417 \\
\hline & Blue-Winged Warbler & & Vermivora pinus & 2 & 0.0833 \\
\hline & Common Yellowthroat & & Geothlypis trichas & 3 & 0.1250 \\
\hline & Eastern Phoebe & & Sayornis phoebe & 1 & 0.0417 \\
\hline & Eastern Towhee & & Pipilo erythrophthalmus & 1 & 0.0417 \\
\hline & Great Crested Flycatcher & & Myiarchus crinitus & 1 & 0.0417 \\
\hline & Mallard & & Anas platyrhynchos & 1 & 0.0417 \\
\hline & Ovenbird & & Seiurus aurocapillus & 2 & 0.0833 \\
\hline & Pileated Woodpecker & & Dryocopus pileatus & 1 & 0.0417 \\
\hline & Red-Eyed Vireo & & Vireo olivaceus & 1 & 0.0417 \\
\hline & Red-Tailed Hawk & & Buteo jamaicensis & 1 & 0.0417 \\
\hline & Red-Winged Blackbird & & Agelaius phoeniceus & 4 & 0.1667 \\
\hline & Swamp Sparrow & & Melospiza georgiana & 1 & 0.0417 \\
\hline & Tufted Titmouse & & Parus bicolor & 3 & 0.1250 \\
\hline \multirow[t]{19}{*}{ SMFOFL } & Site abundance: & 21 & & & \\
\hline & Acadian Flycatcher & & Empidonax virescens & 1 & 0.0476 \\
\hline & Blue-Gray Gnatcatcher & & Polioptila caerulea & 2 & 0.0952 \\
\hline & Carolina Chickadee & & Poecile carolinensis & 1 & 0.0476 \\
\hline & Cerulean Warbler & & Dendroica cerulea & 1 & 0.0476 \\
\hline & Chestnut-Sided Warbler & & Dendroica pensylvanica & 1 & 0.0476 \\
\hline & Chipping Sparrow & & Spizella passerina & 1 & 0.0476 \\
\hline & Common Yellowthroat & & Geothlypis trichas & 2 & 0.0952 \\
\hline & Eastern Towhee & & Pipilo erythrophthalmus & 1 & 0.0476 \\
\hline & Great Crested Flycatcher & & Myiarchus crinitus & 1 & 0.0476 \\
\hline & Hairy Woodpecker & & Picoides villosus & 1 & 0.0476 \\
\hline & Northern Parula & & Parula americana & 1 & 0.0476 \\
\hline & Northern Waterthrush & & Northern Waterthrush & 1 & 0.0476 \\
\hline & Ovenbird & & Seiurus aurocapillus & 1 & 0.0476 \\
\hline & Red-Eyed Vireo & & Vireo olivaceus & 1 & 0.0476 \\
\hline & Scarlet Tanager & & Piranga olivacea & 1 & 0.0476 \\
\hline & Tufted Titmouse & & Parus bicolor & 2 & 0.0952 \\
\hline & White-Breasted Nuthatch & & Sitta carolinensis & 1 & 0.0476 \\
\hline & Yellow-Billed Cuckoo & & Coccyzus americanus & 1 & 0.0476 \\
\hline
\end{tabular}


Appendix C. Continued.

\begin{tabular}{|c|c|c|c|c|c|}
\hline SiteCode & Species & & Latin name & Jumber observed & $\begin{array}{c}\text { Frequency } \\
\text { per Site }\end{array}$ \\
\hline \multirow[t]{19}{*}{ SMLPEM } & Site abundance: & 33 & & & \\
\hline & Black-capped Chickadee & & Poecile atricapilla & 1 & 0.0303 \\
\hline & Blue-Gray Gnatcatcher & & Polioptila caerulea & 1 & 0.0303 \\
\hline & Cedar Waxwing & & Bombycilla cedrorum & 1 & 0.0303 \\
\hline & Common Yellowthroat & & Geothlypis trichas & 3 & 0.0909 \\
\hline & Eastern Phoebe & & Sayornis phoebe & 2 & 0.0606 \\
\hline & Eastern Towhee & & Pipilo erythrophthalmus & 1 & 0.0303 \\
\hline & Gray Catbird & & Dumetella carolinensis & 1 & 0.0303 \\
\hline & Ovenbird & & Seiurus aurocapillus & 1 & 0.0303 \\
\hline & Pileated Woodpecker & & Dryocopus pileatus & 1 & 0.0303 \\
\hline & Red-Winged Blackbird & & Agelaius phoeniceus & 8 & 0.2424 \\
\hline & Savannah Sparrow & & Passerculus sandwichensis & 2 & 0.0606 \\
\hline & Song Sparrow & & Melospiza melodia & 3 & 0.0909 \\
\hline & Song Sparrow & & Melospiza melodia & 1 & 0.0303 \\
\hline & Spotted Sandpiper & & Actitis macularia & 2 & 0.0606 \\
\hline & Swamp Sparrow & & Melospiza georgiana & 1 & 0.0303 \\
\hline & Swamp Sparrow & & Melospiza georgiana & 2 & 0.0606 \\
\hline & Virginia Rail & & Rallus limicola & 1 & 0.0303 \\
\hline & Yellow-Billed Cuckoo & & Coccyzus americanus & 1 & 0.0303 \\
\hline \multirow[t]{17}{*}{ SMSEFL } & Site abundance: & 37 & & & \\
\hline & Blue-Gray Gnatcatcher & & Polioptila caerulea & 1 & 0.0270 \\
\hline & Canada Goose & & Branta canadensis & 6 & 0.1622 \\
\hline & Cedar Waxwing & & Bombycilla cedrorum & 1 & 0.0270 \\
\hline & Common Grackle & & Quiscalus quiscula & 4 & 0.1081 \\
\hline & Common Yellowthroat & & Geothlypis trichas & 2 & 0.0541 \\
\hline & Eastern Towhee & & Pipilo erythrophthalmus & 2 & 0.0541 \\
\hline & Gray Catbird & & Dumetella carolinensis & 1 & 0.0270 \\
\hline & Great Crested Flycatcher & & Myiarchus crinitus & 1 & 0.0270 \\
\hline & Northern Waterthrush & & Northern Waterthrush & 1 & 0.0270 \\
\hline & Pileated Woodpecker & & Dryocopus pileatus & 1 & 0.0270 \\
\hline & Red-Eyed Vireo & & Vireo olivaceus & 1 & 0.0270 \\
\hline & Red-Winged Blackbird & & Agelaius phoeniceus & 6 & 0.1622 \\
\hline & Spotted Sandpiper & & Actitis macularia & 3 & 0.0811 \\
\hline & Swamp Sparrow & & Melospiza georgiana & 2 & 0.0541 \\
\hline & Tree Swallow & & Tachycineta bicolor & 3 & 0.0811 \\
\hline & Wood Duck & & Aix sponsa & 2 & 0.0541 \\
\hline
\end{tabular}


Appendix C. Continued.

\begin{tabular}{|c|c|c|c|c|c|}
\hline SiteCode & Species & & Latin name & Number observed & $\begin{array}{c}\text { Frequency } \\
\text { per Site }\end{array}$ \\
\hline \multirow[t]{13}{*}{ SMSTEM } & Site abundance: & 15 & & & \\
\hline & Blue-Gray Gnatcatcher & & Polioptila caerulea & 1 & 0.0667 \\
\hline & Blue-Winged Warbler & & Vermivora pinus & 1 & 0.0667 \\
\hline & Common Yellowthroat & & Geothlypis trichas & 2 & 0.1333 \\
\hline & Eastern Towhee & & Pipilo erythrophthalmus & 1 & 0.0667 \\
\hline & Mallard & & Anas platyrhynchos & 2 & 0.1333 \\
\hline & Northern Waterthrush & & Northern Waterthrush & 1 & 0.0667 \\
\hline & Ovenbird & & Seiurus aurocapillus & 2 & 0.1333 \\
\hline & Prothonotary Warbler & & Protonotaria citrea & 1 & 0.0667 \\
\hline & Red-Eyed Vireo & & Vireo olivaceus & 1 & 0.0667 \\
\hline & Solitary Sandpiper & & Tringa solitaria & 1 & 0.0667 \\
\hline & Song Sparrow & & Melospiza melodia & 1 & 0.0667 \\
\hline & Yellow Warbler & & Dendroica petechia & 1 & 0.0667 \\
\hline \multirow[t]{16}{*}{ TRSPFO } & Site abundance: & 18 & & & \\
\hline & Acadian Flycatcher & & Empidonax virescens & 1 & 0.0556 \\
\hline & American Robin & & Turdus migratorius & 1 & 0.0556 \\
\hline & Blue Jay & & Cyanocitta cristata & 2 & 0.1111 \\
\hline & Blue-Gray Gnatcatcher & & Polioptila caerulea & 1 & 0.0556 \\
\hline & Blue-Winged Warbler & & Vermivora pinus & 1 & 0.0556 \\
\hline & Common Yellowthroat & & Geothlypis trichas & 1 & 0.0556 \\
\hline & Eastern Towhee & & Pipilo erythrophthalmus & 2 & 0.1111 \\
\hline & Eastern Wood-Pewee & & Contopus virens & 1 & 0.0556 \\
\hline & Field Sparrow & & Spizella pusilla & 1 & 0.0556 \\
\hline & Gray Catbird & & Dumetella carolinensis & 1 & 0.0556 \\
\hline & Northern Parula & & Parula americana & 1 & 0.0556 \\
\hline & Ovenbird & & Seiurus aurocapillus & 1 & 0.0556 \\
\hline & Red-Eyed Vireo & & Vireo olivaceus & 1 & 0.0556 \\
\hline & Scarlet Tanager & & Piranga olivacea & 1 & 0.0556 \\
\hline & Wood Thrush & & Hylocichla mustelina & 2 & 0.1111 \\
\hline
\end{tabular}


Appendix C. Continued.

\begin{tabular}{|c|c|c|c|c|c|}
\hline SiteCode & Species & & Latin name & Number observed & $\begin{array}{c}\text { Frequency } \\
\text { per Site }\end{array}$ \\
\hline \multirow[t]{22}{*}{ TRSPRI } & Site abundance: & 31 & & & \\
\hline & Baltimore Oriole & & Icterus galbula & 1 & 0.0323 \\
\hline & Blue-Gray Gnatcatcher & & Polioptila caerulea & 1 & 0.0323 \\
\hline & Blue-Headed Vireo & & Vireo solitarius & 1 & 0.0323 \\
\hline & Carolina Chickadee & & Poecile carolinensis & 1 & 0.0323 \\
\hline & Carolina Wren & & Thryothorus ludovicianus & 1 & 0.0323 \\
\hline & Common Yellowthroat & & Geothlypis trichas & 1 & 0.0323 \\
\hline & Eastern Kingbird & & Tyrannus tyrannus & 2 & 0.0645 \\
\hline & Eastern Towhee & & Pipilo erythrophthalmus & 1 & 0.0323 \\
\hline & Field Sparrow & & Spizella pusilla & 1 & 0.0323 \\
\hline & Gray Catbird & & Dumetella carolinensis & 1 & 0.0323 \\
\hline & Northern Cardinal & & Cardinalis cardinalis & 1 & 0.0323 \\
\hline & Northern Flicker & & Colaptes auratus & 1 & 0.0323 \\
\hline & Pileated Woodpecker & & Dryocopus pileatus & 1 & 0.0323 \\
\hline & Red-Billed Woodpecker & & Melanerpes carolinus & 1 & 0.0323 \\
\hline & Red-Eyed Vireo & & Vireo olivaceus & 1 & 0.0323 \\
\hline & Red-Winged Blackbird & & Agelaius phoeniceus & 6 & 0.1935 \\
\hline & Song Sparrow & & Melospiza melodia & 2 & 0.0645 \\
\hline & Swamp Sparrow & & Melospiza georgiana & 1 & 0.0323 \\
\hline & Tree Swallow & & Tachycineta bicolor & 3 & 0.0968 \\
\hline & Wood Thrush & & Hylocichla mustelina & 1 & 0.0323 \\
\hline & Yellow Warbler & & Dendroica petechia & 2 & 0.0645 \\
\hline \multirow[t]{11}{*}{ TVFARM } & Site abundance: & 20 & & & \\
\hline & American Robin & & Turdus migratorius & 1 & 0.0500 \\
\hline & Barn Swallow & & Hirundo rustica & 2 & 0.1000 \\
\hline & Blue Jay & & Cyanocitta cristata & 1 & 0.0500 \\
\hline & Common Yellowthroat & & Geothlypis trichas & 1 & 0.0500 \\
\hline & Eastern Phoebe & & Sayornis phoebe & 1 & 0.0500 \\
\hline & Northern Cardinal & & Cardinalis cardinalis & 2 & 0.1000 \\
\hline & Red-Billed Woodpecker & & Melanerpes carolinus & 1 & 0.0500 \\
\hline & Red-Winged Blackbird & & Agelaius phoeniceus & 7 & 0.3500 \\
\hline & Song Sparrow & & Melospiza melodia & 3 & 0.1500 \\
\hline & Tree Swallow & & Tachycineta bicolor & 1 & 0.0500 \\
\hline
\end{tabular}


Appendix C. Continued.

\begin{tabular}{|c|c|c|c|c|c|}
\hline SiteCode & Species & & Latin name & Number observed & $\begin{array}{l}\text { Frequency } \\
\text { per Site }\end{array}$ \\
\hline \multirow[t]{18}{*}{ TVISLE } & Site abundance: & 24 & & & \\
\hline & American Robin & & Turdus migratorius & 1 & 0.0417 \\
\hline & Belted Kingfisher & & Ceryle alcyon & 1 & 0.0417 \\
\hline & Black-capped Chickadee & & Poecile atricapilla & 1 & 0.0417 \\
\hline & Blue Jay & & Cyanocitta cristata & 1 & 0.0417 \\
\hline & Carolina Chickadee & & Poecile carolinensis & 1 & 0.0417 \\
\hline & Carolina Wren & & Thryothorus ludovicianus & 3 & 0.1250 \\
\hline & Common Grackle & & Quiscalus quiscula & 2 & 0.0833 \\
\hline & Common Yellowthroat & & Geothlypis trichas & 1 & 0.0417 \\
\hline & Eastern Wood-Pewee & & Contopus virens & 1 & 0.0417 \\
\hline & European Starling & & Sturnus vulgaris & 2 & 0.0833 \\
\hline & Gray Catbird & & Dumetella carolinensis & 2 & 0.0833 \\
\hline & Northern Cardinal & & Cardinalis cardinalis & 1 & 0.0417 \\
\hline & Red-Eyed Vireo & & Vireo olivaceus & 1 & 0.0417 \\
\hline & Red-Winged Blackbird & & Agelaius phoeniceus & 2 & 0.0833 \\
\hline & Savannah Sparrow & & Passerculus sandwichensis & 1 & 0.0417 \\
\hline & Song Sparrow & & Melospiza melodia & 2 & 0.0833 \\
\hline & Winter Wren & & Troglodytes troglodytes & 1 & 0.0417 \\
\hline
\end{tabular}


Appendix C. Continued.

\begin{tabular}{|c|c|c|c|c|}
\hline SiteCode & Species & Latin name & Number observed & $\begin{array}{c}\text { Frequency } \\
\text { per Site }\end{array}$ \\
\hline \multirow[t]{21}{*}{ TVNEWT } & Site abundance: & & & \\
\hline & American Goldfinch & Carduelis tristis & 1 & 0.0204 \\
\hline & American Robin & Turdus migratorius & 1 & 0.0204 \\
\hline & Barn Swallow & Hirundo rustica & 3 & 0.0612 \\
\hline & Canada Goose & Branta canadensis & 2 & 0.0408 \\
\hline & Carolina Wren & Thryothorus ludovicianus & 2 & 0.0408 \\
\hline & Common Grackle & Quiscalus quiscula & 1 & 0.0204 \\
\hline & Common Yellowthroat & Geothlypis trichas & 2 & 0.0408 \\
\hline & Gray Catbird & Dumetella carolinensis & 1 & 0.0204 \\
\hline & Green Heron & Butorides virescens & 1 & 0.0204 \\
\hline & Hooded Merganser & Lophodytes cucullatus & 2 & 0.0408 \\
\hline & Indigo Bunting & Passerina cyanea & 1 & 0.0204 \\
\hline & Mallard & Anas platyrhynchos & 1 & 0.0204 \\
\hline & Mourning Dove & Zenaida macroura & 1 & 0.0204 \\
\hline & Red-Winged Blackbird & Agelaius phoeniceus & 18 & 0.3673 \\
\hline & Song Sparrow & Melospiza melodia & 2 & 0.0408 \\
\hline & Spotted Sandpiper & Actitis macularia & 1 & 0.0204 \\
\hline & Tree Swallow & Tachycineta bicolor & 2 & 0.0408 \\
\hline & Willow Flycatcher & Empidonax traillii & 2 & 0.0408 \\
\hline & Wood Duck & Aix sponsa & 2 & 0.0408 \\
\hline & Yellow Warbler & Dendroica petechia & 3 & 0.0612 \\
\hline \multirow[t]{16}{*}{ TVPOUT } & Site abundance: & & & \\
\hline & American Redstart & Setophaga ruticilla & 2 & 0.1000 \\
\hline & American Robin & Turdus migratorius & 3 & 0.1500 \\
\hline & Blue Jay & Cyanocitta cristata & 1 & 0.0500 \\
\hline & Common Yellowthroat & Geothlypis trichas & 1 & 0.0500 \\
\hline & Eastern Wood-Pewee & Contopus virens & 1 & 0.0500 \\
\hline & Gray Catbird & Dumetella carolinensis & 3 & 0.1500 \\
\hline & Indigo Bunting & Passerina cyanea & 1 & 0.0500 \\
\hline & Northern Cardinal & Cardinalis cardinalis & 1 & 0.0500 \\
\hline & Northern Waterthrush & Northern Waterthrush & 1 & 0.0500 \\
\hline & Philadelphia Vireo & Vireo philadelphicus & 1 & 0.0500 \\
\hline & Red-Eyed Vireo & Vireo olivaceus & 1 & 0.0500 \\
\hline & Red-Winged Blackbird & Agelaius phoeniceus & 1 & 0.0500 \\
\hline & Ruby-Throated Hummingbird & Archilochus colubris & 1 & 0.0500 \\
\hline & Willow Flycatcher & Empidonax traillii & 1 & 0.0500 \\
\hline & Yellow Warbler & Dendroica petechia & 1 & 0.0500 \\
\hline
\end{tabular}


Appendix C. Continued.

\begin{tabular}{|c|c|c|c|c|c|}
\hline SiteCode & Species & & Latin name & Jumber observed & $\begin{array}{c}\text { Frequency } \\
\text { per Site }\end{array}$ \\
\hline \multirow[t]{6}{*}{ TVVBEM } & Site abundance: & 15 & & & \\
\hline & American Goldfinch & & Carduelis tristis & 2 & 0.1333 \\
\hline & Cedar Waxwing & & Bombycilla cedrorum & 1 & 0.0667 \\
\hline & Common Yellowthroat & & Geothlypis trichas & 1 & 0.0667 \\
\hline & Red-Winged Blackbird & & Agelaius phoeniceus & 10 & 0.6667 \\
\hline & Tree Swallow & & Tachycineta bicolor & 1 & 0.0667 \\
\hline \multirow[t]{14}{*}{ TVVBIM } & Site abundance: & 22 & & & \\
\hline & American Goldfinch & & Carduelis tristis & 1 & 0.0455 \\
\hline & Brown Thrasher & & Toxostoma rufum & 1 & 0.0455 \\
\hline & Cedar Waxwing & & Bombycilla cedrorum & 1 & 0.0455 \\
\hline & Common Yellowthroat & & Geothlypis trichas & 3 & 0.1364 \\
\hline & Eastern Wood-Pewee & & Contopus virens & 1 & 0.0455 \\
\hline & Gray Catbird & & Dumetella carolinensis & 1 & 0.0455 \\
\hline & Great Crested Flycatcher & & Myiarchus crinitus & 1 & 0.0455 \\
\hline & Northern Cardinal & & Cardinalis cardinalis & 1 & 0.0455 \\
\hline & Red-Winged Blackbird & & Agelaius phoeniceus & 5 & 0.2273 \\
\hline & Savannah Sparrow & & Passerculus sandwichensis & 1 & 0.0455 \\
\hline & Song Sparrow & & Melospiza melodia & 3 & 0.1364 \\
\hline & Willow Flycatcher & & Empidonax traillii & 2 & 0.0909 \\
\hline & Winter Wren & & Troglodytes troglodytes & 1 & 0.0455 \\
\hline \multirow[t]{16}{*}{ TVVBRV } & Site abundance: & 25 & & & \\
\hline & American Goldfinch & & Carduelis tristis & 1 & 0.0400 \\
\hline & Carolina Wren & & Thryothorus ludovicianus & 2 & 0.0800 \\
\hline & Cedar Waxwing & & Bombycilla cedrorum & 1 & 0.0400 \\
\hline & Common Grackle & & Quiscalus quiscula & 4 & 0.1600 \\
\hline & Common Yellowthroat & & Geothlypis trichas & 1 & 0.0400 \\
\hline & Gray Catbird & & Dumetella carolinensis & 1 & 0.0400 \\
\hline & Great Crested Flycatcher & & Myiarchus crinitus & 1 & 0.0400 \\
\hline & Hairy Woodpecker & & Picoides villosus & 2 & 0.0800 \\
\hline & Killdeer & & Charadrius vociferus & 1 & 0.0400 \\
\hline & Northern Flicker & & Colaptes auratus & 1 & 0.0400 \\
\hline & Red-Winged Blackbird & & Agelaius phoeniceus & 3 & 0.1200 \\
\hline & Song Sparrow & & Melospiza melodia & 3 & 0.1200 \\
\hline & Spotted Sandpiper & & Actitis macularia & 1 & 0.0400 \\
\hline & Tufted Titmouse & & Parus bicolor & 2 & 0.0800 \\
\hline & Yellow Warbler & & Dendroica petechia & 1 & 0.0400 \\
\hline
\end{tabular}


Appendix C. Continued.

\begin{tabular}{|c|c|c|c|c|c|}
\hline SiteCode & Species & & Latin name & Number observed & $\begin{array}{c}\text { Frequency } \\
\text { per Site }\end{array}$ \\
\hline \multirow[t]{22}{*}{ TVVBSS } & Site abundance: & 40 & & & \\
\hline & Baltimore Oriole & & Icterus galbula & 1 & 0.0250 \\
\hline & Canada Goose & & Branta canadensis & 2 & 0.0500 \\
\hline & Cedar Waxwing & & Bombycilla cedrorum & 2 & 0.0500 \\
\hline & Common Yellowthroat & & Geothlypis trichas & 3 & 0.0750 \\
\hline & Downy Woodpecker & & Picoides pubescens & 1 & 0.0250 \\
\hline & Eastern Bluebird & & Sialia sialis & 1 & 0.0250 \\
\hline & Eastern Kingbird & & Tyrannus tyrannus & 2 & 0.0500 \\
\hline & Eastern Phoebe & & Sayornis phoebe & 1 & 0.0250 \\
\hline & Eastern Wood-Pewee & & Contopus virens & 1 & 0.0250 \\
\hline & Green Heron & & Butorides virescens & 1 & 0.0250 \\
\hline & Hooded Merganser & & Lophodytes cucullatus & 3 & 0.0750 \\
\hline & Indigo Bunting & & Passerina cyanea & 1 & 0.0250 \\
\hline & Mallard & & Anas platyrhynchos & 1 & 0.0250 \\
\hline & Red-Winged Blackbird & & Agelaius phoeniceus & 8 & 0.2000 \\
\hline & Sedge Wren & & Cistothorus platensis & 1 & 0.0250 \\
\hline & Song Sparrow & & Melospiza melodia & 2 & 0.0500 \\
\hline & Tree Swallow & & Tachycineta bicolor & 3 & 0.0750 \\
\hline & Tufted Titmouse & & Parus bicolor & 1 & 0.0250 \\
\hline & Willow Flycatcher & & Empidonax traillii & 2 & 0.0500 \\
\hline & Winter Wren & & Troglodytes troglodytes & 1 & 0.0250 \\
\hline & Yellow Warbler & & Dendroica petechia & 2 & 0.0500 \\
\hline \multirow[t]{12}{*}{ UDC001 } & Site abundance: & 26 & & & \\
\hline & American Robin & & Turdus migratorius & 1 & 0.0385 \\
\hline & Brown Thrasher & & Toxostoma rufum & 1 & 0.0385 \\
\hline & Chimney Swift & & Chaetura pelagica & 2 & 0.0769 \\
\hline & Common Grackle & & Quiscalus quiscula & 5 & 0.1923 \\
\hline & Common Yellowthroat & & Geothlypis trichas & 3 & 0.1154 \\
\hline & Eastern Wood-Pewee & & Contopus virens & 1 & 0.0385 \\
\hline & Gray Catbird & & Dumetella carolinensis & 4 & 0.1538 \\
\hline & Northern Flicker & & Colaptes auratus & 1 & 0.0385 \\
\hline & Osprey & & Pandion haliaetus & 1 & 0.0385 \\
\hline & Red-Winged Blackbird & & Agelaius phoeniceus & 3 & 0.1154 \\
\hline & Song Sparrow & & Melospiza melodia & 4 & 0.1538 \\
\hline
\end{tabular}


Appendix C. Continued.

\begin{tabular}{|c|c|c|c|c|c|}
\hline SiteCode & Species & & Latin name & Number observed & $\begin{array}{c}\text { Frequency } \\
\text { per Site }\end{array}$ \\
\hline \multirow[t]{15}{*}{ UDC002 } & Site abundance: & 28 & & & \\
\hline & Alder Flycatcher & & Empidonax alnorum & 1 & 0.0357 \\
\hline & Barn Swallow & & Hirundo rustica & 2 & 0.0714 \\
\hline & Cedar Waxwing & & Bombycilla cedrorum & 1 & 0.0357 \\
\hline & Chimney Swift & & Chaetura pelagica & 1 & 0.0357 \\
\hline & Chipping Sparrow & & Spizella passerina & 3 & 0.1071 \\
\hline & Common Grackle & & Quiscalus quiscula & 3 & 0.1071 \\
\hline & Common Yellowthroat & & Geothlypis trichas & 2 & 0.0714 \\
\hline & Gray Catbird & & Dumetella carolinensis & 1 & 0.0357 \\
\hline & Mallard & & Anas platyrhynchos & 1 & 0.0357 \\
\hline & Northern Rough-Winged & Swallow & Stelgidopteryx serripennis & 3 & 0.1071 \\
\hline & Red-Winged Blackbird & & Agelaius phoeniceus & 3 & 0.1071 \\
\hline & Song Sparrow & & Melospiza melodia & 3 & 0.1071 \\
\hline & Tree Swallow & & Tachycineta bicolor & 2 & 0.0714 \\
\hline & Yellow Warbler & & Dendroica petechia & 2 & 0.0714 \\
\hline \multirow[t]{12}{*}{ UDC003 } & Site abundance: & 21 & & & \\
\hline & American Goldfinch & & Carduelis tristis & 2 & 0.0952 \\
\hline & American Robin & & Turdus migratorius & 1 & 0.0476 \\
\hline & Black-capped Chickadee & & Poecile atricapilla & 1 & 0.0476 \\
\hline & Chimney Swift & & Chaetura pelagica & 1 & 0.0476 \\
\hline & Common Yellowthroat & & Geothlypis trichas & 1 & 0.0476 \\
\hline & Eastern Phoebe & & Sayornis phoebe & 1 & 0.0476 \\
\hline & Gray Catbird & & Dumetella carolinensis & 2 & 0.0952 \\
\hline & Mallard & & Anas platyrhynchos & 3 & 0.1429 \\
\hline & Red-Winged Blackbird & & Agelaius phoeniceus & 3 & 0.1429 \\
\hline & Song Sparrow & & Melospiza melodia & 5 & 0.2381 \\
\hline & Wood Duck & & Aix sponsa & 1 & 0.0476 \\
\hline \multirow[t]{11}{*}{ UDC004 } & Site abundance: & 15 & & & \\
\hline & American Robin & & Turdus migratorius & 2 & 0.1333 \\
\hline & Common Yellowthroat & & Geothlypis trichas & 2 & 0.1333 \\
\hline & Eastern Wood-Pewee & & Contopus virens & 1 & 0.0667 \\
\hline & Gray Catbird & & Dumetella carolinensis & 1 & 0.0667 \\
\hline & Northern Flicker & & Colaptes auratus & 1 & 0.0667 \\
\hline & Northern Mockingbird & & Mimus polyglottos & 1 & 0.0667 \\
\hline & Song Sparrow & & Melospiza melodia & 2 & 0.1333 \\
\hline & Tufted Titmouse & & Parus bicolor & 1 & 0.0667 \\
\hline & Willow Flycatcher & & Empidonax traillii & 1 & 0.0667 \\
\hline & Yellow Warbler & & Dendroica petechia & 3 & 0.2000 \\
\hline
\end{tabular}


Appendix C. Continued.

\begin{tabular}{|c|c|c|c|c|c|}
\hline SiteCode & Species & & Latin name & Number observed & $\begin{array}{c}\text { Frequency } \\
\text { per Site }\end{array}$ \\
\hline \multirow[t]{8}{*}{ UDC005 } & Site abundance: & 16 & & & \\
\hline & Barn Swallow & & Hirundo rustica & 1 & 0.0625 \\
\hline & Common Grackle & & Quiscalus quiscula & 1 & 0.0625 \\
\hline & Eastern Meadowlark & & Sturnella magna & 1 & 0.0625 \\
\hline & Mallard & & Anas platyrhynchos & 4 & 0.2500 \\
\hline & Red-Winged Blackbird & & Agelaius phoeniceus & 7 & 0.4375 \\
\hline & Savannah Sparrow & & Passerculus sandwichensis & 1 & 0.0625 \\
\hline & Song Sparrow & & Melospiza melodia & 1 & 0.0625 \\
\hline \multirow[t]{10}{*}{ UDC007 } & Site abundance: & 12 & & & \\
\hline & American Robin & & Turdus migratorius & 2 & 0.1667 \\
\hline & Blue Jay & & Cyanocitta cristata & 1 & 0.0833 \\
\hline & Brown Thrasher & & Toxostoma rufum & 1 & 0.0833 \\
\hline & Eastern Phoebe & & Sayornis phoebe & 2 & 0.1667 \\
\hline & Gray Catbird & & Dumetella carolinensis & 1 & 0.0833 \\
\hline & Indigo Bunting & & Passerina cyanea & 1 & 0.0833 \\
\hline & Northern Mockingbird & & Mimus polyglottos & 1 & 0.0833 \\
\hline & Song Sparrow & & Melospiza melodia & 2 & 0.1667 \\
\hline & Yellow-Rumped Warbler & & Dendroica coronata & 1 & 0.0833 \\
\hline \multirow[t]{14}{*}{ UDC008 } & Site abundance: & 23 & & & \\
\hline & American Goldfinch & & Carduelis tristis & 2 & 0.0870 \\
\hline & American Robin & & Turdus migratorius & 1 & 0.0435 \\
\hline & Blue Jay & & Cyanocitta cristata & 1 & 0.0435 \\
\hline & Brown-Headed Cowbird & & Molothrus ater & 1 & 0.0435 \\
\hline & Common Grackle & & Quiscalus quiscula & 2 & 0.0870 \\
\hline & Eastern Phoebe & & Sayornis phoebe & 1 & 0.0435 \\
\hline & Gray Catbird & & Dumetella carolinensis & 3 & 0.1304 \\
\hline & Northern Cardinal & & Cardinalis cardinalis & 1 & 0.0435 \\
\hline & Red-Winged Blackbird & & Agelaius phoeniceus & 4 & 0.1739 \\
\hline & Song Sparrow & & Melospiza melodia & 3 & 0.1304 \\
\hline & Swamp Sparrow & & Melospiza georgiana & 1 & 0.0435 \\
\hline & Wood Duck & & Aix sponsa & 1 & 0.0435 \\
\hline & Yellow Warbler & & Dendroica petechia & 2 & 0.0870 \\
\hline
\end{tabular}


Appendix C. Continued.

\begin{tabular}{|c|c|c|c|c|c|}
\hline SiteCode & Species & & Latin name & Number observed & $\begin{array}{c}\text { Frequency } \\
\text { per Site }\end{array}$ \\
\hline \multirow[t]{20}{*}{ UDC012 } & Site abundance: & 37 & & & \\
\hline & American Goldfinch & & Carduelis tristis & 6 & 0.1622 \\
\hline & American Robin & & Turdus migratorius & 1 & 0.0270 \\
\hline & Blue Jay & & Cyanocitta cristata & 1 & 0.0270 \\
\hline & Brown Thrasher & & Toxostoma rufum & 2 & 0.0541 \\
\hline & Canada Goose & & Branta canadensis & 2 & 0.0541 \\
\hline & Cedar Waxwing & & Bombycilla cedrorum & 2 & 0.0541 \\
\hline & Common Grackle & & Quiscalus quiscula & 1 & 0.0270 \\
\hline & Common Yellowthroat & & Geothlypis trichas & 2 & 0.0541 \\
\hline & Downy Woodpecker & & Picoides pubescens & 1 & 0.0270 \\
\hline & Eastern Wood-Pewee & & Contopus virens & 1 & 0.0270 \\
\hline & Gray Catbird & & Dumetella carolinensis & 1 & 0.0270 \\
\hline & Green Heron & & Butorides virescens & 1 & 0.0270 \\
\hline & Killdeer & & Charadrius vociferus & 1 & 0.0270 \\
\hline & Mallard & & Anas platyrhynchos & 2 & 0.0541 \\
\hline & Northern Cardinal & & Cardinalis cardinalis & 1 & 0.0270 \\
\hline & Red-Winged Blackbird & & Agelaius phoeniceus & 3 & 0.0811 \\
\hline & Song Sparrow & & Melospiza melodia & 3 & 0.0811 \\
\hline & Tree Swallow & & Tachycineta bicolor & 5 & 0.1351 \\
\hline & Willow Flycatcher & & Empidonax traillii & 1 & 0.0270 \\
\hline \multirow[t]{13}{*}{ UDC013 } & Site abundance: & 17 & & & \\
\hline & American Crow & & Corvus brachyrhynchos & 1 & 0.0588 \\
\hline & Black-capped Chickadee & & Poecile atricapilla & 1 & 0.0588 \\
\hline & Blue Jay & & Cyanocitta cristata & 1 & 0.0588 \\
\hline & Common Yellowthroat & & Geothlypis trichas & 2 & 0.1176 \\
\hline & Eastern Towhee & & Pipilo erythrophthalmus & 3 & 0.1765 \\
\hline & Gray Catbird & & Dumetella carolinensis & 2 & 0.1176 \\
\hline & Hermit Thrush & & Catharus guttatus & 1 & 0.0588 \\
\hline & Magnolia Warbler & & Dendroica magnolia & 1 & 0.0588 \\
\hline & Northern Cardinal & & Cardinalis cardinalis & 1 & 0.0588 \\
\hline & Ovenbird & & Seiurus aurocapillus & 1 & 0.0588 \\
\hline & Pileated Woodpecker & & Dryocopus pileatus & 1 & 0.0588 \\
\hline & Song Sparrow & & Melospiza melodia & 2 & 0.1176 \\
\hline
\end{tabular}


Appendix C. Continued.

\begin{tabular}{|c|c|c|c|c|c|}
\hline SiteCode & Species & & Latin name & Number observed & $\begin{array}{c}\text { Frequency } \\
\text { per Site }\end{array}$ \\
\hline \multirow[t]{12}{*}{ UDC014 } & Site abundance: & 14 & & & \\
\hline & Alder Flycatcher & & Empidonax alnorum & 1 & 0.0714 \\
\hline & American Robin & & Turdus migratorius & 1 & 0.0714 \\
\hline & Black-capped Chickadee & & Poecile atricapilla & 2 & 0.1429 \\
\hline & Blue Jay & & Cyanocitta cristata & 1 & 0.0714 \\
\hline & Common Grackle & & Quiscalus quiscula & 1 & 0.0714 \\
\hline & Common Yellowthroat & & Geothlypis trichas & 3 & 0.2143 \\
\hline & Hermit Thrush & & Catharus guttatus & 1 & 0.0714 \\
\hline & Pileated Woodpecker & & Dryocopus pileatus & 1 & 0.0714 \\
\hline & Red-Winged Blackbird & & Agelaius phoeniceus & 1 & 0.0714 \\
\hline & Song Sparrow & & Melospiza melodia & 1 & 0.0714 \\
\hline & Yellow Warbler & & Dendroica petechia & 1 & 0.0714 \\
\hline \multirow[t]{17}{*}{ UDC015 } & Site abundance: & 42 & & & \\
\hline & American Goldfinch & & Carduelis tristis & 4 & 0.0952 \\
\hline & American Robin & & Turdus migratorius & 1 & 0.0238 \\
\hline & Baltimore Oriole & & Icterus galbula & 3 & 0.0714 \\
\hline & Blue Jay & & Cyanocitta cristata & 1 & 0.0238 \\
\hline & Brown-Headed Cowbird & & Molothrus ater & 1 & 0.0238 \\
\hline & Canada Goose & & Branta canadensis & 2 & 0.0476 \\
\hline & Cedar Waxwing & & Bombycilla cedrorum & 1 & 0.0238 \\
\hline & Common Grackle & & Quiscalus quiscula & 15 & 0.3571 \\
\hline & Common Yellowthroat & & Geothlypis trichas & 3 & 0.0714 \\
\hline & House Wren & & Troglodytes aedon & 1 & 0.0238 \\
\hline & Indigo Bunting & & Passerina cyanea & 1 & 0.0238 \\
\hline & Northern Flicker & & Colaptes auratus & 1 & 0.0238 \\
\hline & Pileated Woodpecker & & Dryocopus pileatus & 1 & 0.0238 \\
\hline & Red-Winged Blackbird & & Agelaius phoeniceus & 4 & 0.0952 \\
\hline & Tree Swallow & & Tachycineta bicolor & 2 & 0.0476 \\
\hline & Turkey Vulture & & Cathartes aura & 1 & 0.0238 \\
\hline
\end{tabular}


Appendix C. Continued.

\begin{tabular}{|c|c|c|c|c|}
\hline SiteCode & Species & Latin name & Number observed & $\begin{array}{c}\text { Frequency } \\
\text { per Site }\end{array}$ \\
\hline \multirow[t]{17}{*}{ UDC016 } & Site abundance: & & & \\
\hline & American Robin & Turdus migratorius & 1 & 0.0417 \\
\hline & Baltimore Oriole & Icterus galbula & 1 & 0.0417 \\
\hline & Black-capped Chickadee & Poecile atricapilla & 1 & 0.0417 \\
\hline & Blue Jay & Cyanocitta cristata & 2 & 0.0833 \\
\hline & Canada Goose & Branta canadensis & 2 & 0.0833 \\
\hline & Common Grackle & Quiscalus quiscula & 1 & 0.0417 \\
\hline & Common Yellowthroat & Geothlypis trichas & 2 & 0.0833 \\
\hline & Downy Woodpecker & Picoides pubescens & 1 & 0.0417 \\
\hline & Gray Catbird & Dumetella carolinensis & 2 & 0.0833 \\
\hline & Louisiana Waterthrush & Seiurus motacilla & 1 & 0.0417 \\
\hline & Louisiana Waterthrush & Seiurus motacilla & 1 & 0.0417 \\
\hline & Mourning Dove & Zenaida macroura & 3 & 0.1250 \\
\hline & Northern Cardinal & Cardinalis cardinalis & 2 & 0.0833 \\
\hline & Northern Mockingbird & Mimus polyglottos & 1 & 0.0417 \\
\hline & Song Sparrow & Melospiza melodia & 2 & 0.0833 \\
\hline & Tree Swallow & Tachycineta bicolor & 1 & 0.0417 \\
\hline \multirow[t]{17}{*}{ UDC017 } & Site abundance: & & & \\
\hline & American Goldfinch & Carduelis tristis & 1 & 0.0400 \\
\hline & Baltimore Oriole & Icterus galbula & 1 & 0.0400 \\
\hline & Black-capped Chickadee & Poecile atricapilla & 1 & 0.0400 \\
\hline & Blue Jay & Cyanocitta cristata & 1 & 0.0400 \\
\hline & Chipping Sparrow & Spizella passerina & 1 & 0.0400 \\
\hline & Common Grackle & Quiscalus quiscula & 1 & 0.0400 \\
\hline & Eastern Towhee & Pipilo erythrophthalmus & 3 & 0.1200 \\
\hline & European Starling & Sturnus vulgaris & 1 & 0.0400 \\
\hline & Gray Catbird & Dumetella carolinensis & 4 & 0.1600 \\
\hline & Great Blue Heron & Ardea herodias & 1 & 0.0400 \\
\hline & Northern Cardinal & Cardinalis cardinalis & 1 & 0.0400 \\
\hline & Northern Flicker & Colaptes auratus & 1 & 0.0400 \\
\hline & Red-Winged Blackbird & Agelaius phoeniceus & 2 & 0.0800 \\
\hline & Ruby-Throated Hummingbird & Archilochus colubris & 1 & 0.0400 \\
\hline & Song Sparrow & Melospiza melodia & 3 & 0.1200 \\
\hline & Wood Duck & Aix sponsa & 2 & 0.0800 \\
\hline
\end{tabular}


Appendix C. Continued.

\begin{tabular}{|c|c|c|c|c|c|}
\hline SiteCode & Species & & Latin name & Number observed & $\begin{array}{c}\text { Frequency } \\
\text { per Site }\end{array}$ \\
\hline \multirow[t]{13}{*}{ UDC018 } & Site abundance: & 24 & & & \\
\hline & American Crow & & Corvus brachyrhynchos & 1 & 0.0417 \\
\hline & American Robin & & Turdus migratorius & 1 & 0.0417 \\
\hline & Baltimore Oriole & & Icterus galbula & 2 & 0.0833 \\
\hline & Barn Swallow & & Hirundo rustica & 2 & 0.0833 \\
\hline & Chimney Swift & & Chaetura pelagica & 2 & 0.0833 \\
\hline & Common Yellowthroat & & Geothlypis trichas & 2 & 0.0833 \\
\hline & Gray Catbird & & Dumetella carolinensis & 2 & 0.0833 \\
\hline & Mallard & & Anas platyrhynchos & 2 & 0.0833 \\
\hline & Red-Winged Blackbird & & Agelaius phoeniceus & 6 & 0.2500 \\
\hline & Song Sparrow & & Melospiza melodia & 2 & 0.0833 \\
\hline & Tree Swallow & & Tachycineta bicolor & 1 & 0.0417 \\
\hline & Wood Duck & & Aix sponsa & 1 & 0.0417 \\
\hline \multirow[t]{13}{*}{ UDC019 } & Site abundance: & 26 & & & \\
\hline & Blue Jay & & Cyanocitta cristata & 1 & 0.0385 \\
\hline & Common Yellowthroat & & Geothlypis trichas & 2 & 0.0769 \\
\hline & Common Yellowthroat & & Geothlypis trichas & 3 & 0.1154 \\
\hline & Eastern Bluebird & & Sialia sialis & 1 & 0.0385 \\
\hline & European Starling & & Sturnus vulgaris & 1 & 0.0385 \\
\hline & Gray Catbird & & Dumetella carolinensis & 1 & 0.0385 \\
\hline & Indigo Bunting & & Passerina cyanea & 2 & 0.0769 \\
\hline & Northern Cardinal & & Cardinalis cardinalis & 3 & 0.1154 \\
\hline & Northern Mockingbird & & Mimus polyglottos & 1 & 0.0385 \\
\hline & Red-Winged Blackbird & & Agelaius phoeniceus & 6 & 0.2308 \\
\hline & Song Sparrow & & Melospiza melodia & 3 & 0.1154 \\
\hline & Tufted Titmouse & & Parus bicolor & 2 & 0.0769 \\
\hline
\end{tabular}


Appendix C. Continued.

\begin{tabular}{|c|c|c|c|c|c|}
\hline SiteCode & Species & & Latin name & Number observed & $\begin{array}{c}\text { Frequency } \\
\text { per Site }\end{array}$ \\
\hline \multirow[t]{14}{*}{ UDC020 } & Site abundance: & 35 & & & \\
\hline & American Crow & & Corvus brachyrhynchos & 7 & 0.2000 \\
\hline & American Robin & & Turdus migratorius & 1 & 0.0286 \\
\hline & Common Yellowthroat & & Geothlypis trichas & 3 & 0.0857 \\
\hline & Eastern Wood-Pewee & & Contopus virens & 2 & 0.0571 \\
\hline & Gray Catbird & & Dumetella carolinensis & 1 & 0.0286 \\
\hline & Great Blue Heron & & Ardea herodias & 1 & 0.0286 \\
\hline & Green Heron & & Butorides virescens & 1 & 0.0286 \\
\hline & Killdeer & & Charadrius vociferus & 1 & 0.0286 \\
\hline & Mourning Dove & & Zenaida macroura & 3 & 0.0857 \\
\hline & Red-Winged Blackbird & & Agelaius phoeniceus & 7 & 0.2000 \\
\hline & Song Sparrow & & Melospiza melodia & 3 & 0.0857 \\
\hline & Tree Swallow & & Tachycineta bicolor & 3 & 0.0857 \\
\hline & Virginia Rail & & Rallus limicola & 2 & 0.0571 \\
\hline \multirow[t]{11}{*}{ VEPCON } & Site abundance: & 16 & & & \\
\hline & Alder Flycatcher & & Empidonax alnorum & 1 & 0.0625 \\
\hline & American Robin & & Turdus migratorius & 1 & 0.0625 \\
\hline & Brown-Headed Cowbird & & Molothrus ater & 1 & 0.0625 \\
\hline & Common Yellowthroat & & Geothlypis trichas & 2 & 0.1250 \\
\hline & Field Sparrow & & Spizella pusilla & 1 & 0.0625 \\
\hline & Killdeer & & Charadrius vociferus & 1 & 0.0625 \\
\hline & Mallard & & Anas platyrhynchos & 2 & 0.1250 \\
\hline & Red-Winged Blackbird & & Agelaius phoeniceus & 5 & 0.3125 \\
\hline & Song Sparrow & & Melospiza melodia & 1 & 0.0625 \\
\hline & Tree Swallow & & Tachycineta bicolor & 1 & 0.0625 \\
\hline \multirow[t]{9}{*}{ VEPCOS } & Site abundance: & 11 & & & \\
\hline & American Crow & & Corvus brachyrhynchos & 1 & 0.0909 \\
\hline & American Robin & & Turdus migratorius & 1 & 0.0909 \\
\hline & Brown-Headed Cowbird & & Molothrus ater & 1 & 0.0909 \\
\hline & Common Yellowthroat & & Geothlypis trichas & 2 & 0.1818 \\
\hline & Ovenbird & & Seiurus aurocapillus & 1 & 0.0909 \\
\hline & Red-Winged Blackbird & & Agelaius phoeniceus & 2 & 0.1818 \\
\hline & Savannah Sparrow & & Passerculus sandwichensis & 2 & 0.1818 \\
\hline & Song Sparrow & & Melospiza melodia & 1 & 0.0909 \\
\hline
\end{tabular}


Appendix C. Continued.

\begin{tabular}{|c|c|c|c|c|c|}
\hline SiteCode & Species & & Latin name & Number observed & $\begin{array}{c}\text { Frequency } \\
\text { per Site }\end{array}$ \\
\hline \multirow[t]{19}{*}{ WBBARN } & Site abundance: & 46 & & & \\
\hline & American Robin & & Turdus migratorius & 1 & 0.0217 \\
\hline & Barn Swallow & & Hirundo rustica & 2 & 0.0435 \\
\hline & Common Grackle & & Quiscalus quiscula & 3 & 0.0652 \\
\hline & Eastern Kingbird & & Tyrannus tyrannus & 1 & 0.0217 \\
\hline & Eastern Meadowlark & & Sturnella magna & 1 & 0.0217 \\
\hline & Field Sparrow & & Spizella pusilla & 2 & 0.0435 \\
\hline & Killdeer & & Charadrius vociferus & 2 & 0.0435 \\
\hline & Mallard & & Anas platyrhynchos & 1 & 0.0217 \\
\hline & Red-Billed Woodpecker & & Melanerpes carolinus & 1 & 0.0217 \\
\hline & Red-Winged Blackbird & & Agelaius phoeniceus & 10 & 0.2174 \\
\hline & Savannah Sparrow & & Passerculus sandwichensis & 6 & 0.1304 \\
\hline & Solitary Sandpiper & & Tringa solitaria & 2 & 0.0435 \\
\hline & Song Sparrow & & Melospiza melodia & 2 & 0.0435 \\
\hline & Tree Swallow & & Tachycineta bicolor & 3 & 0.0652 \\
\hline & Turkey Vulture & & Cathartes aura & 1 & 0.0217 \\
\hline & Virginia Rail & & Rallus limicola & 1 & 0.0217 \\
\hline & Wood Duck & & Aix sponsa & 5 & 0.1087 \\
\hline & Yellow Warbler & & Dendroica petechia & 2 & 0.0435 \\
\hline \multirow[t]{12}{*}{ WBCORN } & Site abundance: & 31 & & & \\
\hline & American Goldfinch & & Carduelis tristis & 1 & 0.0323 \\
\hline & American Kestrel & & Falco sparverius & 1 & 0.0323 \\
\hline & Barn Swallow & & Hirundo rustica & 3 & 0.0968 \\
\hline & Eastern Meadowlark & & Sturnella magna & 2 & 0.0645 \\
\hline & Field Sparrow & & Spizella pusilla & 3 & 0.0968 \\
\hline & Killdeer & & Charadrius vociferus & 3 & 0.0968 \\
\hline & Red-Winged Blackbird & & Agelaius phoeniceus & 9 & 0.2903 \\
\hline & Sedge Wren & & Cistothorus platensis & 2 & 0.0645 \\
\hline & Song Sparrow & & Melospiza melodia & 3 & 0.0968 \\
\hline & Wood Duck & & Aix sponsa & 2 & 0.0645 \\
\hline & Yellow Warbler & & Dendroica petechia & 2 & 0.0645 \\
\hline
\end{tabular}


Appendix C. Continued.

\begin{tabular}{|c|c|c|c|c|c|}
\hline SiteCode & Species & & Latin name & Number observed & $\begin{array}{c}\text { Frequency } \\
\text { per Site }\end{array}$ \\
\hline \multirow[t]{10}{*}{ WBROAD } & Site abundance: & 27 & & & \\
\hline & American Goldfinch & & Carduelis tristis & 1 & 0.0370 \\
\hline & Barn Swallow & & Hirundo rustica & 2 & 0.0741 \\
\hline & Eastern Bluebird & & Sialia sialis & 3 & 0.1111 \\
\hline & Eastern Meadowlark & & Sturnella magna & 1 & 0.0370 \\
\hline & Eastern Phoebe & & Sayornis phoebe & 1 & 0.0370 \\
\hline & Field Sparrow & & Spizella pusilla & 3 & 0.1111 \\
\hline & Indigo Bunting & & Passerina cyanea & 1 & 0.0370 \\
\hline & Red-Winged Blackbird & & Agelaius phoeniceus & 12 & 0.4444 \\
\hline & Song Sparrow & & Melospiza melodia & 3 & 0.1111 \\
\hline \multirow[t]{20}{*}{ WYBEAV } & Site abundance: & 27 & & & \\
\hline & American Crow & & Corvus brachyrhynchos & 1 & 0.0370 \\
\hline & American Goldfinch & & Carduelis tristis & 2 & 0.0741 \\
\hline & Black-and-White Warbler & & Mniotilta varia & 1 & 0.0370 \\
\hline & Black-capped Chickadee & & Poecile atricapilla & 3 & 0.1111 \\
\hline & Blue-Gray Gnatcatcher & & Polioptila caerulea & 2 & 0.0741 \\
\hline & Blue-Headed Vireo & & Vireo solitarius & 1 & 0.0370 \\
\hline & Blue-Winged Warbler & & Vermivora pinus & 1 & 0.0370 \\
\hline & Carolina Chickadee & & Poecile carolinensis & 2 & 0.0741 \\
\hline & Carolina Wren & & Thryothorus ludovicianus & 1 & 0.0370 \\
\hline & Common Yellowthroat & & Geothlypis trichas & 1 & 0.0370 \\
\hline & Gray Catbird & & Dumetella carolinensis & 1 & 0.0370 \\
\hline & Great Blue Heron & & Ardea herodias & 1 & 0.0370 \\
\hline & Indigo Bunting & & Passerina cyanea & 2 & 0.0741 \\
\hline & Northern Cardinal & & Cardinalis cardinalis & 1 & 0.0370 \\
\hline & Northern Parula & & Parula americana & 1 & 0.0370 \\
\hline & Red-Billed Woodpecker & & Melanerpes carolinus & 1 & 0.0370 \\
\hline & Red-Eyed Vireo & & Vireo olivaceus & 2 & 0.0741 \\
\hline & Yellow Warbler & & Dendroica petechia & 2 & 0.0741 \\
\hline & Yellow-Breasted Chat & & Icteria virens & 1 & 0.0370 \\
\hline
\end{tabular}


Appendix C. Continued.

\begin{tabular}{|c|c|c|c|c|}
\hline SiteCode & Species & Latin name & Number observed & $\begin{array}{c}\text { Frequency } \\
\text { per Site }\end{array}$ \\
\hline \multirow[t]{13}{*}{ WYCHWE } & Site abundance: & & & \\
\hline & Acadian Flycatcher & Empidonax virescens & 2 & 0.1111 \\
\hline & American Redstart & Setophaga ruticilla & 2 & 0.1111 \\
\hline & Black-throated Green Warbler & Dendroica virens & 1 & 0.0556 \\
\hline & Carolina Chickadee & Poecile carolinensis & 3 & 0.1667 \\
\hline & Carolina Wren & Thryothorus ludovicianus & 1 & 0.0556 \\
\hline & Common Yellowthroat & Geothlypis trichas & 1 & 0.0556 \\
\hline & Hooded Warbler & Wilsonia citrina & 1 & 0.0556 \\
\hline & Indigo Bunting & Passerina cyanea & 2 & 0.1111 \\
\hline & Kentucky Warbler & Oporornis formosus & 1 & 0.0556 \\
\hline & Northern Parula & Parula americana & 2 & 0.1111 \\
\hline & Red-Billed Woodpecker & Melanerpes carolinus & 1 & 0.0556 \\
\hline & Red-Eyed Vireo & Vireo olivaceus & 1 & 0.0556 \\
\hline \multirow[t]{15}{*}{ WYHCEA } & Site abundance: & & & \\
\hline & American Crow & Corvus brachyrhynchos & 1 & 0.0526 \\
\hline & American Goldfinch & Carduelis tristis & 2 & 0.1053 \\
\hline & American Redstart & Setophaga ruticilla & 1 & 0.0526 \\
\hline & Black-capped Chickadee & Poecile atricapilla & 1 & 0.0526 \\
\hline & Black-throated Green Warbler & Dendroica virens & 1 & 0.0526 \\
\hline & Chestnut-Sided Warbler & Dendroica pensylvanica & 1 & 0.0526 \\
\hline & Common Yellowthroat & Geothlypis trichas & 2 & 0.1053 \\
\hline & Gray Catbird & Dumetella carolinensis & 1 & 0.0526 \\
\hline & Indigo Bunting & Passerina cyanea & 2 & 0.1053 \\
\hline & Kentucky Warbler & Oporornis formosus & 1 & 0.0526 \\
\hline & Northern Parula & Parula americana & 1 & 0.0526 \\
\hline & Song Sparrow & Melospiza melodia & 3 & 0.1579 \\
\hline & White-Eyed Vireo & Vireo griseus & 1 & 0.0526 \\
\hline & Yellow Warbler & Dendroica petechia & 1 & 0.0526 \\
\hline
\end{tabular}


Appendix C. Continued.

\begin{tabular}{|c|c|c|c|c|c|}
\hline SiteCode & Species & & Latin name & Number observed & $\begin{array}{c}\text { Frequency } \\
\text { per Site }\end{array}$ \\
\hline \multirow[t]{13}{*}{ WYINTR } & Site abundance: & 16 & & & \\
\hline & American Crow & & Corvus brachyrhynchos & 1 & 0.0625 \\
\hline & American Robin & & Turdus migratorius & 1 & 0.0625 \\
\hline & Blue-Gray Gnatcatcher & & Polioptila caerulea & 1 & 0.0625 \\
\hline & Carolina Chickadee & & Poecile carolinensis & 2 & 0.1250 \\
\hline & Carolina Wren & & Thryothorus ludovicianus & 1 & 0.0625 \\
\hline & Common Yellowthroat & & Geothlypis trichas & 1 & 0.0625 \\
\hline & Eastern Towhee & & Pipilo erythrophthalmus & 2 & 0.1250 \\
\hline & Indigo Bunting & & Passerina cyanea & 2 & 0.1250 \\
\hline & Northern Cardinal & & Cardinalis cardinalis & 2 & 0.1250 \\
\hline & Red-Billed Woodpecker & & Melanerpes carolinus & 1 & 0.0625 \\
\hline & Red-Eyed Vireo & & Vireo olivaceus & 1 & 0.0625 \\
\hline & Yellow Warbler & & Dendroica petechia & 1 & 0.0625 \\
\hline \multirow[t]{17}{*}{ WYTHOR } & Site abundance: & 22 & & & \\
\hline & Blue Jay & & Cyanocitta cristata & 1 & 0.0455 \\
\hline & Blue-Gray Gnatcatcher & & Polioptila caerulea & 1 & 0.0455 \\
\hline & Blue-Winged Warbler & & Vermivora pinus & 1 & 0.0455 \\
\hline & Carolina Chickadee & & Poecile carolinensis & 1 & 0.0455 \\
\hline & Carolina Wren & & Thryothorus ludovicianus & 1 & 0.0455 \\
\hline & Common Yellowthroat & & Geothlypis trichas & 2 & 0.0909 \\
\hline & Eastern Towhee & & Pipilo erythrophthalmus & 2 & 0.0909 \\
\hline & European Starling & & Sturnus vulgaris & 1 & 0.0455 \\
\hline & Field Sparrow & & Spizella pusilla & 1 & 0.0455 \\
\hline & Gray Catbird & & Dumetella carolinensis & 1 & 0.0455 \\
\hline & Henslow's Sparrow & & Ammodramus henslowii & 1 & 0.0455 \\
\hline & Northern Cardinal & & Cardinalis cardinalis & 1 & 0.0455 \\
\hline & Northern Parula & & Parula americana & 1 & 0.0455 \\
\hline & Red-Winged Blackbird & & Agelaius phoeniceus & 5 & 0.2273 \\
\hline & Scarlet Tanager & & Piranga olivacea & 1 & 0.0455 \\
\hline & Yellow-Breasted Chat & & Icteria virens & 1 & 0.0455 \\
\hline
\end{tabular}


Appendix D. Part 1. Sites and corresponding metric values used in developing class-specific avian wetland indices of biologicalintegrity (AW-IBI) in West Virginia, USA from 2005-2006. Blanks indicate a metric value of zero.

\begin{tabular}{|c|c|c|c|c|c|c|c|c|c|c|c|}
\hline Site Code & $\begin{array}{c}\text { Wetland } \\
\text { Dependency }\end{array}$ & $\begin{array}{l}\text { Wetland } \\
\text { Associated }\end{array}$ & $\begin{array}{l}\text { Facultative } \\
\text { Wetland }\end{array}$ & $\begin{array}{l}\text { neotropical } \\
\text { Migrants }\end{array}$ & $\begin{array}{l}\text { Habitat- } \\
\text { specific }\end{array}$ & $\begin{array}{c}\text { neotropical } \\
\text { Habitat-specific }\end{array}$ & $\begin{array}{c}\text { Edge } \\
\text { species }\end{array}$ & $\begin{array}{l}\text { Year-round } \\
\text { edge species }\end{array}$ & $\begin{array}{c}\text { Carnivorous } \\
\text { Habitat specific }\end{array}$ & Omnivorous & Insectivorous \\
\hline CFCROS & 0.0323 & 0.3226 & 0.6452 & 0.4194 & 0.1613 & 0.1613 & 0.8387 & 0.5484 & 0.1290 & 0.4516 & 0.3871 \\
\hline CFECUR & & 0.0625 & 0.4375 & 0.4375 & 0.3125 & 0.3125 & 0.6875 & 0.5000 & 0.2500 & 0.4375 & 0.3750 \\
\hline CFEINC & 0.0526 & 0.3158 & 0.6316 & 0.2632 & 0.3158 & 0.2105 & 0.6842 & 0.6316 & 0.2105 & 0.6316 & 0.2632 \\
\hline CFSLCH & 0.1034 & 0.2069 & 0.6207 & 0.3103 & 0.4828 & 0.2069 & 0.4828 & 0.3793 & 0.1724 & 0.5862 & 0.2759 \\
\hline CFSLIN & 0.0417 & 0.2500 & 0.5417 & 0.4583 & 0.4167 & 0.3750 & 0.5833 & 0.3750 & 0.3750 & 0.3750 & 0.5417 \\
\hline CGBRID & 0.1905 & 0.3810 & 0.6667 & 0.5714 & 0.7143 & 0.5238 & 0.2857 & 0.1429 & 0.6190 & 0.1905 & 0.7619 \\
\hline CGCPAS & 0.1111 & 0.2222 & 0.5556 & 0.6667 & 0.5000 & 0.3889 & 0.5000 & 0.1667 & 0.2778 & 0.3333 & 0.5556 \\
\hline CGROAD & & 0.0769 & 0.3846 & 0.5385 & 0.3846 & 0.1538 & 0.6154 & 0.1538 & 0.3077 & 0.3077 & 0.6154 \\
\hline CGTRHE & & 0.0526 & 0.2632 & 0.6842 & 0.6842 & 0.5263 & 0.3158 & 0.1053 & 0.3684 & 0.4737 & 0.5263 \\
\hline CHNEER & 0.1250 & 0.5000 & 0.7917 & 0.1667 & 0.2500 & 0.1250 & 0.7500 & 0.6667 & 0.2083 & 0.5000 & 0.3333 \\
\hline $\mathrm{CHSACH}$ & 0.0909 & 0.4545 & 0.5455 & 0.0909 & 0.1818 & 0.0606 & 0.8182 & 0.7273 & 0.0909 & 0.6970 & 0.1515 \\
\hline CHSAFO & & & 0.3810 & 0.0476 & 0.1429 & 0.0476 & 0.8571 & 0.8571 & 0.0952 & 0.7619 & 0.0952 \\
\hline CHSARR & 0.4839 & 0.4839 & 0.6452 & 0.0645 & 0.2258 & 0.0323 & 0.7742 & 0.7097 & 0.0968 & 0.7097 & 0.1935 \\
\hline CHTREE & & 0.0588 & 0.2941 & 0.3529 & 0.2353 & 0.0588 & 0.7647 & 0.2941 & 0.0588 & 0.5294 & 0.4118 \\
\hline CHWWBW & 0.1020 & 0.4694 & 0.6327 & 0.1020 & 0.3061 & 0.0204 & 0.6939 & 0.5510 & 0.1224 & 0.6735 & 0.2857 \\
\hline CHWWEM & 0.0238 & 0.3333 & 0.6429 & 0.1429 & 0.1667 & 0.0476 & 0.8333 & 0.6190 & 0.0952 & 0.6190 & 0.2619 \\
\hline CHWWFO & 0.3636 & 0.3864 & 0.5227 & 0.0682 & 0.5227 & 0.0455 & 0.4773 & 0.4545 & 0.2273 & 0.6364 & 0.2045 \\
\hline CVABBW & 0.2353 & 0.4118 & 0.4706 & 0.2941 & 0.5882 & 0.2941 & 0.2941 & 0.1176 & 0.2941 & 0.4706 & 0.4118 \\
\hline CVABCT & 0.1429 & 0.2381 & 0.4286 & 0.4286 & 0.2857 & 0.2381 & 0.6190 & 0.2857 & 0.1905 & 0.3810 & 0.4286 \\
\hline CVTIMB & 0.1765 & 0.6471 & 0.7059 & 0.2941 & 0.2941 & 0.1765 & 0.7059 & 0.4118 & 0.1765 & 0.4706 & 0.4706 \\
\hline DSPICN & & & 0.1250 & 0.6250 & 0.3125 & 0.3125 & 0.6875 & 0.2500 & 0.3125 & 0.2500 & 0.6250 \\
\hline DSROAR & & 0.3571 & 0.5000 & 0.5000 & 0.3571 & 0.2857 & 0.6429 & 0.1429 & 0.2143 & 0.2857 & 0.5714 \\
\hline DSWILD & & & 0.1429 & 0.5000 & 0.4286 & 0.3571 & 0.5714 & 0.2857 & 0.3571 & 0.5000 & 0.5000 \\
\hline EPCMEM & & 0.4737 & 0.7105 & 0.1842 & 0.1316 & 0.1053 & 0.8684 & 0.7632 & 0.1053 & 0.7105 & 0.2105 \\
\hline EPCMFO & 0.2400 & 0.2800 & 0.4000 & 0.0800 & 0.0800 & & 0.9200 & 0.8000 & 0.0400 & 0.7200 & 0.2000 \\
\hline EPDMFO & & & 0.1333 & 0.0667 & 0.2000 & & 0.8000 & 0.7333 & & 0.6000 & 0.1333 \\
\hline
\end{tabular}


Appendix D. Part 1 continued.

\begin{tabular}{|c|c|c|c|c|c|c|c|c|c|c|c|}
\hline Site Code & $\begin{array}{c}\text { Wetland } \\
\text { Dependency }\end{array}$ & $\begin{array}{l}\text { Wetland } \\
\text { Associated }\end{array}$ & $\begin{array}{l}\text { Facultative } \\
\text { Wetland }\end{array}$ & $\begin{array}{c}\text { neotropical } \\
\text { Migrants }\end{array}$ & $\begin{array}{l}\text { Habitat- } \\
\text { specific }\end{array}$ & $\begin{array}{c}\text { neotropical } \\
\text { Habitat-specific }\end{array}$ & $\begin{array}{l}\text { Edge } \\
\text { species }\end{array}$ & $\begin{array}{l}\text { Year-round } \\
\text { edge species }\end{array}$ & $\begin{array}{l}\text { Carnivorous } \\
\text { Habitat specific }\end{array}$ & Omnivorous & Insectivorous \\
\hline EPDMPU & & & 0.0909 & 0.0909 & & & 1.0000 & 0.8182 & & 0.6364 & 0.0909 \\
\hline EPKYVE & 0.2619 & 0.4286 & 0.6190 & 0.1667 & 0.4048 & 0.1190 & 0.5476 & 0.4762 & 0.1905 & 0.3571 & 0.2143 \\
\hline EPRRXC & & & 0.1429 & 0.3571 & 0.2143 & 0.0714 & 0.7857 & 0.4286 & 0.0714 & 0.6429 & 0.2143 \\
\hline EPSHEM & 0.1538 & 0.2692 & 0.4615 & 0.1538 & 0.1538 & 0.1538 & 0.8462 & 0.7692 & 0.1154 & 0.5385 & 0.2308 \\
\hline EPSHSS & 0.1000 & 0.2333 & 0.4667 & 0.2667 & 0.3000 & 0.1333 & 0.7000 & 0.4667 & 0.1667 & 0.4333 & 0.3333 \\
\hline GBBARN & & 0.3333 & 0.6667 & 0.2917 & 0.2500 & 0.2083 & 0.7500 & 0.5833 & 0.2083 & 0.5833 & 0.3750 \\
\hline GBHOEF & 0.1364 & 0.7045 & 0.7955 & 0.5909 & 0.6364 & 0.5682 & 0.3636 & 0.2727 & 0.5682 & 0.2045 & 0.6818 \\
\hline GBJENK & 0.4872 & 0.7692 & 0.8462 & 0.1026 & 0.4872 & 0.0513 & 0.5128 & 0.4103 & 0.0769 & 0.4359 & 0.1538 \\
\hline GBMAPL & & 0.2105 & 0.5263 & 0.3158 & 0.4211 & 0.1579 & 0.5789 & 0.2632 & 0.1579 & 0.4211 & 0.5263 \\
\hline GBNOFO & 0.0769 & 0.3462 & 0.6538 & 0.2308 & 0.1538 & 0.1538 & 0.8462 & 0.6923 & 0.1538 & 0.5769 & 0.3846 \\
\hline GBNOSS & 0.0385 & 0.5385 & 0.7308 & 0.3462 & 0.2308 & 0.1923 & 0.7692 & 0.5385 & 0.1923 & 0.5000 & 0.4615 \\
\hline GBPLOT & 0.4211 & 0.6316 & 0.8684 & 0.1842 & 0.4737 & 0.1316 & 0.5263 & 0.4474 & 0.1316 & 0.4211 & 0.2368 \\
\hline HCBEAV & & 0.1538 & 0.5000 & 0.3077 & 0.2308 & 0.1923 & 0.7692 & 0.5385 & 0.1538 & 0.6538 & 0.3077 \\
\hline HCMITI & 0.1333 & 0.4000 & 0.7000 & 0.2333 & 0.2333 & 0.1667 & 0.7333 & 0.5667 & 0.2000 & 0.5000 & 0.3667 \\
\hline HCPIPE & 0.0571 & 0.4571 & 0.6571 & 0.2000 & 0.1143 & 0.1143 & 0.8857 & 0.6857 & 0.1143 & 0.6000 & 0.2571 \\
\hline HCRANG & 0.1071 & 0.4286 & 0.5714 & 0.2500 & 0.1429 & 0.1429 & 0.8571 & 0.6071 & 0.1429 & 0.5000 & 0.3214 \\
\hline HIBRID & 0.0313 & 0.2188 & 0.5625 & 0.3750 & 0.2188 & 0.1875 & 0.7813 & 0.5625 & 0.1875 & 0.5313 & 0.3750 \\
\hline HIGATE & 0.0833 & 0.1667 & 0.5417 & 0.2917 & 0.3333 & 0.1667 & 0.6250 & 0.3750 & 0.2083 & 0.3750 & 0.4167 \\
\hline HIJHPK & & 0.0833 & 0.2083 & 0.2917 & 0.2917 & 0.1667 & 0.7083 & 0.5000 & 0.1667 & 0.5000 & 0.3750 \\
\hline HIJHTU & & 0.1905 & 0.4762 & 0.2857 & 0.2381 & 0.1905 & 0.7619 & 0.5714 & 0.1905 & 0.5238 & 0.2381 \\
\hline HIPENC & 0.0625 & 0.5000 & 0.6875 & 0.2500 & 0.2813 & 0.2188 & 0.7188 & 0.5625 & 0.2500 & 0.6563 & 0.3125 \\
\hline HISEWG & 0.0476 & 0.0476 & 0.3333 & 0.4286 & 0.3333 & 0.2381 & 0.6190 & 0.3810 & 0.2381 & 0.5238 & 0.4286 \\
\hline HITRLR & & 0.3704 & 0.6296 & 0.2593 & 0.1481 & 0.1111 & 0.8519 & 0.6296 & 0.1111 & 0.6667 & 0.2963 \\
\hline MCFOUR & & 0.1429 & 0.4286 & 0.3810 & 0.2381 & 0.2381 & 0.7619 & 0.3810 & 0.1905 & 0.6667 & 0.2857 \\
\hline MCMEME & 0.2766 & 0.5319 & 0.8085 & 0.2766 & 0.4894 & 0.2340 & 0.5106 & 0.4255 & 0.3191 & 0.4468 & 0.3617 \\
\hline MCMFOR & 0.1875 & 0.3750 & 0.4688 & 0.2500 & 0.3750 & 0.1250 & 0.6250 & 0.4688 & 0.1875 & 0.5000 & 0.3438 \\
\hline
\end{tabular}


Appendix D. Part 1 continued.

\begin{tabular}{|c|c|c|c|c|c|c|c|c|c|c|c|}
\hline Site Code & $\begin{array}{c}\text { Wetland } \\
\text { Dependency }\end{array}$ & $\begin{array}{l}\text { Wetland } \\
\text { Associated }\end{array}$ & $\begin{array}{l}\text { Facultative } \\
\text { Wetland }\end{array}$ & $\begin{array}{l}\text { neotropical } \\
\text { Migrants }\end{array}$ & $\begin{array}{l}\text { Habitat- } \\
\text { specific }\end{array}$ & $\begin{array}{c}\text { neotropical } \\
\text { Habitat-specific }\end{array}$ & $\begin{array}{l}\text { Edge } \\
\text { species }\end{array}$ & $\begin{array}{l}\text { Year-round } \\
\text { edge species }\end{array}$ & $\begin{array}{l}\text { Carnivorous } \\
\text { Habitat specific }\end{array}$ & Omnivorous & Insectivorous \\
\hline MCNPFO & & 0.1429 & 0.2857 & 0.5000 & 0.2143 & 0.2143 & 0.7857 & 0.3571 & 0.1429 & 0.5000 & 0.4286 \\
\hline MCPOND & 0.0667 & 0.2667 & 0.4000 & 0.2000 & 0.2667 & 0.2000 & 0.7333 & 0.6000 & 0.2000 & 0.5333 & 0.2667 \\
\hline MCPOST & 0.0435 & 0.2174 & 0.4783 & 0.2609 & 0.3043 & 0.1304 & 0.6957 & 0.4348 & 0.1304 & 0.6957 & 0.3043 \\
\hline MCTELE & & 0.2000 & 0.4500 & 0.2000 & 0.1000 & 0.1000 & 0.9000 & 0.7500 & 0.1000 & 0.7000 & 0.2000 \\
\hline ME5092 & 0.0952 & 0.4762 & 0.8571 & 0.2857 & 0.1429 & 0.1429 & 0.8571 & 0.6190 & 0.1429 & 0.5238 & 0.3810 \\
\hline MESCOX & & 0.1154 & 0.6538 & 0.3846 & 0.3462 & 0.2308 & 0.6538 & 0.3462 & 0.2308 & 0.4615 & 0.4615 \\
\hline MESCRO & 0.0645 & 0.4839 & 0.8387 & 0.2903 & 0.1613 & 0.1290 & 0.8387 & 0.5806 & 0.1290 & 0.6129 & 0.2903 \\
\hline MESCUP & & 0.0909 & 0.4545 & 0.2727 & 0.3182 & 0.1818 & 0.6818 & 0.4545 & 0.1364 & 0.5909 & 0.2727 \\
\hline MESIGN & & 0.1429 & 0.6190 & 0.0952 & 0.0952 & & 0.9048 & 0.6190 & & 0.6190 & 0.1905 \\
\hline MESILV & & 0.4138 & 0.7931 & 0.3103 & 0.2069 & 0.1724 & 0.7931 & 0.5172 & 0.1724 & 0.5172 & 0.4138 \\
\hline METETR & 0.0909 & 0.5000 & 0.8182 & 0.2273 & 0.2273 & 0.0455 & 0.7727 & 0.5909 & 0.1364 & 0.6818 & 0.2727 \\
\hline MEWOLF & 0.0800 & 0.4000 & 0.8000 & 0.2800 & 0.1200 & 0.0400 & 0.8800 & 0.3600 & 0.0400 & 0.4400 & 0.4400 \\
\hline MRBESS & & 0.3125 & 0.4375 & 0.4375 & 0.4375 & 0.3750 & 0.5625 & 0.3750 & 0.3125 & 0.5000 & 0.4375 \\
\hline MRFARM & & 0.1053 & 0.4211 & 0.3684 & 0.0526 & & 0.9474 & 0.3684 & & 0.4737 & 0.3158 \\
\hline MRFORE & & 0.2000 & 0.3333 & 0.5333 & 0.2667 & 0.2667 & 0.7333 & 0.2000 & 0.2000 & 0.4000 & 0.5333 \\
\hline MRSSSS & & 0.1111 & 0.3333 & 0.4444 & 0.3333 & 0.2778 & 0.6667 & 0.3333 & 0.1111 & 0.6667 & 0.2778 \\
\hline MRWEST & & & 0.2353 & 0.4118 & 0.3529 & 0.2941 & 0.6471 & 0.4118 & 0.2353 & 0.4706 & 0.2941 \\
\hline MU55SS & 0.0556 & 0.2778 & 0.6111 & 0.2222 & 0.0556 & 0.0556 & 0.9444 & 0.5000 & 0.0556 & 0.5556 & 0.3889 \\
\hline MUDBOA & 0.0714 & 0.3571 & 0.4286 & 0.7143 & 0.5714 & 0.5000 & 0.4286 & 0.2143 & 0.5714 & 0.2143 & 0.7857 \\
\hline MUDEND & 0.1136 & 0.2727 & 0.5682 & 0.3864 & 0.5682 & 0.2955 & 0.4318 & 0.2955 & 0.3182 & 0.4091 & 0.4318 \\
\hline MUDRIC & 0.0556 & 0.2222 & 0.2778 & 0.6111 & 0.5000 & 0.3889 & 0.5000 & 0.1111 & 0.3333 & 0.3889 & 0.6111 \\
\hline MUDRIP & 0.0769 & 0.3590 & 0.5641 & 0.3077 & 0.3333 & 0.1795 & 0.6667 & 0.3590 & 0.2564 & 0.3590 & 0.4615 \\
\hline MUDTRA & 0.0645 & 0.2903 & 0.6452 & 0.2903 & 0.2581 & 0.1290 & 0.7097 & 0.3871 & 0.1935 & 0.4839 & 0.4194 \\
\hline MUEPAH & 0.0455 & 0.3636 & 0.6364 & 0.2273 & 0.1818 & 0.0909 & 0.7727 & 0.4091 & 0.1364 & 0.5000 & 0.3182 \\
\hline MUMINE & & 0.1000 & 0.5000 & 0.3000 & 0.4500 & 0.3000 & 0.5000 & 0.4000 & 0.3500 & 0.4500 & 0.4000 \\
\hline MUPOWR & 0.0435 & 0.2174 & 0.4348 & 0.2174 & 0.2174 & 0.1304 & 0.7826 & 0.6087 & 0.1304 & 0.6087 & 0.2609 \\
\hline
\end{tabular}


Appendix D. Part 1 continued.

\begin{tabular}{|c|c|c|c|c|c|c|c|c|c|c|c|}
\hline Site Code & $\begin{array}{c}\text { Wetland } \\
\text { Dependency }\end{array}$ & $\begin{array}{c}\text { Wetland } \\
\text { Associated }\end{array}$ & $\begin{array}{l}\text { Facultative } \\
\text { Wetland }\end{array}$ & $\begin{array}{c}\text { neotropical } \\
\text { Migrants }\end{array}$ & $\begin{array}{l}\text { Habitat- } \\
\text { specific }\end{array}$ & $\begin{array}{c}\text { neotropical } \\
\text { Habitat-specific }\end{array}$ & $\begin{array}{c}\text { Edge } \\
\text { species }\end{array}$ & $\begin{array}{l}\text { Year-round } \\
\text { edge species }\end{array}$ & $\begin{array}{l}\text { Carnivorous } \\
\text { Habitat specific }\end{array}$ & Omnivorous & Insectivorous \\
\hline MUPULL & 0.0968 & 0.3226 & 0.7097 & 0.3548 & 0.2903 & 0.1613 & 0.7097 & 0.4516 & 0.2258 & 0.3871 & 0.4839 \\
\hline MUVBRD & 0.0313 & 0.3438 & 0.7500 & 0.3125 & 0.3438 & 0.2188 & 0.6250 & 0.4375 & 0.2813 & 0.5000 & 0.4063 \\
\hline MUVCRN & 0.2258 & 0.5161 & 0.8387 & 0.2258 & 0.1613 & 0.1290 & 0.8387 & 0.7097 & 0.1290 & 0.6774 & 0.2581 \\
\hline OHHSFO & & 0.1875 & 0.3750 & 0.1875 & 0.3125 & 0.1875 & 0.6875 & 0.5000 & 0.1250 & 0.6250 & 0.3125 \\
\hline OHINNS & 0.0345 & 0.3448 & 0.5862 & 0.3448 & 0.3793 & 0.2759 & 0.6207 & 0.4483 & 0.2759 & 0.5862 & 0.3448 \\
\hline OHKMRT & 0.0400 & 0.3200 & 0.4800 & 0.2400 & 0.1600 & 0.1600 & 0.6000 & 0.5200 & 0.1600 & 0.3600 & 0.2400 \\
\hline PA29TH & 0.0781 & 0.2031 & 0.4531 & 0.1406 & 0.2656 & 0.1250 & 0.7344 & 0.6563 & 0.1563 & 0.3438 & 0.2656 \\
\hline PA83CR & & 0.0769 & 0.2692 & 0.1923 & 0.1154 & 0.0769 & 0.8846 & 0.7308 & 0.0769 & 0.5769 & 0.1154 \\
\hline PAFAMD & 0.2157 & 0.3137 & 0.5098 & 0.1176 & 0.3529 & 0.0588 & 0.6275 & 0.5490 & 0.1373 & 0.4902 & 0.1961 \\
\hline PAJCPY & 0.2941 & 0.3333 & 0.5098 & 0.1765 & 0.3725 & 0.0784 & 0.6275 & 0.4510 & 0.1569 & 0.3333 & 0.4118 \\
\hline PALOUD & 0.0313 & 0.1875 & 0.5313 & 0.4063 & 0.3438 & 0.2500 & 0.6563 & 0.4375 & 0.2500 & 0.5313 & 0.3750 \\
\hline PAPEFO & 0.1000 & 0.1500 & 0.3000 & 0.2500 & 0.2500 & 0.1500 & 0.7500 & 0.5000 & 0.1000 & 0.4500 & 0.3500 \\
\hline PAPEIM & & 0.5172 & 0.6552 & 0.1034 & 0.0690 & 0.0345 & 0.8966 & 0.7586 & 0.0345 & 0.7241 & 0.0690 \\
\hline PAPESW & 0.1000 & 0.3250 & 0.5000 & 0.2500 & 0.4250 & 0.1750 & 0.5750 & 0.4750 & 0.2500 & 0.5500 & 0.3000 \\
\hline PAWILL & 0.1951 & 0.5122 & 0.5854 & 0.0488 & 0.1951 & & 0.8049 & 0.7561 & 0.0732 & 0.5854 & 0.0732 \\
\hline PCBLUE & & 0.2400 & 0.5600 & 0.2400 & 0.1600 & 0.1600 & 0.8400 & 0.6400 & 0.1600 & 0.5600 & 0.3600 \\
\hline PCLPFO & 0.0526 & 0.1053 & 0.2105 & 0.5263 & 0.2105 & 0.1053 & 0.7895 & 0.3158 & 0.1053 & 0.3158 & 0.3684 \\
\hline PCROAD & 0.0714 & 0.2143 & 0.5357 & 0.2857 & 0.2143 & 0.1429 & 0.7857 & 0.5714 & 0.1786 & 0.4286 & 0.3929 \\
\hline PEMIDW & & 0.2273 & 0.5000 & 0.4545 & 0.1818 & 0.1364 & 0.7727 & 0.2727 & 0.0909 & 0.5909 & 0.3182 \\
\hline PERDDP & & 0.4286 & 0.7143 & 0.1429 & 0.1071 & 0.0714 & 0.8929 & 0.7500 & 0.1071 & 0.5714 & 0.2143 \\
\hline PETHUM & & 0.1667 & 0.5000 & 0.3333 & 0.3333 & 0.2222 & 0.6667 & 0.3889 & 0.2222 & 0.4444 & 0.5556 \\
\hline PETOSS & & 0.3600 & 0.7200 & 0.3600 & 0.2400 & 0.1600 & 0.7600 & 0.4800 & 0.1200 & 0.6400 & 0.2800 \\
\hline RIASIA & & 0.1143 & 0.5143 & 0.2857 & 0.1714 & 0.1143 & 0.8286 & 0.5714 & 0.1143 & 0.6857 & 0.2857 \\
\hline RIBRID & 0.0323 & 0.1613 & 0.4839 & 0.3548 & 0.2903 & 0.1935 & 0.7097 & 0.4516 & 0.1935 & 0.5484 & 0.3226 \\
\hline RIEAST & & 0.1739 & 0.5652 & 0.5217 & 0.4783 & 0.3913 & 0.5217 & 0.3043 & 0.3478 & 0.5217 & 0.4348 \\
\hline SJBOAT & 0.0909 & 0.1818 & 0.6364 & 0.6364 & 0.4545 & 0.4091 & 0.5455 & 0.2273 & 0.4091 & 0.4545 & 0.4545 \\
\hline
\end{tabular}


Appendix D. Part 1 continued.

\begin{tabular}{|c|c|c|c|c|c|c|c|c|c|c|c|}
\hline Site Code & $\begin{array}{l}\text { Wetland } \\
\text { Dependency }\end{array}$ & $\begin{array}{c}\text { Wetland } \\
\text { Associated }\end{array}$ & $\begin{array}{l}\text { Facultative } \\
\text { Wetland }\end{array}$ & $\begin{array}{l}\text { neotropical } \\
\text { Migrants }\end{array}$ & $\begin{array}{l}\text { Habitat- } \\
\text { specific }\end{array}$ & $\begin{array}{c}\text { neotropical } \\
\text { Habitat-specific }\end{array}$ & $\begin{array}{l}\text { Edge } \\
\text { species }\end{array}$ & $\begin{array}{l}\text { Year-round } \\
\text { edge species }\end{array}$ & $\begin{array}{c}\text { Carnivorous } \\
\text { Habitat specific }\end{array}$ & Omnivorous & Insectivorous \\
\hline SJBRID & & 0.2609 & 0.5652 & 0.2609 & 0.0870 & 0.0870 & 0.9130 & 0.6522 & 0.0870 & 0.6522 & 0.2174 \\
\hline SJCHUR & 0.1724 & 0.3448 & 0.8276 & 0.4828 & 0.3448 & 0.2759 & 0.6552 & 0.3448 & 0.3103 & 0.5172 & 0.4483 \\
\hline SJGLAD & & 0.1364 & 0.5455 & 0.5455 & 0.3182 & 0.3182 & 0.6818 & 0.3636 & 0.3182 & 0.4545 & 0.4545 \\
\hline SJMUDL & & 0.0833 & 0.4583 & 0.5417 & 0.2917 & 0.2917 & 0.7083 & 0.3333 & 0.2500 & 0.5000 & 0.4583 \\
\hline SJPLOT & 0.0400 & 0.2000 & 0.5600 & 0.4800 & 0.2800 & 0.2800 & 0.7200 & 0.3600 & 0.2800 & 0.3600 & 0.5600 \\
\hline SJTELE & & 0.1579 & 0.5789 & 0.6316 & 0.2632 & 0.2632 & 0.7368 & 0.2632 & 0.2632 & 0.4737 & 0.4737 \\
\hline SMDTSS & 0.0833 & 0.3750 & 0.5833 & 0.2500 & 0.4167 & 0.2083 & 0.5833 & 0.3333 & 0.2500 & 0.4583 & 0.5000 \\
\hline SMFOFL & 0.0476 & 0.2857 & 0.4762 & 0.5714 & 0.5714 & 0.3810 & 0.4286 & 0.0476 & 0.4286 & 0.3810 & 0.6190 \\
\hline SMLPEM & 0.1818 & 0.5152 & 0.7576 & 0.1515 & 0.2727 & 0.1212 & 0.7273 & 0.4545 & 0.1818 & 0.5758 & 0.3333 \\
\hline SMSEFL & 0.3784 & 0.5946 & 0.7297 & 0.2703 & 0.5405 & 0.2432 & 0.4595 & 0.3243 & 0.2703 & 0.4054 & 0.3514 \\
\hline SMSTEM & 0.3333 & 0.4667 & 0.7333 & 0.5333 & 0.4667 & 0.4000 & 0.5333 & 0.2000 & 0.4667 & 0.2667 & 0.7333 \\
\hline TRSPFO & & 0.1667 & 0.3333 & 0.5556 & 0.3889 & 0.3889 & 0.6111 & 0.2778 & 0.2778 & 0.4444 & 0.4444 \\
\hline TRSPRI & 0.0323 & 0.2581 & 0.5806 & 0.3871 & 0.3871 & 0.2581 & 0.6129 & 0.4194 & 0.2581 & 0.5484 & 0.4194 \\
\hline TVFARM & & 0.4000 & 0.6500 & 0.1500 & 0.1000 & 0.0500 & 0.9000 & 0.7000 & 0.0500 & 0.6000 & 0.2500 \\
\hline TVISLE & 0.0417 & 0.2083 & 0.4167 & 0.0833 & 0.1667 & & 0.8333 & 0.6667 & 0.0833 & 0.5417 & 0.2917 \\
\hline TVNEWT & 0.2245 & 0.6327 & 0.8163 & 0.2449 & 0.2449 & 0.1020 & 0.7551 & 0.5714 & 0.1224 & 0.5102 & 0.3265 \\
\hline TVPOUT & 0.1000 & 0.2000 & 0.5000 & 0.4500 & 0.1000 & 0.1000 & 0.9000 & 0.4500 & 0.1000 & 0.4000 & 0.4500 \\
\hline TVVBEM & & 0.7333 & 0.8000 & 0.0667 & 0.0667 & 0.0667 & 0.9333 & 0.8667 & 0.0667 & 0.6667 & 0.1333 \\
\hline TVVBIM & 0.0909 & 0.5000 & 0.7273 & 0.1818 & 0.1818 & 0.1364 & 0.8182 & 0.5909 & 0.1818 & 0.4545 & 0.3636 \\
\hline TVVBRV & 0.0400 & 0.2000 & 0.4800 & 0.1200 & 0.2800 & 0.0800 & 0.7200 & 0.6400 & 0.1600 & 0.5600 & 0.3600 \\
\hline TVVBSS & 0.2250 & 0.5500 & 0.7750 & 0.3000 & 0.4250 & 0.1750 & 0.5750 & 0.3500 & 0.2500 & 0.3750 & 0.4500 \\
\hline UDC001 & 0.0385 & 0.2692 & 0.5769 & 0.1154 & 0.0769 & & 0.9231 & 0.6923 & 0.0385 & 0.7308 & 0.2308 \\
\hline UDC002 & 0.0714 & 0.3571 & 0.6429 & 0.3929 & 0.2143 & 0.2143 & 0.7857 & 0.4286 & 0.2143 & 0.5000 & 0.4643 \\
\hline UDC003 & 0.1905 & 0.3810 & 0.7143 & 0.0476 & 0.0476 & & 0.9524 & 0.8095 & & 0.7143 & 0.1429 \\
\hline UDC004 & 0.0667 & 0.2000 & 0.6667 & 0.3333 & 0.2000 & 0.0667 & 0.8000 & 0.4000 & 0.0667 & 0.5333 & 0.4667 \\
\hline UDC005 & 0.2500 & 0.6875 & 0.8125 & 0.0625 & & & 1.0000 & 0.8750 & & 0.8750 & 0.0625 \\
\hline
\end{tabular}


Appendix D. Part 1 continued.

\begin{tabular}{|c|c|c|c|c|c|c|c|c|c|c|c|}
\hline Site Code & $\begin{array}{c}\text { Wetland } \\
\text { Dependency }\end{array}$ & $\begin{array}{l}\text { Wetland } \\
\text { Associated }\end{array}$ & $\begin{array}{l}\text { Facultative } \\
\text { Wetland }\end{array}$ & $\begin{array}{l}\text { neotropical } \\
\text { Migrants }\end{array}$ & $\begin{array}{l}\text { Habitat- } \\
\text { specific }\end{array}$ & $\begin{array}{c}\text { neotropical } \\
\text { Habitat-specific }\end{array}$ & $\begin{array}{l}\text { Edge } \\
\text { species }\end{array}$ & $\begin{array}{l}\text { Year-round } \\
\text { edge species }\end{array}$ & $\begin{array}{l}\text { Carnivorous } \\
\text { Habitat specific }\end{array}$ & Omnivorous & Insectivorous \\
\hline UDC007 & & & 0.4167 & 0.1667 & 0.0833 & 0.0833 & 0.9167 & 0.6667 & & 0.7500 & 0.1667 \\
\hline UDC008 & 0.0870 & 0.2609 & 0.6087 & 0.0870 & 0.0870 & & 0.9130 & 0.7826 & & 0.6522 & 0.1304 \\
\hline UDC012 & 0.1622 & 0.2973 & 0.5405 & 0.1892 & 0.2432 & 0.1622 & 0.7568 & 0.6757 & 0.1892 & 0.3514 & 0.3243 \\
\hline UDC013 & & 0.1176 & 0.3529 & 0.1765 & 0.1765 & 0.1176 & 0.8235 & 0.4706 & 0.1176 & 0.5882 & 0.2941 \\
\hline UDC014 & 0.0714 & 0.3571 & 0.5000 & 0.2143 & 0.2143 & 0.1429 & 0.7857 & 0.5000 & 0.1429 & 0.5000 & 0.4286 \\
\hline UDC015 & 0.0476 & 0.2143 & 0.2857 & 0.1429 & 0.1429 & 0.0476 & 0.8571 & 0.6667 & 0.0714 & 0.6190 & 0.1905 \\
\hline UDC016 & 0.1250 & 0.2083 & 0.4167 & 0.1250 & 0.1667 & 0.0833 & 0.7917 & 0.6667 & 0.1250 & 0.3750 & 0.2083 \\
\hline UDC017 & 0.1200 & 0.2000 & 0.5200 & 0.0800 & 0.2000 & & 0.8000 & 0.5600 & 0.0400 & 0.7200 & 0.0400 \\
\hline UDC018 & 0.1250 & 0.4583 & 0.6667 & 0.2917 & 0.0833 & 0.0417 & 0.9167 & 0.5833 & 0.0417 & 0.6667 & 0.2917 \\
\hline UDC019 & & 0.4231 & 0.7308 & 0.0769 & 0.1538 & & 0.8462 & 0.5769 & & 0.6538 & 0.1923 \\
\hline UDC020 & 0.1143 & 0.4000 & 0.6000 & 0.1429 & 0.2000 & 0.0857 & 0.8000 & 0.6571 & 0.2000 & 0.5429 & 0.3714 \\
\hline VEPCON & 0.1875 & 0.6250 & 0.7500 & 0.1250 & 0.1250 & 0.1250 & 0.8750 & 0.7500 & 0.1250 & 0.6875 & 0.3125 \\
\hline VEPCOS & & 0.3636 & 0.6364 & 0.0909 & 0.0909 & 0.0909 & 0.9091 & 0.5455 & 0.0909 & 0.5455 & 0.2727 \\
\hline WBBARN & 0.1957 & 0.4130 & 0.7174 & 0.1739 & 0.2826 & 0.0870 & 0.7174 & 0.5000 & 0.1522 & 0.4565 & 0.3043 \\
\hline WBCORN & 0.0645 & 0.4194 & 0.5806 & 0.1613 & 0.1290 & & 0.8710 & 0.6774 & 0.0645 & 0.5484 & 0.3548 \\
\hline WBROAD & & 0.4444 & 0.5926 & 0.1111 & 0.1111 & & 0.8889 & 0.7407 & & 0.8519 & 0.1111 \\
\hline WYBEAV & 0.0370 & 0.1111 & 0.4815 & 0.4815 & 0.3333 & 0.2593 & 0.6667 & 0.4074 & 0.2963 & 0.3704 & 0.5185 \\
\hline WYCHWE & & 0.3889 & 0.5556 & 0.6667 & 0.4444 & 0.3889 & 0.5556 & 0.2222 & 0.3889 & 0.3333 & 0.6667 \\
\hline WYHCEA & & 0.2632 & 0.6316 & 0.4737 & 0.2105 & 0.2105 & 0.7895 & 0.4211 & 0.2105 & 0.4211 & 0.4737 \\
\hline WYINTR & & 0.0625 & 0.3750 & 0.3125 & 0.1250 & 0.0625 & 0.8750 & 0.4375 & 0.0625 & 0.5625 & 0.3125 \\
\hline WYTHOR & & 0.4091 & 0.5909 & 0.2273 & 0.2727 & 0.1818 & 0.7273 & 0.5000 & 0.1818 & 0.5455 & 0.3182 \\
\hline
\end{tabular}


Appendix D. Part 2. Sites and corresponding metric values used in developing class-specific avian wetland indices of biologicalintegrity (AW-IBI) in West Virginia, USA from 2005-2006.Blanks indicate a metric value of zero.

\begin{tabular}{|c|c|c|c|c|c|c|c|c|c|c|c|}
\hline Site Code & Diversity & $\begin{array}{l}\text { Wetland spp. } \\
\text { Diversity }\end{array}$ & Richness & Abundance & $\begin{array}{l}\text { Wetland spp. } \\
\text { Richness }\end{array}$ & $\begin{array}{l}\text { Wetland spp. } \\
\text { abundance }\end{array}$ & $\begin{array}{l}\text { Nest predator, } \\
\text { Brood parasite }\end{array}$ & Shrub nesting & Single Brood & $\begin{array}{c}\text { Shannon's } \\
\text { Evenness index }\end{array}$ & $\begin{array}{c}\text { Forest area } \\
\text { Sensitive }\end{array}$ \\
\hline CFCROS & 5.5588 & 3.2068 & 16 & 31 & 8 & 20 & & 0.7097 & 0.4839 & 0.1509 & 0.0645 \\
\hline CFECUR & 5.7103 & 2.1163 & 13 & 16 & 5 & 7 & & 0.3125 & 0.5000 & 0.1908 & 0.1875 \\
\hline CFEINC & 5.4358 & 2.4844 & 12 & 19 & 6 & 12 & 0.1053 & 0.4211 & 0.3158 & 0.1967 & \\
\hline CFSLCH & 6.5697 & 2.4543 & 21 & 29 & 13 & 19 & 0.0690 & 0.2759 & 0.6207 & 0.1359 & 0.0690 \\
\hline CFSLIN & 7.0517 & 2.0260 & 22 & 24 & 12 & 13 & 0.0417 & 0.3333 & 0.5000 & 0.1392 & 0.2083 \\
\hline CGBRID & 5.7369 & 3.5484 & 13 & 21 & 8 & 14 & 0.0476 & 0.2857 & 0.6667 & 0.1917 & 0.4762 \\
\hline CGCPAS & 5.9460 & 2.5427 & 14 & 18 & 7 & 10 & 0.1111 & 0.2222 & 0.6667 & 0.1845 & 0.4444 \\
\hline CGROAD & 4.9606 & 2.3263 & 11 & 13 & 4 & 5 & & 0.3077 & 0.6923 & 0.1959 & 0.3846 \\
\hline CGTRHE & 6.2758 & 2.3263 & 16 & 19 & 4 & 5 & & 0.1053 & 0.5789 & 0.1703 & 0.7368 \\
\hline CHNEER & 5.1395 & 3.6715 & 13 & 24 & 8 & 19 & 0.0833 & 0.5000 & 0.2500 & 0.1717 & \\
\hline $\mathrm{CHSACH}$ & 5.5975 & 2.7411 & 16 & 33 & 6 & 18 & 0.1818 & 0.4848 & 0.3333 & 0.1519 & \\
\hline CHSAFO & 4.6452 & 1.0953 & 10 & 21 & 3 & 8 & 0.0952 & 0.1429 & 0.3333 & 0.2017 & 0.0476 \\
\hline CHSARR & 5.1773 & 2.4559 & 15 & 31 & 6 & 20 & 0.0968 & 0.1935 & 0.1613 & 0.1499 & \\
\hline CHTREE & 5.9604 & 1.4823 & 14 & 17 & 5 & 5 & & 0.2941 & 0.4706 & 0.1849 & 0.1765 \\
\hline CHWWBW & 5.7290 & 3.4291 & 20 & 49 & 11 & 31 & 0.2245 & 0.4490 & 0.2653 & 0.1244 & 0.0204 \\
\hline CHWWEM & 6.1141 & 3.8593 & 20 & 42 & 10 & 27 & 0.0238 & 0.4524 & 0.3333 & 0.1328 & 0.0714 \\
\hline CHWWFO & 6.3366 & 3.8744 & 20 & 44 & 9 & 23 & 0.1364 & 0.0455 & 0.4773 & 0.1376 & 0.1136 \\
\hline CVABBW & 5.7726 & 2.7931 & 13 & 17 & 5 & 8 & & 0.1176 & 0.4118 & 0.1928 & 0.3529 \\
\hline
\end{tabular}


Appendix D. Part 2 continued.

\begin{tabular}{|c|c|c|c|c|c|c|c|c|c|c|c|}
\hline Site Code & Diversity & $\begin{array}{l}\text { Wetland spp. } \\
\text { Diversity }\end{array}$ & Richness & Abundance & $\begin{array}{l}\text { Wetland spp. } \\
\text { Richness }\end{array}$ & $\begin{array}{l}\text { Wetland spp. } \\
\text { abundance }\end{array}$ & $\begin{array}{l}\text { Nest predator, } \\
\text { Brood parasite }\end{array}$ & Shrub nesting & Single Brood & $\begin{array}{c}\text { Shannon's } \\
\text { Evenness index }\end{array}$ & $\begin{array}{r}\text { Forest area } \\
\text { Sensitive }\end{array}$ \\
\hline CVABCT & 6.4023 & 3.2257 & 17 & 21 & 7 & 9 & 0.1429 & 0.2381 & 0.4286 & 0.1636 & 0.2381 \\
\hline CVTIMB & 5.0676 & 3.1269 & 10 & 17 & 6 & 12 & 0.0588 & 0.5294 & 0.2941 & 0.2201 & 0.1176 \\
\hline DSPICN & 5.3866 & 0.7980 & 11 & 16 & 2 & 2 & 0.1250 & 0.2500 & 0.7500 & 0.2127 & 0.2500 \\
\hline DSROAR & 5.1866 & 2.1043 & 12 & 14 & 6 & 7 & 0.0714 & 0.3571 & 0.4286 & 0.1877 & 0.2143 \\
\hline DSWILD & 5.6206 & 0.7980 & 12 & 14 & 2 & 2 & & 0.1429 & 0.5714 & 0.2034 & 0.3571 \\
\hline ЕРСMEM & 4.7716 & 1.9095 & 16 & 38 & 7 & 27 & 0.0263 & 0.6579 & 0.1842 & 0.1295 & \\
\hline EPCMFO & 5.4796 & 1.7661 & 14 & 25 & 5 & 10 & 0.2000 & 0.2400 & 0.3200 & 0.1700 & 0.0800 \\
\hline EPDMFO & 5.3040 & 0.7980 & 11 & 15 & 2 & 2 & 0.0667 & 0.2667 & 0.6000 & 0.2094 & \\
\hline EPDMPU & 4.0704 & 0.0000 & 7 & 11 & 1 & 1 & 0.0909 & 0.3636 & 0.6364 & 0.2525 & \\
\hline EPKYVE & 6.2875 & 3.9622 & 20 & 42 & 10 & 26 & 0.0238 & 0.4048 & 0.2381 & 0.1365 & \\
\hline EPRRXC & 5.3066 & 0.7980 & 11 & 14 & 2 & 2 & 0.2143 & 0.2143 & 0.4286 & 0.2095 & 0.2143 \\
\hline EPSHEM & 6.0125 & 3.1269 & 15 & 26 & 7 & 12 & 0.0769 & 0.3846 & 0.4231 & 0.1741 & 0.0769 \\
\hline EPSHSS & 6.4082 & 4.1666 & 18 & 30 & 7 & 14 & & 0.4667 & 0.3667 & 0.1546 & 0.1333 \\
\hline GBBARN & 5.6473 & 3.5547 & 14 & 24 & 8 & 16 & 0.0417 & 0.4583 & 0.2917 & 0.1752 & 0.0833 \\
\hline GBHOEF & 4.9345 & 2.8995 & 15 & 44 & 8 & 35 & 0.0227 & 0.2955 & 0.2273 & 0.1429 & \\
\hline GBJENK & 4.4251 & 3.5047 & 12 & 39 & 8 & 33 & 0.1026 & 0.2821 & 0.1795 & 0.1602 & \\
\hline GBMAPL & 5.8130 & 2.7237 & 14 & 19 & 6 & 10 & & 0.4737 & 0.5789 & 0.1803 & 0.1579 \\
\hline GBNOFO & 5.9539 & 2.8088 & 17 & 26 & 9 & 17 & 0.0769 & 0.5385 & 0.3077 & 0.1521 & 0.0385 \\
\hline
\end{tabular}


Appendix D. Part 2 continued.

\begin{tabular}{|c|c|c|c|c|c|c|c|c|c|c|c|}
\hline Site Code & Diversity & $\begin{array}{l}\text { Wetland spp. } \\
\text { Diversity }\end{array}$ & Richness & Abundance & $\begin{array}{l}\text { Wetland spp. } \\
\text { Richness }\end{array}$ & $\begin{array}{l}\text { Wetland spp. } \\
\text { abundance }\end{array}$ & $\begin{array}{l}\text { Nest predator, } \\
\text { Brood parasite }\end{array}$ & Shrub nesting & Single Brood & $\begin{array}{c}\text { Shannon's } \\
\text { Evenness index }\end{array}$ & $\begin{array}{r}\text { Forest area } \\
\text { Sensitive }\end{array}$ \\
\hline GBNOSS & 5.4664 & 3.8054 & 14 & 26 & 8 & 19 & & 0.5769 & 0.1538 & 0.1696 & 0.0385 \\
\hline GBPLOT & 4.8744 & 3.7750 & 14 & 38 & 9 & 33 & 0.0263 & 0.3158 & 0.1579 & 0.1512 & 0.0263 \\
\hline HCBEAV & 6.4735 & 1.7805 & 18 & 26 & 8 & 13 & 0.0769 & 0.3077 & 0.3846 & 0.1562 & 0.0769 \\
\hline HCMITI & 6.2877 & 2.6475 & 19 & 30 & 11 & 21 & 0.0333 & 0.4000 & 0.3333 & 0.1437 & 0.0333 \\
\hline HCPIPE & 5.3695 & 3.1743 & 15 & 35 & 7 & 23 & 0.0571 & 0.6000 & 0.2571 & 0.1555 & \\
\hline HCRANG & 5.4835 & 3.5505 & 13 & 28 & 6 & 16 & 0.0714 & 0.6429 & 0.4286 & 0.1832 & \\
\hline HIBRID & 5.8540 & 3.6517 & 16 & 32 & 6 & 18 & 0.1250 & 0.4063 & 0.5313 & 0.1589 & \\
\hline HIGATE & 6.7857 & 2.2348 & 20 & 24 & 10 & 13 & 0.0417 & 0.3333 & 0.5000 & 0.1474 & 0.0417 \\
\hline НIJHРК & 6.5523 & 1.4823 & 20 & 24 & 6 & 5 & 0.0833 & 0.1250 & 0.5833 & 0.1423 & 0.1250 \\
\hline HIJHTU & 6.1929 & 1.8016 & 16 & 21 & 9 & 10 & 0.0476 & 0.3810 & 0.4762 & 0.1681 & 0.1429 \\
\hline HIPENC & 5.4355 & 1.9103 & 17 & 32 & 8 & 22 & & 0.4063 & 0.2500 & 0.1389 & 0.1250 \\
\hline HISEWG & 5.8239 & 1.8336 & 15 & 21 & 3 & 7 & & 0.0476 & 0.5238 & 0.1686 & 0.2381 \\
\hline HITRLR & 5.7710 & 2.1640 & 17 & 27 & 9 & 17 & 0.0370 & 0.5185 & 0.2963 & 0.1474 & \\
\hline MCFOUR & 5.8315 & 3.5067 & 14 & 21 & 5 & 9 & 0.0952 & 0.3333 & 0.4286 & 0.1809 & 0.0952 \\
\hline MCMEME & 5.3255 & 4.1767 & 14 & 47 & 9 & 38 & 0.0851 & 0.2979 & 0.3191 & 0.1652 & \\
\hline MCMFOR & 6.6081 & 4.5852 & 20 & 32 & 8 & 15 & 0.0938 & 0.2188 & 0.3125 & 0.1435 & 0.0625 \\
\hline MCNPFO & 6.0767 & 1.5960 & 14 & 14 & 4 & 4 & & 0.4286 & 0.4286 & 0.1885 & 0.1429 \\
\hline MCPOND & 6.2355 & 2.0628 & 15 & 15 & 6 & 6 & 0.0667 & 0.4000 & 0.3333 & 0.1805 & 0.0667 \\
\hline
\end{tabular}


Appendix D. Part 2 continued.

\begin{tabular}{|c|c|c|c|c|c|c|c|c|c|c|c|}
\hline Site Code & Diversity & $\begin{array}{l}\text { Wetland spp. } \\
\text { Diversity }\end{array}$ & Richness & Abundance & $\begin{array}{l}\text { Wetland spp. } \\
\text { Richness }\end{array}$ & $\begin{array}{l}\text { Wetland spp. } \\
\text { abundance }\end{array}$ & $\begin{array}{l}\text { Nest predator, } \\
\text { Brood parasite }\end{array}$ & Shrub nesting & Single Brood & $\begin{array}{c}\text { Shannon's } \\
\text { Evenness index }\end{array}$ & $\begin{array}{c}\text { Forest area } \\
\text { Sensitive }\end{array}$ \\
\hline MCPOST & 6.0047 & 2.4313 & 15 & 23 & 8 & 11 & 0.2609 & 0.3043 & 0.4348 & 0.1739 & 0.0435 \\
\hline MCTELE & 6.0397 & 2.7371 & 15 & 20 & 6 & 9 & 0.2000 & 0.4500 & 0.2500 & 0.1749 & 0.0500 \\
\hline ME5092 & 4.9492 & 3.5631 & 10 & 21 & 7 & 18 & & 0.7143 & 0.3810 & 0.2149 & \\
\hline MESCOX & 6.3971 & 2.7109 & 18 & 26 & 11 & 17 & & 0.3846 & 0.4231 & 0.1543 & 0.0385 \\
\hline MESCRO & 5.3341 & 2.4513 & 14 & 31 & 11 & 26 & & 0.6452 & 0.2903 & 0.1655 & \\
\hline MESCUP & 5.9922 & 2.6332 & 15 & 22 & 7 & 10 & 0.1364 & 0.2727 & 0.3182 & 0.1735 & \\
\hline MESIGN & 5.6795 & 3.0139 & 13 & 21 & 7 & 13 & & 0.4762 & 0.2857 & 0.1897 & \\
\hline MESILV & 5.5375 & 3.1861 & 15 & 29 & 9 & 23 & & 0.6552 & 0.2759 & 0.1603 & 0.0690 \\
\hline METETR & 4.0320 & 2.4995 & 8 & 22 & 6 & 18 & & 0.4545 & 0.0909 & 0.2189 & \\
\hline MEWOLF & 5.5109 & 2.5216 & 14 & 25 & 9 & 20 & & 0.6400 & 0.2800 & 0.1710 & 0.0400 \\
\hline MRBESS & 5.9098 & 2.1163 & 14 & 16 & 5 & 7 & 0.0625 & 0.3750 & 0.5625 & 0.1833 & 0.2500 \\
\hline MRFARM & 5.8764 & 2.0439 & 14 & 19 & 6 & 8 & & 0.6316 & 0.4211 & 0.1823 & \\
\hline MRFORE & 5.5971 & 2.3263 & 12 & 15 & 4 & 5 & 0.0667 & 0.4667 & 0.5333 & 0.2026 & 0.2000 \\
\hline MRSSSS & 5.7017 & 2.2184 & 13 & 18 & 5 & 6 & 0.0556 & 0.3333 & 0.4444 & 0.1905 & 0.1667 \\
\hline MRWEST & 5.9604 & 1.5960 & 14 & 17 & 3 & 4 & & 0.2353 & 0.5882 & 0.1849 & 0.1176 \\
\hline MU55SS & 5.7686 & 2.4313 & 13 & 18 & 7 & 11 & & 0.5556 & 0.1667 & 0.1927 & 0.0556 \\
\hline MUDBOA & 5.6206 & 2.0628 & 12 & 14 & 6 & 6 & & 0.1429 & 0.6429 & 0.2034 & 0.5000 \\
\hline MUDEND & 7.3492 & 2.9398 & 28 & 44 & 13 & 25 & 0.0455 & 0.1818 & 0.4773 & 0.1140 & 0.1364 \\
\hline
\end{tabular}


Appendix D. Part 2 continued.

\begin{tabular}{|c|c|c|c|c|c|c|c|c|c|c|c|}
\hline Site Code & Diversity & $\begin{array}{l}\text { Wetland spp. } \\
\text { Diversity }\end{array}$ & Richness & Abundance & $\begin{array}{l}\text { Wetland spp. } \\
\text { Richness }\end{array}$ & $\begin{array}{c}\text { Wetland spp. } \\
\text { abundance }\end{array}$ & $\begin{array}{l}\text { Nest predator, } \\
\text { Brood parasite }\end{array}$ & Shrub nesting & Single Brood & $\begin{array}{c}\text { Shannon's } \\
\text { Evenness index }\end{array}$ & $\begin{array}{c}\text { Forest area } \\
\text { Sensitive }\end{array}$ \\
\hline MUDRIC & 6.4780 & 2.2235 & 17 & 18 & 5 & 5 & & 0.1667 & 0.5000 & 0.1655 & 0.5000 \\
\hline MUDRIP & 7.2440 & 2.7498 & 27 & 39 & 14 & 22 & 0.0256 & 0.4359 & 0.4103 & 0.1165 & 0.1026 \\
\hline MUDTRA & 6.7996 & 3.5908 & 21 & 31 & 12 & 20 & & 0.4839 & 0.3871 & 0.1406 & 0.0645 \\
\hline MUEPAH & 6.1921 & 2.9083 & 16 & 22 & 8 & 14 & & 0.4091 & 0.2273 & 0.1681 & \\
\hline MUMINE & 6.2595 & 1.8016 & 16 & 20 & 7 & 10 & 0.0500 & 0.2500 & 0.6000 & 0.1699 & 0.2000 \\
\hline MUPOWR & 5.9523 & 3.1634 & 15 & 23 & 7 & 10 & 0.1304 & 0.2609 & 0.6522 & 0.1723 & 0.0870 \\
\hline MUPULL & 6.4078 & 4.0010 & 19 & 31 & 12 & 22 & 0.0323 & 0.5806 & 0.5161 & 0.1465 & 0.1290 \\
\hline MUVBRD & 6.0841 & 3.5024 & 19 & 32 & 12 & 25 & 0.0313 & 0.4375 & 0.4063 & 0.1391 & 0.0313 \\
\hline MUVCRN & 5.2752 & 3.6245 & 13 & 31 & 9 & 26 & & 0.5161 & 0.3226 & 0.1762 & \\
\hline OHHSFO & 5.5861 & 2.2184 & 12 & 16 & 5 & 6 & & 0.3125 & 0.3750 & 0.2022 & 0.1250 \\
\hline OHINNS & 6.2610 & 2.8808 & 18 & 29 & 9 & 17 & & 0.3103 & 0.4138 & 0.1511 & 0.1034 \\
\hline OHKMRT & 4.7930 & 2.5146 & 11 & 25 & 7 & 18 & & 0.6000 & 0.3600 & 0.1892 & 0.0800 \\
\hline PA29TH & 6.0637 & 3.9133 & 22 & 64 & 12 & 29 & 0.0313 & 0.2813 & 0.5781 & 0.1197 & \\
\hline PA83CR & 6.2117 & 2.1043 & 17 & 26 & 6 & 7 & 0.2692 & 0.2692 & 0.5385 & 0.1587 & 0.0769 \\
\hline PAFAMD & 7.1560 & 2.5439 & 27 & 51 & 12 & 26 & 0.0196 & 0.2157 & 0.4118 & 0.1151 & 0.0392 \\
\hline PAJCPY & 6.9524 & 2.8634 & 26 & 51 & 14 & 26 & & 0.1765 & 0.4510 & 0.1161 & 0.0980 \\
\hline PALOUD & 6.9073 & 3.0155 & 22 & 32 & 12 & 17 & 0.1250 & 0.2813 & 0.5000 & 0.1364 & 0.0938 \\
\hline PAPEFO & 6.0999 & 2.2184 & 15 & 20 & 5 & 6 & 0.1000 & 0.1500 & 0.4500 & 0.1766 & 0.1500 \\
\hline
\end{tabular}


Appendix D. Part 2 continued.

\begin{tabular}{|c|c|c|c|c|c|c|c|c|c|c|c|}
\hline Site Code & Diversity & $\begin{array}{l}\text { Wetland spp. } \\
\text { Diversity }\end{array}$ & Richness & Abundance & $\begin{array}{l}\text { Wetland spp. } \\
\text { Richness }\end{array}$ & $\begin{array}{l}\text { Wetland spp. } \\
\text { abundance }\end{array}$ & $\begin{array}{l}\text { Nest predator, } \\
\text { Brood parasite }\end{array}$ & Shrub nesting & Single Brood & $\begin{array}{c}\text { Shannon's } \\
\text { Evenness index }\end{array}$ & $\begin{array}{r}\text { Forest area } \\
\text { Sensitive }\end{array}$ \\
\hline PAPEIM & 3.8563 & 1.7775 & 10 & 29 & 5 & 19 & & 0.5172 & 0.1034 & 0.1675 & \\
\hline PAPESW & 6.9069 & 3.0518 & 24 & 40 & 12 & 20 & 0.0250 & 0.2750 & 0.5000 & 0.1250 & 0.1000 \\
\hline PAWILL & 5.7759 & 3.2649 & 17 & 41 & 8 & 24 & 0.0976 & 0.3902 & 0.1463 & 0.1476 & \\
\hline PCBLUE & 6.2626 & 2.5384 & 17 & 25 & 7 & 14 & 0.1200 & 0.5200 & 0.3200 & 0.1600 & \\
\hline PCLPFO & 5.2678 & 2.3940 & 12 & 19 & 4 & 4 & & 0.1579 & 0.7368 & 0.1906 & 0.2105 \\
\hline PCROAD & 6.1046 & 2.8098 & 16 & 28 & 8 & 15 & 0.1071 & 0.4643 & 0.5000 & 0.1657 & \\
\hline PEMIDW & 6.3372 & 2.5335 & 17 & 22 & 8 & 11 & & 0.4091 & 0.4091 & 0.1619 & 0.1364 \\
\hline PERDDP & 4.7101 & 2.4143 & 11 & 28 & 6 & 20 & & 0.5357 & 0.2857 & 0.1860 & 0.0357 \\
\hline PETHUM & 6.3007 & 1.8939 & 16 & 18 & 8 & 9 & & 0.3333 & 0.3333 & 0.1710 & 0.1111 \\
\hline PETOSS & 6.1116 & 2.8085 & 17 & 25 & 10 & 18 & & 0.4000 & 0.3600 & 0.1561 & 0.0400 \\
\hline RIASIA & 6.6584 & 1.1243 & 19 & 35 & 9 & 18 & 0.0857 & 0.3429 & 0.4000 & 0.1522 & \\
\hline RIBRID & 7.0444 & 2.4843 & 23 & 31 & 12 & 15 & & 0.3226 & 0.4839 & 0.1330 & 0.1290 \\
\hline RIEAST & 6.3346 & 2.5596 & 17 & 23 & 8 & 13 & & 0.1739 & 0.5217 & 0.1618 & 0.1739 \\
\hline SJBOAT & 5.8115 & 3.1785 & 14 & 22 & 8 & 14 & & 0.2727 & 0.6364 & 0.1803 & 0.2727 \\
\hline SJBRID & 5.3902 & 2.7428 & 12 & 23 & 5 & 13 & 0.0870 & 0.4783 & 0.2174 & 0.1951 & \\
\hline SJCHUR & 6.4126 & 3.6961 & 19 & 29 & 14 & 24 & 0.0345 & 0.4138 & 0.4138 & 0.1466 & 0.0690 \\
\hline SJGLAD & 6.5370 & 1.6412 & 18 & 22 & 9 & 12 & & 0.3636 & 0.5000 & 0.1577 & 0.2727 \\
\hline SJMUDL & 6.9187 & 1.7176 & 21 & 24 & 9 & 11 & 0.0417 & 0.3333 & 0.4583 & 0.1431 & 0.1250 \\
\hline
\end{tabular}


Appendix D. Part 2 continued.

\begin{tabular}{|c|c|c|c|c|c|c|c|c|c|c|c|}
\hline Site Code & Diversity & $\begin{array}{l}\text { Wetland spp. } \\
\text { Diversity }\end{array}$ & Richness & Abundance & $\begin{array}{l}\text { Wetland spp. } \\
\text { Richness }\end{array}$ & $\begin{array}{l}\text { Wetland spp. } \\
\text { abundance }\end{array}$ & $\begin{array}{l}\text { Nest predator, } \\
\text { Brood parasite }\end{array}$ & Shrub nesting & Single Brood & $\begin{array}{c}\text { Shannon's } \\
\text { Evenness index }\end{array}$ & $\begin{array}{c}\text { Forest area } \\
\text { Sensitive }\end{array}$ \\
\hline SJPLOT & 6.2939 & 2.7023 & 17 & 25 & 9 & 14 & 0.0400 & 0.3600 & 0.4400 & 0.1608 & 0.0800 \\
\hline SJTELE & 5.8764 & 3.2472 & 14 & 19 & 6 & 11 & 0.0526 & 0.2632 & 0.3684 & 0.1823 & 0.2632 \\
\hline SMDTSS & 5.8873 & 3.4185 & 15 & 24 & 6 & 14 & & 0.3750 & 0.5000 & 0.1705 & 0.1250 \\
\hline SMFOFL & 6.5543 & 2.5427 & 18 & 21 & 7 & 10 & & 0.2857 & 0.7619 & 0.1581 & 0.3333 \\
\hline SMLPEM & 6.0434 & 3.5347 & 18 & 33 & 11 & 25 & & 0.3939 & 0.1818 & 0.1458 & 0.0606 \\
\hline SMSEFL & 5.8760 & 4.1135 & 16 & 37 & 10 & 27 & 0.1081 & 0.2703 & 0.3514 & 0.1595 & 0.0541 \\
\hline SMSTEM & 5.5971 & 2.4313 & 12 & 15 & 9 & 11 & & 0.3333 & 0.5333 & 0.2026 & 0.2000 \\
\hline TRSPFO & 6.1233 & 1.3752 & 15 & 18 & 6 & 6 & 0.1111 & 0.1667 & 0.3889 & 0.1773 & 0.1667 \\
\hline TRSPRI & 6.5548 & 3.2022 & 21 & 31 & 9 & 18 & & 0.3871 & 0.4839 & 0.1356 & 0.0645 \\
\hline TVFARM & 4.6311 & 2.4553 & 10 & 20 & 5 & 13 & 0.0500 & 0.5000 & 0.1000 & 0.2011 & \\
\hline TVISLE & 6.3365 & 3.0729 & 17 & 24 & 7 & 10 & 0.2083 & 0.2917 & 0.2917 & 0.1619 & 0.0417 \\
\hline TVNEWT & 5.6855 & 2.7341 & 20 & 49 & 14 & 40 & 0.0204 & 0.5714 & 0.1837 & 0.1235 & \\
\hline TVPOUT & 5.9794 & 2.4222 & 15 & 20 & 8 & 10 & 0.0500 & 0.5000 & 0.3500 & 0.1731 & 0.1500 \\
\hline TVVBEM & 2.4881 & 1.3035 & 5 & 15 & 3 & 12 & & 0.8667 & 0.2667 & 0.2161 & \\
\hline TVVBIM & 5.4401 & 3.6789 & 13 & 22 & 7 & 16 & & 0.6364 & 0.3182 & 0.1817 & 0.0455 \\
\hline TVVBRV & 5.9108 & 3.7141 & 15 & 25 & 7 & 12 & 0.1600 & 0.2800 & 0.5200 & 0.1711 & 0.0800 \\
\hline TVVBSS & 6.4884 & 3.9456 & 21 & 40 & 14 & 31 & & 0.4000 & 0.4000 & 0.1342 & 0.0250 \\
\hline UDC001 & 5.1007 & 1.9685 & 11 & 26 & 5 & 15 & 0.1923 & 0.4231 & 0.3462 & 0.2014 & \\
\hline
\end{tabular}


Appendix D. Part 2 continued.

\begin{tabular}{|c|c|c|c|c|c|c|c|c|c|c|c|}
\hline Site Code & Diversity & $\begin{array}{l}\text { Wetland spp. } \\
\text { Diversity }\end{array}$ & Richness & Abundance & $\begin{array}{l}\text { Wetland spp. } \\
\text { Richness }\end{array}$ & $\begin{array}{l}\text { Wetland spp. } \\
\text { abundance }\end{array}$ & $\begin{array}{l}\text { Nest predator, } \\
\text { Brood parasite }\end{array}$ & Shrub nesting & Single Brood & $\begin{array}{c}\text { Shannon's } \\
\text { Evenness index }\end{array}$ & $\begin{array}{c}\text { Forest area } \\
\text { Sensitive }\end{array}$ \\
\hline UDC002 & 5.8615 & 3.2390 & 14 & 28 & 9 & 18 & 0.1071 & 0.4286 & 0.4643 & 0.1818 & \\
\hline UDC003 & 5.1012 & 3.7756 & 11 & 21 & 6 & 15 & & 0.3810 & 0.1905 & 0.2014 & \\
\hline UDC004 & 5.0912 & 3.3744 & 10 & 15 & 6 & 10 & & 0.5333 & 0.4667 & 0.2211 & \\
\hline UDC005 & 3.6258 & 2.0569 & 7 & 16 & 4 & 13 & 0.0625 & 0.4375 & 0.0625 & 0.2250 & \\
\hline UDC007 & 4.9237 & 1.5851 & 9 & 12 & 4 & 5 & 0.0833 & 0.3333 & & 0.2376 & 0.0833 \\
\hline UDC008 & 5.5883 & 2.6584 & 13 & 23 & 6 & 14 & 0.1739 & 0.5217 & 0.2609 & 0.1867 & \\
\hline UDC012 & 6.3031 & 3.8587 & 19 & 37 & 9 & 20 & 0.0541 & 0.4324 & 0.4595 & 0.1441 & \\
\hline UDC013 & 5.5140 & 1.6864 & 12 & 17 & 3 & 6 & 0.1176 & 0.3529 & 0.2941 & 0.1996 & 0.2353 \\
\hline UDC014 & 5.3066 & 2.7564 & 11 & 14 & 5 & 7 & 0.1429 & 0.4286 & 0.4286 & 0.2095 & 0.1429 \\
\hline UDC015 & 5.2579 & 3.4933 & 16 & 42 & 5 & 12 & 0.4048 & 0.2857 & 0.6429 & 0.1427 & 0.0238 \\
\hline UDC016 & 6.2035 & 3.1450 & 16 & 24 & 7 & 11 & 0.1250 & 0.2917 & 0.2500 & 0.1684 & 0.0417 \\
\hline UDC017 & 6.0385 & 3.8490 & 16 & 25 & 6 & 13 & 0.1200 & 0.3600 & 0.2000 & 0.1639 & \\
\hline UDC018 & 5.3553 & 3.4405 & 12 & 24 & 7 & 16 & 0.0417 & 0.4167 & 0.2500 & 0.1938 & \\
\hline UDC019 & 5.3060 & 3.6285 & 12 & 26 & 7 & 19 & 0.0769 & 0.6923 & 0.0769 & 0.1920 & \\
\hline UDC020 & 5.3445 & 3.3067 & 13 & 35 & 8 & 21 & 0.2000 & 0.3143 & 0.3429 & 0.1785 & \\
\hline VEPCON & 4.8270 & 3.1688 & 10 & 16 & 6 & 12 & 0.0625 & 0.5000 & 0.1250 & 0.2096 & \\
\hline VEPCOS & 4.6508 & 2.2884 & 8 & 11 & 4 & 7 & 0.1818 & 0.3636 & 0.1818 & 0.2525 & 0.0909 \\
\hline WBBARN & 5.9759 & 3.9774 & 18 & 46 & 10 & 33 & 0.0652 & 0.2609 & 0.2174 & 0.1442 & \\
\hline
\end{tabular}


Appendix D. Part 2 continued.

\begin{tabular}{|c|c|c|c|c|c|c|c|c|c|c|c|}
\hline Site Code & Diversity & $\begin{array}{l}\text { Wetland spp. } \\
\text { Diversity }\end{array}$ & Richness & Abundance & $\begin{array}{l}\text { Wetland spp. } \\
\text { Richness }\end{array}$ & $\begin{array}{l}\text { Wetland spp. } \\
\text { abundance }\end{array}$ & $\begin{array}{l}\text { Nest predator, } \\
\text { Brood parasite }\end{array}$ & Shrub nesting & Single Brood & $\begin{array}{c}\text { Shannon's } \\
\text { Evenness index }\end{array}$ & $\begin{array}{c}\text { Forest area } \\
\text { Sensitive }\end{array}$ \\
\hline WBCORN & 5.0471 & 3.1721 & 11 & 31 & 5 & 18 & & 0.3871 & 0.0968 & 0.1993 & \\
\hline WBROAD & 4.0845 & 1.6185 & 9 & 27 & 3 & 16 & & 0.5185 & 0.0370 & 0.1971 & \\
\hline WYBEAV & 6.5985 & 2.0260 & 19 & 27 & 10 & 13 & 0.0370 & 0.4444 & 0.7037 & 0.1508 & 0.0741 \\
\hline WYCHWE & 5.5244 & 2.5427 & 12 & 18 & 7 & 10 & & 0.2778 & 0.6667 & 0.1999 & 0.3889 \\
\hline WYHCEA & 5.8764 & 3.1269 & 14 & 19 & 8 & 12 & 0.0526 & 0.5263 & 0.5789 & 0.1823 & 0.2105 \\
\hline WYINTR & 5.5861 & 2.2184 & 12 & 16 & 5 & 6 & 0.0625 & 0.4375 & 0.4375 & 0.2022 & \\
\hline WYTHOR & 5.9850 & 2.4179 & 16 & 22 & 8 & 13 & 0.0909 & 0.4545 & 0.2273 & 0.1625 & 0.0455 \\
\hline
\end{tabular}


Appendix E. Avian community sampling summary statistics of metric scores statewide and by ecoregion used to form avian wetland indices of biological integrity (AW-IBI) for wetlands in West Virginia, USA 2005-2006.

\begin{tabular}{|c|c|c|c|c|c|c|c|c|c|}
\hline \multicolumn{10}{|c|}{ Statewide Avian Sampling $(\mathrm{N}=151)$} \\
\hline & WET & РCTCB & РСТСВНАВ & РCTCB & РCTOB & PCTCBRES & BIRD & CBPCT & РCTOB \\
\hline & ABUNDANCE & NEOTROP & SPEC & NEOHABS & FORESTS & EDGE & DIVERSITY & CARNHAB & SINGLE \\
\hline Minimum & 1 & 0.048 & 0 & 0 & 0 & 0.048 & 2.488 & 0 & 0 \\
\hline Maximum & 40 & 0.714 & 0.714 & 0.568 & 0.737 & 0.875 & 7.349 & 0.619 & 0.762 \\
\hline Mean & 14.848 & 0.295 & 0.269 & 0.167 & 0.098 & 0.491 & 5.767 & 0.178 & 0.389 \\
\hline \multirow[t]{3}{*}{ Std. Error } & 0.643 & 0.013 & 0.012 & 0.01 & 0.01 & 0.015 & 0.06 & 0.009 & 0.013 \\
\hline & PCTCB & РCTCB & & & & & & & \\
\hline & INSECTI & OMNIVOR & & & & & & & \\
\hline Minimum & 0.04 & 0.19 & & & & & & & \\
\hline Maximum & 0.786 & 0.875 & & & & & & & \\
\hline Mean & 0.349 & 0.522 & & & & & & & \\
\hline Std. Error & 0.012 & 0.01 & & & & & & & \\
\hline \multicolumn{10}{|c|}{ Allegheny Highland Avian Sampling $(\mathrm{N}=65)$} \\
\hline & WET & РCTCB & РСТСВНАВ & PCTCB & PCTOB & PCTCBRES & BIRD & CBPCT & РCTOB \\
\hline & ABUNDANCE & NEOTROP & SPEC & NEOHABS & FORESTS & EDGE & DIVERSITY & CARNHAB & SINGLE \\
\hline Minimum & 4 & 0.048 & 0 & 0 & 0 & 0.105 & 3.626 & 0 & 0 \\
\hline Maximum & 26 & 0.684 & 0.714 & 0.526 & 0.737 & 0.875 & 7.052 & 0.619 & 0.704 \\
\hline Mean & 13.046 & 0.301 & 0.254 & 0.17 & 0.107 & 0.484 & 5.676 & 0.17 & 0.399 \\
\hline \multirow[t]{3}{*}{ Std. Error } & 0.717 & 0.019 & 0.018 & 0.015 & 0.018 & 0.021 & 0.076 & 0.014 & 0.021 \\
\hline & РCTCB & РCTCB & & & & & & & \\
\hline & INSECTI & OMNIVOR & & & & & & & \\
\hline Minimum & 0.04 & 0.19 & & & & & & & \\
\hline Maximum & 0.762 & 0.875 & & & & & & & \\
\hline Mean & 0.353 & 0.528 & & & & & & & \\
\hline Std. Error & 0.017 & 0.016 & & & & & & & \\
\hline
\end{tabular}


Appendix E. Continued.

\begin{tabular}{|c|c|c|c|c|c|c|c|c|c|}
\hline \multicolumn{10}{|c|}{ Ridge and Valley Avian Sampling $(\mathrm{N}=27)$} \\
\hline & WET & РСТСВ & РCTCB & РCTCB & РCTOB & РСТCВ & BIRD & СВPCT & РCTOB \\
\hline & ABUNDANCE & NEOTROP & HABSPEC & NEOHABS & FORESTS & RESEDGE & DIVERSITY & CARNHAB & SINGLE \\
\hline Minimum & 1 & 0.067 & 0 & 0 & 0 & 0.048 & 2.488 & 0 & 0.037 \\
\hline Maximum & 40 & 0.625 & 0.571 & 0.4 & 0.357 & 0.867 & 6.554 & 0.467 & 0.762 \\
\hline Mean & 14.926 & 0.252 & 0.257 & 0.137 & 0.09 & 0.52 & 5.476 & 0.163 & 0.372 \\
\hline \multirow[t]{3}{*}{ Std. Error } & 2.001 & 0.033 & 0.029 & 0.023 & 0.021 & 0.043 & 0.171 & 0.024 & 0.037 \\
\hline & PCTCB & PCTCB & & & & & & & \\
\hline & INSECTI & OMNIVOR & & & & & & & \\
\hline Minimum & 0.091 & 0.25 & & & & & & & \\
\hline Maximum & 0.733 & 0.852 & & & & & & & \\
\hline Mean & 0.343 & 0.508 & & & & & & & \\
\hline Std. Error & 0.032 & 0.028 & & & & & & & \\
\hline \multicolumn{10}{|c|}{ Western Allegheny Plateau Avian Sampling $(\mathrm{N}=59)$} \\
\hline & WET & РCTCB & РCTCB & РCTCB & РCTOB & РСТCВ & BIRD & СВPCT & РСТОВ \\
\hline & ABUNDANCE & NEOTROP & HABSPEC & NEOHABS & FORESTS & RESEDGE & DIVERSITY & CARNHAB & SINGLE \\
\hline Minimum & 4 & 0.048 & 0.069 & 0 & 0 & 0.111 & 3.856 & 0.034 & 0.103 \\
\hline Maximum & 38 & 0.714 & 0.636 & 0.568 & 0.5 & 0.857 & 7.349 & 0.571 & 0.737 \\
\hline Mean & 16.797 & 0.308 & 0.292 & 0.177 & 0.091 & 0.484 & 6 & 0.193 & 0.386 \\
\hline \multirow[t]{3}{*}{ Std. Error } & 1.08 & 0.022 & 0.017 & 0.016 & 0.014 & 0.022 & 0.094 & 0.014 & 0.017 \\
\hline & РCTCB & РСТCВ & & & & & & & \\
\hline & INSECTI & OMNIVOR & & & & & & & \\
\hline Minimum & 0.069 & 0.205 & & & & & & & \\
\hline Maximum & 0.786 & 0.762 & & & & & & & \\
\hline Mean & 0.348 & 0.521 & & & & & & & \\
\hline Std. Error & 0.019 & 0.016 & & & & & & & \\
\hline
\end{tabular}


Appendix F. Avian community metrics box-and-whisker resultsand narrative descriptions for depressional wetlands $(\mathrm{N}=37)$. Classifications are reference $(\mathrm{R})$ and stressed $(\mathrm{S})$.
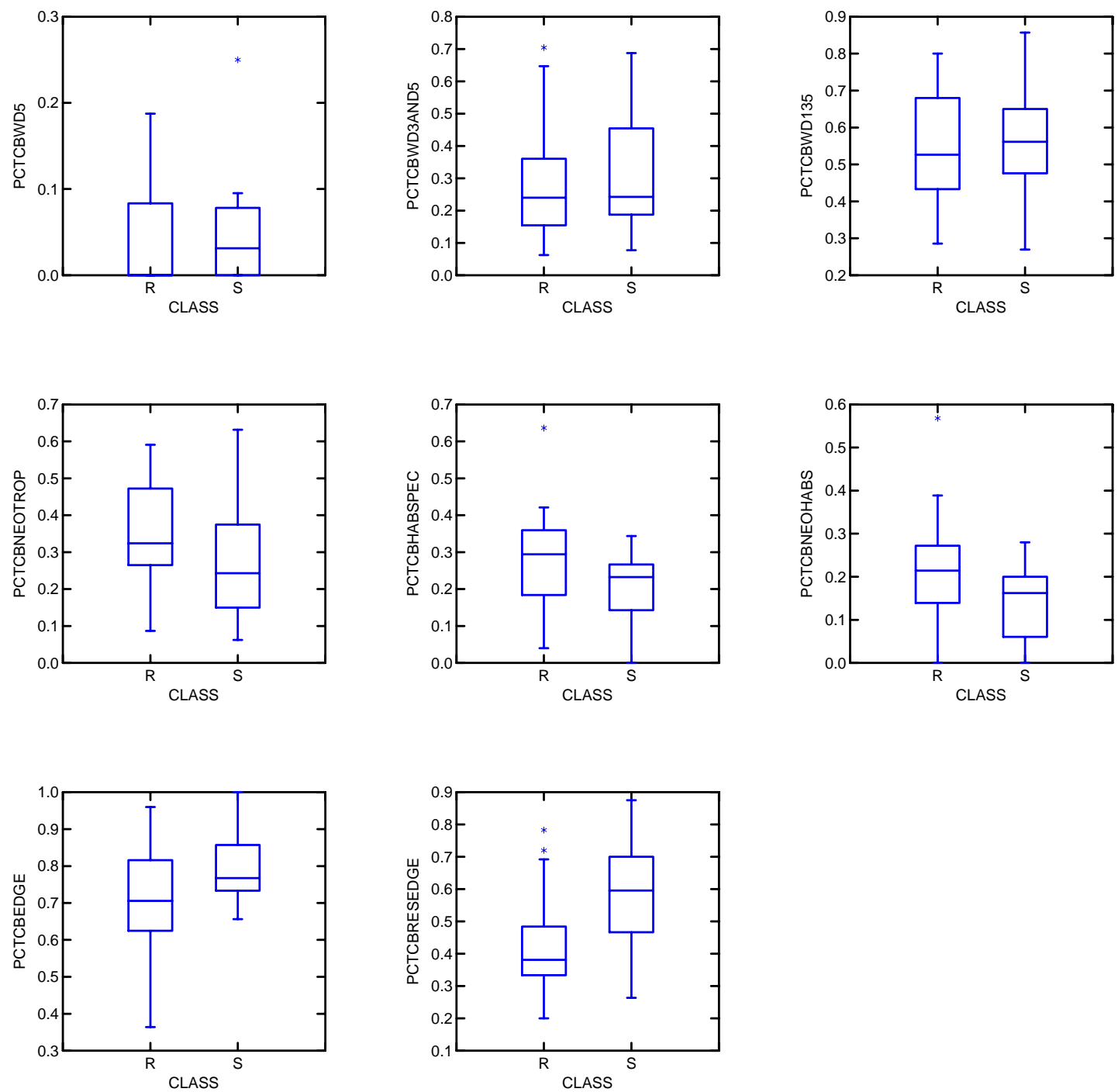

\begin{tabular}{|c|c|c|}
\hline Metric code & Metric Description & Rating \\
\hline PCTWD5 & Proportion wetland dependent spp. & poor \\
\hline PCTWD3AND5 & Proportion wetland associated and dependent spp. & poor \\
\hline PCTWD135 & Proportion facultative wetland and above spp. & poor \\
\hline PCTCBNEOTROP & Proportion neotropical migrants & fair \\
\hline PCTCBHABSPEC & Proportion habitat specific spp. & fair \\
\hline PCTNEOHABSPEC & $\begin{array}{l}\text { Proportion neotropical migrants and habitat } \\
\text { specific spp. }\end{array}$ & fair \\
\hline PCTCBEDGE & Proportion edge spp. & fair \\
\hline PCTCBRESEDGE & Proportion residential and edge spp. & good \\
\hline
\end{tabular}


Appendix F. Continued.
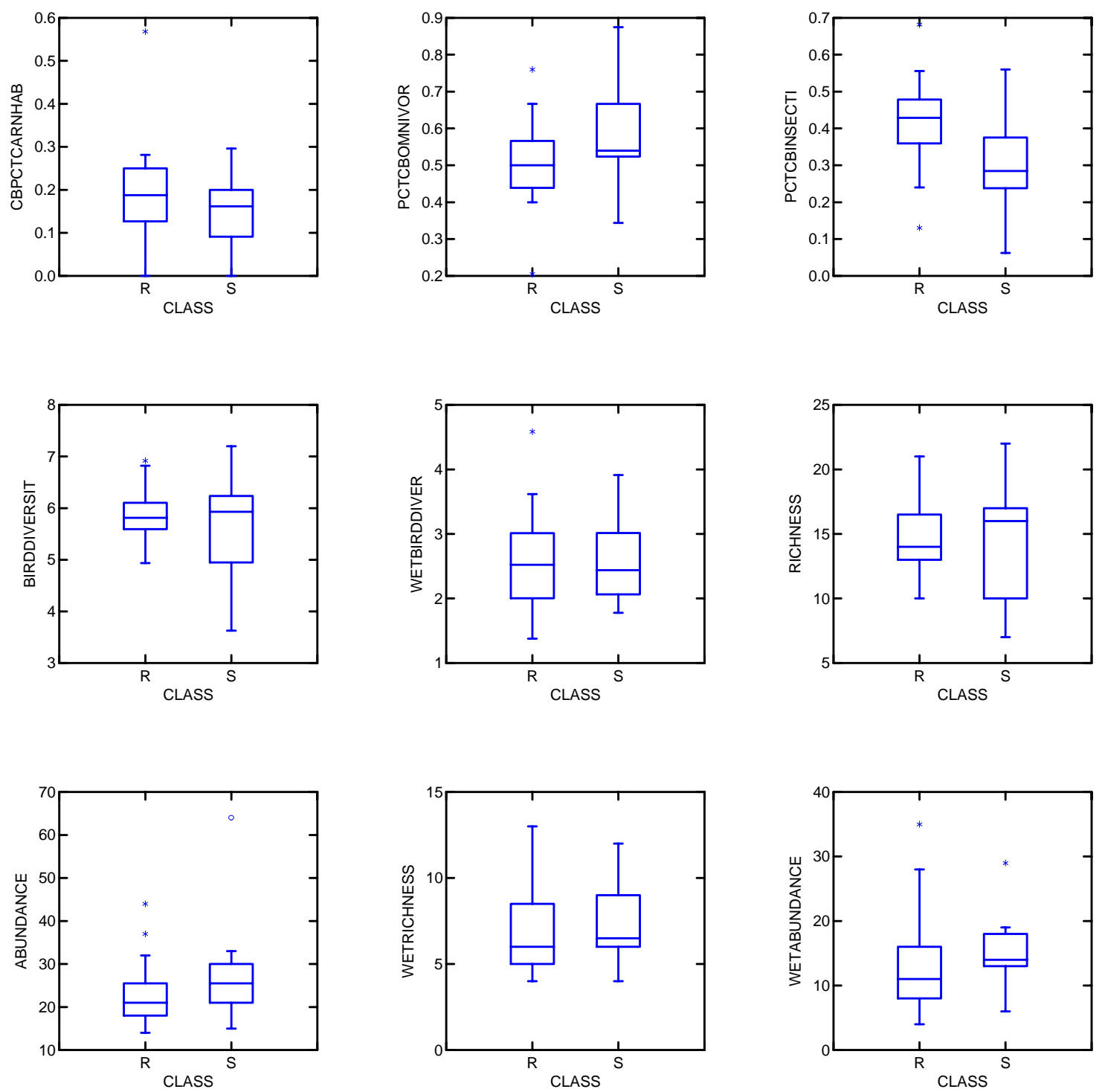

\begin{tabular}{lll} 
Metric code & Metric Description & Rating \\
\hline PCTCBCARNHAB & Proportion carnivorous and habitat specific spp. & poor \\
PCTOMNIVOR & Proportion omnivorous spp. & fair \\
PCTINSECTI & Proportion insectivorous spp. & good \\
BIRDDIVERSIT & Shannon-Weaver diversity index & poor \\
WETBIRDDIVER & Wetland bird S-W diversity index & poor \\
RICHNESS & Richness (number of species) & poor \\
ABUNDANCE & Abundance (count of individuals) & fair \\
WETRICHNESS & Wetland bird richness & poor \\
WETABUNDANCE & Wetland bird abundance & fair \\
\hline
\end{tabular}


Appendix F. Continued.
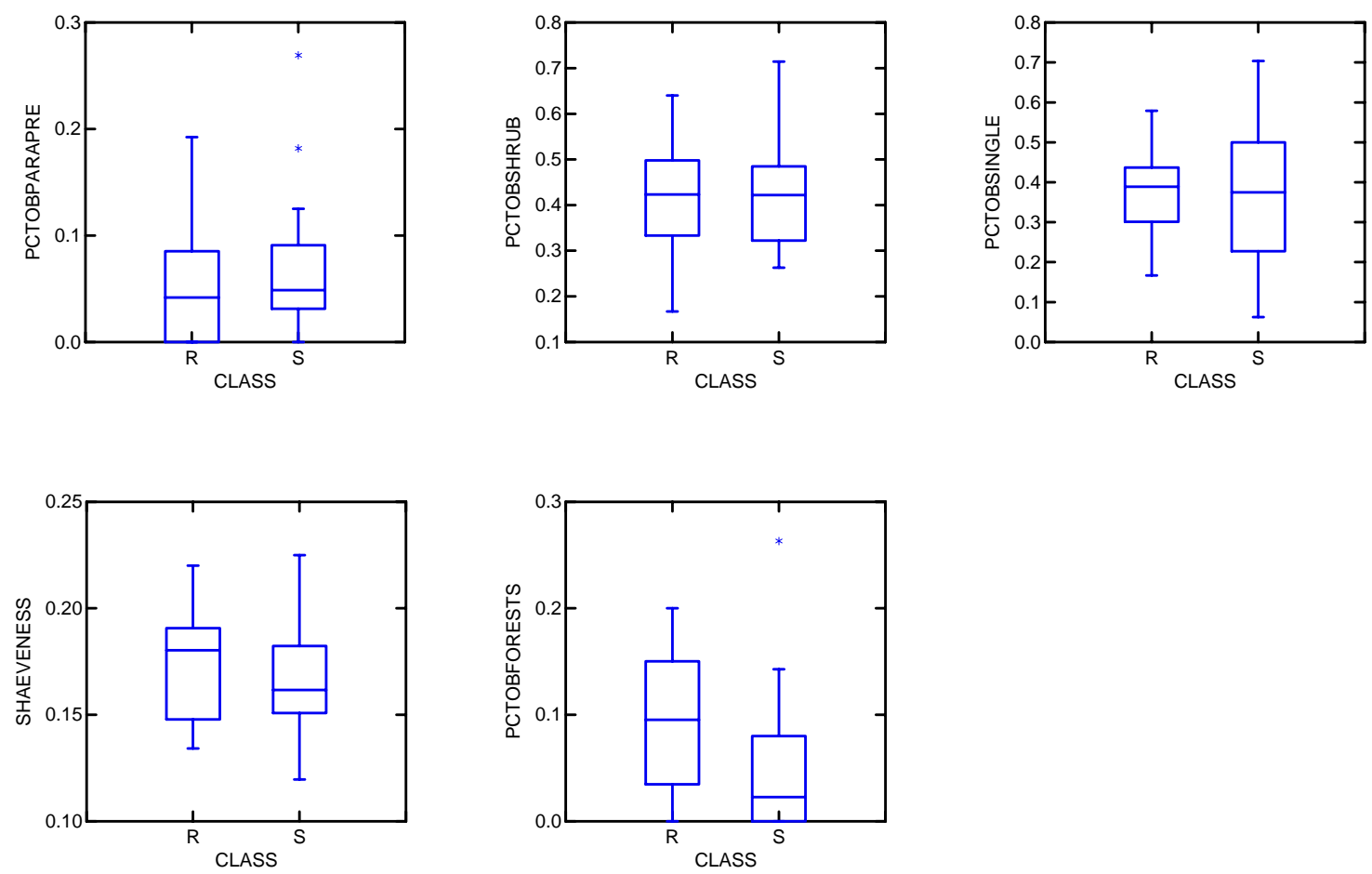

\begin{tabular}{|c|c|c|}
\hline Metric code & Metric Description & Rating \\
\hline$\overline{\text { PCTOBPARAPRED }}$ & Proportion brood parasite / nest predator spp. & poor \\
\hline PCTOBSHRUB & Proportion shrub nesting spp. & poor \\
\hline PCTOBSINGLE & Proportion single brood spp. & poor \\
\hline SHAEVENESS & Shannon evenness index & poor \\
\hline PCTOBFORESTS & Proportion interior forest obligate spp. & fair \\
\hline
\end{tabular}


Appendix G. Avian community metrics box-and-whisker results and narrative descriptions for floodplain wetlands $(\mathrm{N}=19)$. Classifications are reference $(\mathrm{R})$ and stressed $(\mathrm{S})$.
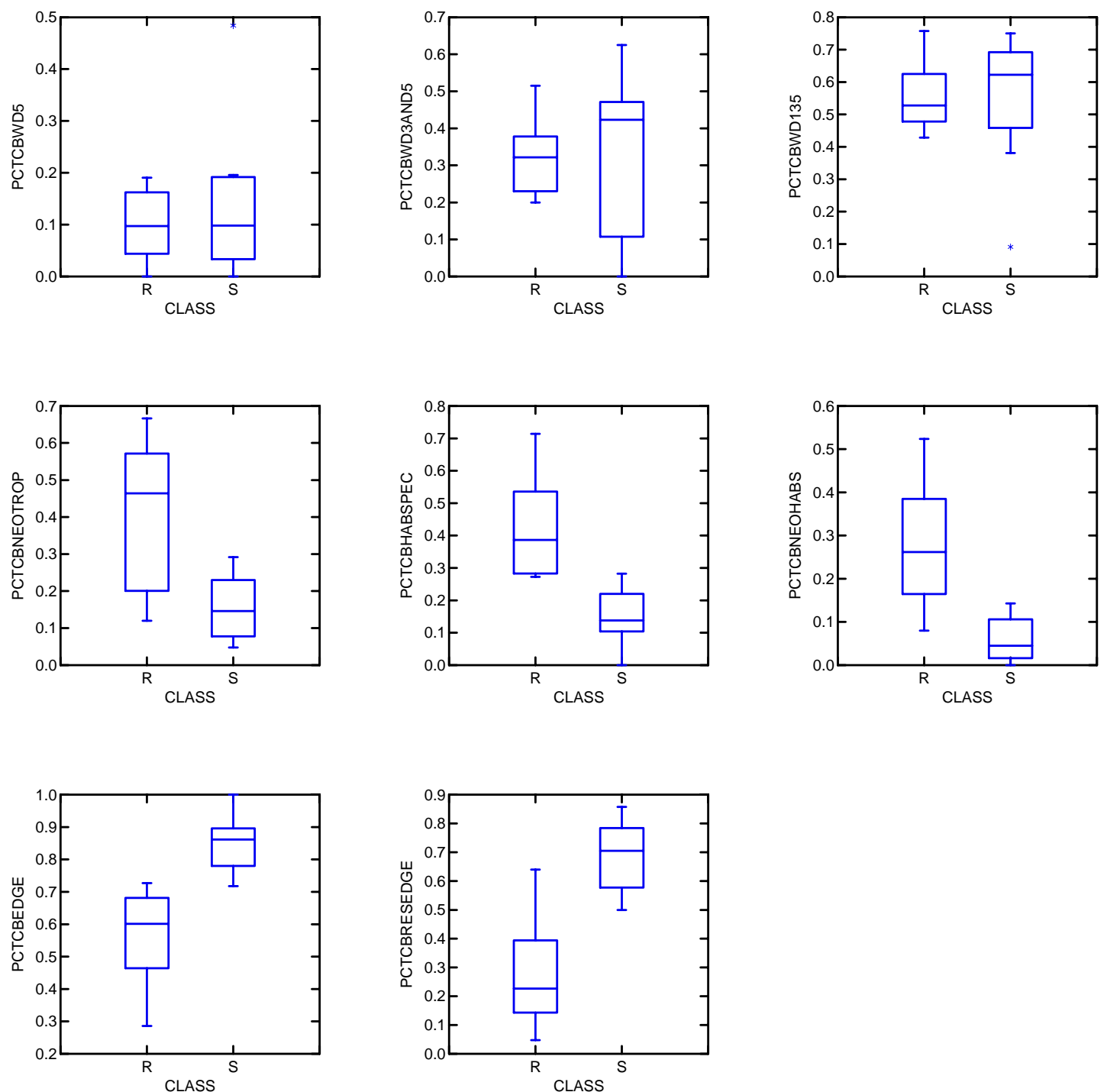

\begin{tabular}{|c|c|c|}
\hline Metric code & Metric Description & Rating \\
\hline PCTWD5 & Proportion wetland dependent spp. & poor \\
\hline PCTWD3AND5 & Proportion wetland associated and dependent spp. & fair \\
\hline PCTWD135 & Proportion facultative wetland and above spp. & fair \\
\hline PCTCBNEOTROP & Proportion neotropical migrants & good \\
\hline PCTCBНABSPEC & Proportion habitat specific spp. & excellent \\
\hline PCTNEOHABSPEC & $\begin{array}{l}\text { Proportion neotropical migrants and habitat specific } \\
\text { spp. }\end{array}$ & excellent \\
\hline PCTCBEDGE & Proportion edge spp. & excellent \\
\hline PCTCBRESEDGE & Proportion residential and edge spp. & excellent \\
\hline
\end{tabular}


Appendix G. Continued.
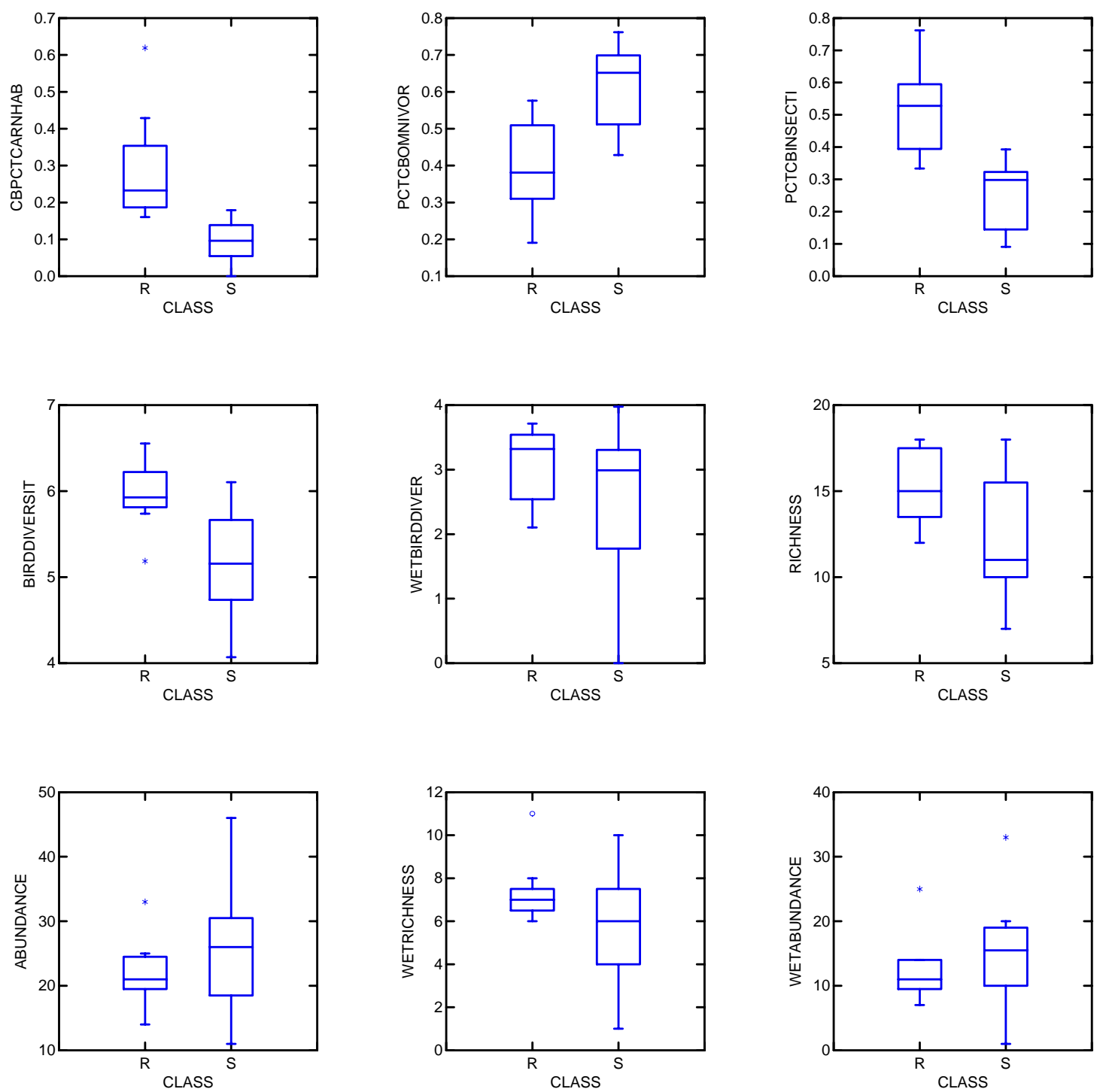

\begin{tabular}{llll} 
Metric code & Metric Description & Rating \\
${$\cline { 1 - 1 }$} }$ & Proportion carnivorous and habitat specific spp. & excellent \\
PCTOMNIVOR & Proportion omnivorous spp. & good \\
PCTINSECTI & Proportion insectivorous spp. & excellent \\
BIRDDIVERSIT & Shannon-Weaver diversity index & excellent \\
WETBIRDDIVER & Wetland bird S-W diversity index & fair \\
RICHNESS & Richness (number of species) & fair \\
ABUNDANCE & Abundance (count of individuals) & fair \\
WETRICHNESS & Wetland bird richness & fair \\
WETABUNDANCE & Wetland bird abundance & fair \\
\hline
\end{tabular}


Appendix G. Continued.
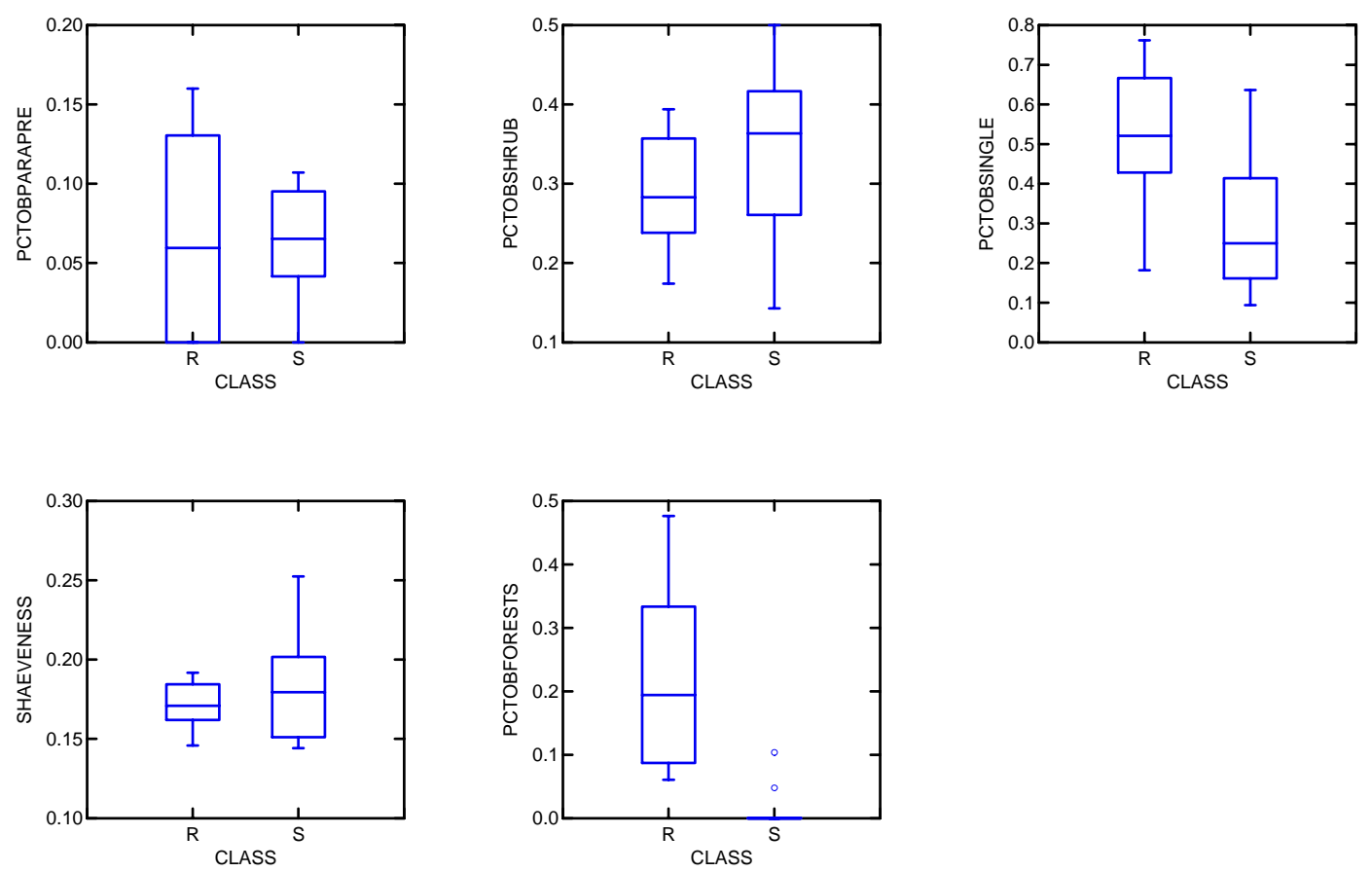

\begin{tabular}{llll} 
Metric code & Metric Description & Rating \\
PCTOBPARAPRED & Proportion brood parasite / nest predator spp. & & poor \\
PCTOBSHRUB & Proportion shrub nesting spp. & fair \\
PCTOBSINGLE & Proportion single brood spp. & excellent \\
SHAEVENESS & Shannon evenness index & poor \\
PCTOBFORESTS & Proportion interior forest obligate spp. & poor \\
\hline
\end{tabular}


Appendix H. Avian community metricsbox-and-whisker results and narrative for impoundment wetlands $(\mathrm{N}=13)$. Classifications are reference $(\mathrm{R})$ and stressed $(\mathrm{S})$.
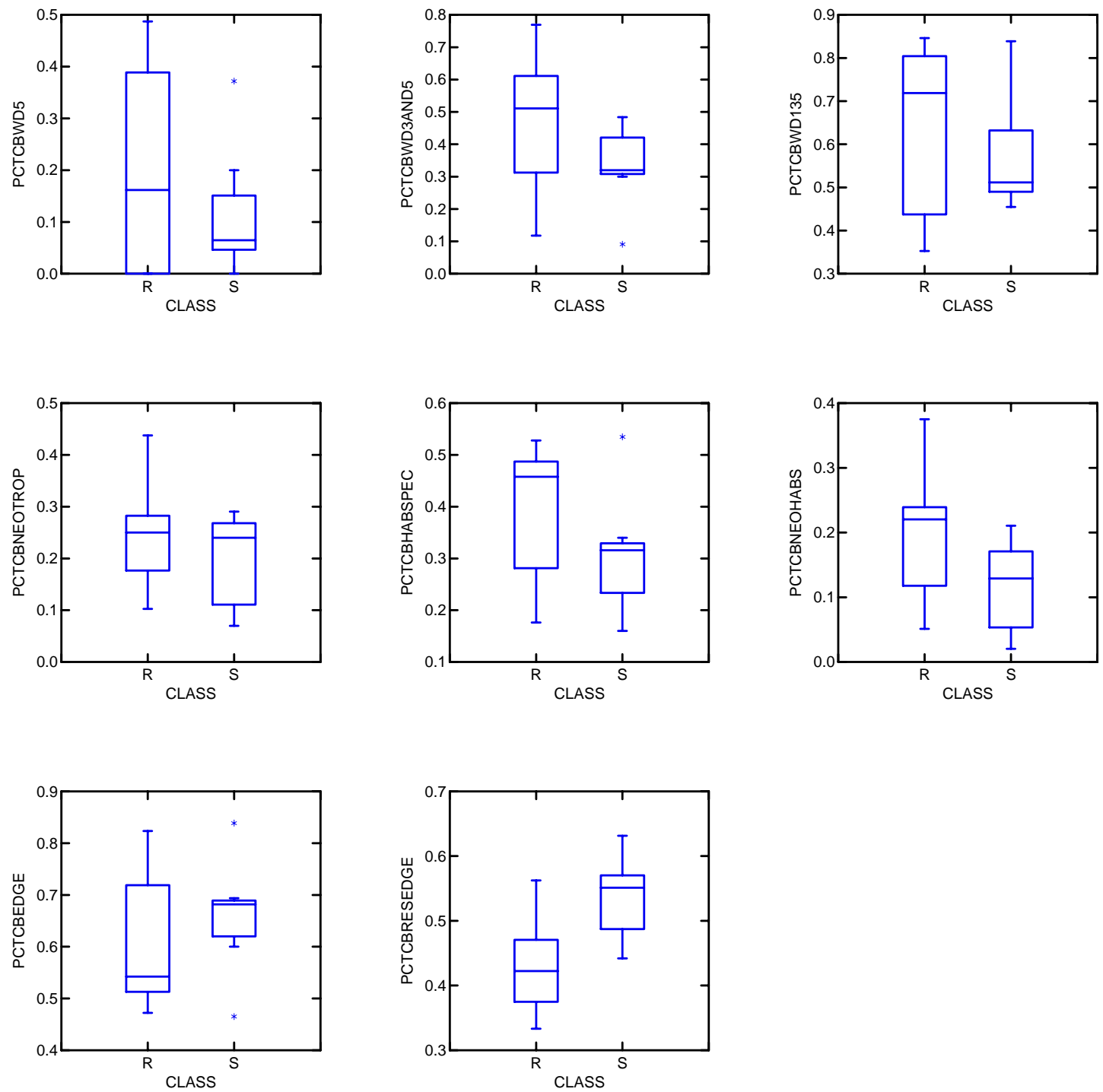

\begin{tabular}{lll} 
Metric code & Metric Description & Rating \\
\hline PCTWD5 & Proportion wetland dependent spp. & fair \\
PCTWD3AND5 & Proportion wetland associated and dependent spp. & fair \\
PCTWD135 & Proportion facultative wetland and above spp. & fair \\
PCTCBNEOTROP & Proportion neotropical migrants & fair \\
PCTCBHABSPEC & Proportion habitat specific spp. & fair \\
PCTNEOHABSPEC & Proportion neotropical migrants and habitat specific spp. & fair \\
PCTCBEDGE & Proportion edge spp. & fair \\
PCTCBRESEDGE & Proportion residential and edge spp. & excellent \\
\hline
\end{tabular}


Appendix H. Continued.
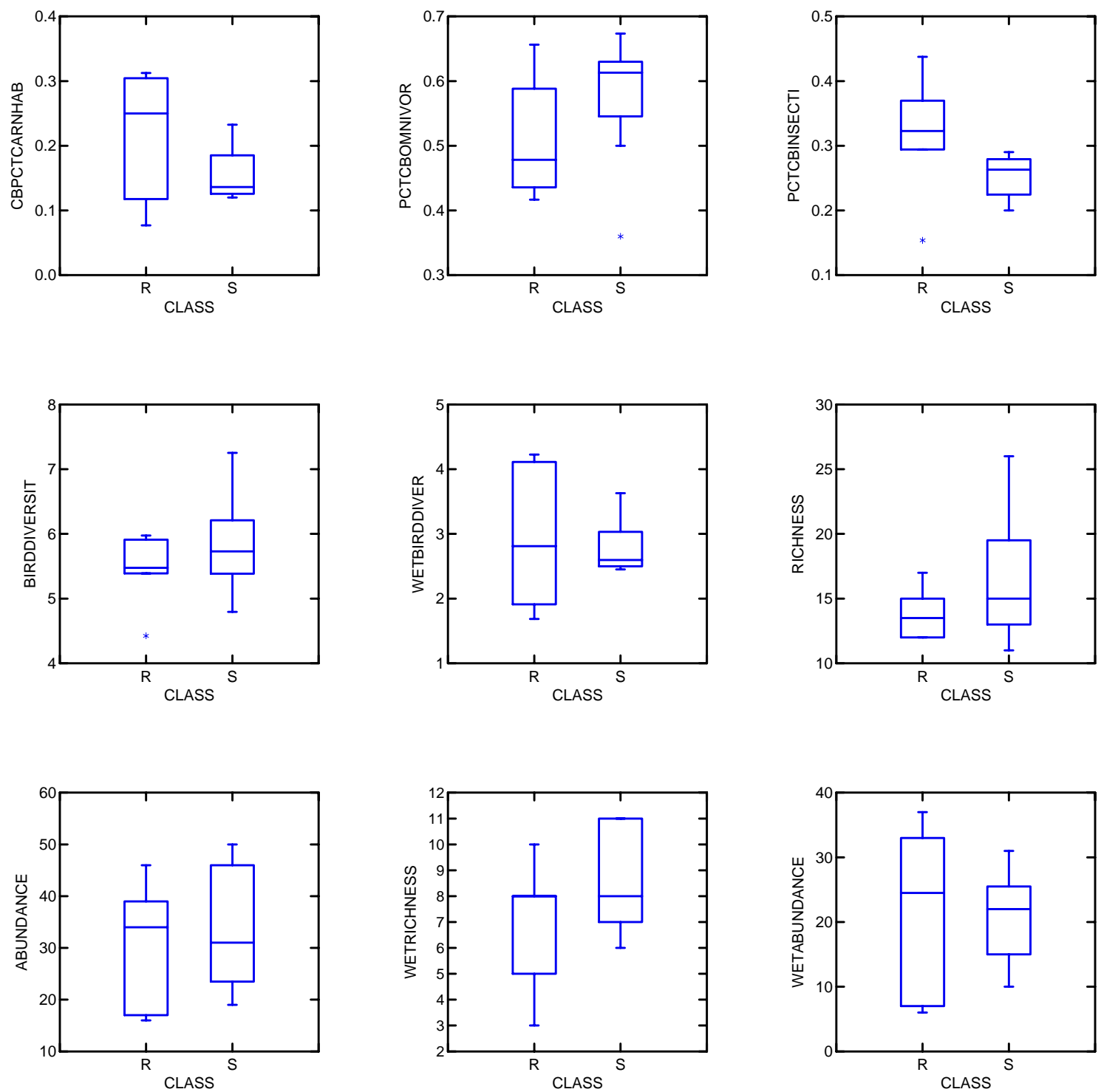

\begin{tabular}{llll} 
Metric code & Metric Description & Rating \\
\cline { 1 - 1 } PCTCBCARNHAB & Proportion carnivorous and habitat specific spp. & fair \\
PCTOMNIVOR & Proportion omnivorous spp. & good \\
PCTINSECTI & Proportion insectivorous spp. & exellent \\
BIRDDIVERSIT & Shannon-Weaver diversity index & poor \\
WETBIRDDIVER & Wetland bird S-W diversity index & poor \\
RICHNESS & Richness (number of species) & poor \\
ABUNDANCE & Abundance (count of individuals) & poor \\
WETRICHNESS & Wetland bird richness & fair \\
WETABUNDANCE & Wetland bird abundance & poor \\
\hline
\end{tabular}


Appendix H. Continued.
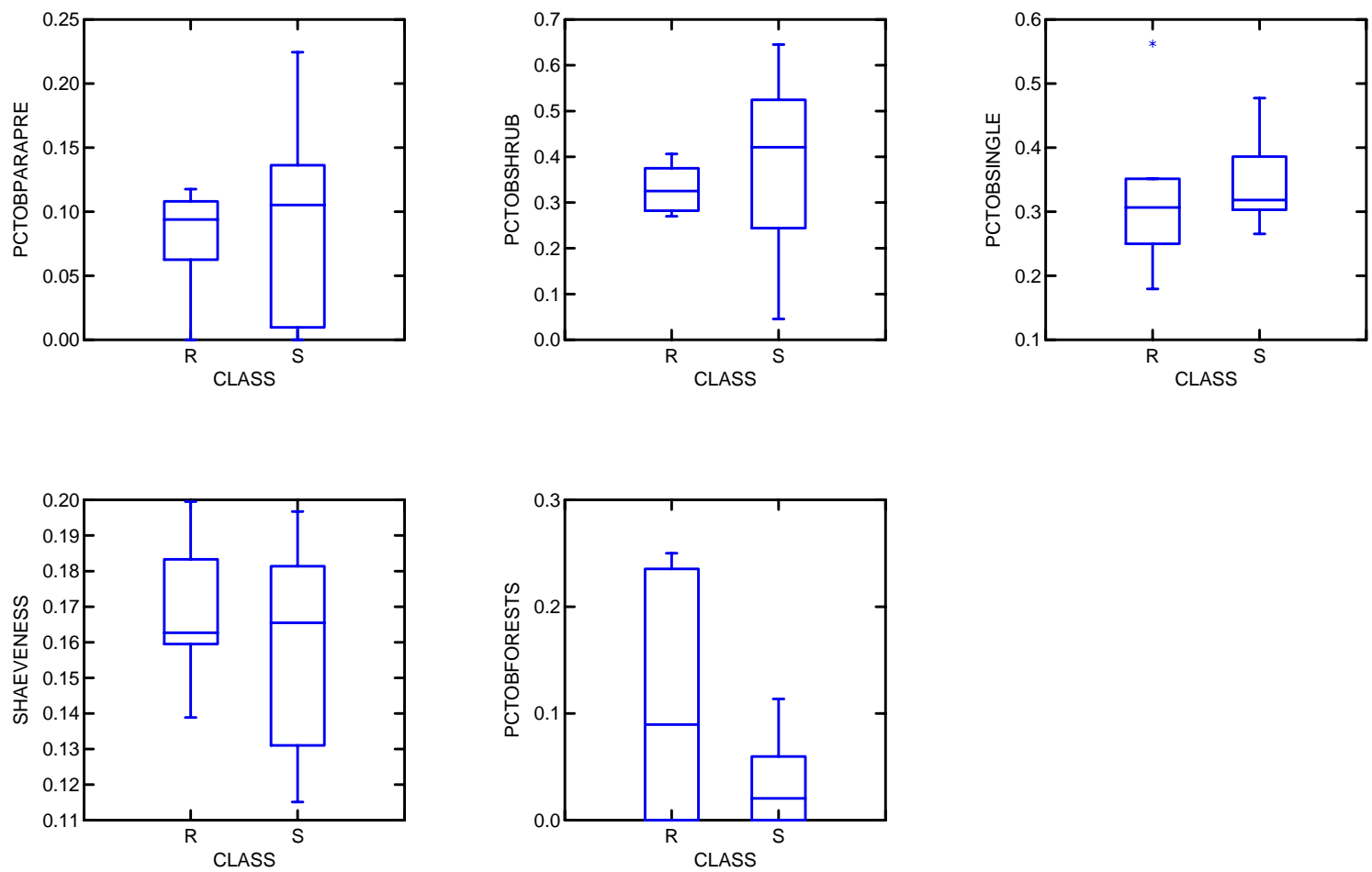

\begin{tabular}{llll} 
Metric code & Metric Description & Rating \\
\cline { 1 - 1 } PCTOBPARAPRED & & Proportion brood parasite / nest predator spp. & poor \\
PCTOBSHRUB & Proportion shrub nesting spp. & fair \\
PCTOBSINGLE & Proportion single brood spp. & poor \\
SHAEVENESS & Shannon evenness index & poor \\
PCTOBFORESTS & Proportion interior forest obligate spp. & poor \\
\hline
\end{tabular}


Appendix I. Avian community metricsbox-and-whisker results and narrative for emergent wetlands $(\mathrm{N}=38)$. Classifications are reference $(\mathrm{R})$ and stressed $(\mathrm{S})$.
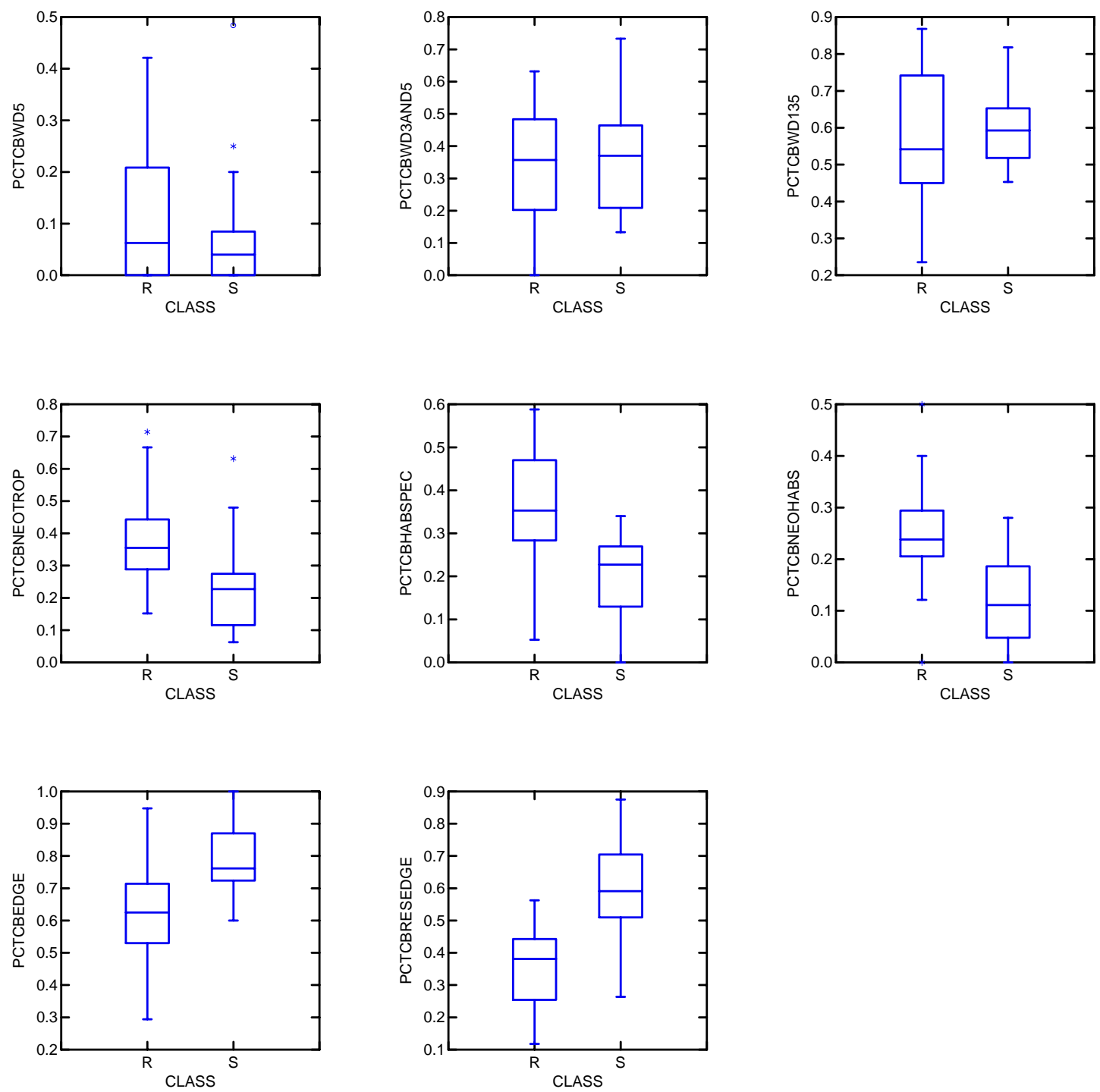

\begin{tabular}{|c|c|c|}
\hline Metric code & Metric Description & Rating \\
\hline PCTWD5 & Proportion wetland dependent spp. & poor \\
\hline PCTWD3AND5 & $\begin{array}{l}\text { Proportion wetland associated and dependent } \\
\text { spp. }\end{array}$ & poor \\
\hline PCTWD135 & Proportion facultative wetland and above spp. & poor \\
\hline PCTCBNEOTROP & Proportion neotropical migrants & excellent \\
\hline PCTCBHABSPEC & Proportion habitat specific spp. & excellent \\
\hline PCTNEOHABSPEC & $\begin{array}{l}\text { Proportion neotropical migrants and habitat } \\
\text { specific spp. }\end{array}$ & excellent \\
\hline PCTCBEDGE & Proportion edge spp. & excellent \\
\hline PCTCBRESEDGE & Proportion residential and edge spp. & excellent \\
\hline
\end{tabular}


Appendix I. Continued.
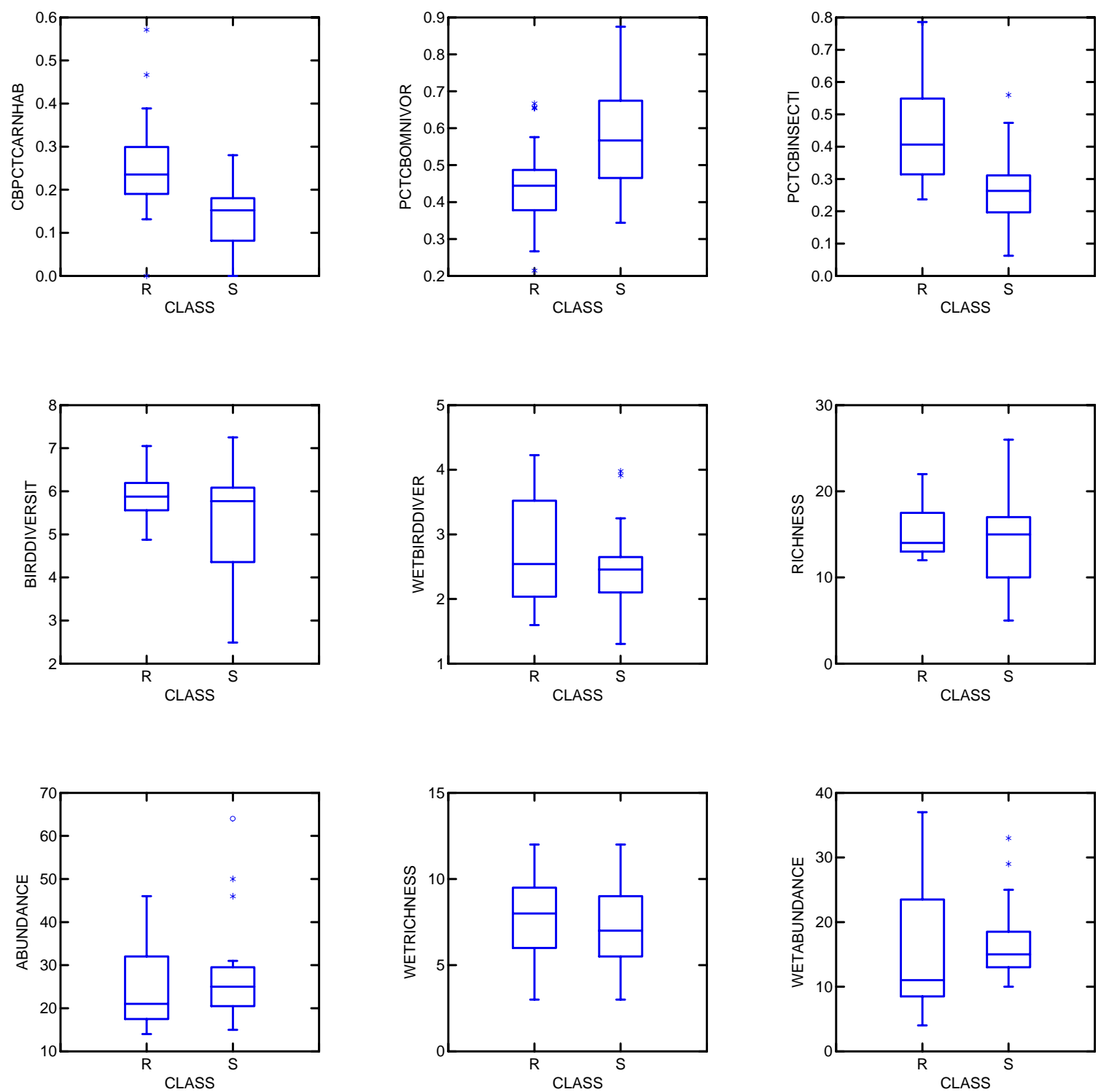

\begin{tabular}{lll} 
Metric code & Metric Description & Rating \\
\cline { 1 - 1 } PCTCBCARNHAB & Proportion carnivorous and habitat specific spp. & $\begin{array}{l}\text { excellent } \\
\text { good }\end{array}$ \\
PCTOMNIVOR & Proportion omnivorous spp. & good \\
PCTINSECTI & Proportion insectivorous spp. & poor \\
BIRDDIVERSIT & Shannon-Weaver diversity index & poor \\
WETBIRDDIVER & Wetland bird S-W diversity index & poor \\
RICHNESS & Richness (number of species) & poor \\
ABUNDANCE & Abundance (count of individuals) & poor \\
WETRICHNESS & Wetland bird richness & fair \\
WETABUNDANCE & Wetland bird abundance &
\end{tabular}


Appendix I. Continued.
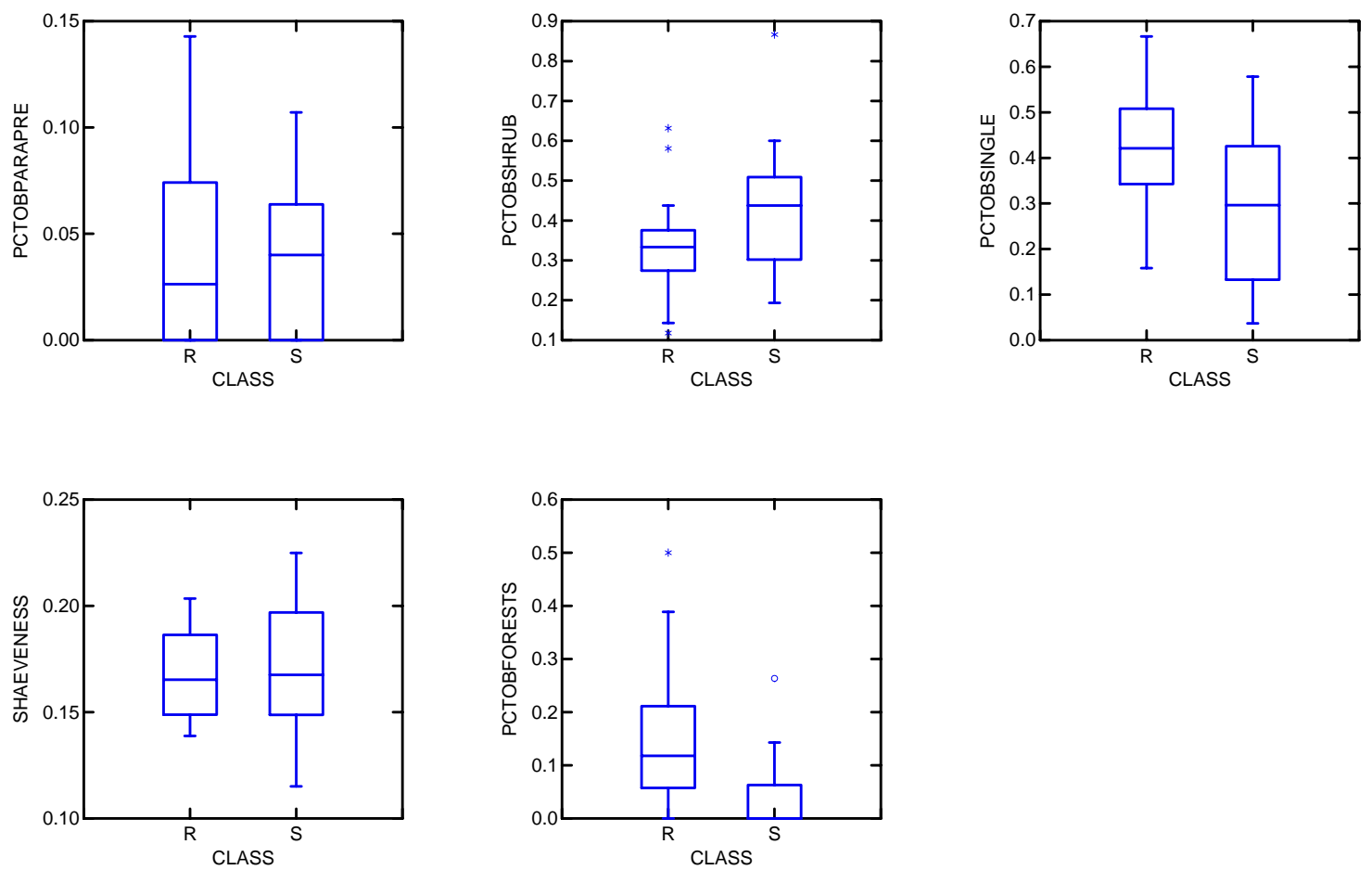

\begin{tabular}{|c|c|c|}
\hline Metric code & Metric Description & Rating \\
\hline$\overline{\text { PCTOBPARAPRED }}$ & Proportion brood parasite / nest predator spp. & poor \\
\hline PCTOBSHRUB & Proportion shrub nesting spp. & fair \\
\hline PCTOBSINGLE & Proportion single brood spp. & good \\
\hline SHAEVENESS & Shannon evenness index & poor \\
\hline PCTOBFORESTS & Proportion interior forest obligate spp. & poor \\
\hline
\end{tabular}


Appendix J. Avian community metricsbox-and-whisker results and narrative for scrubshrub wetlands $(\mathrm{N}=23)$. Classifications are reference $(\mathrm{R})$ and stressed $(\mathrm{S})$.
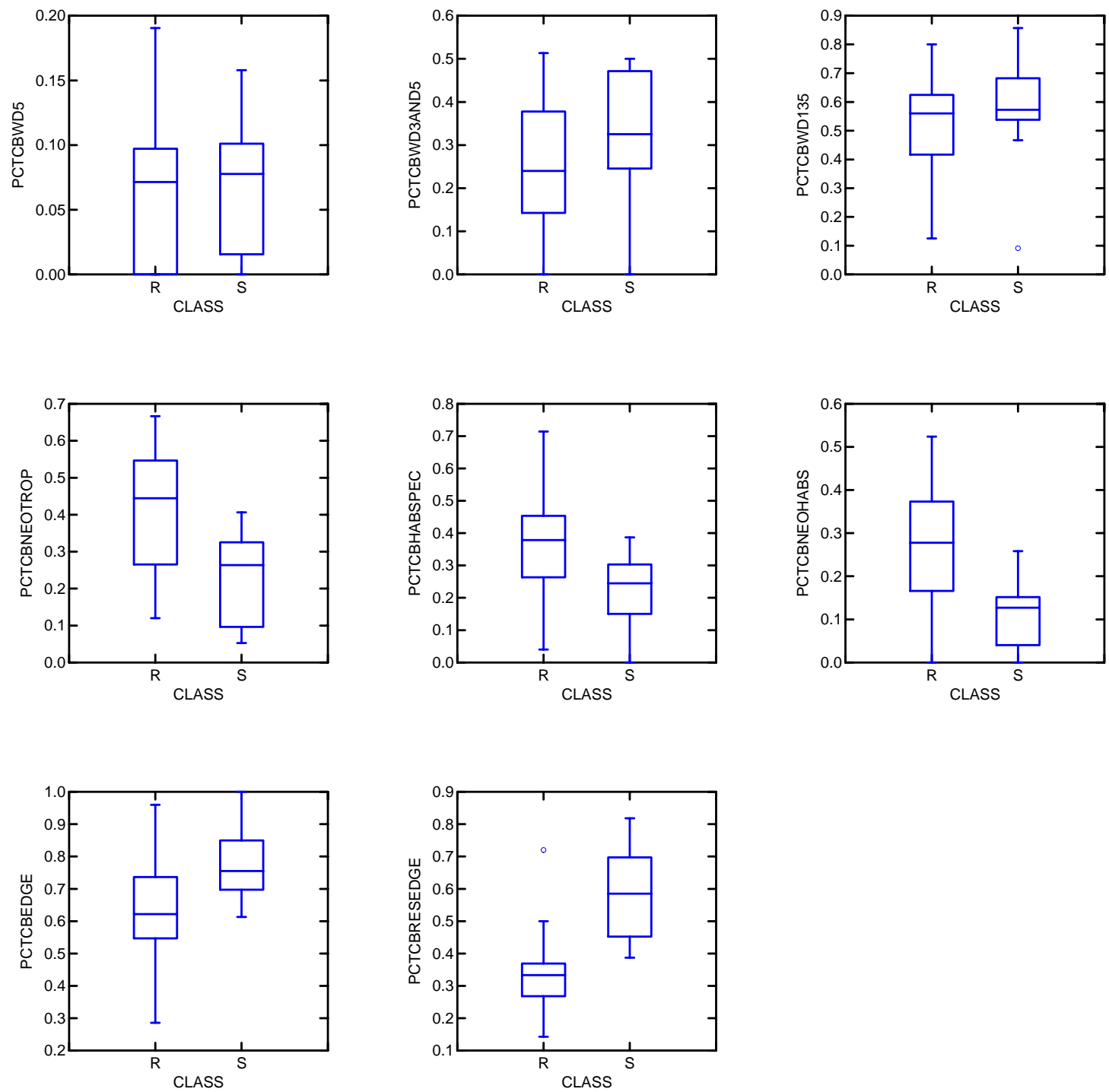

\begin{tabular}{llll} 
Metric code & Metric Description & Rating \\
\cline { 1 - 1 } $\begin{array}{l}\text { PCTWD5 } \\
\text { PCTWD3AND5 }\end{array}$ & $\begin{array}{l}\text { Proportion wetland dependent spp. } \\
\text { Proportion wetland associated and dependent spp. }\end{array}$ & $\begin{array}{l}\text { poor } \\
\text { fair }\end{array}$ \\
PCTWD135 & Proportion facultative wetland and above spp. & poor \\
PCTCBNEOTROP & Proportion neotropical migrants & fair \\
PCTCBHABSPEC & Proportion habitat specific spp. & good \\
PCTNEOHABSPEC & $\begin{array}{l}\text { Proportion neotropical migrants and habitat specific } \\
\text { spp. }\end{array}$ & good \\
PCTCBEDGE & Proportion edge spp. & good \\
PCTCBRESEDGE & Proportion residential and edge spp. & excellent \\
\hline
\end{tabular}


Appendix J. Continued.
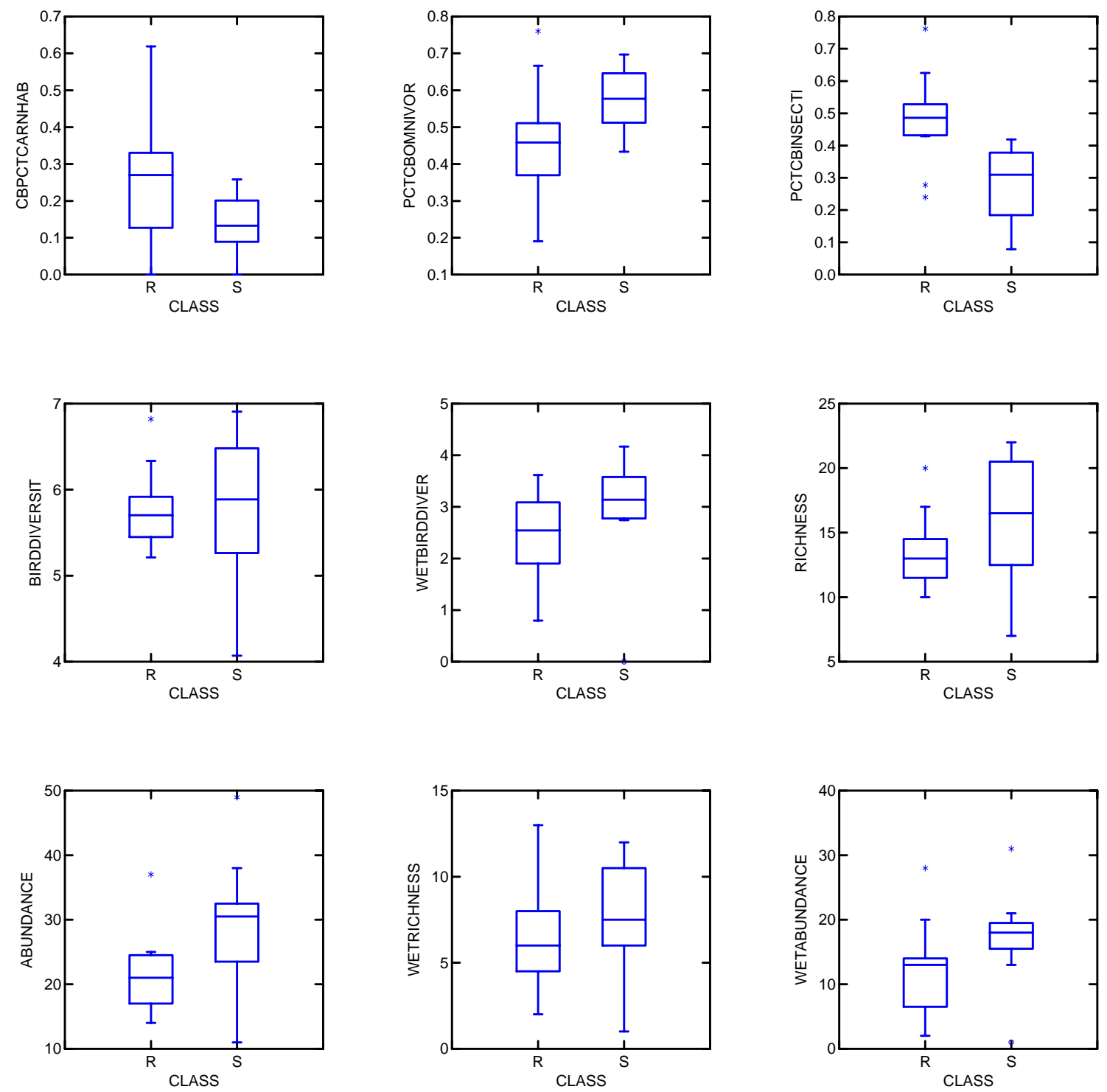

\begin{tabular}{|c|c|c|}
\hline Metric code & Metric Description & Rating \\
\hline PCTCBCARNHAB & Proportion carnivorous and habitat specific spp. & fair \\
\hline PCTOMNIVOR & Proportion omnivorous spp. & good \\
\hline PCTINSECTI & Proportion insectivorous spp. & excellent \\
\hline BIRDDIVERSIT & Shannon-Weaver diversity index & poor \\
\hline WETBIRDDIVER & Wetland bird S-W diversity index & fair \\
\hline RICHNESS & Richness (number of species) & fair \\
\hline ABUNDANCE & Abundance (count of individuals) & good \\
\hline WETRICHNESS & Wetland bird richness & poor \\
\hline WETABUNDANCE & Wetland bird abundance & excellent \\
\hline
\end{tabular}


Appendix J. Continued.
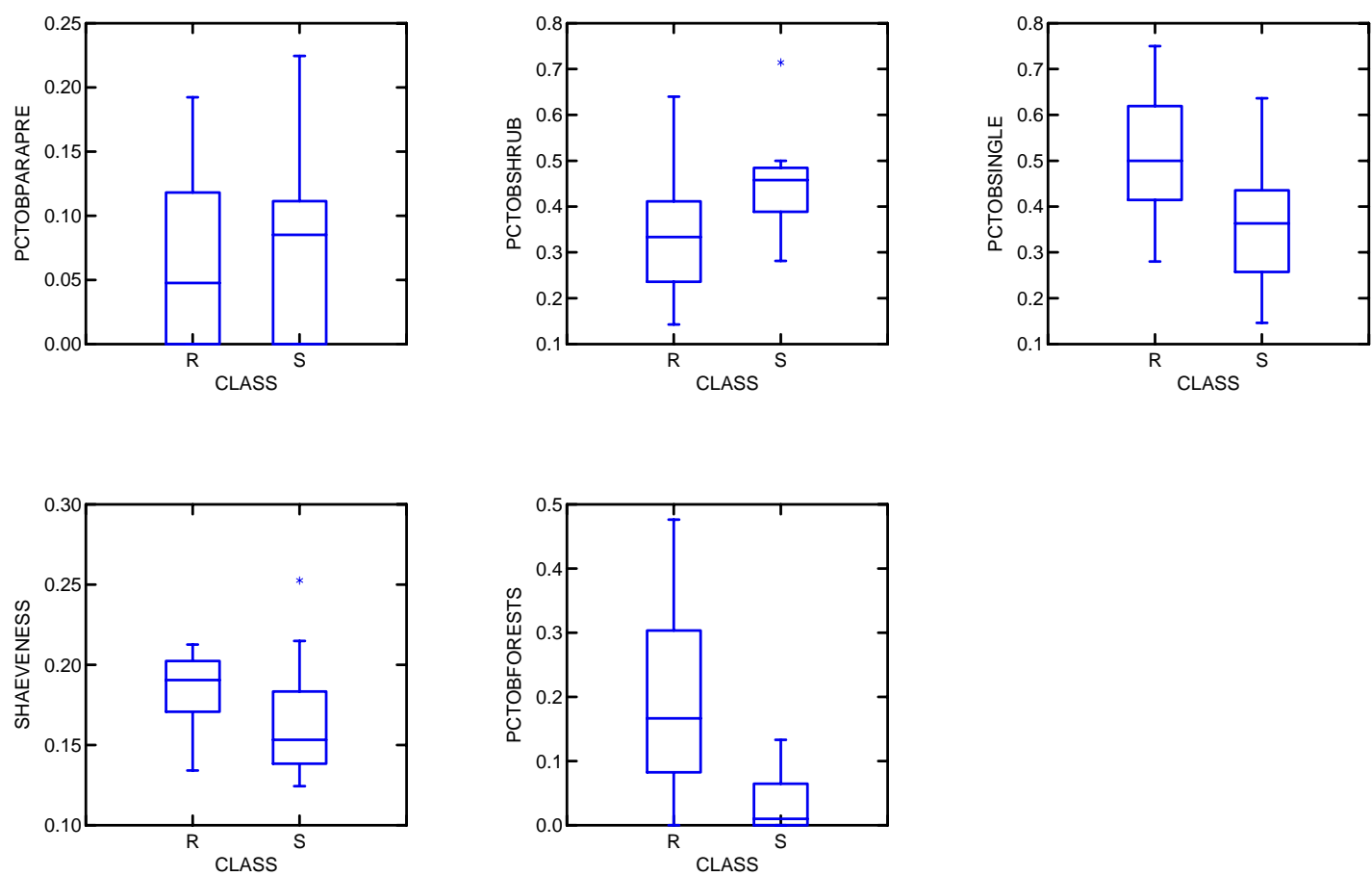

\begin{tabular}{llll} 
Metric code & Metric Description & Rating \\
\cline { 1 - 1 } PCTOBPARAPRED & Proportion brood parasite / nest predator spp. & poor \\
PCTOBSHRUB & Proportion shrub nesting spp. & good \\
PCTOBSINGLE & Proportion single brood spp. & good \\
SHAEVENESS & Shannon evenness index & good \\
PCTOBFORESTS & Proportion interior forest obligate spp. & fair \\
\hline
\end{tabular}


Appendix K. Avian community metricsbox-and-whisker results and narrative for forested wetlands $(\mathrm{N}=16)$. Classifications are reference $(\mathrm{R})$ and stressed $(\mathrm{S})$.
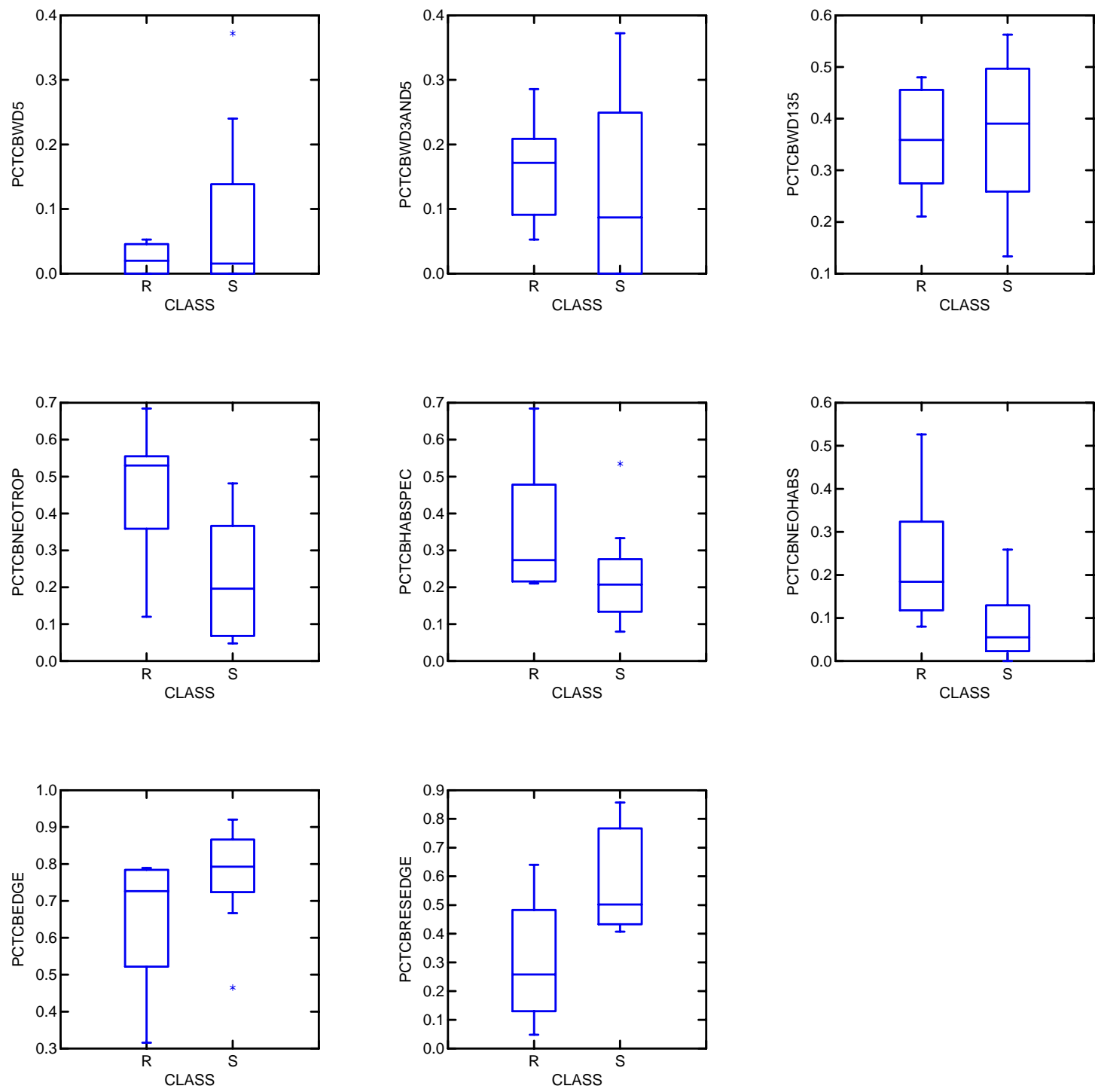

Metric code

PCTWD5 Metric Description Proportion wetland dependent spp.

PCTWD3AND5

Proportion wetland associated and dependent spp.

poor

PCTWD135 Proportion facultative wetland and above spp.

fair

PCTCBNEOTROP Proportion neotropical migrants

poor

PCTCBHABSPEC Proportion habitat specific spp.

good

PCTNEOHABSPEC Proportion neotropical migrants and habitat specific spp. good

PCTCBEDGE

Proportion edge spp.

fair

PCTCBRESEDGE Proportion residential and edge spp.

good 
Appendix K. Continued.
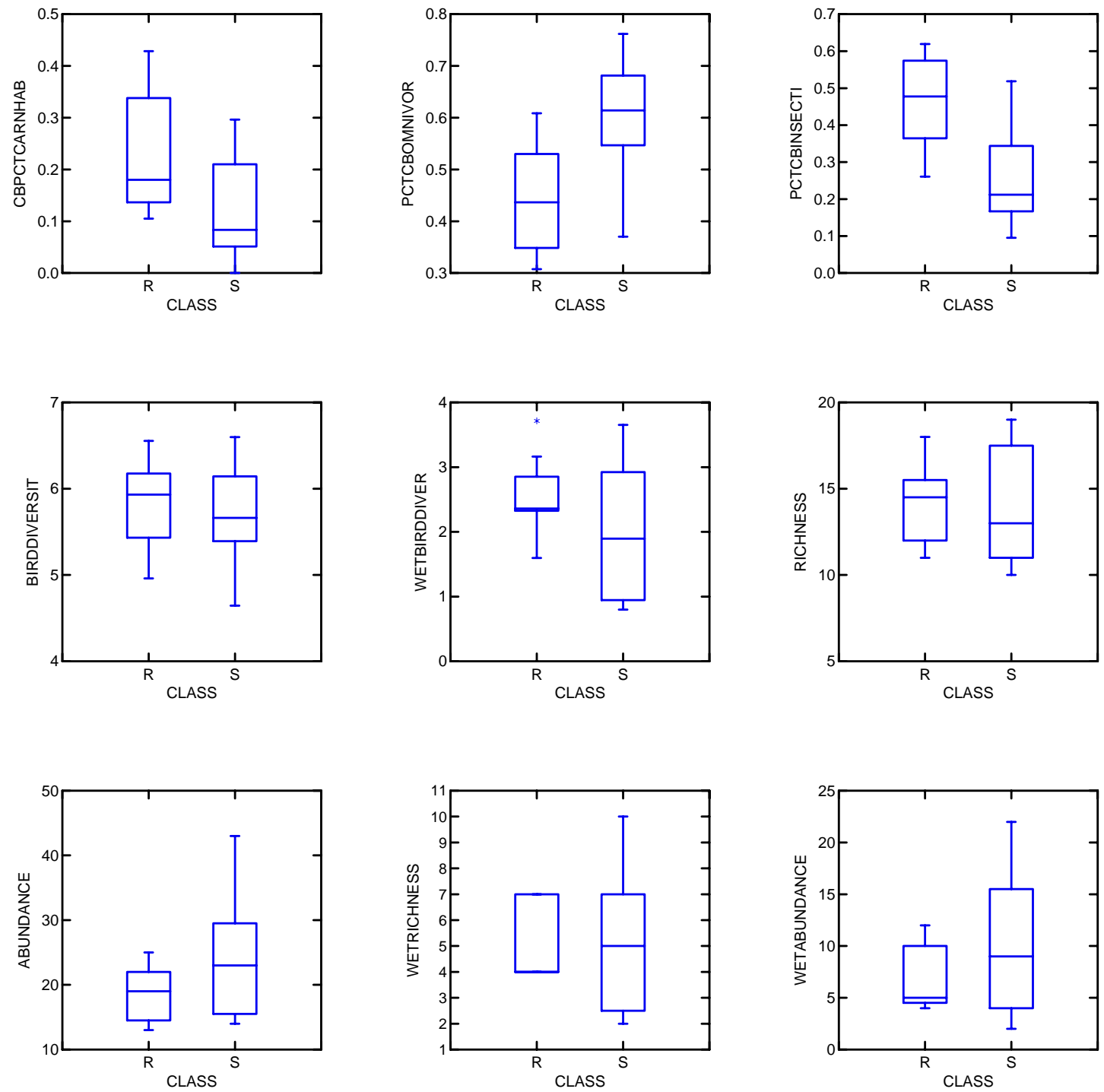

\begin{tabular}{llll}
\cline { 1 - 1 } Metric code & & Metric Description & Rating \\
\cline { 1 - 1 } PCTCBCARNHAB & & Proportion carnivorous and habitat specific spp. & fair \\
PCTINSECTI & & Proportion omnivorous spp. & excellent \\
PCTINSECTI & Proportion insectivorous spp. & excellent \\
BIRDDIVERSIT & Shannon-Weaver diversity index & poor \\
WETBIRDDIVER & Wetland bird S-W diversity index & fair \\
RICHNESS & Richness (number of species) & poor \\
ABUNDANCE & Abundance (count of individuals) & fair \\
WETRICHNESS & Wetland bird richness & fair \\
WETABUNDANCE & Wetland bird abundance & poor \\
\hline
\end{tabular}


Appendix K. Continued.
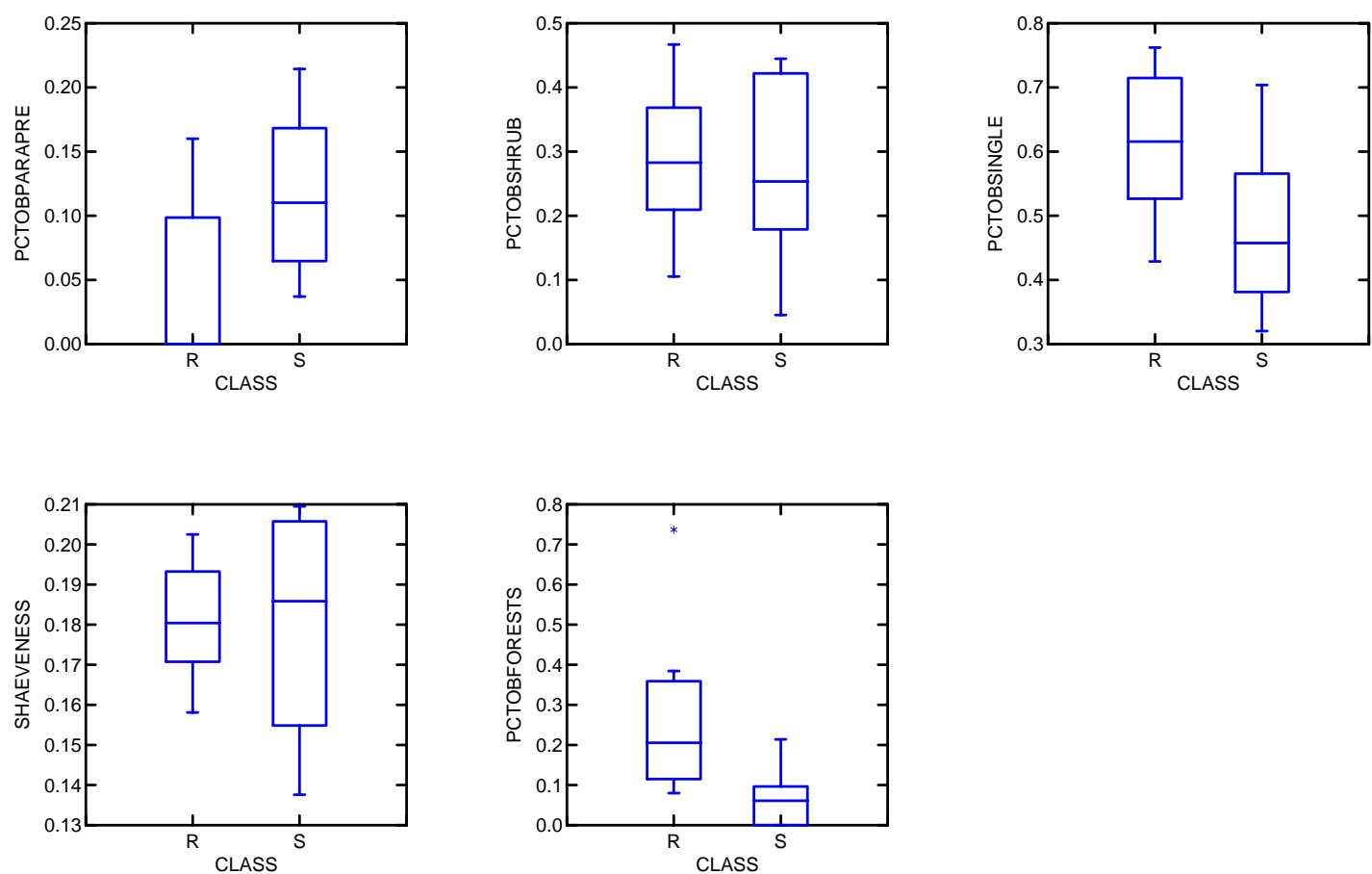

Metric code Metric Description Rating

$\overline{\text { PCTOBPARAPRED }}$ PCTOBSHRUB Proportion brood parasite / nest predator spp. fair PCTOBSINGLE Proportion shrub nesting spp.

Proportion single brood spp. SHAEVENESS Shannon evenness index poor PCTOBFORESTS

Proportion interior forest obligate spp.

good

fair good 
Appendix L. Avian community metrics box-and-whisker results and narrative descriptions for riparian depression wetlands $(\mathrm{N}=27)$. Classifications are reference $(\mathrm{R})$ and stressed $(\mathrm{S})$.
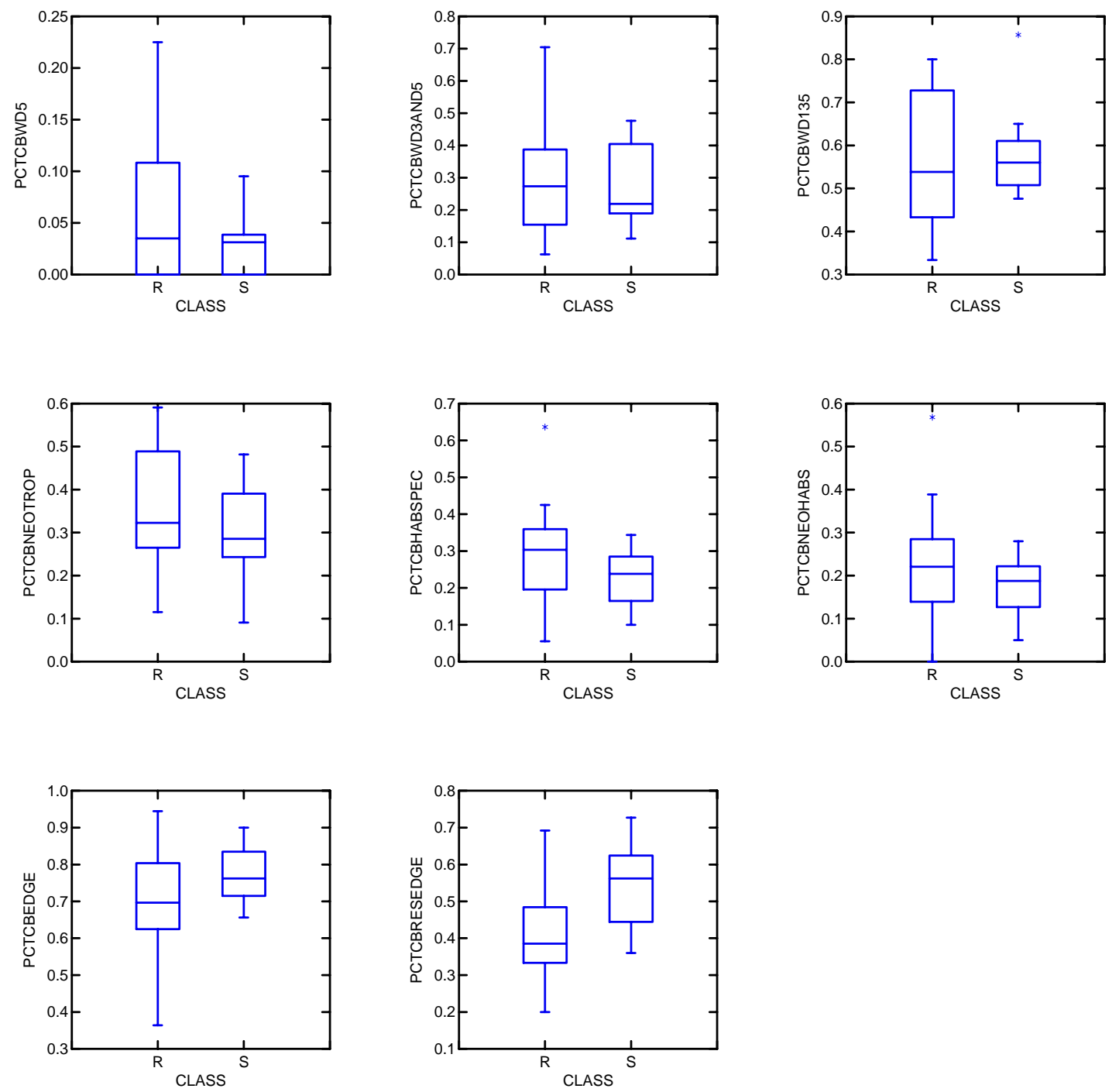

\begin{tabular}{lll} 
Metric code & Metric Description & Rating \\
\cline { 1 - 1 } PCTWD5 & Proportion wetland dependent spp. & poor \\
PCTWD3AND5 & Proportion wetland associated and dependent spp. & poor \\
PCTWD135 & Proportion facultative wetland and above spp. & poor \\
PCTCBNEOTROP & Proportion neotropical migrants & poor \\
PCTCBHABSPEC & Proportion habitat specific spp. & fair \\
PCTNEOHABSPEC & Proportion neotropical migrants and habitat specific spp. & fair \\
PCTCBEDGE & Proportion edge spp. & fair \\
PCTCBRESEDGE & Proportion residential and edge spp. & good \\
\hline
\end{tabular}


Appendix L. Continued.
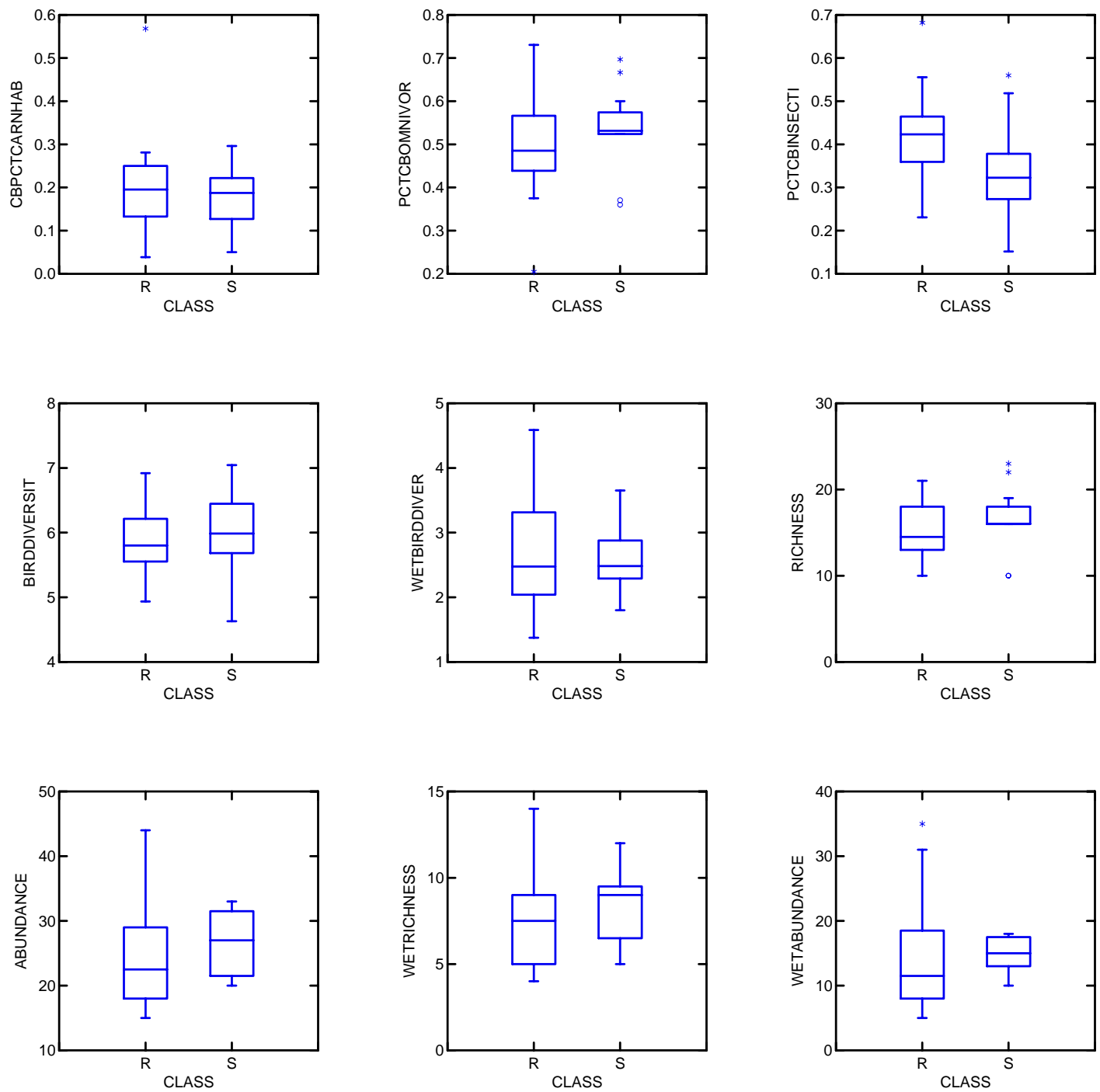

\begin{tabular}{|c|c|c|}
\hline Metric code & Metric Description & Rating \\
\hline PCTCBCARNHAB & Proportion carnivorous and habitat specific spp. & poor \\
\hline PCTOMNIVOR & Proportion omnivorous spp. & fair \\
\hline PCTINSECTI & Proportion insectivorous spp. & good \\
\hline BIRDDIVERSIT & Shannon-Weaver diversity index & poor \\
\hline WETBIRDDIVER & Wetland bird S-W diversity index & poor \\
\hline RICHNESS & Richness (number of species) & poor \\
\hline ABUNDANCE & Abundance (count of individuals) & poor \\
\hline WETRICHNESS & Wetland bird richness & poor \\
\hline WETABUNDANCE & Wetland bird abundance & fair \\
\hline
\end{tabular}


Appendix L. Continued.
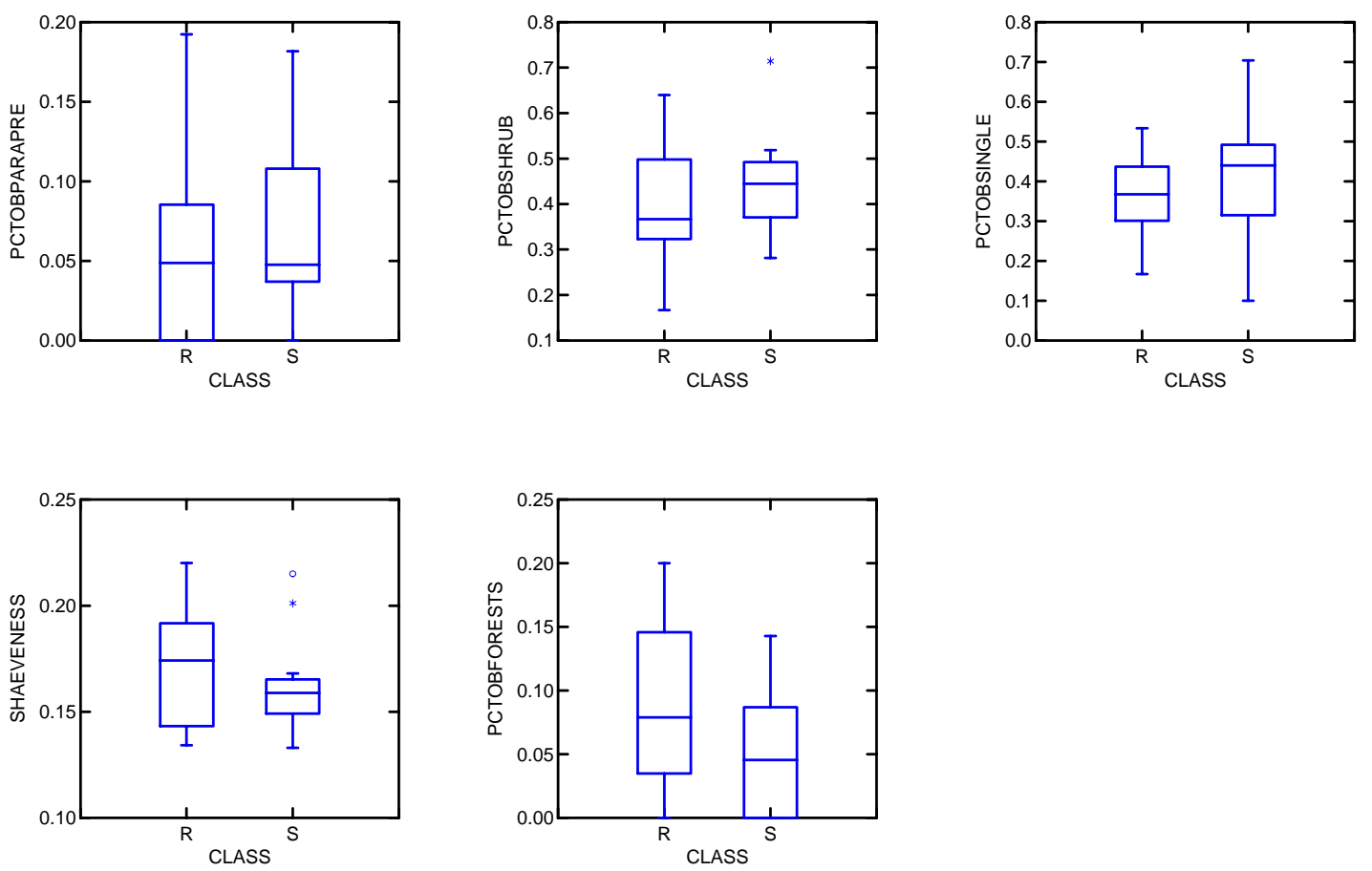

\begin{tabular}{llll} 
Metric code & Metric Description & Rating \\
\cline { 1 - 1 } PCTOBPARAPRED & Proportion brood parasite / nest predator spp. & & poor \\
PCTOBSINGLE & Proportion shrub nesting spp. & fair \\
SHAEVENESS & Proportion single brood spp. & fair \\
PCTOBFORESTS & Proportion interior forest obligate spp. & fair \\
\hline
\end{tabular}


Appendix M. Avian community metrics box-and-whisker results and narrative descriptions for headwater floodplain wetlands $(\mathrm{N}=16)$. Classifications are reference $(\mathrm{R})$ and stressed (S).
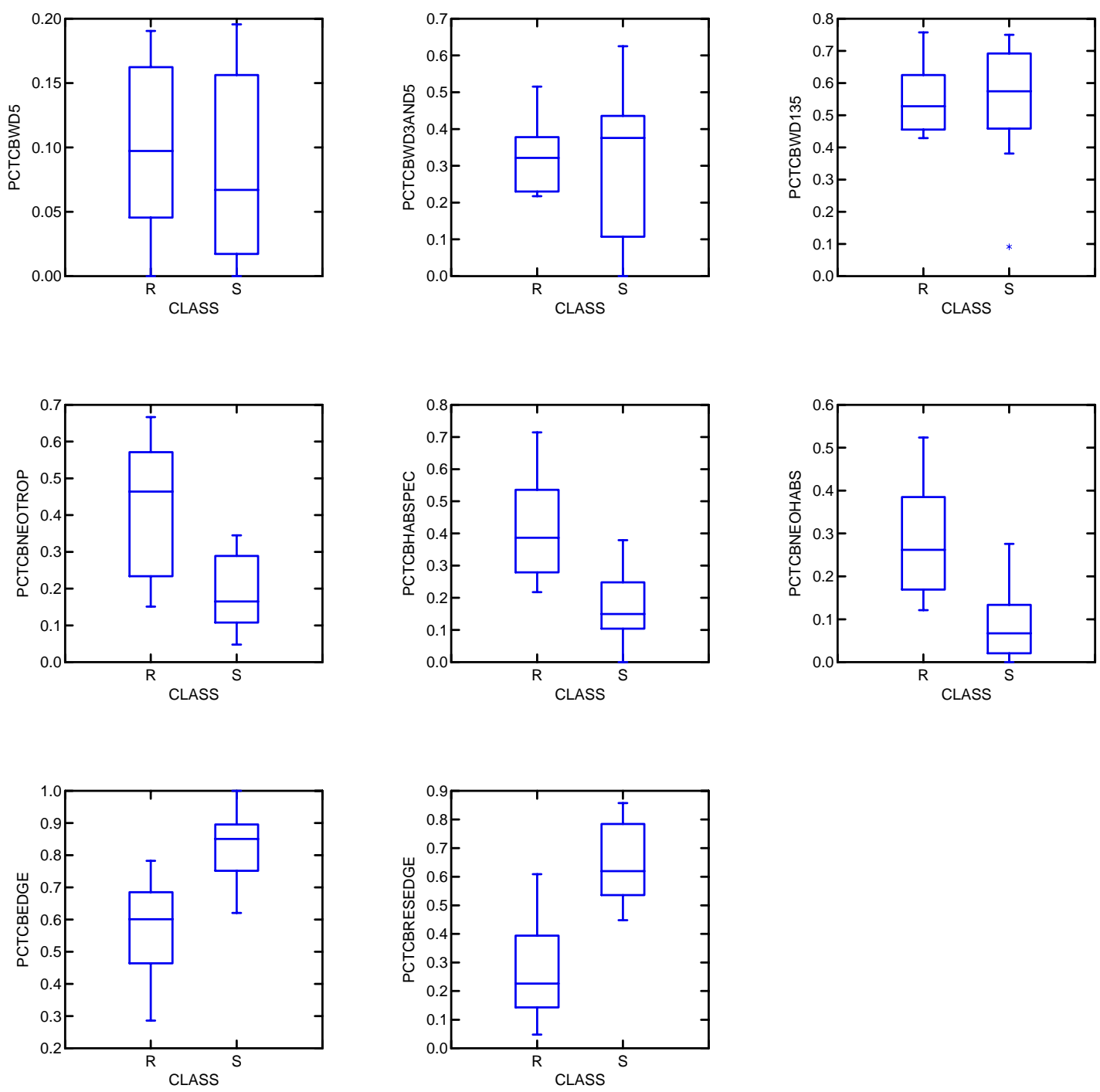

\begin{tabular}{lll} 
Metric code & Metric Description & Rating \\
\cline { 1 - 1 } PCTWD5 & Proportion wetland dependent spp. & poor \\
PCTWD3AND5 & Proportion wetland associated and dependent spp. & fair \\
PCTWD135 & Proportion facultative wetland and above spp. & poor \\
PCTCBNEOTROP & Proportion neotropical migrants & good \\
PCTCBHABSPEC & Proportion habitat specific spp. & excellent \\
PCTNEOHABSPEC & Proportion neotropical migrants and habitat specific spp. & excellent \\
PCTCBEDGE & Proportion edge spp. & excellent \\
PCTCBRESEDGE & Proportion residential and edge spp. & excellent \\
\hline
\end{tabular}


Appendix M. Continued.
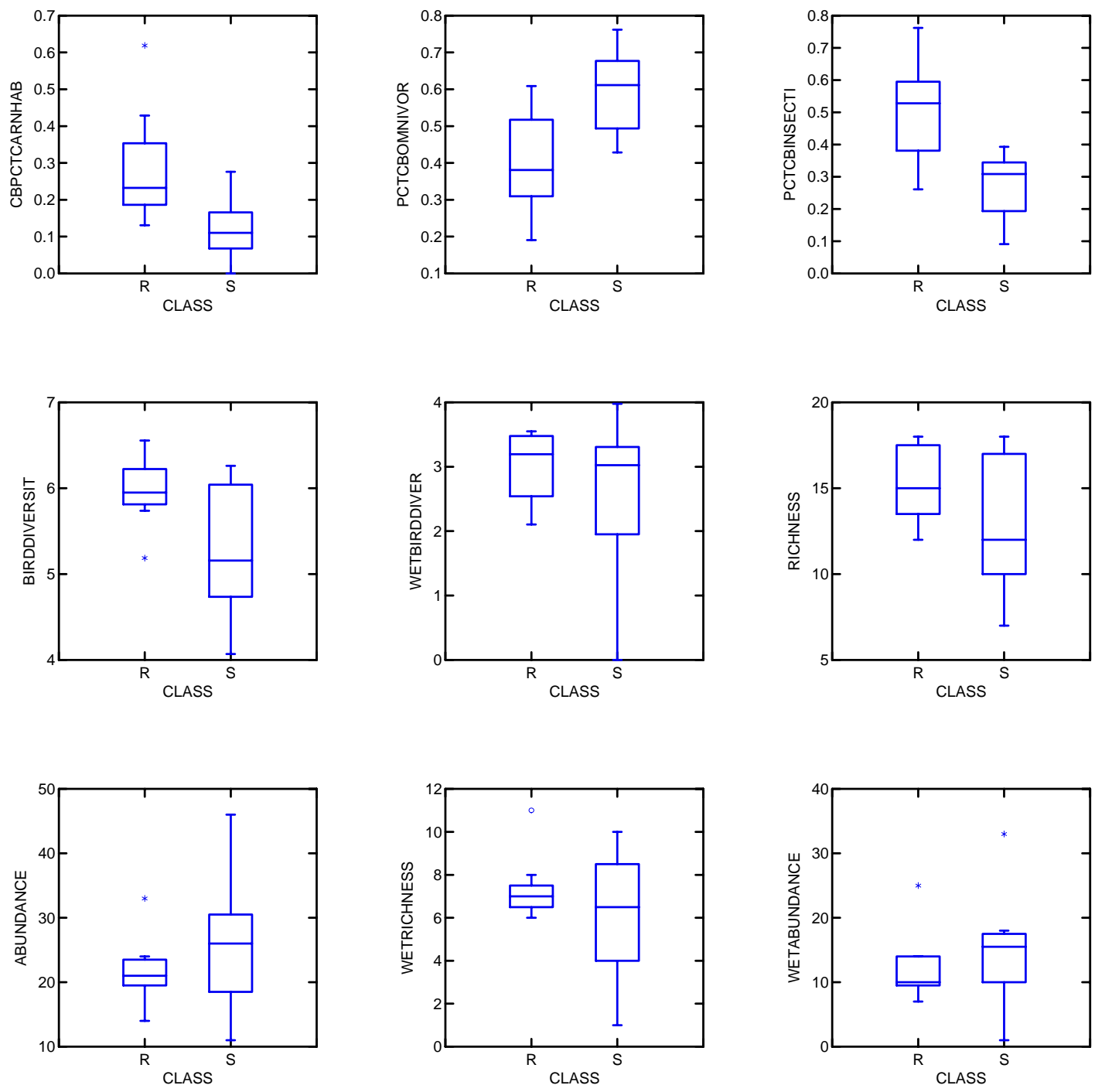

\begin{tabular}{|c|c|c|}
\hline Metric code & Metric Description & Rating \\
\hline PCTCBCARNHAB & Proportion carnivorous and habitat specific spp. & excellent \\
\hline PCTOMNIVOR & Proportion omnivorous spp. & good \\
\hline PCTINSECTI & Proportion insectivorous spp. & excellent \\
\hline BIRDDIVERSIT & Shannon-Weaver diversity index & fair \\
\hline WETBIRDDIVER & Wetland bird S-W diversity index & poor \\
\hline RICHNESS & Richness (number of species) & fair \\
\hline ABUNDANCE & Abundance (count of individuals) & fair \\
\hline WETRICHNESS & Wetland bird richness & fair \\
\hline WETABUNDANCE & Wetland bird abundance & fair \\
\hline
\end{tabular}


Appendix M. Continued.
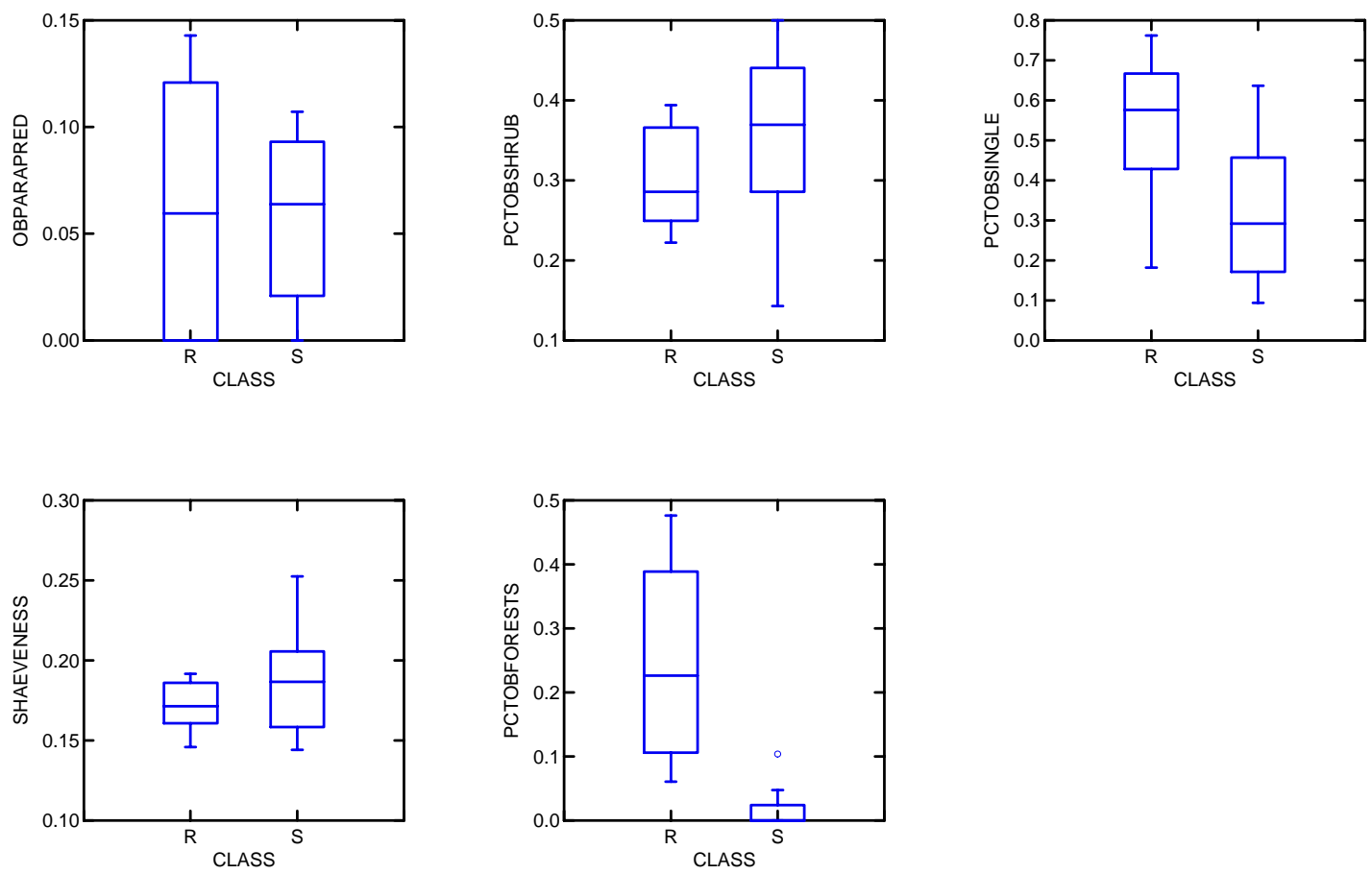

\begin{tabular}{llll}
\cline { 1 - 1 } Metric code & Metric Description & Rating \\
\cline { 1 - 1 } PCTOBPARAPRED & Proportion brood parasite / nest predator spp. & & poor \\
PCTOBSINGLE & Proportion shrub nesting spp. & fair \\
SHAEVENESS & Proportion single brood spp. & good \\
PCTOBFORESTS & Proportion interior forest obligate spp. & fair \\
\hline
\end{tabular}


Appendix N. Anuran richness, maximum Wisconsin Index (WI) call chorus, and max estimate for anuran species bysite used to form anuran acoustically-based indices of biological integrity (AA-IBI) in West Virginia, USA from 2005-2006.

\begin{tabular}{|c|c|c|c|c|}
\hline Site Code & Species & Latin name & Max Chorus & Max Estimate \\
\hline \multirow[t]{5}{*}{ CFCROS } & Richness & 4 & & \\
\hline & Gray treefrog & Hyla versicolor & 1 & 1 \\
\hline & Northern spring peeper & Pseudacris crucifer & 3 & 50 \\
\hline & Mountain chorus frog & Pseudacris brachyphona & 1 & 3 \\
\hline & Wood frog & Rana sylvatica & 2 & 20 \\
\hline \multirow[t]{3}{*}{ CFECUR } & Richness & 2 & & \\
\hline & Northern spring peeper & Pseudacris crucifer & 2 & 25 \\
\hline & Mountain chorus frog & Pseudacris brachyphona & 1 & 2 \\
\hline \multirow[t]{5}{*}{ CFEINC } & Richness & 4 & & \\
\hline & Northern pickerel frog & Rana palustris & 1 & 1 \\
\hline & Northern green frog & Rana clamitans & 1 & 8 \\
\hline & Northern spring peeper & Pseudacris crucifer & 2 & 30 \\
\hline & Eastern American toad & Bufo americanus & 1 & 1 \\
\hline \multirow[t]{8}{*}{$\mathrm{CFSLCH}$} & Richness & 7 & & \\
\hline & American bullfrog & Rana catesbeiana & 1 & 1 \\
\hline & Northern spring peeper & Pseudacris crucifer & 2 & 25 \\
\hline & Mountain chorus frog & Pseudacris brachyphona & 1 & 3 \\
\hline & Northern pickerel frog & Rana palustris & 1 & 1 \\
\hline & Northern green frog & Rana clamitans & 1 & 7 \\
\hline & Wood frog & Rana sylvatica & 2 & 15 \\
\hline & Upland chorus frog & Pseudacris triseriata & 1 & 4 \\
\hline \multirow[t]{7}{*}{ CFSLIN } & Richness & 6 & & \\
\hline & Wood frog & Rana sylvatica & 2 & 25 \\
\hline & Gray treefrog & Hyla versicolor & 1 & 1 \\
\hline & Northern green frog & Rana clamitans & 1 & 5 \\
\hline & Upland chorus frog & Pseudacris triseriata & 1 & 4 \\
\hline & Northern pickerel frog & Rana palustris & 1 & 1 \\
\hline & Northern spring peeper & Pseudacris crucifer & 2 & 40 \\
\hline \multirow[t]{2}{*}{ CGBRID } & Richness & 1 & & \\
\hline & Northern spring peeper & Pseudacris crucifer & 1 & 2 \\
\hline \multirow[t]{2}{*}{ CGCPAS } & Richness & 1 & & \\
\hline & Northern spring peeper & Pseudacris crucifer & 3 & 50 \\
\hline \multirow[t]{2}{*}{ CGROAD } & Richness & 1 & & \\
\hline & Northern spring peeperPseudacris $c$ & ifer & 1 & \\
\hline
\end{tabular}


Appendix N. Continued.

\begin{tabular}{|c|c|c|c|c|}
\hline Site Code & Species & Latin name & Max Chorus & Max Estimate \\
\hline CGTRHE & $\begin{array}{l}\text { Richness } \\
\text { Northern spring peeper }\end{array}$ & $\begin{array}{c}1 \\
\text { Pseudacris crucifer }\end{array}$ & 2 & 8 \\
\hline \multirow[t]{6}{*}{ CHNEER } & $\begin{array}{l}\text { Richness } \\
\text { Cope's Gray treefrog }\end{array}$ & $\begin{array}{c}6 \\
\text { Hyla chrysoscelis }\end{array}$ & 1 & 1 \\
\hline & Upland chorus frog & Pseudacris triseriata & 1 & 4 \\
\hline & American bullfrog & Rana catesbeiana & 2 & 24 \\
\hline & Gray treefrog & Hyla versicolor & 1 & 2 \\
\hline & Northern green frog & Rana clamitans & 2 & 15 \\
\hline & Northern spring peeper & Pseudacris crucifer & 2 & 45 \\
\hline $\mathrm{CHSACH}$ & $\begin{array}{l}\text { Richness } \\
\text { Northern spring peeper }\end{array}$ & $\begin{array}{c}1 \\
\text { Pseudacris crucifer }\end{array}$ & 1 & 3 \\
\hline CHSAFO & $\begin{array}{c}\text { Richness } \\
\text { Gray treefrog }\end{array}$ & $\begin{array}{c}1 \\
\text { Hyla versicolor }\end{array}$ & 1 & 2 \\
\hline \multirow[t]{3}{*}{ CHSARR } & $\begin{array}{c}\text { Richness } \\
\text { Gray treefrog }\end{array}$ & $\begin{array}{c}3 \\
\text { Hyla versicolor }\end{array}$ & 1 & 3 \\
\hline & Northern spring peeper & Pseudacris crucifer & 1 & 3 \\
\hline & Northern green frog & Rana clamitans & 1 & 5 \\
\hline \multirow[t]{2}{*}{ CHTREE } & $\begin{array}{c}\text { Richness } \\
\text { Gray treefrog }\end{array}$ & $\begin{array}{c}2 \\
\text { Hyla versicolor }\end{array}$ & 1 & 1 \\
\hline & Northern spring peeper & Pseudacris crucifer & 1 & 3 \\
\hline \multirow[t]{5}{*}{ CHWWBW } & $\begin{array}{l}\text { Richness } \\
\text { Northern spring peeper }\end{array}$ & $\begin{array}{c}5 \\
\text { Pseudacris crucifer }\end{array}$ & 2 & 35 \\
\hline & Northern pickerel frog & Rana palustris & 1 & 3 \\
\hline & Gray treefrog & Hyla versicolor & 2 & 5 \\
\hline & American bullfrog & Rana catesbeiana & 2 & 21 \\
\hline & Northern green frog & Rana clamitans & 1 & 7 \\
\hline \multirow[t]{7}{*}{ CHWWEM } & $\begin{array}{l}\text { Richness } \\
\text { Upland chorus frog }\end{array}$ & $\begin{array}{c}7 \\
\text { Pseudacris triseriata }\end{array}$ & 2 & 16 \\
\hline & American bullfrog & Rana catesbeiana & 1 & 2 \\
\hline & Northern spring peeper & Pseudacris crucifer & 3 & 50 \\
\hline & Northern green frog & Rana clamitans & 2 & 21 \\
\hline & Northern pickerel frog & Rana palustris & 1 & 2 \\
\hline & Gray treefrog & Hyla versicolor & 1 & 1 \\
\hline & Wood frog & Rana sylvatica & 2 & 15 \\
\hline
\end{tabular}


Appendix N. Continued.

\begin{tabular}{|c|c|c|c|c|}
\hline Site Code & Species & Latin nameMax Chorus & Max Estimate & \\
\hline \multirow[t]{9}{*}{ CHWWFO } & Richness & 8 & & \\
\hline & Eastern American toad & Bufo americanus & 1 & 2 \\
\hline & Northern pickerel frog & Rana palustris & 1 & 5 \\
\hline & Gray treefrog & Hyla versicolor & 3 & 50 \\
\hline & Cope's Gray treefrog & Hyla chrysoscelis & 2 & 5 \\
\hline & Northern green frog & Rana clamitans & 1 & 7 \\
\hline & American bullfrog & Rana catesbeiana & 1 & 10 \\
\hline & Upland chorus frog & Pseudacris triseriata & 1 & 2 \\
\hline & Northern spring peeper & Pseudacris crucifer & 2 & 30 \\
\hline \multirow[t]{3}{*}{ CVABBW } & Richness & 2 & & \\
\hline & Upland chorus frog & Pseudacris triseriata & 1 & 1 \\
\hline & Northern spring peeper & Pseudacris crucifer & 1 & 5 \\
\hline \multirow[t]{2}{*}{ CVABCT } & Richness & 1 & & \\
\hline & Northern spring peeper & Pseudacris crucifer & 1 & 3 \\
\hline \multirow[t]{2}{*}{ CVTIMB } & Richness & 1 & & \\
\hline & Northern spring peeper & Pseudacris crucifer & 2 & 10 \\
\hline \multirow[t]{3}{*}{ DSPICN } & Richness & 2 & & \\
\hline & Wood frog & Rana sylvatica & 1 & 3 \\
\hline & Northern spring peeper & Pseudacris crucifer & 2 & 20 \\
\hline \multirow[t]{2}{*}{ DSROAR } & Richness & 1 & & \\
\hline & Northern spring peeper & Pseudacris crucifer & 1 & 1 \\
\hline \multirow[t]{6}{*}{ EPCMEM } & Richness & 5 & & \\
\hline & Northern green frog & Rana clamitans & 1 & 3 \\
\hline & Northern spring peeper & Pseudacris crucifer & 3 & 50 \\
\hline & Northern pickerel frog & Rana palustris & 1 & 3 \\
\hline & Wood frog & Rana sylvatica & 1 & 1 \\
\hline & Eastern American toad & Bufo americanus & 2 & 4 \\
\hline \multirow[t]{6}{*}{ EPKYVE } & Richness & 5 & & \\
\hline & Northern green frog & Rana clamitans & 1 & 5 \\
\hline & Wood frog & Rana sylvatica & 2 & 15 \\
\hline & Eastern American toad & Bufo americanus & 1 & 3 \\
\hline & Northern spring peeper & Pseudacris crucifer & 2 & 35 \\
\hline & Northern pickerel frog & Rana palustris & 1 & 2 \\
\hline
\end{tabular}


Appendix N. Continued.

\begin{tabular}{|c|c|c|c|c|}
\hline Site Code & Species & Latin name & Max Chorus & Max Estimate \\
\hline EPRRXC & $\begin{array}{l}\text { Richness } \\
\text { Northern green frog }\end{array}$ & $\begin{array}{c}1 \\
\text { Rana clamitans }\end{array}$ & 1 & 1 \\
\hline \multirow[t]{2}{*}{ EPSHEM } & $\begin{array}{l}\text { Richness } \\
\text { Northern spring peeper }\end{array}$ & $\begin{array}{c}2 \\
\text { Pseudacris crucifer }\end{array}$ & 1 & 4 \\
\hline & Northern green frog & Rana clamitans & 1 & 2 \\
\hline \multirow[t]{4}{*}{ EPSHSS } & $\begin{array}{l}\text { Richness } \\
\text { Wood frog }\end{array}$ & $\begin{array}{c}4 \\
\text { Rana sylvatica }\end{array}$ & 1 & 2 \\
\hline & Northern green frog & Rana clamitans & 1 & 2 \\
\hline & Eastern American toad & Bufo americanus & 2 & 5 \\
\hline & Northern spring peeper & Pseudacris crucifer & 2 & 10 \\
\hline \multirow[t]{7}{*}{ GBBARN } & Richness & $\begin{array}{c}7 \\
\text { Psoudarric } r \text { rucifor }\end{array}$ & 3 & 50 \\
\hline & Wood frog & Rana sylvatica & 2 & 12 \\
\hline & Eastern American toad & Bufo americanus & 2 & 15 \\
\hline & American bullfrog & Rana catesbeiana & 1 & 1 \\
\hline & Leopard frog & Rana pipiens & 1 & 4 \\
\hline & Northern green frog & Rana clamitans & 1 & 3 \\
\hline & Northern pickerel frog & Rana palustris & 1 & 8 \\
\hline \multirow[t]{4}{*}{ GBHOEF } & $\begin{array}{l}\text { Richness } \\
\text { Northern spring peeper }\end{array}$ & $\begin{array}{c}4 \\
\text { Pseudacris crucifer }\end{array}$ & 2 & 40 \\
\hline & Wood frog & Rana sylvatica & 2 & 5 \\
\hline & Northern pickerel frog & Rana palustris & 2 & 5 \\
\hline & Northern green frog & Rana clamitans & 1 & 12 \\
\hline \multirow[t]{6}{*}{ GBJENK } & $\begin{array}{l}\text { Richness } \\
\text { Eastern American toad }\end{array}$ & $\begin{array}{c}6 \\
\text { Bufo americanus }\end{array}$ & 2 & 5 \\
\hline & American bullfrog & Rana catesbeiana & 2 & 20 \\
\hline & Northern green frog & Rana clamitans & 1 & 8 \\
\hline & Leopard frog & Rana pipiens & 1 & 1 \\
\hline & Northern pickerel frog & Rana palustris & 1 & 5 \\
\hline & Northern spring peeper & Pseudacris crucifer & 3 & 50 \\
\hline \multirow[t]{6}{*}{ GBMAPL } & Richness & 5 & & \\
\hline & Wood frog & Rana sylvatica & 3 & 50 \\
\hline & Eastern American toad & Bufo americanus & 1 & 1 \\
\hline & Northern pickerel frog & Rana palustris & 1 & 4 \\
\hline & Northern spring peeper & Pseudacris crucifer & 3 & 50 \\
\hline & Leopard frog & Rana pipiens & 1 & 1 \\
\hline
\end{tabular}


Appendix N. Continued..

\begin{tabular}{|c|c|c|c|c|}
\hline Site Code & Species & Latin name & Max Chorus & Max Estimate \\
\hline \multirow[t]{5}{*}{ GBNOFO } & Richness & 4 & & \\
\hline & Northern pickerel frog & Rana palustris & 1 & 2 \\
\hline & Northern spring peeper & Pseudacris crucifer & 2 & 20 \\
\hline & Northern green frog & Rana clamitans & 1 & 3 \\
\hline & Eastern American toad & Bufo americanus & 1 & 1 \\
\hline \multirow[t]{6}{*}{ GBNOSS } & Richness & 5 & & \\
\hline & Northern green frog & Rana clamitans & 1 & 2 \\
\hline & Leopard frog & Rana pipiens & 1 & 1 \\
\hline & Eastern American toad & Bufo americanus & 2 & 6 \\
\hline & American bullfrog & Rana catesbeiana & 1 & 3 \\
\hline & Northern spring peeper & Pseudacris crucifer & 3 & 50 \\
\hline \multirow[t]{8}{*}{ GBPLOT } & Richness & 7 & & \\
\hline & Northern spring peeper & Pseudacris crucifer & 3 & 50 \\
\hline & Eastern American toad & Bufo americanus & 1 & 4 \\
\hline & Northern green frog & Rana clamitans & 2 & 7 \\
\hline & Northern pickerel frog & Rana palustris & 2 & 20 \\
\hline & Leopard frog & Rana pipiens & 1 & 3 \\
\hline & Wood frog & Rana sylvatica & 3 & 50 \\
\hline & American bullfrog & Rana catesbeiana & 2 & 8 \\
\hline \multirow[t]{5}{*}{ HCBEAV } & Richness & 4 & & \\
\hline & Northern pickerel frog & Rana palustris & 1 & 2 \\
\hline & Wood frog & Rana sylvatica & 2 & 20 \\
\hline & Northern green frog & Rana clamitans & 1 & 3 \\
\hline & Northern spring peeper & Pseudacris crucifer & 3 & 50 \\
\hline \multirow[t]{7}{*}{ HCMITI } & Richness & 6 & & \\
\hline & Northern green frog & Rana clamitans & 1 & 1 \\
\hline & Wood frog & Rana sylvatica & 2 & 10 \\
\hline & Northern pickerel frog & Rana palustris & 1 & 5 \\
\hline & Gray treefrog & Hyla versicolor & 2 & 7 \\
\hline & Northern spring peeper & Pseudacris crucifer & 3 & 50 \\
\hline & Mountain chorus frog & Pseudacris brachyphona & 1 & 2 \\
\hline
\end{tabular}


Appendix N. Continued.

\begin{tabular}{|c|c|c|c|c|}
\hline Site Code & Species & Latin name & Max Chorus & Max Estimate \\
\hline \multirow[t]{4}{*}{ HCPIPE } & Richness & 3 & & \\
\hline & Northern green frog & Rana clamitans & 1 & 1 \\
\hline & Northern spring peeper & Pseudacris crucifer & 3 & 50 \\
\hline & Eastern American toad & Bufo americanus & 1 & 2 \\
\hline \multirow[t]{4}{*}{ HCRANG } & Richness & 3 & & \\
\hline & Wood frog & Rana sylvatica & 1 & 2 \\
\hline & Gray treefrog & Hyla versicolor & 1 & 1 \\
\hline & Northern spring peeper & Pseudacris crucifer & 3 & 50 \\
\hline \multirow[t]{2}{*}{ HIBRID } & Richness & 1 & & \\
\hline & Northern spring peeper & Pseudacris crucifer & 1 & 1 \\
\hline \multirow[t]{3}{*}{ HIGATE } & Richness & 2 & & \\
\hline & American bullfrog & Rana catesbeiana & 1 & 3 \\
\hline & Northern spring peeper & Pseudacris crucifer & 2 & 25 \\
\hline \multirow[t]{4}{*}{ HIJHPK } & Richness & 3 & & \\
\hline & Wood frog & Rana sylvatica & 1 & 7 \\
\hline & Eastern American toad & Bufo americanus & 1 & 1 \\
\hline & Northern spring peeper & Pseudacris crucifer & 2 & 24 \\
\hline \multirow[t]{7}{*}{ HIJHTU } & Richness & 6 & & \\
\hline & Northern green frog & Rana clamitans & 1 & 4 \\
\hline & Wood frog & Rana sylvatica & 2 & 20 \\
\hline & Northern spring peeper & Pseudacris crucifer & 3 & 50 \\
\hline & Gray treefrog & Hyla versicolor & 1 & 2 \\
\hline & Eastern American toad & Bufo americanus & 1 & 2 \\
\hline & Cope's Gray treefrog & Hyla chrysoscelis & 1 & 2 \\
\hline \multirow[t]{7}{*}{ HIPENC } & Richness & 6 & & \\
\hline & Northern pickerel frog & Rana palustris & 1 & 12 \\
\hline & American bullfrog & Rana catesbeiana & 1 & 3 \\
\hline & Wood frog & Rana sylvatica & 3 & 50 \\
\hline & Northern spring peeper & Pseudacris crucifer & 3 & 50 \\
\hline & Northern green frog & Rana clamitans & 2 & 13 \\
\hline & Gray treefrog & Hyla versicolor & 1 & 5 \\
\hline
\end{tabular}


Appendix N. Continued.

\begin{tabular}{|c|c|c|c|c|}
\hline Site Code & Species & Latin name & Max Chorus & Max Estimate \\
\hline \multirow[t]{3}{*}{ HISEWG } & Richness & 2 & & \\
\hline & Gray treefrog & Hyla versicolor & 1 & 3 \\
\hline & Eastern American toad & Bufo americanus & 1 & 1 \\
\hline \multirow[t]{6}{*}{ HITRLR } & Richness & 5 & & \\
\hline & Wood frog & Rana sylvatica & 2 & 20 \\
\hline & Gray treefrog & Hyla versicolor & 1 & 4 \\
\hline & Northern spring peeper & Pseudacris crucifer & 3 & 50 \\
\hline & Northern green frog & Rana clamitans & 1 & 1 \\
\hline & Eastern American toad & Bufo americanus & 1 & 1 \\
\hline \multirow[t]{3}{*}{ MCFOUR } & Richness & 2 & & \\
\hline & Northern spring peeper & Pseudacris crucifer & 2 & 18 \\
\hline & Northern pickerel frog & Rana palustris & 1 & 1 \\
\hline \multirow[t]{7}{*}{ MCMEME } & Richness & 6 & & \\
\hline & Northern pickerel frog & Rana palustris & 1 & 3 \\
\hline & Gray treefrog & Hyla versicolor & 2 & 8 \\
\hline & Northern spring peeper & Pseudacris crucifer & 3 & 50 \\
\hline & Northern green frog & Rana clamitans & 1 & 9 \\
\hline & American bullfrog & Rana catesbeiana & 2 & 8 \\
\hline & Wood frog & Rana sylvatica & 1 & 1 \\
\hline \multirow[t]{6}{*}{ MCMFOR } & Richness & 5 & & \\
\hline & Northern pickerel frog & Rana palustris & 1 & 3 \\
\hline & Northern green frog & Rana clamitans & 1 & 4 \\
\hline & Gray treefrog & Hyla versicolor & 2 & 10 \\
\hline & Mountain chorus frog & Pseudacris brachyphona & 1 & 1 \\
\hline & Northern spring peeper & Pseudacris crucifer & 3 & 50 \\
\hline \multirow[t]{2}{*}{ MCNPFO } & Richness & 1 & & \\
\hline & Northern spring peeper & Pseudacris crucifer & 1 & 4 \\
\hline \multirow[t]{3}{*}{ MCPOND } & Richness & 2 & & \\
\hline & American bullfrog & Rana catesbeiana & 1 & 2 \\
\hline & Northern green frog & Rana clamitans & 1 & 3 \\
\hline \multirow[t]{6}{*}{ MCPOST } & Richness & 5 & & \\
\hline & Gray treefrog & Hyla versicolor & 1 & 1 \\
\hline & Northern spring peeper & Pseudacris crucifer & 2 & 15 \\
\hline & American bullfrog & Rana catesbeiana & 2 & 5 \\
\hline & Northern green frog & Rana clamitans & 1 & 8 \\
\hline & Northern pickerel frog & Rana palustris & 2 & 6 \\
\hline
\end{tabular}


Appendix N. Continued.

\begin{tabular}{|c|c|c|c|c|}
\hline Site Code & Species & Latin name & Max Chorus & Max Estimate \\
\hline \multirow[t]{5}{*}{ MCTELE } & Richness & 4 & & \\
\hline & American bullfrog & Rana catesbeiana & 2 & 8 \\
\hline & Northern spring peeper & Pseudacris crucifer & 2 & 8 \\
\hline & Northern green frog & Rana clamitans & 1 & 4 \\
\hline & Gray treefrog & Hyla versicolor & 2 & 8 \\
\hline \multirow[t]{5}{*}{ ME5092 } & Richness & 4 & & \\
\hline & American bullfrog & Rana catesbeiana & 1 & 2 \\
\hline & Northern green frog & Rana clamitans & 1 & 8 \\
\hline & Northern spring peeper & Pseudacris crucifer & 2 & 30 \\
\hline & Gray treefrog & Hyla versicolor & 1 & 3 \\
\hline \multirow[t]{5}{*}{ MESCOX } & Richness & 4 & & \\
\hline & Northern spring peeper & Pseudacris crucifer & 2 & 15 \\
\hline & Northern pickerel frog & Rana palustris & 1 & 1 \\
\hline & Northern green frog & Rana clamitans & 1 & 1 \\
\hline & Wood frog & Rana sylvatica & 1 & 3 \\
\hline \multirow[t]{5}{*}{ MESCRO } & Richness & 4 & & \\
\hline & Wood frog & Rana sylvatica & 2 & 11 \\
\hline & Northern green frog & Rana clamitans & 1 & 2 \\
\hline & Northern pickerel frog & Rana palustris & 1 & 1 \\
\hline & Northern spring peeper & Pseudacris crucifer & 2 & 15 \\
\hline \multirow[t]{5}{*}{ MESCUP } & Richness & 4 & & \\
\hline & Wood frog & Rana sylvatica & 1 & 4 \\
\hline & Northern pickerel frog & Rana palustris & 2 & 7 \\
\hline & Northern spring peeper & Pseudacris crucifer & 2 & 21 \\
\hline & Northern green frog & Rana clamitans & 2 & 20 \\
\hline \multirow[t]{5}{*}{ MESIGN } & Richness & 4 & & \\
\hline & Northern green frog & Rana clamitans & 1 & 4 \\
\hline & Upland chorus frog & Pseudacris triseriata & 1 & 1 \\
\hline & Wood frog & Rana sylvatica & 1 & 4 \\
\hline & Northern spring peeper & Pseudacris crucifer & 2 & 25 \\
\hline
\end{tabular}


Appendix N. Continued.

\begin{tabular}{|c|c|c|c|c|}
\hline Site Code & Species & Latin name & Max Chorus & Max Estimate \\
\hline \multirow{5}{*}{ MESILV } & Richness & 4 & & \\
\hline & Northern green frog & Rana clamitans & 1 & 3 \\
\hline & Wood frog & Rana sylvatica & 1 & 5 \\
\hline & Northern spring peeper & Pseudacris crucifer & 2 & 23 \\
\hline & Gray treefrog & Hyla versicolor & 1 & 3 \\
\hline \multirow[t]{4}{*}{ METETR } & Richness & 3 & & \\
\hline & Upland chorus frog & Pseudacris triseriata & 1 & 5 \\
\hline & Northern spring peeper & Pseudacris crucifer & 2 & 25 \\
\hline & Northern green frog & Rana clamitans & 1 & 1 \\
\hline \multirow[t]{4}{*}{ MEWOLF } & Richness & 3 & & \\
\hline & Northern spring peeper & Pseudacris crucifer & 3 & 50 \\
\hline & Northern green frog & Rana clamitans & 1 & 2 \\
\hline & Wood frog & Rana sylvatica & 1 & 12 \\
\hline \multirow[t]{4}{*}{ MRBESS } & Richness & 3 & & \\
\hline & Wood frog & Rana sylvatica & 1 & 3 \\
\hline & Northern spring peeper & Pseudacris crucifer & 2 & 12 \\
\hline & Northern green frog & Rana clamitans & 1 & 3 \\
\hline \multirow[t]{3}{*}{ MRFARM } & Richness & 2 & & \\
\hline & Northern spring peeper & Pseudacris crucifer & 2 & 40 \\
\hline & Upland chorus frog & Pseudacris triseriata & 1 & 1 \\
\hline \multirow[t]{3}{*}{ MRFORE } & Richness & 2 & & \\
\hline & Eastern American toad & Bufo americanus & 1 & 2 \\
\hline & Northern spring peeper & Pseudacris crucifer & 2 & 10 \\
\hline \multirow[t]{3}{*}{ MRSSSS } & Richness & 2 & & \\
\hline & Northern spring peeper & Pseudacris crucifer & 2 & 25 \\
\hline & Upland chorus frog & Pseudacris triseriata & 1 & 2 \\
\hline \multirow[t]{2}{*}{ MRWEST } & Richness & 1 & & \\
\hline & Northern spring peeper & Pseudacris crucifer & 2 & 12 \\
\hline \multirow[t]{5}{*}{ MU55SS } & Richness & 4 & & \\
\hline & Gray treefrog & Hyla versicolor & 1 & 2 \\
\hline & Northern spring peeper & Pseudacris crucifer & 3 & 50 \\
\hline & Northern green frog & Rana clamitans & 1 & 4 \\
\hline & Wood frog & Rana sylvatica & 2 & 15 \\
\hline
\end{tabular}


Appendix N. Continued.

\begin{tabular}{|c|c|c|c|c|}
\hline Site Code & Species & Latin name & Max Chorus & Max Estimate \\
\hline \multirow[t]{5}{*}{ MUDBOA } & Richness & 4 & & \\
\hline & Gray treefrog & Hyla versicolor & 1 & 1 \\
\hline & Northern spring peeper & Pseudacris crucifer & 1 & 11 \\
\hline & American bullfrog & Rana catesbeiana & 1 & 1 \\
\hline & Northern green frog & Rana clamitans & 1 & 1 \\
\hline \multirow[t]{7}{*}{ MUDEND } & Richness & 6 & & \\
\hline & Gray treefrog & Hyla versicolor & 1 & 1 \\
\hline & Wood frog & Rana sylvatica & 1 & 6 \\
\hline & American bullfrog & Rana catesbeiana & 2 & 21 \\
\hline & Northern spring peeper & Pseudacris crucifer & 2 & 37 \\
\hline & Northern green frog & Rana clamitans & 1 & 7 \\
\hline & Northern pickerel frog & Rana palustris & 1 & 7 \\
\hline \multirow[t]{7}{*}{ MUDRIC } & Richness & 6 & & \\
\hline & Gray treefrog & Hyla versicolor & 2 & 9 \\
\hline & Northern green frog & Rana clamitans & 2 & 11 \\
\hline & American bullfrog & Rana catesbeiana & 2 & 6 \\
\hline & Northern spring peeper & Pseudacris crucifer & 3 & 50 \\
\hline & Wood frog & Rana sylvatica & 2 & 12 \\
\hline & Northern pickerel frog & Rana palustris & 1 & 2 \\
\hline \multirow[t]{7}{*}{ MUDRIP } & Richness & 6 & & \\
\hline & Northern pickerel frog & Rana palustris & 1 & 7 \\
\hline & Northern green frog & Rana clamitans & 1 & 8 \\
\hline & American bullfrog & Rana catesbeiana & 1 & 4 \\
\hline & Northern spring peeper & Pseudacris crucifer & 2 & 35 \\
\hline & Gray treefrog & Hyla versicolor & 2 & 7 \\
\hline & Wood frog & Rana sylvatica & 2 & 10 \\
\hline \multirow[t]{8}{*}{ MUDTRA } & Richness & 7 & & \\
\hline & Wood frog & Rana sylvatica & 1 & 10 \\
\hline & Northern spring peeper & Pseudacris crucifer & 2 & 40 \\
\hline & Northern pickerel frog & Rana palustris & 1 & 5 \\
\hline & American bullfrog & Rana catesbeiana & 1 & 1 \\
\hline & Mountain chorus frog & Pseudacris brachyphona & 1 & 6 \\
\hline & Northern green frog & Rana clamitans & 1 & 3 \\
\hline & Gray treefrog & Hyla versicolor & 2 & 6 \\
\hline
\end{tabular}


Appendix N. Continued.

\begin{tabular}{|c|c|c|c|c|}
\hline Site Code & Species & Latin name & Max Chorus & Max Estimate \\
\hline \multirow[t]{5}{*}{ MUEPAH } & Richness & 4 & & \\
\hline & Northern green frog & Rana clamitans & 1 & 5 \\
\hline & Northern spring peeper & Pseudacris crucifer & 2 & 40 \\
\hline & Wood frog & Rana sylvatica & 2 & 15 \\
\hline & Gray treefrog & Hyla versicolor & 1 & 4 \\
\hline \multirow[t]{2}{*}{ MUMINE } & Richness & 1 & & \\
\hline & Northern spring peeper & Pseudacris crucifer & 1 & 6 \\
\hline \multirow[t]{3}{*}{ MUPOWR } & Richness & 2 & & \\
\hline & Gray treefrog & Hyla versicolor & 1 & 4 \\
\hline & Northern spring peeper & Pseudacris crucifer & 1 & 5 \\
\hline \multirow[t]{5}{*}{ MUPULL } & Richness & 4 & & \\
\hline & Northern spring peeper & Pseudacris crucifer & 3 & 50 \\
\hline & Wood frog & Rana sylvatica & 1 & 12 \\
\hline & Northern pickerel frog & Rana palustris & 1 & 3 \\
\hline & Gray treefrog & Hyla versicolor & 1 & 1 \\
\hline \multirow[t]{5}{*}{ MUVBRD } & Richness & 4 & & \\
\hline & Wood frog & Rana sylvatica & 2 & 12 \\
\hline & Northern green frog & Rana clamitans & 1 & 6 \\
\hline & Northern spring peeper & Pseudacris crucifer & 3 & 50 \\
\hline & Gray treefrog & Hyla versicolor & 1 & 4 \\
\hline \multirow[t]{4}{*}{ MUVCRN } & Richness & 3 & & \\
\hline & Northern green frog & Rana clamitans & 1 & 6 \\
\hline & Northern spring peeper & Pseudacris crucifer & 3 & 50 \\
\hline & Gray treefrog & Hyla versicolor & 2 & 8 \\
\hline \multirow[t]{3}{*}{ OHHSFO } & Richness & 2 & & \\
\hline & Northern spring peeper & Pseudacris crucifer & 1 & 15 \\
\hline & Eastern American toad & Bufo americanus & 1 & 1 \\
\hline \multirow[t]{6}{*}{ OHINNS } & Richness & 5 & & \\
\hline & Northern spring peeper & Pseudacris crucifer & 3 & 50 \\
\hline & Gray treefrog & Hyla versicolor & 2 & 4 \\
\hline & Wood frog & Rana sylvatica & 2 & 12 \\
\hline & Northern green frog & Rana clamitans & 1 & 1 \\
\hline & Northern pickerel frog & Rana palustris & 1 & 2 \\
\hline
\end{tabular}


Appendix N. Continued.

\begin{tabular}{|c|c|c|c|c|}
\hline Site Code & Species & Latin name & Max Chorus & Max Estimate \\
\hline \multirow[t]{4}{*}{ OHKMRT } & Richness & 3 & & \\
\hline & Gray treefrog & Hyla versicolor & 1 & 3 \\
\hline & Northern green frog & Rana clamitans & 1 & 6 \\
\hline & Northern spring peeper & Pseudacris crucifer & 2 & 21 \\
\hline \multirow[t]{5}{*}{ PA29TH } & Richness & 4 & & \\
\hline & Gray treefrog & Hyla versicolor & 1 & 1 \\
\hline & Northern green frog & Rana clamitans & 1 & 3 \\
\hline & Wood frog & Rana sylvatica & 2 & 10 \\
\hline & Northern spring peeper & Pseudacris crucifer & 2 & 30 \\
\hline \multirow[t]{5}{*}{ PA83CR } & Richness & 4 & & \\
\hline & Northern spring peeper & Pseudacris crucifer & 2 & 35 \\
\hline & Northern green frog & Rana clamitans & 1 & 2 \\
\hline & Gray treefrog & Hyla versicolor & 2 & 12 \\
\hline & Wood frog & Rana sylvatica & 1 & 4 \\
\hline \multirow[t]{6}{*}{ PAFAMD } & Richness & 5 & & \\
\hline & Gray treefrog & Hyla versicolor & 2 & 10 \\
\hline & American bullfrog & Rana catesbeiana & 3 & 50 \\
\hline & Northern spring peeper & Pseudacris crucifer & 2 & 10 \\
\hline & Northern green frog & Rana clamitans & 2 & 12 \\
\hline & Northern pickerel frog & Rana palustris & 2 & 12 \\
\hline \multirow[t]{5}{*}{ PAJCPY } & Richness & 4 & & \\
\hline & Northern green frog & Rana clamitans & 1 & 5 \\
\hline & Eastern American toad & Bufo americanus & 1 & 2 \\
\hline & Gray treefrog & Hyla versicolor & 3 & 50 \\
\hline & Northern spring peeper & Pseudacris crucifer & 1 & 8 \\
\hline \multirow[t]{4}{*}{ PALOUD } & Richness & 3 & & \\
\hline & Northern spring peeper & Pseudacris crucifer & 1 & 10 \\
\hline & Northern pickerel frog & Rana palustris & 2 & 10 \\
\hline & Gray treefrog & Hyla versicolor & 2 & 25 \\
\hline \multirow[t]{2}{*}{ PAPEFO } & Richness & 1 & & \\
\hline & Northern spring peeper & Pseudacris crucifer & 1 & 1 \\
\hline
\end{tabular}


Appendix N. Continued.

\begin{tabular}{|c|c|c|c|c|}
\hline Site Code & Species & Latin name & Max Chorus & Max Estimate \\
\hline \multirow[t]{4}{*}{ PAPEIM } & Richness & 3 & & \\
\hline & Eastern American toad & Bufo americanus & 2 & 12 \\
\hline & Northern spring peeper & Pseudacris crucifer & 2 & 25 \\
\hline & Northern green frog & Rana clamitans & 1 & 6 \\
\hline \multirow[t]{4}{*}{ PAPESW } & Richness & 3 & & \\
\hline & Wood frog & Rana sylvatica & 2 & 35 \\
\hline & Northern spring peeper & Pseudacris crucifer & 3 & 50 \\
\hline & Northern green frog & Rana clamitans & 1 & 7 \\
\hline \multirow[t]{7}{*}{ PAWILL } & Richness & 6 & & \\
\hline & Leopard frog & Rana pipiens & 1 & 1 \\
\hline & Northern spring peeper & Pseudacris crucifer & 1 & 16 \\
\hline & Gray treefrog & Hyla versicolor & 1 & 1 \\
\hline & American bullfrog & Rana catesbeiana & 2 & 8 \\
\hline & Eastern American toad & Bufo americanus & 1 & 1 \\
\hline & Northern green frog & Rana clamitans & 1 & 4 \\
\hline \multirow[t]{6}{*}{ PCBLUE } & Richness & 5 & & \\
\hline & Northern pickerel frog & Rana palustris & 1 & 3 \\
\hline & American bullfrog & Rana catesbeiana & 3 & 50 \\
\hline & Northern spring peeper & Pseudacris crucifer & 3 & 50 \\
\hline & Cope's Gray treefrog & Hyla chrysoscelis & 2 & 10 \\
\hline & Northern green frog & Rana clamitans & 1 & 10 \\
\hline \multirow[t]{7}{*}{ PCLPFO } & Richness & 6 & & \\
\hline & Northern pickerel frog & Rana palustris & 1 & 2 \\
\hline & Cope's Gray treefrog & Hyla chrysoscelis & 2 & 25 \\
\hline & Wood frog & Rana sylvatica & 3 & 50 \\
\hline & Northern spring peeper & Pseudacris crucifer & 3 & 50 \\
\hline & Eastern American toad & Bufo americanus & 1 & 2 \\
\hline & Fowlers Toad & Bufo woodhousii fowleri & 1 & 5 \\
\hline \multirow[t]{6}{*}{ PCROAD } & Richness & 5 & & \\
\hline & Northern pickerel frog & Rana palustris & 1 & 3 \\
\hline & Wood frog & Rana sylvatica & 2 & 10 \\
\hline & Northern spring peeper & Pseudacris crucifer & 3 & 50 \\
\hline & American bullfrog & Rana catesbeiana & 1 & 5 \\
\hline & Northern green frog & Rana clamitans & 1 & 5 \\
\hline
\end{tabular}


Appendix N. Continued.

\begin{tabular}{|c|c|c|c|c|}
\hline Site Code & Species & Latin name & Max Chorus & Max Estimate \\
\hline \multirow[t]{7}{*}{ PEMIDW } & Richness & 6 & & \\
\hline & Gray treefrog & Hyla versicolor & 2 & 6 \\
\hline & Cope's Gray treefrog & Hyla chrysoscelis & 1 & 1 \\
\hline & Eastern American toad & Bufo americanus & 1 & 6 \\
\hline & Northern spring peeper & Pseudacris crucifer & 3 & 50 \\
\hline & Northern green frog & Rana clamitans & 1 & 2 \\
\hline & Wood frog & Rana sylvatica & 2 & 20 \\
\hline \multirow[t]{4}{*}{ PERDDP } & Richness & 3 & & \\
\hline & Northern spring peeper & Pseudacris crucifer & 3 & 50 \\
\hline & Wood frog & Rana sylvatica & 2 & 15 \\
\hline & Gray treefrog & Hyla versicolor & 1 & 3 \\
\hline \multirow[t]{3}{*}{ PETHUM } & Richness & 2 & & \\
\hline & Northern spring peeper & Pseudacris crucifer & 3 & 50 \\
\hline & Wood frog & Rana sylvatica & 2 & 23 \\
\hline \multirow[t]{2}{*}{ PETOSS } & Richness & 1 & & \\
\hline & Gray treefrog & Hyla versicolor & 1 & 3 \\
\hline \multirow[t]{7}{*}{ RIASIA } & Richness & 6 & & \\
\hline & American bullfrog & Rana catesbeiana & 1 & 6 \\
\hline & Northern green frog & Rana clamitans & 1 & 1 \\
\hline & Mountain chorus frog & Pseudacris brachyphona & 1 & 2 \\
\hline & Northern spring peeper & Pseudacris crucifer & 2 & 20 \\
\hline & Northern pickerel frog & Rana palustris & 1 & 2 \\
\hline & Gray treefrog & Hyla versicolor & 1 & 4 \\
\hline \multirow[t]{6}{*}{ RIBRID } & Richness & 5 & & \\
\hline & Mountain chorus frog & Pseudacris brachyphona & 2 & 7 \\
\hline & Northern spring peeper & Pseudacris crucifer & 1 & 7 \\
\hline & Cope's Gray treefrog & Hyla chrysoscelis & 1 & 1 \\
\hline & Northern green frog & Rana clamitans & 1 & 1 \\
\hline & American bullfrog & Rana catesbeiana & 1 & 2 \\
\hline \multirow[t]{3}{*}{ RIEAST } & Richness & 2 & & \\
\hline & Leopard frog & Rana pipiens & 1 & 1 \\
\hline & Northern spring peeper & Pseudacris crucifer & 1 & 1 \\
\hline
\end{tabular}


Appendix N. Continued.

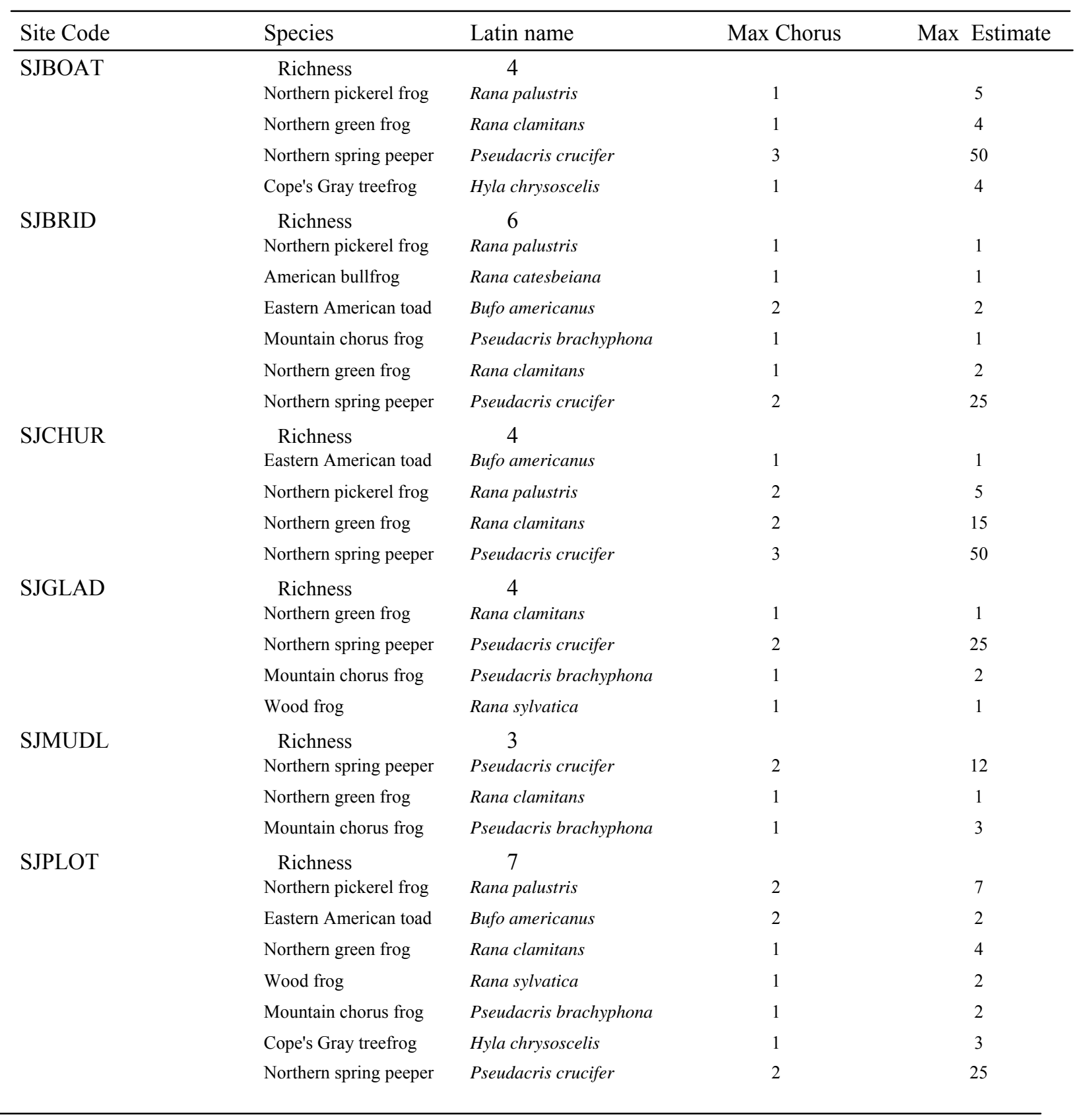


Appendix N. Continued.

\begin{tabular}{|c|c|c|c|c|}
\hline Site Code & Species & Latin name & Max Chorus & Max Estimate \\
\hline \multirow[t]{3}{*}{ SMDTSS } & Richness & 2 & & \\
\hline & Northern pickerel frog & Rana palustris & 1 & 4 \\
\hline & Northern spring peeper & Pseudacris crucifer & 2 & 25 \\
\hline \multirow[t]{2}{*}{ SMFOFL } & Richness & 1 & & \\
\hline & Northern spring peeper & Pseudacris crucifer & 3 & 50 \\
\hline \multirow[t]{4}{*}{ SMLPEM } & Richness & 3 & & \\
\hline & Upland chorus frog & Pseudacris triseriata & 1 & 3 \\
\hline & Northern green frog & Rana clamitans & 1 & 1 \\
\hline & Northern spring peeper & Pseudacris crucifer & 3 & 50 \\
\hline \multirow[t]{5}{*}{ SMSEFL } & Richness & 4 & & \\
\hline & Northern green frog & Rana clamitans & 1 & 5 \\
\hline & Northern pickerel frog & Rana palustris & 2 & 7 \\
\hline & American bullfrog & Rana catesbeiana & 1 & 1 \\
\hline & Northern spring peeper & Pseudacris crucifer & 3 & 50 \\
\hline \multirow[t]{3}{*}{ SMSTEM } & Richness & 2 & & \\
\hline & Northern spring peeper & Pseudacris crucifer & 2 & 25 \\
\hline & Northern pickerel frog & Rana palustris & 1 & 2 \\
\hline \multirow[t]{2}{*}{ TRSPFO } & Richness & 1 & & \\
\hline & Northern green frog & Rana clamitans & 1 & 1 \\
\hline \multirow[t]{6}{*}{ TRSPRI } & Richness & 5 & & \\
\hline & American bullfrog & Rana catesbeiana & 1 & 2 \\
\hline & Wood frog & Rana sylvatica & 2 & 15 \\
\hline & Northern green frog & Rana clamitans & 1 & 2 \\
\hline & Northern spring peeper & Pseudacris crucifer & 3 & 50 \\
\hline & Gray treefrog & Hyla versicolor & 2 & 9 \\
\hline \multirow[t]{4}{*}{ TVFARM } & Richness & 3 & & \\
\hline & Gray treefrog & Hyla versicolor & 1 & 2 \\
\hline & Wood frog & Rana sylvatica & 2 & 25 \\
\hline & Northern spring peeper & Pseudacris crucifer & 3 & 50 \\
\hline
\end{tabular}


Appendix N. Continued.

\begin{tabular}{|c|c|c|c|c|}
\hline Site Code & Species & Latin name & Max Chorus & Max Estimate \\
\hline \multirow[t]{4}{*}{ TVISLE } & Richness & 3 & & \\
\hline & Northern green frog & Rana clamitans & 1 & 1 \\
\hline & Northern spring peeper & Pseudacris crucifer & 2 & 12 \\
\hline & Gray treefrog & Hyla versicolor & 1 & 3 \\
\hline \multirow[t]{7}{*}{ TVNEWT } & Richness & 6 & & \\
\hline & Wood frog & Rana sylvatica & 3 & 50 \\
\hline & Cope's Gray treefrog & Hyla chrysoscelis & 1 & 2 \\
\hline & Gray treefrog & Hyla versicolor & 1 & 5 \\
\hline & Northern green frog & Rana clamitans & 2 & 16 \\
\hline & Eastern American toad & Bufo americanus & 1 & 1 \\
\hline & Northern spring peeper & Pseudacris crucifer & 3 & 50 \\
\hline \multirow[t]{4}{*}{ TVPOUT } & Richness & 3 & & \\
\hline & Northern spring peeper & Pseudacris crucifer & 3 & 50 \\
\hline & Northern green frog & Rana clamitans & 1 & 3 \\
\hline & Wood frog & Rana sylvatica & 2 & 13 \\
\hline \multirow[t]{4}{*}{ TVVBEM } & Richness & 3 & & \\
\hline & Northern green frog & Rana clamitans & 1 & 3 \\
\hline & Wood frog & Rana sylvatica & 1 & 6 \\
\hline & Northern spring peeper & Pseudacris crucifer & 2 & 15 \\
\hline \multirow[t]{4}{*}{ TVVBIM } & Richness & 3 & & \\
\hline & Northern spring peeper & Pseudacris crucifer & 2 & 40 \\
\hline & Wood frog & Rana sylvatica & 2 & 12 \\
\hline & Northern green frog & Rana clamitans & 1 & 1 \\
\hline \multirow[t]{4}{*}{ TVVBRV } & Richness & 3 & & \\
\hline & Northern spring peeper & Pseudacris crucifer & 1 & 4 \\
\hline & Eastern American toad & Bufo americanus & 1 & 1 \\
\hline & Gray treefrog & Hyla versicolor & 1 & 2 \\
\hline \multirow[t]{5}{*}{ TVVBSS } & Richness & 4 & & \\
\hline & Northern green frog & Rana clamitans & 3 & 50 \\
\hline & Northern spring peeper & Pseudacris crucifer & 3 & 50 \\
\hline & Wood frog & Rana sylvatica & 2 & 25 \\
\hline & Northern pickerel frog & Rana palustris & 1 & 1 \\
\hline
\end{tabular}


Appendix N. Continued.

\begin{tabular}{|c|c|c|c|c|c|}
\hline Site Code & Species & Latin name & Max Chorus & Max & Estimate \\
\hline \multirow[t]{6}{*}{ UDC001 } & Richness & 5 & & & \\
\hline & Northern green frog & Rana clamitans & 2 & & 9 \\
\hline & Northern spring peeper & Pseudacris crucifer & 3 & & 50 \\
\hline & Gray treefrog & Hyla versicolor & 2 & & 6 \\
\hline & Wood frog & Rana sylvatica & 2 & & 10 \\
\hline & Eastern American toad & Bufo americanus & 3 & & 50 \\
\hline \multirow[t]{4}{*}{ UDC002 } & Richness & 4 & & & \\
\hline & Eastern American toad & Bufo americanus & 3 & & 50 \\
\hline & Gray treefrog & Hyla versicolor & 1 & & 2 \\
\hline & Northern spring peeper & Pseudacris crucifer & 3 & & 50 \\
\hline \multirow[t]{5}{*}{ UDC003 } & Richness & 4 & & & \\
\hline & American bullfrog & Rana catesbeiana & 1 & & 1 \\
\hline & Eastern American toad & Bufo americanus & 3 & & 50 \\
\hline & Northern green frog & Rana clamitans & 1 & & 4 \\
\hline & Northern spring peeper & Pseudacris crucifer & 3 & & 50 \\
\hline \multirow[t]{6}{*}{ UDC004 } & Richness & 5 & & & \\
\hline & American bullfrog & Rana catesbeiana & 1 & & 3 \\
\hline & Gray treefrog & Hyla versicolor & 1 & & 2 \\
\hline & Northern spring peeper & Pseudacris crucifer & 3 & & 50 \\
\hline & Northern green frog & Rana clamitans & 1 & & 5 \\
\hline & Eastern American toad & Bufo americanus & 1 & & 1 \\
\hline \multirow[t]{3}{*}{ UDC005 } & Richness & 2 & & & \\
\hline & Eastern American toad & Bufo americanus & 1 & & 2 \\
\hline & Northern spring peeper & Pseudacris crucifer & 3 & & 50 \\
\hline \multirow[t]{2}{*}{ UDC007 } & Richness & 1 & & & \\
\hline & Northern spring peeper & Pseudacris crucifer & 3 & & 50 \\
\hline \multirow[t]{2}{*}{ UDC008 } & Richness & 1 & & & \\
\hline & Northern spring peeper & Pseudacris crucifer & 3 & & 50 \\
\hline \multirow[t]{3}{*}{ UDC012 } & Richness & 2 & & & \\
\hline & Northern spring peeper & Pseudacris crucifer & 3 & & 50 \\
\hline & American bullfrog & Rana catesbeiana & 2 & & 13 \\
\hline \multirow[t]{3}{*}{ UDC013 } & Richness & 2 & & & \\
\hline & Northern spring peeper & Pseudacris crucifer & 3 & & 50 \\
\hline & Gray treefrog & Hyla versicolor & 1 & & 4 \\
\hline
\end{tabular}


Appendix N. Continued..

\begin{tabular}{|c|c|c|c|c|}
\hline Site Code & Species & Latin name & Max Chorus & Max Estimate \\
\hline \multirow[t]{3}{*}{ UDC014 } & Richness & 2 & & \\
\hline & Northern spring peeper & Pseudacris crucifer & 3 & 50 \\
\hline & Gray treefrog & Hyla versicolor & 1 & 4 \\
\hline \multirow[t]{4}{*}{ UDC015 } & Richness & 3 & & \\
\hline & American bullfrog & Rana catesbeiana & 1 & 3 \\
\hline & Northern green frog & Rana clamitans & 1 & 5 \\
\hline & Northern spring peeper & Pseudacris crucifer & 3 & 50 \\
\hline \multirow[t]{2}{*}{ UDC016 } & Richness & 1 & & \\
\hline & Northern spring peeper & Pseudacris crucifer & 3 & 50 \\
\hline \multirow[t]{4}{*}{ UDC017 } & Richness & 3 & & \\
\hline & American bullfrog & Rana catesbeiana & 1 & 1 \\
\hline & Northern spring peeper & Pseudacris crucifer & 3 & 60 \\
\hline & Northern green frog & Rana clamitans & 2 & 5 \\
\hline \multirow[t]{2}{*}{ UDC018 } & Richness & 1 & & \\
\hline & Northern spring peeper & Pseudacris crucifer & 3 & 50 \\
\hline \multirow[t]{2}{*}{ UDC019 } & Richness & 1 & & \\
\hline & Northern spring peeper & Pseudacris crucifer & 3 & 50 \\
\hline \multirow[t]{4}{*}{ UDC020 } & Richness & 3 & & \\
\hline & Northern spring peeper & Pseudacris crucifer & 3 & 50 \\
\hline & Northern green frog & Rana clamitans & 2 & 9 \\
\hline & American bullfrog & Rana catesbeiana & 1 & 6 \\
\hline \multirow[t]{4}{*}{ VEPCON } & Richness & 3 & & \\
\hline & Mountain chorus frog & Pseudacris brachyphona & 1 & 5 \\
\hline & Eastern American toad & Bufo americanus & 1 & 1 \\
\hline & Northern spring peeper & Pseudacris crucifer & 3 & 50 \\
\hline \multirow[t]{4}{*}{ VEPCOS } & Richness & 3 & & \\
\hline & Eastern American toad & Bufo americanus & 2 & 3 \\
\hline & Mountain chorus frog & Pseudacris brachyphona & 1 & 6 \\
\hline & Northern spring peeper & Pseudacris crucifer & 3 & 50 \\
\hline \multirow[t]{5}{*}{ WBBARN } & Richness & 4 & & \\
\hline & Wood frog & Rana sylvatica & 1 & 1 \\
\hline & Northern spring peeper & Pseudacris crucifer & 2 & 30 \\
\hline & Eastern American toad & Bufo americanus & 2 & 5 \\
\hline & Northern pickerel frog & Rana palustris & 1 & 2 \\
\hline
\end{tabular}


Appendix N. Continued.

\begin{tabular}{|c|c|c|c|c|c|}
\hline Site Code & Species & Latin name & Max Chorus & Max & Estimate \\
\hline \multirow[t]{5}{*}{ WBCORN } & Richness & 4 & & & \\
\hline & Eastern American toad & Bufo americanus & 2 & & 5 \\
\hline & Northern green frog & Rana clamitans & 1 & & 1 \\
\hline & Northern spring peeper & Pseudacris crucifer & 2 & & 20 \\
\hline & Northern pickerel frog & Rana palustris & 2 & & 7 \\
\hline \multirow[t]{3}{*}{ WBROAD } & Richness & 2 & & & \\
\hline & Northern spring peeper & Pseudacris crucifer & 2 & & 10 \\
\hline & Eastern American toad & Bufo americanus & 1 & & 1 \\
\hline \multirow[t]{4}{*}{ WYBEAV } & Richness & 3 & & & \\
\hline & Northern spring peeper & Pseudacris crucifer & 2 & & 20 \\
\hline & Cope's Gray treefrog & Hyla chrysoscelis & 2 & & 8 \\
\hline & Northern green frog & Rana clamitans & 1 & & 3 \\
\hline \multirow[t]{7}{*}{ WYCHWE } & Richness & 6 & & & \\
\hline & Northern spring peeper & Pseudacris crucifer & 2 & & 10 \\
\hline & American bullfrog & Rana catesbeiana & 2 & & 5 \\
\hline & Mountain chorus frog & Pseudacris brachyphona & 2 & & 3 \\
\hline & Cope's Gray treefrog & Hyla chrysoscelis & 1 & & 1 \\
\hline & Northern pickerel frog & Rana palustris & 1 & & 4 \\
\hline & Northern green frog & Rana clamitans & 1 & & 2 \\
\hline \multirow[t]{9}{*}{ WYHCEA } & Richness & 8 & & & \\
\hline & Cope's Gray treefrog & Hyla chrysoscelis & 1 & & 1 \\
\hline & Northern pickerel frog & Rana palustris & 2 & & 4 \\
\hline & American bullfrog & Rana catesbeiana & 2 & & 2 \\
\hline & Mountain chorus frog & Pseudacris brachyphona & 2 & & 10 \\
\hline & Northern spring peeper & Pseudacris crucifer & 2 & & 30 \\
\hline & Wood frog & Rana sylvatica & 2 & & 10 \\
\hline & Eastern American toad & Bufo americanus & 1 & & 2 \\
\hline & Northern green frog & Rana clamitans & 1 & & 3 \\
\hline \multirow[t]{4}{*}{ WYINTR } & Richness & 3 & & & \\
\hline & Northern spring peeper & Pseudacris crucifer & 2 & & 15 \\
\hline & Eastern American toad & Bufo americanus & 2 & & 8 \\
\hline & Mountain chorus frog & Pseudacris brachyphona & 2 & & 10 \\
\hline \multirow[t]{6}{*}{ WYTHOR } & Richness & 5 & & & \\
\hline & Eastern American toad & Bufo americanus & 1 & & 4 \\
\hline & Northern green frog & Rana clamitans & 1 & & 2 \\
\hline & Cope's Gray treefrog & Hyla chrysoscelis & 2 & & 3 \\
\hline & Northern spring peeper & Pseudacris crucifer & 2 & & 12 \\
\hline & \multicolumn{2}{|c|}{ Mountain chorus frogPseudacris brachyphona } & 1 & & 4 \\
\hline
\end{tabular}


Appendix O. Metrics values by site used to form anuran acoustically-based indices of biological integrity (AA-IBI) in West Virginia, USA from 2005-2006.Blanks indicate a metric value of zero.

\begin{tabular}{|c|c|c|c|c|c|c|c|c|c|c|c|c|c|}
\hline Site Code & Diversity & Sensitive & SOC & Tolerant & WOFRchorus & Richness & Abundance & Evenness & $\mathrm{AQAI}^{\mathrm{a}}$ & $\mathrm{CoC}^{\mathrm{b}}$ & UPLSens $^{c}$ & UPLTol $^{\mathrm{d}}$ & Fish $^{\mathrm{e}}$ \\
\hline CFCROS & 2.94 & 0.29 & & 0.57 & 0.29 & 4.00 & 7.00 & 0.32 & 4.00 & 4.25 & 0.43 & 0.43 & \\
\hline CFECUR & 1.47 & & & 1.00 & & 2.00 & 3.00 & 0.32 & 2.33 & 2.50 & 0.33 & 0.67 & \\
\hline CFEINC & 3.07 & 0.20 & & 0.80 & & 4.00 & 5.00 & 0.33 & 2.80 & 3.00 & & 0.60 & 0.20 \\
\hline CFSLCH & 4.35 & 0.33 & 0.11 & 0.67 & 0.22 & 7.00 & 9.00 & 0.27 & 3.89 & 3.71 & 0.33 & 0.22 & 0.22 \\
\hline CFSLIN & 3.99 & 0.38 & 0.13 & 0.50 & 0.25 & 6.00 & 8.00 & 0.29 & 4.38 & 4.33 & 0.25 & 0.25 & 0.13 \\
\hline CGBRID & 0.00 & & & 1.00 & & 1.00 & 1.00 & 0.00 & 2.00 & 2.00 & & 1.00 & \\
\hline CGCPAS & 0.00 & & & 1.00 & & 1.00 & 3.00 & 0.00 & 2.00 & 2.00 & & 1.00 & \\
\hline CGROAD & 0.00 & & & 1.00 & & 1.00 & 1.00 & 0.00 & 2.00 & 2.00 & & 1.00 & \\
\hline CGTRHE & 0.00 & & & 1.00 & & 1.00 & 2.00 & 0.00 & 2.00 & 2.00 & & 1.00 & \\
\hline CHNEER & 4.00 & & 0.11 & 0.78 & & 6.00 & 9.00 & 0.29 & 2.78 & 3.17 & & 0.22 & 0.44 \\
\hline CHSACH & 0.00 & & & 1.00 & & 1.00 & 1.00 & 0.00 & 2.00 & 2.00 & & 1.00 & \\
\hline CHSAFO & 0.00 & & & & & 1.00 & 1.00 & 0.00 & 5.00 & 5.00 & & & \\
\hline CHSARR & 2.53 & & & 0.67 & & 3.00 & 3.00 & 0.37 & 3.00 & 3.00 & & 0.33 & 0.33 \\
\hline CHTREE & 1.60 & & & 0.50 & & 2.00 & 2.00 & 0.35 & 3.50 & 3.50 & & 0.50 & \\
\hline CHWWBW & 3.59 & 0.13 & & 0.63 & & 5.00 & 8.00 & 0.31 & 3.38 & 3.60 & & 0.25 & 0.38 \\
\hline CHWWEM & 4.29 & 0.25 & 0.17 & 0.67 & 0.17 & 7.00 & 12.00 & 0.27 & 3.67 & 4.00 & 0.17 & 0.25 & 0.25 \\
\hline CHWWFO & 4.56 & 0.08 & 0.08 & 0.50 & & 8.00 & 12.00 & 0.25 & 3.67 & 3.38 & & 0.25 & 0.17 \\
\hline CVABBW & 1.60 & & 0.50 & 1.00 & & 2.00 & 2.00 & 0.35 & 2.50 & 2.50 & & 0.50 & \\
\hline CVABCT & 0.00 & & & 1.00 & & 1.00 & 1.00 & 0.00 & 2.00 & 2.00 & & 1.00 & \\
\hline CVTIMB & 0.00 & & & 1.00 & & 1.00 & 2.00 & 0.00 & 2.00 & 2.00 & & 1.00 & \\
\hline DSPICN & 1.47 & 0.33 & & 0.67 & 0.33 & 2.00 & 3.00 & 0.32 & 3.67 & 4.50 & 0.33 & 0.67 & \\
\hline
\end{tabular}

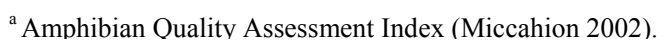

${ }^{\mathrm{b}}$ Average coefficient of conservatism.

${ }^{\mathrm{c}}$ Proportion of upland sensitive species.

${ }^{\mathrm{d}}$ Proportion of upland tolerant species.

${ }^{\mathrm{e}}$ Proportion of fish tolerant species. 
Appendix O. Continued.

\begin{tabular}{|c|c|c|c|c|c|c|c|c|c|c|c|c|c|}
\hline Site Code & Diversity & Sensitive & SOC & Tolerant & WOFRchorus & Richness & Abundance & Evenness & $\mathrm{AQAI}^{\mathrm{a}}$ & $\mathrm{CoC}^{\mathrm{b}}$ & UPLSens $^{\mathrm{c}}$ & $\mathrm{UPLTol}^{\mathrm{d}}$ & Fish $^{\mathrm{e}}$ \\
\hline DSROAR & 0.00 & 1.00 & 1.00 & 1.00 & 0.00 & 2.00 & 2.00 & 1.00 & & & & & \\
\hline DSWILD & & & & & & 0.00 & 0.00 & & & & & & \\
\hline EPCMEM & 3.44 & 0.25 & & 0.75 & 0.13 & 5.00 & 8.00 & 0.30 & 3.00 & 3.80 & 0.13 & 0.63 & 0.13 \\
\hline EPCMFO & & & & & & 0.00 & 0.00 & & & & & & \\
\hline EPDMFO & & & & & & 0.00 & 0.00 & & & & & & \\
\hline EPDMPU & & & & & & 0.00 & 0.00 & & & & & & \\
\hline EPKYVE & 3.57 & 0.43 & & 0.57 & 0.29 & 5.00 & 7.00 & 0.31 & 4.00 & 3.80 & 0.29 & 0.43 & 0.14 \\
\hline EPRRXC & 0.00 & & & 1.00 & & 1.00 & 1.00 & 0.00 & 2.00 & 2.00 & & & 1.00 \\
\hline EPSHEM & 1.60 & & & 1.00 & & 2.00 & 2.00 & 0.35 & 2.00 & 2.00 & & 0.50 & 0.50 \\
\hline EPSHSS & 3.06 & 0.17 & & 0.83 & 0.17 & 4.00 & 6.00 & 0.33 & 2.50 & 3.00 & 0.17 & 0.67 & 0.17 \\
\hline GBBARN & 4.25 & 0.27 & 0.09 & 0.73 & 0.18 & 7.00 & 11.00 & 0.26 & 3.18 & 3.29 & 0.18 & 0.45 & 0.18 \\
\hline GBHOEF & 3.11 & 0.57 & & 0.43 & 0.29 & 4.00 & 7.00 & 0.34 & 4.86 & 4.50 & 0.29 & 0.29 & 0.14 \\
\hline GBJENK & 3.90 & 0.10 & 0.10 & 0.90 & & 6.00 & 10.00 & 0.28 & 2.30 & 2.67 & & 0.50 & 0.30 \\
\hline GBMAPL & 3.37 & 0.44 & 0.11 & 0.56 & 0.33 & 5.00 & 9.00 & 0.29 & 4.11 & 3.80 & 0.33 & 0.44 & \\
\hline GBNOFO & 3.07 & 0.20 & & 0.80 & & 4.00 & 5.00 & 0.33 & 2.80 & 3.00 & & 0.60 & 0.20 \\
\hline GBNOSS & 3.44 & & 0.13 & 1.00 & & 5.00 & 8.00 & 0.30 & 1.75 & 1.80 & & 0.63 & 0.25 \\
\hline GBPLOT & 4.31 & 0.36 & 0.07 & 0.64 & 0.21 & 7.00 & 14.00 & 0.27 & 3.71 & 3.29 & 0.21 & 0.29 & 0.29 \\
\hline HCBEAV & 2.94 & 0.43 & & 0.57 & 0.29 & 4.00 & 7.00 & 0.32 & 4.14 & 4.50 & 0.29 & 0.43 & 0.14 \\
\hline HCMITI & 3.90 & 0.30 & & 0.50 & 0.20 & 6.00 & 10.00 & 0.28 & 4.20 & 4.33 & 0.30 & 0.30 & 0.10 \\
\hline HCPIPE & 2.19 & & & 1.00 & & 3.00 & 5.00 & 0.32 & 1.80 & 1.67 & & 0.80 & 0.20 \\
\hline HCRANG & 2.19 & 0.20 & & 0.60 & 0.20 & 3.00 & 5.00 & 0.32 & 3.60 & 4.67 & 0.20 & 0.60 & \\
\hline
\end{tabular}

${ }^{a}$ Amphibian Quality Assessment Index (Miccahion 2002).

${ }^{\mathrm{b}}$ Average coefficient of conservatism.

${ }^{\mathrm{c}}$ Proportion of upland sensitive species.

${ }^{\mathrm{d}}$ Proportion of upland tolerant species.

${ }^{\text {e }}$ Proportion of fish tolerant species. 
Appendix O. Continued.

\begin{tabular}{|c|c|c|c|c|c|c|c|c|c|c|c|c|c|}
\hline Site Code & Diversity & Sensitive & $\mathrm{SOC}$ & Tolerant & WOFRchorus & Richness & Abundance & Evenness & $\mathrm{AQAI}^{\mathrm{a}}$ & $\mathrm{CoC}^{\mathrm{b}}$ & UPLSens $^{\mathrm{c}}$ & UPLTol $^{\mathrm{d}}$ & Fish $^{\mathrm{e}}$ \\
\hline HIBRID & 0.00 & 1.00 & 1.00 & 1.00 & 0.00 & 2.00 & 2.00 & 1.00 & & & & & \\
\hline HIGATE & 1.47 & & & 1.00 & & 2.00 & 3.00 & 0.32 & 2.00 & 2.00 & & 0.67 & 0.33 \\
\hline HIJHPK & 2.39 & 0.25 & & 0.75 & 0.25 & 3.00 & 4.00 & 0.35 & 3.00 & 3.33 & 0.25 & 0.75 & \\
\hline HIJHTU & 3.86 & 0.22 & & 0.56 & 0.22 & 6.00 & 9.00 & 0.28 & 3.67 & 3.67 & 0.22 & 0.44 & 0.11 \\
\hline HIPENC & 3.85 & 0.36 & & 0.55 & 0.27 & 6.00 & 11.00 & 0.28 & 4.09 & 4.17 & 0.27 & 0.27 & 0.27 \\
\hline HISEWG & 1.60 & & & 0.50 & & 2.00 & 2.00 & 0.35 & 3.00 & 3.00 & & 0.50 & \\
\hline HITRLR & 3.44 & 0.25 & & 0.63 & 0.25 & 5.00 & 8.00 & 0.30 & 3.50 & 3.40 & 0.25 & 0.50 & 0.13 \\
\hline MCFOUR & 1.47 & 0.33 & & 0.67 & & 2.00 & 3.00 & 0.32 & 3.67 & 4.50 & & 0.67 & \\
\hline MCMEME & 3.90 & 0.20 & & 0.60 & 0.10 & 6.00 & 10.00 & 0.28 & 3.60 & 4.17 & 0.10 & 0.30 & 0.30 \\
\hline MCMFOR & 3.44 & 0.13 & & 0.63 & & 5.00 & 8.00 & 0.30 & 3.50 & 3.80 & 0.13 & 0.38 & 0.13 \\
\hline MCNPFO & 0.00 & & & 1.00 & & 1.00 & 1.00 & 0.00 & 2.00 & 2.00 & & 1.00 & \\
\hline MCPOND & 1.60 & & & 1.00 & & 2.00 & 2.00 & 0.35 & 2.00 & 2.00 & & & 1.00 \\
\hline MCPOST & 3.59 & 0.25 & & 0.63 & & 5.00 & 8.00 & 0.31 & 3.63 & 3.60 & & 0.25 & 0.38 \\
\hline MCTELE & 3.11 & & & 0.71 & & 4.00 & 7.00 & 0.34 & 2.86 & 2.75 & & 0.29 & 0.43 \\
\hline ME5092 & 3.07 & & & 0.80 & & 4.00 & 5.00 & 0.33 & 2.60 & 2.75 & & 0.40 & 0.40 \\
\hline MESCOX & 3.07 & 0.40 & & 0.60 & 0.20 & 4.00 & 5.00 & 0.33 & 4.00 & 4.50 & 0.20 & 0.40 & 0.20 \\
\hline MESCRO & 3.06 & 0.50 & & 0.50 & 0.33 & 4.00 & 6.00 & 0.33 & 4.50 & 4.50 & 0.33 & 0.33 & 0.17 \\
\hline MESCUP & 3.11 & 0.43 & & 0.57 & 0.14 & 4.00 & 7.00 & 0.34 & 4.14 & 4.50 & 0.14 & 0.29 & 0.29 \\
\hline MESIGN & 3.07 & 0.20 & 0.20 & 0.80 & 0.20 & 4.00 & 5.00 & 0.33 & 3.20 & 3.50 & 0.20 & 0.40 & 0.20 \\
\hline MESILV & 3.07 & 0.20 & & 0.60 & 0.20 & 4.00 & 5.00 & 0.33 & 3.60 & 4.00 & 0.20 & 0.40 & 0.20 \\
\hline METETR & 2.39 & & 0.25 & 1.00 & & 3.00 & 4.00 & 0.35 & 2.25 & 2.33 & & 0.50 & 0.25 \\
\hline
\end{tabular}

${ }^{a}$ Amphibian Quality Assessment Index (Miccahion 2002).

${ }^{\mathrm{b}}$ Average coefficient of conservatism.

${ }^{\mathrm{c}}$ Proportion of upland sensitive species.

${ }^{\mathrm{d}}$ Proportion of upland tolerant species.

${ }^{\mathrm{e}}$ Proportion of fish tolerant species. 
Appendix O. Continued.

\begin{tabular}{|c|c|c|c|c|c|c|c|c|c|c|c|c|c|}
\hline Site Code & Diversity & Sensitive & SOC & Tolerant & WOFRchorus & Richness & Abundance & Evenness & $\mathrm{AQAI}^{\mathrm{a}}$ & $\mathrm{CoC}^{\mathrm{b}}$ & UPLSens $^{\mathrm{c}}$ & UPLTol $^{\mathrm{d}}$ & Fish $^{\mathrm{e}}$ \\
\hline MEWOLF & 2.19 & 0.20 & 0.80 & 0.20 & 3.00 & 5.00 & 0.32 & 3.00 & 3.67 & 0.20 & 0.60 & 0.20 & \\
\hline MRBESS & 2.39 & 0.25 & & 0.75 & 0.25 & 3.00 & 4.00 & 0.35 & 3.25 & 3.67 & 0.25 & 0.50 & 0.25 \\
\hline MRFARM & 1.47 & & 0.33 & 1.00 & & 2.00 & 3.00 & 0.32 & 2.33 & 2.50 & & 0.67 & \\
\hline MRFORE & 1.47 & & & 1.00 & & 2.00 & 3.00 & 0.32 & 1.67 & 1.50 & & 1.00 & \\
\hline MRSSSS & 1.47 & & 0.33 & 1.00 & & 2.00 & 3.00 & 0.32 & 2.33 & 2.50 & & 0.67 & \\
\hline MRWEST & 0.00 & & & 1.00 & & 1.00 & 2.00 & 0.00 & 2.00 & 2.00 & & 1.00 & \\
\hline MU55SS & 2.94 & 0.29 & & 0.57 & 0.29 & 4.00 & 7.00 & 0.32 & 3.86 & 4.00 & 0.29 & 0.43 & 0.14 \\
\hline MUDBOA & 3.19 & & & 0.75 & & 4.00 & 4.00 & 0.35 & 2.75 & 2.75 & & 0.25 & 0.50 \\
\hline MUDEND & 3.99 & 0.25 & & 0.63 & 0.13 & 6.00 & 8.00 & 0.29 & 3.63 & 4.17 & 0.13 & 0.25 & 0.38 \\
\hline MUDRIC & 4.03 & 0.25 & & 0.58 & 0.17 & 6.00 & 12.00 & 0.29 & 3.75 & 4.17 & 0.17 & 0.25 & 0.33 \\
\hline MUDRIP & 4.00 & 0.33 & & 0.44 & 0.22 & 6.00 & 9.00 & 0.29 & 4.33 & 4.17 & 0.22 & 0.22 & 0.22 \\
\hline MUDTRA & 4.35 & 0.22 & & 0.56 & 0.11 & 7.00 & 9.00 & 0.27 & 3.89 & 4.00 & 0.22 & 0.22 & 0.22 \\
\hline MUEPAH & 3.06 & 0.33 & & 0.50 & 0.33 & 4.00 & 6.00 & 0.33 & 4.17 & 4.00 & 0.33 & 0.33 & 0.17 \\
\hline MUMINE & 0.00 & & & 1.00 & & 1.00 & 1.00 & 0.00 & 2.00 & 2.00 & & 1.00 & \\
\hline MUPOWR & 1.60 & & & 0.50 & & 2.00 & 2.00 & 0.35 & 3.50 & 3.50 & & 0.50 & \\
\hline MUPULL & 2.86 & 0.33 & & 0.50 & 0.17 & 4.00 & 6.00 & 0.31 & 4.17 & 5.25 & 0.17 & 0.50 & \\
\hline MUVBRD & 2.94 & 0.29 & & 0.57 & 0.29 & 4.00 & 7.00 & 0.32 & 3.86 & 4.00 & 0.29 & 0.43 & 0.14 \\
\hline MUVCRN & 2.33 & & & 0.67 & & 3.00 & 6.00 & 0.34 & 3.00 & 3.00 & & 0.50 & 0.17 \\
\hline OHHSFO & 1.60 & & & 1.00 & & 2.00 & 2.00 & 0.35 & 1.50 & 1.50 & & 1.00 & \\
\hline OHINNS & 3.51 & 0.33 & & 0.44 & 0.22 & 5.00 & 9.00 & 0.30 & 4.33 & 4.60 & 0.22 & 0.33 & 0.11 \\
\hline OHKMRT & 2.39 & & & 0.75 & & 3.00 & 4.00 & 0.35 & 2.75 & 3.00 & & 0.50 & 0.25 \\
\hline
\end{tabular}

${ }^{a}$ Amphibian Quality Assessment Index (Miccahion 2002).

${ }^{\mathrm{b}}$ Average coefficient of conservatism.

${ }^{\mathrm{c}}$ Proportion of upland sensitive species.

${ }^{\mathrm{d}}$ Proportion of upland tolerant species.

${ }^{\mathrm{e}}$ Proportion of fish tolerant species. 
Appendix O. Continued.

\begin{tabular}{|c|c|c|c|c|c|c|c|c|c|c|c|c|c|}
\hline Site Code & Diversity & Sensitive & SOC & Tolerant & WOFRchorus & Richness & Abundance & Evenness & $\mathrm{AQAI}^{\mathrm{a}}$ & $\mathrm{CoC}^{\mathrm{b}}$ & UPLSens $^{\mathrm{c}}$ & UPLTol $^{\mathrm{d}}$ & Fish $^{\mathrm{e}}$ \\
\hline PA29TH & 3.06 & 0.33 & & 0.50 & 0.33 & 4.00 & 6.00 & 0.33 & 4.17 & 4.00 & 0.33 & 0.33 & 0.17 \\
\hline PA83CR & 3.06 & 0.17 & & 0.50 & 0.17 & 4.00 & 6.00 & 0.33 & 3.83 & 4.00 & 0.17 & 0.33 & 0.17 \\
\hline PAFAMD & 3.67 & 0.18 & & 0.64 & & 5.00 & 11.00 & 0.32 & 3.45 & 3.60 & & 0.18 & 0.45 \\
\hline PAJCPY & 2.86 & & & 0.50 & & 4.00 & 6.00 & 0.31 & 3.33 & 2.50 & & 0.33 & 0.17 \\
\hline PALOUD & 2.43 & 0.40 & & 0.20 & & 3.00 & 5.00 & 0.35 & 5.20 & 4.67 & & 0.20 & \\
\hline PAPEFO & 0.00 & & & 1.00 & & 1.00 & 1.00 & 0.00 & 2.00 & 2.00 & & 1.00 & \\
\hline PAPEIM & 2.43 & & & 1.00 & & 3.00 & 5.00 & 0.35 & 1.60 & 1.67 & & 0.80 & 0.20 \\
\hline PAPESW & 2.33 & 0.33 & & 0.67 & 0.33 & 3.00 & 6.00 & 0.34 & 3.67 & 3.67 & 0.33 & 0.50 & 0.17 \\
\hline PAWILL & 4.02 & & 0.14 & 0.86 & & 6.00 & 7.00 & 0.29 & 2.29 & 2.33 & & 0.29 & 0.43 \\
\hline PCBLUE & 3.46 & 0.10 & & 0.70 & & 5.00 & 10.00 & 0.30 & 3.10 & 3.60 & & 0.30 & 0.40 \\
\hline PCLPFO & 3.85 & 0.36 & & 0.45 & 0.27 & 6.00 & 11.00 & 0.28 & 4.18 & 3.83 & 0.27 & 0.36 & \\
\hline PCROAD & 3.44 & 0.38 & & 0.63 & 0.25 & 5.00 & 8.00 & 0.30 & 3.88 & 4.00 & 0.25 & 0.38 & 0.25 \\
\hline PEMIDW & 3.90 & 0.20 & & 0.50 & 0.20 & 6.00 & 10.00 & 0.28 & 3.80 & 3.67 & 0.20 & 0.40 & 0.10 \\
\hline PERDDP & 2.33 & 0.33 & & 0.50 & 0.33 & 3.00 & 6.00 & 0.34 & 4.17 & 4.67 & 0.33 & 0.50 & \\
\hline PETHUM & 1.55 & 0.40 & & 0.60 & 0.40 & 2.00 & 5.00 & 0.34 & 4.00 & 4.50 & 0.40 & 0.60 & \\
\hline PETOSS & 0.00 & & & & & 1.00 & 1.00 & 0.00 & 5.00 & 5.00 & & & \\
\hline RIASIA & 4.02 & 0.14 & & 0.71 & & 6.00 & 7.00 & 0.29 & 3.29 & 3.50 & 0.14 & 0.29 & 0.29 \\
\hline RIBRID & 3.59 & & & 0.83 & & 5.00 & 6.00 & 0.31 & 2.83 & 2.80 & 0.33 & 0.17 & 0.33 \\
\hline RIEAST & 1.60 & & 0.50 & 1.00 & & 2.00 & 2.00 & 0.35 & 2.00 & 2.00 & & 0.50 & \\
\hline SJBOAT & 2.86 & 0.17 & & 0.67 & & 4.00 & 6.00 & 0.31 & 3.33 & 4.00 & & 0.50 & 0.17 \\
\hline SJBRID & 3.99 & 0.13 & & 0.88 & & 6.00 & 8.00 & 0.29 & 2.50 & 2.83 & 0.13 & 0.50 & 0.25 \\
\hline
\end{tabular}

${ }^{a}$ Amphibian Quality Assessment Index (Miccahion 2002).

${ }^{\mathrm{b}}$ Average coefficient of conservatism.

${ }^{\mathrm{c}}$ Proportion of upland sensitive species.

${ }^{\mathrm{d}}$ Proportion of upland tolerant species.

${ }^{\mathrm{e}}$ Proportion of fish tolerant species. 
Appendix O. Continued.

\begin{tabular}{|c|c|c|c|c|c|c|c|c|c|c|c|c|c|}
\hline Site Code & Diversity & Sensitive & SOC & Tolerant & WOFRchorus & Richness & Abundance & Evenness & $\mathrm{AQAI}^{\mathrm{a}}$ & $\mathrm{CoC}^{\mathrm{b}}$ & UPLSens $^{\mathrm{c}}$ & UPLTol $^{\mathrm{d}}$ & Fish $^{\mathrm{e}}$ \\
\hline SJCHUR & 3.04 & 0.25 & 0.75 & 4.00 & 8.00 & 0.33 & 3.13 & 3.00 & 0.50 & 0.25 & & & \\
\hline SJGLAD & 3.07 & 0.20 & & 0.80 & 0.20 & 4.00 & 5.00 & 0.33 & 3.20 & 3.50 & 0.40 & 0.40 & 0.20 \\
\hline SJMUDL & 2.39 & & & 1.00 & & 3.00 & 4.00 & 0.35 & 2.25 & 2.33 & 0.25 & 0.50 & 0.25 \\
\hline SJPLOT & 4.34 & 0.30 & & 0.60 & 0.10 & 7.00 & 10.00 & 0.27 & 3.70 & 3.86 & 0.20 & 0.40 & 0.10 \\
\hline SJTELE & 2.53 & & & 1.00 & & 3.00 & 3.00 & 0.37 & 2.00 & 2.00 & 0.33 & 0.33 & 0.33 \\
\hline SMDTSS & 1.47 & 0.33 & & 0.67 & & 2.00 & 3.00 & 0.32 & 3.67 & 4.50 & & 0.67 & \\
\hline SMFOFL & 0.00 & & & 1.00 & & 1.00 & 3.00 & 0.00 & 2.00 & 2.00 & & 1.00 & \\
\hline SMLPEM & 2.19 & & 0.20 & 1.00 & & 3.00 & 5.00 & 0.32 & 2.20 & 2.33 & & 0.60 & 0.20 \\
\hline SMSEFL & 2.94 & 0.29 & & 0.71 & & 4.00 & 7.00 & 0.32 & 3.43 & 3.25 & & 0.43 & 0.29 \\
\hline SMSTEM & 1.47 & 0.33 & & 0.67 & & 2.00 & 3.00 & 0.32 & 3.67 & 4.50 & & 0.67 & \\
\hline TRSPFO & 0.00 & & & 1.00 & & 1.00 & 1.00 & 0.00 & 2.00 & 2.00 & & & 1.00 \\
\hline TRSPRI & 3.51 & 0.22 & & 0.56 & 0.22 & 5.00 & 9.00 & 0.30 & 3.78 & 3.60 & 0.22 & 0.33 & 0.22 \\
\hline TVFARM & 2.33 & 0.33 & & 0.50 & 0.33 & 3.00 & 6.00 & 0.34 & 4.17 & 4.67 & 0.33 & 0.50 & \\
\hline TVISLE & 2.39 & & & 0.75 & & 3.00 & 4.00 & 0.35 & 2.75 & 3.00 & & 0.50 & 0.25 \\
\hline TVNEWT & 3.85 & 0.27 & & 0.55 & 0.27 & 6.00 & 11.00 & 0.28 & 3.82 & 3.67 & 0.27 & 0.36 & 0.18 \\
\hline TVPOUT & 2.33 & 0.33 & & 0.67 & 0.33 & 3.00 & 6.00 & 0.34 & 3.67 & 3.67 & 0.33 & 0.50 & 0.17 \\
\hline TVVBEM & 2.39 & 0.25 & & 0.75 & 0.25 & 3.00 & 4.00 & 0.35 & 3.25 & 3.67 & 0.25 & 0.50 & 0.25 \\
\hline TVVBIM & 2.43 & 0.40 & & 0.60 & 0.40 & 3.00 & 5.00 & 0.35 & 4.00 & 3.67 & 0.40 & 0.40 & 0.20 \\
\hline TVVBRV & 2.53 & & & 0.67 & & 3.00 & 3.00 & 0.37 & 2.67 & 2.67 & & 0.67 & \\
\hline TVVBSS & 3.02 & 0.33 & & 0.67 & 0.22 & 4.00 & 9.00 & 0.33 & 3.67 & 4.50 & 0.22 & 0.33 & 0.33 \\
\hline UDC001 & 3.66 & 0.17 & & 0.67 & 0.17 & 5.00 & 12.00 & 0.32 & 3.08 & 3.40 & 0.17 & 0.50 & 0.17 \\
\hline
\end{tabular}

${ }^{a}$ Amphibian Quality Assessment Index (Miccahion 2002).

${ }^{\mathrm{b}}$ Average coefficient of conservatism.

${ }^{\mathrm{c}}$ Proportion of upland sensitive species.

${ }^{\mathrm{d}}$ Proportion of upland tolerant species.

${ }^{\text {e }}$ Proportion of fish tolerant species. 
Appendix O. Continued.

\begin{tabular}{|c|c|c|c|c|c|c|c|c|c|c|c|c|c|}
\hline Site Code & Diversity & Sensitive & SOC & Tolerant & WOFRchorus & Richness & Abundance & Evenness & $\mathrm{AQAI}^{\mathrm{a}}$ & $\mathrm{CoC}^{\mathrm{b}}$ & UPLSens $^{c}$ & UPLTol $^{\mathrm{d}}$ & Fish $^{\mathrm{e}}$ \\
\hline UDC002 & 2.89 & & & 0.88 & & 4.00 & 8.00 & 0.31 & 1.88 & 2.25 & & 0.88 & \\
\hline UDC003 & 2.89 & & & 1.00 & & 4.00 & 8.00 & 0.31 & 1.63 & 1.75 & & 0.75 & 0.25 \\
\hline UDC004 & 3.40 & & & 0.86 & & 5.00 & 7.00 & 0.30 & 2.29 & 2.40 & & 0.57 & 0.29 \\
\hline UDC005 & 1.29 & & & 1.00 & & 2.00 & 4.00 & 0.28 & 1.75 & 1.50 & & 1.00 & \\
\hline UDC007 & 0.00 & & & 1.00 & & 1.00 & 3.00 & 0.00 & 2.00 & 2.00 & & 1.00 & \\
\hline UDC008 & 0.00 & & & 1.00 & & 1.00 & 3.00 & 0.00 & 2.00 & 2.00 & & 1.00 & \\
\hline UDC012 & 1.55 & & & 1.00 & & 2.00 & 5.00 & 0.34 & 2.00 & 2.00 & & 0.60 & 0.40 \\
\hline UDC013 & 1.29 & & & 0.75 & & 2.00 & 4.00 & 0.28 & 2.75 & 3.50 & & 0.75 & \\
\hline UDC014 & 1.29 & & & 0.75 & & 2.00 & 4.00 & 0.28 & 2.75 & 3.50 & & 0.75 & \\
\hline UDC015 & 2.19 & & & 1.00 & & 3.00 & 5.00 & 0.32 & 2.00 & 2.00 & & 0.60 & 0.40 \\
\hline UDC016 & 0.00 & & & 1.00 & & 1.00 & 3.00 & 0.00 & 2.00 & 2.00 & & 1.00 & \\
\hline UDC017 & 2.33 & & & 1.00 & & 3.00 & 6.00 & 0.34 & 2.00 & 2.00 & & 0.50 & 0.50 \\
\hline UDC018 & 0.00 & & & 1.00 & & 1.00 & 3.00 & 0.00 & 2.00 & 2.00 & & 1.00 & \\
\hline UDC019 & 0.00 & & & 1.00 & & 1.00 & 3.00 & 0.00 & 2.00 & 2.00 & & 1.00 & \\
\hline UDC020 & 2.33 & & & 1.00 & & 3.00 & 6.00 & 0.34 & 2.00 & 2.00 & & 0.50 & 0.50 \\
\hline VEPCON & 2.19 & & & 1.00 & & 3.00 & 5.00 & 0.32 & 2.00 & 2.00 & 0.20 & 0.80 & \\
\hline VEPCOS & 2.33 & & & 1.00 & & 3.00 & 6.00 & 0.34 & 1.83 & 2.00 & 0.17 & 0.83 & \\
\hline WBBARN & 3.06 & 0.33 & & 0.67 & 0.17 & 4.00 & 6.00 & 0.33 & 3.33 & 4.25 & 0.17 & 0.67 & \\
\hline WBCORN & 3.11 & 0.29 & & 0.71 & & 4.00 & 7.00 & 0.34 & 3.14 & 3.00 & & 0.57 & 0.14 \\
\hline WBROAD & 1.47 & & & 1.00 & & 2.00 & 3.00 & 0.32 & 1.67 & 1.50 & & 1.00 & \\
\hline WYBEAV & 2.43 & & & 0.60 & & 3.00 & 5.00 & 0.35 & 3.20 & 3.00 & & 0.40 & 0.20 \\
\hline
\end{tabular}

${ }^{a}$ Amphibian Quality Assessment Index (Miccahion 2002).

${ }^{\mathrm{b}}$ Average coefficient of conservatism.

${ }^{\mathrm{c}}$ Proportion of upland sensitive species.

${ }^{\mathrm{d}}$ Proportion of upland tolerant species.

${ }^{\mathrm{e}}$ Proportion of fish tolerant species. 
Appendix O. Continued.

\begin{tabular}{|c|c|c|c|c|c|c|c|c|c|c|c|c|c|}
\hline Site Code & Diversity & Sensitive & SOC & Tolerant & WOFRchorus & Richness & Abundance & Evenness & $\mathrm{AQAI}^{\mathrm{a}}$ & $\mathrm{CoC}^{\mathrm{b}}$ & $\mathrm{UPLSens}^{\mathrm{c}}$ & UPLTol $^{\mathrm{d}}$ & Fish $^{\mathrm{e}}$ \\
\hline WYCHWE & 4.00 & 0.11 & 0.78 & 6.00 & 9.00 & 0.29 & 3.11 & 3.50 & 0.22 & 0.22 & 0.33 & & \\
\hline WYHCEA & 4.68 & 0.31 & & 0.62 & 0.15 & 8.00 & 13.00 & 0.25 & 3.85 & 3.63 & 0.31 & 0.23 & 0.23 \\
\hline WYINTR & 2.53 & & & 1.00 & & 3.00 & 6.00 & 0.37 & 2.00 & 2.00 & 0.33 & 0.67 & \\
\hline WYTHOR & 3.57 & & & 0.71 & & 5.00 & 7.00 & 0.31 & 2.86 & 2.60 & 0.14 & 0.43 & 0.14 \\
\hline
\end{tabular}

${ }^{a}$ Amphibian Quality Assessment Index (Miccahion 2002).

${ }^{\mathrm{b}}$ Average coefficient of conservatism.

${ }^{\mathrm{c}}$ Proportion of upland sensitive species

${ }^{\mathrm{d}}$ Proportion of upland tolerant species.

${ }^{\mathrm{e}}$ Proportion of fish tolerant species. 
Appendix P. Anuran community sampling summary statistics of metric scores statewide and by ecoregion used to form acoustically-based anuran indices of biological integrity (AA-IBI) for wetlands in West Virginia, USA 2005-2006.

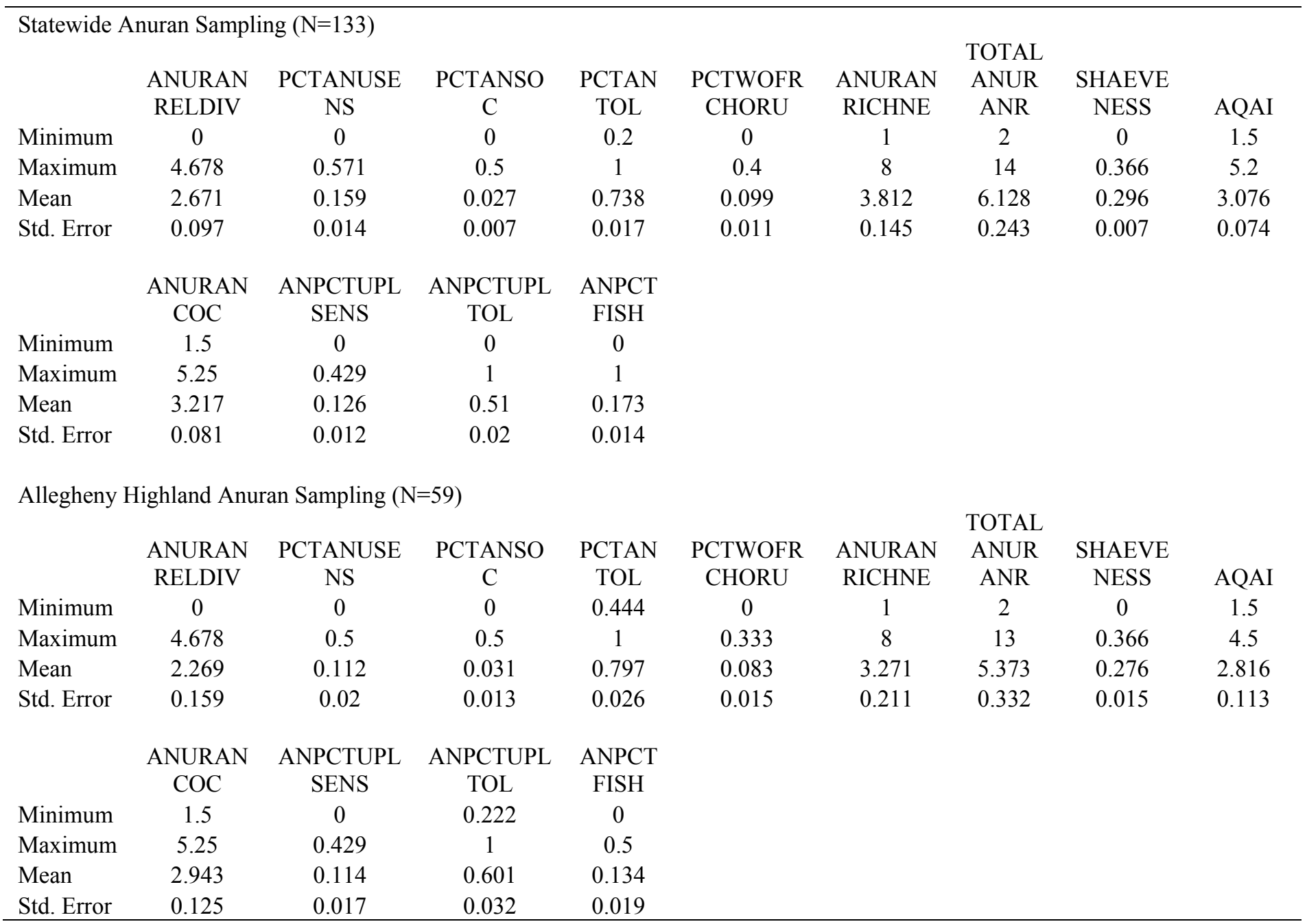


Appendix P. Continued.

\begin{tabular}{|c|c|c|c|c|c|c|c|c|c|}
\hline \multicolumn{10}{|c|}{ Ridge and Valley Anuran Sampling $(\mathrm{N}=21)$} \\
\hline & ANURAN & PCTANUSE & PCTANSO & PCTAN & PCTWOFR & ANURAN & $\begin{array}{l}\text { TOTAL } \\
\text { ANUR }\end{array}$ & SHAEVE & \\
\hline & RELDIV & NS & $\mathrm{C}$ & TOL & CHORU & RICHNE & ANR & NESS & AQAI \\
\hline Maximum & 3.851 & 0.429 & 0.2 & 1 & 0.4 & 6 & 11 & 0.366 & 4.167 \\
\hline Mean & 2.386 & 0.223 & 0.01 & 0.733 & 0.138 & 3.238 & 5.286 & 0.312 & 3.155 \\
\hline \multirow{2}{*}{ Std. Error } & ANURAN & ANPCTUPL & ANPCTUPL & ANPCT & & & & & \\
\hline & COC & SENS & TOL & FISH & & & & & \\
\hline Minimum & 1.5 & 0 & 0.333 & 0 & & & & & \\
\hline Maximum & 4.667 & 0.4 & 1 & 0.5 & & & & & \\
\hline Mean & 3.425 & 0.138 & 0.583 & 0.14 & & & & & \\
\hline \multicolumn{10}{|c|}{ Western Allegheny Plateau Anuran Sampling $(N=53)$} \\
\hline & RELDIV & NS & $\mathrm{C}$ & TOL & CHORU & RICHNE & ANR & NESS & AQAI \\
\hline Minimum & 1.466 & 0 & 0 & 0.2 & 0 & 2 & 2 & 0.247 & 1.6 \\
\hline Maximum & 4.557 & 0.571 & 0.5 & 1 & 0.4 & 8 & 14 & 0.366 & 5.2 \\
\hline Mean & 3.231 & 0.187 & 0.028 & 0.673 & 0.102 & 4.642 & 7.302 & 0.311 & 3.334 \\
\hline \multirow[t]{3}{*}{ Std. Error } & 0.114 & 0.021 & 0.011 & 0.025 & 0.017 & 0.214 & 0.393 & 0.004 & 0.109 \\
\hline & ANURAN & ANPCTUPL & ANPCTUPL & ANPCT & & & & & \\
\hline & COC & SENS & TOL & FISH & & & & & \\
\hline Minimum & 1.667 & 0 & 0 & 0 & & & & & \\
\hline
\end{tabular}


Appendix Q. Anuran community metrics box-and-whisker results and narrative descriptions for floodplain wetlands $(\mathrm{N}=14)$. Classifications are reference $(\mathrm{R})$ and stressed (S).
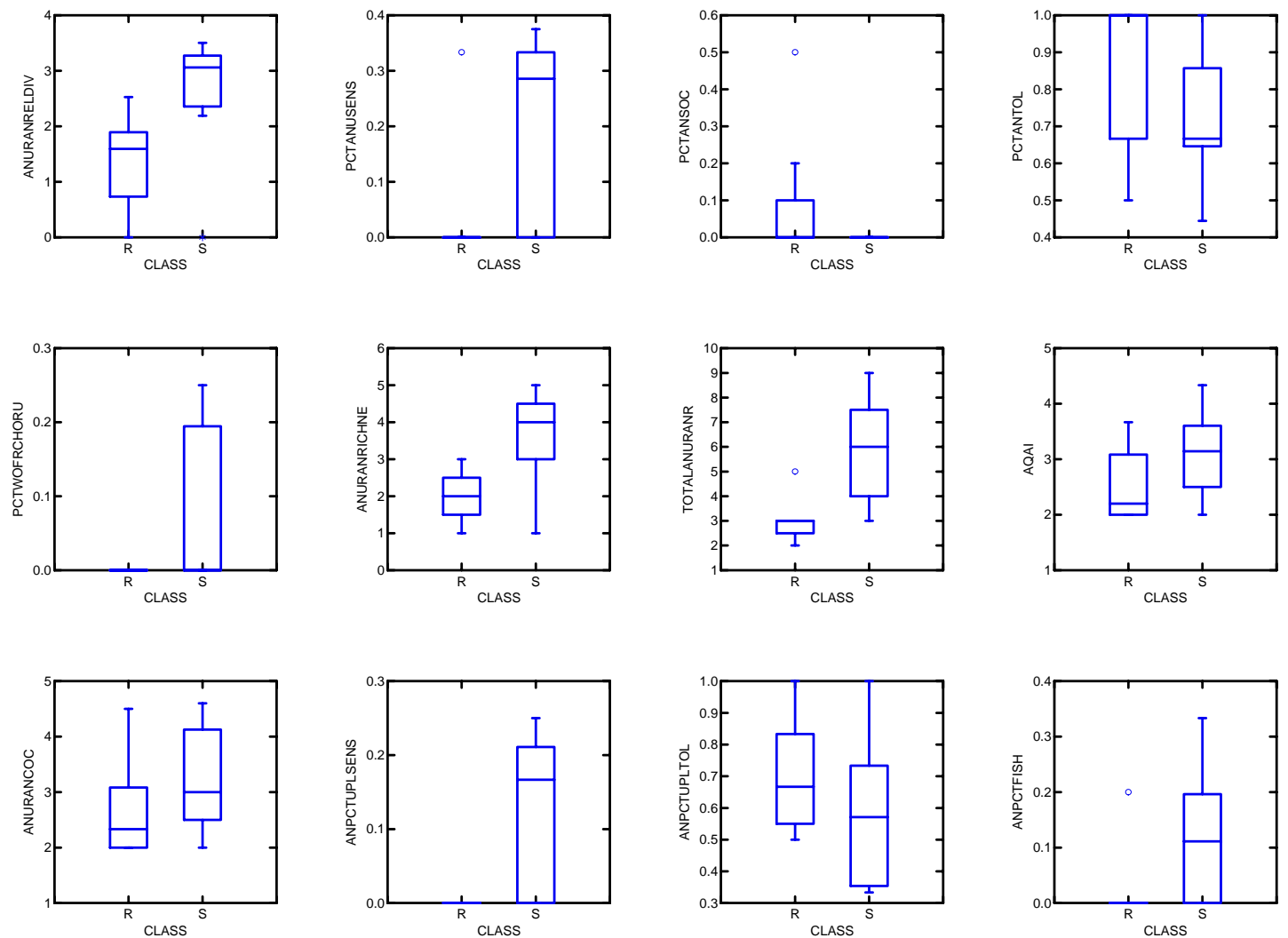

\begin{tabular}{lll} 
Metric Code & Metrics & Rating \\
\hline ANURANRELDIV & Anuran relative diversity & good \\
PCTANUSENS & Proportionsensitive anurans & poor \\
PCTANSOC & Proportionspecies of concern anurans & poor \\
PCTANTOL & Proportiontolerant anurans & fair \\
PCTWOFRCHORU & Proportion of wood frog abundance & poor \\
ANURANRICHNE & Anuran richness & good \\
TOTALANURANRE & Total anuran relative abundance & good \\
AQAI & Amphibian Quality Assessment Index score & fair \\
ANURANCOC & Average coefficient of conservatism & fair \\
ANPCTUPLSENS & Proportionanuran upland sensitive & poor \\
ANPCTUPLTOL & Proportionanuran upland tolerant & poor \\
ANPCTFISH & Proportionanuran fish tolerant & poor \\
\hline
\end{tabular}


Appendix R. Anuran community metrics box-and-whisker results and narrative descriptions for depressionalwetlands $(\mathrm{N}=33)$. Classifications are reference $(\mathrm{R})$ and stressed (S).
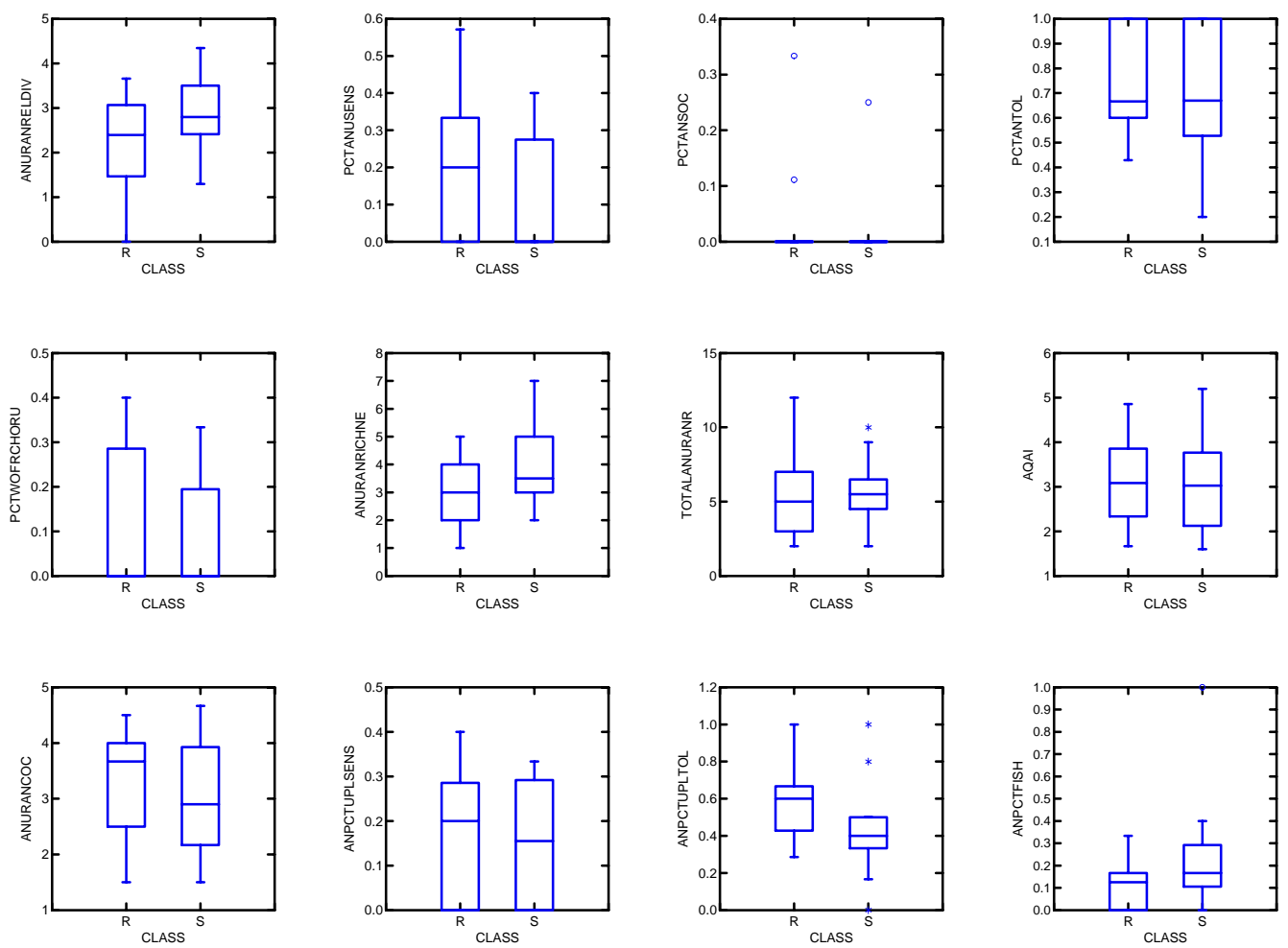

\begin{tabular}{lll} 
Metric Code & Metrics & Rating \\
\hline ANURANRELDIV & Anuran relative diversity & fair \\
PCTANUSENS & Proportion sensitive anurans & poor \\
PCTANSOC & Proportion species of concern anurans & poor \\
PCTANTOL & Proportion tolerant anurans & poor \\
PCTWOFRCHORU & Proportion of wood frog abundance & poor \\
ANURANRICHNE & Anuran richness & fair \\
TOTALANURANRE & Total anuran relative abundance & poor \\
AQAI & Amphibian Quality Assessment Index score & poor \\
ANURANCOC & Average coefficient of conservatism & poor \\
ANPCTUPLSENS & Proportion anuran upland sensitive & poor \\
ANPCTUPLTOL & Proportion anuran upland tolerant & good \\
ANPCTFISH & Proportion anuran fish tolerant & fair \\
\hline
\end{tabular}


Appendix S. Anuran community metrics box-and-whisker results and narrative descriptions for impoundment wetlands $(\mathrm{N}=13)$. Classifications are reference $(\mathrm{R})$ and stressed (S).
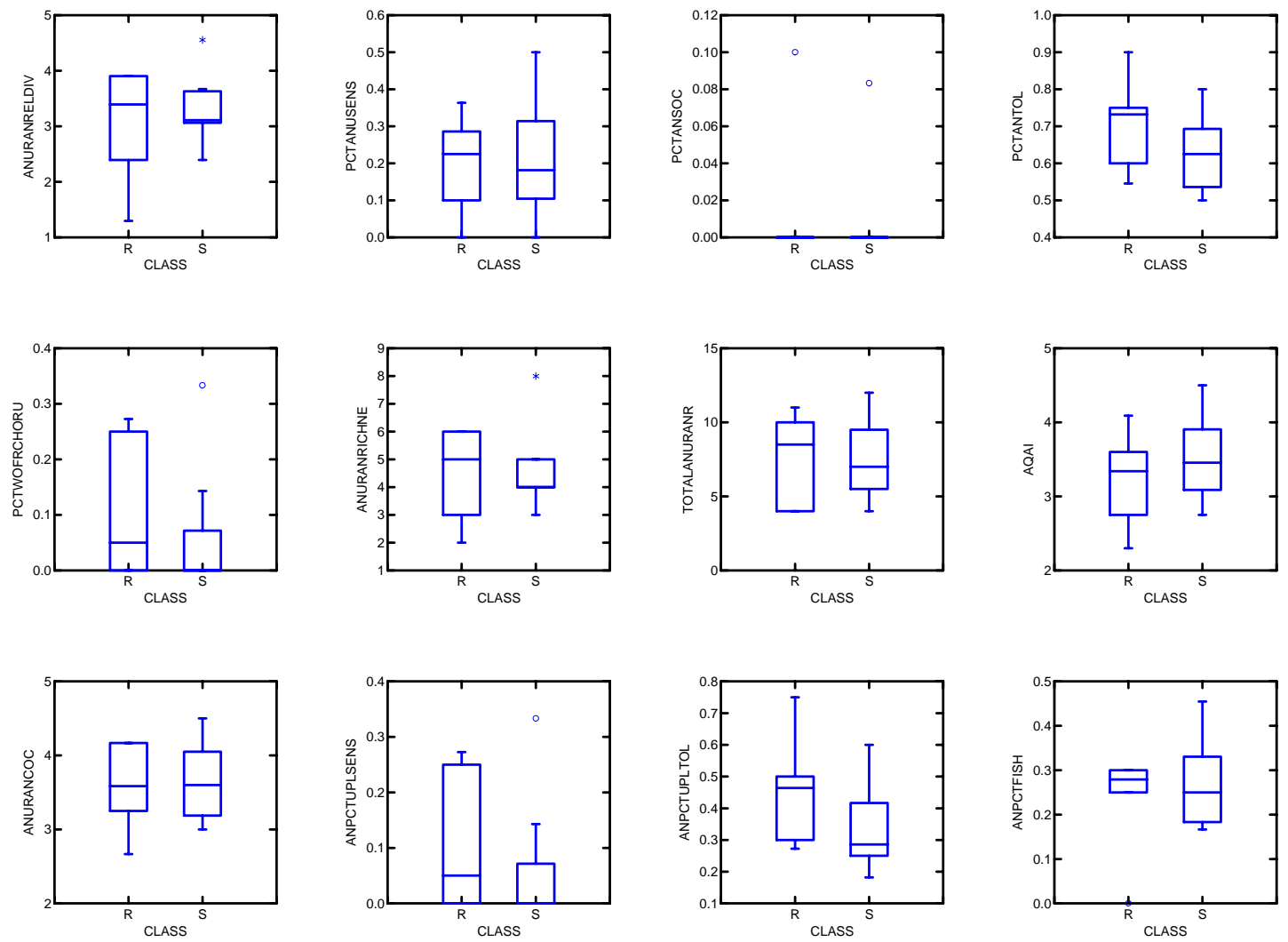

\begin{tabular}{lll} 
Metric Code & Metrics & Rating \\
\hline ANURANRELDIV & Anuran relative diversity & poor \\
PCTANUSENS & Proportion sensitive anurans & poor \\
PCTANSOC & Proportion species of concern anurans & poor \\
PCTANTOL & Proportion tolerant anurans & fair \\
PCTWOFRCHORU & Proportion of wood frog abundance & poor \\
ANURANRICHNE & Anuran richness & poor \\
TOTALANURANRE & Total anuran relative abundance & poor \\
AQAI & Amphibian Quality Assessment Index score & poor \\
ANURANCOC & Average coefficient of conservatism & poor \\
ANPCTUPLSENS & Proportion anuran upland sensitive & poor \\
ANPCTUPLTOL & Proportion anuran upland tolerant & poor \\
ANPCTFISH & Proportion anuran fish tolerant & poor \\
\hline
\end{tabular}


Appendix T. Anuran community metrics box-and-whisker results and narrative descriptions for riparian depression wetlands $(\mathrm{N}=24)$. Classifications are reference $(\mathrm{R})$ and stressed (S).
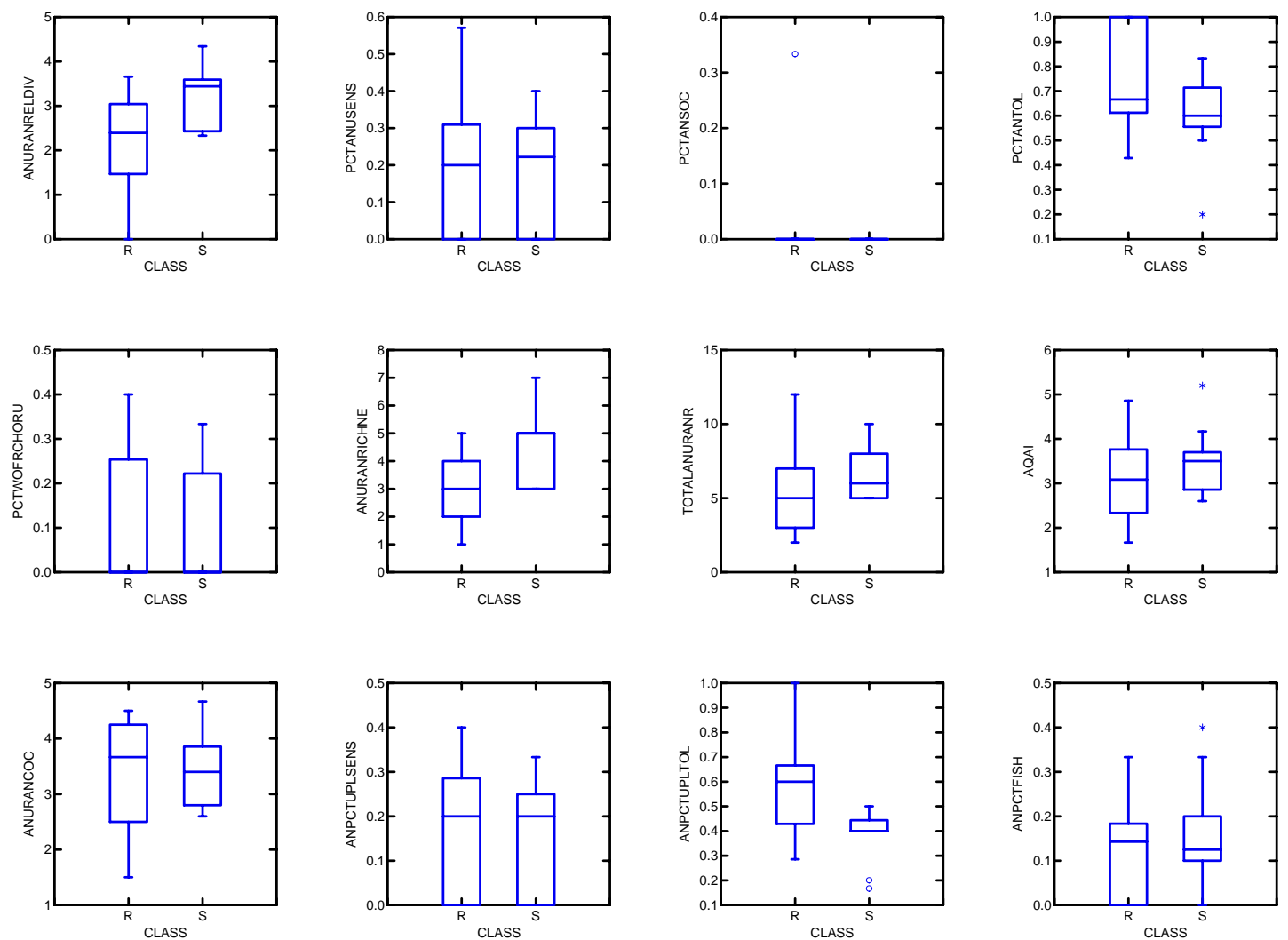

\begin{tabular}{l} 
Metric Code \\
\hline ANURANRELDIV \\
PCTANUSENS \\
PCTANSOC \\
PCTANTOL \\
PCTWOFRCHORU \\
ANURANRICHNE \\
TOTALANURANRE \\
AQAI \\
ANURANCOC \\
ANPCTUPLSENS \\
ANPCTUPLTOL \\
ANPCTFISH
\end{tabular}

Metrics

Rating

Anuran relative diversity

good

Proportion sensitive anurans

poor

Proportion species of concern anurans

poor

Proportion tolerant anurans

poor

Proportion of wood frog abundance poor

Anuran richness

fair

Total anuran relative abundance

poor

Amphibian Quality Assessment Index score

poor

Average coefficient of conservatism poor

Proportion anuran upland sensitive poor

Proportion anuran upland tolerant poor

Proportion anuran fish tolerant

poor 
Appendix U. Anuran community metrics box-and-whisker results and narrative descriptions for headwater floodplain wetlands $(\mathrm{N}=12)$. Classifications are reference $(\mathrm{R})$ and stressed (S).
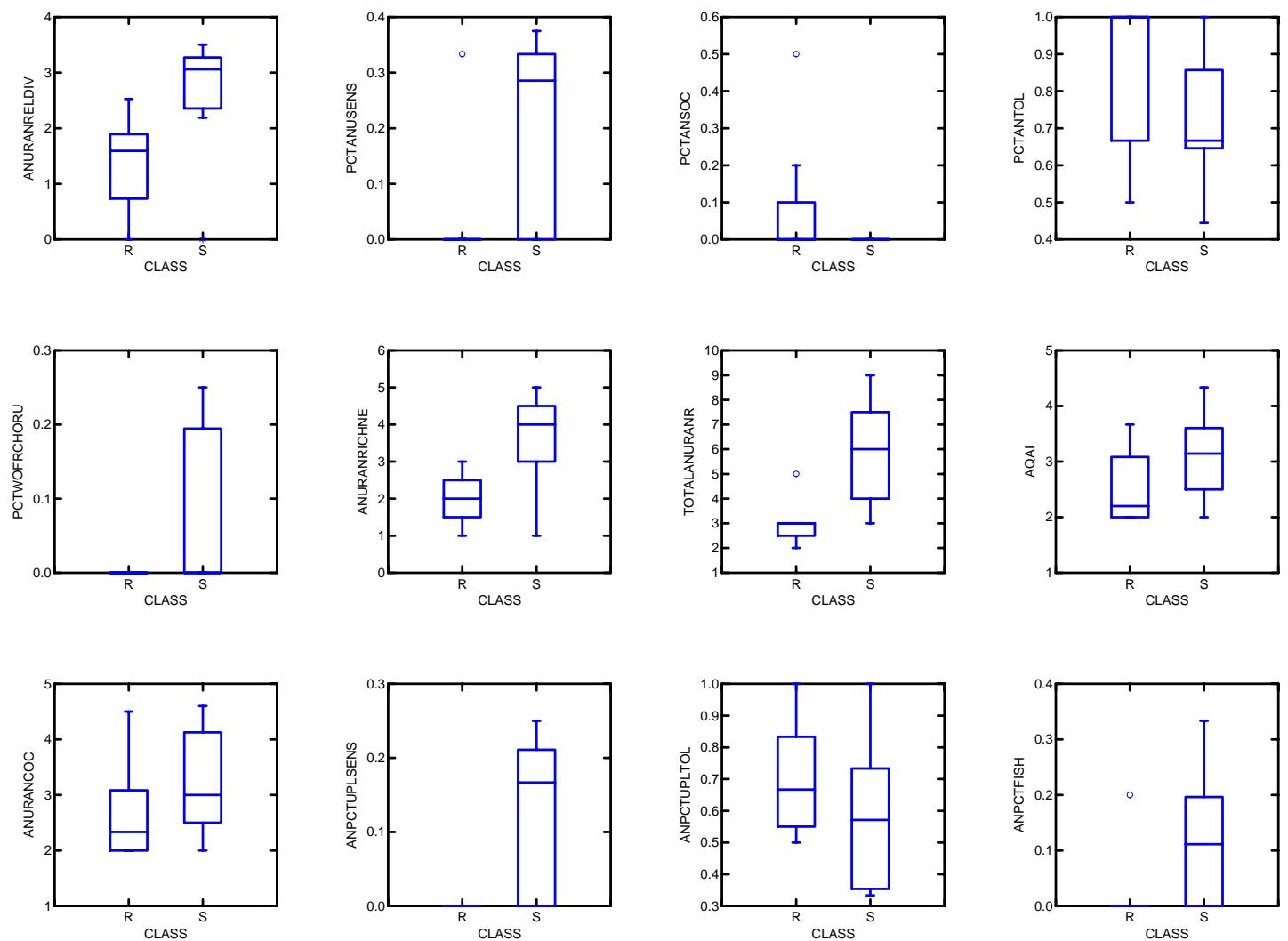

\begin{tabular}{lll} 
Metric Code & Metrics & Rating \\
\hline ANURANRELDIV & Anuran relative diversity & good \\
PCTANUSENS & Proportion sensitive anurans & poor \\
PCTANSOC & Proportion species of concern anurans & poor \\
PCTANTOL & Proportion tolerant anurans & poor \\
PCTWOFRCHORU & Proportion of wood frog abundance & poor \\
ANURANRICHNE & Anuran richness & good \\
TOTALANURANRE & Total anuran relative abundance & good \\
AQAI & Amphibian Quality Assessment Index score & poor \\
ANURANCOC & Average coefficient of conservatism & poor \\
ANPCTUPLSENS & Proportion anuran upland sensitive & poor \\
ANPCTUPLTOL & Proportion anuran upland tolerant & poor \\
ANPCTFISH & Proportion anuran fish tolerant & poor \\
\hline
\end{tabular}


Appendix V. Anuran community metrics box-and-whisker results and narrative descriptions for emergent wetlands $(\mathrm{N}=35)$. Classifications are reference $(\mathrm{R})$ and stressed $(\mathrm{S})$.
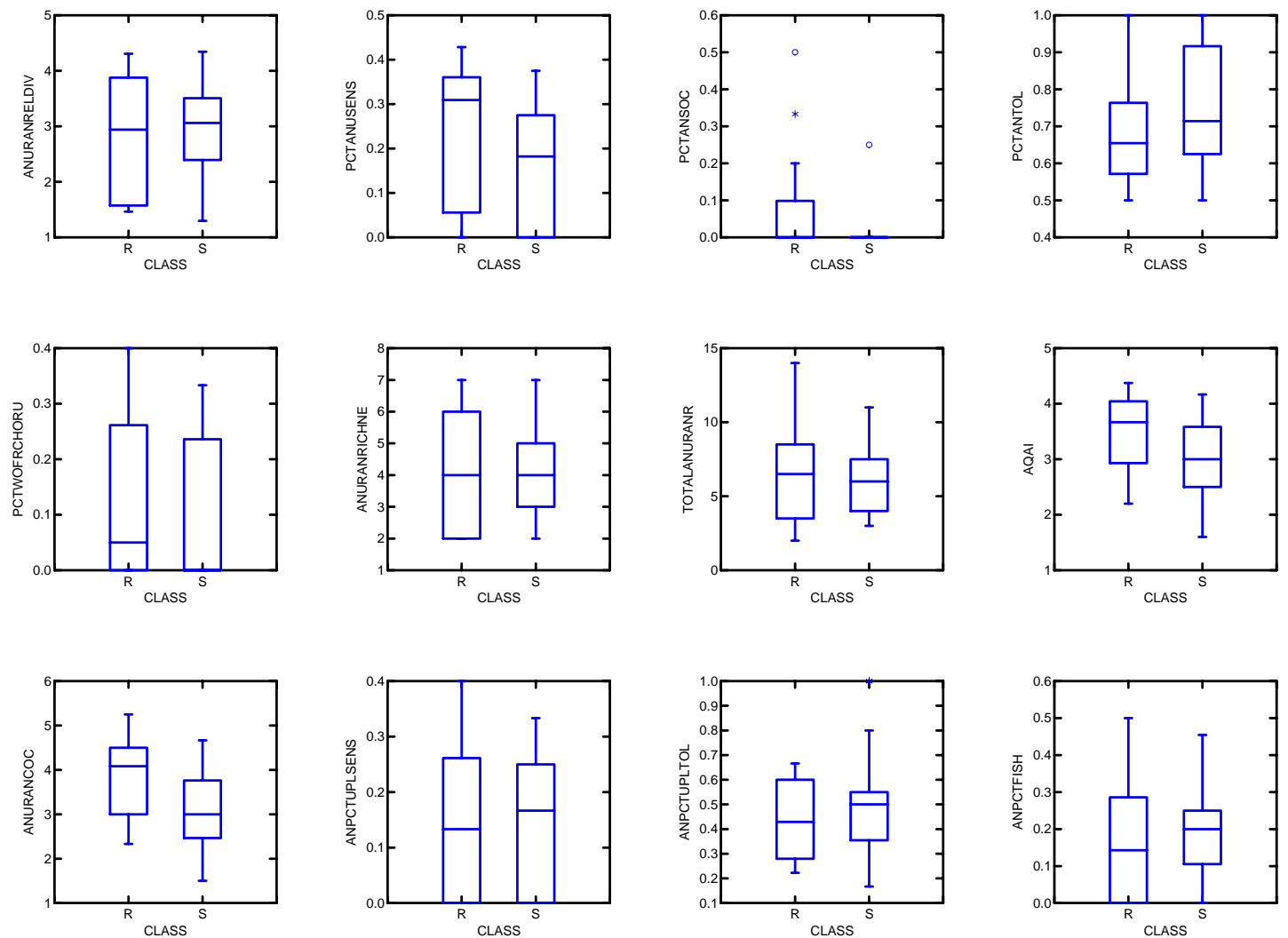

\begin{tabular}{lll} 
Metric Code & Metrics & Rating \\
\hline ANURANRELDIV & Anuran relative diversity & poor \\
PCTANUSENS & Proportion sensitive anurans & fair \\
PCTANSOC & Proportion species of concern anurans & poor \\
PCTANTOL & Proportion tolerant anurans & poor \\
PCTWOFRCHORU & Proportion of wood frog abundance & poor \\
ANURANRICHNE & Anuran richness & poor \\
TOTALANURANRE & Total anuran relative abundance & poor \\
AQAI & Amphibian Quality Assessment Index score & fair \\
ANURANCOC & Average coefficient of conservatism & fair \\
ANPCTUPLSENS & Proportion anuran upland sensitive & poor \\
ANPCTUPLTOL & Proportion anuran upland tolerant & poor \\
ANPCTFISH & Proportion anuran fish tolerant & poor \\
\hline
\end{tabular}


Appendix W. Anuran community metrics box-and-whisker results and narrative descriptions for scrub-shrub wetlands $(\mathrm{N}=18)$. Classifications are reference $(\mathrm{R})$ and stressed (S).
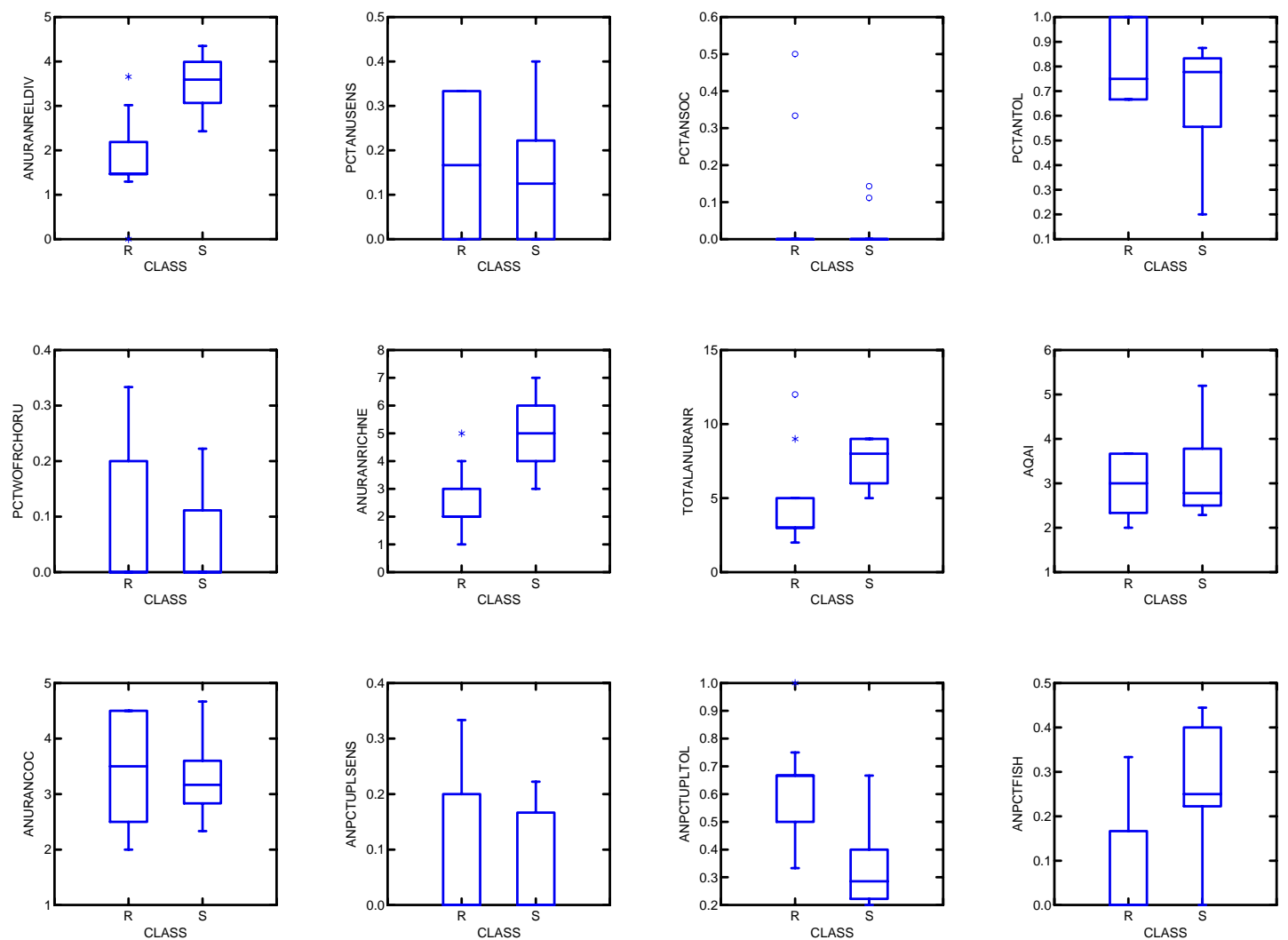

\begin{tabular}{lll} 
Metric Code & Metrics & Rating \\
\hline ANURANRELDIV & Anuran relative diversity & good \\
PCTANUSENS & Proportion sensitive anurans & poor \\
PCTANSOC & Proportion species of concern anurans & poor \\
PCTANTOL & Proportion tolerant anurans & poor \\
PCTWOFRCHORU & Proportion of wood frog abundance & poor \\
ANURANRICHNE & Anuran richness & good \\
TOTALANURANRE & Total anuran relative abundance & good \\
AQAI & Amphibian Quality Assessment Index score & poor \\
ANURANCOC & Average coefficient of conservatism & poor \\
ANPCTUPLSENS & Proportion anuran upland sensitive & poor \\
ANPCTUPLTOL & Proportion anuran upland tolerant & poor \\
ANPCTFISH & Proportion anuran fish tolerant & good \\
\hline
\end{tabular}


Appendix X. Anuran community metrics box-and-whisker results and narrative descriptions for forested wetlands $(\mathrm{N}=9)$. Classifications are reference $(\mathrm{R})$ and stressed $(\mathrm{S})$.
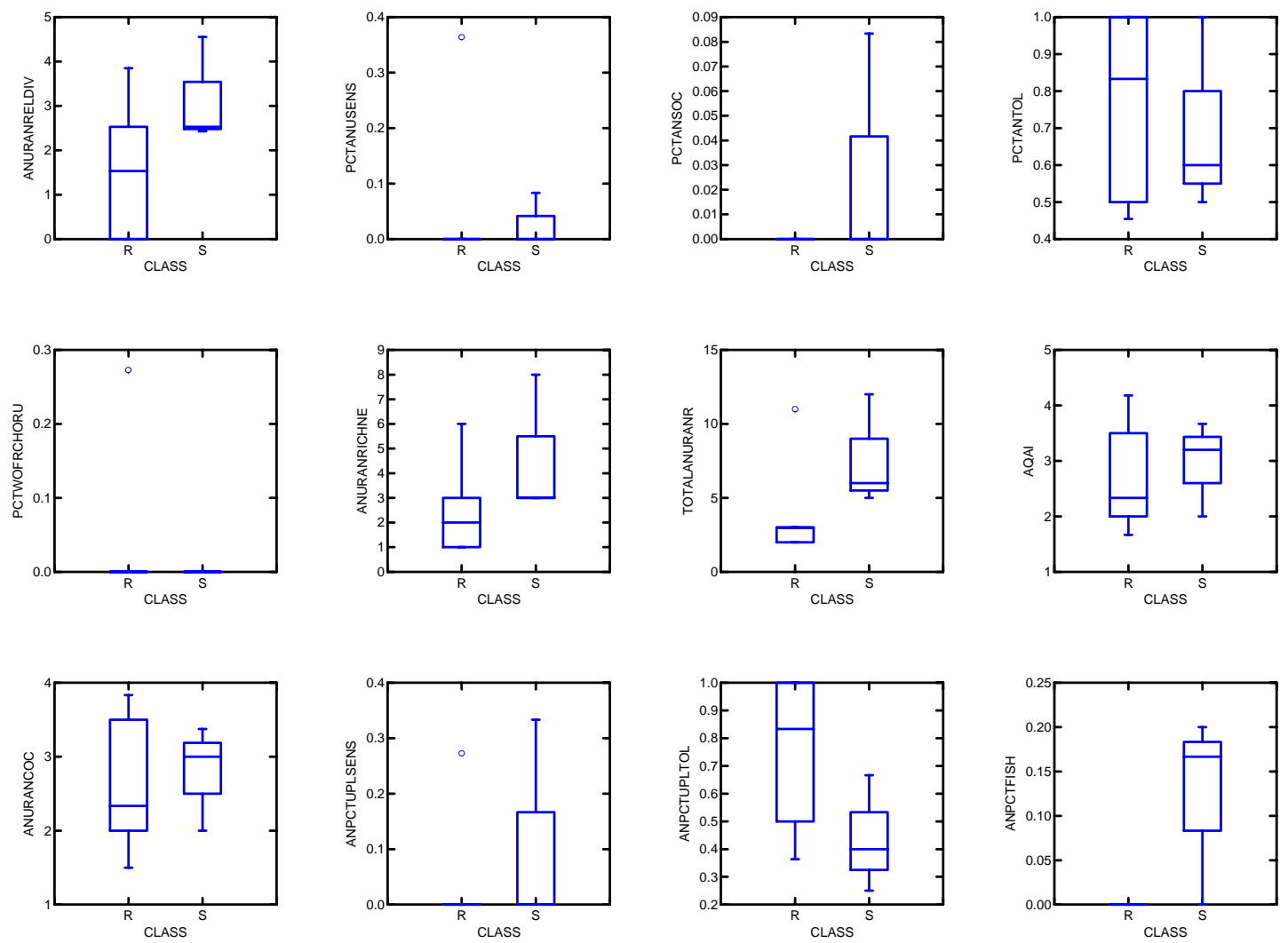

\begin{tabular}{lll} 
Metric Code & Metrics & Rating \\
\hline ANURANRELDIV & Anuran relative diversity & good \\
PCTANUSENS & Proportion sensitive anurans & poor \\
PCTANSOC & Proportion species of concern anurans & poor \\
PCTANTOL & Proportion tolerant anurans & fair \\
PCTWOFRCHORU & Proportion of wood frog abundance & poor \\
ANURANRICHNE & Anuran richness & good \\
TOTALANURANRE & Total anuran relative abundance & good \\
AQAI & Amphibian Quality Assessment Index score & fair \\
ANURANCOC & Average coefficient of conservatism & fair \\
ANPCTUPLSENS & Proportion anuran upland sensitive & poor \\
ANPCTUPLTOL & Proportion anuran upland tolerant & poor \\
ANPCTFISH & Proportion anuran fish tolerant & excellent \\
\hline
\end{tabular}


Appendix Y. Vegetation community metrics box-and-whisker results and narrative descriptions for depressional wetlands $(\mathrm{N}=37)$. Classifications are reference $(\mathrm{R})$ and stressed $(\mathrm{S})$.
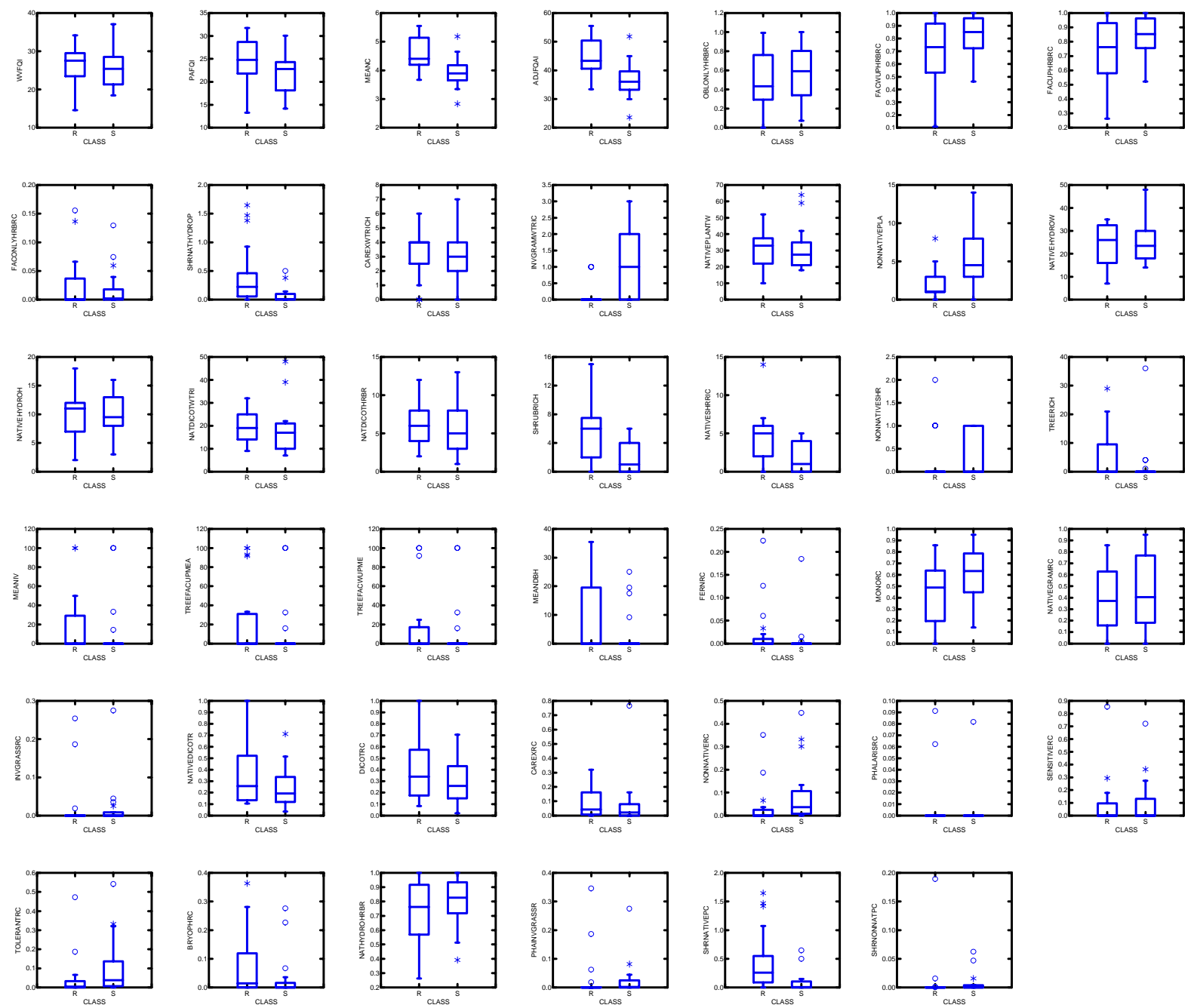
Appendix Y. Continued.

\begin{tabular}{|c|c|c|}
\hline Metric Code & Metric Description & Rating \\
\hline WVFQI & West Virginia Floristic Quality Index & poor \\
\hline PAFQI & Pennsylvania Floristic Quality Index & fair \\
\hline MEANC & Mean Coefficient of Conservatism & good \\
\hline ADJFQAI & Adjusted Floristic Quality Index & good \\
\hline OBLONLYHRBRC & Obligate only Herbaceous relative cover & poor \\
\hline FACWUPHRBRC & Facultative wet and wetter herbaceous relative cover & poor \\
\hline FACUPHRBRC & Facultative and wetter herbaceous relative cover & poor \\
\hline FACONLYHRBRC & Facultative only herbaceous relative cover & poor \\
\hline SHRNATHYDROP & Native shrub hydrophyte percent cover & poor \\
\hline CAREXWTRICH & Carex walk-through richness & poor \\
\hline INVGRAMWTRC & Invasive graminoid walk-through richness & poor \\
\hline NATIVEPLANTW & Native plant walk-through richness & poor \\
\hline NONNNATIVEPLANT & Non-native plant walk-through richness & good \\
\hline NATIVEHYDROW & Native hydrophyte walk-through richness & poor \\
\hline NATIVEHYDROH & Native hydrophyte herbaceous richness & poor \\
\hline NATDICOTWTRI & Native dicot walk-through richness & poor \\
\hline NATDICOTHRB & Native dicot herbaceous richness & poor \\
\hline SHRUBRICH & Shrub richness & good \\
\hline NATIVESHRRIC & Native shrub richness & good \\
\hline NONNATIVESHR & Non-native shrub richness & poor \\
\hline TREERICH & Tree richness & NA \\
\hline MEANIV & Mean Importance Value & poor \\
\hline TREEFACUPMEA & Tree facultative and wetter mean IV & poor \\
\hline TREEFACWUPME & Tree facultative wet and wetter meanIV & poor \\
\hline MEANDBH & Mean DBH & poor \\
\hline FERNRC & Fern relative cover & poor \\
\hline MONORC & Monocot relative cover & fair \\
\hline NATIVEGRAMRC & Native graminoid relative cover & poor \\
\hline INVGRASSRC & Invasive grass relative cover & poor \\
\hline NATIVEDICOTR & Native dicot relative cover & poor \\
\hline DICOTRC & Dicot relative cover & poor \\
\hline CAREXRC & Carex relative cover & poor \\
\hline NONNATIVERC & Non-native relative cover & poor \\
\hline PHALARISRC & Phalaris relative cover & poor \\
\hline SENSITIVERC & Sensitive species relative cover & poor \\
\hline TOLERANTRC & Tolerant species relative cover & good \\
\hline BRYOPHRC & Bryophyte relative cover & poor \\
\hline NATHYDROHRBRC & Native hydrophyte herbaceous relative cover & poor \\
\hline PHAINVGRASSR & Phalaris and invasive grasses relative cover & poor \\
\hline SHRNATIVEPC & Native shrub percent cover & good \\
\hline SHRNONNATPC & Non-native shrub percent cover & poor \\
\hline
\end{tabular}


Appendix Z. Vegetation community metrics box-and-whisker results s and narrative descriptions for floodplain wetlands $(\mathrm{N}=19)$. Classifications are reference $(\mathrm{R})$ and stressed $(\mathrm{S})$.
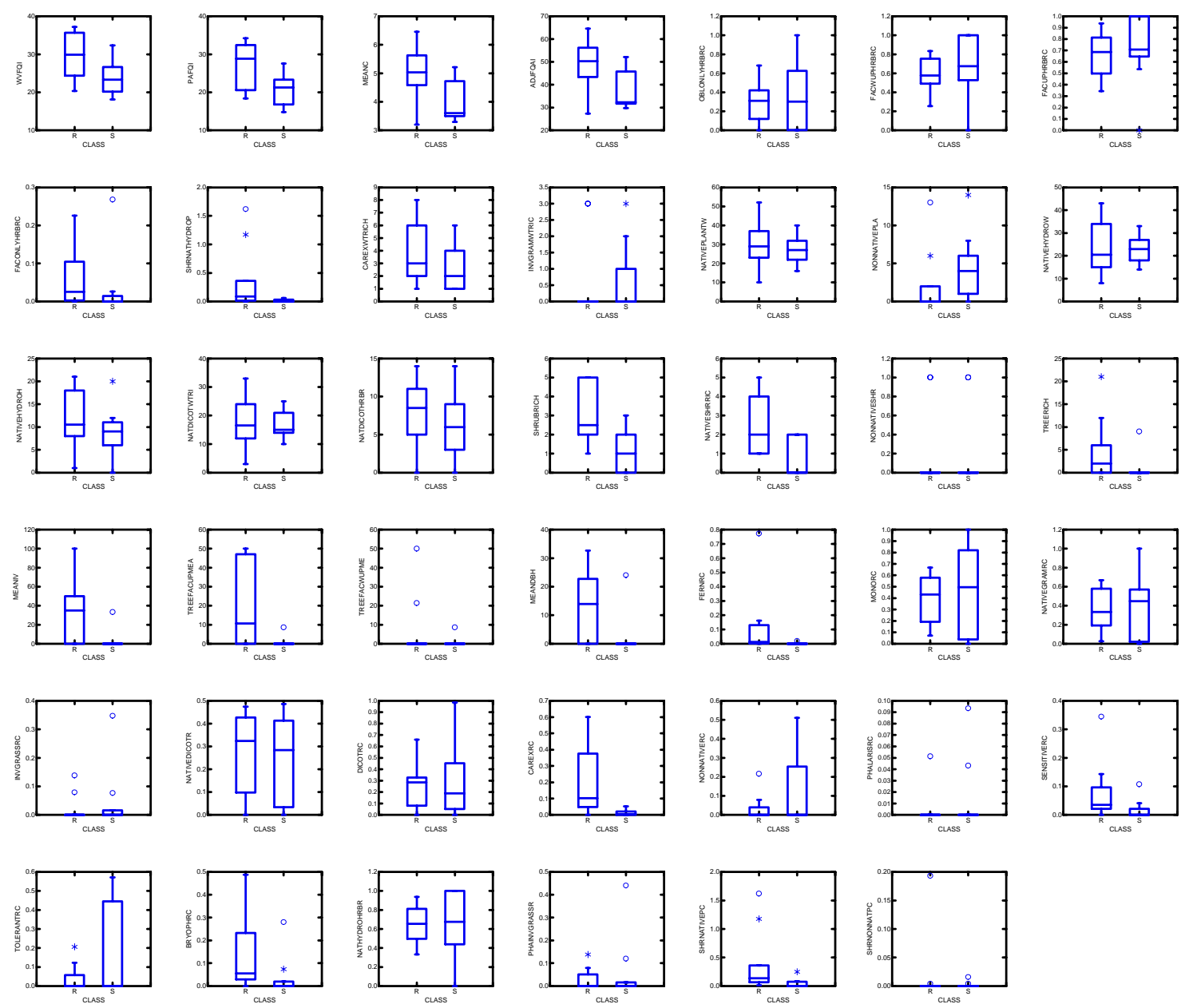
Appendix Z. Continued.

\begin{tabular}{|c|c|c|}
\hline Metric Code & Metric Description & Rating \\
\hline WVFQI & West Virginia Floristic Quality Index & good \\
\hline PAFQI & Pennsylvania Floristic Quality Index & fair \\
\hline MEANC & Mean Coefficient of Conservatism & good \\
\hline ADJFQAI & Adjusted Floristic Quality Index & good \\
\hline OBLONLYHRBRC & Obligate only Herbaceous relative cover & poor \\
\hline FACWUPHRBRC & $\begin{array}{l}\text { Facultative wet and wetter herbaceous relative } \\
\text { cover }\end{array}$ & poor \\
\hline FACUPHRBRC & Facultative and wetter herbaceous relative cover & poor \\
\hline FACONLYHRBRC & Facultative only herbaceous relative cover & poor \\
\hline SHRNATHYDROP & Native shrub hydrophyte percent cover & poor \\
\hline CAREXWTRICH & Carex walk-through richness & fair \\
\hline INVGRAMWTRC & Invasive graminoid walk-through richness & poor \\
\hline NATIVEPLANTW & Native plant walk-through richness & poor \\
\hline NONNNATIVEPLANT & Non-native plant walk-through richness & good \\
\hline NATIVEHYDROW & Native hydrophyte walk-through richness & poor \\
\hline NATIVEHYDROH & Native hydrophyte herbaceous richness & poor \\
\hline NATDICOTWTRI & Native dicot walk-through richness & poor \\
\hline NATDICOTHRB & Native dicot herbaceous richness & poor \\
\hline SHRUBRICH & Shrub richness & good \\
\hline NATIVESHRRIC & Native shrub richness & good \\
\hline NONNATIVESHR & Non-native shrub richness & poor \\
\hline TREERICH & Tree richness & $\mathrm{NA}$ \\
\hline MEANIV & Mean Importance Value & good \\
\hline TREEFACUPMEA & Tree facultative and wetter mean IV & good \\
\hline TREEFACWUPME & Tree facultative wet and wetter meanIV & poor \\
\hline MEANDBH & Mean DBH & good \\
\hline FERNRC & Fern relative cover & poor \\
\hline MONORC & Monocot relative cover & poor \\
\hline NATIVEGRAMRC & Native graminoid relative cover & poor \\
\hline INVGRASSRC & Invasive grass relative cover & poor \\
\hline NATIVEDICOTR & Native dicot relative cover & poor \\
\hline DICOTRC & Dicot relative cover & poor \\
\hline CAREXRC & Carex relative cover & good \\
\hline NONNATIVERC & Non-native relative cover & good \\
\hline PHALARISRC & Phalaris relative cover & poor \\
\hline SENSITIVERC & Sensitive species relative cover & good \\
\hline TOLERANTRC & Tolerant species relative cover & good \\
\hline BRYOPHRC & Bryophyte relative cover & good \\
\hline NATHYDROHRBRC & Native hydrophyte herbaceous relative cover & poor \\
\hline PHAINVGRASSR & Phalaris and invasive grasses relative cover & poor \\
\hline SHRNATIVEPC & Native shrub percent cover & good \\
\hline SHRNONNATPC & Non-native shrub percent cover & poor \\
\hline
\end{tabular}


Appendix AA. Vegetation community metrics box-and-whisker results and narrative descriptions for impoundment wetlands $(\mathrm{N}=13)$. Classifications are reference $(\mathrm{R})$ and stressed (S).
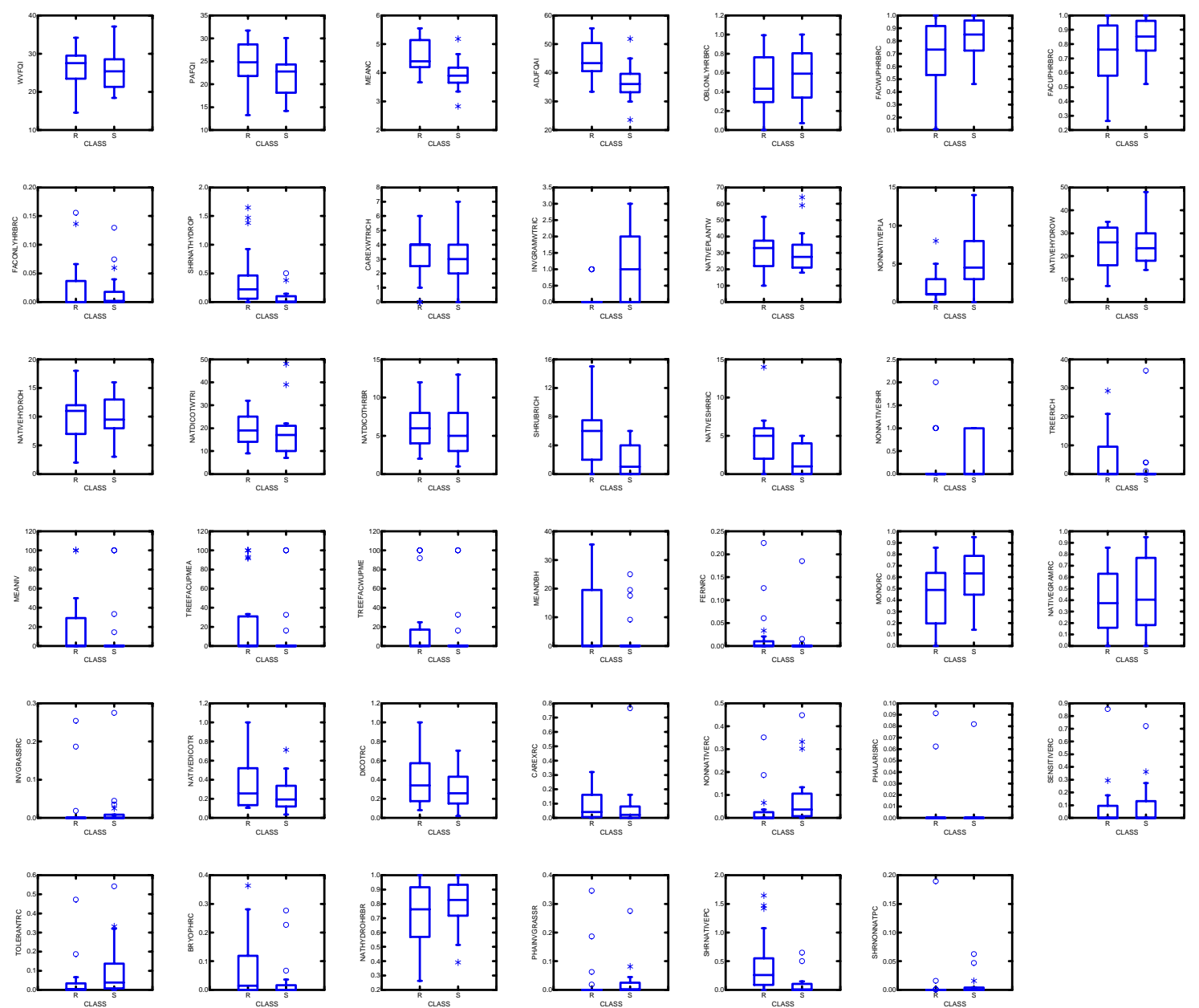
Appendix AA. Continued.

\begin{tabular}{|c|c|c|}
\hline Metric Code & Metric Description & Rating \\
\hline WVFQI & West Virginia Floristic Quality Index & good \\
\hline PAFQI & Pennsylvania Floristic Quality Index & good \\
\hline MEANC & Mean Coefficient of Conservatism & good \\
\hline ADJFQAI & Adjusted Floristic Quality Index & good \\
\hline OBLONLYHRBRC & Obligate only Herbaceous relative cover & poor \\
\hline FACWUPHRBRC & $\begin{array}{l}\text { Facultative wet and wetter herbaceous relative } \\
\text { cover }\end{array}$ & poor \\
\hline FACUPHRBRC & Facultative and wetter herbaceous relative cover & poor \\
\hline FACONLYHRBRC & Facultative only herbaceous relative cover & poor \\
\hline SHRNATHYDROP & Native shrub hydrophyte percent cover & poor \\
\hline CAREXWTRICH & Carex walk-through richness & poor \\
\hline INVGRAMWTRC & Invasive graminoid walk-through richness & poor \\
\hline NATIVEPLANTW & Native plant walk-through richness & poor \\
\hline NONNNATIVEPLANT & Non-native plant walk-through richness & poor \\
\hline NATIVEHYDROW & Native hydrophyte walk-through richness & poor \\
\hline NATIVEHYDROH & Native hydrophyte herbaceous richness & good \\
\hline NATDICOTWTRI & Native dicot walk-through richness & poor \\
\hline NATDICOTHRB & Native dicot herbaceous richness & good \\
\hline SHRUBRICH & Shrub richness & poor \\
\hline NATIVESHRRIC & Native shrub richness & poor \\
\hline NONNATIVESHR & Non-native shrub richness & poor \\
\hline TREERICH & Tree richness & NA \\
\hline MEANIV & Mean Importance Value & poor \\
\hline TREEFACUPMEA & Tree facultative and wetter mean IV & poor \\
\hline TREEFACWUPME & Tree facultative wet and wetter meanIV & poor \\
\hline MEANDBH & Mean DBH & poor \\
\hline FERNRC & Fern relative cover & poor \\
\hline MONORC & Monocot relative cover & good \\
\hline NATIVEGRAMRC & Native graminoid relative cover & poor \\
\hline INVGRASSRC & Invasive grass relative cover & poor \\
\hline NATIVEDICOTR & Native dicot relative cover & poor \\
\hline DICOTRC & Dicot relative cover & good \\
\hline CAREXRC & Carex relative cover & good \\
\hline NONNATIVERC & Non-native relative cover & poor \\
\hline PHALARISRC & Phalaris relative cover & poor \\
\hline SENSITIVERC & Sensitive species relative cover & poor \\
\hline TOLERANTRC & Tolerant species relative cover & poor \\
\hline BRYOPHRC & Bryophyte relative cover & poor \\
\hline NATHYDROHRBRC & Native hydrophyte herbaceous relative cover & poor \\
\hline PHAINVGRASSR & Phalaris and invasive grasses relative cover & poor \\
\hline SHRNATIVEPC & Native shrub percent cover & poor \\
\hline SHRNONNATPC & Non-native shrub percent cover & poor \\
\hline
\end{tabular}


Appendix AB. Vegetation community metrics box-and-whisker results and narrative descriptions for emergent wetlands $(\mathrm{N}=38)$. Classifications are reference $(\mathrm{R})$ and stressed $(\mathrm{S})$.
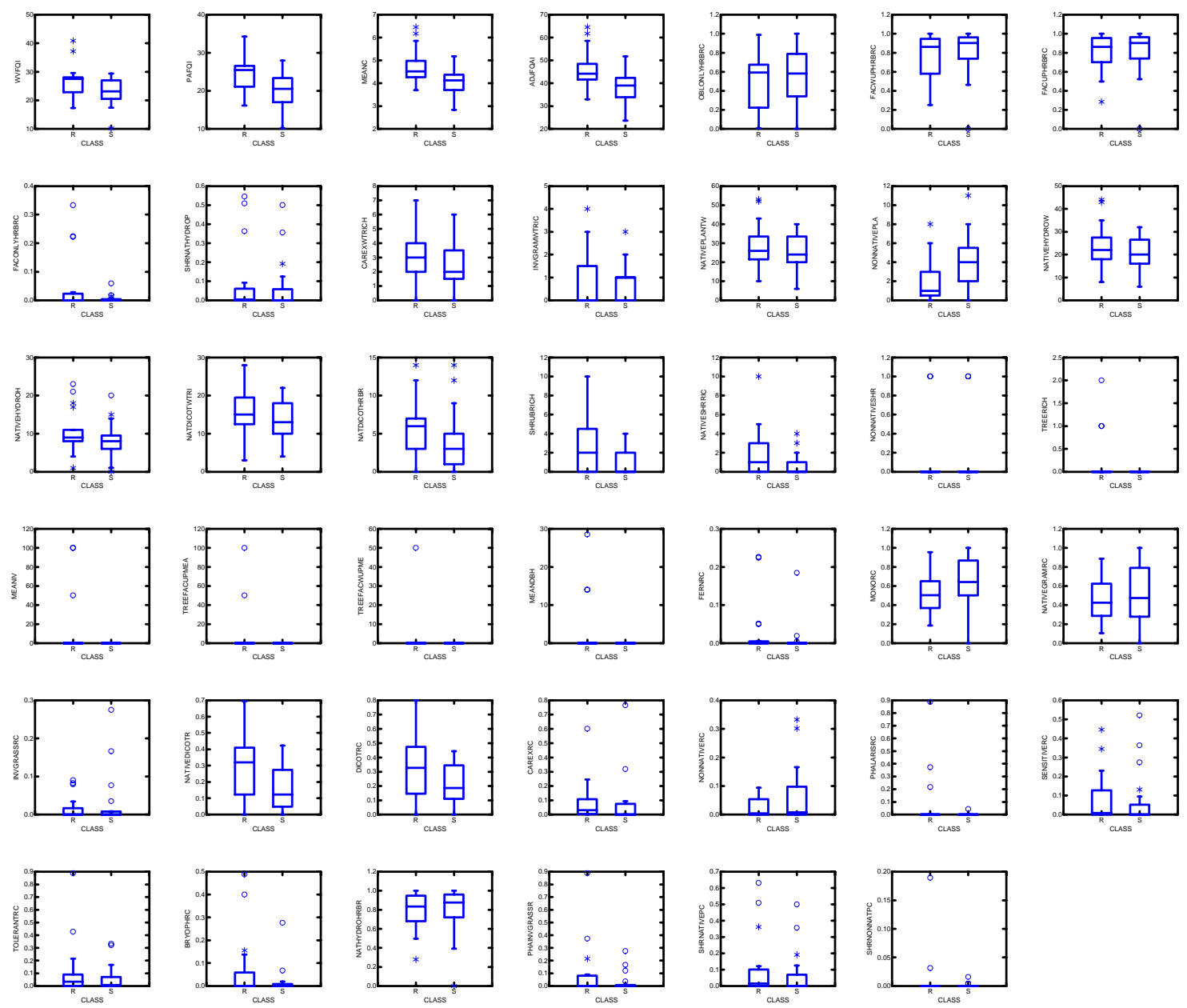
Appendix AB. Continued.

\begin{tabular}{|c|c|c|}
\hline Metric Code & Metric Description & Rating \\
\hline WVFQI & West Virginia Floristic Quality Index & good \\
\hline PAFQI & Pennsylvania Floristic Quality Index & good \\
\hline MEANC & Mean Coefficient of Conservatism & good \\
\hline ADJFQAI & Adjusted Floristic Quality Index & good \\
\hline OBLONLYHRBRC & Obligate only Herbaceous relative cover & poor \\
\hline FACWUPHRBRC & $\begin{array}{l}\text { Facultative wet and wetter herbaceous relative } \\
\text { cover }\end{array}$ & poor \\
\hline FACUPHRBRC & Facultative and wetter herbaceous relative cover & poor \\
\hline FACONLYHRBRC & Facultative only herbaceous relative cover & poor \\
\hline SHRNATHYDROP & Native shrub hydrophyte percent cover & poor \\
\hline CAREXWTRICH & Carex walk-through richness & fair \\
\hline INVGRAMWTRC & Invasive graminoid walk-through richness & poor \\
\hline NATIVEPLANTW & Native plant walk-through richness & poor \\
\hline NONNNATIVEPLANT & Non-native plant walk-through richness & good \\
\hline NATIVEHYDROW & Native hydrophyte walk-through richness & poor \\
\hline NATIVEHYDROH & Native hydrophyte herbaceous richness & poor \\
\hline NATDICOTWTRI & Native dicot walk-through richness & fair \\
\hline NATDICOTHRB & Native dicot herbaceous richness & good \\
\hline SHRUBRICH & Shrub richness & poor \\
\hline NATIVESHRRIC & Native shrub richness & poor \\
\hline NONNATIVESHR & Non-native shrub richness & poor \\
\hline TREERICH & Tree richness & NA \\
\hline MEANIV & Mean Importance Value & poor \\
\hline TREEFACUPMEA & Tree facultative and wetter mean IV & poor \\
\hline TREEFACWUPME & Tree facultative wet and wetter meanIV & poor \\
\hline MEANDBH & Mean DBH & poor \\
\hline FERNRC & Fern relative cover & poor \\
\hline MONORC & Monocot relative cover & fair \\
\hline NATIVEGRAMRC & Native graminoid relative cover & poor \\
\hline INVGRASSRC & Invasive grass relative cover & poor \\
\hline NATIVEDICOTR & Native dicot relative cover & good \\
\hline DICOTRC & Dicot relative cover & poor \\
\hline CAREXRC & Carex relative cover & poor \\
\hline NONNATIVERC & Non-native relative cover & poor \\
\hline PHALARISRC & Phalaris relative cover & poor \\
\hline SENSITIVERC & Sensitive species relative cover & poor \\
\hline TOLERANTRC & Tolerant species relative cover & poor \\
\hline BRYOPHRC & Bryophyte relative cover & poor \\
\hline NATHYDROHRBRC & Native hydrophyte herbaceous relative cover & poor \\
\hline PHAINVGRASSR & Phalaris and invasive grasses relative cover & poor \\
\hline SHRNATIVEPC & Native shrub percent cover & poor \\
\hline SHRNONNATPC & Non-native shrub percent cover & poor \\
\hline
\end{tabular}


Appendix AC. Vegetation community metrics box-and-whisker results and narrative descriptions for scrub-shrub wetlands $(\mathrm{N}=23)$. Classifications are reference $(\mathrm{R})$ and stressed $(\mathrm{S})$.

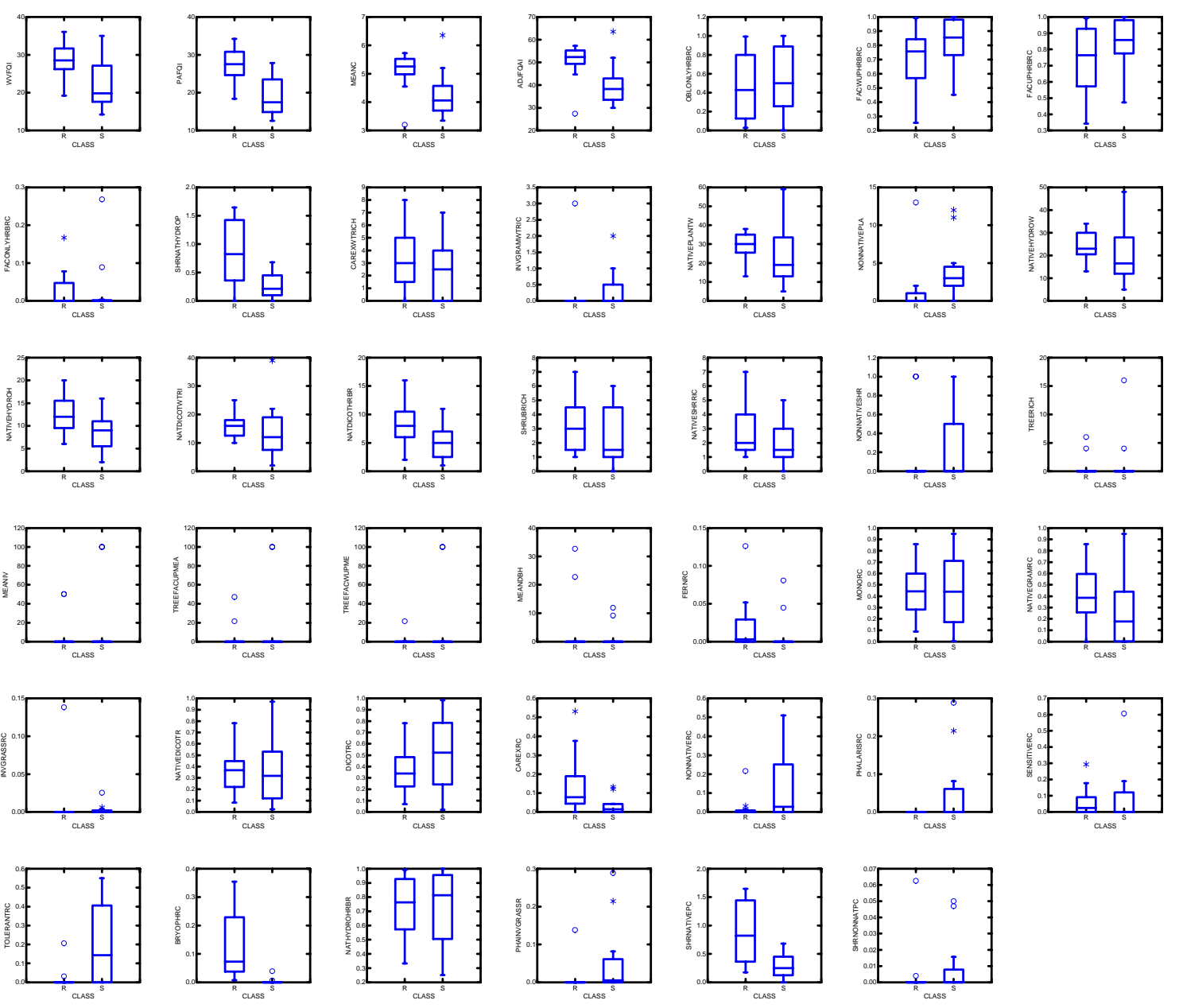


Appendix AC. Continued.

\begin{tabular}{|c|c|c|}
\hline Metric Code & Metric Description & Rating \\
\hline WVFQI & West Virginia Floristic Quality Index & good \\
\hline PAFQI & Pennsylvania Floristic Quality Index & good \\
\hline MEANC & Mean Coefficient of Conservatism & good \\
\hline ADJFQAI & Adjusted Floristic Quality Index & good \\
\hline OBLONLYHRBRC & Obligate only Herbaceous relative cover & poor \\
\hline FACWUPHRBRC & $\begin{array}{l}\text { Facultative wet and wetter herbaceous relative } \\
\text { cover }\end{array}$ & poor \\
\hline FACUPHRBRC & Facultative and wetter herbaceous relative cover & poor \\
\hline FACONLYHRBRC & Facultative only herbaceous relative cover & poor \\
\hline SHRNATHYDROP & Native shrub hydrophyte percent cover & good \\
\hline CAREXWTRICH & Carex walk-through richness & poor \\
\hline INVGRAMWTRC & Invasive graminoid walk-through richness & poor \\
\hline NATIVEPLANTW & Native plant walk-through richness & fair \\
\hline NONNNATIVEPLANT & Non-native plant walk-through richness & good \\
\hline NATIVEHYDROW & Native hydrophyte walk-through richness & fair \\
\hline NATIVEHYDROH & Native hydrophyte herbaceous richness & good \\
\hline NATDICOTWTRI & Native dicot walk-through richness & fair \\
\hline NATDICOTHRB & Native dicot herbaceous richness & poor \\
\hline SHRUBRICH & Shrub richness & poor \\
\hline NATIVESHRRIC & Native shrub richness & poor \\
\hline NONNATIVESHR & Non-native shrub richness & poor \\
\hline TREERICH & Tree richness & NA \\
\hline MEANIV & Mean Importance Value & poor \\
\hline TREEFACUPMEA & Tree facultative and wetter mean IV & poor \\
\hline TREEFACWUPME & Tree facultative wet and wetter meanIV & poor \\
\hline MEANDBH & Mean DBH & poor \\
\hline FERNRC & Fern relative cover & poor \\
\hline MONORC & Monocot relative cover & poor \\
\hline NATIVEGRAMRC & Native graminoid relative cover & fair \\
\hline INVGRASSRC & Invasive grass relative cover & poor \\
\hline NATIVEDICOTR & Native dicot relative cover & poor \\
\hline DICOTRC & Dicot relative cover & fair \\
\hline CAREXRC & Carex relative cover & good \\
\hline NONNATIVERC & Non-native relative cover & poor \\
\hline PHALARISRC & Phalaris relative cover & poor \\
\hline SENSITIVERC & Sensitive species relative cover & poor \\
\hline TOLERANTRC & Tolerant species relative cover & good \\
\hline BRYOPHRC & Bryophyte relative cover & good \\
\hline NATHYDROHRBRC & Native hydrophyte herbaceous relative cover & poor \\
\hline PHAINVGRASSR & Phalaris and invasive grasses relative cover & poor \\
\hline SHRNATIVEPC & Native shrub percent cover & good \\
\hline SHRNONNATPC & Non-native shrub percent cover & poor \\
\hline
\end{tabular}


Appendix AD. Vegetation community metrics box-and-whisker results and narrative descriptions for forested wetlands $(\mathrm{N}=16)$. Classifications are reference $(\mathrm{R})$ and stressed $(\mathrm{S})$.

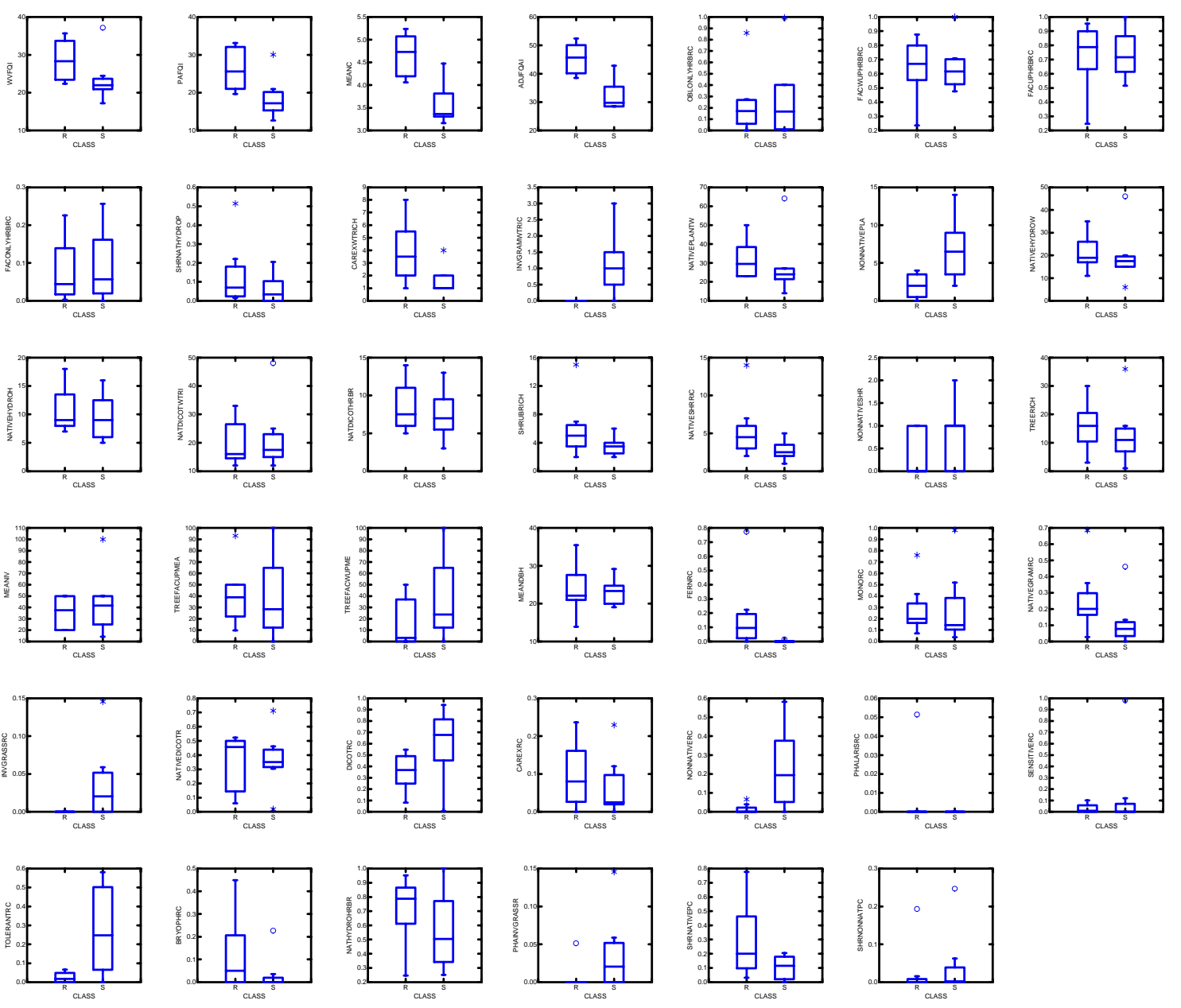


Appendix AD. Continued.

\begin{tabular}{|c|c|c|}
\hline Metric Code & Metric Description & Rating \\
\hline WVFQI & West Virginia Floristic Quality Index & good \\
\hline PAFQI & Pennsylvania Floristic Quality Index & good \\
\hline MEANC & Mean Coefficient of Conservatism & good \\
\hline ADJFQAI & Adjusted Floristic Quality Index & good \\
\hline OBLONLYHRBRC & Obligate only Herbaceous relative cover & poor \\
\hline FACWUPHRBRC & $\begin{array}{l}\text { Facultative wet and wetter herbaceous relative } \\
\text { cover }\end{array}$ & poor \\
\hline FACUPHRBRC & Facultative and wetter herbaceous relative cover & poor \\
\hline FACONLYHRBRC & Facultative only herbaceous relative cover & poor \\
\hline SHRNATHYDROP & Native shrub hydrophyte percent cover & poor \\
\hline CAREXWTRICH & Carex walk-through richness & good \\
\hline INVGRAMWTRC & Invasive graminoid walk-through richness & good \\
\hline NATIVEPLANTW & Native plant walk-through richness & good \\
\hline NONNNATIVEPLANT & Non-native plant walk-through richness & good \\
\hline NATIVEHYDROW & Native hydrophyte walk-through richness & poor \\
\hline NATIVEHYDROH & Native hydrophyte herbaceous richness & poor \\
\hline NATDICOTWTRI & Native dicot walk-through richness & poor \\
\hline NATDICOTHRB & Native dicot herbaceous richness & poor \\
\hline SHRUBRICH & Shrub richness & fair \\
\hline NATIVESHRRIC & Native shrub richness & good \\
\hline NONNATIVESHR & Non-native shrub richness & poor \\
\hline TREERICH & Tree richness & NA \\
\hline MEANIV & Mean Importance Value & poor \\
\hline TREEFACUPMEA & Tree facultative and wetter mean IV & poor \\
\hline TREEFACWUPME & Tree facultative wet and wetter meanIV & poor \\
\hline MEANDBH & Mean DBH & poor \\
\hline FERNRC & Fern relative cover & good \\
\hline MONORC & Monocot relative cover & fair \\
\hline NATIVEGRAMRC & Native graminoid relative cover & good \\
\hline INVGRASSRC & Invasive grass relative cover & good \\
\hline NATIVEDICOTR & Native dicot relative cover & fair \\
\hline DICOTRC & Dicot relative cover & good \\
\hline CAREXRC & Carex relative cover & fair \\
\hline NONNATIVERC & Non-native relative cover & good \\
\hline PHALARISRC & Phalaris relative cover & poor \\
\hline SENSITIVERC & Sensitive species relative cover & poor \\
\hline TOLERANTRC & Tolerant species relative cover & good \\
\hline BRYOPHRC & Bryophyte relative cover & good \\
\hline NATHYDROHRBRC & Native hydrophyte herbaceous relative cover & good \\
\hline PHAINVGRASSR & Phalaris and invasive grasses relative cover & good \\
\hline SHRNATIVEPC & Native shrub percent cover & fair \\
\hline SHRNONNATPC & Non-native shrub percent cover & poor \\
\hline
\end{tabular}


Appendix AE. Vegetation community metrics box-and-whisker results and narrative descriptions for riparian depression wetlands $(\mathrm{N}=27)$. Classifications are reference $(\mathrm{R})$ and stressed (S).

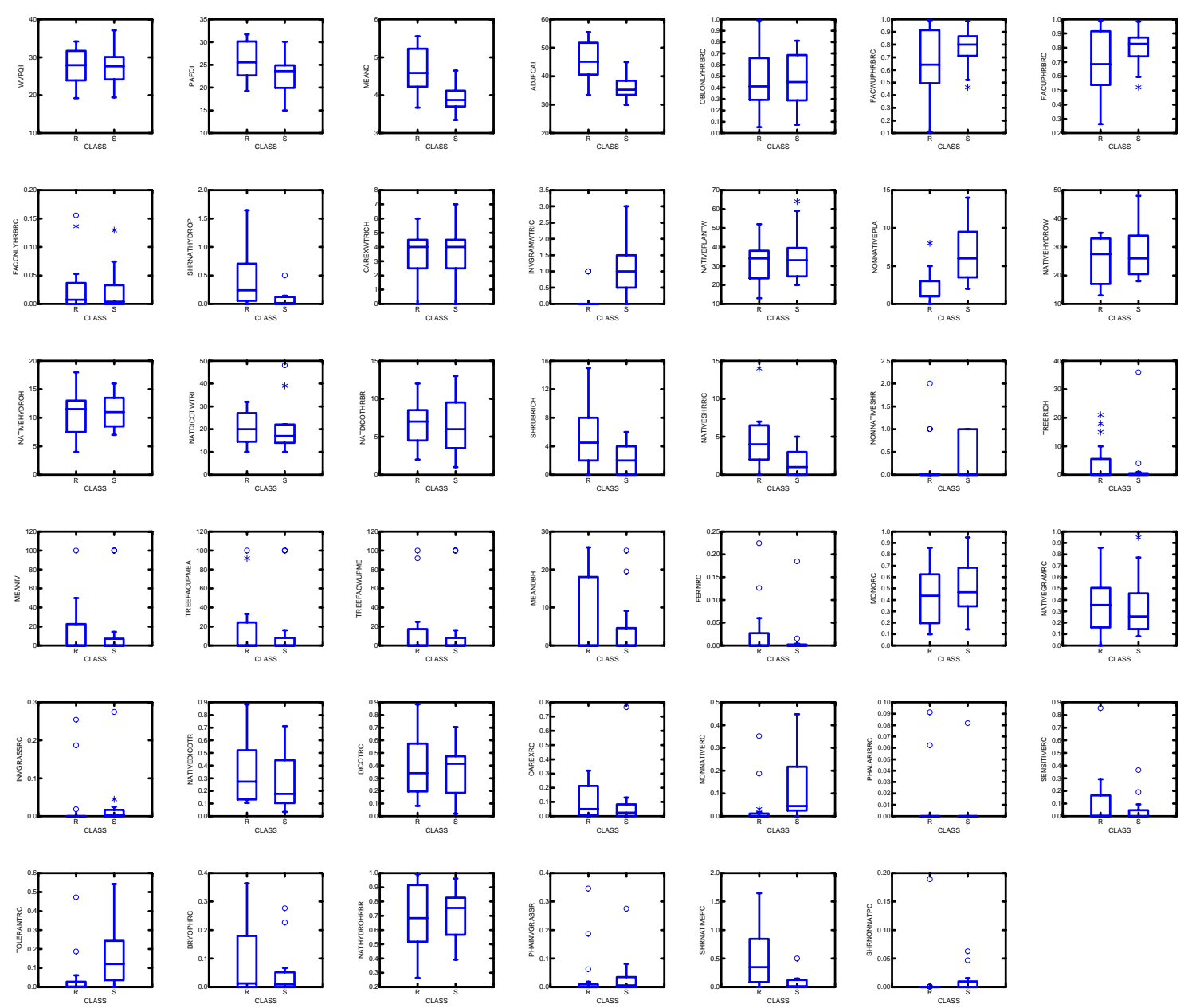


Appendix AE. Continued.

\begin{tabular}{|c|c|c|}
\hline Metric Code & Metric Description & Rating \\
\hline WVFQI & West Virginia Floristic Quality Index & poor \\
\hline PAFQI & Pennsylvania Floristic Quality Index & poor \\
\hline MEANC & Mean Coefficient of Conservatism & excellent \\
\hline ADJFQAI & Adjusted Floristic Quality Index & excellent \\
\hline OBLONLYHRBRC & Obligate only Herbaceous relative cover & poor \\
\hline FACWUPHRBRC & $\begin{array}{l}\text { Facultative wet and wetter herbaceous relative } \\
\text { cover }\end{array}$ & fair \\
\hline FACUPHRBRC & Facultative and wetter herbaceous relative cover & fair \\
\hline FACONLYHRBRC & Facultative only herbaceous relative cover & poor \\
\hline SHRNATHYDROP & Native shrub hydrophyte percent cover & fair \\
\hline CAREXWTRICH & Carex walk-through richness & poor \\
\hline INVGRAMWTRC & Invasive graminoid walk-through richness & fair \\
\hline NATIVEPLANTW & Native plant walk-through richness & fair \\
\hline NONNNATIVEPLANT & Non-native plant walk-through richness & excellent \\
\hline NATIVEHYDROW & Native hydrophyte walk-through richness & poor \\
\hline NATIVEHYDROH & Native hydrophyte herbaceous richness & poor \\
\hline NATDICOTWTRI & Native dicot walk-through richness & poor \\
\hline NATDICOTHRB & Native dicot herbaceous richness & poor \\
\hline SHRUBRICH & Shrub richness & fair \\
\hline NATIVESHRRIC & Native shrub richness & good \\
\hline NONNATIVESHR & Non-native shrub richness & poor \\
\hline TREERICH & Tree richness & poor \\
\hline MEANIV & Mean Importance Value & poor \\
\hline TREEFACUPMEA & Tree facultative and wetter mean IV & poor \\
\hline TREEFACWUPME & Tree facultative wet and wetter meanIV & poor \\
\hline MEANDBH & Mean DBH & poor \\
\hline FERNRC & Fern relative cover & poor \\
\hline MONORC & Monocot relative cover & poor \\
\hline NATIVEGRAMRC & Native graminoid relative cover & poor \\
\hline INVGRASSRC & Invasive grass relative cover & poor \\
\hline NATIVEDICOTR & Native dicot relative cover & poor \\
\hline DICOTRC & Dicot relative cover & poor \\
\hline CAREXRC & Carex relative cover & poor \\
\hline NONNATIVERC & Non-native relative cover & fair \\
\hline PHALARISRC & Phalaris relative cover & poor \\
\hline SENSITIVERC & Sensitive species relative cover & poor \\
\hline TOLERANTRC & Tolerant species relative cover & good \\
\hline BRYOPHRC & Bryophyte relative cover & poor \\
\hline NATHYDROHRBRC & Native hydrophyte herbaceous relative cover & poor \\
\hline PHAINVGRASSR & Phalaris and invasive grasses relative cover & poor \\
\hline SHRNATIVEPC & Native shrub percent cover & good \\
\hline SHRNONNATPC & Non-native shrub percent cover & poor \\
\hline
\end{tabular}


Appendix AF. Vegetation community metrics box-and-whisker results and narrative descriptions for headwater floodplain wetlands $(\mathrm{N}=16)$. Classifications are reference $(\mathrm{R})$ and stressed (S).
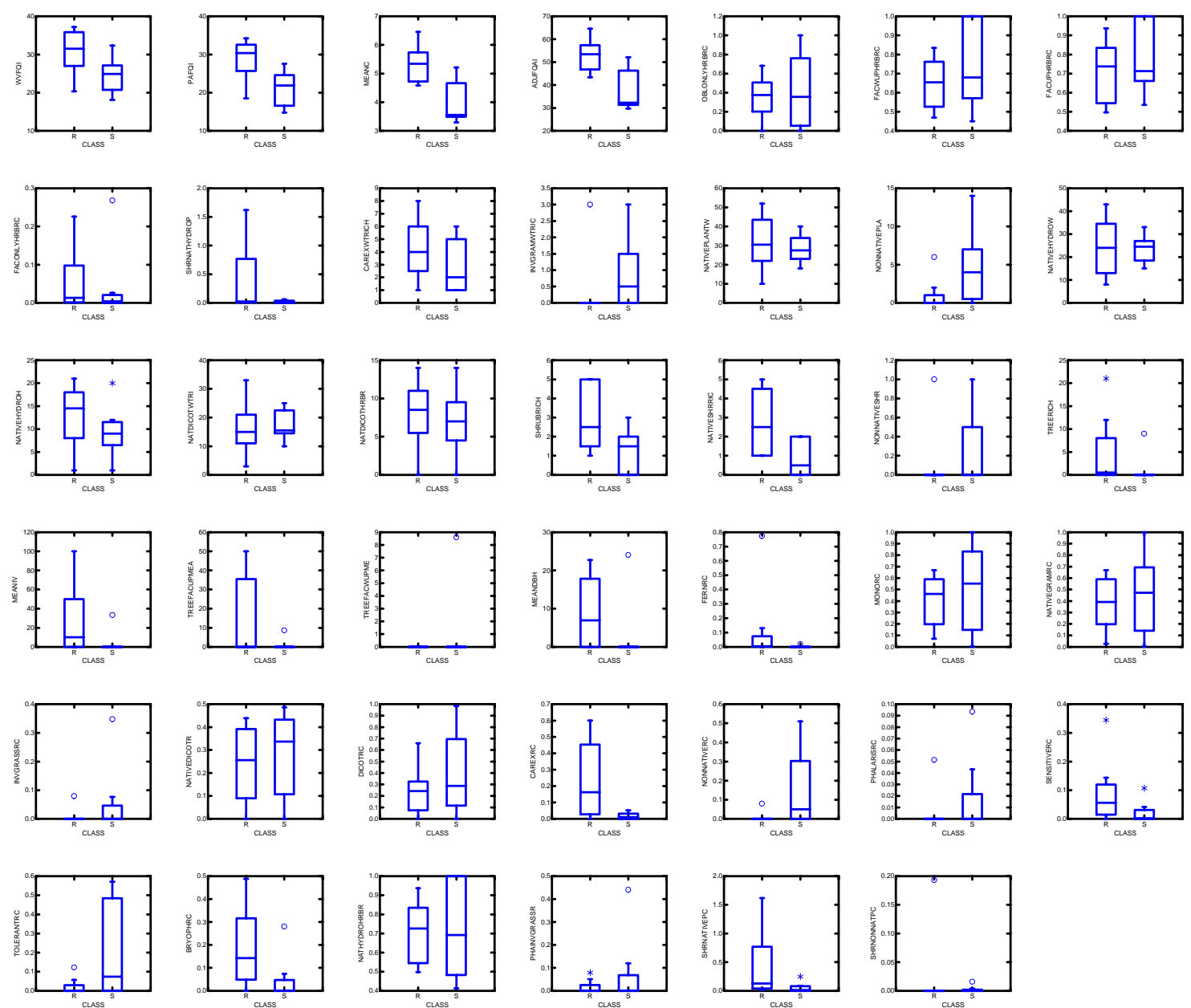
Appendix AF. Continued.

\begin{tabular}{|c|c|c|}
\hline Metric Code & Metric Description & Rating \\
\hline WVFQI & West Virginia Floristic Quality Index & excellent \\
\hline PAFQI & Pennsylvannia Floristic Quality Index & excellent \\
\hline MEANC & Mean Coefficient of Conservatism & excellent \\
\hline ADJFQAI & Adjusted Floristic Quality Index & excellent \\
\hline OBLONLYHRBRC & Obligate only Herbaceous relative cover & poor \\
\hline FACWUPHRBRC & $\begin{array}{l}\text { Facultative wet and wetter herbaceous relative } \\
\text { cover }\end{array}$ & poor \\
\hline FACUPHRBRC & Facultative and wetter herbaceous relative cover & poor \\
\hline FACONLYHRBRC & Facultative only herbaceous relative cover & fair \\
\hline SHRNATHYDROP & Native shrub hydrophyte percent cover & fair \\
\hline CAREXWTRICH & Carex walk-through richness & fair \\
\hline INVGRAMWTRC & Invasive graminoid walk-through richness & fair \\
\hline NATIVEPLANTW & Native plant walk-through richness & poor \\
\hline NONNNATIVEPLANT & Non-native plant walk-through richness & fair \\
\hline NATIVEHYDROW & Native hydrophyte walk-through richness & poor \\
\hline NATIVEHYDROH & Native hydrophyte herbaceous richness & fair \\
\hline NATDICOTWTRI & Native dicot walk-through richness & poor \\
\hline NATDICOTHRB & Native dicot herbaceous richness & poor \\
\hline SHRUBRICH & Shrub richness & fair \\
\hline NATIVESHRRIC & Native shrub richness & good \\
\hline NONNATIVESHR & Non-native shrub richness & poor \\
\hline TREERICH & Tree richness & poor \\
\hline MEANIV & Mean Importance Value & good \\
\hline TREEFACUPMEA & Tree facultative and wetter mean IV & good \\
\hline TREEFACWUPME & Tree facultative wet and wetter meanIV & poor \\
\hline MEANDBH & Mean DBH & good \\
\hline FERNRC & Fern relative cover & poor \\
\hline MONORC & Monocot relative cover & poor \\
\hline NATIVEGRAMRC & Native graminoid relative cover & poor \\
\hline INVGRASSRC & Invasive grass relative cover & poor \\
\hline NATIVEDICOTR & Native dicot relative cover & poor \\
\hline DICOTRC & Dicot relative cover & fair \\
\hline CAREXRC & Carex relative cover & good \\
\hline NONNATIVERC & Non-native relative cover & fair \\
\hline PHALARISRC & Phalaris relative cover & fair \\
\hline SENSITIVERC & Sensitive species relative cover & fair \\
\hline TOLERANTRC & Tolerant species relative cover & fair \\
\hline BRYOPHRC & Bryophyte relative cover & fair \\
\hline NATHYDROHRBRC & Native hydrophyte herbaceous relative cover & poor \\
\hline PHAINVGRASSR & Phalaris and invasive grasses relative cover & fair \\
\hline SHRNATIVEPC & Native shrub percent cover & good \\
\hline SHRNONNATPC & Non-native shrub percent cover & fair \\
\hline
\end{tabular}


Appendix AG. Part 1. Relative and percent cover metric values for use in developing class-specific vegetation-based indices of biological integrity (Veg-IBI) in West Virginia, USA, from 2005-2006. Blanks indicate a metric value of zero.

\begin{tabular}{|c|c|c|c|c|c|c|c|c|c|c|c|}
\hline Site Code & FernRC $^{\mathrm{a}}$ & MonoRC $^{b}$ & $\begin{array}{c}\text { Native } \\
\text { GramRC }^{\mathrm{c}}\end{array}$ & InvGrassRC $^{d}$ & $\operatorname{DicotRC} C^{\mathrm{e}}$ & $\operatorname{DicotRC} C^{f}$ & CarexRC $^{\mathrm{g}}$ & TolerantRC $^{\mathrm{h}}$ & $\begin{array}{c}\text { NatHydro } \\
\text { HrbRC }^{\mathrm{i}}\end{array}$ & $\begin{array}{l}\text { PhalarisInv } \\
\text { GrassRC }^{\mathrm{j}}\end{array}$ & ShrNativePC ${ }^{k}$ \\
\hline CFCROS & & 0.18 & 0.18 & & 0.77 & 0.76 & 0.05 & 0.01 & 0.96 & 0.00 & 0.34 \\
\hline CFECUR & 0.02 & 0.65 & 0.65 & & 0.29 & 0.25 & 0.02 & & 0.26 & 0.00 & 0.61 \\
\hline CFEINC & & 0.94 & 0.79 & & & & 0.32 & & 1.00 & 0.00 & 0.19 \\
\hline CFSLCH & 0.09 & 0.89 & 0.89 & & 0.02 & 0.02 & & 0.28 & 0.91 & 0.28 & 0.17 \\
\hline CFSLIN & & 0.95 & 0.86 & & 0.05 & 0.05 & 0.08 & 0.22 & 1.00 & 0.22 & 0.51 \\
\hline CGBRID & 0.02 & 0.58 & 0.58 & & 0.31 & 0.29 & 0.53 & & 0.94 & 0.00 & 1.62 \\
\hline CGCPAS & 0.00 & 0.09 & 0.09 & & 0.43 & 0.66 & 0.05 & & 0.50 & 0.00 & 1.18 \\
\hline CGROAD & 0.05 & 0.16 & 0.16 & & 0.49 & 0.55 & 0.11 & & 0.61 & 0.00 & 0.63 \\
\hline CGTRHE & & 0.17 & 0.17 & & 0.06 & 0.33 & 0.01 & 0.00 & 0.25 & 0.00 & 0.03 \\
\hline CHNEER & & 0.03 & & & 0.97 & 0.97 & & & 1.00 & 0.00 & 0.40 \\
\hline CHSACH & & 0.47 & 0.47 & & 0.07 & 0.53 & 0.13 & 0.54 & 0.54 & 0.08 & 0.10 \\
\hline CHSAFO & & 0.04 & 0.02 & 0.02 & 0.41 & 0.94 & 0.02 & 0.57 & 0.41 & 0.02 & 0.08 \\
\hline CHSARR & & & & & & & & & & 0.00 & \\
\hline CHTREE & & 0.31 & 0.28 & 0.03 & 0.34 & 0.67 & 0.13 & 0.33 & 0.55 & 0.03 & 0.34 \\
\hline CHWWBW & & 0.80 & & & 0.20 & 0.20 & & & 1.00 & 0.00 & 0.60 \\
\hline CHWWEM & & 0.42 & 0.37 & & 0.55 & 0.55 & 0.03 & & 1.00 & 0.00 & 0.05 \\
\hline CHWWFO & & 0.98 & & & 0.02 & 0.01 & & & 1.00 & 0.00 & 0.21 \\
\hline CVABBW & 0.05 & 0.46 & 0.37 & 0.09 & 0.43 & 0.34 & 0.24 & 0.09 & 0.67 & 0.09 & 0.06 \\
\hline CVABCT & 0.00 & 0.50 & 0.42 & 0.08 & 0.36 & 0.33 & 0.20 & 0.12 & 0.70 & 0.08 & 0.02 \\
\hline CVTIMB & & 0.10 & 0.10 & 0.02 & 0.64 & 0.58 & 0.08 & 0.02 & 0.63 & 0.02 & 0.49 \\
\hline DSPICN & & 0.45 & 0.45 & & 0.47 & 0.47 & 0.10 & & 0.76 & 0.00 & 0.68 \\
\hline DSROAR & & 0.31 & 0.31 & & 0.21 & 0.19 & 0.00 & & 0.50 & 0.00 & 0.12 \\
\hline DSWILD & & 0.21 & 0.21 & & 0.43 & 0.43 & 0.00 & & 0.40 & 0.00 & 0.36 \\
\hline ЕРCMEM & & 0.80 & 0.54 & & 0.16 & 0.20 & & 0.29 & 0.97 & 0.25 & \\
\hline EPCMFO & & 0.25 & 0.05 & 0.15 & 0.30 & 0.66 & 0.03 & 0.36 & 0.27 & 0.15 & 0.02 \\
\hline
\end{tabular}

${ }^{\mathrm{a}}$ Relative cover of ferns and fern allies; ${ }^{\mathrm{b}}$ Relative cover of monocot species; ${ }^{\mathrm{c}}$ Relative cover of native graminoids; ${ }^{\mathrm{d}}$ Relative cover of invasive grasses; ${ }^{\mathrm{e}}$ Relative cover of native dicots;

${ }^{\mathrm{f}}$ Relative cover of dicot species; ${ }^{\mathrm{g}}$ Relative cover of Carex spp.; ${ }^{\mathrm{h}}$ Relative cover of tolerant species; ${ }^{\mathrm{i}}$ Relative cover of native, hydrophytic herbaceous vegetation;

${ }^{\mathrm{j}}$ Relative cover of Phalaris spp.and invasive species; ${ }^{\mathrm{k}}$ Percent cover of native shrub vegetation. 
Appendix AG. Part 1. Continued.

\begin{tabular}{|c|c|c|c|c|c|c|c|c|c|c|c|}
\hline Site Code & FernRC $^{\mathrm{a}}$ & MonoRC $^{b}$ & $\begin{array}{c}\text { Native } \\
\text { GramRC }^{\mathrm{c}}\end{array}$ & InvGrassRC $^{\mathrm{d}}$ & $\operatorname{DicotRC}^{\mathrm{e}}$ & $\operatorname{DicotRC}^{\mathrm{f}}$ & CarexRC $^{g}$ & TolerantRC $^{\mathrm{h}}$ & $\begin{array}{c}\text { NatHydro } \\
\text { HrbRC }^{\mathrm{i}}\end{array}$ & $\begin{array}{l}\text { PhalarisInv } \\
\text { GrassRC }^{\mathrm{j}}\end{array}$ & ShrNativePC \\
\hline EPDMFO & & 0.13 & 0.13 & & 0.36 & 0.70 & 0.12 & 0.43 & 0.25 & 0.00 & 0.19 \\
\hline EPDMPU & & 0.00 & 0.00 & & 0.49 & 0.98 & 0.00 & 0.52 & 0.44 & 0.00 & 0.25 \\
\hline EPKYVE & & 0.78 & 0.78 & & 0.22 & 0.21 & 0.02 & 0.72 & 0.93 & 0.72 & \\
\hline EPRRXC & & 0.08 & 0.08 & & 0.34 & 0.92 & 0.02 & 0.58 & 0.41 & 0.00 & 0.03 \\
\hline EPSHEM & & 0.80 & 0.80 & & 0.04 & 0.20 & & 0.73 & 0.82 & 0.57 & 0.09 \\
\hline EPSHSS & 0.04 & 0.20 & 0.08 & & 0.17 & 0.71 & 0.12 & 0.55 & 0.25 & 0.04 & 0.50 \\
\hline GBBARN & & 0.96 & 0.93 & & 0.03 & 0.03 & & 0.93 & 1.00 & 0.93 & 0.14 \\
\hline GBHOEF & & 0.12 & 0.11 & & 0.88 & 0.88 & & 0.06 & 0.45 & 0.06 & 0.02 \\
\hline GBJENK & & 0.45 & & & 0.55 & 0.55 & & & 0.93 & 0.00 & 1.70 \\
\hline GBMAPL & & & & & 1.00 & 1.00 & & & 1.00 & 0.00 & \\
\hline GBNOFO & & 0.63 & 0.37 & 0.25 & 0.10 & 0.31 & 0.26 & 0.47 & 0.51 & 0.35 & 1.07 \\
\hline GBNOSS & & 0.78 & 0.67 & & 0.20 & 0.18 & 0.01 & & 0.99 & 0.00 & 1.23 \\
\hline GBPLOT & & 0.96 & 0.89 & & 0.04 & 0.04 & & 0.89 & 1.00 & 0.89 & 0.02 \\
\hline HCBEAV & 0.05 & 0.43 & 0.39 & & 0.32 & 0.51 & 0.00 & 0.43 & 0.71 & 0.37 & 0.02 \\
\hline HCMITI & & 0.78 & 0.74 & & 0.06 & 0.20 & 0.06 & 0.01 & 0.81 & 0.01 & 0.00 \\
\hline HCPIPE & & 0.83 & 0.83 & & 0.01 & 0.15 & & 0.84 & 0.85 & 0.83 & 0.17 \\
\hline HCRANG & & 0.68 & 0.13 & & 0.15 & 0.27 & 0.04 & & 0.78 & 0.00 & 0.04 \\
\hline HIBRID & & 0.14 & 0.08 & 0.03 & 0.71 & 0.70 & 0.02 & 0.14 & 0.76 & 0.03 & 0.15 \\
\hline HIGATE & 0.16 & 0.06 & 0.06 & & 0.51 & 0.63 & & 0.14 & 0.74 & 0.00 & 0.45 \\
\hline HIJHPK & & 0.79 & 0.79 & & 0.21 & 0.21 & & & 1.00 & 0.00 & 0.86 \\
\hline HIJHTU & 0.00 & 0.74 & 0.22 & & 0.12 & 0.24 & & 0.03 & 0.72 & 0.00 & 0.09 \\
\hline HIPENC & & 0.60 & 0.53 & & 0.40 & 0.40 & 0.02 & 0.00 & 1.00 & 0.00 & 0.02 \\
\hline HISEWG & 0.05 & 0.27 & 0.03 & 0.23 & 0.40 & 0.44 & & 0.35 & 0.40 & 0.23 & 0.36 \\
\hline HITRLR & & 0.30 & 0.30 & & 0.09 & 0.42 & 0.00 & 0.33 & 0.39 & 0.00 & 0.50 \\
\hline MCFOUR & & 0.18 & 0.16 & & 0.16 & 0.80 & 0.13 & 0.01 & 0.28 & 0.00 & 0.11 \\
\hline
\end{tabular}

${ }^{a}$ Relative cover of ferns and fern allies; ${ }^{b}$ Relative cover of monocot species; ${ }^{\mathrm{c}}$ Relative cover of native graminoids; ${ }^{\mathrm{d}}$ Relative cover of invasive grasses; ${ }^{\mathrm{e}}$ Relative cover of native dicots;

${ }^{\mathrm{f}}$ Relative cover of dicot species; ${ }^{\mathrm{g}}$ Relative cover of Carex spp.; ${ }^{\mathrm{h}}$ Relative cover of tolerant species; ${ }^{\mathrm{i}}$ Relative cover of native, hydrophytic herbaceous vegetation;

${ }^{\mathrm{j}}$ Relative cover of Phalaris spp.and invasive species; ${ }^{\mathrm{k}}$ Percent cover of native shrub vegetation. 
Appendix AG. Part 1. Continued.

\begin{tabular}{|c|c|c|c|c|c|c|c|c|c|c|c|}
\hline Site Code & FernRC $^{\mathrm{a}}$ & MonoRC $^{b}$ & $\begin{array}{c}\text { Native } \\
\text { GramRC }^{\mathrm{c}}\end{array}$ & InvGrassRC $^{d}$ & $\operatorname{DicotRC}^{\mathrm{e}}$ & $\operatorname{DicotRC}^{\mathrm{f}}$ & CarexRC $^{\mathrm{g}}$ & TolerantRC $^{\mathrm{h}}$ & $\begin{array}{c}\text { NatHydro } \\
\text { HrbRC }^{\mathrm{i}}\end{array}$ & $\begin{array}{l}\text { PhalarisInv } \\
\text { GrassRC }^{\mathrm{j}}\end{array}$ & ShrNativePC ${ }^{k}$ \\
\hline MCMEME & & 0.74 & 0.27 & & 0.12 & 0.19 & & 0.08 & 0.83 & 0.00 & 0.09 \\
\hline MCMFOR & & 0.38 & 0.20 & & 0.26 & 0.22 & 0.01 & & 0.61 & 0.00 & 0.05 \\
\hline MCNPFO & & 0.76 & 0.69 & & 0.19 & 0.17 & 0.04 & 0.07 & 0.88 & 0.00 & 0.29 \\
\hline MCPOND & & 0.72 & & & 0.28 & 0.28 & & & 1.00 & 0.00 & \\
\hline MCPOST & & 0.46 & & & 0.54 & 0.54 & & & 1.00 & 0.00 & 0.18 \\
\hline MCTELE & & 0.98 & & & 0.02 & 0.02 & & & 1.00 & 0.00 & 0.01 \\
\hline ME5092 & & 0.39 & 0.18 & 0.01 & 0.52 & 0.52 & 0.02 & 0.12 & 0.80 & 0.01 & 0.14 \\
\hline MESCOX & & 0.34 & 0.34 & & 0.66 & 0.66 & & & 1.00 & 0.00 & 0.02 \\
\hline MESCRO & & 0.85 & 0.85 & & 0.15 & 0.14 & & 0.04 & 1.00 & 0.00 & 0.00 \\
\hline MESCUP & & 0.60 & 0.60 & & 0.39 & 0.39 & 0.03 & & 1.00 & 0.00 & \\
\hline MESIGN & & 0.68 & 0.68 & & 0.32 & 0.24 & & & 1.00 & 0.00 & \\
\hline MESILV & & 0.38 & 0.38 & & 0.48 & 0.37 & 0.18 & & 0.90 & 0.00 & 0.40 \\
\hline METETR & & 0.81 & 0.81 & & 0.12 & 0.19 & & & 0.93 & 0.00 & \\
\hline MEWOLF & & 0.86 & 0.86 & & 0.14 & 0.14 & 0.07 & & 0.99 & 0.00 & 1.65 \\
\hline MRBESS & & 0.87 & 0.87 & & 0.08 & 0.04 & 0.07 & & 0.98 & 0.00 & 0.48 \\
\hline MRFARM & & 0.22 & 0.14 & 0.03 & 0.68 & 0.69 & 0.03 & 0.03 & 0.83 & 0.03 & 0.63 \\
\hline MRFORE & 0.06 & 0.21 & 0.21 & & 0.52 & 0.41 & 0.19 & & 0.76 & 0.00 & 0.26 \\
\hline MRSSSS & 0.13 & 0.39 & 0.39 & & 0.11 & 0.18 & 0.23 & 0.03 & 0.65 & 0.00 & 1.42 \\
\hline MRWEST & & 0.50 & 0.45 & 0.03 & 0.34 & 0.32 & 0.16 & 0.03 & 0.57 & 0.03 & 0.36 \\
\hline MU55SS & & 0.38 & 0.38 & & 0.52 & 0.57 & 0.32 & 0.00 & 0.90 & 0.00 & 0.44 \\
\hline MUDBOA & & 0.29 & 0.23 & & 0.66 & 0.70 & & 0.05 & 0.95 & 0.00 & \\
\hline MUDEND & & 0.52 & 0.46 & & 0.46 & 0.43 & & 0.02 & 0.98 & 0.00 & 0.50 \\
\hline MUDRIC & & 0.42 & 0.21 & 0.21 & 0.27 & 0.47 & & 0.23 & 0.48 & 0.21 & 0.27 \\
\hline MUDRIP & & 0.87 & 0.82 & 0.06 & 0.07 & 0.05 & 0.02 & 0.06 & 0.93 & 0.06 & 0.17 \\
\hline MUDTRA & & 0.41 & 0.41 & & 0.55 & 0.57 & 0.04 & 0.24 & 0.95 & 0.21 & 0.10 \\
\hline
\end{tabular}

${ }^{a}$ Relative cover of ferns and fern allies; ${ }^{b}$ Relative cover of monocot species; ${ }^{\mathrm{c}}$ Relative cover of native graminoids; ${ }^{\mathrm{d}}$ Relative cover of invasive grasses; ${ }^{\mathrm{e}}$ Relative cover of native dicots;

${ }_{\mathrm{f}}^{\mathrm{f}}$ Relative cover of dicot species; ${ }^{\mathrm{g}}$ Relative cover of Carex spp.; ${ }^{\mathrm{h}}$ Relative cover of tolerant species; ${ }^{\mathrm{i}}$ Relative cover of native, hydrophytic herbaceous vegetation;

${ }^{\mathrm{j}}$ Relative cover of Phalaris spp.and invasive species; ${ }^{\mathrm{k}}$ Percent cover of native shrub vegetation. 
Appendix AG. Part 1. Continued.

\begin{tabular}{|c|c|c|c|c|c|c|c|c|c|c|c|}
\hline Site Code & FernRC $^{\mathrm{a}}$ & MonoRC $^{b}$ & $\begin{array}{c}\text { Native } \\
\text { GramRC }^{\mathrm{c}}\end{array}$ & InvGrassRC $^{\mathrm{d}}$ & $\operatorname{DicotRC}^{\mathrm{e}}$ & $\operatorname{Dicot}^{\mathrm{f}}{ }^{\mathrm{f}}$ & CarexRC & TolerantRC $^{\mathrm{h}}$ & $\begin{array}{l}\text { NatHydro } \\
\text { HrbRC }^{\mathrm{i}}\end{array}$ & $\begin{array}{l}\text { PhalarisInv } \\
\text { GrassRC }^{\mathrm{j}}\end{array}$ & ShrNativePC \\
\hline MUEPAH & & 0.54 & 0.54 & & 0.20 & 0.18 & 0.22 & 0.03 & 0.70 & 0.00 & 0.70 \\
\hline MUMINE & 0.04 & 0.50 & 0.40 & 0.10 & 0.36 & 0.39 & 0.02 & 0.27 & 0.74 & 0.27 & 1.06 \\
\hline MUPOWR & 0.13 & 0.42 & 0.36 & & 0.44 & 0.32 & 0.13 & 0.06 & 0.81 & 0.05 & 0.13 \\
\hline MUPULL & 0.23 & 0.64 & 0.64 & & 0.12 & 0.12 & 0.00 & & 0.89 & 0.00 & \\
\hline MUVBRD & 0.22 & 0.66 & 0.66 & & 0.11 & 0.08 & 0.03 & & 0.95 & 0.00 & \\
\hline MUVCRN & & 0.06 & 0.04 & & 0.91 & 0.91 & & & 1.00 & 0.00 & \\
\hline OHHSFO & & 0.26 & 0.26 & & 0.66 & 0.54 & 0.01 & & 0.86 & 0.00 & 0.29 \\
\hline OHINNS & & 0.82 & 0.82 & & 0.18 & 0.18 & 0.04 & & 1.00 & 0.00 & 0.03 \\
\hline OHKMRT & & 1.00 & 1.00 & & & & & & 1.00 & 0.00 & 0.13 \\
\hline PA29TH & & 0.87 & 0.87 & & 0.12 & 0.12 & & & 0.96 & 0.00 & 0.02 \\
\hline PA83CR & & 0.77 & 0.36 & & 0.21 & 0.15 & 0.16 & 0.02 & 0.98 & 0.00 & 0.65 \\
\hline PAFAMD & & 0.63 & & & 0.37 & 0.37 & & & 1.00 & 0.00 & 0.36 \\
\hline PAJCPY & & & & & 0.97 & 0.98 & & 0.03 & 0.97 & 0.00 & \\
\hline PALOUD & & 0.95 & 0.95 & 0.00 & 0.04 & 0.02 & & 0.17 & 0.83 & 0.00 & \\
\hline PAPEFO & 0.00 & 0.17 & 0.17 & & 0.18 & 0.82 & 0.14 & 0.58 & 0.36 & 0.00 & 0.08 \\
\hline PAPEIM & & 0.64 & 0.48 & & 0.25 & 0.32 & & 0.04 & 0.86 & 0.00 & \\
\hline PAPESW & & 0.59 & 0.54 & & 0.41 & 0.41 & & & 1.00 & 0.00 & 0.72 \\
\hline PAWILL & & 0.14 & & & 0.86 & 0.86 & & & 0.96 & 0.00 & 0.17 \\
\hline PCBLUE & & 0.81 & 0.81 & & 0.04 & 0.16 & 0.17 & 0.17 & 0.86 & 0.17 & 0.00 \\
\hline PCLPFO & 0.22 & 0.25 & 0.24 & & 0.51 & 0.49 & 0.24 & 0.03 & 0.95 & 0.00 & 0.78 \\
\hline PCROAD & 0.02 & 0.50 & 0.45 & 0.08 & 0.28 & 0.19 & 0.05 & 0.15 & 0.71 & 0.12 & \\
\hline PEMIDW & & 0.60 & 0.60 & 0.01 & 0.06 & 0.35 & 0.17 & 0.44 & 0.66 & 0.01 & 0.24 \\
\hline PERDDP & & 0.92 & 0.80 & & 0.07 & 0.07 & & & 0.98 & 0.00 & \\
\hline PETHUM & & 0.49 & 0.34 & & 0.42 & 0.44 & & 0.01 & 0.91 & 0.00 & 0.07 \\
\hline PETOSS & & 0.49 & 0.62 & 0.03 & 0.33 & 0.29 & 0.03 & 0.03 & 0.79 & 0.03 & 0.30 \\
\hline
\end{tabular}

${ }^{\mathrm{a}}$ Relative cover of ferns and fern allies; ${ }^{\mathrm{b}}$ Relative cover of monocot species; ${ }^{\mathrm{c}}$ Relative cover of native graminoids; ${ }^{\mathrm{d}}$ Relative cover of invasive grasses; ${ }^{\mathrm{e}}$ Relative cover of native dicots;

${ }^{\mathrm{f}}$ Relative cover of dicot species; ${ }^{\mathrm{g}}$ Relative cover of Carex spp.; ${ }^{\mathrm{h}}$ Relative cover of tolerant species; ${ }^{\mathrm{i}}$ Relative cover of native, hydrophytic herbaceous vegetation;

${ }^{\mathrm{j}}$ Relative cover of Phalaris spp.and invasive species; ${ }^{\mathrm{k}}$ Percent cover of native shrub vegetation. 
Appendix AG. Part 1. Continued.

\begin{tabular}{|c|c|c|c|c|c|c|c|c|c|c|c|}
\hline Site Code & FernRC $^{a}$ & MonoRC $^{\mathrm{b}}$ & $\begin{array}{c}\text { Native } \\
\text { GramRC }^{\mathrm{c}}\end{array}$ & InvGrassRC $^{d}$ & $\operatorname{DicotRC}^{\mathrm{e}}$ & $\operatorname{DicotRC}^{\mathrm{f}}$ & CarexRC ${ }^{g}$ & TolerantRC $^{\mathrm{h}}$ & $\begin{array}{c}\text { NatHydro } \\
\text { HrbRC }^{\mathrm{i}}\end{array}$ & $\begin{array}{l}\text { PhalarisInv } \\
\text { GrassRC }^{\mathrm{j}}\end{array}$ & ShrNativePC \\
\hline RIASIA & 0.02 & 0.82 & 0.75 & & 0.09 & 0.08 & & 0.01 & 0.95 & 0.00 & 0.17 \\
\hline RIBRID & 0.18 & 0.49 & 0.25 & 0.27 & 0.18 & 0.15 & 0.07 & 0.32 & 0.51 & 0.27 & 0.02 \\
\hline RIEAST & 0.04 & 0.44 & 0.31 & 0.14 & 0.34 & 0.27 & 0.08 & 0.21 & 0.33 & 0.14 & 0.36 \\
\hline SJBOAT & & 0.55 & 0.54 & 0.01 & 0.21 & 0.30 & 0.15 & 0.15 & 0.74 & 0.01 & 0.33 \\
\hline SJBRID & & 0.64 & 0.17 & & 0.31 & 0.34 & 0.04 & & 0.47 & 0.00 & 0.25 \\
\hline SJCHUR & & 0.34 & 0.27 & & 0.55 & 0.52 & 0.08 & & 0.81 & 0.00 & 1.00 \\
\hline SJGLAD & 0.01 & 0.65 & 0.19 & 0.03 & 0.28 & 0.29 & 0.10 & 0.03 & 0.67 & 0.03 & 0.10 \\
\hline SJMUDL & & 0.63 & 0.40 & 0.19 & 0.19 & 0.34 & 0.28 & 0.19 & 0.53 & 0.19 & 0.21 \\
\hline SJPLOT & & 0.79 & 0.77 & & 0.13 & 0.17 & 0.77 & 0.04 & 0.89 & 0.00 & \\
\hline SJTELE & & 0.86 & 0.77 & 0.01 & 0.11 & 0.11 & 0.08 & 0.01 & 0.88 & 0.01 & 0.05 \\
\hline SMDTSS & 0.00 & 0.67 & 0.67 & & 0.08 & 0.07 & 0.38 & & 0.75 & 0.00 & 0.36 \\
\hline SMFOFL & 0.77 & 0.07 & 0.03 & & 0.10 & 0.08 & & & 0.86 & 0.00 & 0.07 \\
\hline SMLPEM & & 0.60 & 0.60 & & & & 0.60 & & 0.59 & 0.00 & 0.02 \\
\hline SMSEFL & & 0.69 & 0.69 & & 0.17 & 0.17 & 0.09 & & 0.86 & 0.00 & \\
\hline SMSTEM & & 0.64 & 0.61 & & 0.35 & 0.35 & 0.05 & & 0.96 & 0.00 & \\
\hline TRSPFO & 0.03 & 0.59 & 0.16 & & 0.13 & 0.10 & & & 0.72 & 0.00 & 0.48 \\
\hline TRSPRI & 0.08 & 0.78 & 0.29 & & 0.02 & 0.13 & & 0.29 & 0.89 & 0.29 & 0.68 \\
\hline TVFARM & & 0.62 & 0.10 & & 0.34 & 0.19 & & & 0.96 & 0.00 & \\
\hline TVISLE & 0.30 & & & & 0.61 & 0.61 & & & 0.60 & 0.00 & 0.04 \\
\hline TVNEWT & & 0.30 & 0.05 & & 0.70 & 0.70 & 0.01 & & 1.00 & 0.00 & 0.03 \\
\hline TVPOUT & & 0.58 & 0.50 & & 0.42 & 0.42 & & & 1.00 & 0.00 & 0.24 \\
\hline TVVBEM & & 0.89 & 0.79 & & 0.01 & 0.11 & 0.01 & & 0.90 & 0.00 & \\
\hline TVVBIM & & 0.24 & 0.24 & & 0.76 & 0.76 & & & 1.00 & 0.00 & \\
\hline TVVBRV & 0.16 & 0.19 & 0.19 & & 0.47 & 0.49 & 0.05 & 0.04 & 0.61 & 0.00 & 0.14 \\
\hline TVVBSS & & 0.14 & & & 0.78 & 0.78 & & & 0.92 & 0.00 & 0.17 \\
\hline
\end{tabular}

${ }^{\mathrm{a}}$ Relative cover of ferns and fern allies; ${ }^{\mathrm{b}}$ Relative cover of monocot species; ${ }^{\mathrm{c}}$ Relative cover of native graminoids; ${ }^{\mathrm{d}}$ Relative cover of invasive grasses; ${ }^{\mathrm{e}}$ Relative cover of native dicots;

${ }^{\mathrm{f}}$ Relative cover of dicot species; ${ }^{\mathrm{g}}$ Relative cover of Carex spp.; ${ }^{\mathrm{h}}$ Relative cover of tolerant species; ${ }^{\mathrm{i}}$ Relative cover of native, hydrophytic herbaceous vegetation;

${ }^{\mathrm{j}}$ Relative cover of Phalaris spp.and invasive species; ${ }^{\mathrm{k}}$ Percent cover of native shrub vegetation. 
Appendix AG. Part 1. Continued.

\begin{tabular}{|c|c|c|c|c|c|c|c|c|c|c|c|}
\hline Site Code & FernRC $^{\mathrm{a}}$ & MonoRC ${ }^{b}$ & $\begin{array}{c}\text { Native } \\
\text { GramRC }^{\mathrm{c}}\end{array}$ & InvGrassRC $^{d}$ & $\operatorname{Dicot} R C^{\mathrm{e}}$ & $\operatorname{DicotRC}^{\mathrm{f}}$ & CarexRC ${ }^{g}$ & TolerantRC $^{\mathrm{h}}$ & $\begin{array}{l}\text { NatHydro } \\
\text { HrbRC }^{\mathrm{i}}\end{array}$ & $\begin{array}{c}\text { PhalarisInv } \\
\text { GrassRC }^{\mathrm{j}}\end{array}$ & ShrNativePC \\
\hline UDC001 & & 0.62 & 0.61 & & 0.37 & 0.34 & 0.04 & & 0.99 & 0.00 & 1.47 \\
\hline UDC002 & & 0.39 & 0.39 & & 0.07 & 0.07 & & & 0.46 & 0.00 & \\
\hline UDC003 & & 0.99 & 0.99 & & 0.01 & 0.01 & & 0.99 & 1.00 & 0.99 & \\
\hline UDC004 & & 0.08 & 0.01 & & 0.82 & 0.82 & & 0.01 & 0.70 & 0.00 & 0.51 \\
\hline UDC005 & & 0.51 & 0.47 & 0.04 & 0.26 & 0.44 & 0.08 & 0.10 & 0.72 & 0.04 & \\
\hline UDC007 & 0.02 & 0.13 & 0.11 & 0.02 & 0.80 & 0.81 & 0.00 & 0.13 & 0.35 & 0.12 & 0.06 \\
\hline UDC008 & & 0.81 & 0.72 & & 0.11 & 0.14 & 0.07 & 0.04 & 0.92 & 0.00 & 0.24 \\
\hline UDC012 & 0.06 & 0.11 & 0.10 & & 0.69 & 0.69 & 0.04 & 0.05 & 0.80 & 0.00 & 0.09 \\
\hline UDC013 & & 0.59 & 0.59 & & 0.35 & 0.35 & 0.11 & & 0.92 & 0.00 & \\
\hline UDC014 & 0.05 & 0.35 & 0.30 & & 0.47 & 0.49 & 0.15 & & 0.82 & 0.00 & 0.82 \\
\hline UDC015 & & 0.93 & 0.93 & & 0.02 & 0.02 & 0.12 & & 1.00 & 0.00 & 0.04 \\
\hline UDC016 & 0.01 & 0.90 & 0.90 & & 0.08 & 0.08 & & 0.90 & 0.99 & 0.90 & 0.06 \\
\hline UDC017 & & 0.72 & 0.72 & & 0.27 & 0.27 & & 0.72 & 0.99 & 0.72 & 0.35 \\
\hline UDC018 & & 0.61 & 0.57 & & 0.39 & 0.39 & & & 1.00 & 0.00 & \\
\hline UDC019 & 0.03 & 0.82 & 0.82 & & 0.14 & 0.12 & 0.52 & & 0.99 & 0.00 & \\
\hline UDC020 & & 0.51 & 0.45 & & 0.49 & 0.49 & & & 1.00 & 0.00 & \\
\hline VEPCON & & 0.26 & 0.26 & & 0.45 & 0.45 & & & 0.68 & 0.00 & 0.08 \\
\hline VEPCOS & 0.00 & 0.18 & 0.18 & & 0.26 & 0.15 & 0.02 & 0.01 & 0.38 & 0.00 & 0.03 \\
\hline WBBARN & & 1.00 & 1.00 & & & & & & 1.00 & 0.00 & \\
\hline WBCORN & & 0.85 & 0.50 & 0.35 & 0.03 & 0.05 & 0.02 & 0.44 & 0.53 & 0.44 & \\
\hline WBROAD & & 0.61 & 0.44 & 0.17 & 0.35 & 0.38 & & 0.17 & 0.80 & 0.17 & \\
\hline WYBEAV & 0.01 & 0.15 & 0.10 & 0.04 & 0.46 & 0.43 & 0.07 & 0.06 & 0.60 & 0.04 & 0.00 \\
\hline WYCHWE & 0.01 & 0.19 & 0.10 & 0.08 & 0.69 & 0.74 & 0.08 & 0.09 & 0.81 & 0.08 & \\
\hline WYHCEA & & 0.21 & 0.19 & 0.01 & 0.17 & 0.75 & 0.04 & 0.01 & 0.36 & 0.01 & \\
\hline WYINTR & & 0.52 & 0.46 & 0.06 & 0.33 & 0.47 & 0.23 & 0.07 & 0.79 & 0.06 & 0.17 \\
\hline
\end{tabular}

${ }^{\mathrm{a}}$ Relative cover of ferns and fern allies; ${ }^{\mathrm{b}}$ Relative cover of monocot species; ${ }^{\mathrm{c}}$ Relative cover of native graminoids; ${ }^{\mathrm{d}}$ Relative cover of invasive grasses; ${ }^{\mathrm{e}}$ Relative cover of native dicots;

${ }^{\mathrm{f}}$ Relative cover of dicot species; ${ }^{\mathrm{g}}$ Relative cover of Carex spp.; ${ }^{\mathrm{h}}$ Relative cover of tolerant species; ${ }^{\mathrm{i}}$ Relative cover of native, hydrophytic herbaceous vegetation;

${ }^{\mathrm{j}}$ Relative cover of Phalaris spp.and invasive species; ${ }^{\mathrm{k}}$ Percent cover of native shrub vegetation. 
Appendix AG. Part 1. Continued.

\begin{tabular}{|c|c|c|c|c|c|c|c|c|c|c|c|}
\hline Site Code & FernRC $^{\mathrm{a}}$ & MonoRC $^{b}$ & $\begin{array}{c}\text { Native } \\
\text { GramRC }^{\mathrm{c}}\end{array}$ & InvGrassRC $^{\mathrm{d}}$ & $\operatorname{DicotRC}^{\mathrm{e}}$ & $\operatorname{Dicot}^{\mathrm{f}}{ }^{\mathrm{f}}$ & CarexRC $^{\mathrm{g}}$ & TolerantRC $^{\mathrm{h}}$ & $\begin{array}{l}\text { NatHydro } \\
\text { HrbRC }^{\mathrm{i}}\end{array}$ & $\begin{array}{l}\text { PhalarisInv } \\
\text { GrassRC }^{\mathrm{j}}\end{array}$ & ShrNativePC \\
\hline WYTHOR & & 0.45 & 0.45 & 0.01 & 0.42 & 0.41 & 0.09 & 0.02 & 0.83 & 0.01 & \\
\hline
\end{tabular}

${ }^{a}$ Relative cover of ferns and fern allies; ${ }^{b}$ Relative cover of monocot species; ${ }^{\mathrm{c}}$ Relative cover of native graminoids; ${ }^{\mathrm{d}}$ Relative cover of invasive grasses; ${ }^{\mathrm{e}}$ Relative cover of native dicots;

${ }_{\mathrm{f}}^{\mathrm{f}}$ Relative cover of dicot species; ${ }^{\mathrm{g}}$ Relative cover of Carex spp.; ${ }^{\mathrm{h}}$ Relative cover of tolerant species; ${ }^{\mathrm{i}}$ Relative cover of native, hydrophytic herbaceous vegetation;

${ }^{\mathrm{j}}$ Relative cover of Phalaris spp.and invasive species; ${ }^{\mathrm{k}}$ Percent cover of native shrub vegetation. 
Appendix AG. Part 2. Relative and percent cover metric values for use in developing classspecific vegetation-based indices of biological integrity (Veg-IBI) in West Virginia, USA, from 2005-2006. Blanks indicate a metric value of zero.

\begin{tabular}{|c|c|c|c|c|c|}
\hline Site Code & NonNativeRC ${ }^{a}$ & PhalarisRC $^{b}$ & SensitiveRC ${ }^{\mathrm{c}}$ & BryophRC $^{\mathrm{d}}$ & ShrNonNatPC \\
\hline CFCROS & 0.01 & & & 0.02 & \\
\hline CFECUR & & & & 0.02 & \\
\hline \multicolumn{6}{|l|}{ CFEINC } \\
\hline CFSLCH & & 0.28 & & & \\
\hline CFSLIN & & 0.22 & & & \\
\hline CGBRID & & & 0.14 & 0.05 & \\
\hline CGCPAS & & & 0.03 & 0.23 & \\
\hline CGROAD & & & 0.10 & 0.22 & \\
\hline CGTRHE & 0.00 & & 0.01 & 0.45 & \\
\hline CHNEER & & & 0.03 & & \\
\hline CHSACH & 0.45 & 0.08 & & & \\
\hline CHSAFO & 0.25 & & 0.02 & & 0.02 \\
\hline \multicolumn{6}{|l|}{ CHSARR } \\
\hline CHTREE & 0.33 & & & & \\
\hline CHWWBW & & & 0.61 & & \\
\hline CHWWEM & & & 0.07 & & \\
\hline CHWWFO & & & 0.98 & & \\
\hline CVABBW & 0.09 & & 0.21 & 0.04 & \\
\hline CVABCT & 0.08 & & 0.10 & 0.06 & \\
\hline CVTIMB & 0.02 & & 0.01 & 0.20 & \\
\hline DSPICN & & & & 0.07 & \\
\hline DSROAR & & & 0.34 & 0.49 & \\
\hline DSWILD & & & 0.02 & 0.35 & \\
\hline ЕРСMEM & 0.03 & 0.25 & 0.27 & & \\
\hline EPCMFO & 0.36 & & & 0.00 & 0.25 \\
\hline EPDMFO & 0.39 & & 0.12 & & \\
\hline EPDMPU & 0.51 & & & & \\
\hline EPKYVE & & 0.72 & 0.05 & & \\
\hline EPRRXC & 0.58 & & & & 0.00 \\
\hline EPSHEM & 0.16 & 0.57 & 0.03 & & \\
\hline EPSHSS & 0.51 & 0.04 & & 0.04 & 0.05 \\
\hline GBBARN & & 0.93 & 0.01 & & \\
\hline
\end{tabular}

${ }^{\mathrm{a}}$ Non-native species relative cover; ${ }^{\mathrm{b}}$ Phalaris spp. Relative cover; ${ }^{\mathrm{c}}$ Sensitive species relative cover; ${ }^{\mathrm{d}}$ Bryophyte raltive cover;

${ }^{\mathrm{e}}$ Non-native shrub species percent cover. 
Appendix AG. Part 2. Continued.

\begin{tabular}{|c|c|c|c|c|c|}
\hline Site Code & NonNativeRC ${ }^{a}$ & PhalarisRC $^{\mathrm{b}}$ & SensitiveRC $^{\mathrm{c}}$ & BryophRC $^{\mathrm{d}}$ & ShrNonNatPC \\
\hline GBHOEF & & 0.06 & 0.85 & & \\
\hline GBJENK & & & 0.19 & & \\
\hline \multicolumn{6}{|l|}{ GBMAPL } \\
\hline GBNOFO & 0.35 & 0.09 & & & \\
\hline \multicolumn{6}{|l|}{ GBNOSS } \\
\hline GBPLOT & & 0.89 & 0.02 & & \\
\hline HCBEAV & 0.05 & 0.37 & & & 0.19 \\
\hline HCMITI & & 0.01 & & & \\
\hline HCPIPE & 0.03 & 0.83 & & & \\
\hline HCRANG & & & & 0.00 & \\
\hline HIBRID & 0.13 & & & 0.04 & 0.00 \\
\hline HIGATE & 0.14 & & 0.02 & 0.12 & \\
\hline \multicolumn{6}{|l|}{ НIJHPK } \\
\hline HIJHTU & 0.03 & & 0.36 & 0.02 & 0.02 \\
\hline HIPENC & 0.00 & & 0.01 & & \\
\hline HISEWG & 0.32 & & & 0.19 & \\
\hline HITRLR & 0.33 & & & 0.28 & \\
\hline MCFOUR & 0.01 & & & & \\
\hline MCMEME & 0.08 & & 0.45 & 0.06 & \\
\hline MCMFOR & & & 0.18 & 0.36 & \\
\hline MCNPFO & 0.07 & & & 0.05 & 0.02 \\
\hline MCPOND & & & 0.72 & & \\
\hline MCPOST & & & 0.46 & & \\
\hline MCTELE & & & 1.00 & & \\
\hline ME5092 & 0.05 & & & & 0.05 \\
\hline \multicolumn{6}{|l|}{ MESCOX } \\
\hline \multicolumn{6}{|l|}{ MESCRO } \\
\hline \multicolumn{6}{|l|}{ MESCUP } \\
\hline \multicolumn{6}{|l|}{ MESIGN } \\
\hline MESILV & & & & 0.04 & \\
\hline METETR & & & 0.13 & & \\
\hline MEWOLF & & & & 0.01 & \\
\hline
\end{tabular}

${ }^{\mathrm{a}}$ Non-native species relative cover; ${ }^{\mathrm{b}}$ Phalaris spp. Relative cover; ${ }^{\mathrm{c}}$ Sensitive species relative cover; ${ }^{\mathrm{d}}$ Bryophyte raltive cover;

${ }^{\mathrm{e}}$ Non-native shrub species percent cover. 
Appendix AG. Part 2. Continued.

\begin{tabular}{|c|c|c|c|c|c|}
\hline Site Code & NonNativeRC $^{\mathrm{a}}$ & PhalarisRC $^{b}$ & Sensitive RC $^{\mathrm{c}}$ & BryophRC $^{d}$ & ShrNonNatPC \\
\hline MRBESS & & & 0.03 & 0.01 & \\
\hline MRFARM & 0.03 & & & & \\
\hline MRFORE & & & 0.01 & 0.19 & 0.00 \\
\hline MRSSSS & 0.03 & & 0.29 & 0.28 & \\
\hline MRWEST & 0.03 & & & 0.16 & 0.03 \\
\hline MU55SS & 0.00 & & 0.04 & 0.01 & \\
\hline MUDBOA & 0.05 & & & & \\
\hline MUDEND & 0.02 & & & & \\
\hline MUDRIC & 0.23 & & & & \\
\hline MUDRIP & 0.06 & & & & \\
\hline MUDTRA & 0.03 & 0.21 & & & \\
\hline MUEPAH & 0.03 & & & 0.15 & 0.01 \\
\hline MUMINE & 0.10 & 0.17 & 0.00 & 0.04 & 0.14 \\
\hline MUPOWR & & 0.05 & 0.08 & & 0.19 \\
\hline MUPULL & & & 0.10 & & \\
\hline \multicolumn{6}{|l|}{ MUVBRD } \\
\hline MUVCRN & & & 0.03 & & \\
\hline OHHSFO & & & 0.21 & 0.09 & 0.10 \\
\hline OHINNS & & & 0.04 & & \\
\hline \multicolumn{6}{|l|}{ OHKMRT } \\
\hline PA29TH & & & 0.27 & 0.00 & \\
\hline PA83CR & 0.02 & & & & \\
\hline PAFAMD & & & 0.52 & & \\
\hline PAJCPY & 0.03 & & & & \\
\hline PALOUD & 0.01 & & 0.19 & & \\
\hline PAPEFO & 0.60 & & 0.00 & 0.00 & \\
\hline PAPEIM & 0.11 & & & & \\
\hline \multicolumn{6}{|l|}{ PAPESW } \\
\hline PAWILL & & & 0.11 & & \\
\hline PCBLUE & & 0.17 & & & 0.02 \\
\hline \multicolumn{6}{|l|}{ PCLPFO } \\
\hline PCROAD & 0.10 & 0.04 & & 0.02 & 0.00 \\
\hline
\end{tabular}

${ }^{\mathrm{a}}$ Non-native species relative cover; ${ }^{\mathrm{b}}$ Phalaris spp. Relative cover; ${ }^{\mathrm{c}}$ Sensitive species relative cover; ${ }^{\mathrm{d}}$ Bryophyte raltive cover;

${ }^{\mathrm{e}}$ Non-native shrub species percent cover. 
Appendix AG. Part 2. Continued.

\begin{tabular}{|c|c|c|c|c|c|}
\hline Site Code & NonNativeRC ${ }^{\mathrm{a}}$ & PhalarisRC $^{b}$ & SensitiveRC ${ }^{c}$ & BryophRC $^{\mathrm{d}}$ & ShrNonNatPC \\
\hline PEMIDW & 0.32 & & & 0.01 & \\
\hline PERDDP & & & 0.11 & & \\
\hline PETHUM & & & 0.15 & 0.01 & \\
\hline PETOSS & 0.03 & & 0.14 & & \\
\hline RIASIA & 0.01 & & & & \\
\hline RIBRID & 0.30 & & & 0.01 & 0.00 \\
\hline RIEAST & 0.22 & & 0.04 & 0.03 & 0.00 \\
\hline SJBOAT & 0.18 & & 0.02 & & 0.00 \\
\hline SJBRID & & & & 0.01 & 0.02 \\
\hline \multicolumn{6}{|l|}{ SJCHUR } \\
\hline SJGLAD & 0.03 & & & & 0.19 \\
\hline SJMUDL & 0.19 & & & & 0.19 \\
\hline SJPLOT & 0.04 & & 0.09 & & \\
\hline SJTELE & 0.01 & & & 0.01 & \\
\hline SMDTSS & & & 0.02 & 0.23 & \\
\hline SMFOFL & & & & 0.05 & \\
\hline SMLPEM & & & 0.01 & 0.40 & \\
\hline SMSEFL & & & 0.23 & 0.14 & \\
\hline SMSTEM & & & 0.00 & & \\
\hline TRSPFO & & & & 0.17 & 0.00 \\
\hline TRSPRI & 0.02 & 0.29 & & & \\
\hline \multicolumn{6}{|l|}{ TVFARM } \\
\hline TVISLE & & & & & 0.00 \\
\hline \multicolumn{6}{|l|}{ TVNEWT } \\
\hline TVPOUT & & & 0.11 & & \\
\hline \multicolumn{6}{|l|}{ TVVBEM } \\
\hline TVVBIM & & & 0.15 & & \\
\hline TVVBRV & 0.04 & & 0.03 & & \\
\hline TVVBSS & & & 0.18 & 0.07 & \\
\hline UDC001 & & & & 0.01 & \\
\hline UDC002 & & & & 0.54 & \\
\hline UDC003 & & 0.99 & & & \\
\hline
\end{tabular}

${ }^{\mathrm{a}}$ Non-native species relative cover; ${ }^{\mathrm{b}}$ Phalaris spp. Relative cover; ${ }^{\mathrm{c}}$ Sensitive species relative cover; ${ }^{\mathrm{d}}$ Bryophyte raltive cover;

${ }^{\mathrm{e}}$ Non-native shrub species percent cover. 
Appendix AG. Part 2. Continued.

\begin{tabular}{|c|c|c|c|c|c|}
\hline Site Code & NonNativeRC $^{\text {a }}$ & PhalarisRC $^{b}$ & Sensitive RC $^{\mathrm{c}}$ & BryophRC $^{d}$ & ShrNonNatPC \\
\hline UDC004 & 0.01 & & & 0.03 & \\
\hline UDC005 & 0.09 & & & & \\
\hline UDC007 & 0.03 & 0.11 & & 0.02 & \\
\hline UDC008 & 0.04 & & & 0.04 & \\
\hline UDC012 & 0.05 & 0.00 & 0.19 & 0.04 & \\
\hline UDC013 & & & 0.06 & 0.00 & \\
\hline UDC014 & 0.02 & & & 0.05 & 0.06 \\
\hline \multicolumn{6}{|l|}{ UDC015 } \\
\hline UDC016 & & 0.90 & & 0.01 & \\
\hline UDC017 & & 0.72 & & 0.01 & \\
\hline \multicolumn{6}{|l|}{ UDC018 } \\
\hline UDC019 & 0.01 & & & & \\
\hline UDC020 & & & 0.40 & & \\
\hline VEPCON & & & 0.00 & 0.28 & \\
\hline VEPCOS & & & 0.04 & 0.49 & \\
\hline \multicolumn{6}{|l|}{ WBBARN } \\
\hline WBCORN & 0.35 & 0.09 & 0.11 & 0.07 & \\
\hline WBROAD & 0.17 & & 0.01 & 0.00 & \\
\hline WYBEAV & 0.04 & & & 0.23 & 0.06 \\
\hline WYCHWE & 0.08 & & & 0.01 & \\
\hline WYHCEA & 0.01 & & & & \\
\hline WYINTR & 0.06 & & & & \\
\hline WYTHOR & 0.02 & & & 0.07 & \\
\hline
\end{tabular}

${ }^{\mathrm{a}}$ Non-native species relative cover; ${ }^{\mathrm{b}}$ Phalaris spp. Relative cover; ${ }^{\mathrm{c}}$ Sensitive species relative cover; ${ }^{\mathrm{d}}$ Bryophyte raltive cover;

${ }^{\mathrm{e}}$ Non-native shrub species percent cover. 
Appendix AH. Relative and percent cover metric values of facultative wetland rating and wetter metrics for use in developing class-specific vegetation-based indices of biological integrity (VegIBI) in West Virginia, USA, from 2005-2006. Blanks indicate a metric value of zero.

\begin{tabular}{|c|c|c|c|c|c|}
\hline Site Code & FAConlyHrbRC & ShrNatHydroPC & OblHerbRC $^{c}$ & FACWupHrbRC & FACupHrbRC $^{\mathrm{f}}$ \\
\hline CFCROS & & 0.34 & 0.31 & 0.96 & 0.96 \\
\hline CFECUR & 0.16 & 0.49 & 0.05 & 0.11 & 0.26 \\
\hline CFEINC & & 0.19 & 0.54 & 1.00 & 1.00 \\
\hline CFSLCH & & 0.17 & & 0.91 & 0.91 \\
\hline CFSLIN & & 0.51 & 0.69 & 1.00 & 1.00 \\
\hline CGBRID & 0.17 & 1.62 & 0.42 & 0.77 & 0.94 \\
\hline CGCPAS & 0.00 & 1.17 & 0.14 & 0.49 & 0.50 \\
\hline CGROAD & 0.00 & 0.02 & 0.16 & 0.61 & 0.61 \\
\hline CGTRHE & 0.01 & 0.03 & 0.19 & 0.23 & 0.25 \\
\hline CHNEER & & 0.40 & 1.00 & 1.00 & 1.00 \\
\hline $\mathrm{CHSACH}$ & & 0.10 & 0.81 & 0.98 & 0.98 \\
\hline CHSAFO & 0.03 & 0.06 & & 0.61 & 0.65 \\
\hline \multicolumn{6}{|l|}{ CHSARR } \\
\hline CHTREE & 0.22 & 0.24 & 0.50 & 0.63 & 0.85 \\
\hline CHWWBW & & 0.60 & 1.00 & 1.00 & 1.00 \\
\hline CHWWEM & & 0.05 & 1.00 & 1.00 & 1.00 \\
\hline CHWWFO & & 0.21 & 0.99 & 1.00 & 1.00 \\
\hline CVABBW & 0.00 & 0.05 & 0.35 & 0.68 & 0.69 \\
\hline CVABCT & 0.00 & & 0.36 & 0.72 & 0.72 \\
\hline CVTIMB & 0.05 & 0.35 & 0.31 & 0.58 & 0.63 \\
\hline DSPICN & & 0.68 & 0.48 & 0.76 & 0.76 \\
\hline DSROAR & 0.03 & 0.00 & 0.39 & 0.47 & 0.50 \\
\hline DSWILD & 0.03 & & 0.09 & 0.37 & 0.40 \\
\hline ЕРCMEM & & & 0.55 & 0.97 & 0.97 \\
\hline EPCMFO & 0.04 & 0.00 & 0.24 & 0.48 & 0.52 \\
\hline EPDMFO & 0.01 & 0.00 & & 0.62 & 0.63 \\
\hline EPDMPU & 0.27 & 0.05 & 0.00 & 0.45 & 0.72 \\
\hline EPKYVE & & & 0.06 & 0.93 & 0.93 \\
\hline EPRRXC & 0.19 & & 0.02 & 0.71 & 0.90 \\
\hline EPSHEM & & 0.06 & 0.23 & 0.82 & 0.82 \\
\hline EPSHSS & & 0.50 & 0.09 & 0.76 & 0.76 \\
\hline GBBARN & & & 0.07 & 1.00 & 1.00 \\
\hline
\end{tabular}

${ }^{a}$ Facultative-only herbaceous species relative cover; ${ }^{b}$ Native hydrophytic shrubs percent cover; ${ }^{\mathrm{c}}$ Obligate-only herbaceous species relative cover;

${ }^{\mathrm{d}}$ Facultative-wet and wetter herbaceous species relative cover; ${ }^{\mathrm{e}}$ Facultative and wetter herbaceous species relative cover. 
Appendix AH. Continued.

\begin{tabular}{|c|c|c|c|c|c|}
\hline Site Code & FAConlyHrbRC $^{\mathrm{a}}$ & ShrNatHydroPC & OblHerbRC $^{c}$ & FACWupHrbRC $^{\mathrm{d}}$ & FACupHrbRC \\
\hline GBHOEF & & 0.02 & 0.34 & 0.45 & 0.45 \\
\hline GBJENK & & 1.70 & 0.93 & 0.93 & 0.93 \\
\hline GBMAPL & & & & 1.00 & 1.00 \\
\hline GBNOFO & & 0.93 & 0.36 & 0.55 & 0.55 \\
\hline GBNOSS & & 1.23 & 0.50 & 0.99 & 0.99 \\
\hline GBPLOT & & & 0.11 & 1.00 & 1.00 \\
\hline HCBEAV & 0.22 & 0.01 & 0.04 & 0.49 & 0.71 \\
\hline HCMITI & & 0.00 & 0.73 & 0.81 & 0.81 \\
\hline HCPIPE & & 0.17 & 0.01 & 0.85 & 0.85 \\
\hline HCRANG & 0.01 & 0.04 & 0.66 & 0.77 & 0.78 \\
\hline HIBRID & 0.13 & 0.14 & 0.09 & 0.70 & 0.83 \\
\hline HIGATE & 0.06 & 0.16 & 0.45 & 0.82 & 0.87 \\
\hline HIJHPK & & 0.80 & 1.00 & 1.00 & 1.00 \\
\hline HIJHTU & 0.00 & 0.08 & 0.60 & 0.75 & 0.76 \\
\hline HIPENC & & 0.02 & 0.80 & 1.00 & 1.00 \\
\hline HISEWG & 0.00 & 0.36 & 0.05 & 0.49 & 0.49 \\
\hline HITRLR & & 0.50 & 0.58 & 0.72 & 0.72 \\
\hline MCFOUR & 0.03 & 0.00 & 0.12 & 0.25 & 0.28 \\
\hline MCMEME & & 0.09 & 0.61 & 0.91 & 0.91 \\
\hline MCMFOR & 0.14 & 0.05 & 0.43 & 0.47 & 0.61 \\
\hline MCNPFO & 0.07 & 0.11 & 0.86 & 0.88 & 0.94 \\
\hline MCPOND & & & 1.00 & 1.00 & 1.00 \\
\hline MCPOST & & 0.18 & 1.00 & 1.00 & 1.00 \\
\hline MCTELE & & 0.01 & 1.00 & 1.00 & 1.00 \\
\hline ME5092 & & 0.14 & 0.34 & 0.80 & 0.80 \\
\hline MESCOX & & 0.02 & 1.00 & 1.00 & 1.00 \\
\hline MESCRO & & 0.00 & 0.43 & 1.00 & 1.00 \\
\hline MESCUP & & & 0.86 & 1.00 & 1.00 \\
\hline MESIGN & 0.00 & & 0.75 & 1.00 & 1.00 \\
\hline MESILV & 0.04 & 0.40 & 0.67 & 0.86 & 0.90 \\
\hline METETR & & & 0.54 & 0.93 & 0.93 \\
\hline MEWOLF & & 1.65 & 0.99 & 0.99 & 0.99 \\
\hline
\end{tabular}

${ }^{\mathrm{a}}$ Facultative-only herbaceous species relative cover; ${ }^{\mathrm{b}}$ Native hydrophytic shrubs percent cover; ${ }^{\mathrm{c}}$ Obligate-only herbaceous species relative cover; ${ }^{\mathrm{d}}$ Facultative-wet and wetter herbaceous species relative cover; ${ }^{\mathrm{e}}$ Facultative and wetter herbaceous species relative cover. 
Appendix AH. Continued.

\begin{tabular}{|c|c|c|c|c|c|}
\hline Site Code & FAConlyHrbRC $^{\mathrm{a}}$ & ShrNatHydroPC ${ }^{b}$ & OblHerbRC $^{c}$ & FACWupHrbRC $^{\mathrm{d}}$ & FACupHrbRC ${ }^{f}$ \\
\hline MRBESS & 0.01 & 0.45 & 0.90 & 0.97 & 0.98 \\
\hline MRFARM & 0.33 & 0.54 & 0.01 & 0.50 & 0.83 \\
\hline MRFORE & 0.02 & 0.22 & 0.27 & 0.73 & 0.76 \\
\hline MRSSSS & & 1.38 & 0.11 & 0.65 & 0.65 \\
\hline MRWEST & 0.01 & 0.36 & 0.09 & 0.57 & 0.58 \\
\hline MU55SS & 0.02 & 0.44 & 0.56 & 0.86 & 0.90 \\
\hline MUDBOA & & & 0.99 & 1.00 & 1.00 \\
\hline MUDEND & & 0.49 & 0.94 & 1.00 & 1.00 \\
\hline MUDRIC & & 0.27 & 0.29 & 0.48 & 0.48 \\
\hline MUDRIP & & 0.16 & 0.74 & 0.93 & 0.93 \\
\hline MUDTRA & & 0.10 & 0.48 & 0.98 & 0.98 \\
\hline MUEPAH & 0.03 & 0.10 & 0.53 & 0.70 & 0.73 \\
\hline MUMINE & 0.11 & 0.07 & 0.24 & 0.63 & 0.74 \\
\hline MUPOWR & 0.23 & 0.02 & 0.26 & 0.56 & 0.81 \\
\hline MUPULL & & & 0.60 & 0.89 & 0.89 \\
\hline MUVBRD & & & 0.66 & 0.95 & 0.95 \\
\hline MUVCRN & & & 1.00 & 1.00 & 1.00 \\
\hline OHHSFO & 0.08 & 0.03 & 0.01 & 0.73 & 0.86 \\
\hline OHINNS & & 0.03 & 0.89 & 1.00 & 1.00 \\
\hline OHKMRT & & 0.13 & 1.00 & 1.00 & 1.00 \\
\hline PA29TH & & 0.02 & 0.90 & 0.96 & 0.96 \\
\hline PA83CR & 0.04 & 0.38 & 0.80 & 0.96 & 1.00 \\
\hline PAFAMD & & 0.36 & 1.00 & 1.00 & 1.00 \\
\hline PAJCPY & 0.01 & & 0.94 & 0.99 & 1.00 \\
\hline PALOUD & 0.00 & & 0.80 & 0.82 & 0.83 \\
\hline PAPEFO & 0.05 & 0.01 & 0.61 & 0.89 & 0.94 \\
\hline PAPEIM & 0.02 & & 0.80 & 0.95 & 0.96 \\
\hline PAPESW & & 0.72 & 0.99 & 1.00 & 1.00 \\
\hline PAWILL & & 0.17 & 0.96 & 0.96 & 0.96 \\
\hline PCBLUE & 0.03 & 0.00 & 0.47 & 0.83 & 0.86 \\
\hline PCLPFO & 0.17 & 0.51 & & 0.76 & 0.95 \\
\hline PCROAD & 0.01 & & 0.11 & 0.68 & 0.71 \\
\hline
\end{tabular}

${ }^{\mathrm{a}}$ Facultative-only herbaceous species relative cover; ${ }^{\mathrm{b}}$ Native hydrophytic shrubs percent cover; ${ }^{\mathrm{c}}$ Obligate-only herbaceous species relative cover; ${ }^{\mathrm{d}}$ Facultative-wet and wetter herbaceous species relative cover; ${ }^{\mathrm{e}}$ Facultative and wetter herbaceous species relative cover. 
Appendix AH. Continued.

\begin{tabular}{|c|c|c|c|c|c|}
\hline Site Code & FAConlyHrbRC $^{\mathrm{a}}$ & ShrNatHydroPC ${ }^{b}$ & OblHerbRC $^{c}$ & FACWupHrbRC $^{\mathrm{d}}$ & FACupHrbRC \\
\hline PEMIDW & & 0.24 & 0.42 & 0.66 & 0.66 \\
\hline PERDDP & & & 0.54 & 0.98 & 0.98 \\
\hline PETHUM & & 0.07 & 0.66 & 0.91 & 0.91 \\
\hline PETOSS & 0.09 & 0.30 & 0.38 & 0.70 & 0.79 \\
\hline RIASIA & & 0.17 & 0.89 & 0.96 & 0.96 \\
\hline RIBRID & 0.06 & 0.02 & 0.24 & 0.46 & 0.52 \\
\hline RIEAST & 0.08 & 0.36 & 0.03 & 0.25 & 0.34 \\
\hline SJBOAT & 0.01 & 0.33 & 0.76 & 0.86 & 0.87 \\
\hline SJBRID & & 0.25 & 0.17 & 0.47 & 0.47 \\
\hline SJCHUR & 0.06 & 0.09 & 0.48 & 0.75 & 0.81 \\
\hline SJGLAD & 0.08 & 0.09 & 0.52 & 0.59 & 0.67 \\
\hline SJMUDL & 0.01 & 0.20 & 0.39 & 0.51 & 0.53 \\
\hline SJPLOT & 0.01 & & 0.07 & 0.91 & 0.91 \\
\hline SJTELE & & 0.04 & 0.63 & 0.88 & 0.88 \\
\hline SMDTSS & & 0.36 & 0.68 & 0.75 & 0.75 \\
\hline SMFOFL & 0.02 & 0.03 & & 0.83 & 0.86 \\
\hline SMLPEM & & 0.02 & 0.59 & 0.59 & 0.59 \\
\hline SMSEFL & & & 0.78 & 0.86 & 0.86 \\
\hline SMSTEM & 0.02 & & 0.89 & 0.94 & 0.96 \\
\hline TRSPFO & 0.05 & 0.25 & 0.51 & 0.64 & 0.72 \\
\hline TRSPRI & & 0.68 & 0.52 & 0.89 & 0.89 \\
\hline TVFARM & & & 0.77 & 0.96 & 0.96 \\
\hline TVISLE & 0.31 & & & 0.30 & 0.60 \\
\hline TVNEWT & & 0.03 & 1.00 & 1.00 & 1.00 \\
\hline TVPOUT & & 0.24 & 1.00 & 1.00 & 1.00 \\
\hline TVVBEM & & & 0.72 & 0.90 & 0.90 \\
\hline TVVBIM & & & 1.00 & 1.00 & 1.00 \\
\hline TVVBRV & 0.10 & 0.14 & 0.12 & 0.55 & 0.65 \\
\hline TVVBSS & & 0.17 & 0.92 & 0.92 & 0.92 \\
\hline UDC001 & & 1.47 & 0.96 & 0.99 & 0.99 \\
\hline UDC002 & & & 0.46 & 0.46 & 0.46 \\
\hline UDC003 & & & & 1.00 & 1.00 \\
\hline
\end{tabular}

${ }^{a}$ Facultative-only herbaceous species relative cover; ${ }^{\mathrm{b}}$ Native hydrophytic shrubs percent cover; ${ }^{\mathrm{c}}$ Obligate-only herbaceous species relative cover; ${ }^{\mathrm{d}}$ Facultative-wet and wetter herbaceous species relative cover; ${ }^{\mathrm{e}}$ Facultative and wetter herbaceous species relative cover. 
Appendix AH. Continued.

\begin{tabular}{|c|c|c|c|c|c|}
\hline Site Code & FAConlyHrbRC $^{\mathrm{a}}$ & ShrNatHydroPC $^{b}$ & OblHerbRC ${ }^{c}$ & FACWupHrbRC $^{d}$ & FACupHrbRC \\
\hline UDC004 & 0.04 & 0.51 & & 0.63 & 0.70 \\
\hline UDC005 & & & 0.11 & 0.72 & 0.72 \\
\hline UDC007 & & 0.06 & 0.01 & 0.37 & 0.37 \\
\hline UDC008 & & 0.23 & 0.91 & 0.92 & 0.92 \\
\hline UDC012 & 0.21 & 0.09 & 0.47 & 0.59 & 0.81 \\
\hline UDC013 & & & 0.61 & 0.92 & 0.92 \\
\hline UDC014 & 0.06 & 0.82 & 0.43 & 0.76 & 0.82 \\
\hline UDC015 & & 0.04 & 0.99 & 1.00 & 1.00 \\
\hline UDC016 & & 0.06 & 0.03 & 0.99 & 0.99 \\
\hline UDC017 & & 0.35 & 0.08 & 0.99 & 0.99 \\
\hline UDC018 & & & 0.63 & 1.00 & 1.00 \\
\hline UDC019 & 0.05 & & 0.51 & 0.94 & 0.99 \\
\hline UDC020 & & & 1.00 & 1.00 & 1.00 \\
\hline VEPCON & & & 0.30 & 0.68 & 0.68 \\
\hline VEPCOS & 0.02 & 0.00 & 0.22 & 0.37 & 0.38 \\
\hline WBBARN & & & 1.00 & 1.00 & 1.00 \\
\hline WBCORN & 0.01 & & 0.41 & 0.53 & 0.54 \\
\hline WBROAD & 0.00 & & 0.50 & 0.80 & 0.80 \\
\hline WYBEAV & 0.07 & & 0.40 & 0.52 & 0.60 \\
\hline WYCHWE & 0.22 & & 0.32 & 0.59 & 0.81 \\
\hline WYHCEA & & & 0.33 & 0.36 & 0.36 \\
\hline WYINTR & 0.26 & 0.06 & 0.40 & 0.53 & 0.79 \\
\hline WYTHOR & 0.00 & & 0.45 & 0.82 & 0.83 \\
\hline
\end{tabular}

${ }^{\mathrm{a}}$ Facultative-only herbaceous species relative cover; ${ }^{\mathrm{b}}$ Native hydrophytic shrubs percent cover; ${ }^{\mathrm{c}}$ Obligate-only herbaceous species relative cover;

${ }^{\mathrm{d}}$ Facultative-wet and wetter herbaceous species relative cover; ${ }^{\mathrm{e}}$ Facultative and wetter herbaceous species relative cover 
Appendix AI. Part 1. Richness metrics used in developing vegetation based indices of biological integrity (Veg-IBI) in West Virginia, USA from 2005-2006. Blanks indicate a metric value of zero.

\begin{tabular}{|c|c|c|c|c|c|c|}
\hline Site Code & InvGramWTRich $^{\mathrm{a}}$ & NonNativePlantWTRich ${ }^{\mathrm{b}}$ & ShrubRich $^{\mathrm{c}}$ & NativeShrRich $^{\mathrm{d}}$ & TreeRich $^{\mathrm{e}}$ & NativePlantRich $^{\mathrm{f}}$ \\
\hline CFCROS & 1 & 3 & 1 & 1 & & 40 \\
\hline CFECUR & & 3 & 8 & 6 & & 48 \\
\hline CFEINC & & 1 & 3 & 3 & & 40 \\
\hline CFSLCH & & & 3 & 3 & & 28 \\
\hline CFSLIN & & & 3 & 3 & & 26 \\
\hline CGBRID & & & 1 & 1 & & 36 \\
\hline CGCPAS & & & 2 & 2 & 2 & 37 \\
\hline CGROAD & & & 5 & 4 & 4 & 39 \\
\hline CGTRHE & & 4 & 2 & 2 & 6 & 32 \\
\hline CHNEER & & & 1 & 1 & & 12 \\
\hline $\mathrm{CHSACH}$ & & 11 & 5 & 5 & 1 & 42 \\
\hline CHSAFO & 1 & 6 & 3 & 2 & 3 & 27 \\
\hline CHSARR & & 1 & & & & 16 \\
\hline CHTREE & 1 & 3 & 7 & 7 & 5 & 38 \\
\hline CHWWBW & & & 1 & 1 & & 5 \\
\hline CHWWEM & & 1 & 1 & 1 & & 26 \\
\hline CHWWFO & 1 & 2 & 4 & 4 & 4 & 23 \\
\hline CVABBW & 4 & 8 & 5 & 4 & 1 & 53 \\
\hline CVABCT & 3 & 6 & 2 & 1 & 1 & 52 \\
\hline CVTIMB & 1 & 1 & 2 & 2 & & 21 \\
\hline DSPICN & & & 1 & 1 & & 38 \\
\hline DSROAR & & & 5 & 5 & & 21 \\
\hline
\end{tabular}

${ }^{\mathrm{a}}$ Invasive graminoid walk-through richness; ${ }^{\mathrm{b}}$ Non-native plant walk-though richness; ${ }^{\mathrm{c}}$ Shrub richness; ${ }^{\mathrm{d}}$ Native Shrub Richness; ${ }^{\mathrm{e}}$ Tree species richness; ${ }^{\mathrm{f}}$ Native Plant Richness 
Appendix AI. Part 1. Continued.

\begin{tabular}{|c|c|c|c|c|c|c|}
\hline Site Code & InvGramWTRich $^{\mathrm{a}}$ & NonNativePlantWTRich $^{\mathrm{b}}$ & ShrubRich $^{\mathrm{c}}$ & NativeShrRich $^{\mathrm{d}}$ & TreeRich $^{\mathrm{e}}$ & NativePlantRich $^{\mathrm{f}}$ \\
\hline DSWILD & & & 3 & 3 & & 20 \\
\hline EPCMEM & & 1 & & & & 10 \\
\hline EPCMFO & 1 & 10 & 4 & 2 & 4 & 27 \\
\hline EPDMFO & & 4 & 2 & 2 & 2 & 14 \\
\hline EPDMPU & & 4 & 2 & 2 & & 18 \\
\hline EPKYVE & & 5 & & & & 25 \\
\hline EPRRXC & & 7 & 4 & 3 & 2 & 24 \\
\hline EPSHEM & & 2 & 3 & 3 & & 13 \\
\hline EPSHSS & & 4 & 4 & 3 & & 33 \\
\hline GBBARN & & & 1 & 1 & & 13 \\
\hline GBHOEF & & 1 & 2 & 2 & & 18 \\
\hline GBJENK & & 1 & 1 & 1 & & 17 \\
\hline GBMAPL & & & & & 1 & 10 \\
\hline GBNOFO & 1 & 4 & 8 & 7 & 2 & 21 \\
\hline GBNOSS & & 3 & 2 & 2 & & 28 \\
\hline GBPLOT & 1 & 2 & 1 & 1 & & 14 \\
\hline HCBEAV & 2 & 6 & 5 & 3 & & 24 \\
\hline HCMITI & & 4 & 1 & 1 & & 27 \\
\hline HCPIPE & 1 & 10 & 1 & 1 & & 15 \\
\hline HCRANG & 1 & 3 & 1 & 1 & & 29 \\
\hline HIBRID & 3 & 14 & 6 & 5 & 7 & 64 \\
\hline HIGATE & & 3 & 6 & 6 & 4 & 31 \\
\hline
\end{tabular}

${ }^{\mathrm{a}}$ Invasive graminoid walk-through richness; ${ }^{\mathrm{b}}$ Non-native plant walk-though richness; ${ }^{\mathrm{c}}$ Shrub richness; ${ }^{\mathrm{d}}$ Native Shrub Richness; ${ }^{\mathrm{e}}$ Tree species richness; ${ }^{\mathrm{f}}$ Native Plant Richness 
Appendix AI. Part 1. Continued.

\begin{tabular}{|c|c|c|c|c|c|c|}
\hline Site Code & InvGramWTRich $^{\mathrm{a}}$ & NonNativePlantWTRich $^{\mathrm{b}}$ & ShrubRich $^{\mathrm{c}}$ & NativeShrRich $^{\mathrm{d}}$ & TreeRich $^{\mathrm{e}}$ & NativePlantRich $^{\mathrm{f}}$ \\
\hline HIJHPK & 1 & 4 & 3 & 3 & 3 & 22 \\
\hline HIJHTU & 1 & 6 & 3 & 2 & & 33 \\
\hline HIPENC & & 1 & 1 & 1 & 2 & 22 \\
\hline HISEWG & 1 & 6 & 4 & 4 & 2 & 54 \\
\hline HITRLR & 1 & 4 & 1 & 1 & & 34 \\
\hline MCFOUR & & 3 & 7 & 5 & & 30 \\
\hline MCMEME & & 2 & 2 & 2 & & 27 \\
\hline MCMFOR & & 2 & 3 & 2 & 3 & 37 \\
\hline MCNPFO & & 4 & 6 & 5 & 2 & 23 \\
\hline MCPOND & & 1 & & & & 18 \\
\hline MCPOST & & 1 & 2 & 2 & & 35 \\
\hline MCTELE & 1 & 7 & 3 & 3 & & 34 \\
\hline ME5092 & 2 & 12 & 6 & 4 & & 59 \\
\hline MESCOX & & 2 & 2 & 2 & & 24 \\
\hline MESCRO & & & 1 & 1 & & 20 \\
\hline MESCUP & & & & & & 25 \\
\hline MESIGN & & 3 & & & & 41 \\
\hline MESILV & 1 & 3 & 5 & 5 & 2 & 47 \\
\hline METETR & 1 & 5 & & & & 35 \\
\hline MEWOLF & & 1 & 6 & 5 & & 27 \\
\hline MRBESS & & & 9 & 9 & & 35 \\
\hline MRFARM & 1 & 1 & 10 & 10 & & 31 \\
\hline
\end{tabular}

${ }^{\mathrm{a}}$ Invasive graminoid walk-through richness; ${ }^{\mathrm{b}}$ Non-native plant walk-though richness; ${ }^{\mathrm{c}}$ Shrub richness; ${ }^{\mathrm{d}}$ Native Shrub Richness; ${ }^{\mathrm{e}}$ Tree species richness; ${ }^{\mathrm{f}}$ Native Plant Richness 
Appendix AI. Part 1. Continued.

\begin{tabular}{|c|c|c|c|c|c|c|}
\hline Site Code & InvGramWTRich $^{\mathrm{a}}$ & NonNativePlantWTRich $^{\mathrm{b}}$ & ShrubRich $^{\mathrm{c}}$ & NativeShrRich $^{\mathrm{d}}$ & TreeRich $^{\mathrm{e}}$ & NativePlantRich $^{f}$ \\
\hline MRFORE & & 1 & 15 & 14 & 4 & 38 \\
\hline MRSSSS & & 1 & 7 & 7 & & 26 \\
\hline MRWEST & 2 & 3 & 4 & 3 & & 20 \\
\hline MU55SS & & 5 & 3 & 3 & & 34 \\
\hline MUDBOA & & 2 & & & & 29 \\
\hline MUDEND & & 2 & 4 & 4 & & 36 \\
\hline MUDRIC & 1 & 3 & 2 & 2 & & 39 \\
\hline MUDRIP & 2 & 7 & 5 & 5 & & 39 \\
\hline MUDTRA & & 3 & 1 & 1 & 1 & 27 \\
\hline MUEPAH & 1 & 7 & 5 & 4 & 1 & 39 \\
\hline MUMINE & 2 & 4 & 7 & 5 & 5 & 58 \\
\hline MUPOWR & & 2 & 5 & 4 & 2 & 50 \\
\hline MUPULL & & 1 & & & & 26 \\
\hline MUVBRD & & 1 & & & & 36 \\
\hline MUVCRN & & & & & & 14 \\
\hline OHHSFO & & 4 & 9 & 6 & 6 & 32 \\
\hline OHINNS & & & 2 & 2 & & 24 \\
\hline OHKMRT & & & 2 & 2 & & 6 \\
\hline PA29TH & & & 1 & 1 & & 21 \\
\hline PA83CR & & 3 & 4 & 4 & 3 & 34 \\
\hline PAFAMD & & 4 & 1 & 1 & & 27 \\
\hline PAJCPY & & 1 & & & & 21 \\
\hline
\end{tabular}

${ }^{\mathrm{a}}$ Invasive graminoid walk-through richness; ${ }^{\mathrm{b}}$ Non-native plant walk-though richness; ${ }^{\mathrm{c}}$ Shrub richness; ${ }^{\mathrm{d}}$ Native Shrub Richness; ${ }^{\mathrm{e}}$ Tree species richness; ${ }^{\mathrm{f}}$ Native Plant Richness 
Appendix AI. Part 1. Continued.

\begin{tabular}{|c|c|c|c|c|c|c|}
\hline Site Code & InvGramWTRich $^{\mathrm{a}}$ & NonNativePlantWTRich $^{\mathrm{b}}$ & ShrubRich $^{\mathrm{c}}$ & NativeShrRich $^{\mathrm{d}}$ & TreeRich $^{\mathrm{e}}$ & NativePlantRich $^{\mathrm{f}}$ \\
\hline PALOUD & 1 & 5 & & & & 20 \\
\hline PAPEFO & & 3 & 4 & 4 & 3 & 31 \\
\hline PAPEIM & & 4 & & & & 18 \\
\hline PAPESW & & 4 & 3 & 3 & 1 & 38 \\
\hline PAWILL & & 2 & 1 & 1 & & 14 \\
\hline PCBLUE & & 2 & 2 & 1 & & 29 \\
\hline PCLPFO & & 3 & 7 & 7 & 2 & 27 \\
\hline PCROAD & 2 & 8 & 2 & & & 36 \\
\hline PEMIDW & 1 & 8 & 1 & 1 & & 29 \\
\hline PERDDP & & & & & & 16 \\
\hline PETHUM & & 1 & 2 & 2 & & 40 \\
\hline PETOSS & 1 & 3 & 1 & 1 & & 34 \\
\hline RIASIA & & 5 & 1 & 1 & 1 & 36 \\
\hline RIBRID & 2 & 8 & 2 & 1 & & 37 \\
\hline RIEAST & 3 & 13 & 3 & 2 & 2 & 33 \\
\hline SJBOAT & 1 & 12 & 5 & 3 & & 45 \\
\hline SJBRID & & 2 & 5 & 3 & & 16 \\
\hline SJCHUR & & 2 & 7 & 6 & 1 & 26 \\
\hline SJGLAD & 2 & 4 & 6 & 4 & 1 & 28 \\
\hline SJMUDL & 1 & 8 & 8 & 6 & 1 & 38 \\
\hline SJPLOT & & 6 & & & & 21 \\
\hline SJTELE & 2 & 4 & 4 & 4 & & 22 \\
\hline
\end{tabular}

${ }^{\mathrm{a}}$ Invasive graminoid walk-through richness; ${ }^{\mathrm{b}}$ Non-native plant walk-though richness; ${ }^{\mathrm{c}}$ Shrub richness; ${ }^{\mathrm{d}}$ Native Shrub Richness; ${ }^{\mathrm{e}}$ Tree species richness; ${ }^{\mathrm{f}}$ Native Plant Richness 
Appendix AI. Part 1. Continued.

\begin{tabular}{|c|c|c|c|c|c|c|}
\hline Site Code & InvGramWTRich $^{\mathrm{a}}$ & NonNativePlantWTRich $^{\mathrm{b}}$ & ShrubRich $^{\mathrm{c}}$ & NativeShrRich $^{\mathrm{d}}$ & TreeRich $^{\mathrm{e}}$ & NativePlantRich $^{f}$ \\
\hline SMDTSS & & & 3 & 3 & & 25 \\
\hline SMFOFL & & & 5 & 5 & 5 & 23 \\
\hline SMLPEM & & & 1 & 1 & & 10 \\
\hline SMSEFL & & & & & & 17 \\
\hline SMSTEM & & & & & & 23 \\
\hline TRSPFO & & 2 & 9 & 7 & 4 & 52 \\
\hline TRSPRI & & 2 & 2 & 2 & & 10 \\
\hline TVFARM & & 2 & & & & 30 \\
\hline TVISLE & & 2 & 3 & 2 & 6 & 29 \\
\hline TVNEWT & 1 & 5 & 1 & 1 & & 25 \\
\hline TVPOUT & & 2 & 2 & 2 & & 38 \\
\hline TVVBEM & 1 & 2 & & & & 13 \\
\hline TVVBIM & & 1 & & & & 12 \\
\hline TVVBRV & & 2 & 2 & 2 & 2 & 23 \\
\hline TVVBSS & & & 2 & 2 & & 13 \\
\hline UDC001 & & & 1 & 1 & & 34 \\
\hline UDC002 & & & & & & 16 \\
\hline UDC003 & 1 & 5 & & & & 22 \\
\hline UDC004 & & 2 & 4 & 3 & 2 & 37 \\
\hline UDC005 & 3 & 11 & & & & 24 \\
\hline UDC007 & 1 & 2 & 1 & 1 & 1 & 19 \\
\hline UDC008 & & 1 & 6 & 6 & & 33 \\
\hline
\end{tabular}

${ }^{\mathrm{a}}$ Invasive graminoid walk-through richness; ${ }^{\mathrm{b}}$ Non-native plant walk-though richness; ${ }^{\mathrm{c}}$ Shrub richness; ${ }^{\mathrm{d}}$ Native Shrub Richness; ${ }^{\mathrm{e}}$ Tree species richness; ${ }^{\mathrm{f}}$ Native Plant Richness 
Appendix AI. Part 1. Continued.

\begin{tabular}{|c|c|c|c|c|c|c|}
\hline Site Code & InvGramWTRich $^{\mathrm{a}}$ & NonNativePlantWTRich $^{\mathrm{b}}$ & ShrubRich $^{\mathrm{c}}$ & NativeShrRich $^{\mathrm{d}}$ & TreeRich $^{\mathrm{e}}$ & NativePlantRich $^{\mathrm{f}}$ \\
\hline UDC012 & & 4 & 2 & 2 & 3 & 46 \\
\hline UDC013 & & & & & & 41 \\
\hline UDC014 & & 2 & 6 & 5 & & 30 \\
\hline UDC015 & & & 4 & 4 & & 19 \\
\hline UDC016 & & & 1 & 1 & & 21 \\
\hline UDC017 & & & 2 & 2 & & 22 \\
\hline UDC018 & & 1 & & & & 32 \\
\hline UDC019 & & 2 & & & & 28 \\
\hline UDC020 & & & & & & 22 \\
\hline VEPCON & & & 1 & 1 & & 28 \\
\hline VEPCOS & & & 2 & 2 & & 36 \\
\hline WBBARN & 1 & 4 & & & & 22 \\
\hline WBCORN & 3 & 14 & & & & 40 \\
\hline WBROAD & 1 & 2 & & & & 19 \\
\hline WYBEAV & 1 & 3 & 2 & 1 & 1 & 24 \\
\hline WYCHWE & 2 & 6 & & & & 43 \\
\hline WYHCEA & 1 & 1 & & & & 19 \\
\hline WYINTR & 2 & 8 & 3 & 3 & 2 & 20 \\
\hline WYTHOR & 1 & 2 & & & & 25 \\
\hline
\end{tabular}

a Invasive graminoid walk-through richness; b Non-native plant walk-though richness; c Shrub richness; d Native Shrub Richness; e Tree species richness; f Native Plant Richness 
Appendix AI. Part 2. Richness metrics used in developing vegetation based indices of biological integrity (Veg-IBI) in West Virginia, USA from 2005-2006. Blanks indicate a metric value of zero.

\begin{tabular}{|c|c|c|c|c|c|c|}
\hline Site Code & NativeHydroWTRich $^{\mathrm{a}}$ & NatDicotWTRich $^{\mathrm{b}}$ & NatDicotRich $^{\mathrm{c}}$ & CarexRichness $^{\mathrm{d}}$ & NatHydroHrbRich ${ }^{\mathrm{e}}$ & NonNativeShrRich \\
\hline CFCROS & 31 & 23 & 6 & 4 & 10 & \\
\hline CFECUR & 35 & 32 & 11 & 2 & 11 & \\
\hline CFEINC & 32 & 20 & & 3 & 6 & \\
\hline CFSLCH & 26 & 18 & 1 & 2 & 4 & \\
\hline CFSLIN & 26 & 15 & 3 & 3 & 8 & \\
\hline CGBRID & 34 & 17 & 10 & 8 & 18 & \\
\hline CGCPAS & 29 & 18 & 11 & 6 & 17 & \\
\hline CGROAD & 19 & 25 & 10 & 2 & 11 & \\
\hline CGTRHE & 19 & 16 & 8 & 8 & 9 & \\
\hline CHNEER & 11 & 7 & 1 & & 2 & \\
\hline $\mathrm{CHSACH}$ & 37 & 22 & 3 & 7 & 11 & \\
\hline CHSAFO & 19 & 25 & 10 & 1 & 9 & 1 \\
\hline CHSARR & 14 & 10 & & 2 & & \\
\hline CHTREE & 27 & 26 & 9 & 7 & 12 & \\
\hline CHWWBW & 5 & 2 & 1 & & 4 & \\
\hline CHWWEM & 24 & 12 & 2 & 3 & 9 & \\
\hline CHWWFO & 15 & 17 & 3 & 1 & 5 & \\
\hline CVABBW & 44 & 27 & 14 & 7 & 23 & \\
\hline CVABCT & 43 & 24 & 11 & 6 & 21 & \\
\hline CVTIMB & 16 & 10 & 7 & 4 & 12 & \\
\hline DSPICN & 31 & 16 & 7 & 5 & 12 & \\
\hline DSROAR & 15 & 13 & 6 & 3 & 9 & \\
\hline
\end{tabular}

${ }^{\mathrm{a}}$ Native hydrophyte walk-through richness; ${ }^{\mathrm{b}}$ Native dicot walk-through richness; ${ }^{\mathrm{c}}$ Native dicot herbaceous-layer richness; ${ }^{\mathrm{d}}$ Carex spp. Richness;

${ }^{\mathrm{e}}$ Native hydrophyte herbaceous-layer richness; ${ }^{\mathrm{f}}$ Non-native shrub richness. 
Appendix AI. Part 2. Continued.

\begin{tabular}{|c|c|c|c|c|c|c|}
\hline Site Code & NativeHydroWTRich $^{\mathrm{a}}$ & NatDicotWTRich $^{\mathrm{b}}$ & NatDicotRich $^{\mathrm{c}}$ & CarexRichness $^{\mathrm{d}}$ & NatHydroHrbRich ${ }^{\mathrm{e}}$ & NonNativeShrRich $^{\mathrm{f}}$ \\
\hline DSWILD & 13 & 10 & 8 & 1 & 10 & \\
\hline ЕРCMEM & 10 & 3 & 1 & & 4 & \\
\hline EPCMFO & 20 & 21 & 9 & 1 & 13 & 2 \\
\hline EPDMFO & 6 & 12 & 7 & 1 & 5 & \\
\hline EPDMPU & 15 & 15 & 8 & 2 & 7 & \\
\hline EPKYVE & 16 & 15 & 5 & 1 & 5 & \\
\hline EPRRXC & 15 & 18 & 6 & 1 & 7 & 1 \\
\hline EPSHEM & 12 & 11 & 3 & & 4 & \\
\hline EPSHSS & 30 & 20 & 5 & 3 & 9 & 1 \\
\hline GBBARN & 12 & 8 & 2 & & 6 & \\
\hline GBHOEF & 14 & 12 & 4 & & 6 & \\
\hline GBJENK & 15 & 14 & 2 & & 3 & \\
\hline GBMAPL & 7 & 9 & 2 & 1 & 2 & \\
\hline GBNOFO & 16 & 14 & 5 & 4 & 12 & \\
\hline GBNOSS & 23 & 16 & 6 & 3 & 12 & \\
\hline GBPLOT & 12 & 8 & 4 & & 8 & \\
\hline HCBEAV & 19 & 13 & 6 & 5 & 9 & 1 \\
\hline HCMITI & 22 & 14 & 3 & 6 & 8 & \\
\hline HCPIPE & 14 & 11 & 2 & & 3 & \\
\hline HCRANG & 24 & 13 & 7 & 6 & 13 & \\
\hline HIBRID & 46 & 48 & 13 & 4 & 16 & 1 \\
\hline HIGATE & 24 & 25 & 6 & 1 & 10 & \\
\hline
\end{tabular}

${ }^{\mathrm{a}}$ Native hydrophyte walk-through richness; ${ }^{\mathrm{b}}$ Native dicot walk-through richness; ${ }^{\mathrm{c}}$ Native dicot herbaceous-layer richness; ${ }_{\mathrm{d}}$ Carex spp.Richness;

${ }^{\mathrm{e}}$ Native hydrophyte herbaceous-layer richness; ${ }^{\mathrm{f}}$ Non-native shrub richness. 
Appendix AI. Part 2. Continued.

\begin{tabular}{|c|c|c|c|c|c|c|}
\hline Site Code & NativeHydroWTRich $^{a}$ & NatDicotWTRich $^{\mathrm{b}}$ & NatDicotRich $^{c}$ & CarexRichness $^{\mathrm{d}}$ & NatHydroHrbRich ${ }^{\mathrm{e}}$ & NonNativeShrRich \\
\hline HIJHPK & 20 & 16 & 1 & 2 & 2 & \\
\hline HIJHTU & 26 & 17 & 1 & 2 & 8 & 1 \\
\hline HIPENC & 22 & 12 & 3 & 1 & 11 & \\
\hline HISEWG & 32 & 47 & 15 & & 13 & \\
\hline HITRLR & 31 & 19 & 2 & 4 & 8 & \\
\hline MCFOUR & 18 & 18 & 5 & 4 & 4 & \\
\hline MCMEME & 22 & 17 & 6 & 1 & 11 & \\
\hline MCMFOR & 32 & 26 & 6 & 3 & 7 & \\
\hline MCNPFO & 15 & 14 & 6 & 3 & 8 & 1 \\
\hline MCPOND & 14 & 10 & 1 & & 3 & \\
\hline MCPOST & 28 & 23 & 3 & 4 & 5 & \\
\hline MCTELE & 21 & 23 & 1 & 2 & 3 & \\
\hline ME5092 & 48 & 39 & 11 & 4 & 13 & 1 \\
\hline MESCOX & 22 & 12 & 1 & 2 & 2 & \\
\hline MESCRO & 18 & 11 & 4 & & 11 & \\
\hline MESCUP & 24 & 13 & 4 & 3 & 10 & \\
\hline MESIGN & 36 & 30 & 10 & 4 & 13 & \\
\hline MESILV & 44 & 32 & 14 & 5 & 21 & \\
\hline METETR & 30 & 21 & 3 & 1 & 10 & \\
\hline MEWOLF & 23 & 16 & 2 & 3 & 6 & \\
\hline MRBESS & 34 & 20 & 9 & 7 & 19 & \\
\hline MRFARM & 26 & 18 & 7 & 3 & 10 & \\
\hline
\end{tabular}

${ }^{\mathrm{a}}$ Native hydrophyte walk-through richness; ${ }^{\mathrm{b}}$ Native dicot walk-through richness; ${ }^{\mathrm{c}}$ Native dicot herbaceous-layer richness; ${ }^{\mathrm{d}}$ Carex spp. Richness;

${ }^{\mathrm{e}}$ Native hydrophyte herbaceous-layer richness; ${ }^{\mathrm{f}}$ Non-native shrub richness. 
Appendix AI. Part 2. Continued.

\begin{tabular}{|c|c|c|c|c|c|c|}
\hline Site Code & NativeHydroWTRich $^{a}$ & NatDicotWTRich $^{\mathrm{b}}$ & NatDicotRich $^{\mathrm{c}}$ & CarexRichness ${ }^{\mathrm{d}}$ & NatHydroHrbRich ${ }^{\mathrm{e}}$ & NonNativeShrRich \\
\hline MRFORE & 31 & 28 & 12 & 6 & 16 & 1 \\
\hline MRSSSS & 23 & 15 & 4 & 4 & 11 & \\
\hline MRWEST & 18 & 15 & 7 & 2 & 10 & 1 \\
\hline MU55SS & 34 & 22 & 8 & 4 & 12 & \\
\hline MUDBOA & 26 & 15 & 6 & 4 & 9 & \\
\hline MUDEND & 31 & 18 & 8 & 4 & 15 & \\
\hline MUDRIC & 28 & 24 & 12 & 2 & 16 & \\
\hline MUDRIP & 33 & 23 & 7 & 3 & 13 & \\
\hline MUDTRA & 23 & 14 & 5 & 4 & 11 & \\
\hline MUEPAH & 32 & 21 & 9 & 6 & 13 & 1 \\
\hline MUMINE & 44 & 34 & 10 & 5 & 15 & 1 \\
\hline MUPOWR & 35 & 33 & 14 & 5 & 18 & 1 \\
\hline MUPULL & 22 & 15 & 2 & 3 & 7 & \\
\hline MUVBRD & 29 & 21 & 4 & 6 & 10 & \\
\hline MUVCRN & 12 & 8 & 2 & & 5 & \\
\hline OHHSFO & 18 & 23 & 9 & 4 & 10 & 3 \\
\hline OHINNS & 23 & 14 & 6 & 2 & 12 & \\
\hline OHKMRT & 6 & 4 & & & 1 & \\
\hline PA29TH & 17 & 10 & 3 & & 8 & \\
\hline PA83CR & 27 & 21 & 6 & 5 & 14 & \\
\hline PAFAMD & 25 & 16 & 2 & 3 & 4 & \\
\hline PAJCPY & 19 & 21 & 6 & & 6 & \\
\hline
\end{tabular}

${ }^{\mathrm{a}}$ Native hydrophyte walk-through richness; ${ }^{\mathrm{b}}$ Native dicot walk-through richness; ${ }^{\mathrm{c}}$ Native dicot herbaceous-layer richness; ${ }_{\mathrm{d}}$ Carex spp.Richness;

${ }^{\mathrm{e}}$ Native hydrophyte herbaceous-layer richness; ${ }^{\mathrm{f}}$ Non-native shrub richness. 
Appendix AI. Part 2. Continued.

\begin{tabular}{|c|c|c|c|c|c|c|}
\hline Site Code & NativeHydroWTRich $^{\mathrm{a}}$ & NatDicotWTRich $^{\mathrm{b}}$ & NatDicotRich $^{\mathrm{c}}$ & CarexRichness $^{\mathrm{d}}$ & NatHydroHrbRich ${ }^{\mathrm{e}}$ & NonNativeShrRich \\
\hline PALOUD & 18 & 10 & 6 & & 9 & \\
\hline PAPEFO & 26 & 23 & 8 & 4 & 14 & \\
\hline PAPEIM & 15 & 7 & 4 & 2 & 6 & \\
\hline PAPESW & 33 & 21 & 5 & 6 & 8 & \\
\hline PAWILL & 13 & 8 & 2 & & 3 & \\
\hline PCBLUE & 25 & 15 & 3 & 6 & 15 & 1 \\
\hline PCLPFO & 21 & 15 & 6 & 4 & 9 & \\
\hline PCROAD & 27 & 21 & 14 & 6 & 20 & 1 \\
\hline PEMIDW & 26 & 14 & 4 & 4 & 13 & \\
\hline PERDDP & 15 & 4 & 1 & 2 & 6 & \\
\hline PETHUM & 35 & 28 & 12 & 1 & 18 & \\
\hline PETOSS & 26 & 18 & 9 & 4 & 16 & \\
\hline RIASIA & 25 & 19 & 6 & 5 & 12 & \\
\hline RIBRID & 25 & 22 & 12 & 3 & 14 & 1 \\
\hline RIEAST & 22 & 25 & 12 & 1 & 9 & 1 \\
\hline SJBOAT & 37 & 23 & 10 & 6 & 16 & 1 \\
\hline SJBRID & 14 & 10 & 6 & 3 & 10 & 1 \\
\hline SJCHUR & 19 & 18 & 9 & 2 & 12 & \\
\hline SJGLAD & 23 & 15 & 8 & 6 & 16 & 1 \\
\hline SJMUDL & 33 & 24 & 8 & 6 & 18 & 1 \\
\hline SJPLOT & 18 & 10 & 5 & 5 & 7 & \\
\hline SJTELE & 20 & 13 & 5 & 3 & 10 & \\
\hline
\end{tabular}

${ }^{\mathrm{a}}$ Native hydrophyte walk-through richness; ${ }^{\mathrm{b}}$ Native dicot walk-through richness; ${ }^{\mathrm{c}}$ Native dicot herbaceous-layer richness; ${ }_{\mathrm{d}}$ Carex spp.Richness;

${ }^{\mathrm{e}}$ Native hydrophyte herbaceous-layer richness; ${ }^{\mathrm{f}}$ Non-native shrub richness. 
Appendix AI. Part 2. Continued.

\begin{tabular}{|c|c|c|c|c|c|c|}
\hline Site Code & NativeHydroWTRich $^{\mathrm{a}}$ & NatDicotWTRich $^{\mathrm{b}}$ & NatDicotRich $^{\mathrm{c}}$ & CarexRichness $^{\mathrm{d}}$ & NatHydroHrbRich ${ }^{\mathrm{e}}$ & NonNativeShrRich \\
\hline SMDTSS & 19 & 10 & 5 & 3 & 12 & \\
\hline SMFOFL & 11 & 12 & 7 & 1 & 7 & \\
\hline SMLPEM & 8 & 3 & & 2 & 1 & \\
\hline SMSEFL & 15 & 9 & 2 & 2 & 7 & \\
\hline SMSTEM & 20 & 9 & 3 & 2 & 8 & \\
\hline TRSPFO & 26 & 30 & 9 & 4 & 12 & 2 \\
\hline TRSPRI & 9 & 5 & 3 & 1 & 7 & \\
\hline TVFARM & 28 & 16 & 4 & 5 & 9 & \\
\hline TVISLE & 17 & 24 & 5 & 1 & 4 & 1 \\
\hline TVNEWT & 24 & 10 & 2 & 3 & 7 & \\
\hline TVPOUT & 35 & 25 & 6 & 3 & 10 & \\
\hline TVVBEM & 13 & 6 & 1 & 1 & 6 & \\
\hline TVVBIM & 12 & 5 & 2 & & 3 & \\
\hline TVVBRV & 19 & 16 & 5 & 2 & 8 & \\
\hline TVVBSS & 13 & 10 & 7 & & 8 & \\
\hline UDC001 & 33 & 19 & 8 & 5 & 14 & \\
\hline UDC002 & 15 & 10 & 1 & & 4 & \\
\hline UDC003 & 19 & 11 & 1 & 3 & 2 & \\
\hline UDC004 & 25 & 24 & 13 & 2 & 10 & \\
\hline UDC005 & 15 & 17 & 9 & 2 & 9 & \\
\hline UDC007 & 13 & 13 & 7 & 1 & 7 & \\
\hline UDC008 & 29 & 22 & 4 & 4 & 7 & \\
\hline
\end{tabular}

${ }^{\mathrm{a}}$ Native hydrophyte walk-through richness; ${ }^{\mathrm{b}}$ Native dicot walk-through richness; ${ }^{\mathrm{c}}$ Native dicot herbaceous-layer richness; ${ }_{\mathrm{d}}$ Carex spp.Richness;

${ }^{\mathrm{e}}$ Native hydrophyte herbaceous-layer richness; ${ }^{\mathrm{f}}$ Non-native shrub richness. 
Appendix AI. Part 2. Continued.

\begin{tabular}{|c|c|c|c|c|c|c|}
\hline Site Code & NativeHydroWTRich $^{\mathrm{a}}$ & NatDicotWTRich $^{\mathrm{b}}$ & NatDicotRich $^{c}$ & CarexRichness $^{\mathrm{d}}$ & NatHydroHrbRich ${ }^{\mathrm{e}}$ & NonNativeShrRich \\
\hline UDC012 & 37 & 26 & 13 & 6 & 18 & \\
\hline UDC013 & 36 & 22 & 8 & 5 & 14 & \\
\hline UDC014 & 25 & 18 & 16 & 2 & 20 & 1 \\
\hline UDC015 & 17 & 9 & 1 & 3 & 6 & \\
\hline UDC016 & 19 & 16 & 3 & 2 & 5 & \\
\hline UDC017 & 22 & 13 & 5 & 4 & 6 & \\
\hline UDC018 & 26 & 24 & 3 & 1 & 6 & \\
\hline UDC019 & 24 & 17 & 5 & 3 & 13 & \\
\hline UDC020 & 20 & 8 & 3 & 3 & 7 & \\
\hline VEPCON & 27 & 16 & 9 & 4 & 11 & \\
\hline VEPCOS & 31 & 18 & 12 & 5 & 19 & \\
\hline WBBARN & 18 & 10 & & 1 & 1 & \\
\hline WBCORN & 33 & 15 & 6 & 6 & 9 & \\
\hline WBROAD & 17 & 10 & 5 & 2 & 9 & \\
\hline WYBEAV & 19 & 17 & 7 & 2 & 12 & 1 \\
\hline WYCHWE & 35 & 26 & 11 & 4 & 17 & \\
\hline WYHCEA & 19 & 8 & 8 & 3 & 12 & \\
\hline WYINTR & 16 & 13 & 5 & 2 & 9 & \\
\hline WYTHOR & 22 & 12 & 8 & 4 & 15 & \\
\hline
\end{tabular}

${ }^{\mathrm{a}}$ Native hydrophyte walk-through richness; ${ }^{\mathrm{b}}$ Native dicot walk-through richness; ${ }^{\mathrm{c}}$ Native dicot herbaceous-layer richness; ${ }^{\mathrm{d}}$ Carex spp.Richness;

${ }^{\mathrm{e}}$ Native hydrophyte herbaceous-layer richness; ${ }^{\mathrm{f}}$ Non-native shrub richness. 
Appendix AJ. Importance values (IV) and mean DBH of tree strata metrics used to develop vegetation-based indices of biological integrity (Veg-IBI) for wetlands in West Virginia, USA from 2005-2006. Blanks indicate a metric value of zero.

\begin{tabular}{|c|c|c|c|c|}
\hline Site Code & MeanIV $^{a}$ & TreeFACupMeanIV $^{\mathrm{b}}$ & TreeFACWupMeanIV & MeanDBH $^{\circ}$ \\
\hline \multicolumn{5}{|l|}{ CFCROS } \\
\hline \multicolumn{5}{|l|}{ CFECUR } \\
\hline \multicolumn{5}{|l|}{ CFEINC } \\
\hline \multicolumn{5}{|l|}{ CFSLCH } \\
\hline \multicolumn{5}{|l|}{ CFSLIN } \\
\hline \multicolumn{5}{|l|}{ CGBRID } \\
\hline CGCPAS & 50.00 & 47.13 & & 22.75 \\
\hline CGROAD & 25.00 & 27.96 & 6.42 & 22.55 \\
\hline CGTRHE & 20.00 & 9.79 & & 25.20 \\
\hline \multicolumn{5}{|l|}{ CHNEER } \\
\hline CHSACH & 100.00 & 100.00 & 100.00 & 9.15 \\
\hline CHSAFO & 33.33 & 8.60 & 8.60 & 24.02 \\
\hline \multicolumn{5}{|l|}{ CHSARR } \\
\hline CHTREE & 20.00 & 23.97 & 28.23 & 22.57 \\
\hline \multicolumn{5}{|l|}{ CHWWBW } \\
\hline \multicolumn{5}{|l|}{ CHWWEM } \\
\hline CHWWFO & 25.00 & 30.25 & 21.05 & 29.16 \\
\hline CVABBW & 100.00 & 100.00 & & 14.00 \\
\hline CVABCT & 100.00 & & & 14.00 \\
\hline \multicolumn{5}{|l|}{ CVTIMB } \\
\hline \multicolumn{5}{|l|}{ DSPICN } \\
\hline \multicolumn{5}{|l|}{ DSROAR } \\
\hline \multicolumn{5}{|l|}{ DSWILD } \\
\hline \multicolumn{5}{|l|}{ ЕРCMEM } \\
\hline EPCMFO & 25.00 & 39.80 & 39.80 & 19.05 \\
\hline EPDMFO & 50.00 & 26.66 & 26.66 & 22.64 \\
\hline \multicolumn{5}{|l|}{ EPDMPU } \\
\hline \multicolumn{5}{|l|}{ EPKYVE } \\
\hline EPRRXC & 50.00 & & & 20.48 \\
\hline \multicolumn{5}{|l|}{ EPSHEM } \\
\hline \multicolumn{5}{|l|}{ EPSHSS } \\
\hline \multicolumn{5}{|l|}{ GBBARN } \\
\hline \multicolumn{5}{|l|}{ GBHOEF } \\
\hline \multicolumn{5}{|l|}{ GBJENK } \\
\hline GBMAPL & 100.00 & 100.00 & 100.00 & 21.26 \\
\hline GBNOFO & 50.00 & 91.80 & 91.80 & 20.28 \\
\hline \multicolumn{5}{|l|}{ GBNOSS } \\
\hline GBPLOT & & & & \\
\hline
\end{tabular}

${ }^{\mathrm{a}}$ Mean IV; ${ }^{\mathrm{b}}$ Mean IV of tress facultative or wetter; ${ }^{\mathrm{c}}$ Mean IV of trees facultative-wet or wetter; ${ }^{\mathrm{d}}$ Mean diameter-breast-height. 
Appendix AJ. Continued.

\begin{tabular}{|c|c|c|c|c|}
\hline Site Code & MeanIV $\mathrm{a}^{\mathrm{a}}$ & TreeFACupMeanIV $^{\mathrm{b}}$ & TreeFACWupMeanIV ${ }^{c}$ & MeanDBH $^{\mathrm{d}}$ \\
\hline \multicolumn{5}{|l|}{ HCBEAV } \\
\hline \multicolumn{5}{|l|}{ HCMITI } \\
\hline \multicolumn{5}{|l|}{ HCPIPE } \\
\hline \multicolumn{5}{|l|}{ HCRANG } \\
\hline HIBRID & 14.29 & 17.68 & 17.68 & 19.50 \\
\hline HIGATE & 25.00 & 13.99 & 15.82 & 20.24 \\
\hline HIJHPK & 33.33 & 45.80 & 45.80 & 39.69 \\
\hline \multicolumn{5}{|l|}{ HIJHTU } \\
\hline HIPENC & 50.00 & 50.00 & 50.00 & 28.50 \\
\hline HISEWG & 50.00 & 50.00 & 50.00 & 40.15 \\
\hline \multicolumn{5}{|l|}{ HITRLR } \\
\hline \multicolumn{5}{|l|}{ MCFOUR } \\
\hline \multicolumn{5}{|l|}{ MCMEME } \\
\hline MCMFOR & 33.33 & 33.33 & 10.24 & 25.86 \\
\hline MCNPFO & 50.00 & 93.14 & & 35.44 \\
\hline \multicolumn{5}{|l|}{ MCPOND } \\
\hline \multicolumn{5}{|l|}{ MCPOST } \\
\hline MCTELE & 100.00 & 100.00 & 100.00 & 13.00 \\
\hline \multicolumn{5}{|l|}{ ME5092 } \\
\hline \multicolumn{5}{|l|}{ MESCOX } \\
\hline \multicolumn{5}{|l|}{ MESCRO } \\
\hline \multicolumn{5}{|l|}{ MESCUP } \\
\hline \multicolumn{5}{|l|}{ MESIGN } \\
\hline MESILV & 100.00 & 100.00 & 100.00 & 30.40 \\
\hline \multicolumn{5}{|l|}{ METETR } \\
\hline \multicolumn{5}{|l|}{ MEWOLF } \\
\hline \multicolumn{5}{|l|}{ MRBESS } \\
\hline \multicolumn{5}{|l|}{ MRFARM } \\
\hline MRFORE & 20.00 & 20.00 & 24.21 & 20.93 \\
\hline \multicolumn{5}{|l|}{ MRSSSS } \\
\hline \multicolumn{5}{|l|}{ MRWEST } \\
\hline \multicolumn{5}{|l|}{ MU55SS } \\
\hline \multicolumn{5}{|l|}{ MUDBOA } \\
\hline \multicolumn{5}{|l|}{ MUDEND } \\
\hline \multicolumn{5}{|l|}{ MUDRIC } \\
\hline \multicolumn{5}{|l|}{ MUDRIP } \\
\hline MUDTRA & 100.00 & 100.00 & 100.00 & 11.91 \\
\hline MUEPAH & 100.00 & 100.00 & 100.00 & 8.68 \\
\hline
\end{tabular}

${ }^{\mathrm{a}}$ Mean IV; ${ }^{\mathrm{b}}$ Mean IV of tress facultative or wetter; ${ }^{\mathrm{c}}$ Mean IV of trees facultative-wet or wetter; ${ }^{\mathrm{d}}$ Mean diameter-breast-height. 
Appendix AJ. Continued.

\begin{tabular}{|c|c|c|c|c|}
\hline Site Code & MeanIV ${ }^{a}$ & TreeFACupMeanIV $^{\mathrm{b}}$ & TreeFACWupMeanIV $^{c}$ & MeanDBH \\
\hline MUMINE & 20.00 & 29.40 & 12.39 & 18.78 \\
\hline MUPOWR & 50.00 & 50.00 & & 13.88 \\
\hline \multicolumn{5}{|l|}{ MUPULL } \\
\hline \multicolumn{5}{|l|}{ MUVBRD } \\
\hline \multicolumn{5}{|l|}{ MUVCRN } \\
\hline OHHSFO & 16.67 & 14.86 & & 12.39 \\
\hline \multicolumn{5}{|l|}{ OHINNS } \\
\hline \multicolumn{5}{|l|}{ OHKMRT } \\
\hline \multicolumn{5}{|l|}{ PA29TH } \\
\hline PA83CR & 33.33 & 32.48 & 32.48 & 17.50 \\
\hline \multicolumn{5}{|l|}{ PAFAMD } \\
\hline \multicolumn{5}{|l|}{ PAJCPY } \\
\hline \multicolumn{5}{|l|}{ PALOUD } \\
\hline PAPEFO & 33.33 & 24.55 & 24.55 & 17.47 \\
\hline \multicolumn{5}{|l|}{ PAPEIM } \\
\hline PAPESW & 100.00 & & & 25.45 \\
\hline \multicolumn{5}{|l|}{ PAWILL } \\
\hline \multicolumn{5}{|l|}{ PCBLUE } \\
\hline PCLPFO & 50.00 & 50.00 & 50.00 & 21.00 \\
\hline \multicolumn{5}{|l|}{ PCROAD } \\
\hline \multicolumn{5}{|l|}{ PEMIDW } \\
\hline \multicolumn{5}{|l|}{ PERDDP } \\
\hline \multicolumn{5}{|l|}{ PETHUM } \\
\hline \multicolumn{5}{|l|}{ PETOSS } \\
\hline RIASIA & 100.00 & 100.00 & 100.00 & 28.20 \\
\hline \multicolumn{5}{|l|}{ RIBRID } \\
\hline RIEAST & 50.00 & 21.41 & 21.41 & 32.67 \\
\hline \multicolumn{5}{|l|}{ SJBOAT } \\
\hline \multicolumn{5}{|l|}{ SJBRID } \\
\hline SJCHUR & 100.00 & & & 17.00 \\
\hline SJGLAD & 100.00 & 100.00 & 100.00 & 14.00 \\
\hline SJMUDL & 100.00 & 100.00 & 100.00 & 17.30 \\
\hline \multicolumn{5}{|l|}{ SJPLOT } \\
\hline \multicolumn{5}{|l|}{ SJTELE } \\
\hline \multicolumn{5}{|l|}{ SMDTSS } \\
\hline SMFOFL & 20.00 & 23.91 & & 21.63 \\
\hline \multicolumn{5}{|l|}{ SMLPEM } \\
\hline SMSEFL & & & & \\
\hline
\end{tabular}

${ }^{\mathrm{a}}$ Mean IV; ${ }^{\mathrm{b}}$ Mean IV of tress facultative or wetter; ${ }^{\mathrm{c}}$ Mean IV of trees facultative-wet or wetter; ${ }^{\mathrm{d}}$ Mean diameter-breast-height. 
Appendix AJ. Continued.

\begin{tabular}{|c|c|c|c|c|}
\hline Site Code & MeanIV $^{a}$ & TreeFACupMeanIV & TreeFACWupMeanIV $^{\mathrm{c}}$ & MeanDBH $^{\mathrm{d}}$ \\
\hline \multicolumn{5}{|l|}{ SMSTEM } \\
\hline TRSPFO & 25.00 & 28.75 & 24.88 & 18.80 \\
\hline \multicolumn{5}{|l|}{ TRSPRI } \\
\hline \multicolumn{5}{|l|}{ TVFARM } \\
\hline TVISLE & 14.29 & 26.66 & 26.66 & 34.73 \\
\hline \multicolumn{5}{|l|}{ TVNEWT } \\
\hline \multicolumn{5}{|l|}{ TVPOUT } \\
\hline \multicolumn{5}{|l|}{ TVVBEM } \\
\hline \multicolumn{5}{|l|}{ TVVBIM } \\
\hline TVVBRV & 50.00 & 50.00 & 50.00 & 30.03 \\
\hline \multicolumn{5}{|l|}{ TVVBSS } \\
\hline \multicolumn{5}{|l|}{ UDC001 } \\
\hline \multicolumn{5}{|l|}{ UDC002 } \\
\hline \multicolumn{5}{|l|}{ UDC003 } \\
\hline UDC004 & 50.00 & 33.87 & & 17.92 \\
\hline \multicolumn{5}{|l|}{ UDC005 } \\
\hline UDC007 & 100.00 & & & 12.20 \\
\hline \multicolumn{5}{|l|}{ UDC008 } \\
\hline UDC012 & 50.00 & 50.00 & 80.15 & 30.30 \\
\hline \multicolumn{5}{|l|}{ UDC013 } \\
\hline \multicolumn{5}{|l|}{ UDC014 } \\
\hline \multicolumn{5}{|l|}{ UDC015 } \\
\hline \multicolumn{5}{|l|}{ UDC016 } \\
\hline \multicolumn{5}{|l|}{ UDC017 } \\
\hline \multicolumn{5}{|l|}{ UDC018 } \\
\hline \multicolumn{5}{|l|}{ UDC019 } \\
\hline \multicolumn{5}{|l|}{ UDC020 } \\
\hline \multicolumn{5}{|l|}{ VEPCON } \\
\hline \multicolumn{5}{|l|}{ VEPCOS } \\
\hline \multicolumn{5}{|l|}{ WBBARN } \\
\hline \multicolumn{5}{|l|}{ WBCORN } \\
\hline \multicolumn{5}{|l|}{ WBROAD } \\
\hline WYBEAV & 100.00 & 100.00 & 100.00 & 25.00 \\
\hline \multicolumn{5}{|l|}{ WYCHWE } \\
\hline \multicolumn{5}{|l|}{ WYHCEA } \\
\hline WYINTR & 50.00 & 89.83 & 89.83 & 24.50 \\
\hline WYTHOR & & & & \\
\hline
\end{tabular}

${ }^{\mathrm{a}}$ Mean IV; ${ }^{\mathrm{b}}$ Mean IV of tress facultative or wetter; ${ }^{\mathrm{c}}$ Mean IV of trees facultative-wet or wetter; ${ }^{\mathrm{d}}$ Mean diameter-breast-height. 
Appendix AK. Vegetation summary statistics of metric scores statewide and by ecoregion used to form vegetation-based indices of biological integrity (Veg-IBI) for wetlands in West Virginia, USA 2005-2006.

\begin{tabular}{|c|c|c|c|c|c|c|c|c|c|}
\hline \multicolumn{10}{|c|}{ Statewide Vegetation Sampling $(\mathrm{N}=151)$} \\
\hline & WVFQI & PAFQI & MEANC & ADJFQAI & $\begin{array}{c}\text { OBLONLY } \\
\text { HRBRC }\end{array}$ & $\begin{array}{l}\text { FACWUP } \\
\text { HRBRC }\end{array}$ & $\begin{array}{c}\text { FACUPHR } \\
\text { BRC }\end{array}$ & $\begin{array}{c}\text { FACONLY } \\
\text { HRBRC }\end{array}$ & $\begin{array}{c}\text { SHRNATHY } \\
\text { DROP }\end{array}$ \\
\hline Minimum & 10.174 & 10.174 & 2.831 & 23.593 & 0 & 0 & 0 & 0 & 0 \\
\hline Maximum & 40.851 & 34.262 & 6.459 & 64.586 & 1 & 1 & 1 & 0.333 & 1.696 \\
\hline Mean & 25.47 & 22.71 & 4.386 & 42.172 & 0.497 & 0.778 & 0.812 & 0.033 & 0.208 \\
\hline \multirow[t]{2}{*}{ Std. Error } & 0.44 & 0.426 & 0.054 & 0.627 & 0.028 & 0.018 & 0.017 & 0.005 & 0.028 \\
\hline & $\begin{array}{l}\text { CAREXW } \\
\text { TRICH }\end{array}$ & $\begin{array}{l}\text { INVGRA } \\
\text { MWTRIC }\end{array}$ & $\begin{array}{c}\text { NATIVE } \\
\text { PLANT } \\
\text { W }\end{array}$ & $\begin{array}{l}\text { NONNAT } \\
\text { IVEPLA }\end{array}$ & $\begin{array}{l}\text { NATIVEHY } \\
\text { DROW }\end{array}$ & $\begin{array}{l}\text { NATIVE } \\
\text { HYDROH }\end{array}$ & $\begin{array}{c}\text { NATDICOT } \\
\text { WTRI }\end{array}$ & $\begin{array}{c}\text { NATDICOT } \\
\text { HRBR }\end{array}$ & SHRUBRICH \\
\hline Minimum & 0 & 0 & 5 & 0 & 5 & 0 & 2 & 0 & 0 \\
\hline Maximum & 8 & 4 & 64 & 14 & 48 & 23 & 48 & 16 & 15 \\
\hline Mean & 2.927 & 0.497 & 28.364 & 3.026 & 23.02 & 9.675 & 16.96 & 5.907 & 2.662 \\
\hline \multirow[t]{2}{*}{ Std. Error } & 0.165 & 0.067 & 0.905 & 0.256 & 0.715 & 0.39 & 0.633 & 0.305 & 0.214 \\
\hline & $\begin{array}{l}\text { NATIVES } \\
\text { HRRIC }\end{array}$ & $\begin{array}{l}\text { NONNAT } \\
\text { IVESHR }\end{array}$ & $\begin{array}{l}\text { TREERI } \\
\mathrm{CH}\end{array}$ & MEANIV & $\begin{array}{c}\text { TREEFACU } \\
\text { PMEA }\end{array}$ & $\begin{array}{c}\text { TREEFA } \\
\text { CWUPM } \\
\text { E }\end{array}$ & MEANDBH & FERNRC & MONORC \\
\hline Minimum & 0 & 0 & 0 & 0 & 0 & 0 & 0 & 0 & 0 \\
\hline Maximum & 14 & 3 & 36 & 100 & 100 & 100 & 40.15 & 0.773 & 1 \\
\hline Mean & 2.325 & 0.205 & 3.344 & 17.463 & 14.927 & 12.232 & 6.836 & 0.022 & 0.509 \\
\hline \multirow[t]{2}{*}{ Std. Error } & 0.189 & 0.039 & 0.573 & 2.576 & 2.432 & 2.31 & 0.897 & 0.006 & 0.023 \\
\hline & $\begin{array}{c}\text { NATIVEG } \\
\text { RAMRC }\end{array}$ & $\begin{array}{l}\text { INVGRA } \\
\text { SSRC }\end{array}$ & $\begin{array}{l}\text { NATIVE } \\
\text { DICOTR }\end{array}$ & DICOTRC & CAREXRC & $\begin{array}{l}\text { NONNAT } \\
\text { IVERC }\end{array}$ & $\begin{array}{c}\text { PHALARIS } \\
\text { RC }\end{array}$ & $\begin{array}{c}\text { SENSITIVE } \\
\text { RC }\end{array}$ & $\begin{array}{c}\text { TOLERANTR } \\
\text { C }\end{array}$ \\
\hline Minimum & 0 & 0 & 0 & 0 & 0 & 0 & 0 & 0 & 0 \\
\hline Maximum & 1 & 0.347 & 1 & 1 & 0.766 & 0.601 & 0.993 & 1 & 0.993 \\
\hline Mean & 0.405 & 0.019 & 0.318 & 0.37 & 0.068 & 0.061 & 0.06 & 0.077 & 0.127 \\
\hline \multirow[t]{2}{*}{ Std. Error } & 0.024 & 0.004 & 0.02 & 0.022 & 0.01 & 0.01 & 0.016 & 0.014 & 0.018 \\
\hline & $\begin{array}{c}\text { BRYOPH } \\
\text { RC }\end{array}$ & $\begin{array}{l}\text { NATHYD } \\
\text { ROHRBR }\end{array}$ & $\begin{array}{l}\text { PHAINV } \\
\text { GRASSR }\end{array}$ & $\begin{array}{l}\text { SHRNATI } \\
\text { VEPC }\end{array}$ & $\begin{array}{c}\text { SHRNONN } \\
\text { ATPC }\end{array}$ & & & & \\
\hline Minimum & 0 & 0 & 0 & 0 & 0 & & & & \\
\hline Maximum & 0.541 & 1 & 0.993 & 1.696 & 0.247 & & & & \\
\hline Mean & 0.049 & 0.78 & 0.079 & 0.255 & 0.011 & & & & \\
\hline Std. Error & 0.009 & 0.019 & 0.016 & 0.03 & 0.003 & & & & \\
\hline
\end{tabular}


Appendix AK. Continued.

\begin{tabular}{|c|c|c|c|c|c|c|c|c|c|}
\hline \multicolumn{10}{|c|}{ Allegheny Highlands Vegetation Sampling $(\mathrm{N}=65)$} \\
\hline & WVFQI & PAFQI & MEANC & ADJFQAI & $\begin{array}{c}\text { OBLONLY } \\
\text { HRBRC }\end{array}$ & $\begin{array}{c}\text { FACWUP } \\
\text { HRBRC }\end{array}$ & $\begin{array}{c}\text { FACUPHR } \\
\text { BRC }\end{array}$ & $\begin{array}{c}\text { FACONLY } \\
\text { HRBRC }\end{array}$ & $\begin{array}{l}\text { SHRNATHY } \\
\text { DROP }\end{array}$ \\
\hline Minimum & 10.174 & 10.174 & 2.831 & 23.593 & 0 & 0.108 & 0.247 & 0 & 0 \\
\hline Maximum & 40.851 & 34.262 & 5.624 & 56.243 & 1 & 1 & 1 & 0.333 & 1.647 \\
\hline Mean & 27.369 & 24.976 & 4.479 & 43.501 & 0.453 & 0.769 & 0.809 & 0.037 & 0.256 \\
\hline \multirow[t]{2}{*}{ Std. Error } & 0.706 & 0.653 & 0.068 & 0.802 & 0.04 & 0.028 & 0.025 & 0.009 & 0.05 \\
\hline & $\begin{array}{l}\text { CAREXW } \\
\text { TRICH }\end{array}$ & $\begin{array}{l}\text { INVGRA } \\
\text { MWTRIC }\end{array}$ & $\begin{array}{l}\text { NATIVEP } \\
\text { LANTW }\end{array}$ & $\begin{array}{l}\text { NONNAT } \\
\text { IVEPLA }\end{array}$ & $\begin{array}{c}\text { NATIVEHY } \\
\text { DROW }\end{array}$ & $\begin{array}{l}\text { NATIVE } \\
\text { HYDROH }\end{array}$ & $\begin{array}{c}\text { NATDICOT } \\
\text { WTRI }\end{array}$ & $\begin{array}{c}\text { NATDICOT } \\
\text { HRBR }\end{array}$ & SHRUBRICH \\
\hline Minimum & 0 & 0 & 6 & 0 & 6 & 1 & 4 & 0 & 0 \\
\hline Maximum & 8 & 4 & 64 & 14 & 48 & 23 & 48 & 16 & 15 \\
\hline Mean & 3.354 & 0.585 & 32.308 & 2.615 & 26.631 & 11.015 & 19.585 & 6.846 & 2.985 \\
\hline \multirow[t]{2}{*}{ Std. Error } & 0.243 & 0.116 & 1.463 & 0.383 & 1.112 & 0.629 & 1.071 & 0.536 & 0.377 \\
\hline & $\begin{array}{c}\text { NATIVES } \\
\text { HRRIC }\end{array}$ & $\begin{array}{l}\text { NONNAT } \\
\text { IVESHR }\end{array}$ & $\begin{array}{c}\text { TREERIC } \\
\mathrm{H}\end{array}$ & MEANIV & $\begin{array}{c}\text { TREEFACU } \\
\text { PMEA }\end{array}$ & $\begin{array}{c}\text { TREEFA } \\
\text { CWUPM } \\
\text { E }\end{array}$ & MEANDBH & FERNRC & MONORC \\
\hline Minimum & 0 & 0 & 0 & 0 & 0 & 0 & 0 & 0 & 0.056 \\
\hline Maximum & 14 & 3 & 36 & 100 & 100 & 100 & 40.15 & 0.226 & 1 \\
\hline Mean & 2.646 & 0.2 & 3.708 & 17.297 & 14.594 & 10.625 & 7.101 & 0.022 & 0.492 \\
\hline \multirow[t]{2}{*}{ Std. Error } & 0.338 & 0.063 & 0.992 & 3.864 & 3.553 & 3.309 & 1.414 & 0.006 & 0.035 \\
\hline & $\begin{array}{c}\text { NATIVEG } \\
\text { RAMRC }\end{array}$ & $\begin{array}{l}\text { INVGRA } \\
\text { SSRC }\end{array}$ & $\begin{array}{l}\text { NATIVE } \\
\text { DICOTR }\end{array}$ & $\begin{array}{c}\text { DICOTR } \\
\mathrm{C}\end{array}$ & CAREXRC & $\begin{array}{l}\text { NONNAT } \\
\text { IVERC }\end{array}$ & $\begin{array}{c}\text { PHALARIS } \\
\text { RC }\end{array}$ & $\begin{array}{c}\text { SENSITIVE } \\
\text { RC }\end{array}$ & $\begin{array}{c}\text { TOLERANTR } \\
\text { C }\end{array}$ \\
\hline Minimum & 0.005 & 0 & 0 & 0 & 0 & 0 & 0 & 0 & 0 \\
\hline Maximum & 1 & 0.226 & 0.906 & 0.906 & 0.532 & 0.332 & 0.993 & 0.403 & 0.993 \\
\hline Mean & 0.454 & 0.013 & 0.345 & 0.365 & 0.08 & 0.029 & 0.053 & 0.041 & 0.086 \\
\hline \multirow[t]{2}{*}{ Std. Error } & 0.036 & 0.004 & 0.029 & 0.029 & 0.014 & 0.008 & 0.024 & 0.011 & 0.024 \\
\hline & $\begin{array}{c}\text { BRYOPH } \\
\text { RC }\end{array}$ & $\begin{array}{l}\text { NATHYD } \\
\text { ROHRBR }\end{array}$ & $\begin{array}{l}\text { PHAINV } \\
\text { GRASSR }\end{array}$ & $\begin{array}{l}\text { SHRNAT } \\
\text { IVEPC }\end{array}$ & $\begin{array}{c}\text { SHRNONN } \\
\text { ATPC }\end{array}$ & & & & \\
\hline Minimum & 0 & 0.247 & 0 & 0 & 0 & & & & \\
\hline Maximum & 0.541 & 1 & 0.993 & 1.647 & 0.193 & & & & \\
\hline Mean & 0.073 & 0.797 & 0.066 & 0.312 & 0.01 & & & & \\
\hline Std. Error & 0.015 & 0.027 & 0.024 & 0.052 & 0.004 & & & & \\
\hline
\end{tabular}


Appendix AK. Continued.

\begin{tabular}{|c|c|c|c|c|c|c|c|c|c|}
\hline \multicolumn{10}{|c|}{ Ridge and Valley Vegetation Sampling $(\mathrm{N}=27)$} \\
\hline \multirow[b]{3}{*}{ Minimum } & \multirow{3}{*}{$\begin{array}{c}\text { WVFQI } \\
15.405\end{array}$} & \multirow{3}{*}{$\begin{array}{c}\text { PAFQI } \\
12.658\end{array}$} & \multirow{3}{*}{$\begin{array}{c}\text { MEANC } \\
3.161\end{array}$} & \multirow[b]{2}{*}{ ADJFQAI } & \multirow{2}{*}{$\begin{array}{c}\text { OBLONLY } \\
\text { HRBRC }\end{array}$} & \multirow{2}{*}{$\begin{array}{c}\text { FACWUP } \\
\text { HRBRC }\end{array}$} & \multirow{2}{*}{$\begin{array}{c}\text { FACUPHR } \\
\text { BRC }\end{array}$} & \multirow{2}{*}{$\begin{array}{c}\text { FACONLY } \\
\text { HRBRC }\end{array}$} & \multirow{2}{*}{$\begin{array}{c}\text { SHRNATHY } \\
\text { DROP }\end{array}$} \\
\hline & & & & & & & & & \\
\hline & & & & 28.469 & 0 & 0.295 & 0.405 & 0 & 0 \\
\hline Maximum & 33.656 & 32.815 & 6.459 & 64.586 & 1 & 1 & 1 & 0.307 & 0.675 \\
\hline Mean & 23.972 & 21.107 & 4.558 & 43.788 & 0.464 & 0.751 & 0.789 & 0.039 & 0.085 \\
\hline \multirow[t]{3}{*}{ Std. Error } & 1.014 & 1.049 & 0.18 & 2.072 & 0.071 & 0.042 & 0.035 & 0.016 & 0.033 \\
\hline & CAREXW & INVGRA & NATIVEP & NONNAT & NATIVEHY & NATIVE & NATDICOT & NATDICOT & \\
\hline & TRICH & MWTRIC & LANTW & IVEPLA & DROW & HYDROH & WTRI & HRBR & SHRUBRICH \\
\hline Minimum & 0 & 0 & 10 & 0 & 6 & 1 & 3 & 0 & 0 \\
\hline Maximum & 6 & 3 & 40 & 14 & 35 & 13 & 25 & 9 & 5 \\
\hline Mean & 1.926 & 0.296 & 22.407 & 2.704 & 17.963 & 7.185 & 12.741 & 4.63 & 1.741 \\
\hline \multirow[t]{4}{*}{ Std. Error } & 0.302 & 0.129 & 1.634 & 0.645 & 1.471 & 0.597 & 1.097 & 0.49 & 0.327 \\
\hline & & & & & & TREEFA & & & \\
\hline & NATIVES & NONNAT & TREERIC & & TREEFACU & CWUPM & & & \\
\hline & HRRIC & IVESHR & $\mathrm{H}$ & MEANIV & PMEA & E & MEANDBH & FERNRC & MONORC \\
\hline Minimum & 0 & 0 & 0 & 0 & 0 & 0 & 0 & 0 & 0 \\
\hline Maximum & 5 & 2 & 21 & 50 & 50 & 50 & 34.729 & 0.773 & 1 \\
\hline Mean & 1.556 & 0.185 & 3 & 7.751 & 6.186 & 5.301 & 5.503 & 0.048 & 0.448 \\
\hline \multirow[t]{3}{*}{ Std. Error } & 0.294 & 0.093 & 1.208 & 3.182 & 2.68 & 2.6 & 2.086 & 0.031 & 0.059 \\
\hline & NATIVEG & INVGRA & NATIVE & DICOTR & & NONNAT & PHALARIS & SENSITIVE & TOLERANTR \\
\hline & RAMRC & SSRC & DICOTR & $\mathrm{C}$ & CAREXRC & IVERC & $\mathrm{RC}$ & $\mathrm{RC}$ & $\mathrm{C}$ \\
\hline Minimum & 0 & 0 & 0 & 0 & 0 & 0 & 0 & 0 & 0 \\
\hline Maximum & 1 & 0.347 & 0.782 & 0.984 & 0.601 & 0.581 & 0.723 & 0.344 & 0.73 \\
\hline Mean & 0.364 & 0.024 & 0.31 & 0.401 & 0.06 & 0.115 & 0.062 & 0.063 & 0.179 \\
\hline \multirow[t]{3}{*}{ Std. Error } & 0.059 & 0.015 & 0.045 & 0.057 & 0.026 & 0.037 & 0.034 & 0.018 & 0.05 \\
\hline & BRYOPH & NATHYD & PHAINV & SHRNAT & SHRNONN & & & & \\
\hline & $\mathrm{RC}$ & ROHRBR & GRASSR & IVEPC & ATPC & & & & \\
\hline Minimum & 0 & 0.251 & 0 & 0 & 0 & & & & \\
\hline Maximum & 0.488 & 1 & 0.723 & 0.675 & 0.247 & & & & \\
\hline Mean & 0.071 & 0.717 & 0.087 & 0.122 & 0.011 & & & & \\
\hline Std. Error & 0.026 & 0.049 & 0.037 & 0.034 & 0.009 & & & & \\
\hline
\end{tabular}


Appendix AK. Continued.

\begin{tabular}{|c|c|c|c|c|c|c|c|c|c|}
\hline \multicolumn{10}{|c|}{ Western Allegheny Plateau (N=59) } \\
\hline \multirow[b]{3}{*}{ Minimum } & \multirow{3}{*}{$\begin{array}{c}\text { WVFQI } \\
14.215\end{array}$} & \multirow{3}{*}{$\begin{array}{c}\text { PAFQI } \\
12.552\end{array}$} & \multirow{3}{*}{$\begin{array}{c}\text { MEANC } \\
3.199\end{array}$} & \multirow[b]{2}{*}{ ADJFQAI } & \multirow{2}{*}{$\begin{array}{c}\text { OBLONLY } \\
\text { HRBRC }\end{array}$} & \multirow{2}{*}{$\begin{array}{l}\text { FACWUP } \\
\text { HRBRC }\end{array}$} & \multirow{2}{*}{$\begin{array}{c}\text { FACUPHR } \\
\text { BRC }\end{array}$} & \multirow{2}{*}{$\begin{array}{c}\text { FACONLY } \\
\text { HRBRC }\end{array}$} & \multirow{2}{*}{$\begin{array}{c}\text { SHRNATHY } \\
\text { DROP }\end{array}$} \\
\hline & & & & & & & & & \\
\hline & & & & 26.942 & 0 & 0 & 0 & 0 & 0 \\
\hline Maximum & 34.17 & 31.172 & 6.357 & 63.571 & 1 & 1 & 1 & 0.224 & 1.696 \\
\hline Mean & 24.064 & 20.947 & 4.204 & 39.969 & 0.561 & 0.8 & 0.827 & 0.025 & 0.211 \\
\hline \multirow[t]{3}{*}{ Std. Error } & 0.584 & 0.534 & 0.076 & 0.895 & 0.045 & 0.03 & 0.028 & 0.007 & 0.041 \\
\hline & CAREXW & INVGRA & NATIVEP & NONNAT & NATIVEHY & NATIVE & NATDICOT & NATDICOT & \\
\hline & TRICH & MWTRIC & LANTW & IVEPLA & DROW & HYDROH & WTRI & HRBR & SHRUBRICH \\
\hline Minimum & 0 & 0 & 5 & 0 & 5 & 0 & 2 & 0 & 0 \\
\hline Maximum & 7 & 3 & 52 & 13 & 37 & 20 & 30 & 14 & 9 \\
\hline Mean & 2.915 & 0.492 & 26.746 & 3.627 & 21.356 & 9.339 & 16 & 5.458 & 2.729 \\
\hline \multirow[t]{4}{*}{ Std. Error } & 0.282 & 0.098 & 1.286 & 0.399 & 0.969 & 0.608 & 0.849 & 0.431 & 0.317 \\
\hline & & & & & & TREEFA & & & \\
\hline & NATIVES & NONNAT & TREERIC & & TREEFACU & CWUPM & & & \\
\hline & HRRIC & IVESHR & $\mathrm{H}$ & MEANIV & PMEA & E & MEANDBH & FERNRC & MONORC \\
\hline Minimum & 0 & 0 & 0 & 0 & 0 & 0 & 0 & 0 & 0 \\
\hline Maximum & 7 & 2 & 29 & 100 & 100 & 100 & 35.444 & 0.224 & 0.981 \\
\hline Mean & 2.322 & 0.22 & 3.102 & 22.09 & 19.293 & 17.173 & 7.153 & 0.011 & 0.556 \\
\hline \multirow[t]{3}{*}{ Std. Error } & 0.27 & 0.06 & 0.822 & 4.753 & 4.627 & 4.447 & 1.41 & 0.005 & 0.036 \\
\hline & NATIVEG & INVGRA & NATIVE & DICOTR & & NONNAT & PHALARIS & SENSITIVE & TOLERANTR \\
\hline & RAMRC & SSRC & DICOTR & $\mathrm{C}$ & CAREXRC & IVERC & $\mathrm{RC}$ & $\mathrm{RC}$ & $\mathrm{C}$ \\
\hline Minimum & 0 & 0 & 0 & 0 & 0 & 0 & 0 & 0 & 0 \\
\hline Maximum & 0.949 & 0.275 & 1 & 1 & 0.766 & 0.601 & 0.929 & 1 & 0.929 \\
\hline Mean & 0.369 & 0.022 & 0.291 & 0.361 & 0.06 & 0.071 & 0.067 & 0.122 & 0.148 \\
\hline \multirow[t]{3}{*}{ Std. Error } & 0.039 & 0.008 & 0.034 & 0.036 & 0.015 & 0.017 & 0.026 & 0.033 & 0.031 \\
\hline & BRYOPH & NATHYD & PHAINV & SHRNAT & SHRNONN & & & & \\
\hline & $\mathrm{RC}$ & ROHRBR & GRASSR & IVEPC & ATPC & & & & \\
\hline Minimum & 0 & 0 & 0 & 0 & 0 & & & & \\
\hline Maximum & 0.364 & 1 & 0.929 & 1.696 & 0.189 & & & & \\
\hline Mean & 0.012 & 0.789 & 0.09 & 0.254 & 0.011 & & & & \\
\hline Std. Error & 0.007 & 0.03 & 0.027 & 0.045 & 0.005 & & & & \\
\hline
\end{tabular}


Appendix AL. Nektonic macroinvertebrate community metrics box-and-whisker results and narrative descriptions for depressional wetlands $(\mathrm{N}=22)$. Classifications are reference $(\mathrm{R})$ and stressed (S).
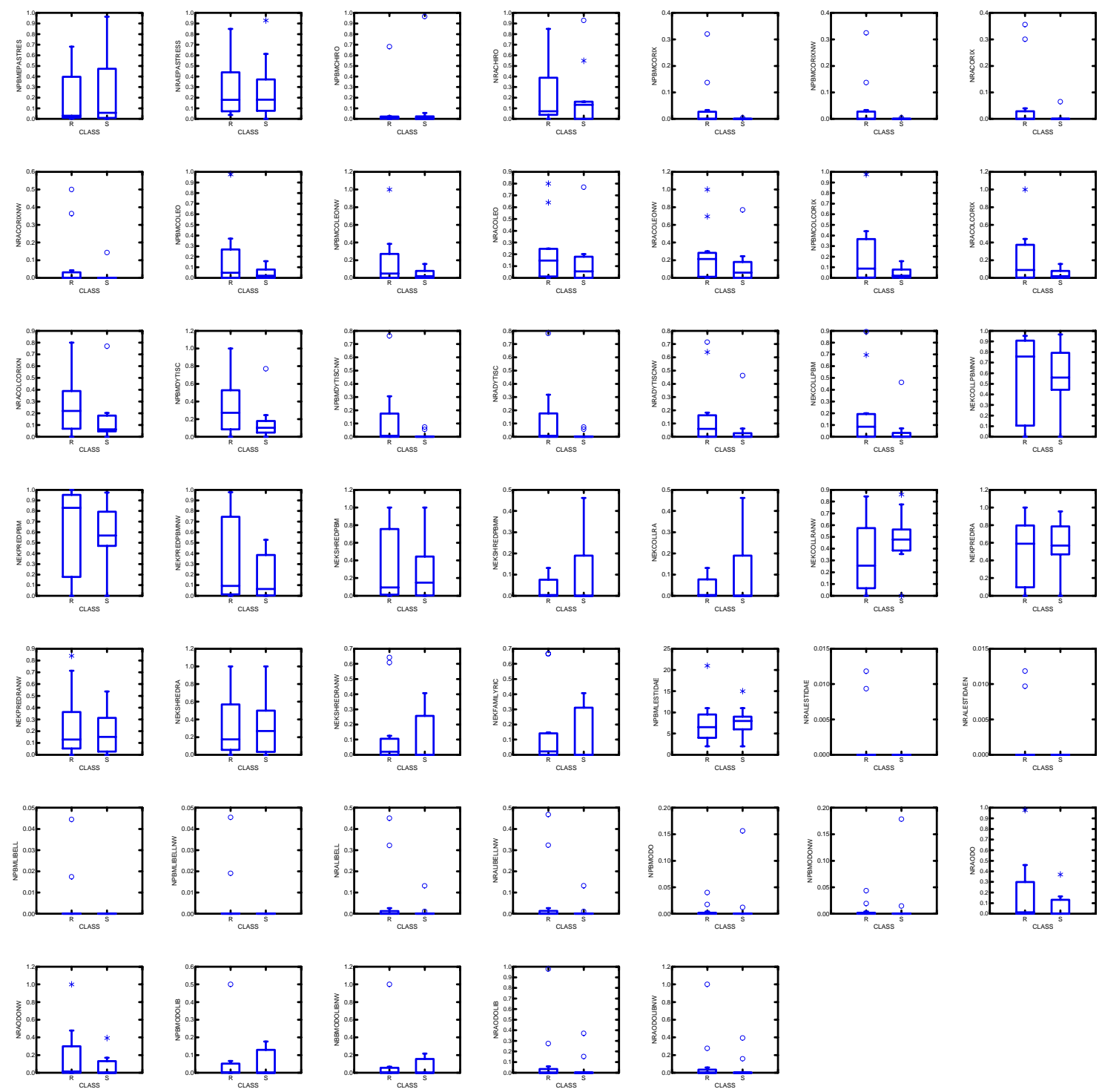


\begin{tabular}{|c|c|c|}
\hline Metric Code & Metric Description & Rating \\
\hline npBMepaStres & $\%$ Biomass EPA stressed & poor \\
\hline nRAepaStress & Relative abundance EPA stressed & poor \\
\hline npBMChiro & \% Biomass Chironomidae & poor \\
\hline nRAChiro & Relative abundance Chironomidae & poor \\
\hline npBMCorix & $\%$ Biomass Corixidae & poor \\
\hline npBMCorixNW & $\%$ Biomass Corixidae $^{a}$ & poor \\
\hline nRACorix & Relative abundance Corixidae & poor \\
\hline nRACorixNW & Relative abundance Corixidae $^{a}$ & poor \\
\hline npBMColeo & $\%$ Biomass Coleoptera & poor \\
\hline npBMColeoNW & $\%$ Biomass Coleoptera $^{\mathrm{a}}$ & poor \\
\hline nRAColeo & Relative abundance Coleoptera & poor \\
\hline nRAColeoNW & Relative abundance Coleoptera ${ }^{a}$ & poor \\
\hline npBMColCorix & $\%$ Biomass Coleoptera + Corixidae & fair \\
\hline npBMColCorixNW & $\%$ Biomass Coleoptera + Corixidae NW & fair \\
\hline nRAColCorix & Relative abundance Coleoptera + Corixidae & fair \\
\hline nRAColCorixN & Relative abundance Coleoptera + Corixidae $^{\mathrm{a}}$ & good \\
\hline npBMDytisc & $\%$ Biomass Dytiscidae & good \\
\hline npBMDytiscNW & \% Biomass Dytiscidae NW & poor \\
\hline nRADytisc & Relative abundance Dytiscidae & poor \\
\hline nRADytiscNW & Relative abundance Dytiscidae ${ }^{a}$ & poor \\
\hline nekCollpBM & $\%$ Biomass collector & poor \\
\hline nekCollpBMNW & $\%$ Biomass collector $^{\mathrm{a}}$ & poor \\
\hline nekPredpBM & $\%$ Biomass predator & fair \\
\hline nekPredpBMNW & $\%$ Biomass predator $^{\mathrm{a}}$ & poor \\
\hline nekShredpBM & $\%$ Biomass shredder & poor \\
\hline nekShredpBMNW & $\%$ Biomass shredder $^{\mathrm{a}}$ & poor \\
\hline nekCollRA & Relative abundance collector & poor \\
\hline nekCollRANW & Relative abundance collector ${ }^{\mathrm{a}}$ & fair \\
\hline nekPredRA & Relative abundance predator & poor \\
\hline nekPredRANW & Relative abundance predator ${ }^{a}$ & poor \\
\hline nekShredRA & Relative abundance shredder & poor \\
\hline nekShredRANW & Relative abundance shredder ${ }^{\mathrm{a}}$ & poor \\
\hline NekFamilyRich & Familial richness & poor \\
\hline npBMLestidae & $\%$ Biomass Lestidae & poor \\
\hline npBMLestidaeN & $\%$ Biomass Lestidae ${ }^{a}$ & poor \\
\hline nRALestidae & Relative abundance Lestidae & poor \\
\hline nRALestidaeN & Relative abundance Lestidae $^{a}$ & poor \\
\hline npBMLibell & \% Biomass Libellulidae & poor \\
\hline npBMLibellNW & $\%$ Biomass Libellulidae $^{\mathrm{a}}$ & poor \\
\hline nRALibell & Relative abundance Libellulidae & poor \\
\hline nRALibellNW & Relative abundance Libellulidae ${ }^{a}$ & poor \\
\hline npBMOdo & $\%$ Biomass Odonata & poor \\
\hline npBMOdoNW & $\%$ Biomass Odonata $^{\mathrm{a}}$ & poor \\
\hline nRAOdo & Relative abundance Odonata & poor \\
\hline nRAOdoNW & Relative abundance Odonata ${ }^{\mathrm{a}}$ & poor \\
\hline npBMOdoLib & \% Biomass Odonata - Libellulidae & poor \\
\hline nbBMOdoLibNW & $\%$ Biomass Odonata - Libellulidae $^{a}$ & poor \\
\hline nRAOdoLib & Relative abundance Odonata - Libellulidae & poor \\
\hline nRAOdoLibNW & Relative abundance Odonata - Libellulidae & poor \\
\hline
\end{tabular}

* Indicates metric calculated without including Chironomidae or Oligochaeta. 
Appendix AM. Benthic macroinvertebrate community metrics box-and-whisker results and narrative descriptions for depressional wetlands $(\mathrm{N}=35)$. Classifications are reference $(\mathrm{R})$ and stressed $(\mathrm{S})$.
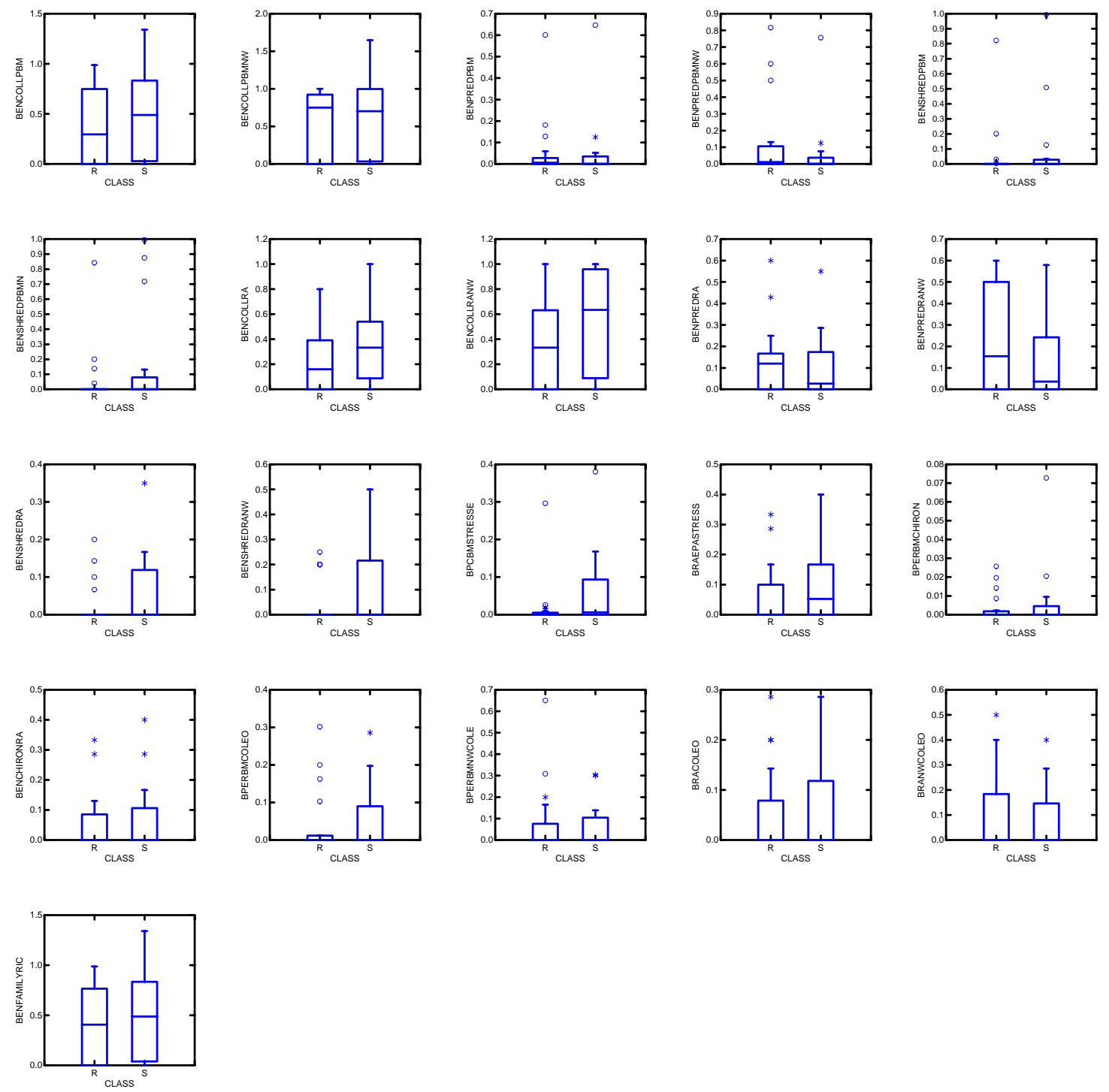


\section{Appendix AM. Continued.}

\begin{tabular}{|c|c|c|}
\hline Metric code & Metric description & Rating \\
\hline benCollpBM & $\%$ Biomass collector & poor \\
\hline benCollpBM* & $\%$ Biomass collector ${ }^{\mathrm{a}}$ & fair \\
\hline benPredpBM & $\%$ Biomass predator & fair \\
\hline benPredpBM* ${ }^{*}$ & $\%$ Biomass predator $^{\mathrm{a}}$ & poor \\
\hline benShredpBM & $\%$ Biomass shredder & poor \\
\hline benShredpBMN & $\%$ Biomass shredder $^{a}$ & poor \\
\hline benCollRA & Relative abundance collector & good \\
\hline benCollRA* & Relative abundance collector ${ }^{\mathrm{a}}$ & good \\
\hline benPredRA & Relative abundance predator & good \\
\hline benPredRA* & Relative abundance predator ${ }^{\mathrm{a}}$ & good \\
\hline benShredRA & Relative abundance shredder & poor \\
\hline benShredRA* & Relative abundance shredder ${ }^{a}$ & poor \\
\hline bPcBMstressed & \% Biomass EPA stressed & poor \\
\hline bRAEPAstressed & Relative abundance EPA stressed & good \\
\hline bPerBMChiron & \% Biomass Chironomidae & poor \\
\hline BenChironRA & Relative abundance chironomidae & poor \\
\hline bPerBMColeo & $\%$ Biomass Coleoptera & poor \\
\hline bPerBM*Coleo & $\%$ Biomass Coleoptera $^{\mathrm{a}}$ & poor \\
\hline bRAColeo & Relative abundance Coleoptera & poor \\
\hline bRA*Coleo & Relative abundance Coleoptera ${ }^{a}$ & poor \\
\hline BenFamilyRic & Familial Richness & poor \\
\hline
\end{tabular}

* Indicates metric calculated without including Chironomidae or Oligochaeta. 
Appendix AN. Nektonic macroinvertebrate community metrics box-and-whisker results and narrative descriptions for floodplain wetlands $(\mathrm{N}=15)$. Classifications are reference $(\mathrm{R})$ and stressed $(\mathrm{S})$.
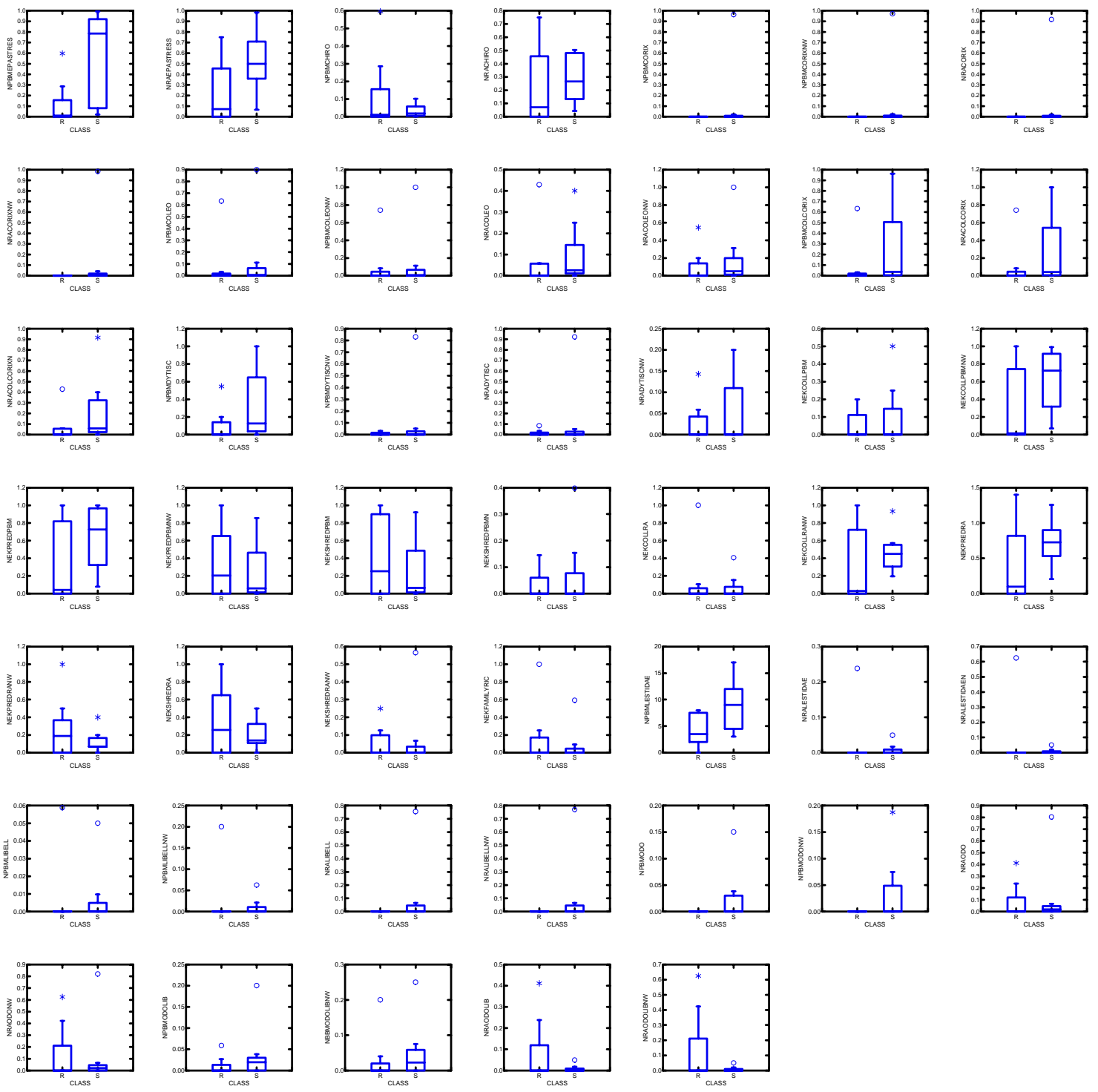


\begin{tabular}{|c|c|c|}
\hline Metric Code & Metric Description & Rating \\
\hline npBMepaStres & \% Biomass EPA stressed & good \\
\hline nRAepaStress & Relative abundance EPA stressed & good \\
\hline npBMChiro & \% Biomass Chironomidae & poor \\
\hline nRAChiro & Relative abundance Chironomidae & fair \\
\hline npBMCorix & $\%$ Biomass Corixidae & poor \\
\hline npBMCorix* & $\%$ Biomass Corixidae $^{a}$ & poor \\
\hline nRACorix & Relative abundance Corixidae & poor \\
\hline nRACorix* & Relative abundance Corixidae ${ }^{a}$ & poor \\
\hline npBMColeo & $\%$ Biomass Coleoptera & poor \\
\hline npBMColeo* & $\%$ Biomass Coleoptera $^{\mathrm{a}}$ & poor \\
\hline nRAColeo & Relative abundance Coleoptera & poor \\
\hline nRAColeo* & Relative abundance Coleoptera $^{\mathrm{a}}$ & poor \\
\hline npBMColCorix & $\%$ Biomass Coleoptera + Corixidae & poor \\
\hline npBMColCorix* & $\%$ Biomass Coleoptera + Corixidae * & poor \\
\hline nRAColCorix & Relative abundance Coleoptera + Corixidae & poor \\
\hline nRAColCorixN & Relative abundance Coleoptera + Corixidae $^{\mathrm{a}}$ & poor \\
\hline npBMDytisc & $\%$ Biomass Dytiscidae & poor \\
\hline npBMDytisc* & $\%$ Biomass Dytiscidae * & poor \\
\hline nRADytisc & Relative abundance Dytiscidae & poor \\
\hline nRADytisc* & Relative abundance Dytiscidae ${ }^{a}$ & poor \\
\hline nekCollpBM & $\%$ Biomass collector & poor \\
\hline nekCollpBM* & $\%$ Biomass collector ${ }^{\mathrm{a}}$ & poor \\
\hline nekPredpBM & $\%$ Biomass predator & fair \\
\hline nekPredpBM* & $\%$ Biomass predator $^{\mathrm{a}}$ & poor \\
\hline nekShredpBM & $\%$ Biomass shredder & poor \\
\hline nekShredpBM* & $\%$ Biomass shredder ${ }^{\mathrm{a}}$ & poor \\
\hline nekCollRA & Relative abundance collector & poor \\
\hline nekCollRA* & Relative abundance collector ${ }^{\mathrm{a}}$ & poor \\
\hline nekPredRA & Relative abundance predator & fair \\
\hline nekPredRA* & Relative abundance predator ${ }^{\mathrm{a}}$ & fair \\
\hline nekShredRA & Relative abundance shredder & fair \\
\hline nekShredRA* & Relative abundance shredder ${ }^{a}$ & poor \\
\hline NekFamilyRich & Familial richness & poor \\
\hline npBMLestidae & $\%$ Biomass Lestidae & good \\
\hline npBMLestidaeN & $\%$ Biomass Lestidae ${ }^{\mathrm{a}}$ & poor \\
\hline nRALestidae & Relative abundance Lestidae & poor \\
\hline nRALestidaeN & Relative abundance Lestidae ${ }^{a}$ & poor \\
\hline npBMLibell & $\%$ Biomass Libellulidae & poor \\
\hline npBMLibell* & $\%$ Biomass Libellulidae $^{\mathrm{a}}$ & poor \\
\hline nRALibell & Relative abundance Libellulidae & poor \\
\hline nRALibell* & Relative abundance Libellulidae ${ }^{a}$ & poor \\
\hline npBMOdo & $\%$ Biomass Odonata & poor \\
\hline npBMOdo* & $\%$ Biomass Odonata $^{\mathrm{a}}$ & poor \\
\hline nRAOdo & Relative abundance Odonata & poor \\
\hline nRAOdo* & Relative abundance Odonata ${ }^{a}$ & poor \\
\hline npBMOdoLib & $\%$ Biomass Odonata - Libellulidae & poor \\
\hline nbBMOdoLib* & $\%$ Biomass Odonata - Libellulidae ${ }^{a}$ & poor \\
\hline nRAOdoLib & Relative abundance Odonata - Libellulidae & poor \\
\hline nRAOdoLib* & Relative abundance Odonata - Libellulidae & poor \\
\hline
\end{tabular}

* Indicates metric calculated without including Chironomidae or Oligochaeta. 
Appendix AO. Benthic macroinvertebrate community metrics box-and-whisker results and narrative descriptions for floodplain wetlands $(\mathrm{N}=17)$. Classifications are reference $(\mathrm{R})$ and stressed $(\mathrm{S})$.
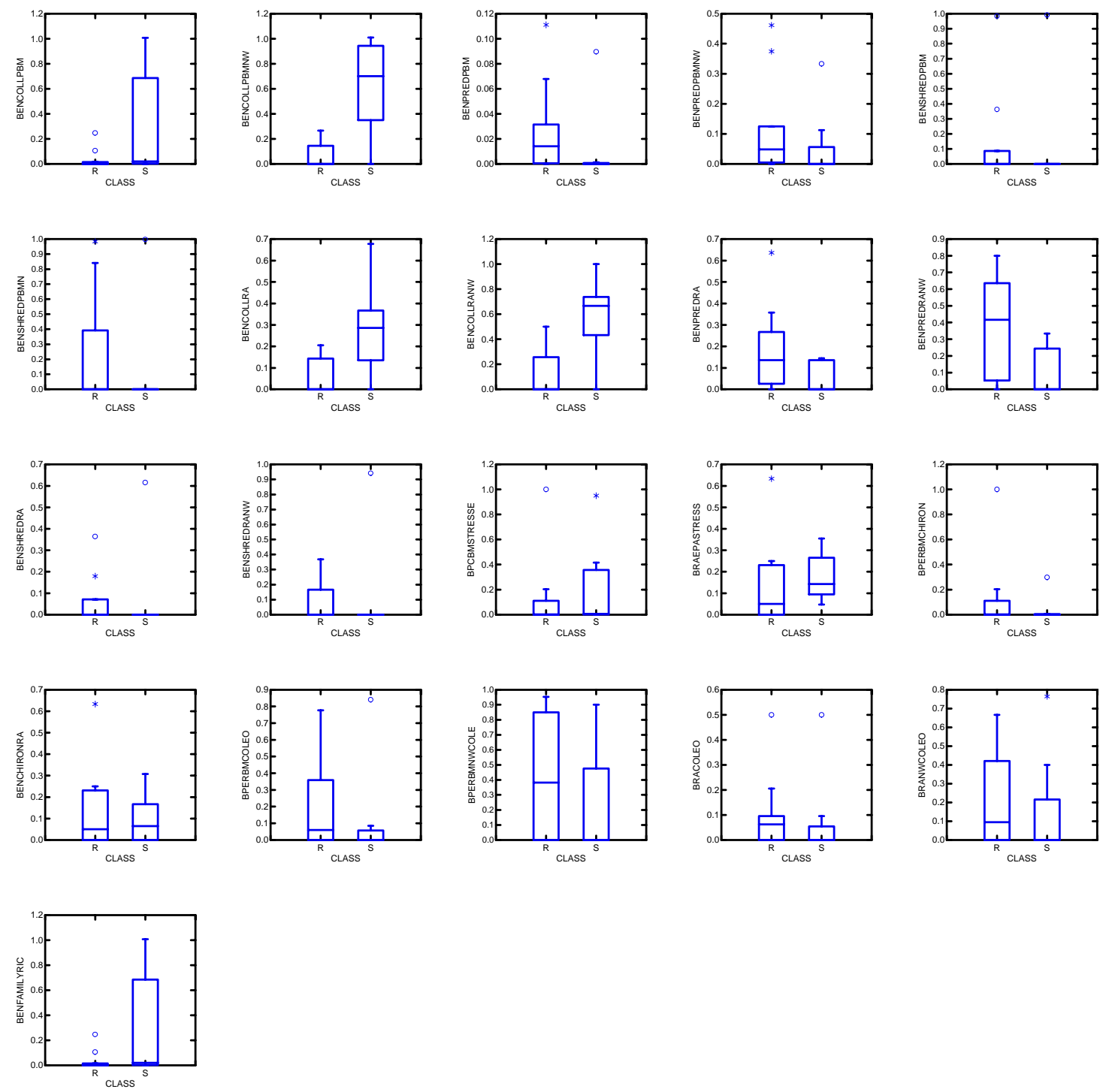


\section{Appendix AO. Continued.}

\begin{tabular}{lll}
\hline Metric code & Metric description & Rating \\
\hline benCollpBM & \% Biomass collector & fair \\
benCollpBM* & \% Biomass collector & good \\
benPredpBM & \% Biomass predator & fair \\
benPredpBM* & \% Biomass predator & poor \\
benShredpBM & \% Biomass shredder & poor \\
benShredpBMN & \% Biomass shredder & poor \\
benCollRA & Relative abundance collector & good \\
benCollRA* & Relative abundance collector & good \\
benPredRA & Relative abundance predator & good \\
benPredRA* & Relative abundance predator & good \\
benShredRA & Relative abundance shredder & poor \\
benShredRA* & Relative abundance shredder & poor \\
bPcBMstressed & \% Biomass EPA stressed & poor \\
bRAEPAstressed & Relative abundance EPA stressed & fair \\
bPerBMChiron & \% Biomass Chironomidae & poor \\
BenChironRA & Relative abundance chironomidae & poor \\
bPerBMColeo & \% Biomass Coleoptera & poor \\
bPerBM*Coleo & \% Biomass Coleoptera & poor \\
bRAColeo & Relative abundance Coleoptera & poor \\
bRA*Coleo & Relative abundance Coleoptera ${ }^{\mathrm{a}}$ & poor \\
BenFamilyRic & Familial Richness & poor \\
\hline
\end{tabular}

* Indicates metric calculated without including Chironomidae or Oligochaeta. 
Appendix AP. Nektonic macroinvertebrate community metrics box-and-whisker results and narrative descriptions for impoundment wetlands $(\mathrm{N}=13)$. Classifications are reference $(\mathrm{R})$ and stressed $(\mathrm{S})$.
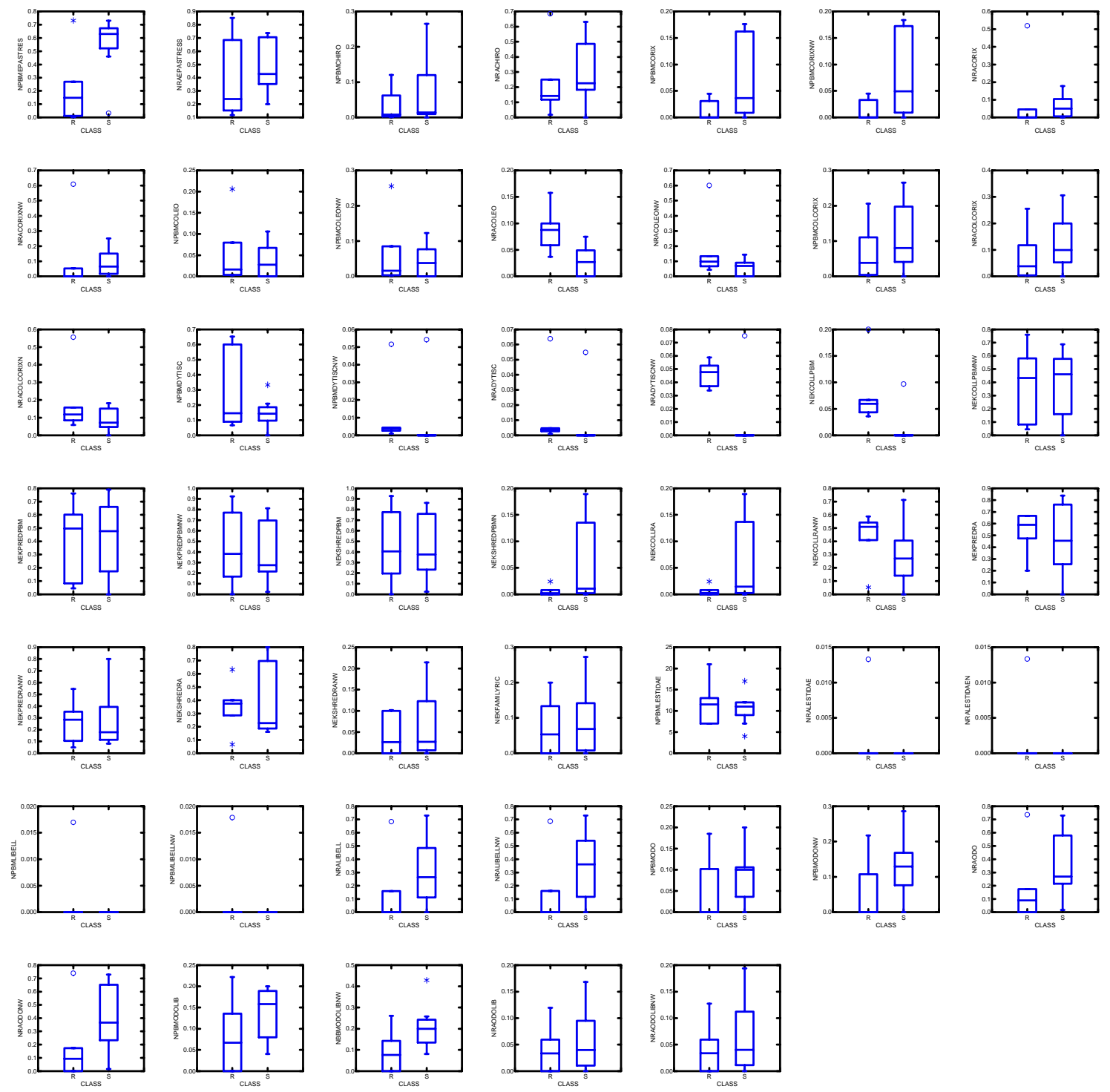


\begin{tabular}{|c|c|c|}
\hline Metric Code & Metric Description & Rating \\
\hline npBMepaStres & $\%$ Biomass EPA stressed & good \\
\hline nRAepaStress & Relative abundance EPA stressed & fair \\
\hline npBMChiro & $\%$ Biomass Chironomidae & poor \\
\hline nRAChiro & Relative abundance Chironomidae & poor \\
\hline npBMCorix & $\%$ Biomass Corixidae & poor \\
\hline npBMCorix* & $\%$ Biomass Corixidae ${ }^{a}$ & poor \\
\hline nRACorix & Relative abundance Corixidae & poor \\
\hline nRACorix* & Relative abundance Corixidae ${ }^{a}$ & poor \\
\hline npBMColeo & $\%$ Biomass Coleoptera & poor \\
\hline npBMColeo* & $\%$ Biomass Coleoptera $^{a}$ & poor \\
\hline nRAColeo & Relative abundance Coleoptera & good \\
\hline nRAColeo* & Relative abundance Coleoptera ${ }^{a}$ & fair \\
\hline npBMColCorix & $\%$ Biomass Coleoptera + Corixidae & fair \\
\hline npBMColCorix* & $\%$ Biomass Coleoptera + Corixidae * & fair \\
\hline nRAColCorix & Relative abundance Coleoptera + Corixidae & fair \\
\hline nRAColCorixN & Relative abundance Coleoptera + Corixidae $^{\mathrm{a}}$ & fair \\
\hline npBMDytisc & \% Biomass Dytiscidae & poor \\
\hline npBMDytisc* & \% Biomass Dytiscidae * & poor \\
\hline nRADytisc & Relative abundance Dytiscidae & poor \\
\hline nRADytisc* & Relative abundance Dytiscidae ${ }^{a}$ & poor \\
\hline nekCollpBM & $\%$ Biomass collector & poor \\
\hline nekCollpBM* & $\%$ Biomass collector $^{\mathrm{a}}$ & poor \\
\hline nekPredpBM & $\%$ Biomass predator & poor \\
\hline nekPredpBM* & $\%$ Biomass predator $^{a}$ & poor \\
\hline nekShredpBM & $\%$ Biomass shredder & poor \\
\hline nekShredpBM* & $\%$ Biomass shredder ${ }^{\mathrm{a}}$ & poor \\
\hline nekCollRA & Relative abundance collector & poor \\
\hline nekCollRA* & Relative abundance collector ${ }^{\mathrm{a}}$ & good \\
\hline nekPredRA & Relative abundance predator & fair \\
\hline nekPredRA* & Relative abundance predator ${ }^{\mathrm{a}}$ & poor \\
\hline nekShredRA & Relative abundance shredder & fair \\
\hline nekShredRA* & Relative abundance shredder ${ }^{a}$ & poor \\
\hline NekFamilyRich & Familial richness & poor \\
\hline npBMLestidae & \% Biomass Lestidae & poor \\
\hline npBMLestidaeN & $\%$ Biomass Lestidae ${ }^{\mathrm{a}}$ & poor \\
\hline nRALestidae & Relative abundance Lestidae & poor \\
\hline nRALestidaeN & Relative abundance Lestidae ${ }^{a}$ & poor \\
\hline npBMLibell & \% Biomass Libellulidae & good \\
\hline npBMLibell* & $\%$ Biomass Libellulidae $^{\mathrm{a}}$ & good \\
\hline nRALibell & Relative abundance Libellulidae & poor \\
\hline nRALibell* & Relative abundance Libellulidae ${ }^{a}$ & poor \\
\hline npBMOdo & $\%$ Biomass Odonata & poor \\
\hline npBMOdo* & $\%$ Biomass Odonata $^{a}$ & fair \\
\hline nRAOdo & Relative abundance Odonata & good \\
\hline nRAOdo* & Relative abundance Odonata ${ }^{\mathrm{a}}$ & good \\
\hline npBMOdoLib & \% Biomass Odonata - Libellulidae & good \\
\hline nbBMOdoLib* & \% Biomass Odonata - Libellulidae & good \\
\hline nRAOdoLib & Relative abundance Odonata - Libellulidae & poor \\
\hline nRAOdoLib* & Relative abundance Odonata - Libellulidae & poor \\
\hline
\end{tabular}

* Indicates metric calculated without including Chironomidae or Oligochaeta. 
Appendix AQ. Benthic macroinvertebrate community metrics box-and-whisker results and narrative descriptions for impoundment wetlands $(\mathrm{N}=13)$. Classifications are reference $(\mathrm{R})$ and stressed $(\mathrm{S})$.
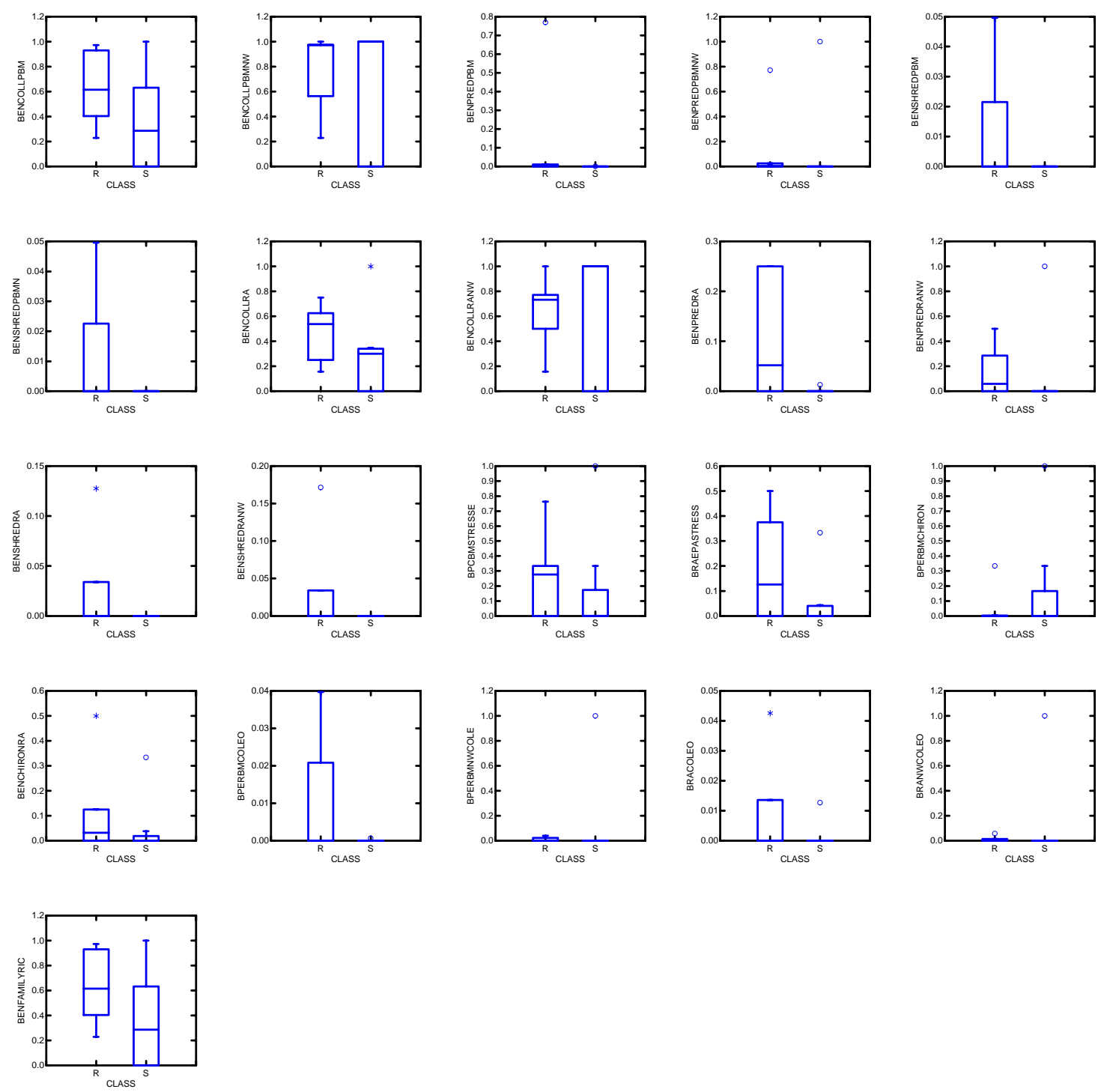


\section{Appendix AQ. Continued.}

\begin{tabular}{lll}
\hline Metric code & Metric description & Rating \\
\hline benCollpBM & \% Biomass collector & good \\
benCollpBM* $^{*}$ & \% Biomass collector & a \\
benPredpBM & \% Biomass predator & fair \\
benPredpBM* & \% Biomass predator & poor \\
benShredpBM & \% Biomass shredder & poor \\
benShredpBMN & \% Biomass shredder & poor \\
benCollRA & Relative abundance collector & poor \\
benCollRA* & Relative abundance collector & fair \\
benPredRA & Relative abundance predator & poor \\
benPredRA* & Relative abundance predator & poor \\
benShredRA & Relative abundance shredder & poor \\
benShredRA* & Relative abundance shredder & poor \\
bPcBMstressed & $\%$ Biomass EPA stressed & poor \\
bRAEPAstressed & Relative abundance EPA stressed & poor \\
bPerBMChiron & $\%$ Biomass Chironomidae & poor \\
BenChironRA & Relative abundance chironomidae & poor \\
bPerBMColeo & \% Biomass Coleoptera & poor \\
bPerBM*Coleo & $\%$ Biomass Coleoptera & poor \\
bRAColeo & Relative abundance Coleoptera & poor \\
bRA*Coleo & Relative abundance Coleoptera & poor \\
BenFamilyRic & Familial Richness & poor \\
\hline
\end{tabular}

* Indicates metric calculated without including Chironomidae or Oligochaeta. 
Appendix AR. Nektonic macroinvertebrate community metrics box-and-whisker results and narrative descriptions for riparian depression wetlands $(\mathrm{N}=17)$. Classifications are reference $(\mathrm{R})$ and stressed $(\mathrm{S})$.
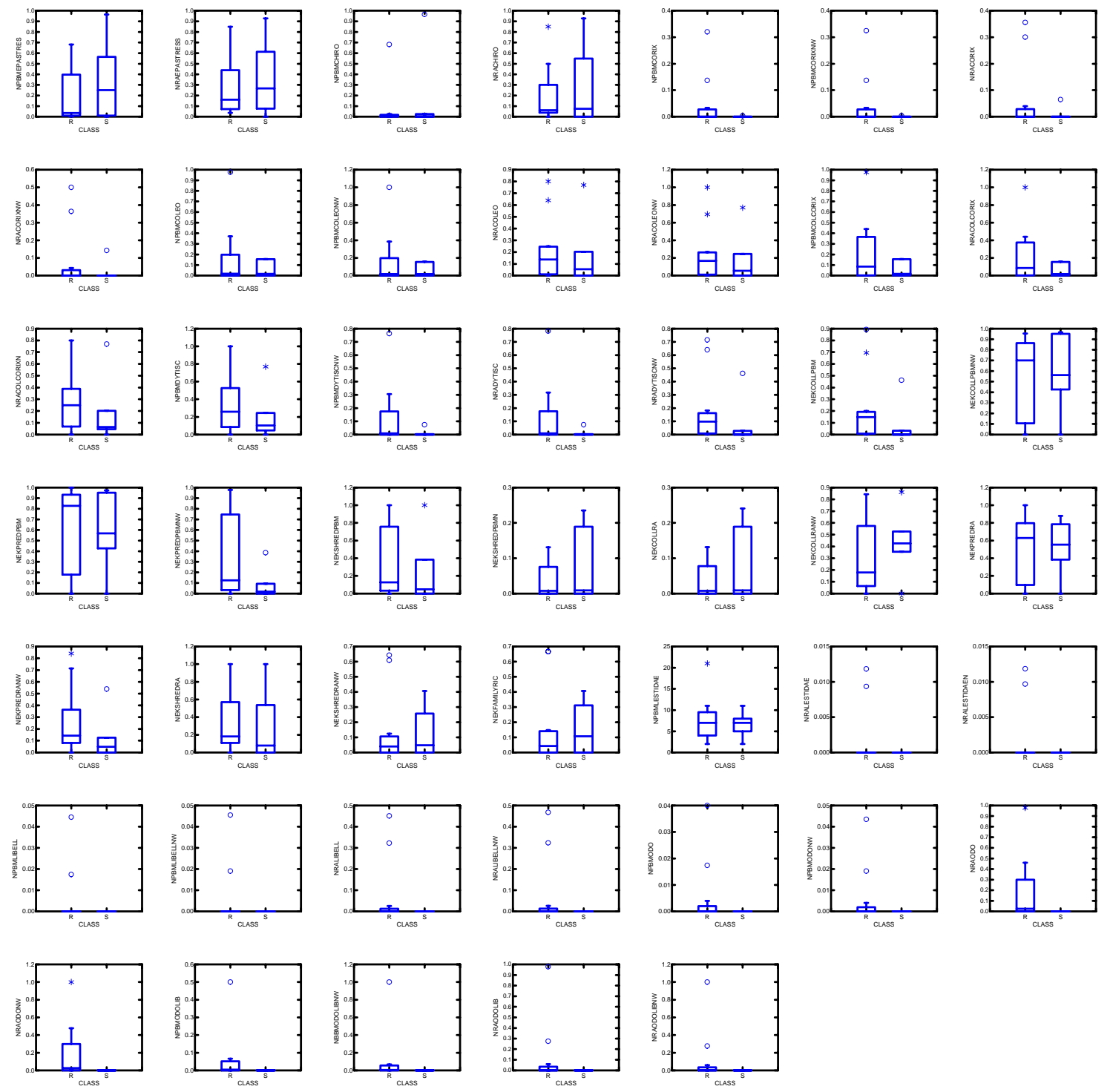


\begin{tabular}{|c|c|c|}
\hline Metric Code & Metric Description & Rating \\
\hline npBMepaStres & \% Biomass EPA stressed & poor \\
\hline nRAepaStress & Relative abundance EPA stressed & poor \\
\hline npBMChiro & \% Biomass Chironomidae & poor \\
\hline nRAChiro & Relative abundance Chironomidae & poor \\
\hline npBMCorix & $\%$ Biomass Corixidae & poor \\
\hline npBMCorix* & $\%$ Biomass Corixidae $^{a}$ & poor \\
\hline nRACorix & Relative abundance Corixidae & poor \\
\hline nRACorix* & Relative abundance Corixidae $^{a}$ & poor \\
\hline npBMColeo & $\%$ Biomass Coleoptera & poor \\
\hline npBMColeo* & $\%$ Biomass Coleoptera $^{\mathrm{a}}$ & poor \\
\hline nRAColeo & Relative abundance Coleoptera & poor \\
\hline nRAColeo* & Relative abundance Coleoptera ${ }^{a}$ & poor \\
\hline npBMColCorix & $\%$ Biomass Coleoptera + Corixidae & poor \\
\hline npBMColCorix* & $\%$ Biomass Coleoptera + Corixidae $*$ & poor \\
\hline nRAColCorix & Relative abundance Coleoptera + Corixidae & poor \\
\hline nRAColCorixN & Relative abundance Coleoptera + Corixidae $^{\mathrm{a}}$ & good \\
\hline npBMDytisc & $\%$ Biomass Dytiscidae & good \\
\hline npBMDytisc* & \% Biomass Dytiscidae * & poor \\
\hline nRADytisc & Relative abundance Dytiscidae & poor \\
\hline nRADytisc* & Relative abundance Dytiscidae ${ }^{a}$ & poor \\
\hline nekCollpBM & $\%$ Biomass collector & poor \\
\hline nekCollpBM* & $\%$ Biomass collector $^{\mathrm{a}}$ & poor \\
\hline nekPredpBM & $\%$ Biomass predator & poor \\
\hline nekPredpBM* & $\%$ Biomass predator $^{\mathrm{a}}$ & poor \\
\hline nekShredpBM & $\%$ Biomass shredder & poor \\
\hline nekShredpBM* & $\%$ Biomass shredder $^{\mathrm{a}}$ & poor \\
\hline nekCollRA & Relative abundance collector & poor \\
\hline nekCollRA* & Relative abundance collector ${ }^{\mathrm{a}}$ & fair \\
\hline nekPredRA & Relative abundance predator & poor \\
\hline nekPredRA* & Relative abundance predator ${ }^{a}$ & poor \\
\hline nekShredRA & Relative abundance shredder & fair \\
\hline nekShredRA* & Relative abundance shredder ${ }^{\mathrm{a}}$ & poor \\
\hline NekFamilyRich & Familial richness & poor \\
\hline npBMLestidae & $\%$ Biomass Lestidae & poor \\
\hline npBMLestidaeN & $\%$ Biomass Lestidae ${ }^{a}$ & poor \\
\hline nRALestidae & Relative abundance Lestidae & poor \\
\hline nRALestidaeN & Relative abundance Lestidae $^{a}$ & poor \\
\hline npBMLibell & \% Biomass Libellulidae & poor \\
\hline npBMLibell* & $\%$ Biomass Libellulidae $^{\mathrm{a}}$ & poor \\
\hline nRALibell & Relative abundance Libellulidae & poor \\
\hline nRALibell* & Relative abundance Libellulidae ${ }^{a}$ & poor \\
\hline npBMOdo & $\%$ Biomass Odonata & poor \\
\hline npBMOdo* & $\%$ Biomass Odonata $^{a}$ & poor \\
\hline nRAOdo & Relative abundance Odonata & poor \\
\hline nRAOdo* & Relative abundance Odonata ${ }^{\mathrm{a}}$ & poor \\
\hline npBMOdoLib & \% Biomass Odonata - Libellulidae & poor \\
\hline nbBMOdoLib* & $\%$ Biomass Odonata - Libellulidae $^{a}$ & poor \\
\hline nRAOdoLib & Relative abundance Odonata - Libellulidae & poor \\
\hline nRAOdoLib* & Relative abundance Odonata - Libellulidae & poor \\
\hline
\end{tabular}

* Indicates metric calculated without including Chironomidae or Oligochaeta. 
Appendix AS. Benthic macroinvertebrate community metrics box-and-whisker results and narrative descriptions for riparian depression wetlands $(\mathrm{N}=26)$. Classifications are reference $(\mathrm{R})$ and stressed $(\mathrm{S})$.
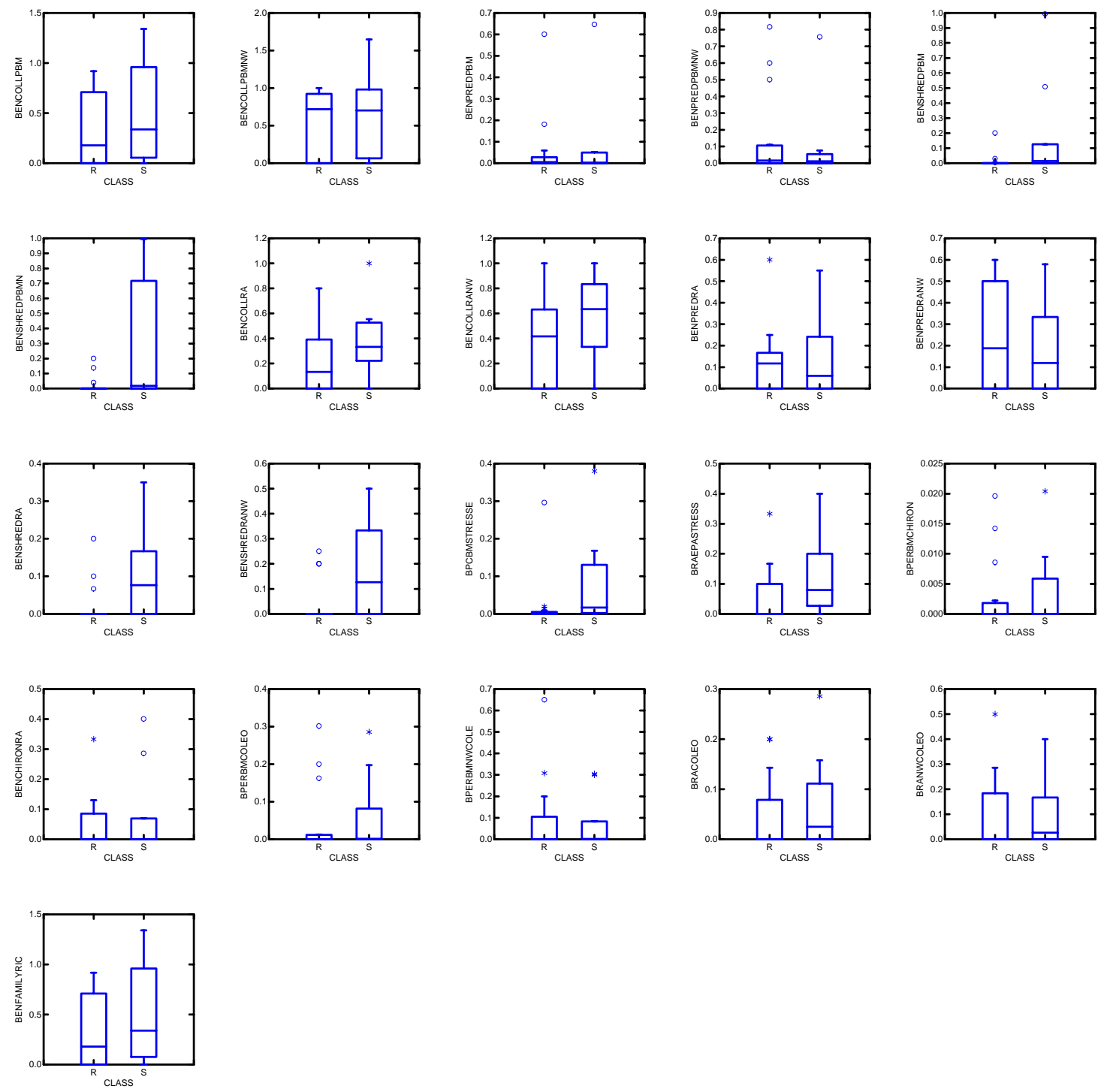


\section{Appendix AS. Continued.}

\begin{tabular}{lll}
\hline Metric code & Metric description & Rating \\
\hline benCollpBM & \% Biomass collector & poor \\
benCollpBM* & \% Biomass collector & poor \\
benPredpBM & \% Biomass predator & poor \\
benPredpBM* & \% Biomass predator ${ }^{\mathrm{a}}$ & poor \\
benShredpBM & \% Biomass shredder & poor \\
benShredpBMN & \% Biomass shredder & poor \\
benCollRA & Relative abundance collector & fair \\
benCollRA* & Relative abundance collector & fair \\
benPredRA & Relative abundance predator & poor \\
benPredRA* & Relative abundance predator & poor \\
benShredRA & Relative abundance shredder & poor \\
benShredRA* & Relative abundance shredder & poor \\
bPcBMstressed & \% Biomass EPA stressed & poor \\
bRAEPAstressed & Relative abundance EPA stressed & poor \\
bPerBMChiron & \% Biomass Chironomidae & poor \\
BenChironRA & Relative abundance chironomidae & poor \\
bPerBMColeo & \% Biomass Coleoptera & poor \\
bPerBM*Coleo & $\%$ Biomass Coleoptera & poor \\
bRAColeo & Relative abundance Coleoptera & poor \\
bRA*Coleo & Relative abundance Coleoptera & poor \\
BenFamilyRic & Familial Richness & fair \\
\hline
\end{tabular}

* Indicates metric calculated without including Chironomidae or Oligochaeta. 
Appendix AT. Nektonic macroinvertebrate community metrics box-and-whisker results and narrative descriptions for headwater floodplain wetlands $(\mathrm{N}=13)$. Classifications are reference $(\mathrm{R})$ and stressed (S).
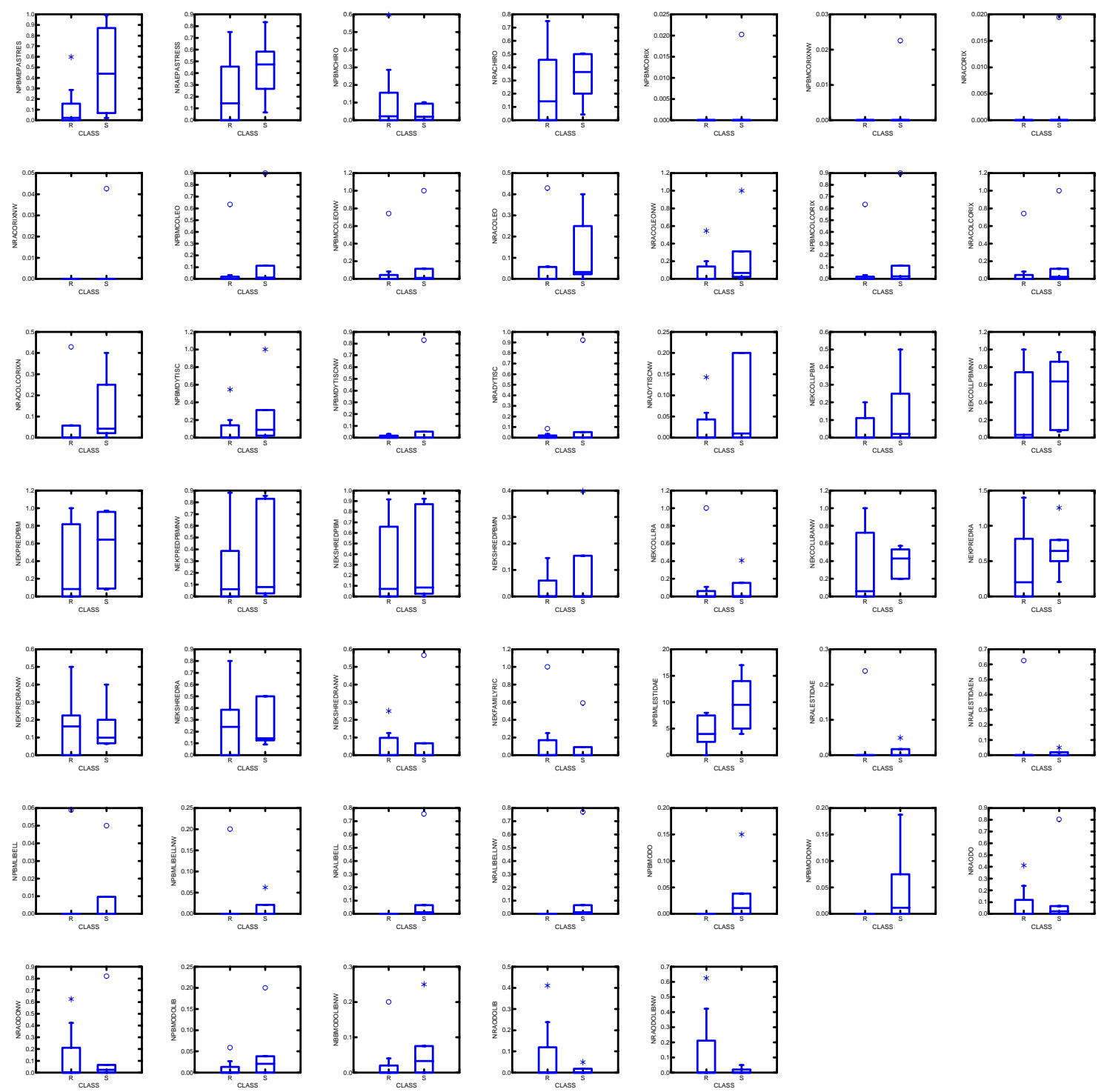


\begin{tabular}{|c|c|c|}
\hline Metric Code & Metric Description & Rating \\
\hline npBMepaStres & $\%$ Biomass EPA stressed & good \\
\hline nRAepaStress & Relative abundance EPA stressed & good \\
\hline npBMChiro & \% Biomass Chironomidae & poor \\
\hline nRAChiro & Relative abundance Chironomidae & fair \\
\hline npBMCorix & $\%$ Biomass Corixidae & poor \\
\hline npBMCorix* & $\%$ Biomass Corixidae $^{\mathrm{a}}$ & poor \\
\hline nRACorix & Relative abundance Corixidae & poor \\
\hline nRACorix* & Relative abundance Corixidae $^{\mathrm{a}}$ & poor \\
\hline npBMColeo & $\%$ Biomass Coleoptera & poor \\
\hline npBMColeo* & $\%$ Biomass Coleoptera $^{a}$ & poor \\
\hline nRAColeo & Relative abundance Coleoptera & poor \\
\hline nRAColeo* & Relative abundance Coleoptera ${ }^{a}$ & poor \\
\hline npBMColCorix & $\%$ Biomass Coleoptera + Corixidae & poor \\
\hline npBMColCorix* & $\%$ Biomass Coleoptera + Corixidae $*$ & poor \\
\hline nRAColCorix & Relative abundance Coleoptera + Corixidae & poor \\
\hline nRAColCorixN & Relative abundance Coleoptera + Corixidae $^{\mathrm{a}}$ & poor \\
\hline npBMDytisc & $\%$ Biomass Dytiscidae & poor \\
\hline npBMDytisc* & $\%$ Biomass Dytiscidae * & poor \\
\hline nRADytisc & Relative abundance Dytiscidae & poor \\
\hline nRADytisc* & Relative abundance Dytiscidae ${ }^{a}$ & poor \\
\hline nekCollpBM & $\%$ Biomass collector & poor \\
\hline nekCollpBM* & $\%$ Biomass collector $^{\mathrm{a}}$ & poor \\
\hline nekPredpBM & $\%$ Biomass predator & fair \\
\hline nekPredpBM* & $\%$ Biomass predator $^{\mathrm{a}}$ & poor \\
\hline nekShredpBM & $\%$ Biomass shredder & poor \\
\hline nekShredpBM* & $\%$ Biomass shredder ${ }^{\mathrm{a}}$ & poor \\
\hline nekCollRA & Relative abundance collector & poor \\
\hline nekCollRA* & Relative abundance collector ${ }^{\mathrm{a}}$ & fair \\
\hline nekPredRA & Relative abundance predator & fair \\
\hline nekPredRA* & Relative abundance predator ${ }^{\mathrm{a}}$ & fair \\
\hline nekShredRA & Relative abundance shredder & fair \\
\hline nekShredRA* & Relative abundance shredder ${ }^{a}$ & poor \\
\hline NekFamilyRich & Familial richness & poor \\
\hline npBMLestidae & $\%$ Biomass Lestidae & good \\
\hline npBMLestidaeN & $\%$ Biomass Lestidae ${ }^{\mathrm{a}}$ & poor \\
\hline nRALestidae & Relative abundance Lestidae & poor \\
\hline nRALestidaeN & Relative abundance Lestidae ${ }^{a}$ & poor \\
\hline npBMLibell & $\%$ Biomass Libellulidae & poor \\
\hline npBMLibell* & $\%$ Biomass Libellulidae ${ }^{\mathrm{a}}$ & poor \\
\hline nRALibell & Relative abundance Libellulidae & poor \\
\hline nRALibell* & Relative abundance Libellulidae $^{\mathrm{a}}$ & poor \\
\hline npBMOdo & $\%$ Biomass Odonata & poor \\
\hline npBMOdo* & $\%$ Biomass Odonata $^{\mathrm{a}}$ & poor \\
\hline nRAOdo & Relative abundance Odonata & poor \\
\hline nRAOdo* & Relative abundance Odonata $\mathrm{a}^{\mathrm{a}}$ & poor \\
\hline npBMOdoLib & \% Biomass Odonata - Libellulidae & poor \\
\hline nbBMOdoLib* & \% Biomass Odonata - Libellulidae ${ }^{\mathrm{a}}$ & poor \\
\hline nRAOdoLib & Relative abundance Odonata - Libellulidae & poor \\
\hline nRAOdoLib* & Relative abundance Odonata - Libellulidae & poor \\
\hline
\end{tabular}

* Indicates metric calculated without including Chironomidae or Oligochaeta. 
Appendix AU. Benthic macroinvertebrate community metrics box-and-whisker results and narrative descriptions for headwater floodplain wetlands $(\mathrm{N}=14)$. Classifications are reference $(\mathrm{R})$ and stressed (S).
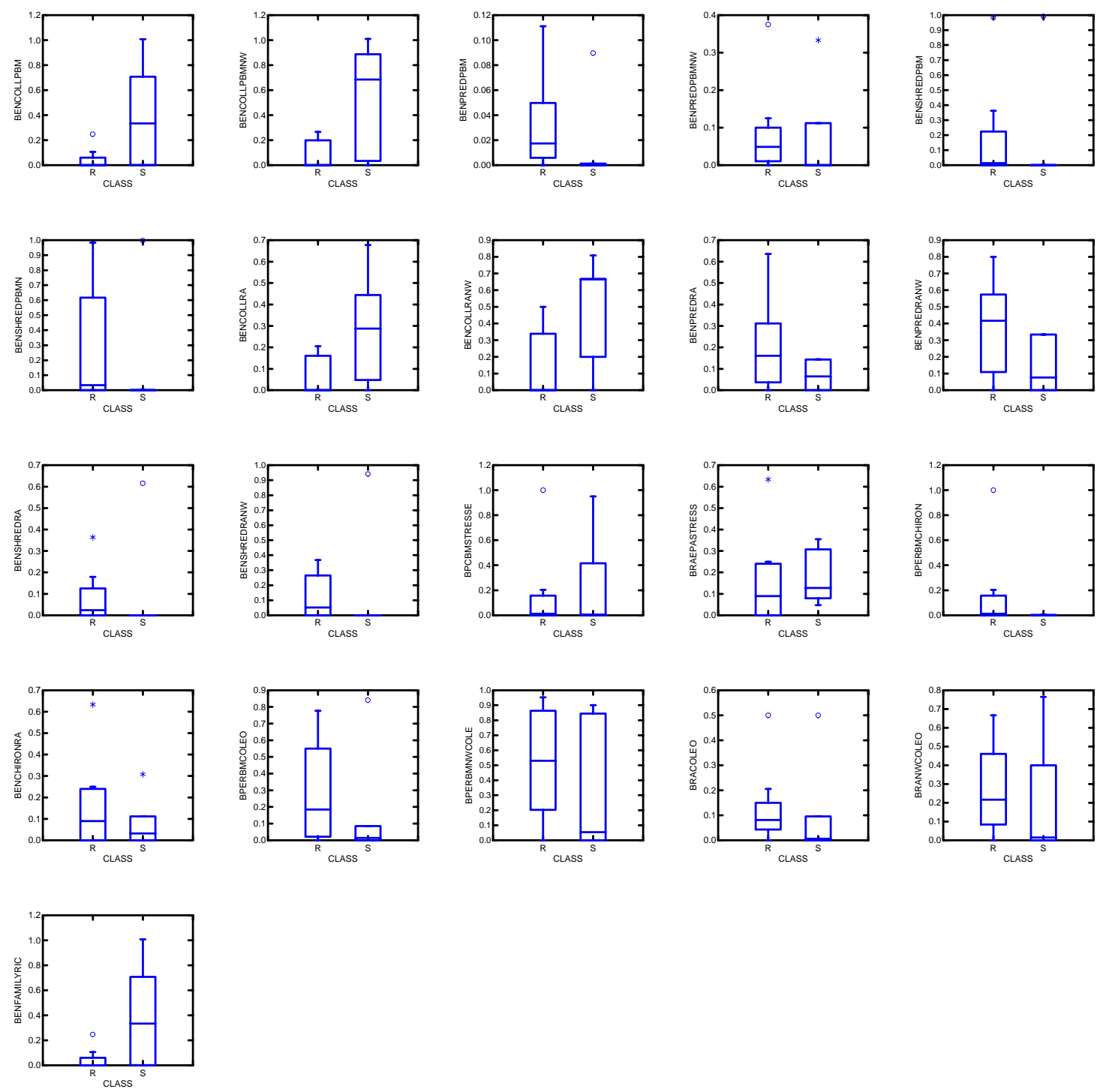


\section{Appendix AU. Continued.}

\begin{tabular}{|c|c|c|}
\hline Metric code & Metric description & Rating \\
\hline benCollpBM & $\%$ Biomass collector & good \\
\hline benCollpBM* ${ }^{*}$ & $\%$ Biomass collector ${ }^{\mathrm{a}}$ & good \\
\hline benPredpBM & $\%$ Biomass predator & fair \\
\hline benPredpBM* ${ }^{*}$ & $\%$ Biomass predator $^{\mathrm{a}}$ & poor \\
\hline benShredpBM & $\%$ Biomass shredder & poor \\
\hline benShredpBMN & $\%$ Biomass shredder ${ }^{\mathrm{a}}$ & poor \\
\hline benCollRA & Relative abundance collector & good \\
\hline benCollRA* & Relative abundance collector ${ }^{\mathrm{a}}$ & fair \\
\hline benPredRA & Relative abundance predator & fair \\
\hline benPredRA* & Relative abundance predator ${ }^{\mathrm{a}}$ & good \\
\hline benShredRA & Relative abundance shredder & fair \\
\hline benShredRA* & Relative abundance shredder ${ }^{\mathrm{a}}$ & fair \\
\hline bPcBMstressed & $\%$ Biomass EPA stressed & fair \\
\hline bRAEPAstressed & Relative abundance EPA stressed & poor \\
\hline bPerBMChiron & $\%$ Biomass Chironomidae & fair \\
\hline BenChironRA & Relative abundance chironomidae & fair \\
\hline bPerBMColeo & $\%$ Biomass Coleoptera & fair \\
\hline bPerBM*Coleo & $\%$ Biomass Coleoptera $^{\mathrm{a}}$ & fair \\
\hline bRAColeo & Relative abundance Coleoptera & fair \\
\hline bRA*Coleo & Relative abundance Coleoptera ${ }^{a}$ & fair \\
\hline BenFamilyRic & Familial Richness & fair \\
\hline
\end{tabular}

* Indicates metric calculated without including Chironomidae or Oligochaeta. 
Appendix AV. Nektonic macroinvertebrate community metrics box-and-whisker results and narrative descriptions for emergent wetlands ( $\mathrm{N}=28)$. Classifications are reference (R) and stressed $(\mathrm{S})$.
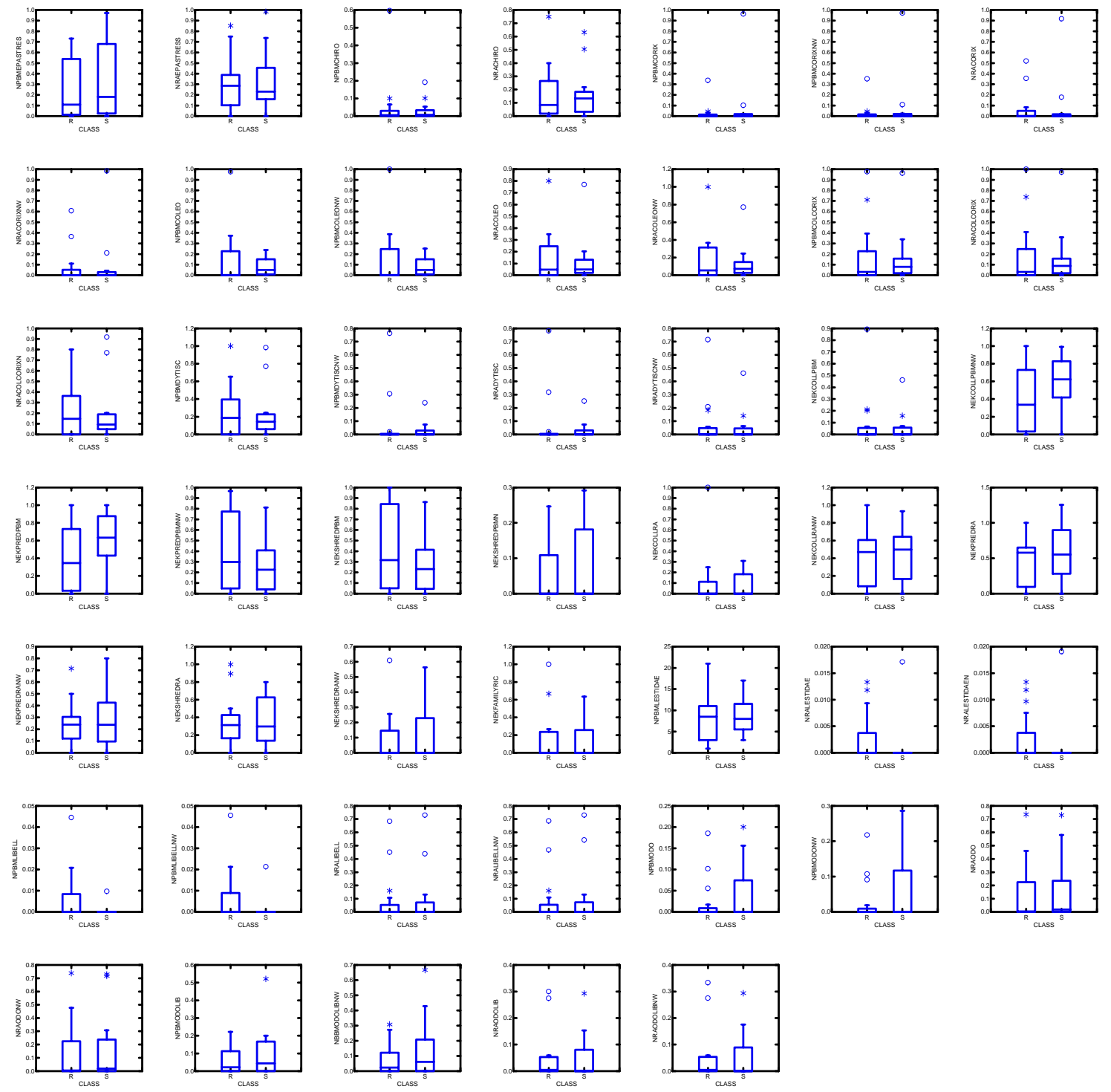


\begin{tabular}{|c|c|c|}
\hline Metric Code & Metric Description & Rating \\
\hline npBMepaStres & $\%$ Biomass EPA stressed & poor \\
\hline nRAepaStress & Relative abundance EPA stressed & poor \\
\hline npBMChiro & $\%$ Biomass Chironomidae & poor \\
\hline nRAChiro & Relative abundance Chironomidae & poor \\
\hline npBMCorix & $\%$ Biomass Corixidae & poor \\
\hline npBMCorix* & $\%$ Biomass Corixidae ${ }^{a}$ & poor \\
\hline nRACorix & Relative abundance Corixidae & poor \\
\hline nRACorix* & Relative abundance Corixidae $^{a}$ & poor \\
\hline npBMColeo & $\%$ Biomass Coleoptera & poor \\
\hline npBMColeo* & $\%$ Biomass Coleoptera $^{a}$ & poor \\
\hline nRAColeo & Relative abundance Coleoptera & poor \\
\hline nRAColeo* & Relative abundance Coleoptera ${ }^{\mathrm{a}}$ & poor \\
\hline npBMColCorix & $\%$ Biomass Coleoptera + Corixidae & poor \\
\hline npBMColCorix* & $\%$ Biomass Coleoptera + Corixidae $*$ & poor \\
\hline nRAColCorix & Relative abundance Coleoptera + Corixidae & poor \\
\hline nRAColCorixN & Relative abundance Coleoptera + Corixidae $^{a}$ & poor \\
\hline npBMDytisc & $\%$ Biomass Dytiscidae & poor \\
\hline npBMDytisc* & $\%$ Biomass Dytiscidae * & poor \\
\hline nRADytisc & Relative abundance Dytiscidae & poor \\
\hline nRADytisc* & Relative abundance Dytiscidae ${ }^{a}$ & poor \\
\hline nekCollpBM & $\%$ Biomass collector & poor \\
\hline nekCollpBM* & $\%$ Biomass collector $^{\mathrm{a}}$ & fair \\
\hline nekPredpBM & $\%$ Biomass predator & fair \\
\hline nekPredpBM* & $\%$ Biomass predator ${ }^{\mathrm{a}}$ & poor \\
\hline nekShredpBM & $\%$ Biomass shredder & poor \\
\hline nekShredpBM* & $\%$ Biomass shredder ${ }^{\mathrm{a}}$ & poor \\
\hline nekCollRA & Relative abundance collector & poor \\
\hline nekCollRA* & Relative abundance collector ${ }^{\mathrm{a}}$ & poor \\
\hline nekPredRA & Relative abundance predator & poor \\
\hline nekPredRA* & Relative abundance predator ${ }^{\mathrm{a}}$ & poor \\
\hline nekShredRA & Relative abundance shredder & poor \\
\hline nekShredRA* & Relative abundance shredder ${ }^{\mathrm{a}}$ & poor \\
\hline NekFamilyRich & Familial richness & poor \\
\hline npBMLestidae & $\%$ Biomass Lestidae & poor \\
\hline npBMLestidaeN & $\%$ Biomass Lestidae $^{a}$ & poor \\
\hline nRALestidae & Relative abundance Lestidae & poor \\
\hline nRALestidaeN & Relative abundance Lestidae $^{a}$ & poor \\
\hline npBMLibell & $\%$ Biomass Libellulidae & poor \\
\hline npBMLibell* & $\%$ Biomass Libellulidae $^{a}$ & poor \\
\hline nRALibell & Relative abundance Libellulidae & poor \\
\hline nRALibell* & Relative abundance Libellulidae ${ }^{a}$ & poor \\
\hline npBMOdo & $\%$ Biomass Odonata & poor \\
\hline npBMOdo* & $\%$ Biomass Odonata $^{a}$ & poor \\
\hline nRAOdo & Relative abundance Odonata & poor \\
\hline nRAOdo* & Relative abundance Odonata ${ }^{\mathrm{a}}$ & poor \\
\hline npBMOdoLib & \% Biomass Odonata - Libellulidae & poor \\
\hline nbBMOdoLib* & $\%$ Biomass Odonata - Libellulidae ${ }^{a}$ & poor \\
\hline nRAOdoLib & Relative abundance Odonata - Libellulidae & poor \\
\hline nRAOdoLib* & Relative abundance Odonata - Libellulidae & poor \\
\hline
\end{tabular}

* Indicates metric calculated without including Chironomidae or Oligochaeta. 
Appendix AW. Benthic macroinvertebrate community metrics box-and-whisker results and narrative descriptions for emergent wetlands $(\mathrm{N}=35)$. Classifications are reference $(\mathrm{R})$ and stressed $(\mathrm{S})$.
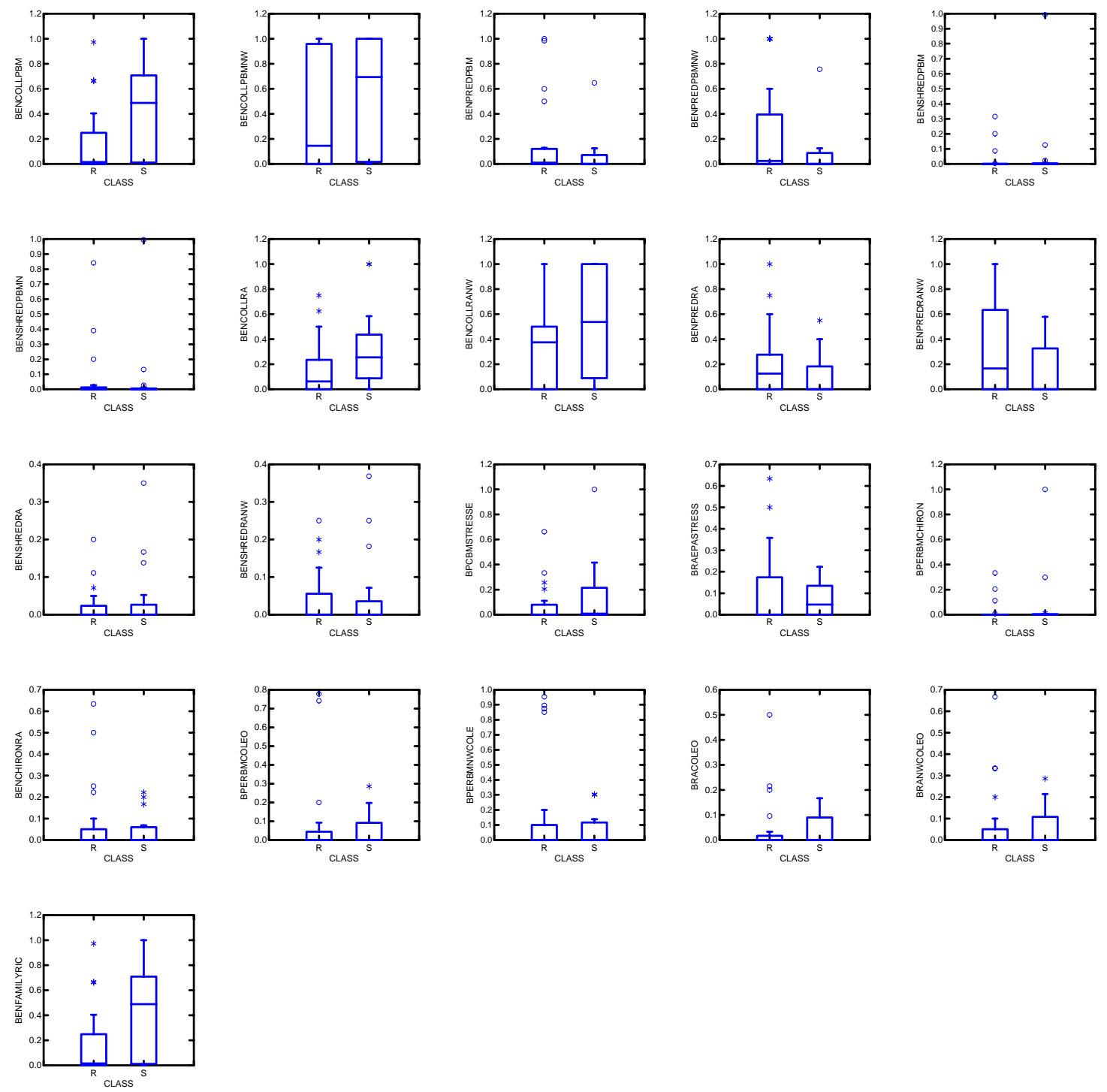


\section{Appendix AW. Continued.}

\begin{tabular}{lll}
\hline Metric code & Metric description & Rating \\
\hline benCollpBM & \% Biomass collector & fair \\
benCollpBM* $^{*}$ & $\%$ Biomass collector & poor \\
benPredpBM & $\%$ Biomass predator & poor \\
benPredpBM* & $\%$ Biomass predator & poor \\
benShredpBM & $\%$ Biomass shredder & poor \\
benShredpBMN & $\%$ Biomass shredder & poor \\
benCollRA & Relative abundance collector & good \\
benCollRA* & Relative abundance collector & fair \\
benPredRA & Relative abundance predator & fair \\
benPredRA* & Relative abundance predator & fair \\
benShredRA & Relative abundance shredder & poor \\
benShredRA* & Relative abundance shredder & poor \\
bPcBMstressed & $\%$ Biomass EPA stressed & poor \\
bRAEPAstressed & Relative abundance EPA stressed & poor \\
bPerBMChiron & $\%$ Biomass Chironomidae & poor \\
BenChironRA & Relative abundance chironomidae & poor \\
bPerBMColeo & $\%$ Biomass Coleoptera & poor \\
bPerBM*Coleo & $\%$ Biomass Coleoptera & poor \\
bRAColeo & Relative abundance Coleoptera & poor \\
bRA*Coleo & Relative abundance Coleoptera & poor \\
BenFamilyRic & Familial Richness & poor \\
\hline
\end{tabular}

* Indicates metric calculated without including Chironomidae or Oligochaeta. 
Appendix AX. Nektonic macroinvertebrate community metrics box-and-whisker results and narrative descriptions for scrub-shrub wetlands $(\mathrm{N}=19)$. Classifications are reference $(\mathrm{R})$ and stressed $(\mathrm{S})$.
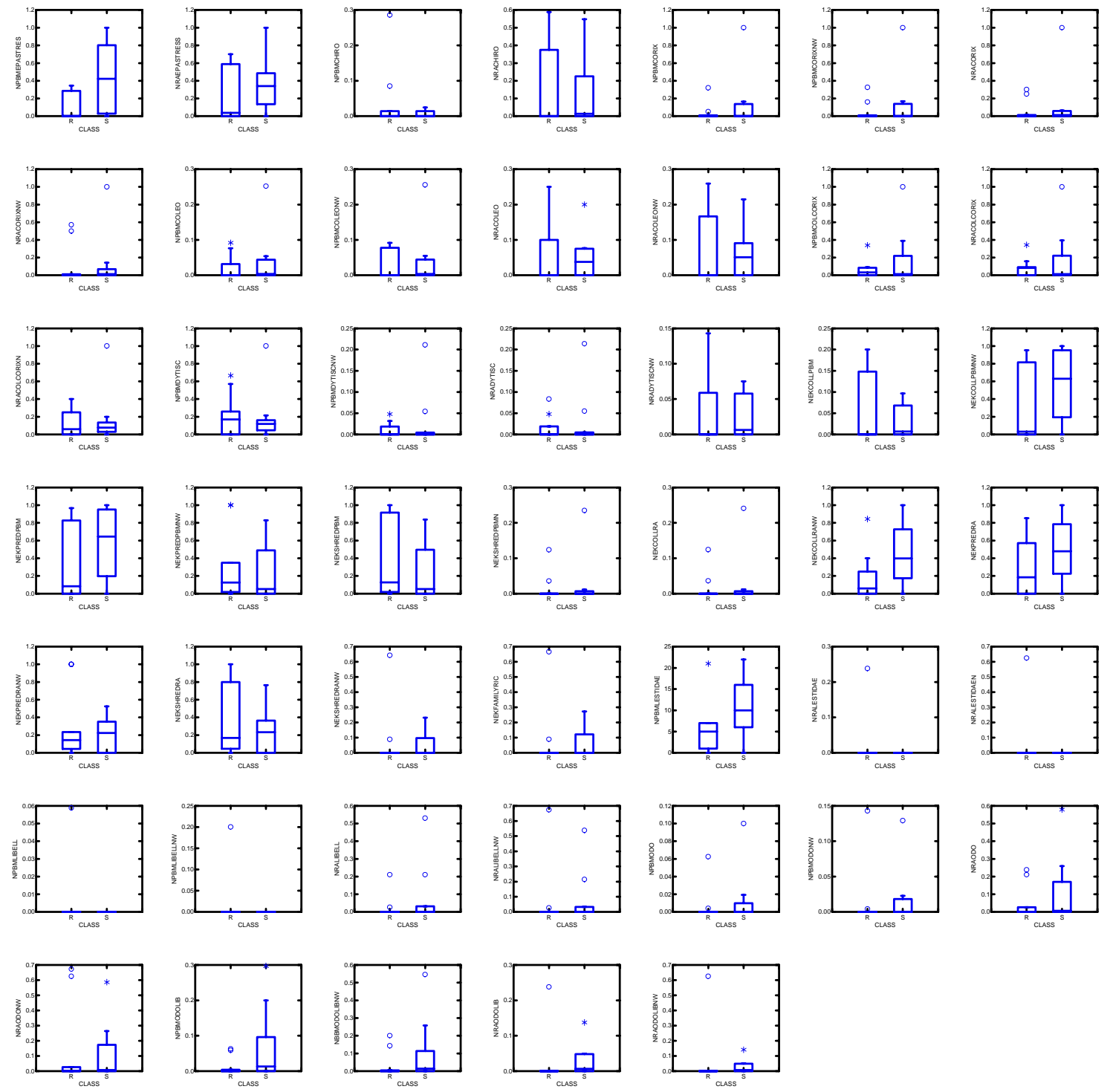


\begin{tabular}{|c|c|c|}
\hline Metric Code & Metric Description & Rating \\
\hline npBMepaStres & \% Biomass EPA stressed & poor \\
\hline nRAepaStress & Relative abundance EPA stressed & poor \\
\hline npBMChiro & \% Biomass Chironomidae & poor \\
\hline nRAChiro & Relative abundance Chironomidae & poor \\
\hline npBMCorix & $\%$ Biomass Corixidae & poor \\
\hline npBMCorix* & $\%$ Biomass Corixidae $^{a}$ & poor \\
\hline nRACorix & Relative abundance Corixidae & poor \\
\hline nRACorix* & Relative abundance Corixidae $^{a}$ & poor \\
\hline npBMColeo & $\%$ Biomass Coleoptera & poor \\
\hline npBMColeo* & $\%$ Biomass Coleoptera $^{a}$ & poor \\
\hline nRAColeo & Relative abundance Coleoptera & poor \\
\hline nRAColeo* & Relative abundance Coleoptera $^{\mathrm{a}}$ & poor \\
\hline npBMColCorix & $\%$ Biomass Coleoptera + Corixidae & poor \\
\hline npBMColCorix* & $\%$ Biomass Coleoptera + Corixidae * & poor \\
\hline nRAColCorix & Relative abundance Coleoptera + Corixidae & poor \\
\hline nRAColCorixN & Relative abundance Coleoptera + Corixidae $^{\mathrm{a}}$ & poor \\
\hline npBMDytisc & \% Biomass Dytiscidae & poor \\
\hline npBMDytisc* & \% Biomass Dytiscidae * & poor \\
\hline nRADytisc & Relative abundance Dytiscidae & poor \\
\hline nRADytisc* & Relative abundance Dytiscidae $^{a}$ & poor \\
\hline nekCollpBM & $\%$ Biomass collector & poor \\
\hline nekCollpBM* & $\%$ Biomass collector $^{\mathrm{a}}$ & poor \\
\hline nekPredpBM & $\%$ Biomass predator & faair \\
\hline nekPredpBM* & $\%$ Biomass predator $^{\mathrm{a}}$ & fair \\
\hline nekShredpBM & $\%$ Biomass shredder & poor \\
\hline nekShredpBM* & $\%$ Biomass shredder $^{\mathrm{a}}$ & poor \\
\hline nekCollRA & Relative abundance collector & poor \\
\hline nekCollRA* & Relative abundance collector ${ }^{\mathrm{a}}$ & good \\
\hline nekPredRA & Relative abundance predator & fair \\
\hline nekPredRA* & Relative abundance predator $^{\mathrm{a}}$ & poor \\
\hline nekShredRA & Relative abundance shredder & poor \\
\hline nekShredRA* & Relative abundance shredder ${ }^{a}$ & poor \\
\hline NekFamilyRich & Familial richness & poor \\
\hline npBMLestidae & $\%$ Biomass Lestidae & good \\
\hline npBMLestidaeN & $\%$ Biomass Lestidae ${ }^{\mathrm{a}}$ & poor \\
\hline nRALestidae & Relative abundance Lestidae & poor \\
\hline nRALestidaeN & Relative abundance Lestidae ${ }^{a}$ & poor \\
\hline npBMLibell & \% Biomass Libellulidae & poor \\
\hline npBMLibell* & $\%$ Biomass Libellulidae $^{\mathrm{a}}$ & poor \\
\hline nRALibell & Relative abundance Libellulidae & poor \\
\hline nRALibell* & Relative abundance Libellulidae ${ }^{a}$ & poor \\
\hline npBMOdo & $\%$ Biomass Odonata & poor \\
\hline npBMOdo* & $\%$ Biomass Odonata ${ }^{a}$ & poor \\
\hline nRAOdo & Relative abundance Odonata & poor \\
\hline nRAOdo* & Relative abundance Odonata ${ }^{\mathrm{a}}$ & poor \\
\hline npBMOdoLib & $\%$ Biomass Odonata - Libellulidae & poor \\
\hline nbBMOdoLib* & $\%$ Biomass Odonata - Libellulidae ${ }^{a}$ & poor \\
\hline nRAOdoLib & Relative abundance Odonata - Libellulidae & poor \\
\hline nRAOdoLib* & Relative abundance Odonata - Libellulidae & poor \\
\hline
\end{tabular}

* Indicates metric calculated without including Chironomidae or Oligochaeta. 
Appendix AY. Benthic macroinvertebrate community metrics box-and-whisker results and narrative descriptions for scrub-shrub wetlands $(\mathrm{N}=22)$. Classifications are reference $(\mathrm{R})$ and stressed $(\mathrm{S})$.
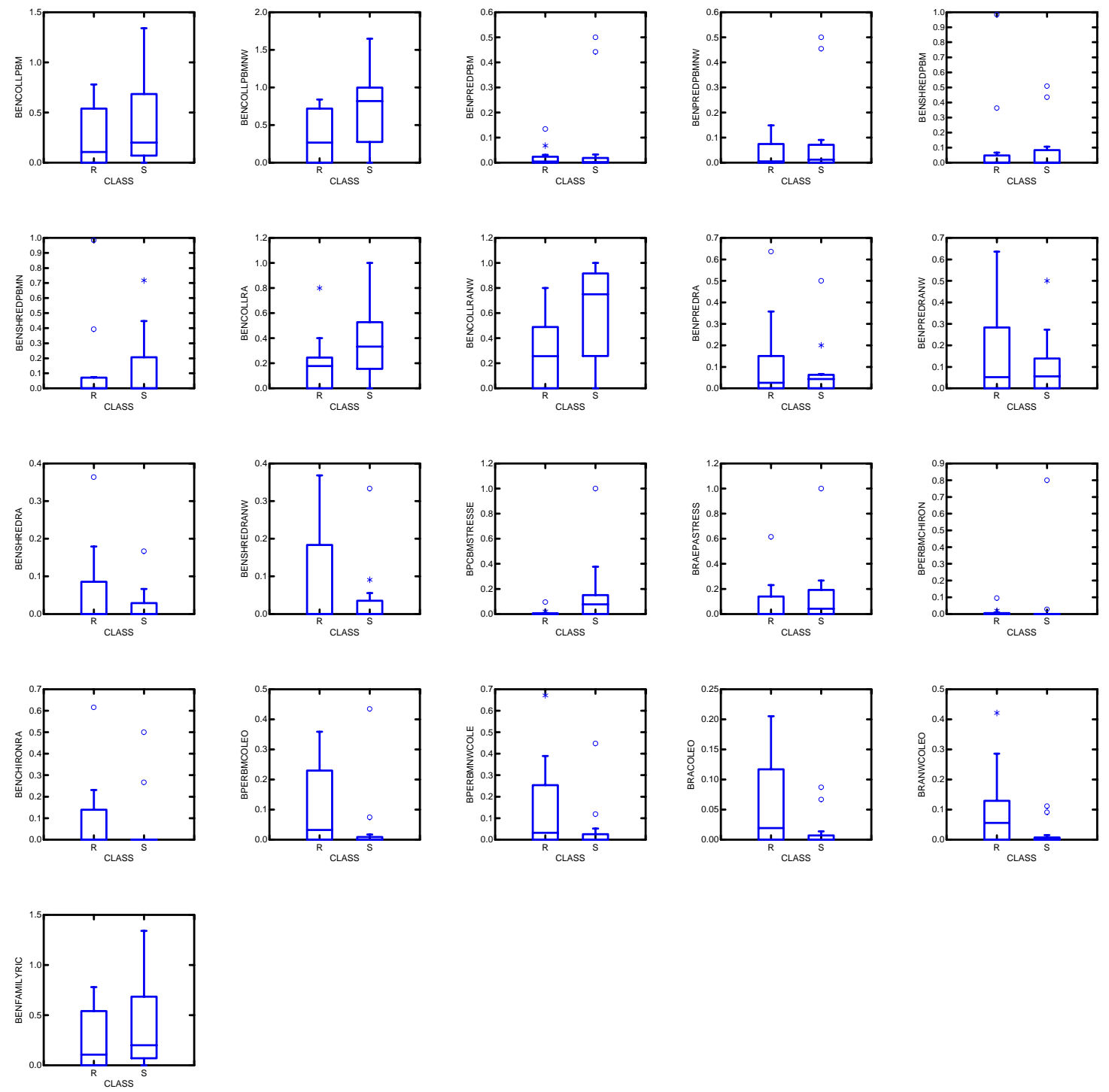


\section{Appendix AY. Continued.}

\begin{tabular}{lll}
\hline Metric code & Metric description & Rating \\
\hline benCollpBM & \% Biomass collector & poor \\
benCollpBM* & \% Biomass collector & good \\
benPredpBM & \% Biomass predator & poor \\
benPredpBM* & \% Biomass predator & a \\
benShredpBM & \% Biomass shredder & poor \\
benShredpBMN & \% Biomass shredder & poor \\
benCollRA & Relative abundance collector & poor \\
benCollRA* & Relative abundance collector & fair \\
benPredRA & Relative abundance predator & good \\
benPredRA* & Relative abundance predator & poor \\
benShredRA & Relative abundance shredder & poor \\
benShredRA* & Relative abundance shredder & poor \\
bPcBMstressed & $\%$ Biomass EPA stressed & poor \\
bRAEPAstressed & Relative abundance EPA stressed & poor \\
bPerBMChiron & $\%$ Biomass Chironomidae & poor \\
BenChironRA & Relative abundance chironomidae & poor \\
bPerBMColeo & \% Biomass Coleoptera & poor \\
bPerBM*Coleo & $\%$ Biomass Coleoptera & poor \\
bRAColeo & Relative abundance Coleoptera & poor \\
bRA*Coleo & Relative abundance Coleoptera & poor \\
BenFamilyRic & Familial Richness & poor \\
\hline
\end{tabular}

* Indicates metric calculated without including Chironomidae or Oligochaeta. 
Appendix AZ. Nektonic macroinvertebrate community metrics box-and-whisker results and narrative descriptions for forested wetlands $(\mathrm{N}=6)$. Classifications are reference $(\mathrm{R})$ and stressed $(\mathrm{S})$.
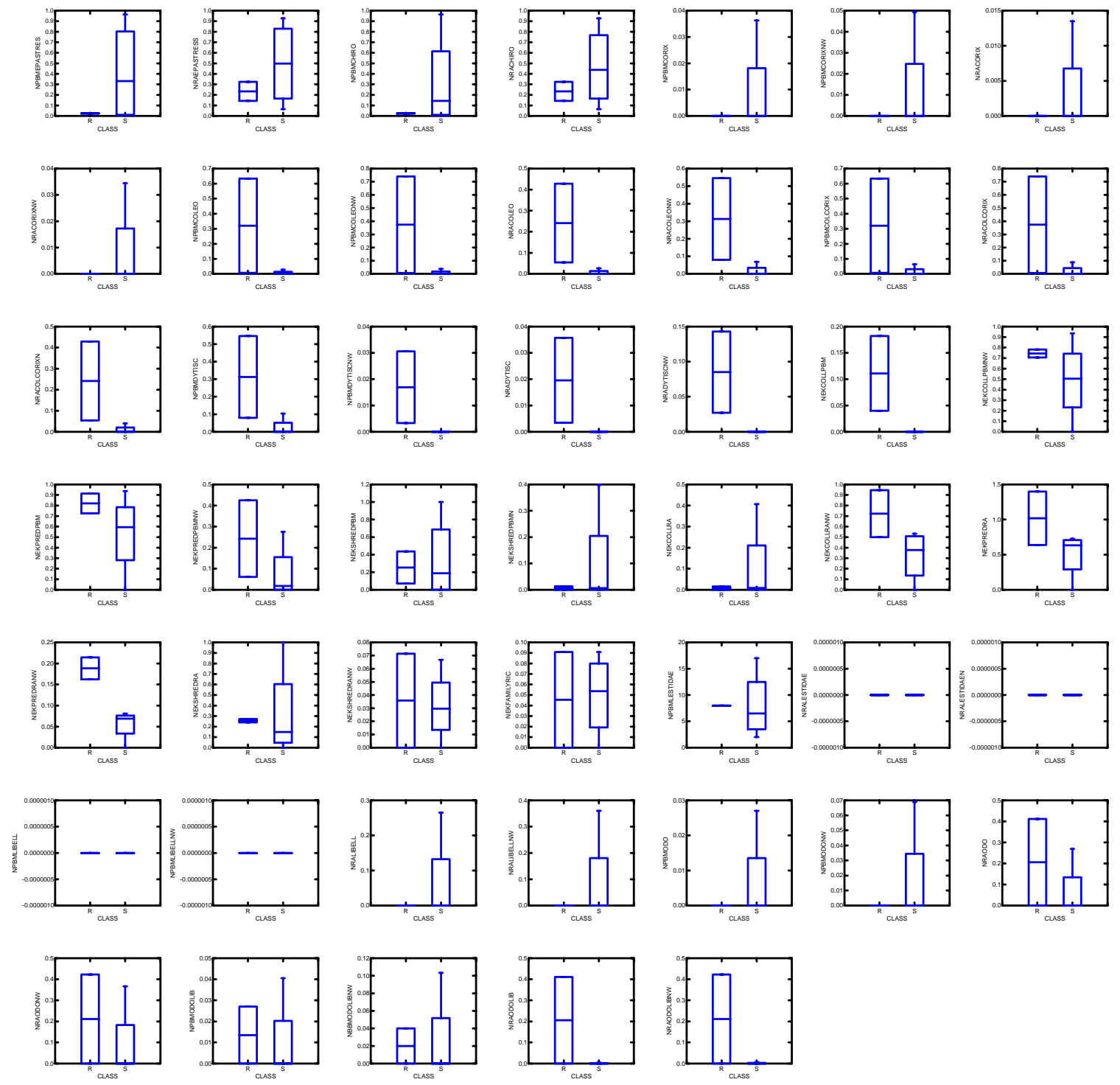


\begin{tabular}{|c|c|c|}
\hline Metric Code & Metric Description & Rating \\
\hline npBMepaStres & $\%$ Biomass EPA stressed & fair \\
\hline nRAepaStress & Relative abundance EPA stressed & poor \\
\hline npBMChiro & $\%$ Biomass Chironomidae & poor \\
\hline nRAChiro & Relative abundance Chironomidae & fair \\
\hline npBMCorix & $\%$ Biomass Corixidae & poor \\
\hline npBMCorix* & $\%$ Biomass Corixidae $^{\mathrm{a}}$ & poor \\
\hline nRACorix & Relative abundance Corixidae & poor \\
\hline nRACorix* & Relative abundance Corixidae $^{\mathrm{a}}$ & poor \\
\hline npBMColeo & $\%$ Biomass Coleoptera & poor \\
\hline npBMColeo* & $\%$ Biomass Coleoptera $^{\mathrm{a}}$ & poor \\
\hline nRAColeo & Relative abundance Coleoptera & poor \\
\hline nRAColeo* & Relative abundance Coleoptera $^{\mathrm{a}}$ & poor \\
\hline npBMColCorix & $\%$ Biomass Coleoptera + Corixidae & poor \\
\hline npBMColCorix* & $\%$ Biomass Coleoptera + Corixidae * & poor \\
\hline nRAColCorix & Relative abundance Coleoptera + Corixidae & poor \\
\hline nRAColCorixN & Relative abundance Coleoptera + Corixidae $^{\mathrm{a}}$ & poor \\
\hline npBMDytisc & $\%$ Biomass Dytiscidae & poor \\
\hline npBMDytisc* & $\%$ Biomass Dytiscidae * & poor \\
\hline nRADytisc & Relative abundance Dytiscidae & poor \\
\hline nRADytisc* & Relative abundance Dytiscidae $^{\mathrm{a}}$ & poor \\
\hline nekCollpBM & $\%$ Biomass collector & poor \\
\hline nekCollpBM* & $\%$ Biomass collector ${ }^{\mathrm{a}}$ & poor \\
\hline nekPredpBM & $\%$ Biomass predator & poor \\
\hline nekPredpBM* & $\%$ Biomass predator $^{\mathrm{a}}$ & good \\
\hline nekShredpBM & $\%$ Biomass shredder & good \\
\hline nekShredpBM* & $\%$ Biomass shredder ${ }^{\mathrm{a}}$ & poor \\
\hline nekCollRA & Relative abundance collector & poor \\
\hline nekCollRA* & Relative abundance collector ${ }^{\mathrm{a}}$ & poor \\
\hline nekPredRA & Relative abundance predator & poor \\
\hline nekPredRA* & Relative abundance predator ${ }^{\mathrm{a}}$ & poor \\
\hline nekShredRA & Relative abundance shredder & poor \\
\hline nekShredRA* & Relative abundance shredder ${ }^{a}$ & poor \\
\hline NekFamilyRich & Familial richness & poor \\
\hline npBMLestidae & $\%$ Biomass Lestidae & poor \\
\hline npBMLestidaeN & $\%$ Biomass Lestidae $^{a}$ & poor \\
\hline nRALestidae & Relative abundance Lestidae & poor \\
\hline nRALestidaeN & Relative abundance Lestidae ${ }^{\mathrm{a}}$ & poor \\
\hline npBMLibell & $\%$ Biomass Libellulidae & poor \\
\hline npBMLibell* & $\%$ Biomass Libellulidae ${ }^{\mathrm{a}}$ & poor \\
\hline nRALibell & Relative abundance Libellulidae & poor \\
\hline nRALibell* & Relative abundance Libellulidae $^{a}$ & poor \\
\hline npBMOdo & $\%$ Biomass Odonata & poor \\
\hline npBMOdo* & $\%$ Biomass Odonata $^{\mathrm{a}}$ & poor \\
\hline nRAOdo & Relative abundance Odonata & poor \\
\hline nRAOdo* & Relative abundance Odonata ${ }^{a}$ & poor \\
\hline npBMOdoLib & \% Biomass Odonata - Libellulidae & poor \\
\hline nbBMOdoLib* & $\%$ Biomass Odonata - Libellulidae ${ }^{a}$ & poor \\
\hline nRAOdoLib & Relative abundance Odonata - Libellulidae & poor \\
\hline nRAOdoLib* & Relative abundance Odonata - Libellulidae & poor \\
\hline
\end{tabular}

* Indicates metric calculated without including Chironomidae or Oligochaeta. 
Appendix BA. Benthic macroinvertebrate community metrics box-and-whisker results and narrative descriptions for forested wetlands $(\mathrm{N}=14)$. Classifications are reference $(\mathrm{R})$ and stressed $(\mathrm{S})$.
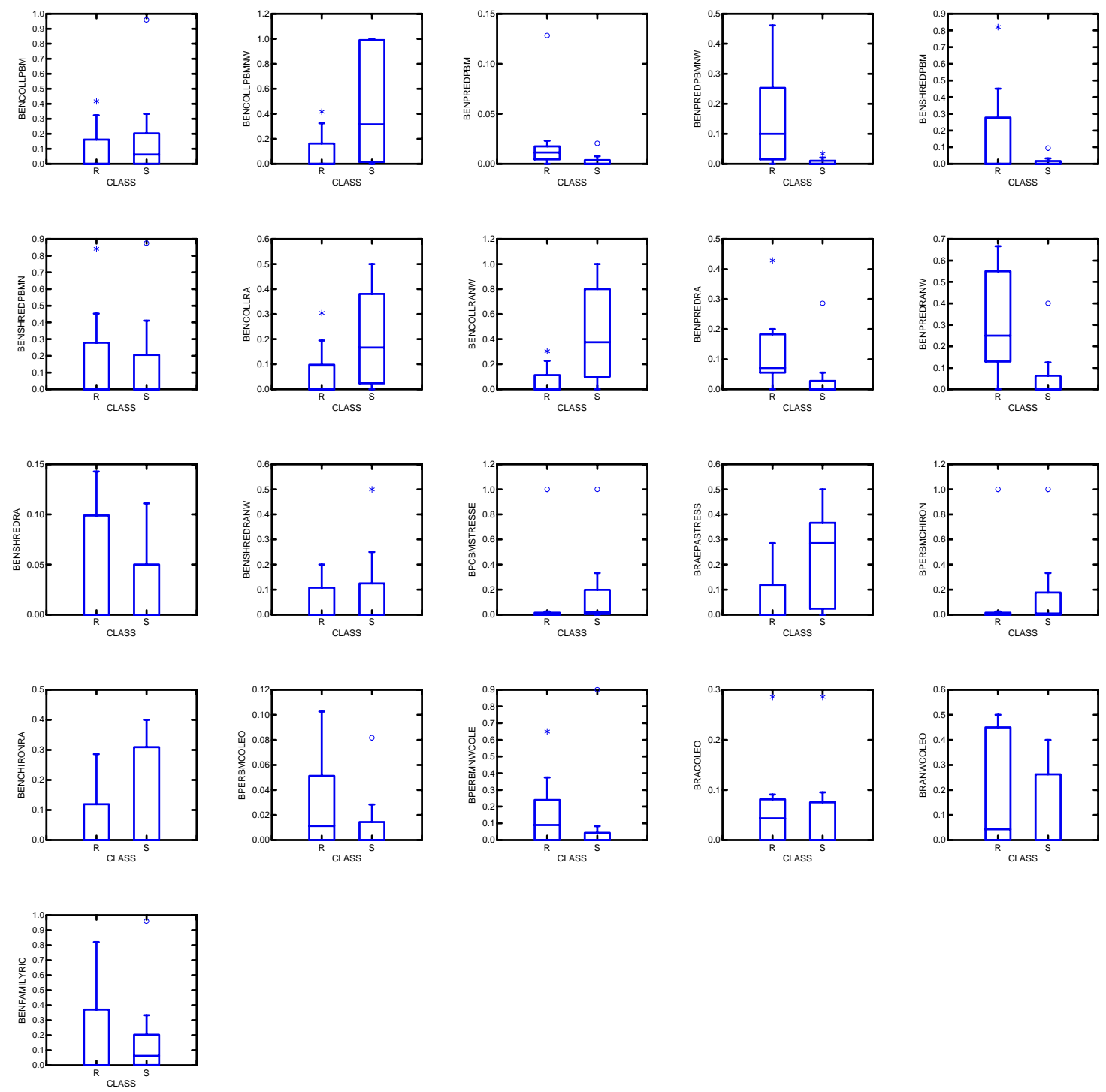


\section{Appendix BA. Continued.}

\begin{tabular}{lll}
\hline Metric code & Metric description & Rating \\
\hline benCollpBM & \% Biomass collector & poor \\
benCollpBM* $^{*}$ & \% Biomass collector & fair \\
benPredpBM & \% Biomass predator & fair \\
benPredpBM* & \% Biomass predator & poor \\
benShredpBM & \% Biomass shredder & poor \\
benShredpBMN & \% Biomass shredder & poor \\
benCollRA & Relative abundance collector & good \\
benCollRA* & Relative abundance collector & good \\
benPredRA & Relative abundance predator & good \\
benPredRA* & Relative abundance predator & good \\
benShredRA & Relative abundance shredder & poor \\
benShredRA* & Relative abundance shredder & poor \\
bPcBMstressed & \% Biomass EPA stressed & poor \\
bRAEPAstressed & Relative abundance EPA stressed & good \\
bPerBMChiron & \% Biomass Chironomidae & poor \\
BenChironRA & Relative abundance chironomidae & poor \\
bPerBMColeo & \% Biomass Coleoptera & poor \\
bPerBM*Coleo & $\%$ Biomass Coleoptera & poor \\
bRAColeo & Relative abundance Coleoptera & poor \\
bRA*Coleo & Relative abundance Coleoptera & poor \\
BenFamilyRic & Familial Richness & poor \\
\hline
\end{tabular}

* Indicates metric calculated without including Chironomidae or Oligochaeta. 
Appendix BB. Nektonic macroinvertebrate richness, count and weight by family used to form macroinvertebrate indices of biological integrity for wetlands in West Virginia, USA 2005-2006.

\begin{tabular}{|c|c|c|c|c|}
\hline SiteCode & Order & Family & Count & Weight \\
\hline \multicolumn{2}{|c|}{ CFCROSNektonic Family Richness } & 4 & & \\
\hline & Diptera & Chironomidae & 3 & 0.0002 \\
\hline & Ephemeroptera & Caenidae & 1 & 0.0002 \\
\hline & Megaloptera & Corydalidae & 1 & 0.0014 \\
\hline & Coleoptera & Elmidae & 1 & 0.0005 \\
\hline \multirow[t]{4}{*}{ CFECUR } & Nektonic Family Richness & 3 & & \\
\hline & Diptera & Chironomidae & 17 & 0.0062 \\
\hline & Ephemeroptera & Caenidae & 1 & 0.0004 \\
\hline & Oligochaeta & NA & 2 & 0.0025 \\
\hline \multirow[t]{8}{*}{ CFEINC } & Nektonic Family Richness & 7 & & \\
\hline & Odonata & Libellulidae & 2 & 0.0071 \\
\hline & Odonata & Coenagrionidae & 1 & 0.0023 \\
\hline & Diptera & Chironomidae & 12 & 0.0031 \\
\hline & Gastropoda & Physidae & 1 & 0.0013 \\
\hline & Hemiptera & Gerridae & 1 & 0.0006 \\
\hline & Ephemeroptera & Caenidae & 1 & 0.0005 \\
\hline & Coleoptera & Staphylinidae & 1 & 0.0013 \\
\hline \multirow[t]{9}{*}{ CFSLCH } & Nektonic Family Richness & 8 & & \\
\hline & Diptera & Chironomidae & 18 & 0.0052 \\
\hline & Isopoda & Asellidae & 5 & 0.0016 \\
\hline & Ephemeroptera & Baetidae & 10 & 0.0065 \\
\hline & Coleoptera & Dytiscidae & 2 & 0.0009 \\
\hline & Gastropoda & Physidae & 2 & 0.033 \\
\hline & Hydracarina & NA & 1 & 0.0001 \\
\hline & Diptera & Culicidae & 3 & 0.0008 \\
\hline & Cladocera & NA & 24 & 0.0018 \\
\hline \multirow[t]{11}{*}{ CFSLIN } & Nektonic Family Richness & 10 & & \\
\hline & Diptera & Culicidae & 1 & 0.0001 \\
\hline & Megaloptera & Sialidae & 1 & 0.0001 \\
\hline & Ephemeroptera & Baetidae & 1 & 0.001 \\
\hline & Hymenoptera & Formicidae & 1 & 0.0002 \\
\hline & Hemiptera & Belostomatidae & 1 & 0.0914 \\
\hline & Odonata & Libellulidae & 1 & 0.0121 \\
\hline & Odonata & Coenagrionidae & 2 & 0.006 \\
\hline & Cladocera & NA & 3 & 0.0001 \\
\hline & Diptera & Chironomidae & 5 & 0.0012 \\
\hline & Oligochaeta & NA & 2 & 0.0012 \\
\hline
\end{tabular}


Appendix BB. Continued.

\begin{tabular}{|c|c|c|c|c|}
\hline SiteCode & Order & Family & Count & Weight \\
\hline \multirow[t]{19}{*}{ CHNEER } & Nektonic Family Richness & 18 & & \\
\hline & Bivalvia & Sphaeriidae & 1 & 0.0004 \\
\hline & Coleoptera & Dytiscidae & 3 & 0.0271 \\
\hline & Diptera & Chaoboridae & 3 & 0.0006 \\
\hline & Diptera & Chironomidae & 8 & 0.0018 \\
\hline & Diptera & Culicidae & 2 & 0.0001 \\
\hline & Gastropoda & Planorbidae & 4 & 0.0016 \\
\hline & Hemiptera & Corixidae & 3 & 0.0176 \\
\hline & Hemiptera & Belostomotidae & 2 & 0.0363 \\
\hline & Hemiptera & Notonectidae & 1 & 0.0018 \\
\hline & Hemiptera & Veliidae & 3 & 0.0001 \\
\hline & Hemiptera & Hydrometridae & 1 & 0.0008 \\
\hline & Podocopa & NA & 1 & 0.0001 \\
\hline & Coleoptera & Hydrophilidae & 1 & 0.0053 \\
\hline & Isopoda & Asellidae & 12 & 0.0015 \\
\hline & Cladocera & NA & 2 & 0.0001 \\
\hline & Odonata & Coenagrionidae & 3 & 0.0038 \\
\hline & Odonata & Libellulidae & 1 & 0.0271 \\
\hline & Odonata & Aeshnidae & 1 & 0.0025 \\
\hline \multirow[t]{6}{*}{ CHSAFO } & Nektonic Family Richness & 5 & & \\
\hline & Decapoda & Cambaridae & 1 & 0.0304 \\
\hline & Gastropoda & Physidae & 8 & 0.0419 \\
\hline & Diptera & Chironomidae & 4 & 0.0016 \\
\hline & Diptera & Stratiomyidae & 1 & 0.0024 \\
\hline & Hemiptera & Veliidae & 1 & 0.0001 \\
\hline \multirow[t]{4}{*}{ CHSARR } & Nektonic Family Richness & 3 & & \\
\hline & Diptera & Chironomidae & 4 & 0.0006 \\
\hline & Bivalvia & Sphaeriidae & 1 & 0.0019 \\
\hline & Hemiptera & Corixidae & 55 & 0.0628 \\
\hline \multirow[t]{13}{*}{ CHWWBW } & Nektonic Family Richness & 12 & & \\
\hline & Ephemeroptera & Baetidae & 2 & 0.0014 \\
\hline & Hemiptera & Pleidae & 4 & 0.0001 \\
\hline & Odonata & Libellulidae & 4 & 0.0363 \\
\hline & Hemiptera & Veliidae & 2 & 0.0001 \\
\hline & Coleoptera & Dytiscidae & 3 & 0.0037 \\
\hline & Hemiptera & Naucoridae & 5 & 0.0036 \\
\hline & Hemiptera & Notonectididae & 1 & 0.0069 \\
\hline & Hemiptera & Corixidae & 2 & 0.0113 \\
\hline & Diptera & Culicidae & 1 & 0.0001 \\
\hline & Diptera & Chaoboridae & 3 & 0.0007 \\
\hline & Diptera & Chironomidae & 9 & 0.0009 \\
\hline & Odonata & Coenagrionidae & 4 & 0.0033 \\
\hline
\end{tabular}


Appendix BB.Continued.

\begin{tabular}{|c|c|c|c|c|}
\hline SiteCode & Order & Family & Count & Weight \\
\hline \multirow[t]{16}{*}{ CHWWEM } & Nektonic Family Richness & 15 & & \\
\hline & Gastropoda & Physidae & 2 & 0.0098 \\
\hline & Diptera & Chironomidae & 17 & 0.0031 \\
\hline & Ephemeroptera & Baetidae & 5 & 0.0027 \\
\hline & Coleoptera & Haliplidae & 1 & 0.0029 \\
\hline & Coleoptera & Dytiscidae & 8 & 0.0172 \\
\hline & Coleoptera & Hydrophilidae & 6 & 0.0137 \\
\hline & Odonata & Coenagrionidae & 1 & 0.0018 \\
\hline & Odonata & Libellulidae & 2 & 0.0114 \\
\hline & Odonata & Aeshnidae & 1 & 0.0222 \\
\hline & Isopoda & Asellidae & 11 & 0.0012 \\
\hline & Hemiptera & Mesoveliidae & 1 & 0.0001 \\
\hline & Diptera & Ceratopogonidae & 2 & 0.0001 \\
\hline & Hemiptera & Corixidae & 1 & 0.0009 \\
\hline & Diptera & Culicidae & 2 & 0.0001 \\
\hline & Hemiptera & Pleidae & 1 & 0.0006 \\
\hline \multirow[t]{18}{*}{ CHWWFO } & Nektonic Family Richness & 17 & & \\
\hline & Isopoda & Asellidae & 2 & 0.0005 \\
\hline & Coleoptera & Haliplidae & 1 & 0.0012 \\
\hline & Coleoptera & Hydrophilidae & 1 & 0.0001 \\
\hline & Hemiptera & Veliidae & 1 & 0.0001 \\
\hline & Hemiptera & Corixidae & 1 & 0.0017 \\
\hline & Ephemeroptera & Baetidae & 1 & 0.0019 \\
\hline & Cladocera & NA & 2 & 0.0001 \\
\hline & Odonata & Libellulidae & 2 & 0.0124 \\
\hline & Odonata & Coenagrionidae & 1 & 0.0002 \\
\hline & Gastropoda & Physidae & 1 & 0.0054 \\
\hline & Bivalvia & Sphaeriidae & 3 & 0.0074 \\
\hline & Gastropoda & Planorbidae & 5 & 0.0022 \\
\hline & Diptera & Chaoboridae & 1 & 0.0001 \\
\hline & Diptera & Ceratopogonidae & 1 & 0.0001 \\
\hline & Diptera & Culicidae & 5 & 0.0009 \\
\hline & Diptera & Chironomidae & 45 & 0.0124 \\
\hline & Calanoida & NA & 1 & 0.0001 \\
\hline CVABBW & $\begin{array}{c}\text { Nektonic Family Richness } \\
\text { Amphipoda }\end{array}$ & $\begin{array}{c}1 \\
\text { Gammaridae }\end{array}$ & 53 & 0.0148 \\
\hline \multirow[t]{3}{*}{ CVABCT } & Nektonic Family Richness & 2 & & \\
\hline & Ephemeroptera & Ephemeridae & 3 & 0.0052 \\
\hline & Amphipoda & Gammaridae & 18 & 0.0226 \\
\hline \multirow[t]{2}{*}{ DSPICN } & Nektonic Family Richness & 1 & & \\
\hline & Megaloptera & Sialidae & 3 & 0.0074 \\
\hline \multirow[t]{5}{*}{ DSROAR } & Nektonic Family Richness & 4 & & \\
\hline & Megaloptera & Sialidae & 1 & 0.0046 \\
\hline & Plecoptera & Leuctridae & 1 & 0.0009 \\
\hline & Diptera & unknown pupae & 1 & 0.0001 \\
\hline & Aranae & NA & 1 & 0.0028 \\
\hline
\end{tabular}


Appendix BB.Continued.

\begin{tabular}{|c|c|c|c|c|}
\hline SiteCode & Order & Family & Count & Weight \\
\hline \multirow[t]{7}{*}{ EPCMEM } & Nektonic Family Richness & 6 & & \\
\hline & Amphipoda & Gammaridae & 12 & 0.0021 \\
\hline & Diptera & Culicidae & 1 & 0.0001 \\
\hline & Diptera & Stratiomyidae & 5 & 0.0141 \\
\hline & Isopoda & Asellidae & 4 & 0.0017 \\
\hline & Gastropoda & Physidae & 14 & 0.0793 \\
\hline & Oligochaeta & NA & 5 & 0.0039 \\
\hline \multirow[t]{9}{*}{ EPCMFO } & Nektonic Family Richness & 8 & & \\
\hline & Oligochaeta & NA & 3 & 0.0001 \\
\hline & Podacopa & NA & 10 & 0.0033 \\
\hline & Amphipoda & Gammaridae & 5 & 0.0056 \\
\hline & Gastropoda & Lynaeidae & 1 & 0.0009 \\
\hline & Gastropoda & Physidae & 4 & 0.03 \\
\hline & Bivalvia & Sphaeriidae & 5 & 0.0152 \\
\hline & Isopoda & Asellidae & 1 & 0.0001 \\
\hline & Diptera & Chironomidae & 2 & 0.0001 \\
\hline \multirow[t]{11}{*}{ EPKYVE } & Nektonic Family Richness & 10 & & \\
\hline & Diptera & Ceratopogonidae & 1 & 0.0002 \\
\hline & Oligochaeta & NA & 2 & 0.0117 \\
\hline & Diptera & Chironomidae & 24 & 0.0046 \\
\hline & Gastropoda & Physidae & 25 & 0.1681 \\
\hline & Hemiptera & Corixidae & 1 & 0.0002 \\
\hline & Coleoptera & Chrysomelidae & 1 & 0.0089 \\
\hline & Isopoda & Asellidae & 12 & 0.0058 \\
\hline & Amphipoda & Gammaridae & 2 & 0.005 \\
\hline & Bivalvia & Sphaeriidae & 1 & 0.0075 \\
\hline & Gastropoda & Lymnaeidae & 2 & 0.012 \\
\hline \multirow[t]{5}{*}{ EPSHEM } & Nektonic Family Richness & 4 & & \\
\hline & Coleoptera & Curculionidae & 1 & 0.0078 \\
\hline & Diptera & Culicidae & 9 & 0.0016 \\
\hline & Gastropoda & Lymnaeidae & 2 & 0.0142 \\
\hline & Aranae & Pisauridae & 2 & 0.0044 \\
\hline
\end{tabular}


Appendix BB.Continued.

\begin{tabular}{|c|c|c|c|c|}
\hline SiteCode & Order & Family & Count & Weight \\
\hline \multirow[t]{13}{*}{ EPSHSS } & Nektonic Family Richness & 12 & & \\
\hline & Aranae & Pisauridae & 1 & 0.0361 \\
\hline & Oligochaeta & NA & 1 & 0.0005 \\
\hline & Hydracarina & NA & 1 & 0.0001 \\
\hline & Gastropoda & Lymnaeidae & 2 & 0.0041 \\
\hline & Collembola & Isotomidae & 1 & 0.0001 \\
\hline & Thysanoptera & NA & 2 & 0.0001 \\
\hline & Coleoptera & Dytiscidae & 1 & 0.0002 \\
\hline & Aranae & Lycosidae & 1 & 0.001 \\
\hline & Cyclopoida & NA & 1 & 0.0001 \\
\hline & Coleoptera & Scirtidae & 2 & 0.0019 \\
\hline & Hemiptera & Gerridae & 1 & 0.0023 \\
\hline & Bivalvia & Sphaeriidae & 1 & 0.0013 \\
\hline \multirow[t]{9}{*}{ GBBARN } & Nektonic Family Richness & 8 & & \\
\hline & Odonata & Libellulidae & 2 & 0.0238 \\
\hline & Ephemeroptera & Baetidae & 2 & 0.0002 \\
\hline & Diptera & Chironomidae & 7 & 0.0009 \\
\hline & Odonata & Coenagrionidae & 2 & 0.0089 \\
\hline & Megaloptera & Corydalidae & 1 & 0.0081 \\
\hline & Diptera & Culicidae & 1 & 0.0001 \\
\hline & Isopoda & Asellidae & 1 & 0.0014 \\
\hline & Hemiptera & Pleidae & 1 & 0.0004 \\
\hline \multirow[t]{8}{*}{ GBHOEF } & Nektonic Family Richness & 7 & & \\
\hline & Hemiptera & Belostomatidae & 2 & 0.0015 \\
\hline & Hemiptera & Naucoridae & 2 & 0.0023 \\
\hline & Hemiptera & Corixidae & 1 & 0.005 \\
\hline & Odonata & Libellulidae & 1 & 0.0118 \\
\hline & Diptera & Chironomidae & 2 & 0.0001 \\
\hline & Coleoptera & Dytiscidae & 16 & 0.0111 \\
\hline & Lepidoptera & Pyralidae & 1 & 0.0048 \\
\hline \multirow[t]{13}{*}{ GBJENK } & Nektonic Family Richness & 12 & & \\
\hline & Hemiptera & Naucoridae & 6 & 0.0096 \\
\hline & Hemiptera & Hebridae & 1 & 0.0001 \\
\hline & Hemiptera & Mesoveliidae & 1 & 0.0001 \\
\hline & Coleoptera & Dytiscidae & 1 & 0.0001 \\
\hline & Coleoptera & Noteridae & 1 & 0.0017 \\
\hline & Diptera & Culicidae & 1 & 0.0001 \\
\hline & Odonata & Aeshnidae & 1 & 0.0027 \\
\hline & Diptera & Chaoboridae & 2 & 0.0002 \\
\hline & Gastropoda & Planorbidae & 1 & 0.004 \\
\hline & Ephemeroptera & Baetidae & 3 & 0.0019 \\
\hline & Diptera & Chironomidae & 3 & 0.0014 \\
\hline & Hemiptera & Corixidae & 1 & 0.0007 \\
\hline
\end{tabular}


Appendix BB.Continued.

\begin{tabular}{|c|c|c|c|c|}
\hline SiteCode & Order & Family & Count & Weight \\
\hline \multirow[t]{9}{*}{ GBPLOT } & Nektonic Family Richness & 9 & & \\
\hline & Hemiptera & Mesoveliidae & 1 & 0.0001 \\
\hline & Diptera & Chironomidae & 3 & 0.0003 \\
\hline & Isopoda & Asellidae & 2 & 0.0018 \\
\hline & Diptera & Ceratopogonidae & 1 & 0.0001 \\
\hline & Coleoptera & Hydrophilidae & 1 & 0.001 \\
\hline & $\begin{array}{l}\text { Hemiptera } \\
\text { Hemiptera }\end{array}$ & $\begin{array}{l}\text { Corixidae } \\
\text { Aphididae }\end{array}$ & $\begin{array}{l}1 \\
1\end{array}$ & $\begin{array}{l}0.0028 \\
0.0001\end{array}$ \\
\hline & Coleoptera & Staphylinidae & 1 & 0.0001 \\
\hline & Coleoptera & Haliplidae & 1 & 0.002 \\
\hline \multirow[t]{9}{*}{ HCBEAV } & Nektonic Family Richness & 8 & & \\
\hline & Copapoda & NA & 1 & 0.0001 \\
\hline & Diptera & Chironomidae & 6 & 0.0003 \\
\hline & Coleoptera & Elmidae & 3 & 0.0007 \\
\hline & Odonata & Coenagrionidae & 4 & 0.0009 \\
\hline & Cladocera & $\mathrm{NA}$ & 2 & 0.0001 \\
\hline & Coleoptera & Hydrophilidae & 1 & 0.0003 \\
\hline & Amphipoda & Gammaridae & 1 & 0.0005 \\
\hline & Ephemeroptera & Caenidae & 1 & 0.0001 \\
\hline \multirow[t]{9}{*}{ HIGATE } & Nektonic Family Richness & 8 & & \\
\hline & Gastropoda & Physidae & 2 & 0.013 \\
\hline & Cladocera & NA & 2 & 0.0001 \\
\hline & Diptera & Chironomidae & 5 & 0.0024 \\
\hline & Diptera & Chaoboridae & 1 & 0.0001 \\
\hline & Cyclopoida & NA & 1 & 0.0001 \\
\hline & Hemiptera & Gerridae & 1 & 0.0001 \\
\hline & Oligochaeta & NA & 1 & 0.0003 \\
\hline & Isopoda & Asellidae & 10 & 0.0085 \\
\hline \multirow[t]{8}{*}{ HIJHPK } & Nektonic Family Richness & 7 & & \\
\hline & Bivalvia & Sphaeriidae & 1 & 0.0114 \\
\hline & Oligochaeta & NA & 3 & 0.005 \\
\hline & Hemiptera & Corixidae & 1 & 0.0002 \\
\hline & Gastropoda & Lymnaeidae & 1 & 0.0014 \\
\hline & Hemiptera & Gerridae & 2 & 0.0035 \\
\hline & Hemiptera & Veliidae & 2 & 0.0002 \\
\hline & Diptera & Chironomidae & 16 & 0.0102 \\
\hline \multirow[t]{12}{*}{ HIJHTU } & Nektonic Family Richness & 11 & & \\
\hline & Bivalvia & Sphaeriidae & 1 & 0.0021 \\
\hline & Coleoptera & Haliplidae & 1 & 0.0019 \\
\hline & Cyclopoida & NA & 2 & 0.0001 \\
\hline & Amphipoda & Gammaridae & 12 & 0.0027 \\
\hline & Isopoda & Asellidae & 19 & 0.0074 \\
\hline & Gastropoda & Physidae & 11 & 0.3933 \\
\hline & Oligochaeta & NA & 2 & 0.0018 \\
\hline & Coleoptera & Dytiscidae & 2 & 0.0014 \\
\hline & Coleoptera & Scirtidae & 12 & 0.0051 \\
\hline & Diptera & Dixidae & 1 & 0.0001 \\
\hline & Diptera & Chironomidae & 11 & 0.0022 \\
\hline
\end{tabular}


Appendix BB.Continued.

\begin{tabular}{|c|c|c|c|c|}
\hline SiteCode & Order & Family & Count & Weight \\
\hline \multirow[t]{22}{*}{ HIPENC } & Nektonic Family Richness & 21 & & \\
\hline & Cyclopoida & NA & 3 & 0.0001 \\
\hline & Decapoda & Cambaridae & 1 & 0.0035 \\
\hline & Odonata & Coenagrionidae & 1 & 0.0002 \\
\hline & Isopoda & Asellidae & 5 & 0.0005 \\
\hline & Hemiptera & Hebridae & 1 & 0.0001 \\
\hline & Gastropoda & Physidae & 12 & 0.1196 \\
\hline & Diptera & Culicidae & 2 & 0.0008 \\
\hline & Odonata & Libellulidae & 6 & 0.0264 \\
\hline & Oligochaeta & NA & 2 & 0.0002 \\
\hline & Coleoptera & Staphylinidae & 1 & 0.0011 \\
\hline & Coleoptera & Haliplidae & 2 & 0.0029 \\
\hline & Odonata & Lestidae & 1 & 0.0022 \\
\hline & Cladocera & NA & 5 & 0.0001 \\
\hline & Gastropoda & Physidae & 2 & 0.003 \\
\hline & Diptera & Dixidae & 1 & 0.0001 \\
\hline & Diptera & Ceratopogonidae & 1 & 0.0001 \\
\hline & Diptera & Chironomidae & 1 & 0.0001 \\
\hline & Coleoptera & Dytiscidae & 2 & 0.0007 \\
\hline & Hemiptera & Veliidae & 2 & 0.0001 \\
\hline & Hemiptera & Gerridae & 1 & 0.0016 \\
\hline & Amphipoda & Gammaridae & 7 & 0.002 \\
\hline \multirow[t]{5}{*}{ HISEWG } & Nektonic Family Richness & 4 & & \\
\hline & Isopoda & Asellidae & 1 & 0.0009 \\
\hline & Oligochaeta & NA & 1 & 0.0015 \\
\hline & Coleoptera & Haliplidae & 1 & 0.0022 \\
\hline & Diptera & Chironomidae & 2 & 0.0002 \\
\hline \multirow[t]{4}{*}{ MCFOUR } & Nektonic Family Richness & 3 & & \\
\hline & Coleoptera & Hydrophilidae & 3 & 0.0159 \\
\hline & Coleoptera & Dytiscidae & 25 & 0.0567 \\
\hline & Diptera & Chironomidae & 7 & 0.0018 \\
\hline \multirow[t]{12}{*}{ MCMEME } & Nektonic Family Richness & 11 & & \\
\hline & Odonata & Coenagrionidae & 3 & 0.0045 \\
\hline & Cladocera & NA & 1 & 0.0001 \\
\hline & Coleoptera & Dytiscidae & 2 & 0.0002 \\
\hline & Hemiptera & Notonectidae & 2 & 0.0185 \\
\hline & Gastropoda & Physidae & 1 & 0.0007 \\
\hline & Diptera & Chironomidae & 4 & 0.0002 \\
\hline & Ephemeroptera & Baetidae & 3 & 0.001 \\
\hline & Hemiptera & Pleidae & 1 & 0.0003 \\
\hline & Hemiptera & Belostomatidae & 4 & 0.0468 \\
\hline & Diptera & Chaoboridae & 1 & 0.0001 \\
\hline & Ephemeroptera & Caenidae & 12 & 0.0034 \\
\hline
\end{tabular}


Appendix BB.Continued.

\begin{tabular}{|c|c|c|c|c|}
\hline SiteCode & Order & Family & Count & Weight \\
\hline \multirow[t]{10}{*}{ MCMFOR } & Nektonic Family Richness & 9 & & \\
\hline & Isopoda & Asellidae & 4 & 0.004 \\
\hline & Coleoptera & Dytiscidae & 5 & 0.0026 \\
\hline & Hemiptera & Mesoveliidae & 1 & 0.0007 \\
\hline & Coleoptera & Scirtidae & 2 & 0.0003 \\
\hline & Bivalvia & Sphaeriidae & 1 & 0.0214 \\
\hline & Gastropoda & Planorbidae & 1 & 0.0004 \\
\hline & Diptera & Chironomidae & 2 & 0.0001 \\
\hline & Oligochaeta & NA & 22 & 0.0193 \\
\hline & Gastropoda & Physidae & 13 & 0.4772 \\
\hline \multirow[t]{10}{*}{ MCPOND } & Nektonic Family Richness & 9 & & \\
\hline & Hemiptera & Pleidae & 1 & 0.0008 \\
\hline & Hemiptera & Hebridae & 6 & 0.0008 \\
\hline & Hemiptera & Veliidae & 1 & 0.0007 \\
\hline & Diptera & Ceratopogonidae & 1 & 0.0001 \\
\hline & Odonata & Coenagrionidae & 4 & 0.004 \\
\hline & Ephemeroptera & Baetidae & 1 & 0.0011 \\
\hline & Ephemeroptera & Caenidae & 11 & 0.0026 \\
\hline & Diptera & Chironomidae & 5 & 0.0006 \\
\hline & Hemiptera & Mesoveliidae & 1 & 0.0001 \\
\hline \multirow[t]{8}{*}{ MCPOST } & Nektonic Family Richness & 7 & & \\
\hline & Odonata & Libellulidae & 1 & 0.0142 \\
\hline & Ephemeroptera & Caenidae & 1 & 0.0001 \\
\hline & Hemiptera & Hebridae & 3 & 0.0001 \\
\hline & Hemiptera & Naucoridae & 1 & 0.0005 \\
\hline & Cladocera & NA & 1 & 0.0001 \\
\hline & Diptera & Chironomidae & 1 & 0.0001 \\
\hline & Odonata & Coenagrionidae & 4 & 0.006 \\
\hline \multirow[t]{9}{*}{ MCTELE } & Nektonic Family Richness & 8 & & \\
\hline & Coleoptera & Hydrophilidae & 1 & 0.0066 \\
\hline & Isopoda & Asellidae & 1 & 0.0001 \\
\hline & Coleoptera & Noteridae & 2 & 0.0049 \\
\hline & Gastropoda & Physidae & 8 & 0.039 \\
\hline & Nematoda & NA & 19 & 0.0192 \\
\hline & Bivalvia & Sphaeriidae & 3 & 0.02 \\
\hline & Gastropoda & Planorbidae & 3 & 0.0038 \\
\hline & Gastropoda & Viviparidae & 1 & 0.0074 \\
\hline
\end{tabular}


Appendix BB.Continued.

\begin{tabular}{|c|c|c|c|c|}
\hline SiteCode & Order & Family & Count & Weight \\
\hline \multirow[t]{9}{*}{ ME5092 } & Nektonic Family Richness & 8 & & \\
\hline & Hemiptera & Corixidae & 2 & 0.0004 \\
\hline & Ephemeroptera & Baetidae & 1 & 0.0012 \\
\hline & Gastropoda & Physidae & 3 & 0.0437 \\
\hline & Bivalvia & Sphaeriidae & 2 & 0.0131 \\
\hline & Diptera & Ephydridae & 2 & 0 \\
\hline & Diptera & Chironomidae & 17 & 0.003 \\
\hline & Decapoda & Cambaridae & 3 & 0.0289 \\
\hline & Odonota & Cordulegastridae & 1 & 0.0327 \\
\hline \multirow[t]{15}{*}{ MESCOX } & Nektonic Family Richness & 14 & & \\
\hline & Hemiptera & Belastomatidae & 1 & 0.0222 \\
\hline & Coleoptera & Elmidae & 1 & 0.0009 \\
\hline & Coleoptera & Curculionidae & 4 & 0.0054 \\
\hline & Ephemeroptera & Baetidae & 1 & 0.0006 \\
\hline & Gastropoda & Lymnaeidae & 1 & 0.0044 \\
\hline & Odonata & Ashnidae & 1 & 0.005 \\
\hline & Odonata & Libellulidae & 6 & 0.0156 \\
\hline & Odonata & Coenagrionidae & 1 & 0.0006 \\
\hline & Diptera & Chironomidae & 4 & 0.0002 \\
\hline & Diptera & Chaoboridae & 1 & 0.0001 \\
\hline & Gastropoda & Physidae & 1 & 0.0078 \\
\hline & Gastropoda & Planorbidae & 1 & 0.001 \\
\hline & Coleoptera & Dytiscidae & 1 & 0.0008 \\
\hline & Colembella & Poduridae & 2 & 0.0001 \\
\hline \multirow[t]{12}{*}{ MESCRO } & Nektonic Family Richness & 11 & & \\
\hline & Gastropoda & Lymnaeidae & 1 & 0.0012 \\
\hline & Ephemeroptera & Baetidae & 1 & 0.0011 \\
\hline & Gastropoda & Planorbidae & 2 & 0.006 \\
\hline & Isopoda & Asellidae & 1 & 0.0001 \\
\hline & Odonata & Libellulidae & 1 & 0.0013 \\
\hline & Odonata & Aeshnidae & 1 & 0.0038 \\
\hline & Hemiptera & Corixidae & 3 & 0.0036 \\
\hline & Coleoptera & Hydrophilidae & 1 & 0.0024 \\
\hline & Oligochaeta & NA & 2 & 0.0019 \\
\hline & Diptera & Chironomidae & 8 & 0.0011 \\
\hline & Diptera & Dixidae & 1 & 0.0001 \\
\hline
\end{tabular}


Appendix BB.Continued.

\begin{tabular}{|c|c|c|c|c|}
\hline SiteCode & Order & Family & Count & Weight \\
\hline \multirow[t]{12}{*}{ MESCUP } & Nektonic Family Richness & 11 & & \\
\hline & Odonata & Coenagrionidae & 1 & 0.0001 \\
\hline & Isopoda & Asellidae & 6 & 0.0017 \\
\hline & Hemipetra & Corixidae & 2 & 0.0031 \\
\hline & Oligocheata & NA & 1 & 0.0001 \\
\hline & Bivalvia & Sphaeriidae & 2 & 0.0036 \\
\hline & Gastropoda & Valvatidae & 4 & 0.0028 \\
\hline & Odonata & Aeshnidae & 1 & 0.0006 \\
\hline & Gastropoda & Physidae & 1 & 0.0006 \\
\hline & Gastropoda & Lymnaeidae & 1 & 0.002 \\
\hline & Diptera & Chironomidae & 6 & 0.0001 \\
\hline & Odonata & Libellulidae & 3 & 0.0029 \\
\hline \multirow[t]{4}{*}{ MESIGN } & Nektonic Family Richness & 3 & & \\
\hline & Coleptera & Hydrophilidae & 1 & 0.0008 \\
\hline & Diptera & Stratiomyidae & 1 & 0.0013 \\
\hline & Gastropoda & Lymnaeidae & 1 & 0.0058 \\
\hline \multirow[t]{9}{*}{ MESILV } & Nektonic Family Richness & 8 & & \\
\hline & Coleoptera & Staphylinidae & 1 & 0.0006 \\
\hline & Isopoda & Asellidae & 16 & 0.0028 \\
\hline & Diptera & Dixidae & 3 & 0.0001 \\
\hline & Diptera & Chironomidae & 3 & 0.0001 \\
\hline & Gastropoda & Lymnaeidae & 2 & 0.0207 \\
\hline & Gastropoda & Physidae & 6 & 0.0502 \\
\hline & Decapoda & Cambaridae & 1 & 0.0029 \\
\hline & Coleoptera & Dytiscidae & 8 & 0.0086 \\
\hline \multirow[t]{7}{*}{ METETR } & Nektonic Family Richness & 6 & & \\
\hline & Coleoptera & Dytiscidae & 2 & 0.0038 \\
\hline & Coleoptera & Hydrophilidae & 2 & 0.0015 \\
\hline & Odonata & Libellulidae & 5 & 0.0088 \\
\hline & Hemiptera & Mesoveliidae & 3 & 0.0012 \\
\hline & Diptera & Chironomidae & 4 & 0.0001 \\
\hline & Gastropoda & Physidae & 16 & 0.0516 \\
\hline \multirow[t]{8}{*}{ MEWOLF } & Nektonic Family Richness & 7 & & \\
\hline & Decapoda & Cambaridae & 2 & 0.0082 \\
\hline & Gastropoda & Physidae & 1 & 0.1469 \\
\hline & Coleoptera & Hydrophilidae & 3 & 0.0082 \\
\hline & Coleoptera & Dytiscidae & 4 & 0.009 \\
\hline & Bivalvia & Sphaeriidae & 1 & 0.0002 \\
\hline & Isopoda & Asellidae & 16 & 0.0151 \\
\hline & Diptera & Chironomidae & 1 & 0.0001 \\
\hline
\end{tabular}


Appendix BB.Continued.

\begin{tabular}{|c|c|c|c|c|}
\hline SiteCode & Order & Family & Count & Weight \\
\hline \multirow[t]{14}{*}{ MRBESS } & Nektonic Family Richness & 13 & & \\
\hline & Cladocera & NA & 1 & 0.0001 \\
\hline & Copepoda & NA & 1 & 0.0001 \\
\hline & Diptera & Culicidae & 1 & 0.0001 \\
\hline & Amphipoda & Talitridae & 1 & 0.0001 \\
\hline & Coleoptera & Dytiscidae & 1 & 0.0001 \\
\hline & Ephemeroptera & Baetidae & 1 & 0.0009 \\
\hline & Diptera & Dixidae & 1 & 0.0001 \\
\hline & Bivalvia & Sphaeriidae & 1 & 0.0104 \\
\hline & Decapoda & NA & 2 & 0.0416 \\
\hline & Gastropoda & Physidae & 2 & 0.0466 \\
\hline & Diptera & Chironomidae & 5 & 0.0012 \\
\hline & Coleoptera & Hydrophilidae & 1 & 0.0003 \\
\hline & Isopoda & Asellidae & 2 & 0.0008 \\
\hline \multirow[t]{6}{*}{ MU55SS } & Nektonic Family Richness & 5 & & \\
\hline & Odonata & Gomphidae & 1 & 0.007 \\
\hline & Decapoda & Cambaridae & 1 & 0.0046 \\
\hline & Diptera & Chironomidae & 1 & 0.0001 \\
\hline & Bivalvia & Sphaeriidae & 12 & 0.105 \\
\hline & Isopoda & Asellidae & 1 & 0.0001 \\
\hline \multirow[t]{16}{*}{ MUDBOA } & Nektonic Family Richness & 15 & & \\
\hline & Coleoptera & Hydrophilidae & 4 & 0.0021 \\
\hline & Coleoptera & Scirtidae & 1 & 0.0001 \\
\hline & Aranae & Pisaurdiae & 1 & 0.0066 \\
\hline & Diptera & Tipulidae & 1 & 0.0001 \\
\hline & Ephemeroptera & Baetidae & 1 & 0.0006 \\
\hline & Hemiptera & Mesoveliidae & 2 & 0.0001 \\
\hline & Coleoptera & Curculionidae & 9 & 0.0103 \\
\hline & Coleoptera & Haliplidae & 1 & 0.001 \\
\hline & Gastropoda & Lymnaeidae & 8 & 0.0239 \\
\hline & Gastropoda & Physidae & 1 & 0.012 \\
\hline & Bivalvia & Sphaeriidae & 8 & 0.0358 \\
\hline & Decapoda & Cambaridae & 1 & 0.0168 \\
\hline & Diptera & Chironomidae & 2 & 0.0006 \\
\hline & Odonata & Coenagrionidae & 1 & 0.0001 \\
\hline & Hemiptera & Veliidae & 2 & 0.0001 \\
\hline \multirow[t]{10}{*}{ MUDEND } & Nektonic Family Richness & 9 & & \\
\hline & Hemiptera & Mesoveliidae & 3 & 0.0003 \\
\hline & Collembola & Isotomidae & 1 & 0.0001 \\
\hline & Odonata & Libellulidae & 1 & 0.0002 \\
\hline & Odonata & Coenagrionidae & 6 & 0.0025 \\
\hline & Hemiptera & Veliidae & 3 & 0.0001 \\
\hline & Gastropoda & Planorbidae & 1 & 0.0168 \\
\hline & Cladocera & NA & 2 & 0.0001 \\
\hline & Diptera & Chironomidae & 7 & 0.0007 \\
\hline & Hemiptera & Belostomatidae & 2 & 0.004 \\
\hline
\end{tabular}


Appendix BB.Continued.

\begin{tabular}{|c|c|c|c|c|}
\hline SiteCode & Order & Family & Count & Weight \\
\hline \multirow[t]{11}{*}{ MUDRIC } & Nektonic Family Richness & 10 & & \\
\hline & Coleopotera & Haliplidae & 1 & 0.0022 \\
\hline & Diptera & Ceratopogonidae & 3 & 0.0001 \\
\hline & Coleoptera & Dytiscidae & 1 & 0.0002 \\
\hline & Hemiptera & Veliidae & 1 & 0.0001 \\
\hline & Odonata & Coenagrionidae & 2 & 0.0027 \\
\hline & Odonata & Libellulidae & 3 & 0.0319 \\
\hline & Gastropoda & Physidae & 1 & 0.0075 \\
\hline & Gastropoda & Planorbidae & 4 & 0.085 \\
\hline & Diptera & Chironomidae & 7 & 0.0006 \\
\hline & Bivalvia & Sphaeriidaer & 6 & 0.0123 \\
\hline \multirow[t]{15}{*}{ MUDRIP } & Nektonic Family Richness & 14 & & \\
\hline & Hemiptera & Belostomatidae & 1 & 0.0016 \\
\hline & Coleoptera & Staphylinidae & 1 & 0.0006 \\
\hline & Gastropoda & Planorbidae & 1 & 0.0042 \\
\hline & Gastropoda & Lymnaeidae & 2 & 0.0024 \\
\hline & Diptera & Dixidae & 1 & 0.0001 \\
\hline & Podocopa & NA & 1 & 0.0001 \\
\hline & Hemiptera & veliidae & 3 & 0.0001 \\
\hline & Hemiptera & Hydrometridae & 1 & 0.0002 \\
\hline & Bivalvia & Sphaeriidae & 1 & 0.0019 \\
\hline & Diptera & Culicidae & 1 & 0.0004 \\
\hline & Diptera & Chironomidae & 5 & 0.0002 \\
\hline & Odonata & Coenagrionidae & 2 & 0.0046 \\
\hline & Hemiptera & Mesoveliidae & 1 & 0.0001 \\
\hline & Oligochaeta & NA & 4 & 0.0031 \\
\hline \multirow[t]{17}{*}{ MUDTRA } & Nektonic Family Richness & 16 & & \\
\hline & Ephemeroptera & Baetidae & 1 & 0.0001 \\
\hline & Hemiptera & Mesoveliidae & 4 & 0.0001 \\
\hline & Coleoptera & Dytiscidae & 3 & 0.0008 \\
\hline & Cladocera & NA & 1 & 0.0001 \\
\hline & Cyclopoida & NA & 1 & 0.0001 \\
\hline & Odonata & Libellulidae & 1 & 0.0057 \\
\hline & Gastropoda & Hydrobiidae & 1 & 0.0044 \\
\hline & Aranae & Pisauridae & 1 & 0.0009 \\
\hline & Homoptera & Aphididae & 7 & 0.0007 \\
\hline & Odonata & Corduliidae & 1 & 0.0154 \\
\hline & Odonata & Coenagrionidae & 28 & 0.0089 \\
\hline & Aranae & hydracarina & 1 & 0.0001 \\
\hline & Diptera & Tabanidae & 1 & 0.0032 \\
\hline & Diptera & Chaoboridae & 2 & 0.0001 \\
\hline & Diptera & Chironomidae & 46 & 0.0035 \\
\hline & Gastropoda & Planorbidae & 2 & 0.1325 \\
\hline
\end{tabular}


Appendix BB.Continued.

\begin{tabular}{|c|c|c|c|c|}
\hline SiteCode & Order & Family & Count & Weight \\
\hline \multirow[t]{13}{*}{ MUEPAH } & Nektonic Family Richness & 12 & & \\
\hline & Hemiptera & Corixidae & 3 & 0.0059 \\
\hline & Hemiptera & Veliidae & 22 & 0.001 \\
\hline & Hemiptera & Gerridae & 1 & 0.0001 \\
\hline & Diptera & Culicidae & 3 & 0.0008 \\
\hline & Diptera & Chironomidae & 5 & 0.0005 \\
\hline & Diptera & Dixidae & 1 & 0.0008 \\
\hline & Diptera & Tabanidae & 1 & 0.0012 \\
\hline & Odonata & Libellulidae & 1 & 0.0008 \\
\hline & Coleoptera & Chrysomelidae & 1 & 0.0034 \\
\hline & Aranae & Pisauridae & 1 & 0.0036 \\
\hline & Hemiptera & Mesoveliidae & 1 & 0.0001 \\
\hline & Coleoptera & Dytiscidae & 4 & 0.0008 \\
\hline \multirow[t]{9}{*}{ MUPOWR } & Nektonic Family Richness & 8 & & \\
\hline & Bivalvia & Sphaeriidae & 2 & 0.0116 \\
\hline & Megaloptera & Corydalidae & 1 & 0.0002 \\
\hline & Ephemeroptera & Baetidae & 16 & 0.0047 \\
\hline & Coleoptera & Dytiscidae & 1 & 0.0001 \\
\hline & Odonata & Calopterygidae & 1 & 0.0123 \\
\hline & Diptera & Ceratopogonidae & 3 & 0.0001 \\
\hline & Diptera & Chironomidae & 12 & 0.0008 \\
\hline & Coleoptera & Elmidae & 1 & 0.0001 \\
\hline \multirow[t]{15}{*}{ MUPULL } & Nektonic Family Richness & 14 & & \\
\hline & Hemiptera & Belostomatidae & 3 & 0.0018 \\
\hline & Diptera & Chironomidae & 1 & 0.0011 \\
\hline & Cladocera & NA & 2 & 0.0001 \\
\hline & Ephemeroptera & Caenidae & 4 & 0.002 \\
\hline & Odonata & Lestidae & 1 & 0.0016 \\
\hline & Hemiptera & Corixidae & 4 & 0.0019 \\
\hline & Coleoptera & Haliplidae & 1 & 0.0024 \\
\hline & Coleoptera & Hydrophilidae & 4 & 0.0014 \\
\hline & Coleoptera & Dytiscidae & 10 & 0.0041 \\
\hline & Bivalvia & Sphaeriidae & 4 & 0.0416 \\
\hline & Gastropoda & Planorbidae & 7 & 0.1148 \\
\hline & Aranae & Pisauridae & 1 & 0.0194 \\
\hline & Decapoda & Cambaridae & 1 & 0.0073 \\
\hline & Gastropoda & Lymnaeidae & 5 & 0.014 \\
\hline \multirow[t]{11}{*}{ MUVBRD } & Nektonic Family Richness & 10 & & \\
\hline & Odonata & Lestidae & 2 & 0.0012 \\
\hline & Diptera & Chironomidae & 6 & 0.0012 \\
\hline & Isopoda & Asellidae & 70 & 0.0142 \\
\hline & Coleoptera & Dytiscidae & 21 & 0.0393 \\
\hline & Hemiptera & Corixidae & 2 & 0.0027 \\
\hline & Coleoptera & Staphylinidae & 1 & 0.0015 \\
\hline & Odonata & Libellulidae & 2 & 0.0579 \\
\hline & Diptera & Culicidae & 1 & 0.0001 \\
\hline & Coleoptera & Hydrophilidae & 6 & 0.0069 \\
\hline & Oligochaeta & NA & 4 & 0.0035 \\
\hline
\end{tabular}


Appendix BB. Continued.

\begin{tabular}{|c|c|c|c|c|}
\hline SiteCode & Order & Family & Count & Weight \\
\hline \multirow[t]{13}{*}{ MUVCRN } & Nektonic Family Richness & 12 & & \\
\hline & Ephemeroptera & Baetridae & 1 & 0.0002 \\
\hline & Diptera & Chironomidae & 20 & 0.0028 \\
\hline & Cyclopoida & NA & 1 & 0.0001 \\
\hline & Gastropoda & Lymnaeidae & 1 & 0.0009 \\
\hline & Cladocera & NA & 9 & 0.0001 \\
\hline & Hemiptera & Veliidae & 1 & 0.0001 \\
\hline & Coleoptera & Dytiscidae & 3 & 0.0033 \\
\hline & Coleoptera & Haliplidae & 2 & 0.0024 \\
\hline & Odonata & Libellulidae & 2 & 0.0057 \\
\hline & Decapoda & Cambaridae & 1 & 0.0084 \\
\hline & Gastropoda & Planorbidae & 1 & 0.0031 \\
\hline & Odonata & Coenagrionidae & 1 & 0.0038 \\
\hline \multirow[t]{3}{*}{ OHHSFO } & Nektonic Family Richness & 2 & & \\
\hline & Bivalvia & Sphaeriidae & 4 & 0.0088 \\
\hline & Isopoda & Asellidae & 11 & 0.0028 \\
\hline \multirow[t]{10}{*}{ OHINNS } & Nektonic Family Richness & 9 & & \\
\hline & Odonata & Lestidae & 1 & 0.0021 \\
\hline & Ephemeroptera & Baetidae & 2 & 0.0009 \\
\hline & Coleoptera & Dytiscidae & 4 & 0.0022 \\
\hline & Coleoptera & Haliplidae & 1 & 0.0026 \\
\hline & Gastropoda & Lymnaeidae & 1 & 0.0016 \\
\hline & Diptera & Culicidae & 2 & 0.0002 \\
\hline & Cladocera & NA & 2 & 0.0001 \\
\hline & Odonata & Libellulidae & 3 & 0.0323 \\
\hline & Diptera & Chironomidae & 4 & 0.0008 \\
\hline \multirow[t]{5}{*}{ OHKMRT } & Nektonic Family Richness & 4 & & \\
\hline & Isopoda & Asellidae & 1 & 0.0007 \\
\hline & Hemiptera & Veliidae & 2 & 0.0001 \\
\hline & Hemiptera & Hebridae & 1 & 0.0002 \\
\hline & Odonata & Libellulidae & 1 & 0.0027 \\
\hline \multirow[t]{10}{*}{ PA83CR } & Nektonic Family Richness & 9 & & \\
\hline & Diptera & Culicidae & 9 & 0.0038 \\
\hline & Hemiptera & Mesoveliidae & 2 & 0.002 \\
\hline & Hemiptera & Veliidae & 3 & 0.0001 \\
\hline & Coleoptera & Dytiscidae & 1 & 0.0004 \\
\hline & Coleoptera & Hydrophilidae & 5 & 0.0036 \\
\hline & Isopoda & Asellidae & 8 & 0.0017 \\
\hline & Bivalvia & Sphaeriidae & 5 & 0.0471 \\
\hline & Decapoda & Cambaridae & 5 & 0.0473 \\
\hline & Coleoptera & Gyrinidae & 1 & 0.0002 \\
\hline
\end{tabular}


Appendix BB.Continued.

\begin{tabular}{|c|c|c|c|c|}
\hline SiteCode & Order & Family & Count & Weight \\
\hline \multirow[t]{13}{*}{ PAFAMD } & Nektonic Family Richness & 12 & & \\
\hline & Hemiptera & Gerridae & 1 & 0.0018 \\
\hline & Hemiptera & Veliidae & 2 & 0.0001 \\
\hline & Ephemeroptera & Baetidae & 3 & 0.0013 \\
\hline & Ephemeroptera & Caenidae & 6 & 0.0025 \\
\hline & Aranae & Hydracarina & 2 & 0.0001 \\
\hline & Diptera & Chironomidae & 11 & 0.0042 \\
\hline & Gastropoda & Physidae & 21 & 0.1032 \\
\hline & Decapoda & Cambaridae & 1 & 0.0525 \\
\hline & Bivalvia & Spaheriidae & 6 & 0.0283 \\
\hline & Mysidacea & Mysidae & 2 & 0.0976 \\
\hline & Odonata & Coenagrionidae & 5 & 0.005 \\
\hline & Hemiptera & Corixidae & 13 & 0.0053 \\
\hline \multirow[t]{7}{*}{ PAJCPY } & Nektonic Family Richness & 6 & & \\
\hline & Aranae & Lycosidae & 1 & 0.0023 \\
\hline & Coleoptera & Carabidae & 1 & 0.0034 \\
\hline & Aranae & Hydracarina & 1 & 0.0001 \\
\hline & Diptera & Culicidae & 5 & 0.0001 \\
\hline & Aranae & Pisauridae & 2 & 0.0002 \\
\hline & Gastropoda & Physidae & 2 & 0.002 \\
\hline \multirow[t]{9}{*}{ PALOUD } & Nektonic Family Richness & 8 & & \\
\hline & Hirudinea & Haemopidae & 3 & 0.0058 \\
\hline & Diptera & Culicidae & 1 & 0.0001 \\
\hline & Gastropoda & Lymnaeidae & 14 & 0.0801 \\
\hline & Amphipoda & Gammaridae & 1 & 0.0001 \\
\hline & Coleoptera & Haliplidae & 2 & 0.0027 \\
\hline & Oligochaeta & NA & 1 & 0.0001 \\
\hline & Gastropoda & Physidae & 17 & 0.0751 \\
\hline & Bivalvia & Sphaeriidae & 4 & 0.0111 \\
\hline \multirow[t]{16}{*}{ PAPEIM } & Nektonic Family Richness & 15 & & \\
\hline & Coleoptera & Hydrophilidae & 4 & 0.0022 \\
\hline & Diptera & Ceratopogonidae & 1 & 0.0001 \\
\hline & Ephemeroptera & Baetidae & 23 & 0.0082 \\
\hline & Hemiptera & Nepidae & 1 & 0.0197 \\
\hline & Odonata & Libellulidae & 1 & 0.0013 \\
\hline & Odonata & Coenagrionidae & 13 & 0.0128 \\
\hline & Odonata & Aeshnidae & 1 & 0.0061 \\
\hline & Hemiptera & Belostomatidae & 4 & 0.0099 \\
\hline & Oligochaeta & NA & 4 & 0.0019 \\
\hline & Bivalvia & Sphaeriidae & 2 & 0.0122 \\
\hline & Hemiptera & Notonectidae & 4 & 0.0032 \\
\hline & Diptera & Chironomidae & 12 & 0.0017 \\
\hline & Gastropoda & Lymnaeidae & 4 & 0.0042 \\
\hline & Gastropoda & Physidae & 10 & 0.0399 \\
\hline & Hemiptera & Mesoveliidae & 1 & 0.0001 \\
\hline
\end{tabular}


Appendix BB.Continued.

\begin{tabular}{|c|c|c|c|c|}
\hline SiteCode & Order & Family & Count & Weight \\
\hline \multirow[t]{14}{*}{ PAPESW } & Nektonic Family Richness & 13 & & \\
\hline & Coleoptera & Hydrophilidae & 2 & 0.001 \\
\hline & Bivalvia & Sphaeriidae & 14 & 0.0711 \\
\hline & Hemiptera & Hydrometridae & 1 & 0.0007 \\
\hline & Hirudinea & Glossiphoniidae & 30 & 0.0109 \\
\hline & Odonata & Coenagrionidae & 6 & 0.0059 \\
\hline & Coleoptera & Dytiscidae & 1 & 0.0045 \\
\hline & Gastropoda & Physidae & 46 & 0.2016 \\
\hline & Coleoptera & Haliplidae & 1 & 0.0023 \\
\hline & Nematoda & NA & 1 & 0.0001 \\
\hline & Amphipoda & Gammaridae & 7 & 0.0038 \\
\hline & Gastropoda & Planorbidae & 6 & 0.0962 \\
\hline & Diptera & Chironomidae & 2 & 0.0001 \\
\hline & Odonata & Libellulidae & 1 & 0.0168 \\
\hline \multirow[t]{23}{*}{ PAWILL } & Nektonic Family Richness & 22 & & \\
\hline & Coleoptera & Staphylinidae & 1 & 0.0001 \\
\hline & Oligochaeta & NA & 1 & 0.0002 \\
\hline & Diptera & Chironomidae & 2 & 0.0005 \\
\hline & Diptera & Chaoboridae & 8 & 0.0006 \\
\hline & Diptera & Tipulidae & 1 & 0.0005 \\
\hline & Coleoptera & Dytiscidae & 1 & 0.0001 \\
\hline & Coleoptera & Chrysomelidae & 1 & 0.0037 \\
\hline & Aranae & Pisauridae & 1 & 0.0006 \\
\hline & Isopoda & Asellidae & 7 & 0.0023 \\
\hline & Hemiptera & Hydrometridae & 1 & 0.0003 \\
\hline & Coleoptera & Hydrophilidae & 2 & 0.001 \\
\hline & Hemiptera & Corixidae & 2 & 0.017 \\
\hline & Odonata & Aeshnidae & 1 & 0.0246 \\
\hline & Odonata & Coenagrionidae & 1 & 0.0004 \\
\hline & Gastropoda & Lymaeidae & 12 & 0.1088 \\
\hline & Hemiptera & Naucoridae & 1 & 0.002 \\
\hline & Hemiptera & Belostomatidae & 5 & 0.105 \\
\hline & Hemiptera & Pleidae & 3 & 0.0008 \\
\hline & Hemiptera & Mesoveliidae & 8 & 0.0013 \\
\hline & Gastropoda & Planorbidae & 13 & 1.6112 \\
\hline & Cladocera & NA & 2 & 0.0001 \\
\hline & Gastropoda & Physidae & 3 & 0.0546 \\
\hline
\end{tabular}


Appendix BB.Continued.

\begin{tabular}{|c|c|c|c|c|}
\hline SiteCode & Order & Family & Count & Weight \\
\hline \multirow[t]{12}{*}{ PEMIDW } & Nektonic Family Richness & 11 & & \\
\hline & Diptera & Culicidae & 4 & 0.0002 \\
\hline & Gastropoda & Lynaeidae & 2 & 0.0024 \\
\hline & Collembola & Isotomidae & 1 & 0.0001 \\
\hline & Ephemeroptera & Baetidae & 2 & 0.002 \\
\hline & Coleoptera & Dytiscidae & 4 & 0.0014 \\
\hline & Hemiptera & Veliidae & 1 & 0.0001 \\
\hline & Gastropoda & Physidae & 1 & 0.0013 \\
\hline & Diptera & Chironomidae & 5 & 0.0009 \\
\hline & Hemiptera & Gerridae & 1 & 0.0024 \\
\hline & Hemiptera & Corixidae & 4 & 0.0036 \\
\hline & Bivalvia & Sphaeriidae & 4 & 0.0144 \\
\hline \multirow[t]{14}{*}{ PERDDP } & Nektonic Family Richness & 13 & & \\
\hline & Ephemeroptera & Baetidae & 10 & 0.0079 \\
\hline & Coleoptera & Hydrophilidae & 1 & 0.0005 \\
\hline & Coleoptera & Dytiscidae & 5 & 0.0053 \\
\hline & Hemiptera & Notonectidae & 2 & 0.0018 \\
\hline & Hemiptera & Gerridae & 1 & 0.0023 \\
\hline & Diptera & Stratiomyidae & 1 & 0.0018 \\
\hline & Diptera & Culicidae & 1 & 0.0006 \\
\hline & Diptera & Chaoboridae & 4 & 0.0001 \\
\hline & Diptera & Chironomidae & 3 & 0.0002 \\
\hline & Gastropoda & Lymnaeidae & 1 & 0.0023 \\
\hline & Gastropoda & Physidae & 50 & 0.3774 \\
\hline & Hemiptera & Corixidae & 1 & 0.0016 \\
\hline & Cladocera & NA & 3 & 0.0002 \\
\hline \multirow[t]{12}{*}{ PETHUM } & Nektonic Family Richness & 11 & & \\
\hline & Diptera & Chironomidae & 1 & 0.0008 \\
\hline & Cladocaera & NA & 1 & 0.0001 \\
\hline & Coleoptera & Dytiscidae & 1 & 0.0006 \\
\hline & Diptera & Culicidae & 4 & 0.0006 \\
\hline & Bivalvia & Sphaeriidae & 13 & 0.3311 \\
\hline & Odonata & Aeshnidae & 1 & 0.1311 \\
\hline & Hemiptera & Corixidae & 16 & 0.0167 \\
\hline & Odonata & Lestidae & 2 & 0.0059 \\
\hline & Hemiptera & Notonectidae & 3 & 0.011 \\
\hline & Diptera & Ceratopogonidae & 1 & 0.0001 \\
\hline & Gastropoda & Physidae & 2 & 0.0012 \\
\hline \multirow[t]{7}{*}{ PETOSS } & Nektonic Family Richness & 6 & & \\
\hline & Ephemeroptera & Heptageniidae & 5 & 0.0078 \\
\hline & Plecoptera & Nemouridae & 1 & 0.0001 \\
\hline & Hemiptera & Veliidae & 1 & 0.0003 \\
\hline & Ephemeroptera & Leptophlebiidae & 1 & 0.0006 \\
\hline & Odonata & Cordulegastridae & 1 & 0.0002 \\
\hline & Ephemeroptera & Siphlonuridae & 2 & 0.0058 \\
\hline
\end{tabular}


Appendix BB.Continued.

\begin{tabular}{|c|c|c|c|c|}
\hline SiteCode & Order & Family & Count & Weight \\
\hline \multirow[t]{12}{*}{ RIASIA } & Nektonic Family Richness & 11 & & \\
\hline & Coleoptera & Staphylinidae & 1 & 0.0004 \\
\hline & Gastropoda & Planorbidae & 1 & 0.0036 \\
\hline & Isopoda & Asellidae & 1 & 0.0001 \\
\hline & Collembola & Poduridae & 1 & 0.0001 \\
\hline & Cladocera & NA & 1 & 0.0001 \\
\hline & Diptera & Chironomidae & 2 & 0.0001 \\
\hline & Bivalvia & Sphaeriidae & 5 & 0.0248 \\
\hline & Diptera & Culicidae & 4 & 0.0001 \\
\hline & Decapoda & Cambaridae & 2 & 0.0104 \\
\hline & Gastropoda & Lymnaeidae & 6 & 0.0212 \\
\hline & Odonata & Coenagrionidae & 1 & 0.0001 \\
\hline \multirow[t]{7}{*}{ RIBRID } & Nektonic Family Richness & 6 & & \\
\hline & Coleoptera & Dytiscidae & 6 & 0.0008 \\
\hline & Hemiptera & Cicadellidae & 1 & 0.0029 \\
\hline & Collembola & Isotomidae & 1 & 0.0001 \\
\hline & Coleoptera & Staphylinidae & 1 & 0.0002 \\
\hline & Coleoptera & Hydrophilidae & 3 & 0.0007 \\
\hline & Gastropoda & Lymnaeidae & 1 & 0.0061 \\
\hline \multirow[t]{3}{*}{ RIEAST } & Nektonic Family Richness & 2 & & \\
\hline & Hemiptera & Gerridae & 2 & 0.0009 \\
\hline & Coleptera & Staphylinidae & 1 & 0.0002 \\
\hline \multirow[t]{8}{*}{ SJBOAT } & Nektonic Family Richness & 7 & & \\
\hline & Oligochaeta & NA & 2 & 0.0001 \\
\hline & Hemiptera & Veliidae & 1 & 0.0001 \\
\hline & Decapoda & Cambaridae & 4 & 0.0504 \\
\hline & Lepidoptera & Pyralidae & 1 & 0.0001 \\
\hline & Coleoptera & Dytiscidae & 0 & 0.0228 \\
\hline & Diptera & Ceratopogonidae & 1 & 0.0001 \\
\hline & Bivalvia & Sphaeriidae & 1 & 0.0003 \\
\hline \multirow[t]{2}{*}{ SJGLAD } & Nektonic Family Richness & 1 & & \\
\hline & Hemiptera & Veliidae & 1 & 0.0005 \\
\hline \multirow[t]{3}{*}{ SJMUDL } & Nektonic Family Richness & 2 & & \\
\hline & Odonata & Gomphidae & 1 & 0.0045 \\
\hline & Diptera & Chironomidae & 1 & 0.0001 \\
\hline \multirow[t]{8}{*}{ SMDTSS } & Nektonic Family Richness & 7 & & \\
\hline & Diptera & Chironomidae & 10 & 0.0018 \\
\hline & Diptera & Culicidae & 1 & 0.0002 \\
\hline & Hemiptera & Veliidae & 1 & 0.0001 \\
\hline & Aranae & Pisauridae & 1 & 0.0004 \\
\hline & Odonata & Lestidae & 1 & 0.0015 \\
\hline & Oligochaeta & NA & 2 & 0.0021 \\
\hline & Coleoptera & Dytiscidae & 1 & 0.0002 \\
\hline
\end{tabular}


Appendix BB.Continued.

\begin{tabular}{|c|c|c|c|c|}
\hline SiteCode & Order & Family & Count & Weight \\
\hline \multirow[t]{9}{*}{ SMFOFL } & Nektonic Family Richness & 8 & & \\
\hline & Plecoptera & Leuctridae & 1 & 0.0003 \\
\hline & Ephemeroptera & Leptophlebiidae & 2 & 0.0039 \\
\hline & Hemiptera & Veliidae & 1 & 0.0007 \\
\hline & Diptera & Culicidae & 1 & 0.0002 \\
\hline & Coleoptera & Hydrophilidae & 4 & 0.0138 \\
\hline & Oligochaeta & NA & 1 & 0.0028 \\
\hline & Diptera & Chironomidae & 2 & 0.0005 \\
\hline & Coleoptera & Dytiscidae & 2 & 0.0007 \\
\hline \multirow[t]{4}{*}{ SMLPEM } & Nektonic Family Richness & 3 & & \\
\hline & Oligochaeta & NA & 2 & 0.0016 \\
\hline & Diptera & Chironomidae & 12 & 0.0037 \\
\hline & Plecoptera & Leuctridae & 2 & 0.0009 \\
\hline \multirow[t]{8}{*}{ SMSEFL } & Nektonic Family Richness & 7 & & \\
\hline & Odonata & Coenagrionidae & 1 & 0.0046 \\
\hline & Trichoptera & Phyrganeidae & 1 & 0.0157 \\
\hline & Hemiptera & Notonectidae & 1 & 0.0028 \\
\hline & Odonata & Libellulidae & 5 & 0.0596 \\
\hline & Hemiptera & Corixidae & 14 & 0.0039 \\
\hline & Diptera & Chironomidae & 4 & 0.0004 \\
\hline & Coleoptera & Dytiscidae & 1 & 0.0003 \\
\hline \multirow[t]{4}{*}{ SMSTEM } & Nektonic Family Richness & 3 & & \\
\hline & Aranae & Pisauridae & 1 & 0.0049 \\
\hline & Diptera & Chironomidae & 4 & 0.0007 \\
\hline & Oligochaeta & NA & 5 & 0.0051 \\
\hline TRSPRI & $\begin{array}{c}\text { Nektonic Family Richness } \\
\text { Hemiptera }\end{array}$ & $\begin{array}{r}1 \\
\text { Corixidae }\end{array}$ & 2 & 0.0003 \\
\hline \multirow[t]{6}{*}{ TVFARM } & Nektonic Family Richness & 5 & & \\
\hline & Isopoda & Asellidae & 13 & 0.0028 \\
\hline & Aranae & Pisauridae & 1 & 0.0036 \\
\hline & Coleoptera & Hydrophilidae & 2 & 0.0023 \\
\hline & Diptera & Culicidae & 13 & 0.004 \\
\hline & Hemiptera & Gerridae & 3 & 0.0021 \\
\hline \multirow[t]{10}{*}{ TVNEWT } & Nektonic Family Richness & 9 & & \\
\hline & Hemiptera & Corixidae & 2 & 0.0051 \\
\hline & Coleoptera & Dytiscidae & 5 & 0.0047 \\
\hline & Coleoptera & Staphylinidae & 1 & 0.0002 \\
\hline & Isopoda & Asellidae & 22 & 0.0043 \\
\hline & Bivalvia & Sphaeriidae & 3 & 0.0978 \\
\hline & Gastropoda & Planorbidae & 1 & 0.001 \\
\hline & Gastropoda & Physidae & 10 & 0.0101 \\
\hline & Oligochaeta & NA & 1 & 0.0007 \\
\hline & Hirudinea & Erpobdellidae & 1 & 0.0173 \\
\hline
\end{tabular}


Appendix BB.Continued.

\begin{tabular}{|c|c|c|c|c|}
\hline SiteCode & Order & Family & Count & Weight \\
\hline \multirow[t]{24}{*}{ TVPOUT } & \multicolumn{2}{|c|}{ Nektonic Family Richness } & 23 & \\
\hline & Ephemeroptera & Baetidae & 4 & 0.0035 \\
\hline & Hemiptera & Gerridae & 1 & 0.0001 \\
\hline & Cyclopoida & NA & 3 & 0.0001 \\
\hline & Hemiptera & Veliidae & 1 & 0.0001 \\
\hline & Coleoptera & Dytiscidae & 10 & 0.0076 \\
\hline & Coleoptera & Hydrophilidae & 3 & 0.0007 \\
\hline & Coleoptera & Curculionidae & 1 & 0.001 \\
\hline & Hemiptera & Belostomatidae & 1 & 0.0012 \\
\hline & Coleoptera & Chrysomelidae & 1 & 0.002 \\
\hline & Hirudinea & Erpobdellidae & 7 & 0.0253 \\
\hline & Coleoptera & Haliplidae & 1 & 0.0033 \\
\hline & Odonata & Lestidae & 4 & 0.0156 \\
\hline & Diptera & Chironomidae & 11 & 0.0011 \\
\hline & Homoptera & Cicadellidae & 1 & 0.0012 \\
\hline & Odonata & Aeshnidae & 4 & 0.0037 \\
\hline & Hemiptera & Corixidae & 6 & 0.0094 \\
\hline & Gastropoda & Physidae & 1 & 0.0022 \\
\hline & Gastropoda & Lymnaeidae & 3 & 0.009 \\
\hline & Bivalvia & Sphaeriidae & 3 & 0.0372 \\
\hline & Isopoda & Asellidae & 2 & 0.0009 \\
\hline & Oligochaeta & NA & 1 & 0.0001 \\
\hline & Hemiptera & Notonectidae & 1 & 0.0047 \\
\hline & Odonata & Libellulidae & 3 & 0.0196 \\
\hline \multirow[t]{10}{*}{ TVVBEM } & Nektonic Family Richness & 9 & & \\
\hline & Hemiptera & Corixidae & 1 & 0.0034 \\
\hline & Hemiptera & Veliidae & 5 & 0.0002 \\
\hline & Coleoptera & Dytiscidae & 10 & 0.008 \\
\hline & Cladocera & NA & 1 & 0.0001 \\
\hline & Isopoda & Asellidae & 40 & 0.0098 \\
\hline & Diptera & Chironomidae & 8 & 0.0018 \\
\hline & Gastropoda & Planorbidae & 2 & 0.0025 \\
\hline & Bivalvia & Sphaeriidae & 2 & 0.0077 \\
\hline & Cyclopoida & NA & 2 & 0.0001 \\
\hline
\end{tabular}


Appendix BB.Continued.

\begin{tabular}{|c|c|c|c|c|}
\hline SiteCode & Order & Family & Count & Weight \\
\hline \multirow[t]{17}{*}{ TVVBIM } & Nektonic Family Richness & 16 & & \\
\hline & Hemiptera & Veliidae & 1 & 0.0001 \\
\hline & Coleoptera & Curculionidae & 1 & 0.0013 \\
\hline & Hirudinea & Erpobdellidae & 1 & 0.0004 \\
\hline & Coleoptera & Dytiscidae & 18 & 0.0251 \\
\hline & Homoptera & Cicadellidae & 1 & 0.0001 \\
\hline & Hemiptera & Notonectidae & 1 & 0.0031 \\
\hline & Hemiptera & Corixidae & 3 & 0.0038 \\
\hline & Isopoda & Asellidae & 30 & 0.0068 \\
\hline & Diptera & Chironomidae & 2 & 0.0007 \\
\hline & Bivalvia & Sphaeriidae & 2 & 0.031 \\
\hline & Gastropoda & Physidae & 5 & 0.0076 \\
\hline & Odonata & Lestidae & 1 & 0.0059 \\
\hline & Gastropoda & Planorbidae & 4 & 0.0366 \\
\hline & Amphipoda & Gammaridae & 1 & 0.0008 \\
\hline & Aranae & Pisauridae & 2 & 0.0251 \\
\hline & Coleoptera & Hydrophilidae & 5 & 0.0419 \\
\hline \multirow[t]{22}{*}{ TVVBSS } & Nektonic Family Richness & 21 & & \\
\hline & Coleoptera & Hydrophilidae & 2 & 0.0079 \\
\hline & Coleoptera & Scirtidae & 24 & 0.0144 \\
\hline & Aranae & Pisauridae & 3 & 0.0356 \\
\hline & Amphipoda & Gammaridae & 140 & 0.0791 \\
\hline & Gastropoda & Physidae & 17 & 0.0864 \\
\hline & Bivalvia & Sphaeriidae & 9 & 0.2175 \\
\hline & Gastropoda & Planorbidae & 14 & 0.0862 \\
\hline & Coleoptera & Curculionidae & 5 & 0.0029 \\
\hline & Coleoptera & Dytiscidae & 4 & 0.0054 \\
\hline & Gastropoda & Lymnaeidae & 1 & 0.0027 \\
\hline & Oligochaeta & NA & 3 & 0.0118 \\
\hline & Hirudinea & Erpobdellidae & 1 & 0.0005 \\
\hline & Ephemeroptera & Caenidae & 1 & 0.0005 \\
\hline & Coleoptera & Haliplidae & 1 & 0.0026 \\
\hline & Odonata & Libellulidae & 1 & 0.016 \\
\hline & Hemiptera & Belostomatidae & 2 & 0.0073 \\
\hline & Hemiptera & Notonectidae & 1 & 0.0124 \\
\hline & Hemiptera & Corixidae & 3 & 0.0053 \\
\hline & Isopoda & Asellidae & 14 & 0.0054 \\
\hline & Coleoptera & Chrysomelidae & 3 & 0.0135 \\
\hline & Homoptera & Aphididae & 1 & 0.0001 \\
\hline \multirow[t]{6}{*}{ UDC001 } & Nektonic Family Richness & 5 & & \\
\hline & Diptera & Chironomidae & 4 & 0.0006 \\
\hline & Hemiptera & Pleidae & 1 & 0.0006 \\
\hline & Gastropoda & Physidae & 1 & 0.0271 \\
\hline & Hemiptera & Corixidae & 3 & 0.0137 \\
\hline & Coleoptera & Dytiscidae & 1 & 0.0008 \\
\hline
\end{tabular}


Appendix BB.Continued.

\begin{tabular}{|c|c|c|c|c|}
\hline SiteCode & Order & Family & Count & Weight \\
\hline \multirow[t]{9}{*}{ UDC002 } & Nektonic Family Richness & 8 & & \\
\hline & Coleoptera & Dytiscidae & 1 & 0.0099 \\
\hline & Diptera & Chironomidae & 50 & 0.0079 \\
\hline & Copepoda & NA & 1 & 0.0001 \\
\hline & Odonata & Aeshnidae & 1 & 0.0036 \\
\hline & Nematoda & NA & 3 & 0.0001 \\
\hline & Hemiptera & Notonectidae & 3 & 0.0228 \\
\hline & Hemiptera & Corixidae & 2 & 0.0055 \\
\hline & Aranae & NA & 1 & 0.0001 \\
\hline \multirow[t]{4}{*}{ UDC004 } & Nektonic Family Richness & 3 & & \\
\hline & Diptera & Chironomidae & 3 & 0.0007 \\
\hline & Hemiptera & Veliidae & 1 & 0.0001 \\
\hline & Diptera & Chaoboridae & 1 & 0.0001 \\
\hline \multirow[t]{7}{*}{ UDC008 } & Nektonic Family Richness & 6 & & \\
\hline & Cladocera & NA & 4 & 0.0001 \\
\hline & Copepoda & NA & 1 & 0.0001 \\
\hline & Coleoptera & Elmidae & 6 & 0.0155 \\
\hline & Diptera & Chironomidae & 12 & 0.0014 \\
\hline & Nematoda & NA & 8 & 0.004 \\
\hline & Gastropoda & Viviparidae & 1 & 0.0452 \\
\hline \multirow[t]{13}{*}{ UDC012 } & Nektonic Family Richness & 12 & & \\
\hline & Coleoptera & Carabidae & 1 & 0.0121 \\
\hline & Ephemeroptera & Caenidae & 1 & 0.0001 \\
\hline & Diptera & Ceratopogonidae & 2 & 0.0008 \\
\hline & Amphipoda & Talitridae & 2 & 0.0001 \\
\hline & Odonata & Coenagrionidae & 4 & 0.0121 \\
\hline & Bivalvia & Sphaeriidae & 5 & 0.0149 \\
\hline & Ephemeroptera & Baetidae & 1 & 0.001 \\
\hline & Gastropoda & Physidae & 29 & 0.2065 \\
\hline & Diptera & Chironomidae & 20 & 0.0116 \\
\hline & Hemiptera & Corixidae & 11 & 0.0072 \\
\hline & Coleoptera & Dytiscidae & 1 & 0.0013 \\
\hline & Cladocera & NA & 6 & 0.0001 \\
\hline \multirow[t]{8}{*}{ UDC013 } & Nektonic Family Richness & 7 & & \\
\hline & Bivalvia & Sphaeriidae & 1 & 0.0113 \\
\hline & Coleoptera & Coccinellidae & 1 & 0.0035 \\
\hline & Oligochaeta & NA & 1 & 0.0017 \\
\hline & Coleoptera & Chrysomelidae & 1 & 0.0001 \\
\hline & Diptera & Tabanidae & 1 & 0.0027 \\
\hline & Diptera & Chironomidae & 13 & 0.0028 \\
\hline & Coleoptera & Dytiscidae & 1 & 0.0012 \\
\hline
\end{tabular}


Appendix BB.Continued.

\begin{tabular}{|c|c|c|c|c|}
\hline SiteCode & Order & Family & Count & Weight \\
\hline \multirow[t]{6}{*}{ UDC014 } & Nektonic Family Richness & 5 & & \\
\hline & Diptera & Chironomidae & 6 & 0.0029 \\
\hline & Hemiptera & Corixidae & 4 & 0.0017 \\
\hline & Megaloptera & Sialidae & 2 & 0.0018 \\
\hline & Odonata & Libellulidae & 1 & 0.0072 \\
\hline & Oligochaeta & NA & 3 & 0.0206 \\
\hline \multirow[t]{5}{*}{ UDC015 } & Nektonic Family Richness & 4 & & \\
\hline & Odonata & Aeshnidae & 1 & 0.0018 \\
\hline & Diptera & Chironomidae & 2 & 0.0002 \\
\hline & Hemiptera & Corixidae & 1 & 0.0003 \\
\hline & Megaloptera & Sialidae & 1 & 0.0013 \\
\hline \multirow[t]{8}{*}{ UDC017 } & Nektonic Family Richness & 7 & & \\
\hline & Diptera & Chironomidae & 1 & 0.0001 \\
\hline & Diptera & Empididae & 1 & 0.0015 \\
\hline & Gastropoda & Planorbidae & 2 & 0.0313 \\
\hline & Diptera & Tabanidae & 1 & 0.0056 \\
\hline & Hemiptera & Notonectidae & 1 & 0.0032 \\
\hline & Bivalvia & Sphaeriidae & 2 & 0.0011 \\
\hline & Hemiptera & Corixidae & 4 & 0.0031 \\
\hline \multirow[t]{15}{*}{ UDC018 } & Nektonic Family Richness & 14 & & \\
\hline & Gastropoda & Hydrobiidae & 1 & 0.0172 \\
\hline & Diptera & Chironomidae & 2 & 0.0001 \\
\hline & Homoptera & Cicadellidae & 1 & 0.0002 \\
\hline & Aranae & Hydracarina & 1 & 0.0004 \\
\hline & Aranae & NA & 1 & 0.0001 \\
\hline & Isopoda & Asellidae & 26 & 0.0182 \\
\hline & Coleoptera & Phalacridae & 1 & 0.0008 \\
\hline & Nematoda & NA & 1 & 0.0013 \\
\hline & Hemiptera & Veliidae & 1 & 0.0035 \\
\hline & Odonata & Libellulidae & 1 & 0.0078 \\
\hline & Gastropoda & Valvatidae & 1 & 0.0047 \\
\hline & Bivalvia & Sphaeriidae & 1 & 0.0026 \\
\hline & Gastropoda & Physidae & 6 & 0.0611 \\
\hline & Diptera & Dolichopodidae & 2 & 0.0001 \\
\hline \multirow[t]{8}{*}{ UDC019 } & Nektonic Family Richness & 7 & & \\
\hline & Nematoda & NA & 2 & 0.0001 \\
\hline & Hemiptera & Hebridae & 1 & 0.0001 \\
\hline & Megaloptera & Sialidae & 2 & 0.0015 \\
\hline & Diptera & Chironomidae & 3 & 0.0003 \\
\hline & Megaloptera & Corydalidae & 1 & 0.0077 \\
\hline & Coleoptera & Elateridae & 1 & 0.0004 \\
\hline & Hemiptera & Corixidae & 2 & 0.0014 \\
\hline
\end{tabular}


Appendix BB.Continued.

\begin{tabular}{|c|c|c|c|c|}
\hline SiteCode & Order & Family & Count & Weight \\
\hline \multirow[t]{7}{*}{ UDC020 } & Nektonic Family Richness & 6 & & \\
\hline & Hirudinea & Glossiphoniidae & 9 & 0.0059 \\
\hline & Oligochaeta & NA & 3 & 0.0005 \\
\hline & Hemiptera & Corixidae & 11 & 0.0062 \\
\hline & Odonata & Libellulidae & 1 & 0.009 \\
\hline & Diptera & Chironomidae & 5 & 0.0015 \\
\hline & Bivalvia & Sphaeriidae & 1 & 0.0004 \\
\hline \multirow[t]{5}{*}{ VEPCON } & Nektonic Family Richness & 4 & & \\
\hline & Coleoptera & Hydrophilidae & 2 & 0.0012 \\
\hline & Oligochaeta & NA & 1 & 0.0001 \\
\hline & Coleoptera & Dytiscidae & 2 & 0.0141 \\
\hline & Diptera & Chironomidae & 5 & 0.0016 \\
\hline \multirow{6}{*}{ VEPCOS } & Nektonic Family Richness & 5 & & \\
\hline & Diptera & Culicidae & 1 & 0.0001 \\
\hline & Odonata & Coenagrionidae & 2 & 0.0015 \\
\hline & Diptera & Chironomidae & 1 & 0.0001 \\
\hline & Coleoptera & Scirtidae & 1 & 0.0003 \\
\hline & Odonata & Libellulidae & 1 & 0.0035 \\
\hline \multirow[t]{18}{*}{ WBBARN } & Nektonic Family Richness & 17 & & \\
\hline & Gastropoda & Physidae & 3 & 0.0095 \\
\hline & Coleoptera & Haliplidae & 2 & 0.0042 \\
\hline & Coleoptera & Dytiscidae & 2 & 0.001 \\
\hline & Amphipoda & Gammaridae & 1 & 0.0002 \\
\hline & Odonata & Lestidae & 1 & 0.0055 \\
\hline & Odonata & Coenagrionidae & 1 & 0.0004 \\
\hline & Nematoda & NA & 1 & 0.0001 \\
\hline & Gastropoda & Planorbidae & 2 & 0.2044 \\
\hline & Hemiptera & Corixidae & 2 & 0.0065 \\
\hline & Bivalvia & Sphaeriidae & 3 & 0.0285 \\
\hline & Diptera & Tabanidae & 2 & 0.0111 \\
\hline & Diptera & Culicudae & 1 & 0.0001 \\
\hline & Oligochaeta & NA & 4 & 0.0003 \\
\hline & Diptera & Ceratopogonidae & 1 & 0.0009 \\
\hline & Diptera & Chironomidae & 52 & 0.0325 \\
\hline & Ephemeroptera & Baetidae & 23 & 0.0116 \\
\hline & Gastropoda & Lymnaeidae & 2 & 0.0046 \\
\hline \multirow[t]{11}{*}{ WBCORN } & Nektonic Family Richness & 10 & & \\
\hline & Hemiptera & Hebridae & 1 & 0.001 \\
\hline & Coleoptera & Haliplidae & 2 & 0.0054 \\
\hline & Ephemeroptera & Caenidae & 1 & 0.0002 \\
\hline & Oligochaeta & NA & 2 & 0.0001 \\
\hline & Gastropoda & Physidae & 7 & 0.018 \\
\hline & Diptera & Chironomidae & 36 & 0.0036 \\
\hline & Diptera & Ceratopogonidae & 1 & 0.0001 \\
\hline & Podacopa & NA & 1 & 0.0001 \\
\hline & Gastropoda & Planorbidae & 24 & 3.2556 \\
\hline & Odonata & Libellulidae & 3 & 0.0873 \\
\hline
\end{tabular}


Appendix BB.Continued.

\begin{tabular}{|c|c|c|c|c|}
\hline SiteCode & Order & Family & Count & Weight \\
\hline \multirow[t]{10}{*}{ WBROAD } & Nektonic Family Richness & 9 & & \\
\hline & Odonata & Libellulidae & 1 & 0.0029 \\
\hline & Coleoptera & Elmidae & 1 & 0.0318 \\
\hline & Hemiptera & Veliidae & 1 & 0.0001 \\
\hline & Ephemeroptera & Baetidae & 1 & 0.0003 \\
\hline & Odonata & Calopterygidae & 1 & 0.0159 \\
\hline & Odonata & Cordulegastridae & 10 & 0.0476 \\
\hline & Diptera & Stratiomyidae & 1 & 0.0071 \\
\hline & Diptera & Chironomidae & 5 & 0.0006 \\
\hline & Gastropoda & Physidae & 2 & 0.1105 \\
\hline \multirow[t]{3}{*}{ WYBEAV } & Nektonic Family Richness & 2 & & \\
\hline & Diptera & Chironomidae & 13 & 0.0028 \\
\hline & Diptera & Chaoboridae & 1 & 0.0001 \\
\hline \multirow[t]{2}{*}{ WYHCEA } & Nektonic Family Richness & 1 & & \\
\hline & Diptera & Chironomidae & 4 & 0.0015 \\
\hline
\end{tabular}


Appendix BC. Benthic macroinvertebrate richness, count and weight by family used to form macroinvertebrate indices of biological integrity for wetlands in West Virginia, USA 2005-2006.

\begin{tabular}{|c|c|c|c|c|}
\hline SiteCode & Order & Family & Count & Weight \\
\hline \multirow[t]{3}{*}{ CFCROS } & Benthic Family Richness & 2 & & \\
\hline & Oligochaeta & NA & 1 & 0.0031 \\
\hline & Nematoda & NA & 2 & 0.0001 \\
\hline \multirow[t]{4}{*}{ CFECUR } & Benthic Family Richness & 3 & & \\
\hline & Oligochaeta & NA & 4 & 0.0015 \\
\hline & Nematoda & NA & 1 & 0.0001 \\
\hline & Diptera & Dolichopodidae & 1 & 0.0001 \\
\hline \multirow[t]{2}{*}{ CFEINC } & Benthic Family Richness & 1 & & \\
\hline & Diptera & Chironomidae & 1 & 0.0001 \\
\hline \multirow[t]{5}{*}{ CFSLCH } & Benthic Family Richness & 4 & & \\
\hline & Nematoda & NA & 1 & 0.0001 \\
\hline & Diptera & Ceratopogonidae & 1 & 0.0001 \\
\hline & Diptera & Chironomidae & 1 & 0.0001 \\
\hline & Diptera & Stratiomyidae & 1 & 0.0022 \\
\hline \multirow[t]{3}{*}{ CFSLIN } & Benthic Family Richness & 2 & & \\
\hline & Diptera & Ceratopogonidae & 1 & 0.0001 \\
\hline & Oligochaeta & NA & 1 & 0.0001 \\
\hline \multirow[t]{11}{*}{ CGBRID } & Benthic Family Richness & 10 & & \\
\hline & Collembola & Onychiuridae & 1 & 0.0001 \\
\hline & Coleoptera & Staphylinidae & 1 & 0.0011 \\
\hline & Coleoptera & Elateridae & 2 & 0.0084 \\
\hline & Diptera & Psychodidae & 1 & 0.0001 \\
\hline & Coleoptera & Hydrophilidae & 5 & 0.0003 \\
\hline & Bivalvia & Sphaeriidae & 1 & 0.0032 \\
\hline & Diptera & Tipulidae & 7 & 0.001 \\
\hline & Diptera & Chironomidae & 9 & 0.0001 \\
\hline & Oligochaeta & $\mathrm{NA}$ & 11 & 0.0202 \\
\hline & Diplura & Japygidae & 1 & 0.0004 \\
\hline
\end{tabular}


Appendix BC. Continued.

\begin{tabular}{|c|c|c|c|c|c|}
\hline SiteCode & Order & & Family & Count & Weight \\
\hline \multirow[t]{14}{*}{ CGCPAS } & Benthic Family Richness & 13 & & & \\
\hline & Oligochaeta & & NA & 7 & 0.0037 \\
\hline & Coleoptera & & Meloidae & 1 & 0.0005 \\
\hline & Hirudinea & & Glossiphoniidae & 1 & 0.0152 \\
\hline & Bivalvia & & Sphaeriidae & 7 & 0.0154 \\
\hline & Diptera & & Ceratopogonidae & 18 & 0.0011 \\
\hline & Hydrocarina & & NA & 1 & 0.0001 \\
\hline & Diptera & & Chironomidae & 10 & 0.0013 \\
\hline & Nematoda & & NA & 1 & 0.0001 \\
\hline & Megaloptera & & Sialidae & 2 & 0.0033 \\
\hline & Coleoptera & & Chrysomelidae & 2 & 0.0228 \\
\hline & Diptera & & Ephydridae & 3 & 0.0006 \\
\hline & Amphipod & & Gammaridae & 1 & 0.0001 \\
\hline & Diptera & & Tipulidae & 2 & 0.0007 \\
\hline \multirow[t]{10}{*}{ CGROAD } & Benthic Family Richness & 9 & & & \\
\hline & Diptera & & Psychodidae & 1 & 0.0007 \\
\hline & Diptera & & Cecidomyidae & 1 & 0.0007 \\
\hline & Nematoda & & NA & 7 & 0.001 \\
\hline & Trichoptera & & Polycentropodidae & 5 & 0.0016 \\
\hline & Diptera & & Tipulidae & 4 & 0.0078 \\
\hline & Bivalvia & & Sphaeriidae & 6 & 0.0049 \\
\hline & Diptera & & Chironomidae & 5 & 0.0001 \\
\hline & Diptera & & Ceratopogonidae & 6 & 0.0004 \\
\hline & Hydracarina & & NA & 1 & 0.0001 \\
\hline \multirow[t]{12}{*}{ CGTRHE } & Benthic Family Richness & 11 & & & \\
\hline & Coleoptera & & Hydrophilidae & 1 & 0.0005 \\
\hline & Diptera & & Cecidomyidae & 1 & 0.0001 \\
\hline & Geophilomorpha & & NA & 3 & 0.0028 \\
\hline & Coleoptera & & Chrysomelidae & 1 & 0.002 \\
\hline & Nematoda & & NA & 19 & 0.0077 \\
\hline & Diptera & & Ceratopogonidae & 2 & 0.0001 \\
\hline & Bivalvia & & Sphaeriidae & 13 & 0.0111 \\
\hline & Nematoda & & NA & 1 & 0.0024 \\
\hline & Diplura & & Japygidae & 1 & 0.0001 \\
\hline & Diptera & & Tipulidae & 3 & 0.0009 \\
\hline & Diptera & & Dolichopodidae & 1 & 0.0001 \\
\hline
\end{tabular}


Appendix BC. Continued.

\begin{tabular}{|c|c|c|c|c|c|}
\hline SiteCode & Order & & Family & Count & Weight \\
\hline \multirow[t]{3}{*}{ CHNEER } & Benthic Family Richness & 2 & & & \\
\hline & Gastropoda & & Planorbidae & 1 & 0.0002 \\
\hline & Diptera & & Chironomidae & 1 & 0.0008 \\
\hline \multirow[t]{6}{*}{$\mathrm{CHSACH}$} & Benthic Family Richness & 5 & & & \\
\hline & Bivalvia & & Sphaeriidae & 3 & 0.0037 \\
\hline & Diptera & & Ceratopogonidae & 1 & 0.0001 \\
\hline & Gastropoda & & Physidae & 1 & 0.0013 \\
\hline & Oligochaeta & & NA & 9 & 0.0478 \\
\hline & Collembola & & Isotomidae & 1 & 0.0001 \\
\hline \multirow[t]{5}{*}{ CHSAFO } & Benthic Family Richness & 4 & & & \\
\hline & Coleoptera & & Tenebrionidae & 2 & 0.0054 \\
\hline & Diplopoda & & $\mathrm{NA}$ & 2 & 0.0004 \\
\hline & Gastropoda & & Planorbidae & 1 & 0.0002 \\
\hline & Oligochaeta & & NA & 16 & 0.1848 \\
\hline \multirow[t]{5}{*}{ CHSARR } & Benthic Family Richness & 4 & & & \\
\hline & Diptera & & Chironomidae & 2 & 0.0045 \\
\hline & Bivalvia & & Sphaeriidae & 1 & 0.0001 \\
\hline & Oligochaeta & & NA & 5 & 0.0103 \\
\hline & Gastropoda & & Physidae & 1 & 0.0002 \\
\hline \multirow[t]{5}{*}{ CHTREE } & Benthic Family Richness & 4 & & & \\
\hline & Bivalvia & & Sphaeriidae & 8 & 0.0083 \\
\hline & Gastropoda & & Lymnaeidae & 2 & 0.0236 \\
\hline & Diptera & & Tabanidae & 2 & 0.0011 \\
\hline & Nematoda & & NA & 5 & 0.0001 \\
\hline \multirow[t]{2}{*}{ CHWWBW } & Benthic Family Richness & 1 & & & \\
\hline & Gastropoda & & Physidae & 1 & 0.0081 \\
\hline \multirow[t]{5}{*}{ CHWWEM } & Benthic Family Richness & 4 & & & \\
\hline & Diptera & & Ceratopogonidae & 1 & 0.0001 \\
\hline & Oligochaeta & & NA & 2 & 0.0004 \\
\hline & Gastropoda & & Physidae & 1 & 0.002 \\
\hline & Coleoptera & & Circulionoidea & 1 & 0.0006 \\
\hline \multirow[t]{4}{*}{ CHWWFO } & Benthic Family Richness & 3 & & & \\
\hline & Diptera & & Chironomidae & 1 & 0.0001 \\
\hline & Cyclopoida & & NA & 1 & 0.0001 \\
\hline & Oligochaeta & & NA & 1 & 0.0001 \\
\hline
\end{tabular}


Appendix BC. Continued.

\begin{tabular}{|c|c|c|c|c|c|}
\hline SiteCode & Order & & Family & Count & Weight \\
\hline \multirow[t]{11}{*}{ CVABBW } & Benthic Family Richness & 10 & & & \\
\hline & Aranae & & NA & 1 & 0.0009 \\
\hline & Diptera & & Ceratopogonidae & 1 & 0.0001 \\
\hline & Diptera & & Ephydridae & 1 & 0.0001 \\
\hline & Bivalvia & & Sphaeriidae & 1 & 0.004 \\
\hline & Oligochaeta & & NA & 10 & 0.0023 \\
\hline & Diptera & & Ceratopogonidae & 1 & 0.0003 \\
\hline & Diptera & & Tipulidae & 1 & 0.0039 \\
\hline & Diptera & & Chironomidae & 2 & 0.0001 \\
\hline & Bivalvia & & Sphaeriidae & 1 & 0.0004 \\
\hline & Diptera & & Dolichopodidae & 1 & 0.0003 \\
\hline \multirow[t]{6}{*}{ CVABCT } & Benthic Family Richness & 5 & & & \\
\hline & Coleoptera & & Chrysomelidae & 1 & 0.0174 \\
\hline & Diptera & & Ceratopogonidae & 1 & 0.0001 \\
\hline & Oligochaeta & & NA & 15 & 0.18 \\
\hline & Bivalvia & & Sphaeriidae & 3 & 0.003 \\
\hline & Coleoptera & & Ptilodactylidae & 1 & 0.0002 \\
\hline
\end{tabular}

CVTIMB Benthic Family Richness

Oligochaeta

6

Coleoptera

Diptera

Aranae

Diptera

Diptera

DSPICN Benthic Family Richness

$$
\text { Diptera }
$$

Diptera

Megaloptera

Coleoptera

Lepidoptera

Oligochaeta

Diptera

Diptera

Bivalvia

NA

Ptilodactylidae

Tipulidae

NA

Chironomidae

Dolichopodidae

$\begin{array}{ll}6 & 0.0376 \\ 1 & 0.0005 \\ 1 & 0.0015 \\ 1 & 0.0068 \\ 5 & 0.0007 \\ 1 & 0.0021\end{array}$

9

Ptychopteridae

0.002

Chironomidae

0.0017

Sialidae

Ptilodactylidae

0.0019

unknown

NA

Ceratopogonidae

Tipulidae

Sphaeriidae

0.0032

0.0009

0.0001

0.0005

0.0003

0.0073 
Appendix BC.Continued.

\begin{tabular}{|c|c|c|c|c|}
\hline SiteCode & Order & Family & Count & Weight \\
\hline \multirow[t]{6}{*}{ DSROAR } & Benthic Family Richness & 5 & & \\
\hline & Diptera & Chironomidae & 19 & 0.0011 \\
\hline & Diptera & Ceratopogonidae & 8 & 0.0001 \\
\hline & Oligochaeta & NA & 1 & 0.0001 \\
\hline & Trichoptera & Polycentropodidae & 1 & 0.0001 \\
\hline & Coleoptera & Chyrosomelidae & 1 & 0.004 \\
\hline \multirow[t]{2}{*}{ DSWILD } & Benthic Family Richness & 1 & & \\
\hline & Nematoda & NA & 1 & 0.0006 \\
\hline \multirow[t]{8}{*}{ EPCMEM } & Benthic Family Richness & 7 & & \\
\hline & Bivalvia & Sphaeriidae & 7 & 0.0068 \\
\hline & Gastropoda & Physidae & 2 & 0.0186 \\
\hline & Diptera & Dolichopodidae & 1 & 0.0001 \\
\hline & Diptera & Stratiomyidae & 2 & 0.0045 \\
\hline & Gastropoda & Planorbidae & 7 & 0.0685 \\
\hline & Oligochaeta & NA & 10 & 0.003 \\
\hline & Gastropoda & Lymnaeidae & 2 & 0.0149 \\
\hline \multirow[t]{2}{*}{ EPCMFO } & Benthic Family Richness & 1 & & \\
\hline & Diptera & Chironomidae & 1 & 0.0001 \\
\hline \multirow[t]{7}{*}{ EPKYVE } & Benthic Family Richness & 6 & & \\
\hline & Diptera & Ephydridae & 1 & 0.0001 \\
\hline & Oligochaeta & NA & 8 & 0.0272 \\
\hline & Bivalvia & Sphaeriidae & 3 & 0.0062 \\
\hline & Gastropoda & Lymnaeidae & 1 & 0.0146 \\
\hline & Gastropoda & Physidae & 7 & 0.1379 \\
\hline & Gastropoda & Hydrophilidae & 4 & 0.0033 \\
\hline \multirow[t]{3}{*}{ EPRRXC } & Benthic Family Richness & 2 & & \\
\hline & Oligochaeta & NA & 1 & 0.009 \\
\hline & Gastropoda & Planorbidae & 1 & 0.0006 \\
\hline \multirow[t]{5}{*}{ EPSHEM } & Benthic Family Richness & 4 & & \\
\hline & Bivalvia & Sphaeriidae & 7 & 0.0186 \\
\hline & Oligochaeta & NA & 1 & 0.0044 \\
\hline & Gastropoda & Sphaeriidae & 4 & 0.0488 \\
\hline & Gastropoda & Physidae & 1 & 0.0001 \\
\hline
\end{tabular}


Appendix BC. Continued.

\begin{tabular}{|c|c|c|c|c|}
\hline SiteCode & Order & Family & Count & Weight \\
\hline \multirow[t]{10}{*}{ EPSHSS } & Benthic Family Richness & 9 & & \\
\hline & Gastropoda & Planorbidae & 1 & 0.0045 \\
\hline & Diptera & Tabanidae & 1 & 0.0031 \\
\hline & Gastropoda & Lymnaeidae & 4 & 0.0316 \\
\hline & Coleoptera & Hydrophilidae & 1 & 0.0012 \\
\hline & Bivalvia & Sphaeriidae & 7 & 0.0025 \\
\hline & Coleoptera & Chrysomelidae & 1 & 0.0059 \\
\hline & Diptera & Ephydridae & 1 & 0.0001 \\
\hline & Oligochaeta & NA & 5 & 0.0356 \\
\hline & Diptera & Stratiomyidae & 2 & 0.0112 \\
\hline \multirow[t]{4}{*}{ GBBARN } & Benthic Family Richness & 3 & & \\
\hline & Bivalvia & Sphaeriidae & 1 & 0.0034 \\
\hline & Gastropoda & Planorbidae & 1 & 0.0054 \\
\hline & Oligochaeta & NA & 14 & 0.0584 \\
\hline \multirow[t]{5}{*}{ GBHOEF } & Benthic Family Richness & 4 & & \\
\hline & Bivalvia & Sphaeriidae & 9 & 0.0034 \\
\hline & Diptera & Chironomidae & 1 & 0.0001 \\
\hline & Diptera & Ceratopogonidae & 2 & 0.0001 \\
\hline & Diptera & Stratiomyidae & 2 & 0.0015 \\
\hline \multirow[t]{6}{*}{ GBJENK } & Benthic Family Richness & 5 & & \\
\hline & Odonata & Libellulidae & 1 & 0.0263 \\
\hline & Diptera & Chironomidae & 1 & 0.0001 \\
\hline & Gastropoda & Physidae & 4 & 0.0077 \\
\hline & Gastropoda & Planorbidae & 1 & 0.0003 \\
\hline & Hemiptera & Naucoridae & 1 & 0.0006 \\
\hline \multirow[t]{3}{*}{ GBMAPL } & Benthic Family Richness & 2 & & \\
\hline & Nematoda & NA & 1 & 0.0001 \\
\hline & Bivalvia & Sphaeriidae & 4 & 0.0076 \\
\hline \multirow[t]{4}{*}{ GBNOFO } & Benthic Family Richness & 3 & & \\
\hline & Oligochaeta & NA & 2 & 0.0029 \\
\hline & Bivalvia & Sphaeriidae & 1 & 0.0089 \\
\hline & Diptera & Ceratopogonidae & 1 & 0.0001 \\
\hline
\end{tabular}


Appendix BC. Continued.

\begin{tabular}{|c|c|c|c|c|}
\hline SiteCode & Order & Family & Count & Weight \\
\hline \multirow[t]{11}{*}{ GBNOSS } & Benthic Family Richness & 10 & & \\
\hline & Diptera & Muscidae & 3 & 0.0002 \\
\hline & Gastropoda & Physidae & 2 & 0.0464 \\
\hline & Homoptera & Cercopidae & 1 & 0.0001 \\
\hline & Nematoda & NA & 10 & 0.0023 \\
\hline & Diptera & Tabanidae & 1 & 0.0042 \\
\hline & Diptera & Chironomidae & 2 & 0.0002 \\
\hline & Diptera & Tipulidae & 2 & 0.0003 \\
\hline & Bivalvia & Sphaeriidae & 75 & 0.1666 \\
\hline & Coleoptera & NA & 1 & 0.0001 \\
\hline & Oligochaeta & NA & 1 & 0.0006 \\
\hline \multirow[t]{4}{*}{ GBPLOT } & Benthic Family Richness & 3 & & \\
\hline & Oligochaeta & NA & 4 & 0.035 \\
\hline & Nematoda & NA & 5 & 0.0013 \\
\hline & Gastropoda & Planorbidae & 5 & 0.071 \\
\hline \multirow[t]{5}{*}{ HCBEAV } & Benthic Family Richness & 4 & & \\
\hline & Oligochaeta & NA & 8 & 0.0701 \\
\hline & Nematoda & NA & 5 & 0.0019 \\
\hline & Bivalvia & Sphaeriidae & 2 & 0.0073 \\
\hline & Gastropoda & Planorbidae & 1 & 0.004 \\
\hline \multirow[t]{7}{*}{ HCMITI } & Benthic Family Richness & 6 & & \\
\hline & Bivalvia & Sphaeriidae & 1 & 0.0001 \\
\hline & Gastropoda & Planorbidae & 2 & 0.0097 \\
\hline & Coleoptera & Hydrophilidae & 1 & 0.0029 \\
\hline & Oligochaeta & NA & 9 & 0.2089 \\
\hline & Nematoda & NA & 19 & 0.0026 \\
\hline & Diptera & Tabanidae & 1 & 0.0018 \\
\hline \multirow[t]{8}{*}{ HCPIPE } & Benthic Family Richness & 7 & & \\
\hline & Oligochaeta & NA & 12 & 0.0724 \\
\hline & Nematoda & NA & 26 & 0.0035 \\
\hline & Hydrocarina & NA & 1 & 0.0001 \\
\hline & Diptera & Dolichopodidae & 1 & 0.0006 \\
\hline & Homoptera & Cicadellidae & 1 & 0.0001 \\
\hline & Coletoptera & Elateridae & 1 & 0.0029 \\
\hline & Diplopoda & NA & 1 & 0.0001 \\
\hline
\end{tabular}


Appendix BC.Continued.

\begin{tabular}{|c|c|c|c|c|}
\hline SiteCode & Order & Family & Count & Weight \\
\hline \multirow[t]{12}{*}{ HCRANG } & Benthic Family Richness & 11 & & \\
\hline & Bivalvia & Sphaeriidae & 2 & 0.0011 \\
\hline & Diptera & Cecidomyidae & 1 & 0.0001 \\
\hline & Diptera & unknown & 1 & 0.0001 \\
\hline & Diptera & Ceratopogonidae & 1 & 0.0001 \\
\hline & Diptera & Tabanidae & 1 & 0.0001 \\
\hline & Coleoptera & Staphylinidae & 2 & 0.0001 \\
\hline & Coleoptera & Carabidae & 5 & 0.0057 \\
\hline & Diptera & Chironomidae & 1 & 0.0001 \\
\hline & Nematoda & NA & 9 & 0.0006 \\
\hline & Diptera & Dolichopodidae & 1 & 0.0017 \\
\hline & Oligochaeta & $\mathrm{NA}$ & 12 & 0.0512 \\
\hline \multirow[t]{5}{*}{ HIBRID } & Benthic Family Richness & 4 & & \\
\hline & Oligochaeta & NA & 4 & 0.0201 \\
\hline & Nematoda & NA & 1 & 0.0001 \\
\hline & Diptera & Chironomidae & 4 & 0.0002 \\
\hline & Diptera & Tipulidae & 1 & 0.0007 \\
\hline \multirow[t]{7}{*}{ HIGATE } & Benthic Family Richness & 6 & & \\
\hline & Oligochaeta & NA & 5 & 0.0012 \\
\hline & Coleoptera & Elmidae & 1 & 0.0003 \\
\hline & Acanae & Lycosidae & 1 & 0.0054 \\
\hline & Diptera & Dolichopodidae & 2 & 0.0002 \\
\hline & Diptera & Ceratopogonidae & 1 & 0.0001 \\
\hline & Diptera & Chironomidae & 6 & 0.0019 \\
\hline \multirow[t]{2}{*}{ НIJHPK } & Benthic Family Richness & 1 & & \\
\hline & Nematoda & NA & 4 & 0.0001 \\
\hline
\end{tabular}


Appendix BC. Continued.

\begin{tabular}{|c|c|c|c|c|c|}
\hline SiteCode & Order & & Family & Count & Weight \\
\hline \multirow[t]{15}{*}{ HIJHTU } & Benthic Family Richness & 14 & & & \\
\hline & Coleoptera & & Helodidae & 2 & 0.0013 \\
\hline & Diptera & & Stratiomyidae & 2 & 0.0179 \\
\hline & Diptera & & Tabanidae & 1 & 0.0769 \\
\hline & Diptera & & Ceratopogonidae & 3 & 0.0001 \\
\hline & Isopoda & & NA & 1 & 0.0023 \\
\hline & Isopoda & & Asellidae & 3 & 0.0007 \\
\hline & Megaloptera & & Corydalidae & 1 & 0.002 \\
\hline & Aranae & & Pisauridae & 1 & 0.0002 \\
\hline & Gastropoda & & Planorbidae & 1 & 0.0011 \\
\hline & Bivalvia & & Sphaeriidae & 3 & 0.0014 \\
\hline & Gastropoda & & Physidae & 3 & 0.0036 \\
\hline & Oligochaeta & & NA & 5 & 0.0189 \\
\hline & Diptera & & Chironomidae & 2 & 0.0008 \\
\hline & Hemiptera & & Hebridae & 1 & 0.0086 \\
\hline \multirow[t]{5}{*}{ HIPENC } & Benthic Family Richness & 4 & & & \\
\hline & Oligochaeta & & NA & 4 & 0.0055 \\
\hline & Gastropoda & & Planorbidae & 1 & 0.0024 \\
\hline & Diptera & & Ceratopogonidae & 2 & 0.0001 \\
\hline & Bivalvia & & Sphaeriidae & 1 & 0.0014 \\
\hline \multirow[t]{4}{*}{ HISEWG } & Benthic Family Richness & 3 & & & \\
\hline & Gastropoda & & Physidae & 1 & 0.0091 \\
\hline & Oligochaeta & & NA & 10 & 0.0966 \\
\hline & Nematoda & & NA & 2 & 0.004 \\
\hline \multirow[t]{8}{*}{ HITRLR } & Benthic Family Richness & 7 & & & \\
\hline & Oligochaeta & & NA & 6 & 0.005 \\
\hline & Nematoda & & NA & 1 & 0.0001 \\
\hline & Gastropoda & & Planorbidae & 1 & 0.0054 \\
\hline & Diptera & & Ceratopogonidae & 4 & 0.0007 \\
\hline & Diptera & & Ephydridae & 1 & 0.0001 \\
\hline & Isopoda & & Asellidae & 3 & 0.0001 \\
\hline & Coleoptera & & Elmidae & 2 & 0.0028 \\
\hline
\end{tabular}


Appendix BC. Continued.

\begin{tabular}{|c|c|c|c|c|}
\hline SiteCode & Order & Family & Count & Weight \\
\hline \multirow[t]{5}{*}{ MCFOUR } & Benthic Family Richness & 4 & & \\
\hline & Diptera & Muscidae & 2 & 0.0002 \\
\hline & Nematoda & NA & 1 & 0.0001 \\
\hline & Coleoptera & Staphylinidae & 1 & 0.0001 \\
\hline & Diptera & Tipulidae & 1 & 0.0001 \\
\hline \multirow[t]{4}{*}{ MCMEME } & Benthic Family Richness & 3 & & \\
\hline & Bivalvia & Sphaeriidae & 1 & 0.0004 \\
\hline & Nematoda & NA & 1 & 0.0001 \\
\hline & Gastropoda & Physidae & 2 & 0.0031 \\
\hline \multirow[t]{9}{*}{ MCMFOR } & Benthic Family Richness & 8 & & \\
\hline & Bivalvia & Sphaeriidae & 10 & 0.0041 \\
\hline & Oligochaeta & NA & 2 & 0.0054 \\
\hline & Diptera & Chironomidae & 3 & 0.0001 \\
\hline & Nematoda & NA & 2 & 0.0001 \\
\hline & Diptera & Ceratopogonidae & 1 & 0.0001 \\
\hline & Diptera & Dolichopodidae & 1 & 0.0001 \\
\hline & Coleoptera & Hydrophilidae & 1 & 0.0001 \\
\hline & Gastropoda & Physidae & 3 & 0.0609 \\
\hline \multirow[t]{6}{*}{ MCNPFO } & Benthic Family Richness & 5 & & \\
\hline & Hymenoptera & Formicidae & 1 & 0.0001 \\
\hline & Coleoptera & Carabidae & 2 & 0.0004 \\
\hline & Isopoda & Asellidae & 1 & 0.0032 \\
\hline & Diptera & Muscidae & 1 & 0.0001 \\
\hline & Diptera & Chironomidae & 2 & 0.0001 \\
\hline \multirow[t]{3}{*}{ MCPOND } & Benthic Family Richness & 2 & & \\
\hline & Oligochaeta & NA & 2 & 0.0051 \\
\hline & Diptera & Chironomidae & 3 & 0.0004 \\
\hline \multirow[t]{3}{*}{ MCPOST } & Benthic Family Richness & 2 & & \\
\hline & Hemiptera & Mesoveliidae & 1 & 0.0001 \\
\hline & Diptera & Chironomidae & 5 & 0.0001 \\
\hline \multirow[t]{6}{*}{ MCTELE } & Benthic Family Richness & 5 & & \\
\hline & Gastropoda & Physidae & 1 & 0.0018 \\
\hline & Bivalvia & Sphaeriidae & 2 & 0.0005 \\
\hline & Diptera & Chironomidae & 1 & 0.0001 \\
\hline & Gastropoda & Planorbidae & 8 & 0.003 \\
\hline & Nematoda & NA & 1 & 0.0002 \\
\hline
\end{tabular}


Appendix BC.Continued.

\begin{tabular}{lc}
\hline SiteCode & Order \\
\hline ME5092 & Benthic Family Richness \\
& Diptera \\
& Oligochaeta \\
& Gastropoda \\
& Bivalvia
\end{tabular}

MESCOX Benthic Family Richness

Gastropoda

Bivalvia

Gastropoda

Diptera

Coleoptera

Oligochaeta

MESCRO Benthic Family Richness

Diptera

Oligochaeta

Coleoptera

MESCUP Benthic Family Richness

Oligochaeta

Bivalvia

MESIGN Benthic Family Richness

Coleoptera

Oligochaeta

Diptera

Bivalvia

MESILV Benthic Family Richness

Oligochaeta

Gastropoda

Diptera

Gastropoda

METETR Benthic Family Richness

Coleoptera

Oligochaeta

Gastropoda

Diptera

Coleoptera

Family

4

Tipulidae

NA

Planorbidae

Sphaeriidae

6

Planorbidae

Sphaeriidae

Physidae

Tabanidae

Staphylinidae

NA

3

Chironomidae

NA

Staphylinidae

2

NA

Sphaeriidae

4

Chyrosomelidae

NA

Tipulidae

Sphaeriidae

4

NA

Physidae

Chironomidae

Planorbidae

5

Elmidae

NA

Physidae

Chironomidae

Hydrophilidae
Count Weight

$\begin{array}{ll}1 & 0.0127 \\ 3 & 0.0073 \\ 1 & 0.0042 \\ 1 & 0.0008\end{array}$

20.0033

$1 \quad 0.0052$

$1 \quad 0.0008$

$1 \quad 0.006$

$1 \quad 0.0001$

$4 \quad 0.0016$

$3 \quad 0.0001$

$75 \quad 0.1532$

$1 \quad 0.0001$

$7 \quad 0.0192$

$3 \quad 0.0077$

$1 \quad 0.0086$

$7 \quad 0.0026$

$1 \quad 0.0012$

$3 \quad 0.0151$

$4 \quad 0.0011$

$2 \quad 0.0411$

$1 \quad 0.0001$

$1 \quad 0.0075$

$1 \quad 0.0015$

$3 \quad 0.0091$

$5 \quad 0.0193$

$2 \quad 0.0001$

$1 \quad 0.0016$ 
Appendix BC. Continued.

\begin{tabular}{|c|c|c|c|c|c|}
\hline SiteCode & Order & & Family & Count & Weight \\
\hline \multirow[t]{7}{*}{ MEWOLF } & Benthic Fami & ness & 6 & & \\
\hline & Coleoptera & & Chysomelidae & 1 & 0.0122 \\
\hline & Oligochaeta & & NA & 2 & 0.0009 \\
\hline & Coleoptera & & unknown & 1 & 0.0012 \\
\hline & Diptera & & Chironomidae & 1 & 0.0001 \\
\hline & Diptera & & Dolichopodidae & 1 & 0.0002 \\
\hline & Bivalvia & & Sphaeriidae & 4 & 0.0299 \\
\hline \multirow[t]{11}{*}{ MRBESS } & Benthic Family Richness & 10 & & & \\
\hline & Oligochaeta & & NA & 9 & 0.0064 \\
\hline & Gastropoda & & Bithyniidae & 2 & 0.0021 \\
\hline & Diptera & & Tabanidae & 1 & 0.0003 \\
\hline & Coleoptera & & Chrysomelidae & 2 & 0.003 \\
\hline & Diptera & & Ceratopogonidae & 1 & 0.0001 \\
\hline & Diptera & & Chironomidae & 3 & 0.0001 \\
\hline & Gastropoda & & Physidae & 3 & 0.0356 \\
\hline & Gastropoda & & Planorbidae & 3 & 0.0428 \\
\hline & Bivalvia & & Sphaeriidae & 19 & 0.0534 \\
\hline & Diptera & & Tipulidae & 4 & 0.0001 \\
\hline \multirow[t]{4}{*}{ MRFARM } & Benthic Family Richness & 3 & & & \\
\hline & Bivalvia & & Sphaeriidae & 10 & 0.0081 \\
\hline & Oligochaeta & & NA & 4 & 0.0811 \\
\hline & Diptera & & Muscidae & 2 & 0.0019 \\
\hline \multirow[t]{6}{*}{ MRFORE } & Benthic Family Richness & 5 & & & \\
\hline & Coleoptera & & Tenebrionidae & 1 & 0.0033 \\
\hline & Coleoptera & & Carabidae & 1 & 0.0006 \\
\hline & Geophilomorpha & & $\mathrm{NA}$ & 1 & 0.0009 \\
\hline & Oligochaeta & & NA & 18 & 0.3016 \\
\hline & Diptera & & Syrphidae & 1 & 0.0012 \\
\hline
\end{tabular}


Appendix BC. Continued.

\begin{tabular}{|c|c|c|c|c|c|}
\hline SiteCode & Order & & Family & Count & Weight \\
\hline \multirow[t]{8}{*}{ MRSSSS } & Benthic Family Richness & 7 & & & \\
\hline & Diptera & & Ceratopogonidae & 1 & 0.0001 \\
\hline & Hydracarina & & NA & 1 & 0.0001 \\
\hline & Isopoda & & Asellidae & 1 & 0.0001 \\
\hline & Diptera & & Chironomidae & 1 & 0.0003 \\
\hline & Diptera & & Muscidae & 1 & 0.0001 \\
\hline & Oligochaeta & & $\mathrm{NA}$ & 4 & 0.0322 \\
\hline & Bivalvia & & Sphaeriidae & 1 & 0.0021 \\
\hline \multirow[t]{6}{*}{ MRWEST } & Benthic Family Richness & 5 & & & \\
\hline & Oligochaeta & & NA & 3 & 0.0937 \\
\hline & Diptera & & Chironomidae & 2 & 0.0001 \\
\hline & Diptera & & Tipulidae & 1 & 0.0001 \\
\hline & Bivalvia & & Sphaeriidae & 2 & 0.0034 \\
\hline & Chilopoda & & NA & 1 & 0.0001 \\
\hline \multirow[t]{4}{*}{ MU55SS } & Benthic Family Richness & 3 & & & \\
\hline & Gastropoda & & Planorbidae & 1 & 0.0016 \\
\hline & Oligochaeta & & NA & 4 & 0.0036 \\
\hline & Diptera & & Dolichopodidae & 1 & 0.0002 \\
\hline \multirow[t]{5}{*}{ MUDBOA } & Benthic Family Richness & 4 & & & \\
\hline & Diptera & & Dolichopodidae & 1 & 0.0001 \\
\hline & Oligochaeta & & $\mathrm{NA}$ & 4 & 0.0031 \\
\hline & Nematoda & & NA & 1 & 0.0001 \\
\hline & Diptera & & Tabanidae & 1 & 0.1839 \\
\hline \multirow[t]{5}{*}{ MUDEND } & Benthic Family Richness & 4 & & & \\
\hline & Nematoda & & NA & 1 & 0.0001 \\
\hline & Oligochaeta & & $\mathrm{NA}$ & 1 & 0.0015 \\
\hline & Gastropoda & & Lymnaeidae & 1 & 0.0058 \\
\hline & Bivalvia & & Sphaeriidae & 4 & 0.0033 \\
\hline \multirow[t]{4}{*}{ MUDRIC } & Benthic Family Richness & 3 & & & \\
\hline & Oligochaeta & & NA & 8 & 0.027 \\
\hline & Diptera & & Ceratopogonidae & 1 & 0.0001 \\
\hline & Gastropoda & & Planorbidae & 1 & 0.0612 \\
\hline \multirow[t]{3}{*}{ MUDRIP } & Benthic Family Richness & 2 & & & \\
\hline & Diptera & & Sciomyzidae & 1 & 0.0001 \\
\hline & Coleoptera & & Elateridae & 1 & 0.0003 \\
\hline
\end{tabular}


Appendix BC. Continued.

\begin{tabular}{|c|c|c|c|c|}
\hline SiteCode & Order & Family & Count & Weight \\
\hline \multirow[t]{5}{*}{ MUDTRA } & Benthic Family Richness & 4 & & \\
\hline & Diptera & Ceratopogonidae & 1 & 0.0001 \\
\hline & Oligochaeta & NA & 8 & 0.0167 \\
\hline & Nematoda & NA & 5 & 0.0001 \\
\hline & Bivalvia & Sphaeriidae & 3 & 0.0009 \\
\hline \multirow[t]{4}{*}{ MUEPAH } & Benthic Family Richness & 3 & & \\
\hline & Diptera & Chironomidae & 2 & 0.0001 \\
\hline & Colcoptera & Chrysomelidae & 3 & 0.0084 \\
\hline & Oligochaeta & NA & 4 & 0.0001 \\
\hline \multirow[t]{5}{*}{ MUMINE } & Benthic Family Richness & 4 & & \\
\hline & Oligochaeta & NA & 7 & 0.0002 \\
\hline & Diptera & Chironomidae & 1 & 0.0001 \\
\hline & Diptera & Ceratopogonidae & 3 & 0.0001 \\
\hline & Diptera & Tabanidae & 2 & 0.0004 \\
\hline \multirow[t]{4}{*}{ MUPOWR } & Benthic Family Richness & 3 & & \\
\hline & Coleoptera & Staphylinidae & 1 & 0.0003 \\
\hline & Nematoda & NA & 1 & 0.0005 \\
\hline & Oligochaeta & NA & 12 & 0.0258 \\
\hline \multirow[t]{3}{*}{ MUPULL } & Benthic Family Richness & 2 & & \\
\hline & Diptera & Ceratopogonidae & 1 & 0.0001 \\
\hline & Diptera & Tabanidae & 2 & 0.0043 \\
\hline \multirow[t]{3}{*}{ MUVBRD } & Benthic Family Richness & 2 & & \\
\hline & Bivalvia & Sphaeriidae & 1 & 0.0001 \\
\hline & Oligochaeta & $\mathrm{NA}$ & 15 & 0.0059 \\
\hline \multirow[t]{2}{*}{ MUVCRN } & Benthic Family Richness & 1 & & \\
\hline & Isopoda & Asellidae & 1 & 0.0001 \\
\hline \multirow[t]{4}{*}{ OHHSFO } & Benthic Family Richness & 3 & & \\
\hline & Diptera & Chironomidae & 1 & 0.0001 \\
\hline & Oligochaeta & NA & 1 & 0.0036 \\
\hline & Diptera & Dolichopodidae & 1 & 0.0001 \\
\hline \multirow[t]{5}{*}{ OHINNS } & Benthic Family Richness & 4 & & \\
\hline & Gastropoda & Planorbidae & 1 & 0.0001 \\
\hline & Bivalvia & Sphaeriidae & 1 & 0.0001 \\
\hline & Oligochaeta & $\mathrm{NA}$ & 4 & 0.0789 \\
\hline & Diptera & Ceratopogonidae & 1 & 0.0001 \\
\hline \multirow[t]{2}{*}{ OHKMRT } & Benthic Family Richness & 1 & & \\
\hline & Nothing & NA & 0 & 0 \\
\hline
\end{tabular}


Appendix BC. Continued.

\begin{tabular}{|c|c|c|c|c|}
\hline SiteCode & Order & Family & Count & Weight \\
\hline \multirow[t]{4}{*}{ PA29TH } & Benthic Family Richness & 3 & & \\
\hline & Gastropoda & Physidae & 1 & 0.0004 \\
\hline & Coleoptera & Staphylinidae & 1 & 0.0001 \\
\hline & Bivavlia & Sphaeriidae & 6 & 0.0003 \\
\hline \multirow[t]{4}{*}{ PA83CR } & Benthic Family Richness & 3 & & \\
\hline & Diptera & Chironomidae & 2 & 0.0001 \\
\hline & Diptera & Ceratopogonidae & 1 & 0.0001 \\
\hline & Bivalvia & Sphaeriidae & 11 & 0.0648 \\
\hline \multirow[t]{5}{*}{ PAFAMD } & Benthic Family Richness & 4 & & \\
\hline & Bivalvia & Sphaeriidae & 1 & 0.0012 \\
\hline & Oligochaeta & NA & 15 & 0.0043 \\
\hline & Gastropoda & Physidae & 6 & 0.0554 \\
\hline & Gastropoda & Planorbidae & 1 & 0.0009 \\
\hline \multirow[t]{5}{*}{ PAJCPY } & Benthic Family Richness & 4 & & \\
\hline & Oligochaeta & $\mathrm{NA}$ & 20 & 0.2384 \\
\hline & Gastropoda & Physidae & 1 & 0.0184 \\
\hline & Gastropoda & Lymnaeidae & 2 & 0.0247 \\
\hline & Bivalvia & Sphaeriidae & 2 & 0.0086 \\
\hline \multirow[t]{9}{*}{ PALOUD } & Benthic Family Richness & 8 & & \\
\hline & Oligochaeta & NA & 25 & 0.1692 \\
\hline & Oligochaeta & NA & 8 & 0.018 \\
\hline & Gastropoda & Physidae & 22 & 0.2739 \\
\hline & Bivalvia & Sphaeriidae & 8 & 0.019 \\
\hline & Gastropoda & Physidae & 6 & 0.0544 \\
\hline & Gastropoda & Lymnaeidae & 2 & 0.0324 \\
\hline & Bivalvia & Sphaeriidae & 2 & 0.0007 \\
\hline & Amphipoda & Gammaridae & 1 & 0.0001 \\
\hline \multirow[t]{5}{*}{ PAPEFO } & Benthic Family Richness & 4 & & \\
\hline & Diptera & Chironomidae & 5 & 0.0001 \\
\hline & Lepidoptera & NA & 1 & 0.0019 \\
\hline & Oligochaeta & NA & 2 & 0.0002 \\
\hline & Bivalvia & Sphaeriidae & 4 & 0.0106 \\
\hline \multirow[t]{4}{*}{ PAPEIM } & Benthic Family Richness & 3 & & \\
\hline & Oligochaeta & NA & 12 & 0.0364 \\
\hline & Gastropoda & Physidae & 3 & 0.017 \\
\hline & Bivalvia & Sphaeriidae & 3 & 0.0237 \\
\hline
\end{tabular}


Appendix BC. Continued.

\begin{tabular}{|c|c|c|c|c|c|}
\hline SiteCode & Order & & Family & Count & Weight \\
\hline \multirow[t]{6}{*}{ PAPESW } & Benthic Far & iess & 5 & & \\
\hline & Oligochaeta & & NA & 1 & 0.0001 \\
\hline & Bivalvia & & Sphaeriidae & 3 & 0.0067 \\
\hline & Gastropoda & & Lymnaeidae & 2 & 0.0122 \\
\hline & Gastropoda & & Physidae & 4 & 0.0608 \\
\hline & Gastropoda & & Planorbidae & 1 & 0.118 \\
\hline \multirow[t]{5}{*}{ PAWILL } & Benthic Family Richness & 4 & & & \\
\hline & Gastropoda & & Physidae & 2 & 0.022 \\
\hline & Gastropoda & & Planorbidae & 1 & 0.0036 \\
\hline & Oligochaeta & & NA & 6 & 0.0012 \\
\hline & Nematoda & & NA & 1 & 0.0001 \\
\hline \multirow[t]{7}{*}{ PEMIDW } & Benthic Family Richness & 6 & & & \\
\hline & Isopoda & & Porcellionidae & 1 & 0.0071 \\
\hline & Gastropoda & & Physidae & 1 & 0.018 \\
\hline & Gastropoda & & Lymnaeidae & 2 & 0.0234 \\
\hline & Nematoda & & $\mathrm{NA}$ & 1 & 0.0006 \\
\hline & Oligochaeta & & NA & 2 & 0.0264 \\
\hline & Bivalvia & & Sphaeriidae & 2 & 0.0019 \\
\hline \multirow[t]{6}{*}{ PERDDP } & Benthic Family Richness & 5 & & & \\
\hline & Coleoptera & & Dytiscidae & 2 & 0.0048 \\
\hline & Oligochaeta & & NA & 3 & 0.0001 \\
\hline & Diptera & & Chironomidae & 1 & 0.0001 \\
\hline & Diptera & & Stratiomyidae & 1 & 0.0144 \\
\hline & Gastropoda & & Physidae & 8 & 0.0586 \\
\hline \multirow[t]{2}{*}{ PETHUM } & Benthic Family Richness & 1 & & & \\
\hline & oligochaeta & & NA & 1 & 0.0001 \\
\hline \multirow[t]{8}{*}{ PETOSS } & Benthic Family Richness & 7 & & & \\
\hline & Diptera & & Ceratopogonidae & 2 & 0.0001 \\
\hline & Collembola & & Isotomidae & 1 & 0.0001 \\
\hline & Diptera & & Ephydridae & 1 & 0.0002 \\
\hline & Coleoptera & & Chrysomelidae & 1 & 0.0063 \\
\hline & Nematoda & & NA & 5 & 0.0011 \\
\hline & Diptera & & Tabanidae & 1 & 0.0063 \\
\hline & Diptera & & Chironomidae & 4 & 0.0004 \\
\hline
\end{tabular}


Appendix BC. Continued.

\begin{tabular}{|c|c|c|c|c|}
\hline SiteCode & Order & Family & Count & Weight \\
\hline \multirow[t]{4}{*}{ RIASIA } & Benthic Family Richness & 3 & & \\
\hline & Oligochaeta & NA & 4 & 0.0001 \\
\hline & Nematoda & NA & 3 & 0.0001 \\
\hline & Bivalvia & Sphaeriidae & 2 & 0.0024 \\
\hline \multirow[t]{4}{*}{ RIBRID } & Benthic Family Richness & 3 & & \\
\hline & Gastropoda & Lymnaeidae & 2 & 0.0068 \\
\hline & Bivalvia & Sphaeriidae & 7 & 0.0404 \\
\hline & Gastropoda & Physidae & 1 & 0.0049 \\
\hline \multirow[t]{2}{*}{ RIEAST } & Benthic Family Richness & 1 & & \\
\hline & Oligochaeta & NA & 8 & 0.0022 \\
\hline \multirow[t]{2}{*}{ SJBOAT } & Benthic Family Richness & 1 & & \\
\hline & Nematoda & NA & 6 & 0.0058 \\
\hline \multirow[t]{3}{*}{ SJBRID } & Benthic Family Richness & 2 & & \\
\hline & Diptera & Dolichopodidae & 1 & 0.0001 \\
\hline & Nematoda & NA & 1 & 0.0001 \\
\hline \multirow[t]{3}{*}{ SJMUDL } & Benthic Family Richness & 2 & & \\
\hline & Nematoda & NA & 16 & 0.0007 \\
\hline & Oligochaeta & NA & 2 & 0.0097 \\
\hline \multirow[t]{2}{*}{ SJTELE } & Benthic Family Richness & 1 & & \\
\hline & Oligochaeta & NA & 2 & 0.0114 \\
\hline \multirow[t]{5}{*}{ SMDTSS } & Benthic Family Richness & 4 & & \\
\hline & Diptera & Tipulidae & 3 & 0.0235 \\
\hline & Diptera & Tabanidae & 1 & 0.0002 \\
\hline & Diptera & Ceratopogonidae & 6 & 0.0002 \\
\hline & Coleoptera & Chrysomelidae & 1 & 0.0008 \\
\hline \multirow[t]{2}{*}{ SMFOFL } & Benthic Family Richness & 1 & & \\
\hline & Diptera & Chironomidae & 2 & 0.0002 \\
\hline \multirow[t]{4}{*}{ SMLPEM } & Benthic Family Richness & 3 & & \\
\hline & Coleoptera & Chyrosomelidae & 2 & 0.0007 \\
\hline & Diptera & Chironomidae & 1 & 0.0001 \\
\hline & Diptera & Ceratopogonidae & 1 & 0.0001 \\
\hline \multirow[t]{3}{*}{ SMSEFL } & Benthic Family Richness & 2 & & \\
\hline & Diptera & Chironomidae & 1 & 0.0003 \\
\hline & Bivalvia & Sphaeriidae & 1 & 0.0006 \\
\hline
\end{tabular}


Appendix BC. Continued.

\begin{tabular}{|c|c|c|c|c|}
\hline SiteCode & Order & Family & Count & Weight \\
\hline \multirow[t]{4}{*}{ SMSTEM } & Benthic Family Richness & 3 & & \\
\hline & Diptera & Tabanidae & 2 & 0.0002 \\
\hline & Oligochaeta & NA & 1 & 0.0116 \\
\hline & Diptera & Dolichopodidae & 1 & 0.0001 \\
\hline \multirow[t]{6}{*}{ TRSPFO } & Benthic Family Richness & 5 & & \\
\hline & Homoptera & Cicadidae & 2 & 0.0001 \\
\hline & Diptera & Dolichopodidae & 1 & 0.0002 \\
\hline & Bivalvia & Sphaeriidae & 5 & 0.0121 \\
\hline & Oligochaeta & NA & 4 & 0.0172 \\
\hline & Diptera & Dolichopodidae & 1 & 0.0002 \\
\hline \multirow[t]{12}{*}{ TRSPRI } & Benthic Family Richness & 11 & & \\
\hline & Bivalvia & Sphaeriidae & 3 & 0.0009 \\
\hline & Coleoptera & Elateridae & 1 & 0.0013 \\
\hline & Homoptera & Cicadellidae & 1 & 0.0002 \\
\hline & Aranae & $\mathrm{NA}$ & 1 & 0.0001 \\
\hline & Homoptera & Aphididae & 1 & 0.0001 \\
\hline & Diptera & Dolichopodidae & 3 & 0.0002 \\
\hline & Gastropoda & Planorbidae & 3 & 0.0058 \\
\hline & Nematoda & NA & 32 & 0.0061 \\
\hline & Oligochaeta & NA & 6 & 0.0495 \\
\hline & Hymenoptera & Formicidae & 20 & 0.0025 \\
\hline & Diptera & Tipulidae & 1 & 0.0079 \\
\hline \multirow[t]{9}{*}{ TVFARM } & Benthic Family Richness & 8 & & \\
\hline & Bivalvia & Sphaeriidae & 3 & 0.0084 \\
\hline & Coleoptera & Scarabaeidae & 1 & 0.0022 \\
\hline & Diptera & Ephydridae & 6 & 0.0011 \\
\hline & Diptera & Tabanidae & 1 & 0.0012 \\
\hline & Coleoptera & Hydrophilidae & 1 & 0.0015 \\
\hline & Oligochaeta & $\mathrm{NA}$ & 5 & 0.0011 \\
\hline & Coleoptera & Chrysomelidae & 1 & 0.0029 \\
\hline & Diptera & Stratiomyidae & 1 & 0.0047 \\
\hline \multirow[t]{2}{*}{ TVISLE } & Benthic Family Richness & 1 & & \\
\hline & Oligochaeta & NA & 3 & 0.0023 \\
\hline
\end{tabular}


Appendix BC. Continued.

\begin{tabular}{|c|c|c|c|c|}
\hline SiteCode & Order & Family & Count & Weight \\
\hline \multirow[t]{2}{*}{ TVNEWT } & Benthic Family Richness & 1 & & \\
\hline & Oligochaeta & NA & 1 & 0.0008 \\
\hline \multirow[t]{5}{*}{ TVPOUT } & Benthic Family Richness & 4 & & \\
\hline & Oligochaeta & NA & 5 & 0.0011 \\
\hline & Bivalvia & Sphaeriidae & 4 & 0.003 \\
\hline & Diptera & Dolichopodidae & 1 & 0.0002 \\
\hline & Gastropoda & Lymnaeidae & 2 & 0.0144 \\
\hline \multirow[t]{2}{*}{ TVVBEM } & Benthic Family Richness & 1 & & \\
\hline & Bivalvia & Sphaeriidae & 2 & 0.0013 \\
\hline \multirow[t]{4}{*}{ TVVBIM } & Benthic Family Richness & 3 & & \\
\hline & Bivalvia & Sphaeriidae & 6 & 0.0165 \\
\hline & Diptera & Chironomidae & 3 & 0.0001 \\
\hline & Hirudinea & Erpobdellidae & 1 & 0.0034 \\
\hline \multirow[t]{5}{*}{ TVVBRV } & Benthic Family Richness & 4 & & \\
\hline & Oligochaeta & NA & 6 & 0.0491 \\
\hline & Diptera & Dolichopodidae & 2 & 0.0006 \\
\hline & Diptera & Chironomidae & 1 & 0.0001 \\
\hline & Nematoda & $\mathrm{NA}$ & 1 & 0.0007 \\
\hline \multirow[t]{3}{*}{ TVVBSS } & Benthic Family Richness & 2 & & \\
\hline & Mysidacca & Mysidae & 1 & 0.0005 \\
\hline & Bivalvia & Sphaeriidae & 4 & 0.0015 \\
\hline \multirow[t]{5}{*}{ UDC001 } & Benthic Family Richness & 4 & & \\
\hline & Oligochaeta & NA & 1 & 0.0003 \\
\hline & Nematoda & NA & 3 & 0.0008 \\
\hline & Coleoptera & unknown & 1 & 0.0031 \\
\hline & Bivalvia & Sphaeriidae & 2 & 0.0149 \\
\hline \multirow[t]{3}{*}{ UDC002 } & Benthic Family Richness & 2 & & \\
\hline & Nematoda & NA & 3 & 0.0001 \\
\hline & Diptera & Chironomidae & 1 & 0.0001 \\
\hline
\end{tabular}


Appendix BC.Continued.

\begin{tabular}{|c|c|c|c|c|}
\hline SiteCode & Order & Family & Count & Weight \\
\hline \multirow[t]{10}{*}{ UDC003 } & Benthic Family Richness & 9 & & \\
\hline & Diptera & Psychodidae & 1 & 0.0004 \\
\hline & Diptera & unknown & 1 & 0.001 \\
\hline & Diptera & Ephydridae & 1 & 0.0001 \\
\hline & Diplura & Japygidae & 1 & 0.0001 \\
\hline & Coleoptera & Scarabaeidae & 1 & 0.0022 \\
\hline & Gastropoda & Viviparidae & 1 & 0.0203 \\
\hline & Bivalvia & Sphaeriidae & 2 & 0.0092 \\
\hline & Nematoda & NA & 175 & 0.0206 \\
\hline & Gastropoda & Physidae & 5 & 0.1004 \\
\hline \multirow[t]{2}{*}{ UDC004 } & Benthic Family Richness & 1 & & \\
\hline & Bivalvia & Sphaeriidae & 1 & 0.005 \\
\hline \multirow[t]{7}{*}{ UDC008 } & Benthic Family Richness & 6 & & \\
\hline & Nematoda & NA & 18 & 0.0028 \\
\hline & Diptera & Ceratopogonidae & 2 & 0.0001 \\
\hline & Diptera & Dolichopodidae & 1 & 0.0001 \\
\hline & Bivalvia & Sphaeriidae & 1 & 0.0024 \\
\hline & Gastropoda & Viviparidae & 2 & 0.0043 \\
\hline & Gastropoda & Hydrobiidae & 1 & 0.0093 \\
\hline \multirow[t]{4}{*}{ UDC012 } & Benthic Family Richness & 3 & & \\
\hline & Gastropoda & Planorbidae & 1 & 0.0048 \\
\hline & Oligochaeta & NA & 16 & 0.0039 \\
\hline & Bivalvia & Sphaeriidae & 1 & 0.0016 \\
\hline \multirow[t]{7}{*}{ UDC013 } & Benthic Family Richness & 6 & & \\
\hline & Nematoda & NA & 109 & 0.0177 \\
\hline & Diptera & Ceratopogonidae & 9 & 0.0002 \\
\hline & Coleoptera & Chrysomelidae & 2 & 0.002 \\
\hline & Bivalvia & Sphaeriidae & 23 & 0.0284 \\
\hline & Gastropda & Physidae & 1 & 0.0016 \\
\hline & Diptera & Tipulidae & 3 & 0.0005 \\
\hline \multirow[t]{2}{*}{ UDC014 } & Benthic Family Richness & 1 & & \\
\hline & Psocoptera & Liposcelidae & 1 & 0.0001 \\
\hline \multirow[t]{2}{*}{ UDC015 } & Benthic Family Richness & 0 & & \\
\hline & Nothing & NA & 0 & 0 \\
\hline \multirow[t]{2}{*}{ UDC017 } & Benthic Family Richness & 0 & & \\
\hline & Nothing & NA & 0 & 0 \\
\hline
\end{tabular}


Appendix BC. Continued.

\begin{tabular}{lllll}
\hline SiteCode & Order & Family & Count & Weight \\
\hline
\end{tabular}

UDC018 Benthic Family Richness

Bivalvia

Diptera

Gastropoda

Diptera

Oligochaeta

UDC019 Benthic Family Richness

Bivalvia

Oligochaeta

Diptera

UDC020 Benthic Family Richness

Diptera

Diptera

Diptera

VEPCON Benthic Family Richness

Oligochaeta

Coleoptera

Diptera

Diptera

Nematoda

VEPCOS Benthic Family Richness

Diptera

Nematoda

Coleoptera

Coleoptera

Diptera

Oligochaeta

WBBARN Benthic Family Richness

Bivalvia

Coleoptera

Gastropoda

Oligochaeta

Diptera

Diptera

Gastropoda
5

Sphaeriidae

Chironomidae

Physidae

Stratiomyidae

NA

3

Sphaeriidae

NA

Tabanidae

3

unknown

unknown

Chironomidae

5

NA

Chrysomelidae

Chironomidae

Tipulidae

NA

6

Tipulidae

NA

Hydrophilidae

Chrysomelidae

Chironomidae

NA

7

Sphaeriidae

Belostomatidae

Physidae

NA

Ceratopogonidae

Dolichopodidae

Planorbidae

$\begin{array}{ll}2 & 0.0055 \\ 1 & 0.0001 \\ 2 & 0.0072 \\ 2 & 0.0054 \\ 2 & 0.0009\end{array}$

1

0.0003

0.0005

$1 \quad 0.0001$

$\begin{array}{ll}1 & 0.0007 \\ 1 & 0.0001 \\ 2 & 0.0001\end{array}$

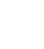

$\begin{array}{rr}1 & 0.0001 \\ 13 & 0.0294 \\ 8 & 0.0001 \\ 3 & 0.0053 \\ 1 & 0.0001\end{array}$

(

$\begin{array}{rl}1 & 0.0004 \\ 1 & 0.0005 \\ 1 & 0.0078 \\ 2 & 0.0011 \\ 18 & 0.0011 \\ 3 & 0.0004\end{array}$

(3.

$\begin{array}{rl}5 & 0.0152 \\ 1 & 0.0248 \\ 11 & 0.0695 \\ 43 & 0.0591 \\ 9 & 0.0011 \\ 1 & 0.0001 \\ 6 & 0.1206\end{array}$


Appendix BC.Continued.

\begin{tabular}{|c|c|c|c|c|}
\hline SiteCode & Order & Family & Count & Weight \\
\hline \multirow[t]{9}{*}{ WBCORN } & Benthic Family Richness & 8 & & \\
\hline & Hemiptera & Cicadellidae & 1 & 0.0001 \\
\hline & Gastropoda & Hydrophilidae & 2 & 0.0089 \\
\hline & Gastropoda & Planorbidae & 9 & 0.8169 \\
\hline & Nematoda & NA & 2 & 0.0001 \\
\hline & Oligochaeta & NA & 3 & 0.0019 \\
\hline & Diptera & Chironomidae & 2 & 0.0001 \\
\hline & Diptera & Ceratopogonidae & 4 & 0.0001 \\
\hline & Gastropoda & Physidae & 8 & 0.0313 \\
\hline \multirow[t]{6}{*}{ WBROAD } & Benthic Family Richness & 5 & & \\
\hline & Diptera & Ephydridae & 1 & 0.0002 \\
\hline & Diptera & Ceratopogonidae & 1 & 0.0001 \\
\hline & Diptera & Chironomidae & 1 & 0.0001 \\
\hline & Diptera & Tabanidae & 1 & 0.0006 \\
\hline & Diptera & Stratiomyidae & 1 & 0.0062 \\
\hline \multirow[t]{5}{*}{ WYBEAV } & Benthic Family Richness & 4 & & \\
\hline & Coleoptera & Hydrophilidae & 2 & 0.0004 \\
\hline & Diptera & Chironomidae & 2 & 0.0001 \\
\hline & Bivalvia & Sphaeriidae & 1 & 0.0043 \\
\hline & Diptera & Muscidae & 2 & 0.0001 \\
\hline \multirow[t]{7}{*}{ WYCHWE } & Benthic Family Richness & 6 & & \\
\hline & Diptera & Tipulidae & 1 & 0.0001 \\
\hline & Coleoptera & Elateridae & 2 & 0.0001 \\
\hline & Coleoptera & NA & 1 & 0.0033 \\
\hline & Nematoda & $\mathrm{NA}$ & 1 & 0.0001 \\
\hline & Homoptera & Aphididae & 4 & 0.0002 \\
\hline & Oligochaeta & NA & 5 & 0.033 \\
\hline \multirow[t]{4}{*}{ WYHCEA } & Benthic Family Richness & 3 & & \\
\hline & Collembola & Poduridae & 1 & 0.0001 \\
\hline & Diptera & Chironomidae & 1 & 0.0001 \\
\hline & Diptera & Ceratopogonidae & 1 & 0.0001 \\
\hline
\end{tabular}


Appendix BC.Continued.

\begin{tabular}{|c|c|c|c|c|}
\hline SiteCode & Order & Family & Count & Weight \\
\hline \multirow[t]{8}{*}{ WYINTR } & Benthic Family Richness & 7 & & \\
\hline & Gastropoda & Hydrobiidae & 1 & 0.01 \\
\hline & Bivalvia & Sphaeriidae & 2 & 0.0041 \\
\hline & Chilopda & NA & 1 & 0.0105 \\
\hline & Coleoptera & NA & 1 & 0.0001 \\
\hline & Diptera & Muscidae & 1 & 0.0015 \\
\hline & Oligochaeta & $\mathrm{NA}$ & 10 & 0.1498 \\
\hline & Diptera & Tipulidae & 2 & 0.0183 \\
\hline \multirow[t]{5}{*}{ WYTHOR } & Benthic Family Richness & 4 & & \\
\hline & Coleoptera & Hydrophilidae & 1 & 0.0001 \\
\hline & Diptera & Ceratopogonidae & 11 & 0.0001 \\
\hline & Diptera & Tipulidae & 7 & 0.0385 \\
\hline & Diptera & Chironomidae & 1 & 0.0001 \\
\hline
\end{tabular}


Appendix BD. Combined and stratified benthic and nektomic data summary statistics of metrics scores statewide and by ecoregion used to used to form macroinvertebrate indices of biological integrity for wetlands in West Virginia, USA 2005-2006.

\begin{tabular}{|c|c|c|c|c|c|c|c|c|c|}
\hline \multicolumn{10}{|c|}{ Benthic and Nektonic Sampling Statewide (N=106) } \\
\hline & $\%$ Biomass & $\%$ Biomass & $\%$ Biomass & $\%$ Biomass & $\%$ Biomass & $\%$ Biomass & $\%$ Biomass & $\%$ Biomass & $\%$ Biomass \\
\hline & EPA Stressed & Collectors & Collectors * & Predators & Predators * & Shredders & Shredders * & Chironomidae & Coleoptera \\
\hline Minimum & 0 & 0 & 0 & 0 & 0 & 0 & 0 & 0 & 0 \\
\hline Maximum & 0.985 & 0.976 & 0.978 & 0.981 & 1 & 0.784 & 0.897 & 0.889 & 0.969 \\
\hline Mean & 0.249 & 0.332 & 0.396 & 0.241 & 0.307 & 0.066 & 0.082 & 0.049 & 0.101 \\
\hline \multirow[t]{2}{*}{ Std. Error } & 0.025 & 0.03 & 0.031 & 0.026 & 0.031 & 0.013 & 0.015 & 0.012 & 0.018 \\
\hline & $\begin{array}{l}\% \text { Biomass } \\
\text { Coleoptera * }\end{array}$ & $\begin{array}{l}\% \text { Biomass } \\
\text { Dytiscidae }\end{array}$ & $\begin{array}{l}\% \text { Biomass } \\
\text { Corixidae }\end{array}$ & $\begin{array}{l}\% \text { Biomass } \\
\text { Corixidae * }\end{array}$ & $\begin{array}{c}\% \text { Biomass } \\
\text { Coleoptera } \\
\text { and Corixidae }\end{array}$ & $\begin{array}{l}\text { \% Biomass } \\
\text { Libellulidae }\end{array}$ & $\begin{array}{c}\text { \% Biomass } \\
\text { Libellulidae * }\end{array}$ & $\begin{array}{c}\text { \% Biomass } \\
\text { Odonata - } \\
\text { Libellulidae }\end{array}$ & $\begin{array}{l}\text { \% Biomass } \\
\text { Odonata - } \\
\text { Libellulidae * }\end{array}$ \\
\hline Minimum & 0 & 0 & 0 & 0 & 0 & 0 & 0 & 0 & 0 \\
\hline Maximum & 0.993 & 0.757 & 0.776 & 0.781 & 0.966 & 0.969 & 0.993 & 0.73 & 0.764 \\
\hline Mean & 0.114 & 0.033 & 0.034 & 0.027 & 0.033 & 0.128 & 0.148 & 0.069 & 0.085 \\
\hline \multirow[t]{2}{*}{ Std. Error } & 0.019 & 0.009 & 0.01 & 0.009 & 0.01 & 0.02 & 0.022 & 0.015 & 0.018 \\
\hline & $\begin{array}{l}\text { \% Biomass } \\
\text { Odonata }\end{array}$ & $\begin{array}{l}\% \text { Biomass } \\
\text { Odonata* }\end{array}$ & $\begin{array}{c}\text { Relative } \\
\text { Abundance } \\
\text { EPA Stressed }\end{array}$ & $\begin{array}{l}\text { Relative } \\
\text { Abundance } \\
\text { Collector }\end{array}$ & $\begin{array}{l}\text { Relative } \\
\text { Abundance } \\
\text { Collector * }\end{array}$ & $\begin{array}{l}\text { Relative } \\
\text { Abundance } \\
\text { Predator }\end{array}$ & $\begin{array}{l}\text { Relative } \\
\text { Abundance } \\
\text { Predator * }\end{array}$ & $\begin{array}{l}\text { Relative } \\
\text { Abundance } \\
\text { Shredder }\end{array}$ & $\begin{array}{l}\text { Relative } \\
\text { Abundance } \\
\text { Shredder * }\end{array}$ \\
\hline Minimum & 0 & 0 & 0 & 0 & 0 & 0 & 0 & 0 & 0 \\
\hline Maximum & 0.5 & 0.865 & 0.948 & 0.957 & 0.884 & 0.812 & 0.966 & 0.8 & 1 \\
\hline Mean & 0.042 & 0.056 & 0.111 & 0.141 & 0.294 & 0.239 & 0.336 & 0.186 & 0.289 \\
\hline \multirow[t]{2}{*}{ Std. Error } & 0.008 & 0.012 & 0.018 & 0.022 & 0.021 & 0.019 & 0.024 & 0.016 & 0.023 \\
\hline & $\begin{array}{c}\text { Relative } \\
\text { Abundance } \\
\text { Chironomidae }\end{array}$ & $\begin{array}{l}\text { Relative } \\
\text { Abundance } \\
\text { Coleoptera }\end{array}$ & $\begin{array}{c}\text { Relative } \\
\text { Abundance } \\
\text { Coleoptera * }\end{array}$ & $\begin{array}{l}\text { Relative } \\
\text { Abundance } \\
\text { Dytiscidae }\end{array}$ & $\begin{array}{c}\text { Relative } \\
\text { Abundance } \\
\text { Dytiscidae * }\end{array}$ & $\begin{array}{c}\text { Relative } \\
\text { Abundance } \\
\text { Coleoptera } \\
\text { and Corixidae }\end{array}$ & $\begin{array}{l}\text { Relative } \\
\text { Abundance } \\
\text { Corixidae }\end{array}$ & $\begin{array}{c}\text { Relative } \\
\text { Abundance } \\
\text { Corixidae * }\end{array}$ & $\begin{array}{c}\text { Relative } \\
\text { Abundance } \\
\text { Libellulidae }\end{array}$ \\
\hline Minimum & 0 & 0 & 0 & 0 & 0 & 0 & 0 & 0 & 0 \\
\hline Maximum & 0.611 & 0.762 & 0.773 & 0.7 & 0.848 & 0.625 & 0.758 & 0.797 & 0.948 \\
\hline Mean & 0.084 & 0.114 & 0.193 & 0.084 & 0.115 & 0.038 & 0.047 & 0.123 & 0.17 \\
\hline Std. Error & 0.014 & 0.017 & 0.019 & 0.011 & 0.015 & 0.008 & 0.01 & 0.014 & 0.018 \\
\hline
\end{tabular}


Appendix BD. Continued.

\begin{tabular}{lccccc} 
& $\begin{array}{c}\text { Relative } \\
\text { Abundance } \\
\text { Libellulidae * }\end{array}$ & $\begin{array}{c}\text { Relative } \\
\text { Abundance } \\
\text { Libellulidae }\end{array}$ & $\begin{array}{c}\text { Relative } \\
\text { Abundance } \\
\text { Libellulidae * }\end{array}$ & $\begin{array}{c}\text { Relative } \\
\text { Abundance } \\
\text { Odonata }\end{array}$ & $\begin{array}{c}\text { Relative } \\
\text { Abundance } \\
\text { Odonata * }\end{array}$ \\
Minimum & 0 & 0 & 0 & 0 & 0 \\
Maximum & 0.797 & 0.948 & 0.2 & 0.286 & 0.5 \\
Mean & 0.04 & 0.056 & 0.018 & 0.028 & 0.042 \\
Std. Error & 0.011 & 0.014 & 0.004 & 0.005 & 0.008 \\
\hline
\end{tabular}




\section{Appendix BD. Continued.}

Allegheny Highlands Benthic and Nektonic Sampling ( $\mathrm{N}=46$

\begin{tabular}{|c|c|c|c|c|c|c|c|c|c|}
\hline & $\begin{array}{l}\% \text { Biomass } \\
\text { EPA Stressed }\end{array}$ & $\begin{array}{l}\% \text { Biomass } \\
\text { Collectors }\end{array}$ & $\begin{array}{l}\% \text { Biomass } \\
\text { Collectors * }\end{array}$ & $\begin{array}{l}\% \text { Biomass } \\
\text { Predators }\end{array}$ & $\begin{array}{l}\% \text { Biomass } \\
\text { Predators * }\end{array}$ & $\begin{array}{l}\% \text { Biomass } \\
\text { Shredders }\end{array}$ & $\begin{array}{l}\% \text { Biomass } \\
\text { Shredders * }\end{array}$ & $\begin{array}{l}\text { \% Biomass } \\
\text { Chironomidae }\end{array}$ & $\begin{array}{l}\% \text { Biomass } \\
\text { Coleoptera }\end{array}$ \\
\hline Minimum & 0 & 0 & 0 & 0 & 0 & 0 & 0 & 0 & 0 \\
\hline Maximum & 0.889 & 0.881 & 0.902 & 0.966 & 0.987 & 0.667 & 0.693 & 0.889 & 0.86 \\
\hline Mean & 0.234 & 0.298 & 0.369 & 0.231 & 0.306 & 0.072 & 0.085 & 0.077 & 0.098 \\
\hline \multirow[t]{2}{*}{ Std. Error } & 0.035 & 0.045 & 0.046 & 0.039 & 0.046 & 0.019 & 0.021 & 0.024 & 0.029 \\
\hline & $\begin{array}{l}\% \text { Biomass } \\
\text { Coleoptera * }\end{array}$ & $\begin{array}{l}\% \text { Biomass } \\
\text { Dytiscidae }\end{array}$ & $\begin{array}{l}\% \text { Biomass } \\
\text { Corixidae }\end{array}$ & $\begin{array}{l}\% \text { Biomass } \\
\text { Corixidae * }\end{array}$ & $\begin{array}{c}\% \text { Biomass } \\
\text { Coleoptera } \\
\text { and Corixidae }\end{array}$ & $\begin{array}{l}\text { \% Biomass } \\
\text { Libellulidae }\end{array}$ & $\begin{array}{l}\text { \% Biomass } \\
\text { Libellulidae * }\end{array}$ & $\begin{array}{l}\% \text { Biomass } \\
\text { Odonata - } \\
\text { Libellulidae }\end{array}$ & $\begin{array}{l}\text { \% Biomass } \\
\text { Odonata - } \\
\text { Libellulidae * }\end{array}$ \\
\hline Minimum & 0 & 0 & 0 & 0 & 0 & 0 & 0 & 0 & 0 \\
\hline Maximum & 0.892 & 0.292 & 0.317 & 0.254 & 0.278 & 0.86 & 0.892 & 0.73 & 0.764 \\
\hline Mean & 0.12 & 0.025 & 0.028 & 0.028 & 0.036 & 0.126 & 0.156 & 0.077 & 0.105 \\
\hline \multirow[t]{2}{*}{ Std. Error } & 0.031 & 0.01 & 0.01 & 0.009 & 0.011 & 0.03 & 0.032 & 0.023 & 0.031 \\
\hline & $\begin{array}{l}\% \text { Biomass } \\
\text { Odonata }\end{array}$ & $\begin{array}{l}\% \text { Biomass } \\
\text { Odonata * }\end{array}$ & $\begin{array}{c}\text { Relative } \\
\text { Abundance } \\
\text { EPA Stressed }\end{array}$ & $\begin{array}{l}\text { Relative } \\
\text { Abundance } \\
\text { Collector }\end{array}$ & $\begin{array}{l}\text { Relative } \\
\text { Abundance } \\
\text { Collector * }\end{array}$ & $\begin{array}{l}\text { Relative } \\
\text { Abundance } \\
\text { Predator }\end{array}$ & $\begin{array}{l}\text { Relative } \\
\text { Abundance } \\
\text { Predator* }\end{array}$ & $\begin{array}{l}\text { Relative } \\
\text { Abundance } \\
\text { Shredder }\end{array}$ & $\begin{array}{l}\text { Relative } \\
\text { Abundance } \\
\text { Shredder* }\end{array}$ \\
\hline Minimum & 0 & 0 & 0 & 0 & 0 & 0 & 0 & 0 & 0 \\
\hline Maximum & 0.5 & 0.529 & 0.73 & 0.813 & 0.803 & 0.74 & 0.885 & 0.8 & 0.8 \\
\hline Mean & 0.036 & 0.048 & 0.113 & 0.153 & 0.336 & 0.194 & 0.308 & 0.163 & 0.271 \\
\hline \multirow[t]{2}{*}{ Std. Error } & 0.013 & 0.016 & 0.026 & 0.034 & 0.034 & 0.025 & 0.033 & 0.023 & 0.032 \\
\hline & $\begin{array}{c}\text { Relative } \\
\text { Abundance } \\
\text { Chironomidae }\end{array}$ & $\begin{array}{l}\text { Relative } \\
\text { Abundance } \\
\text { Coleoptera }\end{array}$ & $\begin{array}{c}\text { Relative } \\
\text { Abundance } \\
\text { Coleoptera * }\end{array}$ & $\begin{array}{l}\text { Relative } \\
\text { Abundance } \\
\text { Dytiscidae }\end{array}$ & $\begin{array}{c}\text { Relative } \\
\text { Abundance } \\
\text { Dytiscidae * }\end{array}$ & $\begin{array}{c}\text { Relative } \\
\text { Abundance } \\
\text { Coleoptera } \\
\text { and Corixidae }\end{array}$ & $\begin{array}{l}\text { Relative } \\
\text { Abundance } \\
\text { Corixidae }\end{array}$ & $\begin{array}{l}\text { Relative } \\
\text { Abundance } \\
\text { Corixidae * }\end{array}$ & $\begin{array}{c}\text { Relative } \\
\text { Abundance } \\
\text { Libellulidae }\end{array}$ \\
\hline Minimum & 0 & 0 & 0 & 0 & 0 & 0 & 0 & 0 & 0 \\
\hline Maximum & 0.611 & 0.762 & 0.773 & 0.472 & 0.81 & 0.196 & 0.211 & 0.472 & 0.81 \\
\hline Mean & 0.103 & 0.144 & 0.245 & 0.073 & 0.116 & 0.027 & 0.036 & 0.114 & 0.183 \\
\hline Std. Error & 0.024 & 0.031 & 0.033 & 0.014 & 0.022 & 0.007 & 0.009 & 0.017 & 0.025 \\
\hline
\end{tabular}


Appendix BD. Continued.

\begin{tabular}{lccccc}
\hline & & & & \\
& Relative & Relative & Relative & Relative & Relative \\
Abundance & Abundance & Abundance & Abundance & Abundance \\
Libellulidae * & Libellulidae & Libellulidae * & Odonata & Odonata * \\
Minimum & 0 & 0 & 0 & 0 & 0 \\
Maximum & 0.333 & 0.5 & 0.2 & 0.286 & 0.5 \\
Mean & 0.04 & 0.067 & 0.025 & 0.039 & 0.036 \\
Std. Error & 0.012 & 0.019 & 0.007 & 0.01 & 0.013 \\
\hline
\end{tabular}




\section{Appendix BD. Continued.}

\begin{tabular}{|c|c|c|c|c|c|c|c|c|c|}
\hline \multicolumn{10}{|c|}{ Ridge and Valley Benthic and Nektonic Sampling $(\mathrm{N}=21)$} \\
\hline & $\%$ Biomass & $\%$ Biomass & $\%$ Biomass & $\%$ Biomass & $\%$ Biomass & $\%$ Biomass & $\%$ Biomass & $\%$ Biomass & \\
\hline & EPA Stressed & Collectors & Collectors * & Predators & Predators * & Shredders & Shredders * & Chironomidae & \\
\hline Minimum & 0 & 0 & 0 & 0 & 0 & 0 & 0 & 0 & \\
\hline Maximum & 0.985 & 0.976 & 0.978 & 0.763 & 1 & 0.784 & 0.897 & 0.535 & \\
\hline Mean & 0.239 & 0.377 & 0.404 & 0.188 & 0.24 & 0.082 & 0.109 & 0.045 & \\
\hline \multirow[t]{4}{*}{ Std. Error } & 0.059 & 0.074 & 0.08 & 0.04 & 0.056 & 0.038 & 0.048 & 0.025 & \\
\hline & & & & & & $\%$ Biomass & & & $\%$ Biomass \\
\hline & $\%$ Biomass & \% Biomass & $\%$ Biomass & $\%$ Biomass & $\%$ Biomass & Coleoptera & $\%$ Biomass & $\%$ Biomass & Odonata - \\
\hline & Coleoptera & Coleoptera * & Dytiscidae & Corixidae & Corixidae * & and Corixidae & Libellulidae & Libellulidae * & Libellulidae \\
\hline Minimum & 0 & 0 & 0 & 0 & 0 & 0 & 0 & 0 & 0 \\
\hline Maximum & 0.628 & 0.74 & 0.229 & 0.242 & 0.097 & 0.103 & 0.628 & 0.74 & 0.676 \\
\hline Mean & 0.1 & 0.109 & 0.023 & 0.024 & 0.013 & 0.013 & 0.113 & 0.122 & 0.041 \\
\hline \multirow[t]{4}{*}{ Std. Error } & 0.032 & 0.037 & 0.012 & 0.012 & 0.006 & 0.006 & 0.034 & 0.038 & 0.032 \\
\hline & $\%$ Biomass & & & Relative & Relative & Relative & Relative & Relative & Relative \\
\hline & Odonata - & $\%$ Biomass & $\%$ Biomass & Abundance & Abundance & Abundance & Abundance & Abundance & Abundance \\
\hline & Libellulidae * & Odonata & Odonata * & EPA Stressed & Collector & Collector * & Predator & Predator * & Shredder \\
\hline Minimum & 0 & 0 & 0 & 0 & 0 & 0 & 0 & 0 & 0 \\
\hline Maximum & 0.681 & 0.283 & 0.284 & 0.728 & 0.734 & 0.828 & 0.788 & 0.798 & 0.536 \\
\hline Mean & 0.041 & 0.026 & 0.026 & 0.066 & 0.067 & 0.303 & 0.293 & 0.379 & 0.169 \\
\hline \multirow[t]{4}{*}{ Std. Error } & 0.033 & 0.014 & 0.014 & 0.037 & 0.038 & 0.051 & 0.049 & 0.061 & 0.03 \\
\hline & & & & & & & Relative & & \\
\hline & Abundance & $\begin{array}{l}\text { Relative } \\
\text { Abundance }\end{array}$ & Abundance & $\begin{array}{l}\text { Relative } \\
\text { Abundance }\end{array}$ & $\begin{array}{l}\text { Relative } \\
\text { Abundance }\end{array}$ & $\begin{array}{l}\text { Relative } \\
\text { Abundance }\end{array}$ & $\begin{array}{l}\text { Abundance } \\
\text { Coleoptera }\end{array}$ & $\begin{array}{l}\text { Relative } \\
\text { Abundance }\end{array}$ & $\begin{array}{l}\text { Relative } \\
\text { Abundance }\end{array}$ \\
\hline & Shredder * & Chironomidae & Coleoptera & Coleoptera * & Dytiscidae & Dytiscidae * & and Corixidae & Corixidae & Corixidae * \\
\hline Minimum & 0 & 0 & 0 & 0 & 0 & 0 & 0 & 0 & 0 \\
\hline Maximum & 1 & 0.548 & 0.615 & 0.65 & 0.375 & 0.545 & 0.205 & 0.217 & 0.517 \\
\hline Mean & 0.281 & 0.116 & 0.154 & 0.207 & 0.085 & 0.108 & 0.039 & 0.047 & 0.117 \\
\hline Std. Error & 0.058 & 0.035 & 0.04 & 0.044 & 0.022 & 0.028 & 0.013 & 0.015 & 0.031 \\
\hline
\end{tabular}


Appendix BD. Continued.

\begin{tabular}{|c|c|c|c|c|c|c|}
\hline & $\begin{array}{c}\text { Relative } \\
\text { Abundance } \\
\text { Libellulidae }\end{array}$ & $\begin{array}{c}\text { Relative } \\
\text { Abundance } \\
\text { Libellulidae * }\end{array}$ & $\begin{array}{c}\text { Relative } \\
\text { Abundance } \\
\text { Libellulidae }\end{array}$ & $\begin{array}{c}\text { Relative } \\
\text { Abundance } \\
\text { Libellulidae * }\end{array}$ & $\begin{array}{l}\text { Relative } \\
\text { Abundance } \\
\text { Odonata }\end{array}$ & $\begin{array}{c}\text { Relative } \\
\text { Abundance } \\
\text { Odonata* }\end{array}$ \\
\hline Minimum & 0 & 0 & 0 & 0 & 0 & 0 \\
\hline Maximum & 0.625 & 0.483 & 0.583 & 0.172 & 0.208 & 0.283 \\
\hline Mean & 0.147 & 0.032 & 0.039 & 0.013 & 0.017 & 0.026 \\
\hline Std. Error & 0.038 & 0.023 & 0.028 & 0.008 & 0.01 & 0.014 \\
\hline
\end{tabular}




\section{Appendix BD. Continued.}

\begin{tabular}{|c|c|c|c|c|c|c|c|c|c|}
\hline \multicolumn{10}{|c|}{ Western Allegheny Plateau Benthic and Nektonic Sampling (N=39) } \\
\hline \multirow[b]{3}{*}{ Minimum } & \multirow{2}{*}{$\begin{array}{l}\text { \% Biomass } \\
\text { EPA Stressed }\end{array}$} & \multirow{2}{*}{$\begin{array}{l}\% \text { Biomass } \\
\text { Collectors }\end{array}$} & \multirow{2}{*}{$\begin{array}{l}\% \text { Biomass } \\
\text { Collectors * }\end{array}$} & \multirow{2}{*}{$\begin{array}{l}\% \text { Biomass } \\
\text { Predators }\end{array}$} & \multirow{2}{*}{$\begin{array}{l}\% \text { Biomass } \\
\text { Predators * }\end{array}$} & \multirow{2}{*}{$\begin{array}{l}\% \text { Biomass } \\
\text { Shredders }\end{array}$} & \multirow{2}{*}{$\begin{array}{l}\% \text { Biomass } \\
\text { Shredders * }\end{array}$} & \multirow{2}{*}{$\begin{array}{c}\text { \% Biomass } \\
\text { Chironomidae }\end{array}$} & \multirow{2}{*}{$\begin{array}{l}\% \text { Biomass } \\
\text { Coleoptera }\end{array}$} \\
\hline & & & & & & & & & \\
\hline & 0 & 0 & 0 & 0 & 0 & 0 & 0 & 0 & 0 \\
\hline Maximum & 0.845 & 0.969 & 0.97 & 0.981 & 1 & 0.634 & 0.634 & 0.265 & 0.969 \\
\hline Mean & 0.273 & 0.349 & 0.425 & 0.282 & 0.344 & 0.052 & 0.065 & 0.017 & 0.104 \\
\hline \multirow[t]{4}{*}{ Std. Error } & 0.046 & 0.047 & 0.052 & 0.048 & 0.055 & 0.019 & 0.022 & 0.007 & 0.032 \\
\hline & & & & & \% Biomass & & & $\%$ Biomass & \% Biomass \\
\hline & \% Biomass & $\%$ Biomass & $\%$ Biomass & \% Biomass & Coleoptera & \% Biomass & $\%$ Biomass & Odonata - & Odonata - \\
\hline & Coleoptera * & Dytiscidae & Corixidae & Corixidae * & and Corixidae & Libellulidae & Libellulidae * & Libellulidae & Libellulidae * \\
\hline Minimum & 0 & 0 & 0 & 0 & 0 & 0 & 0 & 0 & 0 \\
\hline Maximum & 0.993 & 0.757 & 0.776 & 0.781 & 0.966 & 0.969 & 0.993 & 0.667 & 0.673 \\
\hline Mean & 0.11 & 0.047 & 0.048 & 0.035 & 0.041 & 0.139 & 0.151 & 0.074 & 0.085 \\
\hline \multirow[t]{4}{*}{ Std. Error } & 0.033 & 0.022 & 0.023 & 0.02 & 0.025 & 0.038 & 0.041 & 0.025 & 0.028 \\
\hline & & & Relative & Relative & Relative & Relative & Relative & Relative & Relative \\
\hline & $\%$ Biomass & $\%$ Biomass & Abundance & Abundance & Abundance & Abundance & Abundance & Abundance & Abundance \\
\hline & Odonata & Odonata * & EPA Stressed & Collector & Collector * & Predator & Predator * & Shredder & Shredder * \\
\hline Minimum & 0 & 0 & 0 & 0 & 0 & 0 & 0 & 0 & 0 \\
\hline Maximum & 0.3 & 0.865 & 0.948 & 0.957 & 0.884 & 0.812 & 0.966 & 0.7 & 1 \\
\hline Mean & 0.057 & 0.082 & 0.132 & 0.166 & 0.239 & 0.262 & 0.345 & 0.223 & 0.315 \\
\hline \multirow[t]{5}{*}{ Std. Error } & 0.015 & 0.026 & 0.032 & 0.04 & 0.029 & 0.032 & 0.039 & 0.028 & 0.041 \\
\hline & & & & & & Relative & & & \\
\hline & Relative & Relative & Relative & Relative & Relative & Abundance & Relative & Relative & Relative \\
\hline & Abundance & Abundance & Abundance & Abundance & Abundance & Coleoptera & Abundance & Abundance & Abundance \\
\hline & Chironomidae & Coleoptera & Coleoptera * & Dytiscidae & Dytiscidae * & and Corixidae & Corixidae & Corixidae * & Libellulidae \\
\hline Minimum & 0 & 0 & 0 & 0 & 0 & 0 & 0 & 0 & 0 \\
\hline Maximum & 0.312 & 0.357 & 0.597 & 0.7 & 0.848 & 0.625 & 0.758 & 0.797 & 0.948 \\
\hline Mean & 0.045 & 0.057 & 0.124 & 0.096 & 0.117 & 0.051 & 0.061 & 0.139 & 0.168 \\
\hline Std. Error & 0.013 & 0.015 & 0.02 & 0.023 & 0.027 & 0.02 & 0.023 & 0.03 & 0.034 \\
\hline
\end{tabular}


Appendix BD. Continued.

\begin{tabular}{lccccc}
\hline & & & & \\
& Relative & Relative & Relative & Relative & Relative \\
& Abundance & Abundance & Abundance & Abundance & Abundance \\
Libellulidae * & Libellulidae & Libellulidae* & Odonata & Odonata * \\
Minimum & 0 & 0 & 0 & 0 & 0 \\
Maximum & 0.797 & 0.948 & 0.098 & 0.167 & 0.3 \\
Mean & 0.043 & 0.051 & 0.012 & 0.02 & 0.057 \\
Std. Error & 0.022 & 0.026 & 0.004 & 0.006 & 0.015 \\
\hline
\end{tabular}




\section{Appendix BD. Continued.}

\begin{tabular}{|c|c|c|c|c|c|c|c|c|c|}
\hline \multicolumn{10}{|c|}{ Benthic Sampling Statewide (N=140) } \\
\hline & $\begin{array}{l}\% \text { Biomass } \\
\text { Collector }\end{array}$ & $\begin{array}{l}\% \text { Biomass } \\
\text { Collector* }\end{array}$ & $\begin{array}{l}\text { \% Biomass } \\
\text { Predator }\end{array}$ & $\begin{array}{l}\% \text { Biomass } \\
\text { Predator * }\end{array}$ & $\begin{array}{l}\text { \% Biomass } \\
\text { Shredder }\end{array}$ & $\begin{array}{l}\% \text { Biomass } \\
\text { Shredder * }\end{array}$ & $\begin{array}{l}\text { Relative } \\
\text { Abundance } \\
\text { Collector }\end{array}$ & $\begin{array}{l}\text { Relative } \\
\text { Abundance } \\
\text { Collector* }\end{array}$ & $\begin{array}{l}\text { Relative } \\
\text { Abundance } \\
\text { Predator }\end{array}$ \\
\hline Minimum & 0 & 0 & 0 & 0 & 0 & 0 & 0 & 0 & 0 \\
\hline Maximum & 1.34 & 1.647 & 1 & 1 & 1 & 1 & 1 & 1 & 1 \\
\hline Mean & 0.35 & 0.506 & 0.067 & 0.129 & 0.066 & 0.087 & 0.258 & 0.42 & 0.105 \\
\hline \multirow[t]{2}{*}{ Std. Error } & 0.033 & 0.038 & 0.015 & 0.023 & 0.018 & 0.02 & 0.024 & 0.033 & 0.014 \\
\hline & $\begin{array}{l}\text { Relative } \\
\text { Abundance } \\
\text { Predator* }\end{array}$ & $\begin{array}{l}\text { Relative } \\
\text { Abundance } \\
\text { Shredder }\end{array}$ & $\begin{array}{l}\text { Relative } \\
\text { Abundance } \\
\text { Shredder* }\end{array}$ & $\begin{array}{c}\% \text { Biomass } \\
\text { EPA Stressed }\end{array}$ & $\begin{array}{c}\text { Relative } \\
\text { Abundance } \\
\text { EPA Stressed }\end{array}$ & $\begin{array}{c}\text { \% Biomass } \\
\text { Chironomidae }\end{array}$ & $\begin{array}{c}\text { Relative } \\
\text { Abundance of } \\
\text { Chironomidae }\end{array}$ & $\begin{array}{l}\text { \% Biomass } \\
\text { Coleoptera }\end{array}$ & $\begin{array}{c}\text { \% Biomass } \\
\text { Coleoptera * }\end{array}$ \\
\hline Minimum & 0 & 0 & 0 & 0 & 0 & 0 & 0 & 0 & 0 \\
\hline Maximum & 1 & 1 & 1 & 1 & 1 & 1 & 0.833 & 0.84 & 1 \\
\hline Mean & 0.19 & 0.039 & 0.065 & 0.134 & 0.13 & 0.053 & 0.087 & 0.057 & 0.103 \\
\hline \multirow[t]{2}{*}{ Std. Error } & 0.023 & 0.01 & 0.014 & 0.021 & 0.016 & 0.015 & 0.014 & 0.013 & 0.02 \\
\hline & $\begin{array}{l}\text { Relative } \\
\text { Abundance } \\
\text { Coleoptera }\end{array}$ & $\begin{array}{c}\text { Relative } \\
\text { Abundance } \\
\text { Coleoptera * }\end{array}$ & $\begin{array}{c}\text { Family } \\
\text { Richness }\end{array}$ & & & & & & \\
\hline Minimum & 0 & 0 & 1 & & & & & & \\
\hline Maximum & 0.5 & 1 & 14 & & & & & & \\
\hline Mean & 0.04 & 0.078 & 4.307 & & & & & & \\
\hline Std. Error & 0.008 & 0.014 & 0.227 & & & & & & \\
\hline
\end{tabular}




\section{Appendix BD. Continued.}

\begin{tabular}{|c|c|c|c|c|c|c|c|c|c|}
\hline \multicolumn{10}{|c|}{ Allegheny Highlands Benthic Sampling $(\mathrm{N}=62)$} \\
\hline & $\begin{array}{l}\% \text { Biomass } \\
\text { Collector }\end{array}$ & $\begin{array}{l}\% \text { Biomass } \\
\text { Collector * }\end{array}$ & $\begin{array}{c}\text { \% Biomass } \\
\text { Predator }\end{array}$ & $\begin{array}{l}\% \text { Biomass } \\
\text { Predator * }\end{array}$ & $\begin{array}{l}\text { \% Biomass } \\
\text { Shredder }\end{array}$ & $\begin{array}{l}\% \text { Biomass } \\
\text { Shredder * }\end{array}$ & $\begin{array}{l}\text { Relative } \\
\text { Abundance } \\
\text { Collector }\end{array}$ & $\begin{array}{l}\text { Relative } \\
\text { Abundance } \\
\text { Collector* }\end{array}$ & $\begin{array}{l}\text { Relative } \\
\text { Abundance } \\
\text { Predator }\end{array}$ \\
\hline Minimum & 0 & 0 & 0 & 0 & 0 & 0 & 0 & 0 & 0 \\
\hline Maximum & 1 & 1 & 1 & 1 & 1 & 1 & 1 & 1 & 1 \\
\hline Mean & 0.253 & 0.402 & 0.07 & 0.162 & 0.101 & 0.142 & 0.165 & 0.313 & 0.117 \\
\hline \multirow{2}{*}{ Std. Error } & 0.041 & 0.051 & 0.023 & 0.039 & 0.033 & 0.038 & 0.025 & 0.043 & 0.022 \\
\hline & $\begin{array}{l}\text { Relative } \\
\text { Abundance } \\
\text { Predator* }\end{array}$ & $\begin{array}{l}\text { Relative } \\
\text { Abundance } \\
\text { Shredder }\end{array}$ & $\begin{array}{c}\text { Relative } \\
\text { Abundance } \\
\text { Shredder* }\end{array}$ & $\begin{array}{l}\% \text { Biomass } \\
\text { EPA Stressed }\end{array}$ & $\begin{array}{c}\text { Relative } \\
\text { Abundance } \\
\text { EPA Stressed }\end{array}$ & $\begin{array}{l}\% \text { Biomass } \\
\text { Chironomidae }\end{array}$ & $\begin{array}{c}\text { Relative } \\
\text { Abundance of } \\
\text { Chironomidae }\end{array}$ & $\begin{array}{l}\% \text { Biomass } \\
\text { Coleoptera }\end{array}$ & $\begin{array}{l}\% \text { Biomass } \\
\text { Coleoptera * }\end{array}$ \\
\hline Minimum & 0 & 0 & 0 & 0 & 0 & 0 & 0 & 0 & 0 \\
\hline Maximum & 1 & 1 & 1 & 1 & 0.692 & 1 & 0.692 & 0.84 & 1 \\
\hline Mean & 0.235 & 0.068 & 0.123 & 0.077 & 0.116 & 0.041 & 0.098 & 0.062 & 0.132 \\
\hline \multirow[t]{2}{*}{ Std. Error } & 0.039 & 0.02 & 0.03 & 0.022 & 0.019 & 0.019 & 0.019 & 0.021 & 0.035 \\
\hline & $\begin{array}{l}\text { Relative } \\
\text { Abundance } \\
\text { Coleoptera }\end{array}$ & $\begin{array}{c}\text { Relative } \\
\text { Abundance } \\
\text { Coleoptera* }\end{array}$ & $\begin{array}{l}\text { Family } \\
\text { Richness }\end{array}$ & & & & & & \\
\hline Minimum & 0 & 0 & 1 & & & & & & \\
\hline Maximum & 0.5 & 1 & 14 & & & & & & \\
\hline Mean & 0.046 & 0.114 & 4.597 & & & & & & \\
\hline Std. Error & 0.011 & 0.026 & 0.377 & & & & & & \\
\hline
\end{tabular}




\section{Appendix BD. Continued.}

\begin{tabular}{|c|c|c|c|c|c|c|c|c|c|}
\hline \multicolumn{10}{|c|}{ Ridge and Valley Benthic Sampling (N=25) } \\
\hline & $\begin{array}{l}\% \text { Biomass } \\
\text { Collector }\end{array}$ & $\begin{array}{l}\% \text { Biomass } \\
\text { Collector* }\end{array}$ & $\begin{array}{l}\text { \% Biomass } \\
\text { Predator }\end{array}$ & $\begin{array}{l}\% \text { Biomass } \\
\text { Predator * }\end{array}$ & $\begin{array}{l}\text { \% Biomass } \\
\text { Shredder }\end{array}$ & $\begin{array}{l}\% \text { Biomass } \\
\text { Shredder * }\end{array}$ & $\begin{array}{l}\text { Relative } \\
\text { Abundance } \\
\text { Collector }\end{array}$ & $\begin{array}{l}\text { Relative } \\
\text { Abundance } \\
\text { Collector* }\end{array}$ & $\begin{array}{l}\text { Relative } \\
\text { Abundance } \\
\text { Predator }\end{array}$ \\
\hline Minimum & 0 & 0 & 0 & 0 & 0 & 0 & 0 & 0 & 0 \\
\hline Maximum & 1.008 & 1.02 & 0.134 & 1 & 0.984 & 0.984 & 1 & 1.25 & 0.75 \\
\hline Mean & 0.401 & 0.484 & 0.024 & 0.084 & 0.05 & 0.052 & 0.349 & 0.496 & 0.122 \\
\hline \multirow[t]{2}{*}{ Std. Error } & 0.083 & 0.092 & 0.008 & 0.043 & 0.039 & 0.039 & 0.069 & 0.09 & 0.04 \\
\hline & $\begin{array}{l}\text { Relative } \\
\text { Abundance } \\
\text { Predator* }\end{array}$ & $\begin{array}{l}\text { Relative } \\
\text { Abundance } \\
\text { Shredder }\end{array}$ & $\begin{array}{l}\text { Relative } \\
\text { Abundance } \\
\text { Shredder* }\end{array}$ & $\begin{array}{c}\% \text { Biomass } \\
\text { EPA Stressed }\end{array}$ & $\begin{array}{c}\text { Relative } \\
\text { Abundance } \\
\text { EPA Stressed }\end{array}$ & $\begin{array}{c}\text { \% Biomass } \\
\text { Chironomidae }\end{array}$ & $\begin{array}{c}\text { Relative } \\
\text { Abundance of } \\
\text { Chironomidae }\end{array}$ & $\begin{array}{l}\% \text { Biomass } \\
\text { Coleoptera }\end{array}$ & $\begin{array}{c}\text { \% Biomass } \\
\text { Coleoptera * }\end{array}$ \\
\hline Minimum & 0 & 0 & 0 & 0 & 0 & 0 & 0 & 0 & 0 \\
\hline Maximum & 1 & 0.364 & 0.364 & 1 & 0.633 & 1 & 0.633 & 0.778 & 0.952 \\
\hline Mean & 0.196 & 0.021 & 0.026 & 0.245 & 0.17 & 0.111 & 0.107 & 0.087 & 0.103 \\
\hline \multirow[t]{2}{*}{ Std. Error } & 0.059 & 0.015 & 0.016 & 0.071 & 0.042 & 0.056 & 0.04 & 0.043 & 0.051 \\
\hline & $\begin{array}{l}\text { Relative } \\
\text { Abundance } \\
\text { Coleoptera }\end{array}$ & $\begin{array}{c}\text { Relative } \\
\text { Abundance } \\
\text { Coleoptera * }\end{array}$ & $\begin{array}{c}\text { Family } \\
\text { Richness }\end{array}$ & & & & & & \\
\hline Minimum & 0 & 0 & 1 & & & & & & \\
\hline Maximum & 0.5 & 0.667 & 9 & & & & & & \\
\hline Mean & 0.036 & 0.051 & 4.04 & & & & & & \\
\hline Std. Error & 0.021 & 0.028 & 0.54 & & & & & & \\
\hline
\end{tabular}




\section{Appendix BD. Continued.}

\begin{tabular}{|c|c|c|c|c|c|c|c|c|c|}
\hline \multicolumn{10}{|c|}{ Western Allegheny Plateau Benthic Sampling (N=53) } \\
\hline & $\begin{array}{l}\% \text { Biomass } \\
\text { Collector }\end{array}$ & $\begin{array}{l}\% \text { Biomass } \\
\text { Collector * }\end{array}$ & $\begin{array}{l}\text { \% Biomass } \\
\text { Predator }\end{array}$ & $\begin{array}{l}\% \text { Biomass } \\
\text { Predator * }\end{array}$ & $\begin{array}{l}\text { \% Biomass } \\
\text { Shredder }\end{array}$ & $\begin{array}{l}\% \text { Biomass } \\
\text { Shredder * }\end{array}$ & $\begin{array}{l}\text { Relative } \\
\text { Abundance } \\
\text { Collector }\end{array}$ & $\begin{array}{l}\text { Relative } \\
\text { Abundance } \\
\text { Collector* }\end{array}$ & $\begin{array}{l}\text { Relative } \\
\text { Abundance } \\
\text { Predator }\end{array}$ \\
\hline Minimum & 0 & 0 & 0 & 0 & 0 & 0 & 0 & 0 & 0 \\
\hline Maximum & 1.34 & 1.647 & 0.983 & 1 & 0.821 & 0.842 & 1 & 1 & 0.6 \\
\hline Mean & 0.439 & 0.638 & 0.083 & 0.112 & 0.034 & 0.04 & 0.324 & 0.509 & 0.082 \\
\hline \multirow[t]{2}{*}{ Std. Error } & 0.058 & 0.063 & 0.029 & 0.035 & 0.018 & 0.019 & 0.042 & 0.054 & 0.019 \\
\hline & $\begin{array}{l}\text { Relative } \\
\text { Abundance } \\
\text { Predator* }\end{array}$ & $\begin{array}{l}\text { Relative } \\
\text { Abundance } \\
\text { Shredder }\end{array}$ & $\begin{array}{l}\text { Relative } \\
\text { Abundance } \\
\text { Shredder* }\end{array}$ & $\begin{array}{c}\% \text { Biomass } \\
\text { EPA Stressed }\end{array}$ & $\begin{array}{c}\text { Relative } \\
\text { Abundance } \\
\text { EPA Stressed }\end{array}$ & $\begin{array}{c}\% \text { Biomass } \\
\text { Chironomidae }\end{array}$ & $\begin{array}{c}\text { Relative } \\
\text { Abundance of } \\
\text { Chironomidae }\end{array}$ & $\begin{array}{l}\% \text { Biomass } \\
\text { Coleoptera }\end{array}$ & $\begin{array}{c}\% \text { Biomass } \\
\text { Coleoptera * }\end{array}$ \\
\hline Minimum & 0 & 0 & 0 & 0 & 0 & 0 & 0 & 0 & 0 \\
\hline Maximum & 1 & 0.2 & 0.2 & 1 & 1 & 0.8 & 0.833 & 0.75 & 0.9 \\
\hline Mean & 0.135 & 0.012 & 0.016 & 0.149 & 0.129 & 0.04 & 0.066 & 0.038 & 0.069 \\
\hline \multirow[t]{2}{*}{ Std. Error } & 0.031 & 0.005 & 0.007 & 0.036 & 0.029 & 0.019 & 0.021 & 0.017 & 0.026 \\
\hline & $\begin{array}{l}\text { Relative } \\
\text { Abundance } \\
\text { Coleoptera }\end{array}$ & $\begin{array}{c}\text { Relative } \\
\text { Abundance } \\
\text { Coleoptera * }\end{array}$ & $\begin{array}{c}\text { Family } \\
\text { Richness }\end{array}$ & & & & & & \\
\hline Minimum & 0 & 0 & 1 & & & & & & \\
\hline Maximum & 0.5 & 0.5 & 11 & & & & & & \\
\hline Mean & 0.036 & 0.05 & 4.094 & & & & & & \\
\hline Std. Error & 0.013 & 0.016 & 0.32 & & & & & & \\
\hline
\end{tabular}




\section{Appendix BD. Continued.}

\begin{tabular}{|c|c|c|c|c|c|c|c|c|c|}
\hline \multicolumn{10}{|c|}{ Nektonic Sampling Statewide $(\mathrm{N}=111)$} \\
\hline & $\begin{array}{l}\% \text { Biomass } \\
\text { EPA stressed }\end{array}$ & $\begin{array}{c}\text { Relative } \\
\text { Abundance } \\
\text { EPA Stressed }\end{array}$ & $\begin{array}{l}\% \text { Biomass of } \\
\text { Chironomidae }\end{array}$ & $\begin{array}{c}\text { Relative } \\
\text { Abundance of } \\
\text { Chironomidae }\end{array}$ & $\begin{array}{c}\% \text { Biomass of } \\
\text { Corixidae }\end{array}$ & $\begin{array}{c}\% \text { Biomass of } \\
\text { Corixidae * }\end{array}$ & $\begin{array}{l}\text { Relative } \\
\text { abundance of } \\
\text { Corixidae }\end{array}$ & $\begin{array}{l}\text { Relative } \\
\text { abundance of } \\
\text { Corixidae * }\end{array}$ & $\begin{array}{l}\text { Percent } \\
\text { Biomass of } \\
\text { Coleoptera }\end{array}$ \\
\hline Minimum & 0 & 0 & 0 & 0 & 0 & 0 & 0 & 0 & 0 \\
\hline Maximum & 1 & 1 & 0.966 & 0.929 & 1 & 1 & 1 & 1 & 0.976 \\
\hline Mean & 0.289 & 0.319 & 0.056 & 0.204 & 0.045 & 0.048 & 0.053 & 0.069 & 0.092 \\
\hline \multirow[t]{2}{*}{ Std. Error } & 0.029 & 0.025 & 0.014 & 0.021 & 0.014 & 0.014 & 0.014 & 0.017 & 0.016 \\
\hline & $\begin{array}{c}\text { Percent } \\
\text { Biomass of } \\
\text { Coleoptera * }\end{array}$ & $\begin{array}{l}\text { Relative } \\
\text { Abundance of } \\
\text { Coleoptera }\end{array}$ & $\begin{array}{c}\text { Relative } \\
\text { Abundance of } \\
\text { Coleoptera * }\end{array}$ & $\begin{array}{l}\% \text { Biomass of } \\
\text { Coleoptera } \\
\text { and Corixidae }\end{array}$ & $\begin{array}{c}\text { Relative } \\
\text { Abundance of } \\
\text { Coleoptera } \\
\text { and Corixidae }\end{array}$ & $\begin{array}{c}\text { Relative } \\
\text { Abundance of } \\
\text { Coleoptera } \\
\text { and Corixidae } \\
*\end{array}$ & $\begin{array}{l}\% \text { Biomass of } \\
\text { Dytiscidae }\end{array}$ & $\begin{array}{c}\% \text { Biomass of } \\
\text { Dytiscidae * }\end{array}$ & $\begin{array}{l}\text { Relative } \\
\text { Abundance of } \\
\text { Dytiscidae }\end{array}$ \\
\hline Minimum & 0 & 0 & 0 & 0 & 0 & 0 & 0 & 0 & 0 \\
\hline Maximum & 1 & 0.8 & 1 & 1 & 1 & 1 & 1 & 0.829 & 0.922 \\
\hline Mean & 0.1 & 0.095 & 0.128 & 0.137 & 0.147 & 0.148 & 0.197 & 0.04 & 0.042 \\
\hline \multirow[t]{2}{*}{ Std. Error } & 0.018 & 0.014 & 0.018 & 0.021 & 0.022 & 0.019 & 0.023 & 0.012 & 0.012 \\
\hline & $\begin{array}{c}\text { Relative } \\
\text { Abundance of } \\
\text { Dytiscidae * }\end{array}$ & $\begin{array}{l}\% \text { Biomass of } \\
\text { Collectors }\end{array}$ & $\begin{array}{l}\% \text { Biomass of } \\
\text { Collectors * }\end{array}$ & $\begin{array}{l}\% \text { Biomass of } \\
\text { Predators }\end{array}$ & $\begin{array}{c}\% \text { Biomass of } \\
\text { Predators * }\end{array}$ & $\begin{array}{l}\% \text { Biomass of } \\
\text { Shredders }\end{array}$ & $\begin{array}{c}\% \text { Biomass of } \\
\text { Shredders * }\end{array}$ & $\begin{array}{c}\text { Relative } \\
\text { Abundance of } \\
\text { Collectors }\end{array}$ & $\begin{array}{c}\text { Relative } \\
\text { Abundance of } \\
\text { Collectors * }\end{array}$ \\
\hline Minimum & 0 & 0 & 0 & 0 & 0 & 0 & 0 & 0 & 0 \\
\hline Maximum & 0.714 & 0.893 & 1 & 1.087 & 1 & 1 & 0.683 & 1 & 1 \\
\hline Mean & 0.048 & 0.062 & 0.472 & 0.5 & 0.305 & 0.348 & 0.056 & 0.066 & 0.366 \\
\hline \multirow[t]{2}{*}{ Std. Error } & 0.01 & 0.013 & 0.034 & 0.035 & 0.031 & 0.034 & 0.011 & 0.014 & 0.027 \\
\hline & $\begin{array}{l}\text { Relative } \\
\text { Abundance of } \\
\text { Predators }\end{array}$ & $\begin{array}{c}\text { Relative } \\
\text { Abundance of } \\
\text { Predators * }\end{array}$ & $\begin{array}{l}\text { Relative } \\
\text { Abundance of } \\
\text { Shredders }\end{array}$ & $\begin{array}{c}\text { Relative } \\
\text { Abundance of } \\
\text { Shredders * }\end{array}$ & $\begin{array}{l}\text { Family } \\
\text { Richness }\end{array}$ & $\begin{array}{l}\text { Relative } \\
\text { Abundance of } \\
\text { Lestidae }\end{array}$ & $\begin{array}{c}\text { Relative } \\
\text { Abundance of } \\
\text { Lestidae * }\end{array}$ & $\begin{array}{l}\% \text { Biomass of } \\
\text { Libellulidae }\end{array}$ & \\
\hline Minimum & 0 & 0 & 0 & 0 & 0 & 0 & 0 & 0 & \\
\hline Maximum & 1.4 & 1 & 1 & 0.733 & 23 & 0.238 & 0.625 & 0.059 & \\
\hline Mean & 0.472 & 0.233 & 0.327 & 0.092 & 8.207 & 0.004 & 0.008 & 0.003 & \\
\hline Std. Error & 0.031 & 0.022 & 0.028 & 0.016 & 0.478 & 0.002 & 0.006 & 0.001 & \\
\hline
\end{tabular}


Appendix BD. Continued.

\begin{tabular}{|c|c|c|c|c|c|c|c|c|c|}
\hline & $\begin{array}{l}\% \text { Biomass of } \\
\text { Libellulidae * }\end{array}$ & $\begin{array}{c}\text { Relative } \\
\text { Abundance of } \\
\text { Libellulidae }\end{array}$ & $\begin{array}{c}\text { Relative } \\
\text { Abundance of } \\
\text { Libellulidae * }\end{array}$ & $\begin{array}{l}\text { \% Biomass } \\
\text { Odonata }\end{array}$ & $\begin{array}{l}\% \text { Biomass } \\
\text { Odonata * }\end{array}$ & $\begin{array}{c}\text { Relative } \\
\text { Abundance of } \\
\text { Odonata }\end{array}$ & $\begin{array}{c}\text { Relative } \\
\text { Abundance of } \\
\text { Odonata * }\end{array}$ & $\begin{array}{c}\% \text { Biomass of } \\
\text { Odonata - } \\
\text { Libellulidae }\end{array}$ & $\begin{array}{c}\% \text { Biomass of } \\
\text { Odonata - } \\
\text { Libellulidae * }\end{array}$ \\
\hline Minimum & 0 & 0 & 0 & 0 & 0 & 0 & 0 & 0 & 0 \\
\hline Maximum & 0.2 & 0.755 & 0.769 & 0.231 & 0.286 & 0.978 & 1 & 0.522 & 1 \\
\hline Mean & 0.004 & 0.078 & 0.085 & 0.022 & 0.03 & 0.136 & 0.15 & 0.065 & 0.092 \\
\hline \multirow[t]{2}{*}{ Std. Error } & 0.002 & 0.017 & 0.018 & 0.005 & 0.006 & 0.022 & 0.024 & 0.011 & 0.016 \\
\hline & $\begin{array}{c}\text { Relative } \\
\text { Abundance of } \\
\text { Odonata - } \\
\text { Libellulidae }\end{array}$ & $\begin{array}{c}\text { Relative } \\
\text { Abundance of } \\
\text { Odonata - } \\
\text { Libellulidae * }\end{array}$ & & & & & & & \\
\hline Minimum & 0 & 0 & & & & & & & \\
\hline Maximum & 0.978 & 1 & & & & & & & \\
\hline Mean & 0.058 & 0.065 & & & & & & & \\
\hline Std. Error & 0.013 & 0.014 & & & & & & & \\
\hline
\end{tabular}




\section{Appendix BD. Continued.}

\begin{tabular}{|c|c|c|c|c|c|c|c|c|c|}
\hline \multicolumn{10}{|c|}{ Allegheny Highlands Nektonic Sampling(N=46) } \\
\hline & $\begin{array}{l}\% \text { Biomass } \\
\text { EPA stressed }\end{array}$ & $\begin{array}{c}\text { Relative } \\
\text { Abundance } \\
\text { EPA Stressed }\end{array}$ & $\begin{array}{l}\% \text { Biomass of } \\
\text { Chironomidae }\end{array}$ & $\begin{array}{c}\text { Relative } \\
\text { Abundance of } \\
\text { Chironomidae }\end{array}$ & $\begin{array}{l}\% \text { Biomass of } \\
\text { Corixidae }\end{array}$ & $\begin{array}{l}\% \text { Biomass of } \\
\text { Corixidae * }\end{array}$ & $\begin{array}{l}\text { Relative } \\
\text { abundance of } \\
\text { Corixidae }\end{array}$ & $\begin{array}{c}\text { Relative } \\
\text { abundance of } \\
\text { Corixidae * }\end{array}$ & $\begin{array}{c}\text { Percent } \\
\text { Biomass of } \\
\text { Coleoptera }\end{array}$ \\
\hline Minimum & 0 & 0 & 0 & 0 & 0 & 0 & 0 & 0 & 0 \\
\hline Maximum & 0.966 & 0.929 & 0.966 & 0.929 & 0.32 & 0.325 & 0.367 & 0.571 & 0.9 \\
\hline Mean & 0.312 & 0.398 & 0.093 & 0.282 & 0.038 & 0.042 & 0.049 & 0.079 & 0.086 \\
\hline \multirow[t]{2}{*}{ Std. Error } & 0.043 & 0.038 & 0.03 & 0.037 & 0.012 & 0.013 & 0.014 & 0.022 & 0.024 \\
\hline & $\begin{array}{c}\text { Percent } \\
\text { Biomass of } \\
\text { Coleoptera * }\end{array}$ & $\begin{array}{c}\text { Relative } \\
\text { Abundance of } \\
\text { Coleoptera }\end{array}$ & $\begin{array}{c}\text { Relative } \\
\text { Abundance of } \\
\text { Coleoptera * }\end{array}$ & $\begin{array}{l}\% \text { Biomass of } \\
\text { Coleoptera } \\
\text { and Corixidae }\end{array}$ & $\begin{array}{c}\text { Relative } \\
\text { Abundance of } \\
\text { Coleoptera } \\
\text { and Corixidae }\end{array}$ & $\begin{array}{c}\text { Relative } \\
\text { Abundance of } \\
\text { Coleoptera } \\
\text { and Corixidae } \\
*\end{array}$ & $\begin{array}{l}\% \text { Biomass of } \\
\text { Dytiscidae }\end{array}$ & $\begin{array}{l}\% \text { Biomass of } \\
\text { Dytiscidae * }\end{array}$ & $\begin{array}{c}\text { Relative } \\
\text { Abundance of } \\
\text { Dytiscidae }\end{array}$ \\
\hline Minimum & 0 & 0 & 0 & 0 & 0 & 0 & 0 & 0 & 0 \\
\hline Maximum & 1 & 0.4 & 1 & 0.9 & 1 & 0.4 & 1 & 0.829 & 0.922 \\
\hline Mean & 0.098 & 0.086 & 0.138 & 0.124 & 0.14 & 0.135 & 0.217 & 0.041 & 0.044 \\
\hline \multirow[t]{2}{*}{ Std. Error } & 0.028 & 0.015 & 0.029 & 0.026 & 0.03 & 0.018 & 0.032 & 0.019 & 0.021 \\
\hline & $\begin{array}{c}\text { Relative } \\
\text { Abundance of } \\
\text { Dytiscidae * }\end{array}$ & $\begin{array}{l}\% \text { Biomass of } \\
\text { Collectors }\end{array}$ & $\begin{array}{l}\% \text { Biomass of } \\
\text { Collectors * }\end{array}$ & $\begin{array}{l}\% \text { Biomass of } \\
\text { Predators }\end{array}$ & $\begin{array}{l}\% \text { Biomass of } \\
\text { Predators * }\end{array}$ & $\begin{array}{l}\% \text { Biomass of } \\
\text { Shredders }\end{array}$ & $\begin{array}{l}\text { \% Biomass of } \\
\text { Shredders * }\end{array}$ & $\begin{array}{c}\text { Relative } \\
\text { Abundance of } \\
\text { Collectors }\end{array}$ & $\begin{array}{c}\text { Relative } \\
\text { Abundance of } \\
\text { Collectors * }\end{array}$ \\
\hline Minimum & 0 & 0 & 0 & 0 & 0 & 0 & 0 & 0 & 0 \\
\hline Maximum & 0.208 & 0.5 & 1 & 1.087 & 0.966 & 1 & 0.346 & 0.388 & 1 \\
\hline Mean & 0.038 & 0.056 & 0.467 & 0.513 & 0.288 & 0.358 & 0.053 & 0.057 & 0.349 \\
\hline \multirow[t]{2}{*}{ Std. Error } & 0.01 & 0.015 & 0.054 & 0.055 & 0.047 & 0.055 & 0.013 & 0.015 & 0.04 \\
\hline & $\begin{array}{c}\text { Relative } \\
\text { Abundance of } \\
\text { Predators }\end{array}$ & $\begin{array}{l}\text { Relative } \\
\text { Abundance of } \\
\text { Predators * }\end{array}$ & $\begin{array}{c}\text { Relative } \\
\text { Abundance of } \\
\text { Shredders }\end{array}$ & $\begin{array}{c}\text { Relative } \\
\text { Abundance of } \\
\text { Shredders * }\end{array}$ & $\begin{array}{l}\text { Family } \\
\text { Richness }\end{array}$ & $\begin{array}{c}\text { Relative } \\
\text { Abundance of } \\
\text { Lestidae }\end{array}$ & $\begin{array}{c}\text { Relative } \\
\text { Abundance of } \\
\text { Lestidae * }\end{array}$ & $\begin{array}{l}\% \text { Biomass of } \\
\text { Libellulidae }\end{array}$ & \\
\hline Minimum & 0 & 0 & 0 & 0 & 0 & 0 & 0 & 0 & \\
\hline Maximum & 1.4 & 0.8 & 1 & 0.733 & 21 & 0.049 & 0.05 & 0.05 & \\
\hline Mean & 0.495 & 0.181 & 0.298 & 0.111 & 7.348 & 0.002 & 0.002 & 0.002 & \\
\hline Std. Error & 0.048 & 0.027 & 0.041 & 0.029 & 0.62 & 0.001 & 0.001 & 0.001 & \\
\hline
\end{tabular}


Appendix BD. Continued.

\begin{tabular}{|c|c|c|c|c|c|c|c|c|c|}
\hline & $\begin{array}{l}\% \text { Biomass of } \\
\text { Libellulidae * }\end{array}$ & $\begin{array}{c}\text { Relative } \\
\text { Abundance of } \\
\text { Libellulidae }\end{array}$ & $\begin{array}{c}\text { Relative } \\
\text { Abundance of } \\
\text { Libellulidae * }\end{array}$ & $\begin{array}{l}\text { \% Biomass } \\
\text { Odonata }\end{array}$ & $\begin{array}{l}\% \text { Biomass } \\
\text { Odonata * }\end{array}$ & $\begin{array}{c}\text { Relative } \\
\text { Abundance of } \\
\text { Odonata }\end{array}$ & $\begin{array}{c}\text { Relative } \\
\text { Abundance of } \\
\text { Odonata * }\end{array}$ & $\begin{array}{l}\% \text { Biomass of } \\
\text { Odonata - } \\
\text { Libellulidae }\end{array}$ & $\begin{array}{c}\% \text { Biomass of } \\
\text { Odonata - } \\
\text { Libellulidae * }\end{array}$ \\
\hline Minimum & 0 & 0 & 0 & 0 & 0 & 0 & 0 & 0 & 0 \\
\hline Maximum & 0.062 & 0.755 & 0.769 & 0.231 & 0.286 & 0.909 & 0.926 & 0.5 & 0.6 \\
\hline Mean & 0.003 & 0.103 & 0.118 & 0.033 & 0.045 & 0.148 & 0.166 & 0.059 & 0.084 \\
\hline \multirow[t]{2}{*}{ Std. Error } & 0.002 & 0.029 & 0.033 & 0.009 & 0.012 & 0.035 & 0.038 & 0.015 & 0.02 \\
\hline & $\begin{array}{c}\text { Relative } \\
\text { Abundance of } \\
\text { Odonata - } \\
\text { Libellulidae }\end{array}$ & $\begin{array}{c}\text { Relative } \\
\text { Abundance of } \\
\text { Odonata - } \\
\text { Libellulidae * }\end{array}$ & & & & & & & \\
\hline Minimum & 0 & 0 & & & & & & & \\
\hline Maximum & 0.5 & 0.529 & & & & & & & \\
\hline Mean & 0.045 & 0.048 & & & & & & & \\
\hline Std. Error & 0.015 & 0.016 & & & & & & & \\
\hline
\end{tabular}




\section{Appendix BD. Continued.}

\begin{tabular}{|c|c|c|c|c|c|c|c|c|c|}
\hline \multicolumn{10}{|c|}{ Ridge and Valley Nektonic Sampling $(\mathrm{N}=22)$} \\
\hline & $\begin{array}{c}\% \text { Biomass } \\
\text { EPA stresseda }\end{array}$ & $\begin{array}{c}\text { Relative } \\
\text { Abundance } \\
\text { EPA Stressed }\end{array}$ & $\begin{array}{l}\% \text { Biomass of } \\
\text { Chironomidae }\end{array}$ & $\begin{array}{c}\text { Relative } \\
\text { Abundance of } \\
\text { Chironomidae }\end{array}$ & $\begin{array}{l}\% \text { Biomass of } \\
\text { Corixidae }\end{array}$ & $\begin{array}{c}\% \text { Biomass of } \\
\text { Corixidae * }\end{array}$ & $\begin{array}{c}\text { Relative } \\
\text { abundance of } \\
\text { Corixidae }\end{array}$ & $\begin{array}{c}\text { Relative } \\
\text { abundance of } \\
\text { Corixidae * }\end{array}$ & $\begin{array}{l}\text { Percent } \\
\text { Biomass of } \\
\text { Coleoptera }\end{array}$ \\
\hline Minimum & 0 & 0 & 0 & 0 & 0 & 0 & 0 & 0 & 0 \\
\hline Maximum & 0.994 & 0.852 & 0.597 & 0.75 & 0.101 & 0.107 & 0.519 & 0.609 & 0.633 \\
\hline Mean & 0.233 & 0.267 & 0.053 & 0.177 & 0.013 & 0.014 & 0.034 & 0.04 & 0.098 \\
\hline \multirow[t]{2}{*}{ Std. Error } & 0.064 & 0.06 & 0.029 & 0.049 & 0.006 & 0.006 & 0.023 & 0.028 & 0.034 \\
\hline & $\begin{array}{c}\text { Percent } \\
\text { Biomass of } \\
\text { Coleoptera * }\end{array}$ & $\begin{array}{c}\text { Relative } \\
\text { Abundance of } \\
\text { Coleoptera }\end{array}$ & $\begin{array}{c}\text { Relative } \\
\text { Abundance of } \\
\text { Coleoptera * }\end{array}$ & $\begin{array}{l}\% \text { Biomass of } \\
\text { Coleoptera } \\
\text { and Corixidae }\end{array}$ & $\begin{array}{c}\text { Relative } \\
\text { Abundance of } \\
\text { Coleoptera } \\
\text { and Corixidae }\end{array}$ & $\begin{array}{c}\text { Relative } \\
\text { Abundance of } \\
\text { Coleoptera } \\
\text { and Corixidae } \\
*\end{array}$ & $\begin{array}{l}\% \text { Biomass of } \\
\text { Dytiscidae }\end{array}$ & $\begin{array}{l}\% \text { Biomass of } \\
\text { Dytiscidae * }\end{array}$ & $\begin{array}{l}\text { Relative } \\
\text { Abundance of } \\
\text { Dytiscidae }\end{array}$ \\
\hline Minimum & 0 & 0 & 0 & 0 & 0 & 0 & 0 & 0 & 0 \\
\hline Maximum & 0.74 & 0.429 & 0.545 & 0.633 & 0.74 & 0.556 & 0.652 & 0.238 & 0.252 \\
\hline Mean & 0.106 & 0.088 & 0.108 & 0.111 & 0.12 & 0.122 & 0.148 & 0.024 & 0.028 \\
\hline \multirow[t]{2}{*}{ Std. Error } & 0.037 & 0.024 & 0.029 & 0.035 & 0.038 & 0.034 & 0.039 & 0.012 & 0.013 \\
\hline & $\begin{array}{c}\text { Relative } \\
\text { Abundance of } \\
\text { Dytiscidae * }\end{array}$ & $\begin{array}{l}\% \text { Biomass of } \\
\text { Collectors }\end{array}$ & $\begin{array}{l}\% \text { Biomass of } \\
\text { Collectors * }\end{array}$ & $\begin{array}{l}\% \text { Biomass of } \\
\text { Predators }\end{array}$ & $\begin{array}{l}\% \text { Biomass of } \\
\text { Predators * }\end{array}$ & $\begin{array}{l}\text { \% Biomass of } \\
\text { Shredders }\end{array}$ & $\begin{array}{l}\% \text { Biomass of } \\
\text { Shredders * }\end{array}$ & $\begin{array}{c}\text { Relative } \\
\text { Abundance of } \\
\text { Collectors }\end{array}$ & $\begin{array}{c}\text { Relative } \\
\text { Abundance of } \\
\text { Collectors * }\end{array}$ \\
\hline Minimum & 0 & 0 & 0 & 0 & 0 & 0 & 0 & 0 & 0 \\
\hline Maximum & 0.231 & 0.237 & 0.971 & 0.972 & 1 & 1 & 0.292 & 1 & 0.844 \\
\hline Mean & 0.044 & 0.056 & 0.464 & 0.484 & 0.289 & 0.341 & 0.057 & 0.097 & 0.341 \\
\hline \multirow[t]{2}{*}{ Std. Error } & 0.014 & 0.017 & 0.079 & 0.082 & 0.068 & 0.08 & 0.019 & 0.047 & 0.056 \\
\hline & $\begin{array}{c}\text { Relative } \\
\text { Abundance of } \\
\text { Predators }\end{array}$ & $\begin{array}{c}\text { Relative } \\
\text { Abundance of } \\
\text { Predators * }\end{array}$ & $\begin{array}{l}\text { Relative } \\
\text { Abundance of } \\
\text { Shredders }\end{array}$ & $\begin{array}{c}\text { Relative } \\
\text { Abundance of } \\
\text { Shredders * }\end{array}$ & $\begin{array}{l}\text { Family } \\
\text { Richness }\end{array}$ & $\begin{array}{l}\text { Relative } \\
\text { Abundance of } \\
\text { Lestidae }\end{array}$ & $\begin{array}{c}\text { Relative } \\
\text { Abundance of } \\
\text { Lestidae * }\end{array}$ & $\begin{array}{l}\% \text { Biomass of } \\
\text { Libellulidae }\end{array}$ & \\
\hline Minimum & 0 & 0 & 0 & 0 & 0 & 0 & 0 & 0 & \\
\hline Maximum & 1.255 & 1 & 1 & 0.563 & 23 & 0.238 & 0.625 & 0.059 & \\
\hline Mean & 0.436 & 0.21 & 0.301 & 0.128 & 8.727 & 0.018 & 0.035 & 0.006 & \\
\hline Std. Error & 0.074 & 0.051 & 0.068 & 0.038 & 1.286 & 0.012 & 0.029 & 0.004 & \\
\hline
\end{tabular}


Appendix BD. Continued.

\begin{tabular}{|c|c|c|c|c|c|c|c|c|c|}
\hline & $\begin{array}{l}\% \text { Biomass of } \\
\text { Libellulidae * }\end{array}$ & $\begin{array}{c}\text { Relative } \\
\text { Abundance of } \\
\text { Libellulidae }\end{array}$ & $\begin{array}{c}\text { Relative } \\
\text { Abundance of } \\
\text { Libellulidae * }\end{array}$ & $\begin{array}{l}\text { \% Biomass } \\
\text { Odonata }\end{array}$ & $\begin{array}{l}\% \text { Biomass } \\
\text { Odonata * }\end{array}$ & $\begin{array}{c}\text { Relative } \\
\text { Abundance of } \\
\text { Odonata }\end{array}$ & $\begin{array}{c}\text { Relative } \\
\text { Abundance of } \\
\text { Odonata * }\end{array}$ & $\begin{array}{c}\% \text { Biomass of } \\
\text { Odonata - } \\
\text { Libellulidae }\end{array}$ & $\begin{array}{c}\% \text { Biomass of } \\
\text { Odonata - } \\
\text { Libellulidae * }\end{array}$ \\
\hline Minimum & 0 & 0 & 0 & 0 & 0 & 0 & 0 & 0 & 0 \\
\hline Maximum & 0.2 & 0.683 & 0.686 & 0.185 & 0.217 & 0.735 & 0.739 & 0.522 & 0.667 \\
\hline Mean & 0.014 & 0.04 & 0.04 & 0.014 & 0.018 & 0.075 & 0.093 & 0.047 & 0.066 \\
\hline \multirow[t]{2}{*}{ Std. Error } & 0.009 & 0.031 & 0.031 & 0.009 & 0.011 & 0.037 & 0.044 & 0.026 & 0.033 \\
\hline & $\begin{array}{c}\text { Relative } \\
\text { Abundance of } \\
\text { Odonata - } \\
\text { Libellulidae }\end{array}$ & $\begin{array}{c}\text { Relative } \\
\text { Abundance of } \\
\text { Odonata - } \\
\text { Libellulidae * }\end{array}$ & & & & & & & \\
\hline Minimum & 0 & 0 & & & & & & & \\
\hline Maximum & 0.293 & 0.625 & & & & & & & \\
\hline Mean & 0.035 & 0.052 & & & & & & & \\
\hline Std. Error & 0.017 & 0.031 & & & & & & & \\
\hline
\end{tabular}




\section{Appendix BD. Continued.}

\begin{tabular}{|c|c|c|c|c|c|c|c|c|c|}
\hline \multicolumn{10}{|c|}{ Western Alleghany Plateau Nektonic Sampling(N=43) } \\
\hline & $\begin{array}{l}\% \text { Biomass } \\
\text { EPA stresseda }\end{array}$ & $\begin{array}{c}\text { Relative } \\
\text { Abundance } \\
\text { EPA Stressed }\end{array}$ & $\begin{array}{l}\% \text { Biomass of } \\
\text { Chironomidae }\end{array}$ & $\begin{array}{c}\text { Relative } \\
\text { Abundance of } \\
\text { Chironomidae }\end{array}$ & $\begin{array}{l}\% \text { Biomass of } \\
\text { Corixidae }\end{array}$ & $\begin{array}{c}\% \text { Biomass of } \\
\text { Corixidae * }\end{array}$ & $\begin{array}{l}\text { Relative } \\
\text { abundance of } \\
\text { Corixidae }\end{array}$ & $\begin{array}{c}\text { Relative } \\
\text { abundance of } \\
\text { Corixidae * }\end{array}$ & $\begin{array}{l}\text { Percent } \\
\text { Biomass of } \\
\text { Coleoptera }\end{array}$ \\
\hline Minimum & 0 & 0 & 0 & 0 & 0 & 0 & 0 & 0 & 0 \\
\hline Maximum & 1 & 1 & 0.265 & 0.608 & 1 & 1 & 1 & 1 & 0.976 \\
\hline Mean & 0.292 & 0.262 & 0.019 & 0.134 & 0.07 & 0.071 & 0.068 & 0.073 & 0.096 \\
\hline \multirow[t]{2}{*}{ Std. Error } & 0.049 & 0.037 & 0.007 & 0.023 & 0.033 & 0.033 & 0.032 & 0.033 & 0.028 \\
\hline & $\begin{array}{c}\text { Percent } \\
\text { Biomass of } \\
\text { Coleoptera * }\end{array}$ & $\begin{array}{c}\text { Relative } \\
\text { Abundance of } \\
\text { Coleoptera }\end{array}$ & $\begin{array}{c}\text { Relative } \\
\text { Abundance of } \\
\text { Coleoptera * }\end{array}$ & $\begin{array}{l}\% \text { Biomass of } \\
\text { Coleoptera } \\
\text { and Corixidae }\end{array}$ & $\begin{array}{c}\text { Relative } \\
\text { Abundance of } \\
\text { Coleoptera } \\
\text { and Corixidae }\end{array}$ & $\begin{array}{c}\text { Relative } \\
\text { Abundance of } \\
\text { Coleoptera } \\
\text { and Corixidae } \\
*\end{array}$ & $\begin{array}{l}\% \text { Biomass of } \\
\text { Dytiscidae }\end{array}$ & $\begin{array}{l}\% \text { Biomass of } \\
\text { Dytiscidae * }\end{array}$ & $\begin{array}{c}\text { Relative } \\
\text { Abundance of } \\
\text { Dytiscidae }\end{array}$ \\
\hline Minimum & 0 & 0 & 0 & 0 & 0 & 0 & 0 & 0 & 0 \\
\hline Maximum & 1 & 0.8 & 1 & 1 & 1 & 1 & 1 & 0.762 & 0.781 \\
\hline Mean & 0.098 & 0.108 & 0.128 & 0.166 & 0.169 & 0.176 & 0.202 & 0.047 & 0.047 \\
\hline \multirow[t]{2}{*}{ Std. Error } & 0.029 & 0.029 & 0.034 & 0.042 & 0.043 & 0.04 & 0.044 & 0.021 & 0.021 \\
\hline & $\begin{array}{c}\text { Relative } \\
\text { Abundance of } \\
\text { Dytiscidae * }\end{array}$ & $\begin{array}{l}\% \text { Biomass of } \\
\text { Collectors }\end{array}$ & $\begin{array}{l}\% \text { Biomass of } \\
\text { Collectors * }\end{array}$ & $\begin{array}{l}\% \text { Biomass of } \\
\text { Predators }\end{array}$ & $\begin{array}{c}\% \text { Biomass of } \\
\text { Predators * }\end{array}$ & $\begin{array}{l}\% \text { Biomass of } \\
\text { Shredders }\end{array}$ & $\begin{array}{l}\% \text { Biomass of } \\
\text { Shredders * }\end{array}$ & $\begin{array}{c}\text { Relative } \\
\text { Abundance of } \\
\text { Collectors }\end{array}$ & $\begin{array}{c}\text { Relative } \\
\text { Abundance of } \\
\text { Collectors * }\end{array}$ \\
\hline Minimum & 0 & 0 & 0 & 0 & 0 & 0 & 0 & 0 & 0 \\
\hline Maximum & 0.714 & 0.893 & 1 & 1 & 1 & 1 & 0.683 & 0.684 & 1 \\
\hline Mean & 0.061 & 0.072 & 0.482 & 0.496 & 0.331 & 0.34 & 0.06 & 0.06 & 0.397 \\
\hline \multirow[t]{2}{*}{ Std. Error } & 0.024 & 0.028 & 0.054 & 0.054 & 0.054 & 0.054 & 0.022 & 0.022 & 0.045 \\
\hline & $\begin{array}{c}\text { Relative } \\
\text { Abundance of } \\
\text { Predators }\end{array}$ & $\begin{array}{c}\text { Relative } \\
\text { Abundance of } \\
\text { Predators * }\end{array}$ & $\begin{array}{c}\text { Relative } \\
\text { Abundance of } \\
\text { Shredders }\end{array}$ & $\begin{array}{c}\text { Relative } \\
\text { Abundance of } \\
\text { Shredders * }\end{array}$ & $\begin{array}{l}\text { Family } \\
\text { Richness }\end{array}$ & $\begin{array}{c}\text { Relative } \\
\text { Abundance of } \\
\text { Lestidae }\end{array}$ & $\begin{array}{c}\text { Relative } \\
\text { Abundance of } \\
\text { Lestidae * }\end{array}$ & $\begin{array}{l}\text { \% Biomass of } \\
\text { Libellulidae }\end{array}$ & \\
\hline Minimum & 0 & 0 & 0 & 0 & 0 & 0 & 0 & 0 & \\
\hline Maximum & 1 & 1 & 1 & 0.5 & 22 & 0.012 & 0.012 & 0.044 & \\
\hline Mean & 0.466 & 0.302 & 0.373 & 0.054 & 8.86 & 0 & 0 & 0.001 & \\
\hline Std. Error & 0.048 & 0.041 & 0.048 & 0.016 & 0.805 & 0 & 0 & 0.001 & \\
\hline
\end{tabular}


Appendix BD. Continued.

\begin{tabular}{|c|c|c|c|c|c|c|c|c|c|}
\hline & $\begin{array}{l}\% \text { Biomass of } \\
\text { Libellulidae * }\end{array}$ & $\begin{array}{c}\text { Relative } \\
\text { Abundance of } \\
\text { Libellulidae }\end{array}$ & $\begin{array}{c}\text { Relative } \\
\text { Abundance of } \\
\text { Libellulidae * }\end{array}$ & $\begin{array}{l}\text { \% Biomass } \\
\text { Odonata }\end{array}$ & $\begin{array}{l}\text { \% Biomass } \\
\text { Odonata * }\end{array}$ & $\begin{array}{c}\text { Relative } \\
\text { Abundance of } \\
\text { Odonata }\end{array}$ & $\begin{array}{c}\text { Relative } \\
\text { Abundance of } \\
\text { Odonata* }\end{array}$ & $\begin{array}{c}\% \text { Biomass of } \\
\text { Odonata - } \\
\text { Libellulidae }\end{array}$ & $\begin{array}{c}\text { \% Biomass of } \\
\text { Odonata - } \\
\text { Libellulidae * }\end{array}$ \\
\hline Minimum & 0 & 0 & 0 & 0 & 0 & 0 & 0 & 0 & 0 \\
\hline Maximum & 0.045 & 0.673 & 0.676 & 0.118 & 0.2 & 0.978 & 1 & 0.5 & 1 \\
\hline Mean & 0.001 & 0.07 & 0.073 & 0.014 & 0.019 & 0.155 & 0.162 & 0.08 & 0.115 \\
\hline \multirow[t]{2}{*}{ Std. Error } & 0.001 & 0.025 & 0.026 & 0.005 & 0.007 & 0.038 & 0.039 & 0.018 & 0.03 \\
\hline & $\begin{array}{c}\text { Relative } \\
\text { Abundance of } \\
\text { Odonata - } \\
\text { Libellulidae }\end{array}$ & $\begin{array}{c}\text { Relative } \\
\text { Abundance of } \\
\text { Odonata - } \\
\text { Libellulidae * }\end{array}$ & & & & & & & \\
\hline Minimum & 0 & 0 & & & & & & & \\
\hline Maximum & 0.978 & 1 & & & & & & & \\
\hline Mean & 0.085 & 0.089 & & & & & & & \\
\hline Std. Error & 0.027 & 0.027 & & & & & & & \\
\hline
\end{tabular}

